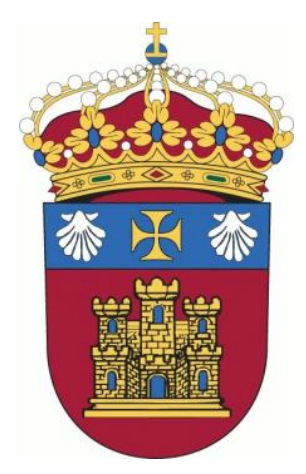

UNIVERSIDAD DE BURGOS DEPARTAMENTO DE INGENIERÍA CIVIL ÁREA DE INGENIERÍA HIDRÁULICA

TESIS DOCTORAL

\title{
INGENIERÍA HIDROELÉCTRICA \\ Evolución histórica y futuro de los aprovechamientos hidroeléctricos, su ingeniería y su función
}

\author{
Autora: María Soledad Martín-Cleto Sánchez \\ Director: Francisco Bueno Hernández
}




\section{ÍNDICE}

AGRADECIMIENTOS

INTRODUCCIÓN.......................................................................................................

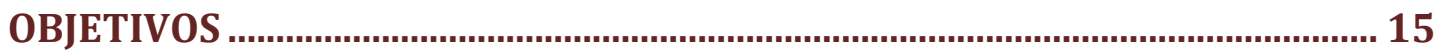

METODOLOGÍA Y ESTRUCTURA.............................................................................. 21

METODOLOGÍA …….......................................................................................................................

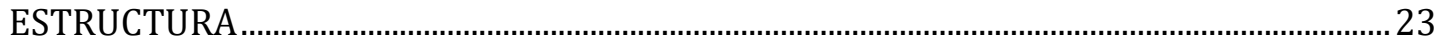

CAPÍTULO 1.

ANÁLISIS ECONÓMICO, POLÍTICO Y ESTRATÉGICO DE LOS APROVECHAMIENTOS HIDROELÉCTRICOS A LO LARGO DE LA HISTORIA. EVOLUCIÓN DEL SECTOR

1.1. EL SECTOR EMPRESARIAL EN EL PERIODO ANTERIOR A LA GUERRA

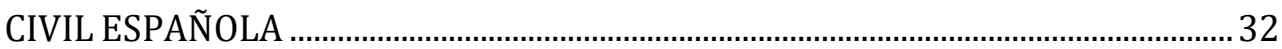

1.2. EL SECTOR EMPRESARIAL EN EL PERIODO 1936-1960 …...................................... 35

1.3. 1960-1975

1.4. EL SECTOR EN LOS AÑOS DE LA CRISIS DEL PETRÓLEO......................................... 42

1.5. EL SECTOR DE 1982-1996 ................................................................................. 44

1.6. LA LIBERALIZACIÓN DEL SECTOR ELÉCTRICO. 1996-ACTUALIDAD ................... 49 CAPÍTULO 2.

EVOLUCIÓN DE LA INGENIERÍA DE TURBINAS Y TURBO-BOMBAS................ 51

2.1. EDAD ANTIGUA (DESDE 3.300 A.C HASTA 476 D.C) ………...................................... 53

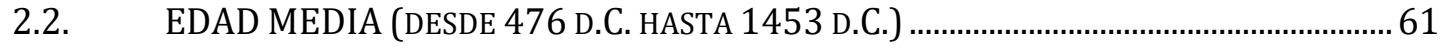

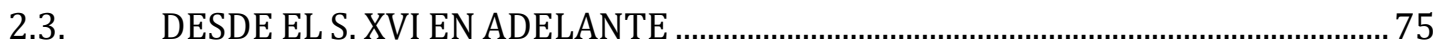

2.4. TURBINAS PARA CARGAS MÍNIMAS Y GRANDES CAUDALES ………..................106

2.5. TURBINAS DE ACCIÓN ……………….................................................................111

2.6. LOS GRUPOS TURBO-BOMBAS …………..........................................................120

2.7. TURBINAS PARA PEQUEÑA HIDROELECTRICIDAD .............................................125 


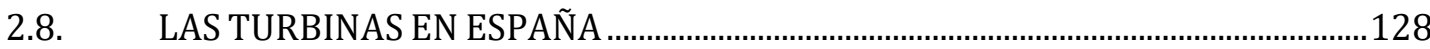

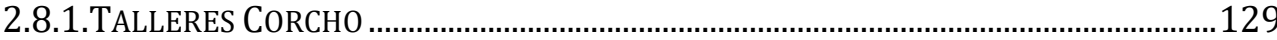

2.8.2.MAQUINARIA Y METALURGIA ARAGONESA. S.A. UTEBO...........................................130

2.8.3.DURO FELGUERA .................................................................................................130

2.8.4.MECÁNICA DE LA PEÑA (MECAPEÑA) ………….......................................................131

2.8.5.TALLERES MIGUEL DE PRADO …..............................................................................131

2.9. TIPOLOGÍAS DE TURBINAS EN ESPAÑA .................................................................133

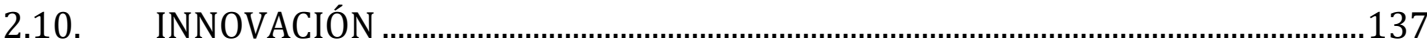

\section{CAPÍTULO 3.}

EVOLUCIÓN DE LA TECNOLOGÍA ELÉCTRICA................................................... 147

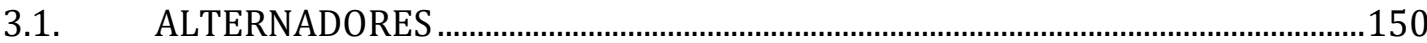

3.2. LOS SISTEMAS DE EXCITACIÓN DE LOS ALTERNADORES.....................................157

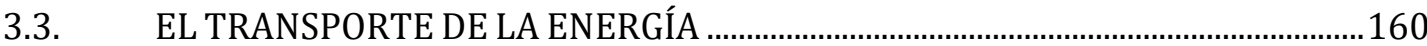

\section{CAPÍTULO 4.}

EVOLUCIÓN DE LA INGENIERÍA DE LAS PRESAS HIDROELÉCTRICAS ........ 165

4.1. EDAD ANTIGUA HASTA LA EDAD MEDIA (3.300 A.C - 476 D.C)...........................166

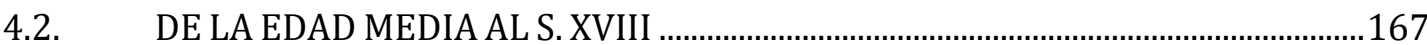

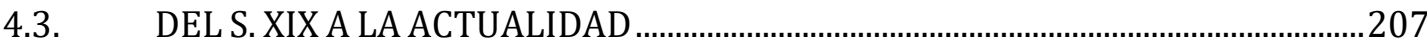

4.4. EL CASO ESPAÑOL

\section{CAPÍTULO 5.}

EVOLUCIÓN DE LA INGENIERÍA DE TÚNELES Y OBRAS

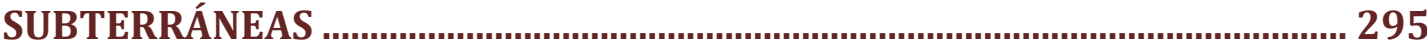

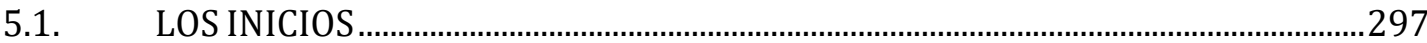

5.2. TÚNELES EN CENTRALES HIDROELÉCTRICAS......................................................... 308

5.3. DESARROLLO TECNOLÓGICO ANTES DE LOS AÑOS 70 ..........................................313

5.4. EVOLUCIÓN TECNOLÓGICA ESPAÑOLA A PARTIR DE LOS AÑOS 70..................339

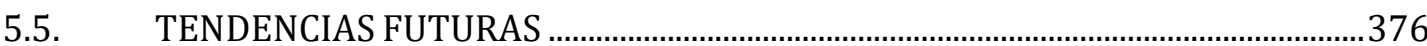




\section{CAPÍTULO 6.}

EVOLUCIÓN DE LOS APROVECHAMIENTOS HIDROELÉCTRICOS 381

6.1. LOS INICIOS DE LA HIDROELECTRICIDAD. PERÍODO 1890-1936......................383

6.2. EL PERIODO DE LA AUTARQUÍA 1936-1960 ……………………………….........400

6.3. LA HIDROELECTRICIDAD EN EL PERIODO 1960-ACTUALIDAD ..........................405

6.3.1.LA ETAPA DE LOS PLANES DE ESTABILIZACIÓN Y DESARROLLO. 1960-1975 .........405

6.3.2.DE 1975-A LA ACTUALIDAD 409

\section{CAPÍTULO 7.}

EVOLUCIÓN ESTÉTICA DE LOS APROVECHAMIENTOS HIDROELÉCTRICOS

7.1. INTRODUCCIÓN Y ENFOQUE GENERAL …............................................................

7.2. CENTRAL HIDROELÉCTRICA DE EL RUN O DE SEIRA (HUESCA)........................438

7.3. CENTRAL HIDROELÉCTRICA DE TAMBRE. NOIA (A CORUÑA) …………............443

7.4. SALTO Y CENTRAL HIDROELÉCTRICA DE GRANDAS DE SALIME

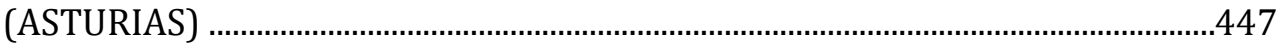

7.5. LA OBRA DE JOAQUÍN VAQUERO PALACIOS (1900-1998) ...................................452

7.6. EMBALSE DE SANTILLANA................................................................................

7.7. CENTRAL HIDROELÉCTRICA DE KEMPTEN …………...........................................47

CAPÍTULO 8.

TENDENCIAS A FUTURO .....................................................................................489

8.1. INTRODUCCIÓN Y ENFOQUE GENERAL ……….....................................................491

8.2. DESARROLLO A MEDIO PLAZO DE LA GENERACIÓN HIDRÁULICA EN ESPAÑA

8.3. PERSPECTIVAS DE DESARROLLO DEL ALMACENAMIENTO HIDRÁULICO EN ESPAÑA A MEDIO Y LARGO PLAZO _..............................................504

8.4. INNOVACIÓN Y TENDENCIAS EN SISTEMAS HIDROELÉCTRICOS.......................506

8.5. BARRERAS DE RECURSO HIDRÁULICO ………………………….........................512

8.6. BARRERAS ADMINISTRATIVAS ………….............................................................512

8.7. ESCENARIOS DE DESARROLLO HIDROELÉCTRICO AL 2020 ................................514 
ÍNDICE

CONCLUSIONES Y LÍNEAS FUTURAS DE INVESTIGACIÓN............................. 515

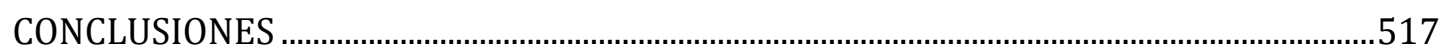

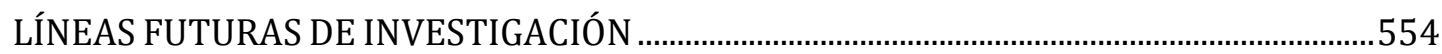

BIBLIOGRAFÍA .................................................................................................. 555

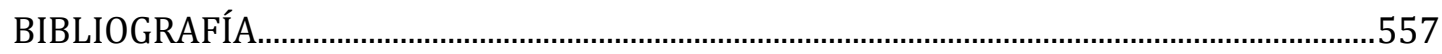




\section{Agradecimientos}



Quiero expresar mi gratitud al Profesor Dr. D. Francisco Bueno Hernández por su tutela durante todo el tiempo de elaboración de esta tesis.

Quiero destacar especialmente, además de su ayuda por su conocimiento exhaustivo del tema que se aborda, su honradez y generosidad con la que me ha tratado desde el mismo instante en que le propuse ser mi tutor. Muchas gracias, de corazón.

Agradecer a mis hijos, Ignacio y Sol, su paciencia. También dar las gracias a mi marido Jose María por su apoyo incondicional y por haber estado ahí, siempre, cuando yo no he podido estar.

Y finalmente expresar mi gratitud infinita a mis padres, por inculcarme desde bien pequeña la pasión por el conocimiento, el afán de superación y los valores del esfuerzo y sacrificio. 



\section{Introducción}



Desde finales del S. XIX, la evolución que ha vivido España como país, ha ido ligada inexorablemente a la que evolución que los propios aprovechamientos hidroeléctricos han sufrido a lo largo de este tiempo.

Los saltos de agua, cuya energía ya aprovechaban los molinos, ejercieron de dinamizadores económicos y sociales de sus respectivos entornos desde hace siglos. Molinos harineros, forjas, batanes, etc. generaban riqueza en aquéllas poblaciones en las que se asentaban.

Este efecto siguió dándose cuando esos molinos evolucionaron a fábricas de fuerza, o cuando, a mayor escala, se iban construyendo centrales de, cada vez, mayor potencia.

La sociedad cambiaba a medida que también lo hacían los aprovechamientos hidroeléctricos, desarrollándose zonas rurales donde se ubicaban los mismos, simplemente porque se les facilitaba el acceso al construir las propias carreteras de los citados saltos, favoreciendo su comunicación con el exterior, antes precaria.

Simplemente esta mayor comunicación ya propició una creciente prosperidad en zonas donde simplemente se subsistía.

Pero es innegable la evolución que la llegada de la electricidad generó en ciudades y fábricas gracias a la energía hidroeléctrica. Ese primer salto a la modernidad ya no tuvo vuelta a atrás.

Y de hecho, y como resultado de muchos años de experiencia, la energía hidroeléctrica es una tecnología renovable de alta eficiencia. España cuenta todavía con potencial hidroeléctrico aun sin explotar, cuyo desarrollo y aportación futura debe ser importante por sus indudables características como energía renovable, limpia y exenta de emisiones $y$, sobre todo, por tratarse de una energía de calidad, ya que contribuye a la seguridad y calidad del sistema eléctrico, como energía regulada rápidamente disponible para el seguimiento de variaciones de la demanda y de la oferta, flexibilidad para control de frecuencia y tensión de la red, etc.

Hoy por hoy, la energía hidroeléctrica es uno de los recursos cuantitativamente más importante dentro de la estructura de las energías renovables y se caracteriza por ser una fuente energética limpia y autóctona. La producción mundial de esta energía alcanza anualmente los 3.000 TWh, lo que representa el $20 \%$ de la producción mundial de electricidad y en los países en desarrollo este 
porcentaje se eleva hasta el $33 \%$, lo que la convierte en la renovable más utilizada en todo el mundo.

El potencial eléctrico de origen hidráulico aun sin aprovechar es enorme, ya que apenas se utiliza el 17\% a escala mundial, cifra que se reduce al $8 \%$ en el Tercer Mundo (según datos de la UNESCO).

En la actualidad, Canada, Estados Unidos y China son los mayores productores del mundo. Durante el primer tercio del presente siglo, la energía hidroeléctrica se mantendrá como una importante fuente de producción hidroeléctrica. A pesar de que la mayor parte de los recursos hidroeléctricos en los países de la OCDE ya están siendo explotados, las posibilidades de crecimiento se estiman en el 1,8\% hasta el año 2030. Los países en vías de desarrollo serán responsables de la mayor parte del crecimiento.

A nivel europeo, la energía hidroeléctrica, al igual que el resto de renovables, encuentra su marco de desarrollo en las políticas de promoción y fomento de la electricidad generada a partir de fuentes de energías renovables desarrolladas por los distintos países, y que persiguen un triple objetivo: reducir las emisiones de dióxido de carbono a la atmosfera, reducir el consumo energético y aliviar la dependencia energética del exterior, especialmente en lo que se refiere a combustibles fósiles.

España ocupa un papel destacado en el área hidroeléctrica a nivel europeo, situándose en tercer lugar respecto al resto de países de la Unión Europea en cuanto a potencia hidroeléctrica instalada con centrales menores de $10 \mathrm{MW}$ y el cuarto lugar en cuanto a centrales de potencia mayor de $10 \mathrm{MW}$.

El parque hidroeléctrico español supone el 10\% del parque de la UE-25. España cuenta con un importante y consolidado sistema de generación hidroeléctrica, como resultado de una larga tradición histórica en el desarrollo de aprovechamientos hidroeléctricos, debido a la orografía del país y a la existencia de un gran número de presas, con una capacidad total de embalses de 55.000 $\mathrm{Hm} 3$, de los cuales el $40 \%$ de esa capacidad embalsable corresponde a embalses hidroeléctricos, que es una de las proporciones más altas de Europa y del mundo.

Aunque la evolución de la energía hidroeléctrica en España ha sido creciente, en los últimos años ha experimentado una importante disminución en la aportación de esta energía a la producción total de la electricidad, en favor de otras energías renovables. No obstante, todavía continúa siendo una de las renovables más productivas junto con la energía eólica, sobre todo por las 
grandes centrales hidroeléctricas, que representan el $90 \%$ de la potencia hidroeléctrica total instalada siendo además de importancia capital su capacidad de almacenamiento a gran escala gracias a la aportación de las centrales hidroeléctricas reversibles.

Por todo lo anterior, se pueden considerar a los aprovechamientos hidroeléctricos infraestructuras principales y dignas de consideración, siendo por tanto, interesante su estudio detallado. 



\section{Objetivos}



Dentro del sistema energético, el sistema eléctrico es uno de los básicos e importantes. Y dentro del sistema eléctrico, los aprovechamientos hidroeléctricos siempre han sido en todas las épocas y siguen siendo en la actualidad una parte esencial en todos los países.

El objetivo principal de la tesis es realizar un análisis completo sobre la evolución histórica y futuro de los aprovechamientos hidroeléctricos, abordando tanto su componente de ingeniería hidroeléctrica como su función en el mercado eléctrico.

A la vista de las obras que hay escritas sobre aprovechamientos hidroeléctricos, que son muchas, sí se echaba de menos alguna que abordara su evolución histórica y su futuro, con carácter totalizador, intentando relacionar las distintas disciplinas que los conforman.

Existen trabajos de gran interés que abordan distintos aspectos, desde las más diversas ópticas, de los aprovechamientos hidroeléctricos. Esta tesis pretende ofrecer un panorama conjunto de la evolución de dichos aprovechamientos no solo en el ámbito de la ingeniería, sino también en su vertiente económica, política y estratégica.

Las tipologías, disposiciones y funciones de los aprovechamientos en su conjunto y de cada uno de los elementos que les conforman han ido variando a lo largo de la historia en función de distintos condicionantes, unos intrínsecos a las distintas ramas de la ingeniería y otros externos y relativos a cuestiones políticas, sociales o económicas.

Para conseguir alcanzar el objetivo principal de la tesis, se deben conseguir una serie de objetivos parciales.

Analizar la influencia de todos estos condicionantes en aquellas -tipologías, disposiciones y funciones- es el primero de los objetivos parciales de esta tesis. Para ello se analizará en primer lugar y de forma individualizada la evolución de las distintas ramas de la ingeniería que intervienen en la ingeniería de los aprovechamientos hidroeléctricos:

- Evolución en la ingeniería de turbinas y turbobombas.

- Evolución de la tecnología eléctrica.

- Evolución de la ingeniería de las presas hidroeléctricas.

- Evolución de la ingeniería de túneles y obras subterráneas. 
Así, como ejemplo sencillo, la evolución de la ingeniería de presas permitió alturas cada vez mayores, lo que a su vez permitió conjugar mayores capacidades de embalse, y como consecuencia mayores caudales regulados, con la consecución de saltos notables sin necesidad de largas conducciones, consiguiéndose de forma conjunta los dos términos que inciden en la potencia de un salto. Otro ejemplo es el del desarrollo de equipos y métodos de construcción de obras subterráneas, que permitió la construcción económica de centrales subterráneas y poder desarrollar, por un lado, aprovechamientos que de otra forma no hubiesen sido viables técnica o ambientalmente $\mathrm{y}$, por otro lado, esquemas más flexibles y funcionalmente más interesantes, caso de las centrales reversibles. Otro ejemplo es el del desarrollo de las turbomáquinas hidráulicas y de las máquinas eléctricas, que ha ido permitiendo pasar de los grupos cuaternarios a los ternarios primero y a los binarios después, con la mayor economía de estos últimos en las centrales reversibles. Y se pueden poner más ejemplos, que se analizarán en esta tesis.

Por otra parte, en el desarrollo de los aprovechamientos ha influido sobremanera la elección en cada momento y época de las distintas fuentes capaces de producir energía eléctrica y alternativas a la hidráulica: nuclear, carbón, petróleo, gas, y más recientemente, el viento o el sol.

El análisis de la disponibilidad y economía de estas fuentes por un lado, y de las decisiones políticas y estratégicas de elección, por otro, es el segundo de los objetivos parciales de esta tesis. Este segundo objetivo parcial se materializará en un análisis económico, político y estratégico de los aprovechamientos hidroeléctricos a lo largo de la historia, y su influencia en la propia evolución del sector hidroeléctrico.

Este desarrollo ha sido diferente a lo largo del siglo XX y lo está siendo en el XXI, tanto en el tiempo como en los distintos países / regiones. Desarrollo no solamente en cuanto a número y magnitud de aprovechamientos, sino también en cuanto a la función desarrollada dentro del conjunto del sistema eléctrico.

En el caso de España, la energía hidroeléctrica fue prácticamente la única que se utilizó hasta casi mitad de siglo. El gran desarrollo económico a partir de los años 50 llevó a la necesidad de grandes instalaciones de producción eléctrica, lo que condujo a los programas de desarrollo de centrales térmicas y nucleares. La energía hidroeléctrica empezó a perder importancia cuantitativa relativa dentro de la producción eléctrica. Pero no pasó lo mismo en cuanto a la importancia cualitativa, ya que los aprovechamientos hidroeléctricos con regulación eran y son los únicos, o al menos los más apropiados, para cumplir distintas funciones dentro del sistema eléctrico: el seguimiento de la carga o curva de demanda, la 
regulación de la frecuencia, el ser los gestores más eficaces de la energía eléctrica intradiaria o ser la única forma de almacenamiento de gran potencia y elevada disponibilidad.

El desarrollo de las energías renovables, fundamentalmente eólica y solar, en la última década del siglo XX y lo transcurrido del XXI, energías que no son gestionables o lo son poco, hace que los aprovechamientos hidroeléctricos sean todavía más necesarios, por su alto grado de gestionabilidad.

Una vez analizados todos estos condicionantes, tanto internos o intrínsecos a aspectos relacionados con la ingeniería -primero de los objetivos- como externos o relacionados con aspectos no ingenieriles -segundo de los objetivos-, la tesis abordará el tercero de los objetivos parciales, que es el análisis propiamente dicho que han sufrido los aprovechamientos hidroeléctricos, incluyendo aquéllos que se consideren representativos de cada época o que sean singulares por distintos motivos. Este tercer objetivo permitirá integrar los dos primeros y comprobar en qué medida dichos condicionantes han influido en el resultado final.

Para completar el estudio que en esta tesis se hace sobre los aprovechamientos hidroeléctricos, se abordará el aspecto estético de los mismos, analizando sus aspectos más relevantes observados a lo largo de sus años de desarrollo en las distintas ejecuciones llevadas a cabo.

El ámbito territorial de la tesis se centrará especialmente en España aunque se indique en determinados aspectos que se vayan tratando a lo largo de la tesis lo que acontece al respecto en otras zonas del mundo.

El estudio de la evolución y del estado actual del arte quedaría, en cierto modo, incompleto si no se realizasen algunas reflexiones sobre su futuro, aún a sabiendas de lo difícil y arriesgado que es realizar este tipo de análisis dada la complejidad de los entornos eléctricos en los que se mueve la hidroelectricidad hoy en día. 



\section{Metodología y estructura}





\section{METODOLOGÍA}

Para conseguir el objetivo principal de esta tesis, a través de los objetivos parciales indicados en el anterior apartado, se ha seguido la metodología que se expone a continuación.

Esta metodología se fundamenta en la documentación exhaustiva sobre los aprovechamientos hidroeléctricos caracterizando la información bajo tres ámbitos principales, estos son, ingeniería hidroeléctrica, historia de la hidroelectricidad, y aspectos económicos y políticos.

A partir de ahí, la integración globalizada de todos los aspectos abordados en la tesis para conseguir el objetivo principal que es la realización de un trabajo lo más totalizador posible sobre la evolución histórica y futuro de los aprovechamientos hidroeléctricos atendiendo a su faceta ingenieril y también funcional en cada una de sus etapas en las que se desarrolla, ha sido necesaria la realización de una investigación exhaustiva, contrastando la información disponible y buscando respuestas, por ejemplo en documentos originales del S. XVI, certificados de patentes antiguas, consulta de activos de empresas o investigando en los expedientes, tanto antiguos como modernos, de concesión.

Ha sido necesaria la realización de una base de datos muy completa de todos los aprovechamientos hidroeléctricos españoles que se han ejecutado desde finales del S. XIX hasta la actualidad, cuyos titulares son las siete mayores compañías hidroeléctricas del país.

Gracias a esta base de datos se han podido realizar diferentes análisis que eran necesarios sobre los patrones tecnológicos españoles seguidos en los diversos ámbitos, principalmente de presas, turbinas y centrales, que han permitido verificar la evolución de los mismos a lo largo de las distintas etapas de la hidroelectricidad.

\section{ESTRUCTURA}

Para conseguir los objetivos indicados en el apartado correspondiente de esta tesis, se han desarrollado los siguientes capítulos entendidos como fundamentales para el fin perseguido. 
Capítulo 1. AnÁlisis ECONómico, político $\quad \mathrm{Y}$ estratégico DE LOS APROVECHAMIENTOS HIDROELÉCTRICOS A LO LARGO DE LA HISTORIA. EVOLUCIÓN DEL SECTOR:

En este capítulo se analizan las coyunturas económicas que se han producido en cada época significativa para la hidroelectricidad, que junto con el entorno político que les caracterizaba en cada caso, han influido en el sector haciéndolo evolucionar de una determinada manera, consecuencia de lo anterior y de las propias estrategias empresariales. Se desgrana cómo influyeron los distintos gobiernos, los distintos conflictos bélicos, las distintas situaciones económicas, las leyes que se aprobaron, las patronales que se formaron, y cómo evolucionaron las empresas explotadoras conforme a todo lo anterior, etc., desde finales del S. XIX hasta la actualidad.

\section{CAPÍTULO 2. EVOLUCIÓN EN LA INGENIERÍA DE TURBINAS Y TURBOBOMBAS}

En este capítulo se desarrolla la evolución que sufrieron los elementos mecánicos precursores de las turbinas hasta que se conoció la turbina propiamente dicha, desde la Edad Antigua hasta la actualidad. Se describe el porqué se dieron avances en las distintas tecnologías que iban apareciendo gracias a un conocimiento cada vez mayor de la hidráulica. Qué necesidades cubrían cada una de las tipologías patentadas. También se estudian las turbobombas dada la importancia creciente de las centrales reversibles. Se describe el sector español manufacturero de turbinas y la evolución que sufrió. Se investiga sobre las turbinas más utilizadas en las centrales españolas, y si siguen los patrones de utilización generalizados en el resto del mundo. Se concluye analizando hacia dónde se dirigen los avances tecnológicos en este tipo de elementos hidromecánicos.

\section{CAPÍtUlo 3. EVOLUCIÓN DE LA TECNOLOGÍA ELÉCTRICA}

En este capítulo se desarrolla la evolución que sufrieron los elementos eléctricos de los aprovechamientos hidroeléctricos y concretamente de los alternadores, los sistemas de excitación del rotor y de las líneas de transporte de electricidad. También se analizan los tres tipos de máquinas síncronas o asíncronas que pueden solucionar el conseguir la velocidad variable en los grupos. 


\section{CAPÍTULO 4. EVOLUCIÓN DE LA INGENIERÍA DE LAS PRESAS HIDROELÉCTRICAS}

En este capítulo se desarrolla la evolución tecnológica de las presas dedicadas al aprovechamiento energético del agua, desde la Edad Antigua hasta la actualidad. Se describen las tipologías que son más usuales en cada época representativa, los materiales que se utilizan. Se explica cómo influye el mayor conocimiento y mejora del cálculo estructural en la construcción de distintas tipologías de presa. Se analiza con detalle el caso español, y las características de las presas ejecutadas según las etapas principales de la hidroelectricidad. También se estudian algunos personajes influyentes en la evolución tecnológica de las presas.

\section{CAPÍTULO 5. EVOLUCIÓN DE LA INGENIERÍA DE TÚNELES Y OBRAS SUBTERRÁNEAS}

En este capítulo se desarrolla la evolución tecnológica que ha sufrido la ejecución de obras subterráneas asociadas a aprovechamientos hidroeléctricos desde las alimentaciones subterráneas a los molinos que aprovechaban la energía del agua, hasta las obras tanto de tomas, conducciones forzadas, pozos y centrales realizadas en la actualidad. Se estudia la evolución de los métodos constructivos aplicados en cada época, y de la maquinaria utilizada en este tipo de trabajos. Se detallan los aspectos técnicos más relevantes de las metodologías empleadas en España con más asiduidad. Se finaliza con los avances tecnológicos más modernos que aportan ventajas a la ejecución de obras subterráneas asociadas a aprovechamientos hidroeléctricos, y las líneas futuras de actuación en este aspecto.

\section{CAPÍTUlo 6. EVOLUCIÓN DE LOS APROVECHAMIENTOS HIDROELÉCTRICOS}

En este capítulo se aborda la evolución de los aprovechamientos hidroeléctricos en las distintas épocas representativas de la hidroelectricidad española dando una visión más global de los aspectos estudiados hasta este capítulo, sin entrar en los detalles de los que ya son objeto cada uno de esos capítulos, desarrollando las características principales de cada periodo que influyen en los aprovechamientos, con el fin principal de explicar de manera clara, porqué se produce esa evolución. En cada uno de esos períodos analizados, se citan y en algún caso se detallan, los aprovechamientos hidroeléctricos más representativos. 


\section{CAPÍTULO 7. EvoluCión ESTÉTICA DE LOS APROVECHAMIENTOS}

En este capítulo se analizan los aspectos estéticos más relevantes observados en las instalaciones eléctricas españolas. Se describen sus características y su influencia en el entorno. También se describe la tendencia estética observada en centrales actuales.

\section{Capítulo 8. Tendencias a Futuro.}

En este capítulo se hace un análisis de hacia dónde se encamina el futuro de la hidroelectricidad en España a medio y largo plazo, desarrollando los aspectos principales que influirán en esa evolución futura. Se aborda tanto el desarrollo de la generación hidráulica como del almacenamiento a gran escala. Se finaliza con los aspectos que pueden ser más interesantes de desarrollo en el campo de la innovación y tendencias en sistemas hidroeléctricos.

\section{CONCLUSIONES Y LÍNEAS FUTURAS DE INVESTIGACIÓN}

Se resumen en este punto las conclusiones fundamentales aportadas tras el desarrollo de cada uno de los capítulos anteriores, indicándose así mismo, las líneas de futura investigación que propicia esta tesis. 


\section{Capítulo 1.}

\section{Análisis económico, político y estratégico de los aprovechamientos hidroeléctricos a lo largo de la historia.}

\section{Evolución del sector}



En España no ha habido monopolio eléctrico (en el sentido de un solo productor o suministrador de energía), pero sí un oligopolio (en el sentido de un número muy pequeño de productores y distribuidores capaces de ponerse de acuerdo para imponer unos precios por encima de los que habría en caso de libre concurrencia).

La verdadera libre competencia en estas industrias conllevaría la construcción de redes paralelas lo cual no sería aceptable por la inversión multiplicada a que daría lugar.

Por otra parte, esas redes de distribución son muy caras de construir y mantener, de manera que la entrada en el mercado es así doblemente difícil e incluso, sobre todo en países poco desarrollados, necesitándose gran cantidad de capital que no siempre son las empresas capaces de conseguir, por lo que frecuentemente requieren incentivos fiscales o de otro tipo para establecerse. Hay indicios de que éste fue, al menos en parte, el caso de España.

La industria de generación y suministro eléctrico a escala industrial comienza en Inglaterra, Alemania, y Estados Unidos a finales del siglo XIX. Aunque España puede enorgullecerse de tener un auténtico pionero en la materia, el científico Francisco Salvá, que en 1795 leyó una memoria sobre la electricidad aplicada a la telegrafía, y realizó experimentos exitosos en este campo, su obra no tuvo continuidad y hasta finales del XIX no se instalan en Barcelona los primeros generadores de electricidad.

El hecho es, sin embargo, que el desarrollo de la industria eléctrica en España en las primeras décadas del siglo XX coincide con el primer gran empuje industrializador.

De este modo, hasta la Guerra Civil aproximadamente, la mayor parte de la electricidad generada es hídrica gracias a las buenas condiciones que tiene España como país montañoso con saltos capaces de generar electricidad de forma barata. Sin embargo, esta modalidad de producción presenta en nuestro país el problema serio de estiaje: el régimen de lluvias es muy irregular y estacional de modo que las posibilidades de generación fluctúan excesivamente, por lo que se fue haciendo cada vez más necesario recurrir a la generación térmica. Pero aquí se daba otro problema: la carestía del carbón español, al que, sin embargo, el Estado siempre ha querido proteger; al imponer cuotas de consumo de carbón nacional, el Estado contribuía a encarecer la electricidad.

Éste, sin embargo, mostró interés en apoyar a esta industria, especialmente durante la dictadura de Primo de Rivera, que veía en la electricidad un 
instrumento clave en su política de industrialización. Otra fuente de energía a la que Primo de Rivera prestó atención (en especial su ministro de Hacienda, José Calvo Sotelo) fue el petróleo; siguiendo directrices típicamente estatistas, la dictadura instituyó el monopolio estatal de petróleos, que creó más problemas políticos que beneficios económicos.

Pero fue con la dictadura de Franco cuando se consagró el bloque oligopolístico eléctrico. A pesar de sus tendencias intervencionistas y totalitarias, Franco manifestó gran respeto por los intereses económicos privados, especialmente cuando las figuras destacadas de tal sector habían contribuido sustancialmente a financiar la sublevación que inició la Guerra Civil, como fueron los casos de Juan March y José Luis de Oriol, por ejemplo.

Oriol fue un gran empresario eléctrico; March era un potentado en el sector petrolífero que se convirtió más tarde en propietario de una de las mayores eléctricas. Ambos se interesaron, sin embargo, en otros campos económicos. Cuando llegó el momento de renovar la legislación bancaria, en 1946, muchos creyeron que el régimen de Franco nacionalizaría los bancos y, posiblemente también, la electricidad, como se había hecho en Francia y, para la electricidad, en Inglaterra. Pero no fue así.

Al contrario, la banca, aunque muy sujeta a lo que después se llamó "represión bancaria", siguió en manos privadas, y haciendo grandes beneficios. Lo mismo ocurrió con las grandes eléctricas, cuyo número se iba reduciendo inexorablemente por la ley de las economías de escala. En virtud de esta ley económica, ciertas industrias de técnica avanzada, como la eléctrica, requieren producir en gran escala para ser rentables. Así, gradualmente, las mayores empresas (Iberduero, Unión Eléctrica Madrileña, Hidrola, Sevillana, Barcelona Traction, Eléctricas Reunidas, etcétera) iban absorbiendo a las pequeñas, que no podían competir en precios y calidad de suministro. Por otra parte, aunque el mercado eléctrico ya presentaba considerable complejidad, las grandes compañías conseguían esquivar el control de tarifas que el Estado les imponía para combatir la inflación y mostraban altos beneficios. Esto las hizo muy interesantes para los grandes bancos: los dos bancos vascos (Vizcaya y Bilbao), el Banco de Santander, el Central y el Urquijo fueron los mayores inversores, que acabaron formando un compacto bloque de poder financiero-energético.

En 1944 se crea Unesa (Unidad Eléctrica, SA), a propuesta de José María de Oriol Urquijo, hijo y heredero de José Luis de Oriol. Oriol hijo fue el primer presidente de la nueva sociedad. Lo reseñable de Unesa, que era una empresa privada participada por las grandes del sector, es que debía coordinar la distribución nacional del fluido eléctrico, es decir, coordinar la producción de las distintas 
empresas, en especial las que eran sus propias accionistas. Como se decía en un decreto posterior (1951), Unesa asumía así, por delegación del Estado, las funciones de coordinación de la industria eléctrica nacional que normalmente hubieran correspondido a una oficina estatal, como ocurría en los países que, como Francia e Inglaterra, y más tarde Italia, habían nacionalizado el sector.

Se daba así en España el caso único de "un verdadero régimen de autorregulación por las empresas eléctricas afectadas". Y el ya entonces complicado sistema de tarifas vigente era, en definitiva, pactado con las empresas en virtud de un sistema polinómico y unos factores adicionales que, de hecho, garantizaban una alta rentabilidad al sector. Por otra parte, el exacerbado nacionalismo de la dictadura contribuyó a beneficiar a este bloque a expensas de los inversores y accionistas extranjeros.

El caso más sonado fue el de la Barcelona Traction Light and Power. Era ésta una empresa internacional que abastecía a gran parte del mercado barcelonés y catalán, empresa del interés de Juan March pero cuyos directivos no querían vendérsela.

Con el apoyo manifiesto del Estado español, March consiguió que un tribunal declarara a esta empresa en quiebra y la subastara. March la adquirió a muy buen precio en 1948 y la convirtió en Fuerzas Eléctricas de Cataluña (FECSA), que décadas más tarde se fusionaría con Endesa.

Los pleitos internacionales a que este asunto dio lugar se prolongaron unos 20 años; Juan March llevaba mucho tiempo fallecido cuando se publicó la sentencia final, que le dio la razón, provocando un gran escándalo. Otro asunto parecido, aunque menos ruidoso, fue la cuasi expropiación de las acciones del banco suizo Elektrobank, propietario de un paquete de control en Sevillana de Electricidad, también con el apoyo del Estado español. Este caso hizo menos ruido porque los suizos cedieron el control y vendieron su participación, de modo que no hubo escándalo ni procesos judiciales.

Este compacto bloque de poder financiero-eléctrico fue una de las herencias que el franquismo legó a la democracia.

Han ocurrido muchas cosas desde la Transición, pero sería absurdo no reconocer el poder que las empresas eléctricas siguen teniendo. Otros países de la Unión Europea, como los antes citados, han resuelto la cuestión hace ya mucho tiempo nacionalizando una industria que propende al monopolio y es crucial para la economía del país. 
A continuación se describen con mayor detalle los aspectos más destacables de cada una de las etapas indicadas anteriormente.

\subsection{EL SECTOR EMPRESARIAL EN EL PERIODO ANTERIOR A LA GUERRA CIVIL ESPAÑOLA}

En los años treinta estaban presentes en el sector eléctrico español la mayoría de las empresas que habrían de ser protagonistas de su historia.

La primera compañía eléctrica española era la Unión Eléctrica de Cataluña o Barceloona Traction Light and Power. Constituida en Toronto en 1911 y popularmente conocida por ello como "la Canadiense", la sociedad que dirigía el norteamericano Frank S. Pearson había adquirido o controlado sucesivamente la Compañía Barcelonesa de Electricidad, la de Energía Eléctrica de Cataluña y la Sociedad Productora de Fuerzas Motrices. Tenía prácticamente el monopolio de la electricidad en Cataluña, salvo una pequeña parte del mercado barcelonés al que suministraba Catalana de Gas y Electricidad. Las centrales de la Canadiense representaban el 24 por ciento de la potencia total instalada en el país y producían anualmente algo más del 23 por ciento del total nacional, cifras que se elevaban al 27 y al 26 por ciento, respectivamente, si sumamos la potencia y la producción de la Sociedad Productora de Fuerzas Motrices, controlada por ella.

La segunda empresa productora era Hidroeléctrica Española, constituida en 1907 por Juan de Urrutia, Lucas de Urquijo, José Luis Oriol y el Banco de Vizcaya. Suministraba en Madrid y la zona de Levante y representaba un poco más del 10 por ciento de la potencia total instalada, con una producción anual del 11,5 por ciento.

A Hidroeléctrica Española seguía muy de cerca Hidroeléctrica Ibérica, fundada en 1901 por iniciativa de Juan de Urrrutia, con el apoyo del mismo Banco de Vizcaya. Tenía el monopolio casi total del País Vasco, el 8 por ciento de la potencia y el 10 por ciento de la producción nacionales.

La cuarta empresa productora, que se aproximaba al 6 por 100 de la potencia total y al 4 por ciento de la producción, era la Cooperativa de Fluido Eléctrico de Barcelona. La Cooperativa era una asociación de grandes consumidores industriales de Cataluña, creada en 1920 para evitar el monopolio de la Canadiense, y explotaba en arrendamiento las centrales de Catalana de Gas y Electricidad. 
Saltos del Alberche, constituida en 1926, tenía el 5 por ciento de la potencia instalada y producía solamente el 1 por ciento del conjunto nacional. Electra de Viesgo, fundada en 1906 y también vinculada al Banco de Vizcaya, alcanzaba el 4,5 por ciento de la potencia total y producía el 5,5 por ciento de la electricidad del país. La Compañía Sevillana de Electricidad, creada en 1894 por un grupo de inversores locales con el respaldo de Allgemeine Electricitát Gesellschaft (AEG) y del Deutsche Bank, y que también pasó al Banco de Vizcaya después de la primera guerra mundial, representaba el 4,5 por ciento de la potencia y de la producción nacionales.

Con potencia instalada y producción anual inferiores, aparecían entre las diez primeras empresas eléctricas la Cooperativa Eléctrica de Langreo, constituida en 1923, y la Compañía de Luz y Fuerza de Levante, resultado de la fusión en 1930 de una serie de pequeñas empresas valencianas.

A esos nombres pueden añadirse los de otras sociedades que venían operando desde comienzos del siglo, como la Sociedad General Gallega de Electricidad (1899), la Sociedad Hidroeléctrica del Chorro (1903) y Mengemor (1904). En el decenio siguiente, habían surgido Eléctricas Reunidas de Zaragoza (1910) y Unión Eléctrica Madrileña (1912), nacidas de la fusión de antiguas empresas con pequeñas térmicas y redes de distribución y de nuevas sociedades hidroeléctricas, y otras empresas de ámbito regional, corno Energía e Industrias Aragonesas (1918) e Hidroeléctrica del Cantábrico (1919).

Saltos del Duero, constituida en 1917 para llevar a cabo un ambicioso proyecto de José Orbegozo, consiguió en 1926 la concesión de diversos aprovechamientos escalonados en el último tramo del río que daba nombre a la sociedad. El aprovechamiento integral de esta cuenca suponía duplicar la producción nacional de electricidad de aquella época.

Hay que poner de relieve el alto grado de concentración que el sector eléctrico había alcanzado ya en 1930. Las cinco mayores empresas sumaban el 53 por ciento de toda la potencia instalada y el 50 por ciento de la producción nacional anual. Las diez primeras, el 70 por ciento de la potencia y el 67 por 100 de la producción. Además, las empresas más importantes se repartían en dos grandes grupos, que controlaban en conjunto más del 50 por 100 de la potencia y de la producción: uno, el de la Barcelona Traction, formado por ella y por la Sociedad Productora de Fuerzas Motrices; otro, el de las empresas vinculadas al Banco de Vizcaya, como Hidroeléctrica Española, Hidroeléctrica Ibérica, Electra de Viesgo, Sevillana y Mengemor. Mientras que sociedades como Unión Eléctrica Madrileña y Saltos del Alberche, pertenecían al grupo industrial del Banco Urquijo. 
Pese a esas vinculaciones accionariales, las compañías eléctricas actuaban con independencia, en mercados predominantemente regionales. Las empresas eléctricas españolas habían sido pioneras en el tendido de grandes líneas para hacer frente a sus propias necesidades de abastecimiento: la primera línea de transporte a $30 \mathrm{kV}$ de Europa fue la de Quintana-Bilbao, construida por Hidroeléctrica Ibérica en 1908, y la primera línea a 66 kV, la de Júcar-MadridValencia, construida por Hidroeléctrica Española en 1909. Sin embargo, no existía una red general de interconexión entre las zonas y mercados de las diferentes compañías. La construcción de una red eléctrica nacional había sido propuesta por el Padre Pérez del Pulgar en 1915, por la Comisión Permanente Española de Energía en 1918 y por el Primer Congreso de Ingeniería en 1919, y la Administración llegó a convocar un concurso en 1926 para su estudio y diseño. Pese a ello, nada se hizo en la práctica hasta que fue necesario dar salida a la energía generada por Saltos del Duero, y ésta sociedad construyó en los años treinta las líneas a $132 \mathrm{kV}$ Esla-Valladolid, Valladolid-Bilbao y ValladolidMadrid, principio de lo que llegará a ser, muchos años después, la red nacional.

En materia de tarifas, se daba la misma dispersión que en las zonas de suministro. Las tarifas de la electricidad eran fijadas en las concesiones de los aprovechamientos hidroeléctricos y en las concesiones municipales para establecer las canalizaciones que utilizaban las compañías en las zonas urbanas. La declaración del suministro de electricidad como servicio público, por un Real Decreto Ley de 1924, amplió las competencias de la Administración para una mayor intervención en la industria eléctrica. Las regulaciones administrativas, hasta entonces limitadas a velar por la seguridad de las instalaciones, podían, a partir de la declaración de servicio público, exigir la obligatoriedad y regularidad de los suministros y fijar tarifas máximas "de aplicación", que no excederían de las tarifas "de concesión" existentes. En la práctica, se establecieron tarifas de explotación por zonas o centros urbanos, ajustándose posteriormente las de concesión cuando una pluralidad de aprovechamientos alimentaba la misma red o zona de suministro.

El panorama de la industria a comienzos de los años treinta se completa con el nacimiento de la primera organización nacional de empresas eléctricas. El desarrollo de la industria y la creciente intervención administrativa en ella llevaron a las empresas a considerar la conveniencia de estudiar y afrontar conjuntamente la amplia problemática común. En 1929, se constituyó con tal fin la Asociación de Productores y Distribuidores de Electricidad. Un año más tarde, recibió la consideración de Cámara Oficial.

En 1935, en vísperas de la Guerra Civil, España había llegado a un satisfactorio nivel de electrificación. Sin contar los autoproductores, la potencia instalada era 
de 1.480 MW (el 75 por ciento de ellos en centrales hidroeléctricas, debido a la orografía española, y el 25 por ciento restante en centrales térmicas). La producción anual era de 3.272 GWh. Desde 1901 a 1935, la potencia instalada se había incrementado a un ritmo de un 8 por ciento acumulativo y la producción lo había hecho a un 9,4 por ciento. El consumo de electricidad por habitante era todavía muy inferior al de los países industrializados. Mientras que Cataluña y el País Vasco tenían consumos similares a los de Alemania, Francia y Gran Bretaña, sin embargo, Andalucía, Castilla y León, Castilla-La Mancha y Galicia quedaban muy lejos de ellos, debido a su menor grado de desarrollo, pese a la abundancia de recursos hidroeléctricos en algunas de estas regiones. Sin embargo, el consumo aumentaba de año en año y existía un margen de potencia no utilizada y suficiente para atender ese crecimiento.

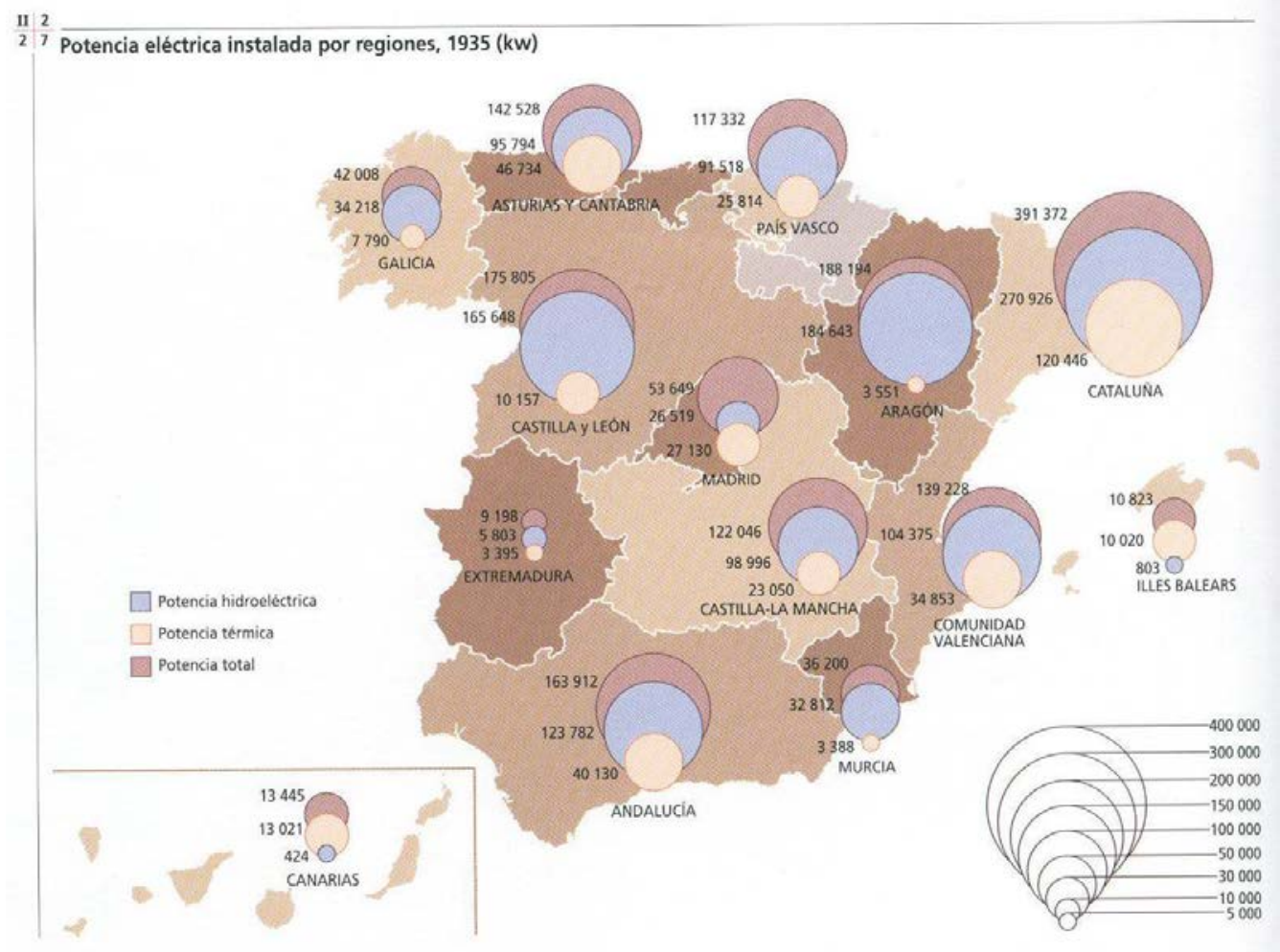

En síntesis: el sector eléctrico había superado ya la etapa de formación y primer crecimiento y había sentado las bases para su posterior desarrollo.

\subsection{EL SECTOR EMPRESARIAL EN EL PERIODO 1936-1960}

Al final de la Guerra Civil el sector eléctrico quedó estrechamente controlado por el Estado. El Gobierno establecía los precios a los que había de venderse la electricidad. 
El sistema eléctrico español no había sufrido daños graves y existía cierto margen de potencia infrautilizada. No obstante, aunque las destrucciones de equipo productor y líneas de transporte no habían sido en sí muy importantes, todas las instalaciones se resentían de la falta de atención durante los tres años de la guerra. Para la reconstrucción o reparación de lo destruido y la puesta a punto de lo deteriorado o simplemente obsoleto, eran necesarias importantes inversiones.

El sector eléctrico trató de cubrirlas mediante créditos exteriores, pero su formalización no llegó a efectuarse por el temprano estallido de la Segunda Guerra Mundial. Las empresas eléctricas tuvieron así que afrontar la reconstrucción de sus instalaciones a ritmo más lento y con los limitados recursos nacionales de que disponían, en una época de casi total aislamiento exterior.

En esta etapa fueron muy pocas las empresas privadas de nueva creación. Sólo hay que destacar la puesta en explotación de las enormes reservas hidroeléctricas de Galicia, hasta entonces prácticamente intactas, que llevaron a cabo Fuerzas Eléctricas del Noroeste (Fenosa) y Saltos del Sil, fundadas respectivamente en 1943 y 1945.

Cuando esa tarea podía considerarse terminada, hubo unos años de extrema sequía, que obligaron a implantar restricciones de suministro, dada la gran dependencia de la producción hidráulica que el sistema eléctrico nacional tenía en aquella época.

Las condiciones meteorológicas vinieron a anticipar una situación que era inevitable, por otra parte, por los defectos estructurales que presentaba el sistema eléctrico español y por la falta de inversiones y nuevas instalaciones para atender al crecimiento de la demanda, acelerado por el proceso de reindustrialización en marcha.

Las dificultades del comercio exterior suponían sin duda un freno para emprender nuevos proyectos, pero la ausencia de éstos era debida fundamentalmente a que las empresas eléctricas no tenían incentivos. Durante la década de 1940-1950, la doctrina oficial defiende el principio de retorno a los niveles de precios y de salarios de 1936. Así, en una época de gran inflación, las tarifas permanecieron congeladas a los niveles de 1936, hasta el año 1951.

En el sector eléctrico acontecieron, en estos años, hechos de gran trascendencia. En 1944, cuando se iniciaron las restricciones eléctricas, las diecisiete empresas más importantes del sector constituyeron, por iniciativa de José María de Oriol y 
Urquijo, la sociedad Unidad Eléctrica, S.A. (Unesa), con el fin de hacer posible una explotación racional y unificada del sistema eléctrico nacional, conservando las compañías integrantes su propia personalidad, libertad de decisión y ámbito de actuación empresarial.

Según sus Estatutos, Unesa tenía corno objetivo "conjugar" las producciones de sus socios mediante los programas de utilización de la energía, para el más completo abastecimiento de los mercados, y estudiar las cuestiones de carácter general que interesaran a las empresas eléctricas. Bajo la forma de una sociedad anónima, para eludir la prohibición de organizaciones sindicales y empresariales establecida en la Ley Sindical de 1940, se constituyó una verdadera patronal eléctrica, continuadora de la antigua Asociación de Productores y Distribuidores de Electricidad, a la que además se atribuyó estatutariamente la tarea de coordinación de las empresas integradas en ella.

La necesidad de esa explotación unitaria y coordinada era evidente, ante las dificultades por las que atravesaban los suministros eléctricos, y ya había motivado diversas medidas administrativas, como el reparto del territorio nacional en diferentes zonas, al cargo de las cuales se nombraron Delegados Técnicos con amplias atribuciones.

Ahora, al crearse Unesa, la Administración le encomendó expresamente esa función coordinadora en una Orden ministerial de diciembre de 1944, dictada para hacer frente a la circunstancia de excepción que suponían las restricciones eléctricas.

Años más tarde, en 1953, normalizados ya los suministros, el Ministerio de Industria asignó esa función de coordinación con carácter permanente al Repartidor Central de Cargas (Reca) de Unesa, delegando en él las competencias administrativas para la gestión de la Red General Peninsular y de los intercambios forzosos de energía a través de ella. La coordinación de las empresas eléctricas como si una sola entidad produjese, transportara y distribuyera la energía en nuestro país, evitó la nacionalización del sector en momentos en que otros países, como Gran Bretaña, Francia, Italia o Portugal, procedieron a la catalización de las empresas eléctricas.

En 1944, tuvo lugar la fusión de Hidroeléctrica Ibérica y de Saltos del Duero, naciendo Iberduero, que pasó a ser la mayor compañía eléctrica española. Por las mismas fechas, el Instituto Nacional de Industria, el INI, decidió participar en el sector y encomendó la instalación de varias centrales térmicas a la Empresa Nacional "Calvo Sotelo". Además, creó una nueva sociedad, la Empresa Nacional de Electricidad (ENDESA), para instalar una gran central térmica en Ponferrada. 
Un año después, en 1945, el INI creó otra sociedad eléctrica, la Empresa Nacional Hidroeléctrica del Ribagorzana (Enher), para el aprovechamiento integral de la cuenca de este río pirenaico.

Asimismo, en 1945, se constituyó, con el apoyo del Banco Central, otra empresa eléctrica, Saltos del Sil, para construir y explotar importantes aprovechamientos hidroeléctricos en el último tramo de este río y sus afluentes. En los años siguientes, se crearon otras sociedades, como Saltos del Nansa, Hidroeléctrica de Galicia e Hidroeléctrica Moncabril, para llevar a cabo el aprovechamiento de diferentes cuencas.

La amenaza de las restricciones hizo nacer una nueva generación de sociedades eléctricas, debidas unas a decisiones gubernamentales y las otras a la iniciativa privada. Con la excepción de Enher, las sociedades de creación estatal se dedicaron a la construcción de centrales térmicas, buscando la diversificación del parque de generación eléctrica y un efecto dinamizador de otro sector estratégico, el de la minería del carbón.

Las iniciativas particulares se orientaron a la construcción de aprovechamientos hidroeléctricos, que a la larga ofrecían mayor rentabilidad, dando paso a una época de grandes realizaciones en este campo.

Para consolidar las inversiones en esta nueva etapa fue preciso modernizar la gestión del sistema eléctrico y reformar y actualizar sus tarifas eléctricas, mediante el Decreto de 12 de enero de 1951.

Por ello, la nueva organización del servicio eléctrico mantenía la propiedad de los medios de producción y la pluralidad de sus gestores, pero procedía a su unificación en todo el ámbito nacional, lo que algunos autores han considerado una "nacionalización" del servicio.

A tal fin, el Decreto estableció y reguló el régimen de la Red General Peninsular, integrada por los sistemas eléctricos de las entidades que produjeran o distribuyeran al menos $25 \mathrm{GWh}$ anuales. Las empresas integradas en esa Red venían obligadas a efectuar los transportes e intercambios de energía acordados con otras empresas u ordenados por la Administración por razones de utilidad pública, así como a adquirir la energía disponible de reservas a favor del Estado o producida por centrales de empresas públicas o privadas.

El Decreto de 1951 estableció también un sistema único de tarifas, las "tarifas tope unificadas", de aplicación en todo el territorio nacional, determinadas según una fórmula polinómica que tomaba en consideración los diferentes 
factores de coste de la electricidad con referencia al año 1935. El valor resultante de la aplicación de la fórmula se incrementaba en un porcentaje, "el recargo r", destinado a una Oficina Liquidadora de Energía (Ofile) y que ésta destinaba a compensar el mayor coste de producción de la energía térmica, el mayor coste de instalación de las centrales construidas a partir de 1939 y ciertos suministros especiales para los que la tarifa generaría pérdidas.

La prima a las nuevas construcciones fue decisiva para que las empresas intensificaran el amplio programa de aprovechamientos hidroeléctricos, sobredimensionándolos en su potencia para percibir mayor prima.

En los años cincuenta, se produjeron también algunos importantes cambios estructurales en el sector eléctrico. La Compañía Sevillana de Electricidad reforzó su presencia en Andalucía llevando a cabo la absorción de algunas pequeñas empresas distribuidoras en la región y, sobre todo, la de Mengemor en 1951.

Además, se produjo la quiebra y liquidación del grupo de la Barcelona Traction, que solicitó el financiero Juan March en el Juzgado de Reus, porque la sociedad eléctrica no había pagado a sus vencimientos las obligaciones en moneda extranjera que tenía emitidas desde hacía años. La Canadiense alegó en su defensa que no había podido efectuar ese pago en virtud del régimen de cambios entonces vigente, ya que el Instituto Español de Moneda Extranjera no le había facilitado las divisas necesarias, y llegó a demandar al Estado español ante el Tribunal Internacional de la Haya. Pero lo cierto es que la justicia española declaró la quiebra de la Barcelona Traction y que March se adjudicó en subasta los activos de la empresa y constituyó con ellos la sociedad Fuerzas Eléctricas de Cataluña, Fecsa.

Tras esos cambios, el sector seguía fuertemente concentrado a finales de los años cincuenta. El Banco de Vizcaya controlaba casi el 40 por ciento de la potencia instalada en España a través de las sociedades en que participaba. Ese porcentaje era del 60 por ciento si al grupo eléctrico del Banco de Vizcaya se sumaban Fecsa y las empresas eléctricas del INI.

Con todo, al término del período de la autarquía económica, el sector eléctrico había experimentado un gran crecimiento. Pese a las dificultades de la posguerra y a los problemas de abastecimiento en la época de las restricciones, el sector había tenido un desarrollo que le permitía continuar prestando un buen servicio al país, en momentos de despegue de la economía nacional. 
Desde 1940 a 1957, el consumo había pasado de 4.050 a 14.696 GWh, con un incremento anual medio acumulativo cercano al 10 por ciento. Para atenderlo, la potencia instalada se había triplicado, pasando de 1.851 MW (1.402 hidráulicos y 449 térmicos) a 5.486 MW (3.876 hidráulicos y 1.610 térmicos). La red había crecido en mucha mayor proporción. Los 2.126 kilómetros de líneas existentes en 1940, a la tensión de $110 / 138 \mathrm{kV}$ se multiplicaron por seis y eran ahora 12.360 kilómetros, de los que 10.188 correspondían a líneas a $110 / 138 \mathrm{kV}$ y 2.172 a líneas a $220 \mathrm{kV}$, tensión de servicio inexistente al principio del período. El sector eléctrico podía así afrontar con optimismo los tiempos de liberalización que se anunciaban.

\section{3. $\underline{1960-1975}$}

En los últimos años cincuenta y en la década de los sesenta, el sector eléctrico español vivió una de las mejores etapas de su historia. En el año 1969, el consumo llegó a $49.750 \mathrm{GWh}$, lo que suponía un incremento anual medio acumulativo del 10,5 por ciento. La producción fue de $52.090 \mathrm{GWh}$, pues los intercambios internacionales de ese año 1969 tuvieron un saldo exportador de $2.340 \mathrm{GWh}$. Esa producción fue posible gracias a que la potencia instalada era ya de $15.665 \mathrm{MW}$, de los que 9.356 (el 59,7 por ciento) correspondían a centrales hidroeléctricas, 6.156 a centrales térmicas convencionales y 153 a la central de Zorita, la primera nuclear instalada en España.

La red alcanzaba una longitud total de 25.906 kilómetros, de los que 13.548 eran líneas a $110 / 138 \mathrm{kV}, 10.759$, líneas a $220 \mathrm{kV}$, y los restantes 1.599, líneas a la tensión de $380 \mathrm{kV}$, introducida en el sistema eléctrico español en ese período.

En los primeros años del periodo, el crecimiento del parque de generación español se debió principalmente a las instalaciones hidroeléctricas. Se construyeron grandes embalses y centrales muy notables de la ingeniería española, con una potencia conjunta superior a los 3.000 MW. Fue la última gran expansión hidroeléctrica.

Sin embargo por sus reducidas horas de utilización, ese aumento de la capacidad hidroeléctrica no fue suficiente para atender a un incremento de la demanda todavía mayor. Hubo que aumentar también el parque termoeléctrico y se instalaron otros $2.000 \mathrm{MW}$ en nuevas centrales térmicas, diseñadas en su gran mayoría para consumir carbón.

En la segunda etapa del período, continuó la construcción de centrales térmicas, diseñadas ahora para funcionar con combustibles líquidos derivados del 
petróleo, aprovechando su bajo precio. Mientras que el carbón subió un 19 por ciento entre 1960 y 1970, el fueloil bajó en ese mismo tiempo un 34 por ciento. El precio del combustible, la mayor simplicidad de las instalaciones de fueloil y, consiguientemente, unos menores costes de explotación, inclinaron mayoritariamente a las empresas eléctricas a construir centrales de este tipo. La energía termoeléctrica aumentaba así, año tras año, su cuota de participación en el balance energético nacional, hasta llegar a superar en importancia a la producción hidroeléctrica y convertirse en la base del sistema eléctrico nacional.

El sector eléctrico entró también en los sesenta en el campo nuclear. Unión Eléctrica Madrileña puso en servicio en 1968 la central de Zorita de los Canes (Guadalajara). Por las mismas fechas, Nuclenor, constituida al 50 por ciento por Iberduero y Electra de Viesgo, construía la central de Santa María de Garoña, junto al río Ebro, en la provincia de Burgos, y la sociedad Hispano Francesa de Electricidad (Hifrensa), constituida a partes iguales por las tres empresas catalanas (Fecsa, Enher e Hidroeléctrica de Cataluña) y por la francesa EDF, instalaba la central de Vandellós I, en la costa de Tarragona. Cuando estas centrales todavía estaban en construcción (entraron en servicio en 1971 y 1972, respectivamente, con lo que el parque nuclear español sumó 1.120 MW), las empresas eléctricas proyectaban ya la instalación de otros doce grupos nucleares.

Ante tal número de iniciativas y proyectos, la Administración consideró necesario poner orden en las inversiones de las empresas eléctricas y coordinarlas en lo posible. Era la época de los planes de desarrollo. El Ministerio de Industria comenzó también la planificación del sector con carácter indicativo. Las iniciativas de las empresas se refundieron por Unesa y el Plan Eléctrico Nacional propuesto por ésta para los años 1972-1982, fue aprobado por una Orden ministerial de 31 de julio de 1969. Por primera vez en la historia del sector, la construcción de nuevas instalaciones se trató en el plano nacional, en función de las proyecciones de crecimiento de la demanda total.

Durante esta etapa, prosiguió también el proceso de concentración empresarial en el sector. El número de empresas eléctricas disminuyó drásticamente, apareciendo grupos empresariales claramente más importantes, que fueron el embrión de los actuales.

La compañía Sevillana de Electricidad quedó como única empresa en Andalucía y Badajoz, al absorber a Hidroeléctrica del Chorro, la única firma importante que quedaba en la región, e integrar las instalaciones eléctricas que el INI había construido en ella en los últimos quince años. Unión Eléctrica Madrileña 
absorbió a Saltos del Alberche a principios de los sesenta, a Hidroeléctrica de Moncabril a finales de ese decenio y a la distribuidora Eléctricas Leonesas dos años después, cambiando su nombre por el de Unión Eléctrica, más acorde con los nuevos límites de su actuación empresarial, que quedó muy reforzada en la generación hidroeléctrica después de esas operaciones.

\subsection{EL SECTOR EN LOS AÑOS DE LA CRISIS DEL PETRÓLEO}

La planificación eléctrica de 1969 hizo ver la necesidad de modificar el sistema vigente de tarifas tope unificadas. Por ello, el Gobierno sentó las bases para su perfeccionamiento ese mismo año y, por Decreto de 16 de agosto de 1969, se establecieron tarifas de estructura binómica. Se trataba de retribuir, no sólo la energía consumida, sino también la potencia contratada, que es la que obliga a las empresas a aumentar su capacidad de generación y a realizar las más cuantiosas nuevas inversiones. Las tarifas binomias se aplicaron a partir de 10 de enero de 1971.

Sin embargo, el Sistema Integrado de Facturación de Energía, el nuevo régimen tarifario que vino a sustituir a las tarifas tope unificadas de 1951, no se implantó hasta más tarde, por Decreto de 21 de diciembre de 1972.

El cambio del sistema de tarificación se aprovechó para suprimir las primas y compensaciones de Ofile y para extinguir este organismo, que arrastraba un gran déficit. Fue sustituido por la Oficina de Compensación de la Energía Eléctrica (Cecoel).

Casi al mismo tiempo, por Orden ministerial del siguiente día 23, se establecieron las "Bases para el desarrollo y explotación conjunta del sistema eléctrico peninsular". En ellas se avanzaba en la gestión global del sistema eléctrico y se planificaba también la construcción de las nuevas instalaciones, conforme a las previsiones del Plan Eléctrico Nacional.

Poco después, en el otoño de 1973, la Organización de Países Exportadores de Petróleo (Opep) llevó a cabo un repentino y brusco aumento de los precios del crudo. Con ello, puso fin a la etapa de gran expansión económica de que había disfrutado el mundo occidental en los dos últimos decenios, gracias, en gran parte, a la disponibilidad de energía abundante y barata. Al multiplicarse por tres en muy pocos meses el precio de los crudos, que eran la principal fuente de energía primaria (el 44 por ciento del consumo mundial), la economía entró en una crisis mundial, que obligó a los países más industrializados a adoptar serias medidas para contener el consumo y superar la situación. 
En España, pese a que la dependencia del petróleo era aún mayor (el crudo representaba el 68 por ciento del consumo bruto de energía), las circunstancias políticas y sociales por las que atravesaba el país llevaron al Gobierno a demorar la aplicación de medidas correctoras y de contención del consumo, absorbiendo en las cuentas del Estado gran parte del incremento del coste de los productos petrolíferos. La Administración se limitó, en un primer momento, a promover la construcción de nuevas centrales hidráulicas o de carbón que permitieran reducir la dependencia del petróleo, pero el consumo de éste se mantuvo y las centrales de fuel siguieron funcionando como años antes. Después, al producirse en 1979 la segunda crisis del petróleo, avanzada ya la transición a la democracia, el Gobierno hubo de modificar esta política de simples medidas de fomento y las acompañó con la aprobación de un nuevo Plan Energético Nacional (PEN) y la paralización de las centrales de fuel, para reducir las importaciones de petróleo.

Durante el estudio y la tramitación del PEN-79, se vio que la actuación del Reca de Unesa no siempre era objetiva y que podía mejorarse, por lo que se llegó a plantear la conveniencia de encomendar la gestión de la red y del sistema eléctrico a una empresa estatal.

El gobierno de la UCD no llegó a hacerlo, pero por un Real Decreto de 1980 se atribuyeron las funciones del Reca a Aseléctrica, una asociación de todas las empresas eléctricas bajo la supervisión de un Delegado del Gobierno.

Aún antes de que la Administración decidiera cambiar su política energética para hacer frente a la crisis económica, los efectos de ésta afectaban muy duramente al sector eléctrico.

El aumento anual de la demanda se redujo sensiblemente. El incremento del precio de los combustibles y de los demás costes de explotación sólo se compensó en parte con el aumento de las tarifas, para no disparar más aún la elevada inflación de aquellos años.

Además, los altos tipos de interés y la devaluación de la peseta encarecieron notablemente las inversiones en curso. Las consecuencias no pudieron ser otras que el deterioro de las cuentas de las empresas eléctricas y la bajada de sus cotizaciones en Bolsa.

Ocurría todo esto, además, en un momento en que el sector estaba inmerso en un ambicioso plan de crecimiento. Durante esos años, entraron en servicio o estaban próximos a hacerlo veinte grupos termoeléctricos de al menos $350 \mathrm{MW}$ 
de potencia. De ellos, cuatro de 350 MW y tres de 550 MW habían sido diseñados para fuel y quedaron pronto inactivos.

Estaban en construcción ocho grandes grupos nucleares de 1.000 MW cada uno, cuyo montaje se demoró y encareció mucho más de lo previsto por la conflictividad laboral, la creciente oposición ecologista y las rigurosas condiciones medioambientales y de seguridad que se exigían. La Red General Peninsular, que a finales de 1973 alcanzaba 30.197 kilómetros, creció en los ocho años siguientes un 33 por ciento y en 1981 tenía una longitud de 40.245 kilómetros, de los que $8.905 \mathrm{kms}$ (el 22 por ciento) eran a $380 \mathrm{kV}, 13.958 \mathrm{kms}$ (el 34 por ciento) a $220 \mathrm{kV}$ y los restantes $17.382 \mathrm{kms}$ (el 44 por ciento) a 110/132 kV. Como la demanda de electricidad se había estancado, era previsible una situación de sobre equipamiento que dejaría sin rentabilizar durante varios años el esfuerzo inversor hecho.

El panorama que queda expuesto explica muchas de las situaciones y de los cambios que se producirían en los años siguientes en el sector eléctrico. Por lo demás, éste continuó en la etapa que hemos resumido el proceso de concentración empresarial, ininterrumpido en toda su historia. En 1973, Saltos del Sil se fusionó con Iberduero, con lo que ésta reforzó su primacía indiscutible en la generación hidroeléctrica y, consiguientemente, la importante función que venía desempeñando en la regulación del sistema eléctrico en la mayor parte del territorio nacional. En 1975, Hidroeléctrica Española absorbió a la Compañía de Riegos de Levante y en 1980 formuló una OPA sobre las acciones de la Compañía Eléctrica de Langreo y tomó su control. En 1981, Unión Eléctrica y Fuerzas Eléctricas del Noroeste acordaron fusionarse en Unión EléctricaFenosa.

\subsection{EL SECTOR DE 1982-1996}

La llegada del PSOE al Gobierno, a finales de 1982, fue recibida con inquietud por el sector eléctrico. Las proclamas antinucleares de significados militantes socialistas y las medidas de intervención en sectores estratégicos, incluidas en el programa electoral, hacían temer a muchos el cierre de centrales nucleares y la nacionalización del sector.

Esto era, junto con la delicada situación económica por la que atravesaban algunas empresas, causa de que las eléctricas cotizaran en Bolsa a precios inferiores a su valor real. Después, sólo se nacionalizó la red de transporte. Empresas y Estado acordaron el procedimiento de traspaso de la red al sector público, la revisión del Plan Energético Nacional de 1979 y la adopción de 
diversas medidas para el saneamiento económico del sector, entre ellas una política de tarifas suficiente.

Poco después el Consejo de Ministros autorizó al INI a reordenar sus participaciones en el sector eléctrico y traspasarlas a la empresa estatal más saneada y con mayores beneficios. ENDESA se constituyó así en la sociedad matriz y cabecera del grupo eléctrico público.

La operación respondió fundamentalmente a razones presupuestarias, pero fue también un paso más (protagonizado por el grupo de empresas estatales) en el proceso histórico de concentración del sector eléctrico español.

Al año siguiente, en 1984, el Ministerio de Industria presentó la revisión del Plan Energético Nacional al Congreso de los Diputados, que le dio su aprobación el 24 de junio de 1984. Lo más significativo del Plan Energético Nacional revisado era que, al tiempo que autorizaba el funcionamiento de centrales nucleares, decretaba una moratoria nuclear parcial, rechazando nuevos proyectos y ordenando la paralización del montaje de cinco grupos nucleares cuya construcción estaba debidamente autorizada: los dos grupos de la central de Lemóniz, a punto de entrar en servicio; los dos de la de Valdecaballeros, cuya construcción estaba avanzada; y el grupo 2 de la central de Trillo, en fase de iniciación y con cuestiones técnicas pendientes de resolver. Esta decisión se presentó a la opinión pública como fruto de la posición antinuclear del partido gobernante, pero tenía también justificación en la situación de sobre equipamiento del sector. En el caso de Lemóniz, era, además, una consecuencia más de la conflictiva situación del País Vasco.

Por las mismas fechas en que se aprobaba el PEN, el Gobierno revisó las tarifas y destinó un porcentaje de ellas a un programa de saneamiento financiero para las empresas que cumplieran determinados requisitos de información y económico financieros. La Administración completó estas medidas estableciendo un nuevo sistema de compensaciones entre las empresas, para tener en cuenta las diferencias de producción y mercado existentes entre ellas y su repercusión en los costes de abastecimiento del sistema.

El Gobierno sometió a la aprobación del Parlamento la ley de nacionalización de la red de transporte. La Ley 49/1984, de Explotación Unificada del Sistema Eléctrico Nacional, fue aprobada el 26 de diciembre de ese año y autorizó la creación de una empresa mixta con mayoría de capital público, que sería la propietaria de la red de alta tensión necesaria para optimizar la explotación unificada del sistema eléctrico. La sociedad cuya creación se autorizaba se constituyó a principios de 1985 con el nombre de Red Eléctrica de España, 
asumió la titularidad del Centro de Control Eléctrico de Aseléctrica y sustituyó a esta asociación en la gestión de la producción y del transporte eléctrico. Su función iba más allá de la explotación unificada que, primero el Reca y después el Cecoel, habían venido realizando desde 1953, para la coordinación de las producciones de las empresas. La explotación unificada pasó ahora a tener por objeto la optimización global del sistema eléctrico, como una sola unidad, mediante la programación vinculante de todas las instalaciones de producción y transporte, siguiendo las directrices gubernamentales de política energética y el criterio del mínimo coste. La generación de electricidad y su distribución en el mercado quedaban ahora separadas e independizadas funcionalmente en las empresas eléctricas.

Finalmente, como última actuación en el sector y para reducir sus costes de explotación, el Gobierno estudió una nueva configuración de las zonas del mapa eléctrico nacional y una reordenación de los mercados de las compañías distribuidoras, dispersos y entremezclados sobre todo en la zona cantábrica y en Cataluña. Sin embargo, la puesta en práctica de esta idea presentó muchas dificultades, agravadas por la situación de hechos consumados que crearon algunas empresas. Hidroeléctrica Española se anticipó a cualquier decisión ministerial y, en un paso más del proceso de concentración que venían siguiendo las principales sociedades del sector, formuló una OPA sobre Hidroeléctrica de Cataluña y tomó el control de esta compañía.

La idea del mapa eléctrico hubo de abandonarse y se sustituyó, como solución pragmática, por un acuerdo para la reordenación del sector y su saneamiento económico-financiero, negociado en el seno de Unesa.

Parte esencial de este acuerdo fue un "intercambio de activos" mediante la compraventa de instalaciones de generación y mercados de distribución entre las empresas del sector, para redistribuir entre ellas los programas de inversiones y la deuda que venían soportando.

El intercambio de activos, por un precio total cercano al billón de pesetas, se llevó a cabo el 31 de diciembre de 1985, último día en que pudo efectuarse con los beneficios fiscales que concedía la Ley 49/1984 debido a la complejidad de la operación y los problemas que hubieron de superarse hasta llegar a su realización. En el intercambio, el grupo eléctrico público tuvo importante participación y salió de él notablemente reforzado.

El sector eléctrico tachaba de intervencionismo las actuaciones del Gobierno, aún reconociendo que muchas de ellas contribuyeron a sanear y mejorar la situación de las empresas. 
Éstas habían de enfrentarse además a otros problemas, como el exceso de potencia instalada. Mientras que la demanda eléctrica sólo crecía anualmente en torno a un 3 por ciento, el parque de generación de base se había incrementado considerablemente.

Estaban paralizadas las centrales de fuel, por la carestía del petróleo, pero en la primera mitad de los ochenta se habían puesto en servicio las centrales nucleares de Almaraz, Ascó y Cofrentes, con cinco grupos de más de 930 MW de potencia unitaria. En el mismo tiempo habían iniciado también la producción seis grupos termoeléctricos de 350 MW y otros tres de 550 MW. Además, la construcción de las centrales nucleares de Vandellós 2 y Trillo se encontraba muy avanzada y su próxima entrada en funcionamiento supondría la incorporación de otros 2.025 MW de nueva potencia.

En la primavera de 1987, Fecsa, cuya cotización en Bolsa había sido suspendida unos meses antes por el regulador del mercado de valores, solicitó a los Bancos acreedores la refinanciación de su deuda. La noticia tuvo gran repercusión entre los inversores y entidades crediticias, españolas y extranjeras, con riesgo de endurecer y encarecer la financiación de todo el sector eléctrico, por lo que tanto éste como el Gobierno hubieron de acudir rápidamente en ayuda de Fecsa. Las empresas eléctricas se comprometieron a suscribir ampliaciones del capital de la compañía catalana, para que ésta incrementara sus fondos propios y pudiera reducir su endeudamiento, según el plan de saneamiento estudiado por la dirección de la compañía.

El Gobierno anunció la implantación de un nuevo sistema de cálculo de la tarifa eléctrica, que daría solución al problema de sobrecapacidad existente y aseguraría a las empresas una remuneración suficiente. La tarifa cubriría todos los costes estándares de explotación de las empresas eléctricas y garantizaría la total recuperación de sus inversiones, a lo largo de la vida útil de las instalaciones.

El nuevo régimen tarifarlo, conocido como Marco Legal Estable, se implantó por Real Decreto de 11 de diciembre de 1987 y entró en vigor a partir de 1 de enero del año siguiente. Inicialmente, fue muy bien recibido por el sector eléctrico. Las críticas que éste formuló más tarde fueron dirigidas, más que al sistema en sí, al reparto que hacía de la tarifa entre las diferentes empresas del sector. Para corregir las desigualdades y falta de transparencia que se achacaban al Marco, éste fue modificado en diciembre de 1993.

Criticas aparte, la conjunción del final de un ciclo inversor del sector eléctrico y la aplicación del Marco Legal Estable permitió a las empresas superar sus 
problemas financieros y sanear sus cuentas, de tal manera que su situación económica en 1998, cuando el Marco dejó de aplicarse, era radicalmente distinta a la de diez años antes, cuando entró en vigor.

Ello hizo posible que las empresas se encontraran después en condiciones de hacer frente a la competencia, cuando se produjo la liberalización del mercado eléctrico.

Durante el periodo del Marco Legal Estable, se modificó sustancialmente la estructura empresarial del sector. En 1991, dos de las grandes compañías privadas, Iberduero e Hidroeléctrica Española, acordaron fusionarse y formaron Iberdrola, que representaba el 40 por ciento del sector eléctrico español. En ese año y en los siguientes, el grupo eléctrico público creció hasta hacerse con otro 40 por ciento del sector, mediante sucesivas compras de acciones de otras compañías. El 20 por ciento restante se distribuiría entre Unión Fenosa (un 15 por ciento) e Hidroeléctrica del Cantábrico.

Cuando la Administración decidió modificar el Marco Legal Estable en 1993, el sector eléctrico demandaba también una solución al problema de la moratoria nuclear, que lastraba pesadamente las cuentas de algunas de las empresas. El Gobierno rehusó resolver el problema mediante una ley o disposición con rango de ley dictada específicamente para ello, y dejó la regulación de la moratoria y la definitiva paralización de las instalaciones afectadas para cuando aprobara una nueva ordenación legal del sector eléctrico. Ésta era a todas luces necesaria para dar seguridad jurídica a un sector que venía siendo regido por normas dispersas de muy diverso rango, para consolidar y perfeccionar el modelo de regulación aplicado en los últimos años y para avanzar en la adecuación de la legislación española a los criterios de liberalización y competencia que inspiraban las Directivas de la Unión Europea en fase de discusión en Bruselas.

Con esos objetivos, el Gobierno remitió al Congreso de los Diputados en junio de 1994 un proyecto de Ley de Ordenación del Sistema Eléctrico Nacional. Tras su tramitación parlamentaria, el proyecto se convirtió en la Ley 40/1994, de 30 de diciembre, que entró en vigor en enero de 1995.

La Losen representó un tímido intento de modernización del sistema eléctrico, manteniendo en lo sustancial su regulación anterior. La corta vigencia de la ley, derogada antes de que se cumplieran dos años desde su promulgación, hizo que los escasos y limitados elementos de competitividad existentes en ella no llegaran a ponerse en práctica en ningún proyecto. 
La Losen, en cambio, dio solución satisfactoria al ya viejo problema de la moratoria nuclear, ordenando, en una de sus disposiciones adicionales, la paralización definitiva de las instalaciones en moratoria y la compensación a las empresas propietarias con un porcentaje de la tarifa eléctrica durante el plazo máximo de veinticinco años.

\subsection{LA LIBERALIZACIÓN DEL SECTOR ELÉCTRICO. 1996- ACTUALIDAD}

Poco después de la aprobación de la Losen, el Partido Popular había anunciado que la regulación en ella establecida sería radicalmente modificada cuando llegara al Gobierno de la nación. Consecuente con este anuncio, su programa para las elecciones de 1996 incluyó la liberalización del sector eléctrico y ésta fue una de sus primeras tareas cuando llegó al Gobierno en mayo de 1996. Las bases de la nueva regulación fueron discutidas con las empresas eléctricas y acordadas en un Protocolo que el Ministro de Industria y Energía y los Presidentes de ENDESA, Iberdrola, Fecsa, Sevillana y Unión Fenosa firmaron el 11 de diciembre de 1996. Hidroeléctrica del Cantábrico se adhirió a este Protocolo meses más tarde, en marzo de 1997.

Esa regulación había sido pedida en los últimos años por las empresas eléctricas privadas, y sobre todo por Iberdrola. Una vez que se hicieron públicas las bases de la nueva regulación, se abría la puerta a la privatización de ENDESA, pues la venta de las empresas estatales era otro de los puntos programáticos del nuevo Gobierno. Sin embargo, antes de que esa privatización se produjera, se dio un nuevo paso en el proceso de concentración empresarial del sector eléctrico español. En octubre de 1996, ENDESA tomó la mayoría del capital y el control de Fecsa y Sevillana.

El Gobierno preparó un proyecto de Ley del Sector Eléctrico que, tras su tramitación parlamentaria, fue aprobado el 27 de noviembre. La Ley 54/1997 liberalizaba el sector e iba en muchos de sus puntos más allá de lo que exigía la Directiva 96/92/CE sobre Normas Comunes para el Mercado Interior de Electricidad que, poco después, el 19 de diciembre, iba a aprobar la Unión Europea.

En aplicación de la Ley, a partir de 1 de enero de 1998, comenzó a funcionar en España un mercado mayorista de producción de electricidad, gestionado por una entidad independiente. 
La Sociedad Operadora del Mercado determina el orden de funcionamiento de los diferentes grupos generadores del sistema en función del precio que ofertan para cada período horario de programación (de menor a mayor, hasta cubrir la demanda) y retribuye toda la energía en función del precio de la oferta marginal. A este mercado tienen acceso los distribuidores, los comercializadores de electricidad y los grandes consumidores o consumidores cualificados, a quienes se exige unos mínimos de consumo cada vez más reducidos, hasta adquirir esa condición todos los consumidores a partir del 2007.

Para que sea posible acudir al mercado o establecer contratos con los comercializadores, se reconoce el libre acceso de terceros a las redes de transporte y distribución, que son las dos únicas actividades eléctricas que quedan reguladas. Los suministros a tarifa continuarán siendo efectuados por los distribuidores.

Al entrar en vigor esta nueva regulación, las empresas eléctricas dejaron de percibir la retribución que les aseguraba el Marco Legal Estable. Para compensar los menores ingresos que se pudieran obtener en el mercado en relación con los que tenían garantizados por el Marco, que permitían a las compañías la recuperación de los capitales invertidos como consecuencia de decisiones de planificación energética adoptadas por los poderes públicos y que les habían sido impuestas en el pasado, la Ley del Sector Eléctrico les reconoció unos costes de transición a la competencia, los CTC, durante un plazo de diez años y por un importe máximo global próximo a los dos billones de pesetas, cuestión que todavía está en discusión con la Unión Europea.

El sector eléctrico español se enfrentaba, así, por primera vez en su historia, a la competencia.

Las directivas europeas y la creciente globalización de los mercados han conducido a que esa competencia sea, no sólo entre empresas españolas, sino también con empresas extranjeras. En este escenario nuevo, los actuales actores del sector podrán moverse satisfactoriamente gracias a la concentración empresarial que en él se ha producido a lo largo de su historia. Ahora, cada empresa habrá de establecer necesariamente sus propias políticas industriales y comerciales, que ya no podrán ser comunes a todo el sector. 


\section{Capítulo 2.}

\section{Evolución de la ingeniería de turbinas y turbo-bombas}





\subsection{EDAD ANTIGUA (DESDE 3.300 A.C HASTA 476 D.C)}

La rueda hidráulica es el motor hidráulico más antiguo que aprovecha la fuerza de la corriente del agua, pero no existe certeza sobre su origen.

Hay autores que aseguran que la rueda hidráulica era conocida por el hombre desde hace unos 5000 años siendo el pueblo sumerio el que empieza a utilizar este invento para aprovechar la energía de los cauces, disponiendo de molinos movidos por agua. También los griegos y los romanos emplearon estas ruedas.

Sin embargo, otros autores indican que el primer conocimiento sobre el uso de ruedas hidráulicas para aprovechamiento de la Energía Hidráulica data de la época de los griegos, quienes empleaban una rueda hidráulica horizontal de eje vertical llamada noria o "molino griego", inventada por Filón de Bizancio en el siglo III a.C. Las describía como una serie de cucharas que se sumergen dispuestas a lo largo de una cadena en forma de rueda.

No hay que olvidar que la palabra "hidráulica" proviene del griego "hydraulikós" que, a su vez, viene de hydraulos (tubo de agua), palabra compuesta por hydor (agua) y aulos (tubo).

Inicialmente la rueda se usó para elevar agua pero más tarde se destinó a la molienda utilizándose a partir de ahí el nombre de molinos de agua.

En el siglo I a.C., un poeta latino, Antipater de Tesalónica hace la siguiente cita, referente al uso de la rueda hidráulica en las tareas de molienda: "mujer deja de trabajar afanosamente en el molino, sigue durmiendo aunque el gallo madrugador anuncia ya el amanecer, porque Demeter ha ordenado a sus ninfas realizar el trabajo que hacían vuestra manos, y ellas, encaramándose en lo alto de la rueda, hacen girar sus ejes provistos de radios, que a su vez obligan también a girar a las cóncavas piedras del molino".

Strabo relata que el rey griego Mitríades VI usaba un molino de agua en Asia menor sobre el año 88 a. C.

Además de los griegos y los romanos, en la antigüedad los egipcios emplearon la Sakia, (rueda hidráulica de compartimientos o cubos) para elevar agua.

Sin embargo, las primeras referencias detalladas de la rueda hidráulica, así como sus aplicaciones son de tiempos del imperio romano, cuando aparece la rueda hidráulica vertical, también llamada "molino romano". 
A principios de esta era, las civilizaciones que desarrollan la energía hidráulica, al mismo tiempo, son Roma y China. Cada uno de estos dos mundos hace de polo de difusión hacia las regiones vecinas. Y entre el Este y el Oeste los desarrollos hidráulicos toman formas bastante distintas. En ambos casos, la energía hidráulica ocupa un puesto importante en el desarrollo económico de los pueblos que se confirmará y ampliará durante el periodo medieval sin grandes rupturas respecto de las bases tecnológicas establecidas en el curso de los primeros siglos.

El tipo de molino hidráulico de rueda vertical con eje horizontal que se comenzó a construir en el siglo I a.C. (sobre el año 25 a.C.) por el ingeniero Marco Vitruvio, puede que inspirándose en la rueda persa o "saqia", se llamó "molino tipo vitruviano" y también "rota aquaria". Este tipo de rueda fue desarrollada por los romanos debido a su insatisfacción con la rueda horizontal de los griegos debido a su baja eficiencia.

Se han realizado estudios, tanto teóricos como experimentales, que calculan los rendimientos hidráulicos máximos de los molinos de rodete vertical, alcanzando valores del 65\% para los de alimentación mediante canal inferior, 71\% para alimentación por canal superior y $66 \%$ para los de caída libre. Sin embargo, las estimaciones realizadas para los molinos clásicos de rodete horizontal son del orden del $50 \%$.

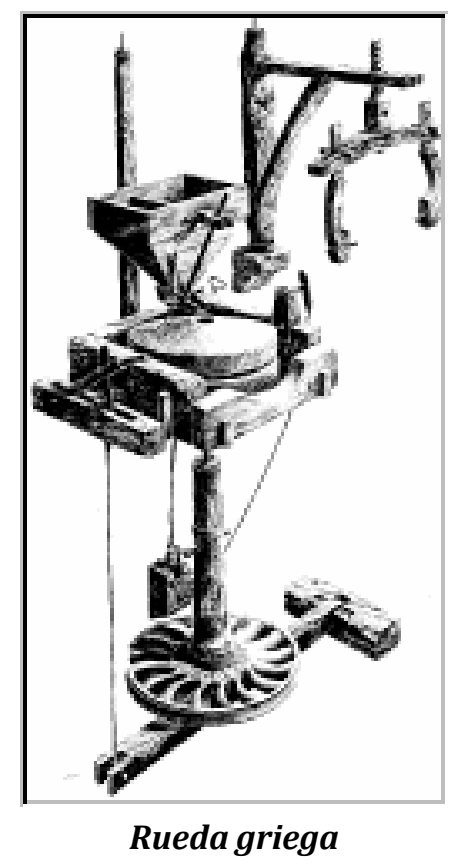

Este tipo de molino fue el más común por muchos siglos, no solo en Europa sino también en América, principalmente en el norte del continente. 


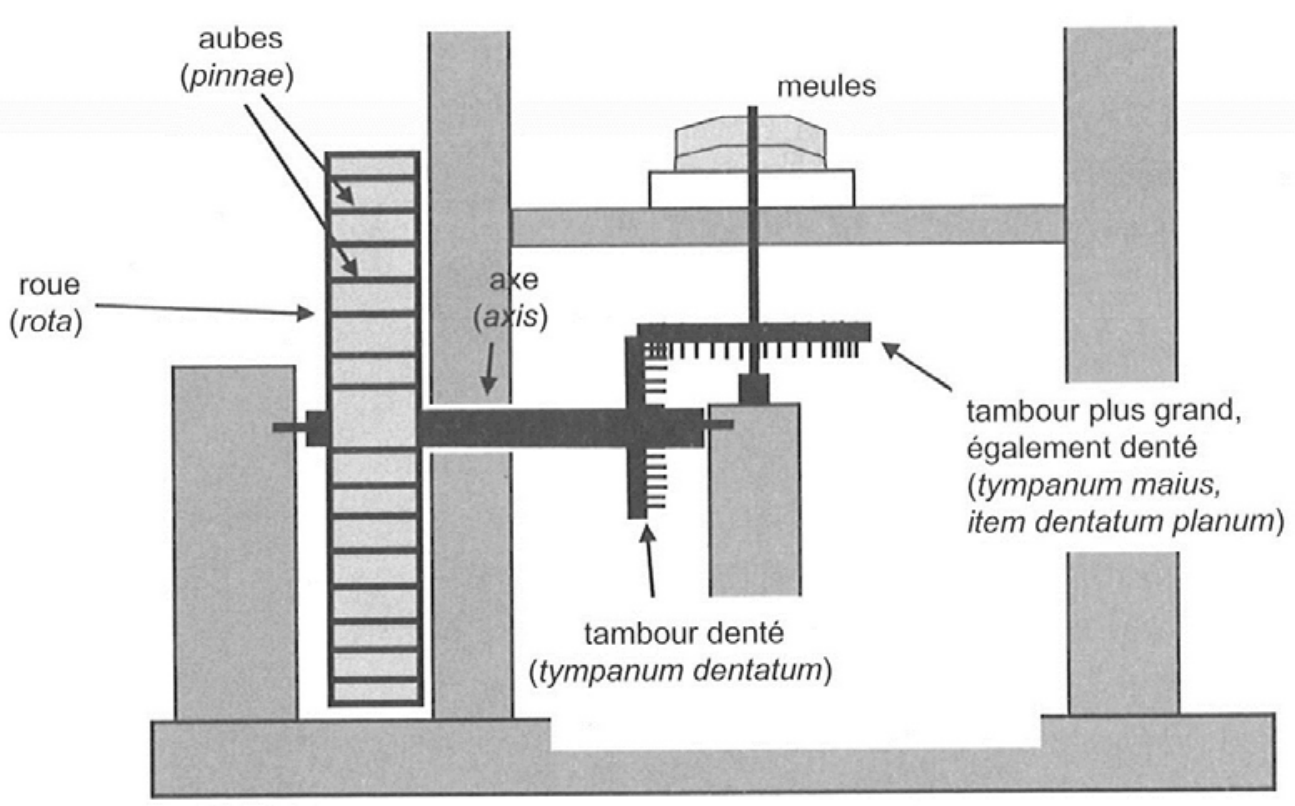

Ilustración de la descripción más antigua de molino de agua con rueda vertical por Vitruvio

Este molino de rueda vertical descrito por Vitruvio, tiene una rueda con eje horizontal que hace girar un tambor dentado, que se llamará más tarde "rodete". Sus dientes se entrelazan con los de otro tambor más grande, según la descripción de Vitruvio, cuyo eje vertical da lugar directamente al movimiento de rotación de las muelas. El molino descrito por Vitruvio tiene una tipología muy próxima al tipo de molinos medievales de Occidente, salvo porque en la Edad Media, el tambor horizontal, que será más tarde llamado "linterna", acabará siendo progresivamente más pequeño que el rodete, dando lugar a una mayor velocidad de rotación de las muelas.

Es probable que esta evolución del diseño del molino de rueda vertical ya estuviera desarrollada de lejos en la época romana, tal y como puede verse en la figura que se adjunta a continuación.

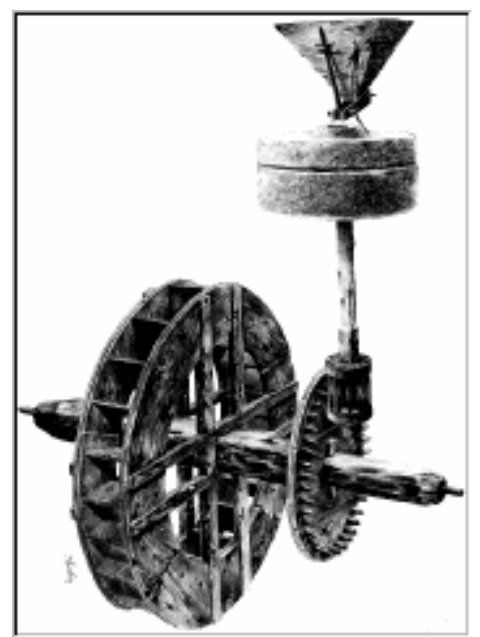

Rueda romana 
En la antigua Roma, las ruedas hidráulicas se utilizaban tanto como molinos como para cortar piedra.

En el primer siglo de esta era, Plinio el Viejo (23-79 d.C.) escribe en sus Historias Naturales que para moler el grano, en Italia, se hacía servir un martillo movido por ruedas de agua, en las que también se adosa una muela.

Recientemente se ha estudiado en Suiza, cerca de la antigua villa romana de Avenches, un molino vertical galo-romano contemporáneo de Plinio, que data de los años 57-58 d.C. Es el molino más antiguo conocido por la arqueología. Tiene una rueda vertical única, adosada a una pequeña edificación que contiene los engranajes y los mecanismos de molienda. La rueda era alimentada por su parte inferior gracias a un canal delimitado por dos planchas de madera.

Otro molino del siglo primero ha sido identificado en Martres de Veyre, dentro del Puy de Dome, molino que fue reconstruido en el siglo II.

Los arqueólogos han encontrado numerosos restos de molinos del siglo II en la Galia y Germania.

En Barbegal, población francesa, próxima a la ciudad de Arlés en el sur de Francia, los romanos construyeron en el siglo II o III de nuestra era un impresionante complejo industrial harinero, formado por 16 molinos, del tipo conocido como aceña, pero con rueda vertical no de aletas, como la descrita por Vitruvio, sino dotada de cangilones. Los molinos, construidos en cadena, estaban distribuidos en dos hileras y en ocho niveles. A los primeros de cada hilera el agua les era suministrada por un acueducto: los demás reutilizaban el agua que salía del anterior. Esta factoría romana tenía la capacidad de moler unos nueve mil kilos de trigo al día.
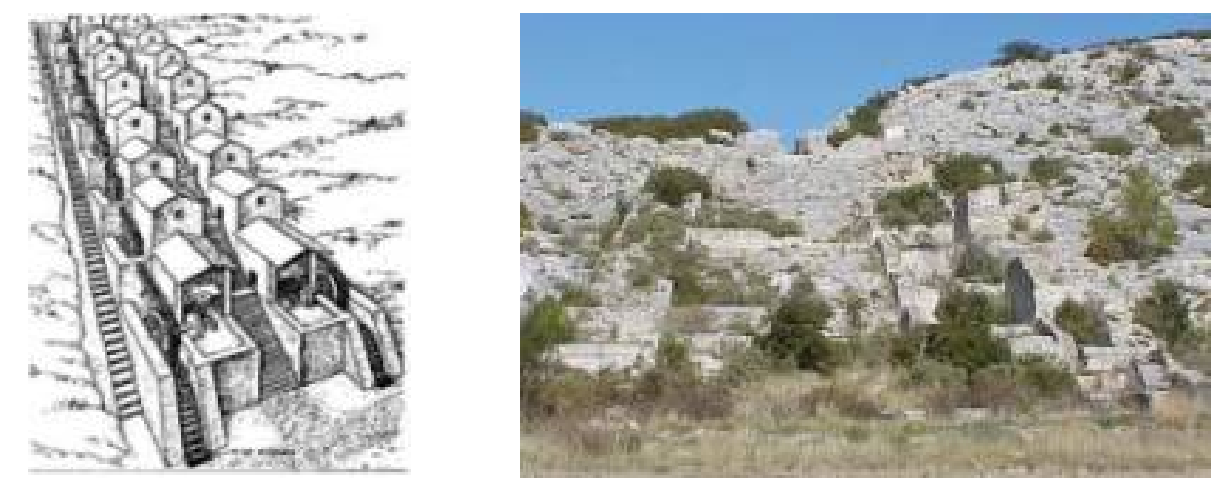

A lo largo del muro de Adriano en Escocia se han encontrado 3 molinos del siglo II y III. 
En la propia Roma se encuentran restos antiguos de molinos de rueda vertical del siglo III, que eran alimentados por acueductos, en la colina Junícula y en el subsuelo de las termas de Caracalla. Eran las primeras ruedas de agua públicas.

Según Ausonio, se instalaron en el siglo IV en el río Mosel y sus afluentes, que discurren por Francia y Alemania, molinos de agua con el fin de convertirse en sierras hidráulicas, y obviamente fueron utilizados para cortar piedra y producir adoquines para las antiguas calzadas romanas en la parte alemana del imperio romano. Otras sierras hidráulicas similares encontradas en Jordania para cortar mármol datan, probablemente, del siglo VI.

Varios molinos, situados en el ágora de Atenas son del siglo V.

En provincias como Hispania, que ha sido reconocida como parte importante en la producción y exportación de granos para Roma, prácticamente la totalidad del grano era molido para obtener harina, materia prima básica en la fabricación de pan, que constituía el principal pilar de la dieta de la época. Para esto, la mayoría de los molinos de grano estaban constituidos por dos muelas (una fija llamada solera y otra móvil o corredera), estas eran poco peraltadas y de pequeño diámetro, y podían moverse gracias al movimiento de la rueda producida por el agua, y en algunas ocasiones con la ayuda de un hombre, a través de un taladro en el que se encajaba un mango de madera que se empuñaba con una mano.

Con menor frecuencia han aparecido en otras provincias romanas molinos de muelas muy peraltadas, llamados molinos pompeyanos -por los magníficos ejemplares de este tipo hallados en la ciudad de Pompeya. Estos molinos requerían, por su tamaño mucho mayor, ser tirados por asnos y tenían naturalmente una capacidad de molienda bastante mayor.

Los tipos de alimentación de los molinos romanos son diversos:

- Alimentación inferior, como el descrito por Vitruvio

- Alimentación por la espalda o a media altura

- Alimentación superior

Las dimensiones de los molinos romanos están comprendidas entre 1,5 y 3 metros de diámetro de rueda según el tipo, y ancho de 25 a $70 \mathrm{~cm}$. Las muelas son de un diámetro comprendido entre los 55 y $85 \mathrm{~cm}$.

La ubicación del molino romano es diversa. Se encuentran molinos ubicados en la ribera de ríos, pero gracias a la alimentación mediante acueducto, y por tanto, 
alimentación artificial, es posible ubicarlos en el sitio donde fuera más conveniente de cara a la proximidad a centros de consumo. Además de esta ventaja, la alimentación por canal o acueducto permitía tener los molinos al abrigo de cualquier destrucción que pudieran causar las avenidas de los ríos. Otro tipo de molino distinto al de rueda vertical, tan desarrollado en las regiones del Imperio Romano, es digno de estudio como precursor de las primeras turbinas. Éste es el molino de rueda horizontal.

Su eje vertical hace directamente girar la muela sin la necesidad de tambores dentados como ocurre en el molino vitruviano. Este molino es más adecuado para aguas poco abundantes, pero necesita una altura de caída bastante grande, por otra parte, como las ruedas verticales de alimentación superior.

No es fácil situar su aparición ya que hay pocos vestigios que ayuden a datarlos con precisión pero sin embargo, parece que su desarrollo se realiza en África en el siglo IV, zona donde el agua no es tan abundante como en otras tierras romanas.

Sin embargo, anteriormente se ha citado este tipo de molino como molino griego ya que otra línea de investigación los ubica en esos territorios, siendo justamente los molinos romanos un desarrollo posterior a los griegos por su baja eficiencia (a juicio de los romanos).

Son conocidos varios molinos de rueda horizontal construidos según distintos conceptos que a continuación se desarrollan.

El primero de ellos es el de las instalaciones de Chemtou y Testour en Túnez, sobre el río Medjerda. A partir de un embalse de toma de agua en el cauce, tres canales conducen el agua a tres pozos cilíndricos, de 0,9 m de diámetro, dentro de los cuales el agua llega tangencialmente, dando lugar a un flujo en remolino dentro de los pozos, que hace rotar a la rueda horizontal que está en el fondo.

Sólo un desnivel de 2 metros es necesario para el funcionamiento de estas instalaciones que datan del siglo IV.

Otro concepto de molino de rueda horizontal o turbina, es el molino con torre de caída, conocido después por el término árabe arubah. El agua llega por canal a una torre de caída de cuatro a diez metros, cuya parte baja hace que salga a presión hacia las palas de una rueda horizontal. 


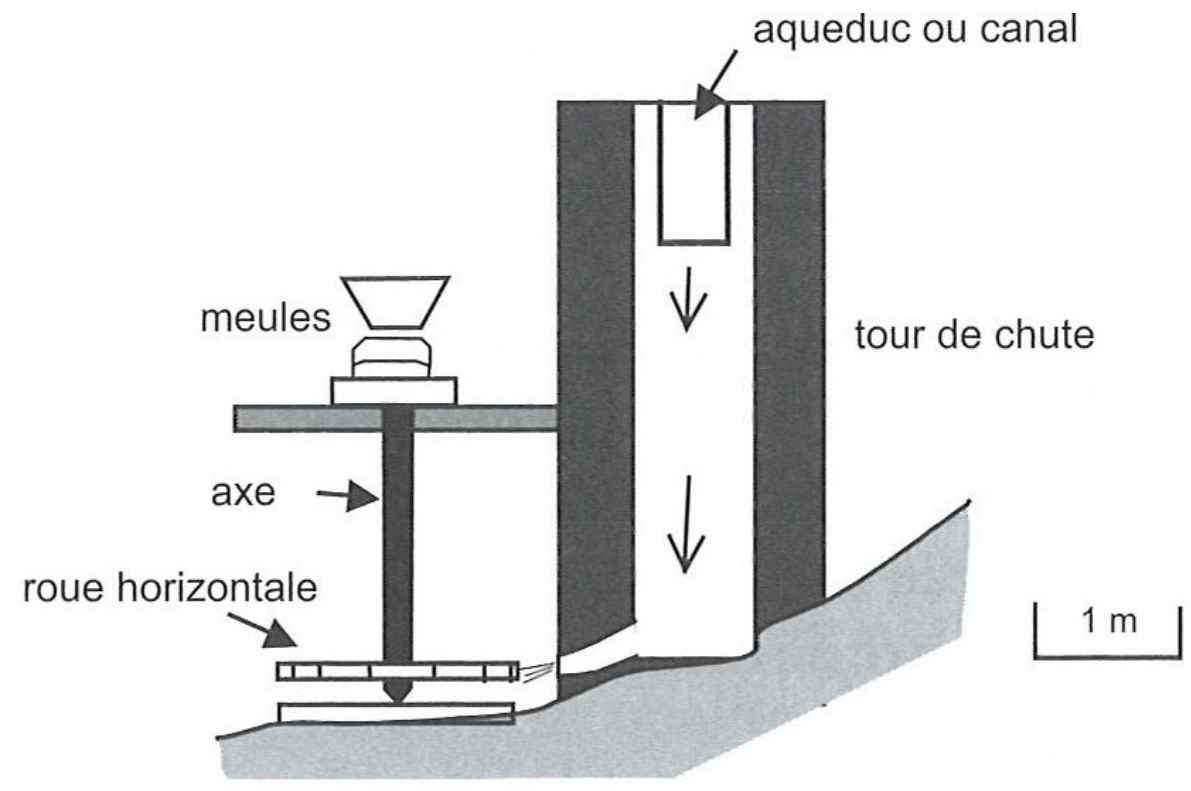

Se han encontrado molinos de este tipo en Cherchell (Argelia), en Mauritania, y otros similares también de rueda horizontal en Siria, en general en zonas semiáridas, etc.

En lo que respecta a la otra gran civilización de la época, China, el desarrollo de la energía hidráulica en la Antigüedad, en el transcurso de los primeros siglos, se concentra en los usos industriales principalmente para la molienda de grano.

Los cereales constituyen en esta época el recurso agrícola principal de China. No será hasta el siglo VI cuando se desarrolle la cultura del arroz en la cuenca del Yantzé. El molino hidráulico de cereales puede ser que sea sobre el siglo IV cuando esté en pleno desarrollo en China.

El primer vestigio escrito del uso de la rueda de agua se sitúa en el período entre reinos (8-25 d.C). Se trata de una rueda cuyo fin era el movimiento de martillos. En el año 21 d.C aparece incluido en un resumen histórico que relata que Fu Xi inventó el martillo pilón y el mortero, los cuales fueron muy útiles, para ser más tarde mejorados para que todo el peso del cuerpo pudiera ser utilizado para mover el martillo pilón, aumentando diez veces su eficacia. Después, la fuerza de los animales fue aplicada mediante mecanismos además de la energía hidráulica, consiguiendo multiplicar por cien su eficacia. El pilón hidráulico conoció un gran desarrollo en los siglos III y IV. Se utiliza para picar el arroz, forjar el metal y triturar el mineral.

Los monjes taoístas, que se especializaron en la fabricación de productos farmacéuticos, utilizaron la energía hidráulica para triturar las materias primas necesarias para ello, en particular la mica. 
En el año 31 d.C, otra referencia literaria evoca una rueda de agua utilizada esta vez para mover los fuelles de las forjas en el centro metalúrgico de Nanyang. En este caso, el objetivo era economizar el trabajo de la gente común, en la línea del pensamiento confucionista, ideología dominante entre los funcionarios chinos.

Para entender el contexto técnico, hace falta señalar la calidad de la metalurgia china de la época, que va ligada a las altas temperaturas que se podían conseguir en los hornos chinos.

Sobre el año 238, un funcionario venido de la misma ciudad de Nanyang, es nombrado sobreintendente de la producción metalúrgica. Él es el encargado de difundir esta innovación con gran éxito parece ser, hacia otros centros metalúrgicos de China. En el siglo V, la gran difusión de esta tecnología es clara. La tipología de rueda de agua china utilizada es la siguiente:

Son ruedas horizontales simples, en la que los álabes son simplemente placas verticales, que son alimentadas por la corriente de agua. El eje vertical lleva una pequeña rueda, alrededor de la cual pasa una correa. Esta correa hace girar una tercera rueda, más pequeña aún, que entonces gira muy rápido. El eje de esta tercera rueda lleva una articulación excéntrica sobre la que pivota un brazo animado de un rápido movimiento alternativo.

Esta descripción se ha obtenido de ilustraciones datadas en épocas posteriores pero que hace suponer que éste era el tipo de rueda en la época antigua. Sólo puede suponerse que las técnicas representadas en las ilustraciones de la Edad Media ya estaban en uso en los comienzos de la energía hidráulica en China, siendo las ruedas hidráulicas utilizadas, ruedas horizontales con palas planas para la molienda de cereales o para los fuelles de las forjas, y ruedas verticales para los pilones hidráulicos.

La energía hidráulica china de los primeros siglos se amplifica hasta el fin de la antigüedad, usándose para otros fines como podían ser, además de los indicados, el movimiento de lentes astronómicas, ventiladores para refrescar el aire, etc. Lo que es seguro es que China ejerció una influencia clara en la difusión de las innovaciones que creaba, hecho que se confirmará en la Edad Media. En efecto, en el año 610 el molino de agua se transmite hacia Corea, y en el año 670, de Corea a Japón. Y también desde China, la energía hidráulica se trasmite hacia el Tibet en el año 641.

Todos estos ejemplos de molinos o ruedas hidráulicas desarrolladas en este apartado demuestran la importancia que tuvieron los molinos hidráulicos para 
las sociedades preindustriales ya que fueron una herramienta primordial para el cambio de una economía de subsistencia a una economía de mercado.

\subsection{EDAD MEDIA (DESDE 476 D.C. HASTA 1453 D.C.)}

En la Edad Media, cuyo comienzo se establece en el año 476 con la caída del Imperio Romano en Occidente, la importancia de las ruedas hidráulicas debía ser más que reseñable porque era objeto de búsqueda de sabotaje en las mismas en las contiendas bélicas como si de una infraestructura esencial se tratara.

Sirva como ejemplo el tipo especial de rueda hidráulica que fue inventada en el año 536 cuando la ciudad de Roma fue asediada por los Godos y las líneas de suministro para los molinos fueron destruidas. Belizar, el comandante bizantino, ordenó montar los molinos sobre vehículos introducidos primeramente en el Tíber para que las ruedas hidráulicas de alimentación inferior fueran movidas por el flujo del río. Vitiges, el rey de los ostrogodos, que sucedió a Teodato en 526, después de haberse distinguido como general de Teodorico I, intentó destruirlas lanzando vigas aguas arriba de las ruedas, pero los sitiados evitaron el daño sobre las mismas consiguiendo parar las vigas gracias a unas cadenas colocadas en el río de manera transversal.

Era el germen de los molinos-barco que tenían la gran ventaja de estar situados en las ciudades propiamente dichas, en las líneas de consumo de la harina, y además eran fáciles de desplazar en función de los periodos de crecidas o sequías.

Que se tenga constancia, en el margen derecho del río Segura a su paso por la ciudad de Murcia, existían molinos sobre barcas al menos desde el siglo XII.

Eran comunes en el río Segura este tipo de artilugios. Muy prácticos, ya que podían ser trasladados hasta los lugares donde la corriente fuese más fuerte. Y mucho más económicos y menos costosos que construir un molino de piedra. 


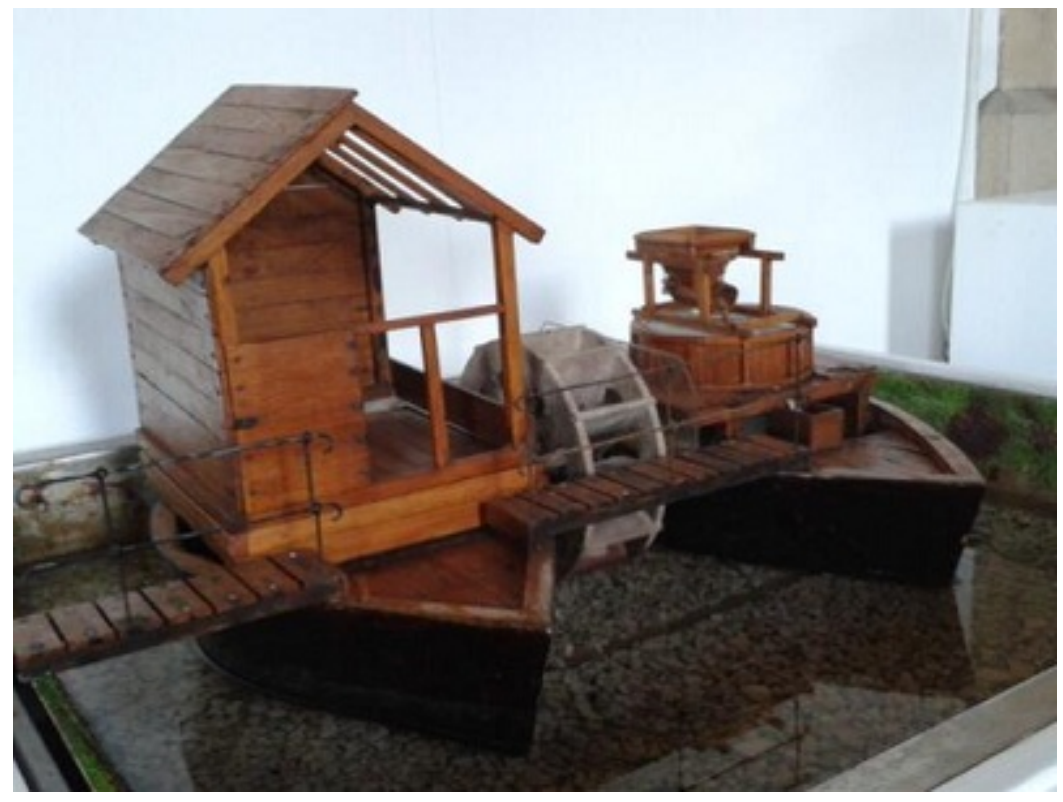

Como casos de molinos más particulares, también existieron, por ejemplo en París, molinos sobre pilotes en pleno cauce y no en la ribera, para disponer de suficiente corriente de agua que en los bancos de ribera no se tenía. Se accedía a ellos mediante pasarelas. Y también existieron los molinos de marea, que funcionaban en marea baja y en general para moler solamente grano, ya que otros usos industriales se acomodarían mal a la intermitencia que imponían las mareas.

En el mundo árabe, chino y bizantino, no existe una ruptura cultural ni tecnológica ente la Antigüedad y la Edad Media. Diferente es el caso de Occidente tras la caída del imperio romano.

Los movimientos de población tras la caída, favorecieron la difusión de los molinos más allá de sus antiguas fronteras. En el siglo VII, los molinos de agua son frecuentes en Irlanda y parecen expandirse a la Germania no romanizada en el siglo VIII. Sin embargo, en el interior de las antiguas fronteras del imperio, los acueductos no se mantienen y caen en la ruina, lo que provoca que las villas acerquen sus centros urbanos a la riberas de los ríos salvo en Roma.

Puede pensarse que los molinos que en la época romana eran alimentados superiormente a partir de acueductos, de tipología de rueda vertical, se desplazan hacia las riberas y entonces son movidos por las corrientes de agua alimentados inferiormente. El uso principal es la molienda de la harina, diversificándose su utilización a partir del siglo XI.

En la época de Carlomagno (S. VIII-IX) se da una circunstancia relevante para la pujanza del molino hidráulico. San Benedicto, fundador del monasterio de Mont 
Cassin entre Roma y Nápoles, estableció hacia el año 530 una regla que adoptarían los benedictinos. Ésta es que cada monasterio, en la medida posible, dispusiera de agua, molino, jardín y talleres para que se pudieran practicar los diversos oficios en el interior de los mismos.

Esta regla se extiende en toda Europa en el siglo VII, a partir del cual, el desarrollo de nuevos monasterios en el medio rural se da de manera intensa.

Este desarrollo no se queda confinado en esa zona en esta época, sino que se conoce la existencia de numerosos molinos en Suiza, en la Península Ibérica, en la que ya existían los molinos incluso antes de la conquista árabe según documentos que datan de la época de la ocupación de España por los visigodos. En el mundo bizantino también existían numerosos molinos igualmente.

El molino hidráulico ganó terreno en toda Europa durante el siglo VIII. Esto se puede concluir por una gran cantidad de certificados sobre leyes y deberes correspondientes a ellos. En el período feudal, el trovador alemán Wirnt von Gravenberge describe, incluso, la puerta de una fortaleza que era protegida por medio de una rueda de agua de hierro armada por hoces en toda su periferia. Lo que no describía era su forma de alimentación.

La presencia del molino hidráulico aumenta en la Edad Media pudiendo decir que la edad de oro del molino hidráulico se desarrolla entre el S XI-XIII. Este desarrollo va acompañado del crecimiento demográfico tanto en Occidente como en Oriente ya que la construcción de molinos se desarrolla paralelamente al incremento poblacional.

En Occidente, las invasiones vikingas tan numerosas en el siglo IX están prácticamente olvidadas, y el desarrollo de los molinos hidráulicos se produce hasta el fin del S. XIII.

De todos los progresos técnicos en esa época, quizás el más remarcable y de mayor expansión fue el molino hidráulico y su adaptación a multitud de industrias. En el S. XIII se podían contar por miles y de hecho, sirva como ejemplo, que a finales del S. XI, el "Domesday Book" censaba ya 5.624 molinos hidráulicos en Inglaterra. Esto da una idea de la importancia que tomó esta nueva fuente de energía.

Es reseñable el uso de la energía del agua a través de molinos para otros usos diferentes a la molienda, en Inglaterra. En investigaciones sobre los templarios, se han encontrado referencias del uso en 1185 de los "molendium fulerez" o molinos bataneros (o batán) en Newsham en Yorkshire, y otro en Barton en 
Cotswolds. El batanado es el proceso realizado en la lana que se hacía de forma manual.

El batán es una máquina destinada a transformar unos tejidos abiertos en otros más tupidos. Funcionaban por la fuerza de una corriente de agua que hace mover una rueda hidráulica, que activa los mazos que posteriormente golpeaban los tejidos hasta compactarlos. Estas máquinas, que se empleaban también mucho en España, estuvieron en funcionamiento hasta finales del siglo XIX.

La primera referencia que se tiene en España de los batanes es del siglo XII, unos documentos con fecha de 1160 sitúan dos batanes cerca de Girona.

Los batanes se extendieron por España, siendo numerosos los existentes en Galicia y destacando la comunidad asturiana en la que, a mediados del siglo XVII, había cerca de 200. Hoy en día la mayoría de ellos se encuentran en estado ruinoso o incluso totalmente desaparecidos, siendo muy pocos los que se conservan y destinados únicamente a museo.

Un ejemplo de batán-museo, en la provincia de La Coruña, está en la parroquia de Mezonzo en el ayuntamiento de Vilasantar. Se cree que fue construido por los monjes que habitaban el monasterio de Mezonzo, donde ahora se encuentra la iglesia parroquial que data del siglo XII. De ser cierta la creencia popular, sería uno de los batanes más antiguos de España. Estuvo en funcionamiento hasta el año 1954, en que se abandona hasta su restauración en el año 2001 y ahora puede visitarse por el público.

Mientras estuvo en activo, el batán funcionaba desde el mes de febrero hasta junio. Durante el verano permanecía cerrado porque el río no tenía suficiente agua para su accionamiento y en el invierno no se podía utilizar porque era muy difícil el secado de las mantas.

Otro ejemplo de batán-museo se puede encontrar en la provincia de Huesca, concretamente está en la localidad de Fiscal, en la comarca del Sobrarbe. Se lo conoce como el Batán de Lacort.

El emplazamiento de los batanes siempre era en la orilla de los ríos para aprovechar la fuerza hidráulica. En el cauce del río se construía una pequeña presa, desde ella el agua se conducía por un canal con fuerte pendiente hasta la rueda. Al impactar el agua contra las cucharas de la rueda, esta giraba llevando solidario el eje, cuyas levas accionaban los mazos que golpeaban las mantas. 
Otro canalillo llevaba un poco de agua hasta la cuba para mantener mojadas las mantas durante buena parte del proceso, evitando su desgaste por rozamiento. Este chorrito de agua, a la vez también servía para refrigerar los soportes del eje.

Las partes más importantes del batán son:

- La rueda, con un diámetro de tres metros y una serie de cucharas (a menudo dieciséis) repartidas regularmente en el perímetro, sobre las que impacta el agua que baja por el canal, produciendo el movimiento de la máquina.

- El eje que gira solidario a la rueda y por medio de unas levas hace mover los mazos.

- Los mazos, son dos que al caer golpean los paños que están situadas en la cuba.

- La cuba es el lugar en el que se colocan los paños. Está constituido a partir de un tronco de $230 \mathrm{~cm}$ de largo y $95 \mathrm{~cm}$ de diámetro que se excava en el centro hasta conseguir el hueco necesario para el sufridero de los mazos y los paños.
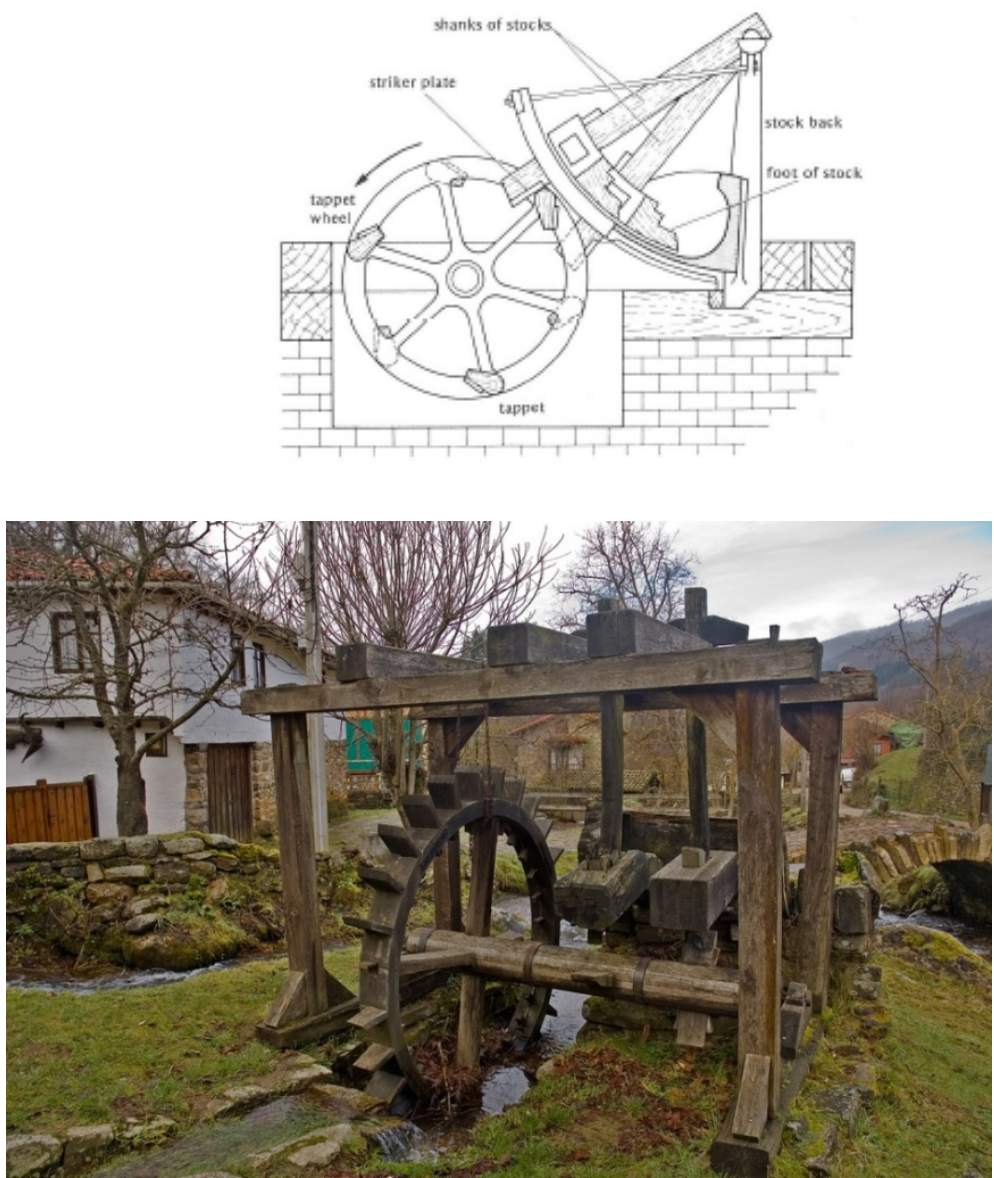

Batán en la localidad de Aniezo (Cantabria, España) 
En 1245, el ingeniero francés Wilars describe un molino automático cuya rueda de alimentación inferior mueve simultáneamente la madera que va a ser serrada contra la sierra y tira de la última mediante unas levas que actúan periódicamente en la dirección necesaria. Como un resorte, la viga de madera sujeta en su extremo, mueve la sierra en la dirección inversa.

Es importante el auge de los molinos en Andalucía desde el S. IX por la necesidad de abastecimiento de redes de riego.

Un geógrafo árabe fallecido en el año 1094 señala la gran variedad de ruedas hidráulicas existentes en España.

El primer molino de hierro que se conoce es el de Cardedeu en Cataluña, datado en el año 1104.

En Mallorca se cuenta en el S. XII con numerosos molinos y también durante el S. XII y XIII se reconstruyen los molinos de la época musulmana. En Lérida, había en el S. XII, en la ciudad, sobre la red hidrográfica urbana, 10 molinos harineros, 5 molinos aceiteros y un número indeterminado de molinos para serrar.

La rueda hidráulica aparece como fuerza motriz en Alemania para diversos usos como, por ejemplo, los molinos papeleros como el de Ravensburg en 1290, molinos de martillo para trabajar metales como el de Dobrilugk en 1320, para moler en Ausburg en 1389, molinos para accionar fuelles de fundiciones en 1438, y en general, en todos los oficios de Alemania desde el año 1500.

Oriente presenta las mismas características, con una expansión demográfica bastante continua desde el S. VIII hasta el S. XIII, durante los cuales las riberas de los ríos se equipan de molinos hidráulicos al máximo de su capacidad. De hecho, en el mundo árabe, era habitual definir el flujo o caudal de un rio por el número de molinos que era capaz de alimentar en el mismo punto.

La rueda hidráulica se transformó en la gran máquina de la Edad Media, utilizándose en molinos harineros, en aserraderos, martillos y bombas, para accionar fuelles, para la batanadura de la lana, para exprimir la caña de azúcar (principalmente en África del Norte, España y Oriente), primer paso para la fabricación del azúcar; incluso fueron usadas ruedas hidráulicas para ayudar en el proceso de extracción de los minerales en la famosa mina del Potosí, en Bolivia. Las grandes ruedas hidráulicas medievales de madera desarrollaban una potencia máxima de cincuenta caballos de potencia. En este tiempo se las empleó tanto en posición vertical, como en posición horizontal para mover 
directamente una estructura vertical. Cabe destacar el uso de la energía hidráulica generalizadamente en la metalurgia en el S. XII en occidente para mover los martillos y los fuelles de las forjas, con mil años de retardo respecto a China. La mención más antigua conocida en Occidente data de 1135 en la abadía de Clairvaux. Además su difusión no fue rápida ya que, por ejemplo, esta técnica no llegaría a España hasta el S. XIV.

En Oriente, en la segunda mitad del S. XIII y en Occidente, el comienzo del S. XIV, marcan el fin de este gran periodo de desarrollo, de esta edad de oro medieval. En el S. XIV la despoblación es general y la edad de oro medieval se da por terminada. Edad de oro en la que la energía hidráulica ha sido una de sus principales fuerzas motrices.

Las evoluciones técnicas que se observan en la Edad Media son las que se describen a continuación.

- En el mundo árabe se encuentran ruedas horizontales en las que los álabes forman un ángulo con el eje de rotación y son curvos o en forma de cuchara. La rotación de la rueda es provocada por la caída del agua sobre los álabes en el primer caso y por el impacto tangencial de un jet de agua en el segundo caso.

- En el mundo chino, en el que el agua es abundante, la rueda horizontal de palas planas, paralelas al eje de rotación para ser la tipología dominante, pero las ruedas verticales también aparecen en los grabados del S. XIV.

- En el mundo occidental, sin embargo, se observa una separación entre el norte y el sur. En el norte, los molinos hidráulicos son de rueda vertical, que fueron los molinos romanos de occidente. Este molino de rueda vertical, molino vitruviano, es en el S. X alimentado principalmente inferiormente a partir de una pequeña corriente. A partir del S. XI, sobre todo en los monasterios de montaña, se ven molinos hidráulicos de cubo alimentados por arriba como era más habitual en la época romana. Éstos permiten la utilización de cursos de agua de poco caudal pero como es propio de los sitios de montaña, con posibilidad de encontrar una buena altura de caída de agua. Fue una innovación medieval la creación del "cubo", que empezó a utilizarse generalizadamente en el siglo XIII. El "cubo" era un gran depósito que servía para aumentar la presión del agua y que consecuentemente permitía aprovechar mejor las corrientes con escaso caudal, como gargantas y arroyos. El "cubo" se aplicó a los molinos que utilizaban rueda hidráulica horizontal y un único eje para transmitir el movimiento a las muelas. 
- En el sur, los molinos hidráulicos eran principalmente de rueda horizontal, como los molinos romanos de África del Norte y como la mayoría de los molinos chinos.

Las ruedas siguientes, que aparecen en grabados del S. XVIII, son probablemente representativas de ruedas medievales.

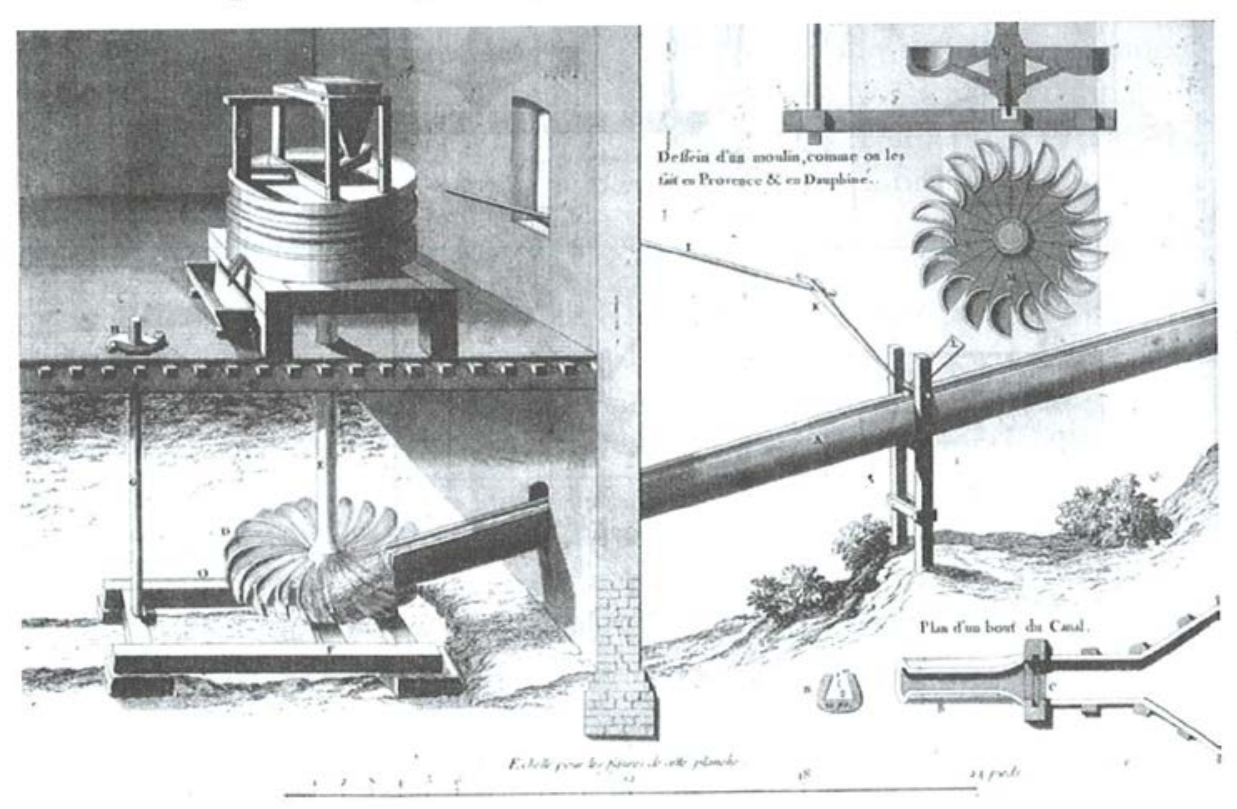

Figure 3.2. Type de moulin à roue horizontale, traditionnel en Provence et en Dauphiné (Bélidor, 1737): ce moulin est dit à « rodet volant ». La roue tourne à l'air libre, sous

l'action du jet amené par le canal en bois

(collection et cliché de l'École nationale des ponts et chaussées, cote 4.1995).
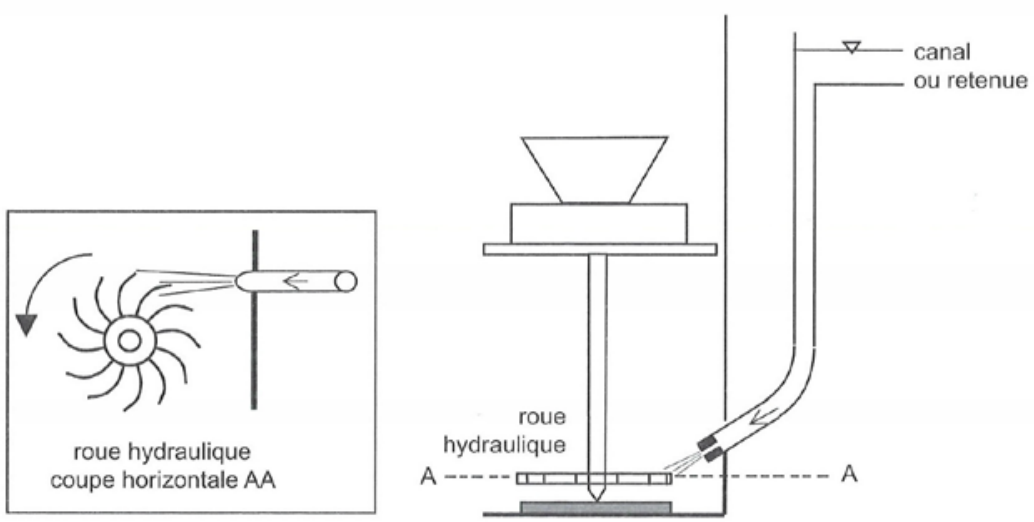

Figure 3.8. Roue hydraulique horizontale à pales courbes ou évidées, alimentée tangentiellement (moulin dit arubah ). Héritier du moulin romain à tour de chute, ce type de moulin est fréquent dès $\mathrm{le} \mathrm{v}^{\mathrm{e}}$ siècle, en Europe du Sud et en Orient (Hill, 1997, p. 41). On le trouve encore utilisé en Espagne au xvII' siècle (figure 5.13). 


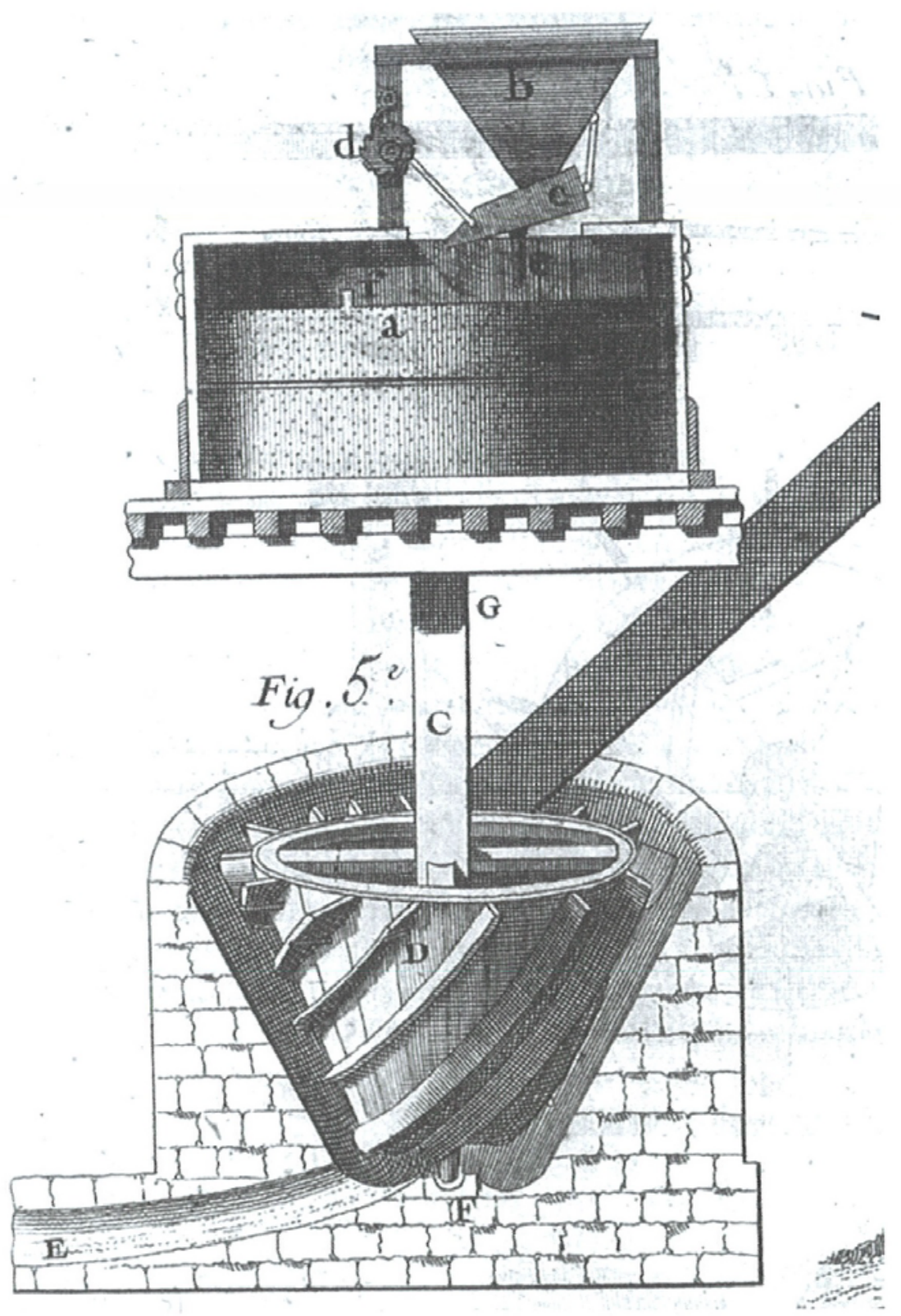

Figure 3.3. Moulin à roue horizontale dit « moulin à cuve » (Bélidor, 1737). La roue est contenue dans une cuve en maçonnerie, bien ajustée pour que les interstices soient juste suffisants pour l'évacuation de l'eau. Selon Bélidor, ce moulin était commun sur la Garonne: « l'on voit encore à quelques endroits sur la Garonne des moulins qui sont encore d'une construction assez singulière ; la roue est une espèce de tambour qui a la figure d'un cône tronqué renversé, qui tourne dans une cuve de maçonnerie faite exprès: les aubes de cette roue sont appliquées obliquement sur la surface du tambour où elles forment des portions de spirales. Ces aubes ainsi disposées obligent la roue à tourner avec une extrême vitesse, par conséquent la meule qui répond à son essieu, et pour cela il ne faut qu'un filet d'eau. »

(collection et cliché de l'École nationale des ponts et chaussées, cote 4.1995).

En la Península Ibérica, los molinos de rueda horizontal eran conocidos al principio del período musulmán. La rueda horizontal de álabes planos parece preexistir y la introducción más tardía de cubetas o álabes perfilados aparece como un avance para permitir la turbinación de pequeños caudales. 
Entre el Duero y el Tajo, no fue sino hasta después de la reconquista, en los siglos XII y XIII, cuando aparecieron nuevos molinos de rueda vertical. En todo caso, los dos tipos de molino reciben nombres distintos: molinus o rodezno para el molino de rueda horizontal, y aceña para el nuevo modelo de rueda vertical. El término aceña que podría venir del árabe saniya, aparece igualmente en Castilla a partir del S. XI o XII.

Las diferencias entre Molinos y Aceñas de la Edad Media, son las siguientes:

$\underline{\text { Molino }}$

1. Lo que se conoce con el simple nombre de molino utiliza una rueda o turbina horizontal, llamada rodezno, que gira movida por la fuerza del agua.

2. El molino se sitúa en arroyos o gargantas.

3. Los molinos para garantizarse el suministro del agua están dotados de una presa para almacenar agua. El

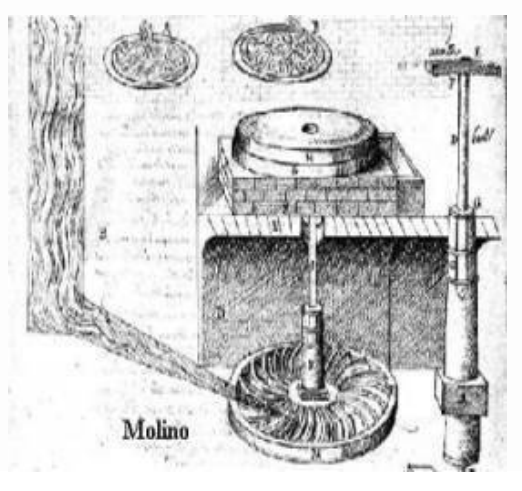
charco formado por la presa suele llamarse pesquera o alberca. Desde la pesquera el agua se desvía por un canal hasta el molino.

4. En el molino la rueda hidráulica y la piedra volandera están unidas por un solo eje.

5. Los molinos podían construirse por cualquier campesino o grupo de campesinos sin que se necesitaran permisos especiales.

$\underline{\text { Aceña }}$

1. La palabra aceña es árabe y significa rueda hidráulica. Se aplica el nombre de aceña a los molinos hidráulicos dotados de una rueda o turbina vertical

2. La aceña se sitúa en los grandes ríos.

3. La aceña se encontraba en el interior de los ríos o bien en alguna roca que sobresalía del curso. Las aceñas, como los molinos, están dotadas de una presa.

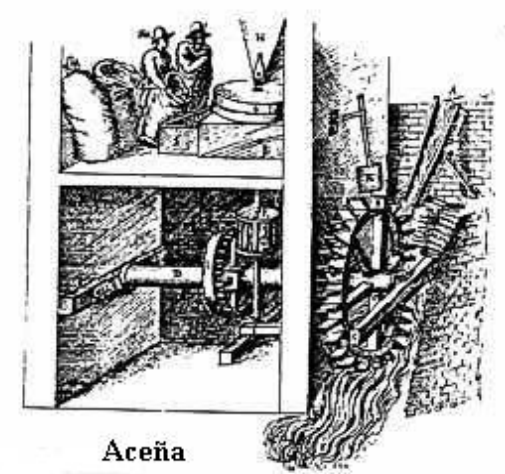

4. La aceña necesita dos ejes perpendiculares entre sí y engranados mediante una rueda dentada y una linterna (Rueda formada por dos discos paralelos fijos en el mismo eje y unidos en la circunferencia con barrotes cilíndricos en donde engranan los dientes de otra rueda). 
5. La construcción de la aceña, al ser más compleja, necesitaba de un poder señorial o abacial.

En Extremadura, en el S XII, los molinos se colocan en pequeños cursos de agua, mientras que las aceñas se colocan en los ríos más importantes, como por ejemplo en el Duero y sus principales afluentes asociados a presas de piedra que generan un embalse. Es notable el uso de los términos rodete y rodezno para denominar al que era el molino más tradicional, éste es el de rueda horizontal. Los rendimientos de este tipo de molinos, tal y como se ha indicado con anterioridad, eran del $71 \%$ como máximo para el molino vertical y del 50\% para el molino de rodete horizontal. Ello dio lugar a que se sustituyeran posteriormente, por turbinas hidráulicas, que ofrecen rendimientos del 90\%, o simplemente desaparecieran.

Pero no fue así en todos los casos, y contrariamente al pensamiento habitual de que estos artilugios hidráulicos se quedaron obsoletos, hay, sin embargo, estudios que evidencian que los molinos hidráulicos de rodete horizontal sufrieron una evolución tecnológica significativa que permitió mejorar rendimientos en los mismos de manera sustancial, lo que dio lugar a que se mantuvieran en uso hasta incluso este siglo.

La utilización de grandes conductos presurizados con varios inyectores y rodetes de fundición con un número elevado de pequeños álabes, generó un avance significativo en los molinos acercándose a los principios de funcionamiento de las turbinas hidráulicas que dieron lugar a rendimientos hidráulicos cercanos al 81\%.

El consumo de agua por unidad de energía extraída también alcanzaba una cifra cinco veces inferior al del diseño clásico por lo que eran especialmente útiles estos molinos con las innovaciones indicadas incorporadas, para ubicaciones lejanas a los principales cursos de agua.

Estas diferencias pueden observarse en dos molinos de rodete horizontal situados en Girona. El de Besalú, molino hidráulico de rodete horizontal clásico, situado en la orilla norte del rio Fluviá, abandonado en el año 1965 y recuperado en el año 2009. Y el molino de rodete horizontal modificado situado en Gaserans, ubicado a $4.5 \mathrm{~km}$ de la riera de Arbúcies, que estuvo en uso hasta el año 2005. En resumen, a este último molino se le sustituyó la compuerta de salida del chorro de agua por un canal presurizado de sección rectangular con ocho pequeños canales de descarga en su parte inferior, que funcionaban a modo de inyectores que impulsaban chorros de agua contra el rodete de fundición que contenía 63 álabes pequeños. 
En toda España, numerosos emplazamientos hidroeléctricos actuales conservan los nombres de los molinos que fueron precursores de los mismos. Los edificios que hoy en día alojan las centrales, fueron en su época molinos harineros o herreros.

A continuación se adjunta un ejemplo de molino extremeño que funciona hoy en día. 


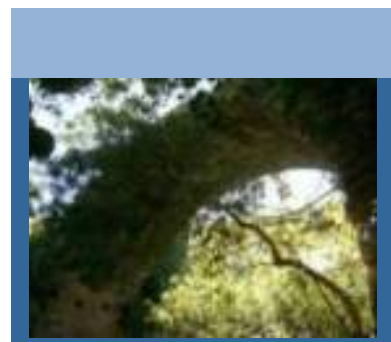

\section{MOLINO DEL PUENTE DE LAS VEREDAS}

Puente de las Veredas sobre el río Ibor, construido por La Mesta en la Edad Media. El texto del cartel de madera está situado en el tejado del molino.

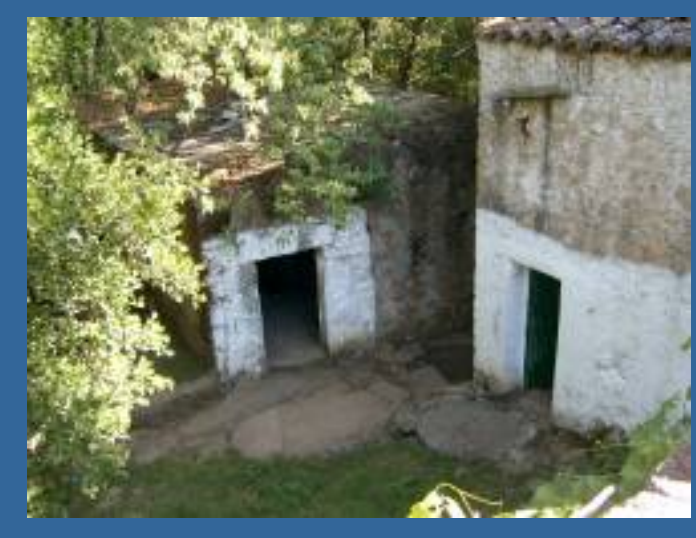

La puerta de la izquierda da entrada al molino; la puerta de la derecha da entrada a lo que fue primero una centralita hidroeléctrica y luego un molino con "cubo": hoy no funciona.

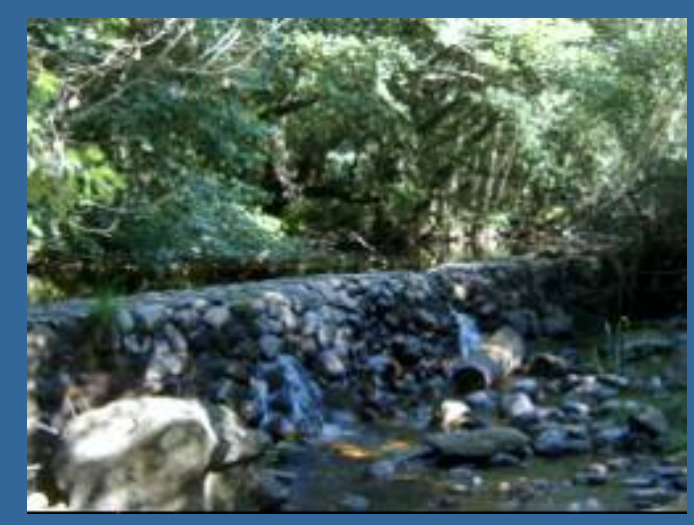

Zúa, (azuda, azud o presa) que embalsa el agua para el funcionamiento de la aceña. Tiene algo más de un metro de altura y unos cien metros de longitud.

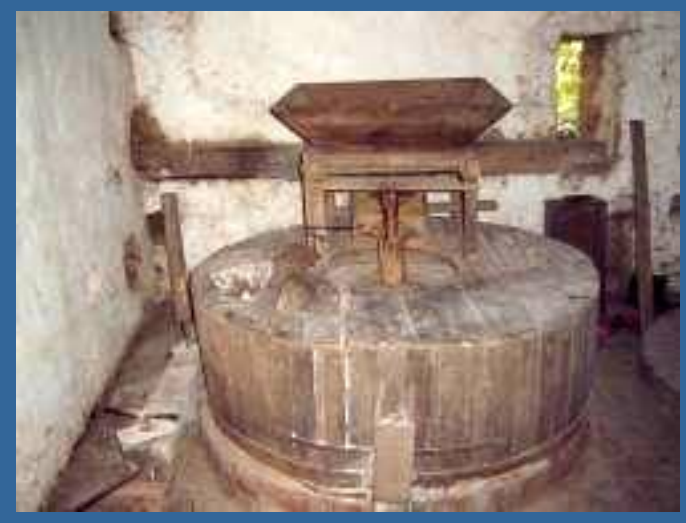

Tolva y muelas del molino. Las muelas no se ven por estar cubiertas con un guardapolvo.

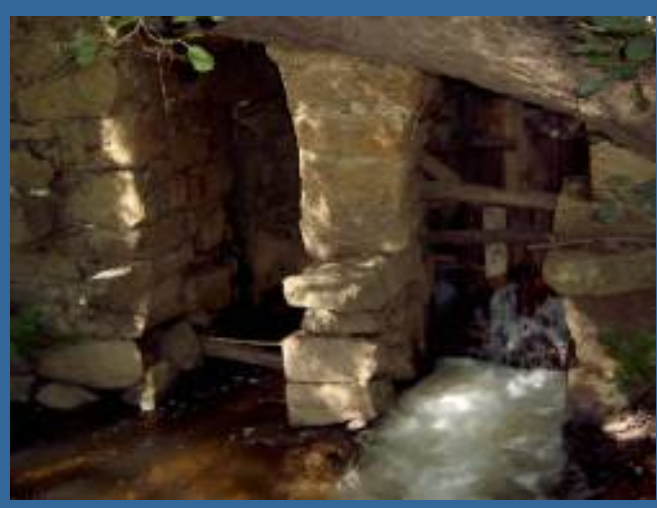

Corriente de agua que está saliendo del socaz correspondiente al rodete $y$ muelas que están funcionando. 


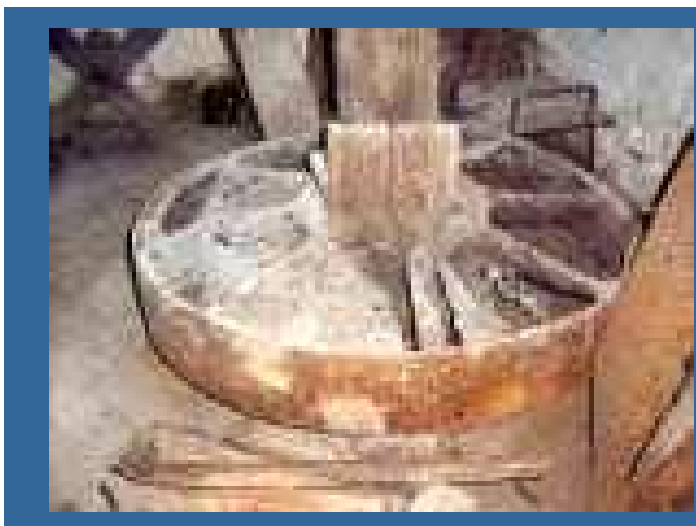

Un rodete viejo, con nos 10 álabes de madera de encina.

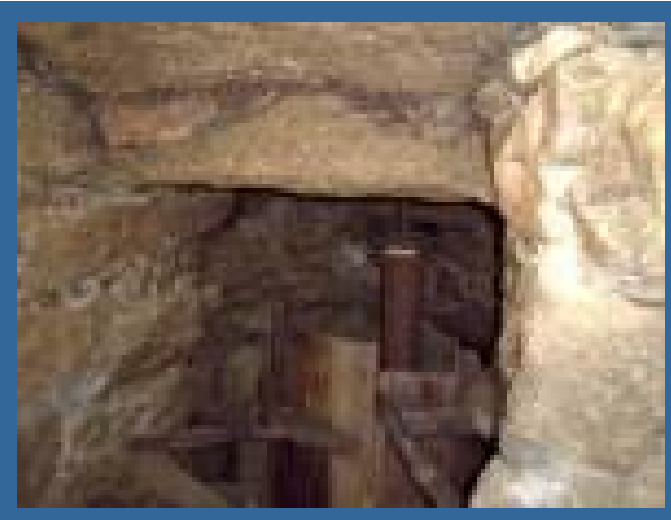

Eje que une el rodete con las muelas.

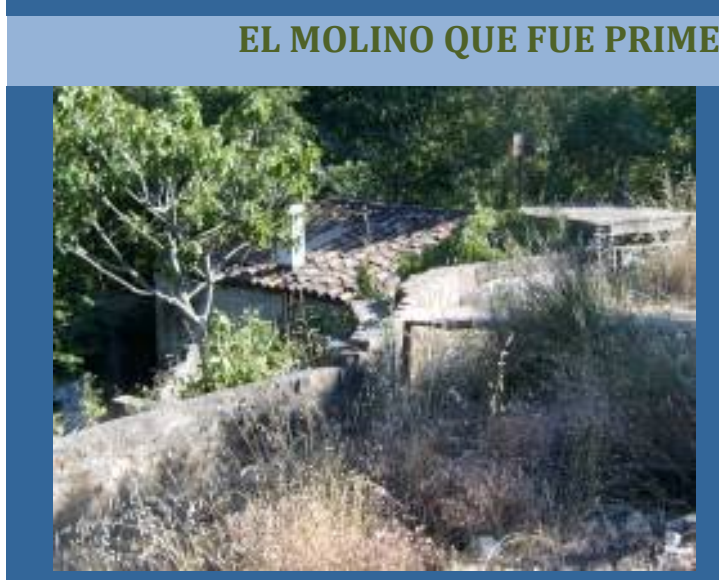

Molino, situado al lado del anteriormente descrito. Ya no funciona, porque no tiene instaladas ni las muelas ni el rodezno. Es un molino con cubo, a donde llega el agua a través de un canal. Durante algún tiempo funcionó como central hidroeléctrica.
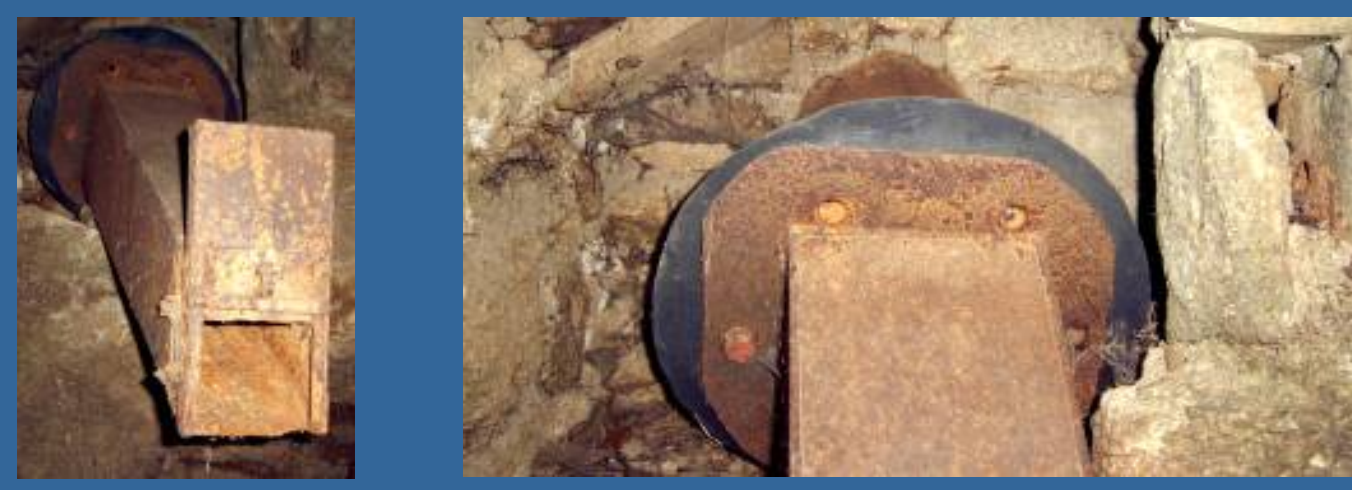

Saetín y cerraja del molino. El saetín es la tobera que conduce el agua a presión desde el fondo del cubo al rodezno haciéndole girar. La cerraja es una pequeña compuerta al final del saetín que permite regular el caudal de agua. Esta compuerta se accionaba con un mecanismo, llamado "llave del saetín" situado junto a las muelas. 
Durante la época romana e incluso carolingia en Occidente, en general, sólo las riberas de pequeños ríos estaban dotadas de molinos, pero en la Edad Media, tanto en Oriente como en Occidente, se aprovechan progresivamente los cursos de agua más importantes. Para ello se crean presas con su embalse asociado para elevar el nivel de agua y así crear la altura de caída de agua necesaria para colocar los molinos. Las ruedas hidráulicas se colocan en las márgenes del embalse propiamente dicho o bien, se realizan derivaciones desde los mismos embalses hasta donde se ubique el molino, incluso de algunos kilómetros.

La importancia de las presas y embalses en los aprovechamientos energéticos hidráulicos, serán objeto de un apartado independiente de esta tesis y ahí se desarrollará este aspecto.

\subsection{DESDE EL S. XVI EN ADELANTE}

A lo largo de los siglos XVI y XVII se desarrolló un nuevo género de literatura técnica conocido como Teatro de las máquinas. Como su propio nombre indica se trataba de repertorios de diseños de máquinas y artificios ingeniosos, a veces incluso imposibles de construir, realizados por el hombre para resolver problemas de la vida práctica.

Uno de los primeros tratados fue el libro de Jacques Besson "Teatro de los instrumentos y figuras matemáticas y mecánicas". Este bello tratado de ingeniería fue escrito en el siglo XVI.

De la vida de Jacques Besson apenas se conocen datos. Se sabe que nació en Grenoble en 1540 y que estuvo al servicio de Francisco II, como consejero o asesor en cuestiones prácticas. Murió en Inglaterra en 1573, país al que había ido huyendo de las intrigas y luchas religiosas de la época.

La obra más representativa de Jacques Besson fue su "Theatre des Instrumens mathematiques et mechaniques", obra que editó por primera vez en francés y en latín, ambas en 1578, y que llegó a hacerse muy popular como lo demuestran las numerosas ediciones que se fueron sucediendo. Así entre 1578 y 1602 se realizaron traducciones al italiano, español y alemán.

El libro pertenece a la edición que se hizo en español en 1602, fue publicada por Horacio Cardón, reconocido librero que ejerció su profesión en sus tiendas de Lyon y de Tournon. 
Este libro, dedicado al Duque de Lerma, es una bella y cuidada edición con una portada xilografiada con grutescos y figuras alegóricas, idéntica a la utilizada para las restantes versiones en otras lenguas. En la portada aparece el título del libro flanqueado por las figuras de los dos matemáticos más importantes de la antigüedad, Arquímedes y Euclides.

La obra consta de 60 magníficos grabados de diferentes ingenios o máquinas destinadas al aprovechamiento máximo de la energía, soluciones a problemas constructivos, carros de transporte pesado, aparatos de elevación, molinos y un largo etc.

Acompañan a cada lámina un texto explicativo del autor seguido de la Declaración de Francisco Beroaldo.

En la Figura XXVIII, se muestra un bosquejo de una turbina de álabes helicoidales confinada en una cuba de piedra inventada en 1.565. Según el propio Besson, es una nueva manera de hacer un molino de agua. Del que se pueden abastecer muchos, para casos en que la corriente sea escasa pero se disponga de una caída de agua.

Además de esta edición de 1602, la biblioteca de la Escuela Técnica Superior de Ingenieros de Caminos, Canales y Puertos conserva otro ejemplar de la anterior edición de 1582, esta última escrita en latín que era la lengua culta de la época. 


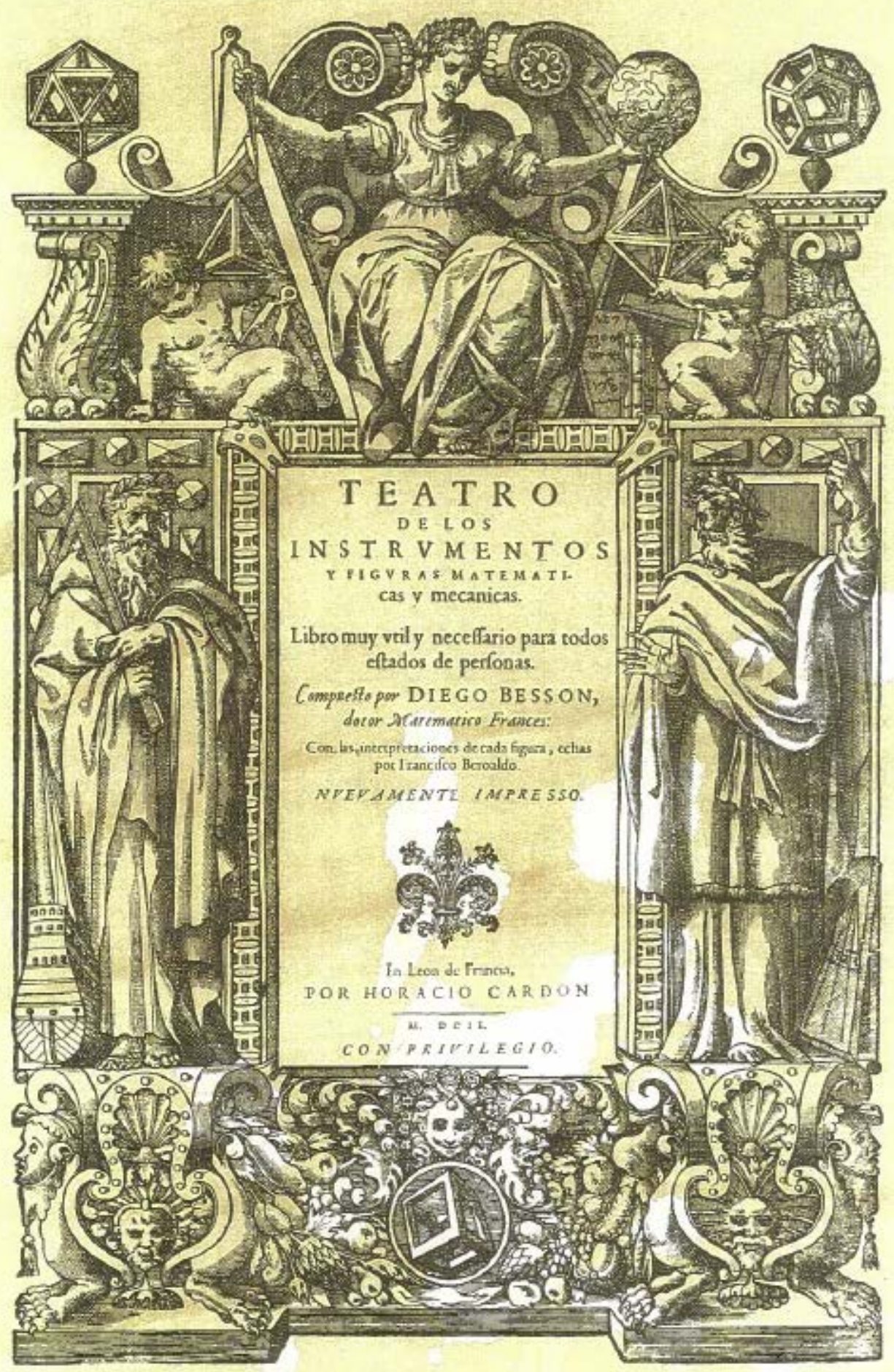




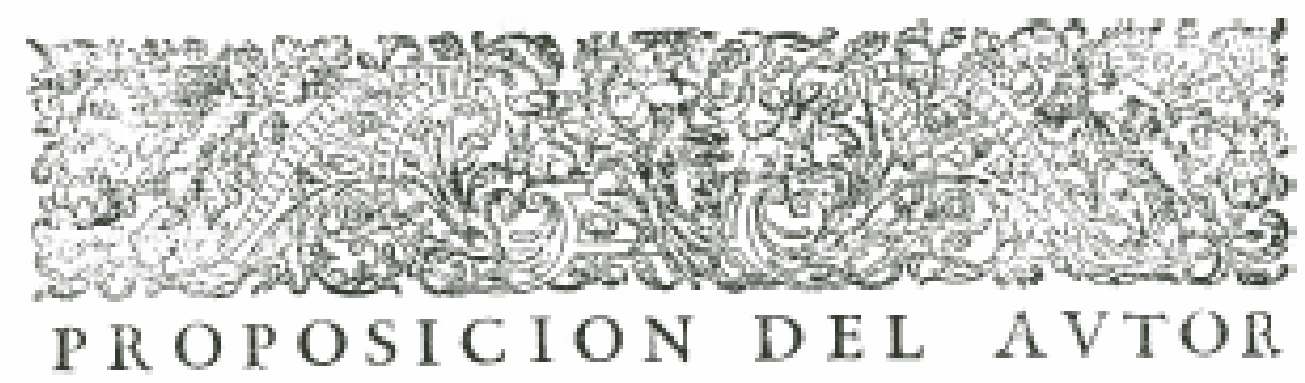

\section{A LA XKVIII FIGVAA}

WVEVA MANEAA DE HAZEA YN MOLINO DE AGVA, QVE PVE DAN DEL, MTCHOS BASTANTEMENTE SEAVHSE AHVNGYE HJ. YA MENOS AGVA DE AQYELLA QYE ES NECE5AREA EN LGS MOLINOS COMVAES, CON TAL QVE LAGVA YENGA A CAHE DE ALGYN LYGAR ALGO MAS ALTO.

\section{Declaracion de la melma X X V III. Figura.}

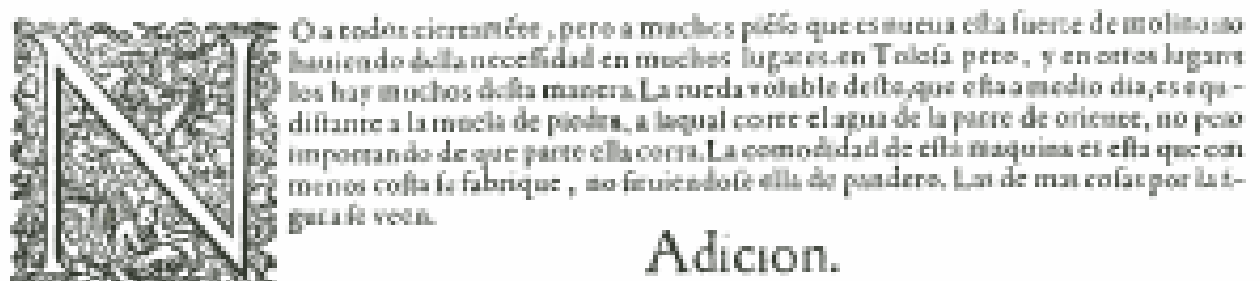

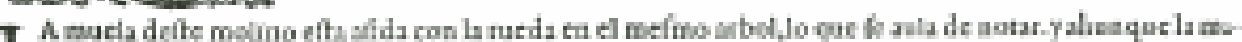

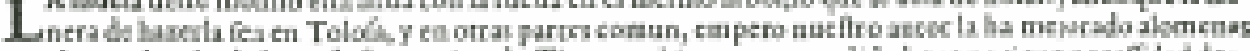

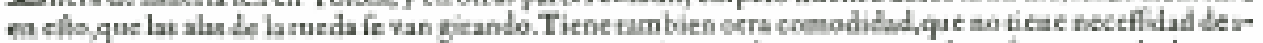

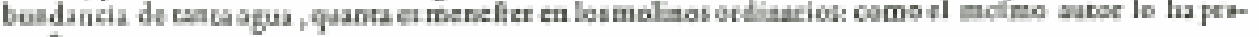
poctld.

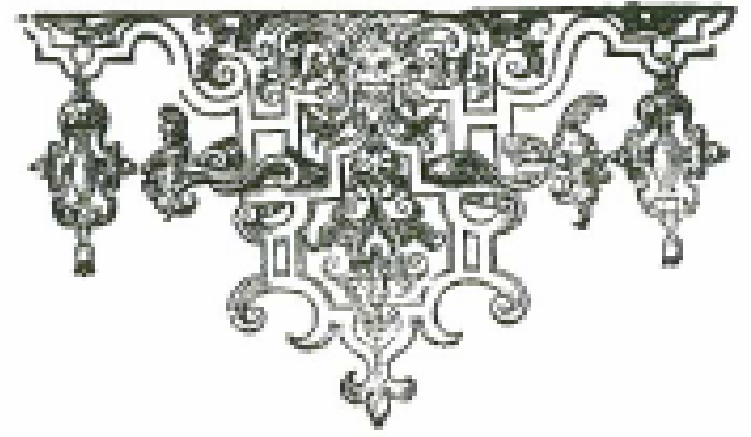




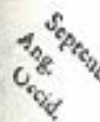

LINEA SEPTENTRIONAL.

Vigefimaoctaua Figura,

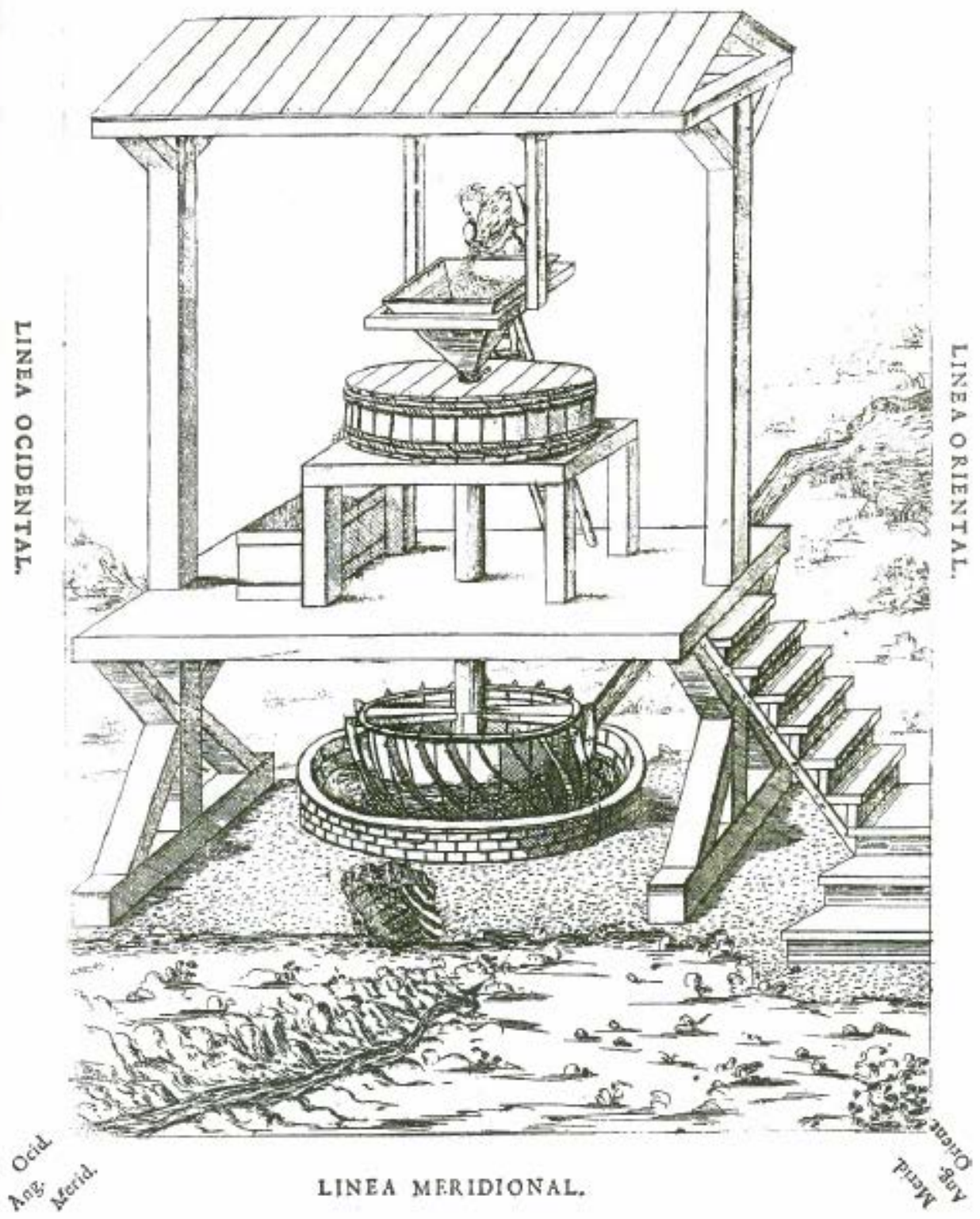


En 1607, Strada, describió en un libro las ruedas con cucharas similares a la posterior turbina Pelton.

En esta época se da una importante concentración industrial en las riberas de los ríos importantes, hecho que no es un fenómeno nuevo si se recuerdan los molinos cordobeses o los de Bazacle en el Garona en Toulouse. Éstas últimas son descritas por Bélidor en el S. XVIII en su libro "Arquitectura hidráulica". Las ruedas horizontales de Bazacle llamadas en su época, rodetes, son de hecho, modelos de turbinas horizontales, sin duda inspirados en modelos de turbinas en uso en el mundo árabe.

Los elementos arquitectónicos más antiguos son el tajamar hexagonal de la galería que atraviesa el río y la nave del edificio situado en la isla Île du Bazacle. Estos elementos ya figuraban en el plano catastral de Toulouse de 1690. Por aquel entonces, el molino comprendía «casa, torre y edificio du Bazacle»y, según se observa en el plano Collignon, parece ser una descripción fiel.

A orillas del Garonne, paralela al río, una parte del edificio compuesta de torres fortificaba la entrada al molino. En el interior, habían graneros para almacenar los cereales y sacos de harina. Los textos mencionan una «casa de pesados», donde se pesaban los cereales y la molienda, una caballeriza y una leñera. En la gran galería que atravesaba el brazo del río se guardaban los motores hidráulicos y las muelas. La galería, que antiguamente era de madera, tenía una cubierta de tejas y estaba sostenida por pilote. Situado contracorriente, el tajamar de fábrica hexagonal servía para cortar la corriente del río y proteger la galería. A través de ella se accedía al tercer módulo del complejo, construido en la isla y denominado «Tour du Bazacle» en un plano de 1728.
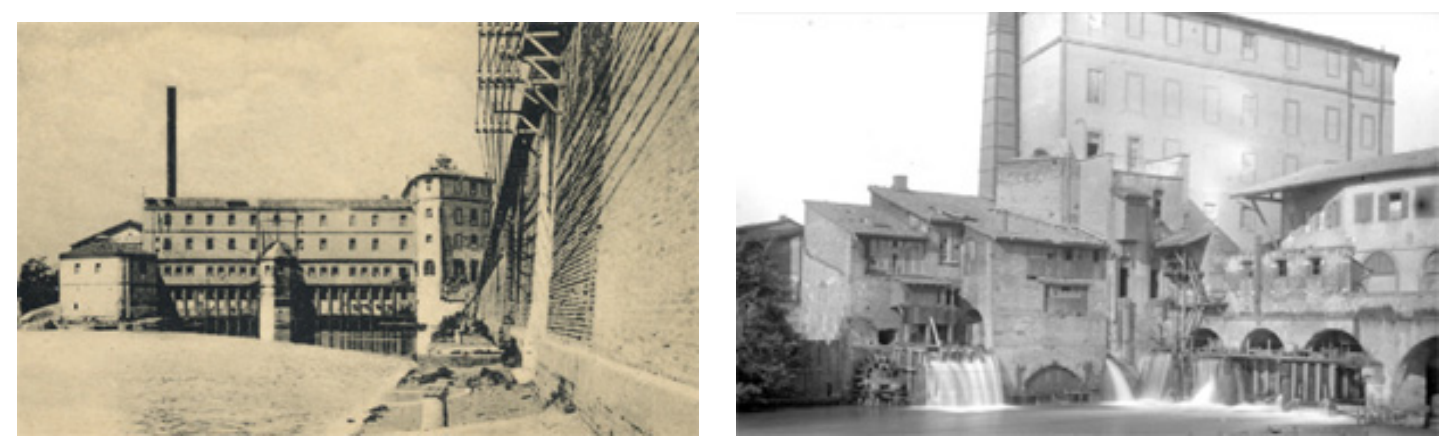

En el S. XVIII la construcción de grandes molinos en los ríos importantes se generaliza.

En el siglo XVIII los ilustrados franceses los estudian y describen en la enciclopedia de Diderot y D'Alembert y muestran la perfección técnica que los molinos hidráulicos habían alcanzado en aquella época. 
Los cinco dibujos insertados debajo de estas líneas pertenecen a la enciclopedia de Diderot y D'Alembert reeditada por la editorial Hachette en 1985.

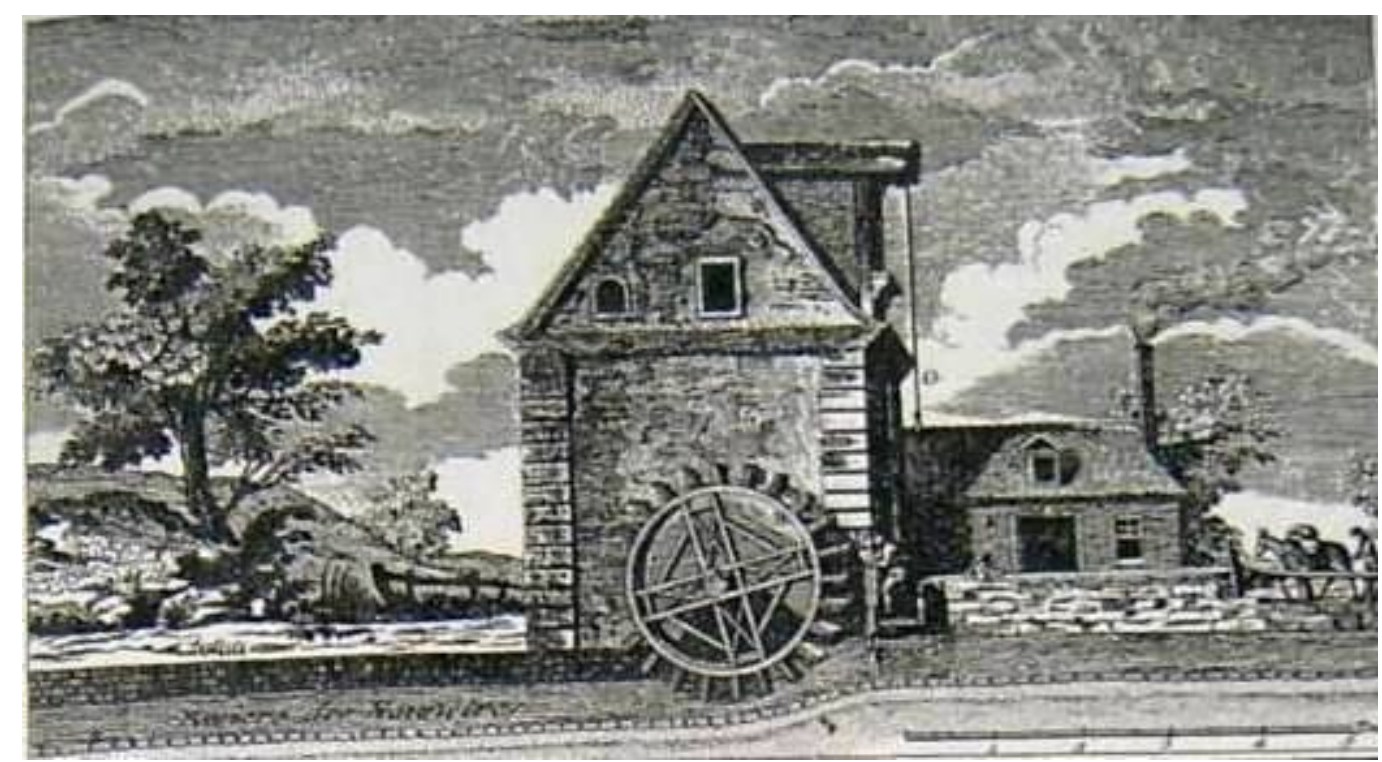

Dibujo 1:

Molino hidráulico con rueda vertical, movida por la corriente de un río.
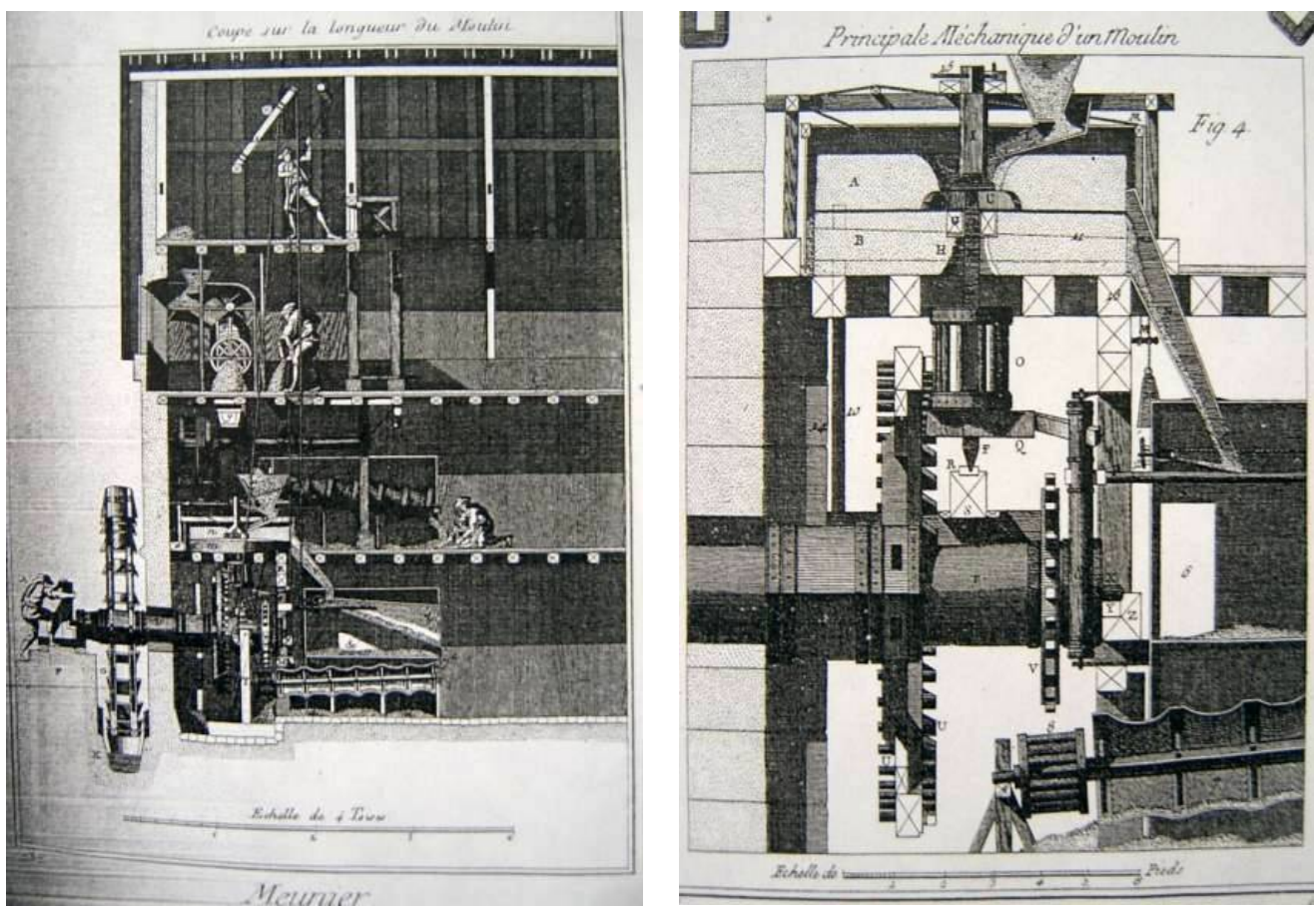

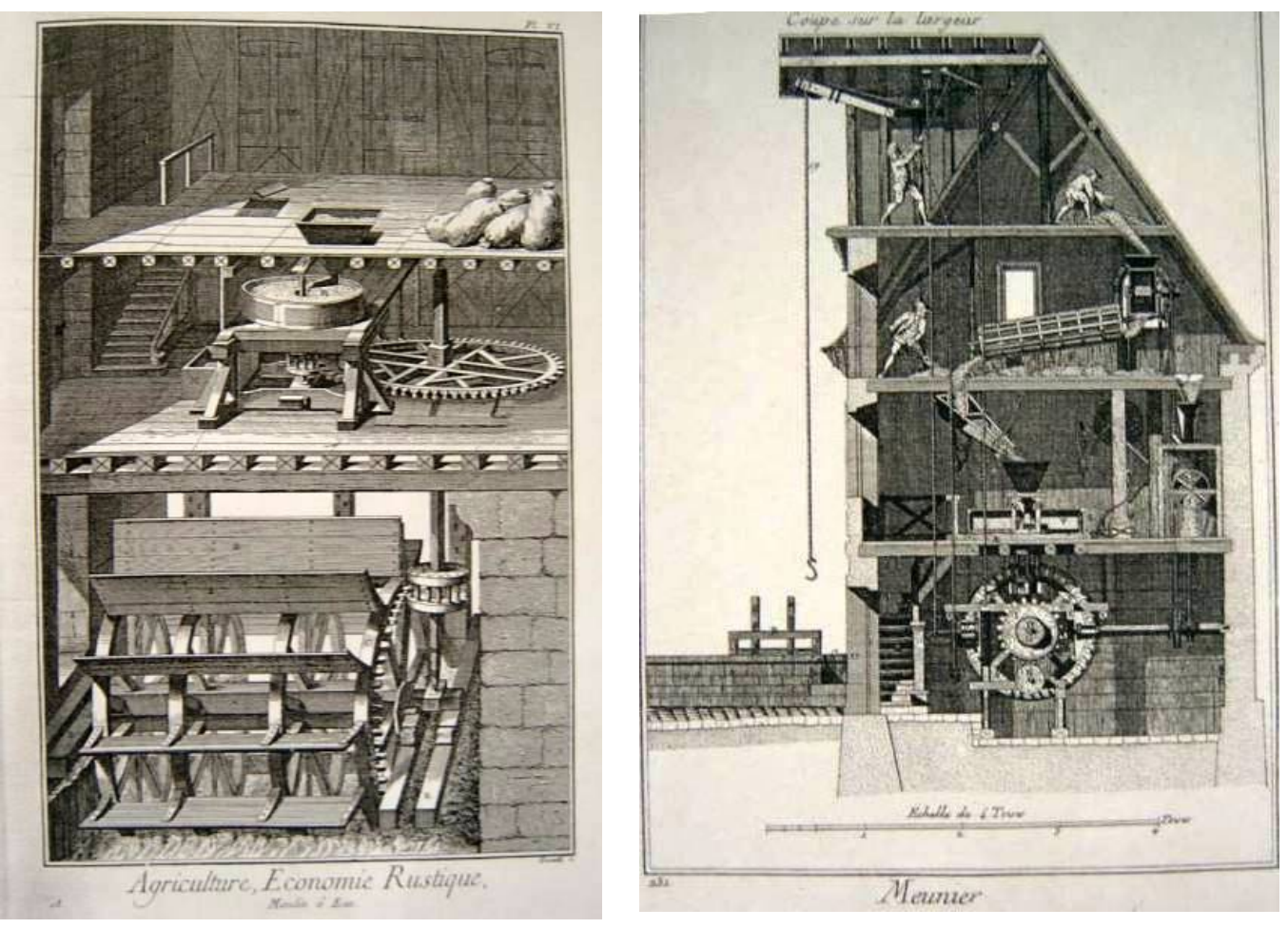

En un molino de tres ejes como el que aparece en la figura 5, por cada vuelta de la rueda hidráulica se producen más vueltas en las muelas que en un molino de dos ejes. Esta técnica ya era conocida en el siglo XVI.

Los dibujos 2 y 3 presentan dos cortes, uno frontal y otro lateral, del molino que aparece en el dibujo 1. Este molino es del tipo "aceña", con rueda hidráulica vertical y con dos ejes, tal como lo describe Vitruvio en el S. I a.C., pero en este molino de la enciclopedia de Diderot y D'Alembert pueden apreciarse notables mejoras técnicas con respecto al molino romano:

- el trigo es subido a un cuarto piso mediante poleas y antes de caer en la tolva, que está en la segunda planta,

- $\quad$ pasa por una criba limpiadora situada en la tercera planta;

- la harina al salir de las muelas pasa a una cernedora, situada en la primera planta;

- la harina, ya cernida, sube a la segunda planta, mediante una cinta transportadora y elevadora, donde es envasada.

Todo el sistema funciona con la fuerza generada por la rueda hidráulica, fuerza que es distribuida mediante engranajes, poleas, correajes a las diferentes máquinas que integran el molino. 
El dibujo 4 de la enciclopedia del Diderot y D'Alembert muestra en detalle la parte mecánica del molino anterior. La rueda hidráulica queda fuera del dibujo, pero en él aparecen:

- la conexión de los dos ejes;

- la conexión del eje vertical con la muela volandera;

- la entrada del trigo desde la tolva en las muelas;

- la caída de la harina en el cedazo;

- el sistema de engranajes para mover el cedazo.

En el quinto dibujo, aparece un molino con tres ejes. La finalidad de este sistema es aumentar el número de las rotaciones de la muela, con respecto a la rotación de la rueda hidráulica. Esta técnica ya era conocida por lo menos en el siglo XVI, pues aparece en las ilustraciones de la obra de Juanelo Turriano.

Mención especial merece el complejo de los Molinos Nuevos de Murcia. En Murcia, en el río Segura, se construyen en 1743 los Molinos Nuevos para reemplazar a otro diseño antiguo de madera que fue destruido por una avenida. Éstos Molinos Nuevos eran 6 ruedas hidráulicas situadas en una estructura que bloquea el rio perpendicularmente a éste, diseño que parece olvidar las lecciones aprendidas de sus predecesores árabe-andaluces, y de hecho, tras una crecida importante del río Segura, los destrozos sobre los molinos son tan enormes que tienen que reconstruirlos totalmente en 1784. Varios nombres ha tenido este complejo de molienda, que es el más grande que hay en Europa. Se les ha llamado: Molinos de las 21 piedras, de las 24 piedras, Molinos de Allende, Molinos del Matadero, Molinos de Hernández Águila o de Juan Lasheras.

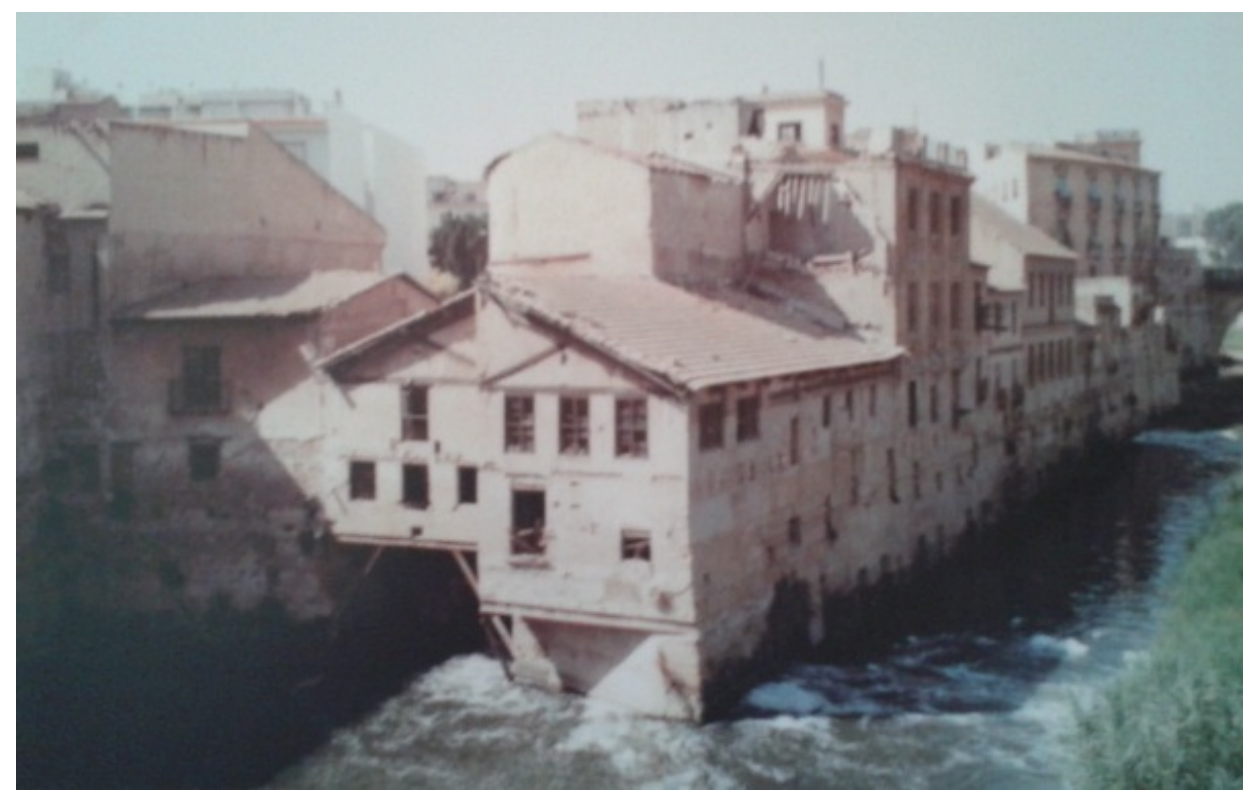




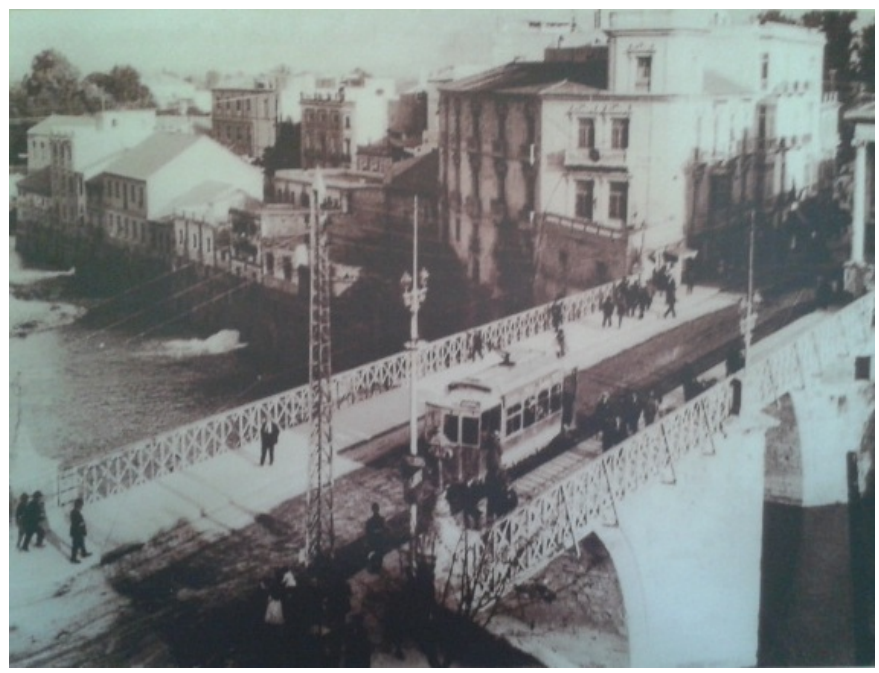

En la actualidad los Molinos Nuevos o Molinos de las 24 piedras, se encuentran alojados en un edificio neoclásico construido en 1785, bajo el patrocinio del Conde de Floridablanca.

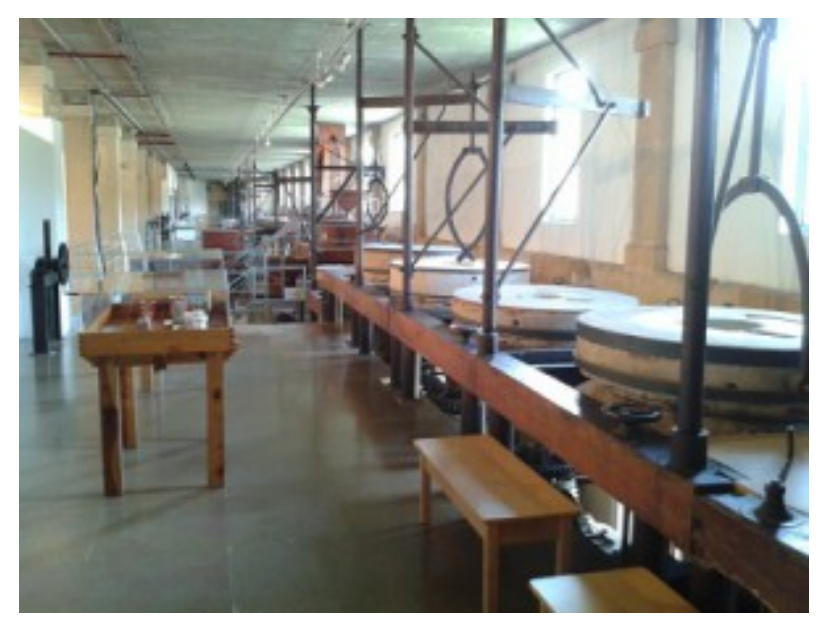

En su interior, la ingeniería hidráulica permitía accionar 24 piedras para la molienda.

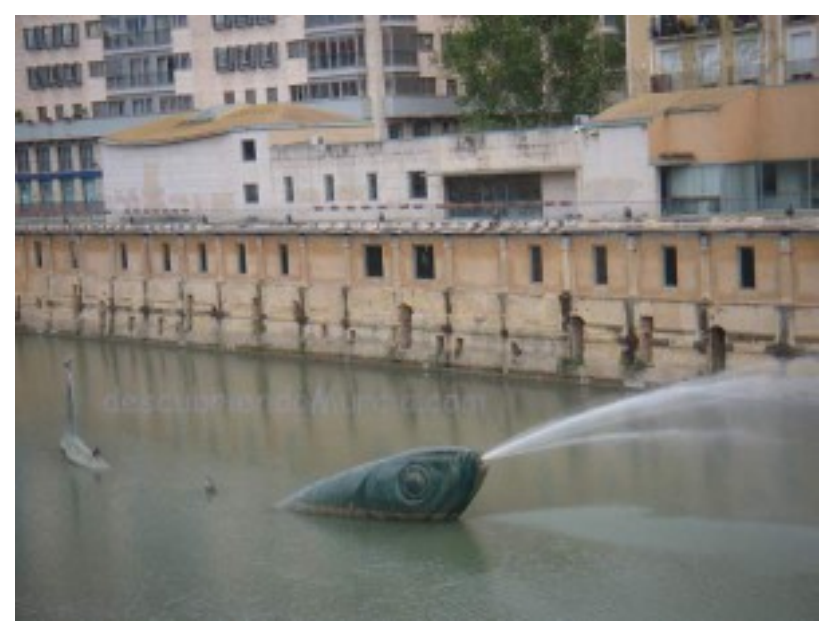


Los Molinos Nuevos, están situados en la margen derecha del río Segura, a su paso por Murcia.

Su nombre viene dado en contraposición de los molinos antiguos que quedaban en la margen izquierda.

También fueron conocidos en su origen como: molinos de allende, por estar situados en la zona nueva de la ciudad (el Barrio del Carmen).

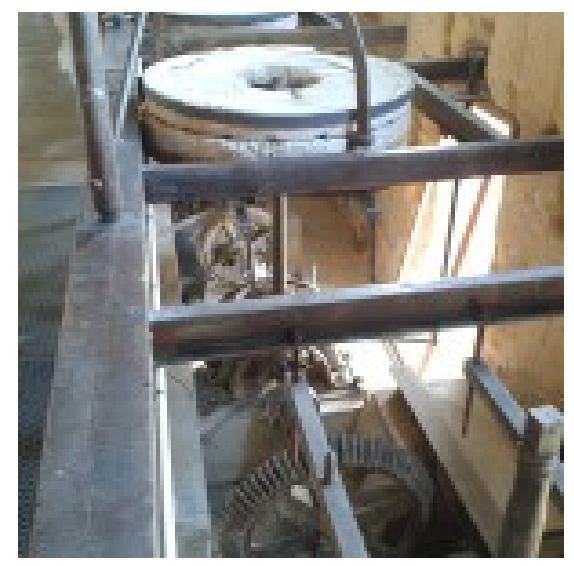

Más tarde se les llamaron molinos del matadero, cuando éste se estableció en las inmediaciones.

Cuando se construyeron en el siglo XIV, contaban con 6 ruedas (rodetes) horizontales. Tras diversas riadas y destrucciones es el Conde de Floridablanca el que manda levantar un azud (el del Puente Viejo), con el fin de calmar las aguas del Segura y conducir éstas hacia los molinos.

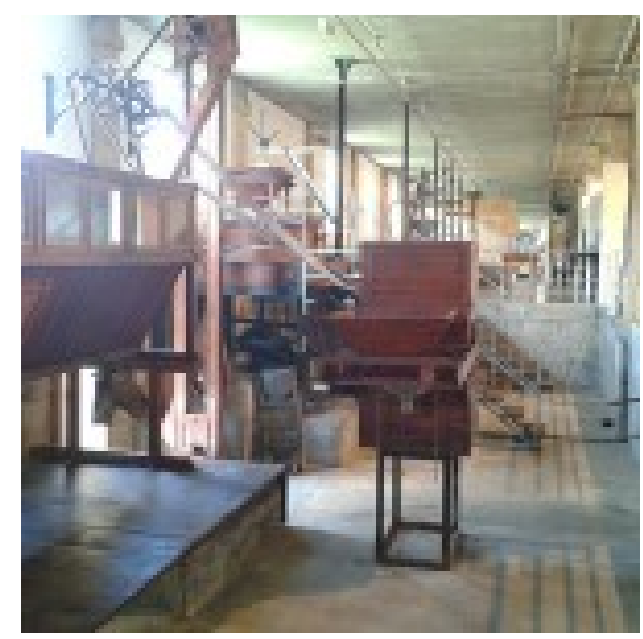

Fue entonces cuando se instaló un espectacular complejo de molienda única en toda la Región, compuesto por 7 ruedas de 3 piedras cada uno. 
Lo que propició que se les conociera también como los de las 21 piedras. En 1908 se incorporaron otras tres con lo que pasó a llamarse de las 24 piedras.

Sobre la segunda mitad del siglo XIX, empezó su decadencia debido a las nuevas formas energéticas, que permitían la elaboración de harinas a precios más rentables.

Siguiendo con el desarrollo temporal de la técnica relativa al agua, es importante reseñar lo siguiente.

Desde 1686, la aparición de Principia Mathematica de Newton estimula la hidrodinámica moderna dando lugar a la publicación de Hydrodynamica, de Daniel Bernoulli en 1738 en Estrasburgo.

En 1750, Johann Andreas Segner, profesor de física en Gottingen, diseña una rueda a reacción. Fue el primer científico en usar la fuerza de reacción de agua y construyó la denominada rueda de Segner (1750), por ello es conocido como el padre de la turbina de agua, aunque este término se usó definitivamente a partir de 1825. Segner debió inspirarse en D. Bernouilli que dedujo y confirmó experimentalmente el efecto de la reacción del agua.

Algunos molinos se operaron con turbinas Segner en Alemania poco después de su invención. Por ejemplo el de Norten cerca de Hannover donde hizo mediciones de velocidad y par.

En la imagen adjunta puede verse un esquema del funcionamiento de esta rueda: A: entrada de agua, B: tubo vertical con rotor, C: rotor con boquillas (vista lateral), D: rotor con boquillas (vista desde arriba), E: agujero en el suelo, F: correa-polea transmisión, G: dispositivo de alimentación.

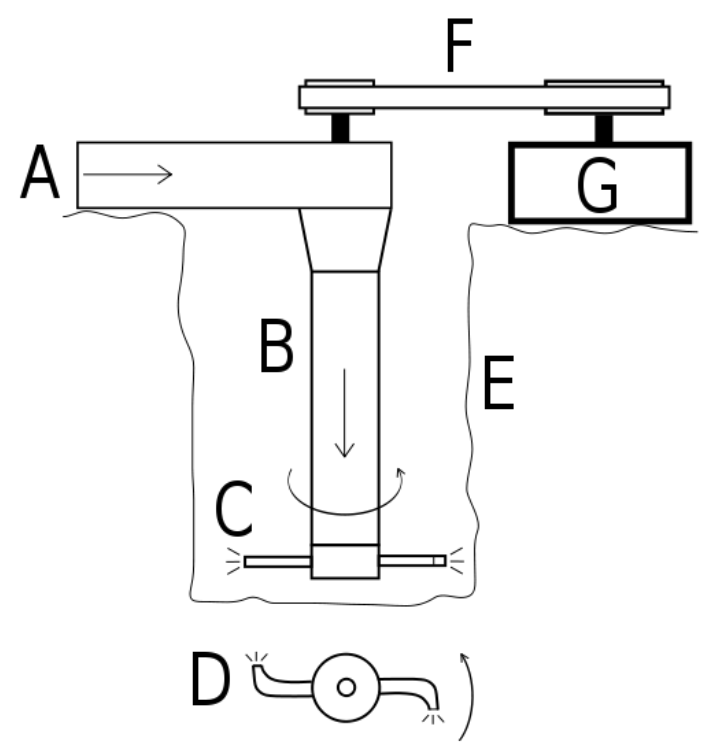


Sin embargo, el pueblo británico atribuye legítimamente la invención de Segner al ingeniero Barker, ya que introdujo una rueda a reacción, similar a la de Segner pero con sólo dos brazos rotatorios, en la industria británica hacia el año 1744. El último probaría la supuesta duplicidad de los casos, sin saber la invención del uno por el otro.

A mediados del S XVIII, el gran científico suizo Leonhart Euler, tuvo ocasión de estudiar de cerca la invención de su colega Segner.

Euler, quien tenía en alta consideración a Segner, y estimulado por su turbina, escribió en un documento de la Academia de Ciencias de Berlín, un artículo sobre la optimización de la turbina de Segner.

En 1751 Euler escribió una segunda publicación sobre la turbina de Segner en la que la comparaba con las ruedas más comunes utilizadas en la época. En otra publicación con el mismo nombre, Euler estimó la eficiencia de la rueda de alimentación inferior en aproximadamente 4/27 y la turbina de Segner incluyendo fricción, sobre 3/4. En esta publicación, Euler proponía numerosas mejoras sobre la turbina Segner que afectaban a la fricción y a la reducción de peso, dándole una forma acampanada.

El nuevo concepto de turbina lo materializó en un último escrito en noviembre de $\mathbf{1 7 5 4}$ en un artículo que publica con la ayuda de su hijo en Berlín, en francés, bajo el título "Théorie plus complète des machines qui sont mises en mouvement par la réaction de l'eau".

Es una rueda de flujo anular que tiene forma de campana, que termina en la parte inferior en la tobera curvada. Mayor innovación es la alimentación de la rueda en su parte superior por un distribuidor fijo que induce una rotación en el agua en el mismo sentido que las toberas curvadas situadas en la parte baja de la rueda.

Euler también mencionó que la presión siempre debe ser positiva. En el caso de presión negativa el flujo se desprendería de la pared y el cálculo fracasaría. Es la descripción temprana de la cavitación en turbomáquinas hidráulicas.

En cualquier caso, las variaciones respecto de la turbina de Segner son tan notables que se puede hablar de turbina de Euler. 


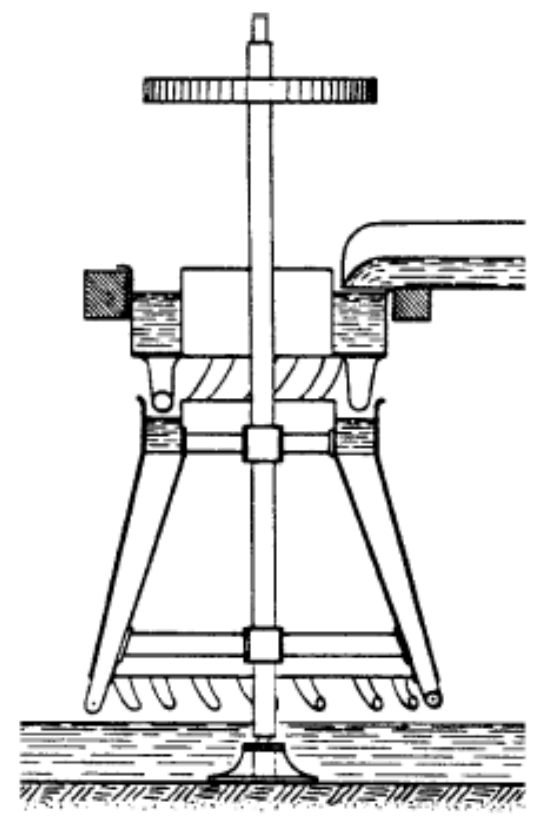

El estudio de las turbomáquinas hidráulicas como ciencia no se crea hasta la publicación de Euler en 1754 en la que expone su teoría de las máquinas de reacción y desarrolla por primera vez la ecuación fundamental de las turbomáquinas hidráulicas, deducida igualando el par a la variación de cantidad de movimiento del fluido a su paso por el rotor.

Las ideas de base ya están aquí expuestas aunque aún harán falta cerca de 80 años para que la turbina a reacción llegue a su madurez.

Se denomina ecuación de Euler a la ecuación fundamental que describe el comportamiento de una turbomáquina bajo la aproximación de flujo unidimensional.

$$
\dot{W}=\dot{m}\left(c_{1 u} u_{1}-c_{2 u} u_{2}\right)
$$

donde:

$\dot{W} \quad$ es la potencia desarrollada por la máquina.

$\dot{m}$ es el caudal másico que atraviesa la máquina.

c es la velocidad absoluta del fluido. El subíndice u indica que se considera solo la velocidad tangencial. Los subíndices 1 y 2 indican entrada y salida respectivamente.

$\mathrm{u} \quad$ es la velocidad del rodete. Se ve que $u=\omega R$

Cabe mencionar que la ecuación de Euler en notación moderna fue usada primero por Zeuner en un libro de texto alemán en 1899, 145 años después de su publicación. 
En los años 1820-1824, un profesor de la escuela de minas de Saint Etienne llamado Claude Burdin, intentó mejorar la rueda a reacción de Euler. El interés por el distribuidor fijo inventado por Euler no escapa a Burdin. Y tras largos trabajos, Burdin diseña una máquina en la que el distribuidor se posiciona en su interior y no arriba como en sus anteriores máquinas inspiradas en la de Euler.

En esta máquina, el distribuidor y la rueda están provistos, ambos, de álabes verticales perfilados, y puede funcionar inmersa en agua. A esta máquina la bautiza como turbina.

La palabra turbina la introduce Burdin en un escrito para la Academia de Paris en 1824 y diseña, por tanto, la primera turbina centrífuga con admisión de flujo a través de álabes inclinados.

En este contexto aparece Benoit Fourneyron, posiblemente alentado por el premio de la Sociedad de estímulo industrial en Francia. Premio que no pudo ganar Burdin al no estar su máquina operativa cuando la presentó en 1826 a este certamen.

Sin embargo Fourneyron consigue finalizar la turbina centrífuga, mejorando principalmente las pérdidas en la misma respecto de la turbina de Burdin, y probarla en las forjas de Pont-sur-l'Ognon en el Franco-condado, en 1827, donde trabajaba como ingeniero. Es una pequeña turbina que aprovecha un salto de solo 1,4 metros. Da una potencia de 4,5 kW y gira a 60 vueltas por minuto, pero su rendimiento se estima en un $83 \%$, variable en realidad entre el 51 y el 88 \% según el régimen de funcionamiento, pero que mejora notablemente las ruedas hidráulicas horizontales antiguas que conseguían un rendimiento de apenas un $35 \%$.

En 1832, Fourneyron instala su primer modelo industrial. Saca una patente ese mismo año, y obtiene en 1833 el premio de la Sociedad de estímulo industrial francesa, lo que le convierte en una celebridad. Los encargos son numerosos. 

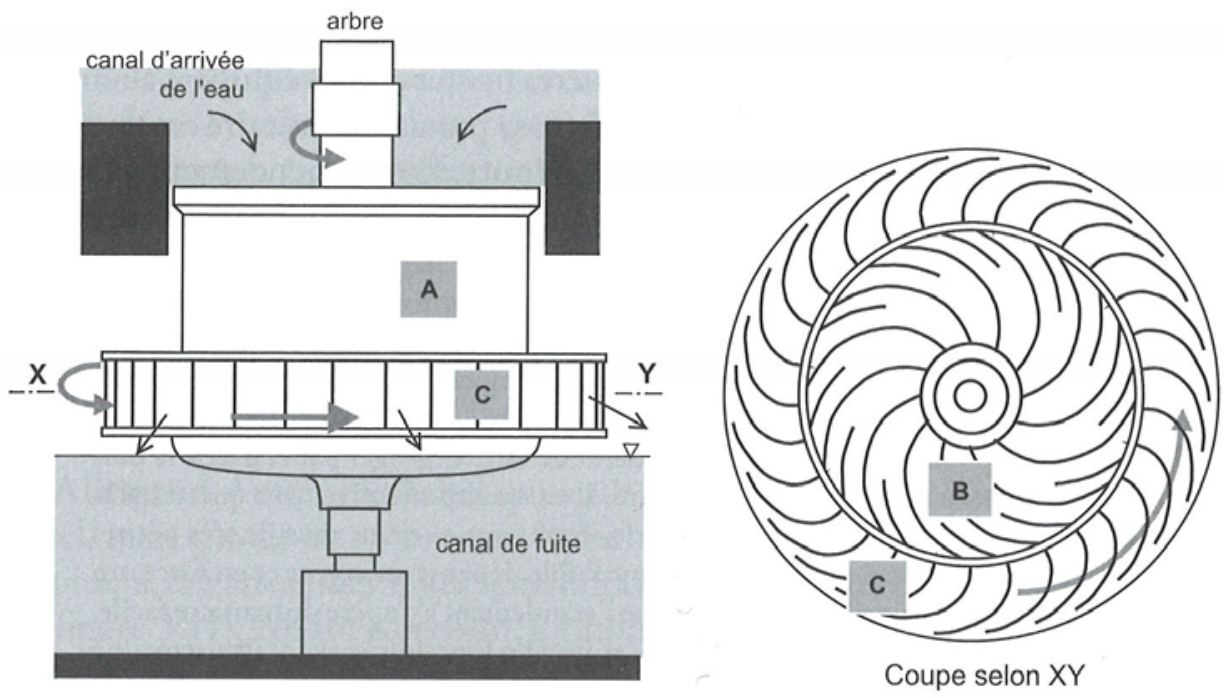

Figure 6.5. Turbine de Fourneyron (vers 1835). L'eau s'écoule de l'intérieur vers l'extérieur et de haut en bas. Elle arrive dans le cylindre (A), appelé la huche, et pénètre dans le distributeur (B) situé juste en-dessous. Le distributeur (B) est muni d'aubes verticales orientées et profilées pour que l'écoulement pénètre tangentiellement dans le rotor $(C)$, situé à l'extérieur par rapport au distributeur fixe, et muni lui aussi d'aubes verticales profilées. Le rotor est solidaire d'un arbre de rotation, dont le bas repose sur le fond du canal de fuite, et dont le haut se prolonge au-dessus du cylindre. Entre le distributeur (B) et le rotor (C), il y a un anneau cylindrique que l'on peut monter ou descendre afin de régler le débit de la turbine. La turbine peut fonctionner aussi bien noyée que dénoyée, c'est-à-dire avec un niveau d'eau en aval situé en dessous de la sortie du rotor, ou au-dessus.
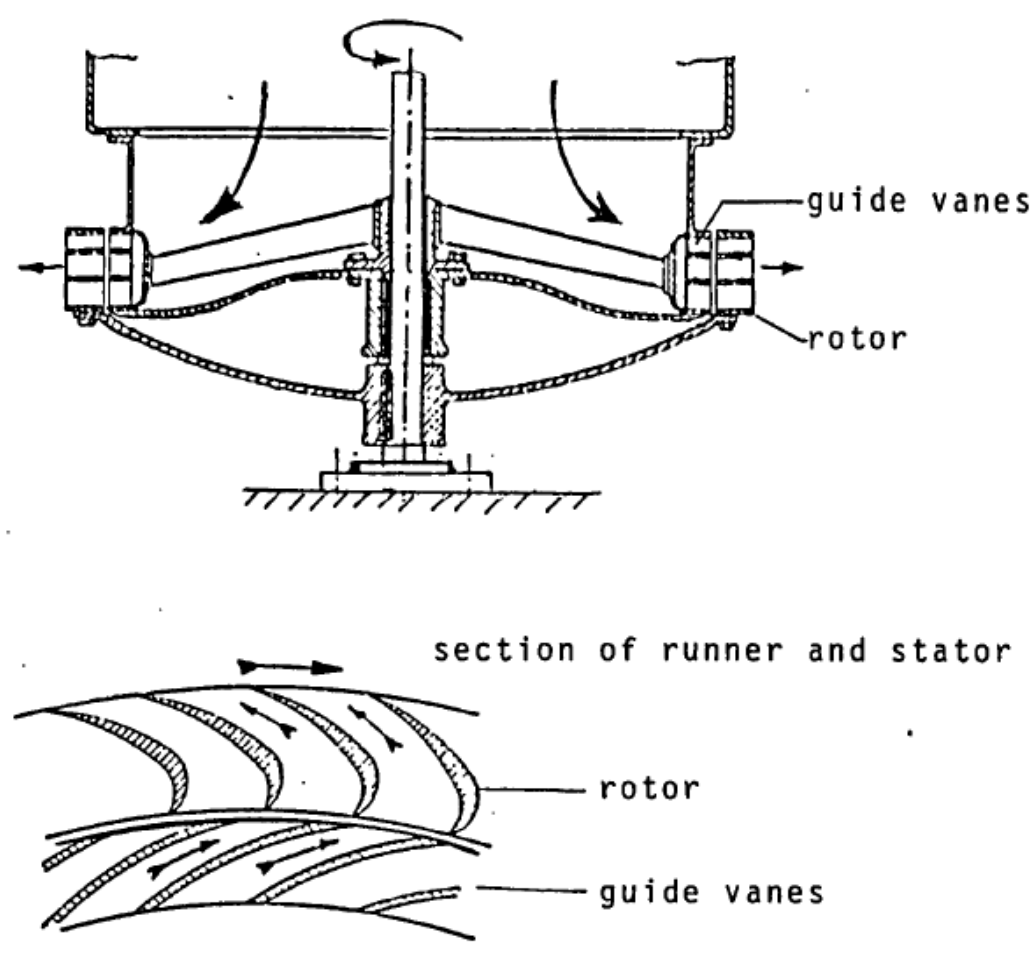

Fourneyon turbine 
En 1837-1838, Fourneyron equipa dos saltos importantes en las hilaturas de San Blas. Con alturas de 108 y 114 metros son los primeros grandes saltos equipados en el mundo. La turbina tiene un diámetro exterior de 0.55 metros y su potencia unitaria es de $45 \mathrm{~kW}$, la velocidad de rotación es de 2300 vueltas por minuto con un rendimiento superior al $80 \%$.

En 1839, Fourneyron obtiene la medalla de oro en la Exposición Universal.

Entre 1837 y 1840, Fourneyron hace construir en el departamento del Alto Loira, el establecimiento de Chambon-Feugerolles, con un taller de fabricación de turbinas y un banco de ensayo.

En 1849 ya hay 129 fábricas dotadas de turbinas Fourneyron en Europa e incluso en Méjico.

En 1870 se colocan turbinas Fourneyron en el complejo industrial papelero, metalúrgico y textil de Holyoke en Massachusetts.

En 1895, las turbinas Fourneyron equipan la primera gran instalación hidroeléctrica estadounidense en las cataratas del Niágara. Son tres turbinas de $3.700 \mathrm{~kW}$ cada una, para una altura del salto de 60 metros.

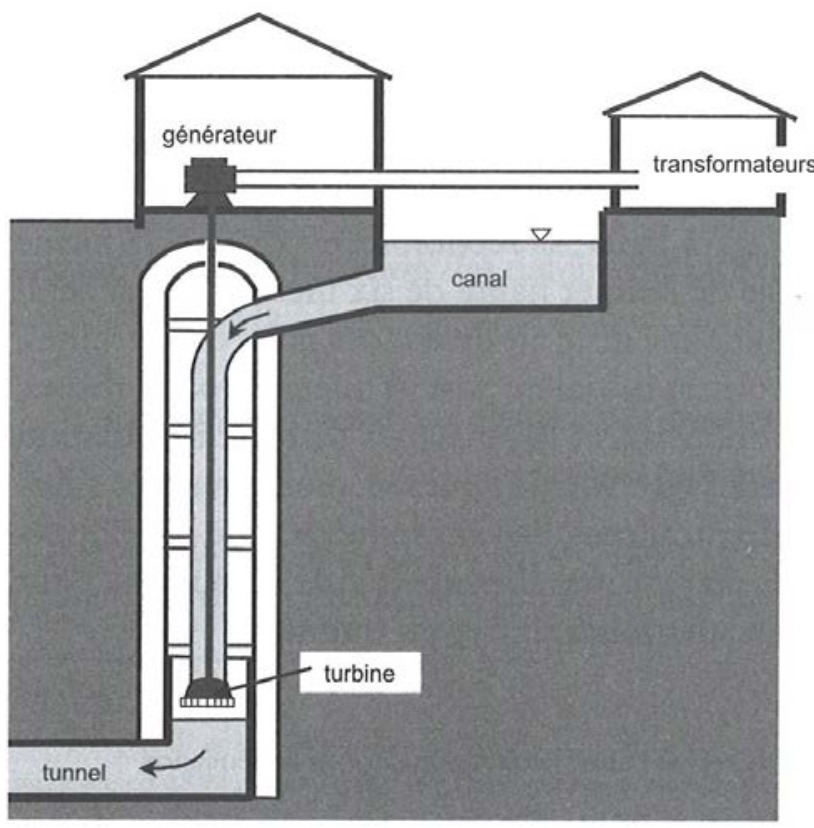

Figure 7.4. Schéma d'installation des turbines pour la première grande usine des chutes du Niagara (1895).

Tras el éxito obtenido por Fourneyron, las turbinas suscitan numerosas innovaciones y patentes. 
En 1840 se patenta la turbina Fontaine-Baron (y se construye en 1843 en Chartres). El agua llega al rotor por la parte de arriba, después pasa a través de un disco superior fijo dotado de álabes haciendo las veces de distribuidor. Para regular el caudal de agua que atraviesa la turbina, este distribuidor tiene pequeñas compuertas que permiten abrir u obturar cada canal inter-álabes del distribuidor. Este sistema de compuertas, sin duda bastante frágil, será simplificado seguidamente.

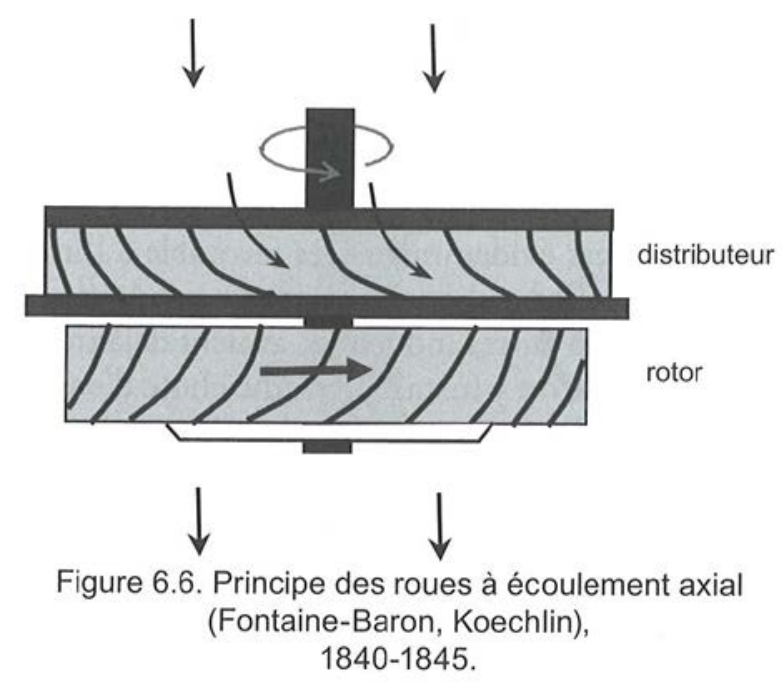

En 1841, se patenta la turbina Jonval que es también de alimentación vertical. Consiste en una rueda de álabes curvos y eje vertical dispuesto dentro de la parte estrechada de un conducto vertical. Jonval había tomado esta idea del alemán Henschel que había construido una turbina semejante en 1838 en Kassel pero no había podido patentar la idea. Es la primera turbina de reacción con tubo de aspiración.

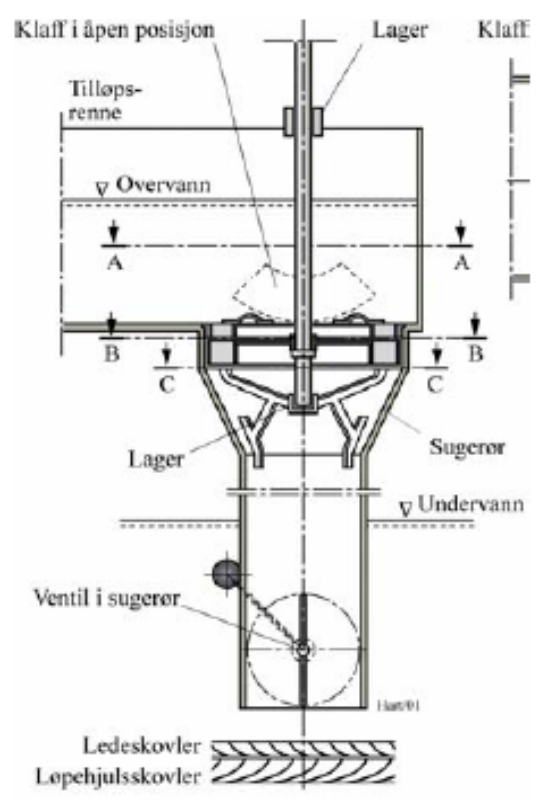



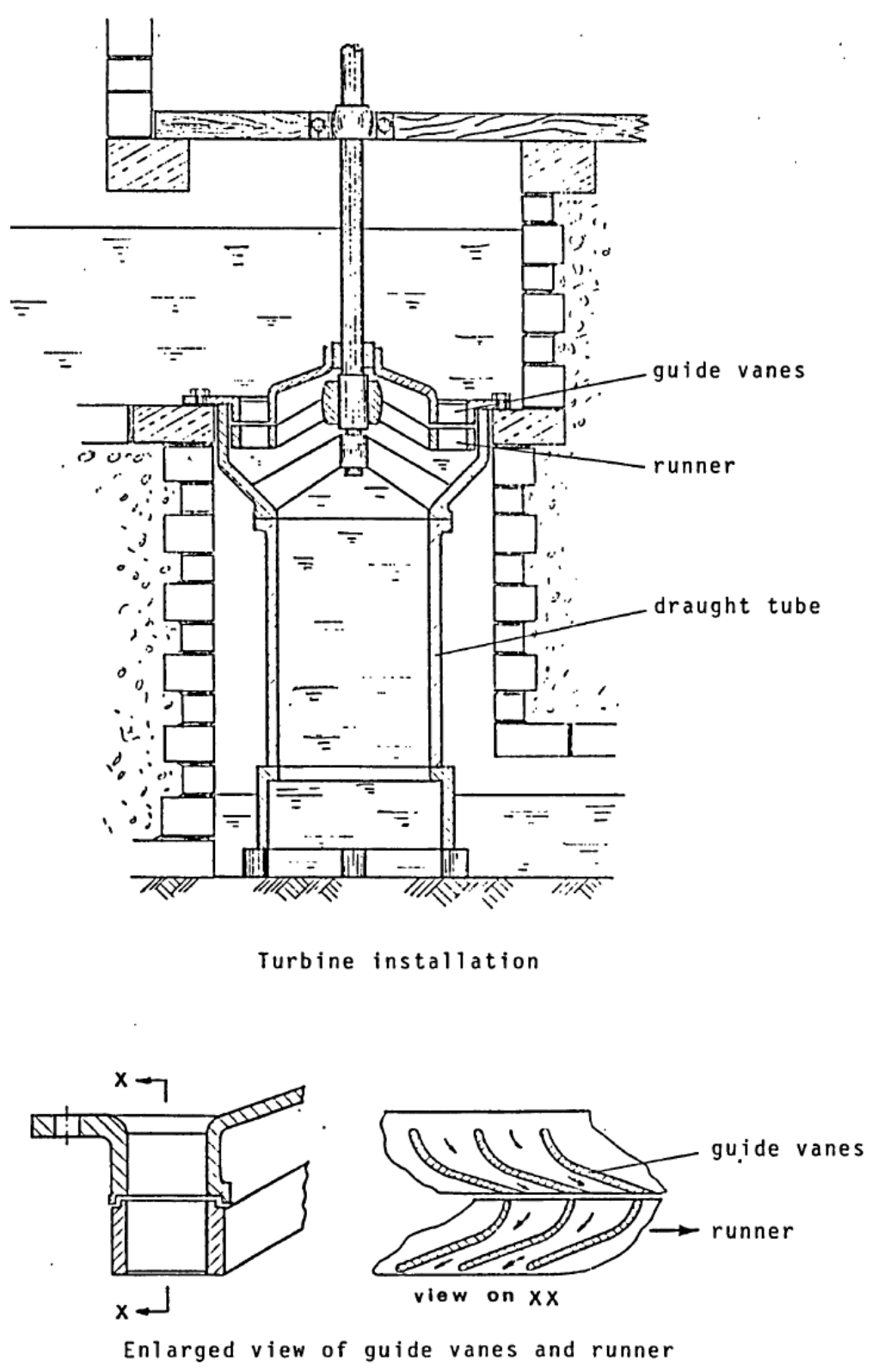

Enlarged view of guide vanes and runner

The Jonval axial flow turbine

André Koechlin compra los derechos de la patente Jonval después de mostrar interés por la sección estrechada, y adjunta encima de la rueda con álabes un distribuidor fijo, como lo había hecho Fontaine-Baron algunos años antes.

El sistema de compuertas que permite regular el caudal permanece exterior a la turbina, en la alimentación de agua. Este concepto resulta ser idóneo para saltos de 3 a 5 metros de altura, por lo que es largamente utilizado en este rango. Incluso, a partir de los años 1850, tiene un cierto éxito en los Estados Unidos. 
El movimiento se internacionaliza con el inglés James Thomson que obtiene una patente en $\mathbf{1 8 5 0}$ para una turbina tipo "vortex" producido durante 24 años en los talleres de Kendal.
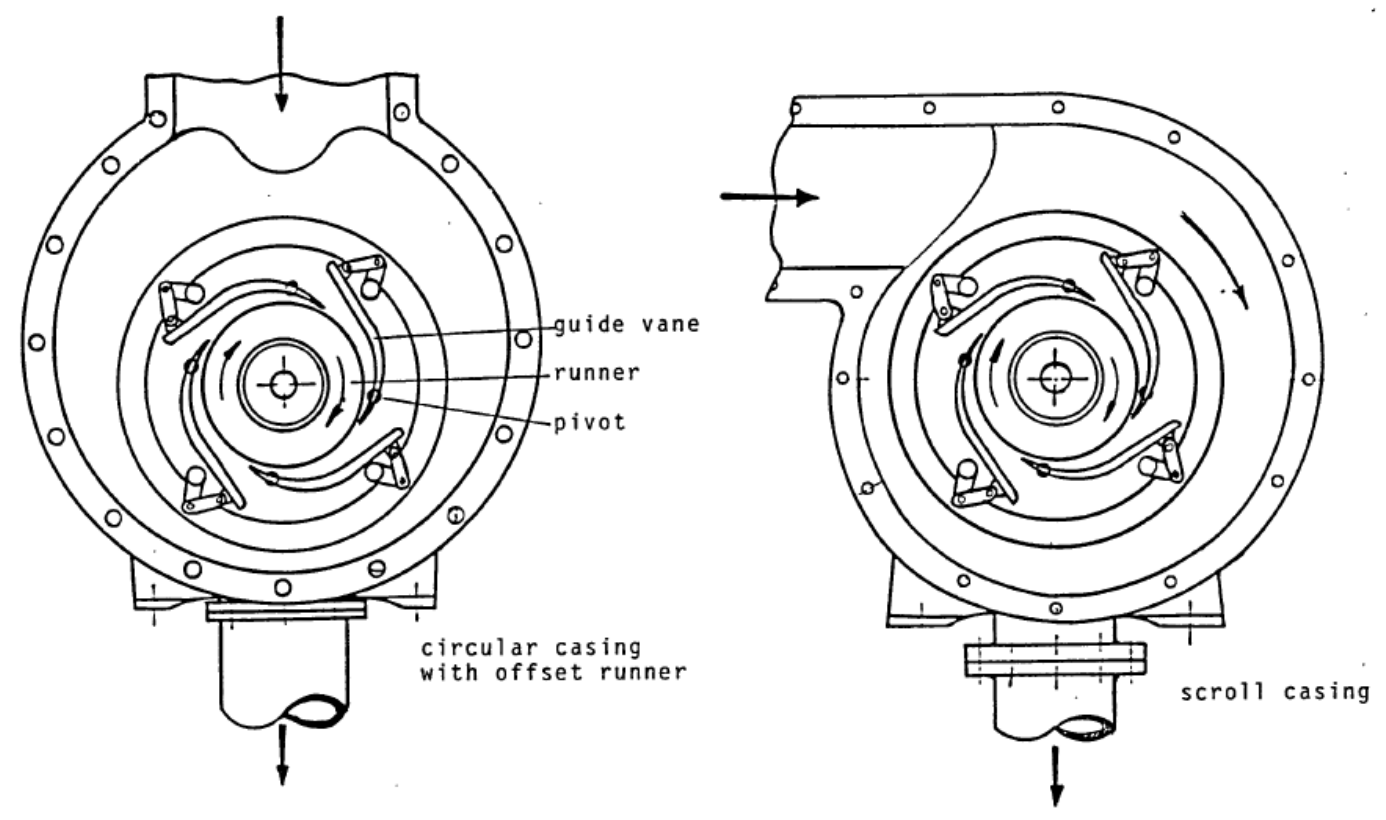

Thomson's vortex turbine

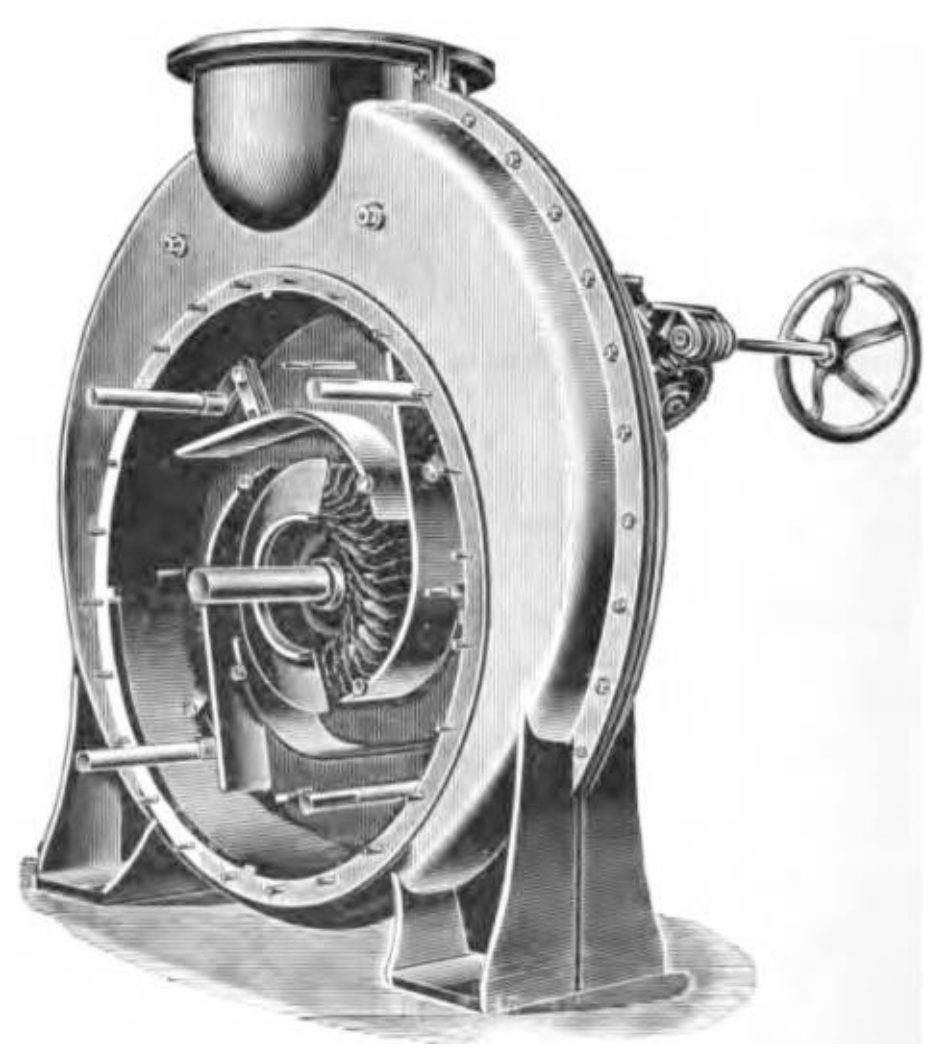

El desarrollo posterior en las turbinas será liderado por los ingenieros americanos. 
En 1843 se introduce la turbina Fourneyron en Estados Unidos. Al año siguiente, el ingeniero Uriah Boyden adapta la turbina Fourneyron dotándola de un dispositivo de alimentación cónico convergente en la entrada (en lugar de cilíndrico) y de un difusor tras el rotor. Desde el año 1844 que se instalan este tipo de turbinas en los molinos de la Appleton Company en Lowell en el Massachusetts, un gran número de turbinas Boyden se construyen en el país.

En las turbinas Fourneyron y Boyden, la alimentación es axial y el flujo va del interior a la periferia. Además el rotor está en el exterior del difusor.

En 1838, Samuel B. Howd, patenta en los Estados Unidos un dispositivo inverso, pero sin gran éxito.

Sin embargo, es el ingeniero James B. Francis el que recibe el mérito de realizar en 1849, la puesta a punto de la turbina de alimentación radial, es decir, con el flujo circulando desde el exterior hacia el interior. Es la famosa turbina Francis que se impondrá a partir de este momento como la más eficaz para los saltos de mediana altura con un caudal importante.

A partir de la turbina de Howd y la de Fourneyron, Francis hace ensayos sistemáticos para optimizar las turbinas en Lowell, donde él desarrolla el puesto de ingeniero jefe en la Locks and Canal Company. Y publica en 1855 los resultados de éstos en el "Lowell Hydraulic Experiments". Francis es uno de los miembros de la American Society of Civil Engineers.

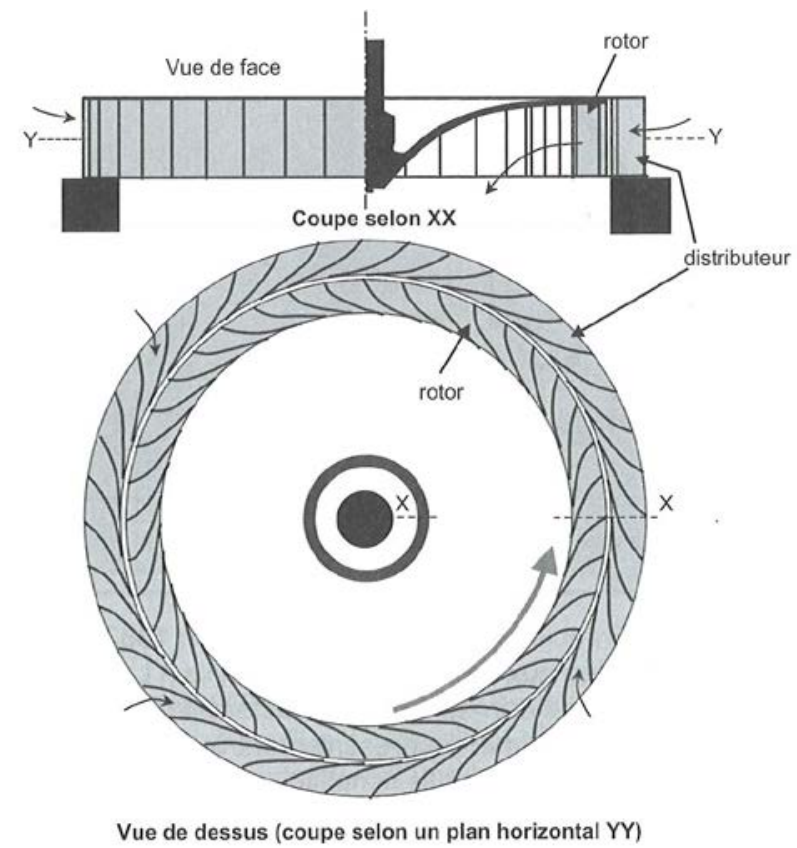

Figure 6.7. La turbine Francis (1855). À ses débuts, cette turbine était caractérisée (comme sur cette figure) par un écoulement strictement radial dans le rotor. 

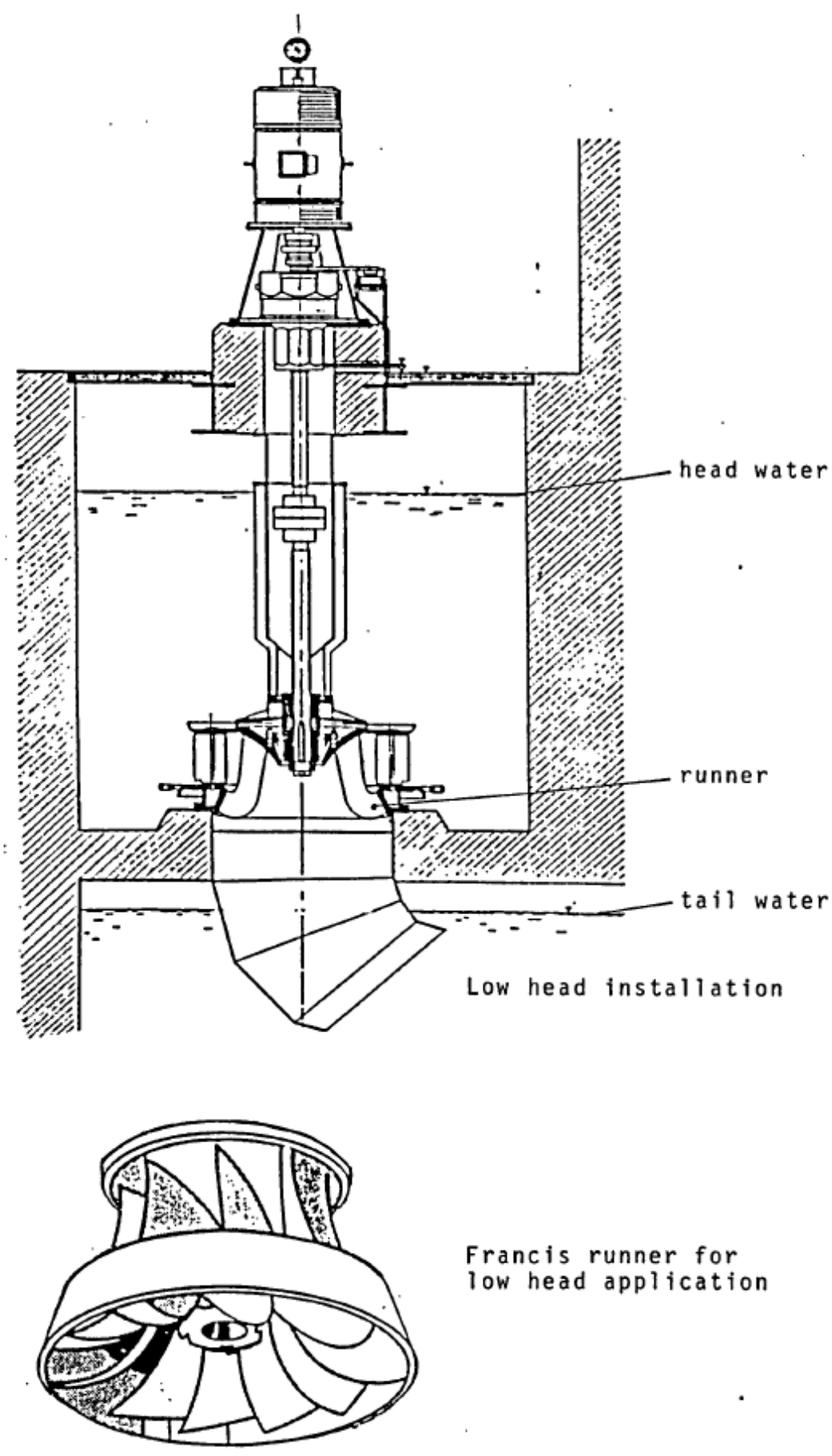

Francis turbine

El Diseño de la turbina Francis evoluciona rápidamente de tal manera que la alimentación dentro del rotor se incurva hacia abajo. A partir de los años 1886, se dotará a la turbina Francis de un tubo de alimentación en espiral que contribuirá a la orientación de la alimentación a la entada del distribuidor. Así, la turbina Francis verá ampliarse su dominio de aplicación hacia grandes saltos con caudales importantes. De hecho, en 1922, las turbinas Francis son las que equiparon la grana maquinaria canadiense de los saltos del Niágara, de 89 
metros con $40.000 \mathrm{kw}$ de potencia. En la parte americana de los saltos del Niágara, se instalarán en 1961 también turbinas Francis de 150.000 kw de potencia unitaria.

Las turbinas Francis son turbinas de reacción, es decir, parte de la energía intercambiada es de presión y parte es energía cinética. Dentro de este tipo de turbinas se puede establecer una división en máquinas de flujo radial, figura a, y de flujo diagonal o mixto, figura b. A las primeras se les denomina Francis lentas por ser de baja velocidad específica, y a las segundas Francis rápidas debido a su mayor velocidad específica.

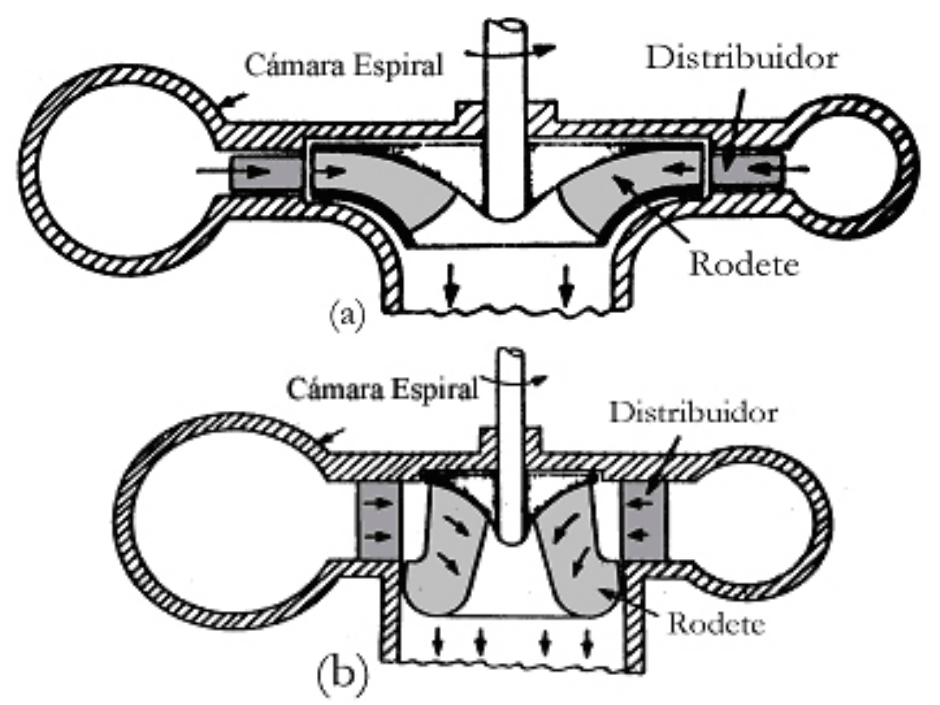

Sus principales elementos son: la cámara espiral, el distribuidor, el rodete y el tubodifusor. La cámara espiral reparte el líquido a la entrada del distribuidor y le imprime una apreciable componente tangencial. Normalmente tiene la forma de una espiral (caracol) de sección transversal circular decreciente. De esta manera, se consiguen una velocidad media y presión uniformes en la entrada del distribuidor, lo que asegura que no existan cambios bruscos de velocidad, que podrían dar lugar a desprendimientos de la corriente y un buen equilibrado radial del rodete.

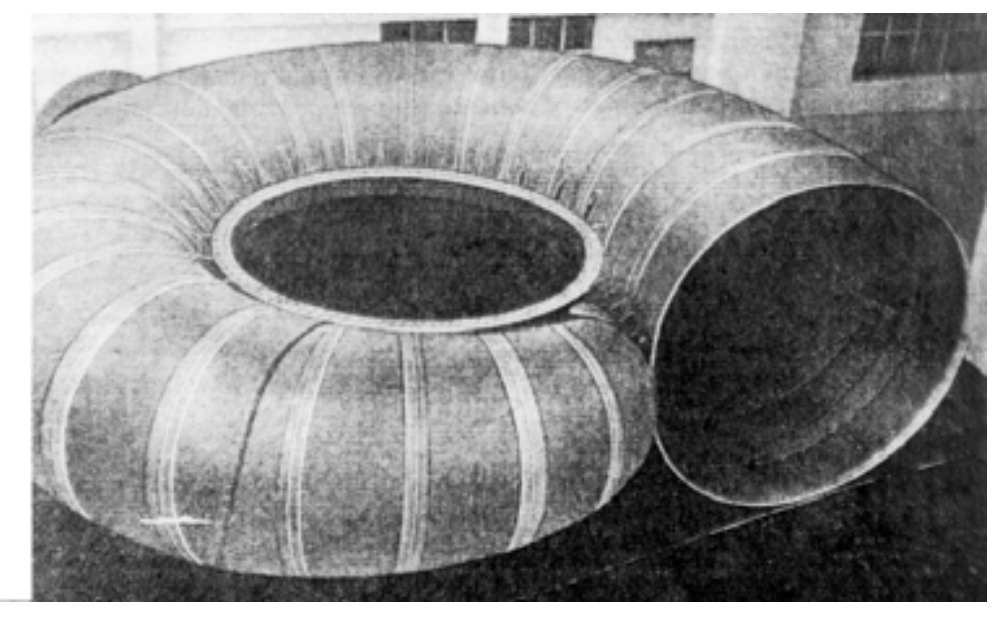


El distribuidor está constituido por dos coronas de álabes concéntricas, una exterior de álabes fijos (predistribuidor) y otra interior de álabes móviles (orientables). La corona exterior está anclada a la carcasa de la turbina y tiene una finalidad doble: conducir el líquido desde la carcasa hasta la corona de álabes móviles, además de servir de arriostramiento y elemento de rigidización de dicha carcasa. En la corona interior los álabes pueden girar alrededor de un eje que los atraviesa, lo que permite abrir o cerrar completamente el paso de líquido hacia el rodete. La misión de esta corona de álabes móviles es guiar el líquido hacia el rodete con la dirección más adecuada, así como regular el caudal (desde cierre total hasta apertura total) de acuerdo con la potencia demandada. Estos álabes están dispuestos de manera que forman conductos convergentes lo que da lugar a que en la entrada del rodete el flujo sea más uniforme.

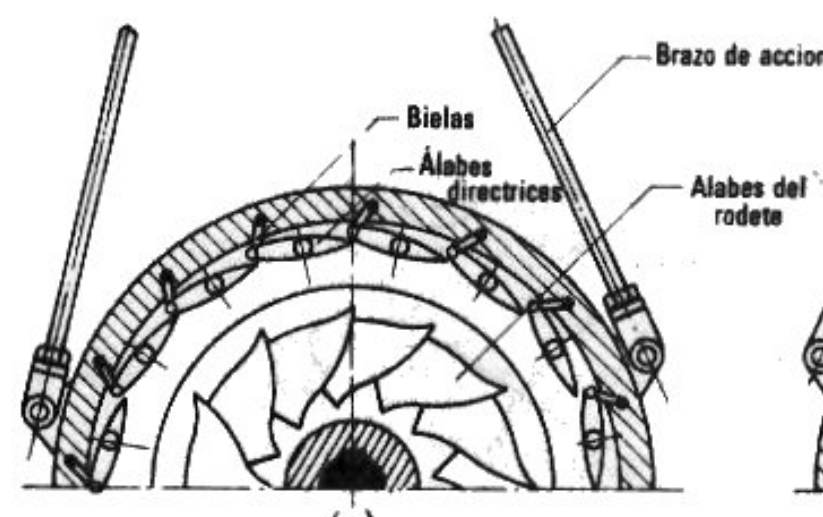

(a)

a) cerrado

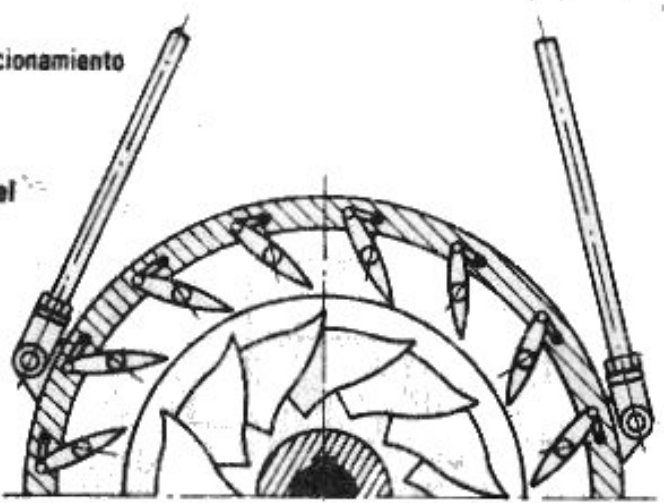

(b)

b) abierto

El rodete está formado por álabes fijos (no orientables) cuya disposición depende del tipo de turbina. En las turbinas Francis lentas, el flujo a la entrada es prácticamente radial, con lo que se aprovecha al máximo la acción centrífuga, sin embargo, la descarga por el centro del rodete es complicada, por lo que el caudal se halla limitado. En las turbinas Francis rápidas, el flujo es diagonal, ya que el líquido penetra en el rodete con una cierta componente axial.

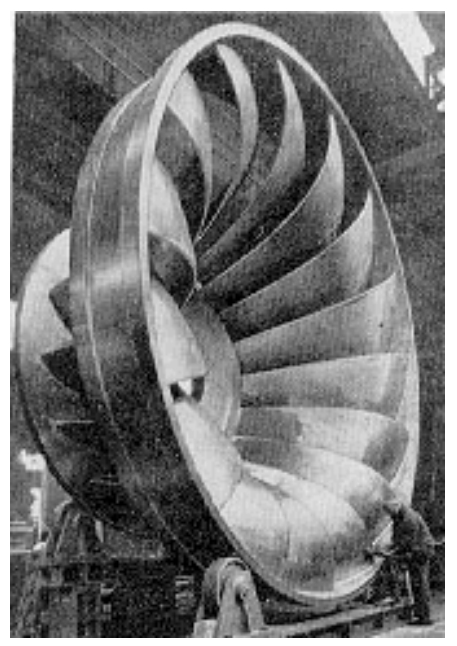


El tubo difusor está constituido por un tubo divergente que conduce el líquido hacia un canal o tubería de descarga y su finalidad es doble. La primera es el aprovechamiento de la altura a la que normalmente está montado el rodete por encima del nivel del agua en el canal de descarga. Para ello sería suficiente emplear una tubería de sección constante. La segunda es la recuperación de la energía cinética del líquido a la salida del rodete, que puede ascender a más del $20 \%$ de la altura neta. Para cumplir esta finalidad el tubo difusor debe ser divergente. Estos tubos son generalmente metálicos en las turbinas Francis, sin embargo en turbinas de grandes caudales y velocidades específicas elevadas se construyen en hormigón. En estos casos es necesario proteger la zona próxima a la salida del rodete con placas de acero pues en dicha zona el líquido tiene una velocidad elevada que podría, con el tiempo, erosionar el hormigón. Dependiendo de las características de la central, el tubo de descarga puede ser acodado.

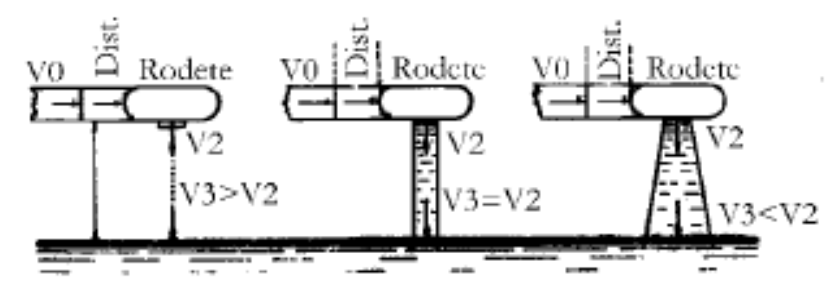

El campo de aplicación de las turbinas Francis para centrales convencionales es muy amplio, ya que se pueden emplear para saltos desde $30 \mathrm{~m}$ hasta $700 \mathrm{~m} \mathrm{y}$ potencias desde $1 \mathrm{MW}$ hasta $250 \mathrm{MW}$. Para saltos elevados se emplean las Francis radiales o lentas y para los saltos bajos se emplean las Francis diagonales o rápidas. Para las pequeñas centrales se pueden encontrar en el mercado turbinas Francis para saltos desde $10 \mathrm{~m}$ hasta $200 \mathrm{~m}$ para potencias que van desde $0.1 \mathrm{MW}$ hasta $4 \mathrm{MW}$. Como ejemplos, se pueden citar las turbinas Francis de la central de Hornberg (Alemania) cada una de las cuales desarrollan $262 \mathrm{MW}$ bajo un salto de $652 \mathrm{~m}$ y las de la central de Isla Solteira (Brasil) que desarrollan una potencia de $193 \mathrm{MW}$ bajo un salto de $48 \mathrm{~m}$.

En 1872, se construye un sistema de control de caudal (distribuidor), sistema FINK, aplicado hasta hoy en día. 


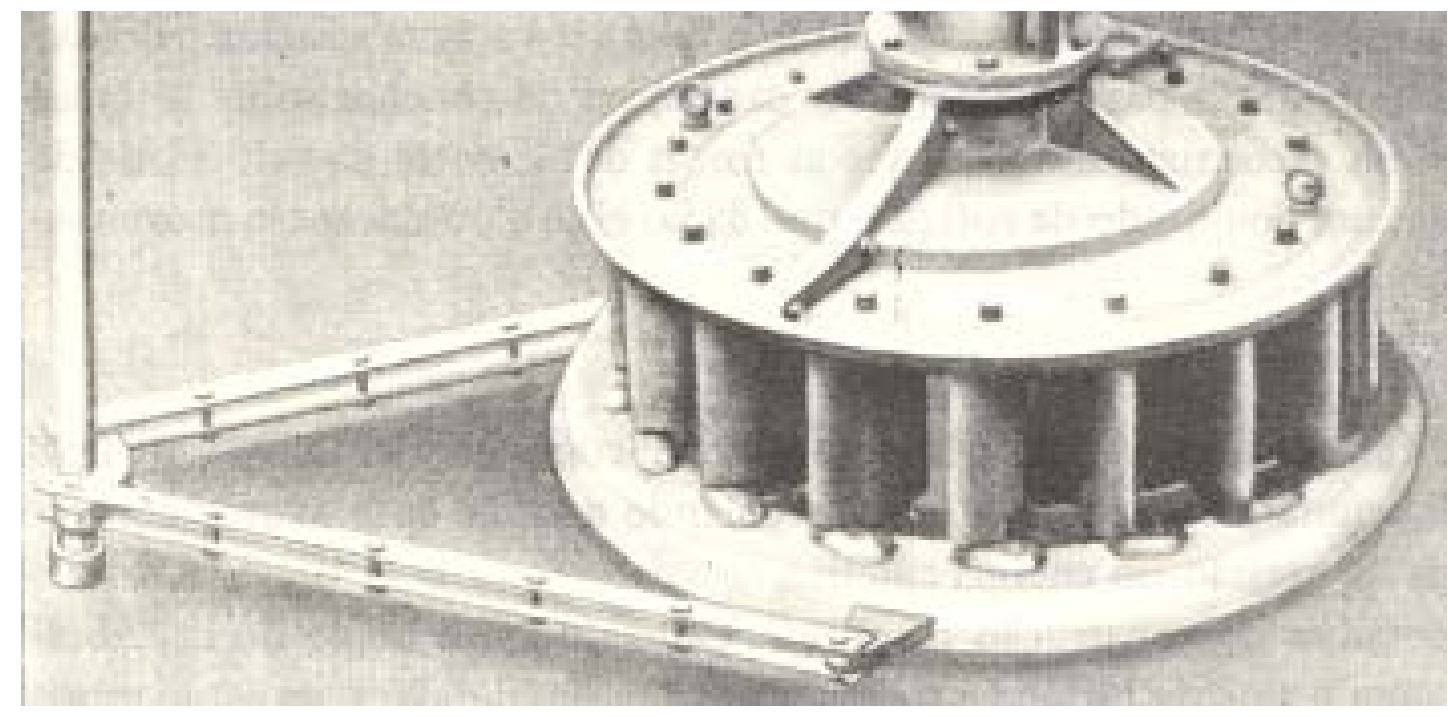

En la última etapa de lo que se puede considerar como la génesis de las turbinas modernas aparece Víctor Kaplan y su patente de $\mathbf{1 9 1 2}$ para una turbina con un rotor en forma de hélice con los álabes de ángulo variable para optimizar el rendimiento en función de la velocidad del agua. La turbina Kaplan se acepta como mejor que la turbina Francis para alturas de salto bajas.

La evolución que se produjo hasta llegar a la turbina Kaplan es la siguiente:

- Se empezó a construir rodetes más rápidos del tipo Francis - $\mathrm{n}_{\mathrm{s}}=450$ rpm;

- Para estos rodetes hay un gran espacio entre el rodete y distribuidor, lo que permitía la obtención de mejores rendimientos debido la disminución de la fricción;

- Alrededor de 1912, Victor Kaplan construyó una turbina similar a del tipo Francis, en que el agua penetraba en dirección radial y después de dejar el distribuidor, circulaba sobre el rodete y caía completamente libre, alcanzando el mismo con dirección preponderantemente axial;

- Después, se siguió con una serie de perfeccionamientos hasta llegar a las formas actuales, tanto de los rodetes Hélices como de los rodetes Kaplan;

- Como primera etapa de perfeccionamiento, fue suprimida la corona exterior del rodete.

- Posteriormente, como resultado de varias experiencias, se observó que la curva de rendimiento en función de las diversas aperturas de los álabes del distribuidor se presentaba siempre muy aguda para el rodete con palas fijas. Es decir que la turbina solamente operaba con buenos rendimientos para determinadas posiciones de los álabes del 
distribuidor (aperturas correspondientes a los caudales próximos al caudal de diseño).

- Descubría que había una estrecha relación entre la posición de los álabes del rodete con la apertura del distribuidor y el rendimiento óptimo.

- Después de esto, empezó a construir turbinas dotada de un dispositivo de regulación que posibilitase las palas del rodete acompañar la variación de posición de los alabes del distribuidor, tomando siempre la correspondencia óptima entre $\beta 2$ (ángulo que define la posición de las palas del rodete) y $\alpha$ (ángulo que define la apertura de los alabes del distribuidor).

- De esta manera, las turbinas de esto tipo, con palas móviles, pasaron a ser llamadas de Turbinas Kaplan, en cuanto las de palas fijas recibieran la denominación de Turbinas Hélice.

- La curva de la turbina Kaplan es la envolvente de las curvas de rendimiento de diversas turbinas Hélice.

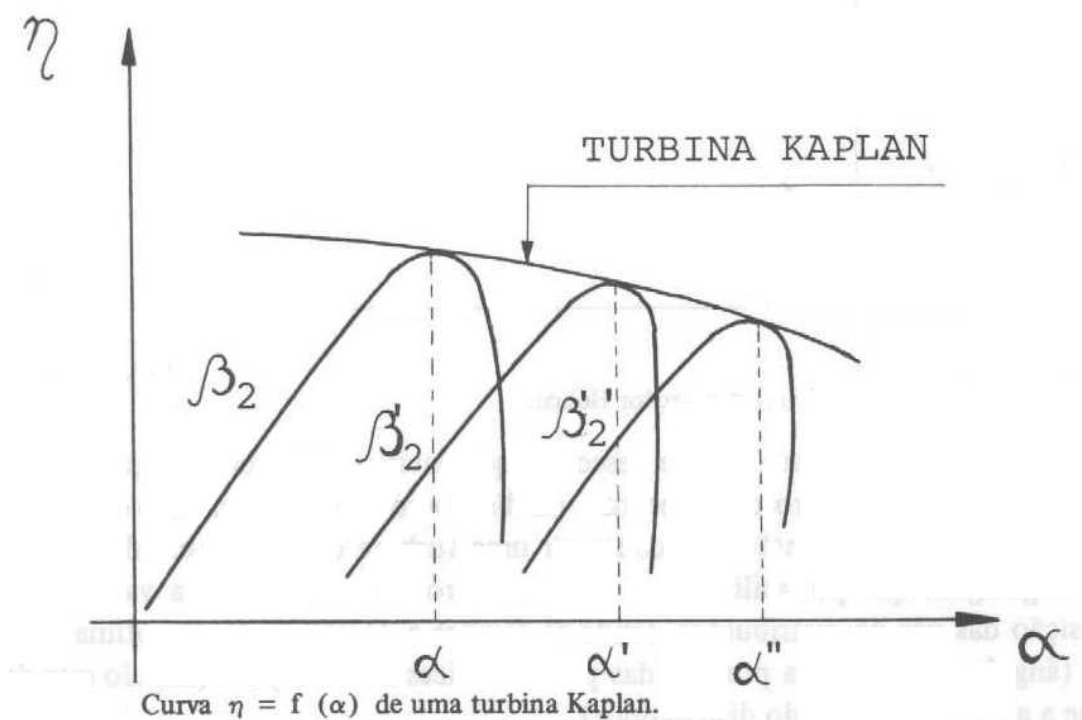

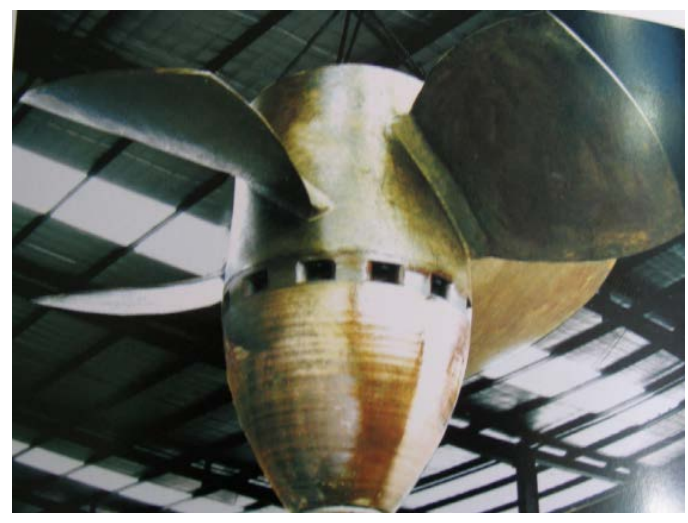

Turbina Hélice

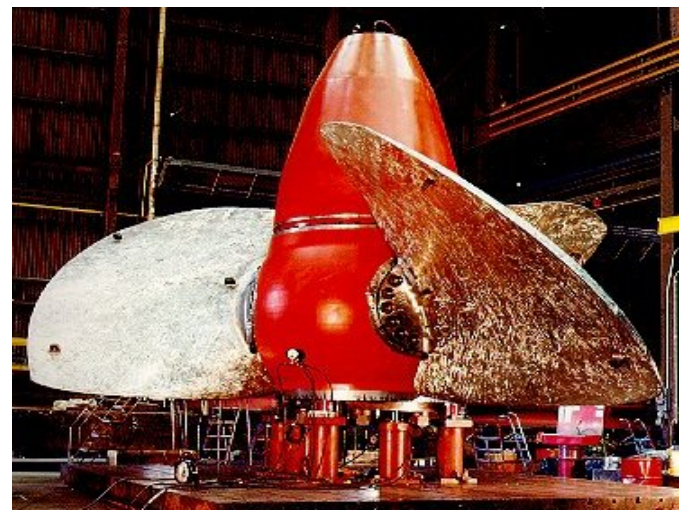

Turbina Kaplan 
Las turbinas hélice y Kaplan también son de reacción, pero de tipo axial. Constan fundamentalmente de una cámara espiral, un distribuidor, un rodete y un tubo de descarga.
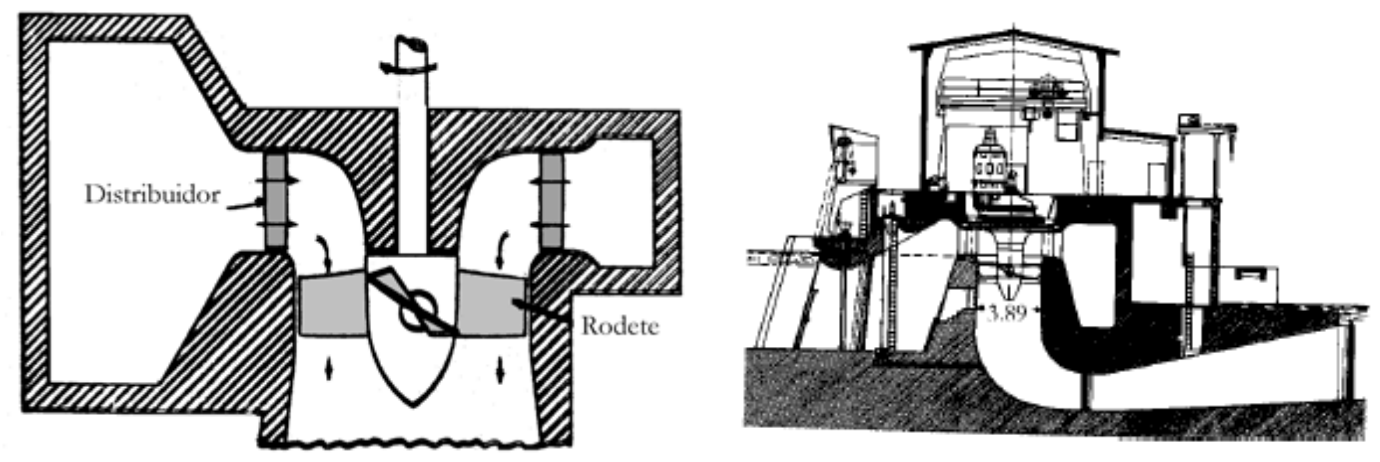

La cámara suele estar construida en hormigón cuando la altura del salto es pequeña (menor que $20 \mathrm{~m}$ ) pues al ser, en este caso, los caudales que circulan por la turbina muy grandes, las dimensiones de la cámara también lo serán.

Cuando se trata de saltos mayores, las cámaras espirales se fabrican de chapa de acero formadas por virolas o segmentos sueltos, que se unen mediante soldaduras al anillo de los álabes fijos del distribuidor. Este último, de acero colado, puede constar de una sola pieza o de varias, según sea su tamaño.

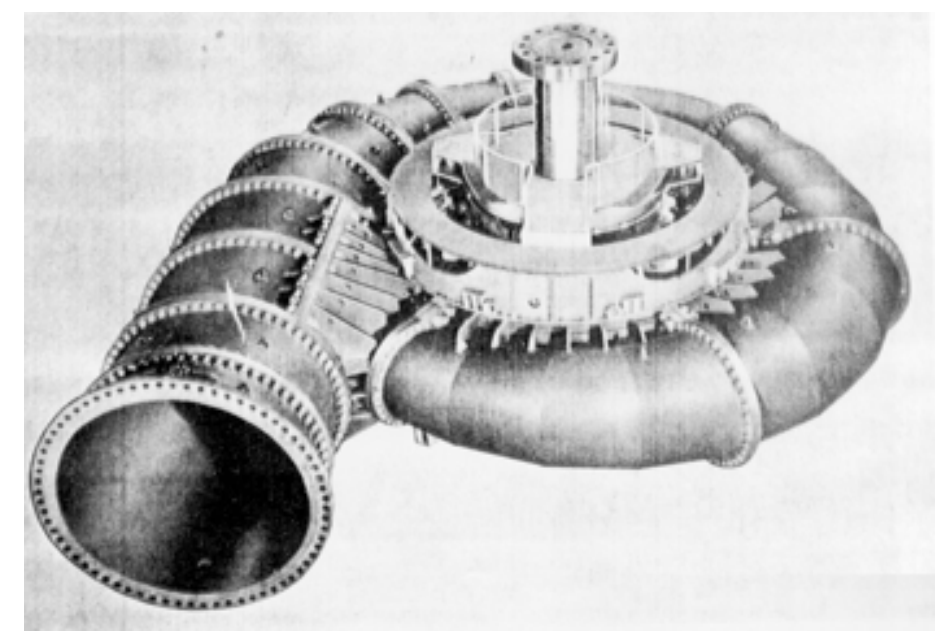

El distribuidor es prácticamente el mismo que el empleado en las turbinas Francis.

El rodete tiene forma de hélice y está constituido por un cubo en el que van montados los álabes encargados de transformar la energía hidráulica en mecánica. Los álabes tienen forma de perfiles aerodinámicos y en las turbinas Kaplan son orientables, pudiendo ser variado su ángulo de incidencia mediante un mecanismo alojado en el interior del cubo del rodete; por el contrario, los de las turbinas hélice se encuentran fijos, fundidos con el cubo o atornillados al 
mismo. El número de álabes depende de la altura del salto y puede variar desde 4 hasta 8. Cuanto mayor sea el número de álabes menor será el rendimiento de la máquina, ya que a igualdad de diámetro del rodete al aumentar el número de álabes aumenta la superficie de fricción con el líquido.

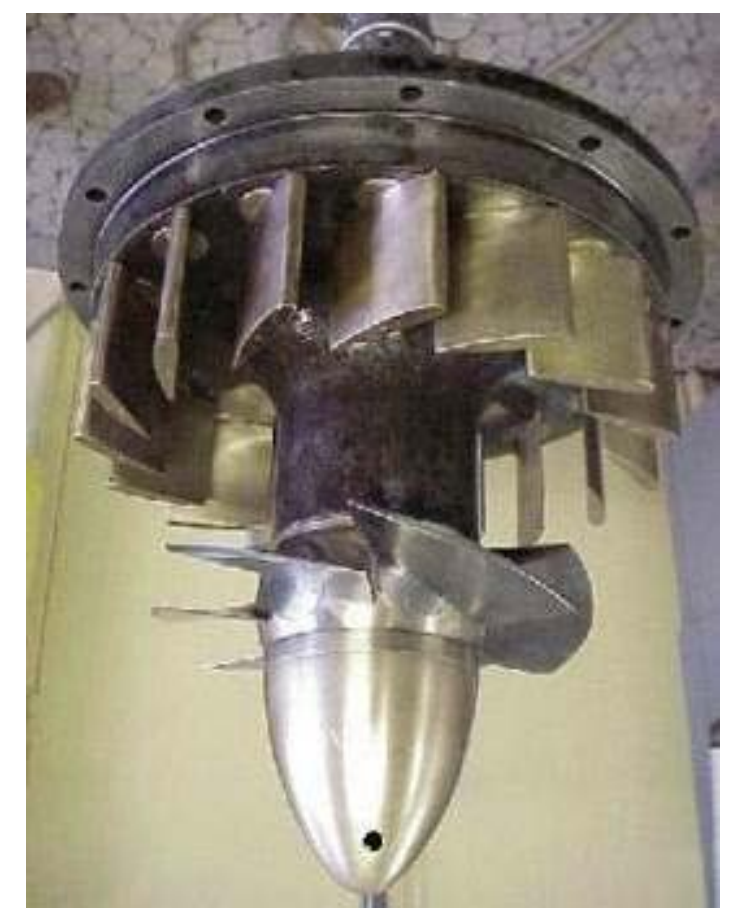

El tubo de descarga se construye generalmente con hormigón. Cuando se trata de turbinas que desaguan grandes caudales, la velocidad del agua a la salida del rodete puede ser muy elevada de manera que, con el tiempo, existe el riesgo de que se erosione el hormigón de la parte del tubo de descarga inmediata al rodete, para evitarlo se suele revestir dicha parte con un blindaje de chapa de acero. En las turbinas pequeñas el tubo de descarga se construye en la mayoría de los casos con chapa de acero soldada.

Las turbinas Kaplan se emplean generalmente para caudales grandes y saltos pequeños, más concretamente se utilizan para saltos de $6 \mathrm{~m}$ a $70 \mathrm{~m}$ y potencias de $20 \mathrm{MW}$ a $100 \mathrm{MW}$, aunque estos límites pueden ser superados en algunos casos. Gracias a los álabes móviles, las turbinas Kaplan mantienen rendimientos elevados, aún en los casos de grandes variaciones de salto y de caudal. Cuando por el contrario, se disponga de un caudal suficientemente constante, las turbinas hélice resultan más ventajosas, por lo que a coste se refiere.

Comparando el campo de aplicación de las turbinas Kaplan con el de las turbinas Francis se puede concluir que ambos tipos de turbinas entran en competencia para saltos comprendidos entre $30 \mathrm{~m}$ y $70 \mathrm{~m}$. Aunque la elección de la turbina adecuada depende de muchos factores, mediante un análisis simple se pueden hacer las siguientes consideraciones: 
1. Las turbinas Kaplan se adaptan mejor a las variaciones de carga, debido a que su curva de rendimiento en función de la carga es muy plana.

2. Cuando las turbinas Francis funcionan con caudales inferiores al correspondiente a un $60 \%$ de la carga máxima, aparece en el tubo de descarga un fenómeno denominado antorcha que puede dar lugar a fuertes vibraciones, mientras que las turbinas Kaplan funcionan con normalidad incluso a carga parcial de $40 \% \div 50 \%$ de carga máxima.

3. Las turbinas Kaplan son más fáciles de transportar, pues el rodete es desmontable y el diámetro máximo del cubo del rodete es de $3.5 \mathrm{~m}$.

4. Para saltos superiores a los $50 \mathrm{~m}$, a igualdad de potencia, las turbinas Kaplan tienen diámetros de rodete mayores que las turbinas Francis. Sólo variaciones importantes en el salto o en la carga justificarían en este caso, el empleo de turbinas Kaplan.

La primera turbina Kaplan se instaló en 1919 en una fábrica textil de Velm en Austria, de $20 \mathrm{Kw}$ de potencia para una altura de salto de 2,3 metros. Esta turbina sedujo desde el primer momento porque su rendimiento llega al 90\% cuando funciona para entre el $100 \%$ y el $70 \%$ del caudal máximo de dimensionamiento, pero incluso cuando circula el $20 \%$ de este caudal, el rendimiento es del $75 \%$.

Pero Kaplan se da cuenta, que en este tipo de turbina, el fenómeno de la cavitación erosiona los álabes de la turbina debido a la gran velocidad de rotación del rotor. Aunque este aspecto se resuelve en 1926 gracias a Olov Englesson, ingeniero jefe de la Karlstads Mekaniska Werkstad, sociedad sueca con un importante aprovechamiento hidroeléctrico que tenía una licencia de la patente de Kaplan, que concibe un mecanismo de control hidráulico que permite ajustar el ángulo de las palas. La turbina puesta en servicio en 1926 en la central hidráulica de Lilla Edet en Suecia, desarrolla $7500 \mathrm{kw}$ de potencia para una altura de 6,5 metros y a hélice tenía un diámetro de 5,8 metros.

Una variante de la turbina Kaplan es la turbina Deriaz. Esta turbina es relativamente moderna, ya que la primera turbina de este tipo fue puesta en servicio en 1957 en los saltos del Niágara. La turbina Dériaz es una variante de la turbina Kaplan que consiste en disponer el eje de giro en los álabes del rodete inclinado respecto del eje de giro del rotor. Normalmente el distribuidor de estas turbinas es cónico, a fin de conducir mejor el flujo a través del rodete. 


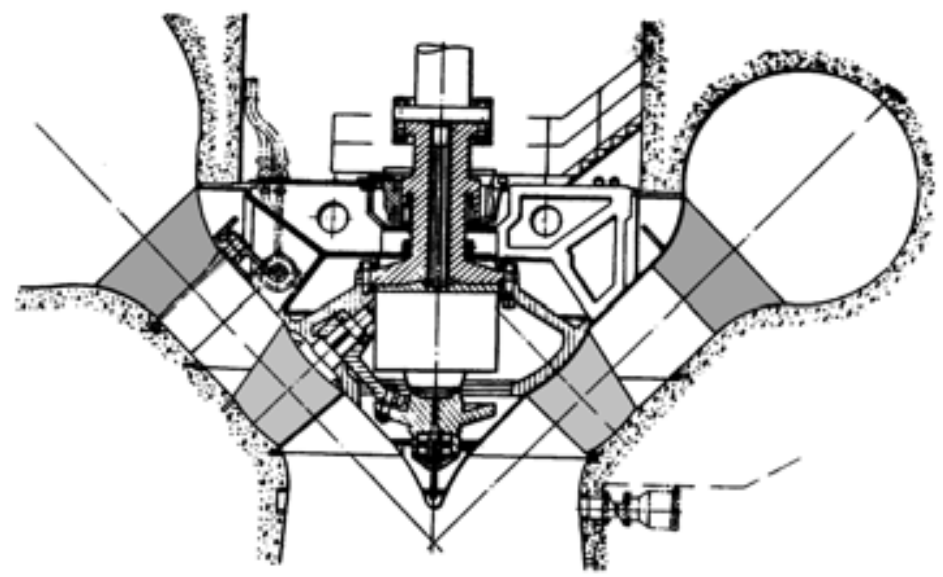

Esta turbina es la indicada para la explotación de los saltos de mediana y elevada altura, es decir de $20 \mathrm{~m}$ a $400 \mathrm{~m}$, y una potencia máxima de $300 \mathrm{MW}$.

Estas turbinas se emplean normalmente en centrales reversibles, ya que por su diseño se consigue un buen rendimiento tanto funcionando como turbina o como bomba, lo que no sucede en el caso de las turbinas Francis.

Como ejemplo de construcción de central que emplea este tipo de turbinas se puede citar la de Valdecañas, situada en el río Tajo, que consta de 3 grupos verticales reversibles de $75 \mathrm{MW}$ cada uno que disponen de un salto de $110 \mathrm{~m}$.

Kaplan. Los expertos que han analizado las ventajas y desventajas de cada una de dichas turbinas establecen que:

- Para saltos comprendidos entre 75 y 170 m es mejor emplear la turbina Dériaz que la Francis por las siguientes razones:

- El número de grupos se puede reducir entre 10 y $20 \%$ debido a que la turbina Dériaz admite una mayor sobrecarga.

- Se reduce el volumen de excavación entre un 10 y $15 \%$.

- La velocidad de giro de la máquina es menor, con lo que se reduce el tamaño de la turbina.

- El rendimiento cambia poco al variar la carga.

- Para saltos comprendidos entre 35 y 70 m es mejor emplear la Turbina Dériaz que la Kaplan por:

- A igualdad de potencia, la Dériaz tiene menor diámetro, con lo cual la masa de la turbina es un $10 \%$ menor.

- El rendimiento de la Dériaz es un 3\% mayor que el de la Kaplan para las mismas condiciones de funcionamiento. 


\subsection{TURBINAS PARA CARGAS MÍNIMAS Y GRANDES CAUDALES}

La creciente demanda energética obligó a pensar en el posible aprovechamiento de saltos con pequeñas cargas, que no era viable con los tipos tradicionales de turbinas. El rendimiento de estos tipos de turbina, sin embargo, es tan satisfactorio como el de la turbina Kaplan. La curva de rendimiento se mantiene casi plana, en torno al 90\%, para diferentes valores de la potencia.

Por ello, fueron apareciendo las siguientes tipologías de turbinas:

- Turbinas tubulares

- Turbinas Bulbo

- Turbinas de pozo

- Turbinas Straflo

- Turbinas S

La particularidad fundamental en todas ellas es que el eje se ha dispuesto en dirección horizontal o ligeramente inclinado, con el objeto de reducir las dimensiones verticales y por tanto las costosas excavaciones.

En estos tipos desaparece la cámara espiral (caracol), practicándose la alimentación directamente desde el embalse, por medio de un tubo de aspiración rectilíneo que mantiene el agua sobre el rotor de la turbina.

El rotor, tipo hélice, con álabes fijos o ajustables, tiene su eje en la misma dirección que el conducto, facilitando el paso de grandes caudales. La descarga se logra por una continuidad del citado conducto, en forma análoga a las turbinas convencionales. Sólo en el tipo tubular se hace necesario un cambio en la dirección del conducto, para dar salida al eje del generador.

En la turbina tubular, el generador va instalado al exterior, fuera del conducto de paso del agua. Esto reduce el coste del generador que puede ser de tipo convencional, pero presenta problemas de vibración y sellado.

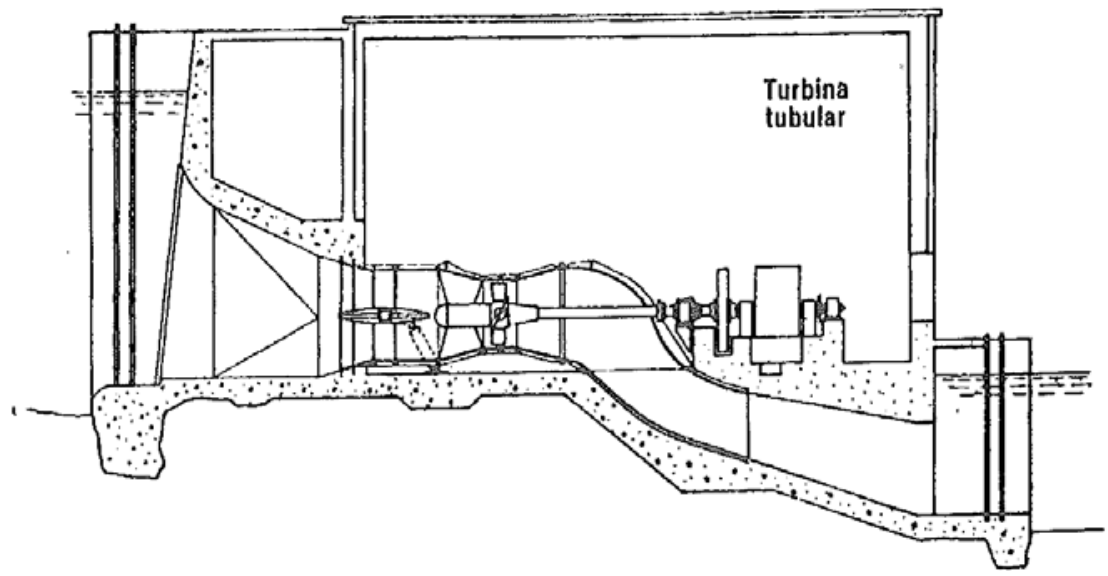


Su desarrollo se debe a la creciente demanda de energía ya que permiten aprovechar saltos que antiguamente no era rentable explotar con turbinas Kaplan. Las turbinas tubulares permiten explotar saltos de $2 \mathrm{~m}$ a $20 \mathrm{~m}$ y potencias de $0.1 \mathrm{MW}$ a $40 \mathrm{MW}$.

Las turbinas tubulares no tienen cámara espiral y son alimentadas directamente desde el embalse por medio de una tubería rectilínea, generalmente muy corta, que lleva el agua al rodete a través de un distribuidor cónico de palas orientables o fijas. El rodete está constituido por una hélice con álabes orientables o fijos y su eje de giro coincide con el eje de la tubería de alimentación, lo que facilita el paso de grandes caudales. La descarga se realiza mediante una tubería divergente, en forma análoga a una turbina Kaplan.

Existe una variante de la turbina Kaplan para alturas de salto muy bajas, es la llamada turbina bulbo. Y aunque su desarrollo es más tardío que las turbinas antes expuestas, puede englobarse dentro del desarrollo de las turbinas modernas.

El alternador está montado en un recinto estanco de forma hidrodinámica (bulbo) situado en el conducto de alimentación de la turbina, de manera que el conjunto alternador y turbina están totalmente sumergidos. El alternador puede estar acoplado al rodete directamente o mediante una caja reductora a fin de disminuir el coste del generador. Este sistema es más costoso y que requiere generadores de diseño especial, pero tiene la ventaja de que facilita la descarga, incrementando la energía recuperada en el mismo.

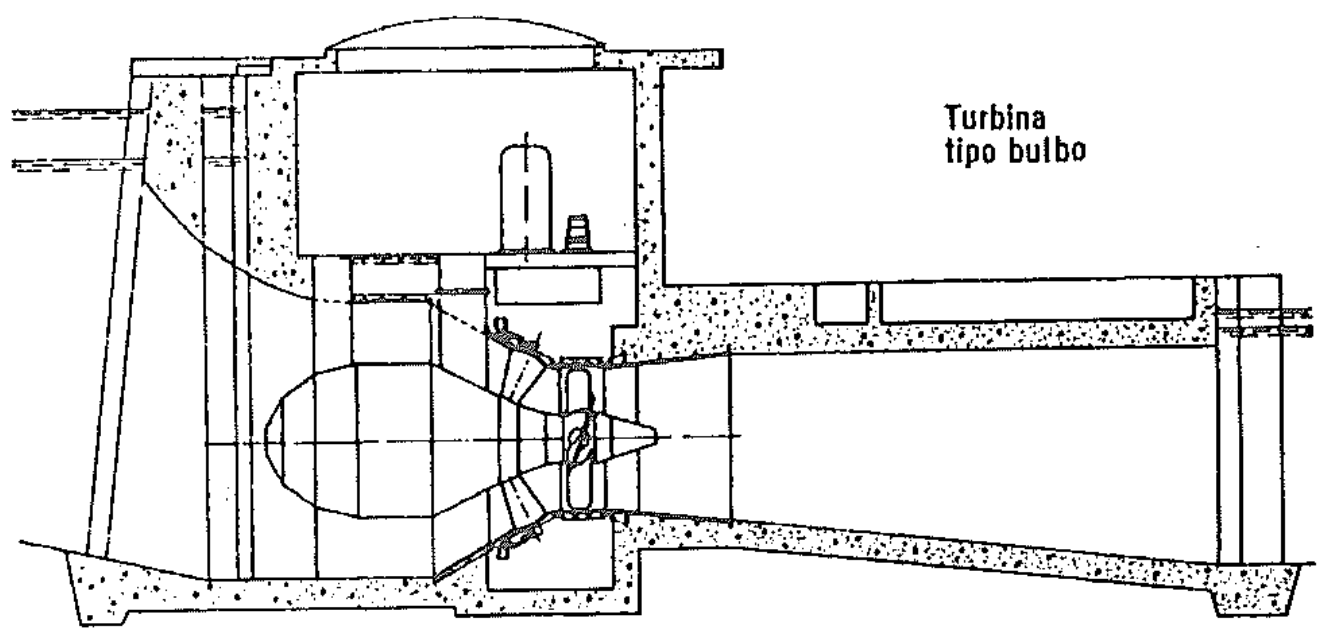

El campo de aplicación de los grupos bulbo puede dividirse en las categorías siguientes: 
1. Grupos para pequeñas centrales (100 KW - $5 \mathrm{MW})$ y saltos inferiores a $20 \mathrm{~m}$. La regulación del grupo se realiza únicamente con las palas orientables del rodete. Los álabes del distribuidor son fijos. Estos grupos suelen emplear generadores síncronos.

2. Grupos para ríos de gran caudal que pueden explotar saltos de 5 $\mathrm{m}$ a $20 \mathrm{~m}$ y generar potencias de hasta $50 \mathrm{MW}$. Emplean doble regulación, es decir, los álabes del distribuidor y del rodete son orientables. Como ejemplos más importantes se pueden citar: la central de Shingo (Japón), que dispone de grupos que desarrollan una potencia unitaria de $41 \mathrm{MW}$ bajo un salto de $22,5 \mathrm{~m}$ y la de Altenwórth (Austria) con potencia unitaria de $40 \mathrm{MW}$ y salto de $14 \mathrm{~m}$. En el caso de saltos pequeños es necesario acoplar el generador a la turbina por medio de una caja reductora.

3. Grupos bulbo reversibles empleados en centrales maremotrices que funcionan con saltos variables. El ejemplo más importante es el de la central de La Rance (Francia) que está equipada con 24 grupos de $10 \mathrm{MW}$. El nivel del embalse puede variar desde 0 a 13,5 m. A la cota máxima de $13,5 \mathrm{~m}$, el volumen de agua almacenada es de 184 millones de metros cúbicos.

Las turbinas bulbo entran en competencia con las Kaplan de eje vertical para saltos inferiores a $20 \mathrm{~m}$. A continuación se analizan las ventajas y desventajas de las turbinas bulbo frente a las Kaplan.

Ventajas de las turbinas bulbo con respecto a las turbinas Kaplan a igualdad de salto y caudal:

1. El flujo directo da lugar a menores pérdidas hidráulicas y por tanto a un rendimiento mayor, que puede ser superior en un $2 \%$ al de la turbina Kaplan.

2. Al ser las dimensiones transversales menores, se reduce la obra civil al mínimo. Este punto es indiscutible cuando el salto es inferior a $10 \mathrm{~m}$.

3. La inversión es más rentable en cuanto a producción y funcionamiento.

4. Se comporta mejor frente a la cavitación y permite que la altura de montaje del rodete sea mucho más baja.

5. Estadísticamente entre 1970 y 1984 se han instalado 87 turbinas bulbo frente a 48 turbinas Kaplan, todas ellas de potencias superiores a los $5 \mathrm{MW}$. 
Desventajas de las turbinas bulbo con respecto a las turbinas Kaplan a igualdad de salto y caudal:

1. El diseño del sistema de refrigeración del alternador es difícil.

2. El montaje y revisión del grupo es más difícil. Para acceder a los mecanismos encerrados en el bulbo es necesario detener la turbina.

3. Se deben emplear materiales de mejor calidad en la construcción de la turbina, a fin de reducir las revisiones por mantenimiento.

4. No se pueden acoplar a redes independientes con débil coeficiente de autorregulación, pues los tiempos de embalamiento son muy cortos, del orden de 1.5 a 2 segundos, por lo que la respuesta a un cambio en la demanda de potencia debe ser muy rápida.

Otra turbina es la que surge de la patente Harza de 1919-1924 que describe una hélice con un alternador periférico. Pero el concepto que se impondrá verdaderamente consiste en tener el alternador integrado en la turbina en el interior de un bulbo sumergido aguas arriba o debajo de la hélice. De esta turbina derivan las llamadas Straflo (Straight Flow).

Esta máquina está montada horizontalmente en la dirección del flujo. Los polos del generador se montan en un anillo que está acoplado directamente a la periferia del rodete, dicho anillo gira en una ranura del conducto de paso del agua. El estator del generador rodea dicha ranura. El grupo straflo es una máquina de flujo axial para pequeños saltos. Su campo de aplicación cubre tanto el campo de las demás turbinas tubulares como el de las turbinas Kaplan de eje vertical, ya que es aplicable para saltos de hasta $20 \mathrm{~m}$ y aún mayores.

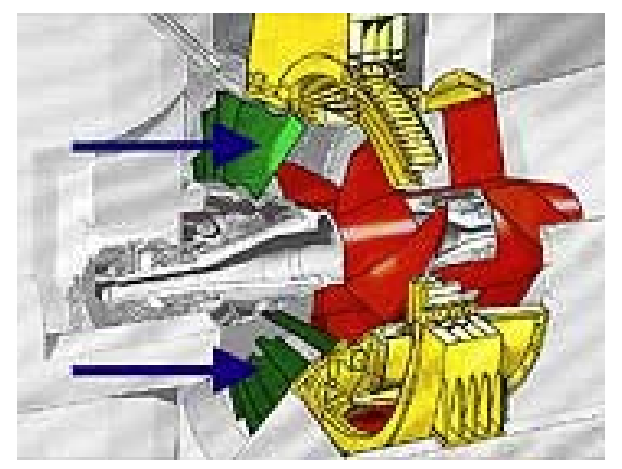

En Anápolis (U.S.A.) existe una planta piloto con grupos que desarrollan una potencia unitaria de $20 \mathrm{MW}$. La mayoría de estos grupos trabaja con regulación simple (rodete con palas orientables), aunque también se construyen con doble regulación para obtener elevados rendimientos en todo el rango posible de alturas y caudales. Estos grupos pueden ser empleados en grandes centrales y 
utilizados para estabilizar la frecuencia de la red, gracias a la elevada inercia del rotor.

Otras turbinas de esta tipología son las turbinas S. Estas turbinas disponen un rodete axial (tipo Kaplan), en una tubería en forma de $S$, acoplado al generador que queda fuera del conducto de paso del agua. También se encuentran máquinas con engranaje cónico que no necesitan disponer de la tubería en forma de S. Estas máquinas pueden ser empleadas para saltos de $3 \mathrm{~m}$ a $20 \mathrm{~m}$ y potencias de $0.1 \mathrm{MW}$ a $10 \mathrm{MW}$. Aunque hay centrales que disponen de este tipo de turbinas, que desarrollan una potencia unitaria de $50 \mathrm{MW}$ bajo un salto de 9,8 m, las turbinas $\mathrm{S}$ son preferidas para las micro y minicentrales. Estas turbinas están normalizadas y existen varias empresas que las comercializan.

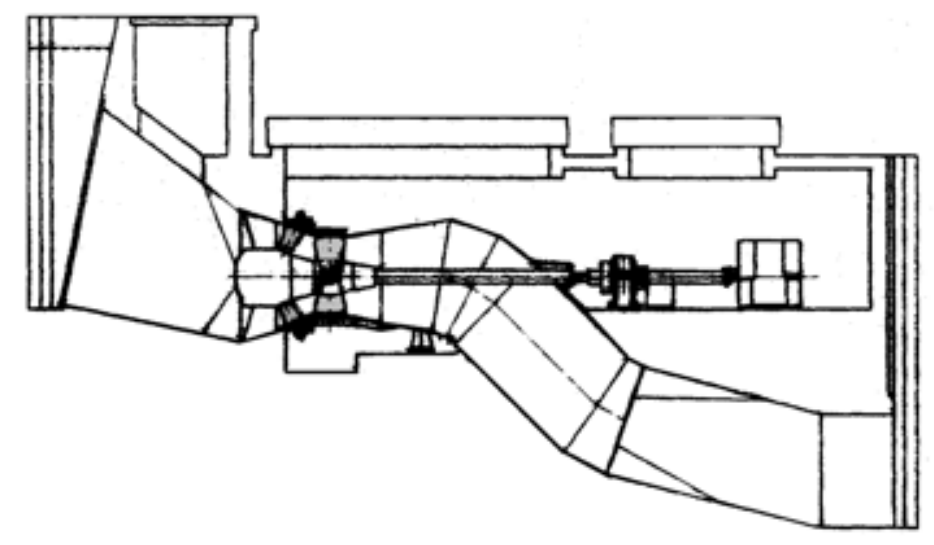

Las turbinas de pozo también pueden englobarse en este tipo de turbinas para cargas mínimas y grandes caudales. En este caso, el generador se independiza del roto por medio de muros de hormigón. La obra de fábrica es un poco complicada y esto limita su empleo.

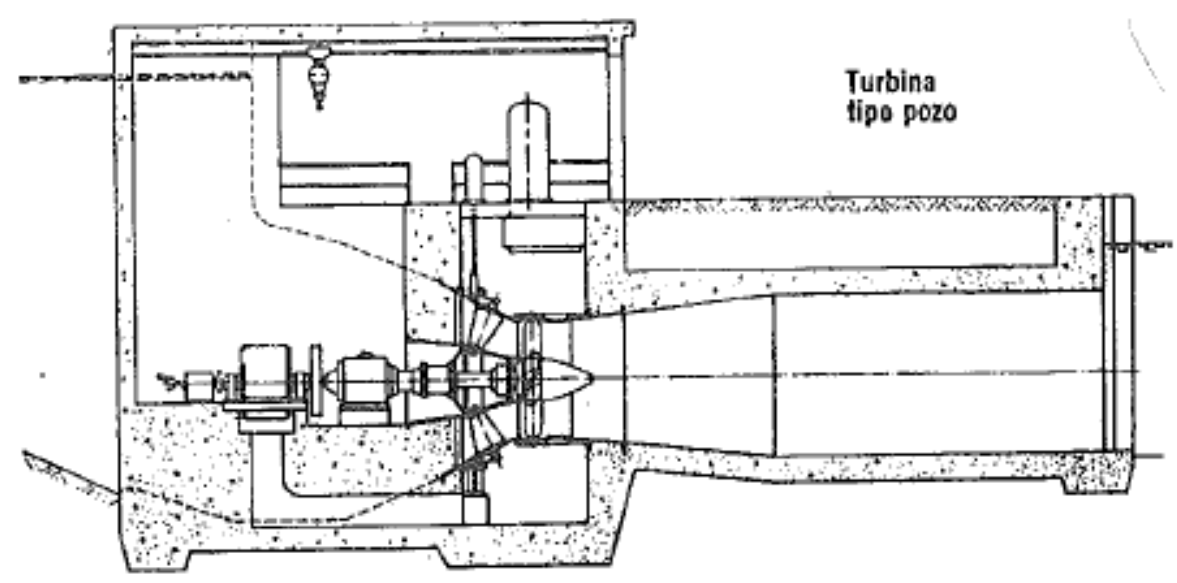


Por último, la patente Huguenin de 1924 comprende un conjunto que comporta una hélice adosado a un bulbo que contiene un alternador, con este gran bulbo arriba de la hélice. Se plantea la patente como una mejora a las turbinas hélice y kaplan para saltos de muy baja altura. Este concepto será realmente aplicado a partir de los años 1960.

\subsection{TURBINAS DE ACCIÓN}

En 1848, se crea la primera turbina de acción, la SCHWANKRUG, adecuada para saltos grandes con poco caudal.

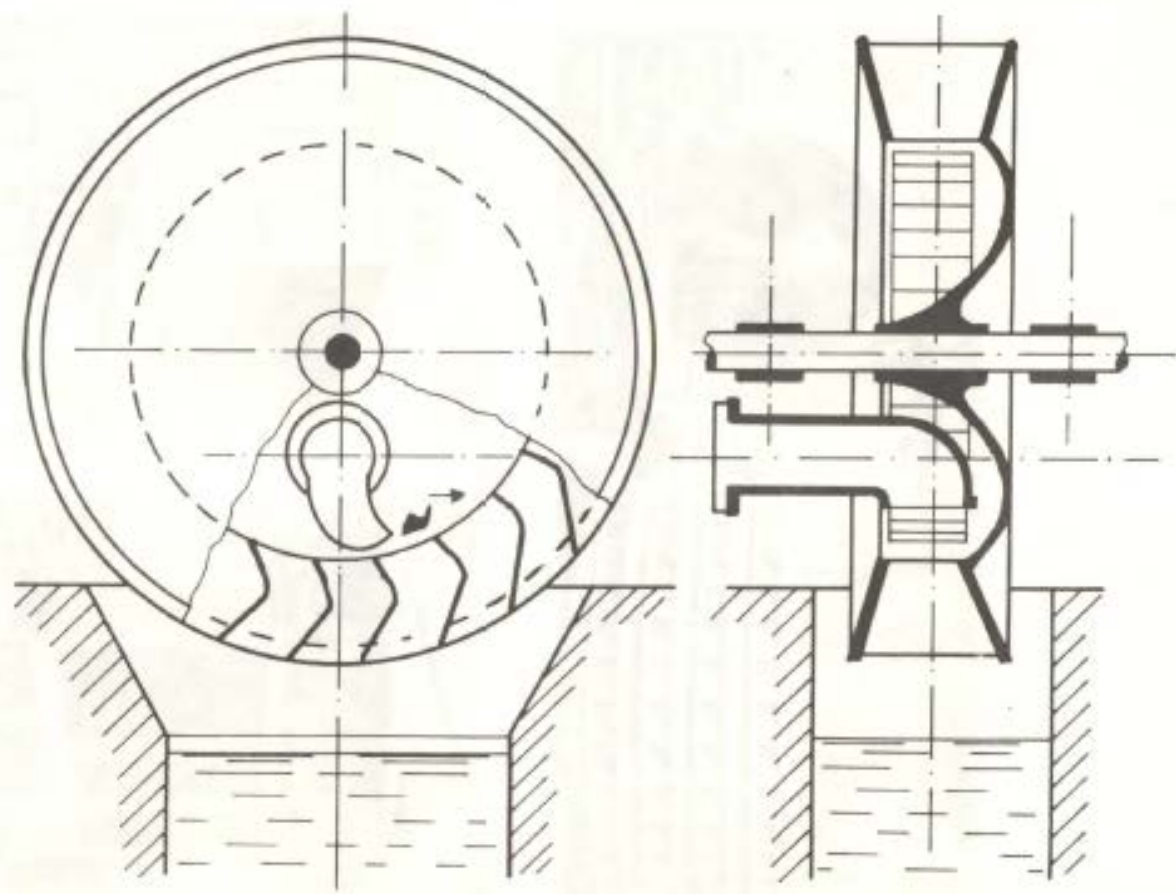

En 1854, Louis-Dominique Girard crea una variante de la turbina, la turbina de impulsión, que se adapta bien a las alturas de salto de cientos de metros, que se pueden tener en los Alpes. Es una turbina de eje horizontal en la que es posible controlar el flujo de agua enviado a las palas del rotor, regulando de esta manera la velocidad de rotación de la turbina. Ésta será la turbina clave a utilizar en los Alpes franceses en los años 1890 (Calypso 1891, La Praz 1893, Prémont 1894, la Saussaz 1905) hasta que sea sustituida por la turbina Pelton. 

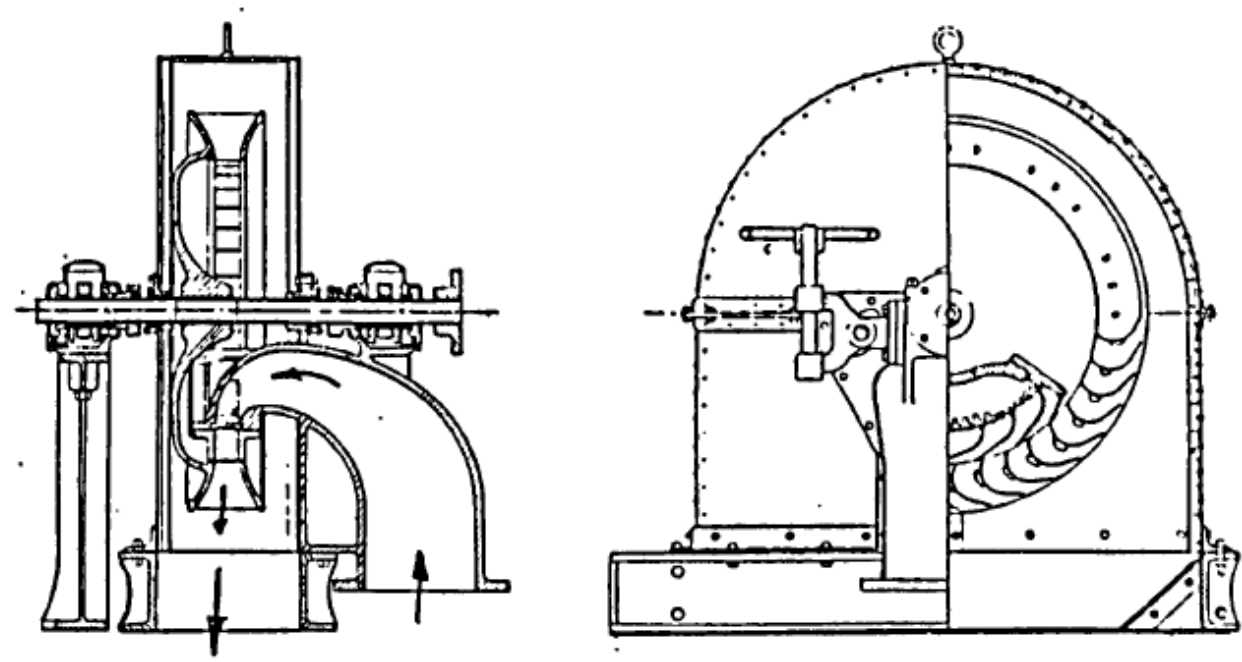

Horizontal axis Girard turbine

En cuanto a la turbina de acción o de impulsión, la turbina Girard fue reemplazada por la turbina Pelton y la Turgo. La evolución que se produjo fue la siguiente.

Volviendo al siglo XIX y a mediados del mismo, en California se perfecciona el antiguo concepto de la rueda a impulsión donde los álabes, reperfilados en forma de cuchara, son impactados directamente por un jet líquido. Sobre el año 1860 la fiebre del oro en Estados Unidos hace que se necesiten muchas tomas de agua para limpieza del mineral aurífero con los jets de agua a presión. En los años 1870 se utilizan esos jets de agua para mover las ruedas hidráulicas. Es entonces cuando un ingeniero de Minas llamado Pelton insiste en que una rueda de cucharas ve su rotación acelerada si el jet, en lugar de impactar en el fondo de la cuchara, impacta en la arista. En estas condiciones, el jet de agua transmite al álabe una cantidad de movimiento mayor.
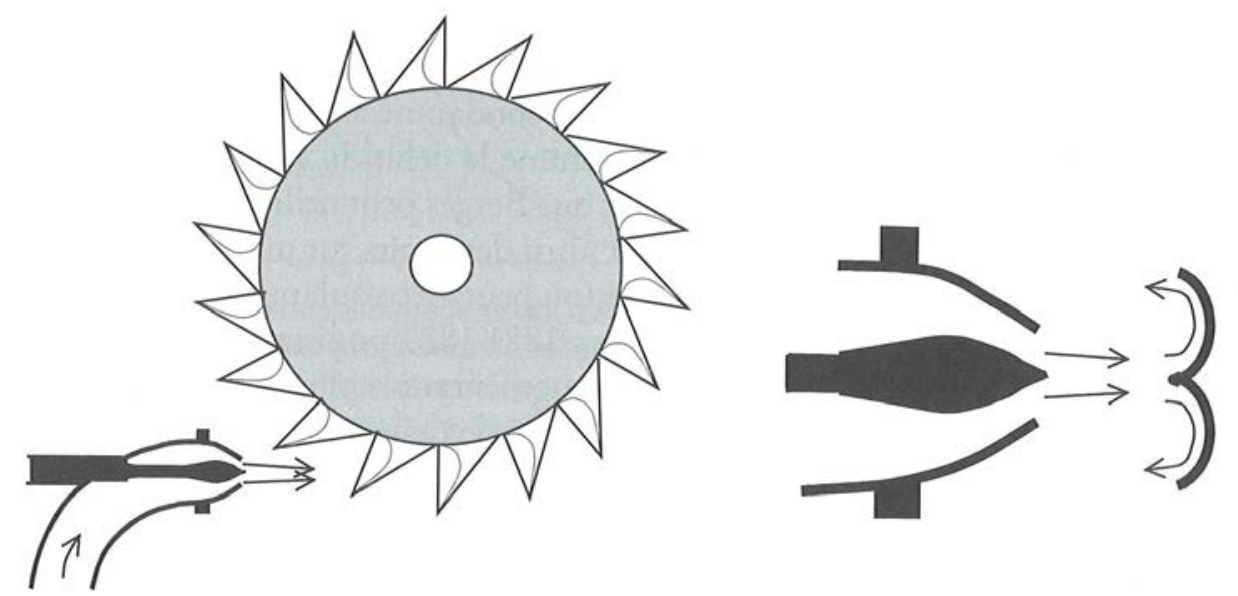
En 1878 en Camptonville, Pelton aplica este principio introduciendo en el nuevo modelo de rueda con cucharas, unos álabes de doble curvatura y lo patenta en 1880. En 1888 funda la Pelton Water Wheel Company. La turbina Pelton es mejorada posteriormente por el ingeniero alemán Breuer, y después por un ingeniero de San Francisco llamado William Doble que obtiene una patente en $\mathbf{1 8 9 9}$ y llega a ser el ingeniero jefe de la Pelton Company en 1912.

Como su ancestro árabe-andaluza, la rueda Pelton se adapta bien a caudales pequeños con grandes alturas de salto.

Las turbinas Pelton son máquinas de acción, que solamente aprovechan la energía cinética del agua, por tanto, no existe diferencia de presión entre la entrada y la salida del rodete de la máquina. En la turbina Pelton, la admisión del agua se realiza por medio de una tobera situada al final de la tubería forzada que trae agua desde el embalse hasta la turbina y en el mismo plano de la rueda.

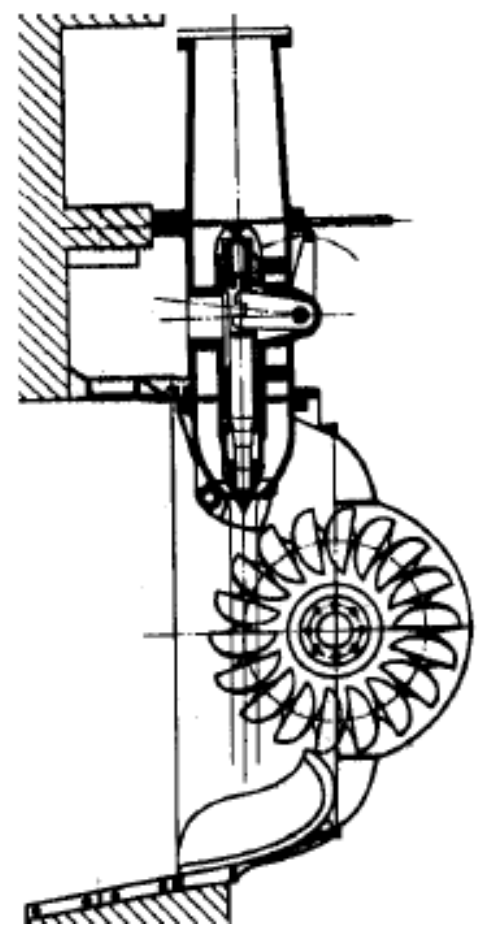

El chorro que sale de la tobera impacta sobre las cucharas de la rueda originándose así la transformación de la energía cinética del fluido en giro del rodete. La regulación del caudal se realiza por variación de la sección de salida de la tobera debido al desplazamiento horizontal de una aguja situada en el eje del inyector. 


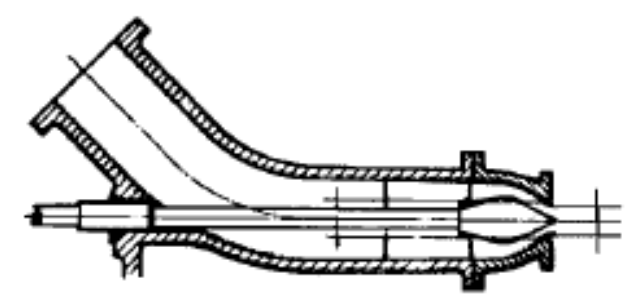

La mayoría de las turbinas están acopladas a alternadores que alimentan redes eléctricas. En ocasiones, es necesario desconectar rápidamente el alternador de la red, lo que originaría el embalamiento del rodete al trabajar la turbina en vacío. Para estos casos, se dispone a la salida de la tobera de un deflector que desvía el chorro para que este no incida sobre el rodete mientras se cierra lentamente la admisión de agua.
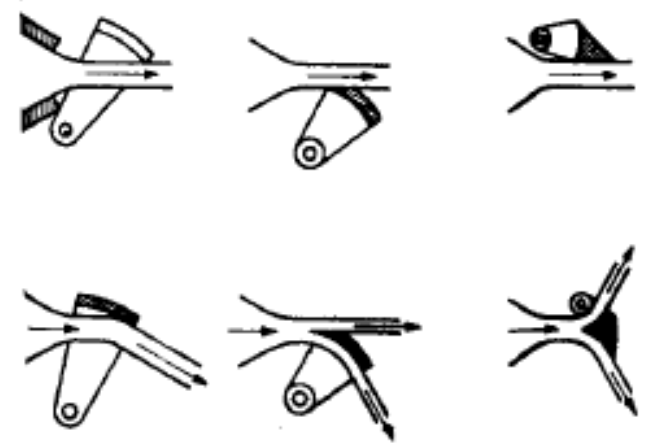

El rodete está constituido por unos álabes compuestos por dos alvéolos simétricos respecto a una arista central situada en el plano de simetría del chorro. El agua incide sobre dicha arista repartiéndose de forma simétrica entre los alvéolos. El agua saliente es recogida por una carcasa que envuelve el rodete.

El árbol de turbinas Pelton puede ser:

- horizontal, en cuyo caso dispone de hasta dos inyectores

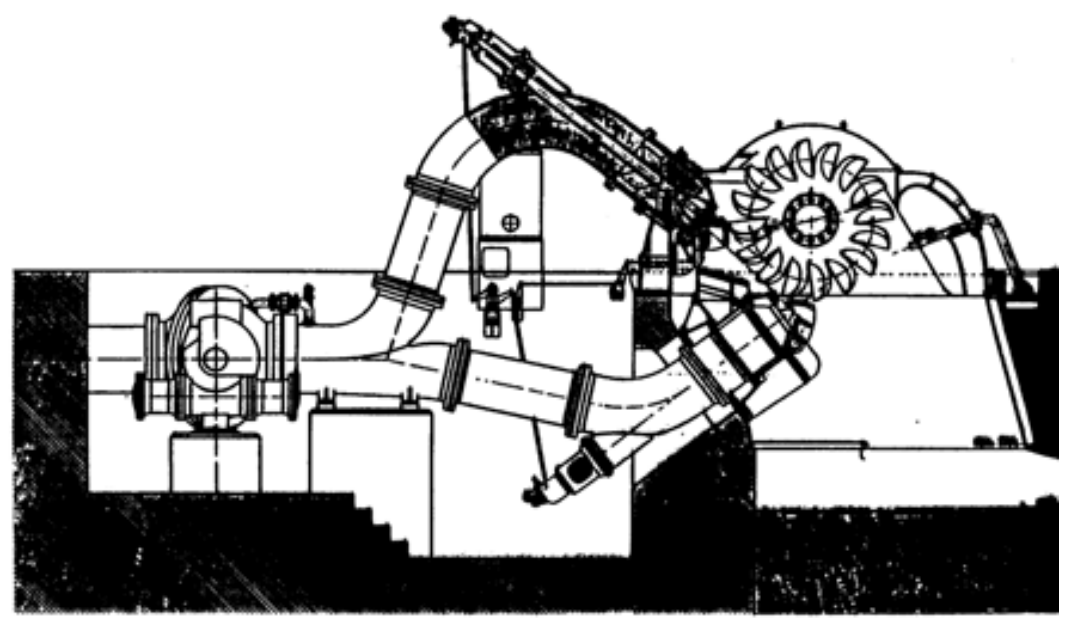


- vertical, pudiendo disponer de hasta seis inyectores

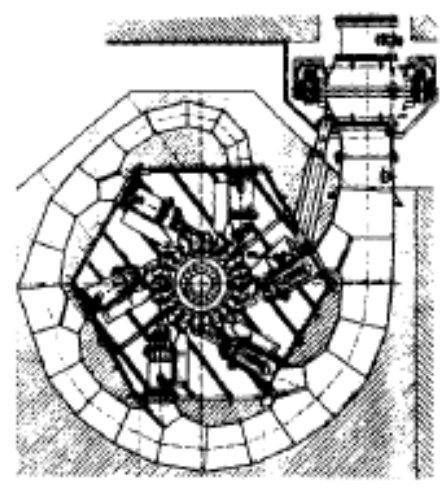

El campo de aplicación de las turbinas Pelton se limita a los saltos más elevados, superiores a $200 \mathrm{~m}$. En los últimos años, con objeto de explotar pequeñas centrales, se ha ampliado el rango de aplicación a saltos entre 45 y $700 \mathrm{~m} \mathrm{y}$ potencias de 0.1 a $15 \mathrm{MW}$.

Las turbinas Francis y las Pelton entran en competencia para los saltos comprendidos entre 200 y $700 \mathrm{~m}$. El tipo óptimo de máquina depende de las condiciones de funcionamiento, pero se pueden establecer ciertas premisas:

Ventajas de las turbinas Francis frente a las Pelton:

- A igualdad de salto y potencia, la turbina Francis posee dimensiones globales menores aunque las Pelton requieren un volumen de excavación mínimo.

- Debido a la erosión de la arena, el rendimiento de las turbinas Francis empeora menos que el de las Pelton, ya que la erosión producida en la aguja y en las cucharas es importante.

Ventajas de las turbinas Pelton frente a las Francis:

- En las turbinas Pelton no existe peligro de cavitación, mientras que en las Francis es inevitable.

- El rendimiento a carga parcial de las Pelton es prácticamente constante ya que únicamente hay que cerrar alguna tobera de los distintos chorros, sin embargo el rendimiento a carga parcial de las Francis decrece considerablemente respecto a su óptimo.

Dentro de las turbinas de impulsión, se diseña la turbina Turgo para saltos de desnivel medio. 
Fue desarrollada por la compañía Gilkes en 1919 a partir de una modificación de la turbina Pelton; la Turgo tiene varias ventajas sobre la turbina Francis y la Pelton en determinadas aplicaciones.

En primer lugar, el rodete es más barato de fabricar que el de una Pelton. En segundo lugar no necesita una carcasa hermética como la Francis. En tercer lugar tiene una velocidad específica más elevada y puede manejar un mayor flujo para el mismo diámetro que una turbina Pelton, conllevando por tanto una reducción del coste del generador y de la instalación.

Las Turgo operan en un campo de desniveles en el que se solapan las turbinas Francis y Pelton. Aunque existen muchas instalaciones grandes con turbinas Turgo, estas se utilizan más en instalaciones hidráulicas pequeñas en las que es importante el bajo coste.

La turbina Turgo es una turbina de tipo impulso. El agua no cambia de presión cuando pasa a través de los álabes de la turbina. La energía potencial del agua se convierte en energía cinética en la tobera de entrada o inyector. El chorro de agua a alta velocidad se dirige contra los álabes de la turbina que lo desvían e invierten el flujo. El impulso resultante hace girar el rodete de la turbina, comunicando la energía al eje de la turbina. Finalmente el agua sale con muy poca energía. Los rodetes de una turbina Turgo pueden tener un rendimiento por encima del $90 \%$.

El rodete de una Turgo se parece a un rodete Pelton partido por la mitad. Para la misma potencia, el rodete Turgo tiene la mitad del diámetro que el de un rodete Pelton y dobla la velocidad específica. El turgo puede manejar un mayor flujo de agua que el pelton debido a que el agua que sale no interfiere con las paletas adyacentes.

La velocidad específica de los rodetes Turgo se encuentra situada entre la de las turbinas Francis y Pelton. Se pueden usar una o varias toberas o inyectores. Incrementando el número de inyectores se incrementa la velocidad específica del rodete en la raíz cuadrada del número de chorros (cuatro chorros rinden dos veces la velocidad específica de un chorro para la misma turbina). 


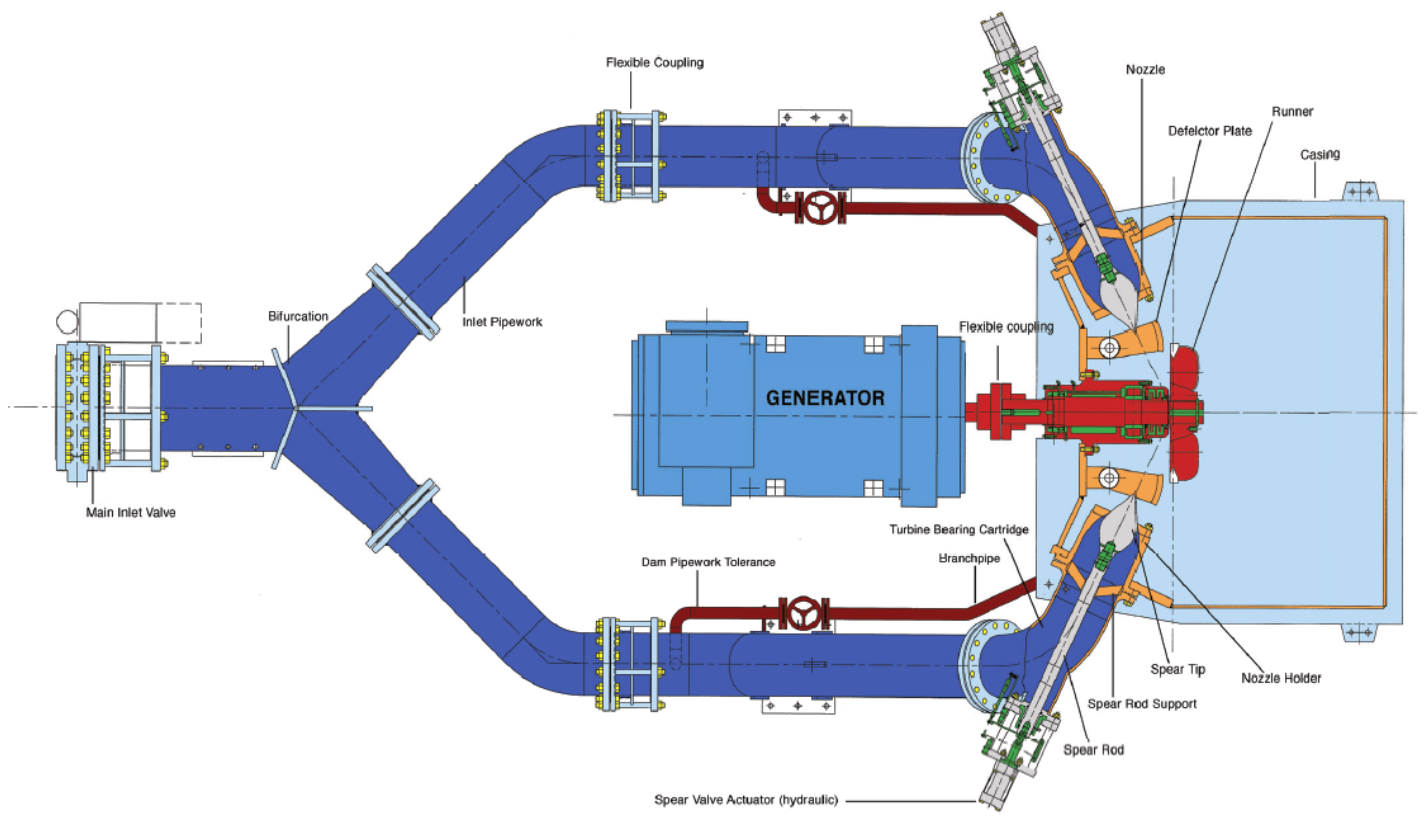

También, dentro de la clasificación de turbinas de acción, destaca la turbina Crossflow. Es una turbina de flujo transversal o turbina de flujo cruzado (también llamada por los nombres comerciales turbina Banki-Michell o Turbina Ossberger). Fue desarrollada por el australiano Anthony Michell, el húngaro Donát Bánki y el alemán Fritz Ossberger. Michell obtuvo una patente por su diseño en 1903 y la compañía Weymouth la fabricó durante años. La patente de Ossberger data de 1933 ("Free Jet Turbine" 1922, Imperial Patent No. 361593 y "Cross Flow Turbine" 1933, Imperial Patent No. 615445), y fabricó dicha turbina desde entonces. A día de hoy la compañía de Ossberger es el principal fabricante mundial de este tipo de turbinas.

A diferencia de la mayoría de turbinas hidráulicas, que tienen un flujo axial o radial, en la turbina de flujo transversal el fluido atraviesa los álabes de forma diagonal. Como en una rueda hidráulica, el agua entra en el borde de la turbina saliendo por el interior. Tras atravesar el vano central sale por el lado opuesto. Es una máquina de acción.

Al pasar dos veces se obtiene una eficiencia elevada para flujos variables, además de limpiar el rotor de residuos. La máquina es de baja velocidad, apta para bajas alturas pero elevados caudales. Gracias a su simplicidad constructiva, suelen ser máquinas de coste reducido. Todo ello lo hace apropiado para centrales de pequeño tamaño (minihidráulica, centrales fluyentes...)

La turbina se compone de una rueda hidráulica con un eje horizontal. Dicha rueda tiene diversos álabes (hasta 37) dispuestos radialmente con una torsión que hace que el extremo tenga una cierta inclinación tangencial. Los bordes se 
afilan para reducir la resistencia al flujo. Los álabes conforman una sección cicular y tiene los extremos soldados a un disco para formar una "jaula de ardillas" donde las barras han sido reemplazadas por los álabes.

Las turbinas de flujo transversal se suelen construir como dos turbinas de diferente capacidad que comparten un mismo eje. Las ruedas son del mismo diámetro, pero diferentes longitudes para manejar distintos volúmenes a la misma presión. Las "subruedas" se suelen construir con una relación de 1:2. La operación a cargas parcial se suele lograr mediante la admisión, usualmente con graduaciones en el distribuidor a 33\%, 66\% y 100\% de la carga máxima.

La geometría de la turbina busca que el chorro de agua sea efectivo. El agua actúa dos veces, pero casi toda la energía se transmite en la primera pasada. Así el agua pasa dos veces: del exterior al interior y del interior al exterior. Solo un tercio del trabajo se efectúa en la segunda pasada, al salir el flujo del rotor. Este rotor funciona como una máquina de acción, donde la presión en el rodete se mantiene constante.

El agua fluye primero por el exterior de la turbina hacia el interior. El distribuidor conforma un vano que varía la sección de paso. De ahí pasa a toberas que aceleran el flujo haciéndolo incidir sobre el rotor con un ángulo de 45/120 grados para que transmita la energía cinética a los álabes.

El sistema de regulación controla el flujo según la potencia deseada y el agua disponible. El ratio de agua (porcentaje de agua sobre el máximo) es proporcional al porcentaje equivalente de álabes sobre los que incide. La admisión de las toberas está estrangulada por dos conductos de admisión que dirigen el flujo para que el agua entre suavemente para cualquier grado de apertura. Dichos conductos sellan los extremos de la turbina permitiendo cerrar el suministro de agua cuando el caudal cae por debajo del mínimo. De esa forma actúan como válvulas entre la tubería forzada y la turbina. Pueden ser controladas manualmente o de forma automática.

La mayoría de las turbinas transversales funcionan con dos inyectores, dispuestos de forma que sus flujos no se perturben entre sí. Sin embargo es esencial que la altura y la velocidad de turbina estén armonizadas.

La eficiencia máxima de una turbina de flujo transversal es algo menor que la de una turbina Kaplan, Francis o Pelton equivalente. Sin embargo, esta eficiencia varía menos con la carga lo que permite operar en un rango desde 1/6 de la carga máxima hasta el $100 \%$. 
Además de su buena regulación, tiene un precio bajo lo que lo hace ideal para proyectos de minihidráulica (menos de $2000 \mathrm{~kW}$ y alturas menores de 200 metros). Particularmente con pequeñas centrales fluyentes, esta curva de eficiencia "plana" suele dar una producción anual superior a otras turbinas, al ser la hidrología de los ríos irregular en algunos meses. La turbina transversal logra unos rendimientos mejores en los meses de menor caudal, logrando un rendimiento promedio mejor.

Es frecuente usarlo para producción autónoma, sin presencia de operarios. $\mathrm{Su}$ construcción hace el mantenimiento menor que en otras turbinas: solo dos cojinetes deben ser mantenidos y solo hay tres piezas rotando. El sistema mecánico es pues simple y puede ser reparado por mecánicos locales. Otra ventaja relacionada es que la turbina se limpia sola: el agua en su salida elimina los sedimentos depositados, reduciendo el mantenimiento aún más. Además, evita ciclos de limpieza invirtiendo el flujo o variando la velocidad, lo que junto a las menores paradas por mantenimiento da una mayor utilización.

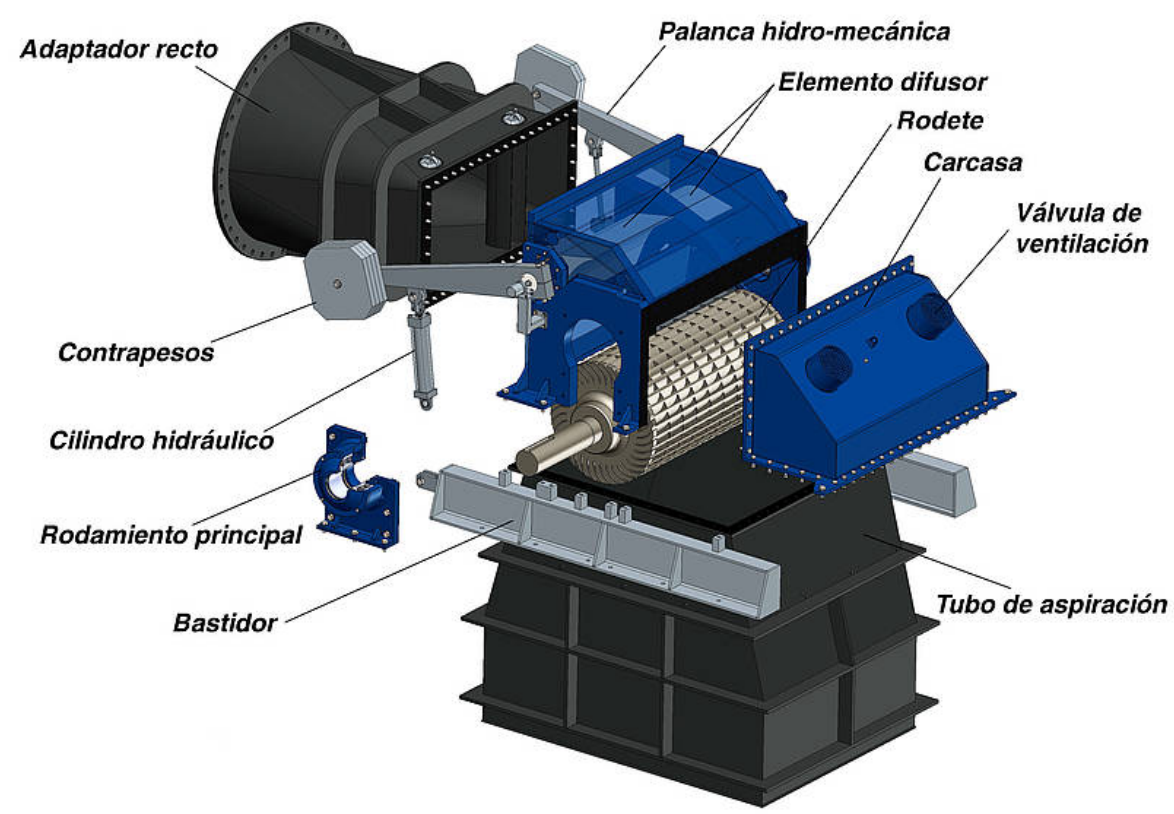




\subsection{LOS GRUPOS TURBO-BOMBAS}

Las centrales reversibles deben disponer de elementos electromecánicos que permitan tanto turbinar como bombear, por lo que deben disponer de bombas y turbinas por un lado y de motores y generadores, respectivamente, por otro.

En un principio así era y algunas de estas centrales disponían de dos circuitos hidráulicos diferentes, uno para el proceso de turbinado y otro para el de bombeo, que a partir de un punto se unían. Esto evidentemente hacía inviable en muchos casos la construcción de las centrales por su encarecimiento, al duplicar equipos y obras subterráneas. Son los conocidos como "esquemas cuaternarios".

Los alternadores síncronos (ver apartado correspondiente) pueden acondicionarse para su utilización como motores sin mayor problema, por lo que ya desde el principio de la utilización de este tipo de centrales se utilizó el esquema formado por un alternador-motor conectado por un lado a una turbina y por el otro a una bomba. Son los conocidos como "esquemas ternarios".

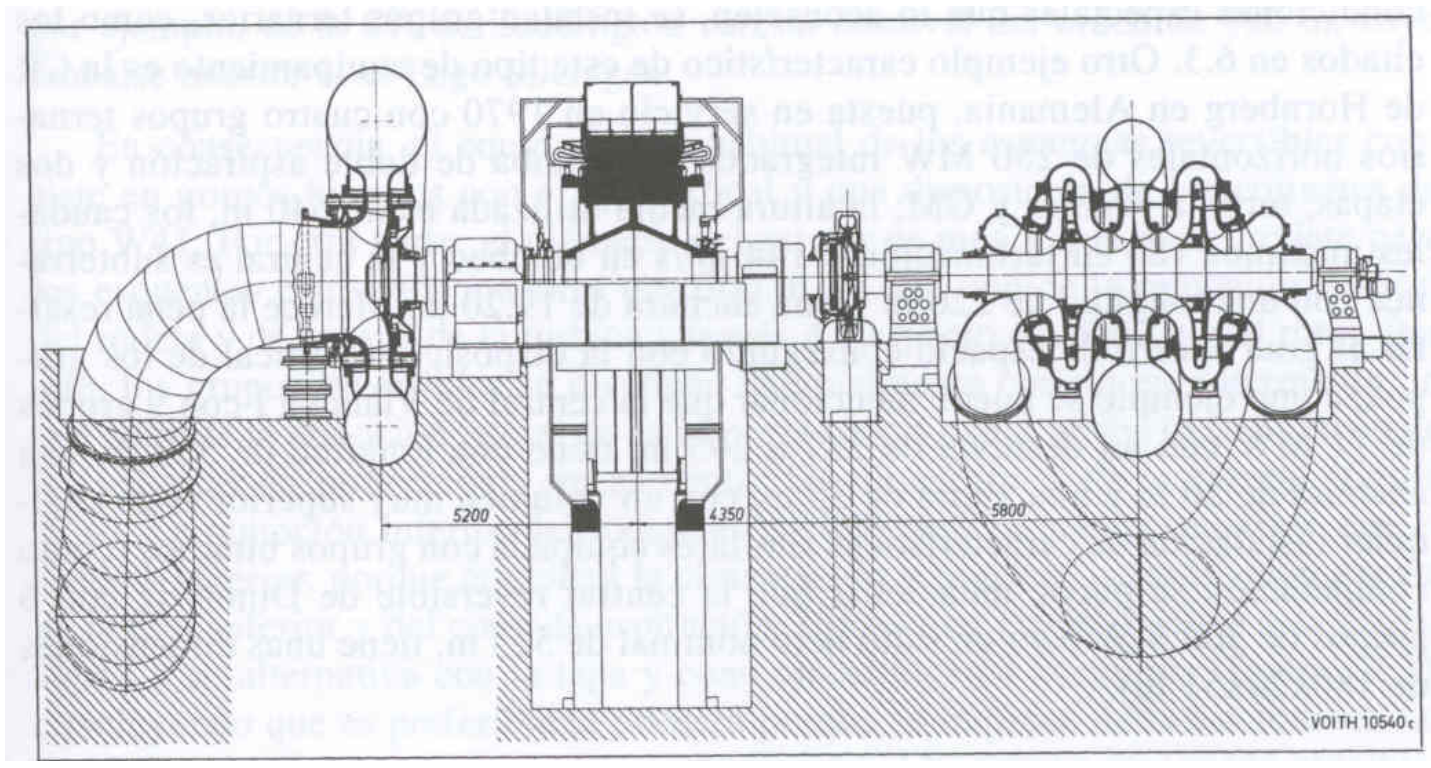

Grupo reversible ternario de la central de Vianden, con el motor-alternador en el centro, la turbina a la izquierda en el dibujo y la bomba de tres etapas a la derecha en el dibujo.

El siguiente paso en orden cronológico fue la utilización de "esquemas binarios", formados por un elemento generador-motor y por otro turbina-bomba, aprovechando que las bombas pueden funcionar razonablemente bien también como turbinas. Lo contrario no es cierto; las turbinas no funcionan bien como bombas, por lo que el diseño de estos grupos se asemejan más a las bombas, con rodetes más bien planos y con pocos álabes más largos que en aquellas. 
Este tipo de esquemas pronto fue implantándose de forma generalizada, debido al gran ahorro económico que suponía, suprimiendo una máquina y sus conducciones hidráulicas y sus válvulas asociadas, además de la reducción en sus dimensiones y por lo tanto en las de las construcciones que han de albergarlos, generalmente cavernas subterráneas. En la actualidad los grupos reversibles son en su casi totalidad de este tipo.

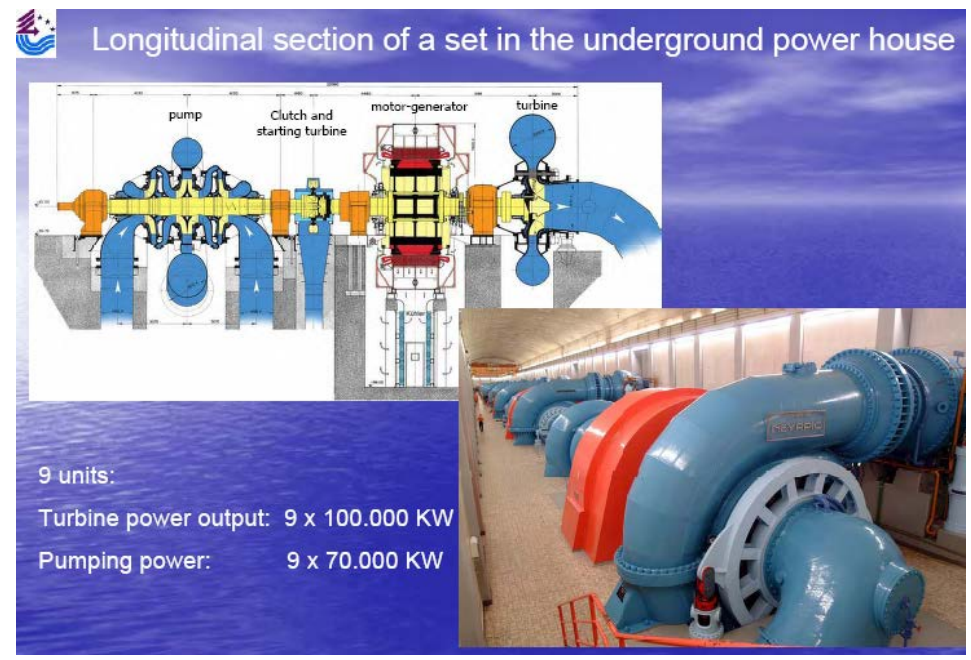

Esquema y fotografías de los grupos reversibles de la central Vianden I

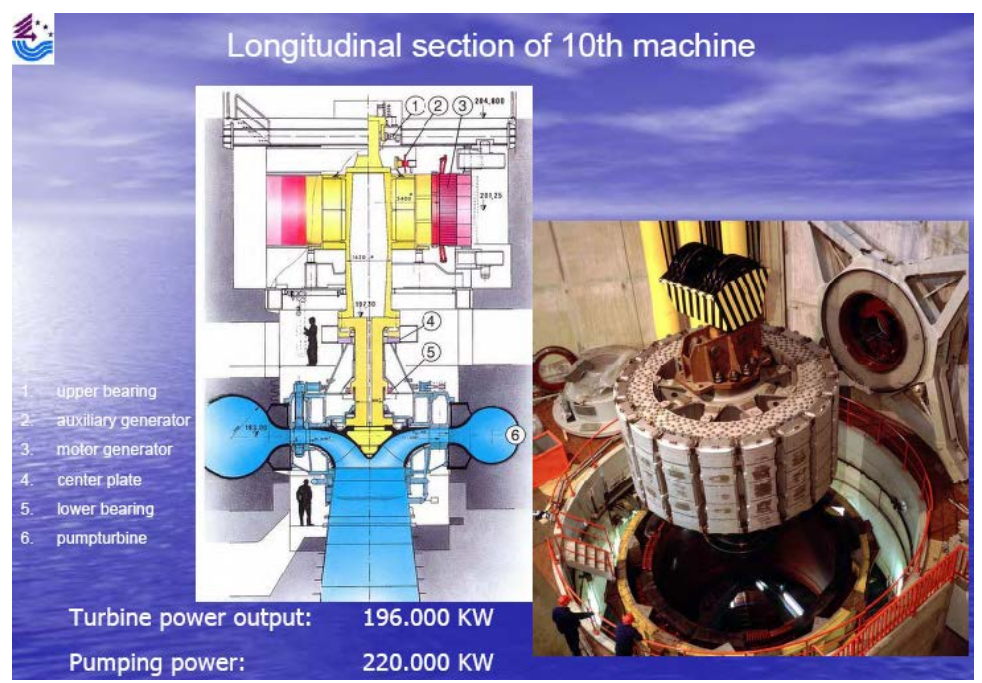

Esquema y fotografías de los grupos reversibles de la central Vianden II

La funcionalidad de las centrales reversibles ha ido cambiando a lo largo de las pocas décadas que tienen de existencia. En la década de los 70 su justificación se basaba, en gran parte, en servir de apoyo a sistemas nucleares y térmicos rígidos, utilizándose para servir la parte de la demanda más flexible, las semipuntas y las puntas, además de servir para gestionar la energía sobrante en horas valle y almacenarla para servirla en horas punta. En un pasado reciente eso no es exactamente así, aunque en países como España que han tenido una fuerte componente térmica esa justificación era también bastante real. 
Para cumplir esa función estas centrales fueron teniendo cada vez saltos mayores, al necesitarse grandes potencias instantáneas. Asi se pasó de los 350400 metros de altura máxima en la década de los 60 a los 500-600 metros en los $70^{\prime}$ y a los 700 en los 80’y a los próximos a 1000 en la actualidad.

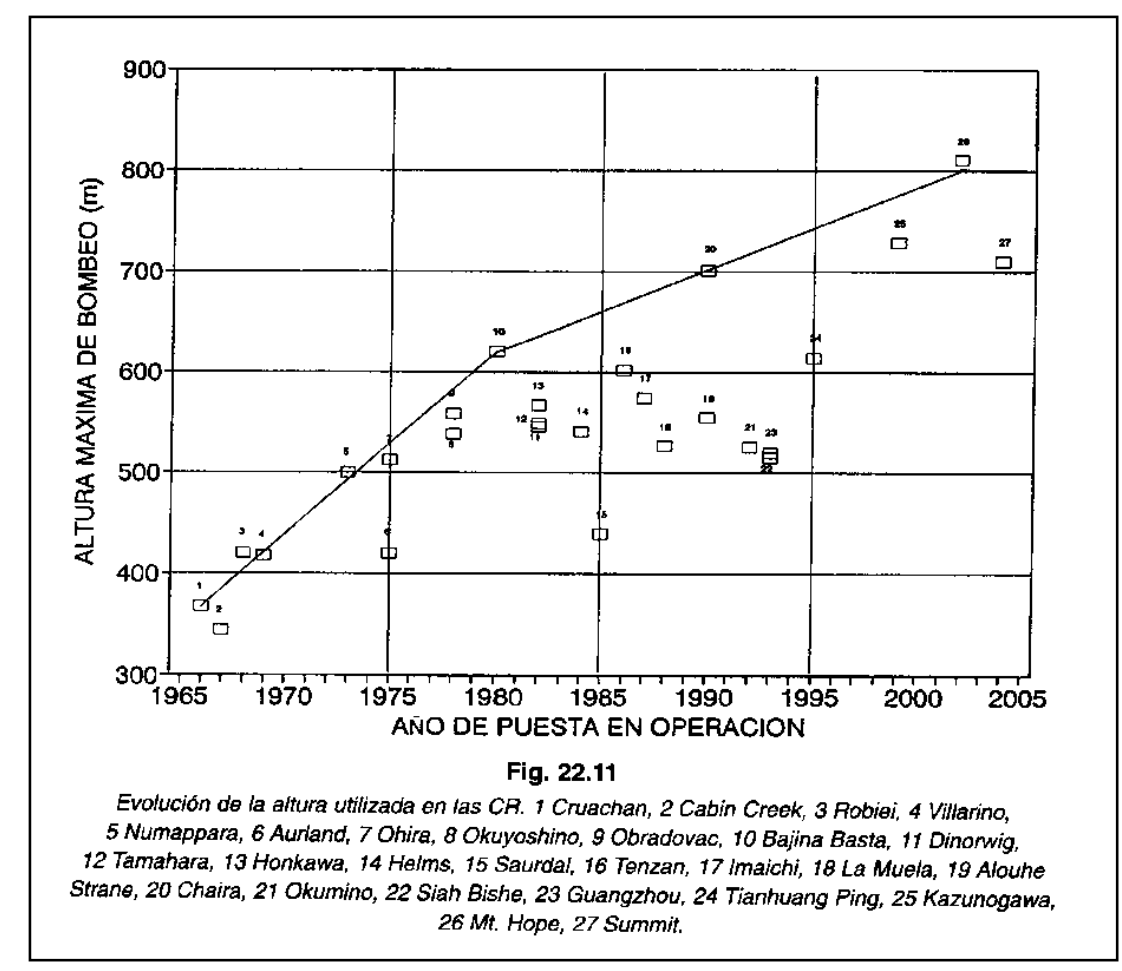

Pero los grupos turbobombas de una etapa -los habituales- no funcionaban demasiado bien para alturas superiores a 200-300 metros, por lo que a partir de los años 70 y sobre todo los 80 , se han generalizado las turbobombas multietapas, en los que la impulsión se realiza en tres etapas sucesivas. De esta forma las monoetapas se utilizan hasta esas alturas, aunque en ocasiones se utilizan hasta los 600 e incluso los 800 metros, mientras que a partir de los 600 metros son las multietapa las que se utilizan de forma casi única.

En estos momentos y en un futuro próximo, la justificación y la necesidad de estas centrales no es tanto lo anterior, que también en buena medida, sino el servir de complemento a las energías no gestionables como la energía eólica y la energía solar fotovoltaica. Eso hace que necesiten ser más flexibles y que se adapten todavía con mayor rapidez que anteriormente a las fluctuaciones de la carga en sistemas de fuerte implantación renovable.

Eso ha llevado en los últimos diez-quince años a que se hayan ido desarrollando disposiciones nuevas y turbinas de velocidad variable que sean capaces de variar de forma casi inmediata su potencia. 
Pero eso tiene un problema desde el punto de vista del alternador, ya que en los sistemas síncronos, el conjunto turbina-alternador, rígidamente unido, tiene que girar siempre a la misma velocidad, la de sincronismo, marcada por el alternador. Para ello ha habido que desarrollar soluciones diferentes, que se analizan con detalle en el apartado correspondiente, al que nos remitimos.

Las soluciones y disposiciones que se están adoptando en los últimos años, desde el punto de vista de las turbinas, son las siguientes:

- Disposición de sistemas ternarios.

- Utilización de turbinas de velocidad variable.

- Utilización de spleeters en las turbinas convencionales.

La vuelta a la disposición de sistemas ternarios se ha empezado a utilizar en algunos casos para conseguir capacidad de regulación en bombeo, cosa que no se tiene en los equipos convencionales actuales.

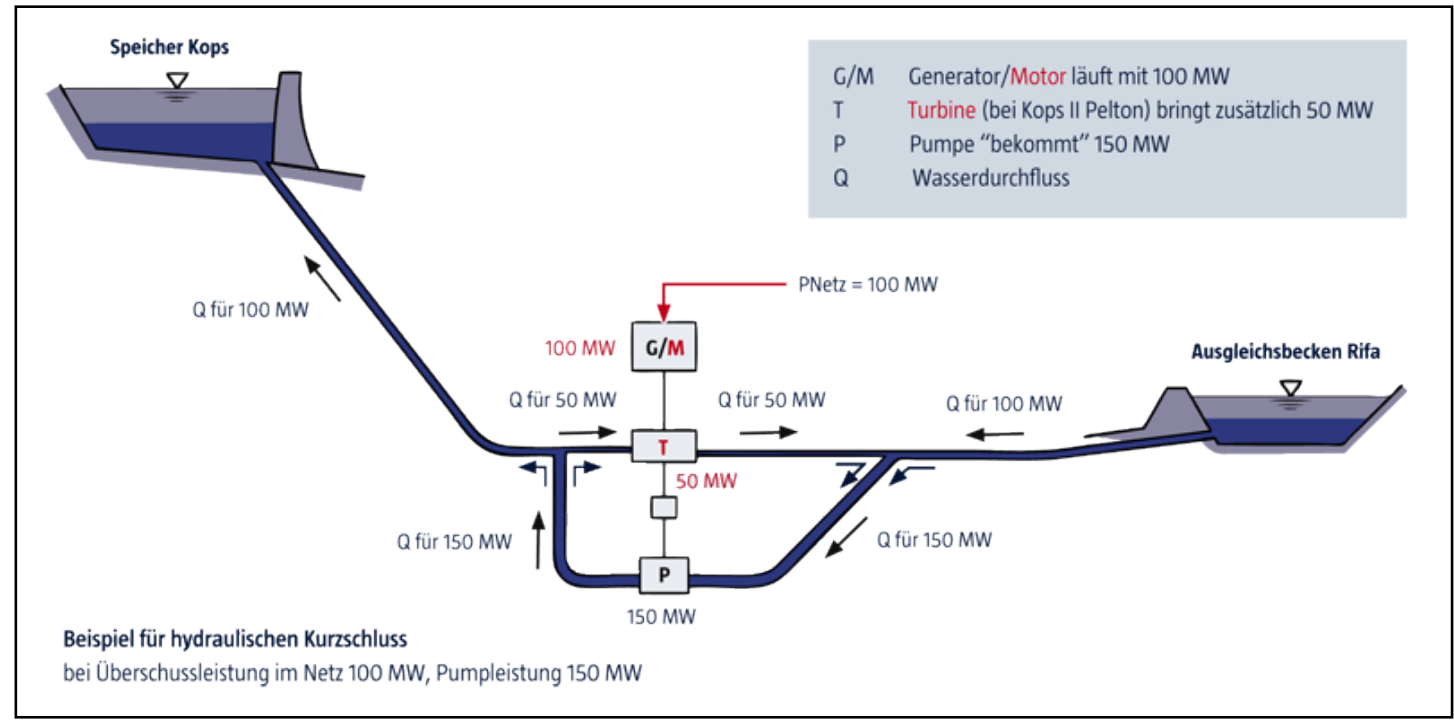

Esquema de funcionamiento de la central reversible de Kops II

En estos casos lo que se hace es disponer de dos circuitos hidráulicos diferentes para el turbinado y para el bombeo, conjugando en cada momento los caudales de uno y otro para tener la potencia requerida.

Por otro lado esta situación viene impuesta en aquellos casos en que el salto sea muy elevado, condición que lleva a la conveniencia de utilizar turbinas Pelton para obtener mayor rendimiento. Como la turbina Pelton es de acción y funciona a la presión atmosférica, no puede funcionar en presión, por lo que su circuito hidráulico tiene que ser distinto del de la bomba. 


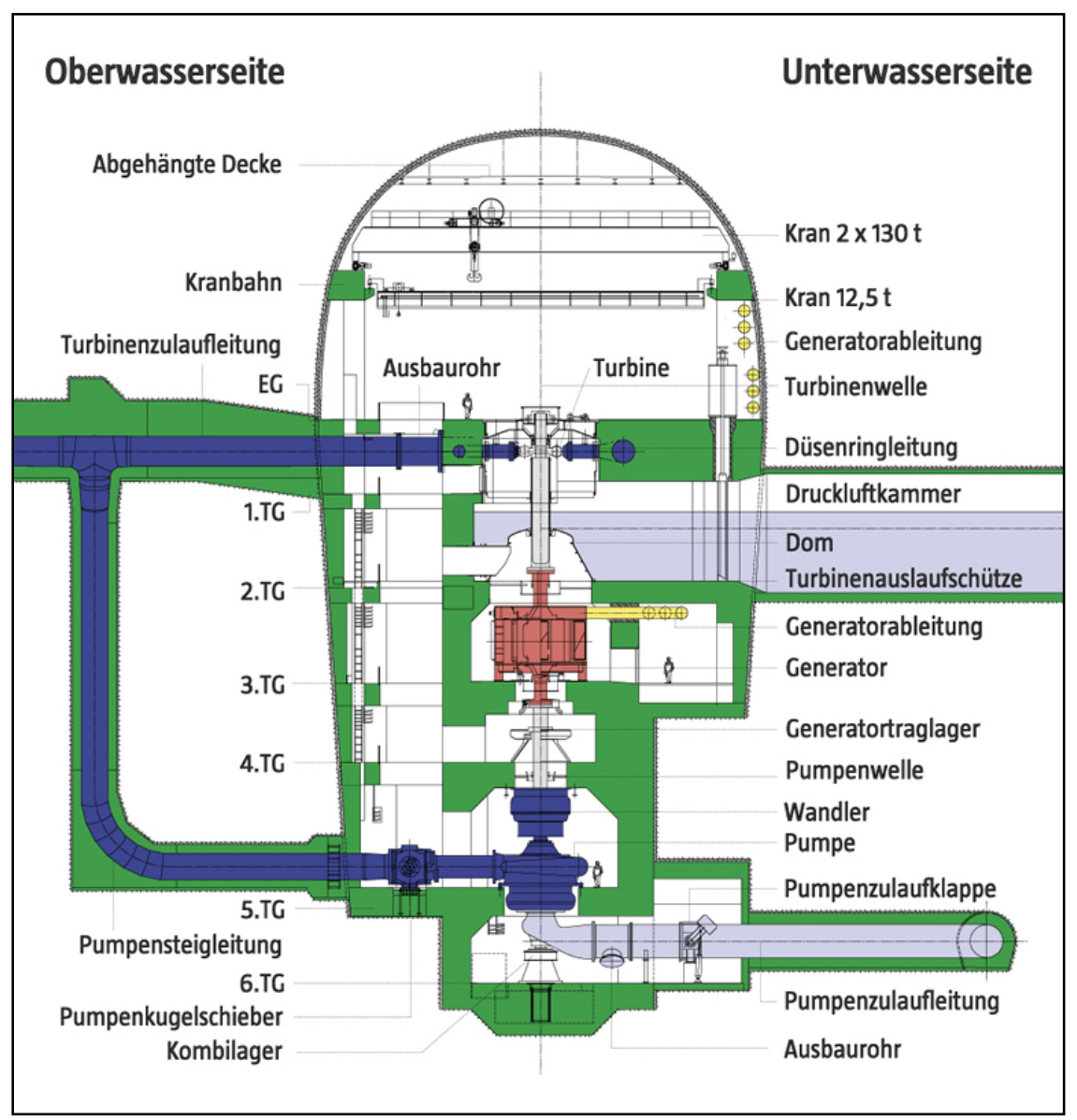

Equipo de la central reversible de Kops II.

La utilización de turbinas de velocidad variable es aconsejable respecto a la anterior por sus menores costes, ya que en general el aumento en el coste del equipo compensa el aumento en el coste general de la central.

Para compensar todo este aumento de costes debido a: el aumento de las alturas de los saltos y al aumento del coste de equipos, instalaciones, obras, etc, se trabaja en la actualidad en el aumento de la velocidad de funcionamiento de los equipos lo que implica una disminución en sus dimensiones y por ende en la de toda la central. 


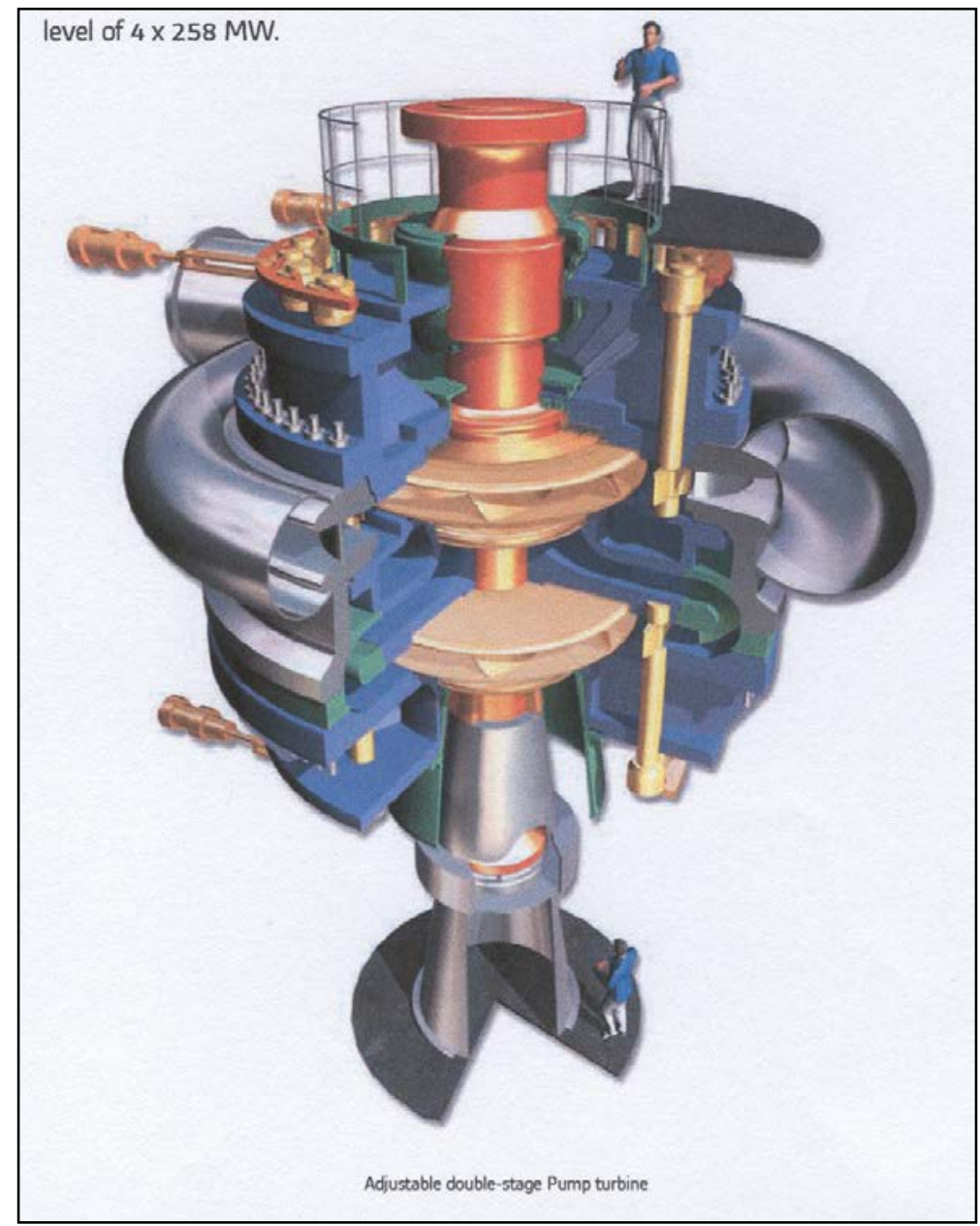

\subsection{TURBINAS PARA PEQUEÑA HIDROELECTRICIDAD}

La tendencia actual, paralela a los grandes desarrollos hidroeléctricos, va encaminada al aprovechamiento de los pequeños saltos que se producen sin la existencia de presas, o incluso aprovechamientos hidroeléctricos por turbinas situadas en los propios cauces.

En este sentido, han aparecido en el mercado una serie de turbinas como la Gorlov, Darrieus, Tyson, Hydraulienne, Syphon, etc. Como ejemplo de todas ellas, se describe a continuación las dos últimas.

Por ejemplo, la turbina Hydraulienne aprovecha la velocidad del agua de un cauce para producir electricidad mediante una rueda flotante.

Como en el resto de turbinas de este estilo, se caracteriza por su simplicidad. En el caso de la Hydraulienne, consta principalmente de un flotador, un rotor y un estabilizador. Son hidrogeneradores flotantes en un rio en un punto donde la velocidad no supere los $2 \mathrm{~m} / \mathrm{s}$. La corriente hace girar la rueda que produce electricidad. Cuando la altura de agua crece o decrece, el flotador obliga a la Hydraulienne a moverse verticalmente en consecuencia. 
La profundidad del agua debe ser como mínimo, de 0.5 metros y por cada rueda, la potencia disponible puede ser de hasta $15 \mathrm{~kW}$.

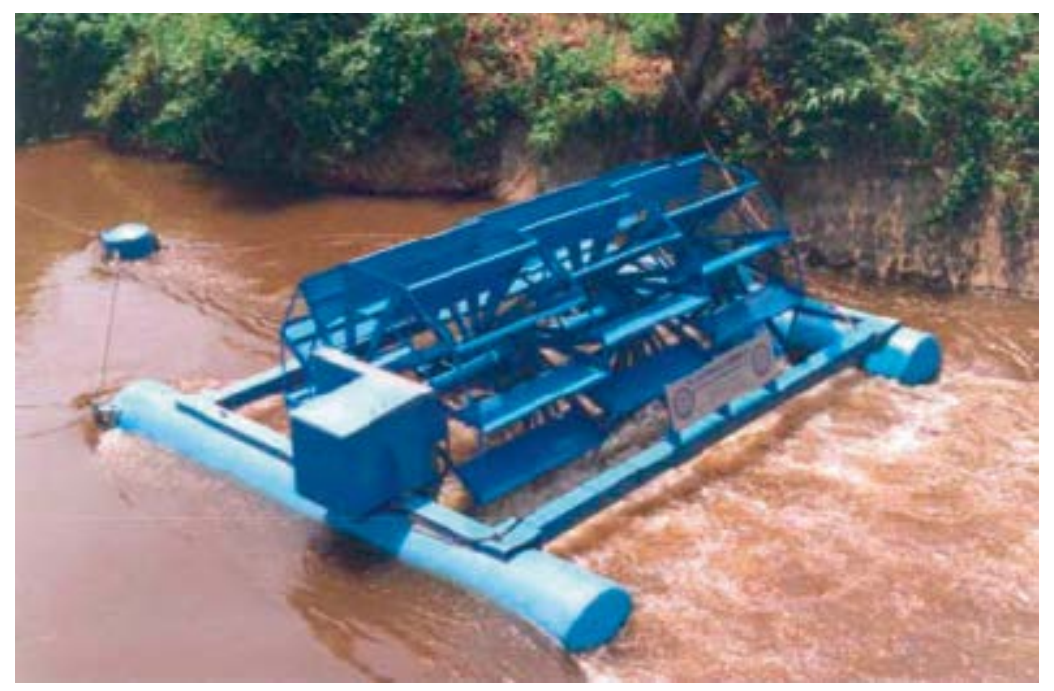

La turbina Siphon, cuyo esquema de la instalación se adjunta a continuación, necesita una profundidad de agua de 0.5 metros como mínimo y la potencia disponible es de 10 a $200 \mathrm{~kW}$. 


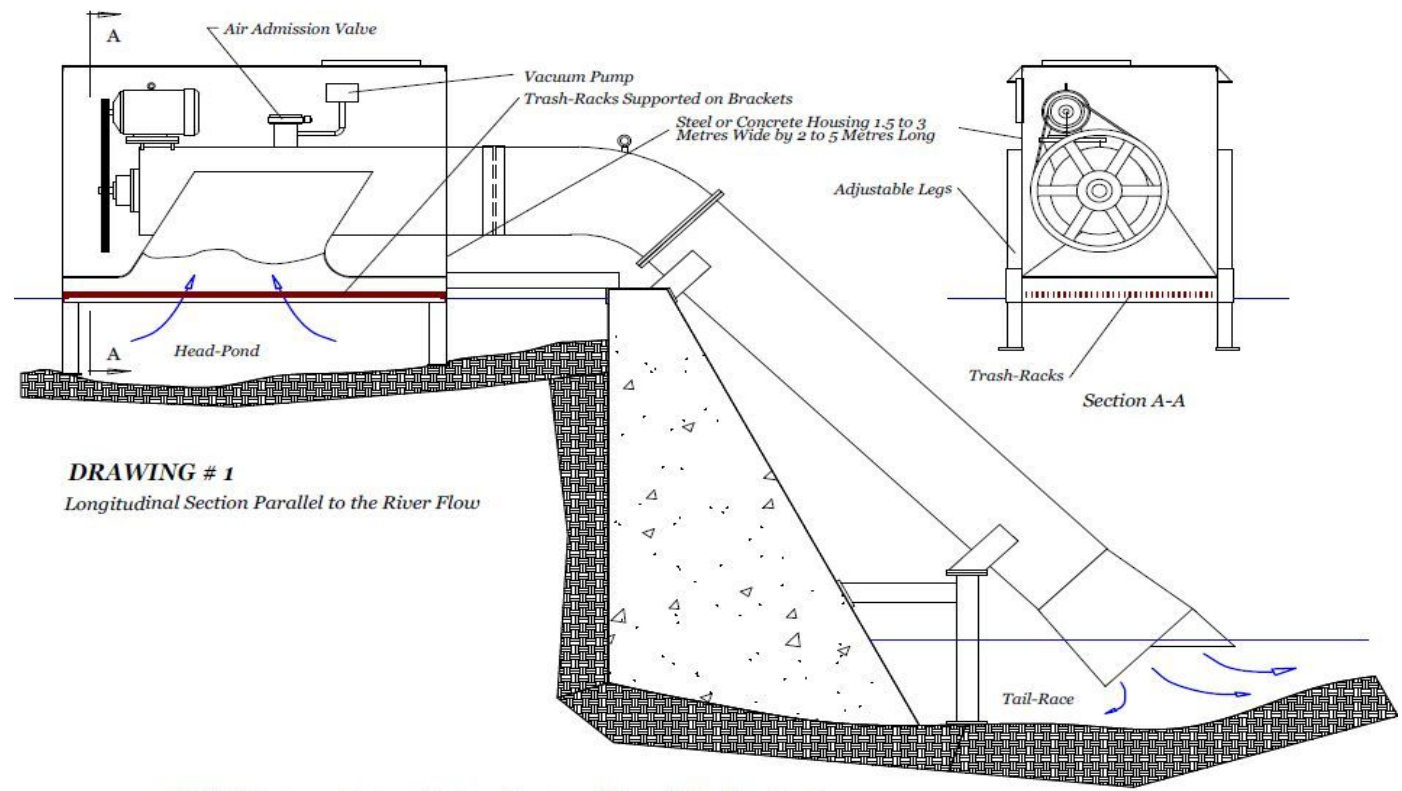

Fig. 1 Longitudinal Section Drawing of BEST(Bottom Entry Siphon Turbine)

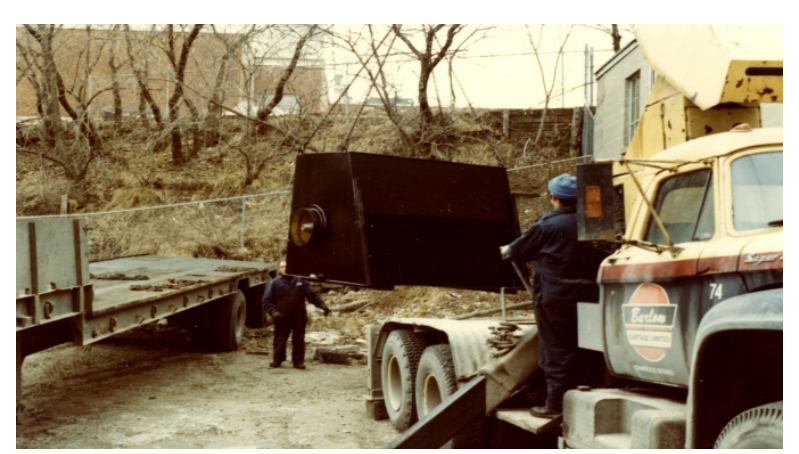

Photo 1 Packaged station being loaded for shipment 1983

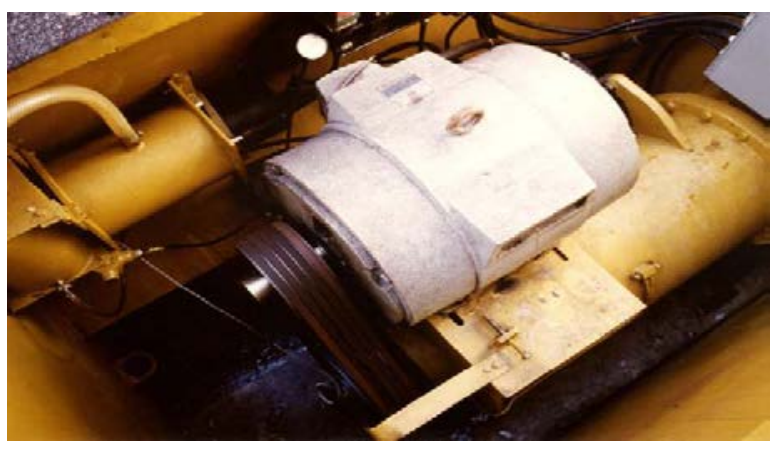

Photo 3 Interior view showing turbine and generator

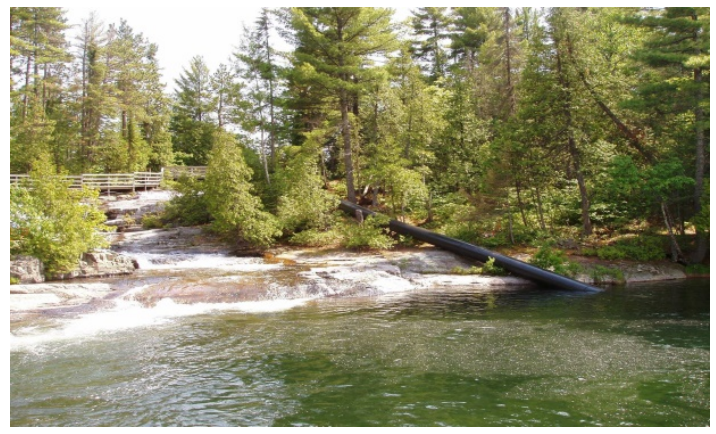

Photo 2 View of the discharge pipe entering the tailrace with the bridge seen at top

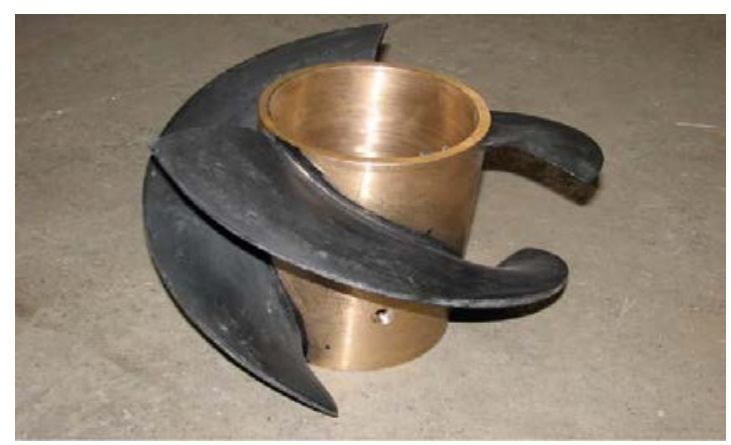

Photo 4 A view of the fish-friendly model runner 


\subsection{LAS TURBINAS EN ESPAÑA}

Actualmente se puede afirmar que la fabricación de los bienes de equipo de una central hidroeléctrica se realiza prácticametne en España, existiendo un número suficiente de empresas con la capacidad tecnológica necesaria para satisfacer las demandas del mercado proporcionando un servicio óptimo.

Las empresas principales fabricantes de turbinas son empresas extranjeras con fabricación en España, como es el caso de Voith (Dinamarca), Alstom Hydro (Francia) o Andryzt (Austria), lo que es considerado como una barrera operativa al existir una fuerte dependencia tecnológica del exterior, principalmente en la fabricación de turbinas.

Analizando los fabricantes de turbinas instaladas en las centrales de Iberdrola y de Endesa, puede observarse lo indicado anteriormente. El número de centrales estudiadas en este aspecto se considera suficientemente representativo siendo dichos fabricantes los siguientes:

\begin{tabular}{|l|l|l|l|}
\hline Escher Wyss & Charmilles & Neyrpic & Sulzer \\
\hline Voith & Kossler & Hite & Boll \\
\hline KMW & Boving & $\begin{array}{l}\text { Karistad } \\
\text { Makaniska }\end{array}$ & Vevey \\
\hline Piccard-Pictet & Theodore Bell & Morgan Smith & Nohab \\
\hline English Electric & Franco Tossi & Tegsa & MTM \\
\hline E. Sabadell & Miguel de Prado & $\begin{array}{l}\text { Maquinaria } \\
\text { Metalúrgica } \\
\text { Aragonesa Utebo }\end{array}$ & Talleres Martín \\
\hline Corcho e Hijos & Duro Felguera & $\begin{array}{l}\text { Mecánica de la } \\
\text { Peña }\end{array}$ & \\
\hline
\end{tabular}

Entre todos los fabricantes anteriormente expuestos llaman la atención algunas empresas españolas de los que merece la pena hacer una breve mención a continuación: 


\subsubsection{TALLERES CoRCHO}

Talleres Corcho fue una empresa industrial fundada en Santander (España), en los inicios de la segunda revolución industrial (1855). Su nombre procede del apellido del padre de su fundador Domingo Corcho, el italiano Giussepe Corcio.

Impulsada a partir de las dos últimas décadas del siglo XIX gracias a la dirección técnica del ingeniero Leonardo Corcho Zárraga, se dedicó a la metalistería, fumistería, instalaciones balnearias, saneamiento, hidráulica e instalaciones eléctricas, industria naval, del ferrocarril, militar, agrícola, química y otra variada producción de ingeniería. Las turbinas hidráulicas las fabrica a partir de 1880. 1913 - Talleres de San Martín S.A. cede a Corcho Hijos, que ya tenía mayoría accionarial (789 de 950 acciones) los terrenos y edificios de San Martín. Continuarán trabajando en la empresa Miguel López-Dóriga y Francisco Mirapeix (afamado especialista en turbinas, con varias patentes propias).

Al adquirir los Corcho los Talleres de San Martín de los López-Dóriga, amplían la construcción naval, así como la fabricación, con secciones como las turbinas hidráulicas, reguladores para centrales eléctricas, calderería, vagones y contenedores, y otra maquinaria, que se añaden a la fabricación de cocinas, elementos de hidroterapia y bombeo y demás procesos de su sede de la Bajada de Sotileza, que, en principio, tras el traslado, ostenta aún la sede administrativa y comercial.

En 1921 muere el 23 de noviembre Leonardo Corcho Zárraga, tras haber dejado convertida la empresa en Sociedad Anónima. Le sucede en la dirección su hijo Leonardo Corcho Pila (tiene otros tres hermanos: Manuel, Enrique y Ángel). En la dirección técnica Evaristo Lavín del Noval (más tarde Félix Aniel Quiroga y Valeriano González Puertas, ambos Ingenieros de la Armada); destacan como técnicos el inglés M. Miller (sustituyó como especialista en turbinas a Mirapeix), el técnico alemán Grossman y Miguel López-Dóriga y Gayé.

En 1926 en sus tres emplazamientos de Sotileza, La Reyerta y San Martín, "Corcho Hijos (S.A.) Ingenieros" se dedica a "Construcciones metálicas y mecánicas. Fundiciones, Bronces, Reparación de buques, Calderería gruesa. Especialidades de Fumistería, Hidroterapia, Saneamiento, Calefacciones, Turbinas hidráulicas, Maquinaria en general."

Terminó su existencia dedicándose predominantemente al sector de electrodomésticos, a partir de 1962. 
Su denominación fue cambiando a lo largo del tiempo: Talleres de Corcho e Hijos; Corcho Hijos, S.R.C.; Corcho Hijos, S.A.; Corcho, S.A. y, finalmente, Corcho, S.L., justo antes de la definitiva desaparición de su entidad jurídica.

Su razón social y marca, ya inexistentes ambos, tuvieron gran prestigio en la España de finales del XIX y todo el siglo XX, vinculadas a las instalaciones balnearias y cocinas de carbón y leña.

\subsubsection{MAQUINARIA Y METALURGIA ARAGONESA. S.A. UTEBO}

Empresa fundada en Zaragoza en 1902. Amplia muestra de las actividades e instalaciones de la empresa en distintos campos de la industria metalúrgica como turbinas hidráulicas y maquinaria diversa para centrales eléctricas, presas, azucareras, fábricas de cemento, industrias químicas, reparación de locomotoras, etc.

\subsubsection{DURO FELGUERA}

En 1858, Pedro Duro Benito crea la empresa Duro y Compañía en La Felguera (Asturias) aprovechando los ricos recursos de la zona (carbón, agua, transporte...). Está dedicada a la producción siderúrgica y la extracción de carbón. La compañía se convierte a finales del siglo XIX la principal siderurgia española.

En 1900 Duro y Compañía se transforma en la Sociedad Metalúrgica DuroFelguera, S.A. y en 1902 sale a la Bolsa de valores. En 1920 es la mayor empresa carbonera española.

Las décadas de 1940 y 1950 son de bonanza para la minería y la compañía dominará el mercado siderúrgico español junto a Altos Hornos de Vizcaya hasta aproximadamente 1960 .

En la década de 1960 se inicia un proceso de reestructuración minera e industrial en España. En 1961 se crea la Unión de Siderúrgicas Asturianas (Uninsa), formada por Duro Felguera, Fábrica de Mieres y la Fábrica de la Sociedad Industrial Asturiana, que constituirá el germen de las instalaciones de Ensidesa en Veriña. Con respecto al carbón, en 1967 Duro Felguera y otras empresas mineras transfieren su patrimonio a la empresa pública Hunosa.

A partir de entonces la compañía, liderada por D. Dimas Menéndez Magdalena (director general y consejero delegado durante varios años), cambia su orientación y se dedica a la producción de bienes de equipo, potenciando sus 
talleres y desprendiéndose de forma progresiva de las empresas no relacionadas directamente con la actividad de fabricación.

En la década de 1980 Duro Felguera vuelve a cambiar su modelo de negocio y se centra en la ejecución de proyectos "llave en mano" para el sector energético y la industria y la fabricación de bienes de quipo, extendiéndose por buena parte del mundo. En 1991 la empresa cambia su nombre a Grupo Duro Felguera, S.A. y en 2001 lo vuelve a hacer pasando a denominarse Duro Felguera, S.A.

A partir de 2008, la empresa lleva a cabo un plan para la concentración de sus sedes asturianas en Gijón y Llanera, trasladando empleados desde su primitivo origen decimonónico, Langreo. Finalmente en 2013 anuncian el cierre o traslado del resto de sus plantas en Langreo, pasando en un lustro de 600 empleos a cero.

\subsubsection{MeCánica de la PeÑa (MeCaPeña)}

La compañía ERHARDT \& Co. cuya propietaria es la familia del mismo nombre de origen alemán se transforma en 1921 en sociedad limitada española. Sus actividades principales eran la representación de armadores e industriales, y el comercio exterior, pero en los años 50 y 60 sufre una época de expansión consecuencia de la cual, se fundan varias sociedades industriales, entre ellas, Mecánica de la Peña, cuya misión es la fabricación de bienes de equipo incluyendo en los mismos turbinas hidráulicas. Se ubicó en Urduliz desarrollando su labor hasta el año 1999 que entra en suspensión de pagos.

\subsubsection{TAlleres Miguel De Prado}

En 1874 se establece en Valladolid los Talleres Miguel de Prado empresa especializada en la fabricación de motores y turbinas y cesa su actividad en 1972.

Se adjunta a continuación una reseña de esta empresa que aparece en el periódico ABC del viernes, 28 de septiembre de 1956, en el que se refleja su actividad de fabricación de turbinas para centrales hidroeléctricas. 


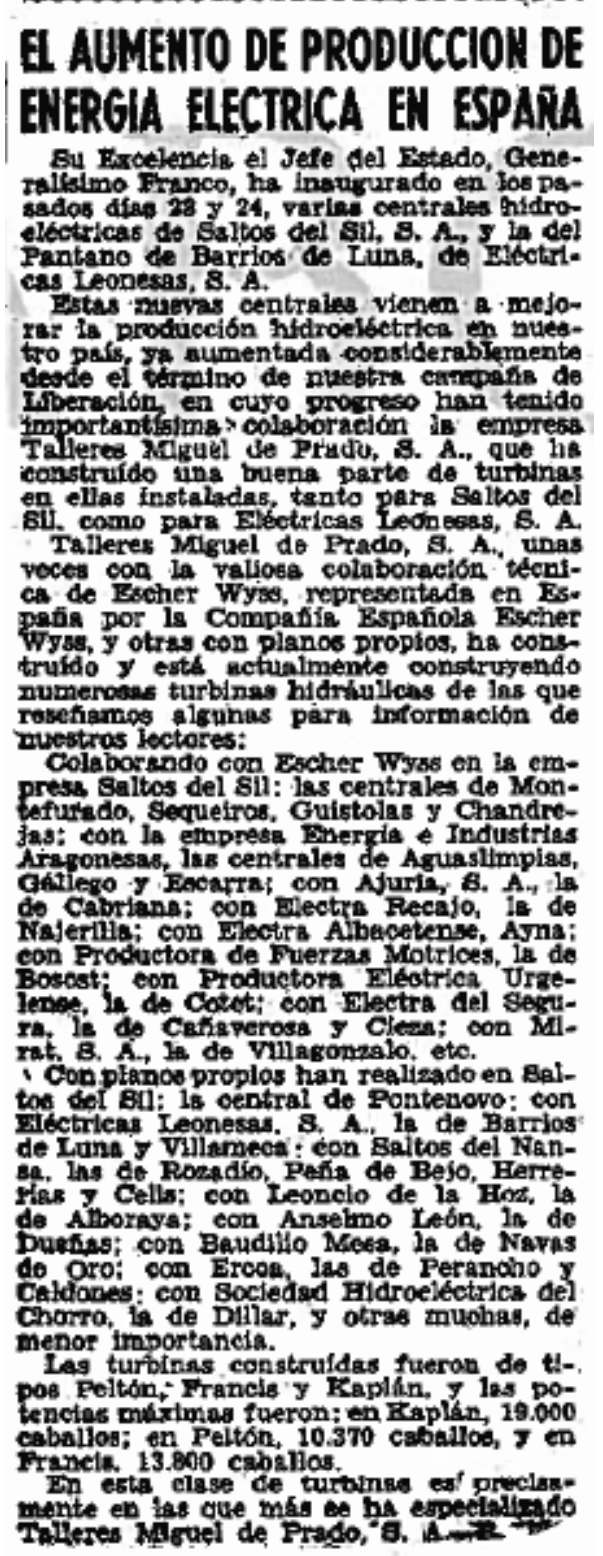

Es llamativo el hecho de que entre las empresas españolas indicada anteriormente no haya empresas vascas dedicadas a la fabricación de turbinas hasta 1950 cuando, sin embargo, entre 1880 y 1890 se multiplica la extracción de hierro en Vizcaya, llegando a alcanzarse la décima parte de la producción mundial, pasando de obtenerse más de 3.5 millones de toneladas en 1880, a 6.5 millones de toneladas en 1890, de las cuales se exportaron unos 4.8 millones de toneladas, principalmente a Inglaterra y Escocia (aproximadamente el 70\%), y a Holanda y Alemania (aproximadamente el 25\%), que sin embargo, sí producían turbinas hidráulicas al tener la tecnología suficiente para fabricarlas.

También la ausencia de empresas vascas en épocas tempranas de la hidroelectricidad es llamativa porque sin embargo, el grado de industrialización del País Vasco en 1860 y particularmente en Guipúzcoa, era 2,5 veces superior a 
la media del resto de España, siendo además una industria movida por agua. Por ejemplo, las fábricas de papel en las que se trituraba el trapo en cilindros movidos por turbinas hidráulicas, la tecnología y los técnicos procedían de Francia, sobre todo de la zona de Angulema, que es de donde provenían también parte de los capitales. A partir de 1850 casi todas las fábricas adoptan turbinas, a veces en combinación con las antiguas paletas.

\subsection{TIPOLOGÍAS DE TURBINAS EN ESPAÑA}

En cuanto a la tipología de las turbinas instaladas en España, se hace a continuación un análisis habiéndose estudiado las centrales de las empresas hidroeléctricas siguientes:

- Endesa

- Iberdrola

- Ferroatlántica

- Hidronitro

- EDP

- EON

- Union Fenosa

En total aúnan casi 300 centrales hidroeléctricas principales que han arrojado el siguiente resultado en cuanto a tipologías de turbinas (hay que tener en cuenta que aunque se han analizado casi 300 centrales, hay un mayor número de turbinas porque en algunas centrales coexisten varios tipos de turbina):

- 188 Turbinas Francis

- 64 Turbinas Kaplan

- 47 Turbinas Pelton

- 6 Turbinas Bulbo

- 2 Turbinas Hélice

- 1 Turbina Deriaz

Si consideramos que las turbinas bulbo, hélice y Deriaz son una variación de las turbinas Kaplan englobándolas en este grupo, resulta la siguiente clasificación:

- 188 Turbinas Francis

- 73 Turbinas Kaplan

- 47 Turbinas Pelton 
Que sobre el total de las 308 turbinas estudiadas, suponen los siguientes porcentajes de utilización:

- Turbinas Francis: $61 \%$

- Turbinas Kaplan: $23.7 \%$

- Turbinas Pelton: $15.3 \%$

En general, las turbinas españolas siguen el criterio de selección según los parámetros fundamentales de utilización de cada tipología en función de salto y caudal.

Las turbinas Pelton se emplean en saltos elevados que tienen poco caudal. Las turbinas Francis son las más implantadas ya que se adaptan muy bien a casi todo tipo de saltos y caudales, siendo su rango de utilización, por tanto, muy grande.

Las turbinas Kaplan (semikaplan, hélice, etc...) se utilizan en saltos pequeños con caudales variables y/o grandes.

Como primera aproximación para selección de turbina en función del salto, se ha tenido en cuenta la siguiente distribución:

- Turbinas Kaplan: para saltos de menos de 50 metros

- Turbinas Francis: para saltos comprendidos entre 30 y 500 metros

- Turbinas Pelton: para saltos mayores de 400 metros

Evidentemente, esta discretización debe considerarse como primera aproximación y no de manera estricta, pero se ha contemplado para poder comprobar si las turbinas españolas estudiadas (308) siguen o no, este patrón.

Y en este sentido, cabe decir que respecto a las Turbinas Francis analizadas (188), todas ellas se utilizan en el rango de salto antes mencionado salvo en las siguientes centrales:

- San Mateo:

13.60 metros (1957)

- Jauja-Malpasillo:

19.24 metros (1951)

- Fervenza:

25.50 metros (1966)

- El Cortijo:

15.50 metros (1931)

- Jándula:

27.00 metros (1930)

- Bembézar:

22.50 metros (1962) 
- Embid:

18.81 metros (1946)

- Azud de toma Aragón:

8.20 metros (1952)

- Azud de Calabuig:

9.38 metros (1913)

- Azud de Les Illes:

12.90 metros (1904)

- Azud de El Molí:

6.00 metros (1896)

- Azud de Orfes:

12.00 metros (1935)

- Baserca-Llauset (Moralets)

801.50 metros (1985)

Como puede comprobarse, la utilización de turbinas Francis en saltos que diferen de los habituales no puede asociarse a una época concreta del desarrollo de la hidroelectricidad en España, ni tampoco a un área geográfica concreta.

Respecto a las Turbinas Kaplan (incluyendo aquí turbinas semikaplan, Bulbo y Deriaz) analizadas (73), todas ellas se utilizan en el rango de salto antes mencionado salvo en la central de Valdecañas en que el salto es de 75 metros.

Respecto a las Turbinas Pelton analizadas (47), todas ellas se utilizan en el rango de salto antes mencionado salvo en las centrales siguientes:

- Chíllar I:

272.80 metros (1932)

- Ronda:

120.20 metros (1955)

- El Chorro:

209.00 metros (1921)

- Guriezo Superior:

250.00 metros (1930)

En el resto del mundo se replica lo que se observa en España respecto a la utilización de cada tipología de turbinas como puede observarse en los gráficos que se adjuntan a continuación: 

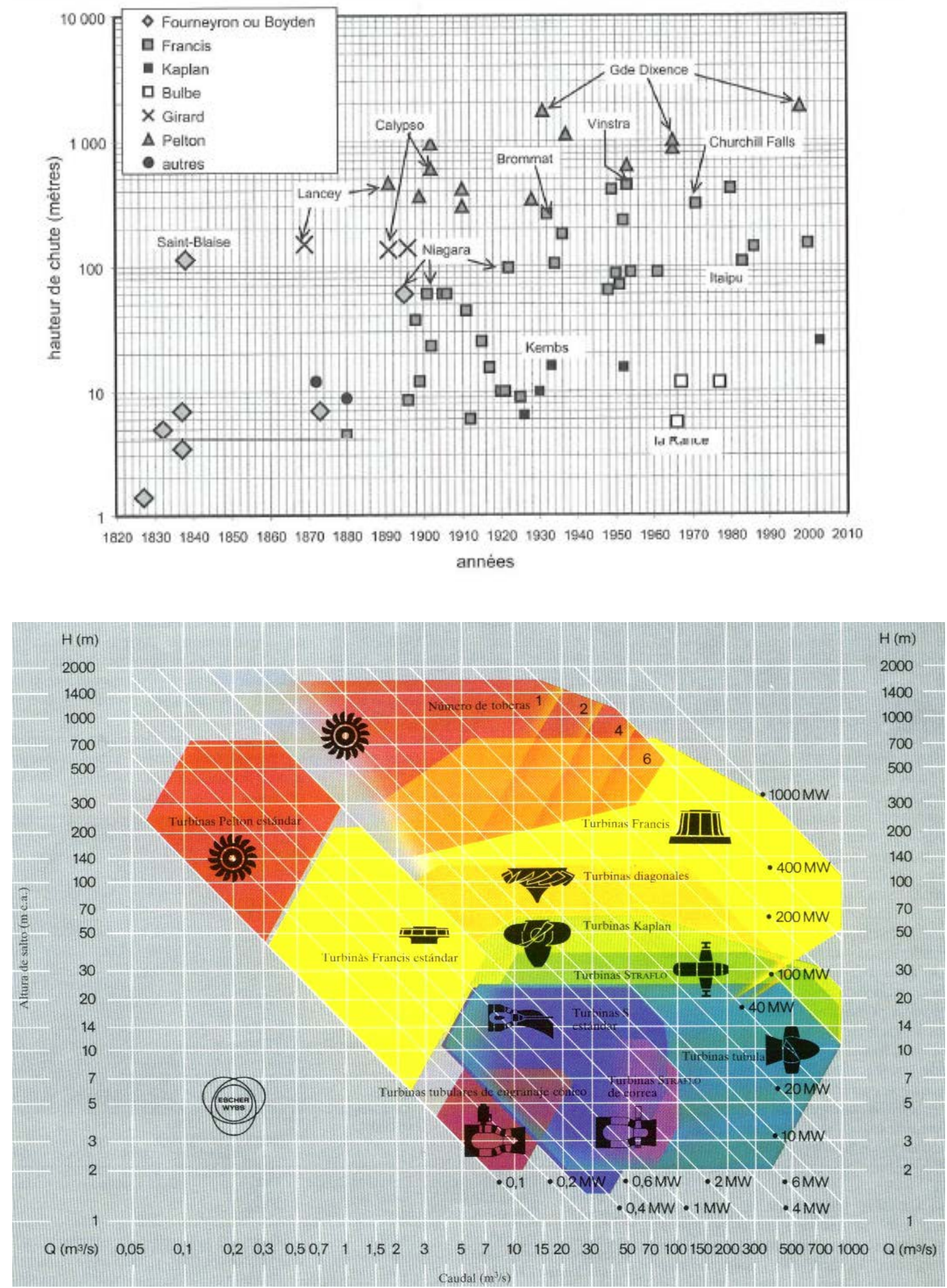


\subsection{INNOVACIÓN}

Los avances tecnológicos en el equipamiento de una central hidroeléctrica, por tratarse de una tecnología madura y consolidada, actualmente van dirigidos a obtener la máxima eficiencia, mejora de rendimientos y reducción de costes, sin olvidar la protección medioambiental en cuanto a evitar cualquier tipo de fugas de aceite o grasas al medio acuático.

En general, los nuevos desarrollos en turbinas se basan en adaptar las mejoras de los grupos turbogeneradores de la gran hidráulica para los equipos minihidráulicos.

A continuación se relacionan algunas tendencias en la innovación en el campo de las turbinas:

- Utilización de nuevos materiales, como polímeros reforzados de alta tecnología, en los cojinetes de turbinas: los cojinetes de bronce han sido la solución tradicional en las turbinas hidráulicas, pero requieren lubricación para vencer las fricciones de trabajo. Durante su funcionamiento, los lubricantes pueden pasar al agua, provocando graves daños en los ecosistemas fluviales. Las nuevas demandas medioambientales imponen que deban instalarse cojinetes sin engrases (autolubricados), que no sean perjudiciales para la vida acuática. Asimismo, como material polímero, la elasticidad es significativa, no es tan rígido, y tiene un coeficiente de fricción dinámico muy bajo.

- Empleo de métodos numéricos de cálculo de flujo tridimensional, que permitirá la mejora del rendimiento de las turbinas.

- Nuevos tipos de álabes, para la mejora de eficiencias y poder aumentar el rango de operación.

- Refrigeración de generadores con agua e hidrógeno, para la mejora de la eficiencia.

- Frenado electromagnético, que elimina daños y recalentamientos al disminuir el tiempo de frenado, evitando costosas reparaciones e indisponibilidades.

- Rotores autoventilados, para reducir pérdidas por fricción, aumentan eficiencia, pero costos elevados.

- Generadores con bobinas de cable aislado, para la mejora de la eficiencia y reducción de costos.

- Equipos de control para monitoreos de eficiencia y cavitación, para la mejora del mantenimiento durante la operación. 
Las tipologías Pelton y Francis tienen un grado de madurez tecnológico muy alto, en cambio las tipologías de hélice (Kaplan o Semikaplan) aunque su madurez es alta, su evolución tecnológica puede ser mayor pasando por poder aprovechar ubicaciones de muy bajo salto, por debajo de los 2,5-3 m, que hasta la fecha no se han desarrollado porque, aunque técnicamente realizables, los costes de inversión hacían inviable la instalación, ya que las turbinas convencionales necesitan una infraestructura importante de obra civil aguas arriba y aguas abajo de la misma para minimizar las pérdidas de carga y las pérdidas de producción.

No obstante, en los últimos años, se han desarrollado nuevas patentes de grupos turbogeneradores para centrales hidroeléctricas de muy bajo salto.

Estos nuevos diseños están basados en grupos compactos de simple regulación, totalmente sumergibles y de baja velocidad de paso, lo que hace que sus afecciones medioambientales sean mínimas y que requieran una infraestructura mínima en obra civil, lo que puede hacer viables económicamente el aprovechamiento energético de estos pequeños saltos.

Asimismo, se están desarrollando microturbinas hidráulicas con potencias inferiores a los $10 \mathrm{~kW}$, pensando en aprovechar la fuerza cinética de los ríos y generar electricidad en zonas aisladas. Laturbina produce electricidad directamente en corriente alterna y no necesita caídas de aguas, infraestructuras adicionales ni elevados costes de mantenimiento, lo que las convierte en una óptima solución en sistemas aislados.

En las obras civiles, su desarrollo tecnológico se basa en evitar en lo posible los daños medioambientales; en este sentido, la tendencia es el uso de nuevos materiales y sistemas de construcción y, sobre todo, el empleo de elementos prefabricados.

A continuación, se describirán ejemplos de desarrollos tecnológicos actuales que van en la línea de lo indicado anteriormente.

En la última década, el uso de la modelización computacional ha dado lugar a mejoras significantes en la eficiencia de las turbinas.

La posibilidad actual de simulación en laboratorio de las condiciones idénticas a aquéllas que se dan en la planta hidroeléctrica, permite entender y resolver fenómenos hidráulicos complejos y, en consecuencia, desarrollar soluciones innovadoras e imaginativas que mejoran el comportamiento de las turbinas actuales. 
El rendimiento de las turbinas ha alcanzado niveles difícilmente superables ya que se encuentran en valores por encima del 90\%. De hecho, la eficiencia de las turbinas hidráulicas es, desde el año 1925, superior al 93\%.

Sin embargo, se siguen realizando mejoras en este sentido como es, por ejemplo, el incremento de la eficiencia de las turbinas Pelton gracias a la selección del número de jets activos con el objeto de asegurar siempre la operatividad de la turbina en el punto óptimo.

El sistema de jets gestiona la secuencia de apertura y cierre de los inyectores para balancear la carga en la turbina para minimizar las fluctuaciones de potencia y las cargas mecánicas transversales durante la configuración de las transiciones.

De esta manera, y con el empleo de 6 jets, se pueden llegar a eficiencias cercanas al $100 \%$.

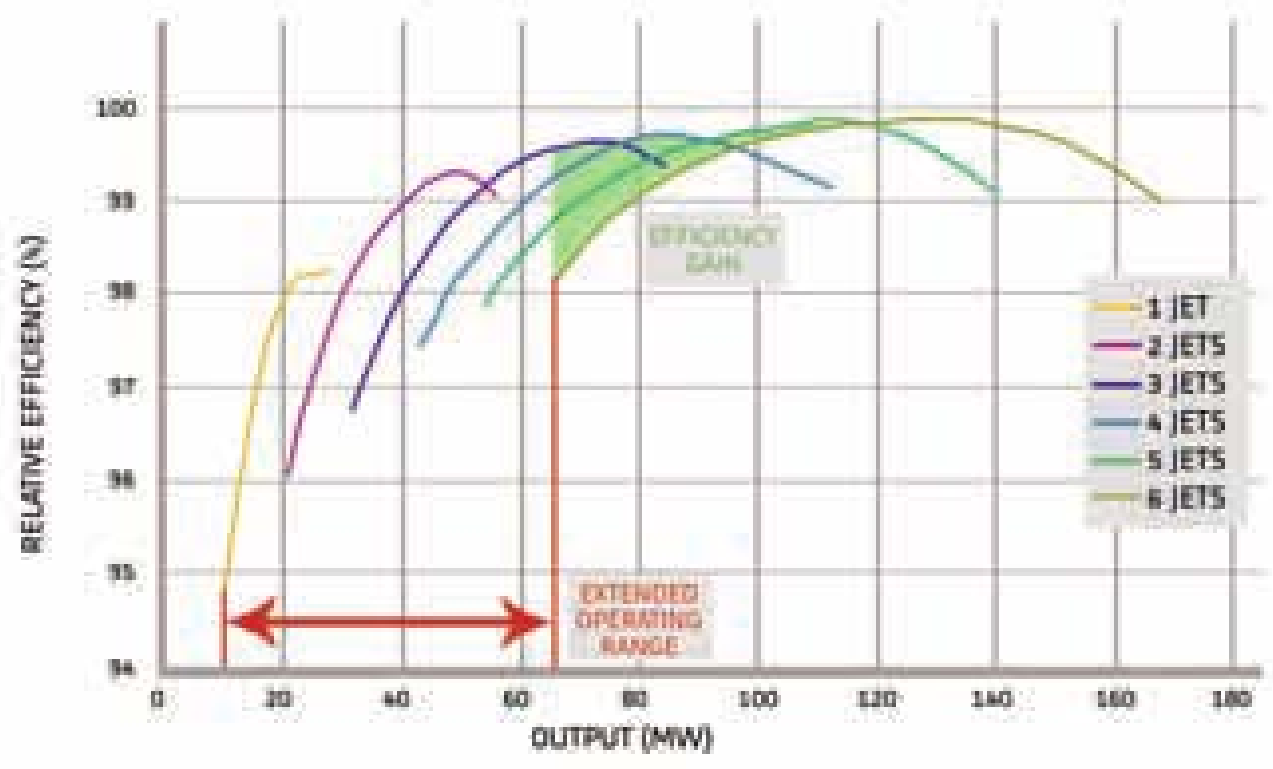

También los esfuerzos en innovación van encaminados más en el sentido de ejecutar máquinas hidráulicas más robustas.

De hecho, hoy en día, gran parte de los trabajos que se realizan en hidroelectricidad van encaminados a la rehabilitación, sustitución y reparación de erosiones por cavitación que sufren las turbinas. 


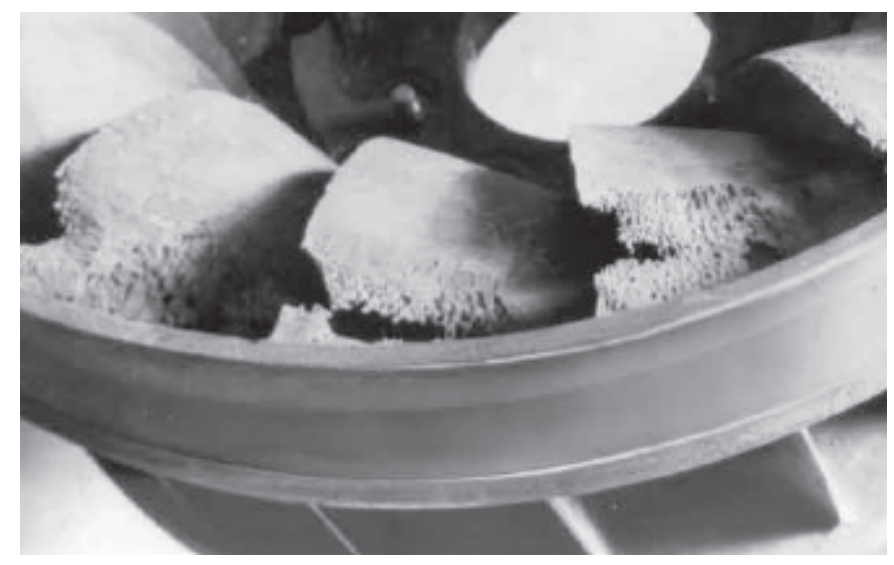

Como ejemplo de tecnologías innovadoras en la hidroelectricidad, se describe a continuación la Turbina Pelton de anillo (Hooped Pelton).

El hooped Pelton es un nuevo diseño innovador basado en la separación de la función entre cubetas y anillos perimetrales. Esta turbina está compuesta por cubetas separadas mecánicamente que se conectan al anillo perimetral. Esto es una gran ventaja para el mantenimiento, con características mecánicas además mejoradas.

El comportamiento de la turbina se mejora en operación y el plazo de entrega está más controlado y es más corto. También se reduce al mínimo el riesgo de que se fisure durante la operación debido a la mejora de la calidad de la metalurgia y a la redistribución de las tensiones dinámicas.

También se reduce el coste por la optimización de piezas de recambio, debido a la posibilidad de sustituir pocas cubetas en vez de todo el sistema completo.

Por ello, también el mantenimiento es más fácil al tener la posibilidad de que las cubetas se puedan sacar independientemente.

La turbina Hooped Pelton es de diámetros de $1200 \mathrm{~mm}$ en adelante. Su utilización es para plantas hidroeléctricas. 

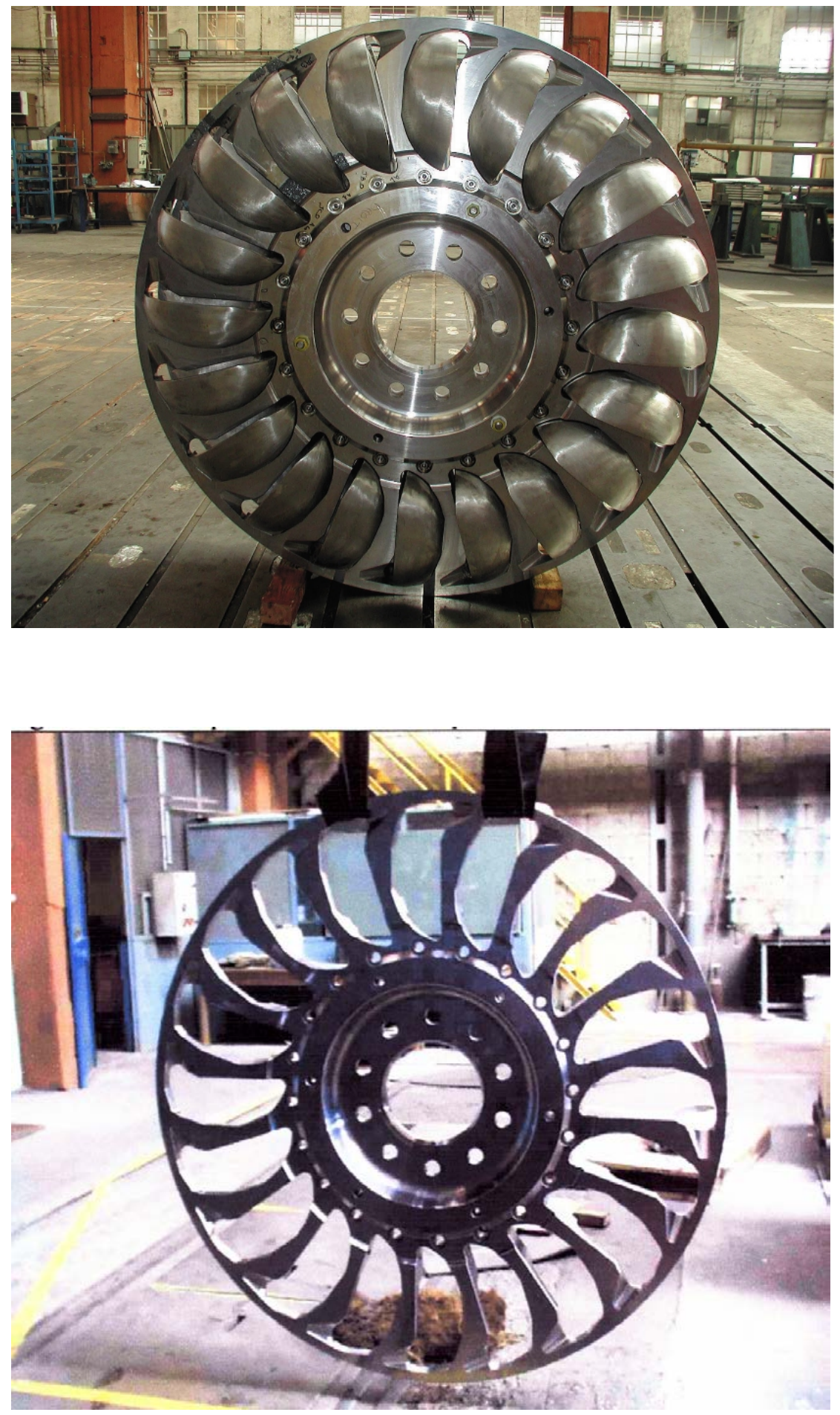

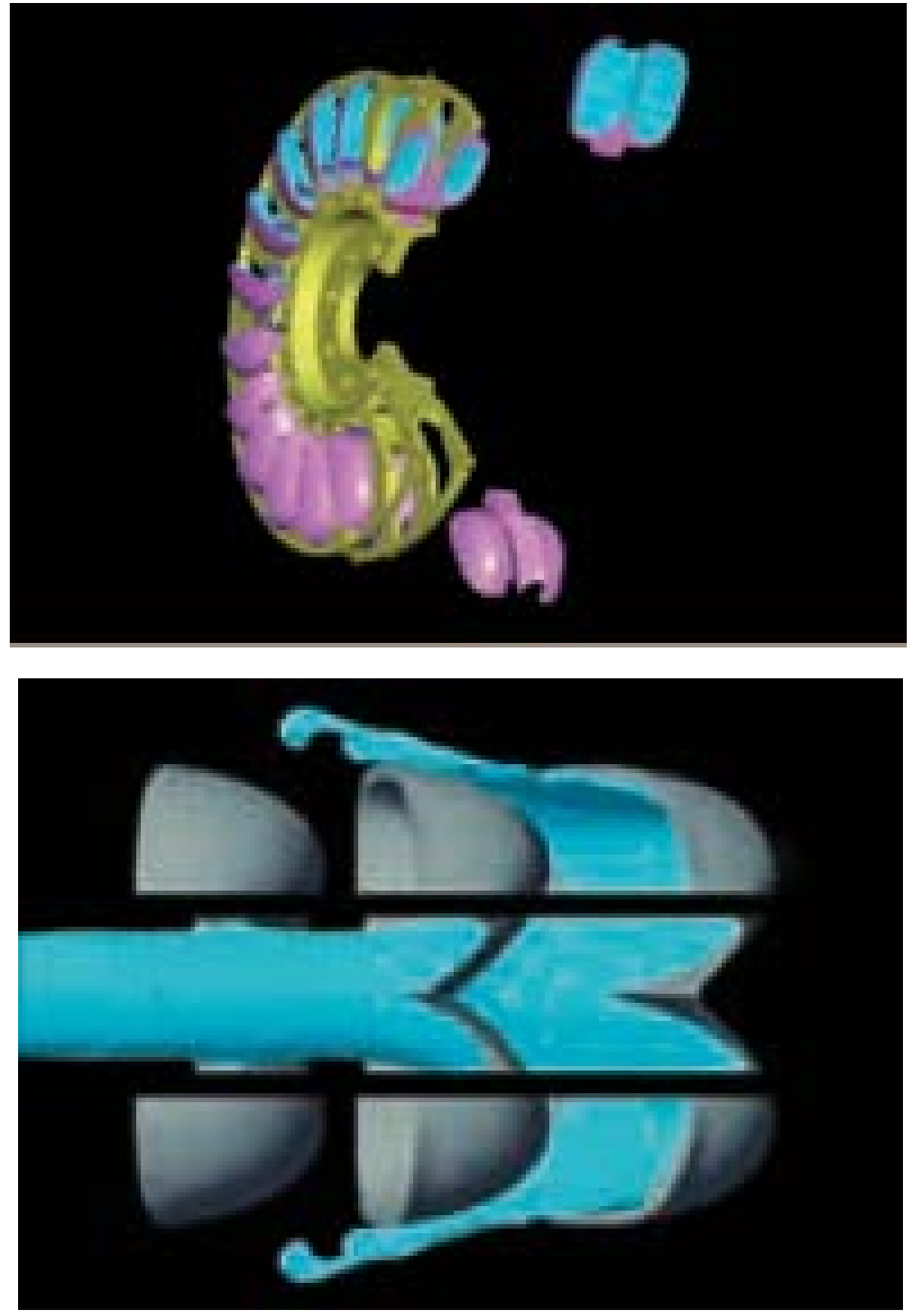

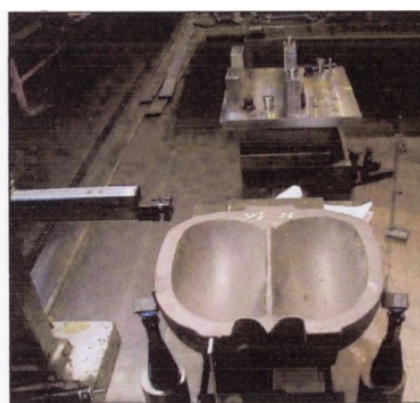

(a) cast piece

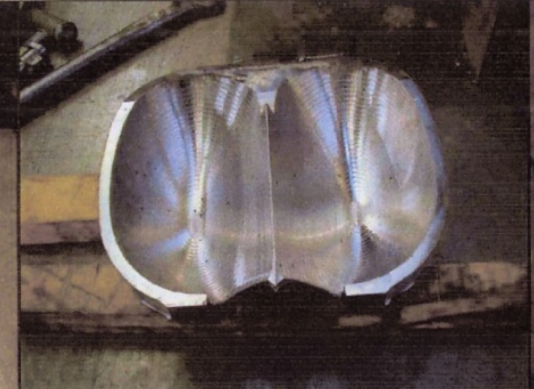

(b) after NC-machining

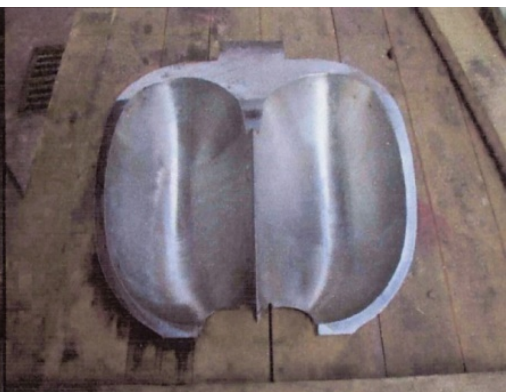

(c) after polishing 
Los grandes proyectos hidroeléctricos en los que sean necesarias turbinas de gran potencia se desarrollarán principalmente en África, Asia y América Latina, para suministrar la creciente demanda eléctrica de estas regiones.

Sin embargo, en Norteamérica y Europa en el que el mercado de la hidroelectricidad es más maduro o tiene condicionantes legales o políticos determinados, su desarrollo irá probablemente más orientado al aumento de la eficacia de la planta y su flexibilidad, disminuyendo la huella ambiental, además de augurarse en estas regiones un incremento de los desarrollos de pequeña hidroelectricidad.

En este sentido, se están produciendo innovaciones tecnológicas encaminadas a la realización de turbinas adecuadas para poca altura de agua, o incluso ubicadas en cauces, o en presas existentes que no tienen aprovechamiento hidroeléctrico alguno, y con un interés especial en que sean "amigables" para los peces.

Como ejemplo de estos últimos desarrollos, se describe a continuación la turbina Hydromatix, que es de tipo axial con diseño simple del bulbo para aprovechamientos de bajo salto.

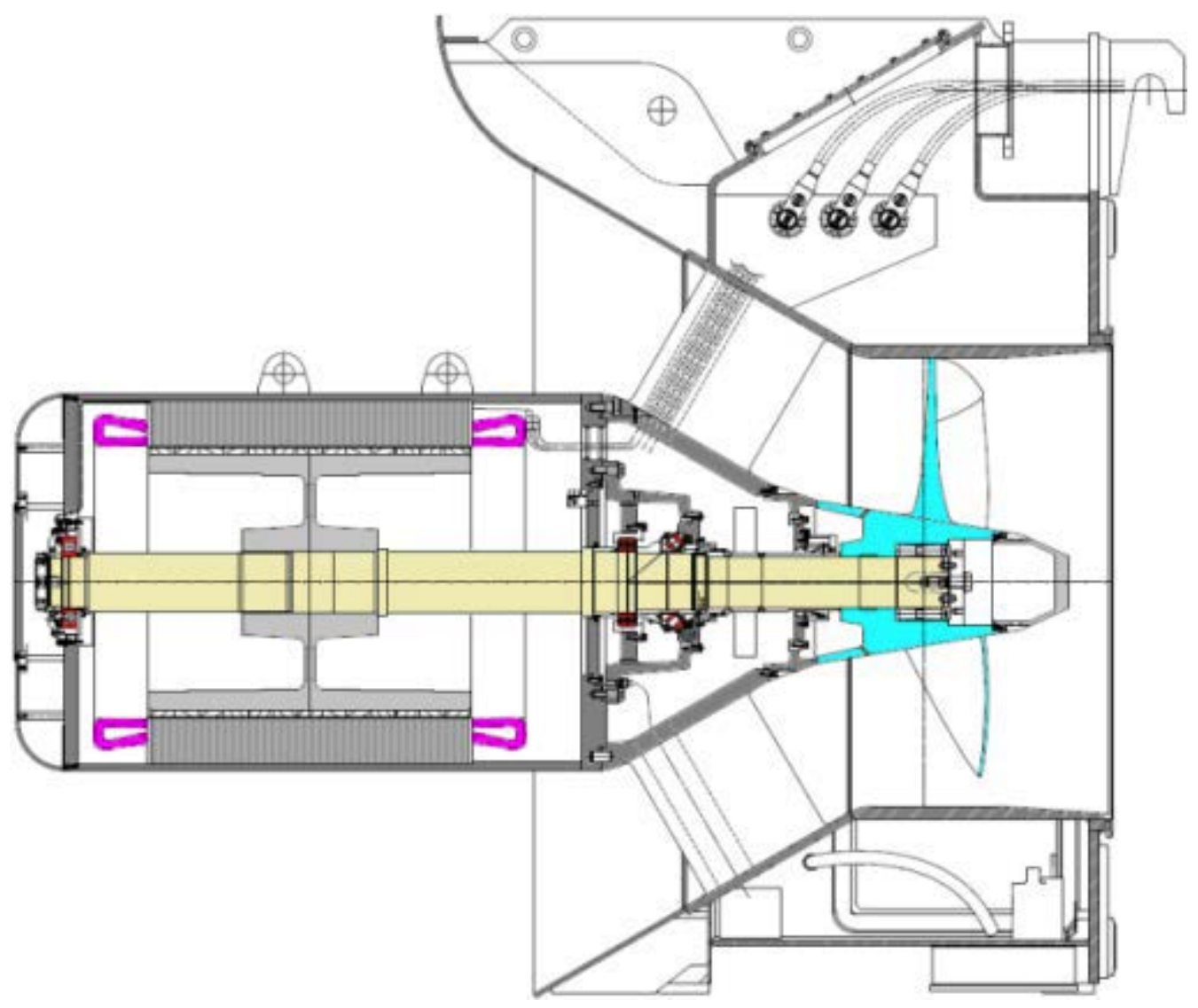


Se puede colocar en presas, torres de toma, esclusas o diques de navegación existentes y genera, por tanto, energía limpia y compatible con el medio ambiente, cumpliendo así el protocolo de Kyoto. La ubicación en estructuras existentes genera ahorros importantes en cuanto a la obra civil necesaria (que serán únicamente modificaciones simples), por tanto sin riesgo geológico, que da lugar a un coste de implantación reducido.
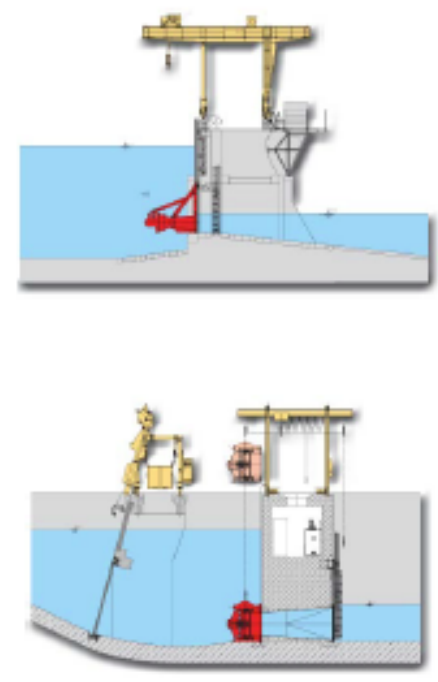

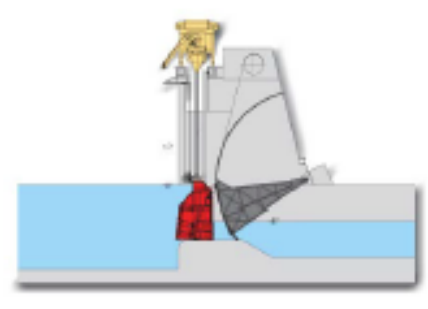

Pres as para riego
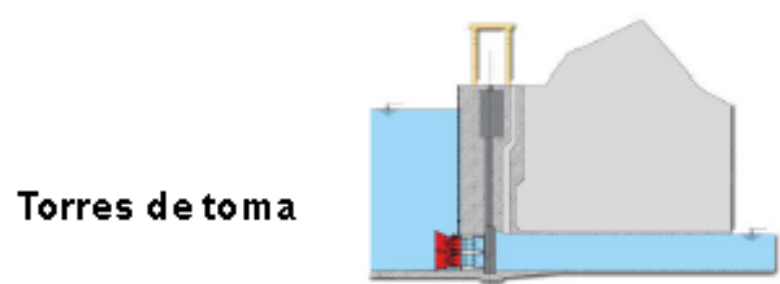

\section{Esclusas}

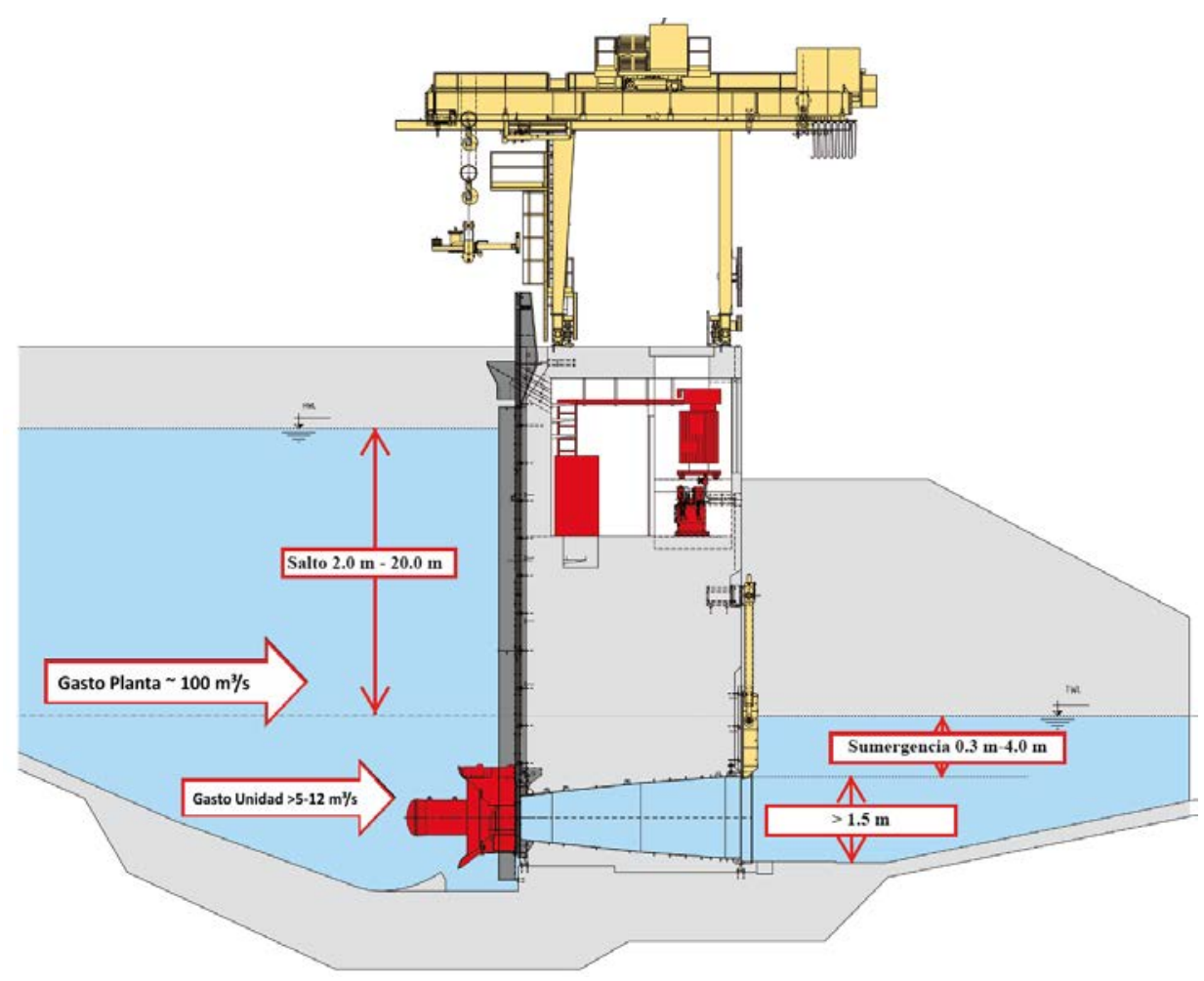




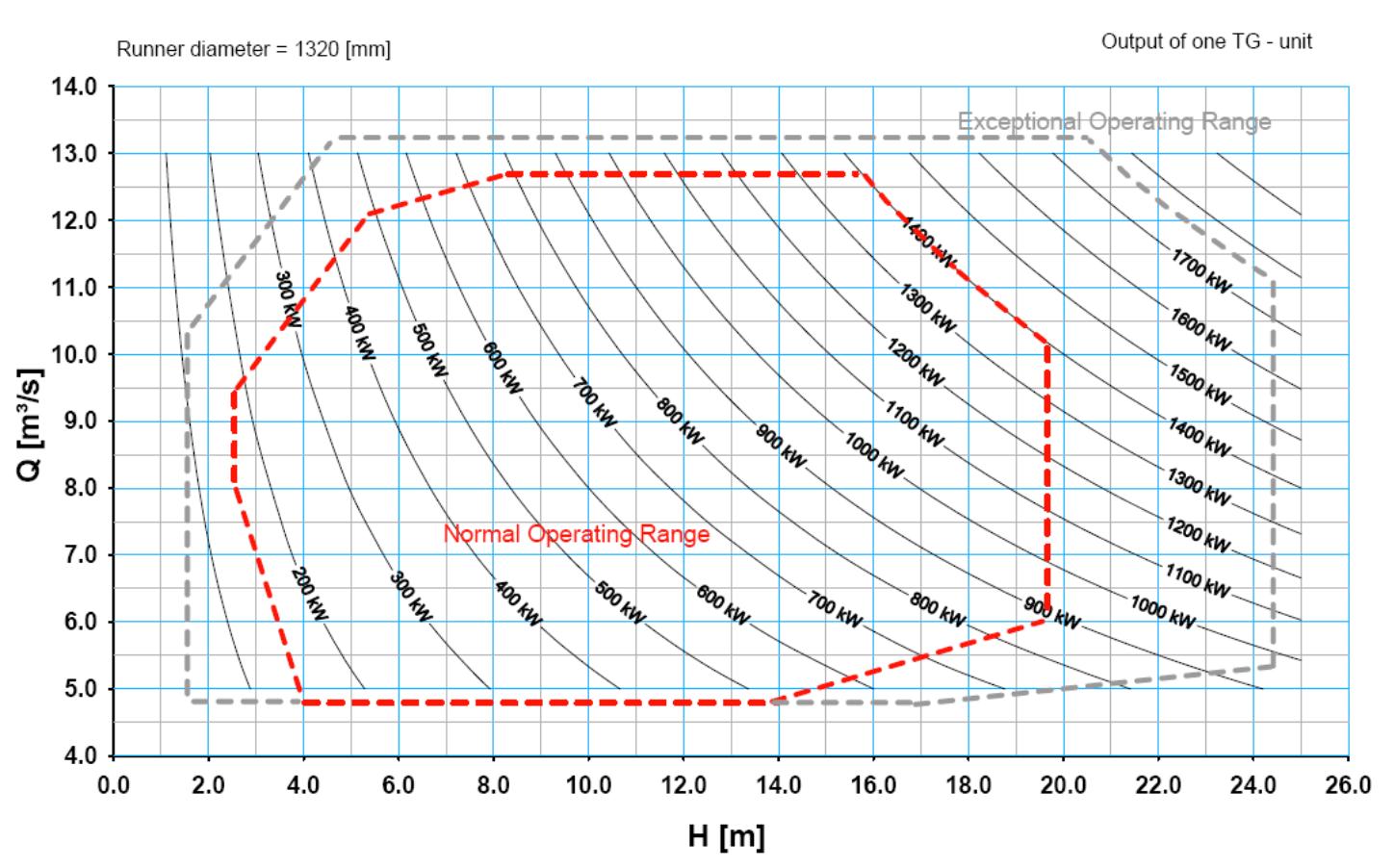

La Turbina Siphon antes descrita también es un desarrollo innovador en el ámbito de los pequeños aprovechamientos ya que proporciona un método barato y ecológico de extraer la energía de ríos y corrientes respetando la fauna acuática.

Otro desarrollo innovador es la Turbina de Bulbo Vertical aplicada en emplazamientos con relativa baja carga hidráulica ha sido desarrollada para reducir al mínimo el espacio necesario de instalación de unidad acortando también el período de montaje/desmontaje de la unidad, comparada con la turbina de eje horizontal Bulbo y la turbina Kaplan de eje vertical. La turbina y el generador pueden ser desmontados hacia arriba levantados por grúa.

La eficacia de turbina es ligeramente más alta que la turbina convencional Kaplan. El mantenimiento es fácil debido a la construcción simplificada y se puede reducir el período de revisión y reparación de Bulbo Vertical a 2/3 del tiempo que necesitaría una unidad de Bulbo Horizontal.

Esta turbina es apropiada para saltos de menos de 30 metros. Su localización es para ríos y hay que tener en cuenta el espacio vertical requerido para montaje y desmontaje de la turbina. 


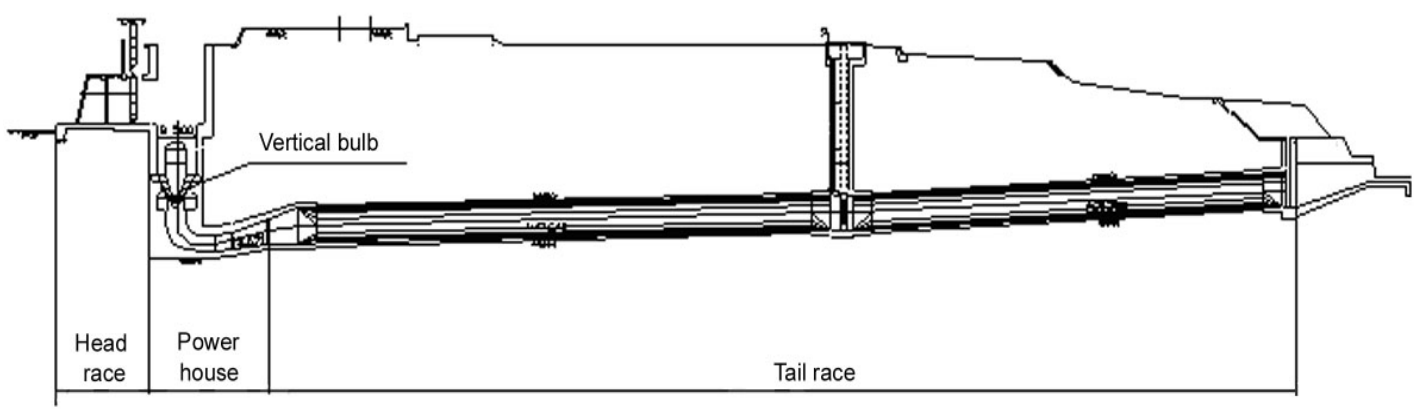

Fig. 1 General Arrangement of Vertical Bulb Turbine Generator in existing power house (Existing Unit: Vertical Shaft Kaplan Turbine)

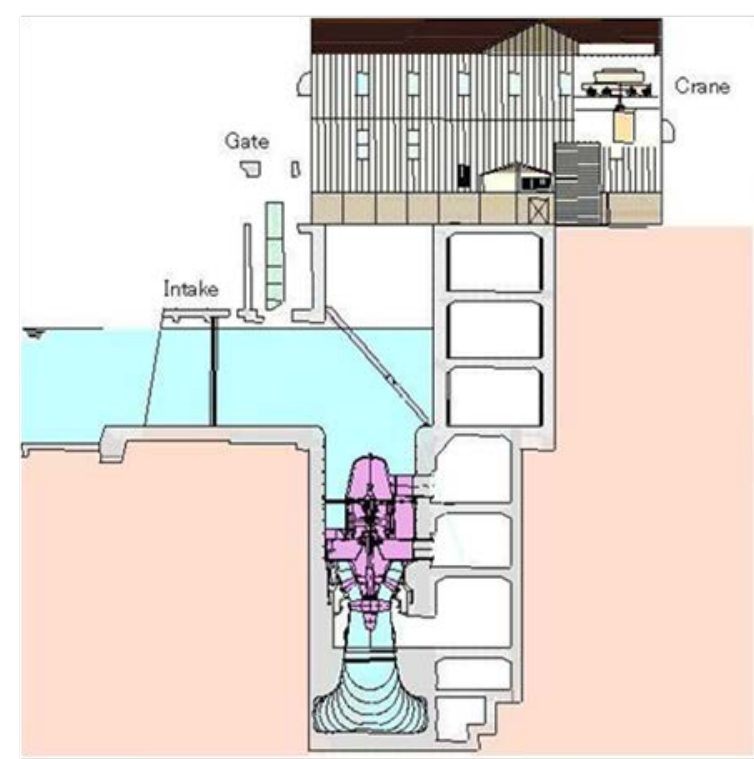

Fig. 2 Sectional Drawing of Vertical Bulb Turbine Installation

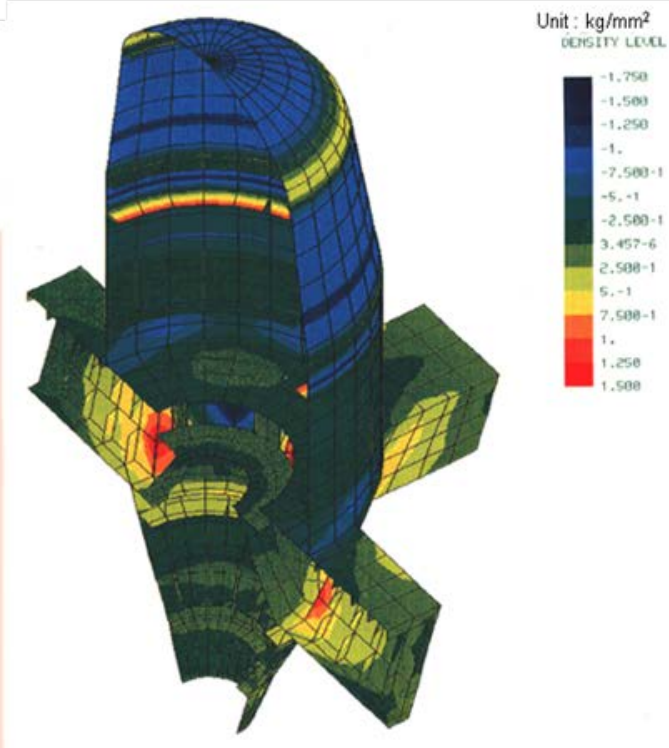

Fig. 3 Stress Analysis by computer 


\section{Capítulo 3.}

\section{Evolución de la tecnología eléctrica}



En las centrales hidroeléctricas el objetivo final es el de producir energía eléctrica, por lo que los elementos y componentes eléctricos son, evidentemente, de gran importancia. Se encuentran en la parte final del proceso de conversión de la energía potencial del agua en energía eléctrica, tras la primera conversión de aquella en energía mecánica de rotación y se ubican tanto dentro de la propia central, caso de los alternadores y de los sistemas de excitación del rotor, como fuera de la central, caso de los transformadores, de los parques de transformación o de las líneas de transporte.

Para la obtención de energía eléctrica a partir de la mecánica de rotación disponible en la turbina, se utilizan alternadores, máquinas generalmente síncronas que a partir de un devanado inductor (rotor) alimentado por una corriente continua, genera un campo electromagnético que corta otro devanado inducido y fijo (estator), formado por un arrollamiento trifásico recorrido por una corriente alterna que es la producida en la central.

El que sean máquinas síncronas significa que su velocidad de rotación está asociada de forma rígida a la frecuencia de la red, lo que supone que su velocidad es y debe ser constante en funcionamiento estable. No obstante esta velocidad de giro única presenta algunos problemas en determinadas ocasiones. Buena parte de los últimos desarrollos en la tecnología de centrales hidroeléctricas está pasando por la utilización de grupos de velocidad variable, sobre todo, aunque no únicamente, en grupos reversibles turbo-bomba.

Otro de los puntos en los que la evolución de los equipos eléctricos tuvo un importante avance fue en la forma de conseguir la corriente continua a introducir en el rotor, que ha evolucionado desde los anteriores sistemas de "dinamo excitatriz" a los actuales sistemas de "excitación electrónica".

Los alternadores tienen limitada su tensión de salida por cuestiones constructivas. A mayor potencia unitaria mayor tensión de salida. Pero en cualquier caso esta tensión de salida no es suficiente para que las pérdidas en el transporte sean suficientemente bajas, por lo que en todas las centrales existe un parque de transformación de tensión que la eleve lo suficiente para disminuir las pérdidas por efecto Joule, principalmente.

Hasta ahora la forma de transporte de la energía eléctrica ha sido de forma generalizada en corriente alterna. No obstante, cada vez se utiliza más el transporte en corriente continua para largas distancias y para conducciones que discurren por los fondos marinos, casos en los que su mayor coste queda compensado por las menores pérdidas y la posibilidad de transportar mayores potencias. 
Así, los principales elementos y componentes eléctricos, a cuya evolución nos referiremos aquí, de forma breve, son:

- Alternador.

- Sistemas de excitación del rotor.

- Líneas de transporte de electricidad.

Evidentemente existen otros elementos y sistemas, pero desde el punto de vista de esta tesis no han tenido ni tienen la relevancia que adquieren estos.

\subsection{ALTERNADORES}

El funcionamiento de los alternadores de corriente alterna no ha cambiado básicamente desde sus orígenes hasta nuestros días. Las mejoras han venido por el lado de la optimización del diseño, la mejora en los materiales utilizados, tanto los conductores como, sobre todo, los aislantes, y en la resolución de los problemas ligados a la necesidad de obtener cada vez mayores potencias.

Inicialmente buena parte de los generadores eléctricos eran de corriente continua, que tuvieron un gran desarrollo a partir de 1870 y hasta poco antes del cambio de siglo. Sin embargo se fueron evidenciando algunos problemas técnicos que fueron limitando su uso: principalmente los problemas en obtener altas potencias unitarias y en obtener altas tensiones de salida entre sus terminales. A estos habría que sumarle la dificultad en tener un sistema de transporte en corriente continua eficaz.

A partir del descubrimiento de los transformadores de tensión, a mediados de la década de los 80 del siglo XIX, los generadores y el transporte de corriente alterna, que se habían quedado rezagados en su desarrollo frente a los anteriores, volvieron a recobrar protagonismo.

La disputa entre el uso de la corriente continua y el de la corriente alterna estuvo presente tanto en el campo técnico como en el campo económico, con fervientes seguidores y detractores de ambos. Es de sobras conocida la disputa que encabezaron durante un largo periodo de tiempo Edison y Tesla, entre otras personalidades.

La disputa se resolvió finalmente con la decisión de utilizar corriente alterna en la central de Niagara Falls en 1893, que supuso un hito en la construcción de aprovechamientos hidroeléctricos, con sus $50.000 \mathrm{CV}$, un salto de 54 metros y sus 10 turbinas del tipo Fourneyron. Los alternadores eran bifásicos (frente a los trifásicos actuales), de $2.300 \mathrm{~V}$ de tensión e inducido interior y fijo e inductor 
móvil y exterior (al contrario de lo que hoy es habitual de rotor interior y estator exterior).

En palabras de Jesús Fraile:

“... la injusticia histórica con el generador de corriente continua: después de dedicar multitud de esfuerzos los científicos y los ingenieros para conseguir una dinamo eficiente, dotada de un rectificador mecánico ingenioso y práctico como es el colector de delgas, en plena adolescencia deberá dar paso a ese gran neófito que es la corriente alterna y que se irá imponiendo paulatinamente ...".

No obstante este cambio se debió a las grandes virtudes de la corriente alterna: su mayor sencillez en la generación, en el transporte, en la distribución y en la utilización. En este cambio fue actor principal el desarrollo de los transformadores de tensión, tal y como se ha expuesto.

A partir de ese momento, el desarrollo económico y la mayor utilización de la energía eléctrica dentro de los sistemas energéticos, fue haciendo necesario disponer de potencias unitarias y totales mayores en las centrales, lo que ha conducido a tener que disponer de generadores cada vez mayores.

Así, se ha pasado desde las potencias máximas del orden de $100 \mathrm{MV}$ de los años 30, a los 300 MVA de los años 60, a los 500 de los años 70 o, las actuales del orden de 850 conseguidas en centrales como las de Guri (Venezuela), Itaipu (Brasil-Paraguay), Tres Gargantas (China).

En la actualidad hay proyectos en los que las potencias unitarias son del orden de 950 MVA y se está trabajando para conseguir hasta 1100 MVA, lo que previsiblemente se conseguirá a partir del año 2020 aproximadamente.

El aumento de las potencias unitarias supone un aumento en el peso de los equipos y en especial de los rotores. Y también de las necesidades de refrigeración, tanto del alternador -para extraer el calor generado por el campo electromagnético en el entrehierro-, como de los circuitos de aceite de los cojinetes de empuje que sustentan el gran peso y permiten el giro.

Este aumento de potencias conlleva por lo tanto la necesidad de utilizar cada vez más refrigeración mediante agua, en lugar de la clásica por aire. Es de prever que ambos sistemas se repartirán, dependiendo de las ocasiones, su utilización en los grupos de potencias superiores a los 400 MVA. 

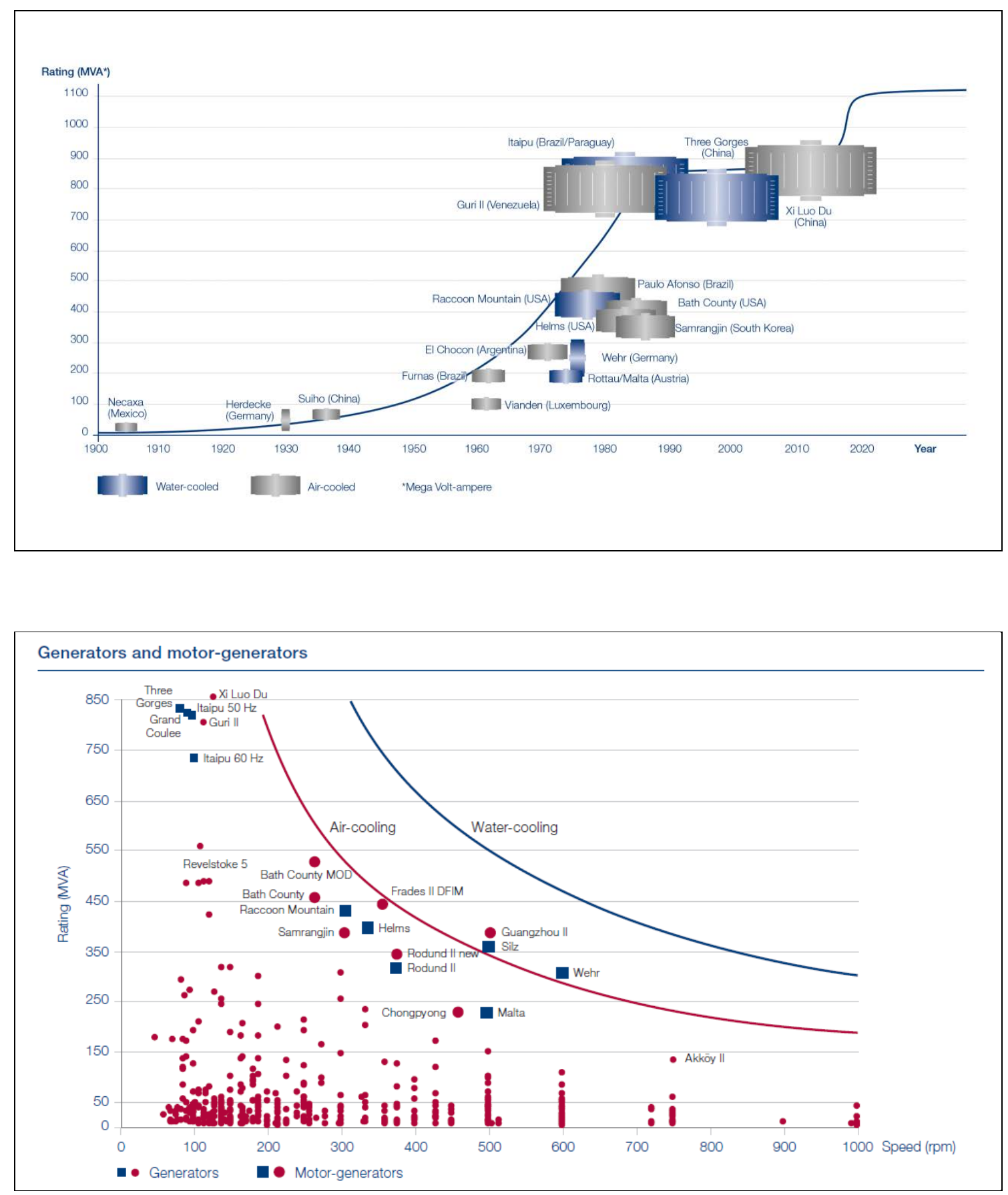

\section{La utilización de generadores asíncronos y máquinas de velocidad variable}

La mayor parte de los alternadores que se utilizan en las centrales hidroeléctricas son de tipo síncrono, esto es, giran a una velocidad determinada y constante que depende de la frecuencia de la red y del número de pares de polos.

Estos alternadores síncronos consisten en una masa giratoria -rotor- en cuya periferia se disponen unos electroimanes -los polos-, que giran en el interior de un cilindro hueco -el estator-, compuesto por chapas magnéticas de acero al 
silicio. Tanto el rotor como el estator tienen devanados construidos con cobre electrolítico. Los devanados del rotor se sitúan en los polos y se conectan a través de anillos y escobillas a una fuente externa de corriente continua -la excitatriz-.
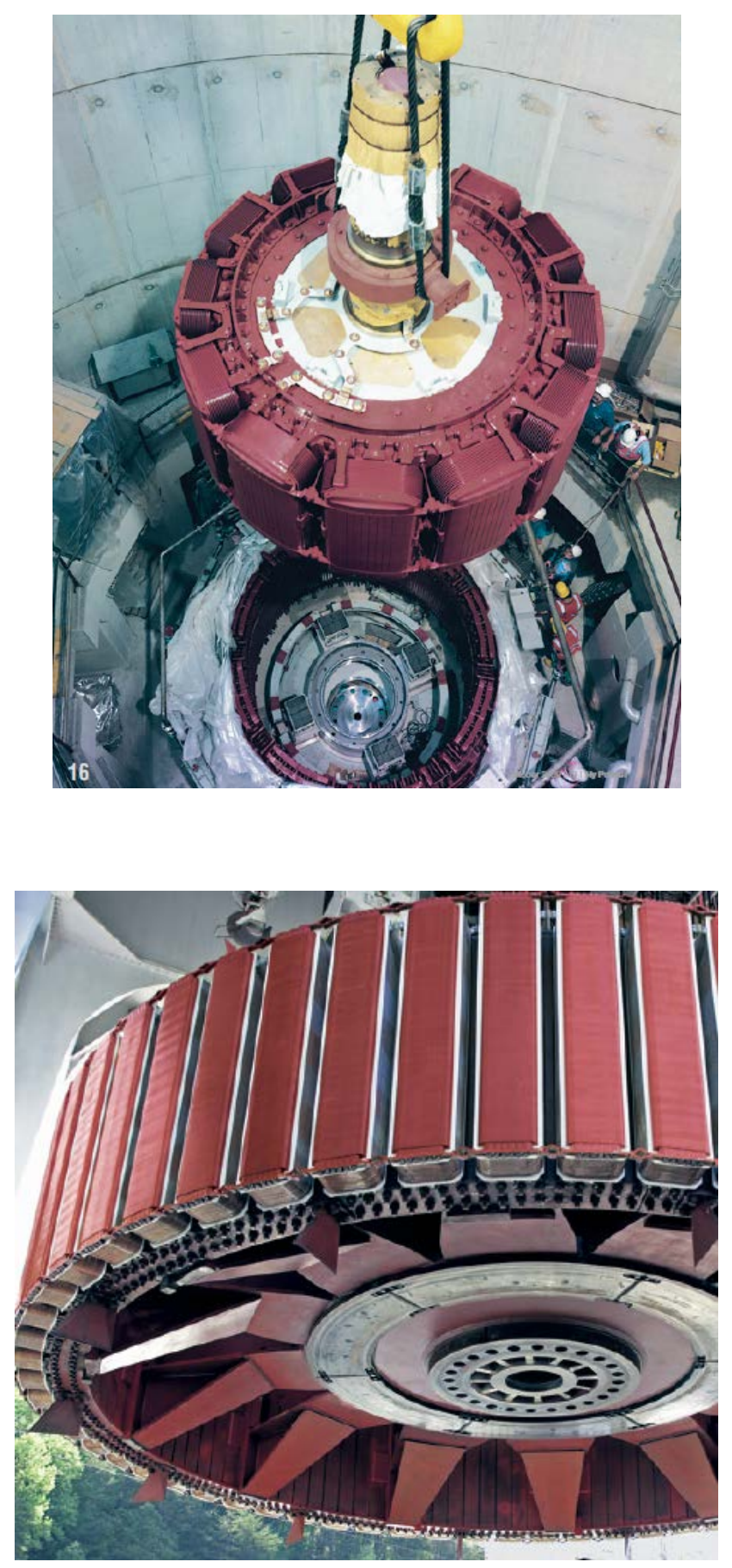

El flujo magnético creado por la corriente de excitación pasa a través del espacio entre el rotor y el estator $y$, al girar el rotor, induce en el devanado del estator una fuerza electromotriz que al aplicarla a un circuito exterior (la red) hace fluir una corriente eléctrica. 
No todos los alternadores de las centrales hidroeléctricas son síncronos. En las centrales de pequeña potencia suelen instalarse alternadores asíncronos o de inducción, que se caracterizan por no necesitar la corriente continua de excitación, sino que utilizan la propia corriente de la red para la creación del campo magnético.

Los alternadores de este tipo son más sencillos y económicos, características buscadas en las minicentrales al no poder utilizar éstas las economías de escalas que se tienen en las de potencias mayores. Estos alternadores tienen problemas de operación por lo que solo se utilizan para potencias pequeñas y para grupos que deban operar a velocidades altas. Por dar algunos valores, se utilizan para potencias inferiores a 1-3 MW y para velocidades superiores a 600-800 rpm.

La utilización de los alternadores asíncronos ha sido práctica habitual desde principios del siglo XX en las centrales de poca potencia.

Pero recientemente, en los últimos tiempos -a comienzos del siglo XI- este tipo de alternadores se ha empezado a utilizar en otras ocasiones, en grupos convencionales y en centrales reversibles.

Como ya se ha dicho, las turbinas convencionales operan con una velocidad de giro constante igual a la de sincronismo con la red. Para adaptarse a las necesidades de la red, puede variar la potencia entregada variando la apertura del distribuidor.

Esto no es así, por ejemplo, en los grupos turbobombas utilizados de forma generalizada en las centrales reversibles, en los que si bien en modo turbinación puede variarse la potencia entregada en cada momento, en modo bombeo el caudal operativo depende casi unívocamente del salto neto. En estas circunstancias si bien en modo turbinación generalmente se puede intervenir en el control de la frecuencia de la red, en modo bombeo no es así.

Esto puede conseguirse si se puede variar la velocidad de giro de los grupos, manteniendo evidentemente la frecuencia de la energía entregada o cogida de la red. Esta variación de la velocidad de giro permite además ubicar el modo bombeo a su punto de rendimiento óptimo, diferente del de turbinación.

Aun cuando el uso de la velocidad variable es objeto de desarrollo e implementación en estos momentos sobre todo en centrales reversibles, también lo es en grupos convencionales de turbinado, en los que esta técnica permite ubicarse cerca de los puntos de rendimientos altos para distintos valores de la carga o salto. 
De forma genérica, existen tres tipos de soluciones para conseguir esa velocidad variable en los grupos:

- Máquinas síncronas con regulación por cambio del número de polos.

- Máquinas asíncronas con rotor de anillos colectores, de doble alimentación.

- Máquinas síncronas con rotor o con estator (más habitual) alimentado con frecuencia variable por un convertidor de frecuencia conmutado con la carga.

La segunda de las soluciones ya hemos dicho que se ha utilizado de forma habitual en centrales pequeñas. Para potencias mayores se comenzó a experimentar en la segunda mitad de los 80. En España tenemos el ejemplo de la central hidroeléctrica de Compuerto, en el río Carrión, en Palencia. Dotada de dos turbinas Francis de eje horizontal y $600 \mathrm{rpm}$ de velocidad de giro, utiliza saltos comprendidos entre 63 y 102 metros. Inicialmente disponía de dos alternadores síncronos habituales con rotores de polos salientes, de potencias nominales unitarias 12,5 MVA. En el citado año se cambió en uno de ellos el rotor de polos salientes por otro asíncrono trifásico con anillos colectores, de potencia $10 \mathrm{MVA}$.

Puesta en funcionamiento en 1995, tras unos primeros años de ajustes, ha funcionado de forma satisfactoria y similar al otro grupo, con el que trabaja en paralelo. El grado de disponibilidad es también similar en ambos tipos de grupos.

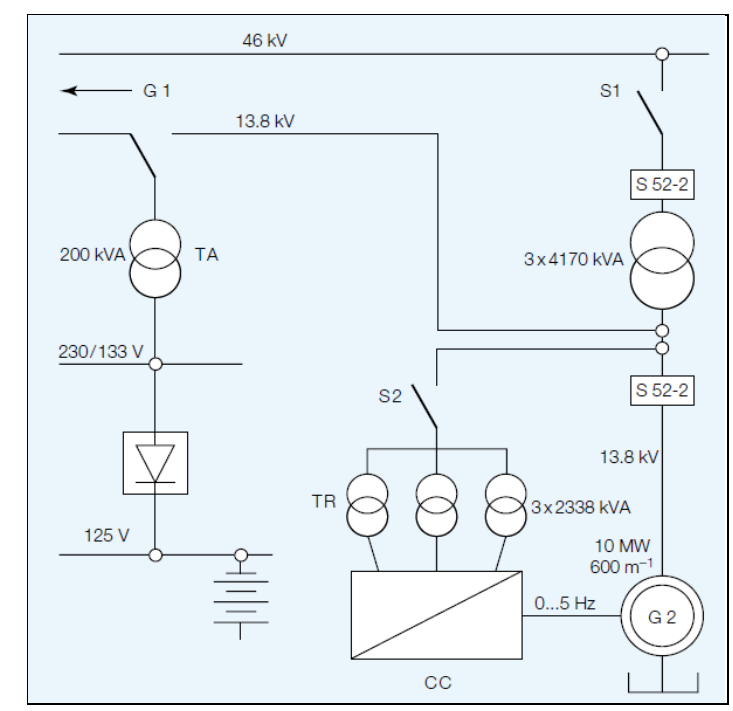



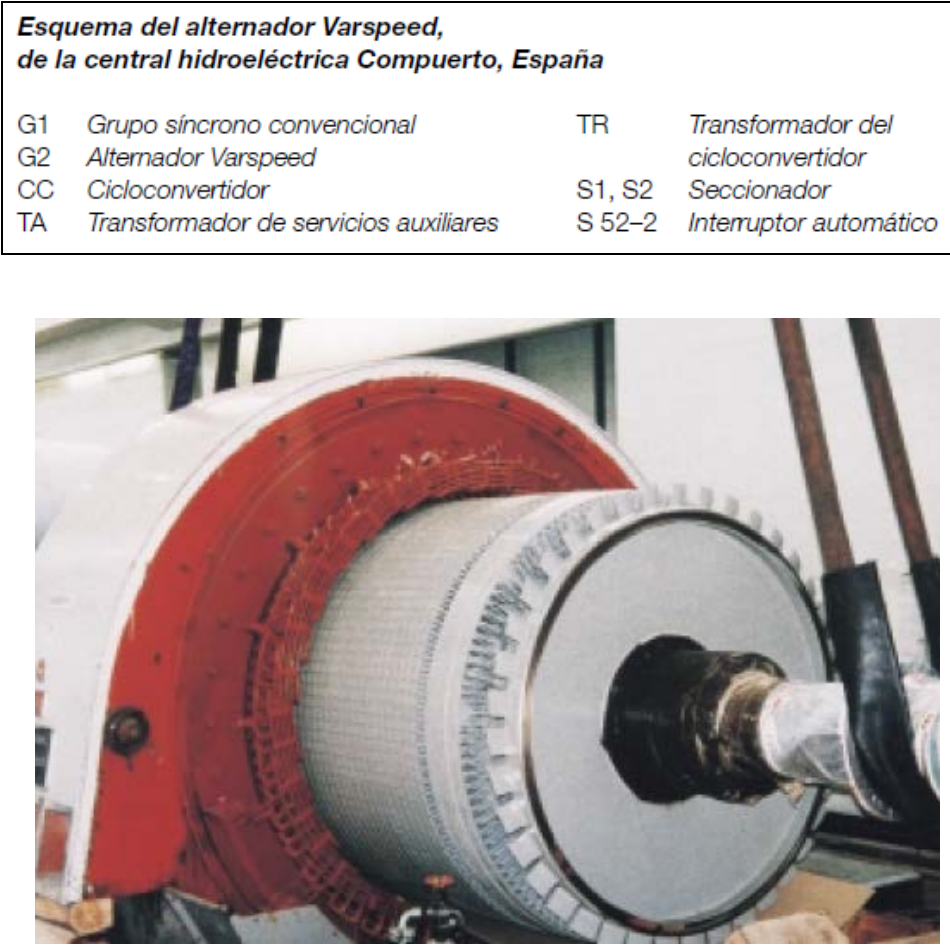

En el caso de alternadores de este tipo conectados a turbinas Pelton, se tiene el ejemplo reciente de la central de Forte Busso, con saltos variables entre poco más de 50 y 100 metros -en el límite inferior del rango de utilización de estas turbinas para caudales pequeños-

Para saltos pequeños, con caudales superiores a 4-5 m3/s la velocidad variable permite la sustitución de las turbinas Kaplan -más caras por su doble regulación- por turbinas hélice axiales, mucho más sencillas y económicas. Es el caso, por ejemplo, de los generadores del tipo ECOBulb o los Hydromatryx.

La tercera de las soluciones empezó a utilizarse a partir de los años 90 del siglo XX, sobre todo en Japón, destacando las centrales de Yagisawa (1990) con 3 grupos de 90 MW o la de Ohkawachi (1995) con 4 grupos de 320 MW.

Fuera de Japón la central reversible alemana de Goldisthal fue la primera en utilizar la velocidad variable. Inaugurada en 2003 tiene un salto de 338 metros y potencia unitaria de 325 MVA.

En este año de 2015 entrará en funcionamiento la central reversible de Frades II en Portugal. Dispone de dos generadores/motores de este tipo, con potencias unitarias de $385 \mathrm{MVA}$, lo que le convertirá en la central de este tipo de mayor potencia de Europa. 
Además de las ventajas ya señaladas, la velocidad variable permite por un lado tiempos de respuesta rápidos y flexibles a las demandas de potencia activa y reactiva de la red. Por otro lado, proporcionan mayor estabilidad en caso de caídas de tensión.

En unos momentos en los que las centrales reversibles juegan y jugarán cada vez más un papel decisivo en la regulación de los sistemas eléctricos, este tipo de grupos colaborará de forma aún más eficaz que los grupos clásicos.
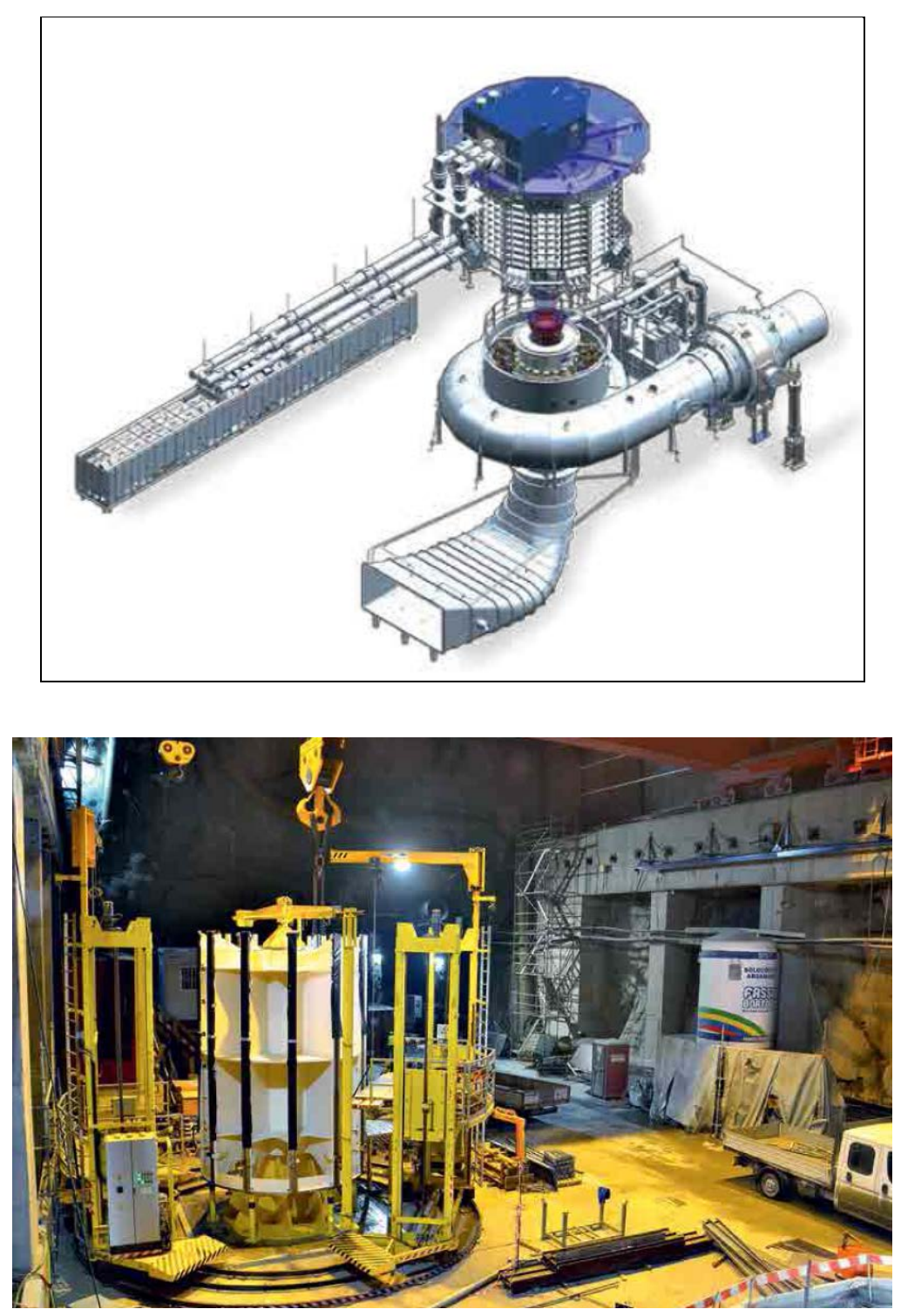

\subsection{LOS SISTEMAS DE EXCITACIÓN DE LOS ALTERNADORES.}

El sistema de excitación es el sistema de alimentación de corriente continua al rotor que necesitan los alternadores síncronos, tal y como se comentó anteriormente. Su evolución a lo largo de la historia de la energía hidroeléctrica tuvo un salto importante a partir de los años 60, y consistió en el paso de un 
sistema de rotativo de excitación a uno estático. A partir de entonces la evolución de estos elementos ha sido la lógica, con mejoras pequeñas pero continuas, características de una tecnología madura.

Los sistemas rotativos de excitación estaban generalmente formados por una excitatriz principal -una dinamo o generador de corriente continua- ubicado en prolongación hacia arriba del alternador, que se complementaba con una excitatriz auxiliar o excitatriz piloto.

En los sistemas de excitación estática la corriente continua se obtiene a partir de una fuente de corriente alterna, que se rectifica mediante rectificadores de silicio o tiristores, ubicados generalmente fuera del alternador. La toma suele hacerse de los transformadores de servicios auxiliares de las propias centrales. En algunas ocasiones se hace en un pequeño alternador síncrono ubicado en prolongación del alternador principal.

En este importante cambio influyó evidentemente la "electrónica de potencia", término que engloba a los dispositivos electrónicos utilizados en la transformación y cambio de corrientes y tensiones de valores significativos. La disponibilidad comercial de esta tecnología fue la que permitió a partir de entonces su generalización.

Este cambio tecnológico permitió ahorros económicos, pero sobre todo una mayor simplicidad en la disposición de los elementos en la central. Y esto a su vez cambió el aspecto estético de las "playas" o niveles de operación de las centrales. 

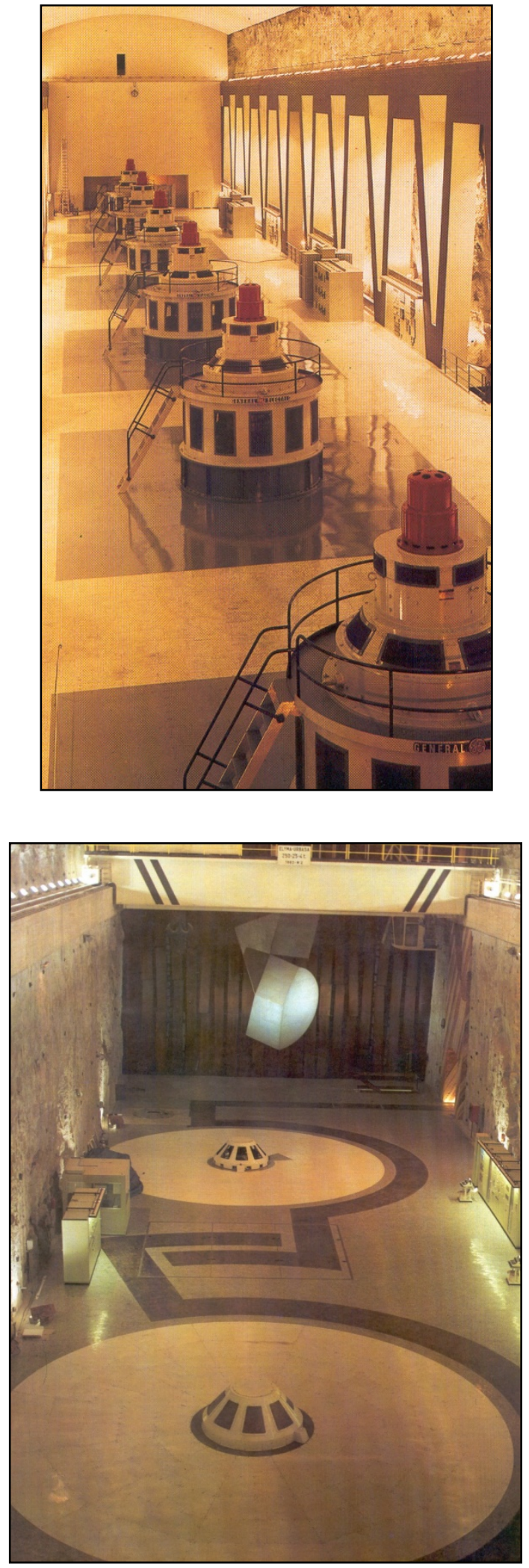

Las excitatrices rotatorias, ubicadas como se ha comentado por encima de los alternadores, era y es la parte más visible de los grupos hidroeléctricos. En la mayor parte de los casos el nivel de operación de una central coincide con el de su ubicación. Por debajo se situaban los niveles de alternador, y más abajo los de las turbinas. 
La utilización de las excitatrices estáticas, mucho más pequeñas, ha permitido liberar espacio, mejorando la operatividad de las zonas de maniobra. En cuanto al aspecto estético lo único que puede afirmarse es que ha cambiado el aspecto de forma radical. Se ha pasado de un aspecto más "industrial" y masivo a otro más limpio pero más "aséptico".

\subsection{EL TRANSPORTE DE LA ENERGÍA}

El transporte de la energía eléctrica se hace en corriente alterna y en alta tensión desde los primeros tiempos de la energía eléctrica. En corriente alterna debido al triunfo de los generadores de este tipo frente a los de corriente continua, al desarrollo de los transformadores y al desarrollo de los sistemas trifásicos, todo ello antes del cambio del siglo XIX al XX. Y en alta tensión debido a las menores pérdidas al circular intensidades menores por los conductores.

No obstante los primeros transportes se hicieron en corriente continua, en los momentos en los que aquella parecía que iba a ser la que se impusiese, cosa que evidentemente no ocurrió.

El desarrollo de los transformadores fue posiblemente la primera y directa causa del desarrollo de las primeras centrales hidroeléctricas. Hay que tener en cuenta que las primeras centrales eléctricas que suministraban energía a los alumbrados públicos eran centrales térmicas o motores de combustión que utilizaban petróleo, (grupos electrógenos), ubicados en las propias ciudades.

El mayor coste de explotación se compensaba con los mayores costes de la energía hidroeléctrica, ubicada lejos de los centros de consumo. Costes debidos no sólo a la construcción de las líneas, sino sobre todo por las pérdidas de potencia que se derivaban de la necesidad de transportarla a las tensiones que salían de los generadores, que era muy baja. En el momento en que esas tensiones se pudieron elevar, las pérdidas se redujeron y empezaba a ser factible el transporte a largas distancias.

De forma genérica el transporte ha sido desde entonces mayoritariamente en corriente alterna (HVAC). No obstante el transporte en corriente continua (HVDC) presenta una serie de ventajas, entre las que cabe señalar:

a) Mientras en la HVDC la potencia transmitida se mantiene prácticamente constante con la distancias, en la HVAC la capacidad de transmisión disminuye, debido a los efectos inductivos.

b) En la HVAC se producen desfases entre ambos extremos de la línea de transporte, debido a esos mismos efectos inductivos. 
Por otro lado, en HVAC no se pueden conectar distintos sistemas que funcionan a distintas frecuencias, casos en los que también se hace necesario el HVDC.

Desde un punto de vista económico existe una longitud crítica, por debajo de la cual las líneas en corriente alterna resultan ventajosas, mientras que por encima lo son las de corriente continua. Esta longitud es aquella en las que las ventajas de la HVDC -menores pérdidas y menores costes de la conducción- se igualan a los inconvenientes -incremento de costes de la conversión respecto de los de transformación-.

Por otro lado existen otra serie de ventajas no menos importantes a favor de la HVDC, como son la menor ocupación de espacio y los menores impactos ambientales.

Para poder hacer el transporte en corriente continua a partir de un generador o un sistema de corriente alterna a otro de las mismas características es necesaria hacer una conversión de un tipo de electricidad a la otra. Esto es posible gracias a la utilización de electrónica de potencia que permite rectificar ondas alternas y pasarlas a continuas gracias, de nuevo, a la electrónica de potencia. Esto se realiza en las "estaciones conversoras", que son centros en los que se ubican los siguientes elementos:

- Convertidores AC/DC (rectificadores) y convertidores DC/AC (inversores).

- Transformadores de conversión.

- Filtros AC/DC.

Ya en 1954 se construyó la primera línea comercial de corriente continua y a partir de entonces se ha ido desarrollando de forma continuada. Este primer sistema en HVDC se construyó entre Suecia y la isla de Gotland, con una longitud de 98 kilómetros, con una tensión de $100 \mathrm{kV}$ y una potencia máxima de 20 MW.

A partir de entonces el desarrollo fue continuado. Un hito importante fue el comienzo de la utilización de tiristores (válvulas en estado sólido), hecho que también se produjo en Gotland. Un año más tarde se utilizaron éstos de forma masiva en la interconexión Cabora Bassa-Apollo, que batió varios récord: el de mayor tensión (533 kV), el de mayor longitud (1420 km), el de mayor potencia (1920 MW) y el primero que instalaba válvulas de intemperie. Esta línea se ha ampliado recientemente y a partir de 2013 cuenta con una capacidad de transporte de $3.960 \mathrm{MW}$ a $600 \mathrm{kV}$. 
En 2004 ya se habían construido líneas de transporte de este tipo por un total de 70.000 MW de capacidad. En ese momento destacaban:

- La línea de Itaipú (1985) que conectaba la mayor central hidroeléctrica en ese momento con el sistema brasileño, con una capacidad de 6.300 MW y a una tensión de $600 \mathrm{kV}$.

- La línea T.Gorges - Changxhou, donde se instaló en 2002 el mayor convertidor, de una potencia de $1.500 \mathrm{MW}$ a $500 \mathrm{kV}$.

- El mayor cable subterráneo de este tipo en Murraylink, en Australia (2002), de 180 kilómetros de longitud y 200 MW de potencia.

- El cable subterráneo a mayor profundidad, entre Italia y Grecia, ubicado a 1000 metros bajo la superficie del mar.

- La línea Quebec-Nueva Inglaterra entre Canadá y Estados Unidos, uniendo sistemas asíncronos (de distinta frecuencia).

A partir de ese año los proyectos se han sucedido en todo el mundo, destacando los situados en China, con el fin de transportar la energía hidroeléctrica producida en las grandes centrales que se han construido y se construyen en lugares alejados de los centros de consumo.

En España en los últimos años se han utilizado esta tecnología en dos líneas de transporte: la que conecta la península con Baleares y la que conecta España con Francia.

La primera de ellas se trata de una línea submarina con 2 cables de alta tensión y uno de retorno, con 237 kilómetros de longitud y una potencia máxima de 200 MW por cable. Discurre a una profundidad máxima de 1.485 metros, tan sólo superada en Europa por la línea que discurre entre Italia y Cerdeña, que lo hace a 1.600 metros. Las dos estaciones conversoras se ubican en Morvedre (Sagunto - 400 kV) y Santa Ponsa (Calvía, Mallorca 20 kV). 

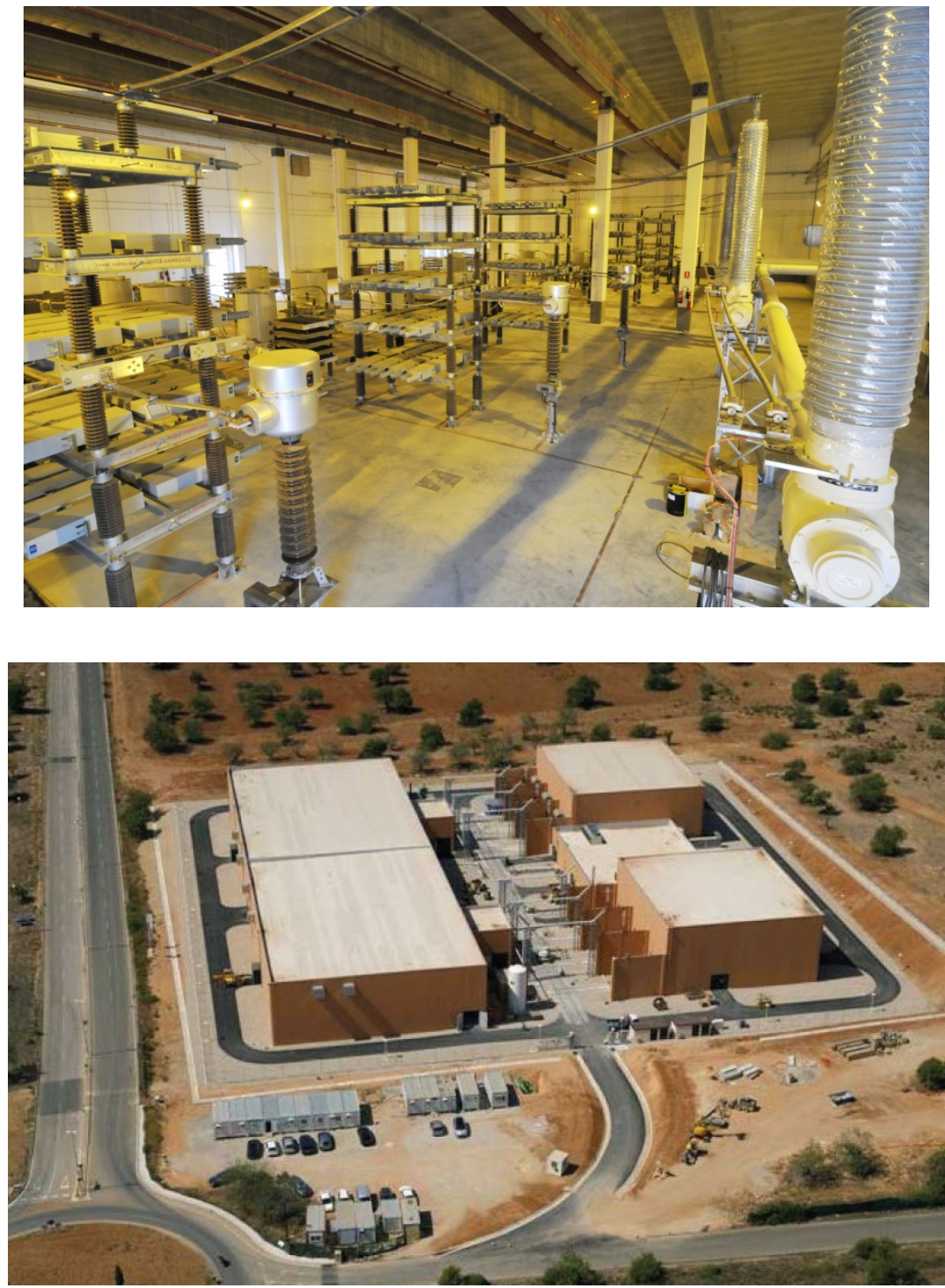

La anterior se inauguró en 2013. Poco después se ha tendido la línea de Mallorca a Ibiza, que en contraposición a la anterior se ha realizado en corriente alterna, con una potencia de $100 \mathrm{MW}$ en cada una de las dos líneas, de 126 kilómetros de longitud. La máxima profundidad alcanzada es de 800 metros, una de las mayores en líneas de corriente alterna en el mundo.

En 2015 se están terminando las obras de construcción de una nueva línea de interconexión entre España y Francia, que permitirá pasar de una capacidad de 1.400 MW a 2.800 MW. Se trata de una línea de 64,5 kilómetros que discurre entre la estación conversora de Santa Llogaia (España) y la de Baixas (Francia). De esta longitud 8,5 kilómetros discurren en túnel, mientras que el resto lo hace soterrada en zanja. La tensión de transporte es de $320 \mathrm{kV}$. Utiliza por primera vez en instalaciones de esta importancia la tecnología VSC, que parece será la de mayor desarrollo futuro. 



\section{Capítulo 4.}

\section{Evolución de la ingeniería de las presas hidroeléctricas}


En este capítulo se desarrolla la evolución tecnológica que se dio en las presas asociadas a los aprovechamientos hidroeléctricos. Para ello es necesario remontarse a los albores de estas estructuras de cierre en los que fueron los precedentes de las centrales hidroeléctricas posteriores, éstos son los molinos y aceñas. También se tendrán en cuenta las llamadas presas de "fuerza" por el aprovechamiento energético del agua a que dan lugar.

A partir de ahí, se avanzará observando y describiendo los cambios que sufrieron las tipologías y las características de las presas asociadas a molinos o centrales, a lo largo de los siglos hasta llegar a la actualidad.

\subsection{EDAD ANTIGUA HASTA LA EDAD MEDIA (3.300 A.C - 476 D.C)}

No son numerosas las referencias de presas de esta época cuyo fin (entre otros) sea el movimiento de molinos, o el uso de fuerza en general.

De los primeros años del S. I d.C. se tiene conocimiento de presas de origen romano, aunque incierto, cuyo uso era de Fuerza en Portugal, ésta es la presa arco de Monte Novo, y las presas españolas de gravedad de Melque I, II, III, IV y $\mathrm{V}$ en Toledo cuyo uso era abastecimiento y fuerza, y la presa de gravedad zaragozana de San Marcos destinada a riego y fuerza.

La presa de Monte Novo es de 5.7 metros de altura, 52 metros de longitud, 19 metros de radio de curvatura y ángulo central de $90^{\circ}$. Los materiales utilizados son bloques de esquisto colocados horizontalmente en mortero de cal.

La característica clave de la presa Monte Novo, en el sudeste de Portugal, fue que la parte curva de sus dos extremos descansaba en los estribos apoyando directamente en las laderas sin contrafuertes ni zócalos que absorbiesen los empujes de los arcos. Al parecer los constructores de la presa Monte Novo no confiaron por completo en su atrevido diseño porque unieron dos contrafuertes al paramento de aguas abajo. Hoy por hoy se encuentra sumergida en un embalse de nueva construcción. 


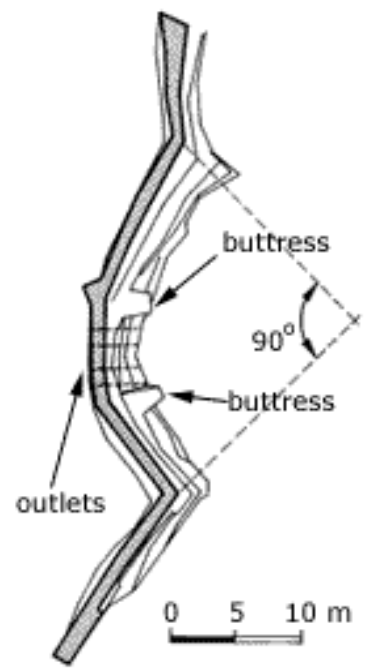

Las presas Melque en Toledo, todas ellas de gravedad, tenían las siguientes características:

\begin{tabular}{|c|c|c|c|}
\hline Nombre & Altura (m) & Longitud (m) & Ancho base (m) \\
\hline Melque I & 5 & 60 & 5.8 \\
\hline Melque II & 2.2 & 57 & 2.3 \\
\hline Melque III & 1.7 & 11 & 2 \\
\hline Melque IV & 9 & 60 & 14 \\
\hline Melque V & 6 & 40 & 4 \\
\hline
\end{tabular}

Y la presa de San Marcos en Zaragoza, era de 10.7 metros de alto, 33 metros de longitud y 2.2 metros de ancho de base.

\subsection{DE LA EDAD MEDIA AL S. XVIII}

Mientras que en la época romana y todavía hasta la época carolingia, en occidente, aparentemente sólo los pequeños ríos fueron equipados con molinos, a partir de la Edad Media, son los ríos más importantes para los que progresivamente se planifica cada vez más su aprovechamiento.

Los pequeños azudes que empiezan a realizarse surgen con el fin de elevar el nivel de agua de los ríos para crear la altura de salto necesaria en el sitio donde se colocan los molinos. De esta manera, las ruedas hidráulicas pueden estar implantadas al lado mismo aguas abajo del embalse o también pueden realizarse tomas desde el embalse para transportar el caudal de alimentación a los molinos a algunos kilómetros de distancia del embalse.

Por la influencia de las técnicas hidráulicas que existían en Oriente desde hace tiempo, se comienzan a construir sobre los grandes ríos, las presas cuyos 
embalses que alimentan un gran número de molinos. Un buen ejemplo es el río Guadalquivir.

Las aguas del río Guadalquivir conocieron algunos usos imprescindibles para el desarrollo de las actividades económicas llevadas a cabo en la Córdoba del siglo X. En primer término, destaca su empleo como fuente de energía hidráulica. Las instalaciones industriales que hicieron uso de ella estuvieron colocadas junto a presas de derivación que encauzaban la corriente hacia canales situados en las márgenes fluviales, donde se disponían las ruedas hidráulicas.

La primera mención que tenemos sobre tales presas procede del Ajbar Machmu'a, una colección de relatos compilada durante el siglo IX donde se menciona la existencia de la parada del Puente.

Sobre todo, después de la llegada de los musulmanes en el siglo IX, los conquistadores construyen en Córdoba un embalse sobre el río Guadalquivir, justo aguas abajo del puente romano. Este azud que alimenta doce ruedas hidráulicas, se construye con línea quebrada, colocando en cada uno de los tres ángulos que generan esos quiebros de línea, un molino equipado con cuatro ruedas.

Algo más tarde, en la segunda mitad del siglo X, el gran cronista cordobés Ibn Hayyan testimonia la realización de importantes obras de reparación de este azud, "con ramaje de jara traído de la sierra, grandes piedras, arena y arcilla pura".

Sobre estas presas se situaron los molinos hidráulicos que molturaban el cereal traído desde los cercanos campos de la fértil campiña cordobesa. Son varios los autores que hacen alusión a molinos harineros que funcionaron en la Córdoba califal. Tanto el Ajbar Machmu'a, ya citado, como el Fath al-Ándalus, relato anónimo compilado hacia principios del siglo XII, indican que el valí Abu-l Jattar, huyendo de los sirios en el transcurso de las luchas civiles que asolaron AlAndalus el año 748, se escondió en el molino de Kulayb, que puede ser identificado con el llamado de Culeb en documentos cristianos del siglo XIII; de igual forma, el documento de donación del molino de Martos por parte del monarca Alfonso X a la Orden de Calatrava, en 1257, indica que este molino había recibido en época árabe el nombre de Albolabez.

No fue la molturación de harina la única aplicación industrial que se benefició del uso de la energía hidráulica. Aunque se carece de menciones expresas sobre la existencia de batanes de paños o molinos papeleros en la Córdoba califal, alHimyarí afirma, en la descripción que realiza de la almunia de Nasr situada 
cerca de Córdoba y a la orilla del Guadalquivir, que dicha finca era también conocida como ahra al-hinna o "de los molinos de alheña", instalaciones donde se trituraban las cortezas de esta planta de amplio uso en el Islam medieval, en forma de polvo, para la realización de cosméticos, drogas y perfumes.

Mediante el Decreto 291/2009, de 30 de junio, se inscriben en el Catálogo General del Patrimonio Histórico Andaluz como Bien de Interés Cultural, con la tipología de monumento, los Molinos del Guadalquivir, en Córdoba.

En este Decreto, se recoge como anexo, una descripción de los mismos.

"Los Molinos del Guadalquivir comprenden once edificios independientes repartidos a lo largo del curso del río que cruza la ciudad. Los denominados Molinos de San Antonio, de Enmedio, Pápalo y de la Albolafia se encuentran situados muy próximos al Puente Romano y están conectados por la azuda árabe de Culeb; mientras que los de la Alegría, San Rafael y San Lorenzo, junto al Puente de San Rafael, comparten y se conectan por la azuda árabe de la Alhadra.

Aguas arriba del casco urbano se encuentran los de Lope García y Carbonell. El Molino de Martos se sitúa en la margen derecha del río Guadalquivir, cerca de donde estuvo situada la puerta de Martos de la muralla, de donde recibió el topónimo. Aguas abajo del casco urbano de Córdoba, junto al polígono la Torrecilla, se halla el molino de Casillas. La antigüedad de la mayoría de estos inmuebles se remonta a las épocas omeya y califal ( ${ }^{*}$ ), como atestiguan las crónicas árabes que mencionan los molinos ubicados en las azudas de Culeb y de Alhadra. Posteriormente, con la conquista cristiana, Fernando III se hace con la propiedad de éstos y los reparte entre las órdenes militares y religiosas, así como entre sus familiares y la nobleza. La mayoría de ellos, durante la época medieval y moderna, quedan en manos de la Iglesia. La Albolafia, Lope García y de Pápalo pasan al Convento de Jesús y María. El Molino de Martos, igualmente de origen árabe (conocido como Albolabez), fue de la Familia Real, si bien en el siglo XIII se donó a la Orden de Calatrava. El Molino de la Alegría y el Molino de Lope García fueron propiedad del Cabildo. En el siglo $X I X$, con la desamortización, la Iglesia es expropiada de estos bienes, pasando a ser de propiedad privada, a excepción de la Albolafia, San Antonio y de la Alegría que adquiere el Ayuntamiento de Córdoba.

Desde el siglo XIII hasta 1942 (cuando se prohibió la molienda artesanal) estos inmuebles han seguido funcionando y han sido readaptados a sus distintos usos, experimentando obras de restauración y de transformación. 
Por tanto, son edificios en los que se aprecia la huella de distintas épocas históricas.

Casi todos ellos han sido molinos harineros, de los siglos XIII al XVI. Varios de ellos compatibilizaron dicha actividad con la textil, introduciendo en ellos batanes, que respondieran a la demanda de la floreciente industria textil castellana. Aunque el desempeño de ambas actividades en tiempos de sequía entraba en competencia y en pleito por la ejecución en exclusividad.

En el siglo XIX varios de estos edificios se convirtieron en pequeñas centrales hidroeléctricas. Fue entonces cuando las piedras de moler y los mazos de batanes de las antiguas aceñas fueron sustituidos por las grandes turbinas de hierro fundido. Esta reconversión tuvo una corta duración, pues poco después su suministro resultó insuficiente y se sustituyeron por las grandes centrales asociadas a embalses. Actualmente, salvo el Molino de la Alegría, hoy Museo Paleobotánico de la ciudad, y el Molino de Martos, actual Museo Hidrológico, el resto están inactivos.". (*): Nota no incluida en el anexo: siglo VIII a XI.

También en el S. X, en Fars, una región al sur de Persia y aunque ya usaban las presas con fines de embalsar agua para el riego, se equipan también con presas para molinos. En el río Karun, en Shushtar, el embalse de Bulaiti alimenta los molinos instalados dentro de túneles excavados en la roca en cada estribo de la presa. En la misma región, en la ribera del río Kor, cerca de Shiraz, las presas de Amir y de Feizabad se equipan en el S.X. de 30 y 22 ruedas horizontales, respectivamente. Estos molinos son tipo aruba.

La presa de Amir se construye aproximadamente hacia el año 960 y poco después su construcción es descrita por el geógrafo al-Muqaddasi (945-1000) indicando que Adud al-Dawla que era el soberano reinante en aquella época en el sur de Irán e Irak, cerró el río entre Shiraz e Istakhr, gracias a un gran muro reforzado con plomo. El agua acumulada tras la presa constituyó un gran lago. En cada una de sus estribos había ruedas hidráulicas como aquéllas existentes en Khuzistan. Aguas abajo de cada rueda, había un molino que era una de las maravillas de Fars.

Era de 9 metros de altura, 103 metros de longitud, y tenía una sección transversal, con el paramento de aguas arriba vertical y el de aguas abajo con un talud 1/1,4, siendo el ancho de la base algo superior al doble de la altura. Los materiales utilizados fueron sillería unida con mortero de cal. Y servía de soporte a un puente. 
También se conoce la existencia de embalses por la realización de azudes en el S. XII en Oriente, gracias a la descripción que hace un peregrino andaluz llamado Ibn Jubayr de un embalse que permite alimentar al sistema de molinos situados en el río Khabour, afluente del Eufrates, en el sur de Anatolia.

Al principio del S. XII, tecnología similar a la indicada anteriormente se manifiesta al otro lado de los Pirineos con la construcción en el río Garona de la presa de Bazacle que junto con otras dos presas más pequeñas, permite alimentar más de 60 molinos-barco. Las presas cuya tipología era de pilotes de madera con piedras entre estos pilotes, permiten generar una alimentación de un flujo más fuerte en la ribera derecha donde se sitúan los molinos-barco. Sobre el año 1180 todos estos molinos-barco se sustituyen por molinos fijos de rueda horizontal, ya que los primeros se evidenciaron mucho más débiles que los segundos. En cualquier caso, en el Occidente medieval, unas instalaciones tan importantes como las de Bazacle no eran habituales.

A continuación se adjunta una tabla con las presas que alimentaban molinos de rueda horizontal en la Edad Media.

\begin{tabular}{|l|l|c|c|c|c|}
\hline \multicolumn{5}{|c|}{ CARACTERÍSTICAS DE LA PRESA } \\
FECHA & \multicolumn{1}{|c|}{ NOMBRE } & $\begin{array}{c}\text { No DE } \\
\text { RUEDAS }\end{array}$ & TIPO & $\begin{array}{c}\text { ALTURA } \\
\text { (m) }\end{array}$ & $\begin{array}{c}\text { LONGITUD } \\
\text { (m) }\end{array}$ \\
\hline S. IX & $\begin{array}{l}\text { Córdoba } \\
\text { (R. Guadalquivir) }\end{array}$ & 12 & mampostería & - & 425 \\
\hline S. X & $\begin{array}{l}\text { Feizabad } \\
\text { (R. Kor) }\end{array}$ & 22 & mampostería & 7 & 222 \\
\hline S. X & Amir (R. Kor) & 30 & mampostería & 9 & 103 \\
\hline S. XII & $\begin{array}{l}\text { Bazacle } \\
\text { (R. Garona) }\end{array}$ & $\begin{array}{c}12 \text { inicial } \\
24 \text { final }\end{array}$ & $\begin{array}{c}\text { Pilotes de madera y } \\
\text { piedras }\end{array}$ & - & 400 \\
\hline
\end{tabular}

A partir del S. XV, se multiplican sobretodo en Suiza y en España, las presas para molinos en los que los saltos son cada vez más grandes, de muchos metros hasta alcanzar más de la decena. A partir del S. XVI según una evolución que es paralela a la que se produce para las presas mineras y que se resume en la siguiente tabla: 


\begin{tabular}{|c|c|c|c|c|c|}
\hline \multirow[b]{2}{*}{ Date } & \multirow[b]{2}{*}{ Nom } & \multirow[b]{2}{*}{ Région } & \multicolumn{3}{|c|}{ Caractéristiques du barrage } \\
\hline & & & Type & \begin{tabular}{|c|}
$\begin{array}{c}\text { Hauteur } \\
(\mathrm{m})\end{array}$ \\
\end{tabular} & \begin{tabular}{|c} 
Longueur \\
(m)
\end{tabular} \\
\hline 1150 & Lucelle & Région de Bâle (Suisse) & Digue en terre & 4 & 70 \\
\hline 1170 & Bazacle & Toulouse (France) & Pieux en bois & $?$ & 400 \\
\hline 1424 & Biessenhofen & Saint-Gall (Suisse) & Digue en terre & 4 & 150 \\
\hline 1450 & Centro & S.-E. de Bologne (Italie) & Maçonnerie & 6 & 71 \\
\hline 1460 & Bommer & Saint-Gal (Suisse) & Digue en terre & 5 & 100 \\
\hline 1500 & Albuhera de Castellar & Au sud de Mérida (Espagne) & Maçon. avec contreforts & 19 & 100 \\
\hline 1500 & Kornthan & NE de Nurenberg (Allemagne) & Digue en terre & 5 & $?$ \\
\hline 1558 & Arroyo de la Luz & Province de Cáceres (Espagne) & Maçon. avec contreforts & 4,8 & 329 \\
\hline 1570 & Casillas & Trujillo, province de Cáceres (Espagne) & Maçon. avec contreforts & 8,7 & 80 \\
\hline 1610 & Kreuz & Saint-Gall (Suisse) & Digue en terre & 7 & 60 \\
\hline 1615 & Knaben & Saint-Gall (Suisse) & Digue en terre & 7 & 70 \\
\hline 1690 & Albuhera de San Jorge & Trujillo, province de Cáceres (Espagne) & Maçon. avec contreforts & 11 & 144 \\
\hline 1713 & Mannen & Saint-Gall (Suisse) & Digue en terre & 9 & 70 \\
\hline 1737 & Charca del Lugar & Cáceres (Espagne) & Maçon. avec contreforts & 6 & 268 \\
\hline 1744 & Lancho & Cáceres (Espagne) & Maçon. avec contreforts & 5 & 379 \\
\hline 1747 & Albuhera de Feria & Au sud de Mérida (Espagne) & Maçon. avec contreforts & $\begin{array}{c}20 \\
\text { puis } 22\end{array}$ & 149 \\
\hline 1749 & Monte Branco & Evora (Portugal) & Maçonnerie & 12 & $?$ \\
\hline 1755 & Las Charcas de Arce & Province de Cáceres (Espagne) & Maçon. avec contreforts & 5,2 & 259 \\
\hline $1755 ?$ & La Generala & Province de Cáceres (Espagne) & Maçon. avec contreforts & 9,3 & 198 \\
\hline 1780 & Penedos & Evora (Portugal) & Maçonnerie & 13 & 120 \\
\hline 1795 & La Charca de Gracia & Province de Cáceres (Espagne) & Maçon. avec contreforts & 6,6 & 238 \\
\hline Fin $x \mathrm{~V} 11^{\circ}$ & La Charca de Greña & Province de Cáceres (Espagne) & Maçon. avec contreforts & 7 & 240 \\
\hline Fin $x v I^{e}$ & Molino de Cabra & Province de Cáceres (Espagne) & Barrage-poids & 4,5 & 70 \\
\hline 1816 & Zalamea & Province de Badajoz (Espagne) & Maçon. avec contreforts & 17 & $?$ \\
\hline
\end{tabular}

Del Anuario de estudios medievales de diciembre del año 2011 se desprende, por ejemplo, que en la época bajomedieval existían numerosos batanes en la cuenca del Guadalquivir y en concreto en Córdoba, documentados por sus contratos de arrendamiento según protocolos notariales.

Los batanes se hallaban instalados en las paradas, presas o azudas, tanto del río Guadalquivir como del Guadajoz, donde también se ubicaron aceñas, molinos y norias. Estas presas, que cortaban la corriente para encauzar el agua hacia las orillas del río, a fin de conducirla y hacerla transitar por los canales donde se disponían las ruedas hidráulicas, pertenecieron a la tipología de las llamadas "estacadas", es decir, obras sostenidas sobre estacas de madera hincadas en el lecho de la corriente fluvial, que posteriormente se unían y rellenaban mediante ripio, cascajo y cal, formando una obra de mampostería. Sobre su construcción y reparación en los últimos años de la Edad Media se dispone de distintos testimonios, como el acuerdo firmado en junio de 1504 por Sancho González del Cañaveral, como tutor de los hijos de Pedro Fernández de la Membrilla, para liquidar cuentas con Juan Jiménez del Portillo, mayordomo de la hacienda de los dichos menores, entre las que se citaban 1.463 metros que había gastado en la azuda del batán, de la piedra, cal y estacas que en ellas se había puesto para su reparación. 
El río Eresma en Segovia, es otro ejemplo de la construcción de azudes o presas para obtener la energía que hacía mover las máquinas o ingenios que hoy forman parte de su patrimonio industrial, ligado al comercio de la lana, la pañería fina, los batanes, los tintes, molinos harineros luego convertidos en fábricas de harinas, producción de moneda, papel, loza, borra o hielo, que se van implantando en las orillas del río Eresma, cuyas aguas fueron finalmente utilizadas para la producción de electricidad.

La mención más antigua que se tiene de industrias ligadas al río, son los documentos de una concesión Real de los años 1122 y 1123 que se conservan en el Archivo de la Catedral. En ellos se hace donación al obispo de Segovia y a la Catedral de Santa María, de unas aceñas con su presa y unas tierras bajo el Alcázar, a orillas del río Eresma, otorgada por Alfonso I "El Batallador" y su esposa, la reina Doña Urraca, y confirmada posteriormente por Alfonso VII.

En otro documento posterior, fechado en 1186, el rey Alfonso VIII hace donación de una presa en el río Eresma al Monasterio de Nuestra Señora de los Huertos, de frailes premostratenses, que se encontraba en la Alameda. Esta presa derivaría el agua hacia las extensas propiedades del monasterio, que incluían una amplia huerta - la denominada huerta grande, también regada por otros manantiales cercanos - y un molino.

Esta presa podría ser la existente detrás de la fábrica de hielo, aunque, posiblemente modificada en época posterior. Serviría igualmente para el funcionamiento del molino de papel situado en el lugar que después ocuparon las fábricas de hielo y la antigua de borra.

Los azudes para aprovechamiento industrial del Eresma se construían oblicuos a la corriente y por consiguiente con mayor longitud que el ancho del río. Lo que se pretendía alargando la presa es que, en caso de crecidas, la lámina de agua que sobrepasara la coronación del azud tuviera la menor altura posible y por tanto, menor efecto destructivo. En la mayoría de los casos no sobrepasan los tres metros de altura.

Los constructores ponían especial cuidado en la parte superior del azud, su coronación, que se denominaba chapadura, que era la que tenía que aguantar el paso de la lámina de agua sin alterarse.

Los seis azudes comprendidos entre el que facilita la toma de la Cacera de Regantes, aguas arriba del Puente de la Loza, hasta el que conducía el agua para la Fábrica de Borra, al principio de La Alameda, presentan actualmente unas características constructivas muy similares: son presas constituidas por un 
fuerte muro de sección rectangular de algo más de tres metros de grosor y, en la mayoría de los casos, formado por dos hojas exteriores de sillería o mampostería bien trabada con relleno, entre las dos hojas, de cal y canto. Todos son, en mayor o menor medida y como era costumbre, oblicuos a la corriente.

Estos azudes, además de seguir las recomendaciones anteriores presentan una singularidad en su diseño: la forma en la coronación no está realizada por un plano horizontal, sino por dos planos inclinados, a modo de tejado a dos aguas, con el caballete paralelo a los paramentos de la presa. El faldón de aguas arriba es muy pequeño y el de aguas abajo mucho mayor. Esta forma hace que el agua, al coronar la presa, adquiera mayor velocidad y se aleje en su caída del muro de la presa para evitar el efecto de socavación.

Se podían construir de piedra o madera. Un magnífico ejemplo de este tipo de azudes es, por ejemplo, la "Tizona" que era aprovechado por los cuatro molinos de la calle de Los Molinos (molinos de La Presa, El Portalejo, La Peña del Pico y La Aceña). Respecto a la presa Tizona se tiene conocimiento de un hecho curioso que revela los problemas que había entre molinos colindantes. En 1491, Rodrigo de Mansilla, dueño del molino de Cabila por donación de los Reyes Católicos, está en pleitos con los herederos de Alonso de Guadalajara, dueños del molino siguiente - el que conocemos como La Perla-, por haber recrecido la presa -la que posteriormente se denominará Tizona- lo cual "diz que faze retenimiento e rebalsa e fase empalagar el calze y rodezno del dicho su molino de tal manera que non puede andar libremente segund y commo antes solia andar..." y como manifiesta que, al parecer, su molino es más antiguo que el de Guadalajara, los Reyes emplazan a los herederos que demuelan lo construido de más sobre la presa y además le paguen por las fanegas de pan que ha tenido de pérdida.

La Tizona está constituida por un fuerte muro de sección rectangular de algo más de tres metros de grosor, formado por dos hojas y con relleno de cal y canto. 


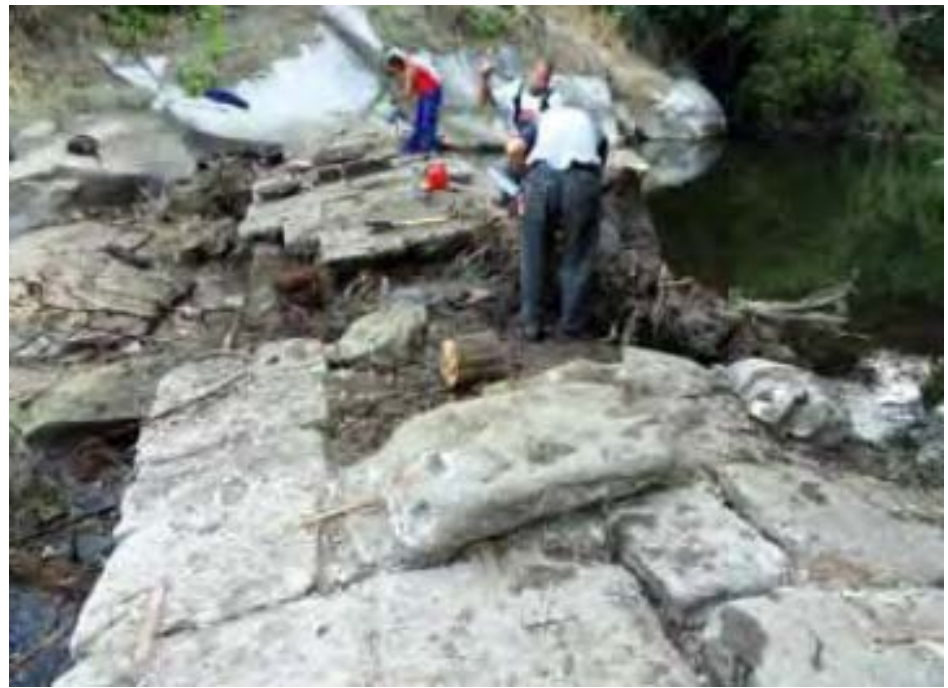

Reparación de la chapadura de La Tizona

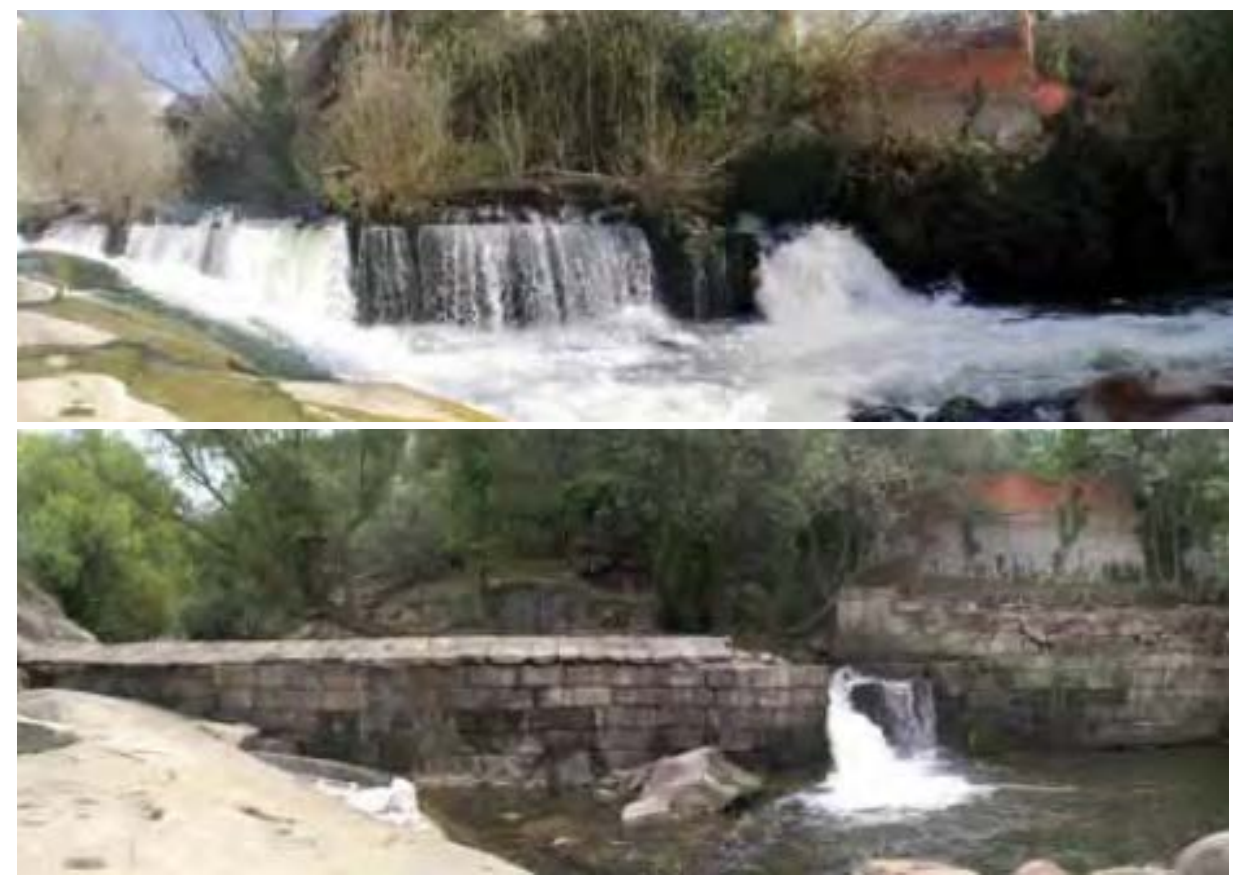

Las presas de los molinos se podían construir con piedra, con madera y piedra e incluso sólo con madera. Se sabe que al Bachiller Alonso de Guadalajara se le concedió madera del pinar de Valsaín para arreglar este azud en 1538 y en 1541.

El azud de la Casa de Moneda es un magnífico ejemplo de la tecnología hidráulica del siglo XVI. Su tipología es algo distinta a las presas situadas aguas arriba. Su sección tiene forma trapezoidal, con el paramento de aguas arriba vertical y el de aguas abajo formando un plano inclinado. Cuenta además con dos compuertas laterales que permiten aliviar la presa en caso de avenidas. Esta tipología nos remite a su primitiva reconstrucción cuando se edifica la Casa de Moneda. Es conocido que el primitivo molino de Antonio de San Millán contaba 
con su azud pero éste debía estar en mal estado y, por supuesto, no tenía la capacidad necesaria que requería la nueva ceca en construcción.

En vista de los documentos sobre la construcción de la Casa de la Moneda estudiados, la reconstrucción del azud fue total y no un simple recrecimiento. Se empezó desde los cimientos y se trabajó intensamente, incluso durante las noches de luna, por temor a una crecida del río que arruinara la obra empezada. La presa era de construcción mixta, con estructura de gruesas vigas de madera formando un entramado o cajas fijadas con grandes clavos, rellena en el interior y chapada en el exterior de piedra.

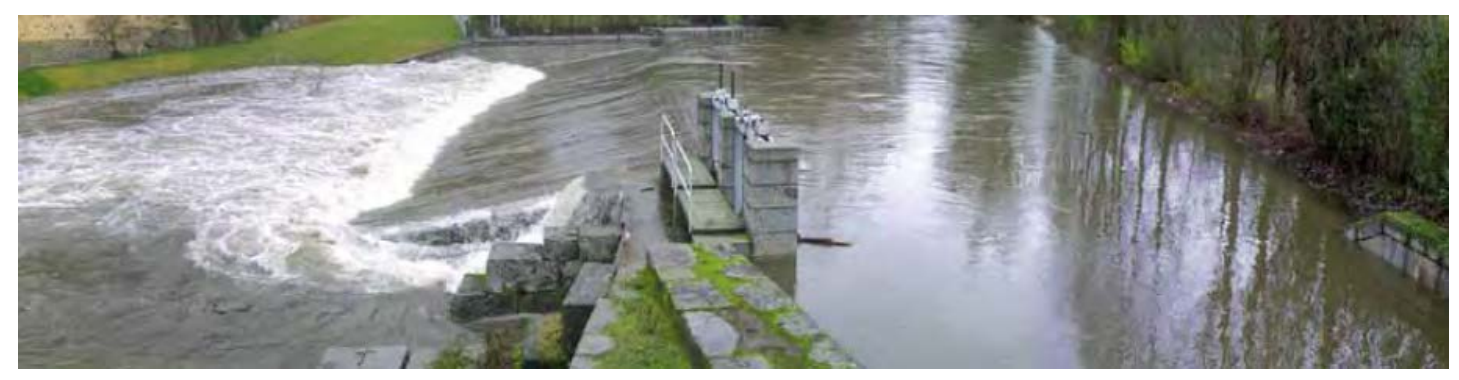

En 1995 el Ministerio de Obras Públicas, Trasportes y Medio Ambiente, a través de la Dirección General de Obras Hidráulicas y la Confederación Hidrográfica del Duero y a propuesta del Ayuntamiento de Segovia, acometen el acondicionamiento de dicho azud. Según se recoge en la publicación que se realizó, la rehabilitación era muy necesaria "presentando en el verano de 1994 un aspecto de total abandono, ya que incluso habían desaparecido la mayor parte de las losas de granito que cubrían el paramento de aguas abajo, así como la totalidad del pie del azud".

En la reconstrucción, apareció la primitiva estructura de la presa de madera y piedra que fue sustituida por los materiales actuales en esta clase de obras, si bien se mantienen las dimensiones y acabados primitivos.

Sin duda, el acondicionamiento del azud, fue la primera obra en la recuperación de la Casa de la Moneda de Segovia.

Las presas españolas son muy interesantes. Son ciertamente herederas de las técnicas romanas que pueden observarse en las presas que aún están en pie y en uso como Proserpina y Cornalbo en Extremadura, de 15 y 19 metros de altura respectivamente. En las regiones agrícolas alineadas con los grandes ríos (excepto el Duero) parece natural que se extrapole la antigua técnica de las presas romanas también para alimentar molinos. 
La presa de Castellar, en el sur de España, con su altura de 19 metros se mantiene durante largo tiempo como record de la presa más alta. El molino se construye justo al pie de la presa, con 3 ruedas horizontales alimentadas por 3 conductos verticales situados en el interior mismo de la presa de mampostería. Por desgracia, esta presa no está visible.

Es importante hacer una mención especial a las presas extremeñas, ya que ocupan un gran protagonismo entre las grandes presas construidas para proveer de energía a los molinos en Europa Occidental, entre los siglos XII y XVIII. Esta descripción se hace a continuación.

De época bajomedieval se tienen dos presas posibles, y una segura. Las dos posibles son la de Belvís de Monroy, asociada al castillo de dicha localidad, del siglo XV (aunque también se considera de posible origen romano) y la de Lancho (Alcántara), pues aunque la presa existente en la actualidad es de 1744, según una lápida existente en la misma, en dicha lápida se dice que la presa original se comenzó en 1398.

La presa bajomedieval sobre la que no hay dudas es la "presa del estanque de Guadalupe", asociada lógicamente al monasterio, y construida hacia 1420-1425. Está documentado que durante la visita a Guadalupe del Rey de Castilla Juan II (un Trastámara), el mismo navegó en una barca por el estanque (es decir, el embalse creado por la presa en el río Guadalupejo). Se trata de una presa de unos $15 \mathrm{~m}$ de altura, de contrafuertes, con diversos molinos (función primordial de ésta y muchas de las posteriores presas extremeñas) adosados aguas abajo del muro de presa, con una estructura de tres niveles y cierta complejidad arquitectónica.

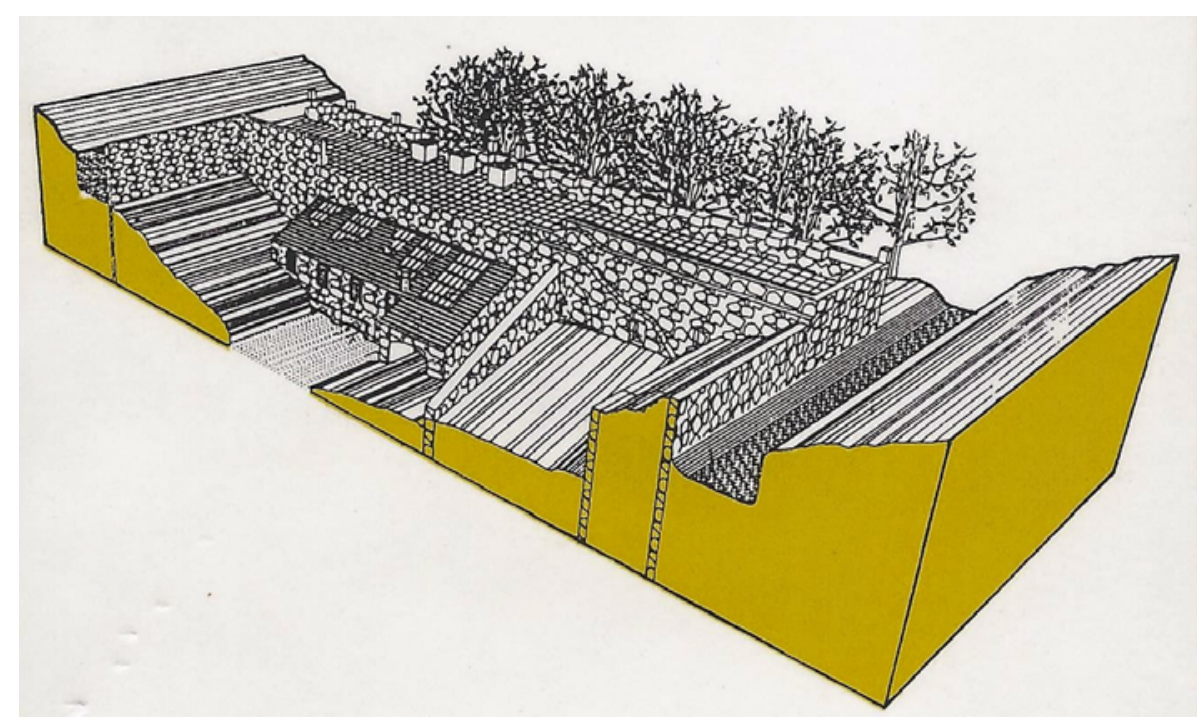


La presa del estanque de Guadalupe puede considerarse además la precursora de una "especie autóctona" de presas en esta región: las "albueras extremeñas". El término albuera, de origen árabe, es sinónimo de laguna, en referencia al embalse creado por la presa. Se trata de presas de fábrica (básicamente mampostería), con sección transversal más o menos rectangular (como la mayoría de las presas "precientíficas", es decir las diseñadas sin aplicación de los principios de la mecánica racional), en la mayor parte de los casos con contrafuertes y molinos adosados aguas abajo.

Una presa construida en 1558 (y recrecida en 1683) en Arroyo de la Luz, en Cáceres, que alcanza 4,8 metros de altura, tiene la chimenea vertical que alimenta el molino adosado al paramento de aguas abajo y es alimentado por la parte superior por una compuerta situado en la parte alta de la presa. Esta presa es la llamada Charca de la Luz.

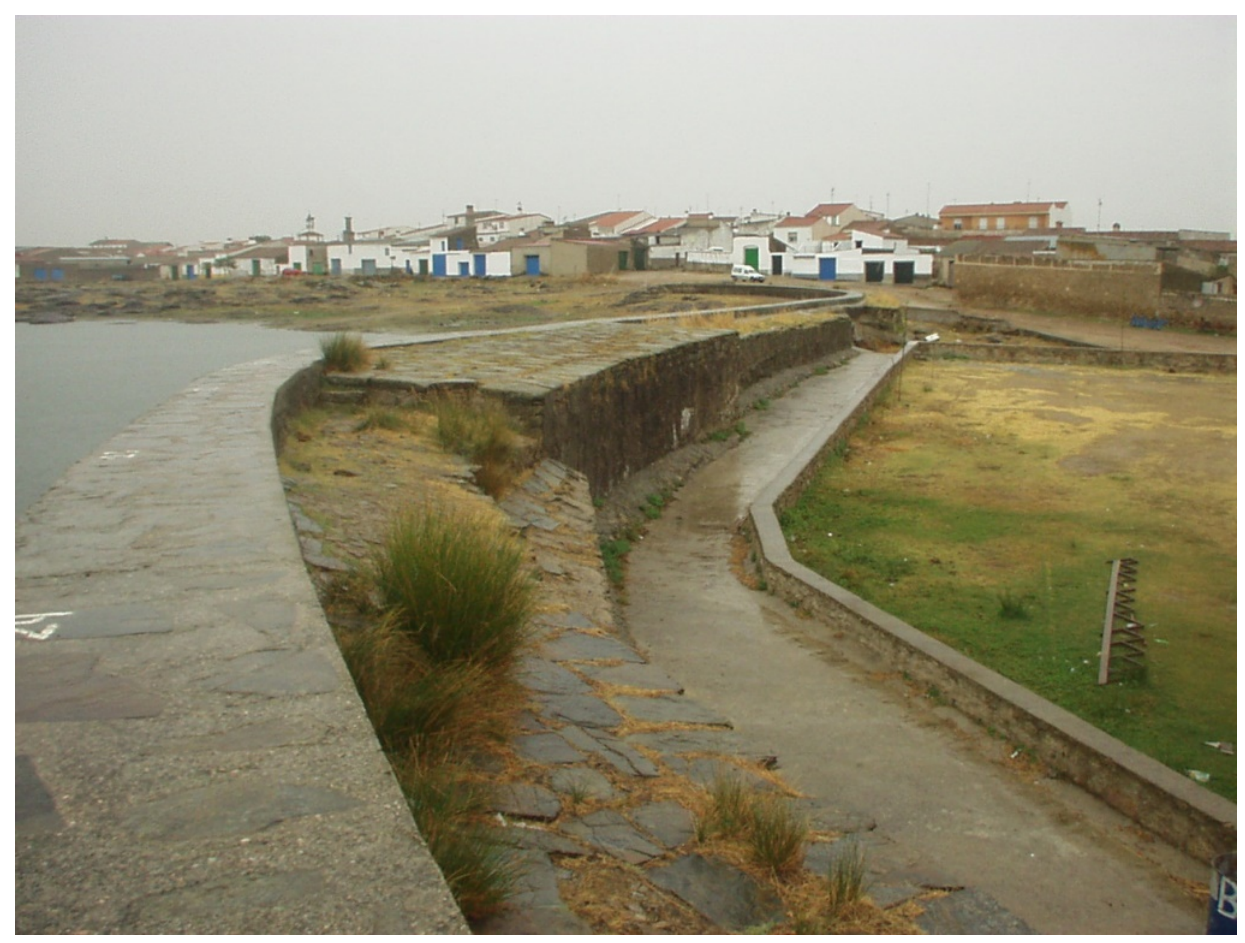



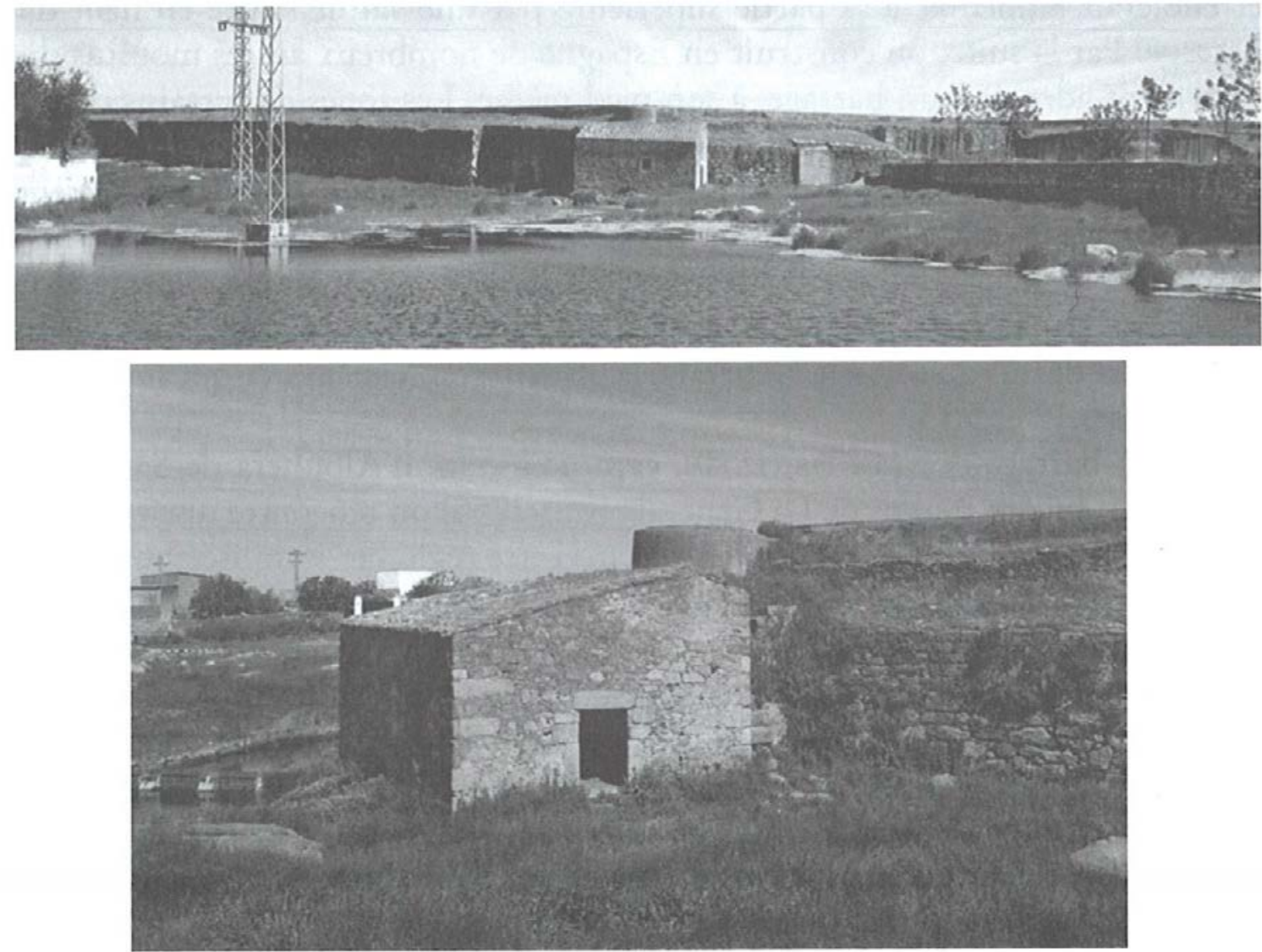

No hay que confundir la presa de Charca de Arroyo de la Luz con la presa de Arroyo de la Luz posiblemente de la misma época que la anterior, también con molino a pie de presa, pero que fue demolida y sustituida por la actual, en 1992 y destinada a abastecimiento.

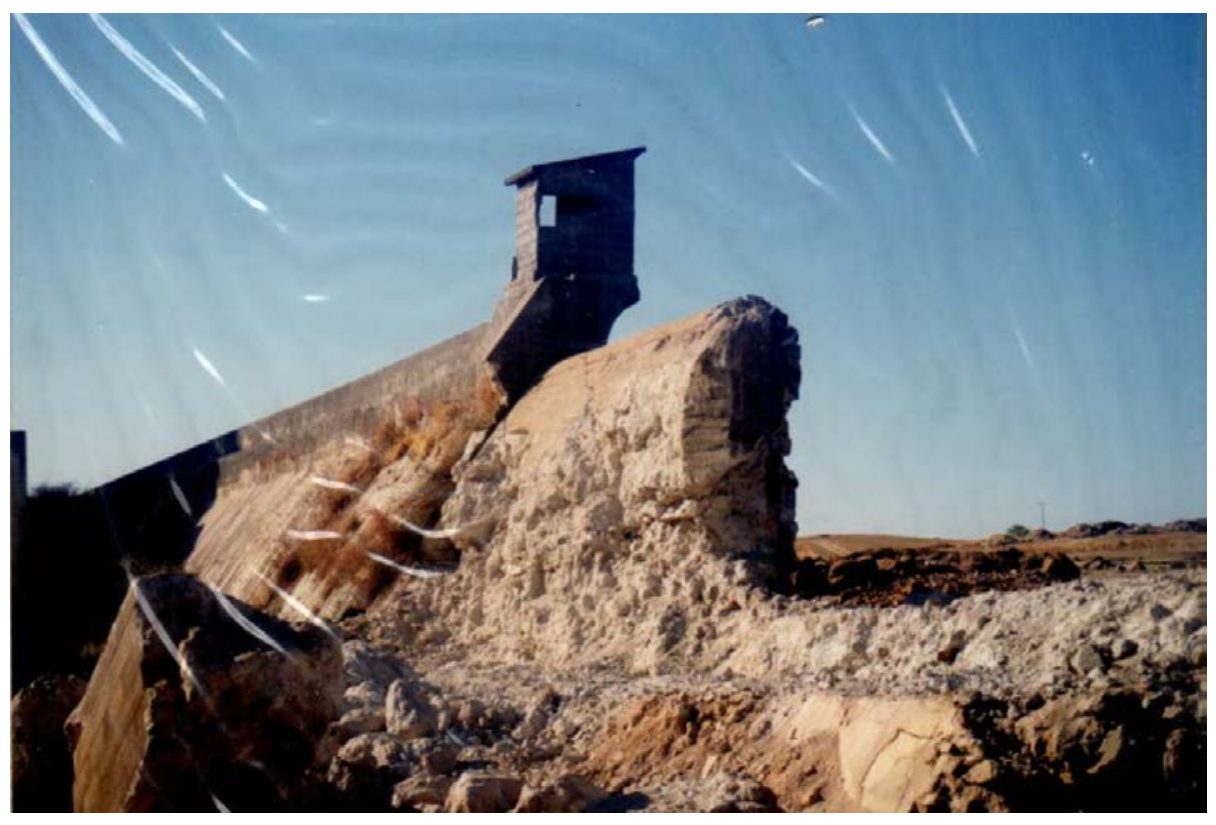



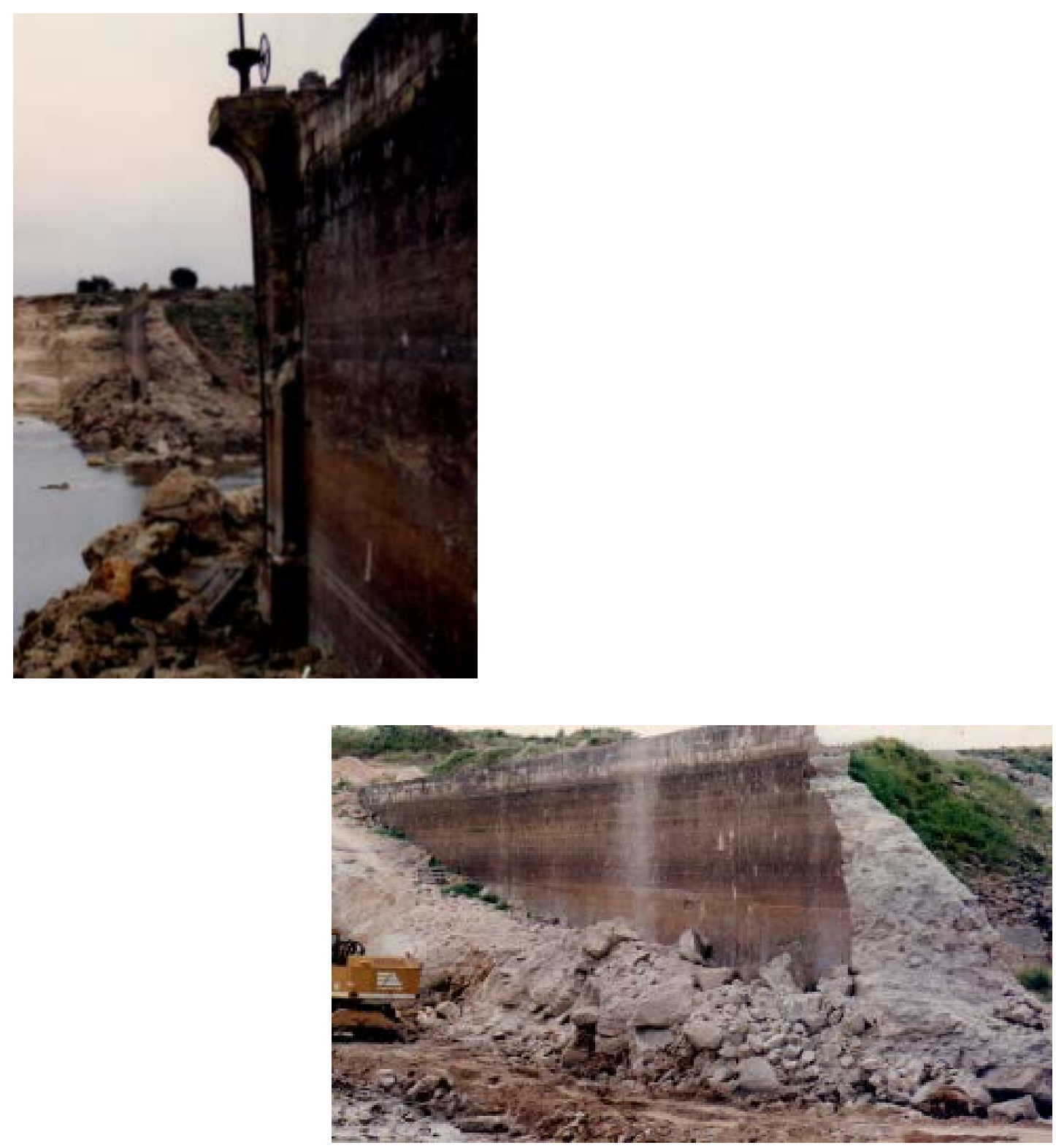

En las fotos de la obra de la nueva presa y en la fase de demolición, puede apreciarse la tipología de la presa original y los materiales que se utilizaron en la construcción de la misma.

En España, se construyen numerosos molinos directamente adosados a la presa, al pie de la misma. Algunos alimentados como en Charca del Arroyo de la Luz, y otros movidos por un chorro de agua a presión proveniente de una toma de fondo como en Casillas, en que el molino es alimentado directamente por un chorro de agua que provenía de una abertura situada a una profundidad de 5,5 metros respecto de la coronación de la presa, y 3,3 metros aproximadamente sobre el suelo. En La Generala el principio es el mismo y se muestra a continuación. 


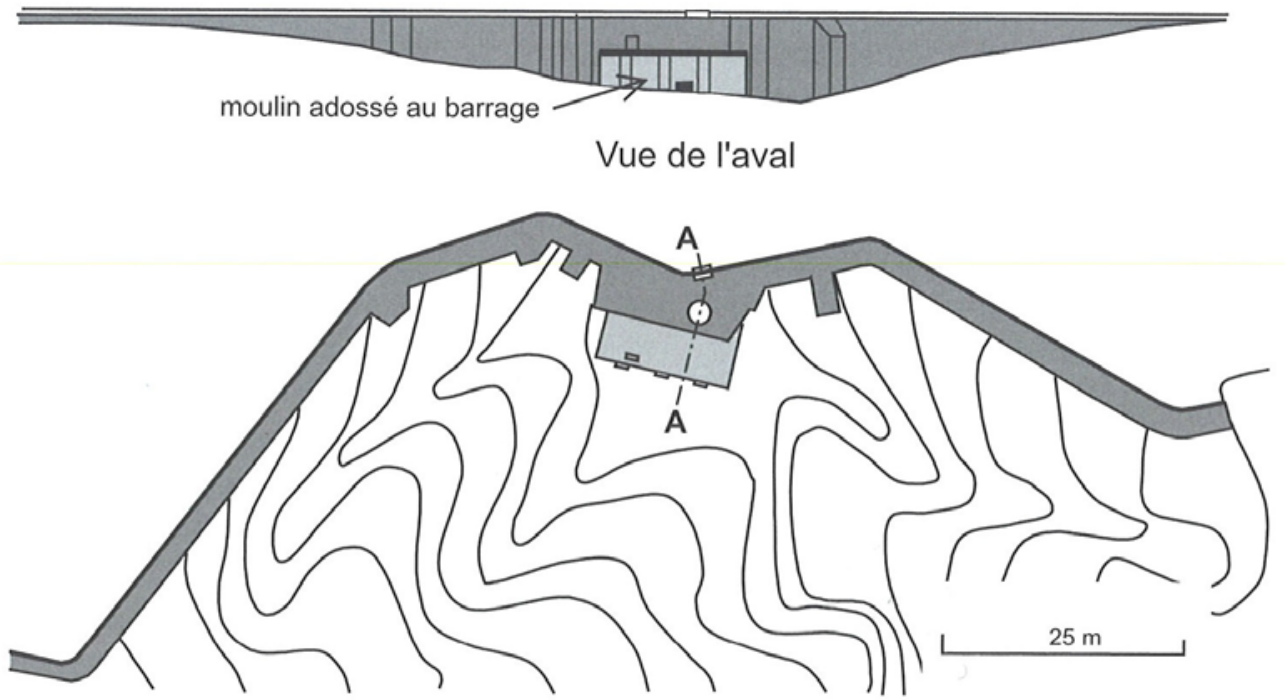

Vue de dessus

Figure 5.12. Le barrage de la Generala et son moulin adossé, vers 1755 (Fernandez Ordonez, 1984).

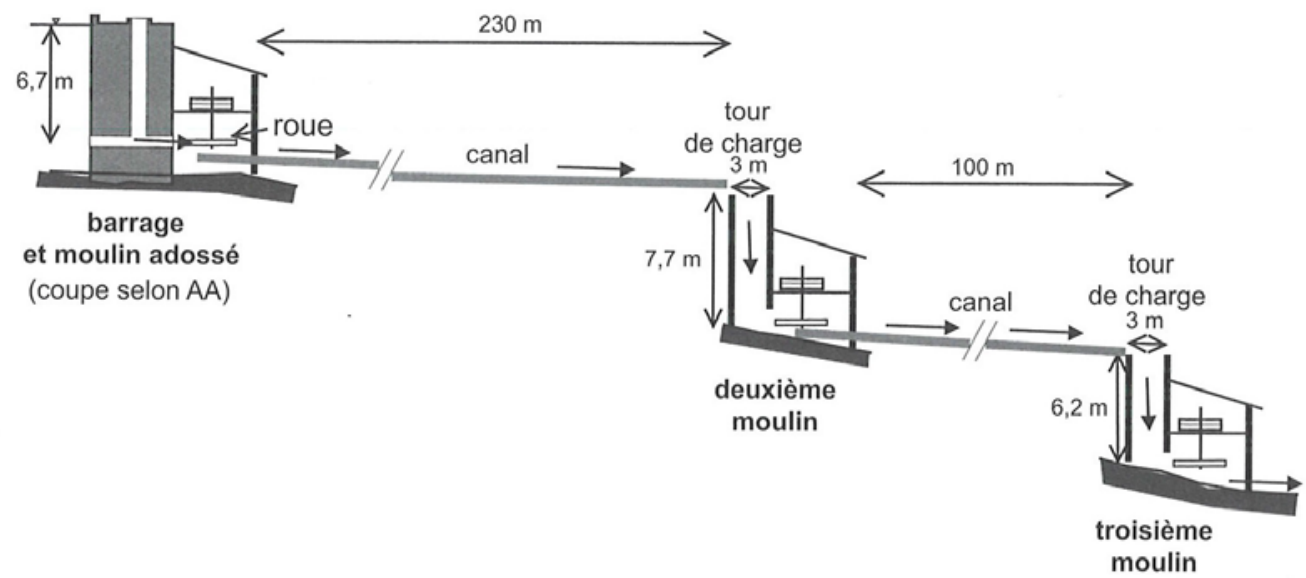

En la presa de Casillas (1570), como en la de Albuhera de San Jorge (1690), y en La Generala (hacia 1755) se encuentra una configuración bien típica, de aquí en adelante clásica para esta región, y establecida por 3 siglos. Es similar al indicado en la figura anterior. Hay un primer molino que está adosado a la presa, el agua que sale del molino es recogido por un canal, construido de manera que conserve un nivel suficiente para alimentar un segundo molino, y lo mismo ocurre con un tercer molino situado más aguas abajo.

Los dos molinos de Albuhera de San Jorge, así como los de la Generala, son alimentados por una chimenea vertical siendo las alturas del salto de estas chimeneas del orden de 6 a 7 metros. Estos molinos son del tipo arubah cuyo 
origen se remonta al Oriente romano, un tipo muy reproducido en el mundo medieval musulmán.

La mayor de todas estas presas es la de Albuhera de Feria, una gran presa de 22 metros de altura, construida en 1747 para alimentar los molinos de la región, y recrecida un par de metros en el año 1800.

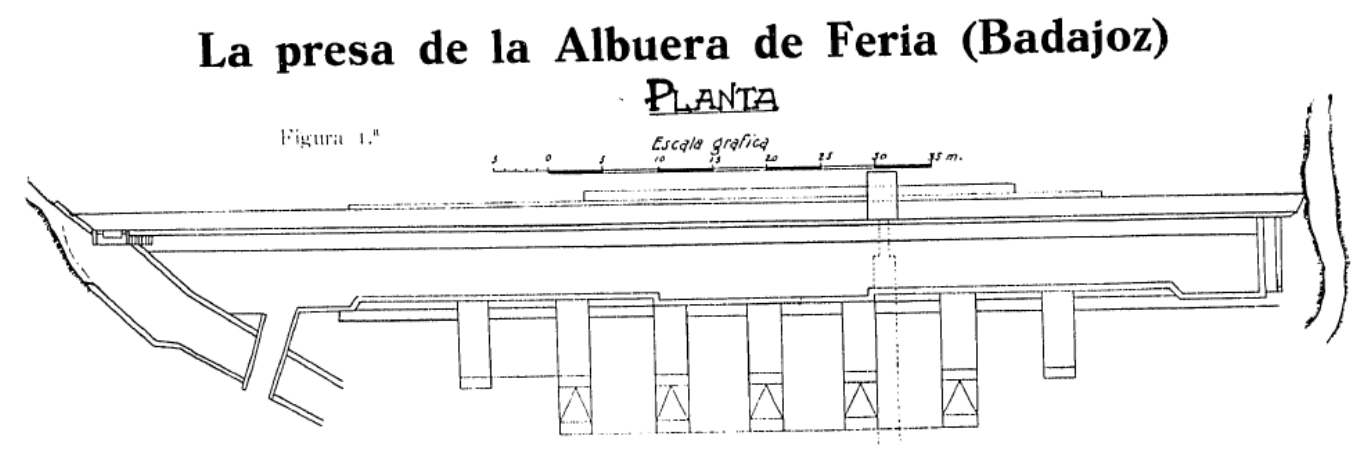

Fue construida en el año indicado por el obispo D. Amador Merino Malaquilla, según aparece en datos existentes en un convento de monjas de Badajoz. Cierra el valle de un pequeño arroyo y en principio, todo apunta a que se construyó para accionar un molino harinero que sirviera a los pueblos próximos, Feria y La Parra.

Un molino de fecha indeterminada es adosado en el paramento aguas abajo de la presa, utilizando como muros laterales dos de los contrafuertes de la presa, distantes 9 metros, de tal manera que da la impresión de estar el molino totalmente embebido en el interior de la estructura de la presa.

Dos molinos situados más aguas abajo son alimentados por una toma de agua. Un pequeño canal de derivación termina en una cámara de carga de fábrica con contrafuertes que recuerdan algo a la estructura de la presa, estando el edificio del molino adosado a dicha cámara.

Un poco más tarde, esta presa será equipada con una turbina para producir electricidad para dotar de ella a los pueblos de la región.

La estructura de la presa consiste en un muro de paramentos sensiblemente verticales, el de aguas arriba con retallos como se aprecia en el perfil trasversal adjunto. También hay un retallo en el paramento de aguas abajo. Adosado al muro de aguas abajo hay contrafuertes de 3,20 metros de espesor que contribuyen a estabilizar la obra. 


\section{PERFIL TIPO}

\section{Escala 1:300}

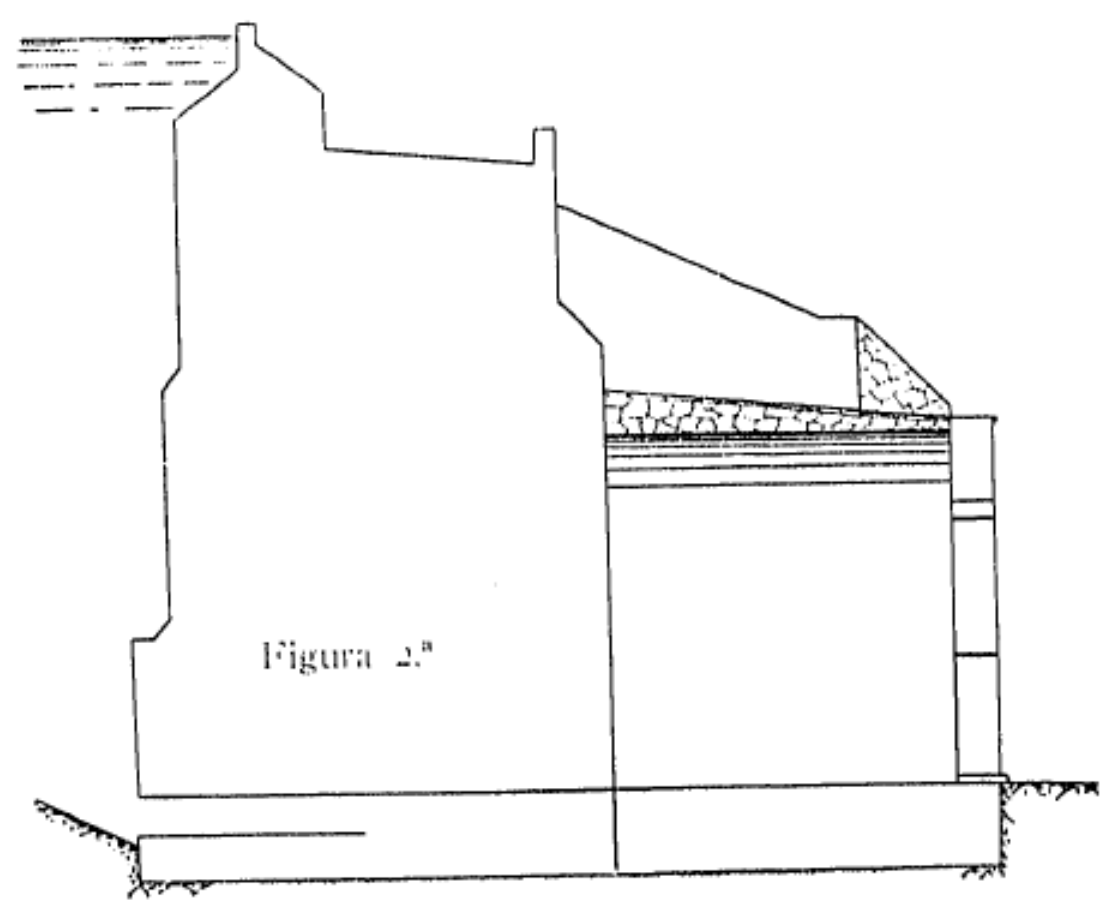

La entrada de agua al molino se hacía por un tubo embebido en el macizo de la presa que la atravesaba, hoy taponado. Existe un desagüe de fondo con una compuerta metálica colocada posteriormente. Tiene un aliviadero a cada lado del valle, mayor el de la margen derecha, y construido muy posteriormente. Parece ser que en el año 1950 se hizo alguna actuación en la presa.

La coronación de la presa tiene un pretil de gran espesor que parece un recrecimiento posterior y sobre el cual existen unos remates. La presa es de mampostería con mortero de cal.

Los espacios entre contrafuertes se han cerrado por delante con un muro de fachada y cubierto con bóvedas, sobre las que se apoya un enlosado inclinado para facilitar la salida de aguas pluviales. De esta manera, quedan una serie de locales habitables. Uno de ellos parece ser que fue capilla. 


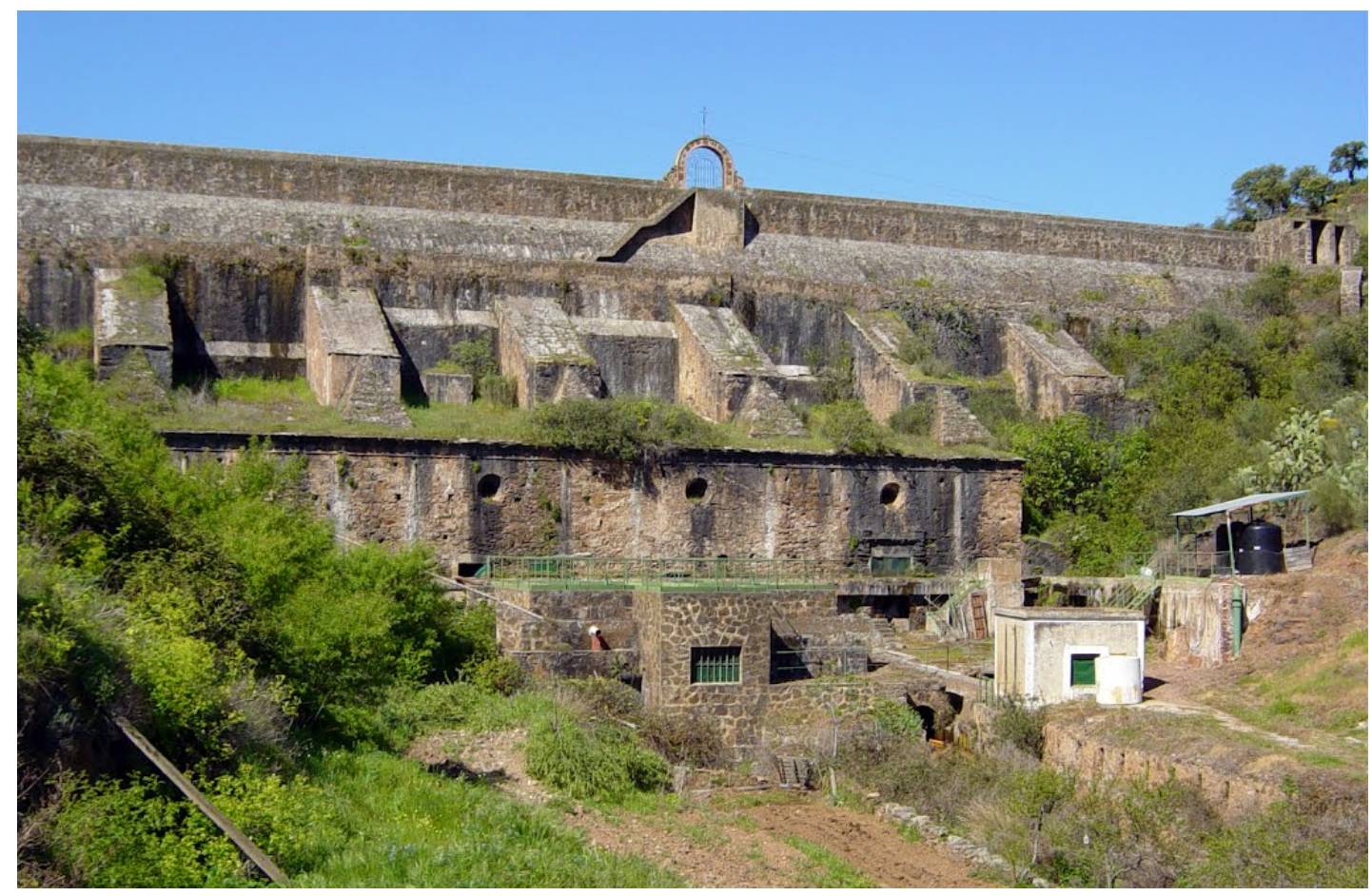

Se construyeron entre los siglos XVI y XIX, y por orden cronológico, las más importantes son las siguientes:

La Albuera de Castellar, en Zafra, con unos 19 m de altura, construida en 1500. Actualmente esta presa está sumergida bajo las aguas del embalse de Zafra, construido en los años 70 del siglo XX para abastecimiento de dicha localidad.

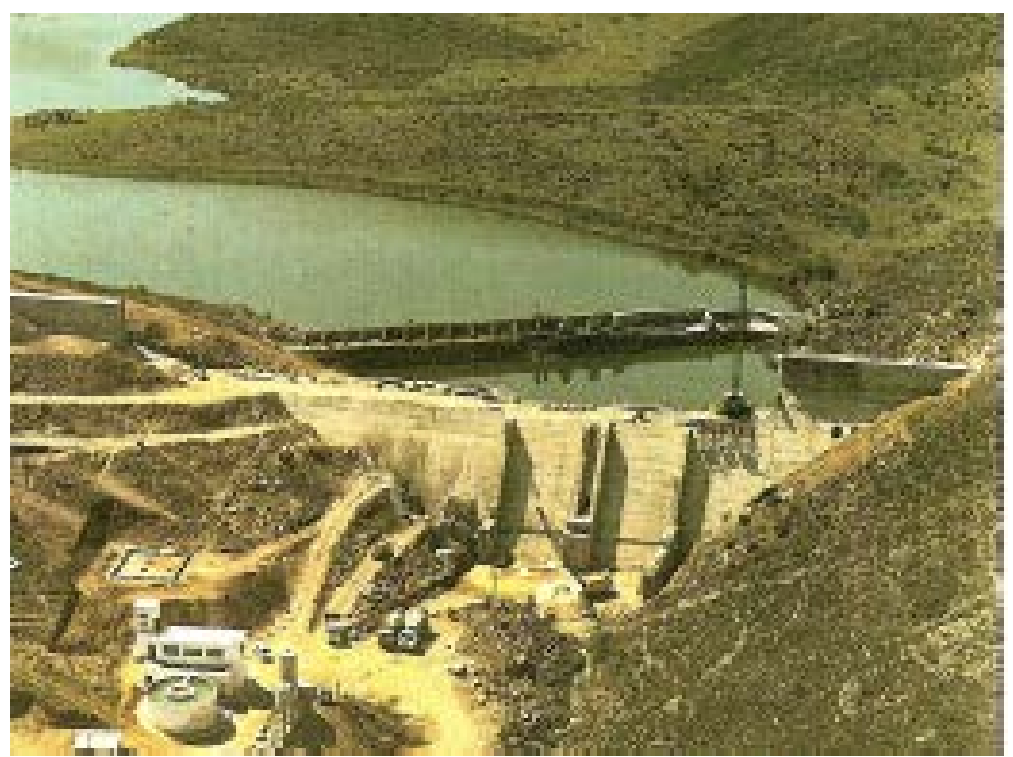

Presa de Zafra, en construcción, y detrás la presa de La Albuera de Castelar

La Albuera de San Jorge, en Trujillo, con unos $11 \mathrm{~m}$ de altura, construida hacia 1577 según consta en una lápida situada sobre la puerta del molino adosado a la presa. 


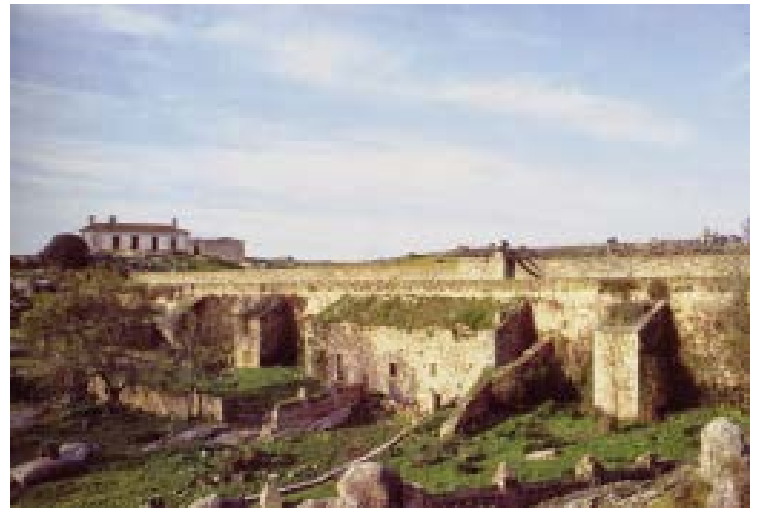

La Albuera de Casabaya, en Jerez de los Caballeros, con unos $16 \mathrm{~m}$ de altura, y datada a finales del siglo XVII.

La Albuera de Feria, cerca de la localidad de dicho nombre, con unos $24 \mathrm{~m}$ de altura, construida en 1747 a instancias del Obispo de Badajoz, D. Amador Merino Malaquilla, según está documentado, y como ya se ha descrito con anterioridad.

La Presa de Zalamea, en Zalamea de la Serena, de $17 \mathrm{~m}$ de altura, construida entre finales del siglo XVIII y principios del XIX (fecha del Inventario: 1816), que aunque se llame habitualmente "presa" (o a veces "charca") y no "albuera", pertenece claramente a este grupo.

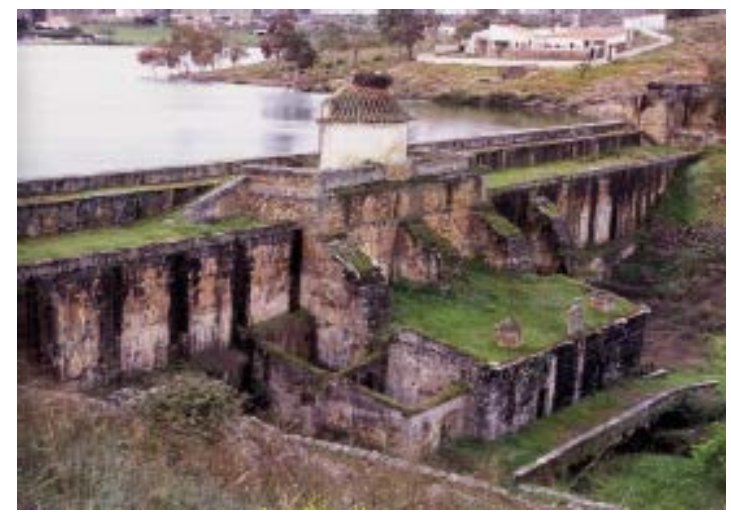

Además, se construyeron otras presas de características similares, aunque algo más pequeñas (alturas entre 4 y $9 \mathrm{~m}$ ), denominadas por lo general "charcas", Entre los siglos XVI y XVII la Charca de Arroyo de la Luz, y durante el siglo XVIII, también en la zona entre Cáceres y Alcántara las de la Charca de la Generala (Cáceres), Charca del Lugar, Barrueco de Arriba y Barrueco de Abajo (Malpartida de Cáceres), Arce de Arriba, Arce de Abajo y Greña (Brozas), García (Villa del Rey) y la ya citada, por su posible origen medieval, de Lancho (Alcántara). Entre este grupo hay que citar también la presa de Casillas 2 (Valdefuentes) datada en el siglo XVI, que debió de ser una omisión en el 
Inventario de 1986, de forma que la designada en el mismo como "Casillas 1" es posterior (fecha del Inventario: 1870).

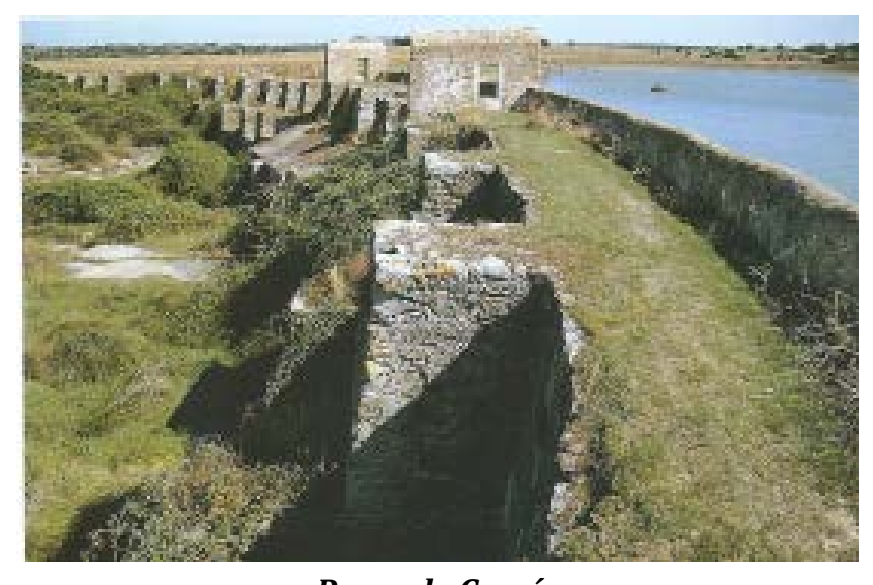

Presa de García

Mención aparte merecen dos presas, sobre las que prácticamente no existen fuentes bibliográficas, y que suelen considerarse romanas, aunque realmente no lo parecen, al menos la parte actualmente visible de las mismas.

Una de ellas es la presa de la Charca del Bercial, sobre el río Guadámez, en Campillo de Llerena, de unos $9 \mathrm{~m}$ de altura, con contrafuertes, en la que la parte de la presa observable actualmente parece haber sido realizada entre los siglos XVI y XVIII.

La otra ni siquiera tiene un nombre "oficial”, nombrándose por lo general "presa de Loriana" o "presa de Lorianilla", e incluso también llamada por los lugareños "presa del molino del Cura". Se encuentra en Puebla de Obando, sobre el arroyo Valhelechoso, tributario del arroyo Lorianilla. Y se cree que lo más probable es que esté relacionada con el Monasterio de San Isidro de Loriana, que existió entre 1551 y la desamortización (1836), y cuyas ruinas (lamentablemente en pésimo estado y absoluto abandono) se encuentran en las proximidades. No es descabellado suponer a la presa coetánea del monasterio primitivo, y por tanto datarla a mediados del siglo XVI.

Se trata de una presa de unos $7 \mathrm{~m}$ de altura, con el paramento de aguas abajo vertical (con un pequeño escalón), sin que se aprecien contrafuertes. El embalse está totalmente aterrado, saltando el arroyo sobre la coronación de la presa, lo que ha originado una charca aguas abajo, dando lugar a un paraje de gran belleza. 


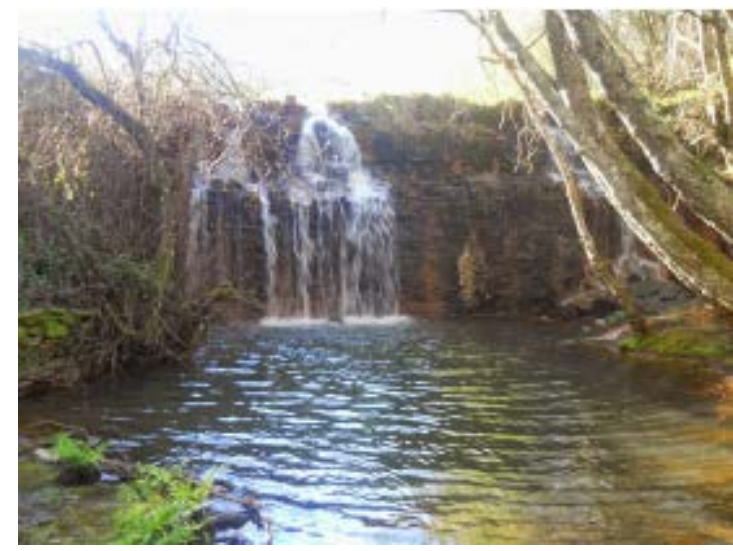

Presa de Lorianilla vertiendo el arroyo sobre la misma

No solo se construyen presas nuevas, sino que se restauran las existentes para poder seguir siendo aprovechadas. En este sentido cabe citar la importante restauración del paramento de aguas arriba de la presa de Proserpina, realizada a principios del siglo XVII. Se ha especulado mucho con una posible restauración integral de la presa de Cornalbo a cargo del Conde de Campomanes, a finales del siglo XVIII, pero nada se ha podido demostrar al respecto.

En la primera mitad del siglo XIX se construyen nuevamente numerosas presas en la antes citada zona entre Cáceres y Alcántara, pudiendo citarse las de Petit 1 y Petit 2 (Arroyo de la Luz), Brozas 1 (localidad del mismo nombre), Barroso y Cueto (Villa del Rey) y Mata de Alcántara y Molino de Cabra (Mata de Alcántara). Son presas de las mismas alturas que las anteriormente construidas en esta zona (entre 3 y 6 m de altura) y de similar tipología, excepto las dos últimas citadas, que son de materiales sueltos.

También se construyen, a lo largo del siglo XIX, presas en otras zonas, como la de Quebrada de Tiendas, en Talayuela, Zamores en Membrío, o Casillas 1 en Trujillo.

Cabe hacer mención especial a Pedro Bernardo Villarreal de Bérriz por su importante aportación técnica al diseño y ejecución de presas en el S. XVIII, en el País Vasco y su influencia en el resto de España. 


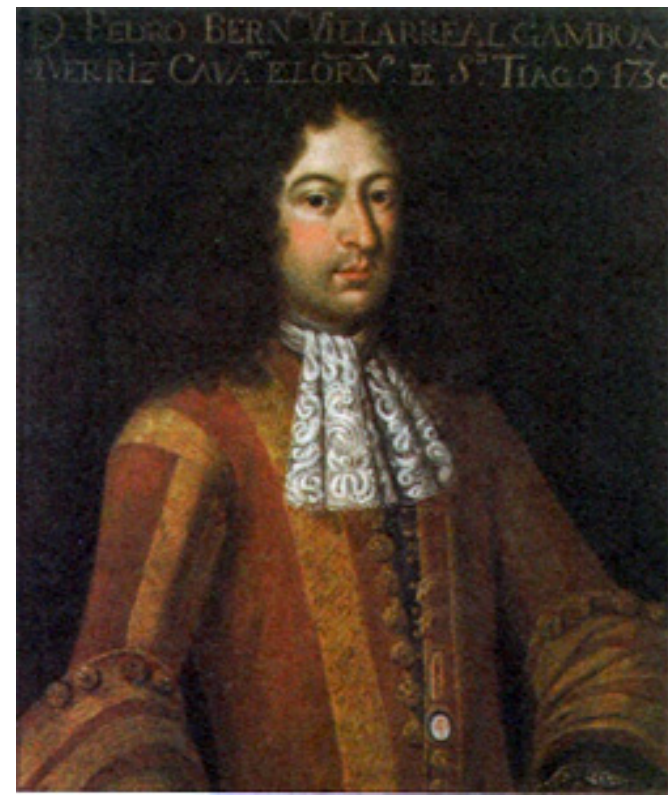

Industrial e ingeniero español, nacido en Mondragón (Vizcaya) en 1670, y murió en Lequeitio (Vizcaya) en 1740.

Aunque de familia noble, no fue educado en Francia (como era usual entre la aristocracia vasca), y hacia 1680 fue enviado a Bergara, en cuyo Colegio de los jesuitas se aficionó a las ciencias aplicadas, y en particular, a las matemáticas. Prosiguió sus estudios medios en Pamplona, donde cursó dos años de Filosofía. En 1684 se trasladó a Salamanca a estudiar leyes, siguiendo, probablemente, a un pariente suyo, Juan de Andicano, que era catedrático en dicha universidad. La encontró, sin embargo, demasiado burocrática, prefiriendo, en su lugar, el pragmatismo de la mecánica o la hidráulica, estudiadas con los jesuitas.

Una vez emancipado, a la edad de 18 años, comenzó a trabajar en algunas de las ferrerías familiares, a caballo entre Mondragón y Berriz. Aunque apenas tenía experiencia, logró administrar una notable hacienda. Más tarde confesó: 'desde que me emancipé...en cuarenta y ocho años continuos apenas me han faltado Obras en mi hacienda y la de mis hijos, siendo las más en Herrerías y Molinos' (Villarreal, 1736: prólogo). Sorprende, en efecto, la ingente actividad que desarrolló: reedificó la ferrería de Berriz, el palacio de Uriarte en Lekeitio, reconstruyó las casas quemadas de Lauritz, Beaskoa y Gizaburuaga Biazkoa, hizo el molino de agua pasada de Bengolea, plantó todos los montes despoblados de su hacienda, acometió proyectos arquitectónicos, y, fue alcalde de Lekeitio, en tres ocasiones.

A través de estas actividades, Villarreal encarnó cabalmente al hidalgo activo que poseía fábricas y se dedicaba al comercio, 'sin perder su nobleza', como rezaba la Real Cédula de 1783 . Y es que la organización técnico-comercial que creó es modélica por su planteamiento sencillo aunque efectivo; puesto que no se limitó a trabajar el hierro en las ferrerías reformadas, sino que se valió, para 
las mismas, de la energía que le procuraban sus molinos y explotaciones forestales; y lo que es más, llegó a fabricarse una flota propia (de hasta ocho navíos), sirviéndose del hierro y la madera de su hacienda, para comercializar sus productos.

No es posible apreciar la dimensión de la aportación de Villarreal sin tomar en consideración su obra principal: Máquinas hidráulicas de molinos y herrerías y gobierno de los árboles y montes de Vizcaya (1736), su contribución más original a la ingeniería del XVIII.

En el prólogo a la misma, justificaba su publicación por no existir, ni en España ni en Europa, 'nada científicamente escrito sobre el tema', y para remediarlo, añadía, nada mejor que ofrecer, a sus compaisanos, un pequeño manual de observaciones e instrucciones prácticas, que 'los ayudase para el mejor adelantamiento de sus haciendas'.

Importantes en este sentido fueron las presas de contrafuertes, que, aunque ya habían sido utilizadas en época romana, fueron estudiadas, por primera vez en la época moderna, de manera innovadora y analítica. Esa originalidad residía en proporcionar relaciones empíricas y criterios de diseño, lo que permitía construir con seguridad ese tipo de presas. Se hacía así patente que los cálculos de estabilidad y de hidráulica eran necesarios para construir las presas industriales. A ese diseño se ajustaron las cinco presas que construyó: las de Bedia, Ansotegi y Barroeta (Markina), y Asenzibia-Errota y Laisota (Gizaburuaga).

Las presas de contrafuertes constituían un ejemplo de las posibilidades todavía sin desarrollar en el horizonte de la energía hidráulica destinada a las industrias ferrona y molinera.

El avance tecnológico, entendido éste como la aplicación práctica de la ciencia, era fundamental para la competitividad de la industria. Y tales conocimientos científicos eran 'importados', por diversas vías y desde diferentes naciones, al círculo erudito de Lekeitio. Da idea de la inquietud científico-técnica que colmó a Villarreal el que hiciese traer cajones de libros desde Italia, Inglaterra y Holanda: en el umbral de su muerte, dijo tener 'mil cuerpos de Libros, de Mapas, Historia y Matemáticas'. 
赵

MAQUINAS

HYDRAULICAS

DE MOLINOS,

Y HERRERIAS,

Y GOVIERNO DE LOS

Arboles, y Montes de

Vizcaya.

POR DON PEDR O BERNARDQ

Villa-Real de Berriz, Cavallero.

del Orden de Santiago.

DE D I C A D O

A LOS AMIGOS CAVALLEROS;

y Proprietarios del Infanzonado del muy

Noble, y muy Leal Seńorio de Vizcaya,

y muy Noble, y muy Leal Provin-

cia de Guipuzcoa.

CON PRIVILEGIO : En Madrid, en la Oficina

de Antonio Marin, Ańo de 1736 .

\section{TABLA}

DE IOS CAPITULOS de efte Tratado.

\section{LIBRO PRIMERO.}

AP. I. De las Prefas antiguas de 1. Vizcaya , y Molinos, con algunas reglas de los nirividos, Pag.I.

CAP. II. De las Pre eas en arco, de invencion del Autor, contoda la forma de fu conftruccion, pag. 8.
El Tratado de Hidráulica que Pedro Bernardo dedica al estudio de pequeñas presas o azudes, imprescindibles para derivar el agua hacia los caces de los molinos, o las anteparas de las herrerías, ocupa los dos primeros capítulos del Libro Primero de la obra.

Las presas tradicionales de gravedad, empleadas no sólo en Vizcaya, sino en toda la Península, forman parte del capítulo primero, dedicado íntegramente a los molinos harineros. Este tipo de presas de gravedad, eran muy frecuentes en la España renacentista.

Su experiencia como constructor de presas y azudes de escasa altura -entre tres y seis metros aproximadamente- no aportaba nuevos conocimientos de utilidad en el primer Capítulo de su obra.

Las reglas que expone para el diseño de las presas tradicionales de gravedad se basan en su altura o salto $(\mathrm{H})$ y dice que la coronación debe tener una anchura igual a la altura de la lámina de agua en máxima avenida (A max), que la base del 
trapecio que forma su sección debe ser igual a la suma del salto aumentado en un $20 \%$ como margen de seguridad, más el ancho de la coronación. El paramento de aguas arriba será una superficie con la inclinación resultante de las anteriores dimensiones.
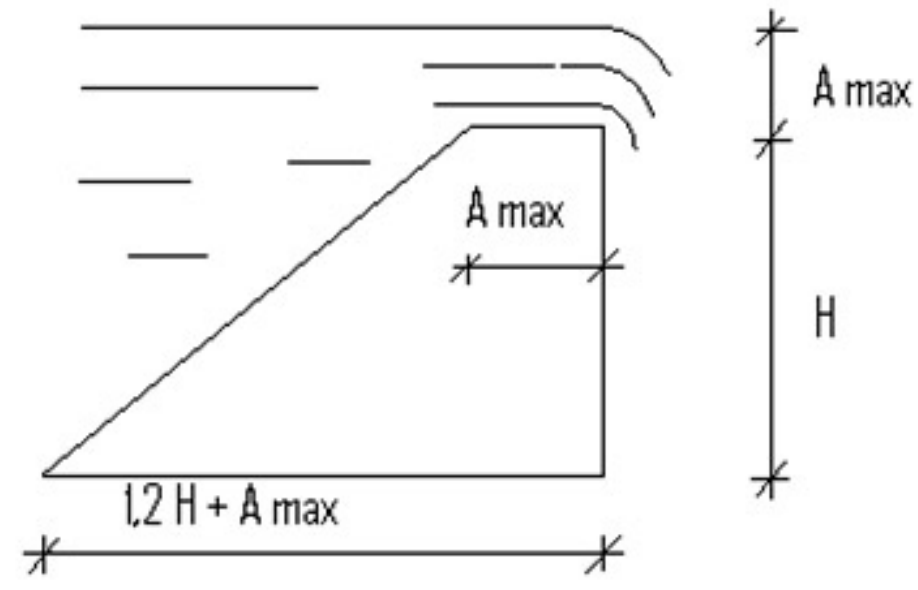

Una nueva materia, las presas en arco con contrafuertes, expuesta en su Capítulo II sí que constituye una verdadera aportación de gran originalidad. Por ello escribe:

«Ya se ha dicho como son las Presas antiguas de Vizcaya: y aunque son hechas según arte, y buenas reglas, y no se pueden reprobar, hallo ser más seguras, firmes y de menor coste las de arco, como se demostrará.»

La mayor aportación de Pedro Bernardo en el diseño de presas de gravedad es que establece un criterio preciso y claro que es además ajustado al cálculo estático de equilibrio de la presa, tal y como hoy se realiza.

Aunque Villarreal aborda su propuesta partiendo de una altura de presa de diez pies de altura (2.80 m), a partir de aquí se realizará una generalización que nos sirva para una altura cualquiera «H». Contempla además Villarreal que las presas de gravedad que diseña, han de comportarse como azudes, siendo rebasables con frecuencia, por lo que establece un altura «s» de la lámina de agua sobre la coronación que es preciso estimar mediante observaciones previas del régimen de avenidas del río, ya que es un parámetro necesario para el diseño de la presa.

Una vez conocida la altura de la presa «H» y estimada la lámina de vertido sobre la coronación «s», quedan fijados todos los demás parámetros. 


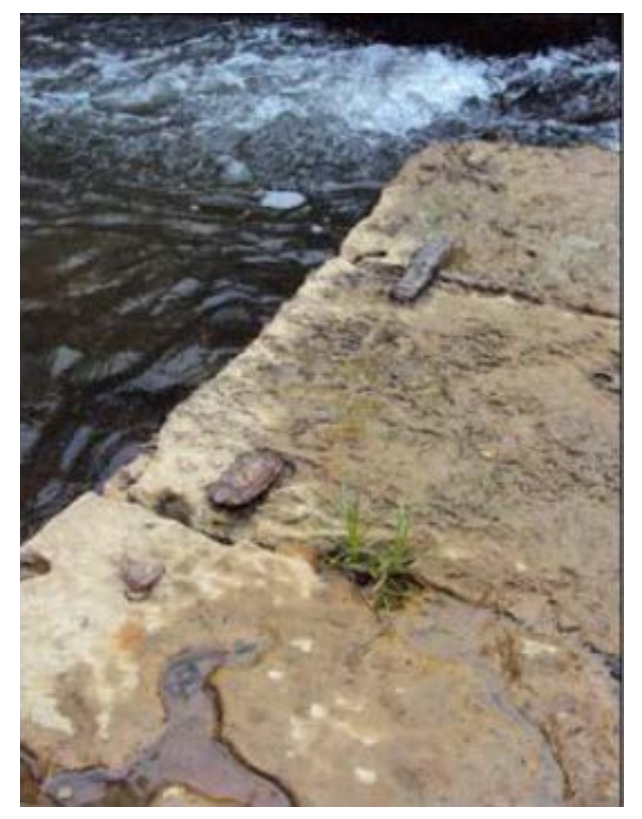

Villarreal indica que para resistir el vertido del agua a gran velocidad sobre la coronación se requieren «buenas losas ligadas con grampones de hierro emplomados».

Además, con el fin de prevenir la erosión debido al chorro de agua que rebasa la presa, el muro vertical se fabrica de «piedra labrada con buenas juntas», mientras que el talud tendido, en contacto siempre con el agua, se impermeabiliza con «maderas $y$ tablas que llaman colomas, y se calafatea muy bien». Esta impermeabilización con tablones de madera es solamente temporal, para evitar que la obra recién construida se arruine a causa de una crecida imprevista; el propio Villarreal señala que la presa «después de algunos años no necesita defensa de tabla, como muestra la experiencia».

En cuanto al talud tendido en el paramento en contacto con el agua, tiene algunas ventajas en relación con la estabilidad (el empuje del agua proporciona una componente vertical favorable) y facilita además la construcción, permitiendo la colocación del recubrimiento de madera.

Las innovadoras presas de arcos escarzanos y contrafuertes son el orgullo de Villarreal, y, sin duda, su aportación más original a la ingeniería de su tiempo. La importancia radica en que proporciona relaciones empíricas y criterios de diseño que permiten construir con seguridad este tipo de presas.

Aunque está hoy fuera de duda que las presas de contrafuertes fueron ya utilizadas en época romana, los ejemplos que conocemos son escasos y de relevancia menor. La presa quizá más antigua de bóvedas y contrafuertes conservada hasta hoy, aunque con cambios significativos, está emplazada cerca del pueblo de Esparragalejo, localidad próxima a Mérida.

Con una altura máxima difícil de precisar hoy día, pero del orden de los seis metros, constituye un ejemplo notable de este tipo de estructuras hidráulicas que los romanos emplearon raramente. La presa consta de 12 arcos de medio punto - el único empleado por los ingenieros romanos-y por tanto de 13 contrafuertes. 
Por su parte, Norman Smith data también otra presa romana de contrafuertes en Tripolitania - la de Wadi Caam-de menor importancia. Y aunque en época medieval se pierda la pista de este tipo de presas, no se olvidan totalmente; así García-Diego señala el dibujo de una presa de este tipo en los manuscritos renacentistas conocidos como «Los Veintiún Libros de los Ingenios y de las Máquinas».

Se añade también aquí otro ejemplo de bóveda simple, que aunque en un extremo estriba directamente en la roca, en el otro requiere un enorme contrafuerte o estribo, la presa de Elche sobre el río Vinalopó, de 23 metros de altura, cuyo empuje no puede resistirse simplemente por gravedad, con una anchura de $9 \mathrm{~m}$ en coronación y tan sólo 12 en cimientos. Proyectada y construida por Joanes del Temple, la presa se terminó en 1640, justo un siglo antes de la muerte de Villarreal.

Todos estos antecedentes ponen de manifiesto la existencia de presas de bóvedas y contrafuertes mucho antes de que Villarreal realizase sus experiencias; sus innovaciones son sin embargo notables y confieren a sus diseños un aire inconfundible.

En primer lugar, se conciben asociadas a unas industrias determinadas, molinos harineros y herrerías, que requieren saltos hidráulicos comprendidos entre los tres y seis metros, que es el rango que establece Villarreal.

Tampoco pierde de vista el régimen de los ríos de su territorio (aguas abundantes, régimen irregular, pendientes longitudinales fuertes) y por ello, a diferencia de otras presas anteriores de este tipo, se contempla el vertido frecuente de los excedentes de agua sobre la coronación sin que por ello se arruine la obra.

Los dos parámetros que precisan ser conocidos o estimados son la altura de presa $(\mathrm{H})$ y el «álveo» o anchura del cauce en época de crecidas (A). La anchura máxima de la presa en cimientos será algo superior al doble de la altura de agua (es decir, 2H).

El número de bóvedas se establecerá en función del álveo (A) de manera que la cuerda de cada uno de los arcos escarzanos (L) esté comprendida entre 30 y 40 pies, teniendo en cuenta que el grueso o espesor de los contrafuertes es la cuarta parte de la cuerda del arco (L/4). 
Otra norma establece que cada arco ha de tener en su clave un espesor de 2,5 pies $(0,7 \mathrm{~m})$, valor que creemos busca a limitar el tamaño de esta importante dovela, expuesta a la erosión del paso frecuente del agua.

Otra particularidad, que indica lo consciente que era Villarreal sobre el modo de trabajar los arcos, queda reflejada en su criterio de realizarla por hiladas horizontales, construyendo una hilada sobre la siguiente con un pequeño retranqueo al que Villarreal no concede mucha importancia, y que justifica por razones constructivas, de manera que la pendiente sea de cinco pies horizontales por cada 9,5 verticales.

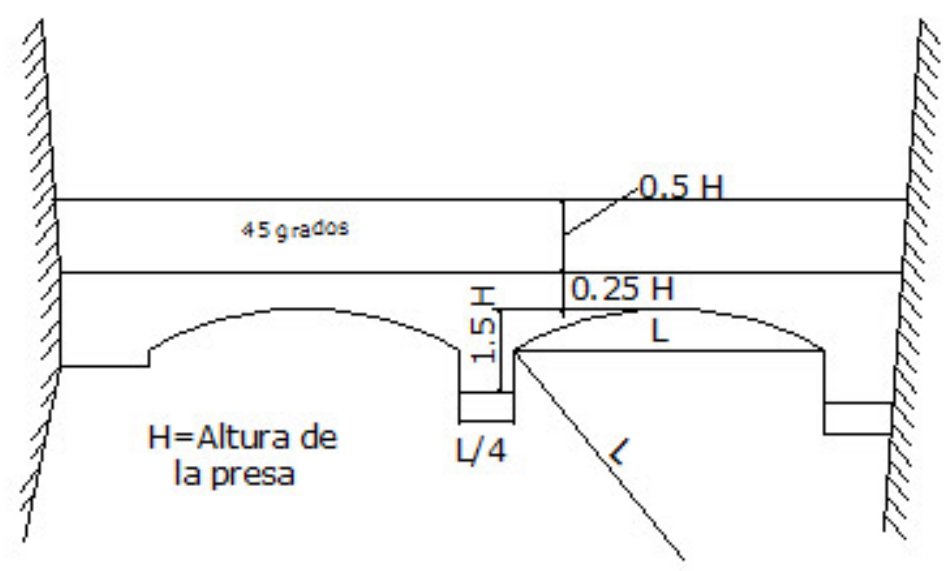

Esquema de los criterios de P. B. Villareal para dimensionar la planta de presas de arcos y contrafuertes

El propio Villarreal, según él mismo cuenta en su obra, escribió el tratado para transmitir sus criterios de diseño bastante experimentados, ya que cuenta que por entonces había llevado a cabo cinco presas no lejos de Lequeitio, su centro de operaciones.

El mismo las describe así:

«La Presa de Ansotegui y la de Barroeta (Osiyán) ambas en Marquina, la primera de un arco, y la segunda de dos, se han fabricado de esta forma, $y$ han quedado hermosas, fuertes, y muy a gusto de sus dueños: y yo edifiqué en Guizaburuaga otra en la misma forma con tres arcos de desiguales cuerdas, por aprovechar unos peñascos levantados...» 


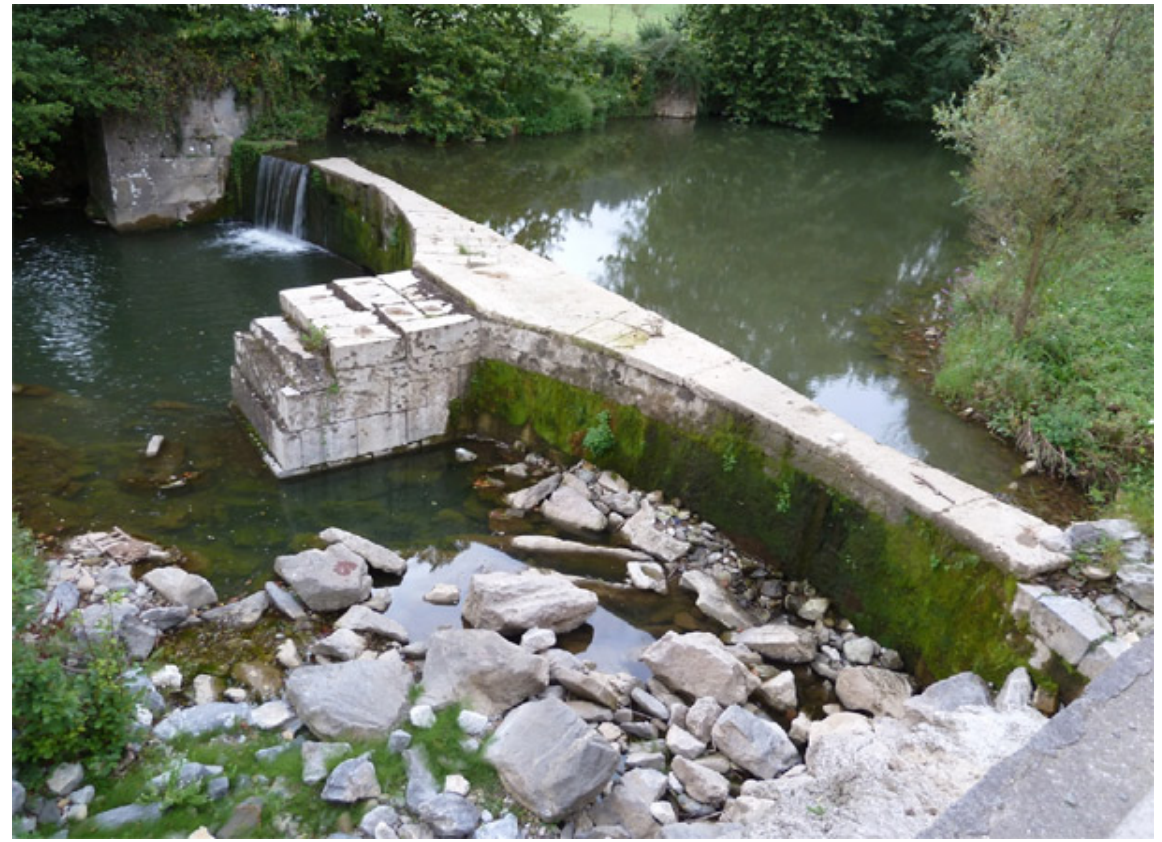

Presa de Barroeta

Más adelante añade:

«También se ha fabricado en Bedia, cerca de Vilbao, en el Río caudaloso que pasa por dicho Bedia, y Galdacano, una Presa con cinco arcos, después que se llevó la que se fabricó en el mismo sitio avrà dos años, muy costosa, de piedra en un arco; pero siendo su cuerda ciento y noventa pies, $(53,20$ $m)$ no pudieron tener tirantes las dovelas, y se la llevó el agua: y se ha visto la firmeza con que ha quedado esta nueva de cinco arcos.»

Del propio texto se deduce que se construyó en 1734 ó 1735.

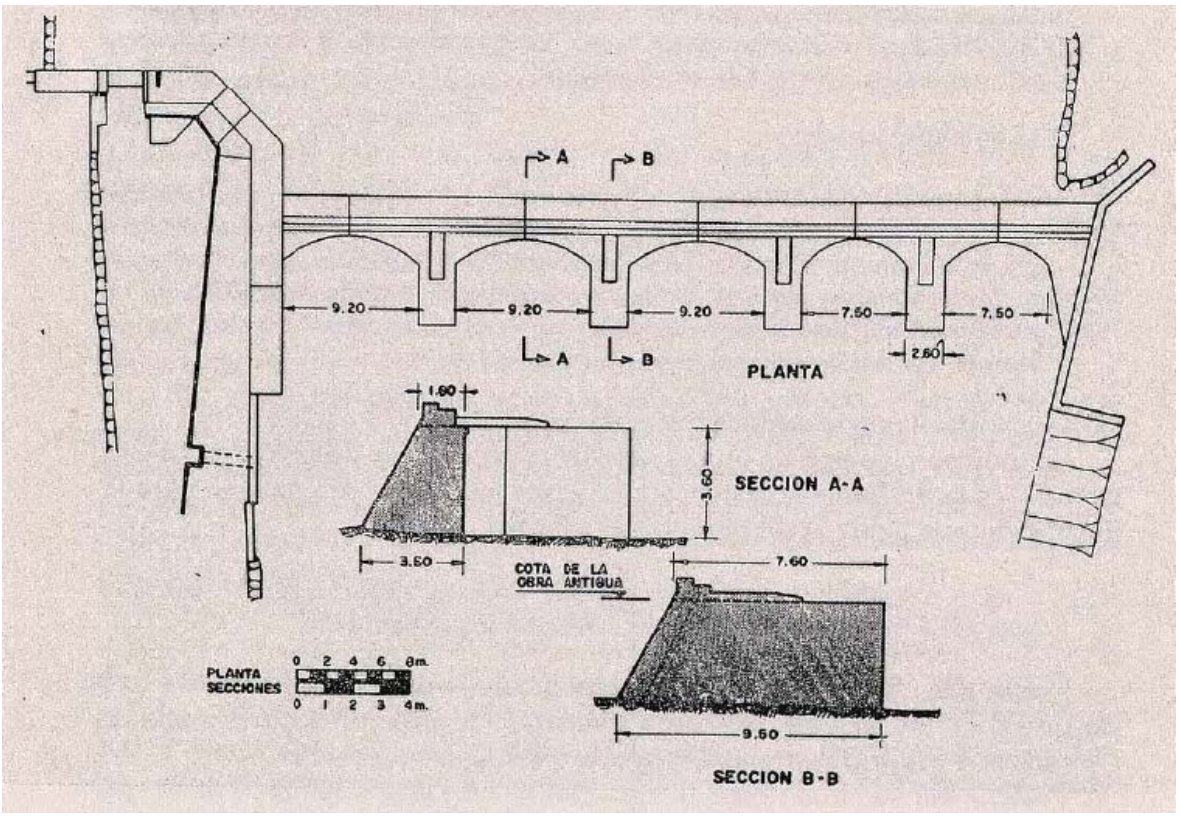

Planos de la presa de Bedia 
La última de las presas, aún en construcción cuando Villarreal escribe su tratado, es la de Laisota, de dos arcos, y que le sirvió como modelo para la ilustración que figura en el libro. Sobre ella nos dice:

«...y actualmente estoy labrando otra Presa en dicho Lugar de Guizaburuaga de las medidas, y forma, que muestra dicha figura 2.»

Las cinco presas de las que nos da referencias Villarreal, tienen unas dimensiones básicas de altura (H) y luz de la cuerda del arco (L) que encajan dentro de las normas de Villarreal.

- Barroeta-Osiyán $(\mathrm{H}=3 \mathrm{~m} ; \mathrm{L}=12 \mathrm{~m})$

- Ansotegui $(\mathrm{H}=5 \mathrm{~m} ; \mathrm{L}=11.40 \mathrm{~m})$

- Arencibia-Errota $(\mathrm{H}=2 \mathrm{~m} ; \mathrm{L}=10.50 \mathrm{~m})$

- Bedia $(\mathrm{H}=4.50 \mathrm{~m} ; \mathrm{L}=9.20 \mathrm{~m})$

- Laisota $(\mathrm{H}=4.50 \mathrm{~m} ; \mathrm{L}=12 \mathrm{~m})$

La mayor cuerda de un arco está en 12 metros, unos 43 pies, que exceden en muy poco su límite superior de 40 pies.

A estas cinco presas, bien conocidas y estudiadas, hay que añadir al menos una más que fue construida en fecha posterior, ya que no hay referencias a ella en el tratado y que posiblemente se proyectó utilizando el libro pero sin la intervención directa del autor.

Su ubicación está lejos de Lequeitio, centro de operaciones de Pedro Bernardo, aunque se encuentra muy próxima a Liérganes, población de Cantabria donde se instalaron los primeros altos hornos españoles en las primeras décadas del siglo XVIII.

Estas factorías, en plena producción cuando Villarreal escribe su libro, empleaban las aguas del río Miera para soplar, mediante ruedas hidráulicas, los grandes hornos donde se fundía el mineral y el hierro. $Y$ aunque por entonces no estaba introducido en España el procedimiento de obtención de hierro dulce, apto para la forja, a partir de la fundición - llamado procedimiento indirectoy por tanto el hierro colado no le hacía la competencia al hierro obtenido por el procedimiento directo en las herrerías tradicionales vascas y catalanas, sabemos que Villarreal se interesó en las Reales Fundiciones, pues con seguridad estaba ya al tanto de la posibilidad del procedimiento indirecto.

De hecho, esta nueva técnica se implantó en España por vez primera muy pocos años antes de la publicación del libro de Villarreal, pero en un escenario 
geográfico tan apartado del suyo, por lo que es posible que Pedro Bernardo no estuviese al tanto de la innovación.

Se trata de una presa de dos arcos escarzanos (análoga por tanto a la que ilustra el libro de Villarreal) levantada en el cauce del río Miera en la población de Liérganes (Cantabria). Esta presa se construyó para dar agua a un molino harinero cuya fábrica aún permanece en pie, aunque con bastante prudencia no se adosa a la presa, sino que se instala en la margen izquierda el río, en un lugar apartado del lecho del mismo.

De su buen comportamiento da cumplida muestra su perfecto estado de conservación, pese a la violencia de las crecidas del río Miera, que arruinaron, según recoge Madoz, las presas, cauces y ruedas de la Real Fábrica de Cañones de Liérganes-La Cavada.

Hay una razón de cierto peso para pensar que Villarreal no realizó esta presa entre la fecha de la publicación del libro (1736) y su muerte (1740). De hecho el propio Ayuntamiento de Liérganes data su construcción en 1799.

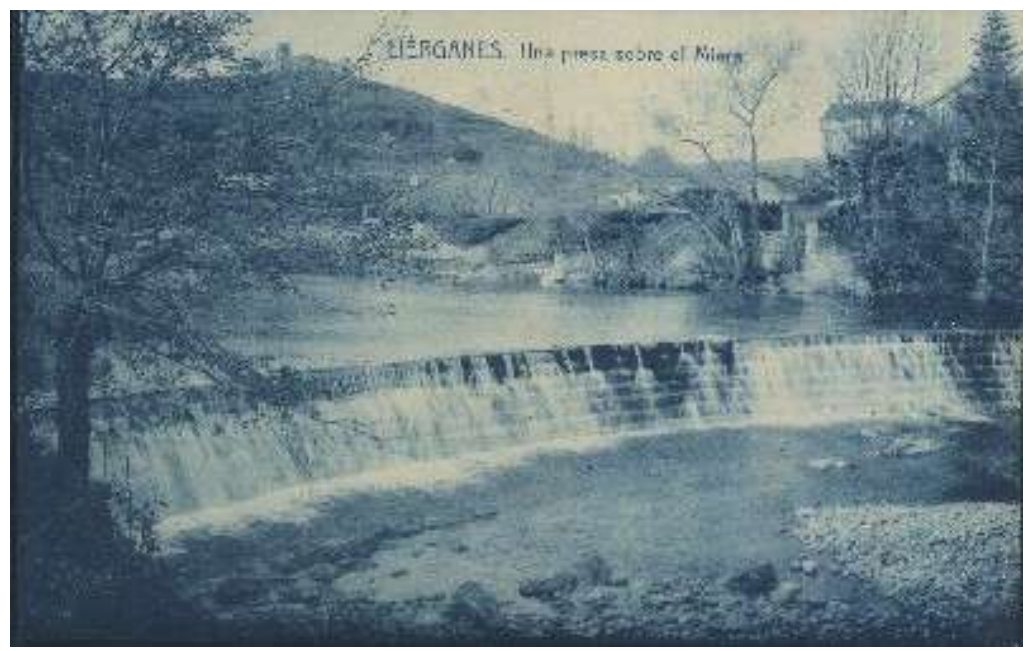

Presa de Liérganes también Ilamada de Regolgo (1799)

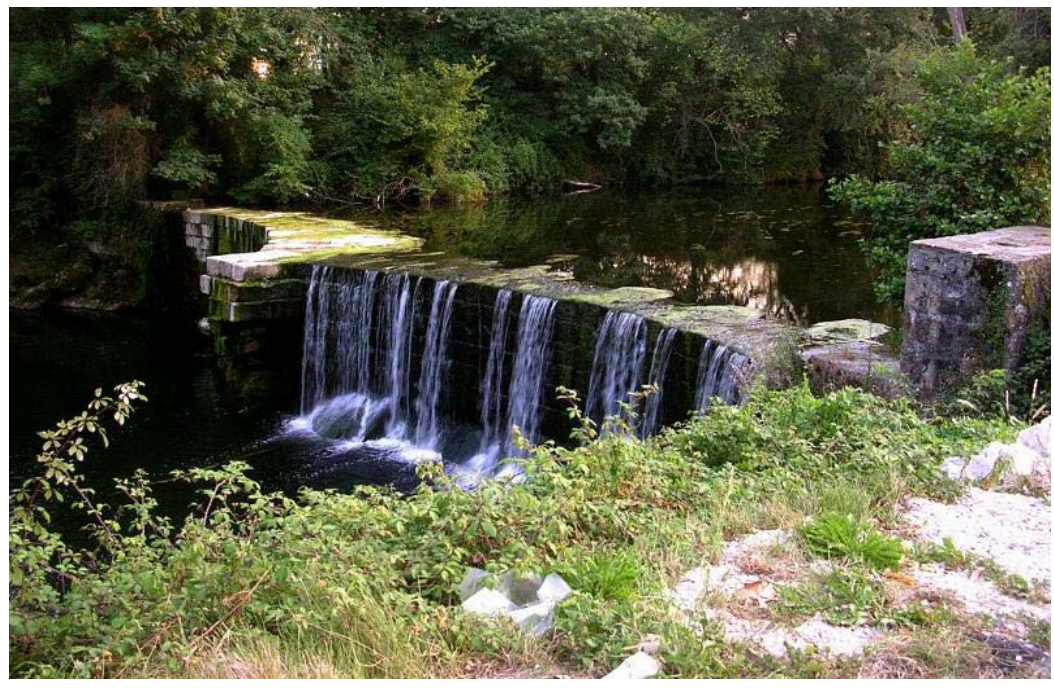


La altura de la presa encaja bien dentro de los criterios de Villarreal $(\mathrm{H}=4.20$ $\mathrm{m})$, pero no así la cuerda de los arcos escarzanos $(\mathrm{L}=14.20 \mathrm{~m})$ que supera ampliamente el criterio de no rebasar los 40 pies $(11.20 \mathrm{~m})$.

Excesivamente arriesgado es también la anchura del contrafuerte, pues tiene tan sólo 2.20 m, cuando según el criterio de Villarreal debería de ser L/4 = 3.55 $\mathrm{m}$.

Para compensar, el espesor mínimo del arco en su clave, es en la presa de Liérganes $1.30 \mathrm{~m}$, frente a los 2,5 pies $(0.7 \mathrm{~m})$ que recomienda Villarreal.

La otra dimensión importante, el talud o incremento de la anchura con la profundidad no se puede establecer por encontrarse completamente aterrada, pero si se admite que la pendiente del paramento aguas arriba está ataluzado de acuerdo con la pendiente sugerida por Villarreal, la relación entre la anchura en cimentación y la altura es del orden de 1,6, muy inferior al valor de 2 recomendado por Villarreal.

La factura de la obra es sin embargo perfecta, disponiéndose los planos paralelos como recomienda Villarreal:

«...poniendo el sobrelecho de dicha primera hilera de dovelas a nivel, góvernando la altura de ellas según los saltos, o desigualdades del cimiento, para que todas las otras hileras hasta el remate sean iguales, y horizontales en la altura de cada hilera.»

También es justo reseñar la importancia de Aragón en cuanto a patrimonio hidráulico de presas y azudes antiguos se refiere. Su antigüedad no se conoce con exactitud ya que los documentos que se conservan suelen ser de reparaciones de los mismos, del S. XVI, lo que evidencia su existencia en siglos anteriores. Incluso algunos, podrían haber sido de factura romana posteriormente rehabilitada conforme los iban dañando las riadas que sufrían sucesivamente.

Los azudes, de menor entidad que las presas, sin embargo, se han construido en Aragón con todos los materiales que el ingenio del hombre ha sido capaz de utilizar y la naturaleza de proporcionarle, sin embargo hay unas tipologías típicas para los azudes que proporcionaban el agua para mover los molinos que después se convertirían muchos de ellos en fábricas de luz, y también para riego, que se pasan a describir a continuación:

Azud de piedra suelta y escollera. Se componen de rocas de tamaño variable, que se cruzan en el lecho del río y derivan parte de su caudal hacia el molino. En 
algunos casos se componen de piedras de tamaño medio y en otros de grava del mismo lecho. Presentan la ventaja de ser muy baratos y no necesitar de ninguna técnica especial para su construcción; sus inconvenientes son la poca longevidad y los daños que sufren en las riadas, pero su reconstrucción es rápida y barata.

Azud de "selva" o estacada. Ésta es la denominación que se da en "Los Veintiún Libros de los Ingenios y las Máquinas" a los constituidos fundamentalmente con materias vegetales (ramas, gavillas de sarmientos de vid, fresno, etc.) trabadas con barro y césped para hacerlos más impermeables.

Presentan las mismas ventajas e inconvenientes que el método anterior.

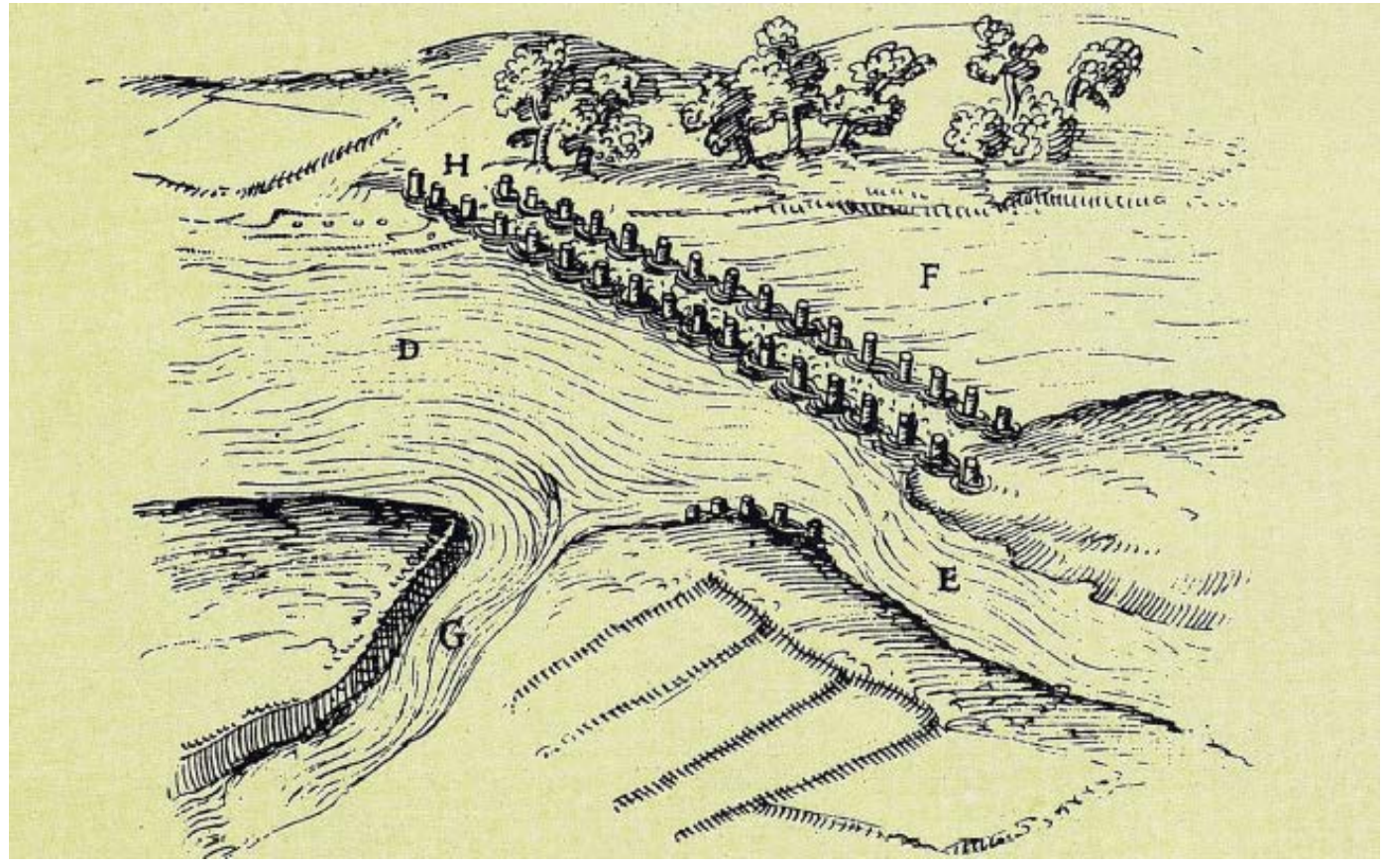

Azud de selva

Azudes de madera. Pueden dividirse en dos grupos: los constituidos por troncos sin trabajar o los de carpintería más elaborada. En Aragón son extremadamente raros en nuestros días, si bien hasta el siglo XVII o XVIII fueron los más comunes.

Dentro de los más sencillos, podemos encontrar desde el simple tronco atravesado en el río, que deriva el suficiente caudal para una acequia, hasta otros también muy simples en su concepto, pero grandiosos en su tamaño, como eran los que tradicionalmente se han construido en los ríos del Somontano oscense y de los que tan sólo persisten las huellas de los grandes agujeros excavados en las rocas del lecho del río, en los cuales se introducían troncos de hasta setenta centímetros de diámetro. Delante de éstos se colocaban en 
posición horizontal otros troncos menores hasta alcanzar la altura requerida, que en algunos casos era de hasta siete metros; su fragilidad era compensada con el menor coste de su construcción, especialmente en las épocas en que abundaban los árboles de gran tamaño.

Buenos ejemplos al respecto podemos hallar especialmente en los antiguos azudes que alimentaban al extraordinario molino de las Bellostas, de difícil acceso.

En un precioso paraje y más fáciles de encontrar -aunque mucho más pequeñasson las huellas dejadas por los azudes que alimentaban el complejo industrial de La Almunia del Romeral.

Los azudes de madera más elaborados, que podemos denominar de carpintería, poseían un concepto muy diferente. En ellos no era la resistencia de la madera la que tenía que oponerse a la del agua, sino que las vigas eran empleadas como contenedores de rocas menudas que, de estar solas en el lecho del río, habrían sido arrastradas fácilmente, pero con el envoltorio de madera trabajaban de forma parecida a como lo harían si estuviesen fabricadas con sillares, pero con un precio de construcción notablemente inferior. De este tipo de azud no ha quedado ninguno, al menos visible, en nuestros días.

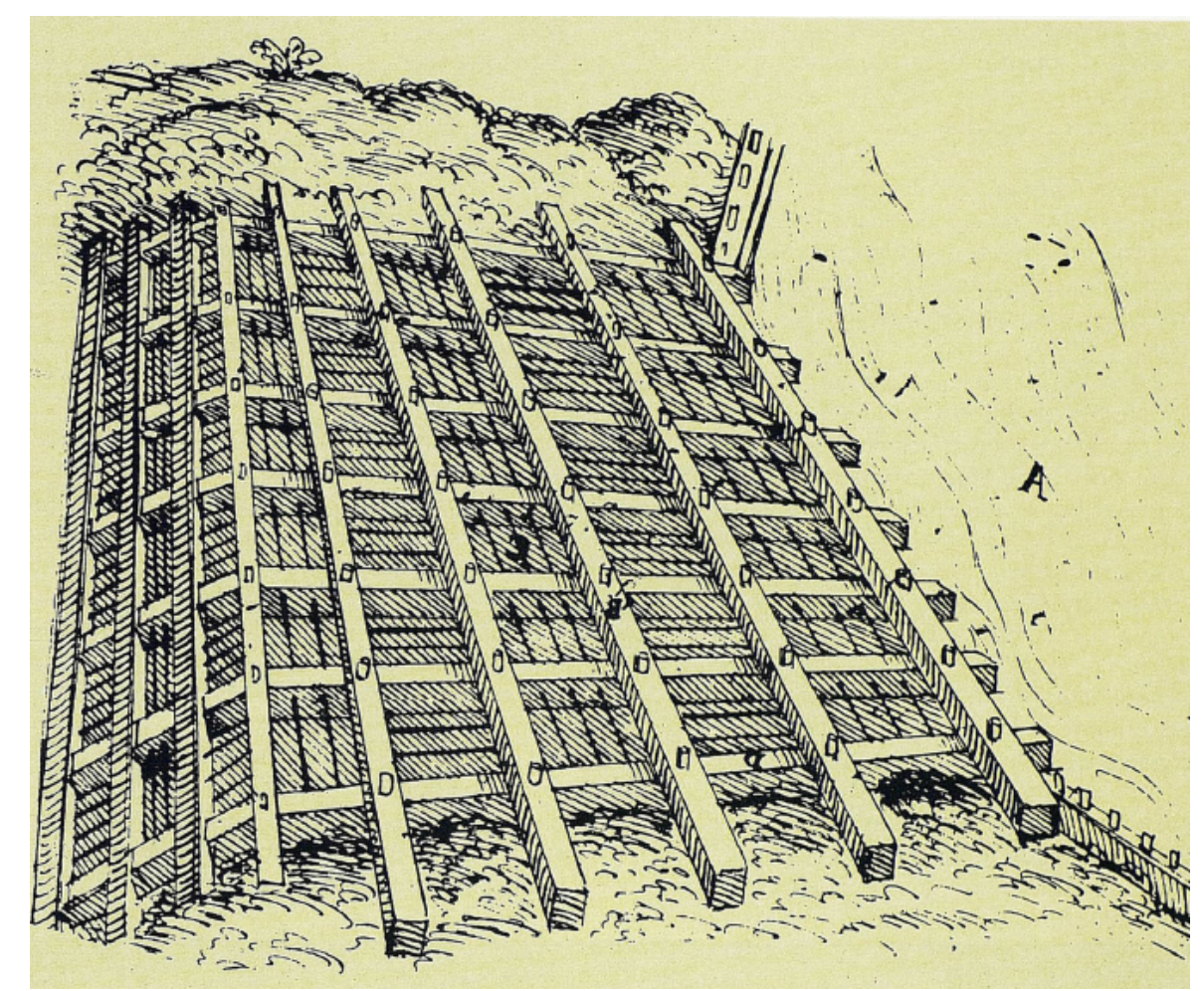




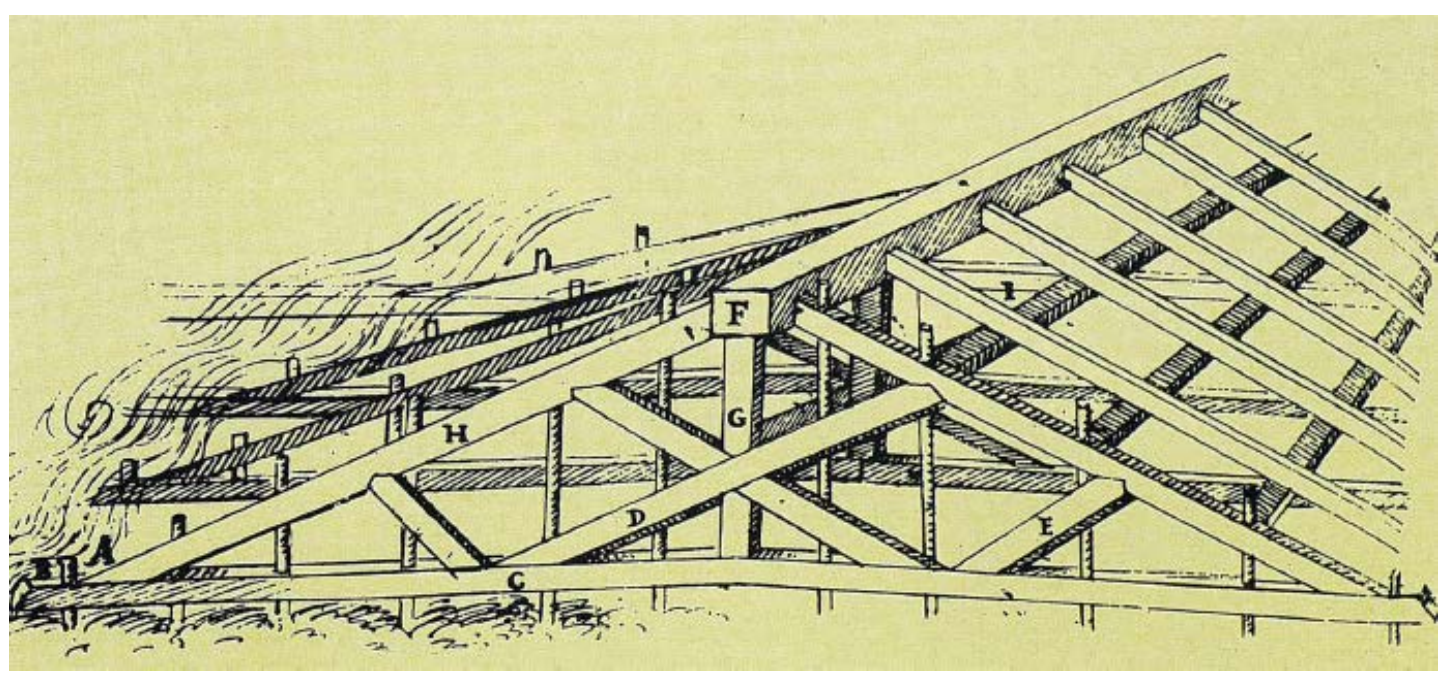

Azudes de cantería. Han sido los más sólidos y más caros que se han opuesto a la furia de los ríos aragoneses y los únicos que les han hecho frente durante largo tiempo con pleno éxito. Su tipología es muy amplia, dependiendo su forma del lugar de su ubicación y la experiencia o conocimientos de su constructor.

Predominan los de líneas rectas en posición oblicua a la corriente del río y en dirección a su toma o bocal, aunque también los hay que presentan una curvatura más o menos acusada, con el fin de ejercer mayor resistencia al empuje del agua y mayor longitud de coronación.

En la edificación de un azud de este tipo era fundamental la cimentación, puesto que, debido a la esmerada construcción que por lo general los ha caracterizado, la causa más frecuente de quebranto era la socavación de sus cimientos, tanto por la erosión que provocaba la caída del agua desde su coronación como por el efecto de sifonamiento que podía producirse, cuando la presión de las aguas era tan intensa que empujaba la gravilla o arena sobre la que se asentaba y la hacía salir aguas abajo, inutilizando el azud que de ese modo quedaba como un puente.

Para evitar la erosión aguas abajo, los azudes se han construido dejando escalones que amortiguaban la fuerza del agua en su caída o bien mediante una suave pendiente que finalizaba en concavidad, de tal modo que las aguas eran impulsadas hacia arriba, alejándolas de la cimentación.

El sifonamiento se producía, por lo general, en los primeros años de vida de los embalses y azudes de cierta capacidad que no poseían buena cimentación; si conseguían superar cierto período de tiempo los aterramientos y consiguiente colmatación de su vaso, aguas arriba, amortiguaban este efecto. 
Los azudes de buena sillería rara vez han sido arrastrados por las aguas, si no ha mediado alguno de los defectos mencionados. En caso de sifonamiento han volcado hacia arriba, y en caso de socavamiento de la cimentación, aguas abajo.

No siempre han sido destruidos los azudes a causa de defectos de construcción o mantenimiento, sino que a veces, como en el caso del gigantesco dique edificado aguas abajo de la confluencia del Alcanadre y Guatizalema (entre Huerto y Peralta de Alcofea), ha sido al parecer la cimentación la que ha fallado, tal y como atestigua un enorme tramo de muro volcado aguas abajo, en el que podemos apreciar cómo el desprendimiento de una enorme laja de roca (que aún está unida al muro) pudo suponer el corrimiento y fractura de tan colosal obra.

Podríamos establecer también otras tipologías de azudes atendiendo a la colocación de los sillares en el muro, puesto que, además de los mostrados en los famosos "Veintiún Libros. „..", encontramos otros en que los sillares son cosidos mediante "gafas" o grapas, engarzados con escalones verticales en sus caras laterales o dejando en éstas unas muescas a modo de chavetero, en las que posteriormente se introducían barras también de piedra, con el fin de que la fuerza de las aguas no pudiese mover una sola piedra sin hacerlo con toda la hilera.

Sin embargo no sólo los azudes de sillería han respondido bien los embates de las aguas, buena parte de los existentes en los ríos aragoneses son de mampostería más o menos basta y también han resistido dignamente.

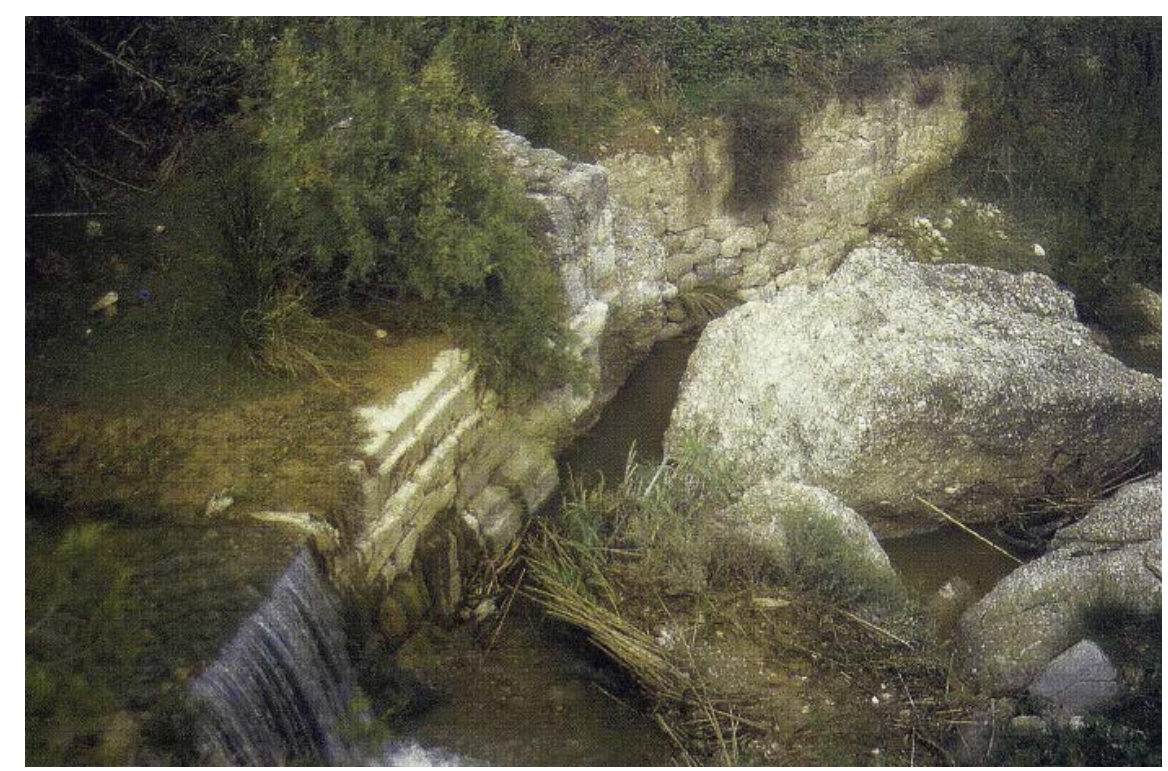

Azud del molino de Naval 
De las más de 5000 presas y azudes antiguos en Aragón, de los destinados a alimentación de molinos, destacan los siguientes:

Azud del molino de Abiego. Notable obra que, a juzgar por su factura, no resultaría extraña su filiación romana.

Azud del molino de Calatayud. Construido en el siglo XVI, este azud alimentaba al renacentista molino municipal bilbilitano.

Azud del molino de Ansó. Este buen azud alimentaba la acequia del recientemente desaparecido molino.

Azud de Beceite. De este azud sobre el Matarraña, en Beceite, se tomaba la acequia que movía la maquinaria de las fábricas de papel de la localidad.

Azud Pueyee o Pueyé. En 1576, el maestro Juan de Aracil se hizo cargo de la construcción de un buen azud en el río Vero, aguas arriba de Barbastro. Éste fue uno de los pocos azudes de Aragón que se construyeron de nueva planta en esa época, puesto que la mayoría de los trabajos que se realizaron en este tipo de obras consistieron en reparar los destrozos que las avenidas de los ríos causaban en construcciones antiguas. El de Barbastro se lo encargaron a Aracil el concejo de la ciudad, los propietarios de varios molinos y los herederos del llamado "Regano Viejo", nombre con el que se designaba una partida donde se encontraban varios huertos, probablemente para sustituir alguno más antiguo de madera.

El azud tenía que construirse con piedra de sillería y "zaborra". Los sillares formaban las caras exteriores del muro y el "enzaborrado" rellenaba el interior. La base del azud (asentada sobre roca) medía 20 palmos de ancho y 10 la coronación. Esta "filada mas alta de dicho azut" debía estar formada por dos tipos de enormes sillares: unos de diez palmos de largo y otros de cinco.

De la base a la coronación, la diferencia de anchura se lograba escalonando el muro ("gradones retrayendose"). Para dar más firmeza a la obra se proyectaron dos refuerzos en los extremos y uno, mayor, en el centro: "en medio de la dicha azut haya de hazer y haga el dicho maestro una torrezica de piedra picada de la manera que parescera al dicho maestro convenir para seguredad y fortaleza de la dicha açut y yendo trabada con la dicha obra asci mesmo otra media torrezica al cabo de la dicha açut de la otra parte del río hacia el castillo de Pueyo y otra media torrezica y embocage a la parte de la cequia". 
Azud de Castillazuelo. Este magnífico azud era de madera hasta al menos 1606, año en que los Ruesta -padre e hijo y ambos de nombre Luis- se ocuparon de su construcción con madera de roble.

Posteriormente, quizá a causa de alguna riada, y al comprobar que la cercana obra del maestro Aracil resistía las violentas riadas a las que acostumbraba el Vero, construyeron la obra actual, similar en su estilo.

Azudes del Ebro. Los azudes construidos en el S XVI desde Tudela (Acequia Imperial) hasta la actual provincia de Tarragona eran:

- Acequia Imperial

- Gelsa

- La Zaida

- Alforque

- Cinco Olivas

- Alborge

- Sástago (2 azudes)

- Escatrón

- Chiprana

- Caspe

Entre Caspe y Tortosa existían tres azudes más: los de Mequinenza, Flix y Cherta.

A continuación desarrollaremos de los que se tiene constancia que servían de alimentación a molinos, algunos de los cuales se transformaron en centrales con posterioridad.

De ellos cabe destacar el primer azud aguas abajo de Zaragoza que es el de Pina. De remoto origen, puesto que se remonta a 1178, fecha de la autorización de Alfonso II de Aragón para su apertura. Este privilegio fue ampliado en 1185, 1223 y 1256, ratificados en 1513 por Fernando II. Riega los términos de Pina, Osera y Villafranca.

En 1554 estaba situado probablemente en lo que hoy es el galacho de la Alfranca, después se situó en un lugar que actualmente se encuentra cubierto por la actual "presa" de Pina. Los cambios de posición se debían a las notables riadas que sucesivamente lo destruían, puesto que al parecer ha sido siempre de piedra suelta, quizá ayudada mediante una estacada. Junto al molino de Pina, cerca de Villafranca, persisten los restos de una estacada que atraviesa el Ebro, 
puede que restos de uno de los múltiples azudes de la acequia de Pina, quizá también el que alimentaba un molino de barcas o ambas cosas.

Los siguientes azudes se encuentran en Gelsa, que comienzan con el del Puerto y sigue con el que originalmente alimentaba las tres grandes norias y el molino, pero hoy lo hace con la planta de bombeo que sustituyó a las primeras y la moderna central hidroeléctrica casi adosada al molino.

En La Zaida hay otro azud al que siguen los de Alforque, Cinco Olivas, que alimentaba el molino, la noria y la central de Sástago.

Más azudes tenemos en Alborge -uno-, en Sástago hay cuatro, uno aguas arriba y tres más abajo, de los que el primero alimentaba las interesantes norias que vimos más atrás y los dos últimos a la central de Menuza y la acequia de Gertusa, respectivamente.

El azud de Escatrón dirigía sus aguas hacia el molino y la famosa noria del monasterio de Rueda y es el último de los azudes visibles del Ebro aragonés, puesto que aguas abajo también los había en Chiprana y la Herradura de Caspe.

Azud de Montearagón. El monasterio de Montearagón domina desde la cima de su desforestado promontorio toda la llanura de Huesca. A los pies del amurallado recinto, por su parte oriental, discurre el río Flumen cuyo valle, bien angosto hasta aquí, comienza a abrirse frente al castillo para formar una vega amplia y productiva. Cerca del monasterio-fortaleza había un antiguo azud "vulgarmente llamado de Montearagón" del que se tomaba agua para regar el término de Quicena y mover varios molinos.

En 1563 el azud debía presentar un estado de ruina total. Los canónigos que gobernaban Montearagón y todos los pueblos de su rico señorío decidieron reedificarlo y encargaron la realización de la obra a Miguel de Betania, que debía llevar a cabo un proyecto bastante novedoso.

Los de Montearagón estaban decididos a levantar un azud muy robusto, preparado para resistir durante muchos años los embates de las aguas. Detallan en la capitulación con gran esmero, la solidez que deberán tener los cimientos y, convencidos de que en ellos radica la futura firmeza de la obra, señalan que "se haya de buscar fundamento y camino firme y seguro en penya o en salagón y se haya de fondar lo que fuere necesario para seguridad de dicha obra".

No podrá comenzarse la construcción hasta que dos expertos dictaminen que se han hallado fundamentos de firmeza suficiente. Como en casi todos los azudes, 
para reforzar el muro debían levantarse sendas torres o "turriones" en cada extremo.

La gran novedad de la obra encargada a Betania estaba en su perfil. Mientras que en los azudes tradicionales el perfil exterior del muro era recto o escalonado, el de Montearagón ofrecía un perfil formado por tres curvas que tenían por finalidad lograr que el agua, al caer, no formara turbulencias al pie del muro que socavaran los fundamentos del azud.

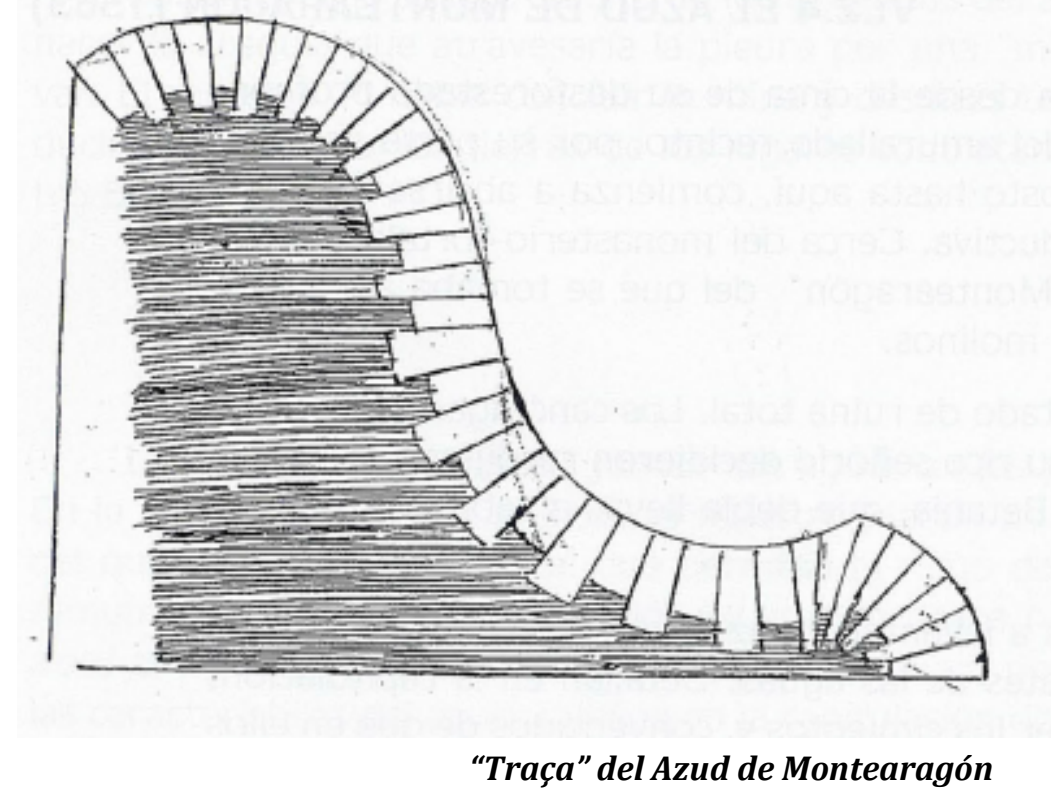

La gravedad de este problema se señala en "Los Veintiún libros" con claridad: "Todos los afutes tienen menester mucha más fuerza en la parte de abajo que no de delante, y esto es por causa de la cayda del agua que escava el suelo por causa del grande ímpetu con que cae con tanto rigor que llega hasta el suelo y aqui viene a hacer grandes remolinos y cavar el suelo, por donde los mas afutes fallan por la parte de abajo...".

Para solucionar esta dificultad, el autor de "Los Veintiún libros" propone un remedio similar al planteado en la "traça" o dibujo que se adjuntó a la capitulación de Montearagón.

Al pie del azud el muro se curvará formando un vaso para detener las aguas : "aunque cayga el agua con furor ella dando en la mesma agua que esta parada que no corre pierde la fuerfa es cierta cosa que en toda parte que tenga cayda el agua cae dentro de la misma agua mas como es agua que corre como la demas va cavando el suelo y esto es la causa los grandes retorfimientos que hace el agua hallando lugar de poderlos hazer essos remolinos por causa de lo dicho y caso que los hiciese en el levantarse en lo alto no puede entonfes haber para abéijo por 
causa que la fuerza del agua que cae abéijo se haze levantar para arriba y ansi no puede cavar".

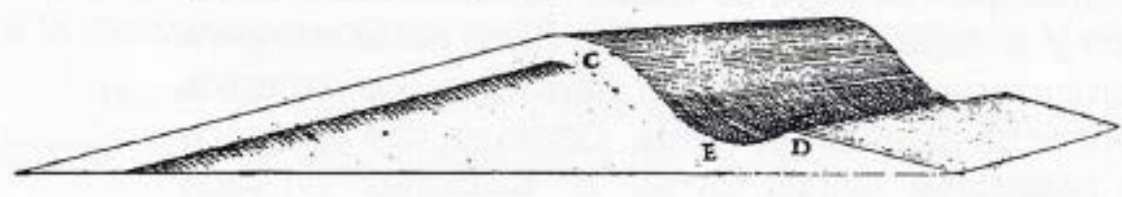

Tipología de Azud de "Los veintiún libros...."

\subsection{DEL S. XIX A LA ACTUALIDAD}

Como se ha visto con anterioridad, existían numerosas retenidas de agua mediante presas o azudes tanto en montaña como en valle, antes de la aparición de la electricidad. No siempre eran de pequeña importancia y se destinaban a mover molinos que en muchos casos fueron los precursores de las posteriores centrales hidroeléctricas o "fábricas de luz".

Pero las necesidades de producción de electricidad mediante el empleo de la energía hidráulica transformaron en gran medida las técnicas de construcción de presas.

La importancia de los saltos de agua como nueva fuente de energía había sido demostrada desde la puesta en funcionamiento de las primeras turbinas de Fourneyron.

Desde 1837, Fourneyron equipó los saltos de más de 100 metros de desnivel. En Francia, en la segunda mitad del S. XIX, Aristide Bergès se convierte en el precursor de aquello que se llamará el carbón blanco.

Es él el que formula la noción del equipamiento de todo un sistema hidráulico desviando las aguas, creando embalses mediante presas perforando el fondo del lago mediante túnel para explotar al máximo la reserva de agua, dirigiendo mediante conductos el agua hacia las turbinas. Bergès equipa un sistema hidráulico cerca de Lancey en el Isère para accionar los molinos de papel. Se enfrentará a lo largo de su carrera a numerosos conflictos con la justicia por el uso de los cursos de agua sin tener en cuenta la legislación reglamentaria.

En los orígenes de la hidroelectricidad, para establecer las grandes retenidas de agua, solo se conocía un tipo de presa, la presa de gravedad, enorme prisma de mampostería en que la masa compensaba el empuje del agua. 
Hasta el S. XIX no se proyectaron presas cuyo diseño fuera exclusivamente producto de cálculo matemático. En 1826, Navier plantea la necesidad de considerar la distribución de tensiones en la estructura y los conceptos de módulo de elasticidad y coeficiente de seguridad. Una vez admitidos los principios de la mecánica racional, se comienzan a aplicar al diseño de presas. Durante este cambio y hasta que se instauran definitivamente las teorías racionales, la aplicación se hace con variados criterios, en ocasiones mezclados con reglas experimentales.

Posteriormente, en 1850, Sazilly defiende el perfil de igual resistencia, como resultado de imponer la condición de que la tensión en el paramento de aguas arriba, cuando el embalse está vacío, sea igual a la de aguas abajo, cuando el embalse está lleno, limitando, además, la tensión máxima admisible en la fábrica, para impedir la excesiva deformación y fisuración, así como, asegurando que no se produce el deslizamiento en cualquier plano horizontal del cuerpo de presa.

Sus teorías las pone en práctica Delocre en la construcción de la presa de Furens (1859 -1866) que se diseña con planta curva, pero sin tener en cuenta la reserva de seguridad debida al efecto resistente de la forma en arco.

No es hasta este momento del desarrollo teórico y científico cuando se puede considerar que los fundamentos racionales influyen en la realidad práctica de la construcción de las presas españolas, ya que con anterioridad se habían ejecutado la presa de Isabel II en Níjar (1841-1850) y la presa del Pontón de la Oliva (1851-1855), consideradas la últimas grandes presas "intuitivas" construidas en España basándose en criterios empíricos.

En España la primera presa que se proyecta teniendo en cuenta la Mecánica Racional, de 1882, es la presa de El Villar. Volviendo a ser utilizado en la tercera presa de Puentes (comienzo construcción en 1881), Escuriza (1890), segunda de Mezalocha (1798-1913) y en el proyecto de la presa del Pantano del Pasillo (1908). 


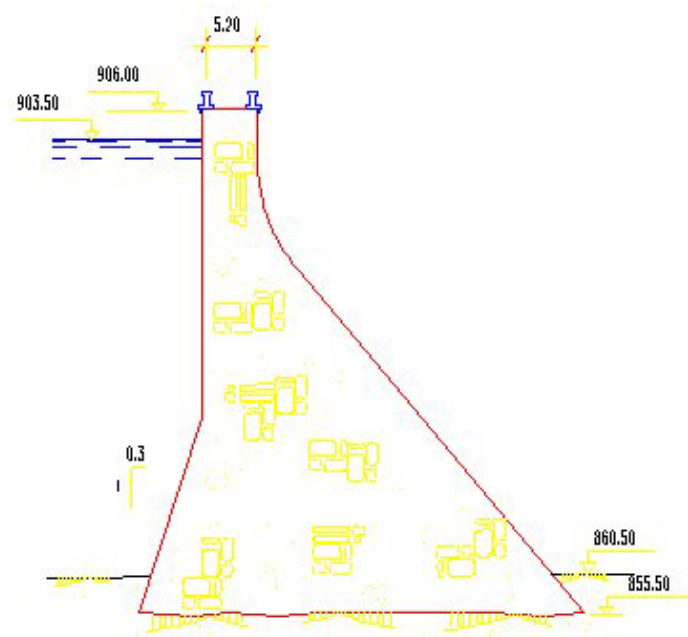

Sección tipo de la Presa de El Villar

Las modificaciones sucesivas de ese primer perfil darían lugar hacia el año 1900 a un tipo de presa de gravedad que fue conocida en el mundo entero bajo la denominación de presa francesa o perfil tipo Delocre, y que evolucionaría finalmente en 1923 en una presa de perfil triangular.

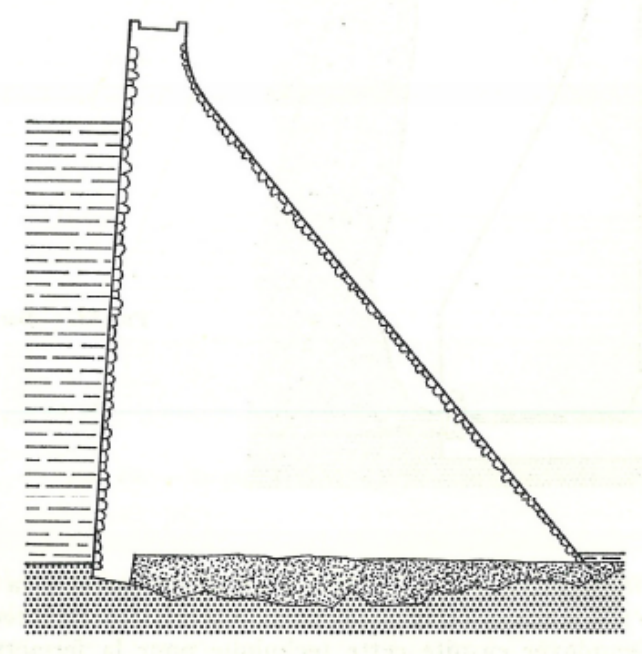

En España, entre los años 1885 y 1920, también son reseñables las presas asociadas a zonas mineras, que aunque su uso oficial es el industrial, en realidad suministraban agua y fuerza. Su sección tipo recuerda a las indicadas anteriormente.

Destacan las presas de Puerto León de 1887, 23 metros de altura sobre cimientos, 139 metros de longitud de coronación y de tipología de gravedad. Es una de las más altas de las del grupo de presas mineras de Huelva. Su titular es la Compañía Azufre y Cobre Tharsis y se encuentra sobre el río Naranjo. 


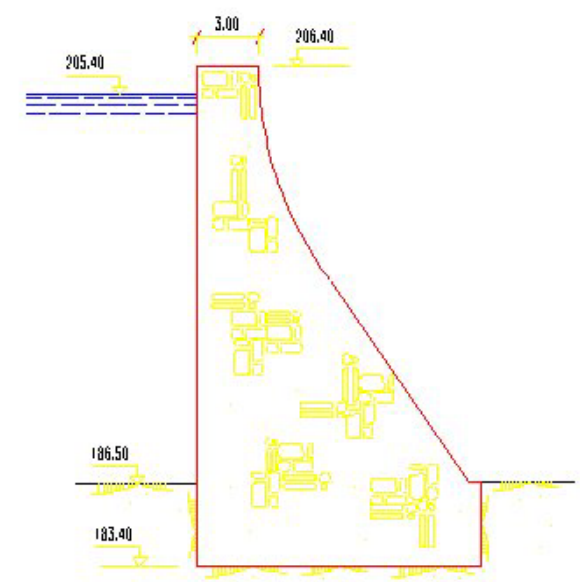

Y la presa del Alisal, del año 1900, de 24 metros de altura sobre cimientos, 111 metros de longitud de coronación, de tipología de gravedad, y junto con la presa de Puerto León, es una de las presas más altas del grupo de las mineras de Huelva. Su titular es Riotinto Minera, y se encuentra sobre el río Alisal en la provincia de Huelva.

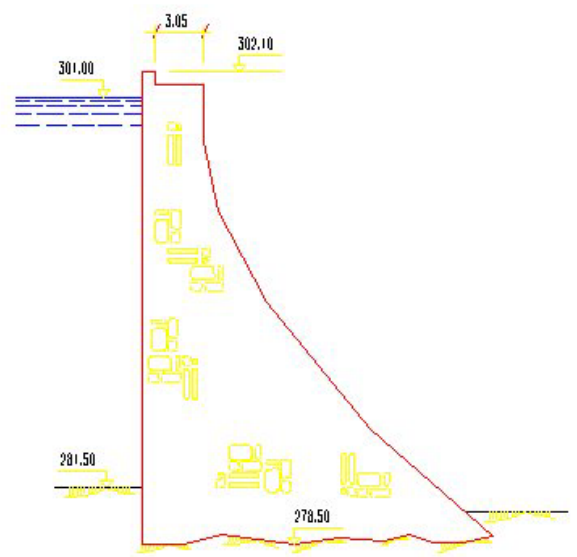

Las propiedades resistentes de las bóvedas conocidas desde hace milenios para la construcción de distintos tipos de edificaciones fueron pronto aplicadas al diseño y construcción de presas. En este tipo de presas las tensiones se transfieren a los estribos y una de las presas más antiguas de este tipo, la presa Zola, fue construida en 1843 cerca de Aix-en-Provence. 

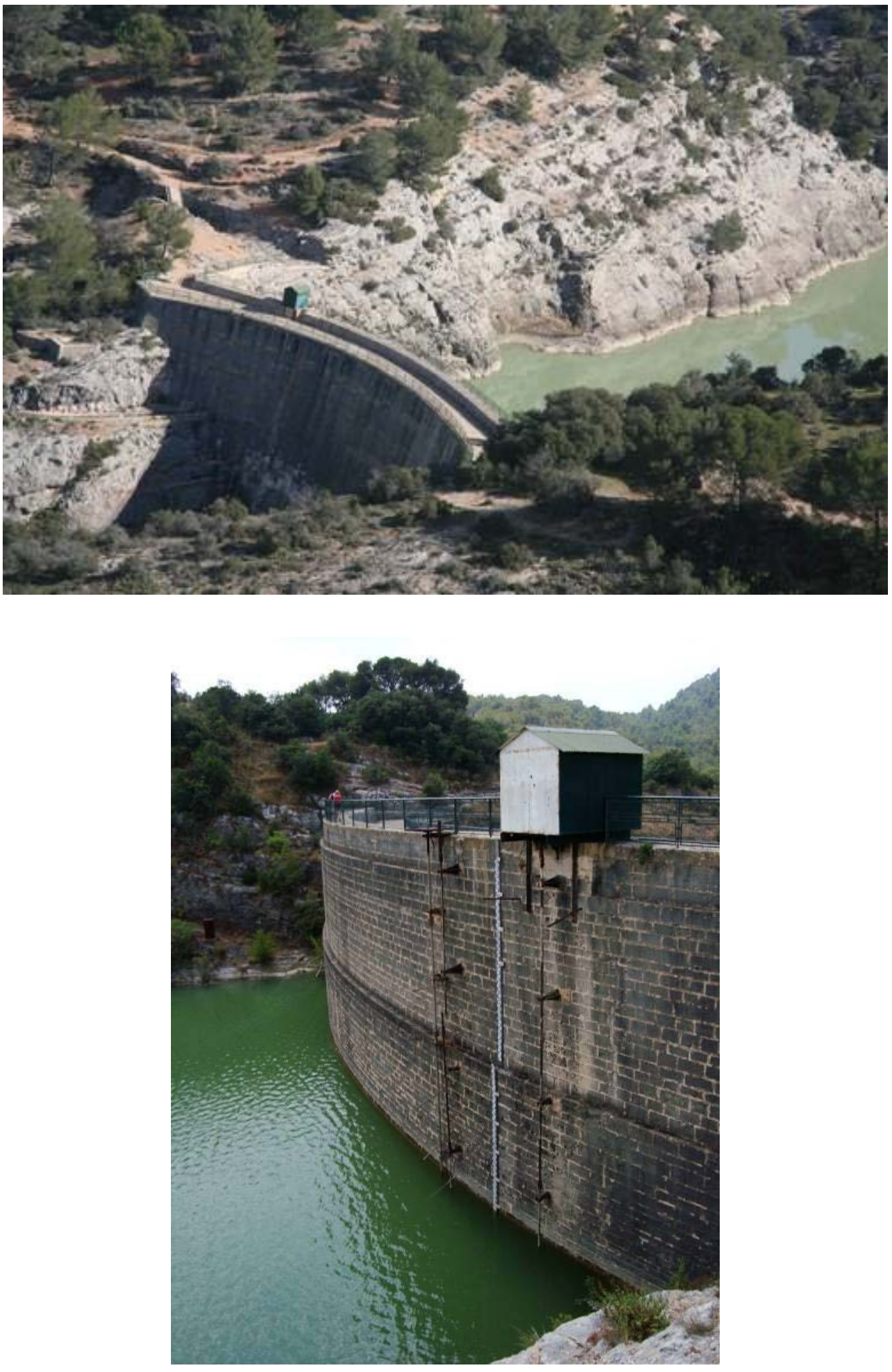

Considerada como la precursora directa de las presas arco modernas, pues las anteriores o bien tenían perfiles muy gruesos o se situaban en cerradas tan estrechas que intuitivamente invitaban a construir este tipo de presas. La presa de Zola tenía una altura de 38 metros, un espesor en la base de poco menos de 13 metros, un paramento de aguas arriba sensiblemente vertical y un 
paramento de aguas abajo de talud decreciente de forma prácticamente lineal con la altura.

En estos años destaca también la construcción en Italia de las presas de Madruzza (1883) y de Pontalto, situadas a poca distancia y en las que se aprecia claramente la diferencia de diseño entre ambas.

La sustitución de la mampostería por hormigón favorece en Estados Unidos la aplicación de esta técnica de presas bóveda que se adaptan perfectamente a los valles estrechos.

La maestría adquirida rápidamente por los constructores americanos les permite emplear seguidamente esta técnica en valles más abiertos.

La primera presa arco "moderna" fue la de Bear Valley construida en Estados Unidos entre 1883 y 1884 en California. Fue construida por F.E. Brown y estaba formada por un muro que tenía en proyección horizontal la forma de un arco de 90 metros de radio y 140 metros de longitud, muy encajada en el valle y notable por su escaso espesor.

Estaba compuesto por bloques de granito con juntas de mortero de cemento. La altura total era de 19.50 metros y el espesor, de 6 metros en la base y 0.95 metros en coronación.

Parece ser que su embalse se quedó insuficiente para las necesidades de la región por lo que se consideró su recrecimiento. Se desechó la posibilidad de recrecer la presa tal y como existía porque tenían serias dudas sobre su resistencia, por lo que resolvieron construir más aguas abajo una nueva presa en los años 1910-1911.

En el caso de la nueva presa ya no se utilizó la mampostería ordinaria al no disponer de piedra en cantidad suficiente y se adoptó el hormigón.

La tipología adoptada para la nueva presa fue la de bóvedas múltiples con contrafuertes que se detalla a continuación por su singularidad máxime teniendo en cuenta los años tan tempranos del S.XX en que se ejecutó.

La presa se compone de una serie de bóvedas inclinadas, cuyos arranques se enlazan a contrafuertes. De esta manera, la obra comprende 11 contrafuertes paralelos, separados 10 metros entre ejes, y de forma triangular. La altura máxima de estos contrafuertes es de 28 metros aproximadamente sobre 
cimientos, en tanto que su espesor varía de 45 centímetros en su vértice, a 1.20 metros aproximadamente en la base.

El cierre de aguas arriba se realiza mediante 10 bóvedas rebajadas e inclinadas que se apoyan en sus arranques sobre las caras verticales y oblicuas a los contrafuertes. El extradós de estas bóvedas construidas en hormigón armado, es cilíndrico de 5.18 metros de radio en toda su longitud, firma un arco de abertura constante de $140.6^{\circ}$ con una flecha de 3.41 metros. El espesor de la bóveda varía de 30 centímetros en la parte superior, a 66 centímetros aproximadamente en la inferior.

Para dar más estabilidad a los contrafuertes se los arriostró transversalmente por tres vigas en $\mathrm{T}$ horizontales regularmente espaciadas a lo largo de la arista de aguas abajo, de 0.75 metros de anchura de ala y de 0.61 metros de altura. Estas vigas descansan entre los contrafuertes sobre arcos rebajados de $0.30 \times 0.30$ metros de sección en la clave y de 0.38 x 0.38 metros en los arranques.

Unos soportes verticales transmiten la carga de las vigas al riñón de la bóveda entre la clave y los arranques.

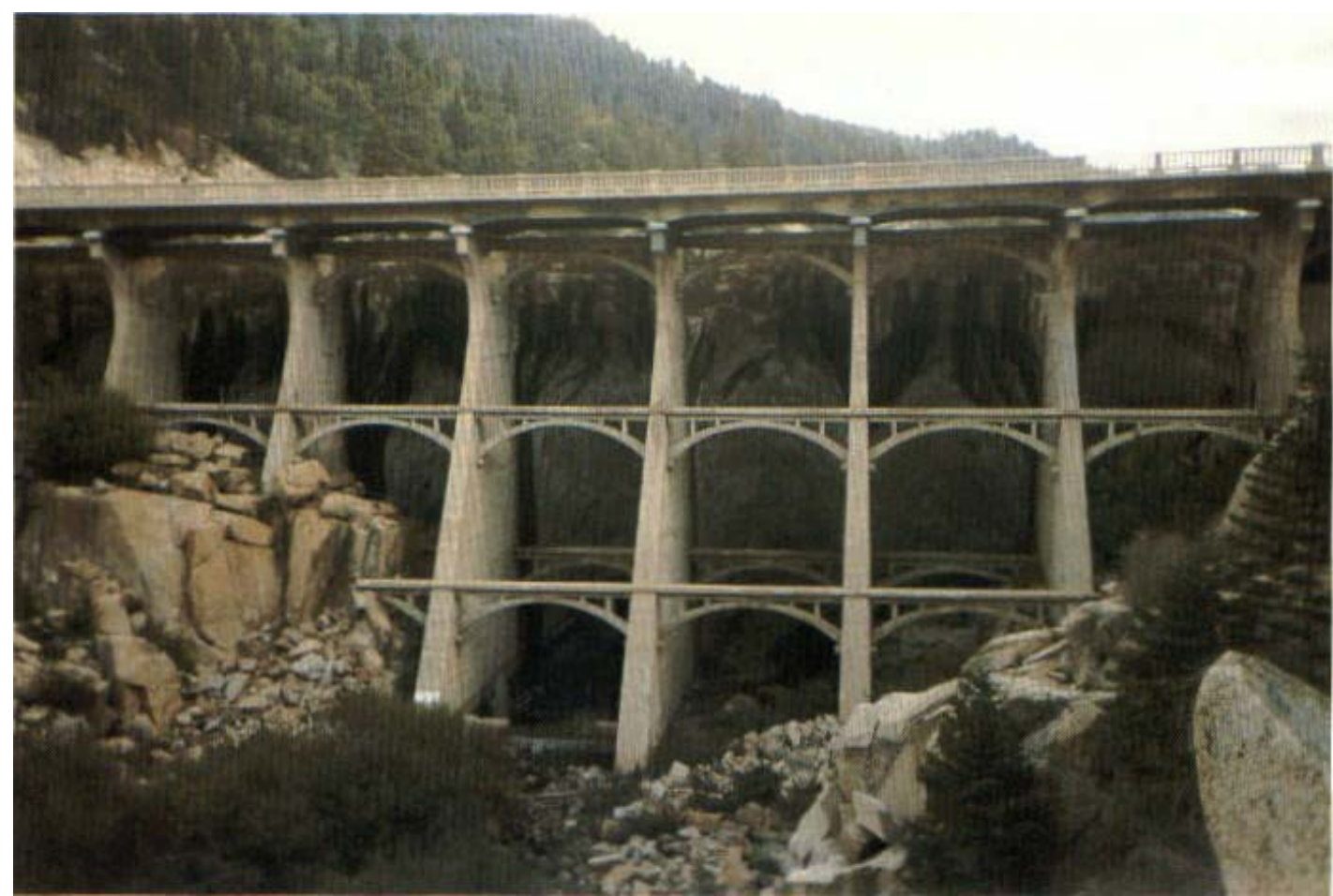



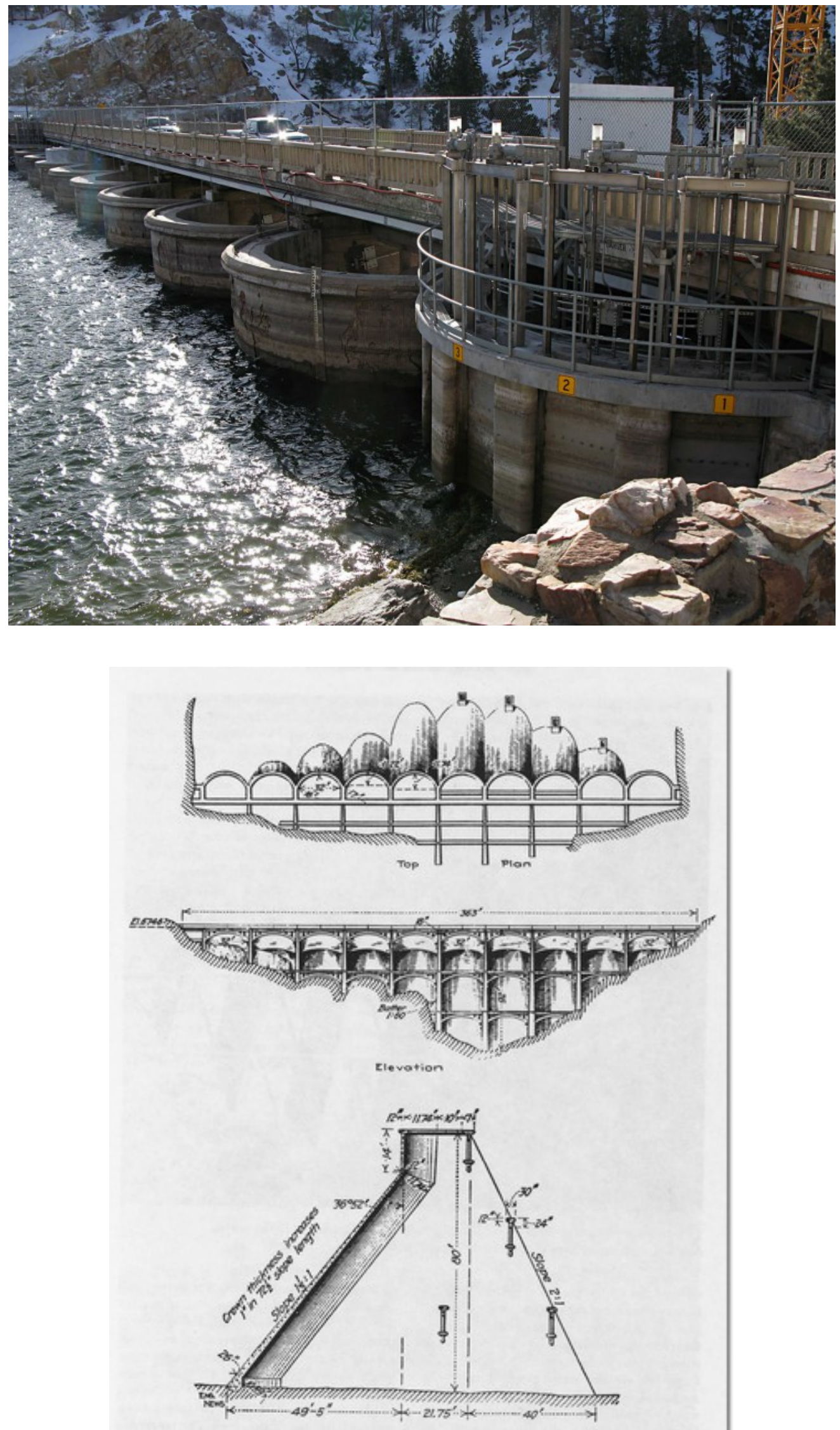

5.14 Drawings of Earmoods Big Bear Walley Dam, induding a plan, an elewation, and a crosi section of a buttress (Engineering News, 1913)

\section{Planos de Eastwood de la presa Big Bear}


Las presas de bóvedas múltiples, en definitiva son presas de contrafuertes con pantallas entre los mismos en forma de arco o bóveda.

El nacimiento de este tipo de presas se debe principalmente al objetivo de reducir el ancho a cubrir en una cerrada, cortando el vano en tramos de menor longitud (distancia entre contrafuertes) donde ya es factible cubrirlo con arcos.

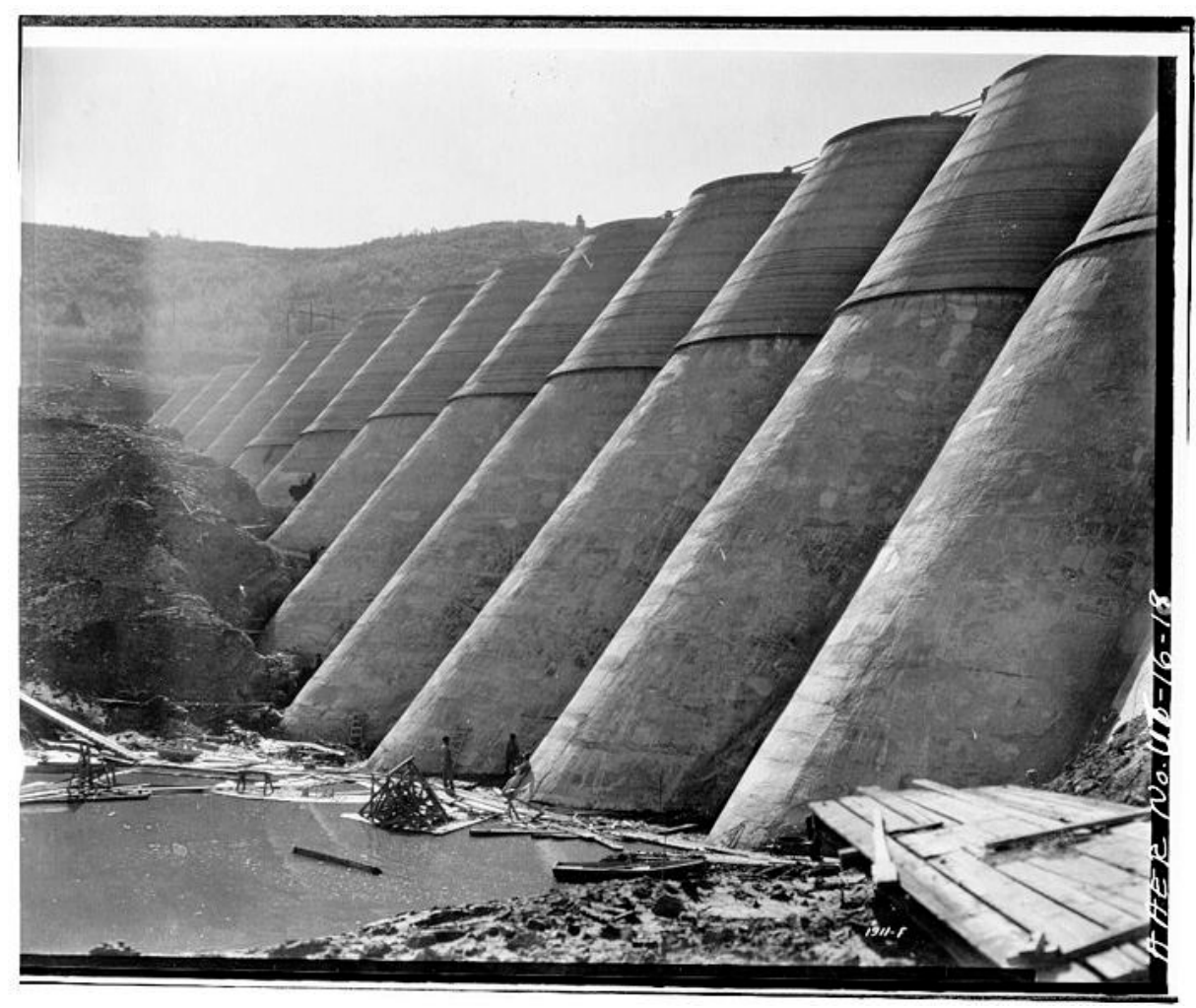

Presa Mountain Dell, Estados Unidos

El primero en explorar estas soluciones fue el Imperio Romano, en el siglo I DC, con 2 obras que aún siguen en pie: la presa Esparragalejo, en Mérida (España) y la presa Muro, en Portugal. Ambas son presas bajas (alrededor de 5m) y construidas en mampostería. Las bóvedas apoyan en 13 contrafuertes. Mide $3,20 \mathrm{~m}$ de largo, 2,20m de ancho y 5,60m de alto. Se trata en líneas generales de un muro rectilíneo con ligero abombamiento en su parte central. 


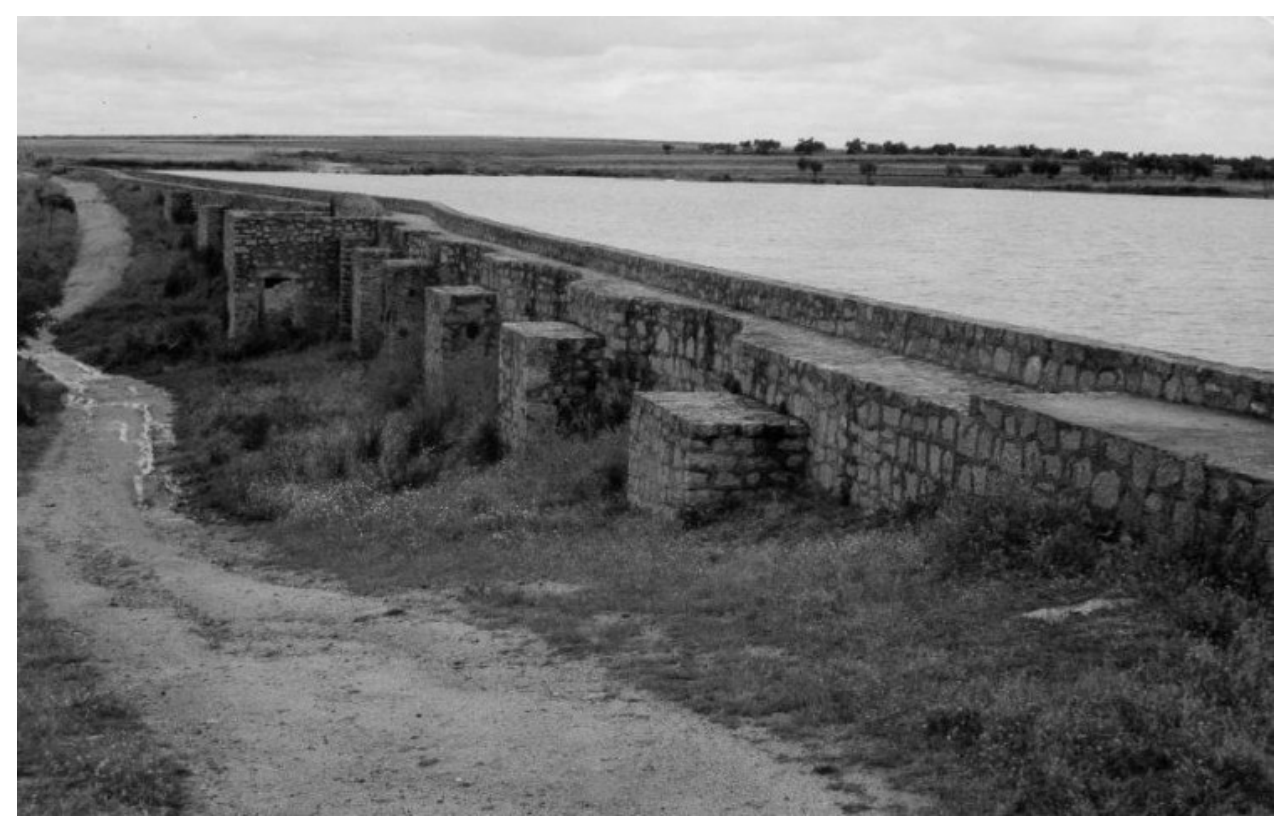

Presa Esparragalejo, España

Durante muchos siglos se siguieron desarrollando diversos proyectos en el mundo, como la presa de Meer Allum, construida en 1804 en India que cuenta con 15m de altura. Ya hacia 1908, el Ingeniero John Eastwood estuvo a cargo del proyecto y la construcción de la presa del lago Hume, California, que con 18m de altura y $203 \mathrm{~m}$ de largo fue la primera presa de hormigón armado de este tipo.

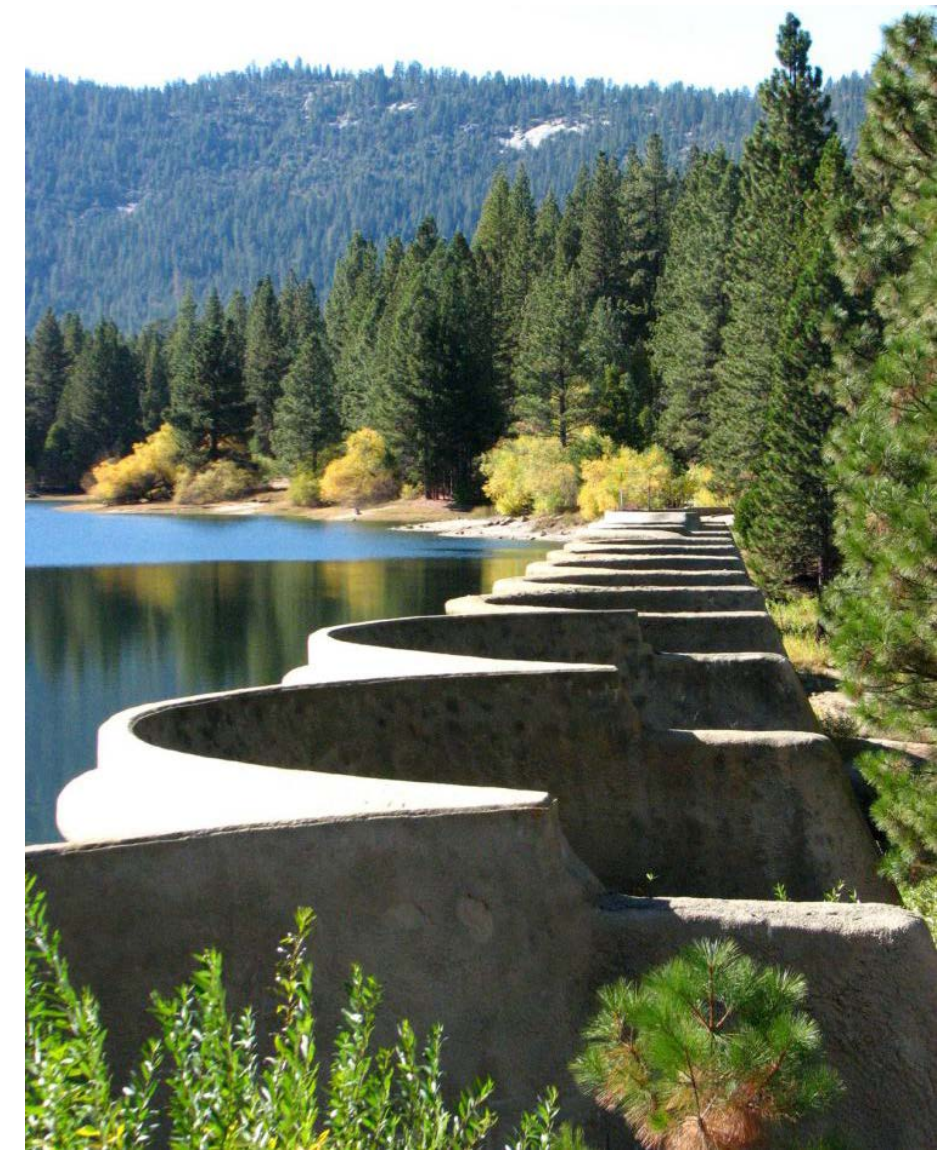

Presa Hume, Estados Unidos 


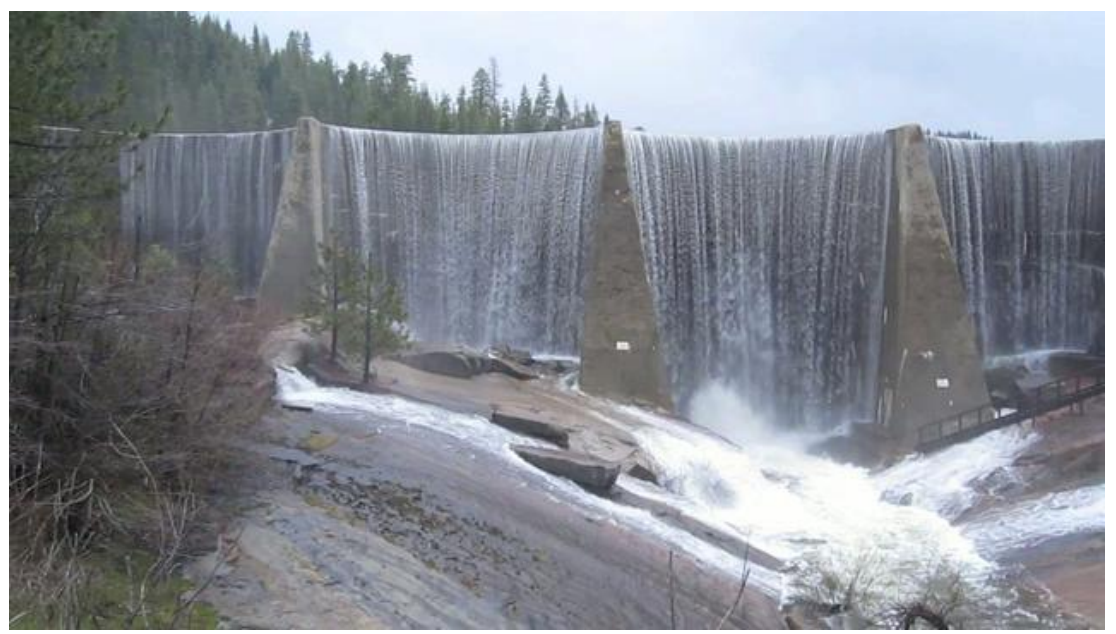

Presa Hume, durante una crecida

Tras demostrar las practicidad de este tipo de presas, además de la notable reducción en los costos de materiales, Eastwood tuvo participación en una gran cantidad de proyectos de este tipo como la presa de Big Bear antes descrita.

Otra presa de característica belleza, también diseñada por Eastwood, es la presa Lake Hodges, construida en 1918 con 41 metros de altura.

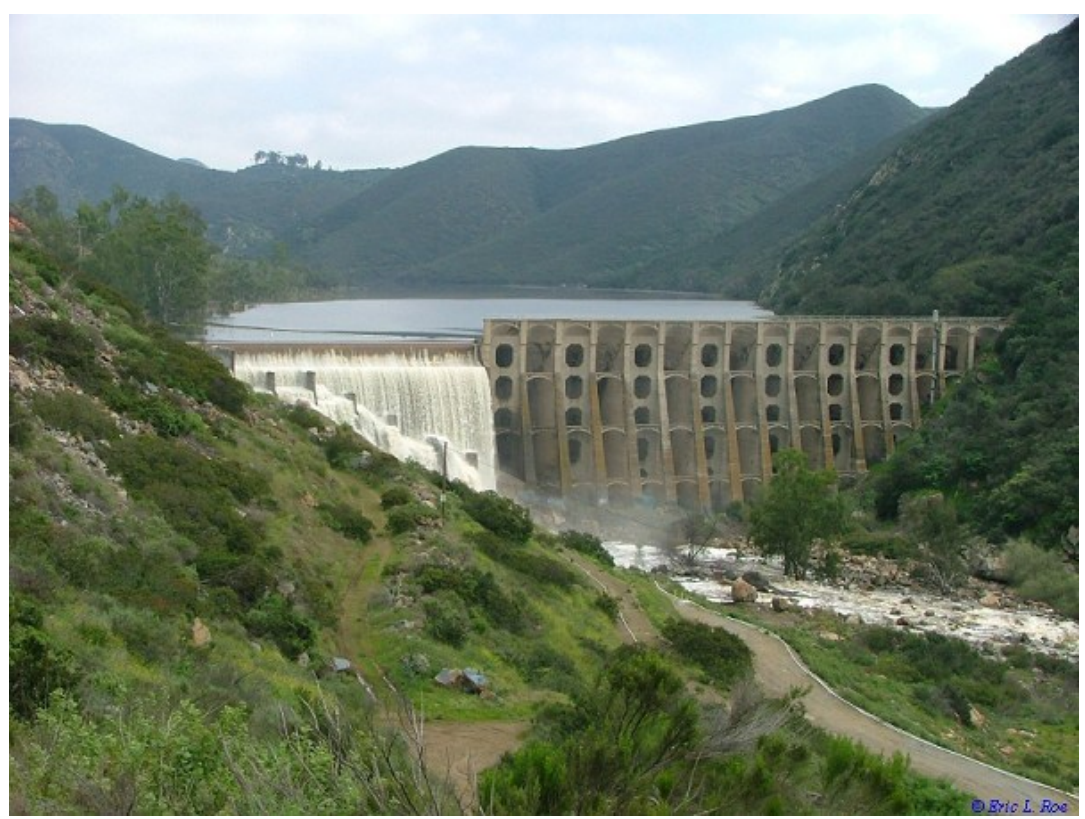

Presa Lake Hodges, California, Estados Unidos

La presa de arcos múltiples de mayor altura en la actualidad es la presa DanielJohnson, cerca de Quebec, Canadá. Presenta una altura de $214 \mathrm{~m}$ y una longitud de coronación de $1300 \mathrm{~m}$. La presa está compuesta por 14 contrafuertes y 13 arcos, de los cuales el central, cubre una distancia entre estribos de $162 \mathrm{~m}$. La estructura, desgraciadamente, está bastante fisurada. 


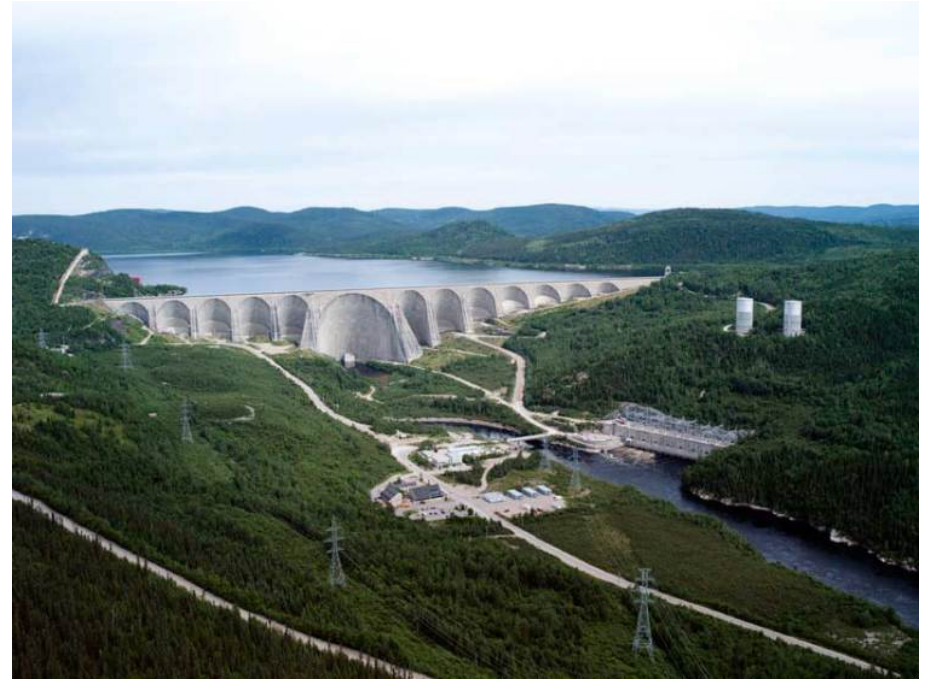

Presa Daniel-Johnson, Canadá

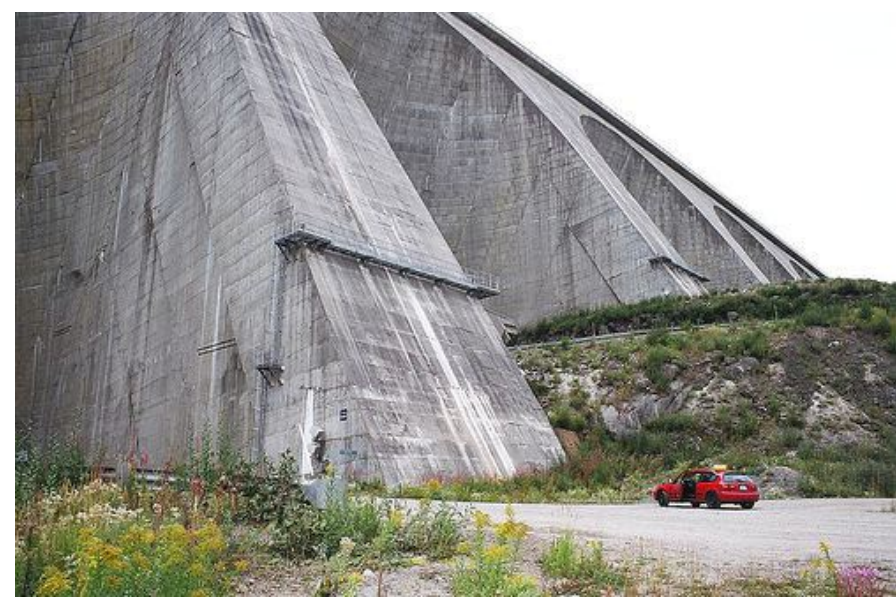

Uno de los contrafuertes del vano central de la presa Daniel-Johnson, Canadá

Otra presa de contrafuertes emblemática fue la presa de Dixence, en Suiza, diseñada por Alfred Stucky. La latitud a la que se encontraba (cota 2200 aprox.) hizo necesario hacer contiguos a los contrafuertes en el paramento de aguas abajo para disminuir los efectos térmicos. Al hacer contiguos dos contrafuertes (y sus consiguientes cabezas), se redujeron las juntas de contracción a la mitad, quedando cada elemento en forma de TT. El paramento de aguas arriba era prácticamente vertical y la planta curva para dotarle de mayor estabilidad.

Fue record mundial de altura de presa de contrafuertes hasta después de la Segunda Guerra Mundial, con sus 87 metros, y quedó sumergida en 1957 en el embalse de la presa de Grande Dixence, de gravedad y 285 metros de altura. El diseño de la presa de Dixence fue referente para otras presas como la de Trona e Inferno italianas.

En Francia, la realización más bella de este tipo de obras fue la presa de Roselend. 
La presa de Roselend es una presa francesa de contrafuertes situada en Beuafortain, en el Departamento de Saboya. Cuenta con una longitud de 800 metros, una altura de 150 metros, y una capacidad de hasta 185 millones de metros cúbicos. Está unida a las presas de Gittaz y de Saint-Guérin, así como a la central de la Bâthie, componiendo el complejo hidráulico de Beaufortin, y es considerada la presa más estética de las de Saboya. Los trabajos de construcción comenzaron en 1955, y finalizaron en 1962.
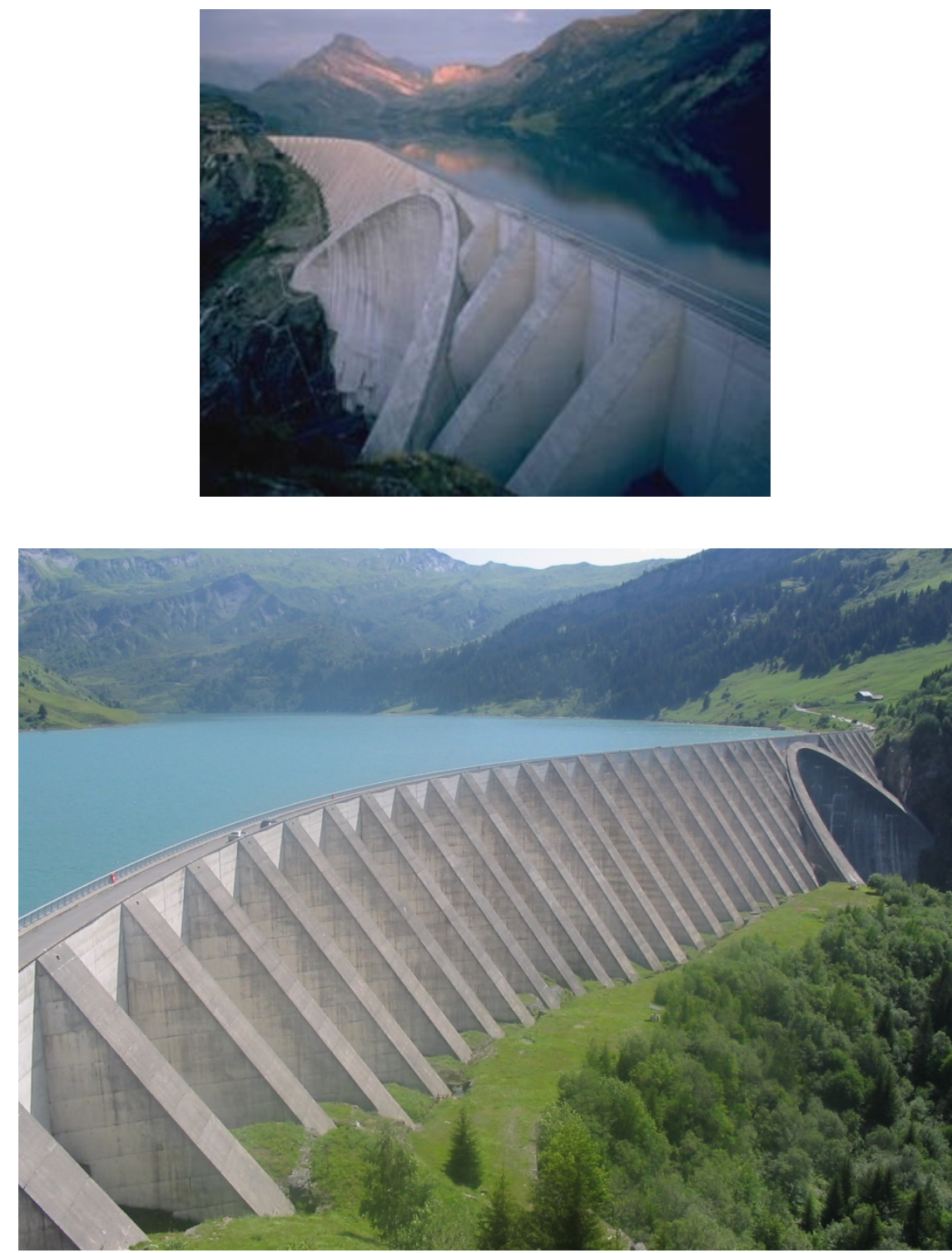

Rápidamente la construcción de presas se convierte en una técnica muy flexible por la multiplicación de formas gracias al empleo del hormigón armado. Las bóvedas múltiples y los contrafuertes aparecían como la solución que podía adaptarse a cualquier sitio en el que se quisiera implantar una presa.

Las presas de contrafuertes fueron perdiendo preponderancia debido fundamentalmente a razones económicas. Sin embargo, en 1984 se construyó la 
gran presa de Itaipú sobre el río Paraná, que abastece a la central hidroeléctrica del mismo nombre, entre la frontera de Brasil y Paraguay, con una potencia de 14 GW, siendo la citada presa de contrafuertes dobles con una altura extraordinaria de 196 metros y 872 metros de longitud de coronación, con un dique lateral de contrafuertes simples.

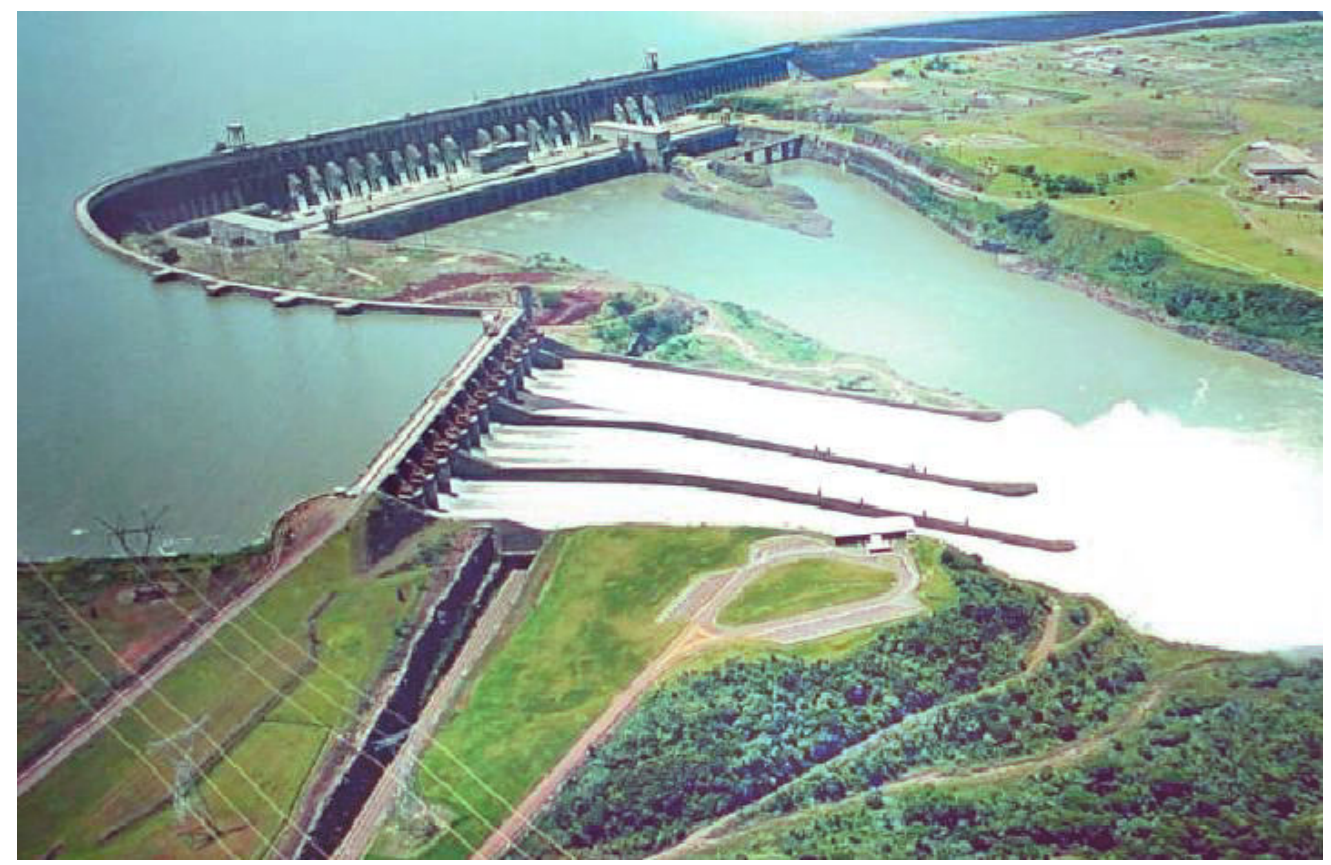

Pero volviendo a las presas arco, la presa de Sweetwater, terminada en un principio en 1886 y recrecida en numerosas ocasiones a lo largo de los años, era también de radio constante. De las actuaciones realizadas en la presa aquí interesan las efectuadas entre 1887 y 1888, es decir las que configuraron la presa hasta dos décadas después, momento en el que volvió a sufrir una radical transformación. Cuando en 1888 se terminó lo que podemos denominar "primera fase" de construcción, se convirtió en la más alta del mundo de este tipo con 30 metros y más de 100 de longitud en coronación. El perfil de la presa era bastante más robusto que el de la presa de Zola y según sus cálculos la resultante de las fuerzas externas quedaba dentro de la base.

En Estados Unidos a partir de la de Bear Valley y antes de 1900 se construyeron no menos de 4 presas arco y en Australia más de 10. Estos dos países, con realizaciones tan notables como la presa de Baroosa de cerca de 38 metros de altura, pueden considerarse pioneros en la construcción de presas arco.

Tras haber hecho pruebas, la presa bóveda fue adoptada en Francia a partir de 1920 aproximadamente para los sistemas hidroeléctricos de montaña, evitando de esta manera las enormes masas de material que tendrían que ser ejecutadas en el caso de realizar presas de gravedad convencionales. 
El número de países con suficiente conocimiento y maestría para construir una presa arco de características modernas a finales del siglo XIX y principios del XX era muy reducido en contraste con el altísimo número de arcos y bóvedas de edificación existentes en casi todo el mundo, lo que pone de manifiesto el respeto que al entorno y condicionantes naturales de las presas le han tenido históricamente los arquitectos, ingenieros y constructores y el hecho incuestionable de que las presas son algo más que una estructura al uso.

La sofisticación de la construcción da lugar a lo largo de los años 50 al empleo de bóvedas delgadas permitiendo una economía de materiales sin sacrificar la seguridad, asegurando ésta por la forma rigurosamente calculada de la bóveda.

Es muy interesante comprobar el estado de conocimiento que en España se tenía respecto a las presas bóvedas en los años 40, gracias a las aportaciones de Enrique Becerril, Ingeniero de Caminos que en el año 1941 hace una reflexión sobre la evolución de las formas en las presas bóveda. En ella indica que el perfeccionamiento de los métodos de cálculo, los resultados y observaciones de las presas bóveda construidas y la experimentación sobre modelos, dan lugar a un cuerpo de doctrina homogéneo acerca del modo de resistir de estas estructuras.

A continuación se detalla lo anterior basado en este documento tan significativo relativo al nivel de conocimiento que existía en España de las presas y en concreto de las de tipo bóveda.

Los ingenieros españoles desconocían las realizaciones notables que durante los años de la guerra civil española se habían realizado a nivel mundial.

El cálculo matemático de este tipo de presas se reconocía que aún sufrían dificultades para desarrollarlo hasta decir que "todo cálculo mecánico procede, más o menos, de una ficción, por cuanto introduce hipótesis simplificadoras que afectan a las condiciones intrínsecas del material y a la sustentación. Tales hipótesis constituyen, y muy particularmente en nuestro caso, un conjunto que define un estado arbitrario, del cual derivan los resultados del cálculo que, aparte de las imperfecciones propias de éste, no podrán tener otra validez que la que tenga la hipótesis originaria".

Por tanto, la evolución de las presas arco comprendía dos ámbitos simultáneos, el de las formas y el de los métodos de cálculo. 
En cuanto a las formas se habían dado dos criterios opuestos, el de las formas gruesas y el de las formas ligeras, que tendían ya a converger para dar lugar a tipos mixtos predominantes en los últimos años 30 .

Modelos característicos de estos dos extremos son, de una parte, las presas de Shoshone y Pathfinder, y de otra, la antigua presa de Bear Valley antes mencionada.

En tales construcciones ha predominado el empirismo, el análisis mecánico es elemental y el resultado, imperfecto. Las presas de Shoshone y Pathfinder hubieran podido sustituirse por estructuras más ligeras y adecuadas, y en cuanto a la de Big Valley, se consideró preferible anegarla con la construcción de otra aguas abajo tal y como se ha descrito con anterioridad.

La presa de Pathfinder se construyó en los años 1905-1909 aunque posteriormente sufrió numerosas modificaciones en años posteriores. Se construyó en mampostería ciclópea.

El cambio de uso del material para este tipo de presas de mampostería a hormigón armado, favoreció la realización de estructuras más esbeltas.

Ejemplos de secciones tipo de presas bóveda en las que se puede observar esas tendencias distintas en cuanto a la esbeltez de la estructura, se adjunta a continuación.

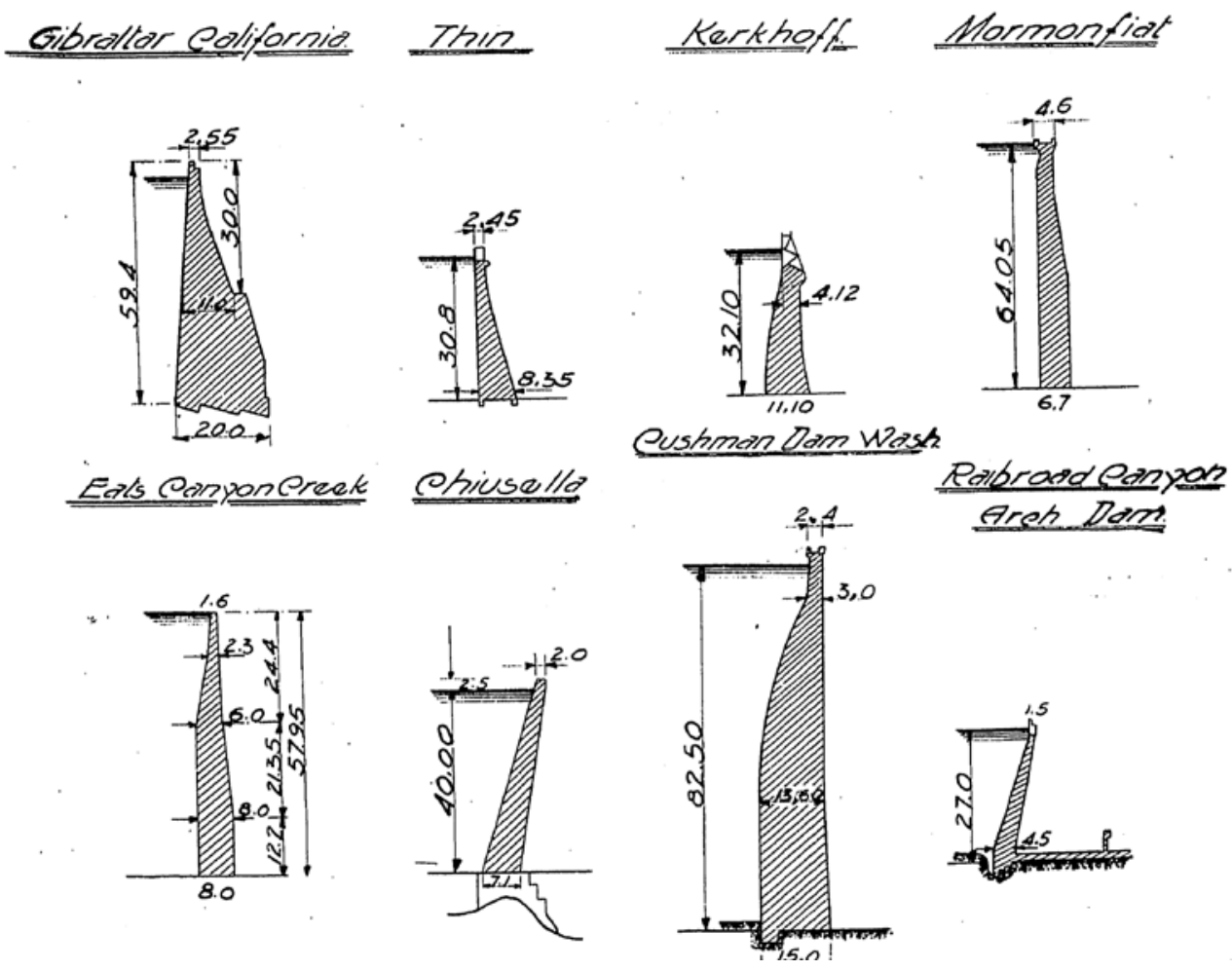




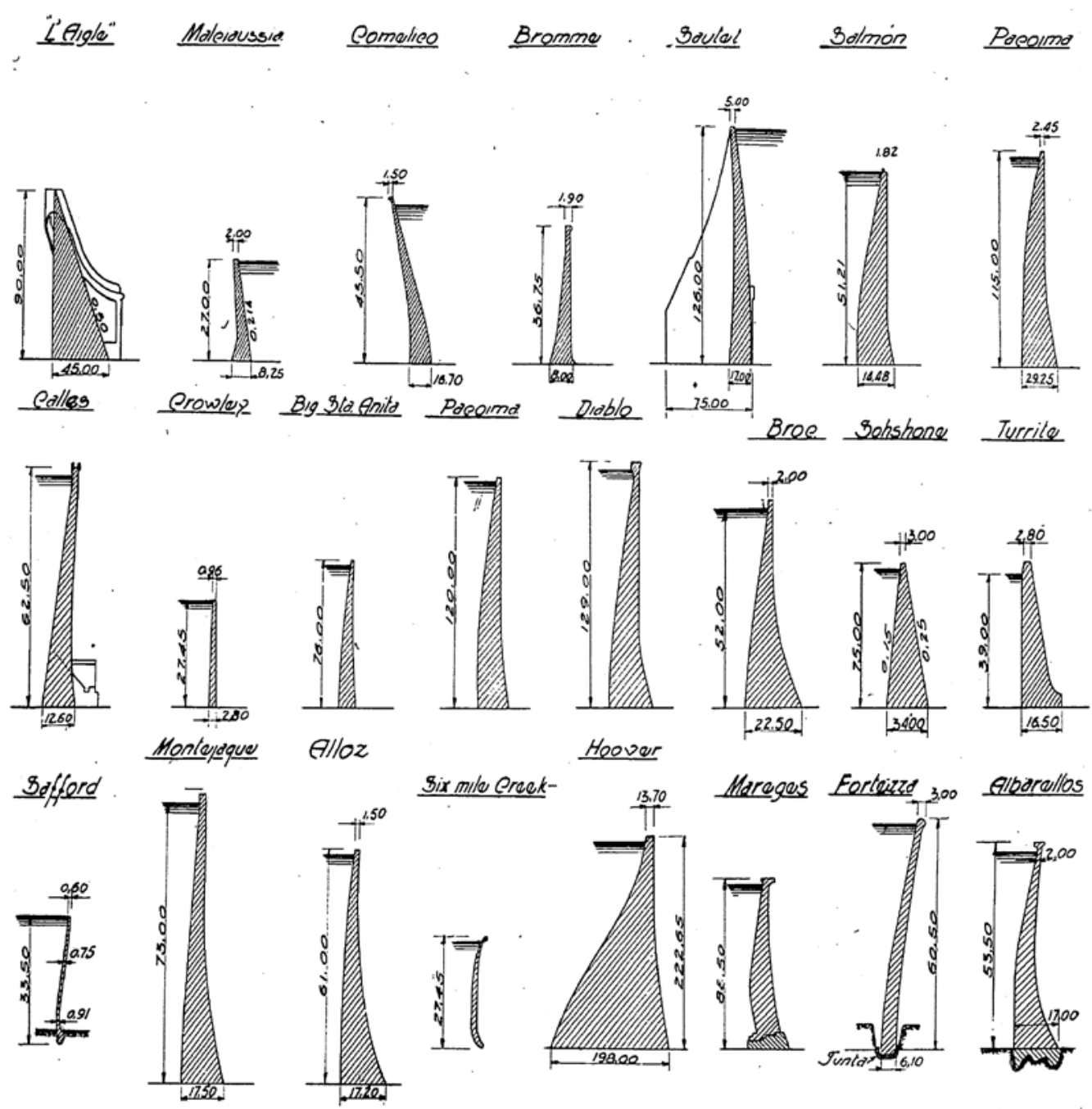

En cuanto a los métodos de cálculo, en 1941, consideraban que las hipótesis de cálculo habían evolucionado de lo sencillo a lo complejo, clasificándose de la siguiente forma:

1) En razón de los elementos que se suponen resistentes:

a. Los elementos resistentes son exclusivamente horizontales y no se influyen mutuamente (fórmulas de los tubos, métodos de Guidi Ippolito, etc.)

b. Los elementos resistentes son horizontales y verticales, cumpliéndose una condición de continuidad (Ritter, Stucky, Trial Load system, etc.).

2) En razón del cálculo de los arcos:

a. Método del anillo circular, delgado o grueso, sometido a cargas normales a su directriz.

b. Por la consideración del arco, empotrado o apoyado, sometido a cargas normales a su trasdós (uniformes o variadas). 
c. Por la consideración de la misma hipótesis, imaginando, además, una deformación de los apoyos (Vogt.).

A parte, quedaba el procedimiento de cálculo que entendían más perfecto desde el punto de vista teórico, éste es, la consideración total de la estructura como una superficie, a la manera del cálculo de las bóvedas delgadas, "por más que su aplicación tropiece con considerables dificultades de planteamiento y desarrollo, que han impedido, hasta la fecha, por lo menos su generalización".

Entendían en esos años que los procedimientos usuales del tanteo de cargas permitían un suficiente conocimiento de la distribución de esfuerzos y, en consecuencia, la intuición del régimen de trabajo, "lo que consideramos fundamental, porque de ella derivarán, como consecuencias necesarias, la adecuación de las formas y aun el perfeccionamiento de los métodos de cálculo". Recordaba que el Reclamation Service norteamericano utilizaba esos métodos.

"Además, y es tema en el que valdría la pena insistir, la experimentación en obra y sobre modelos confirma, en líneas generales, el acuerdo con estos cálculos, si bien las influencias termométricas, y otras, pueden dificultar la interpretación correcta de los resultados.".

En cualquier caso y dados los problemas de cálculo que eran conscientes que tenían, se recurre al ensayo sobre modelo lo que consideran asimismo de interés para obtener conclusiones sobre el comportamiento de este tipo de presas.

Records de presas arco de radio variable con uso hidroeléctrico:

\begin{tabular}{|l|l|l|l|l|l|}
\hline Presa & Año & País & Altura & Longitud & Vol. hormigón \\
\hline Salmon Creek & 1914 & EE.UU & 51 & 195 & 40.000 \\
\hline Spaulding & 1919 & EE.UU & 84 & 244 & 147.000 \\
\hline Cushman I & 1926 & EE.UU & 84 & 339 & 69.000 \\
\hline Diablo & 1930 & EE.UU & 119 & 360 & 268.000 \\
\hline Lumieri & 1947 & Italia & 136 & 138 & 100.000 \\
\hline Mauvoisin & 1957 & Suiza & 237 & 520 & 2.030 .000 \\
\hline Vaiont & 1960 & Italia & 262 & 190 & 351.000 \\
\hline Inguri & 1980 & Georgia & 272 & 680 & 3.960 .000 \\
\hline
\end{tabular}


Presas de gravedad de hormigón de carácter hidroeléctrico record del mundo:

\begin{tabular}{|l|l|l|l|l|l|}
\hline Presa & Año & País & Altura & Longitud & Vol. hormigón \\
\hline Perolles & 1872 & Suiza & $21+3$ & 195 & 32.000 \\
\hline Periyar & 1897 & India & 54 & 439 & 140.000 \\
\hline Schrach & 1924 & Suiza & 112 & 156 & 237.000 \\
\hline Chambon & 1934 & Francia & 136 & 294 & 295.000 \\
\hline Grande Dixence & 1961 & Suiza & 285 & 695 & 5.957 .000 \\
\hline Sayano & 1983 & Rusia & 245 & 1066 & 9.075 .000 \\
\hline
\end{tabular}

Sin embargo, el progreso de la construcción en hormigón no hace abandonar totalmente la realización de presas de mampostería, ni ciertas técnicas tradicionales como las presas de materiales sueltos, derivadas de la técnica de construcción de diques marítimos y los diques de tierra.

De las presas de mampostería, citar solamente las presas de esta tipología que fueron record del mundo, las presas indias de Mettur, de 1934, de 70 metros de altura y 1615 metros de longitud, y la de Nagarjuna, de 1974, de 125 metros de altura y 1450 metros de longitud que sufrió un segundo recrecimiento que ya fue realizado en hormigón.

Respecto a las presas de materiales sueltos, formadas principalmente por un núcleo central impermeable constituido por arcilla compactada introduciéndose en parte en la cimentación, se utilizan en sustitución de las presas de gravedad en el caso de largas cerradas o bajos saltos, cada vez que los imperativos económicos entran en juego.

La primera gran presa en tierras fue construida en Panamá en 1912. La técnica se fue perfeccionando en el curso de los años 30 para regularizar y explotar los grandes ríos.

Las grandes realizaciones de esa época, aunque no de este tipo de presas, es la presa Hoover en el río Colorado, que empezó a construirse en el año 1931 finalizando su construcción dos años antes de lo previsto, en 1936, y la famosa serie de presas de aprovechamiento hidroeléctrico del Valle de Tennessee entre las que sí se encuentran tipologías de presas de materiales sueltos además de presas de gravedad de hormigón.

En el año 1923 comenzó la construcción de la presa de Dix, concluyéndose en 1927, en Kentucky, presa de materiales sueltos con pantalla de hormigón. De 87 metros de altura, 331 metros de longitud y 230 metros de ancho de base, esta 
presa hidroeléctrica, fue record de altura en presas de materiales sueltos en Estados Unidos antes de 1930.

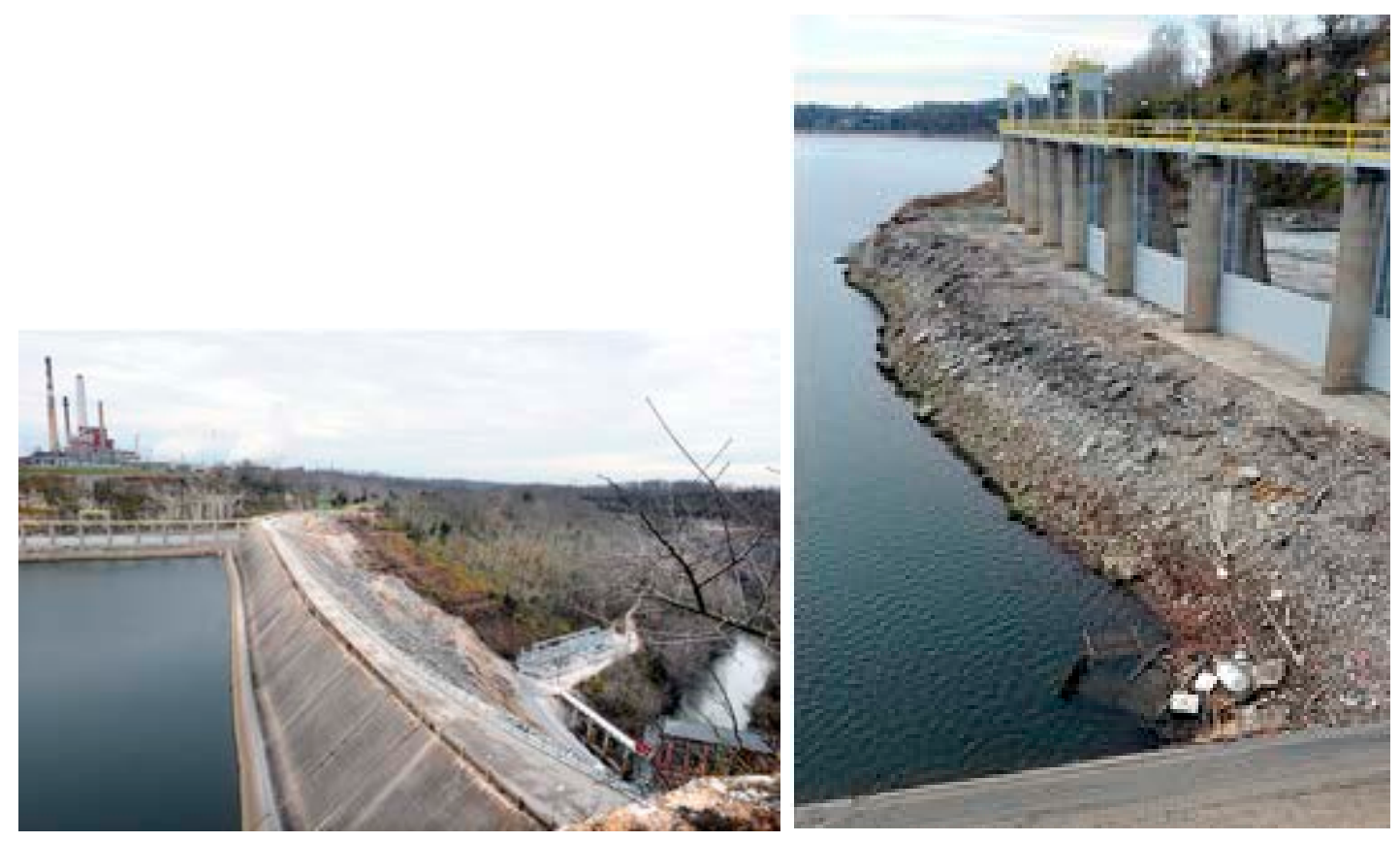

Otras grandes presas de tierras han seguido haciéndose, como la de SerrePonçon en Francia, terminada en 1961,

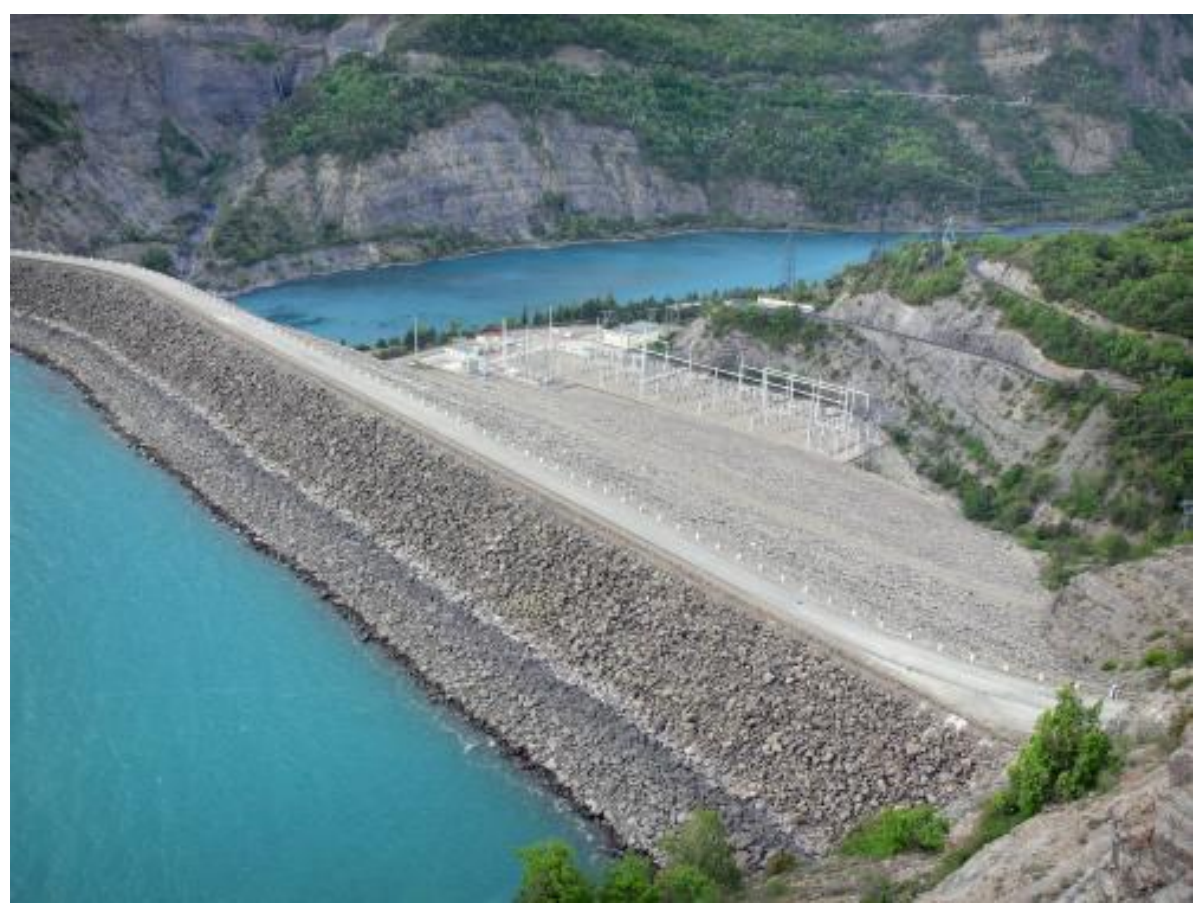

y la presa de Asuán (presa Alta de Asuán) en Egipto (1960-1971). Es la 8aa presa mayor del mundo por superficie y la $4^{a}$ por volumen. Tiene 111 metros de altura de presa, 980 metros de anchura de la base, 40 metros de anchura de coronación y 3830 metros de longitud de coronación. 


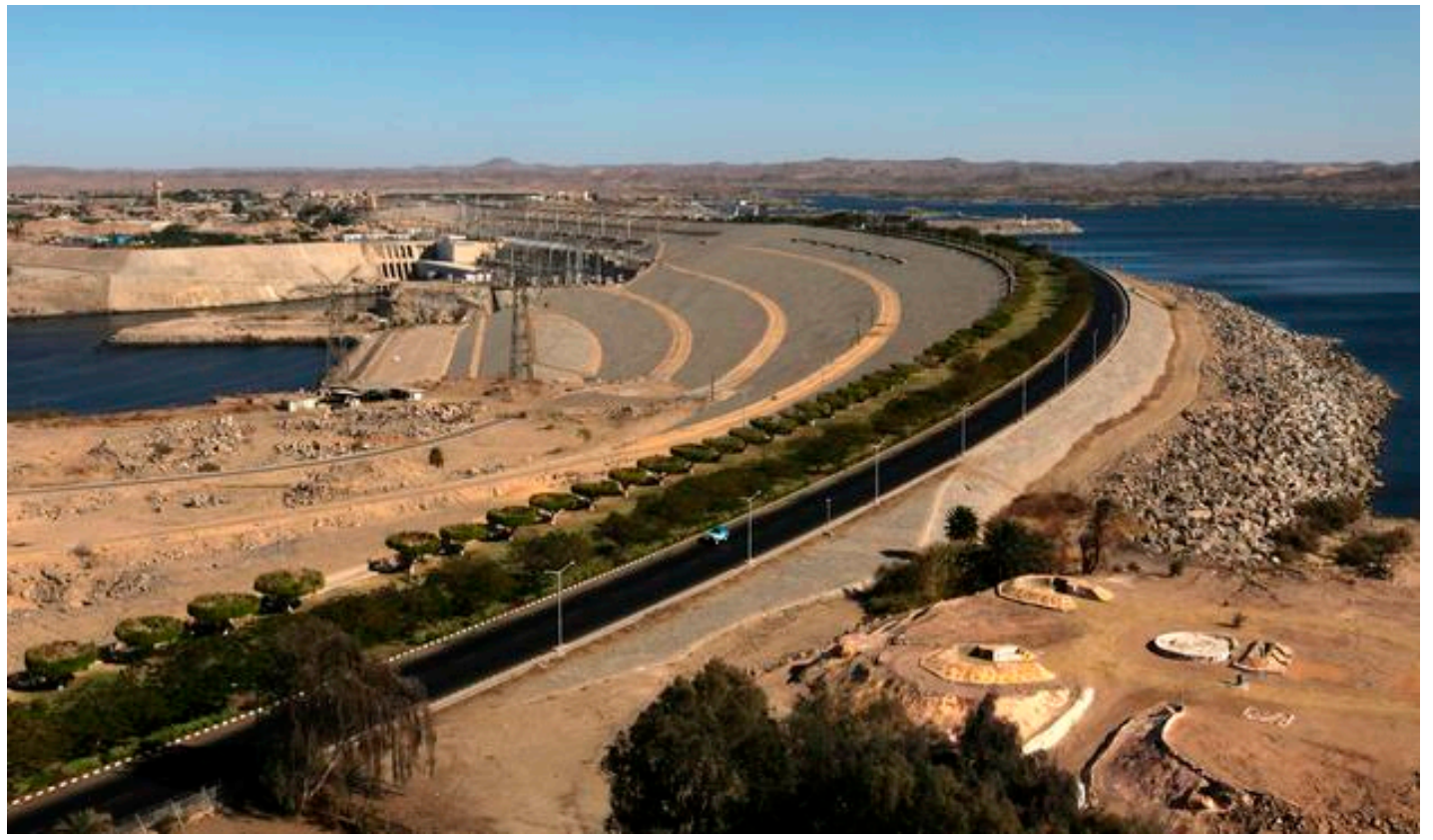

En España, una de las mayores presas de materiales sueltos con núcleo de arcilla destinada a uso hidroeléctrico, es la de Portodemouros de 1967.

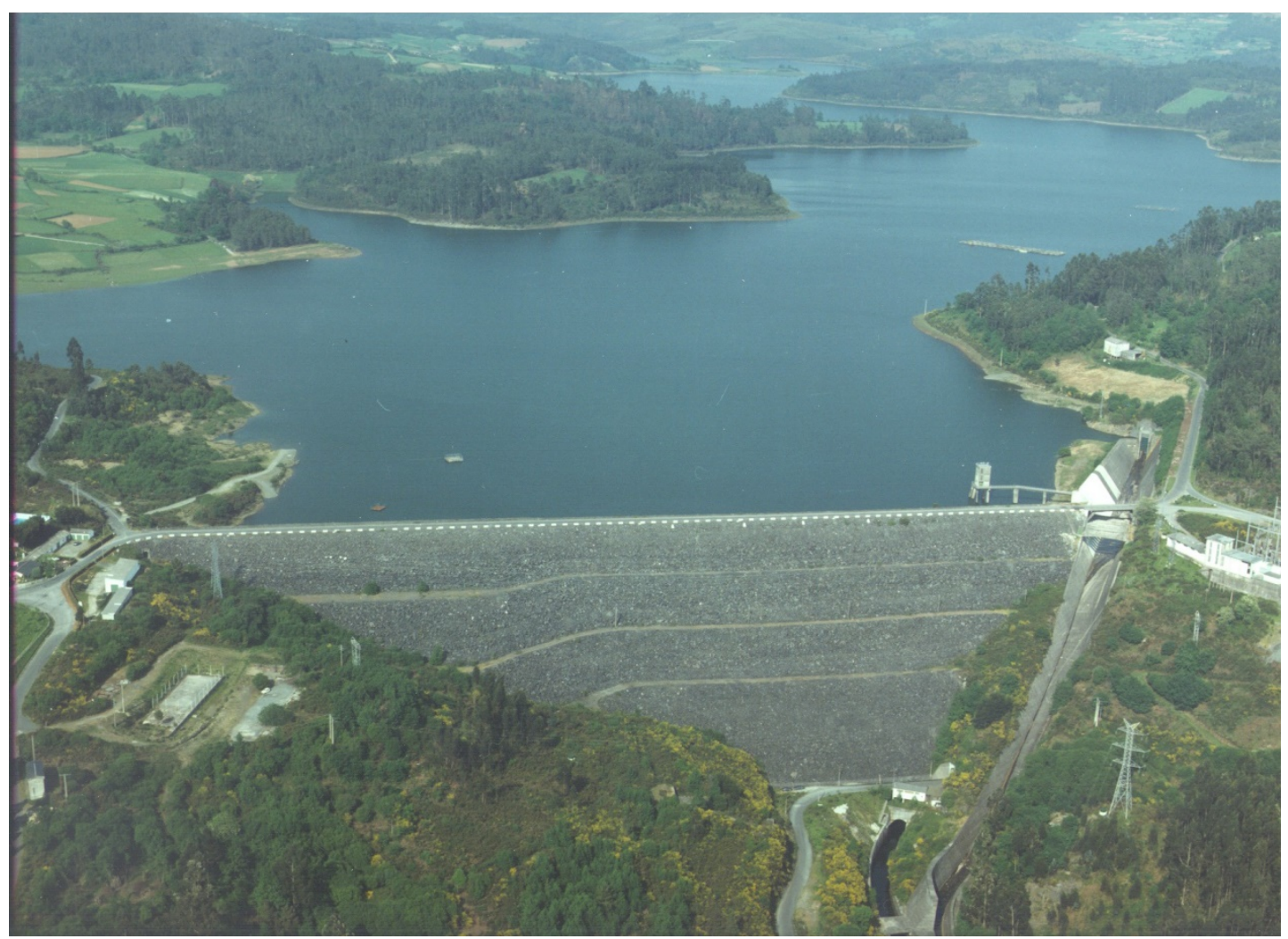


Presas de materiales sueltos de carácter hidroeléctrico que han sido record del mundo en altura o volumen de embalse desde el año 1930 al 1989, fueron:

\begin{tabular}{|l|l|l|l|l|l|l|}
\hline Presa & Año & País & Tipo & Altura & Embalse \\
\hline $\begin{array}{l}\text { Salt } \\
\text { Springs }\end{array}$ & 1931 & EEUU & $\begin{array}{l}\text { Escollera con pantalla de } \\
\text { hormigón }\end{array}$ & 100 & 2.3 \\
\hline Swift & 1958 & EEUU & M.S. heterogénea & 156 & 11.8 \\
\hline Bennett & 1967 & Canadá & M.S. heterogénea & 183 & 43.7 \\
\hline Mica & 1972 & Canadá & M.S. heterogénea & 242 & 32.1 \\
\hline Tarbela & 1976 & Pakistán & M.S. heterogénea & 143 & 105.6 \\
\hline Moreno & 1980 & Méjico & $\begin{array}{l}\text { Escollera con núcleo } \\
\text { impermeable }\end{array}$ & 261 & 15.4 \\
\hline Nurek & 1980 & Tajikistán & M.S. heterogénea & 300 & 58 \\
\hline
\end{tabular}

A continuación, se adjunta una tabla con algunas de las principales presas asociadas a instalaciones hidroeléctricas a nivel mundial, algunos de los cuales fueron en su día, record de altura de presa, de potencia instalada o de volumen de embalse. 
Tableau 7.VII. Quelques très grands barrages-réservoirs associés à des installations hydroélectriques ${ }^{38}$.

En gras: records de hauteur du barrage, de puissance installée, ou de volume de réservoir.

\begin{tabular}{|c|c|c|c|c|c|c|c|}
\hline \multirow[b]{2}{*}{ Date } & \multirow[b]{2}{*}{ Rivière } & \multirow[b]{2}{*}{ Nom } & \multicolumn{3}{|c|}{ Caractéristiques du barrage } & \multirow{2}{*}{$\begin{array}{l}\text { Puissance } \\
\text { installée } \\
(\mathrm{MW})\end{array}$} & \multirow{2}{*}{$\begin{array}{c}\text { Volume } \\
\text { du réservoir } \\
\text { (millions de } \\
\mathrm{m}^{3} \text { ) }\end{array}$} \\
\hline & & & $\begin{array}{l}\text { Hauteur } \\
\qquad(\mathrm{m})\end{array}$ & $\begin{array}{l}\text { Longueur } \\
\text { à crête } \\
(\mathrm{m})\end{array}$ & Type & & \\
\hline 1934 & $\begin{array}{c}\text { Romanche } \\
\text { (France) }\end{array}$ & Chambon & 136 & 294 & poids (béton) & & 50 \\
\hline 1936 & Colorado (USA) & Hoover & 221 & 380 & poids (béton) & $1350^{a}$ & 37000 \\
\hline 1942 & Columbia (USA) & Grand Coulee & 168 & 1272 & poids (béton) & $\begin{array}{c}2000 \text { puis } \\
6200 \\
\end{array}$ & 11800 \\
\hline 1948 & Rhône (France) & Génissiat & 104 & 140 & poids (béton) & 400 & 12 \\
\hline 1952 & Isère (France) & Tignes & 180 & 295 & voûte & 100 & 230 \\
\hline 1959 & $\begin{array}{l}\text { Zambèze } \\
\text { (Zambie) } \\
\end{array}$ & Kariba & 128 & 617 & voûte & 1500 & 160000 \\
\hline 1960 & $\begin{array}{l}\text { Doron de Beaufort } \\
\text { (France) }\end{array}$ & Roselend & 150 & 804 & $\begin{array}{c}\text { poids } \\
\text { à contreforts }\end{array}$ & 530 & 200 \\
\hline 1960 & Durance (France) & Serre-Ponçon & 129 & 600 & en terre & 350 & 1300 \\
\hline 1962 & Dixence (Suisse) & $\begin{array}{l}\text { Grande } \\
\text { Dixence } \\
\end{array}$ & 285 & 695 & poids (béton) & 700 & 400 \\
\hline 1964 & Angara (Sibérie) & Bratsk & 125 & 1430 & à contreforts & 4600 & 169000 \\
\hline \multirow[t]{2}{*}{1965} & Volta (Ghana) & Akosombo & 141 & 640 & enrochements & 770 & 148000 \\
\hline & Sira (Norvège) & Svartevatn & 128 & & enrochements & 200 & 1400 \\
\hline 1968 & $\begin{array}{l}\text { Manicouagan } \\
\text { (Canada) }\end{array}$ & $\begin{array}{l}\text { Daniel John- } \\
\text { son } \\
\end{array}$ & 214 & 1314 & $\begin{array}{c}\text { voûtes } \\
\text { multiples }\end{array}$ & 1350 & 142000 \\
\hline 1970 & Nil (Égypte) & Assouan & 111 & 3820 & enrochements & 2100 & 164000 \\
\hline 1972 & $\begin{array}{c}\text { Orange } \\
\text { (Afrique du Sud) }\end{array}$ & $\begin{array}{l}\text { Hendrick } \\
\text { Verwoerd }\end{array}$ & 88 & 914 & voûte & 320 & 6000 \\
\hline 1976 & Indus (Pakistan) & Tarbela & 143 & 2743 & terre & 2100 & 164000 \\
\hline 1977 & $\begin{array}{c}\text { Vakhsh } \\
\text { (Tadjikistan) }\end{array}$ & Nurek & 317 & 730 & terre & 2700 & 10400 \\
\hline 1977 & Inguri (Sibérie) & Inguri & 272 & 766 & voûte & 1600 & 1100 \\
\hline 1979 & $\begin{array}{c}\text { Bandama } \\
\text { (Côte-d'lvoire) }\end{array}$ & Taabo & 30 & 7850 & & 210 & 600 \\
\hline 1983 & (Russie) & Sayano & 245 & 1066 & poids (béton) & $6450 ?$ & \\
\hline 1983 & $\begin{array}{c}\text { Parana } \\
\text { (Brésil-Paraguay) } \\
\end{array}$ & Itaïpu & 196 & 7744 & à contreforts & $\begin{array}{c}12600 \\
(18 \times 700) \\
\end{array}$ & 29000 \\
\hline 1986 & $\begin{array}{c}\text { Caroni } \\
\text { (Venezuela) }\end{array}$ & $\begin{array}{c}\text { Guri-Raul } \\
\text { Leoni }\end{array}$ & 162 & 1300 & terre + béton & 10000 & 111000 \\
\hline $\begin{array}{l}1993 \\
2009\end{array}$ & Yangzi (Chine) & Trois-Gorges & 175 & 1331 & poids (béton) & $\begin{array}{c}18200 \\
(26 \times 700)\end{array}$ & 39000 \\
\hline
\end{tabular}

a. En 1961. Depuis 1993: 2000 MW. 


\subsection{EL CASO ESPAÑOL}

En España, la evolución de la tipología de presas en un siglo (1900-2000) fue la siguiente. Se observó un claro predominio de las presas de gravedad hasta la década de los años 70. Incluso a nivel europeo, también en las primeras décadas del S.XX la tipología de gravedad era por la que mayormente se decantaba la comunidad presística. El propio Juillard, decía en 1935 que durante largo tiempo había prevalecido (y seguía prevaleciendo) en los técnicos la idea de que las presas de gravedad eran las únicas que ofrecían garantías suficientes de estabilidad y de seguridad. Hasta tal punto que se realizaban presas de gravedad en ubicaciones en las que otro tipo de presas hubiera sido más racional.

Aunque desde la primera mitad de la década de los 60 comenzó a ser habitual la construcción de presas de materiales sueltos, no es hasta los años 70 cuando empiezan a adquirir mayor importancia. Debido a su menor coste, se produce un despegue en la construcción de este tipo de presa que, posiblemente, no se había producido con anterioridad por la falta de maquinaria que hiciese viable su construcción. Sin embargo y debido a los accidentes de los 80 producidos en las presas de esta última tipología debido a las avenidas, la tendencia que se venía dando se compensa, siendo al final del siglo XX el porcentaje de ambas tipologías, similar.

Las presas bóveda ocupan un lugar significativo a partir de la década de los 70, con porcentajes entre el 5-8\% aunque sí son una gran parte de las presas más importantes. Tardaron en aceptarse las presas arco en Europa debido principalmente a la inercia de técnicos y responsables administrativos de seguir aplicando soluciones ya experimentadas y conocidas, y también a la dificultad de conocer el estado tensional, lo que provocaba incertidumbres inaceptables para muchos.

Poco a poco se fue venciendo esta resistencia por los esfuerzos de algunos ingenieros como Juillard, Grunner y Stucky, que demostraron que las incertidumbres a que daba lugar el cálculo de las presas de gravedad, eran tan importantes como las de las presas arco. También, el buen comportamiento de presas arco como las de Amsteg, Spitallam, y Montejaque y Alloz en España, favorecieron ese cambio de mentalidad en la comunidad presística. Posteriormente, los ensayos en modelo reducido fueron un espaldarazo importante para la construcción de presas según esta tipología, ya que demostraron ser una herramienta muy útil para comprobar los resultados obtenidos de manera analítica a cerca de su comportamiento, y permitieron depurar y optimizar más aún las secciones. 
Las presas de contrafuertes constituyeron también alrededor de un 10\% de las presas construidas hasta la década de los 70. De hecho, la escasez de materiales y una cierta experiencia en la realización de proyectos de este tipo a lo largo de décadas anteriores, dieron lugar a un principal apogeo de esta tipología de presas en los años 50. Sin embargo, a partir de los setenta no se construyeron más presas de esta tipología.

A continuación se va a analizar si las presas de carácter hidroeléctrico siguen este patrón en cuanto a la evolución tipológica de las mismas. Para ello se han tomado de referencia las pertenecientes a las principales empresas de hidroelectricidad españolas que aglutinan las presas de importancia del sector (que se han ido listando con anterioridad), lo que se considera suficientemente representativo para la obtención de conclusiones.

De las más de 250 presas analizadas puede observarse que en todas las épocas estudiadas, las presas de gravedad han sido las de tipología preponderante con diferencia. De hecho, hasta el año 1936, de todas las presas estudiadas en esa época, sólo hay 3 de materiales sueltos, 3 bóvedas, 2 móviles, siendo el resto de gravedad.

A partir de los años 40 al 1975 es cuando aparecen las de tipología de contrafuertes, 7 en total, construidas en los años 50 principalmente, salvo dos de ellas que son del año 1969. En esta etapa (1940-1975) de desarrollo intensivo de la hidroelectricidad, es cuando se detecta la mayor construcción de presas de materiales sueltos de todas las existentes de carácter hidroeléctrico, concentradas en las décadas de los 60 y 70. También es en esta etapa de desarrollo intensivo es cuando se construyen en mayor medida presas bóveda.

Luego, puede concluirse que las presas asociadas al sector hidroeléctrico, aunque su desarrollo tipológico es similar a las del resto de usos construidas en España, sí muestran un aspecto diferenciador, éste es, la apuesta más temprana por las presas bóveda, aunque en todas las décadas, el mayor desarrollo tipológico sea con diferencia la de gravedad, ya sea de planta recta o curva. Pero sin embargo sí hay coincidencia en que las presas de materiales sueltos analizadas se construyeron mayoritariamente en las décadas de los 60 y 70, y las presas de contrafuertes son todas ellas anteriores a los 70 .

Lo que es innegable es la importancia de las presas hidroeléctricas españolas, algunas de ellas record en altura, o volumen de embalse según su tipología, que han colaborado indudablemente a enriquecer y engrandecer el conocimiento y desarrollo del diseño y construcción de presas en España. 
La tabla siguiente muestra un listado de las mayores presas hidroeléctricas a nivel nacional con sus características principales.

\begin{tabular}{|c|c|c|c|c|c|c|}
\hline Nombre & $\begin{array}{c}\text { Altura } \\
\text { (m) }\end{array}$ & Tipo & $\begin{array}{c}\text { Año } \\
\text { Constr. }\end{array}$ & $\begin{array}{c}\text { Vol. } \\
\text { Embalse } \\
\text { (Hm3) }\end{array}$ & Río & Provincia \\
\hline Almendra & 202 & Bóveda & 1970 & 2649 & Tormes & Salamanca \\
\hline Canelles & 151 & Bóveda & 1960 & 687 & $\begin{array}{l}\text { Noguera } \\
\text { Ribagorzana }\end{array}$ & Huesca \\
\hline Las Portas & 141 & Bóveda & 1974 & 535 & Camba & Ourense \\
\hline Aldeadávila & 140 & $\begin{array}{l}\text { Arco } \\
\text { gravedad }\end{array}$ & 1963 & 114 & Duero & Salamanca \\
\hline Susqueda & 135 & Bóveda & 1968 & 233 & Ter & Girona \\
\hline Belesar & 132 & Bóveda & 1963 & 654 & Miño & Lugo \\
\hline José Ma Oriol & 130 & Contafuertes & 1969 & 3162 & Tajo & Cáceres \\
\hline Escales & 125 & Gravedad & 1955 & 153 & $\begin{array}{l}\text { Noguera } \\
\text { Ribagorzana }\end{array}$ & Huesca \\
\hline Salime & 125 & Gravedad & 1956 & 266 & Navia & Oviedo \\
\hline La Cohilla & 116 & Bóveda & 1950 & 12 & Nansa & Santander \\
\hline Cortes II & 116 & $\begin{array}{l}\text { Arco } \\
\text { gravedad }\end{array}$ & 1988 & 118 & Júcar & Valencia \\
\hline Matalavilla & 115 & Bóveda & 1967 & 65 & Valseco & León \\
\hline San Esteban & 115 & $\begin{array}{l}\text { Arco } \\
\text { gravedad }\end{array}$ & 1955 & 213 & Sil & Ourense \\
\hline Bao & 107 & Gravedad & 1960 & 238 & Bibey & Ourense \\
\hline Eume & 103 & Bóveda & 1960 & 123 & Eume & A Coruña \\
\hline Ricobayo & 99 & Gravedad & 1934 & 1150 & Esla & Zamora \\
\hline Doiras & 95 & Gravedad & 1934 & 96 & Navia & Oviedo \\
\hline Tanes & 95 & Gravedad & 1978 & 33 & Nalón & Oviedo \\
\hline Los Peares & 94 & Gravedad & 1955 & 182 & Miño & Lugo \\
\hline Portodemouros & 91 & $\begin{array}{l}\text { Materiales } \\
\text { Sueltos }\end{array}$ & 1967 & 297 & Ulla & A Coruña \\
\hline
\end{tabular}

A continuación se adjunta listado de las presas españolas cuyo embalse es superior a $1.000 \mathrm{Hm} 3$. Se refieren en esta tesis porque es de destacar que todos sean de uso hidroeléctrico (algunos de ellos con otros usos compartidos):

\begin{tabular}{|l|l|l|l|l|l|}
\hline \multicolumn{1}{|c|}{ Embalse } & \multicolumn{1}{c|}{$\begin{array}{c}\text { Año } \\
\text { finalización }\end{array}$} & \multicolumn{1}{|c|}{ Tipo } & Altura & \multicolumn{1}{c|}{$\begin{array}{c}\text { Vol. Embalse } \\
\text { (Hm3) }\end{array}$} & \multicolumn{1}{c|}{ Río } \\
\hline La Serena & 1989 & Gravedad & 91 & 3232 & Zújar \\
\hline $\begin{array}{l}\text { Alcántara (José M Ma } \\
\text { Oriol) }\end{array}$ & 1969 & Contrafuertes & 130 & 3162 & Tajo \\
\hline Almendra & 1970 & Bóveda & 202 & 2649 & Tormes \\
\hline Buendía & 1958 & Gravedad & 78.9 & 1638 & Guadiela \\
\hline
\end{tabular}




\begin{tabular}{|l|l|l|l|l|l|}
\hline \multicolumn{1}{|c|}{ Embalse } & \multicolumn{1}{c|}{$\begin{array}{c}\text { Año } \\
\text { finalización }\end{array}$} & \multicolumn{1}{|c|}{ Tipo } & Altura & $\begin{array}{c}\text { Vol. Embalse } \\
\text { (Hm3) }\end{array}$ & \multicolumn{1}{|c|}{ Río } \\
\hline Mequinenza & 1964 & Gravedad & 79 & 1530 & Ebro \\
\hline Cijara & 1956 & Gravedad & 80 & 1505 & Guadiana \\
\hline Valdecañas & 1964 & Bóveda & 98 & 1446 & Tajo \\
\hline Ricobayo & 1934 & Gravedad & 99.4 & 1200 & Esla \\
\hline Alarcón & 1955 & Gravedad & 67 & 1112 & Júcar \\
\hline
\end{tabular}

Seguidamente se describe con mayor detalle cada época significativa de las presas hidroeléctricas.

Los primeros aprovechamientos hidroeléctricos en España se construyeron a finales del S. XIX. Eran de pequeña potencia disponiéndose cerca de los centros de consumo ya que el transporte de la energía era en corriente continua y no podía realizarse a largas distancias.

Existen pocas instalaciones de este tipo que no contaban con grandes presas al no ser necesarios por la escasez de consumo. De hecho, algunas de estas instalaciones se han recuperado equipándose con equipos de corriente alterna, acoplándose a las redes de media y alta tensión. Esta etapa inicial puede acotarse hasta el año 1916 inclusive.

En estos años de principios del S. XX es interesante resaltar el proyecto hidroeléctrico de Santillana llamado así porque fue el marqués de Santillana el promotor de tal proyecto. Éste proponía aprovechar las aguas de los ríos Manzanares, Guadarrama y Guadalix para producir saltos de agua para aprovechamiento hidroeléctrico, transporte de fuerza, riegos, abastecimientos de poblaciones y saneamiento de Madrid. Finalmente solo le permitieron realizar actuaciones en el primero de los ríos citados.

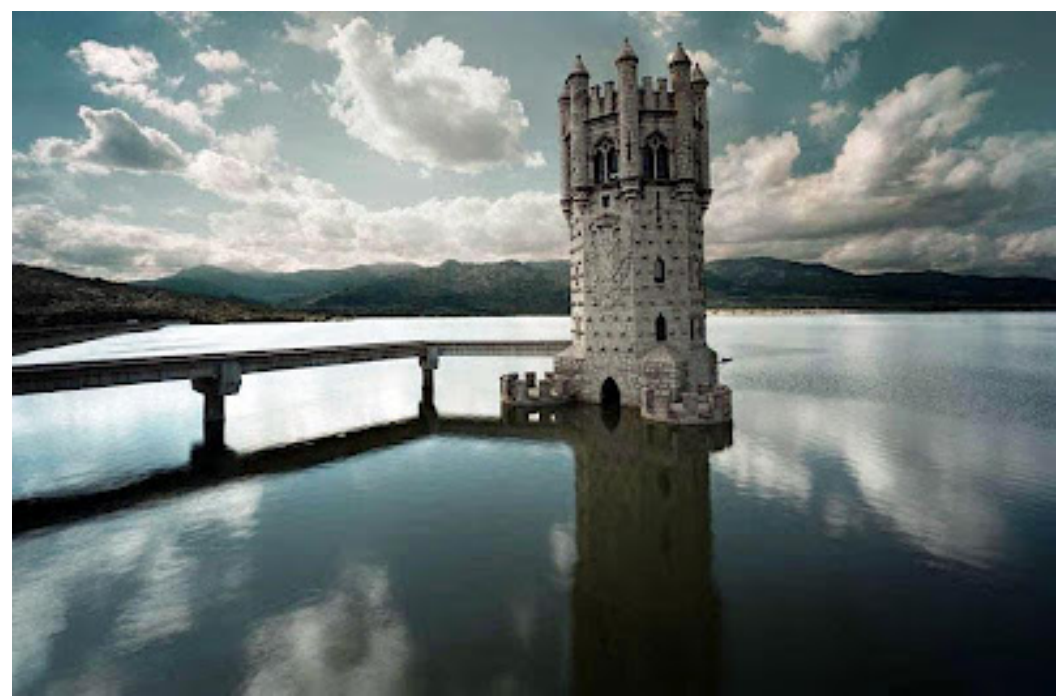

Restos de la antigua presa de Santillana 
Muchas de las publicaciones de la época hacían referencia nada alentadoras del caudal del río Manzanares, por lo que el centro de atención como río aprovechable estaba centrado en el Lozoya.

Hasta la fecha, se le concebía al Manzanares como un aprendiz de río. Incluso Quevedo lo cita como el "arroyo aprendiz de río" y también como "muy ético de corriente, muy angosto y muy roído, con dos charcos por muletas en pie se levantó y dijo.". Sin embargo se habían realizado minuciosos aforos, los primeros de ellos datan de cuando la corte se trasladó a Madrid. Otros los llevaron a cabo los ingenieros José Morer y Ricardo Whagon, pero los más modernos fueron realizados por los ingenieros que participarían en el proyecto del Marqués de Santillana, Carlos Mendoza y Alfredo Moreno. De la medida que hicieron del río a lo largo de un año, llegaron a la conclusión que tenía de media un caudal del 3000 litros/segundo.

En aquel momento nadie se creía el proyecto de González Echarte, sólo el Marqués de Santillana y los jóvenes ingenieros Carlos Mendoza y Alfredo Moreno. Los tres ingenieros fundarían más tarde Mengemor, acróstico formado por la unión de los tres apellidos, la primera empresa constructora de la historia española.

En una conversación mantenida entre Vicente Machimbarrena (el que fuera Presidente de la Sociedad Anónima Hidráulica del Guadarrama) y el Marqués de Santillana vieron claro que para solucionar el problema eléctrico eran necesarios ingenieros especializados como el amigo de Machimbarrena, Antonio González Echarte, reconocido especialista en el campo de la electricidad que se empapó de libros y revistas publicadas en el extranjero, sobre todo en Francia y en Suiza. Fueron los años en los que ya se podían contemplar maravillas como en la Exposición Universal de París de 1889, en la que Siemens ya había presentado la Dinamo Eléctrica.

A su vez, Mendoza y Moreno al terminar la carrera establecieron una oficina técnica en Madrid. Poco tiempo después de asociarse surgió una oferta que resultó fundamental Moreno, ya que era primo del hijo primogénito del marqués de Santillana y para la dirección de obras del salto de Navallar quería contar con su pariente.

Joaquín de Arteaga y Echagüe (1870-1947), marqués de Santillana y duque del Infantado, empleó buena parte de su fortuna en un ambicioso plan, del que salió la primera red hidroeléctrica que llevó energía a Madrid. 
Todo empezó en 1899, cuando el marqués adquirió los derechos de tres metros cúbicos por segundo de las aguas del río Manzanares.

En 1905 se constituyó la Sociedad Anónima Hidráulica Santillana. Fue necesario crear una Sociedad Anónima para realizar una gran presa que embalsara 45 millones de m3, y en 1908 se inauguró el embalse de Santillana, cuya finalidad era regular el caudal con el que se iban a alimentar diferentes saltos de agua, para la producción de electricidad.

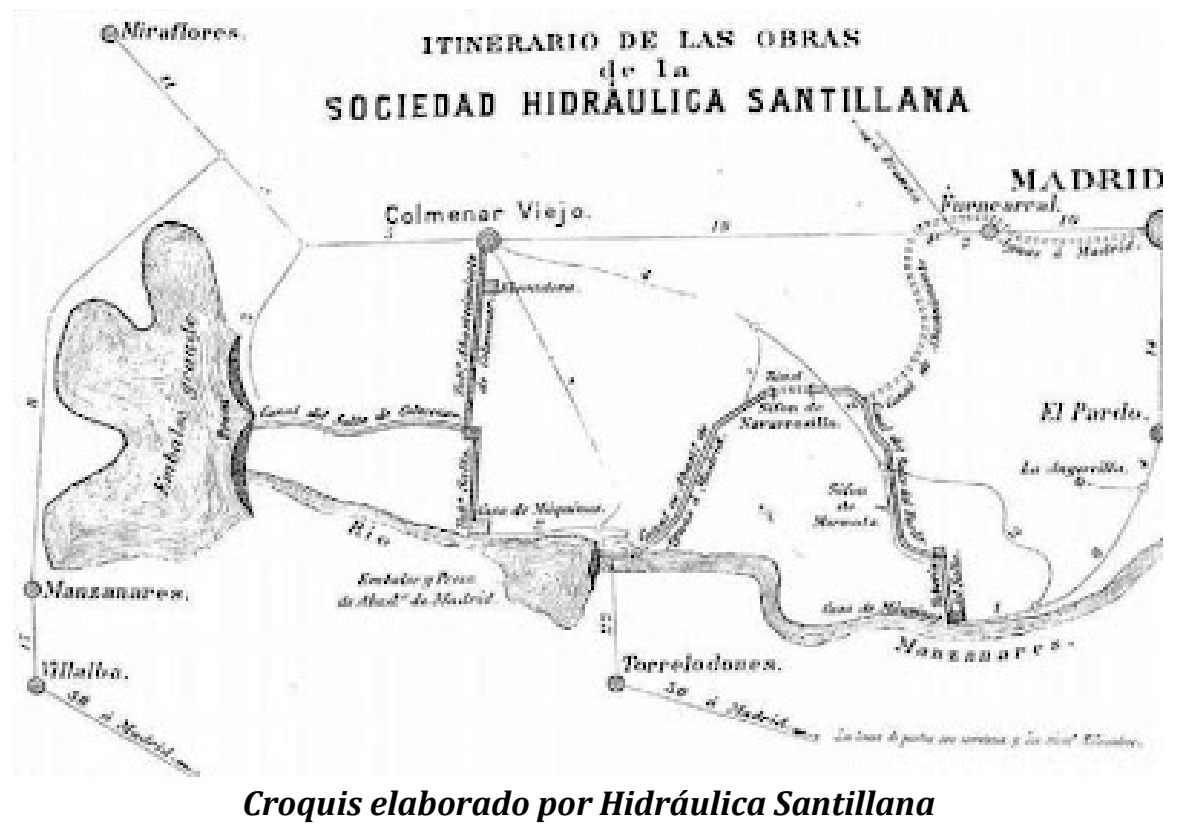

Se pusieron en marcha tres saltos (uno en la propia presa, otro en Navallar, en el término municipal de Colmenar Viejo, y otro en el Cerro de la Marmota, en las lindes del Monte de El Pardo), según el proyecto desarrollado por los ingenieros Antonio González Echarte, Carlos Mendoza y Alfredo Moreno.

El complejo, que era capaz de generar una corriente de $15 \mathrm{KW}$, daba servicio a Colmenar Viejo, Fuencarral, El Pardo, Chamartín, San Sebastián de los Reyes, Alcobendas, Pozuelo de Alarcón y a distintas instituciones radicadas en Madrid, como el Palacio Real y la desaparecida Diputación Provincial.

Además, llevaba agua potable a la zona septentrional de la capital, allá donde no llegaba el Canal de Isabel II, entidad que, por otra parte, realizó una feroz oposición a la labor de Hidráulica Santilllana, recelosa de su rápida expansión.

En 1930 Hidráulica Santillana fue absorbida por Hidroeléctrica Española y Unión Eléctrica Madrileña. En 1965 un decreto ley permitió al Canal de Isabel II hacerse con el control del Embalse de Santillana, que, desde entonces, tiene como uso principal el abastecimiento de agua. 


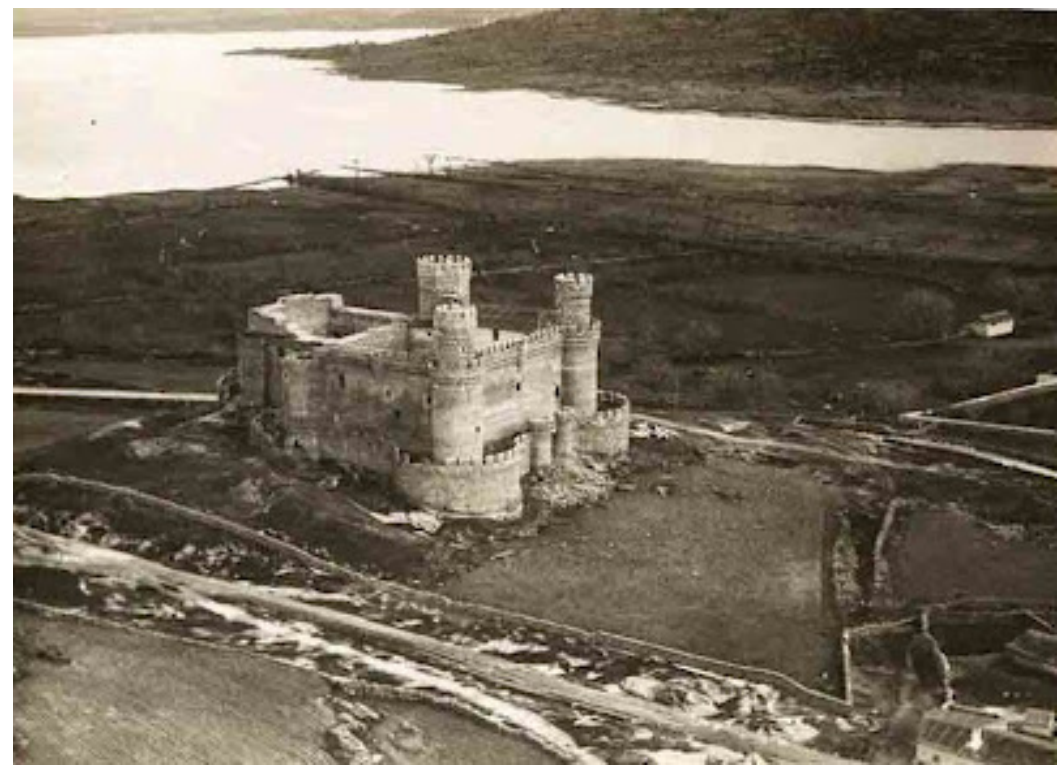

EI Embalse de Santillana en el primer tercio del siglo XX, custodiado por el Castillo de Manzanares el Real.

Para reforzar esta función, en 1971 se construyó una nueva presa junto a la antigua, que, con una altura de 40 metros, permitió duplicar la capacidad del embalse original (de 47 a 91,2 hectómetros cúbicos).

La estructura primitiva fue sumergida, aunque quedaron al descubierto varios elementos arquitectónicos de gran singularidad, de los que se hablan a continuación.

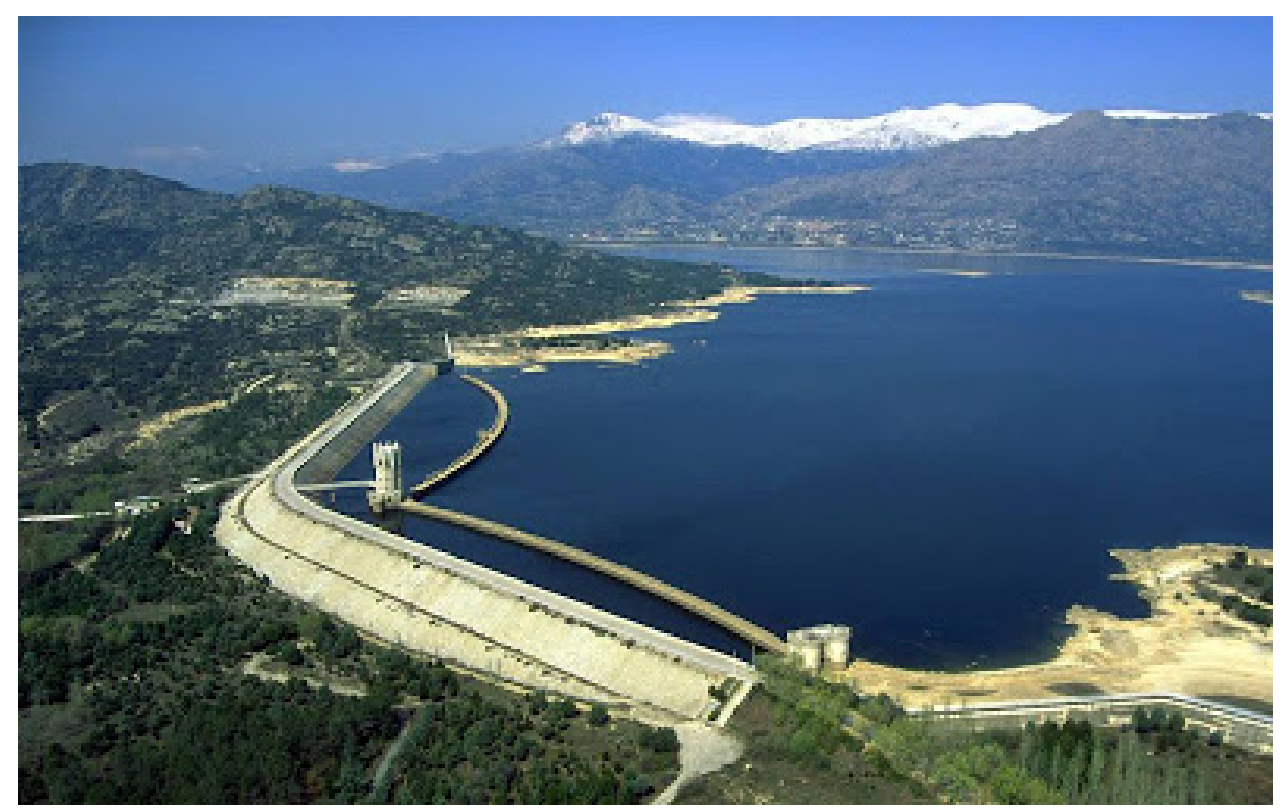

La presa moderna se antepone a la antigua 


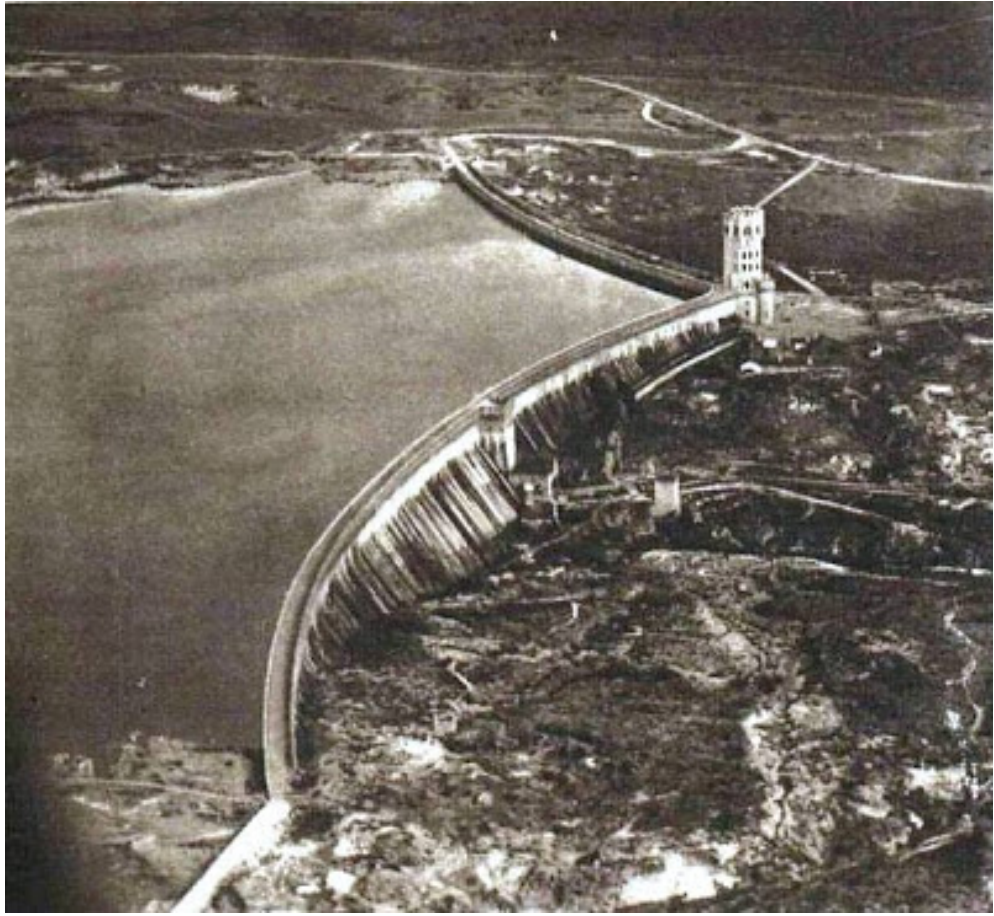

La presa en 1930

La descripción que se hace de la presa de Santillana original en la publicación Madrid Científico de abril de 1902, se resume a continuación.

La presa se halla emplazada en un estrechamiento que el río Manzanares presenta 100 metros aguas abajo de su confluencia con el arroyo de Chozas. La naturaleza granítica del terreno ofrece buenas condiciones para la cimentación como para la impermeabilidad del vaso. La obra tiene en planta un arco de círculo de 200 metros de radio y 145 metros de desarrollo. Su altura es de 10 metros. Su espesor en la base es de 7 metros y 3 metros en coronación.

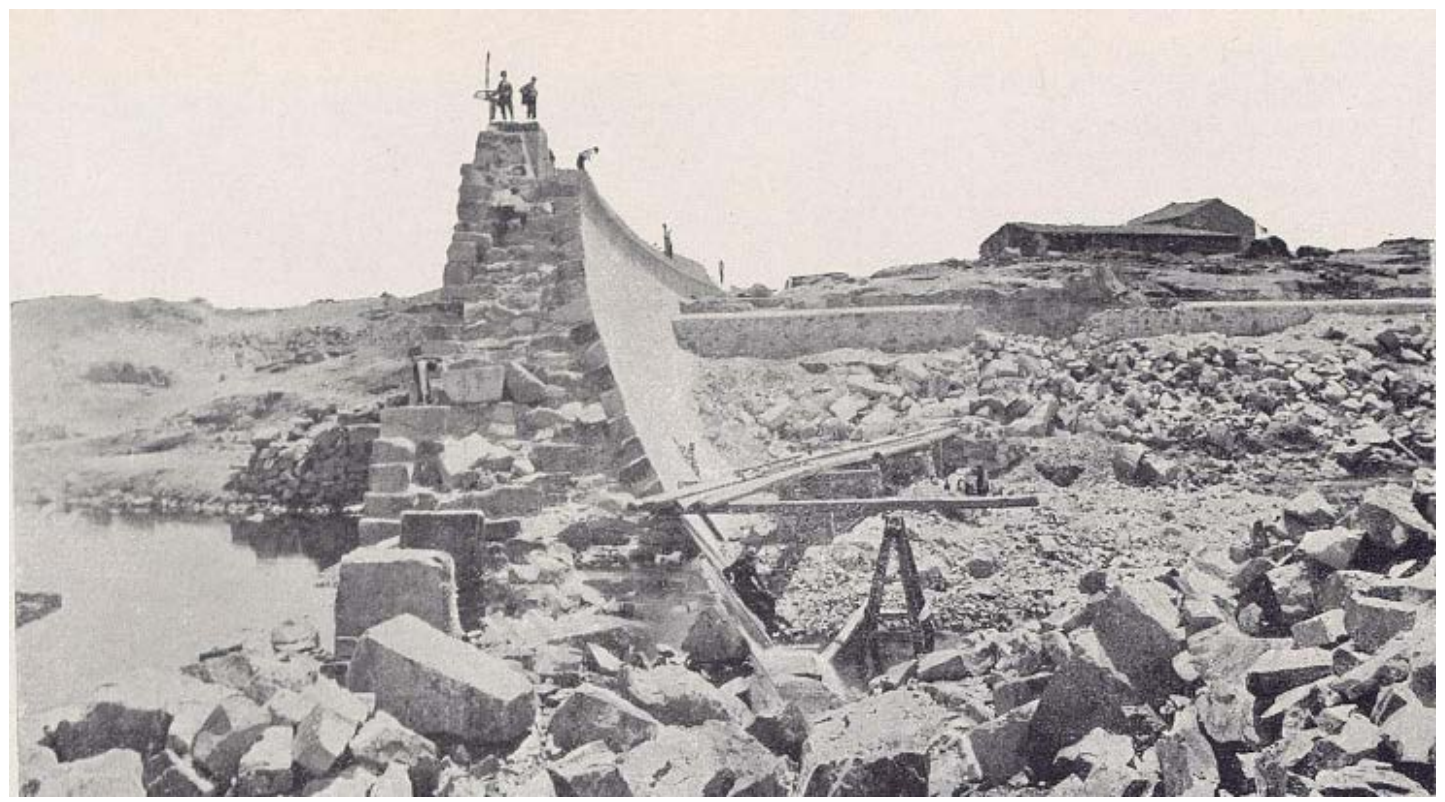


El perfil transversal de la presa está formado por una vertical en el paramento de aguas arriba y un arco de parábola en el de aguas abajo. Esta parábola, teniendo su vértice sobre el plano de la coronación a 3 metros del paramento de aguas arriba viene a ser tangente aproximadamente a la recta que formaría con la hipotenusa del triángulo de Castigliani. El cálculo de este perfil fue realizado teniendo en cuenta la regla de Castigliani y comprobando la estabilidad con la investigación de la curva de presiones a la que se le impuso la condición, tanto para una carga de agua de 11 metros como de embalse vacío, de pasar siempre dentro del núcleo central, sin que las presiones máximas excedan nunca de los límites corrientes que se imponen a las mamposterías.

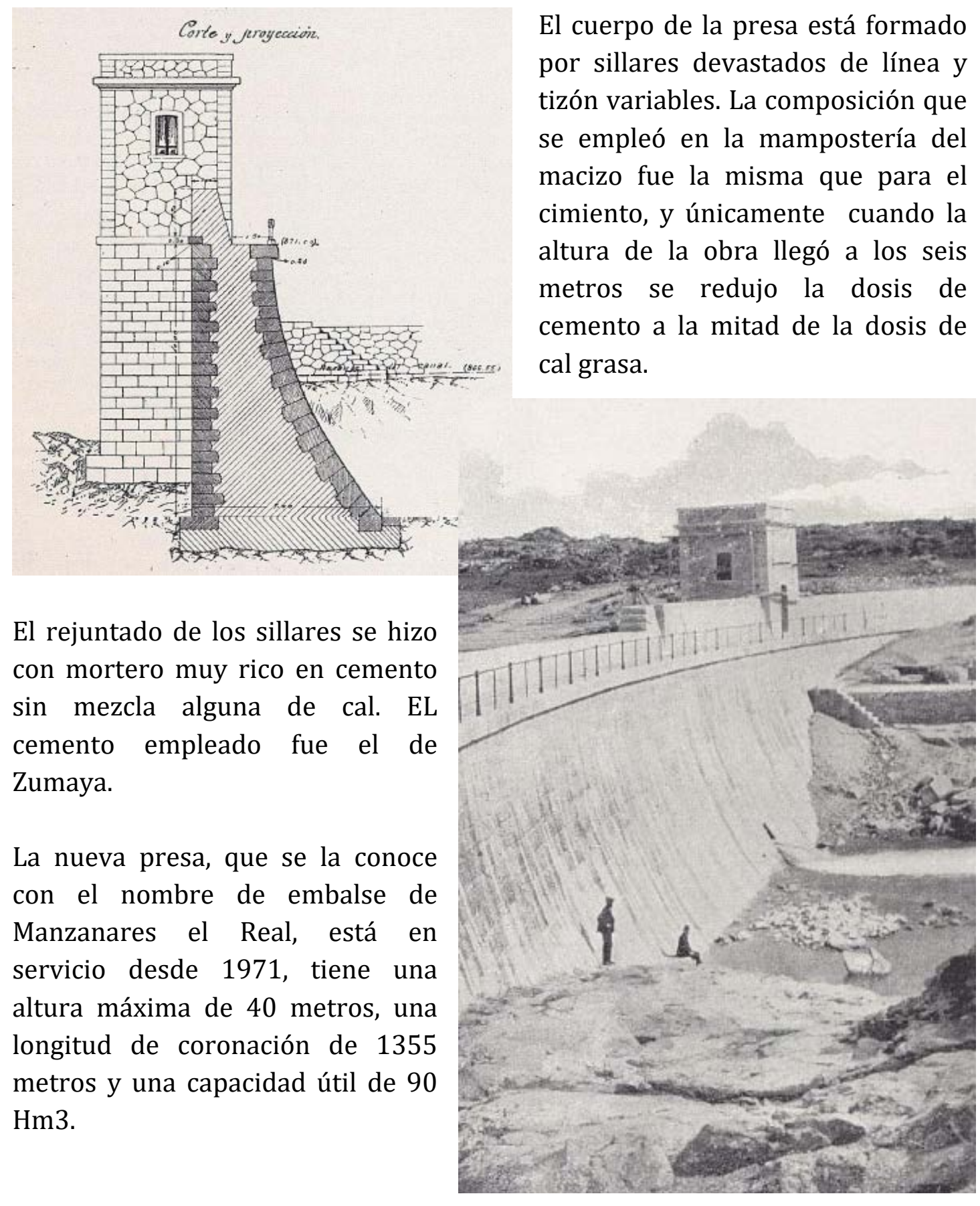


Se adjunta un plano general de las obras proyectadas:

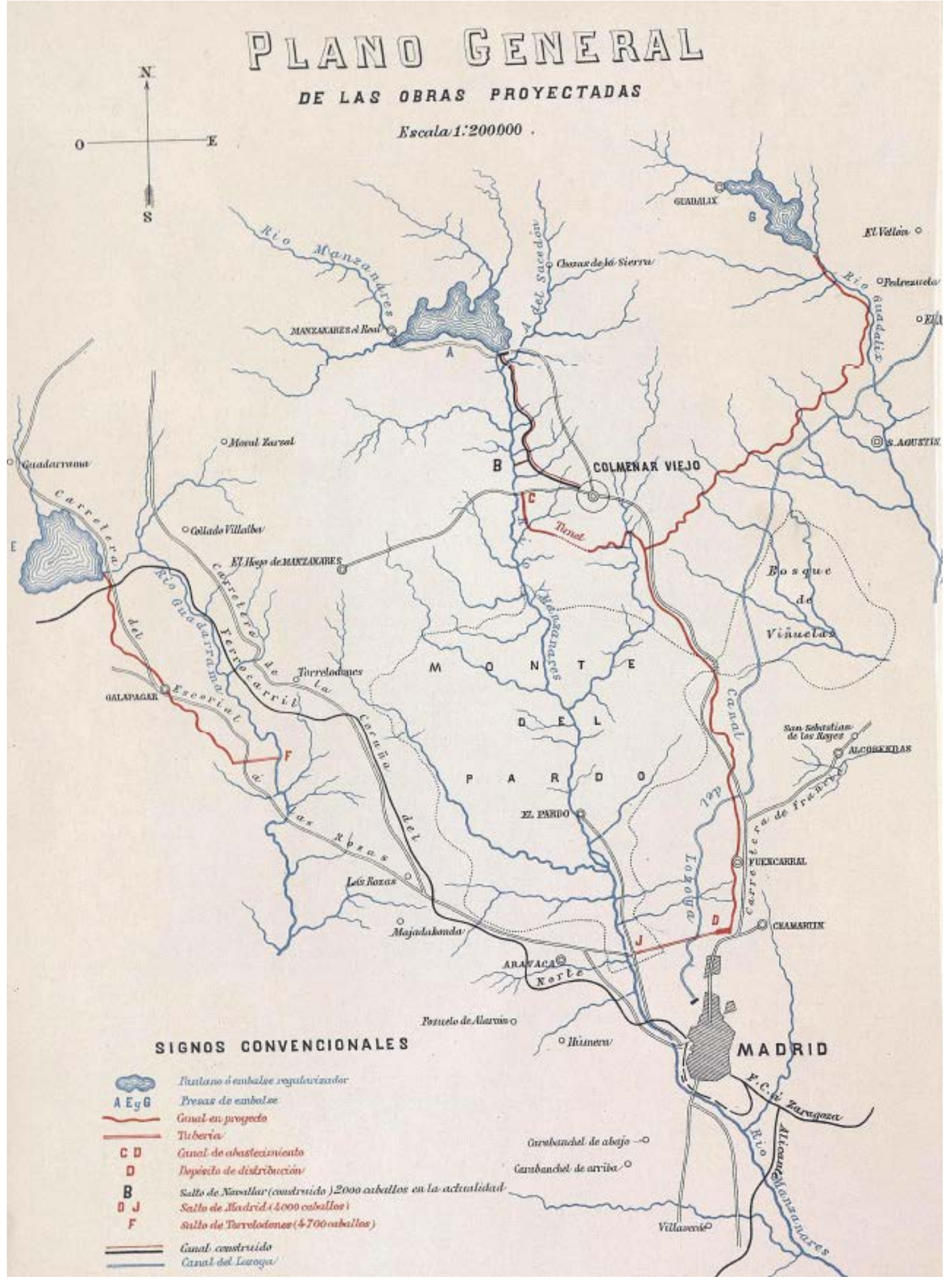


Desde el embalse de Santillana, se hizo un canal de $7.5 \mathrm{~km}$ hasta el lugar B. La caída del canal al río es de unos 100 metros y como el caudal constante será de 3000 litros por segundo, la energía aprovechada en dicho salto será de 3000 caballos permanentes.

Poco más debajo de $\mathrm{B}$, y siguiendo el curso del río, en el lugar $\mathrm{C}$ se construye una nueva presa de dimensiones reducidas. Ésta es la Presa del Grajal cuya última piedra la colocó el rey Alfonso XIII el 19 de junio de 1908.

Se encuentra aguas abajo de la central de Navallar y tiene una capacidad de $80.000 \mathrm{~m} 3$.

La obra resultante es una pequeña presa de arco de sillería de piedra de 10.5 metros de altura con rebosaderos del mismo material, formando un pequeño pórtico de arcos rebajados en su coronación. Fue remodelada en el año 2000.

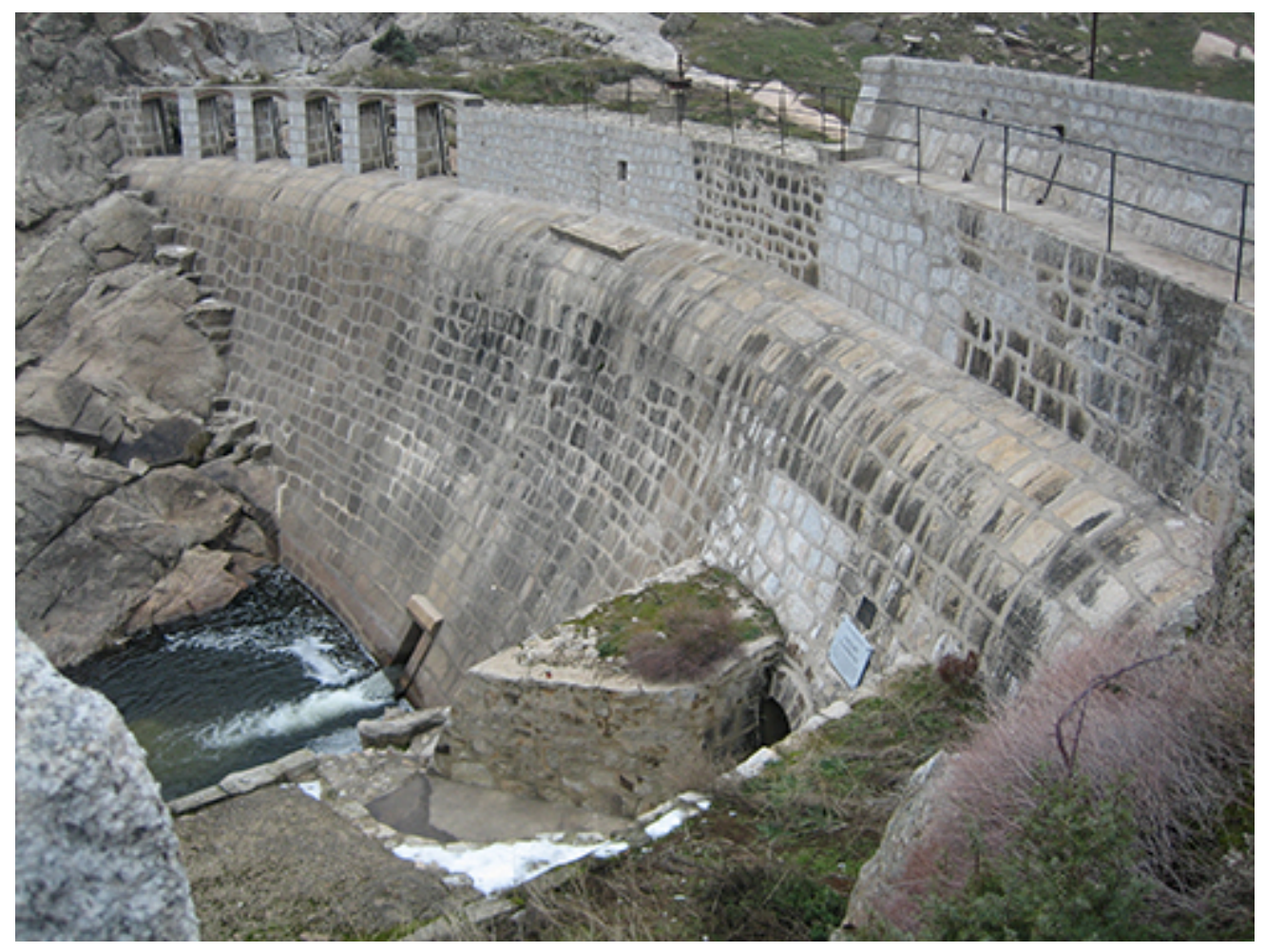


Las centrales hidroeléctricas, con presas o azudes, de este periodo inicial de la hidroelectricidad española, asociadas a las empresas hidroeléctricas principales actuales, son:

\begin{tabular}{|l|l|l|}
\hline \multicolumn{1}{|c|}{ CENTRAL (CIUDAD) } & TIPO DE PRESA & \multicolumn{1}{c|}{$\begin{array}{c}\text { PUESTA EN } \\
\text { SERVICIO }\end{array}$} \\
\hline CABDELLA II (LLEIDA) & GRAVEDAD & 1914 \\
\hline TALARN II (LLEIDA) & GRAVEDAD & 1916 \\
\hline SERÓS II (LLEIDA) & AZUD & 1914 \\
\hline CALABUIG (GIRONA) & AZUD & 1913 \\
\hline LES ILLES (BARCELONA) & AZUD & 1904 \\
\hline EL MOLÍ (BARCELONA) & AZUD & 1896 \\
\hline MARRACOS (ZARAGOZA) & GRAVEDAD & 1903 \\
\hline LUCAS URQUIJO - VÍLLORA & GRAVEDAD & 1914 \\
\hline CARCAVILLA (HUESCA) & GRAVEDAD & $1902 / 1981$ \\
\hline LA HIDRO (HUESCA) & GRAVEDAD & $1901 / 1989$ \\
\hline
\end{tabular}

De entre estas presas destaca Talarn por ser la presa mayor en su época con 86 metros de altura, y la segunda de Europa. Su tipología es de gravedad ligeramente arqueada con aliviadero en la margen izquierda.

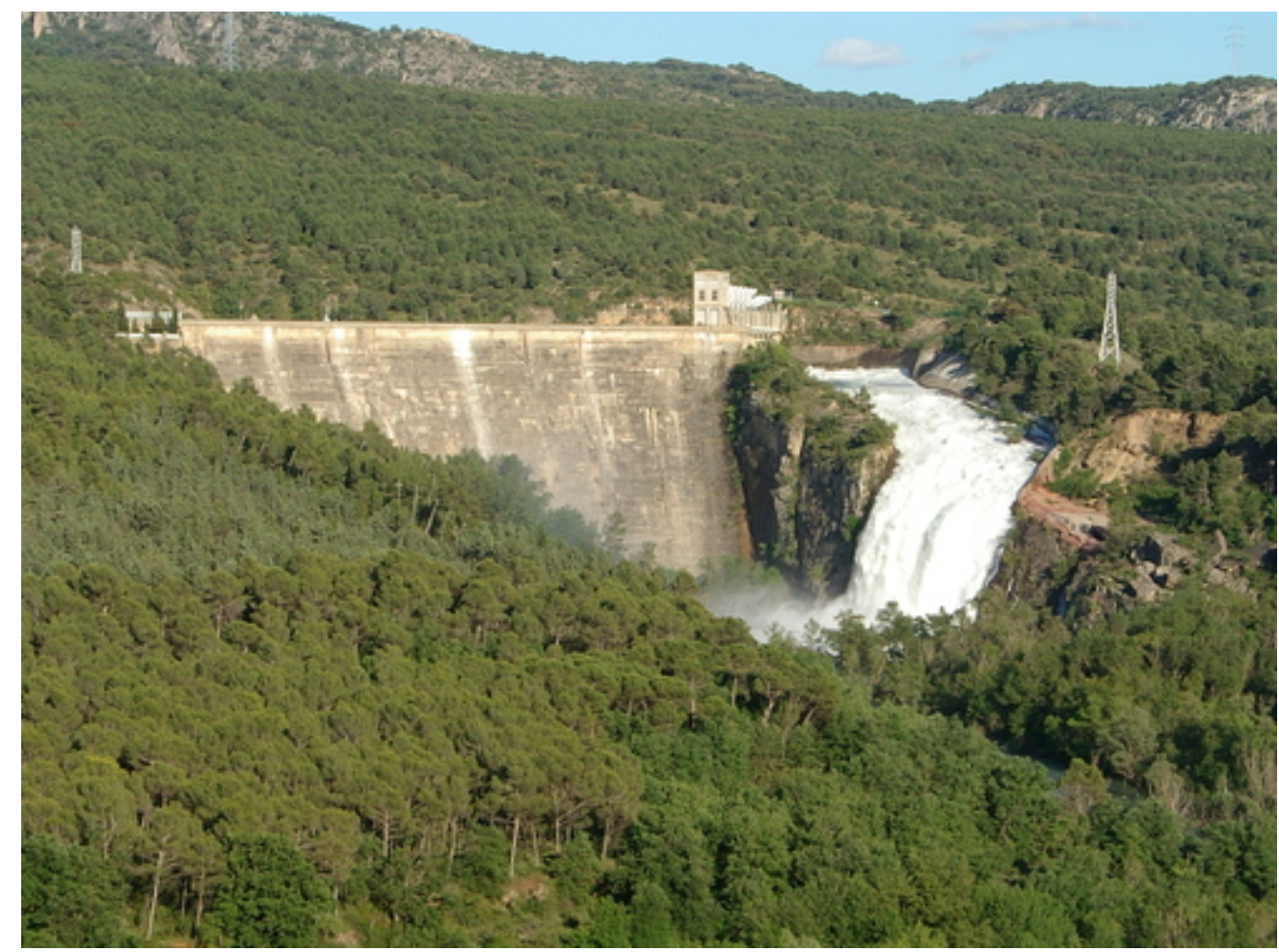



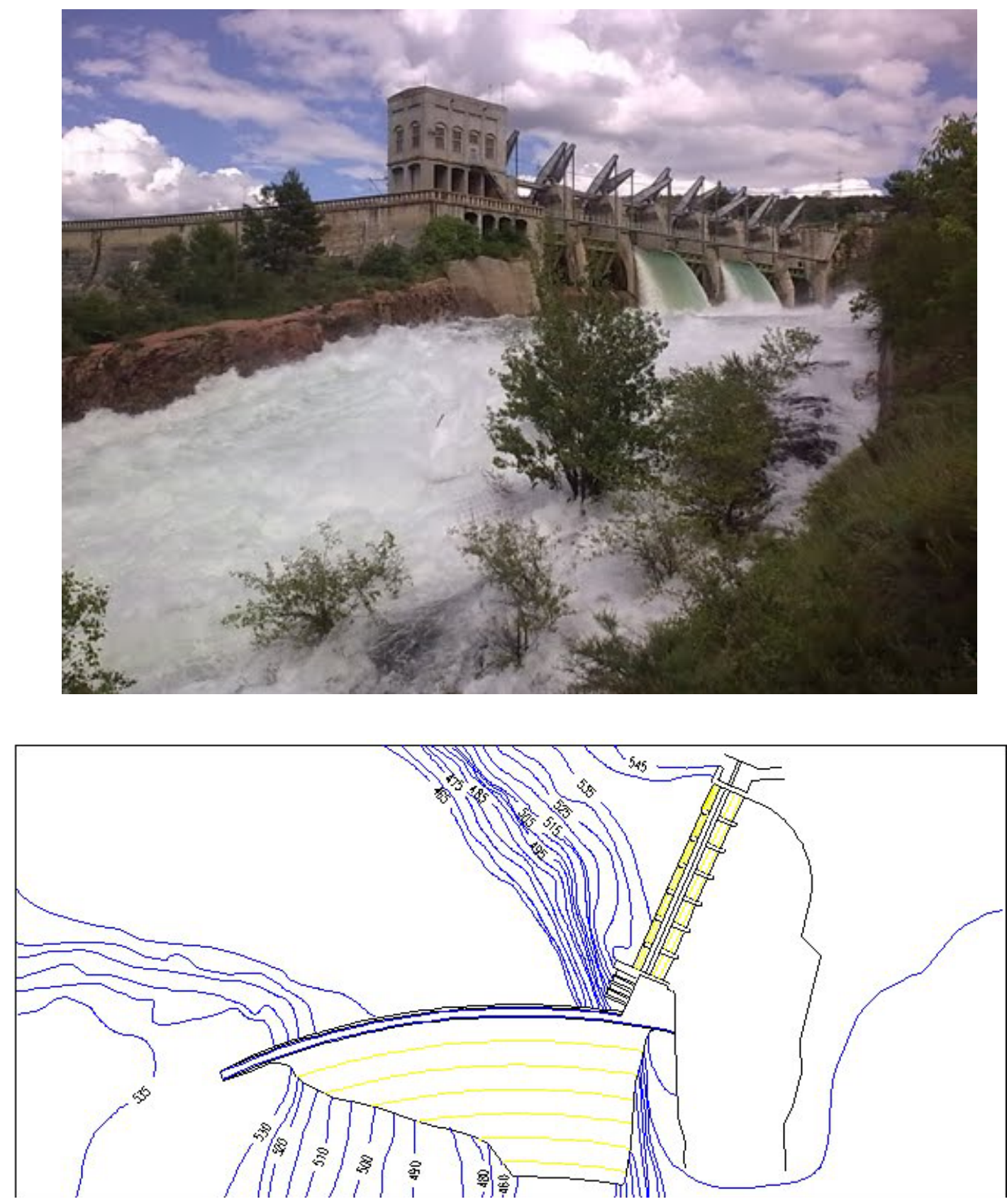

Desde el año 1917 al 1936 se desarrolla la llamada época "heroica" de la hidroelectricidad en España, que es cuando se iniciaron los grandes proyectos de centrales hidroeléctricas con grandes embalses que garantizaban el suministro. Este salto cualitativo se debe a la aparición de la corriente alterna que permitió la construcción de líneas de alta tensión que permitían el transporte de electricidad a grandes distancias sin, prácticamente, pérdida de energía.

A continuación se describe otra experiencia muy interesante, también de comienzos del S. XX, que cabalga entre la época inicial de la hidroelectricidad y la ya citada época heroica, que confirma el interés que por esas fechas 
suscitaban los aprovechamientos hidroeléctricos en España. En este caso, se plantea en el Sur de España y en concreto en el río Guadalquivir por la empresa Mengemor (antes citada) fundada en 1904 y su "Proyecto de canalización y aprovechamiento de energía del Guadalquivir entre Córdova y Sevilla" redactado por el ingeniero de caminos, D. Carlos Mendoza en 1919.

Se describe en esta parte de la presente tesis ya que la tipología de presas planteada en el citado proyecto fue escogida a conciencia para poder suministrar de manera simultánea el servicio tanto de la navegabilidad como de la producción hidroeléctrica.

La Compañía Mengemor de Electricidad, fundada en 1904 tal y como se ha señalado anteriormente, llevó a cabo en el río Guadalimar, afluente del Guadalquivir, en la provincia de Jaén, tres instalaciones hidroeléctricas y estableció líneas de transporte de 25.000 voltios, con el fin de abastecer de energía eléctrica a las ricas zonas plomíferas de Linares y La Carolina.

La aplicación de la electricidad a estas instalaciones mineras puso de manifiesto sus ventajas, y seguidamente la demanda de energía fue en aumento, por lo que Mengemor amplió sus medios de producción, llevando a cabo las obras de un nuevo aprovechamiento en el río Guadalquivir, aguas abajo de la confluencia del Guadalimar, cerca de Mengíbar.

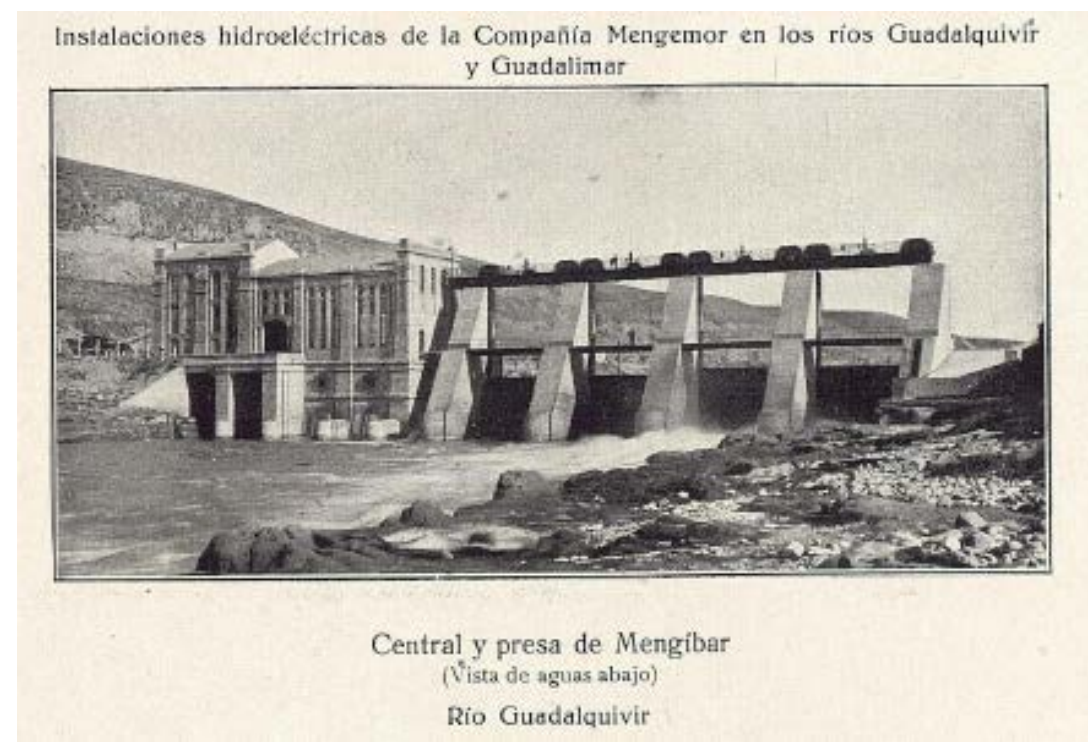



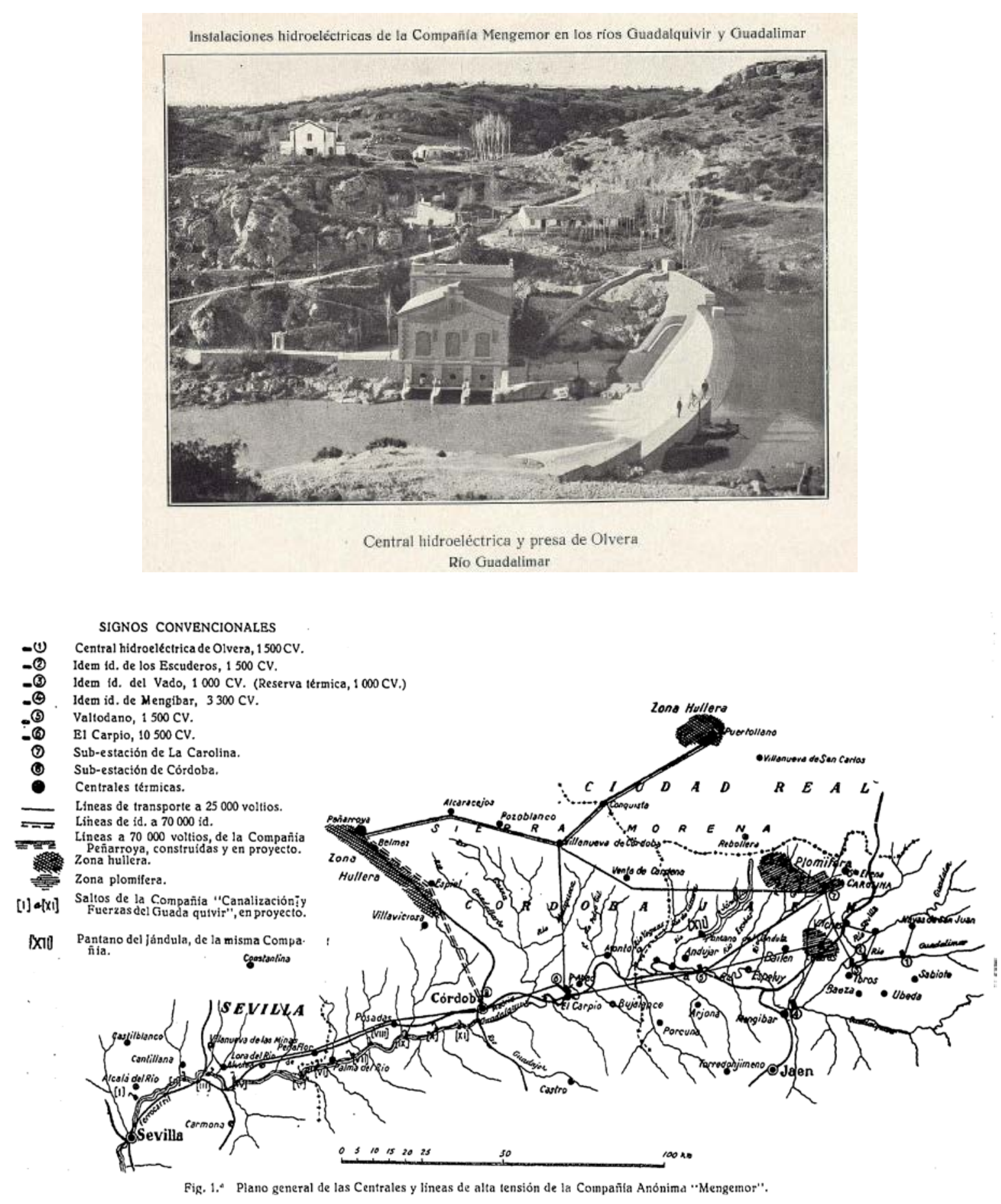

La potencia de la nueva instalación (3300 CV) fue rápidamente absorbida, teniendo también aplicación en el alumbrado de algunas poblaciones y tracción eléctrica.

Como las demandas de energía siguieron en aumento, Mengemor amplió sus instalaciones pudiendo disponer de una nueva sobre el río Guadalquivir cerca de Andújar, con una potencia de $1500 \mathrm{CV}$. Inmediatamente después se comenzaron las obras de otra nueva instalación sobre el mismo río 
Guadalquivir, junto al Carpio, con una potencia de $10.500 \mathrm{CV}$ que fue puesta en servicio en 1923.

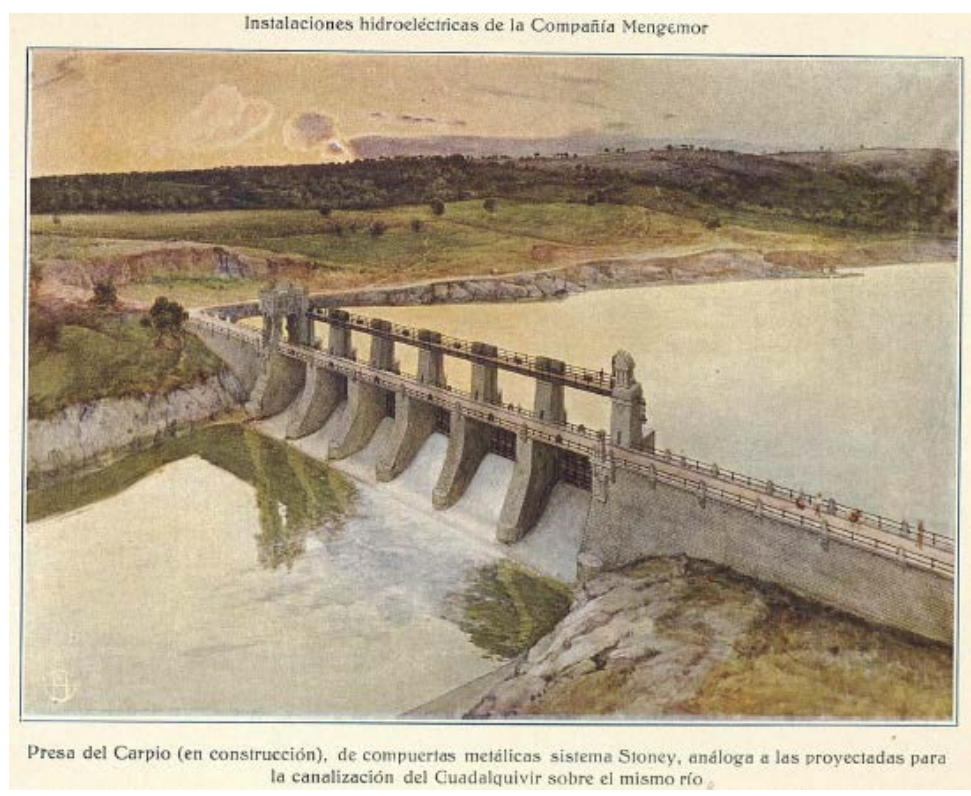

Las crecientes necesidades del mercado dio lugar al pensamiento de nuevos aprovechamientos de energía, y con este motivo se hizo el estudio y reconocimiento del tramo de rio comprendido entre Córdoba y el puerto de Sevilla, que comprende un desnivel de 98 metros en una longitud superior a 150 $\mathrm{km}$.

Pronto se pudo apreciar que existen realmente algunas secciones aprovechables, en las cuales puede llevarse a cabo algunas instalaciones hidroeléctricas de importancia en condiciones económicas.

Fue entonces cuando Mengemor pensó en la secular aspiración de convertir en navegable todo este tramo de río entre Sevilla y Córdoba, juntamente con la idea de que, una vez realizadas importantes instalaciones hidroeléctricas de aquél, se dificultaría, o cuanto menos, se dificultaría el intento. Por ello se pensó en dotar de una solución armónica entre ambas aspiraciones, a fin de que las aspiraciones industriales particulares no fueran un obstáculo para el desarrollo de los demás aprovechamientos.

Este pensamiento es el que dio origen al Proyecto de canalización $y$ aprovechamiento de energía del Guadalquivir entre Córdova y Sevilla, presentado para su aprobación el 14 de marzo de 1919.

El proyecto en líneas generales era como sigue. El curso del Guadalquivir entre Córdoba y Sevilla comprende una longitud aproximada de $170 \mathrm{~km}$. El desnivel 
entre uno y otro extremo es de 88 metros. La pendiente disminuye gradualmente, desde 1.36 milésimas en Córdoba, a 0.27 milésimas en Alcalá del Río. Estos datos evidencian que en la zona superior de este tramo, la navegación por su cauce no sería posible durante la mayor parte del año, aun regularizando aquél, por las velocidades que llegaría a alcanzar el agua, incompatible con la navegación en condiciones económicas.

La única solución, en principio, viable era la canalización por medio de presas y esclusas, convirtiéndose en vía navegable el curso mismo que el río tenía excepto en un pequeño tramo en las inmediaciones de Lora del Río en que parece mejor opción la construcción de un canal lateral. 

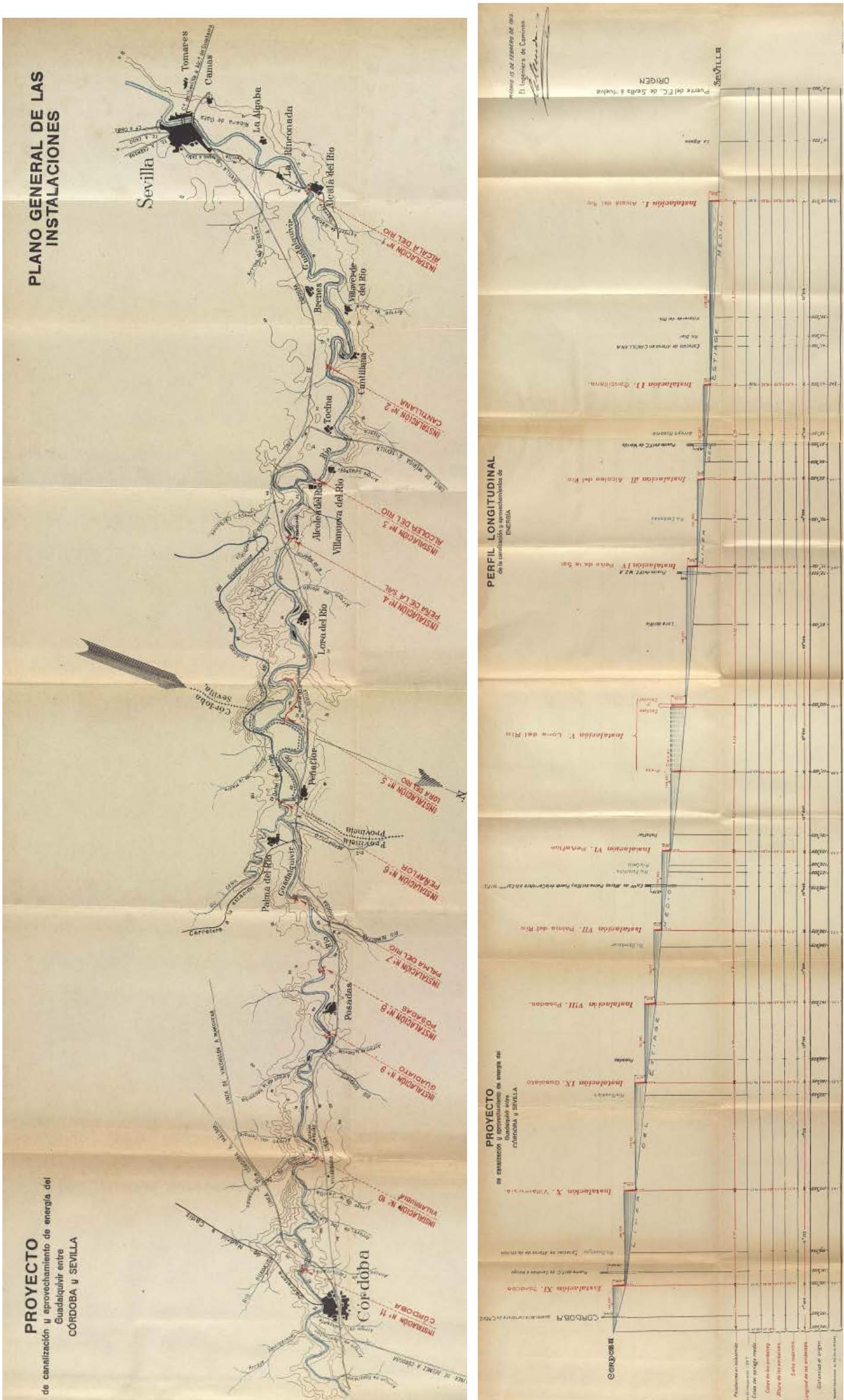
Las presas serán 11, todas ellas movibles, del sistema de compuertas Stoney, análogas a las ya construidas aguas arriba de Córdoba para dos de los aprovechamientos hidroeléctricos de la compañía Mengemor, el de Carpio y el de Mengíbar.

La altura de las presas variará entre 5.25 y 10 metros. Los embalses que generen se solaparán de tal manera que a lo largo de toda la vía navegable existirá un calado mínimo de 2 metros.

\section{Energía hidráulica utilizable}

\begin{tabular}{|c|c|c|c|c|c|}
\hline 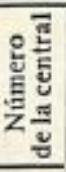 & EMPLAZAMIENTO & 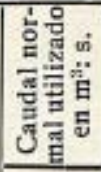 & $\begin{array}{l}\text { Salto má- } \\
\text { ximo en m. }\end{array}$ & $\begin{array}{l}\text { Potencia } \\
\text { máxima } \\
\text { en HP. (1) }\end{array}$ & $\begin{array}{l}\text { Trabajo hidráulico } \\
\text { utilizable en } k w \times \text { h }\end{array}$ \\
\hline 1 & Alcalá del Río...... & 90,00 & 8,00 & 6.400 & 19.713 .024 \\
\hline 2 & Cantillana......... & . & 5,25 & 3.915 & 11.870 .502 \\
\hline 3 & Alcolea del Río..... & , & 5,75 & 4.797 & 14.731 .776 \\
\hline 4 & Pefia de la Sal.... & , & 8,00 & 6.858 & 21.196 .800 \\
\hline 5 & Lora del Río..... & , & 11,50 & 9.747 & 30.099 .456 \\
\hline 6 & Peñaflor...... & , & 6,50 & 5.418 & 15.473 .664 \\
\hline 7 & Palma del Rio... & 60,00 & 5,75 & 3.300 & 11.870 .208 \\
\hline 8 & Posadas....... & , & 8,25 & 4.800 & 17.381 .376 \\
\hline 9 & Guadiato..... & . & 9,75 & 5.550 & 20.136 .560 \\
\hline 10 & Villarrubia,..... & = & 9,25 & 5.190 & 18.462 .412 \\
\hline \multirow[t]{2}{*}{11} & \multirow[t]{2}{*}{ Córdoba.. } & . & \multirow[t]{2}{*}{10,00} & 5.850 & 20.560 .896 \\
\hline & & Suma & & 61.825 & 201.497 .074 \\
\hline
\end{tabular}

OBSERVACIONES:

(1) Estas potencias se han deducido teniendo en cuenta las pérdidas del motor hidráulico (Rendimiento supuesto $=0,75$ ).

(2) Descontadas las pérdidas debidas a la oscilación de las potencias instantáneas, apreciadas con un factor de carga de 0,75 . Este trabajo se refiere a un año medio.

El motivo por el que eligen presas móviles es porque consideran que las presas fijas supondrían serios inconvenientes que imposibilitarían su adopción en este proyecto. Esos inconvenientes, que no existirían en el caso de construir presas móviles, eran los siguientes:

- El Guadalquivir, con sus crecidas enormes y sus arrastres sólidos, impide el establecimiento de presas fijas de más de 2 a 2,50 metros de altura. Se puede aumentar el desagüe hidráulico aumentando las longitudes de las presas, pero el coste crece proporcionalmente, $\mathrm{y}$, sobre todo, aumenta el peligro de que el río se abra en sus crecidas nuevos cauces.

- Los embalses se llegarían a cegar casi por completo con los arrastres sólidos; la navegación perdería el calado necesario, y al elevarse el lecho 
del río aumentaría la altura de las crecidas y sobrevendría acaso el rompimiento de nuevos cauces.

- No serían regulares los niveles de los embalses.

- Las obras de canalización y ele aprovechamientos no ofrecerían seguridad, garantía de duración, ni economía de establecimiento y de explotación.

En el proyecto se indica lo que se adjunta a continuación relativo al diseño de las presas.

"Estos inconvenientes se salvan con las presas movibles. Las presas movibles se componen, como es bien sabido, en esencia, de una solera general que transmite al suelo los empujes del agua y de una parte movible; muchas veces tiene, además, apoyos intermedios para subdividir la longitud de la presa en vanos; estos apoyos son unas veces fijos y otras son también movibles.

Las partes movibles se quitan en las crecidas para dejarlas paso libre. Todos los inconvenientes de las presas de fábrica arrancan de la fijeza del obstáculo opuesto a las crecidas. Al eliminar la causa desaparecen los efectos; no se producirá sobre elevación del nivel ele crecidas ni aterramientos de los embalses; además la movilidad de la pantalla podrá utilizarse para regular el nivel de los embalses y mantenerlo invariable, cualquiera que sea el caudal aportado por el río.

Entre la infinidad de sistemas de presas movibles hemos preferido las de grandes compuertas Stoney.

Para comprender lo que es una de estas presas basta imaginarse un verdadero puente metálico sobre pilas de fábrica cruzando el río en el emplazamiento elegido para la presa.

Procúrase elegir éste teniendo en cuenta, entre otras consideraciones, la de que el río ocupe una posición fija allí desde tiempo inmemorial a ser posible, y si alguna duda pudiera tenerse acerca de la fijeza del cauce se proyectarán en la sección transversal correspondiente, en toda su longitud y a través del valle, las obras necesarias para estar bien seguros de que en las crecidas más extraordinarias, y aun cuando el nivel se eleve a la máxima altura conocida en aquel punto, el eje principal del río pasará por entre las pilas de dicho puente como hasta ahora han venido pasando por los puentes del ferrocarril ya establecidos. 
Por esta razón, en algunos emplazamientos será preciso prolongar los estribos de la presa construyendo verdaderos malecones que corten el valle entero transversalmente, enrasados a una cota uno o dos metros superior a la de las avenidas más altas que puedan racionalmente preverse. Es preciso estar seguros de que la sección de desagüe en todo el transversal del río en cada emplazamiento es suficiente y no ha de producirse un resalto de más de unos centímetros en el nivel superior del agua, arriba del mismo, en el momento de la crecida máxima.

Siendo esto así, ya podemos imaginarnos construidos los once puentes entre once contrahuellas de los peldaños de la escalera hidráulica en que se va a convertir el río.

Ni estos puentes constituirán una barrera u obstáculo que pueda influir en el curso del río, ni el río deberá causar grandes daños en obras que no se oponen sensiblemente a su paso.".

Cada presa va acompañada de una central hidroeléctrica en una de las márgenes y de una esclusa en la otra, para que los barcos puedan salvar el desnivel entre los dos tramos consecutivos, aprovechándose las pilas de las presas para el establecimiento de puentes de comunicación entre ambas márgenes. Se crea, en definitiva, una escalera de 11 peldaños tal y como puede verse en el perfil longitudinal anterior.

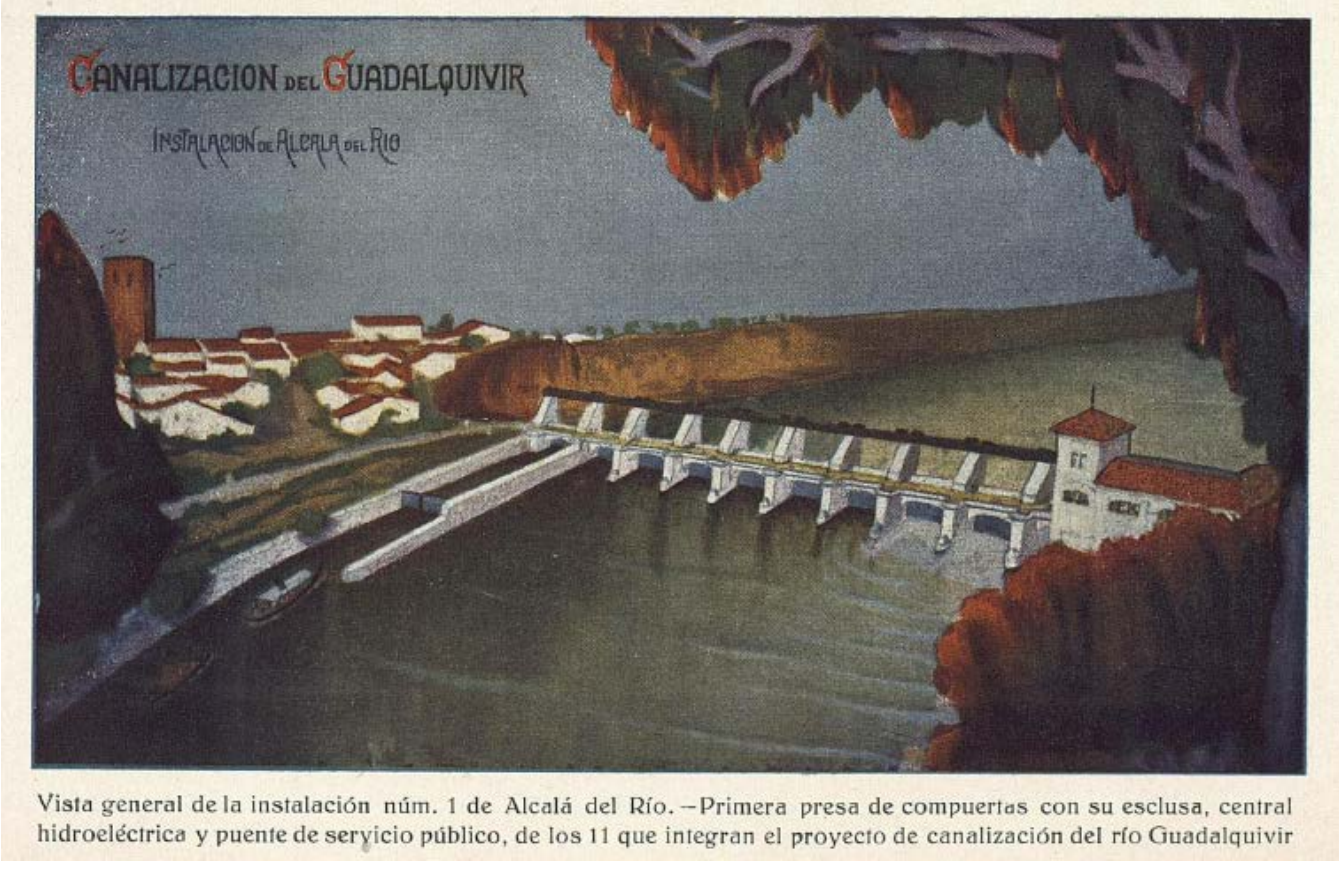




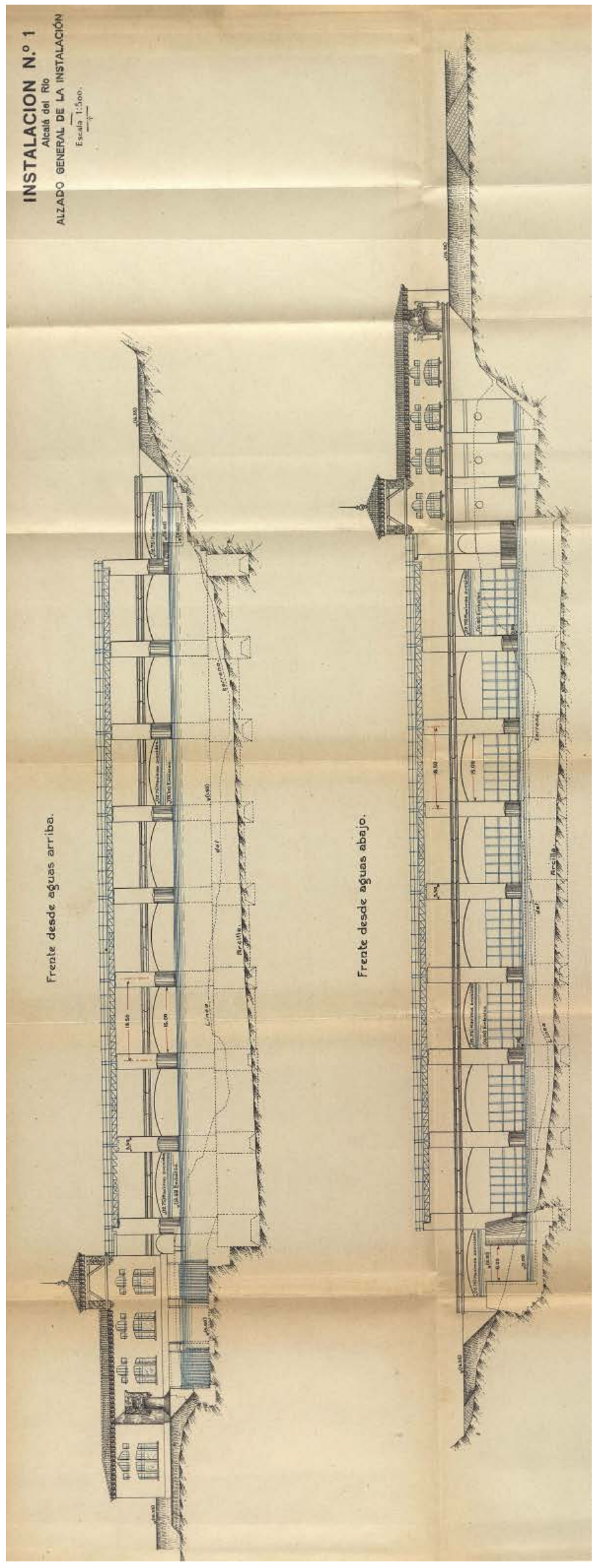



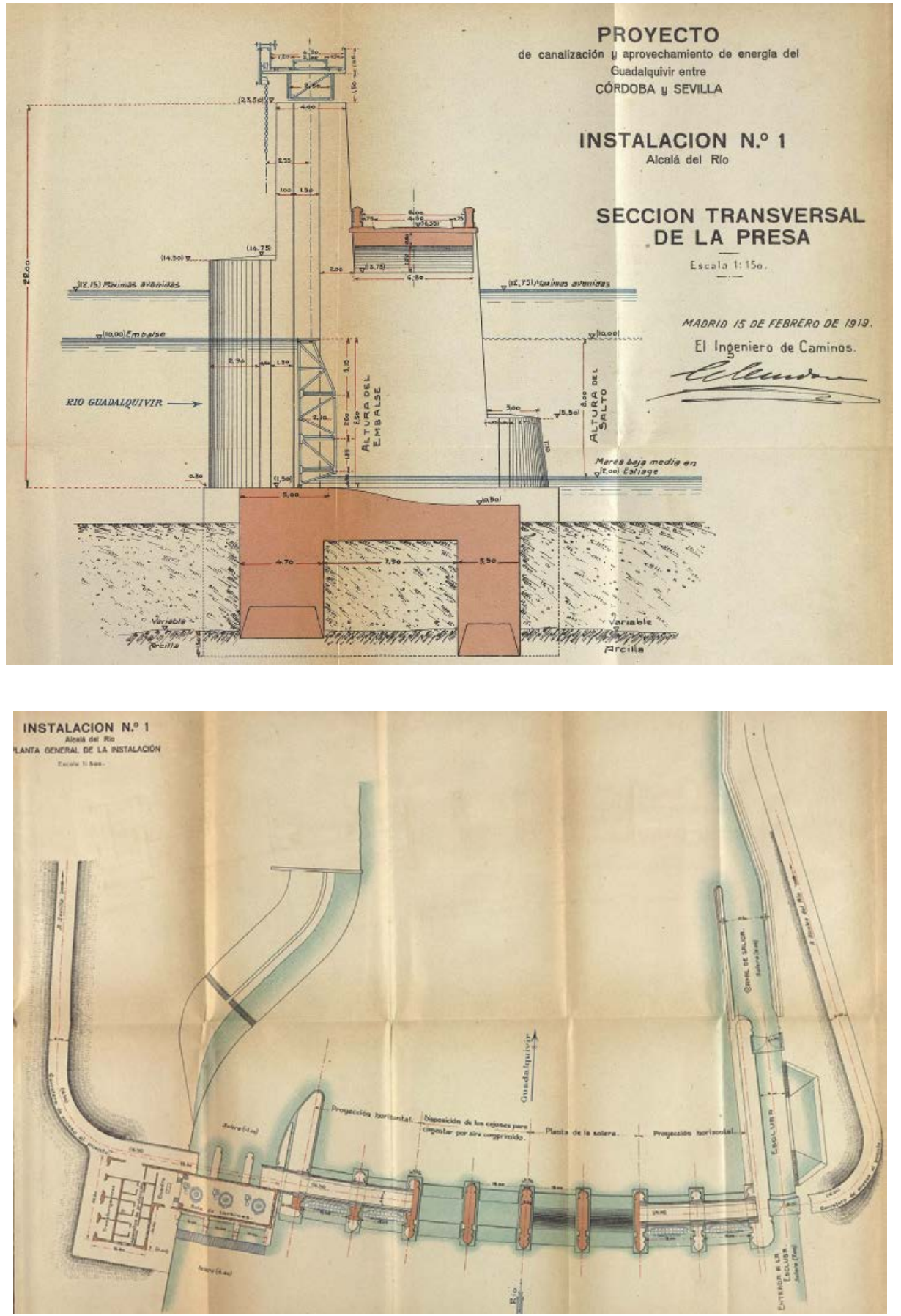
Durante el primer tercio del S. XX, antes de la Guerra Civil, las centrales asociadas a las mayores presas estaban conectadas directamente con las poblaciones más importantes. Y durante el período "heroico" de 1917 a 1939, se pusieron en servicio las siguientes centrales con presas o azudes asociados de las empresas hidroeléctricas principales actuales:

\begin{tabular}{|c|c|c|c|}
\hline CENTRAL (CIUDAD) & PRESA ASOCIADA & TIPO DE PRESA & $\begin{array}{l}\text { PUESTA EN } \\
\text { SERVICIO }\end{array}$ \\
\hline POBLA II (LLEIDA) & SENTERADA & & 1920 \\
\hline TERRADETS (LLEIDA) & TERRADETS & GRAVEDAD & 1935 \\
\hline $\begin{array}{l}\text { CAMARASA II } \\
\text { (LLEIDA) }\end{array}$ & CAMARASA & GRAVEDAD & 1920 \\
\hline $\begin{array}{l}\text { SANT LLORENÇ } \\
\left(\text { LLEIDA) }\left({ }^{*}\right)\right.\end{array}$ & SANT LLORENÇ & MÓVIL+TIERRA & 1930 \\
\hline BAÑOS (HUESCA) & AZULES & GRAVEDAD MAMPOSTERÍA & 1927 \\
\hline BARROSA (HUESCA) & BARROSA & MAMPOSTERÍA & 1930 \\
\hline $\begin{array}{l}\text { LAFORTUNADA-CINCA } \\
\text { (HUESCA) }\end{array}$ & PINETA & GRAVEDAD & 1923 \\
\hline $\begin{array}{l}\text { LAFORTUNADA- } \\
\text { CINQUETA (HUESCA) }\end{array}$ & PLANESCUN & GRAVEDAD & 1932 \\
\hline URDICETO (HUESCA) & BARANETAS & GRAVEDAD & 1930 \\
\hline URDICETO (HUESCA) & URDICETO & $\begin{array}{l}\text { MATERIALES SUELTOS CON } \\
\text { PANTALLA DE HORMIGÓN }\end{array}$ & 1930 \\
\hline $\begin{array}{l}\text { EL CARPIO } \\
\text { (CÓRDOBA) } \\
\end{array}$ & EL CARPIO & GRAVEDAD & 1922 \\
\hline ENCINAREJO (JAÉN) & ENCINAREJO & GRAVEDAD & 1930 \\
\hline JÁNDULA (JAÉN) & JÁNDULA & GRAVEDAD & 1930 \\
\hline $\begin{array}{l}\text { ALCALÁ DEL RÍO } \\
\text { (SEVILLA) }\end{array}$ & ALCALÁ DEL RÍO & COMPUERTAS & 1932 \\
\hline CALA (SEVILLA) & RIVERA DE CALA & GRAVEDAD & 1927 \\
\hline LUCAS URQUIJO & EL BUJIOSO & $\begin{array}{l}\text { MATERIALES SUELTOS CON } \\
\text { PANTALLA DE HORMIGÓN }\end{array}$ & 1925 \\
\hline URROZ & LEURTZA INFERIOR & GRAVEDAD & 1920 \\
\hline URROZ & LEURTZA SUPERIOR & GRAVEDAD & 1920 \\
\hline - 2--- & EL DUQUE & GRAVEDAD & 1921 \\
\hline GOBANTES (MÁLAGA) & $\begin{array}{c}\text { CONDE DEL } \\
\text { GUADALHORCE }\end{array}$ & GRAVEDAD & 1921 \\
\hline EL BATANEJO & EL BATANEJO & GRAVEDAD & 1921 \\
\hline ALMADENES & ALMADENES & GRAVEDAD & 1925 \\
\hline GURIEZO SUPERIOR & EL JUNCAL & ESCOLLERA & 1930 \\
\hline EL CORTIJO & EL CORTIJO & GRAVEDAD & 1931 \\
\hline RICOBAYO I Y II & RICOBAYO & GRAVEDAD & 1933 \\
\hline LA MALVA & $\begin{array}{c}\text { LAGOS DE } \\
\text { SOMIEDO/RIO } \\
\text { VALLE/SALIENCIA }\end{array}$ & GRAVEDAD & 1917 \\
\hline TAMBRE I Y II & BARRIE DE LA MAZA & GRAVEDAD & 1927 \\
\hline
\end{tabular}




\begin{tabular}{|l|c|c|c|}
\hline CENTRAL (CIUDAD) & PRESA ASOCIADA & TIPO DE PRESA & $\begin{array}{c}\text { PUESTA EN } \\
\text { SERVICIO }\end{array}$ \\
\hline VILLALBA & DERIVACIÓN & MAMPOSTERÍA & 1924 \\
\hline GÜIMIL & GÜIMIL & GRAVEDAD & 1935 \\
\hline ANZÁÑIGO (HUESCA) & ANZÁÑIGO & GRAVEDAD & 1923 \\
\hline BIESCAS I (HUESCA) & $\begin{array}{c}\text { AZUD DE TOMA } \\
\text { SANTA }\end{array}$ & MAMPOSTERÍA & 1921 \\
\hline CASTIELLO (HUESCA) & $\begin{array}{c}\text { AZUD DE TOMA } \\
\text { ARAGÓN }\end{array}$ & GRAVEDAD & 1921 \\
\hline EL PUEYO (HUESCA) & BAÑOS & MAMPOSTERÍA & 1927 \\
\hline CHORRO (MÁLAGA) & GAITANEJO & GRAVEDAD & 1927 \\
\hline & MONTEJAQUE & BOVEDA & 1924 \\
\hline MAÑERU & ALLOZ & BOVEDA & 1930 \\
\hline EL PELGO & EL PELGO & BÓVEDA & 1925 \\
\hline
\end{tabular}

La presa de Gaitanejo es de gravedad y fue construida en el año 1927 sobre el río Guadalhorce en la provincia de Málaga. Su altura es de 34.5 metros sobre cimientos y la longitud de coronación es de 55 metros.

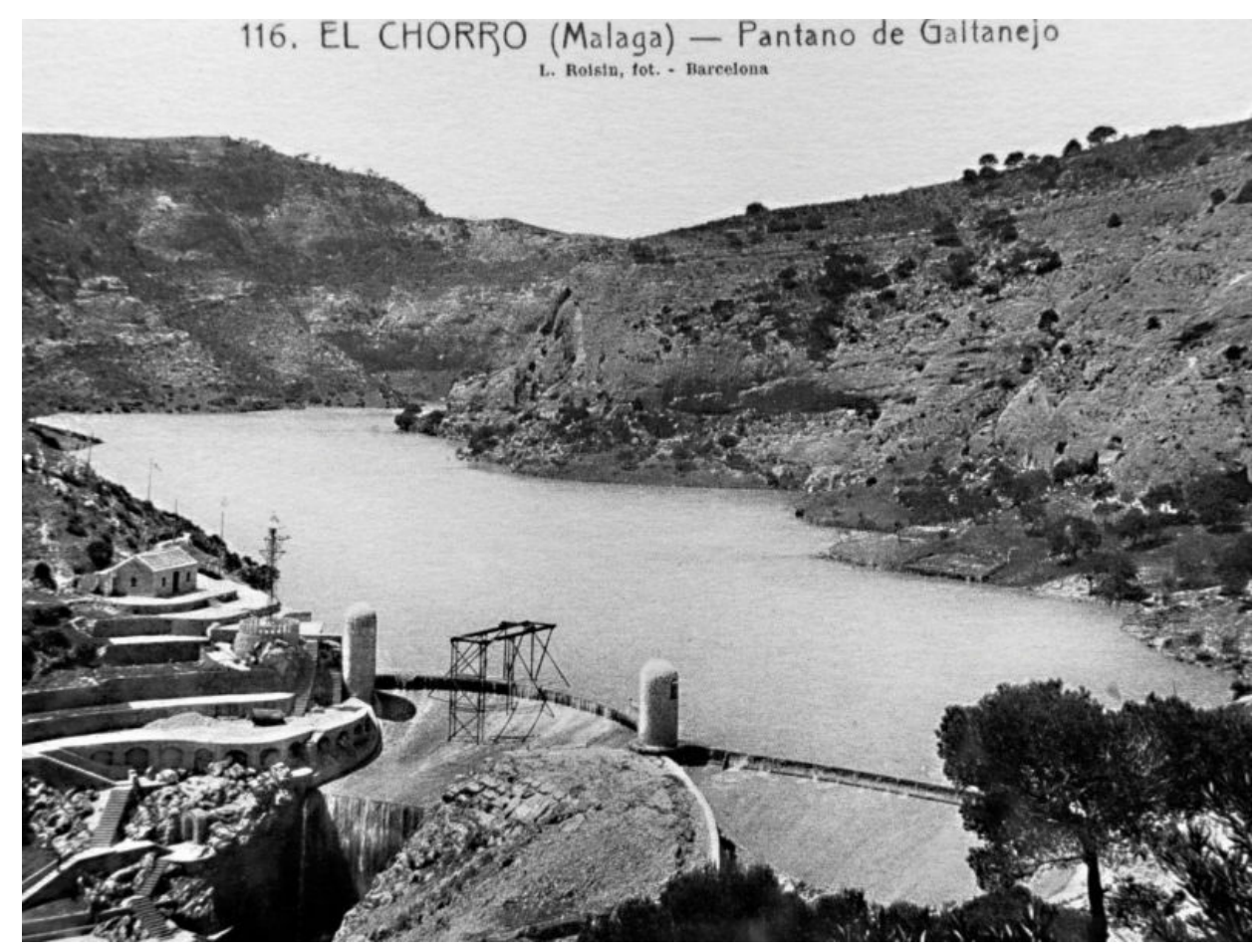



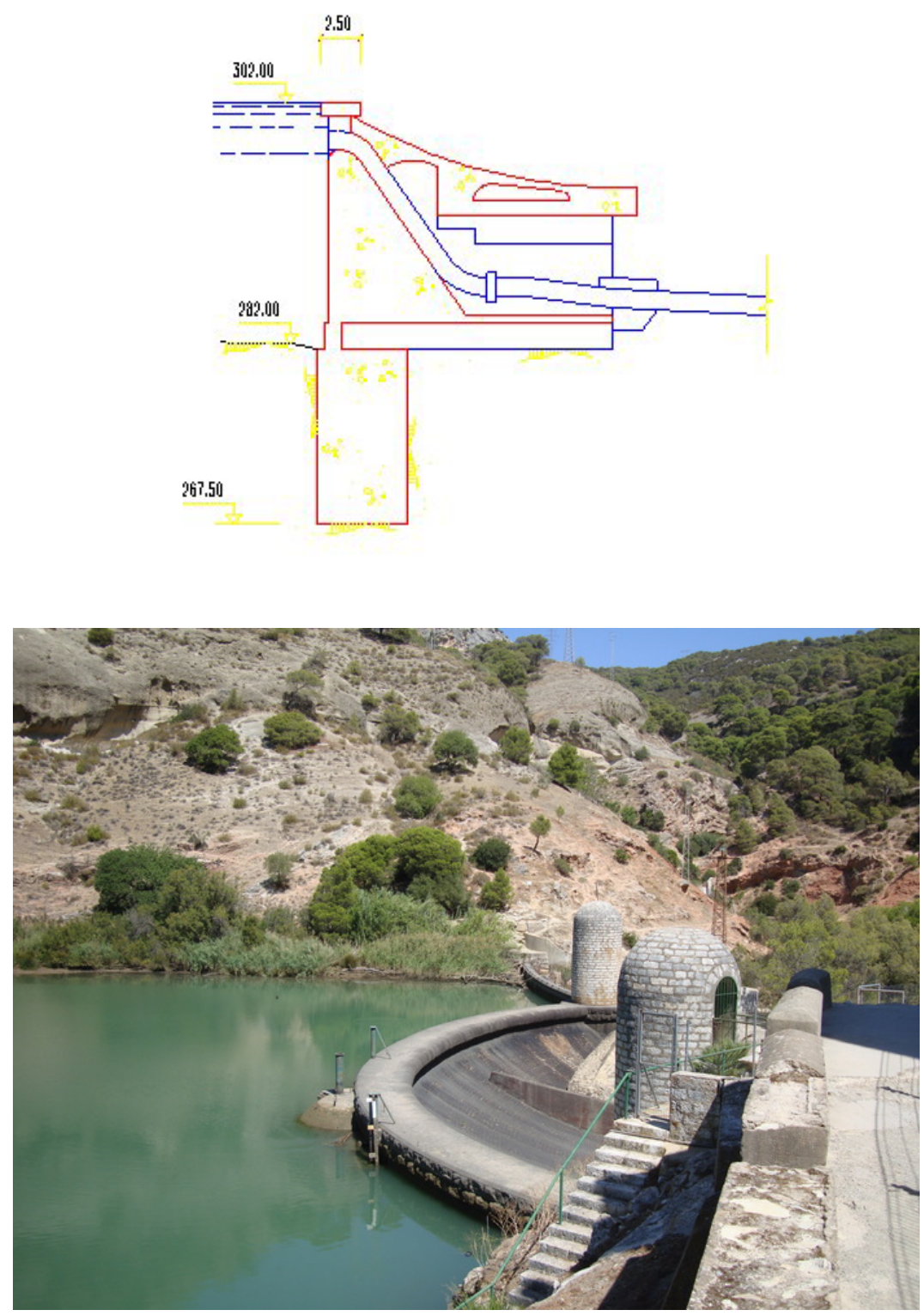

De entre todas las presas realizadas en este período, destacan las de Montejaque, Camarasa y Ricobayo.

Montejaque es una presa bóveda construida en el año 1924, sobre el río Campobuche, en la provincia de Málaga, de 83.75 metros de altura sobre cimientos. Fue un proyecto fallido de la Compañía Sevillana de Electricidad, ya que tenía la pretensión de construir la Central eléctrica o Fábrica de Montejaque, para le aprovechamiento hidroeléctrico del río antes citado. Para ello era necesario la construcción de la presa de Montejaque que fue lo único que se ejecutó además de la galería subterránea que atravesaba la Sierra de Mures.

Sin embargo, la presa no llegó a ser efectiva para el fin que fue construida, no por la propia estructura, sino porque el vaso del embalse tenía grandes 
filtraciones que dio lugar al vaciado del mismo en 2 meses, por lo que se abandonó la presa tras la Guerra Civil. Hoy por hoy es considerado un monumento de arqueología industrial.
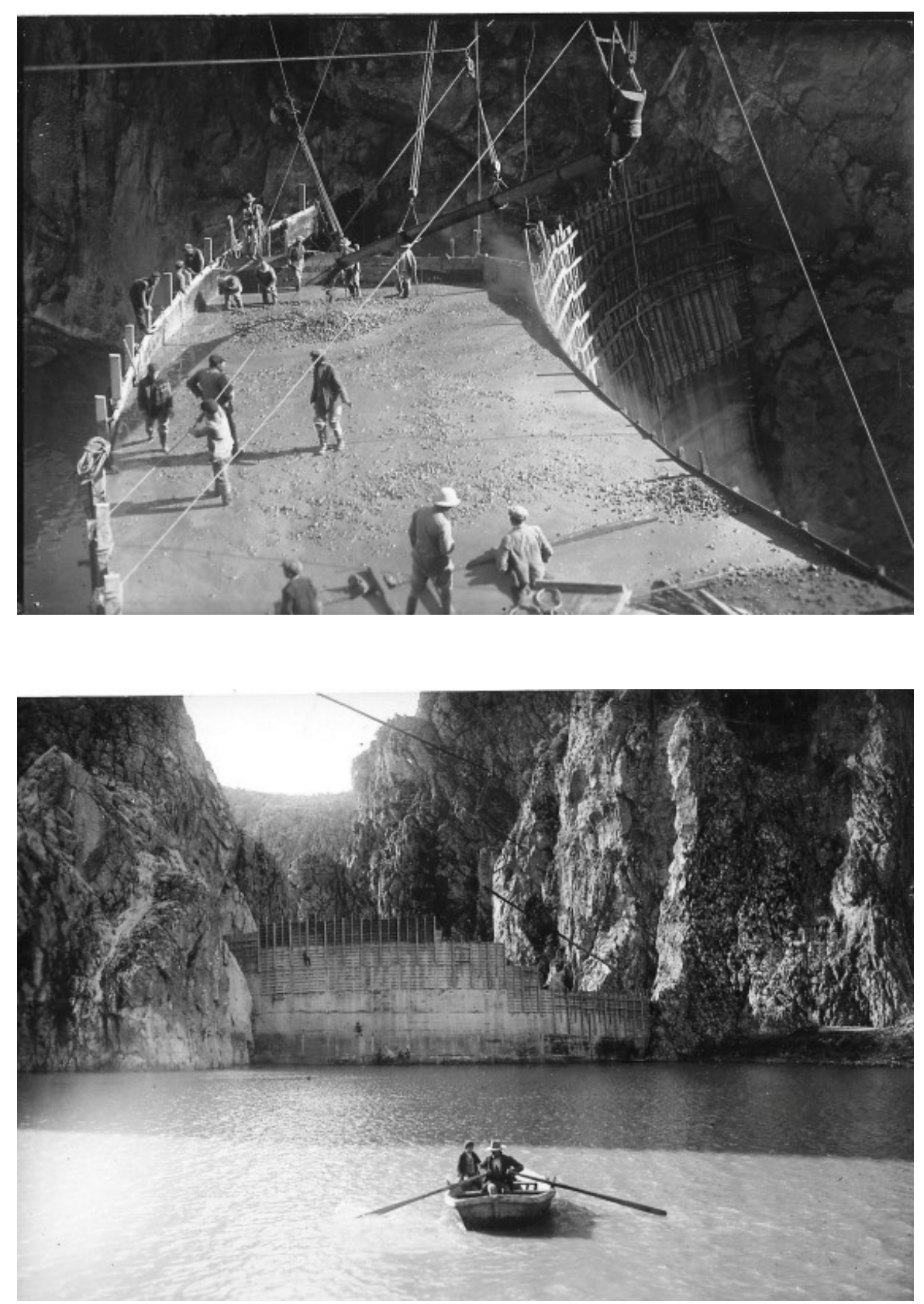

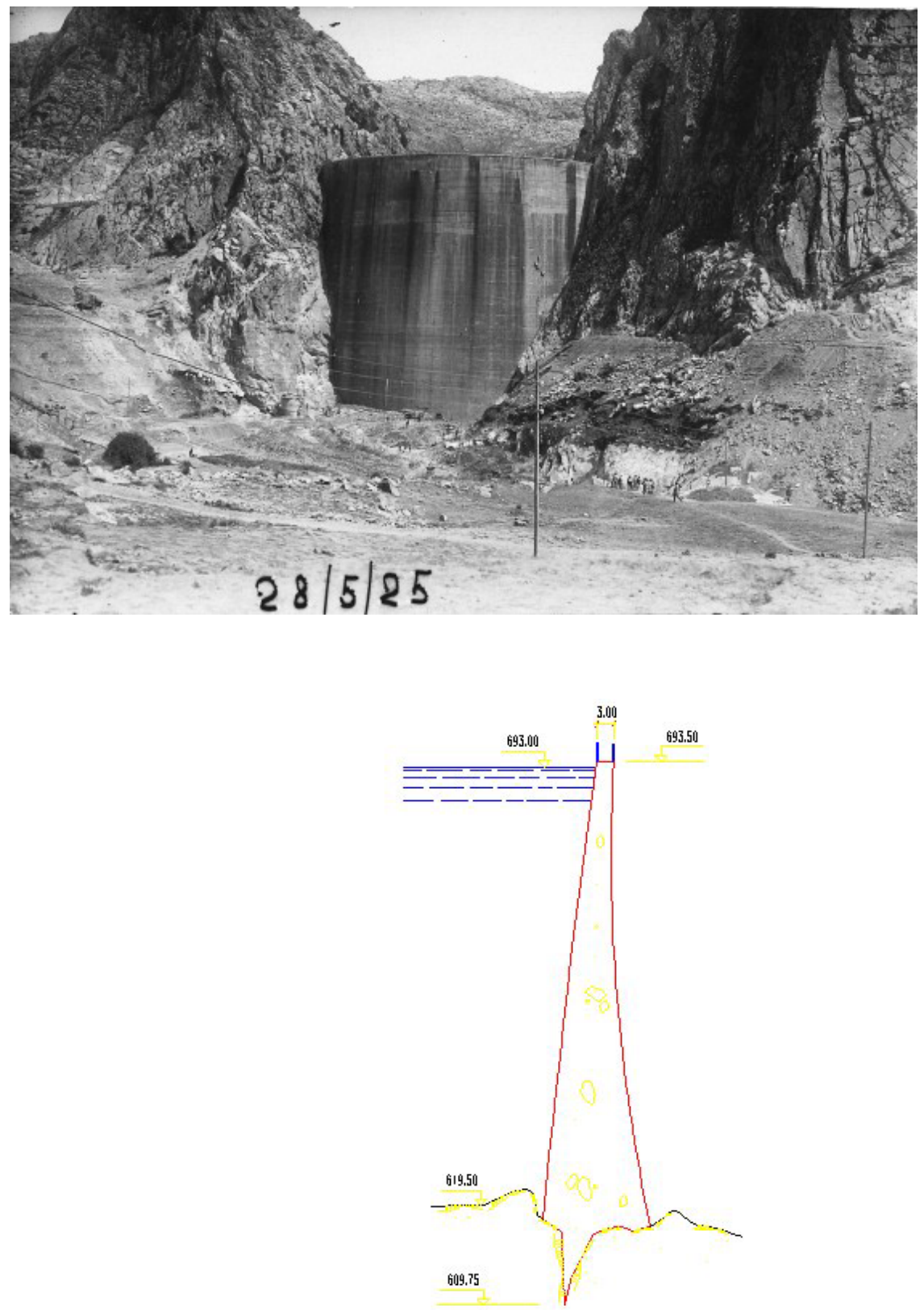

Camarasa se construyó entre 1917 y 1920 aguas abajo de Talarn. Con 103 metros sobrepasó la altura de Talarn y ostentó el record de altura de presas españolas, siendo además la segunda de Europa y la cuarta del mundo. Su tipología es de gravedad ligeramente arqueada con el aliviadero situado en la margen derecha. 
EVOLUCIÓN DE LA INGENIERÍA DE LAS PRESAS HIDROELÉCTRICAS
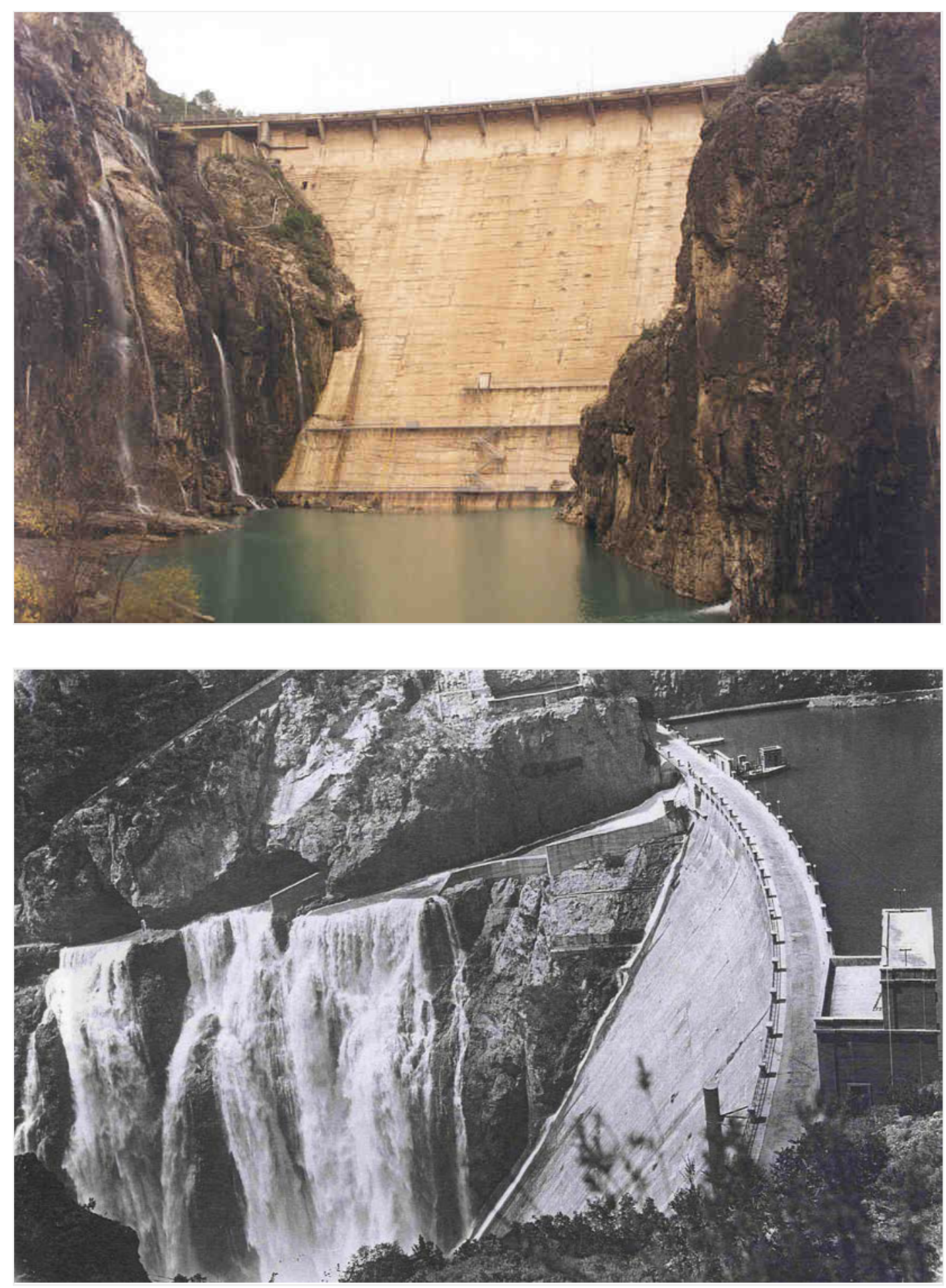


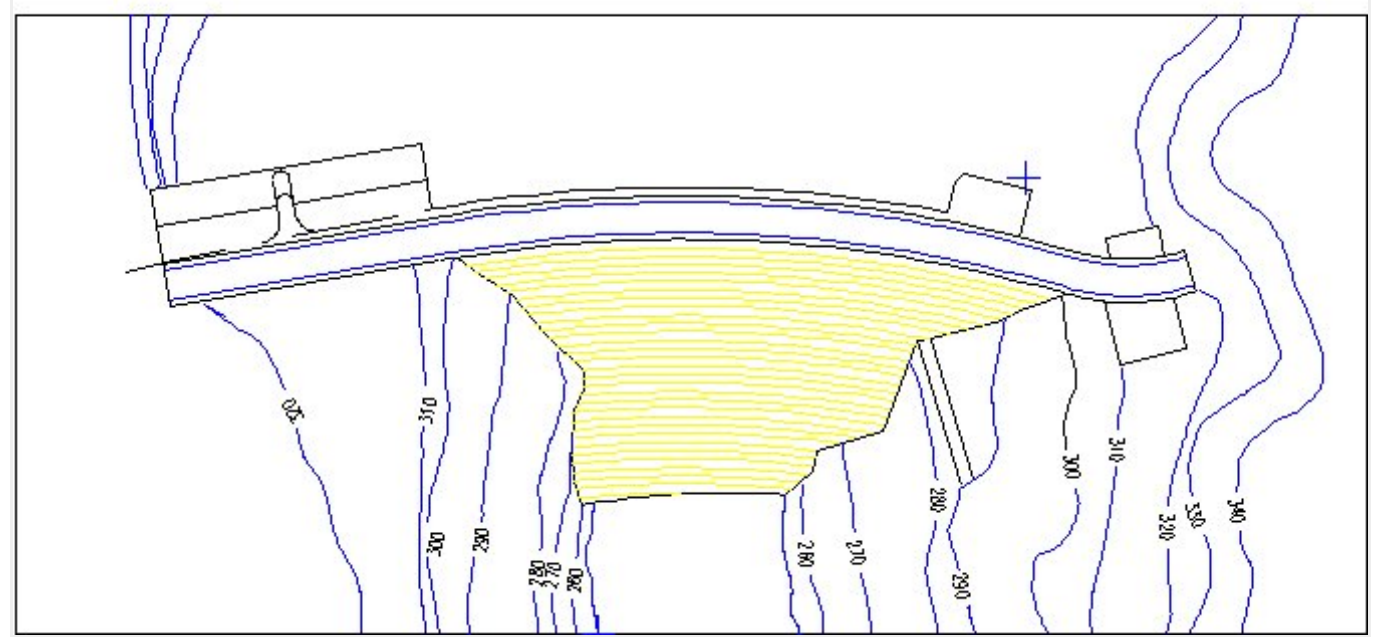

La empresa que construyó los saltos del Noguera Pallaresa y otros saltos en la vertiente española de los Pirineos, fue la sociedad conocida como La Canadiense, aunque la mayoría de su capital fuese belga. La principal figura de este grupo es Z.W.K. Billings, que dio gran impulso a los medios constructivos y a la fabricación y puesta en obra de los hormigones. Fue co-proyectista de las presas de Talarn y Camarasa, entre otras.

La presa de Ricobayo en Zamora, fue en su momento la de mayor volumen de presa y embalse de España además de ser el aprovechamiento hidroeléctrico más importante de Europa. La presa, sobre el río Esla, afluente del Duero, se terminó en 1933 siendo su tipología de gravedad de planta curva. Alcanza los 99,40 metros de altura sobre cimientos creando un embalse de más de 1.000 Hm3.

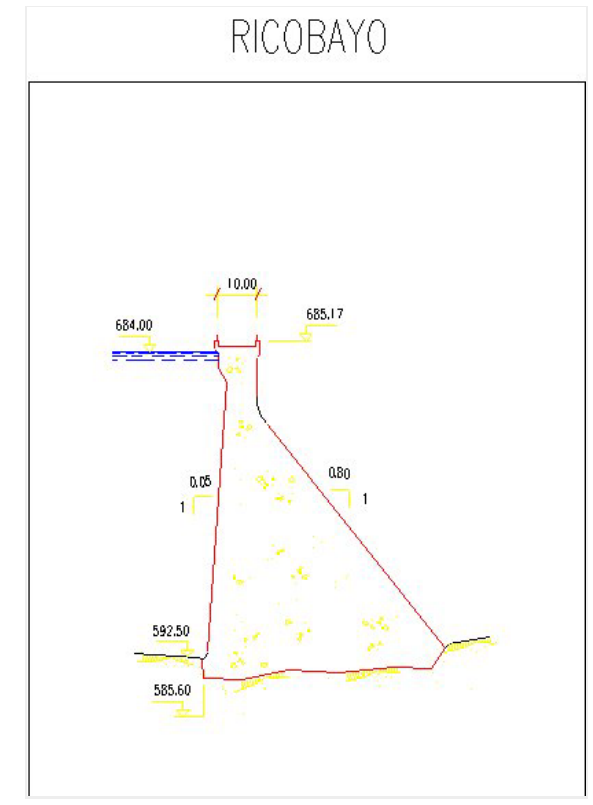




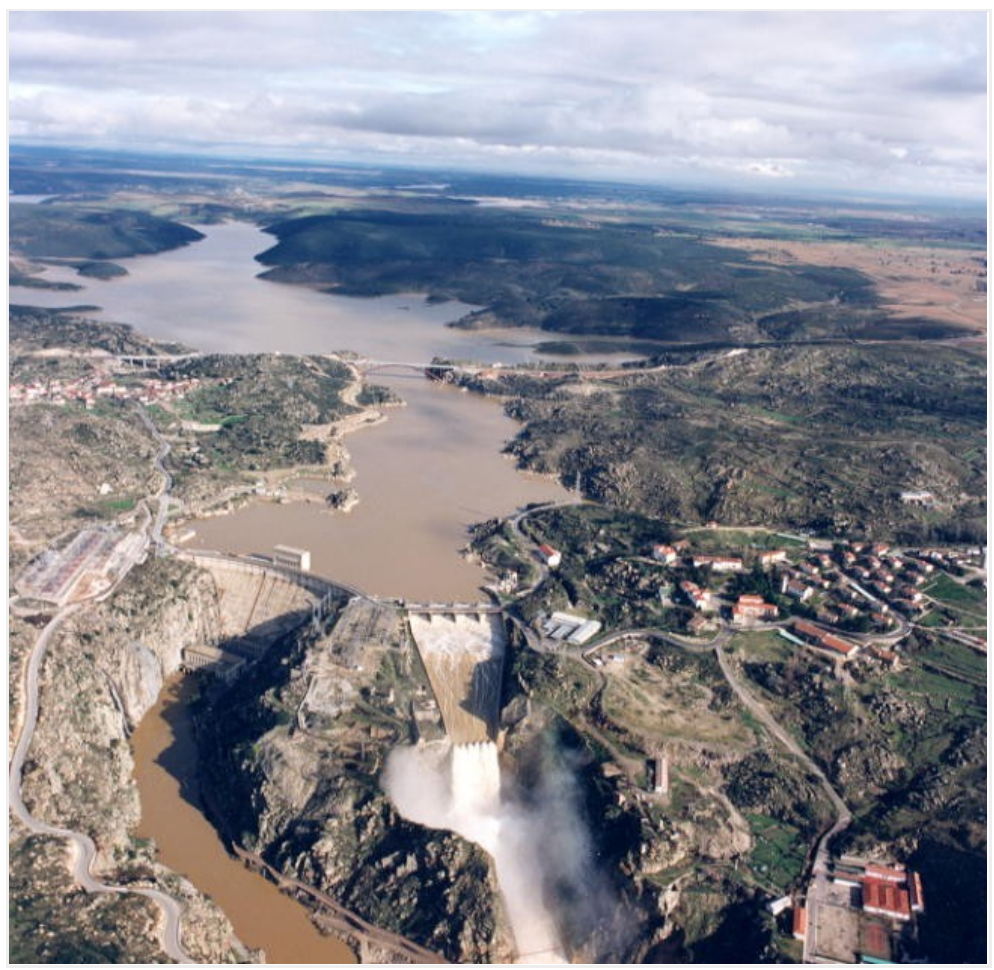

RICOBAYO

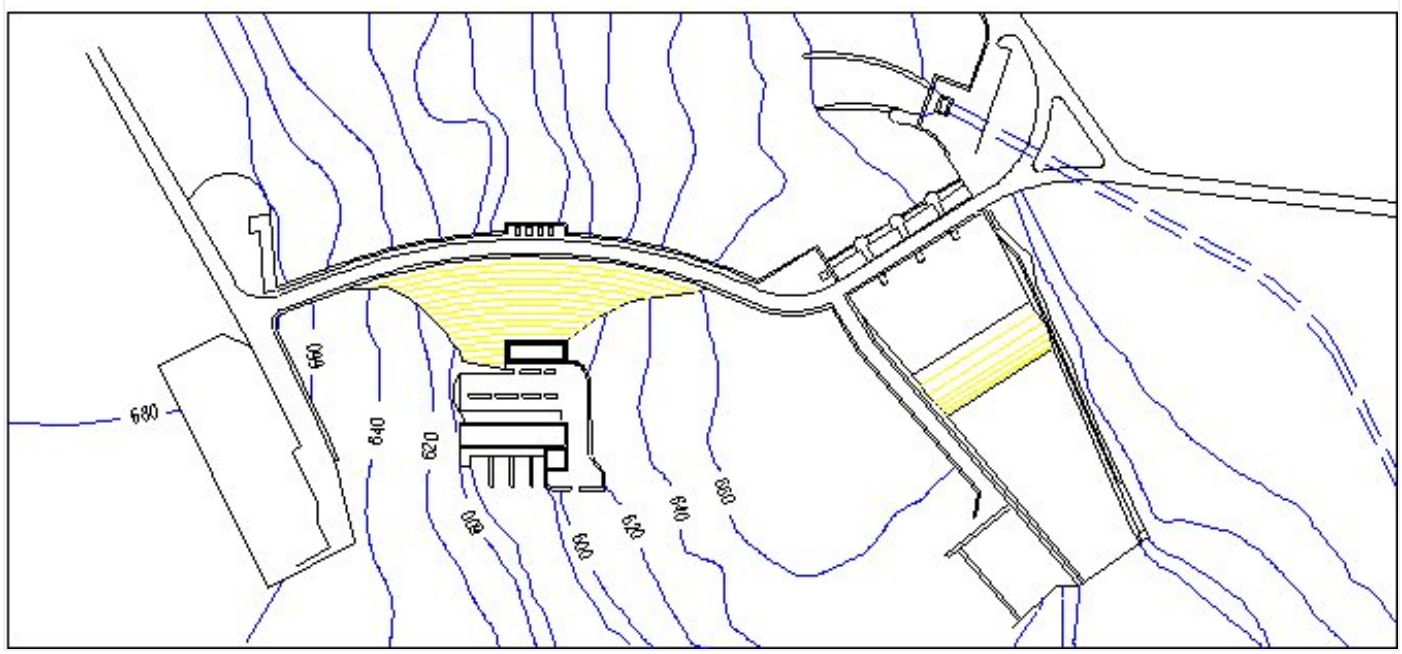

Como es lógico, en el período en el que se desarrolló la Guerra Civil española (1936-1939), no se puso en servicio central alguna.

Antes de seguir con la siguiente etapa en la evolución de las presas hidroeléctricas españolas, se analizan las presas de gravedad de más de 35 metros de altura que estaban construidas o en construcción en 1932. A partir de ese año, y debido a la situación política del país con el posterior enfrentamiento bélico que se produjo, no se realizan importantes obras de carácter hidroeléctrico hasta bien entrados los años 40, en el segundo lustro de esa década. 
En este análisis se abordan las tipologías de gravedad al ser las que se realizaban en su mayoría y su interés se justifica por lo que son de representativas en cuanto a tipología y uso de materiales que se daba lugar en España antes de la entrada masiva del cemento Portland.

Presas de las características antes señaladas, existían en España 38, de las cuales 18 se destinaban a uso hidroeléctrico (a veces compartido con riego), y el resto se dedicaban a riego salvo 2 de ellas destinadas exclusivamente a abastecimiento. Éstas son las presas de El Villar y Puentes Viejas en el río Lozoya (cuenca del Tajo), destinadas al abastecimiento a Madrid y propiedad de la entidad Canales del Lozoya.

Las 18 presas de gravedad de 35 metros de altura o superior, destinadas a aprovechamiento hidroeléctrico en España en explotación o construcción en el año 1932, eran las siguientes:

\begin{tabular}{|c|c|c|c|c|}
\hline NOMBRE & RIO & TITULAR & PROVINCIA & $\begin{array}{l}\text { FÁBRICA DEL } \\
\text { CUERPO DE } \\
\text { PRESA }\end{array}$ \\
\hline BARASONA & Ésera & $\begin{array}{l}\text { Mancomunidad } \\
\text { Hidrográfica del } \\
\text { Ebro }\end{array}$ & Huesca & $\begin{array}{l}\text { Hormigón con } \\
\text { 12\% de bloques de } \\
200 \mathrm{Kg} . \mathrm{c} / \mathrm{m} 3\end{array}$ \\
\hline $\begin{array}{l}\text { MEDIANO } \\
\text { (en const.) }\end{array}$ & Cinca & $\begin{array}{l}\text { Mancomunidad } \\
\text { Hidrográfica del } \\
\text { Ebro }\end{array}$ & Huesca & $\begin{array}{l}\text { Hormigón con } \\
20 \% \text { de bloques de } \\
200 \mathrm{Kg} . \mathrm{c} / \mathrm{m} 3\end{array}$ \\
\hline YESA (en const.) & Aragón & $\begin{array}{l}\text { Mancomunidad } \\
\text { Hidrográfica del } \\
\text { Ebro }\end{array}$ & Navarra & $\begin{array}{l}\text { Hormigón con } \\
180-300 \text { Kg.c/m3 }\end{array}$ \\
\hline TALARN & \begin{tabular}{|l} 
Noguera \\
Pallaresa
\end{tabular} & \begin{tabular}{|ll} 
Riegos y & Fuerza \\
del Ebro & \\
\end{tabular} & Lérida & \begin{tabular}{|ll}
$\begin{array}{l}\text { Hormigón } \\
\text { bloques }\end{array}$ & con \\
\end{tabular} \\
\hline CAMARASA & $\begin{array}{l}\text { Noguera } \\
\text { Pallaresa }\end{array}$ & $\begin{array}{l}\text { Riegos y Fuerza } \\
\text { del Ebro }\end{array}$ & Lérida & $\begin{array}{l}\text { Hormigón con } \\
\text { sand-cement } \\
\text { (arena fina 45\%- } \\
\text { Klinker 55\%) }\end{array}$ \\
\hline CAMPORREDONDO & Carrión & \begin{tabular}{|l}
\multicolumn{2}{|l}{ Mancomunidad } \\
Hidrográfica del \\
Duero
\end{tabular} & Palencia & \begin{tabular}{|lr} 
Mampostería & $35 \%$, \\
mampuestos & $55 \%$, \\
Hormigón r con \\
$400-300$ Kg.c/m3 \\
(promedio \\
kg.c/m3)
\end{tabular} \\
\hline $\begin{array}{l}\text { RICOBAYO } \\
\text { const.) }\end{array}$ & Esla & $\begin{array}{l}\text { Saltos del Duero, } \\
\text { S.A. }\end{array}$ & Zamora & $\begin{array}{l}\text { Hormigón con } \\
150-250 \mathrm{Kg} . c / m 3\end{array}$ \\
\hline $\begin{array}{ll}\text { PTE. } & \text { DEL } \\
\text { BURGUILLO } & \end{array}$ & Alberche & $\begin{array}{ll}\text { Saltos del } & \text { derche, S.A. } \\
\text { Alberch }\end{array}$ & Ávila & $\begin{array}{l}\text { Pantalla con } 300 \\
\text { kg.c/m3, hormigón } \\
\text { con } 15 \% \text { bloques y } \\
250-150 \text { kg.c/m3 }\end{array}$ \\
\hline $\begin{array}{l}\text { FUENSANTA (en } \\
\text { const.) }\end{array}$ & Segura & $\begin{array}{l}\text { Mancomunidad } \\
\text { Hidrográfica del } \\
\text { Segura }\end{array}$ & Albacete & $\begin{array}{l}\text { Hormigón con } \\
\text { 300-167 Kg.c/m3 }\end{array}$ \\
\hline
\end{tabular}




\begin{tabular}{|c|c|c|c|c|}
\hline NOMBRE & RIO & TITULAR & PROVINCIA & $\begin{array}{l}\text { FÁBRICA DEL } \\
\text { CUERPO DE } \\
\text { PRESA }\end{array}$ \\
\hline $\begin{array}{l}\text { CAMARILLAS } \\
\text { const.) }\left(^{*}\right)\end{array}$ & Mundo & $\begin{array}{l}\text { Mancomunidad } \\
\text { Hidrográfica del } \\
\text { Segura }\end{array}$ & Albacete & \\
\hline $\begin{array}{l}\text { LA LÓBREGA (en } \\
\text { const.) }\end{array}$ & Rumblar & $\begin{array}{l}\text { Mancomunidad } \\
\text { Hidrográfica del } \\
\text { Guadalquivir }\end{array}$ & Jaén & $\begin{array}{lr}\text { Hormigón } & \text { con } \\
20 \% \text { bloques con } & \text { co } \\
300-175 \text { kg } & \text { de } \\
\text { sand-cement } & \end{array}$ \\
\hline $\begin{array}{l}\text { TRANCO DE BEAS } \\
\text { (en const.) }\end{array}$ & Guadalquivir & $\begin{array}{l}\text { Mancomunidad } \\
\text { Hidrográfica del } \\
\text { Guadalquivir }\end{array}$ & Jaén & $\begin{array}{l}\text { Hormigón con } \\
\text { bloques con } 300- \\
250-200 \text { kg de } \\
\text { sand-cement de } \\
45 \% \text { arena fina y } \\
55 \% \text { de Klinker }\end{array}$ \\
\hline JÁNDULA & Jándula & $\begin{array}{lr}\text { Canalización } & \mathrm{y} \\
\text { Fuerzas } & \text { del } \\
\text { Guadalquivir } & \\
\end{array}$ & Jaén & Hormigón ciclópeo \\
\hline CALA & \begin{tabular}{ll|} 
Ribera de \\
Cala
\end{tabular} & $\begin{array}{ll}\text { Compañía } & \\
\text { Sevillana } & \text { de } \\
\text { Electricidad } & \\
\end{array}$ & Sevilla & Hormigón ciclópeo \\
\hline CHORRO & Turón & $\begin{array}{lr}\text { Sindicato } & \text { de } \\
\text { Riegos } & \text { del } \\
\text { Pantano } & \text { del } \\
\text { Chorro } & \\
\end{array}$ & Málaga & $\begin{array}{l}\text { Mampostería } \\
\text { ciclópea } \\
\text { hormigón }\end{array}$ \\
\hline DOIRAS (en const.) & Navia & $\begin{array}{l}\text { Electra de Viesgo, } \\
\text { S.A. }\end{array}$ & Oviedo & \\
\hline $\begin{array}{l}\text { ORDUNTE } \\
\text { const.) }\end{array}$ & Ordunte & $\begin{array}{l}\text { Abastecimiento } \\
\text { de aguas de } \\
\text { Bilbao }\end{array}$ & Burgos & \\
\hline TOBA (en const.) & Júcar & $\begin{array}{l}\text { Eléctrica } \\
\text { Castilla, S.A. }\end{array}$ & Cuenca & $\begin{array}{l}\text { Hormigón } \quad 300 \\
\text { kg.c/m3 cimiento } \\
\text { Id. } 275 \text { kg.c/m3 en } \\
\text { pantalla } \\
\text { Id. } 250 \text { y } 200 \\
\text { kg.c/m3 cuerpo de } \\
\text { presa }\end{array}$ \\
\hline
\end{tabular}

$\left(^{*}\right)$ La presa de Camarillas se empezó a construir teniendo en cuenta su uso para aprovechamiento hidroeléctrico compatible con otros usos. Los usos previstos de la presa proyectada eran la laminación de avenidas, regulación de caudales para riegos y abastecimiento de Hellín y producción de energía hidroeléctrica. En la actualidad sus usos principales son defensa frente a avenidas y regulación. 


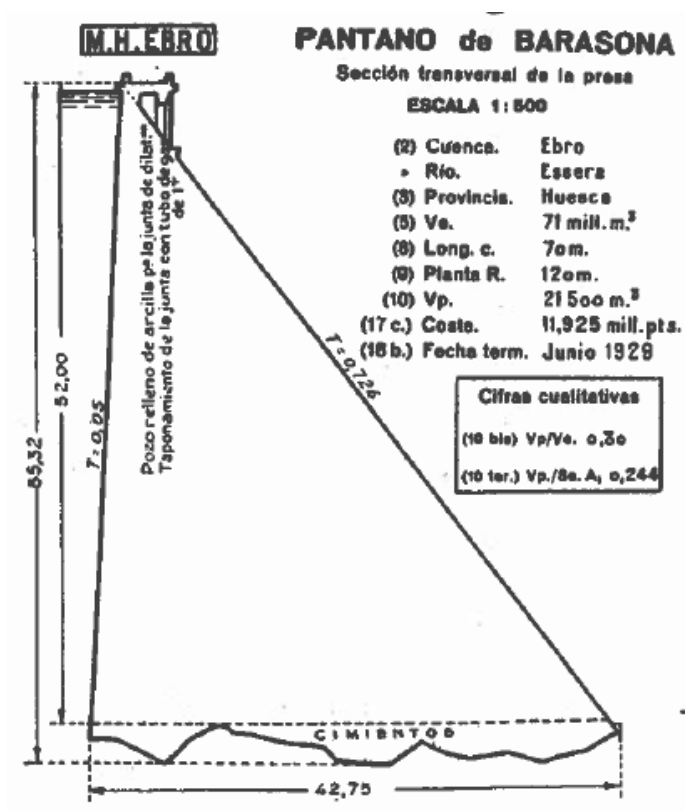

C.H.ERO
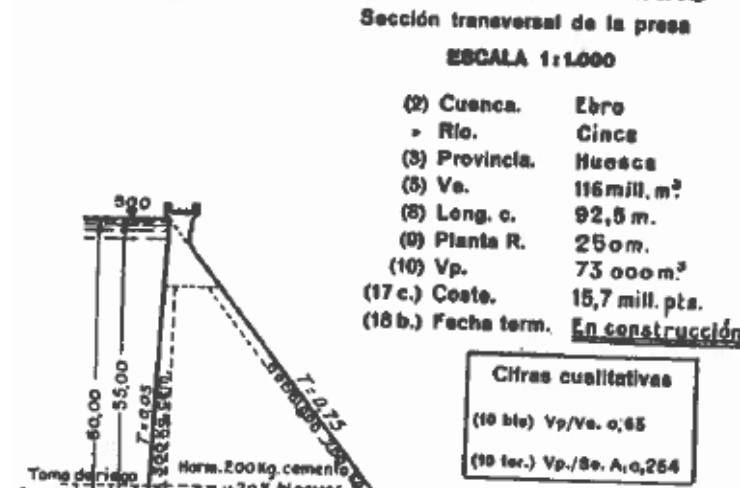
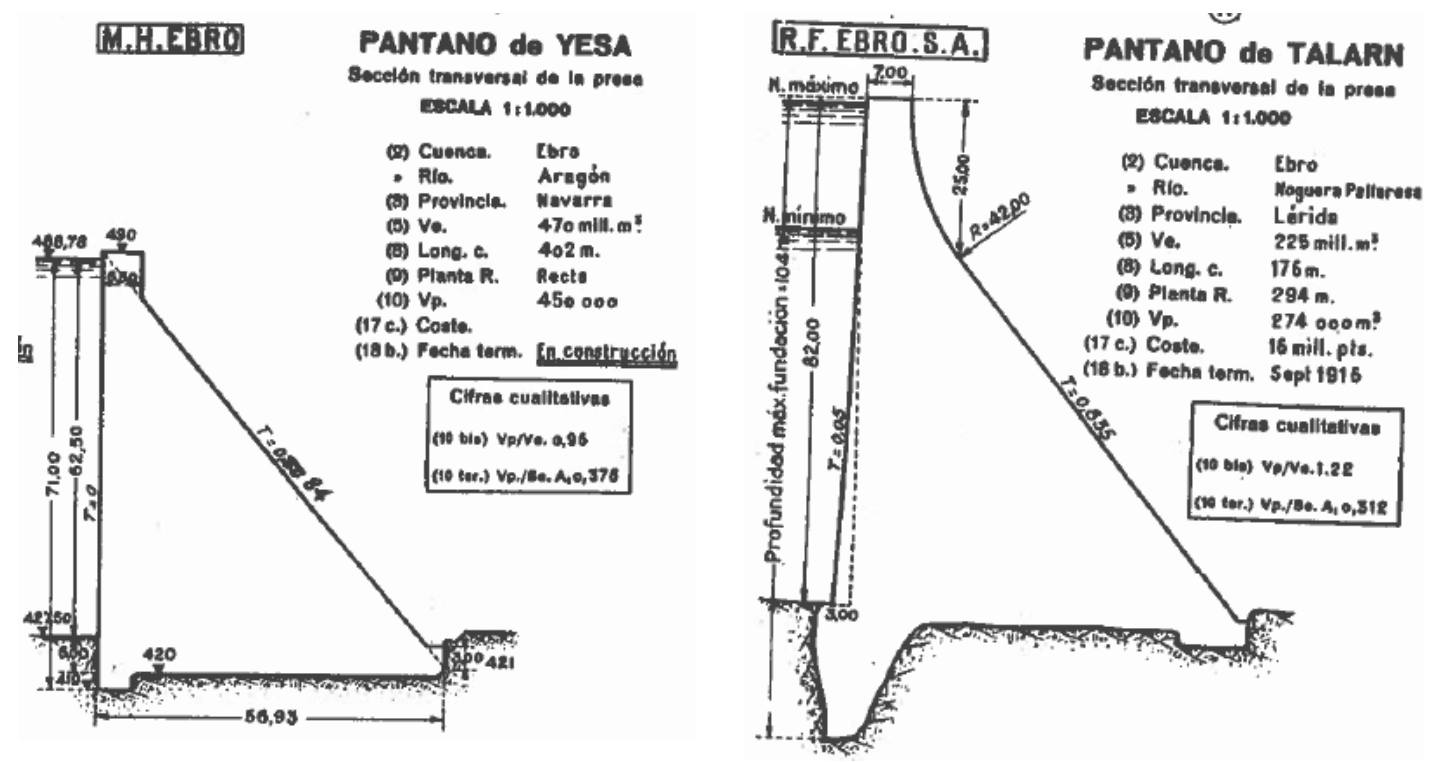

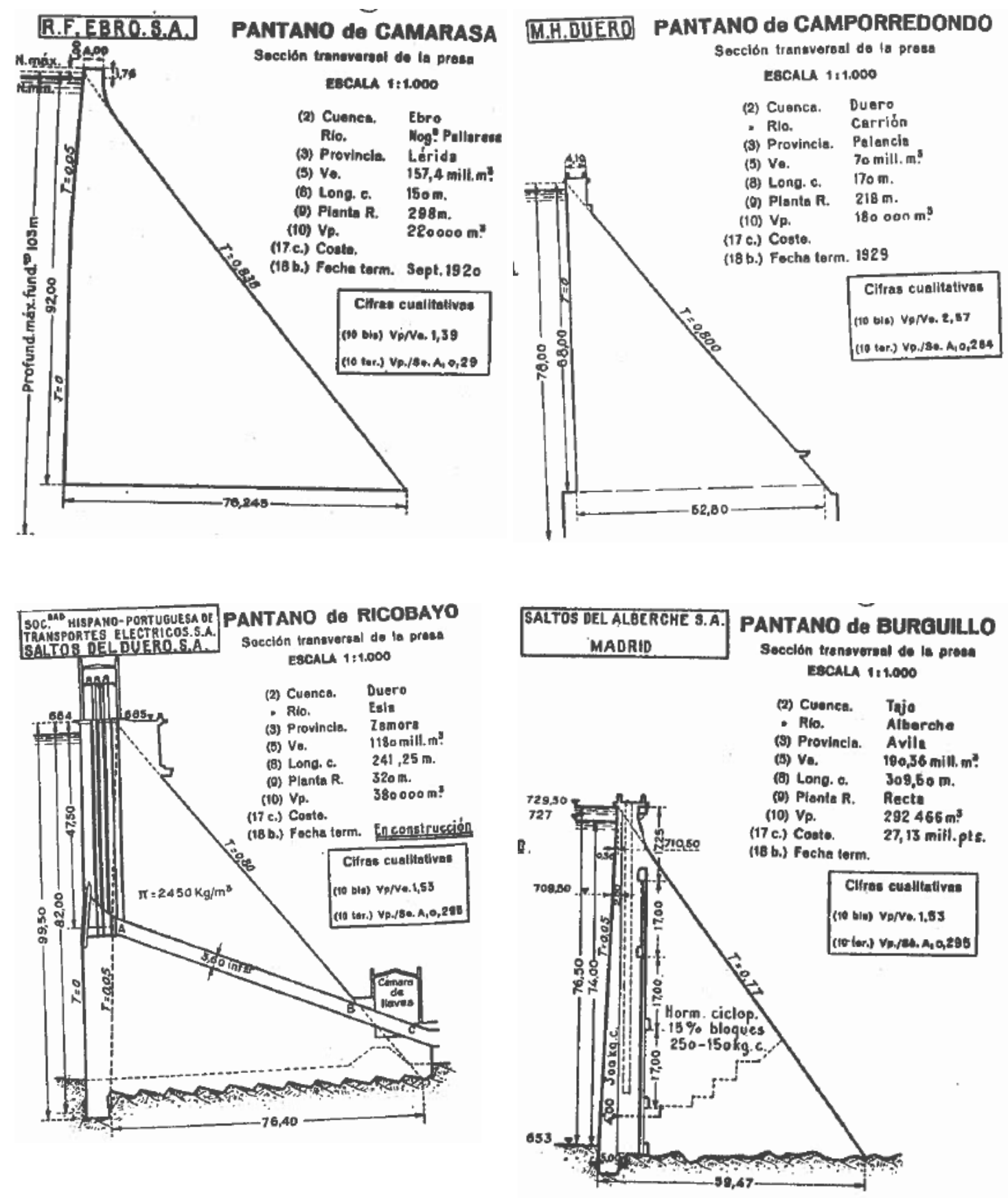


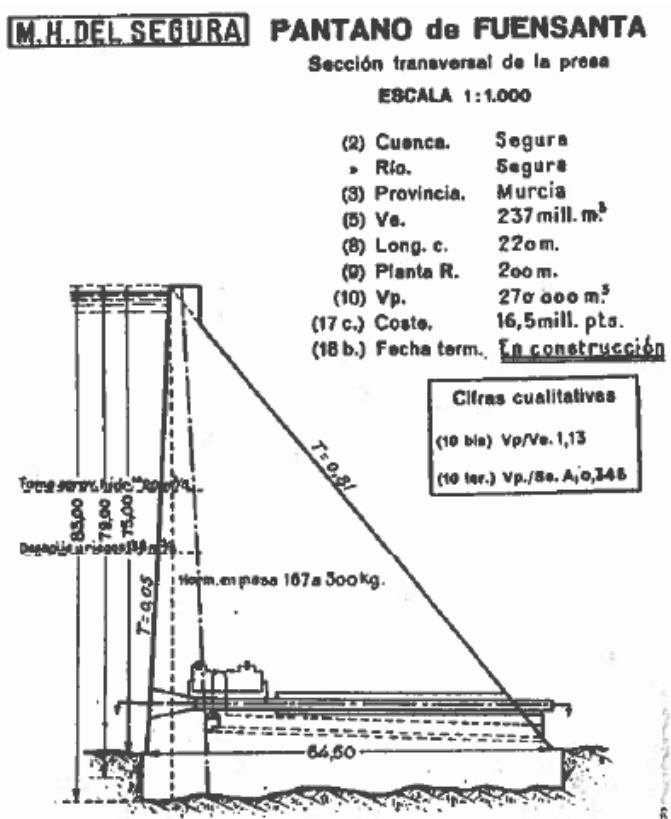

M.H.DELGUADALQUIVIR PANTANO de la LOBREGA Secctón tranaversal de la preate ESCALA 1: 1,000

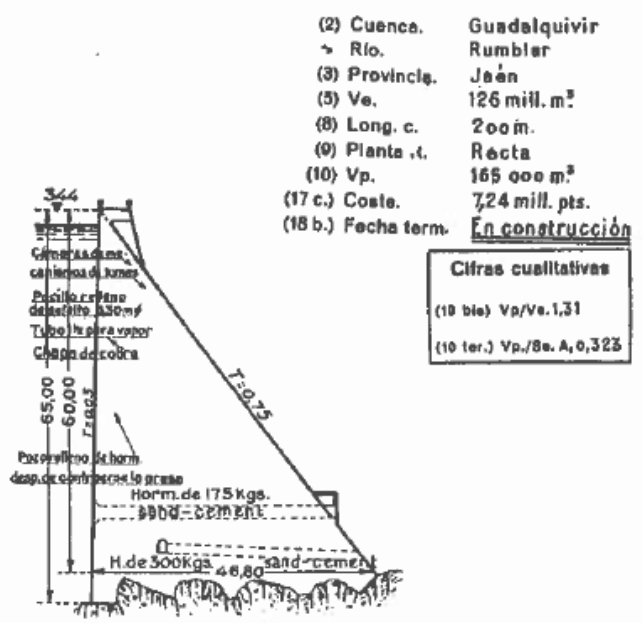

M.H.DELSEGURA PANTANO do CAMARILLAS seceion traneversal de la prese EBCALA 1: 1.000

(2) Cuenca. Begurs - Rlo. Mundo (9) Provincle. Murcia (5) Vo. $\quad 39,9$ mill. $\mathrm{m}^{3}$ (B) Long. c. $14 \mathrm{~m}$. (פ) Planta $R$. (10) Vp. (17 c.) Costo.

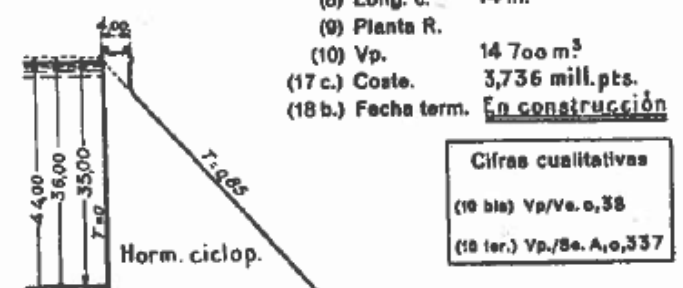

\section{M.H.OEL GUADALQUIVIR PANTANO de BEAS} Secelón transversal de le prosa EScALA 1: 1.000

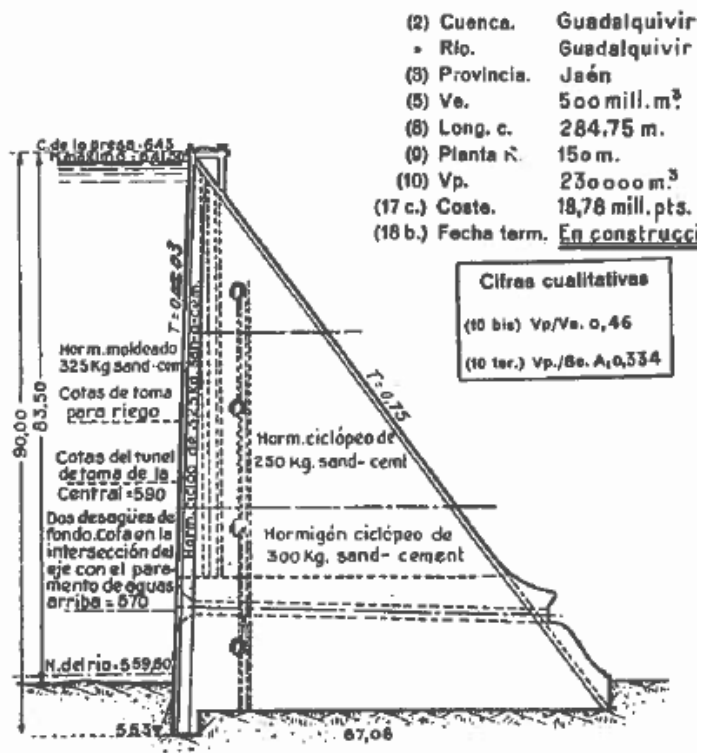



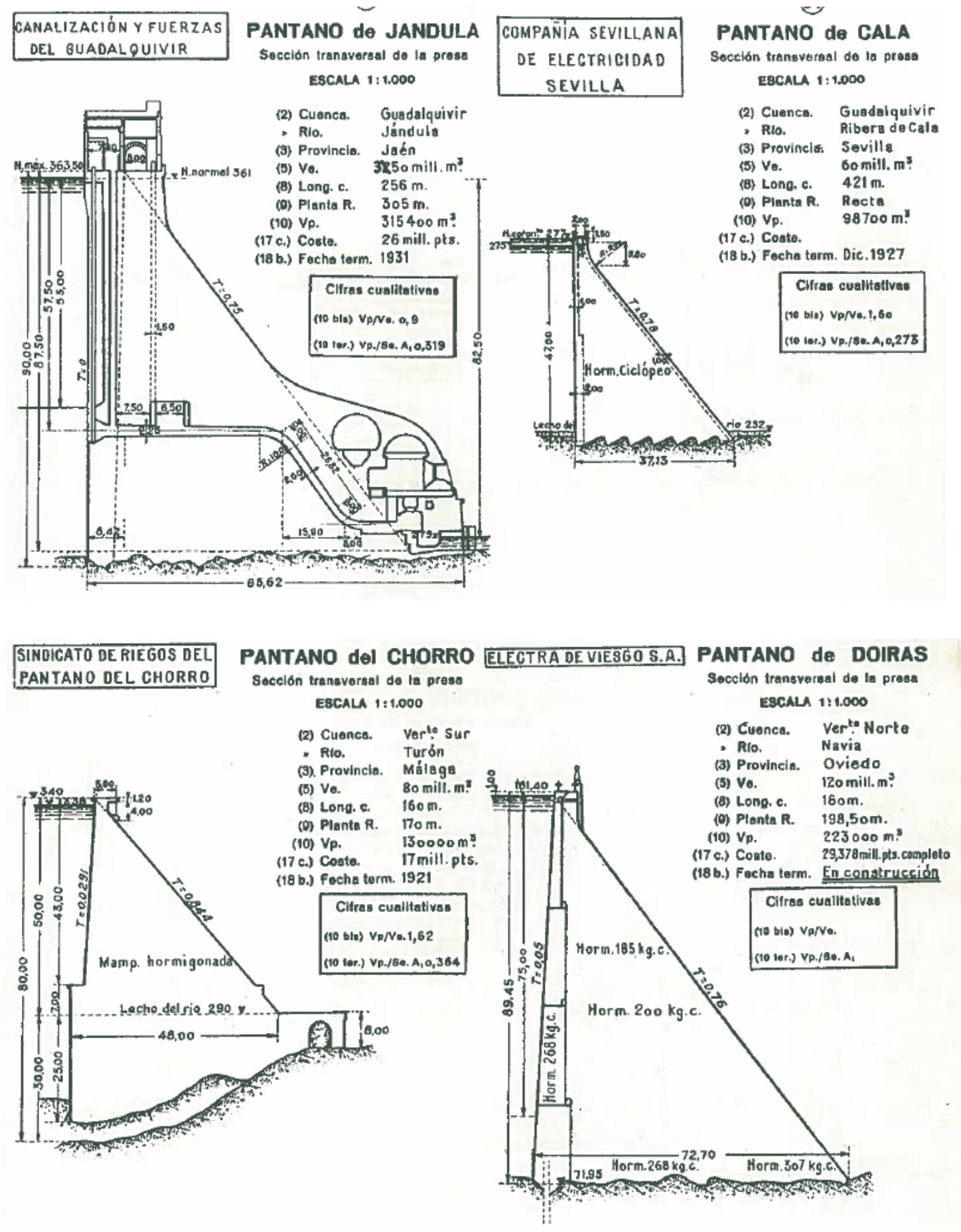

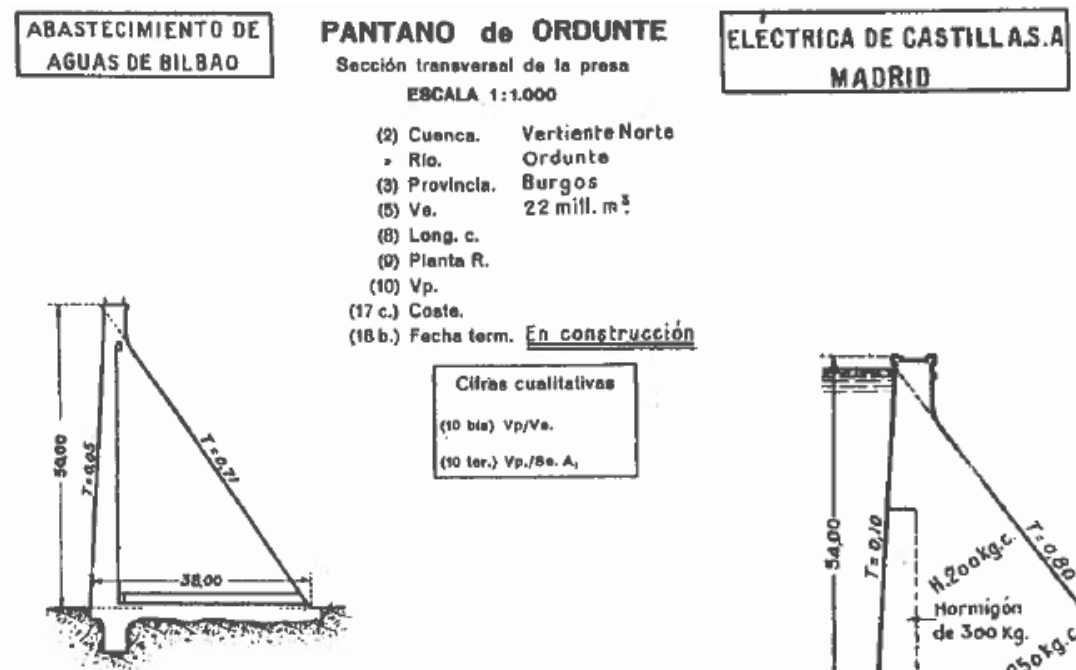

PANTANO de TOBa

Sección transverual do la presa

ESCALA $1: 1.000$

(2) Cuenca. Jücar

- Rio. Júcar

(8) Provincia. Cuencs

(5) Ve. 39 mill. m.

(6) Long. c. $252 \mathrm{~m}$.

(9) Plants R. $600 \mathrm{~m}$.

(10) Vp. $\quad 150000 \mathrm{~m}^{3}$

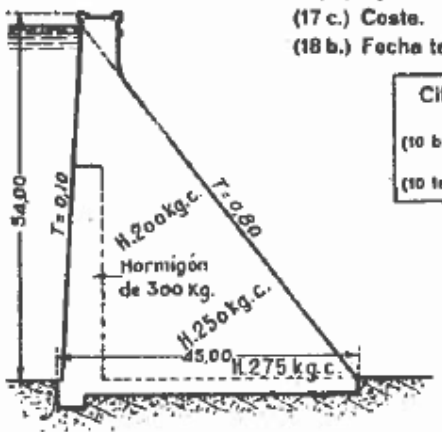

18 mill. pts.

Cifras cualitativas (10 b/8) Vp/Vo. 3,85 (10 ter.) Vp./80. A,0,45

Además de las presas que ya se han descrito con mayor profusión con anterioridad, especial interés tiene la presa de Jándula, sobre el cauce del mismo nombre, que como puede verse en la sección tipo antes indicada, tiene la central dentro del cuerpo de presa. Fue pionera de esta tipología que luego se utilizó en Francia y otros países, especialmente adecuada para valles angostos.

El salto del Jándula se encuentra situado en el extremo oriental de la Sierra Morena, en la serranía de Andújar, un ámbito territorial agreste de paisajes naturales. Está construido sobre una cerrada granítica en el paraje de La Lancha, en el río Jándula, afluente por la derecha del río Guadalquivir. El proyecto de la presa fue visado el 29 de abril de 1925. Su construcción se inició en febrero de 1927 y comenzó a prestar servicio en 1930, concluyéndose oficialmente las obras el 30 de junio de 1931. En esta presa colaboraron también Antonio del Águila (1893-1962) y el arquitecto Casto Fernández-Shaw.

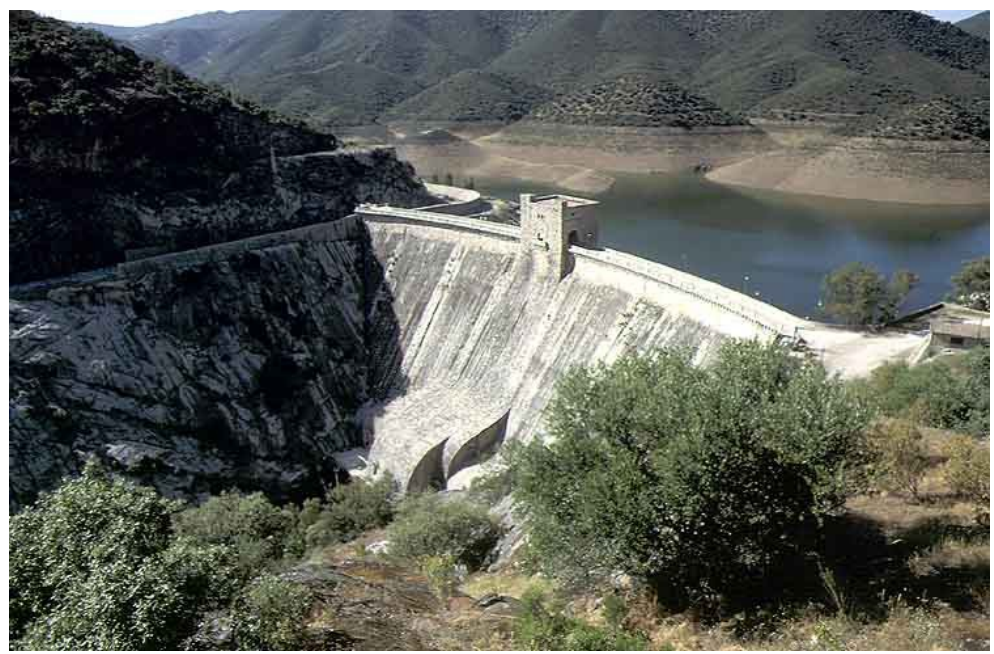


El tipo de presa es de gravedad, de planta curva y sección triangular, cuenta con una altura de 83.5 metros sobre el cauce, tiene una longitud de 240 metros. A pie de presa se encuentra integrada la central hidroeléctrica.

Su coronación se convierte en un adarve almenado que adopta la forma de Torre del Homenaje y que aloja las compuertas. Este torreón se abre a la cara aguas abajo del río Jándula con un balcón en ménsula.

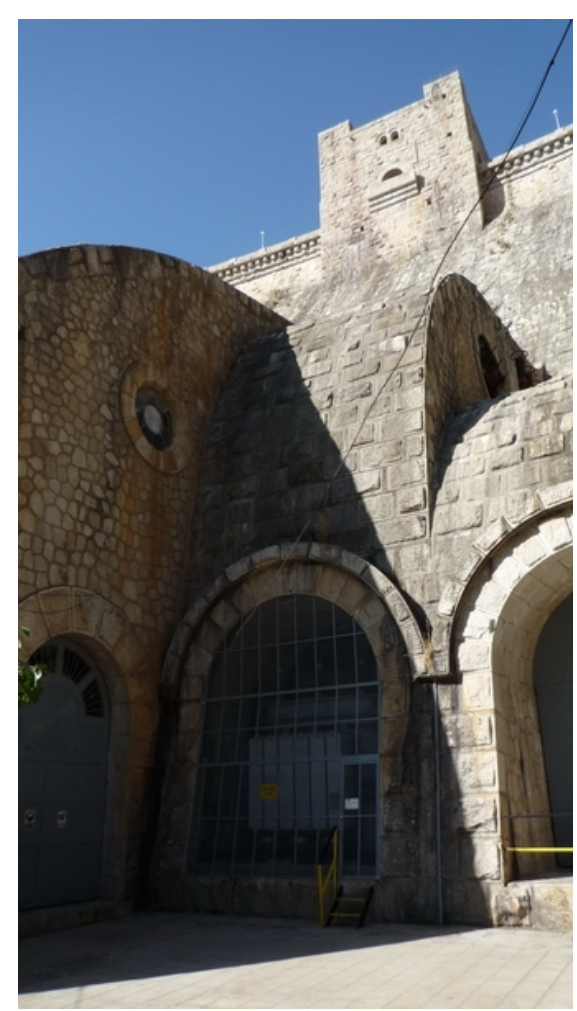

El conjunto está construido con hormigón ciclópeo vertido en encofrado visto de sillares de granito extraídos de la cantera situada junta a la presa, mostrando una clara intención de integrarlo en su entorno. Utiliza un lenguaje moderno, expresionista, acentuado por el tratamiento de la central con remate ondulado en referencia al movimiento de las aguas.

Como muestra de la influencia que la construcción de una presa originaba en el entorno social de los pueblos colindantes en esa época, destacar que para la construcción y mantenimiento de la presa fue construido un poblado para 3000 personas en los terrenos colindantes a La Charca del Fraile, nombre que recibía el emplazamiento antes de la construcción de la presa.

Durante el año 1926 se saneó la zona y se construyó el campamento. Se trataba de una pequeña ciudad para mil trabajadores junto a sus familias. Este nuevo poblado, situado a 40 kilómetros de la ciudad más cercana, Andújar, disponía de alcantarillado, agua potable, luz, y teléfono. Entre los edificios estaba una iglesia, que hizo las veces de escuela, un hospital, un economato, una cantina, una cuadra, un teatro, un cuartel de la Guardia Civil, un frontón, etc.

En la actualidad se conserva en buen estado la iglesia y las viviendas de técnicos situadas en hilera en torno a ella. De las viviendas de los trabajadores quedan algunos restos de los muros de carga. Se conserva el frontón.

La presa y central hidroeléctrica del Jándula es una pieza ejemplar del patrimonio cultural andaluz por diversas cuestiones. 
En primer lugar, por su valor histórico, como muestra del espíritu de modernización del territorio rural andaluz surgido a finales del siglo XIX en Andalucía, testimonio del ambicioso proyecto de Canalización y Aprovechamientos de Energía del Guadalquivir que pretendía hacer navegable el río Guadalquivir en su tramo entre Sevilla y Córdoba. Un proyecto que, como ya se ha comentado en párrafos anteriores de esta tesis, y pese a que finalmente vio frustrados sus objetivos iniciales, fue el motor que permitió contener y dominar el agua de esta arteria fluvial de Andalucía con la construcción de tres de las once presas proyectadas: la presa del Jándula y la del Encinarejo en Andújar y la presa de Alcalá del Río en Sevilla.

Mengemor (Carlos Mendoza, José Moreno y Antonio González Echarte) en el año 1924 funda una compañía independiente: Canalización y Fuerzas del Guadalquivir, compañía anónima filial de Mengemor. Así, el proyecto de presa de Jándula pasaría a depender de esta entidad.

Por su valor tipológico, como ejemplo de presa de gravedad, tipología que marca, a finales del siglo XIX en España, un punto de inflexión en la evolución de las presas de fábrica haciendo uso de criterios racionales abandonando el puro empirismo.

Por su valor tecnológico, que permitió la construcción de un salto de casi 90 metros incorporando el edificio de la central eléctrica al pie de la presa para ahorrar espacio, haciendo así de la escasez de espacio, virtud del proyecto.

Por último, por su valor estilístico, como ejemplo de historicismo, uno de los caminos que tomó la arquitectura española de principios del siglo XX en su búsqueda por una nueva identidad arquitectónica que permitiese situar a España de nuevo en el contexto internacional. Este lenguaje historicista andaluz beberá de todas aquellas épocas de gran esplendor para Andalucía: de sus raíces musulmanas, como es el caso de esta presa, de su periodo conquistador o de aquella época en que la capital andaluza era metrópoli de Indias, en busca de un sueño: situar de nuevo a la sociedad en un momento de esplendor.

En resumen, con anterioridad a 1940 sólo se habían construido en España dos presas arco de gran altura -Montejaque y Alloz- y otras dos presas arco de mediana importancia -El Pelgo y Tenebroso- siendo el resto de las presas de fábrica de gravedad. También se hicieron algunas presas de materiales sueltos de alturas inferiores a 30 metros. 
España se encontraba al nivel de otros países en cuanto a diseño y construcción de presas en las primeras décadas del siglo XX, no apreciándose diferencias grandes entre los países europeos hasta 1930.

Basta como ejemplo, observar el listado adjunto de las mayores presas europeas anteriores a 1933 (algunas de ellas se encontraban en construcción en el año de referencia indicado anteriormente).

\begin{tabular}{|c|c|c|c|c|c|}
\hline Presa & País & H.cauce & H.máx. & Volumen & Tipo \\
\hline Dnieper & Rusia & 42 & 62 & 760.000 & Gravedad \\
\hline Sarnas & Francia & 95 & 105 & 405.000 & Gravedad \\
\hline Dixence & Suiza & & 87 & 400.000 & Gravedad \\
\hline Ricobayo & España & 92 & 103 & 380.000 & Gravedad \\
\hline Grimsell & Suiza & & 115 & 340.000 & $\begin{array}{l}\text { Arco } \\
\text { Gravedad }\end{array}$ \\
\hline Jándula & España & 85 & 90 & 315.000 & Gravedad \\
\hline Chavanon & Francia & 90 & 96 & 300.000 & Gravedad \\
\hline Burguillo & Burguillo & 77 & 82 & 292.000 & Gravedad \\
\hline Chambon & Francia & 90 & 135 & 290.000 & Gravedad \\
\hline Suviana & Italia & & 90 & 280.000 & Gravedad \\
\hline Talarn & España & 82 & 104 & 274.000 & Gravedad \\
\hline Fuensanta & España & 75 & 83 & 270.000 & Gravedad \\
\hline Campliccioli & Italia & & 72 & 237.000 & Gravedad \\
\hline Schrach & Suiza & 66 & 110 & 233.000 & Gravedad \\
\hline $\begin{array}{l}\text { Tranco de } \\
\text { Beas }\end{array}$ & España & 84 & 90 & 230.000 & Gravedad \\
\hline Barberine & Suiza & 65 & 85 & 225.000 & Gravedad \\
\hline Camarasa & España & 92 & 103 & 220.000 & Gravedad \\
\hline P. Alfonso & España & 68 & 78 & 180.000 & Gravedad \\
\hline Breilock & Alemania & 61 & 65 & 179.000 & Gravedad \\
\hline Tirso & Italia & 59 & 70 & 163.000 & Contrafuertes \\
\hline Barbellino & Italia & 67 & 70 & 150.000 & Gravedad \\
\hline Cardanello & Italia & & 75 & 112.000 & Gravedad \\
\hline Coghinas & Italia & & 58 & 112.000 & Gravedad \\
\hline Sautet & Francia & 130 & 135 & 60.000 & Arco \\
\hline Montejaque & España & & 83 & 27.000 & Arco \\
\hline Alloz & España & & 66.8 & 18.470 & Arco \\
\hline
\end{tabular}

Cabe destacar que de las 26 presas referidas, 10 son españolas y de ellas, todas menos una (P. Alfonso) tenían como uso (no siempre en exclusiva) el aprovechamiento hidroeléctrico.

Terminada la Guerra Civil se produjo una etapa de desarrollo intensivo desde 1940 hasta 1975. Los parámetros económicos cambiaron radicalmente para 
España quedando el país muy empobrecido caracterizado por una situación de precariedad absoluta en la que la producción de energía eléctrica se focalizó principalmente en saltos hidráulicos, teniendo, por tanto, las presas un papel capital en la regulación y garantía de suministro. Las empresas eléctricas construyen sus presas con un criterio de rentabilidad por producción de energía, permitiendo asimismo, que sus embalses se empleen para usos múltiples, como el abastecimiento y el riego, de acuerdo con los requerimientos de la política de la época.

En esta época, los grandes aprovechamientos que se construyeron se fundamentaron en presas de gravedad, tipología de presas en la que España adquirió una experiencia tecnológica importante que permitió calcular y construir, sobre todo al final de esta etapa, grandes bóvedas como Almendra (202 metros), Canelles (151 metros) y Susqueda (135 metros).

Las centrales, con sus presas o azudes asociados, de las empresas hidroeléctricas principales actuales, que se pusieron en servicio en esta etapa fueron:

\begin{tabular}{|l|c|c|c|}
\hline \multicolumn{1}{|c|}{ CENTRAL (CIUDAD) } & PRESA ASOCIADA & TIPO DE PRESA & $\begin{array}{c}\text { PUESTA EN } \\
\text { SERVICIO }\end{array}$ \\
\hline PORTO (ZAMORA) & VALDESIRGAS & MATERIALES SUELTOS & 1963 \\
\hline PRADA (ORENSE) & PRADA & GRAVEDAD & 1958 \\
\hline $\begin{array}{l}\text { SAN AGUSTÍN } \\
\text { (ORENSE) }\end{array}$ & PÍAS & MATERIALES SUELTOS & 1961 \\
\hline $\begin{array}{l}\text { SAN SEBASTIÁN } \\
\text { (ZAMORA) }\end{array}$ & SAN SEBASTIÁN & GRAVEDAD & 1959 \\
\hline EUME (A CORUÑA) & EUME & BÓVEDA & 1960 \\
\hline $\begin{array}{l}\text { LA RIBEIRA (A } \\
\text { CORUÑA) }\end{array}$ & LA RIBEIRA & GRAVEDAD & 1965 \\
\hline $\begin{array}{l}\text { PEÑA DE BEJO } \\
\text { (SANTANDER) }\end{array}$ & PRESA DE COHILLA & BÓVEDA & 1947 \\
\hline CELÍS (SANTANDER) & AZUD DE CELIS & HORMIGÓN & 1952 \\
\hline BÁRCENA (LEÓN) & BÁRCENA & GRAVEDAD & 1959 \\
\hline CORNATEL (ORENSE) & CAMPAÑANA, & GRAVEDAD & 1964 \\
\hline $\begin{array}{l}\text { LAS ONDINAS (LEÓN) } \\
\text { MONTEARENAS }\end{array}$ & $\begin{array}{c}\text { ROZAS Y } \\
\text { MATALAVILLA }\end{array}$ & BÓVEDA-GRAVEDAD & 1966 \\
\hline PEÑADRADA (LEÓN) & AZUD DE ONDINAS & GRAVEDAD & 1963 \\
\hline QUEREÑO (ORENSE) & EIRÓS Y PEÑARRUBIA & GRAVEDAD & 1961 \\
\hline $\begin{array}{l}\text { SANTA MARINA I } \\
\text { (LEÓN) }\end{array}$ & $\begin{array}{l}\text { AZUD DE } \\
\text { MATARROSA }\end{array}$ & BÓVEDA & 1958 \\
\hline $1,2,3$ (ZAMORA) & PUENTE PORTO & CONTRAFUERTES/MATE & 1954 \\
\hline & \multicolumn{2}{|l}{ RIALES SUELTOS } & \\
\hline
\end{tabular}


EVOLUCIÓN DE LA INGENIERÍA DE LAS PRESAS HIDROELÉCTRICAS

\begin{tabular}{|c|c|c|c|}
\hline CENTRAL (CIUDAD) & PRESA ASOCIADA & TIPO DE PRESA & $\begin{array}{l}\text { PUESTA EN } \\
\text { SERVICIO }\end{array}$ \\
\hline $\begin{array}{l}\text { MONCABRIL GRUPO } \\
\text { AUXILIAR (ZAMORA) }\end{array}$ & $\begin{array}{l}\text { PUERTO PORTO, } \\
\text { PLAYA, CÁRDENA, }\end{array}$ & GRAVEDAD & 1954 \\
\hline FLIX (TARRAGONA) & FLIX & MÓVIL & 1948 \\
\hline $\begin{array}{l}\text { MEQUINENZA } \\
\text { (ZARAGOZA) }\end{array}$ & MEQUINENZA & GRAVEDAD & 1964 \\
\hline $\begin{array}{l}\text { RIBARROJA } \\
\text { (TARRAGONA) }\end{array}$ & RIBARROJA & GRAVEDAD & 1968 \\
\hline BALAGUER (LLEIDA) & PARTIDOR & AZUD & 1960 \\
\hline CANELLES (LLEIDA) & CANELLES & BÓVEDA & 1959 \\
\hline OLIANA (LLEIDA) & LA OLIANA & GRAVEDAD & 1956 \\
\hline SANTA ANA (HUESCA) & SANTA ANA & GRAVEDAD & 1962 \\
\hline TERMENS (LLEIDA) & & & 1964 \\
\hline PASTERAL I (GIRONA) & PASTERAL I & GRAVEDAD & 1962 \\
\hline $\begin{array}{l}\text { PASTERAL II } \\
\text { (GIRONA) }\end{array}$ & & AZUD & 1946 \\
\hline SAU (BARCELONA) & SAU & GRAVEDAD & 1963 \\
\hline SUSQUEDA (GIRONA) & SUSQUEDA & BÓVEDA & 1967 \\
\hline TREGURÁ (GIRONA) & & $\begin{array}{l}\text { AZUDES CATLLAR Y } \\
\text { TREGURÁ }\end{array}$ & 1950 \\
\hline ESPOT (LLEIDA) & AZUD ESPOT & & 1953 \\
\hline ESTERRI (LLEIDA) & LAGO BOREN & GRAVEDAD & 1958 \\
\hline $\begin{array}{l}\text { LA TORRASA } \\
\text { (LLEIDA) }\end{array}$ & TORRASA & GRAVEDAD ARCO & 1955 \\
\hline LLADRES (LLEIDA) & LAGO NEGRO & ESCOLLERA & 1956 \\
\hline LLAVORSÍ (LLEIDA) & TAVASCAN & GRAVEDAD & 1966 \\
\hline $\begin{array}{l}\text { MONTAMARA } \\
\text { (LLEIDA) }\end{array}$ & GRAUS/RUMEDO & GRAVEDAD & 1974 \\
\hline $\begin{array}{l}\text { SANT MAURICI } \\
\text { (LLEIDA) }\end{array}$ & SANT MAURICI & GRAVEDAD & 1954 \\
\hline $\begin{array}{l}\text { TAVASCAN INFERIOR } \\
\text { (LLEIDA) }\end{array}$ & GRAUS & GRAVEDAD & 1971 \\
\hline $\begin{array}{l}\text { TAVASCAN SUPERIOR } \\
\text { (LLEIDA) }\end{array}$ & RUMEDO & GRAVEDAD & 1971 \\
\hline UNARRE (LLEIDA) & LAGO LA GOLA & GRAVEDAD & 1958 \\
\hline AIGUAMOIX (LLEIDA) & AIGUAMOIX & ESCOLLERA & 1965 \\
\hline ARTÍES (LLEIDA) & $\begin{array}{c}\text { RESTANCA- } \\
\text { MONTCASAU- } \\
\text { COLOMERS } \\
\end{array}$ & GRAVEDAD & 1955 \\
\hline $\begin{array}{l}\text { PONT DE REI } \\
\text { (LLEIDA) }\end{array}$ & TORÁN & GRAVEDAD & 1960 \\
\hline $\begin{array}{l}\text { TORÁN (LLEIDA) } \\
\text { BONO (HUESCA) }\end{array}$ & $\begin{array}{l}\text { SAN JUAN TORÁN } \\
\text { SENET }\end{array}$ & GRAVEDAD & $\begin{array}{l}1963 \\
1953\end{array}$ \\
\hline CALDAS (LLEIDA) & CAVALLERS & CONTRAFUERTES & 1959 \\
\hline
\end{tabular}


EVOLUCIÓN DE LA INGENIERÍA DE LAS PRESAS HIDROELÉCTRICAS

\begin{tabular}{|c|c|c|c|}
\hline CENTRAL (CIUDAD) & PRESA ASOCIADA & TIPO DE PRESA & $\begin{array}{l}\text { PUESTA EN } \\
\text { SERVICIO }\end{array}$ \\
\hline ESCALES (HUESCA) & ESCALES & GRAVEDAD & 1955 \\
\hline LLESP (LLEIDA) & LLESP & GRAVEDAD & 1955 \\
\hline $\begin{array}{l}\text { MONTANYANA } \\
\text { (LLEIDA) }\end{array}$ & SOPEIRA & GRAVEDAD & 1958 \\
\hline $\begin{array}{l}\text { PONT DE SUERT } \\
\text { (LLEIDA) }\end{array}$ & PONT DE SUERT & & 1955 \\
\hline BIESCAS II (HUESCA) & BUBAL & ARCO GRAVEDAD & 1969 \\
\hline IP (HUESCA) & CONTRAEMBALSE & TIERRA & 1972 \\
\hline $\begin{array}{l}\text { JABARRELLA } \\
\text { (HUESCA) }\end{array}$ & JABARRELLA & & 1961 \\
\hline JACA (HUESCA) & JACA & GRAVEDAD & 1968 \\
\hline $\begin{array}{l}\text { JAVIERRELATRE } \\
\text { (HUESCA) }\end{array}$ & JAVIERRELATRE & GRAVEDAD & 1965 \\
\hline LA SARRA (HUESCA) & ARRIELES & GRAVEDAD & 1954 \\
\hline $\begin{array}{l}\text { SABIÑÁNIGO } \\
\text { (HUESCA) }\end{array}$ & SABIÑÁNIGO & GRAVEDAD & 1964 \\
\hline $\begin{array}{l}\text { SALLENT-AGUAS } \\
\text { LIMPIAS (HUESCA) }\end{array}$ & GÁLLEGO & ESCOLLERA & 1953 \\
\hline $\begin{array}{l}\text { SALLENT-ESCARRA } \\
\text { (HUESCA) }\end{array}$ & ESCARRA & ESCOLLERA HORMIGÓN & 1955 \\
\hline ARGONÉ (HUESCA) & AZUD DE SEIRA & AZUD DE DERIVACIÓN & 1947 \\
\hline BIELSA (HUESCA) & BIELSA & & 1949 \\
\hline ERISTE (HUESCA) & ESTÓS & GRAVEDAD & 1969 \\
\hline GRADO I (HUESCA) & EL GRADO I & & 1967 \\
\hline GRADO II (HUESCA) & EL GRADO II & GRAVEDAD ARCO & 1968 \\
\hline LASPUÑA (HUESCA) & LASPUÑA & GRAVEDAD & 1965 \\
\hline MEDIANO (HUESCA) & MEDIANO & & 1969 \\
\hline SESUÉ (HUESCA) & LINSOLES & GRAVEDAD & 1964 \\
\hline $\begin{array}{l}\text { CORDOBILLA } \\
\text { (CÓRDOBA) }\end{array}$ & CORDOBILLA & GRAVEDAD & 1952 \\
\hline IZNÁJAR (MÁLAGA) & IZNÁJAR & GRAVEDAD & 1968 \\
\hline JAUJA (CÓRDOBA) & JAUJA-MALPASILLO & CONTRAFUERTES & 1951 \\
\hline $\begin{array}{l}\text { DOÑA ALDONZA } \\
\text { (JAÉN) }\end{array}$ & DOÑA ALDONZA & GRAVEDAD & 1956 \\
\hline GUADALÉN (JAÉN) & GUADALÉN & GRAVEDAD & 1959 \\
\hline GUADALMENA (JAÉN) & GUADALMENA & GRAVEDAD & 1970 \\
\hline LOS ÓRGANOS (JAÉN) & LOS ÓRGANOS & GRAVEDAD & 1955 \\
\hline MENGÍBAR (JAÉN) & MENGÍBAR & GRAVEDAD & 1975 \\
\hline PEDRO MARÍN (JAÉN) & PEDRO MARÍN & GRAVEDAD & 1954 \\
\hline $\begin{array}{l}\text { TRANCO DE BEAS } \\
\text { (JAÉN) }\end{array}$ & TRANCO DE BEAS & GRAVEDAD & $1944 / 1953$ \\
\hline $\begin{array}{l}\text { BEMBÉZAR } \\
\text { (CÓRDOBA) }\end{array}$ & BEMBÉZAR & GRAVEDAD & 1962 \\
\hline
\end{tabular}


EVOLUCIÓN DE LA INGENIERÍA DE LAS PRESAS HIDROELÉCTRICAS

\begin{tabular}{|c|c|c|c|}
\hline CENTRAL (CIUDAD) & PRESA ASOCIADA & TIPO DE PRESA & $\begin{array}{l}\text { PUESTA EN } \\
\text { SERVICIO }\end{array}$ \\
\hline $\begin{array}{l}\text { GUADALMELLATO } \\
\text { (CÓRDOBA) }\end{array}$ & GUADALMELLATO & GRAVEDAD & 1963 \\
\hline LA VEGA (CÓRDOBA) & & & 1946 \\
\hline MARMOLEJO (JAÉN) & MARMOLEJO & GRAVEDAD & 1962 \\
\hline $\begin{array}{l}\text { VILLAFRANCA } \\
\text { (CÓRDOBA) }\end{array}$ & VILLAFRANCA & GRAVEDAD & 1948 \\
\hline $\begin{array}{l}\text { ORELLANA CANAL } \\
\text { (BADAJOZ) }\end{array}$ & ORELLANA & GRAVEDAD & 1964 \\
\hline $\begin{array}{l}\text { ORELLANA PRESA } \\
\text { (BADAJOZ) }\end{array}$ & ORELLANA & GRAVEDAD & 1961 \\
\hline $\begin{array}{l}\text { PUERTO PEÑA } \\
\text { (BADAJOZ) }\end{array}$ & GARCÍA DE SOLA & GRAVEDAD & 1962 \\
\hline ZÚJAR (BADAJOZ) & ZÚJAR & GRAVEDAD & 1964 \\
\hline $\begin{array}{l}\text { CANTILLANA } \\
\text { (SEVILLA) }\end{array}$ & CANTILLANA & COMPUERTAS & 1956 \\
\hline GUILLENA (SEVILLA) & DEPÓSITO SUPERIOR & GRAVEDAD & 1973 \\
\hline $\begin{array}{l}\text { EL PINTADO } \\
\text { (SEVILLA) }\end{array}$ & CONTRAEMBALSE & GRAVEDAD & 1961 \\
\hline LA RETORNA & RETORNA & BÓVEDA & 1944 \\
\hline MAÑERU & $\begin{array}{c}\text { CONTRAEMBALSE DE } \\
\text { ALLOZ }\end{array}$ & GRAVEDAD & 1944 \\
\hline TRESPADERNE & CERECEDA & GRAVEDAD & 1948 \\
\hline RIBESALBES & RIBESALBES & GRAVEDAD & 1948 \\
\hline VILLALCAMPO & VILLALCAMPO & GRAVEDAD & 1949 \\
\hline COFRENTES & EL MOLINAR & MATERIALES SUELTOS & 1951 \\
\hline $\begin{array}{l}\text { SEQUEIROS-SAN } \\
\text { CLODIO }\end{array}$ & SEQUEIROS & GRAVEDAD & 1951 \\
\hline $\begin{array}{l}\text { GUÍSTOLAS Y } \\
\text { PONTENOVO }\end{array}$ & GUÍSTOLAS & GRAVEDAD & 1952 \\
\hline CASTRO & CASTRO & GRAVEDAD & 1953 \\
\hline CASTRO & $\begin{array}{l}\text { CASTRO. DIQUE DE } \\
\text { CENTRAL }\end{array}$ & GRAVEDAD & 1953 \\
\hline $\begin{array}{l}\text { CHANDREJA Y SAN } \\
\text { CRISTOBAL }\end{array}$ & CHANDREJA & CONTRAFUERTES & 1953 \\
\hline EL PICAZO & HENCHIDEROS & GRAVEDAD & 1953 \\
\hline ALBENTOSA & TORANES & GRAVEDAD & 1954 \\
\hline MONTEFURADO & MONTEFURADO & GRAVEDAD & 1954 \\
\hline SAN ESTEBAN & SAN ESTEBAN & ARCO-GRAVEDAD & 1955 \\
\hline BARÁZAR & URRÚNAGA & CONTRAFUERTES & 1955 \\
\hline BARÁZAR & ULLÍVARRI & CONTRAFUERTES & 1956 \\
\hline $\begin{array}{l}\text { SAN MARTÍN Y } \\
\text { MONTEFURADO }\end{array}$ & SAN MARTÍN & GRAVEDAD & 1956 \\
\hline
\end{tabular}


EVOLUCIÓN DE LA INGENIERÍA DE LAS PRESAS HIDROELÉCTRICAS

\begin{tabular}{|c|c|c|c|}
\hline CENTRAL (CIUDAD) & PRESA ASOCIADA & TIPO DE PRESA & $\begin{array}{l}\text { PUESTA EN } \\
\text { SERVICIO }\end{array}$ \\
\hline SAUCELLE & SAUCELLE & $\begin{array}{c}\text { VERTEDERO SOBRE } \\
\text { PRESA }\end{array}$ & 1956 \\
\hline MILLER & ANCHURICAS & CONTRAFUERTES & 1957 \\
\hline $\begin{array}{l}\text { QUINTANA MARTÍN } \\
\text { GALÍNDEZ }\end{array}$ & CILLAPERLATA & GRAVEDAD & 1959 \\
\hline MILLER & NOVIA-LA VIEJA & GRAVEDAD & 1959 \\
\hline SAN PEDRO & SAN PEDRO & GRAVEDAD & 1959 \\
\hline PUENTE-BIBEY & $\mathrm{BAO}$ & GRAVEDAD & 1960 \\
\hline PUENTE BIBEY & CEA & GRAVEDAD & 1962 \\
\hline PUENTE BIBEY & MOURELA & GRAVEDAD & 1962 \\
\hline SOBRÓN & SOBRÓN & GRAVEDAD & 1961 \\
\hline CIRAT & CIRAT & GRAVEDAD & 1962 \\
\hline ALDEADÁVILA & ALDEADÁVILA I Y II & VERTEDERO & 1963 \\
\hline VALDECAÑAS & VALDECAÑAS & BÓVEDA & 1964 \\
\hline $\begin{array}{l}\text { VILLALBA Y ACERA } \\
\text { DE LA VEGA }\end{array}$ & VELILLA & GRAVEDAD & 1965 \\
\hline SANTIAGO-JARES & SANTA EULALIA & BÓVEDA & 1966 \\
\hline VALLAT & VALLAT & GRAVEDAD & 1966 \\
\hline TORREJÓN & TORREJÓN-TAJO & GRAVEDAD & 1966 \\
\hline TORREJÓN & TORREJÓN-TIÉTAR & GRAVEDAD & 1967 \\
\hline PUENTELARRÁ & PUENTELARRÁ & GRAVEDAD & 1968 \\
\hline SANTIAGO-SIL & SANTIAGO & GRAVEDAD & 1968 \\
\hline AZUTÁN & AZUTÁN & CONTRAFUERTES & 1969 \\
\hline CERNADILLA & CERNADILLA & GRAVEDAD & 1969 \\
\hline JOSÉ MARIA DE ORIOL & JOSÉ MARÍA DE ORIOL & CONTRAFUERTES & 1969 \\
\hline VILLARINO & ALMENDRA & BÓVEDA & 1970 \\
\hline SOBRADELO & PUMARES & GRAVEDAD & 1971 \\
\hline SOBRADELO & CASOYO & ARCO-GRAVEDAD & 1971 \\
\hline CAMBA-CONSO & LAS PORTAS & BÓVEDA & 1974 \\
\hline CEDILLO & CEDILLO & ARCO-GRAVEDAD & 1975 \\
\hline CASTRELO & CASTRELO & MAMPOSTERIA & 1956 \\
\hline CARANTOÑA & CARANTOÑA & & 1963 \\
\hline FERVENZA & FERVENZA & GRAVEDAD & 1966 \\
\hline PONTE OLVEIRA & PUENTE OLVEIRA & GRAVEDAD & 1966 \\
\hline BARASONA & $\begin{array}{c}\text { BARASONA (JOAQUIN } \\
\text { COSTA) }\end{array}$ & GRAVEDAD & 1949 \\
\hline EL CIEGO & $\begin{array}{c}\text { BARASONA (JOAQUIN } \\
\text { COSTA) }\end{array}$ & GRAVEDAD & 1952 \\
\hline ARIAS 1 & AZUD & $\begin{array}{c}\text { ESCOLLERA } \\
\text { HORMIGONADA }\end{array}$ & 1973 \\
\hline ARIESTOLAS & AZUD & $\begin{array}{c}\text { GAVIONES } \\
\text { HORMIGONADOS }\end{array}$ & 1955 \\
\hline
\end{tabular}


EVOLUCIÓN DE LA INGENIERÍA DE LAS PRESAS HIDROELÉCTRICAS

\begin{tabular}{|c|c|c|c|}
\hline CENTRAL (CIUDAD) & PRESA ASOCIADA & TIPO DE PRESA & $\begin{array}{l}\text { PUESTA EN } \\
\text { SERVICIO }\end{array}$ \\
\hline PROAZA & VALDEMURIO Y OLID & GRAVEDAD & 1968 \\
\hline LA RIERA & $\begin{array}{l}\text { SOMIEDO Y } \\
\text { SALIENCIA }\end{array}$ & GRAVEDAD & 1946 \\
\hline PRIAÑES & FURACÓN Y PRIAÑES & GRAVEDAD & 1952 \\
\hline LA BARCA & CALABAZOS & BOVEDA & 1967 \\
\hline MIRANDA & $\begin{array}{c}\text { AZUDES DE COBACHO } \\
\text { Y PIGÜEÑA }\end{array}$ & GRAVEDAD & 1962 \\
\hline SALIME & SALIME & GRAVEDAD & 1954 \\
\hline LA FLORIDA & PILOTUERTO & GRAVEDAD & 1952 \\
\hline DOIRAS & DOIRAS & GRAVEDAD & 1944 \\
\hline SILVON & DOIRAS & GRAVEDAD & 1959 \\
\hline ARBON & ARBON & MATERIALES SUELTOS & 1967 \\
\hline BELESAR & BELESAR & BÓVEDA & 1963 \\
\hline VELLE & VELLE & GRAVEDAD & 1966 \\
\hline SAN JUAN & SAN JUAN & GRAVEDAD & 1963 \\
\hline ENTREPEÑAS & ENTREPEÑAS & GRAVEDAD & 1955 \\
\hline BOLARQUE II (REV.) & BOLARQUE & GRAVEDAD & 1955 \\
\hline ALMOGUERA & ALMOGUERA & GRAVEDAD & 1945 \\
\hline BUENDÍA & BUENDÍA & GRAVEDAD & 1944 \\
\hline ZORITA & ZORITA & GRAVEDAD & 1945 \\
\hline BURGOMILLODO & BURGOMILLODO & GRAVEDAD & 1951 \\
\hline CASTRELO & CASTRELO & GRAVEDAD & 1971 \\
\hline FRIEIRA & FRIEIRA & GRAVEDAD & 1971 \\
\hline LAS CONCHAS & LAS CONCHAS & GRAVEDAD & 1957 \\
\hline LEBOREIRO & $\mathrm{MAO}$ & GRAVEDAD & 1971 \\
\hline REGUEIRO & EDRADA & GRAVEDAD & 1971 \\
\hline SALAS & SALAS & GRAVEDAD & 1972 \\
\hline LOS PEARES & LOS PEARES & GRAVEDAD & 1958 \\
\hline MEZONZO & MEZONZO & GRAVEDAD & 1962 \\
\hline PORTODEMOUROS & PORTODEMOUROS & MATERIALES SUELTOS & 1970 \\
\hline $\begin{array}{l}\text { ROZADÍO } \\
\text { (SANTANDER) }\end{array}$ & $\begin{array}{c}\text { CONTRAEMBALSE } \\
\text { LASTRA-NANSA }\end{array}$ & GRAVEDAD & $1946 / 75$ \\
\hline $\begin{array}{l}\text { HERRERÍAS } \\
\text { (SANTANDER) }\end{array}$ & PRESA PALOMBERA & GRAVEDAD & $1949 / 50$ \\
\hline \multirow[t]{3}{*}{ SALIME (OVIEDO) } & SALIME & GRAVEDAD & $1953 / 54 / 55$ \\
\hline & Y PUENTE DE AZUFRE & & \\
\hline & $\begin{array}{l}\text { GARANDONES Y VEGA } \\
\text { DEL CONDE }\end{array}$ & & \\
\hline $\begin{array}{l}\text { CÍJARA MARGEN } \\
\text { IZQUIERDA } \\
\text { (BADAJOZ) }\end{array}$ & CÍJARA & GRAVEDAD & $1956 / 57 / 69$ \\
\hline BARÁZAR & $\begin{array}{l}\text { URRÚNAGA. DIQUE } \\
\text { LATERAL. }\end{array}$ & CONTRAFUERTES & 1957 \\
\hline
\end{tabular}




\begin{tabular}{|c|c|c|c|}
\hline CENTRAL (CIUDAD) & PRESA ASOCIADA & TIPO DE PRESA & $\begin{array}{l}\text { PUESTA EN } \\
\text { SERVICIO }\end{array}$ \\
\hline CERNADILLA & $\begin{array}{l}\text { CERNADILLA. DIQUE } \\
\text { LATERAL }\end{array}$ & GRAVEDAD & 1969 \\
\hline VILLARINO & ALMENDRA & BÓVEDA & 1970 \\
\hline VILLARINO & $\begin{array}{l}\text { ALMENDRA. DIQUE } \\
\text { LATERAL DERECHO }\end{array}$ & $\begin{array}{c}\text { ESCOLLERA CON } \\
\text { PANTALLA ASFÁLTICA }\end{array}$ & 1970 \\
\hline VILLARINO & $\begin{array}{l}\text { ALMENDRA. DIQUE } \\
\text { LATERAL IZQUIERDO }\end{array}$ & $\begin{array}{l}\text { CONTRAFUERTES Y } \\
\text { ESCOLLERA CON } \\
\text { PANTALLA ASFÁLTICA } \\
\text { CON RODILLO }\end{array}$ & 1970 \\
\hline CASTREJON & CASTREJON & TIERRAS & $1949(1914)$ \\
\hline LA TOBA & LA TOBA & GRAVEDAD & $\begin{array}{c}1960 \\
\text { ANTERIOR }\end{array}$ \\
\hline BURGUILLO & BURGUILLO & GRAVEDAD & 1961 (1912) \\
\hline ESPINOSA & SELGA ORDÁS & GRAVEDAD & $1966(1961)$ \\
\hline LAS VENCÍAS & LAS VENCÍAS & BOVEDA & 1968 (1957) \\
\hline $\begin{array}{l}\text { LINARES DEL } \\
\text { ARROYO }\end{array}$ & $\begin{array}{c}\text { LINARES DEL } \\
\text { ARROYO } \\
\end{array}$ & GRAVEDAD & $*(1956)$ \\
\hline BARRIOS DE LUNA & BARRIOS DE LUNA & GRAVEDAD & $\begin{array}{c}1964 \\
(1945 / 53)\end{array}$ \\
\hline PUENTE NUEVO & CHARCO DEL CURA & GRAVEDAD & $\begin{array}{c}1961 \\
(1912 / 20)\end{array}$ \\
\hline ALBARELLOS & ALBARELLOS & BOVEDA & $1975(1962)$ \\
\hline CABANELAS & CABANELAS & GRAVEDAD & $1969(1945)$ \\
\hline FERVENZA & FERVENZA & GRAVEDAD & $\begin{array}{c}1966 \\
\text { (PROYECTO } \\
\left.1900^{*}\right) \\
\end{array}$ \\
\hline BUENAMESÓN & BUENAMESÓN & GRAVEDAD & $\begin{array}{c}1972(1969 / 1 \\
950 / 1902) \\
\end{array}$ \\
\hline PICADAS & PICADAS & GRAVEDAD & $1961(1926)$ \\
\hline
\end{tabular}

De esta época destacan las presas de Alloz, Aldeadávila, Almendra, Escales, José Ma de Oriol y Portodemouros.

La presa y el embalse de Alloz están situados al Suroeste de Pamplona, Comunidad Foral de Navarra, sobre el río Salado, afluente por la margen derecha del río Arga, que es afluente a su vez del río Aragón. Proyectada en 1.929 por D. Enrique Becerril y D. Francisco Caballero, se inició su construcción en 1.930, siendo una de las primeras bóvedas de doble curvatura realizadas en España. 

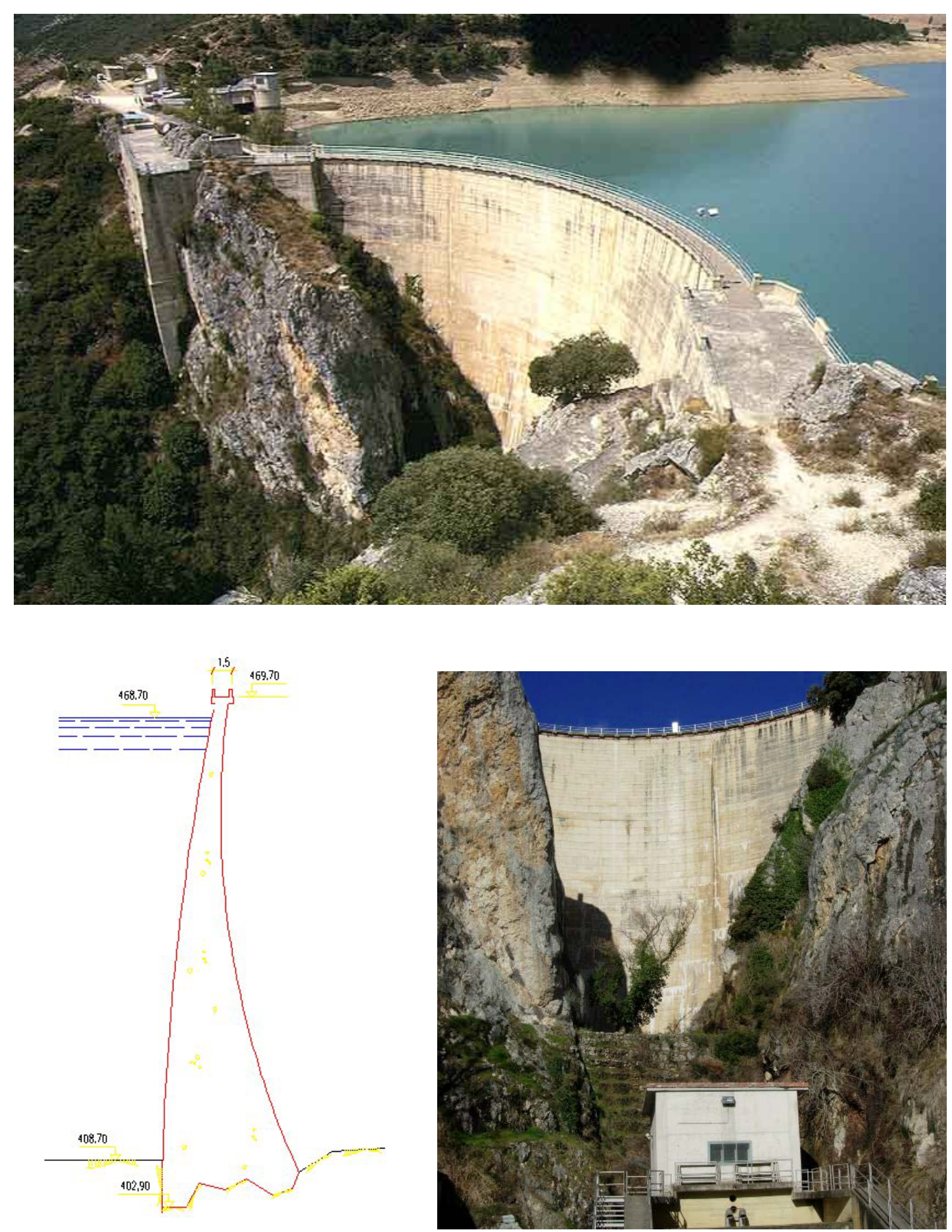


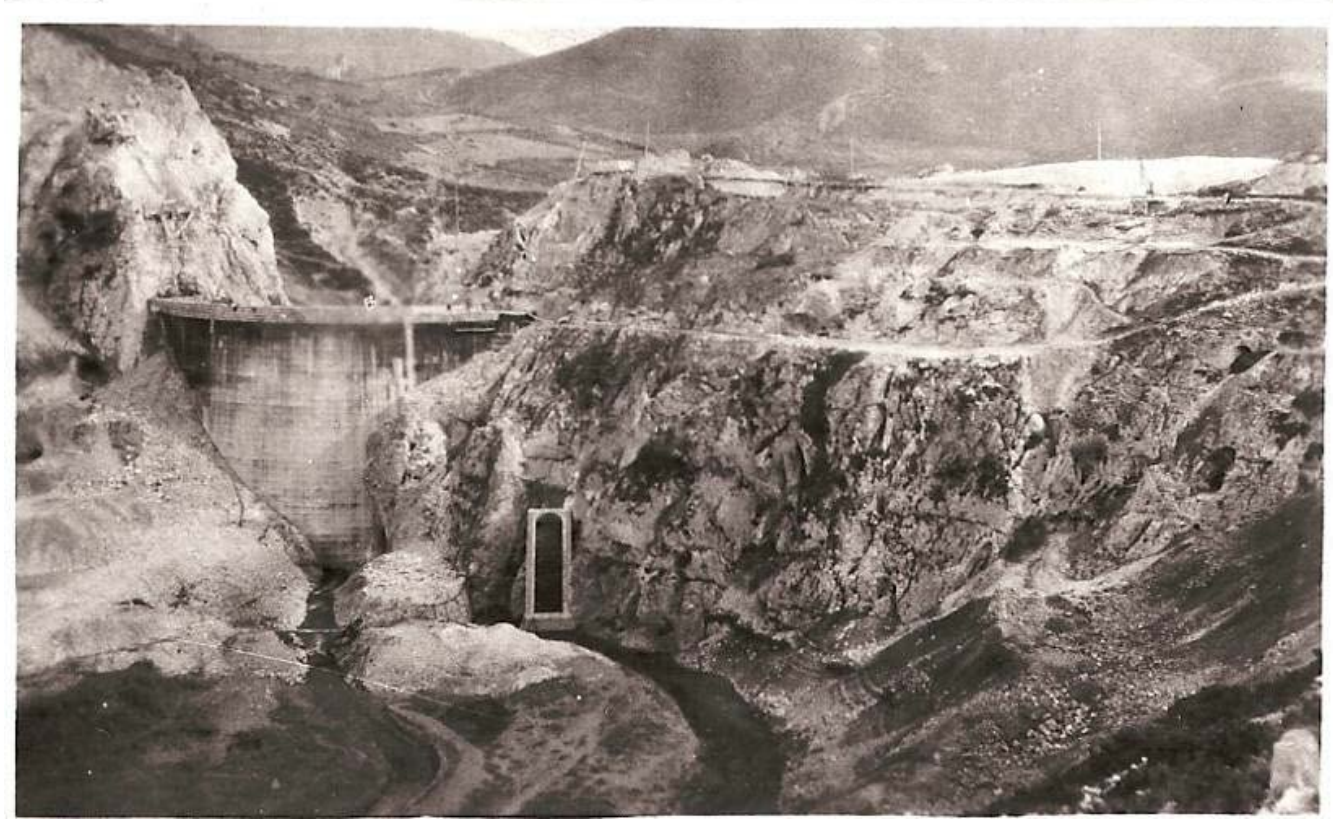

Con una altura sobre cimientos de 66.8 m y 75.1 m. de longitud de coronación, almacena un volumen útil de $65.10 \mathrm{Hm} 3$. A través de las calizas eocenas, el río Salado fue tallando su cauce y formando, por retroceso, la hoz en la que se construyó la presa.

Aldeadávila es la primera presa española de la tipología arco gravedad, con 139,50 metros de altura sobre cimientos.

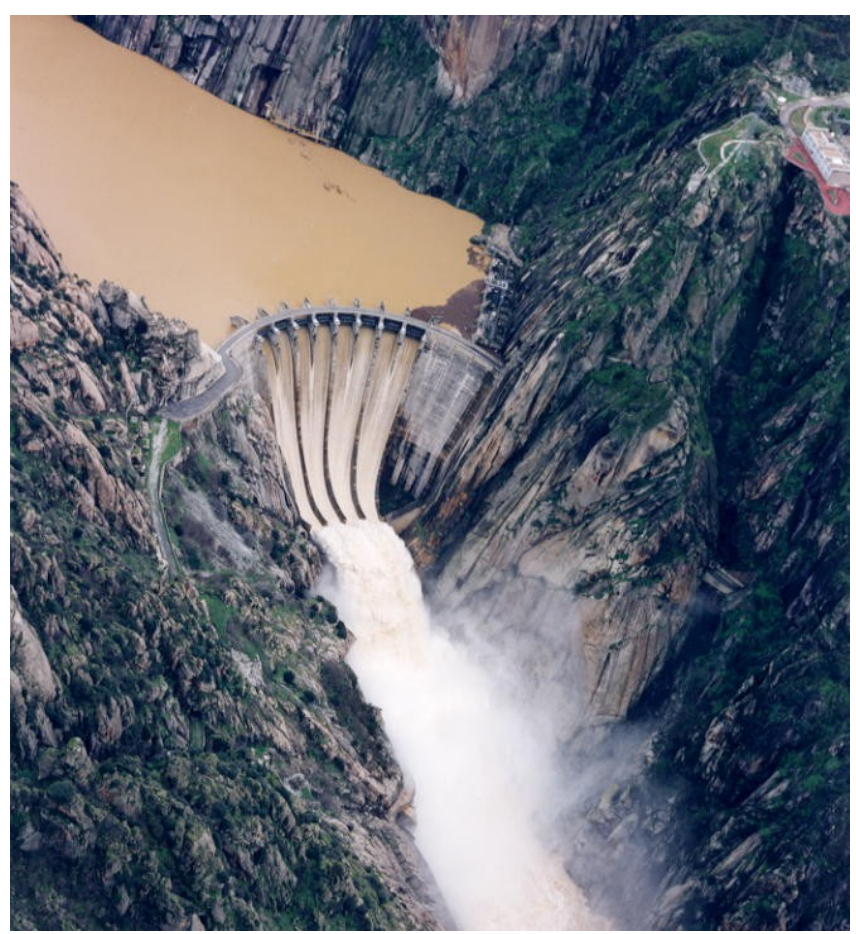



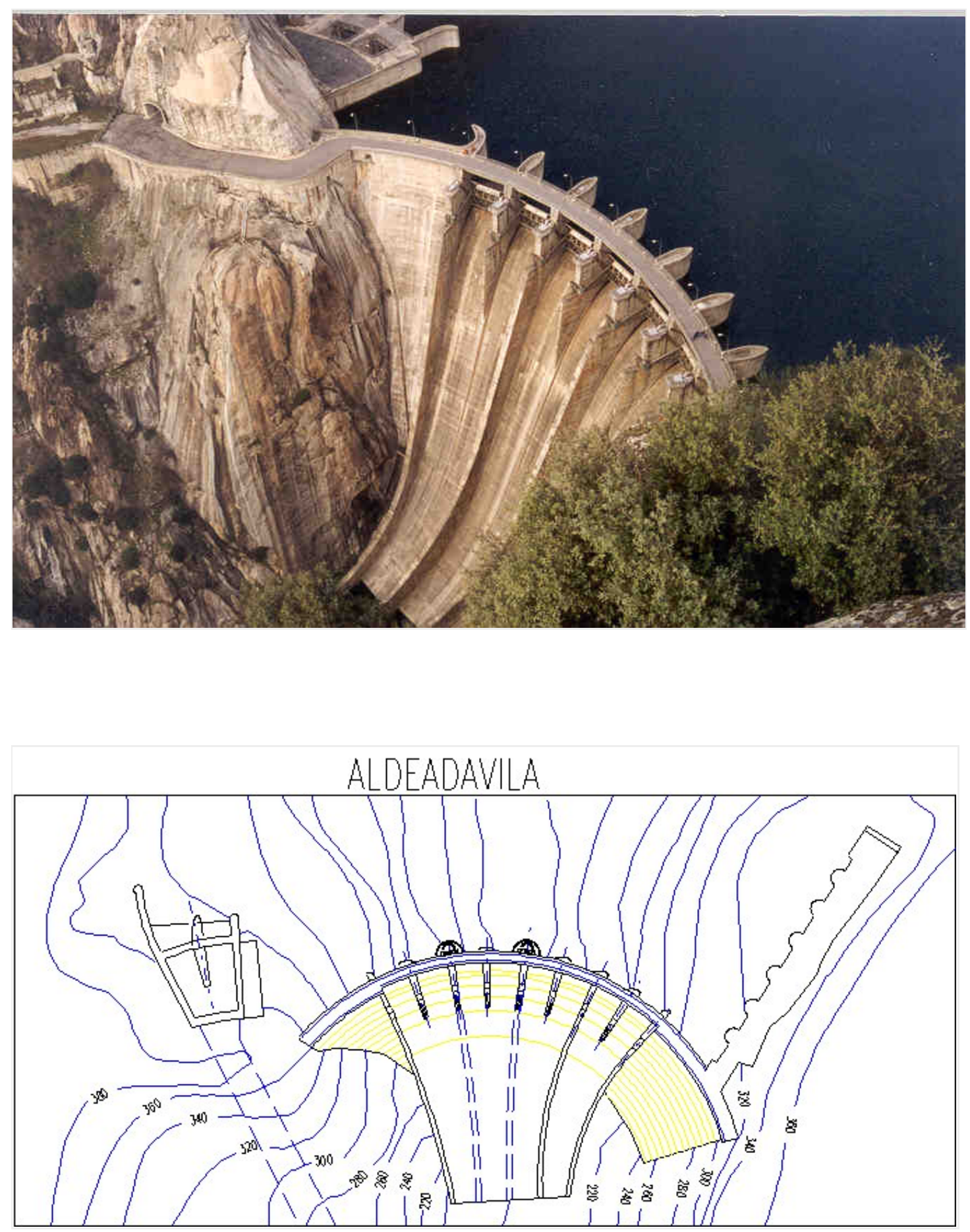
La presa de Almendra es la presa más alta de España con 202 metros de altura. Su tipología es bóveda.
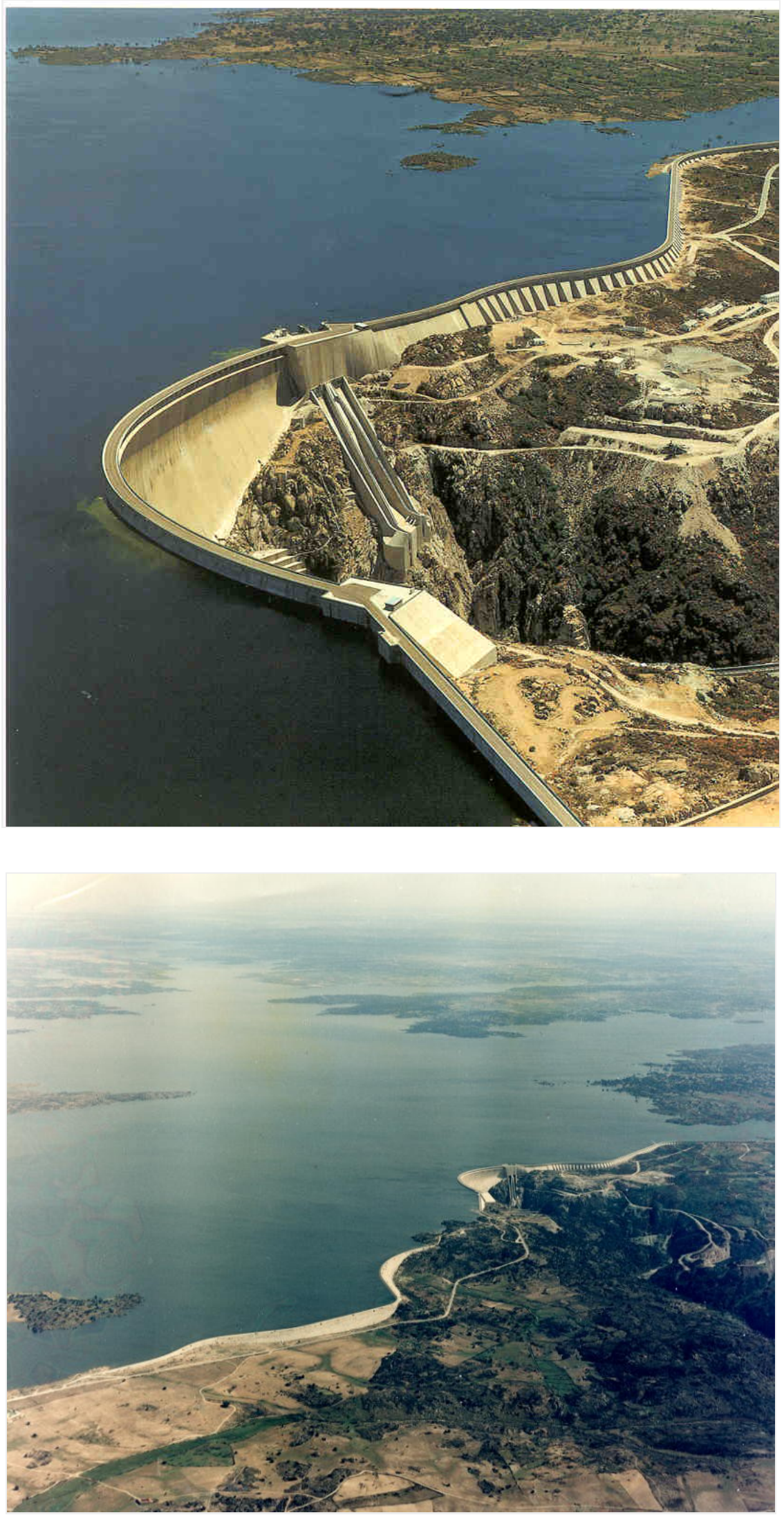
ALMENDRA
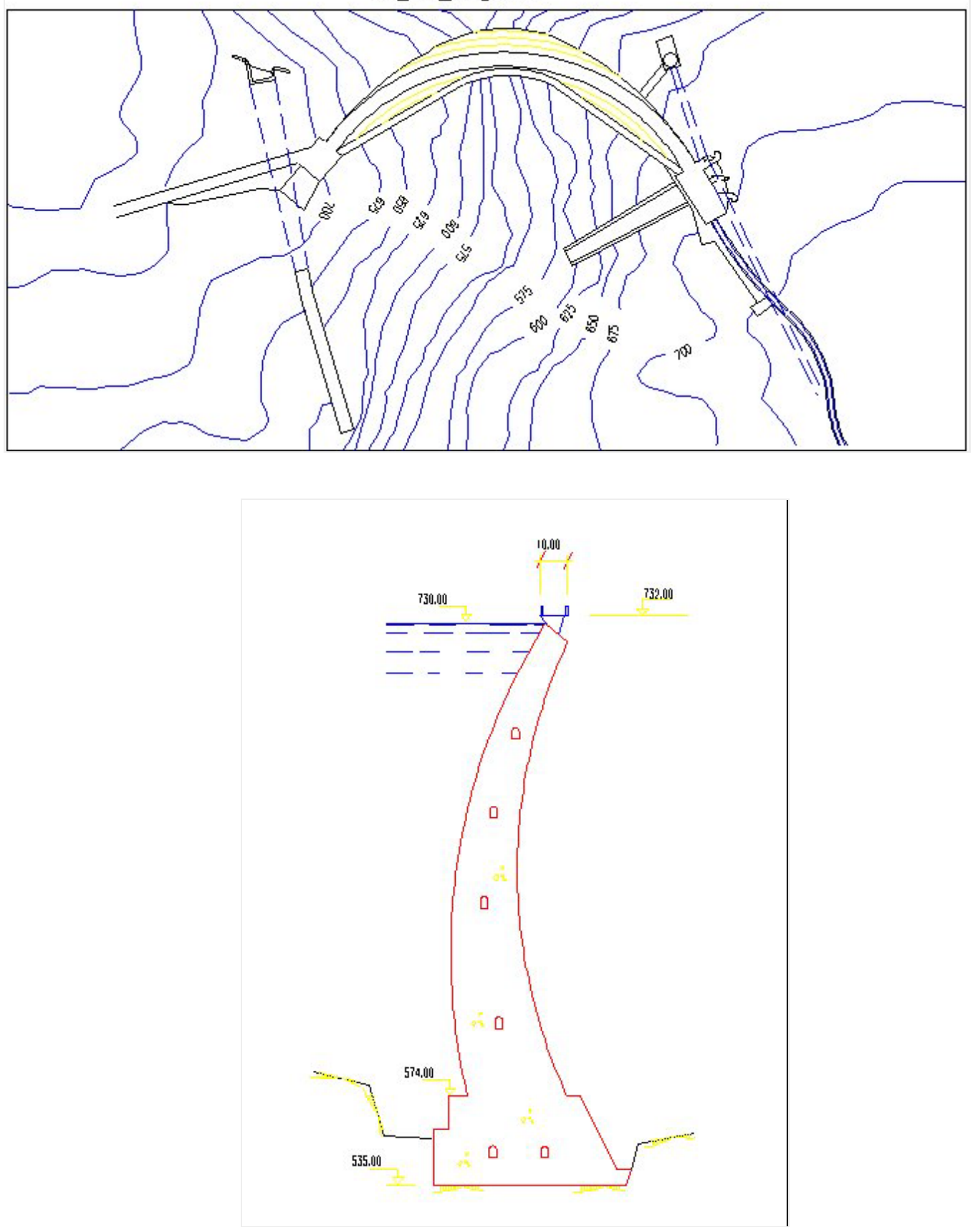
La presa de Escales, en Huesca, se terminó su construcción en 1955. Tiene una altura de 125 metros desde cimientos y ocupa el cuarto lugar en las presas de gravedad españolas en cuanto a altura pero es la más alta destinada a hidroelectricidad.

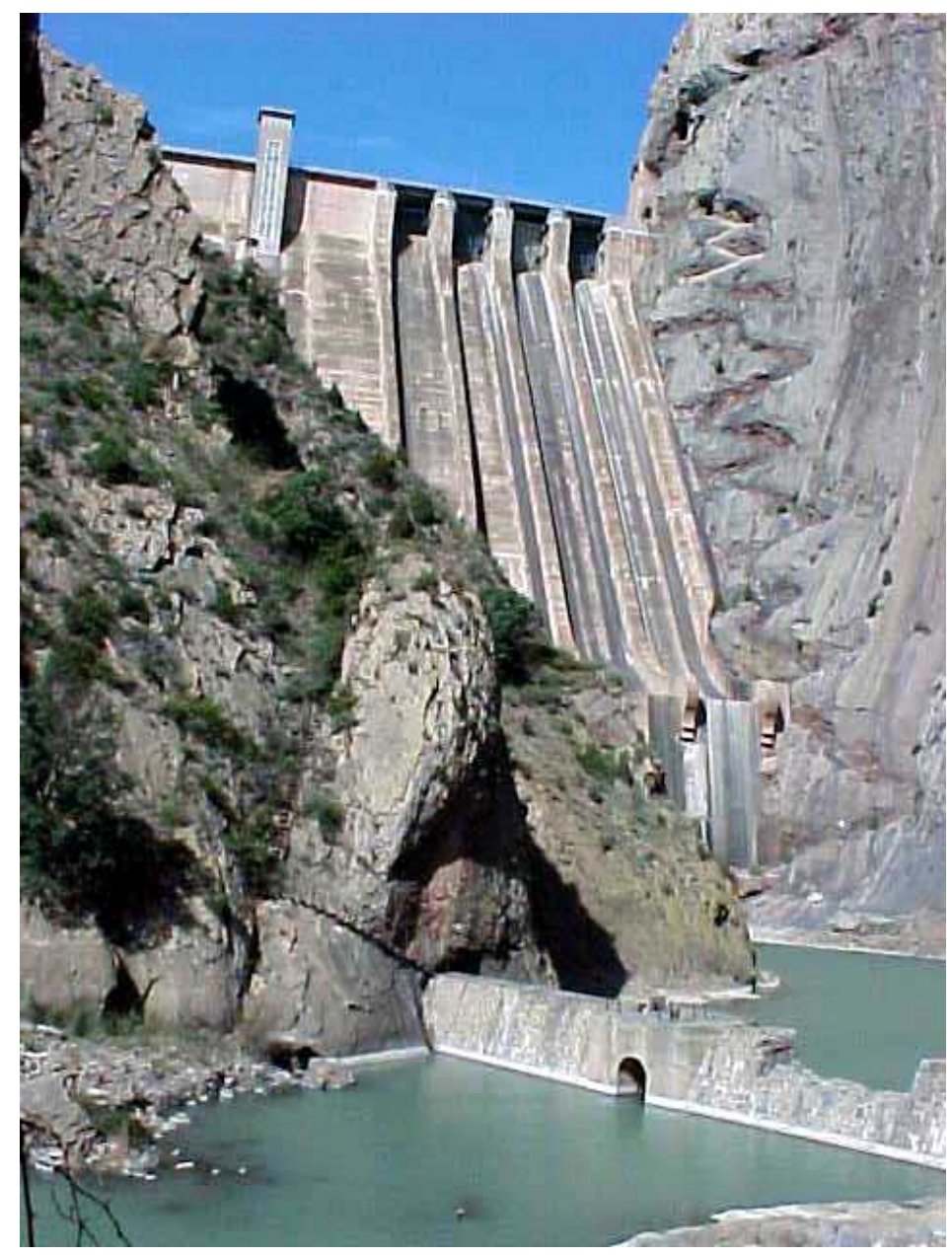

ESCALES

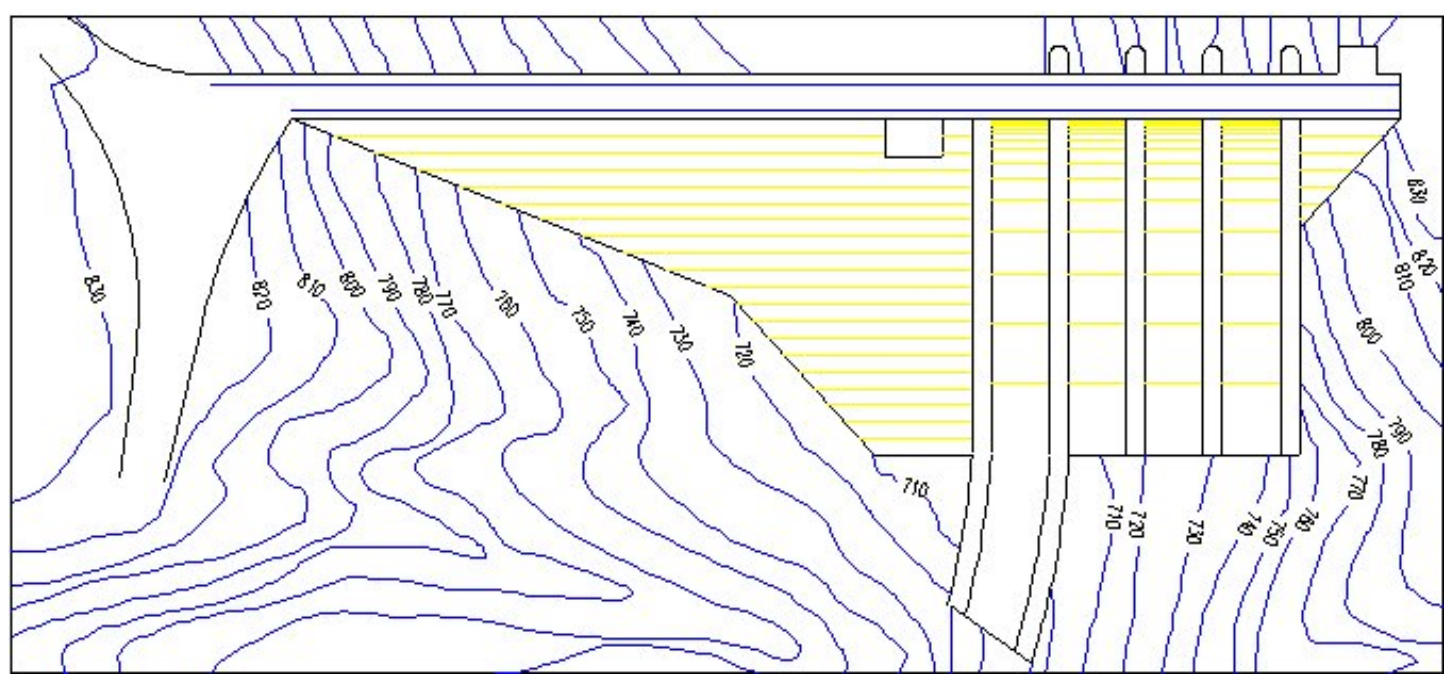




\section{ESCALES}

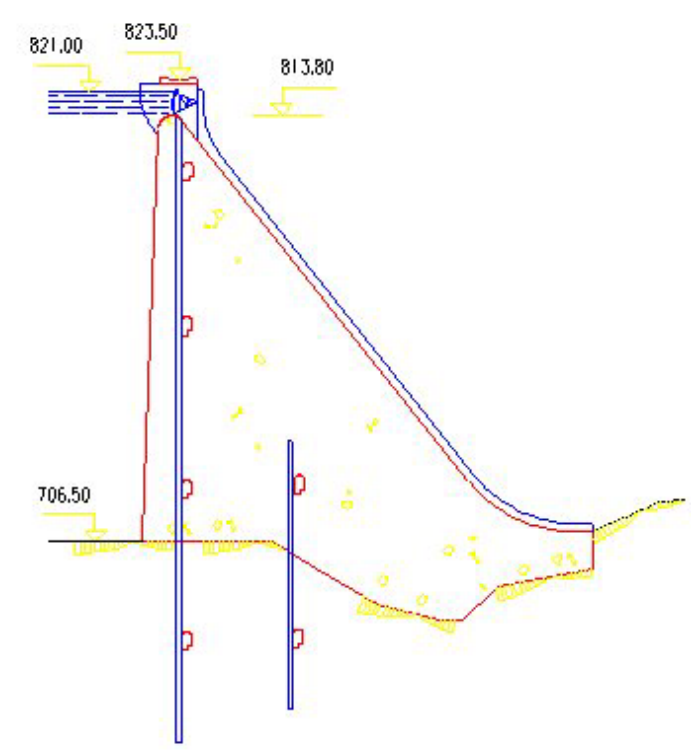

La presa de Portodemouros, en A Coruña, se acabó de construir en 1967. De 91 metros de altura sobre cimientos, su tipología es de materiales sueltos con núcleo arcilloso.

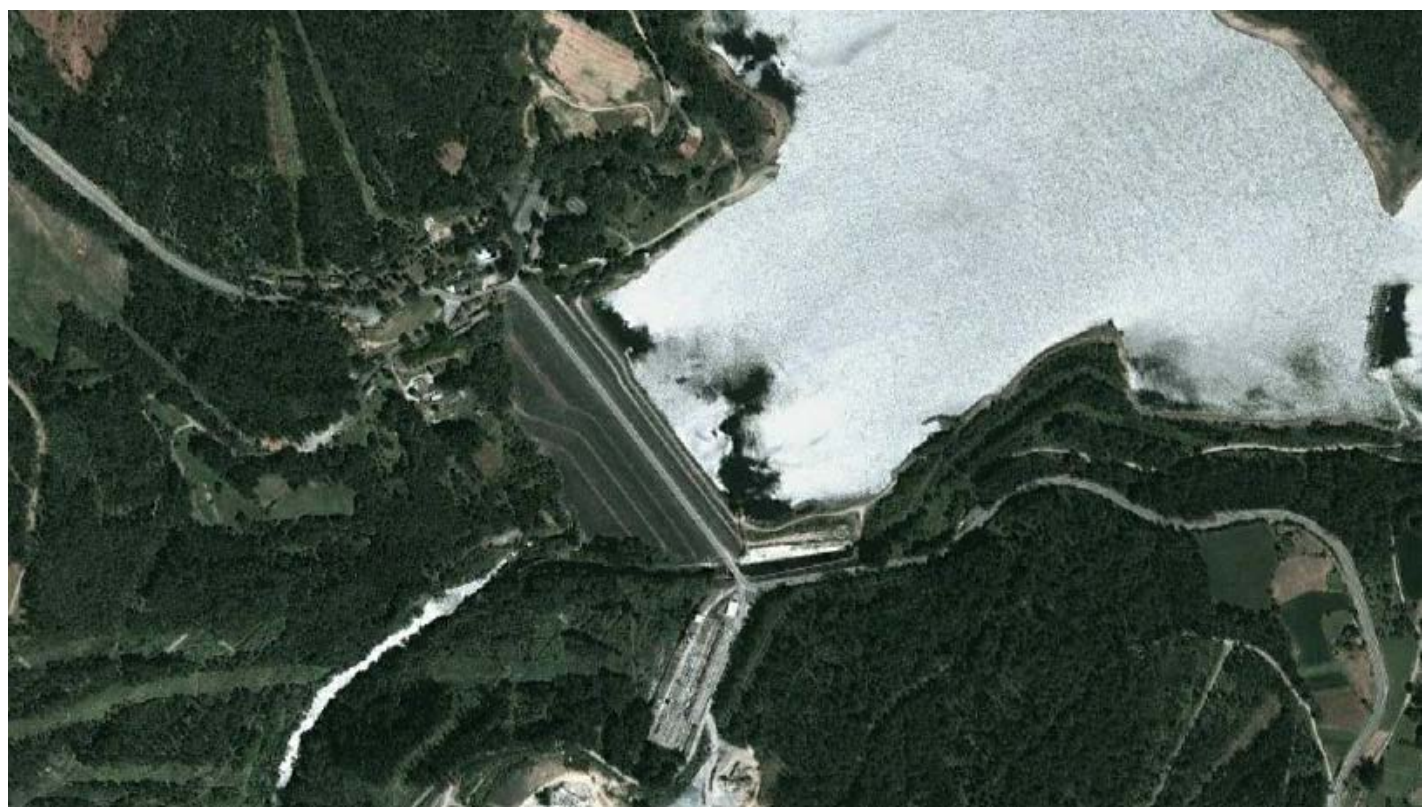



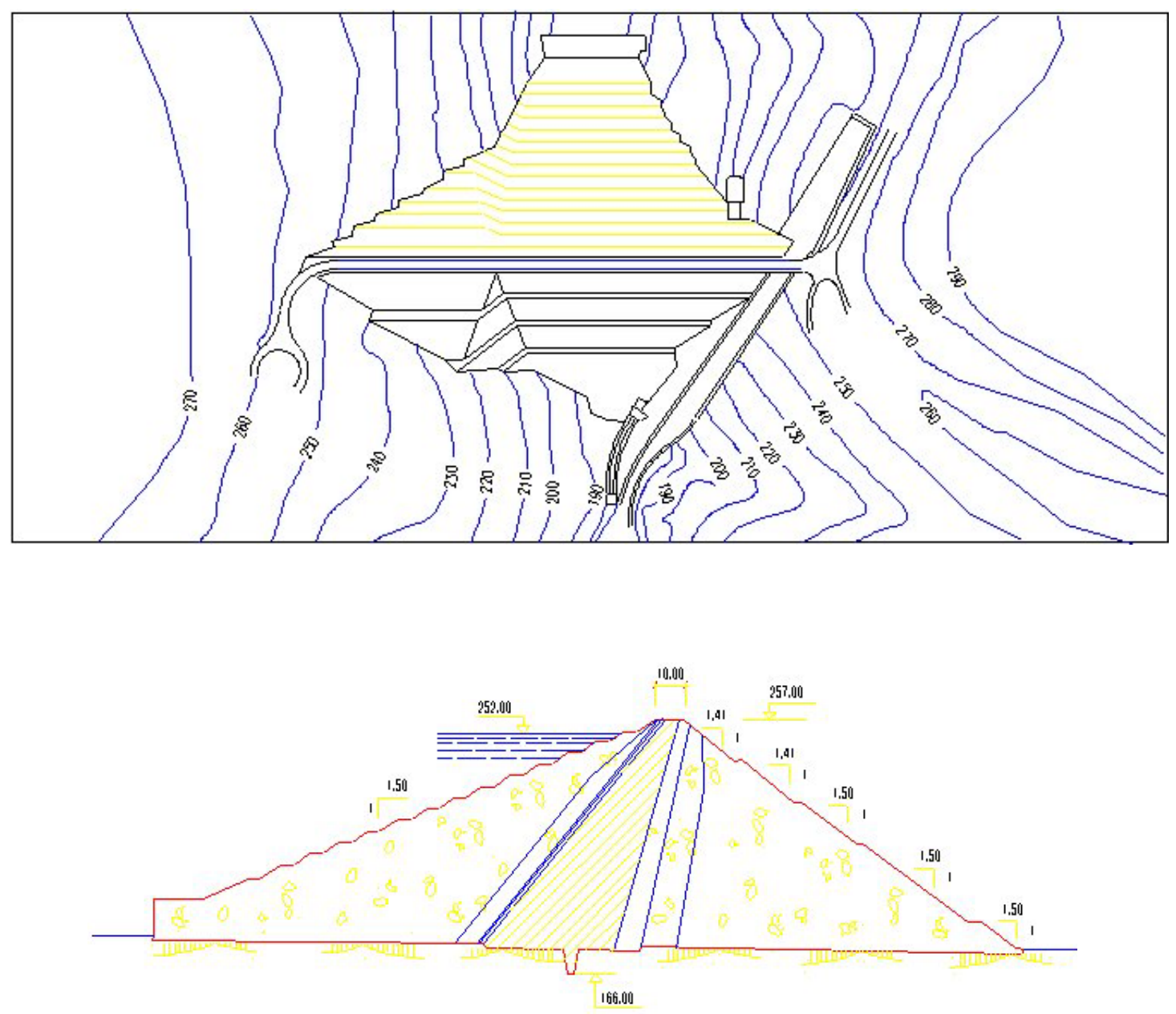

En las cuencas del Tajo y del Júcar operó Hidroeléctrica Española, que bajo la dirección de Manuel Castillo efectuó el aprovechamiento hidroeléctrico del Tajo inferior, realizando cuatro saltos de gran originalidad: 
La presa de Valdecañas, en Cáceres, se terminó su construcción en 1962. Su tipología es bóveda de 98 metros de altura sobre cimientos, en que la central reversible queda aguas abajo, protegida por una contrabóveda.
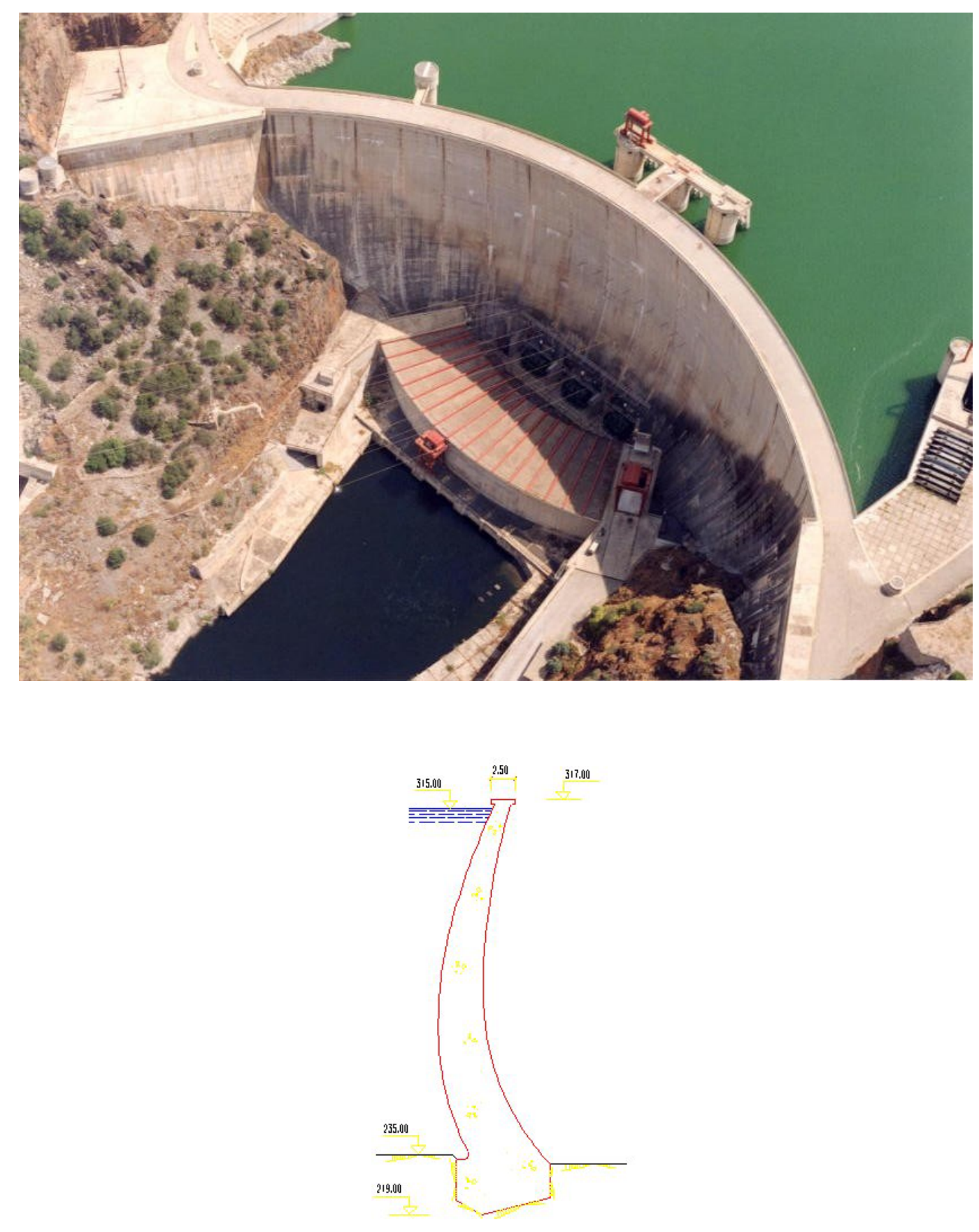


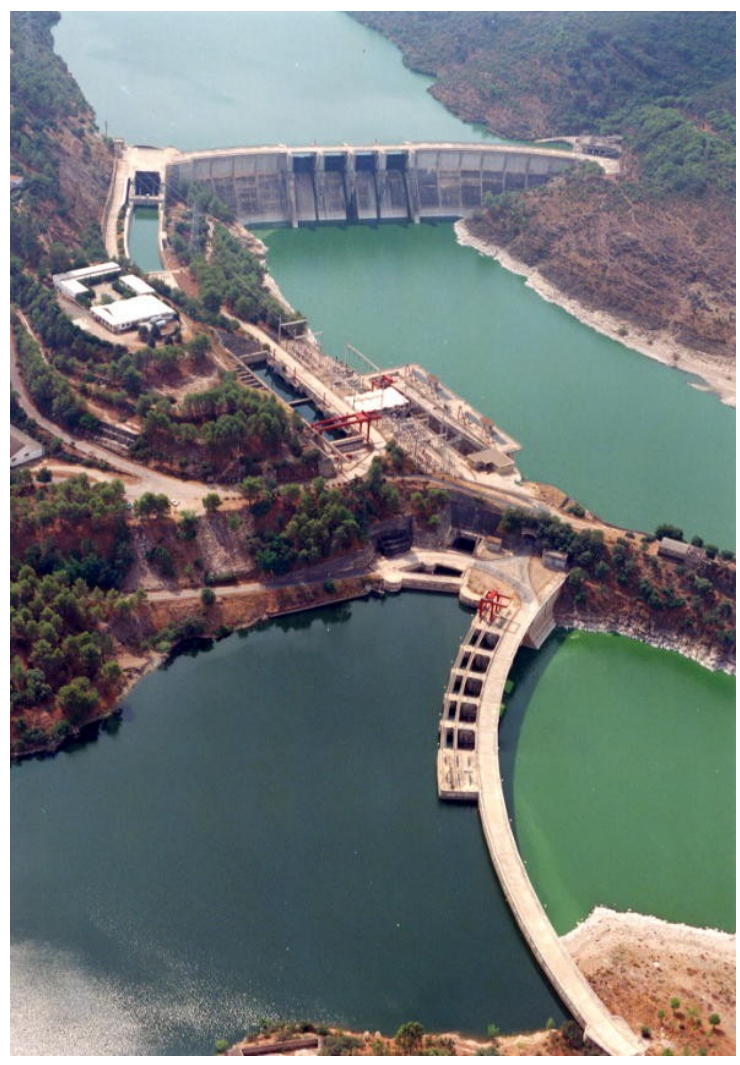

La presa de Torrejón, en Cáceres (Torrejón Tajo/Torrejón Tiétar), es original por ser una doble presa en la confluencia del río Tiétar, con un complejo sistema de bombeo. Tipología de gravedad de 34 y 62 metros de altura sobre cimientos. Son del año 1966-1967.

La presa de José Mํㅡㅁ Oriol (también llamada Alcántara II), en Cáceres, se terminó su construcción en 1969, de 130 metros de altura desde cimientos, es la mayor presa de contrafuertes de Europa y la segunda a nivel mundial.

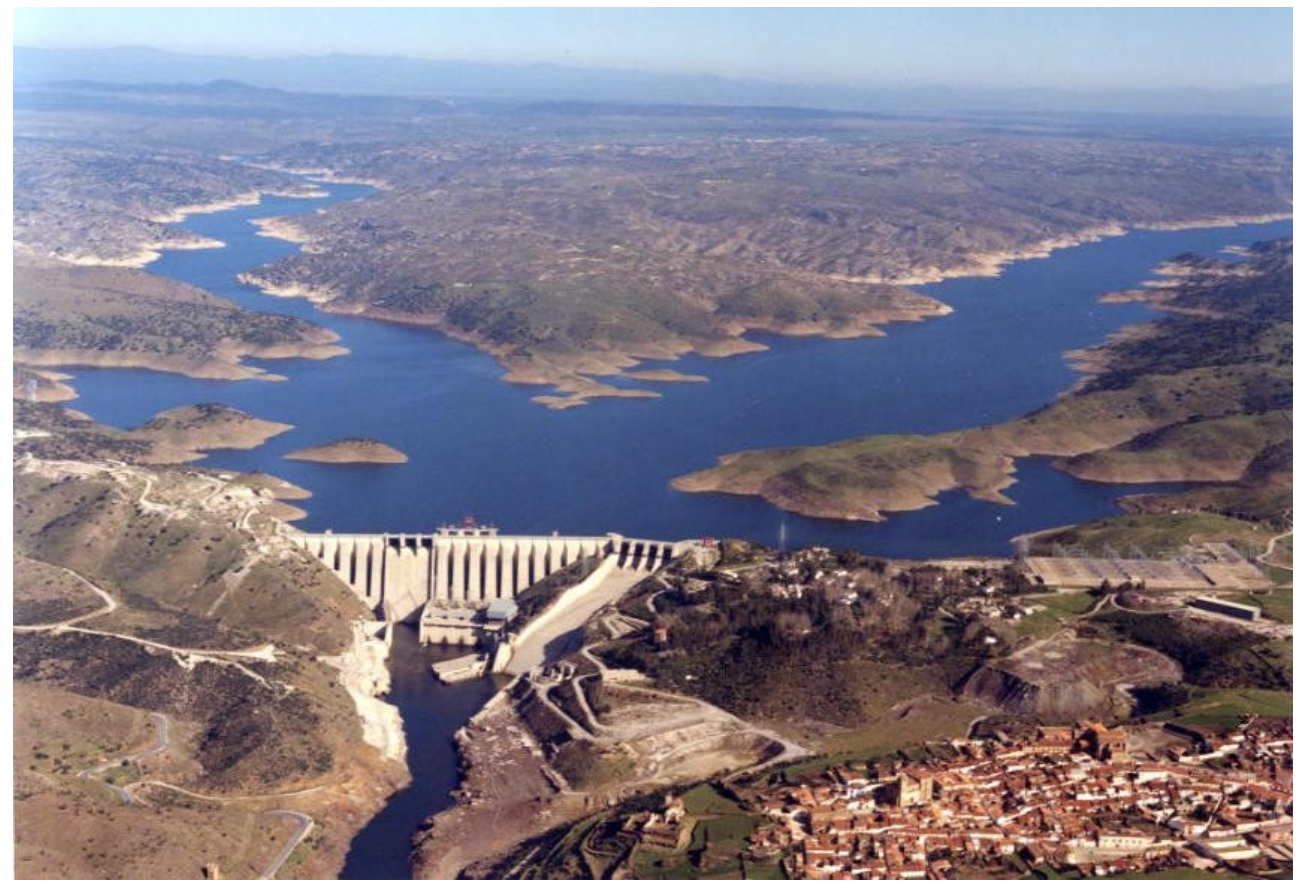



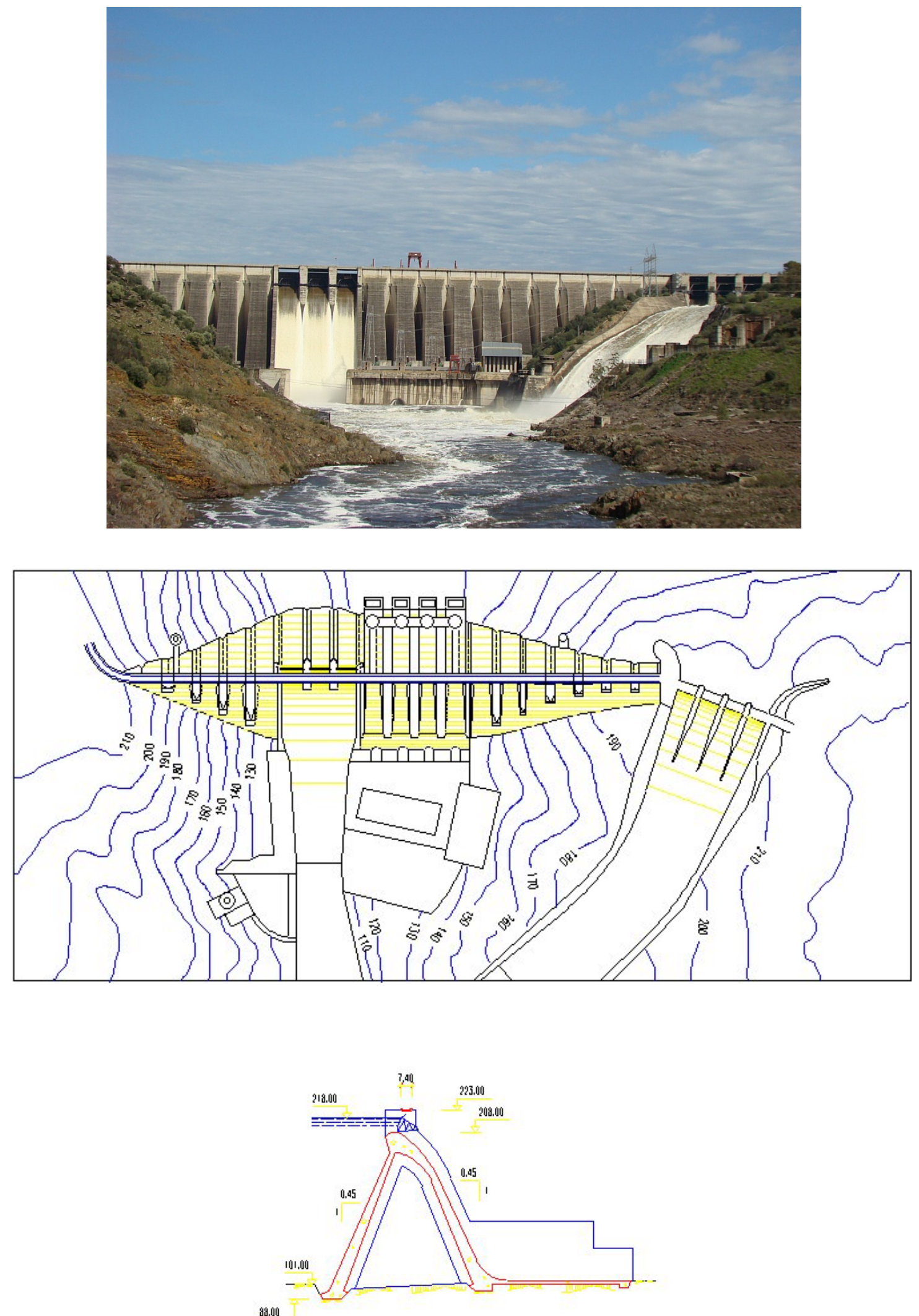
La presa de Cedillo, en Cáceres, ya en la frontera con Portugal, es del año 1975, de tipología arco gravedad, tiene 66 metros de altura sobre cimientos. Se caracteriza porque sus dos estribos están en territorio portugués.
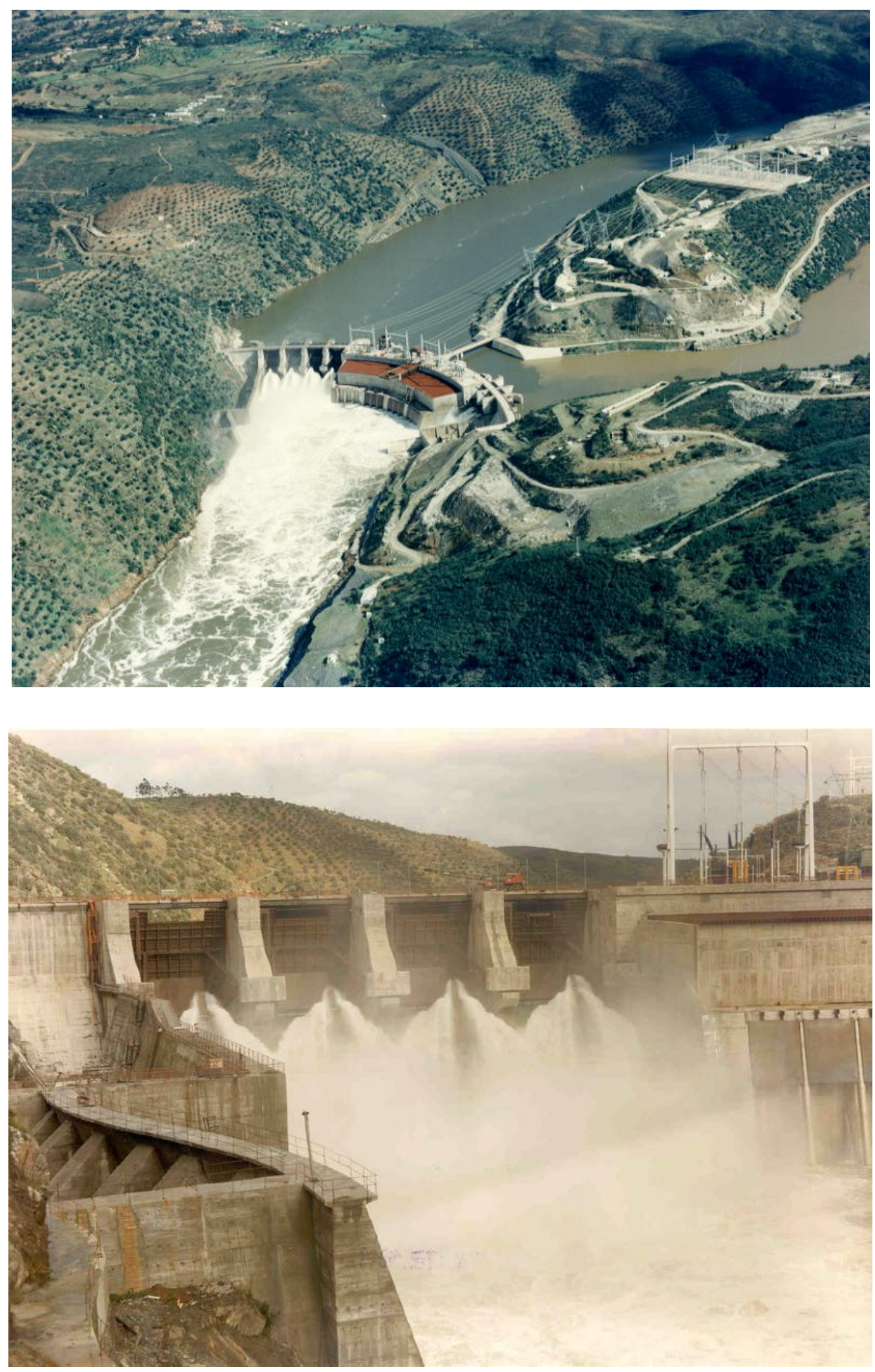
Tras esta etapa de desarrollo intensivo, llegó a partir de 1975 una etapa de sostenimiento en la que la construcción de presas con fines exclusivamente hidroeléctricos se redujo drásticamente. Quizás la característica principal de este último periodo en España sea el interés por la construcción de minicentrales hidroeléctricas de hasta $50 \mathrm{MW}$ que en general, no necesita de grandes presas.

Las centrales, con sus presas o azudes asociados, de las empresas hidroeléctricas principales actuales, que se pusieron en servicio en esta etapa fueron:

\begin{tabular}{|c|c|c|c|}
\hline $\begin{array}{l}\text { CENTRAL } \\
\text { (CIUDAD) }\end{array}$ & PRESA ASOCIADA & TIPO DE PRESA & $\begin{array}{c}\text { PUESTA EN } \\
\text { SERVICIO }\end{array}$ \\
\hline RIOSCURO (LEÓN) & VILLAR Y VILLASECA & GRAVEDAD & 1992 \\
\hline $\begin{array}{l}\text { SANTA MARINA II } \\
\text { (LEÓN) }\end{array}$ & $\begin{array}{c}\text { AZUD DE } \\
\text { MATARROSA }\end{array}$ & GRAVEDAD & 1992 \\
\hline $\begin{array}{l}\text { SALLENTE } \\
\text { (LLEIDA) }\end{array}$ & $\begin{array}{l}\text { ESTANYGENTO } \\
\text { /SALLENTE }\end{array}$ & GRAVEDAD/ESCOLLERA & 1985 \\
\hline $\begin{array}{l}\text { LA BAELLS } \\
\text { (BARCELONA) }\end{array}$ & LA BAELLS & GRAVEDAD & 1988 \\
\hline $\begin{array}{l}\text { BOADELLA } \\
\text { (GIRONA) }\end{array}$ & BOADELLA & GRAVEDAD & 1984 \\
\hline $\begin{array}{l}\text { MONTESQUIU } \\
\text { (BARCELONA) }\end{array}$ & & AZUD & 1986 \\
\hline $\begin{array}{l}\text { BASERCA } \\
\text { (LLEIDA) }\end{array}$ & BASERCA & BÓVEDA & 1985 \\
\hline $\begin{array}{l}\text { MORALETS } \\
\text { (HUESCA) }\end{array}$ & BASERCA-LLAUSET & BÓVEDA & 1985 \\
\hline $\begin{array}{l}\text { LANUZA } \\
\text { (HUESCA) }\end{array}$ & LANUZA & ARCO GRAVEDAD & 1977 \\
\hline SEIRA (HUESCA) & VILLANOVA & AZUD DE DERIVACIÓN & 1996 \\
\hline $\begin{array}{l}\text { TAJO DE LA } \\
\text { ENCANTADA } \\
\text { (MÁLAGA) }\end{array}$ & DEPÓSITO SUPERIOR & GRAVEDAD & 1977 \\
\hline $\begin{array}{l}\text { CANALES } \\
\text { (GRANADA) }\end{array}$ & CANALES & ESCOLLERA & 1988 \\
\hline $\begin{array}{l}\text { DUQUE } \\
\text { (GRANADA) }\end{array}$ & & & 1982 \\
\hline $\begin{array}{l}\text { NEGRATÍN } \\
\text { (GRANADA) }\end{array}$ & NEGRATÍN & $\begin{array}{c}\text { GRAVEDAD y MATERIALES } \\
\text { SUELTOS CON PANTALLA } \\
\text { ASFÁLTICA }\end{array}$ & 1990 \\
\hline $\begin{array}{l}\text { CÍJARA MARGEN } \\
\text { DERECHA } \\
\text { (CÁCERES) }\end{array}$ & CÍJARA & GRAVEDAD & 1981 \\
\hline
\end{tabular}


EVOLUCIÓN DE LA INGENIERÍA DE LAS PRESAS HIDROELÉCTRICAS

\begin{tabular}{|c|c|c|c|}
\hline $\begin{array}{l}\text { CENTRAL } \\
\text { (CIUDAD) }\end{array}$ & PRESA ASOCIADA & TIPO DE PRESA & $\begin{array}{c}\text { PUESTA EN } \\
\text { SERVICIO }\end{array}$ \\
\hline $\begin{array}{l}\text { LA SERENA } \\
\text { (BADAJOZ) }\end{array}$ & LA SERENA & GRAVEDAD & 1993 \\
\hline CAMBA-CONSO & EDRADA & BÓVEDA CILÍNDRICA & 1976 \\
\hline $\begin{array}{l}\text { GUIJO DE } \\
\text { GRANADILLA }\end{array}$ & $\begin{array}{c}\text { GUIJO DE } \\
\text { GRANADILLA }\end{array}$ & BÓVEDA & 1982 \\
\hline $\begin{array}{l}\text { CENTRAL } \\
\text { TÉRMICA DE } \\
\text { GUARDO }\end{array}$ & BESANDINO & ARCO-GRAVEDAD & 1984 \\
\hline VALPARAÍSO & VALPARAÍSO & GRAVEDAD & 1987 \\
\hline $\begin{array}{l}\text { CORTES-LA } \\
\text { MUELA }\end{array}$ & LA MUELA & ESCOLLERA CON PANTALLA & 1988 \\
\hline CORTES II & CORTES II & ARCO-GRAVEDAD & 1988 \\
\hline MAILLARES II & NARANJERO & ARCO-GRAVEDAD & 1988 \\
\hline SOUTELO & CENZA & GRAVEDAD COMPACTADA & 1994 \\
\hline SANTA UXIA & SANTA UXIA & GRAVEDAD & 1988 \\
\hline NUEVO PINDO & SANTA UXIA II & GRAVEDAD & 2004 \\
\hline ARIAS 2 & AZUD & GAVIONES & 1979 \\
\hline TANES & $\begin{array}{c}\text { TANES Y } \\
\text { CONTRAEMBALSE } \\
\text { DE RIOSECO }\end{array}$ & GRAVEDAD & 1978 \\
\hline AGUAYO-AGUILAR & AGUAYO-AGUILAR & GRAVEDAD & 1982 \\
\hline BOLARQUE I & BOLARQUE & GRAVEDAD & 1983 \\
\hline LA BUJEDA & LA BUJEDA & TIERRAS & 1976 \\
\hline $\begin{array}{l}\text { ÍZBOR } \\
\text { (GRANADA) }\end{array}$ & BÉZNAR & BÓVEDA-CÚPULA & 1986 \\
\hline $\begin{array}{l}\text { № S } \mathbf{a} \text { DEL } \\
\text { AGAVANZAL }\end{array}$ & $\begin{array}{c}\text { № S } \text { - DEL } \\
\text { AGAVANZAL }\end{array}$ & GRAVEDAD & 1994 \\
\hline
\end{tabular}

Las de tipología algo más particular pueden ser la presa de Sallente y la de Negratín.

La presa de Sallente se construyó en el año 1985 sobre el río Flamisell en la provincia de Lleida. Es de materiales sueltos con pantalla asfáltica. Su altura es de 89 metros sobre cimientos y su longitud de coronación es de 398 metros. Ésta estaba formada por diversas capas de hormigón asfáltico, mastic asfáltico, emulsión asfáltica y capa de regularización. Se restituyó el mástic bituminoso en 2005. 
EVOLUCIÓN DE LA INGENIERÍA DE LAS PRESAS HIDROELÉCTRICAS
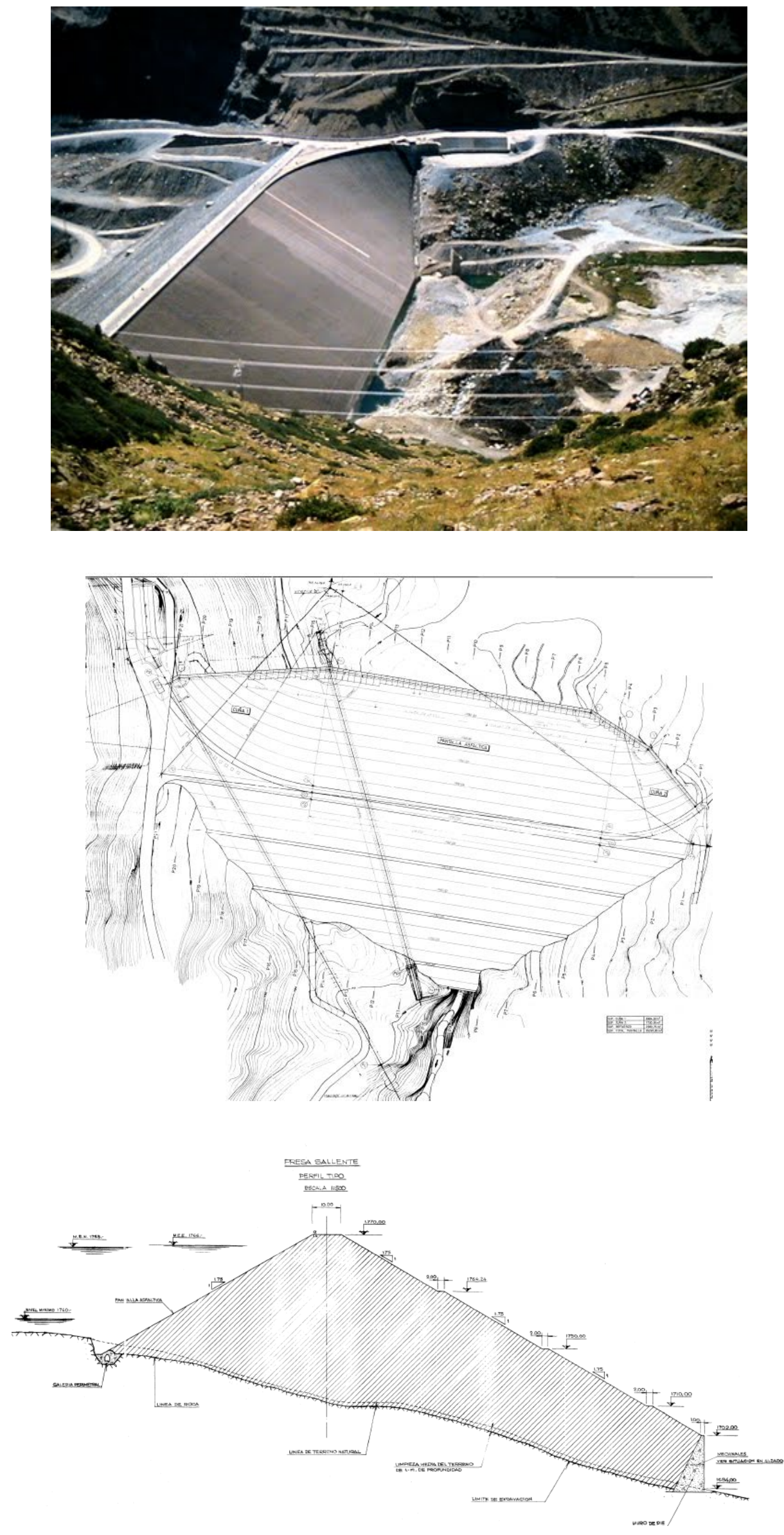
La presa de Negratín destaca por ser de gravedad pero también de materiales sueltos con pantalla asfáltica, usándose ambas tipologías en la misma cerrada.
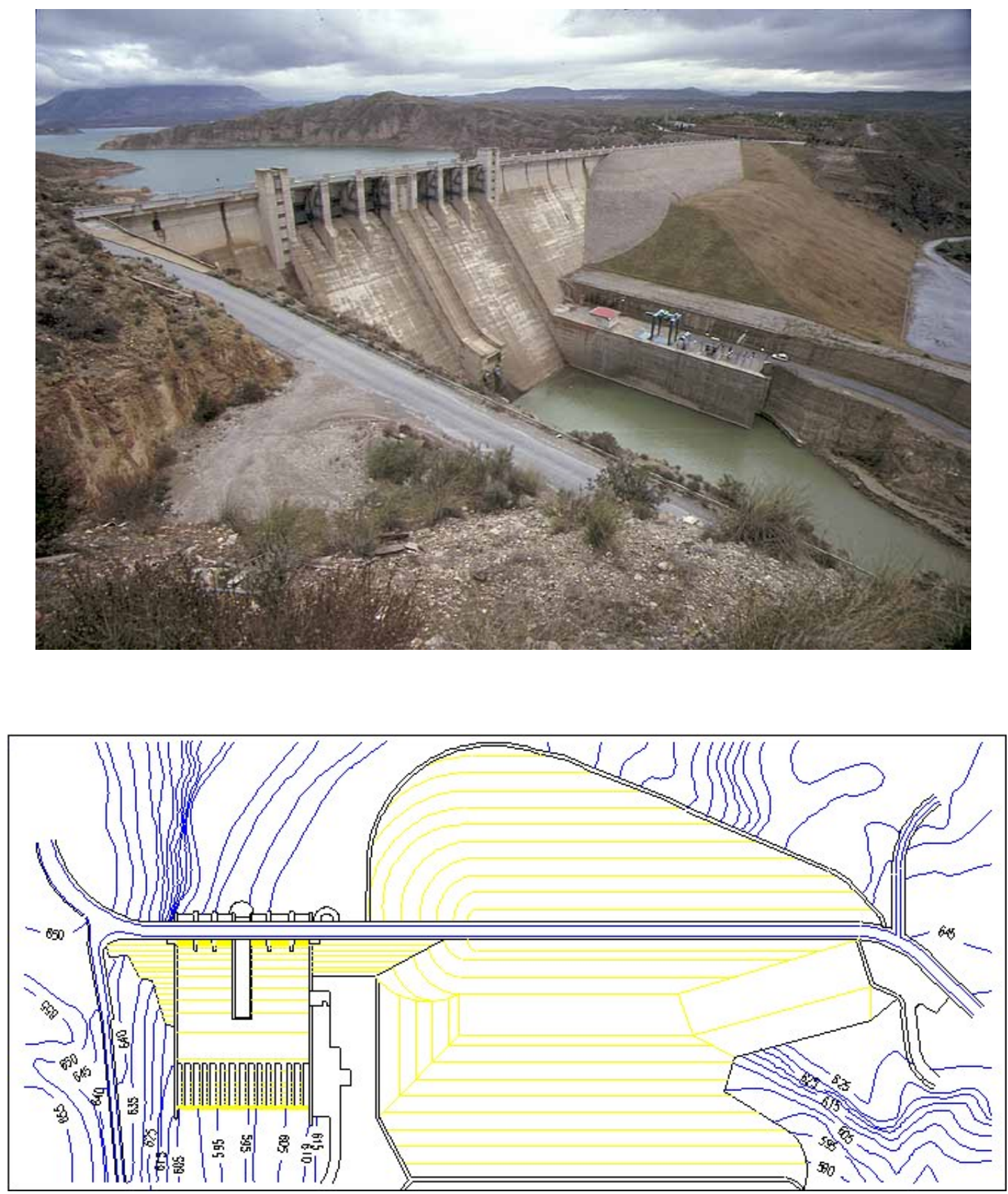



\section{Capítulo 5.}

\section{Evolución de la ingeniería de túneles y obras subterráneas}



En este capítulo se desarrolla la evolución tecnológica que se produjo en los túneles, cavernas y obras subterráneas asociadas a los aprovechamientos hidroeléctricos.

\subsection{LOS INICIOS}

La construcción de obras subterráneas es una actividad que se remonta a los mismos orígenes de la humanidad. Inicialmente se trataban de primitivas faenas excavadas de modo manual y sin soporte activo, que dependían mayormente de la capacidad autoportante del terreno. Muchas de estas construcciones antiguas, que datan de periodos anteriores a Cristo, aún existen y están operativas a día de hoy.

Sólo a partir del siglo XIV, las técnicas y la preponderancia de este tipo de construcciones comenzaron a progresar hacia el estado del arte actual.

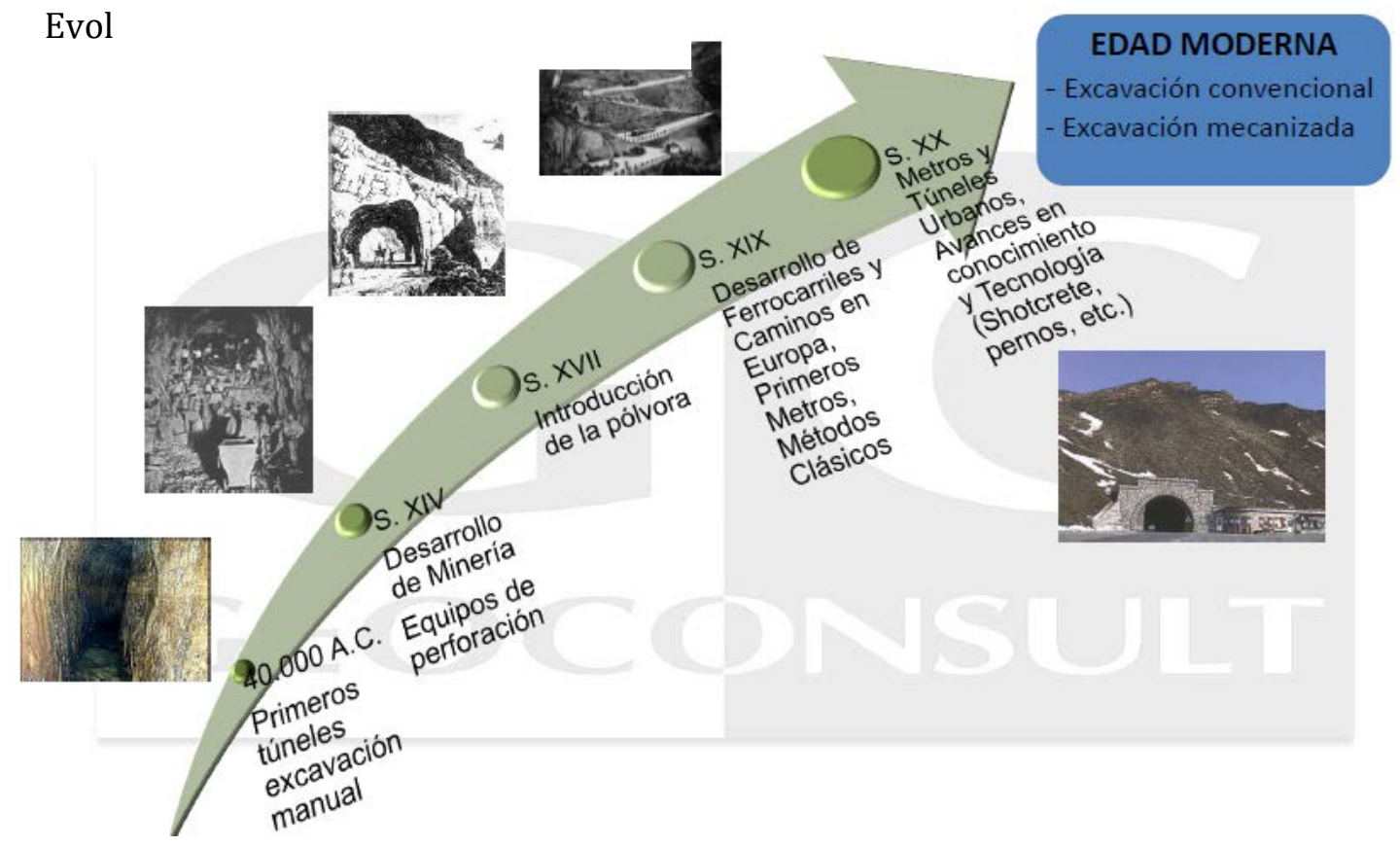

Posiblemente, las primeras actuaciones en túneles u obras subterráneas hidráulicas que se produjeron a lo largo de la historia, son las minas, galerías drenantes, qanat's, foggaras, m'koula, khettara, pukio, mina o mambo, que se realizaron para alimentar a los precedentes de los aprovechamientos actuales, es decir, los molinos hidráulicos.

Se trata de un sistema de captación tradicional de aguas subterráneas o subálveas que se origina en Persia en el siglo VII a. C. Las galerías drenantes, que guardan una estrecha relación con ambientes áridos o con regiones de escasos 
recursos hídricos superficiales, tienen su origen en los sistemas de captación empleados al sur del Cáucaso (Persia) y en Próximo Oriente. Denominados en aquella región con la voz qanat, son utilizados desde hace más de 2.500 años. Existen diferentes e interesantes hipótesis acerca de la difusión de los qanat por el mundo desde Persia. En la Antigüedad los aqueménides ampliaron sus territorios hacia el Nilo por el Oeste y hacia la Península del Indostán por el Este exportando la técnica de los qanats. A través de Afganistán y los oasis de la Ruta de la Seda, las galerías drenantes se expandieron por el Turkistán chino (cuenca del Turpan), Corea, llegando incluso a Japón. Por lo que respecta al sector más occidental del Mediterráneo, fue la expansión islámica medieval por el norte de África, especialmente por los territorios de los actuales Túnez, Argelia y Marruecos, la responsable de su llegada a la Península Ibérica. Son elementos que poseen una importancia destacada, ya que forman parte del patrimonio cultural de las sociedades donde se localizan.

En España es más habitual llamarlas galerías drenantes y minas.

Una galería drenante es un túnel que se abre por debajo de la superficie terrestre, cuya suave pendiente permite la captación y extracción al exterior, por la acción de la gravedad, de las aguas freáticas desde los acuíferos más superficiales o colgados. Algunas de estas galerías subterráneas cuentan en su trazado con pozos verticales, denominados pozos de aireación, registros, lumbreras o espejuelos, que la conectan con la superficie. Estos elementos de la galería guardan especial interés por un doble motivo. En primer lugar porque los pozos de aireación son imprescindibles para extraer escombros y proporcionar ventilación durante la fase de apertura de la galería. En segundo lugar, porque en su parte superior quedan por encima del nivel de la superficie del suelo, lo que los convierte en el único componente visible de la galería y en un hito paisajístico especialmente en ambientes poco vegetados.

El empleo de esta técnica comporta una serie de ventajas frente a las dificultades iniciales que plantea su construcción. Por un lado, la captación y transporte de agua por debajo de la superficie terrestre en un medio donde la insolación y las temperaturas son elevadas, impiden pérdidas por evaporación, que serían notables en el caso de discurrir el agua canalizada en superficie. Por otro, la salida del agua desde el interior, prácticamente horizontal debido a la mínima pendiente, por acción de la gravedad evita el gasto de energía (fuerza humana o tracción animal) en la extracción al exterior del agua.

Este sistema, mayormente utilizado para abastecimiento y regadío en zonas áridas, también se usó para la alimentación de molinos. 
Las características constructivas y funcionales permiten establecer las tipologías y subtipologías, ya que cada una de ellas se define por modo de excavación y por la solución técnica utilizada para la captación del agua. En una misma galería pueden darse técnicas de construcción correspondientes a diferentes tipologías. Las principales tipologías y subtipologías de galerías presentes en España son las siguientes:

- Mina: su excavación se realiza por la profundización de una surgencia o manantial. Las aguas captadas tienen un origen subterráneo. No disponen de pozo madre ni de lumbreras verticales intermedias para la extracción de escombros. Suelen tener una longitud inferior a los 100 metros, salvo en las minas canarias, donde pueden alcanzar longitudes kilométricas. Ej. Arca del Agua (Guadalupe, Cáceres).

- Mina con lumbrera: poseen las mismas características que las minas, pero con la particularidad de que en su trazado cuenta con una o dos lumbreras verticales, edificadas una vez la galería es profundizada y la distancia con la bocamina es mayor. Su principal localización suele producirse en ambientes de montaña. Ej. Mina de O Ulleiriño (Baiona, Pontevedra).

- Qanat sin lumbreras: el origen de la captación lo constituye el pozo madre, que se excava desde la superficie hasta alcanzar el nivel freático. Una vez construido, la galería se perfora desde la bocamina hasta el pozo madre. No dispone de lumbreras intermedias en su trazado. Ej. Mina Segunda de la Umbría (Ontur, Albacete).

- Qanat: es el sistema original en la captación de aguas subterráneas. La perforación comienza con la construcción del pozo madre, hasta llegar a la zona saturada del acuífero. Se caracterizan por disponer de varias lumbreras verticales o respiraderos en su trazado. Su ubicación más característica se encuentra en espacios intermedios o de transición como son los piedemontes, los glacis o los conos de deyección. Ej. Mina Pública d'Ajgües de Terrassa.

- Qanat con lumbreras laterales: es una subtipología que posee las mismas características que los qanats, pero además dispone de varias lumbreras laterales u horizontales cerca de la bocamina, cuya función es la de ser el inicio de una acequia de riego, al tiempo que facilita el acceso a la captación para tareas de construcción, limpieza y mantenimiento. Ej. El Molinillo (Lúcar, Almería). 
- Mina-alcavón: es un tipo de captación singular, ya que es una mina que se abastece con aguas subterráneas y superficiales. En la cabeza del minado existe una surgencia y posteriormente dispone de varias lumbreras. La galería se utiliza también como una galería filtrante, ya que recoge por medio de los hastiales y la bóveda, las filtraciones procedentes de la escorrentía subsuperficial, al tiempo que transporta el agua derivada del manantial situado en cabeza. Ej. Raudal de la Magdalena (Jaén).

- Galería-alcavón: aprovecha las aguas subterráneas y superficiales. Dispone de varias lumbreras laterales u horizontales y ninguna vertical. Además de las aguas captadas en la cabeza del minado existe un azud que posibilita la entrada de aguas desde el cauce fluvial por una de las lumbreras laterales, lo que la convierte en un caso excepcional de galería. Ej. Fuente de los Molinos del Río Aguas (Sorbas, Almería).

- Cimbra: suelen localizarse en un ambiente de cursos y terrazas fluviales y se aprovechan de las aguas subálveas y/o detríticas aluviales cuaternarias. No disponen de un pozo madre y cuentan con varias lumbreras verticales en su trazado. Se abren desde la bocamina hasta la cabeza mediante una excavación subterránea. Son características del sureste pensinsular, aunque también pueden estar presentes en otros espacios. Ej. Galería de las Angosturas (Jete-Almuñecar, Granada).

- Cimbra-alcavón: es una variedad de cimbra. Se sitúa en un ambiente de cursos y terrazas fluviales y obtiene su caudal de las aguas subálveas y/o detríticas cuaternarias, aunque en momentos de avenida pueden obtener un suplemento de aguas superficiales que se filtran por los hastiales y la bóveda de la captación, en su trazado por el subsuelo de la rambla. El origen principal del agua consiste en un minado situado en el interior de una excavación realizada a cielo abierto en la terraza fluvial en la cabeza del sistema. No dispone de lumbreras. Ej. La Fonnueva (Bulbuente, Zaragoza).

- Cimbra con lumbreras laterales: la particularidad de esta captación estriba en que tiene varias lumbreras laterales, que poseen la doble función de ser el inicio de una acequia de riego, antes de llegar a la bocamina, y la de ser un acceso a la captación para facilitar las tareas de limpieza y mantenimiento. Este subtipo de cimbra no dispone de pozo madre y cuenta con varias lumbreras verticales. Ej. Fuente del Abastecimiento Público (Santa Fe de Mondújar, Almería).

- Zanja: suelen ubicarse en cursos y terrazas fluviales. En su construcción no se utiliza una técnica minera, ya que se abre una zanja a cielo abierto en los materiales aluviales y posteriormente se cubre con lajas de piedra y se 
rellena con lo materiales removidos en su excavación. Es difícil encontrarlas en estado puro, ya que suele combinarse con otras técnicas constructivas. No tienen pozo madre ni lumbreras verticales en su recorrido. Ej. Fuente de la Montalvana (Torralba del Pinar, Castellón).

- Cimbra-zanja: esta tipología combina las técnicas constructivas de perforación subterránea, propias de las cimbras, con la excavación de una zanja a cielo abierto. Se ubican en un ambiente de cursos y terrazas fluviales. En su trazado cuenta con varias lumbreras verticales o pozos de aireación. Ej. Fuente Madre (Castejón de Monegros, Huesca).

- Galería con lumbreras laterales: se emplazan en ambientes de terrazas fluviales y utilizan técnicas propias de la minería en su excavación. Debido al espesor de los sedimentos de la terraza es más fácil acceder a la captación con una excavación horizontal, que perforando lumbreras verticales, mucho más profundas desde la terraza fluvial. Las lumbreras laterales se utilizan como el comienzo de un canal de regadío, anterior a la propia bocamina, y como un punto de acceso a la captación en el momento de su construcción o en el posterior mantenimiento. Ej. Salinas de la Ramona (Calasparra, Murcia).

Si bien es cierto que existe una clara concentración en las regiones peninsulares mediterráneas, también se han identificado galerías en espacios de clima oceánico, como en Galicia.

\begin{tabular}{|c|c|c|c|c|c|}
\hline C. Autónoma & $\begin{array}{c}\text { IGME } \\
\left({ }^{1}\right)\end{array}$ & $\begin{array}{c}\text { Confederaciones } \\
\text { Hidrográficas }\end{array}$ & $\begin{array}{c}\text { Agencias del } \\
\text { Agua (2) }\end{array}$ & $\begin{array}{c}\text { Trabajo de } \\
\text { campo }\end{array}$ & Total \\
\hline Cataluxĩa & 165 & 92 & 876 & 10 & 1.143 \\
\hline C. Valenciana & 53 & 25 & 98 & 539 & 715 \\
\hline Murcia & 86 & 86 & 24 & 148 & 344 \\
\hline Andalucia & 2.698 & 149 & - & 165 & 3.012 \\
\hline Galicia & 13 & 154 & - & 60 & 227 \\
\hline Asturias & 45 & 22 & - & - & 67 \\
\hline Cantabria & 1 & 3 & - & - & 4 \\
\hline Pais Vasco & 12 & 24 & - & - & 36 \\
\hline Navarma & - & 7 & - & - & 7 \\
\hline La Rioja & 9 & 32 & - & - & 41 \\
\hline Aragón & 35 & 43 & - & 16 & 94 \\
\hline Castilla-León & 6 & 23 & - & 2 & 31 \\
\hline Madrid & 20 & 65 & - & 50 & 135 \\
\hline Castilla-La Mancha & 76 & 85 & - & 149 & 310 \\
\hline Extremadura & 2 & - & - & 1 & 3 \\
\hline Baleares & 97 & - & 248 & 50 & 395 \\
\hline Canarias & 468 & - & 1.085 & 19 & 1.572 \\
\hline TOTAL & 3.786 & 810 & 2.331 & 1.209 & 8.136 \\
\hline
\end{tabular}

№ de galerías georreferenciadas en España por diversos organismos 


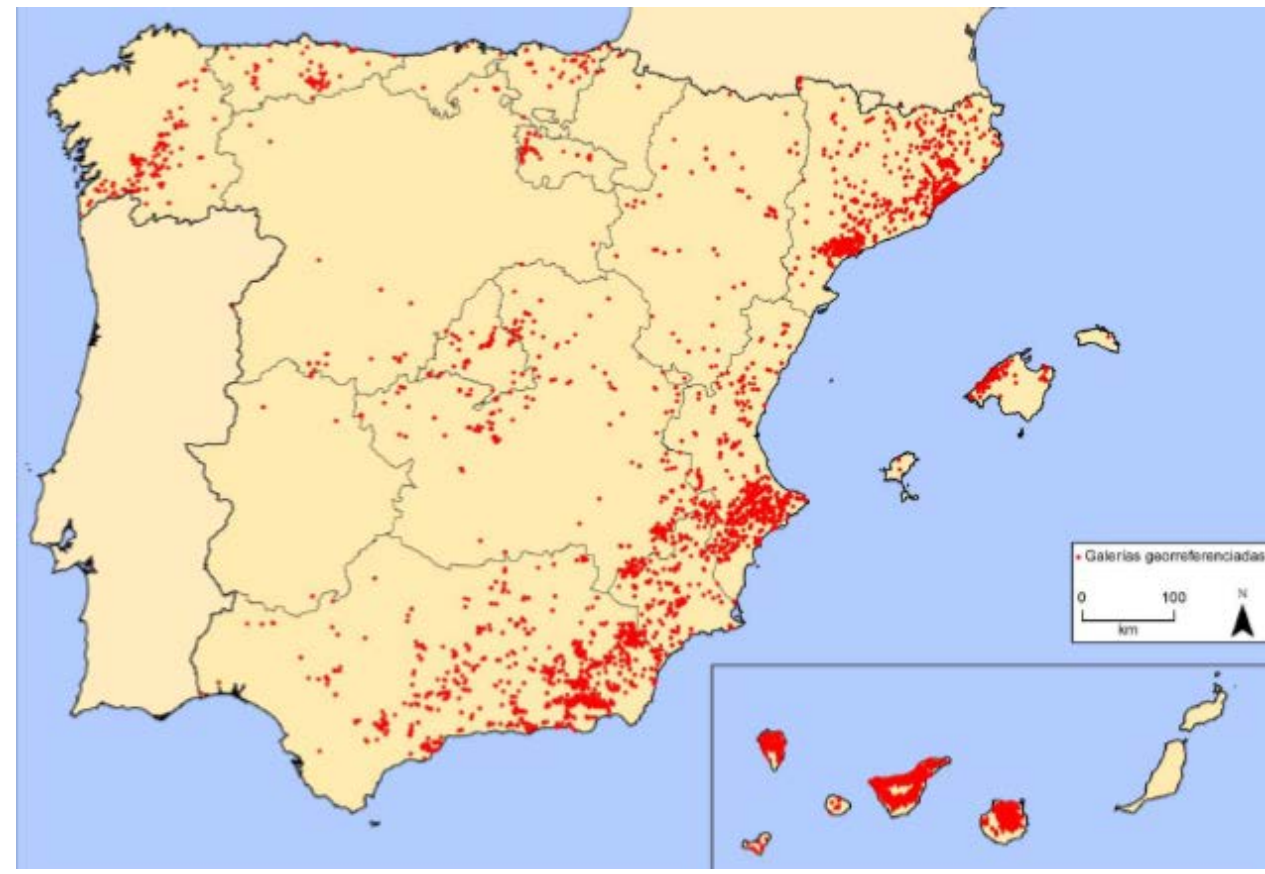

Por ejemplo, en la cuenca del Júcar en la que se han estudiado con detalle las galerías drenantes aún existentes, algunas de ellas alimentan sistemas hidráulicos complejos, normalmente de gran longitud, en los que existen varios molinos.

Es el caso del constituido por las galerías de la Fuente Redonda y las Dos Hermanas con la Acequia de Aguas de Alpera (Albacete), con trece molinos; la Acequia Mayor de Zucaña de Almansa (Albacete), con ocho molinos; y la Font del Port d'Albaida (Valencia), de la que se conoce la existencia de cuatro molinos documentados en 1248. De manera excepcional, el agua obtenida en alguna galería se aprovechó para la obtención de electricidad, como es el caso de la Fuente Redonda con la Fábrica de Luz “La Máquina” (Alpera).

Las técnicas básicas empleadas en la excavación de estas galerías son de carácter minero, y varían en función del desarrollo tecnológico propio de cada periodo histórico. En general no experimentan cambios importantes en la época preindustrial, y es desde mediados del siglo XIX cuando se introducen los medios mecánicos y los explosivos. De la misma manera, las técnicas y materiales empleados en las labores de refuerzo de los hastiales y bóvedas se han caracterizado por su continuidad a lo largo de los siglos, hasta la introducción del hormigón y el hierro en época reciente.

Algunos aspectos de las galerías, como su amplitud y longitud, pueden estar relacionados con el nivel tecnológico de la época de su construcción, por lo que generalmente son mayores en aquellas excavadas en época contemporánea cuando ha sido posible emplear procedimientos mecánicos. 
Sin embargo, hay que destacar que algunas galerías excavadas en época preindustrial alcanzan considerables dimensiones, como es el caso de la Mina de Aguas de Zucaña, de 1.625 m.

Sin embargo, aparte de estos casos extraordinarios, las dimensiones más frecuentes son mucho más modestas y varían desde un mínimo de $5 \mathrm{~m}$, la menor, hasta algunas decenas o centenares de metros. La altura de las galerías es también bastante variable, aunque normalmente se ajusta a la de un ser humano para facilitar el trabajo de excavación y limpieza. En algunos casos, alcanzan alturas considerables, como la espectacular mina que alimentaba al Molino del Huerto, en Aragón.

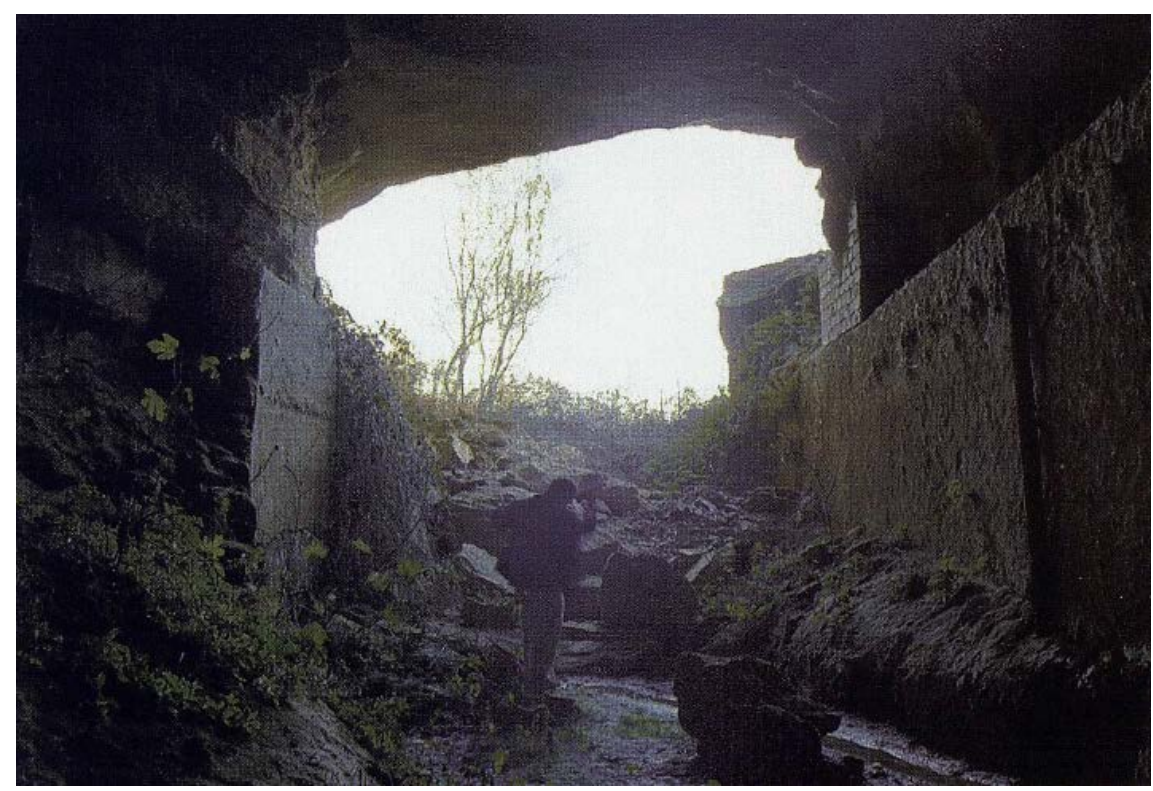

La técnica empleada en las galerías es la excavación de una zanja o túnel ligeramente inclinado que permita la captación y extracción por gravedad del agua. Según el tipo de que se trate, la galería puede ir acompañada de un pozo madre, cuya excavación es el primer paso en la modalidad de los qanats. A lo largo de su recorrido pueden excavarse otros pozos para la extracción de materiales y la aireación, las lumbreras. Las herramientas que se usan son el pico y la picoleta para la excavación de los materiales menos consistentes, el cincel y el mazo para los tramos rocosos y la pala y la legona para su recogida. En algunos casos se conservan en las paredes de la galería trazas de las herramientas utilizadas. En las galerías modernas, cuando los recursos económicos lo permitían, se utilizaron conjuntamente las técnicas tradicionales y los explosivos como la dinamita para los tramos con materiales rocosos, e incluso de compresores en las más recientes. De la misma manera, la extracción de materiales puede llegar a realizarse con procedimientos mecánicos como los tornos para la elevación en el caso de los pozos y la instalación de vías férreas para las vagonetas que la facilitaban. 
Tanto la morfología de las galerías como los materiales empleados en su refuerzo presentan una gran variabilidad, incluso en diferentes tramos de una misma galería que puede haber sido reformada en diferentes épocas. Las características geológicas, topográficas e hidrogeológicas de la zona donde se ha de excavar condicionan la estructura interna de la galería, tanto en sus dimensiones, como en la profundidad, forma, refuerzos, etc. Cuando los materiales excavados son rocosos o suficientemente consistentes, tanto las paredes como el techo pueden quedar formados por la misma roca. En estos casos aquél suele tener forma abovedada, con las irregularidades propias de la excavación manual. Si la galería ha sido excavada atravesando materiales de diferente consistencia, los tramos más inestables pueden ser reforzados, tanto en los hastiales como en las bóvedas, con el fin de evitar el cegamiento de la galería. Los materiales empleados en estos refuerzos suelen ser la piedra seca o la mampostería. En época reciente se incorporan el ladrillo hueco y el hormigón. En las galerías que han estado en uso durante largos periodos de tiempo se han ido incorporando estos materiales, y en algunos casos puede observarse cómo en una misma galería se han empleado distintas técnicas y materiales, mientras que en otras, las reformas modernas han hecho desaparecer los restos de las obras anteriores.

Cuando por su longitud los qanats o las galerías cuentan con pozos de aireación o lumbreras, las diferencias que éstos pueden presentar respecto al pozo madre no suelen ser significativas (sección, refuerzos). Su excavación es similar y la sección puede ser circular, ovalada, cuadrada o rectangular. Pueden reforzarse con distintos tipos de materiales, normalmente la piedra seca, la mampostería y en algunos casos la sillería, aunque en las galerías más modernas suele utilizarse el ladrillo e incluso el hormigón. Lo mismo sucede con los brocales, normalmente sencillos y de escasa altura. En cuanto a las distancias que separan las lumbreras, éstas suelen ser variables en función de las características del terreno y las técnicas de construcción.

En Mallorca, por ejemplo, en el conjunto hidráulico de la Font de Sa Mola, el agua se obtiene a través de una font de mina o qanat, construcción para la captación de aguas subterráneas por drenaje, cuyos orígenes se pueden remontar a la época islámica (s. X-XIII). 
La Font de Sa Mola, que da nombre a todo el sistema, está ubicada en la ladera de una montaña, y aparece integrada en un marge. No se puede acceder al interior de la galería de la font de mina, debido a que sus reducidas dimensiones la hacen intransitable. Sin embargo, contaría con los elementos propios de estos sistemas, esto es, un qanat con pozo madre, del que se obtiene el agua y una galería corta, construida con la mínima pendiente necesaria para conducir el agua desde el punto de captación hacia el exterior, sin necesidad de utilizar ningún artilugio mecánico. Constructivamente, el qanat muestra evidencias de remodelaciones, consistentes en refuerzos realizados con mortero sobre los paramentos originarios de "pedra en sec", lo que indica un uso continuado a lo largo del tiempo. De la Font de sa Mola nace la acequia encargada de conducir el agua hasta el molino, a lo largo de unos 400 metros.
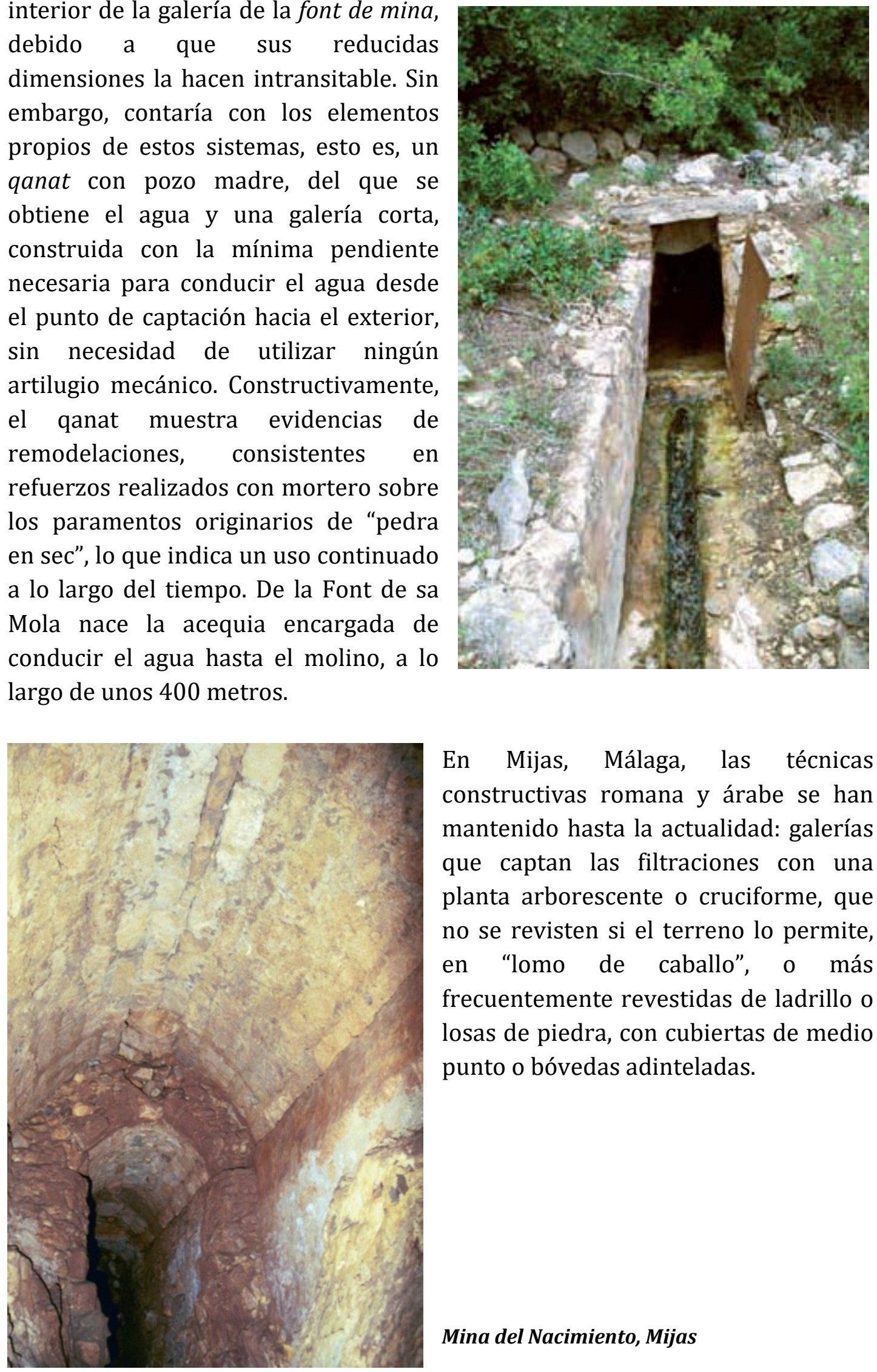

En Mijas, Málaga, las técnicas constructivas romana y árabe se han mantenido hasta la actualidad: galerías que captan las filtraciones con una planta arborescente o cruciforme, que no se revisten si el terreno lo permite, en "lomo de caballo", o más frecuentemente revestidas de ladrillo o losas de piedra, con cubiertas de medio punto o bóvedas adinteladas.

Mina del Nacimiento, Mijas 
Con una longitud de más de cien metros presenta varios tramos con un marcado carácter monumental con diversos tipos de cubiertas (bóvedas de medio punto, adinteladas planas, adinteladas a dos aguas, etc.) y alturas que alcanzan casi los $6 \mathrm{~m}$, presentando una anchura media de unos $40 \mathrm{~cm}$ en el tramo sur, dimensión que se ve ampliada hacia la parte más profunda. Su cronología es de época medieval con reconstrucciones y ampliaciones de época moderna.

Es notable también el caso de las captaciones en forma de galería drenante ubicadas en la comarca de la Safor en Alicante. Como ejemplo de éstas, se adjuntan las siguientes fichas que describen la tipología de las mismas, y como se podrá observar, tienen un nombre tan representativo como la Font del Molí.

Son interesantes dado que la primera de ellas podría considerarse de construcción contemporánea siguiendo en uso, y la segunda, que hace referencia a la galería antigua en desuso, muestran tipologías constructivas diferentes:

\begin{tabular}{|c|c|}
\hline \multicolumn{2}{|l|}{ FONT DEL MOLÍ } \\
\hline \multicolumn{2}{|l|}{ 1. Localización } \\
\hline Municipio & Xeresa \\
\hline Comarca & La Safor \\
\hline Partida rural $\quad E$ & Barranc del Montduver-Horta del Molr \\
\hline Coordenadas UTM $X$ & $X: 739722 \quad Y: 4321118$ \\
\hline Altitud & 70 m.s.n.m. \\
\hline Acceso & Desde Xeresa tomar el Camí del Molí \\
\hline Propietario & Comunidad de Regantes de I' Horta del Molí \\
\hline \multicolumn{2}{|l|}{ 2. Contexto geográfico } \\
\hline $\begin{array}{l}\text { Geomorfología del área } \\
\text { de la ceptación }\end{array}$ & a Ladera abancalada \\
\hline $\begin{array}{l}\text { Materiales que atraviesa } \\
\text { la captación }\end{array}$ & Coluviones, calizas arenosas y margas. \\
\hline Buzamiento de los estratos & No reconocible \\
\hline Vegetación del entorno & - Monte mediterráneo \\
\hline Usos del Suelo & Uso rústico (saltus: rios y barrancos) \\
\hline Tipo de cultivos & Regadio arbolado \\
\hline Relación con otros sistemas & Is Independiente \\
\hline Usos del agua & $\begin{array}{l}\text { Muxto (Regadio, industrial y abestecimiento } \\
\text { de la población) }\end{array}$ \\
\hline Área irrigada & 21 Hectáreas. 4 Áreas . 58 Centiáreas \\
\hline
\end{tabular}

3. Análisis de la captación

\begin{tabular}{|c|c|}
\hline Ti pusioga de la captación & Qanat con lumbreras \\
\hline Caudal permanente & Si, entre $15 \mathrm{~V} / \mathrm{s}$ y $50 \mathrm{~V} / \mathrm{s}$ \\
\hline Longitud de la captación & 453 metros \\
\hline Número de lumbreras & 12 \\
\hline $\begin{array}{l}\text { Distancia entre las } \\
\text { lumbreras }\end{array}$ & De 20 a 25 metros \\
\hline Forma de las lumbreras & Redondas \\
\hline $\begin{array}{l}\text { Fábrica de las } \\
\text { lumbreras }\end{array}$ & $\begin{array}{l}\text { Exterior de piedra y cemento; Interior } \\
\text { picado sobre el material originario }\end{array}$ \\
\hline $\begin{array}{l}\text { Época de construcción } \\
\text { de la captación }\end{array}$ & $1911-1912$ \\
\hline $\begin{array}{l}\text { Estructura interna de } \\
\text { la captación }\end{array}$ & Mxta (abovedada e irregular) \\
\hline Paredes internas & Moxta (Mamposteria y piceda en roca madre) \\
\hline Suelo de la captación & Roce madre con sedimentos \\
\hline Refuerzos intemos & $\begin{array}{l}\text { Piedra, ladrillos y mampuestos. En algún } \\
\text { tramo la bóveda está reforzada }\end{array}$ \\
\hline Bifurcaciones & $\begin{array}{ll}\mathrm{Si} & \text { Numero: } 2\end{array}$ \\
\hline $\begin{array}{l}\text { Bocamina } \\
\text { (Descripción) }\end{array}$ & $\begin{array}{l}\text { Estrecha y reforzada con bloques de } \\
\text { hormigón. El agua se embalsa ligeramente } \\
\text { antes de conducirse por una atarjea. } \\
\text { Dispone de una puerta en la entrada para } \\
\text { evitar el paso }\end{array}$ \\
\hline Balsa a la salida & No \\
\hline
\end{tabular}

4. Otras observaciones

Se trata de un auténtico qanat en cuanto a los elementos que lo componen en su tramo superior (galería y pozos de aireación) como en su tramo inferior (acequia, molino y cultivos). asi como en las técnicas empleadas para su construcción. La Font del Moli aqui descrita no es la originaria. Antiguamente hubo otro qanat que se denominaba de la misma manera. Asi pues, la construcción de esta galeria es de principios del siglo veinte y para su construcción se emplearon herramientas y explosivos. En el interior de la galeria se pueden observar las: marcas de las herramientas al picar la roca.

Aunque la galeria esta en óptimas condiciones tanto junto a la bocamina como en el tramo medio y final, se observan restos de derrumbes y su posterior limpieza y reparación de la galeria. El paso de camiones de gran tonelaje por el camino que hay junto a la Font. está estrechando cada vez más la entrada de la galeria. Desde la bocamina, una acequia cubierta (atarjea) conduce las aguas hacia ef exterior.

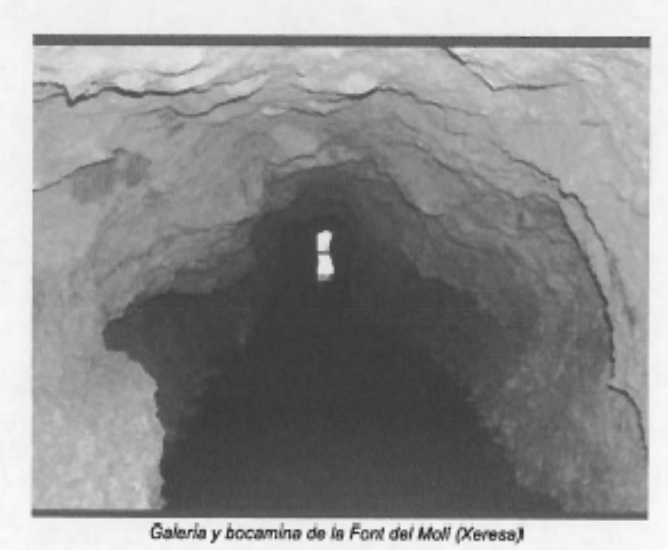




\section{FONT DEL MOLÍ (ANTIGUA)}

1. Localización

\begin{tabular}{l|l} 
Municipio & Xeresa \\
Comerca & La Safor \\
Partida rural & Barranc del Montdúver-Horta del Moli \\
Coordenadas UTM & X: 739083 Y: 4306411 \\
\hline Altitud & 80 m.s.n.m. \\
\hline Acoeso & Desde Xeresa por el Cami del Moli \\
Propietario & Comunidad de Regantes
\end{tabular}

2. Contexto geográfico

Geomortologia del área Ladera abancalada
de la captación

Ladera abancalada

Materiales que atraviesa la captación

Coluvión, calizas arencess y margas.

Buzamiento de los estratos No reconccible

Vegetación del entorno Monte mediterráneo

Usos del Suelo Uso ristico (saltus: rios y barrancos)

Tipo de cultivos Regadio arbolado y hortalizas

Relaciín con otros sistemas Independiente

Usos del agua Mixto, pero actualmente fuera de usa Área irrigada Actualmente fuera de uso

\section{Otras observaciones}

La construcc ón de esta Font del Moli, según datos del archivo de Xeresa, tuvo lugar en 1877. Se trata de una tipologia clara de qanat ya que dispone de todos sus elementos y tecnología constructiva. Se puede apreciar que esta galeria es más antigua que la que actualmente está en activo sólo por los materiales empleados en su construcción.

La Font está fuera de uso y en algunos tramos aterrada por derrumbes. Aún asi y pese a que su estado de deterioro es avanzado, mantiene unos elementos y estructura básica perfectamente reconocible, que deberia ser conservada.

\section{Análisis de la captación}

Tipologia de la captación Qanat con lumbreras

Caudal permanente No, fuera de uso

Forma deles lumb reras Pedondas

Fábrica de las

lumbreras

Mamposteria con mortero

Época de construcción

de la captación

Estructura interna de

la captación

1877

Paredes internas

Mxta (Rectangular y abovedada)

Suelo de la captación De tierra

Refuerzos internos No

Bifurcaciones Desconocido Numero:

Bocamina La bocamina es rectangular y una

(Descripción) hipótesis es que la construcción, duranté los primeros metros, fuese a modo de: zanja que posteriormente es cublerta con un techo de piedra

Balşa a la şalida No

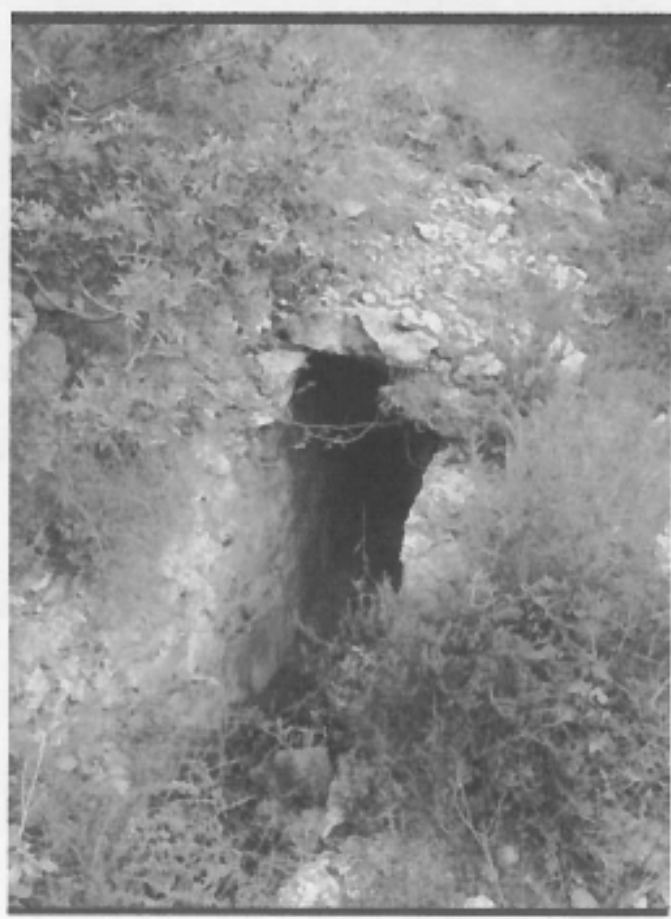

Antiga Font del Moli (Xeresa) 


\subsection{TÚNELES EN CENTRALES HIDROELÉCTRICAS}

La evolución tecnológica que han sufrido los túneles o galerías ejecutados para la construcción de centrales hidroeléctricas, es la que se ha producido en la disciplina de ejecución de túneles de cualquier tipo, en general.

La primera central hidroeléctrica subterránea del mundo que todavía abastece al área de Seattle es Snoqualmie falls en King County, Washington, EEUU.

La mayor central subterránea del mundo se encuentra en Quebec, Canadá, y es la planta de Robert-Bourassa, capaz de producir 5616 MW con sus 16 turbinas.

Tomando datos del año 2010, las regiones con más desarrollo en la ejecución de hidrocavernas son África (40\%), Asia (32\%), y Europa (32\%). Sin embargo, los países con menos preferencia hacia la realización de centrales subterráneas son Norte América, Sudamérica y Australia. En cambio, en China, India y Japón se espera un crecimiento notable en este sentido.

De hecho, si tenemos en cuenta los siguientes parámetros para hacer un ranking de las mayores cavernas (profundidad mayor de $32 \mathrm{~m}$., altura mayor de $70 \mathrm{~m}$., longitud mayor de 320 m., área de la sección mayor de $1900 \mathrm{~m} 2$, volumen de excavación mayor de $390.000 \mathrm{~m} 3$, capacidad total/unitaria mayor de 4200 MW/mayor de $550 \mathrm{MW}$ ), siete de las 10 mayores centrales subterráneas están construyéndose en China.

Si se tiene en cuenta el salto neto, las mayores cavernas se sitúan en Francia, Italia, Perú y Suiza. Seis de los diez principales proyectos con más cubierta de roca se sitúan en Noruega.

Las diez hidrocavernas mayores teniendo en cuenta únicamente la altura, son todas ellas chinas salvo una mejicana, ésta es, Serra de Mesa, y sus alturas están comprendidas entre los 72 y los 87 metros. La de mayor altura, la de las Tres Gargantas 2, en China.

Teniendo en cuenta sólo el criterio de volumen, nuevamente las diez mayores del mundo son chinas, salvo La Grande 2, que es canadiense. Lo mismo ocurre si se tiene en cuenta la capacidad en MW, donde también aparece otra central canadiense además de La Grande 2, ésta es, Churchill Falls.

En cuanto a longitud, además de las cavernas chinas, aparecen centrales canadienses, una de India y otra de Luxemburgo, siendo la mayor de todas ellas en longitud, La Grande 2 de Canadá con 484 metros. 
Respecto a sección, las diez mayores cavernas son todas chinas salvo Serra de Mesa en Méjico.

Hay que señalar que en el ranking de las diez mayores hidrocavernas de todos los criterios expuesto, aparece la central china de las Tres Gargantas 2, en diferentes posiciones.

También resulta interesante comprobar qué sección tipo se ha utilizado para realizar las mayores cavernas hidroeléctricas del mundo. Sobre 420 hidrocavernas de las que se tienen datos, la distribución de tipologías ejecutadas es la siguiente:

Sección tipo:

$\begin{array}{lc}\text { Bullet } & 26,2 \% \\ \text { Mushroom } & 60,0 \% \\ \text { Horseshoe } & 10,5 \% \\ \text { Circular (semi) } & 2,8 \% \\ \text { Trapezoidal } & 0,5 \%\end{array}$

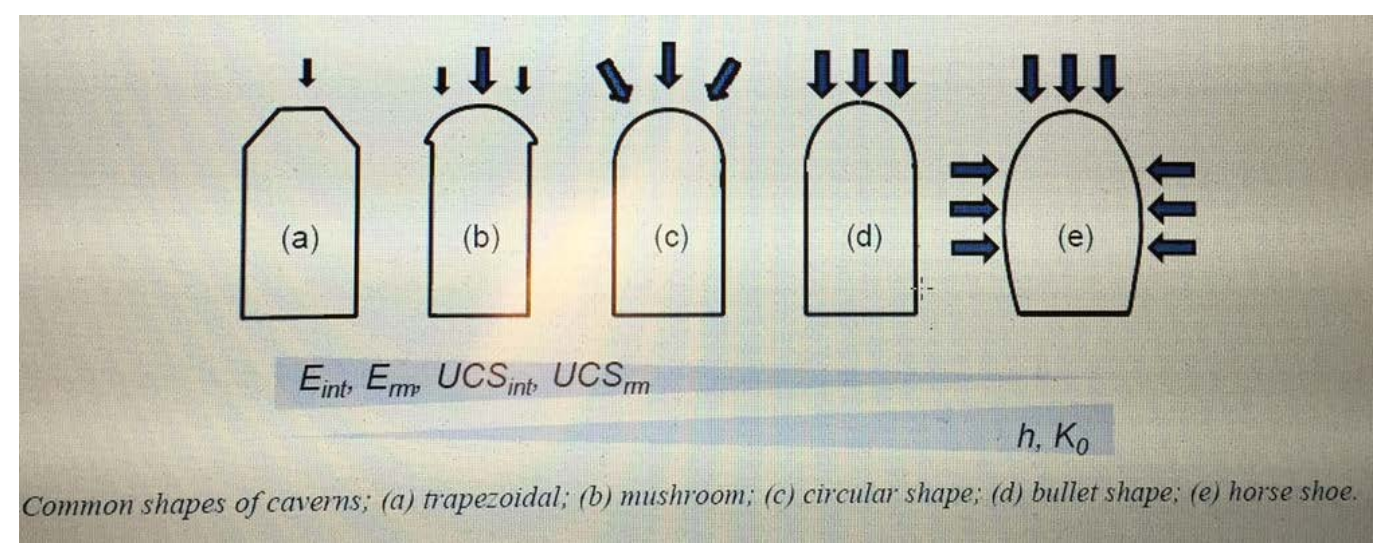

Aunque no se dispone de datos en cantidad suficiente como para hacer un mayor análisis, sin embargo, se puede indicar respecto al tipo de roca que se atravesaba en cada caso, que cuando se utilizó la sección trapecial, el terreno era regular y de matriz arcillosa. Cuando se utilizó la sección tipo Mushroom, se hizo en todo tipo de roca (Muy buena (RMR $>80, Q>50)$, buena $(R M R>60, Q>5)$, regular-mala $(\mathrm{RMR}>40, \mathrm{Q}>0.7) \quad \mathrm{y}$ mala-muy mala $(\mathrm{RMR}<40, \mathrm{Q}<0.7)$ ), prevaleciendo su aplicación en roca buena. Lo mismo ocurre con la sección tipo Bullet aunque ésta no se utilizó prácticamente nunca con roca mala. La sección tipo Horseshoe observa una dispersión de uso entre todo tipo de roca. Y la sección circular, sin embargo, sólo con roca buena o regular.

Insistir que no son suficientes los datos de que se disponía para obtener una conclusión de sección tipo a aplicar por tipo de roca, aunque sí existe a nivel 
mundial un banco de datos en el que se van implementando este tipo de información (más exhaustiva en cuanto a la caracterización del terreno), para en un futuro, sacar conclusiones al respecto con criterio estadístico. El estado del mismo es aún muy incompleto.

En cuanto a la sección tipo de galería aplicada a nivel mundial, con los datos de que se dispone, en el 73,5\% de los casos se aplica la sección (semi-)circular.

En España, túneles hidráulicos de referencia, son los túneles del Salto de Miranda en Asturias, y el Salto de Villarino en Salamanca.

Las obras del Salto de Miranda comenzaron en el año 1958 y se prolongaron durante cuatro años. La conducción principal empieza en la toma de El Covacho. Está formada por varios túneles revestidos de hormigón, de 3,5 metros de altura y una sección de $10 \mathrm{~m}^{2}$, en forma de herradura. La maquinaria era muy limitada, con voladuras de perforación de sólo 3,20 metros, y lo que primaba el esfuerzo físico de las cuadrillas. A pesar de ello, en un día se llegó a perforar 6,70 metros. Su trazado perfora la cadena montañosa situada en la margen derecha del río Pigüeña. Tras 2 kilómetros de recorrido, recibe las aguas del río Pigüeña y continúa, a lo largo de otros 19 kilómetros, hasta la localidad de Vigaña, dejando atrás La Bustariega, Llamoso y Tiblós. En este tramo, recibe la aportación de varios arroyos de cierta importancia.

Tres kilómetros después de Vigaña se encuentra la chimenea de equilibrio y la válvula de cabecera que permiten regular la presión y el flujo de entrada a la tubería forzada metálica.

En conjunto, por tanto, las longitudes de los túneles hidráulicos son $19 \mathrm{~km}$ de la derivación principal, la longitud del túnel de la derivación secundaria es de 5 km y la de la galería de presión, $3 \mathrm{~km}$.

En el caso de Almendra-Villarino, las turbinas no se encuentran a pie de presa, con lo que se conseguiría una altura de $202 \mathrm{~m}$., sino que tiene una toma de agua casi en la cota inferior y ésta discurre por un túnel excavado en la roca de 7,5 m de diámetro y $15.000 \mathrm{~m}$ de longitud. Esta galería, casi al final, se bifurca en dos de $5 \mathrm{~m}$ de diámetro y cada una de éstas a su vez, en dos metálicas de 2,8 $\mathrm{m}$, las cuales alimentan a cada uno de los cuatro grupos turbina-alternador, desaguando éstos en el embalse de Aldeadávila, en el río Duero. Así se consigue obtener una altura de $410 \mathrm{~m}$.

En la actualidad, los aspectos técnicos generales destacables en las obras subterráneas son: 
- Mayor investigación y comprensión del comportamiento del Terreno.

- Mejor conciencia sobre gestión de riesgo y evolución del monitoreo e instrumentación de obras.

- Modernas Tecnologías: construcción más eficiente, económica y segura.

- Mayor grado de mecanización y automatización del proceso de construcción.

- Innovaciones en los ámbitos de prospección, excavación, soporte, impermeabilización, extracción, entre otros.

- Negativo: Accidentes indeseables aún ocurren puntualmente.

En las modernas estaciones generadoras de energía hidráulica subterráneas se construye una compleja red de túneles con distintas funciones: túneles de acceso desde el exterior hasta la sala de máquinas y de transformadores, túneles que conducen los cables, y los propios para la generación de la energía que se puede clasificar, por sus distintas características, en tres tipos: de descarga libre, de alta presión y salas de máquinas y transformadores.

Se consideran túneles de descarga libre al túnel para la captación del agua y al de desagüe; el primero suele estar siempre lleno pero a una presión relativamente baja, y debe tener una pendiente suave para que una vez vacío se pueda realizar su inspección y mantenimiento. El túnel para el desagüe tendrá la mínima pendiente ya que la sala de turbinas conviene situarla al nivel más bajo posible para aprovechar la máxima carga hidrostática del agua. La sección tipo, normalmente circular, y el revestimiento debe prever ser capaz de soportar la erosión bajo cualquier condición de descarga.

Los túneles de alta presión o conducciones forzadas suelen tener una fuerte pendiente, e incluso pueden ser verticales por lo que en su construcción se emplean técnicas propias de la construcción de pozos; es muy importante hacer mínima la pérdida de carga hidrostática por lo que un revestimiento liso es imprescindible. Se producen muy altas presiones en los tramos próximos a las turbinas, y además en todo el túnel, cuando se cierran o abren las tuberías de alimentación de las turbinas según las necesidades de producción, se producen presiones por ondas de choque que se controlan construyendo chimeneas. El revestimiento debe ser capaz de soportar estas altas presiones y además ser impermeable, por lo que a menudo será de acero o de hormigón con un revestimiento interior de acero. También se puede excavar un túnel en el que se instala una tubería de acero de menor diámetro y al que se puede acceder para su mantenimiento. 


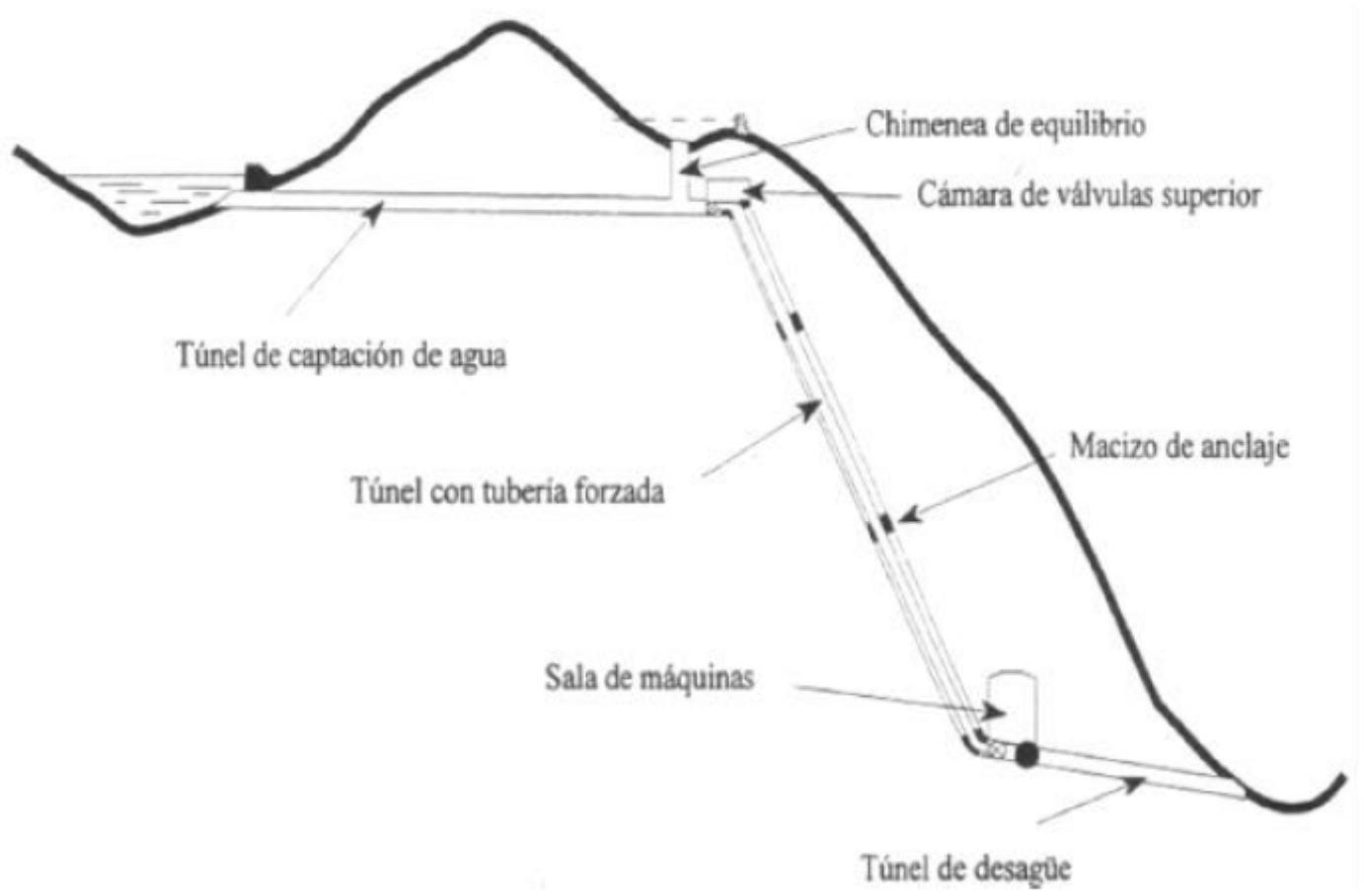

Túneles hidráulicos en una central hidroeléctrica

\section{Circuito hidráulico}

longitud galeria de abastecimiento $3.600 \mathrm{~m}$

longitud tuberia de presión $\quad 1.050 \mathrm{~m}$

longitud galeria de desagüe $\quad 620 \mathrm{~m}$

salto bruto medio $762 \mathrm{~m}$

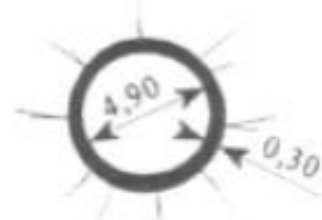

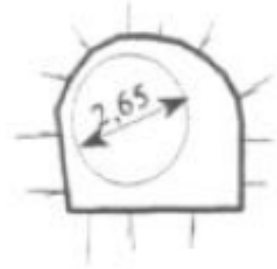

sección tipo

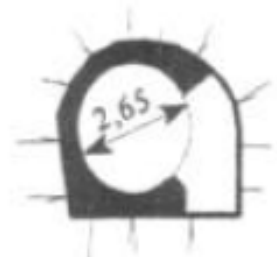

sección con anclaje

Túneles de descarga libre

Túnel con tuberia forzada

\section{Características del salto de Moralets}

Las salas de máquinas y de transformadores son grandes cavernas que albergan todo tipo de equipos (turbogeneradores, transformadores, tuberías de alimentación a las turbinas, etc.). Suelen tener paredes verticales y techo en bóveda (sección de herradura). La construcción de estas grandes salas requiere, en general, una roca resistente.

A continuación, se describe cómo se realizaban las obras hidroeléctricas subterráneas en España antes de los años 70 que es cuando irrumpen en el 
mercado internacional las máquinas de excavación puntual, es decir, las rozadoras. También es en los años 70 cuando aparecen, inicialmente en Japón, las máquinas tuneladoras tipo EPB, aunque en Europa no tengan presencia notable hasta mediados de los años 90.

Tras el desarrollo de la situación española previa a la entrada de las modernas máquinas tuneladoras, se describirá la evolución que hasta la actualidad ha supuesto la irrupción de este tipo de nuevas tecnologías.

\subsection{DESARROLLO TECNOLÓGICO ANTES DE LOS AÑOS 70}

Antes de los años 70, la realización de excavaciones subterráneas en España era una labor de artesanía hasta que se produjo la evolución y mejora de los procedimientos y medios auxiliares, así como la técnica en el uso de explosivos. Ello condujo, también, a una reducción en los plazos de ejecución de este tipo de obras.

Los reconocimientos previos del terreno, aunque imprecisos, eran necesarios. Los estudios geológicos desde la superficie, las prospecciones geofísicas en profundidad, los sondeos, la realización de galerías y pozos de reconocimiento en las zonas más dudosas de la traza, no podían dar más que una ligera noción de cómo se iba a producir el sostenimiento del terreno al ser excavado, de las magnitudes de las filtraciones del agua, y del grado de alteración de la roca a lo largo de toda la obra. Los resultados de esos reconocimientos y estudios geológicos eran más inciertos cuanto mayor era la cobertura de montaña sobre la galería, teniendo además en cuenta la compleja tectónica española.

El estudio geológico y geofísico del macizo y especialmente la ejecución de galerías de reconocimiento, daban a conocer directamente la naturaleza de la roca, la catalogación geológica del terreno y su estado de alteración. Los ensayos in situ que proporcionaba la entonces moderna mecánica de rocas, permitían además determinar, además de la deformabilidad de la roca, el estado tensional del macizo y sus características mecánicas.

Los sondeos ofrecían la posibilidad de reconocer y situar geométricamente los accidentes geológicos, fallas, litoclasas importantes, etc.

Todo ello, en su conjunto, permitía definir la situación y orientación más conveniente para la caverna de la central.

En cambio, en el caso de galerías de cierta longitud, no se tenía más información que la general de tipo geológico y geofísico, y la proporcionada por los 
reconocimientos directos en algunas zonas particulares, tales como galerías y pozos de ataque.

Entrando en el aspecto concreto de la ejecución de galerías, el éxito de la misma estaba condicionada a la correcta fijación del los ataques intermedios, tanto en número como en situación, aunque la tendencia en ese aspecto según mejoraba la capacidad de la maquinaria de excavación subterránea, era reducir al mínimo el número de ataques intermedios para centralizar en pocos puntos las instalaciones auxiliares de la obra.

Este criterio anteriormente expuesto no era extrapolable de forma directa a todo el territorio nacional, ya que no se tenían, en todos los casos, grandes probabilidades de encontrar terreno suficientemente competente para la utilización económica de los costosos equipos, entonces modernos, de excavación, proyectados para grandes velocidades de avance, como eran los jumbos con martillos pesados, los trenes bunker, etc.

Los puntos de ataque intermedios se situaban tanto más próximos cuanto peor se estimaba que fuera a ser el terreno a atravesar. El trazado en planta de la galería se solía acercar a los puntos de emboquille de las galerías de ataque lateral, para reducir la longitud de éstas, en cuanto fuera compatible con el recubrimiento mínimo deseable para la galería, y esto en función de la presión interior a que fuera a estar sometida en su explotación.

Antes de los años 70 era normal, como criterio general, no pasar de $4 \mathrm{~km}$. de longitud en los tramos sin ataque intermedio, a pesar de que existían galerías que habían sobrepasado con creces esa cifra como, por ejemplo, la galería de Bao-Bibey, con un tramo de $6 \mathrm{Km}$., y la del Salto de San Agustín, con uno de 7,7 $\mathrm{Km}$.

Era conocida la ventaja que suponía orientar correctamente la galería, en la medida de lo posible, a la dirección general de la estratificación, esquistosidad y orientación de la red principal de litoclasas del macizo rocoso, ya que la experiencia acumulada indicaba que las galerías que seguían "al hilo" estas direcciones, presentaban más problemas en la excavación, exigiendo mayor proporción de tramos entibados.

Por esos años, el coste de la excavación de una galería con entibación podía ser el triple del de una excavación sin ella, y además, la velocidad de avance, en cuanto aparecían problemas de sostenimiento, se reducía notablemente lo que también penalizaba el coste global de las obras. 
También el perfil longitudinal de las galerías solía acomodarse en lo posible a la economía en su construcción, teniendo en cuenta que excavando a favor de la pendiente, la velocidad de avance se reducía muy sensiblemente debido a la acumulación de agua en el frente de trabajo. Por ello, tenían como criterio que con tener contrapendientes del orden del 2 al 4 por mil, el agua de filtración y de los trabajos de perforación se podía evacuar mediante cunetas hacia el exterior. Si las cunetas resultaban insuficientes, se tenía que recurrir al bombeo del exceso de caudal mediante tuberías colgadas en ese tramo, para mantenerlo en seco. La presencia de agua en el frente de trabajo reducía notablemente la velocidad de avance a más del 50\% de la normal en seco.

Durante la etapa de excavación de la galería no era extraño y resultaba eficaz, variar el trazado en planta con el fin de separarse de las zonas de mal terreno. Para ello se establecía una correlación entre los estudios geológicos de superficie, y los del terreno que se atravesaba a medida que avanzaba la excavación. Además se realizaban reconocimientos en galerías de sección reducida excavadas desde el interior de la galería principal y perpendicularmente a ésta.

Un ejemplo de esto último es la galería de presión del Salto de Bao-Bibey, en dos tramos de gneis micáceo, en que se pudo salir del terreno que requería entibación continua, hacia otras zonas de roca menos alteradas que permitieron el avance a sección plena y sin entibación.
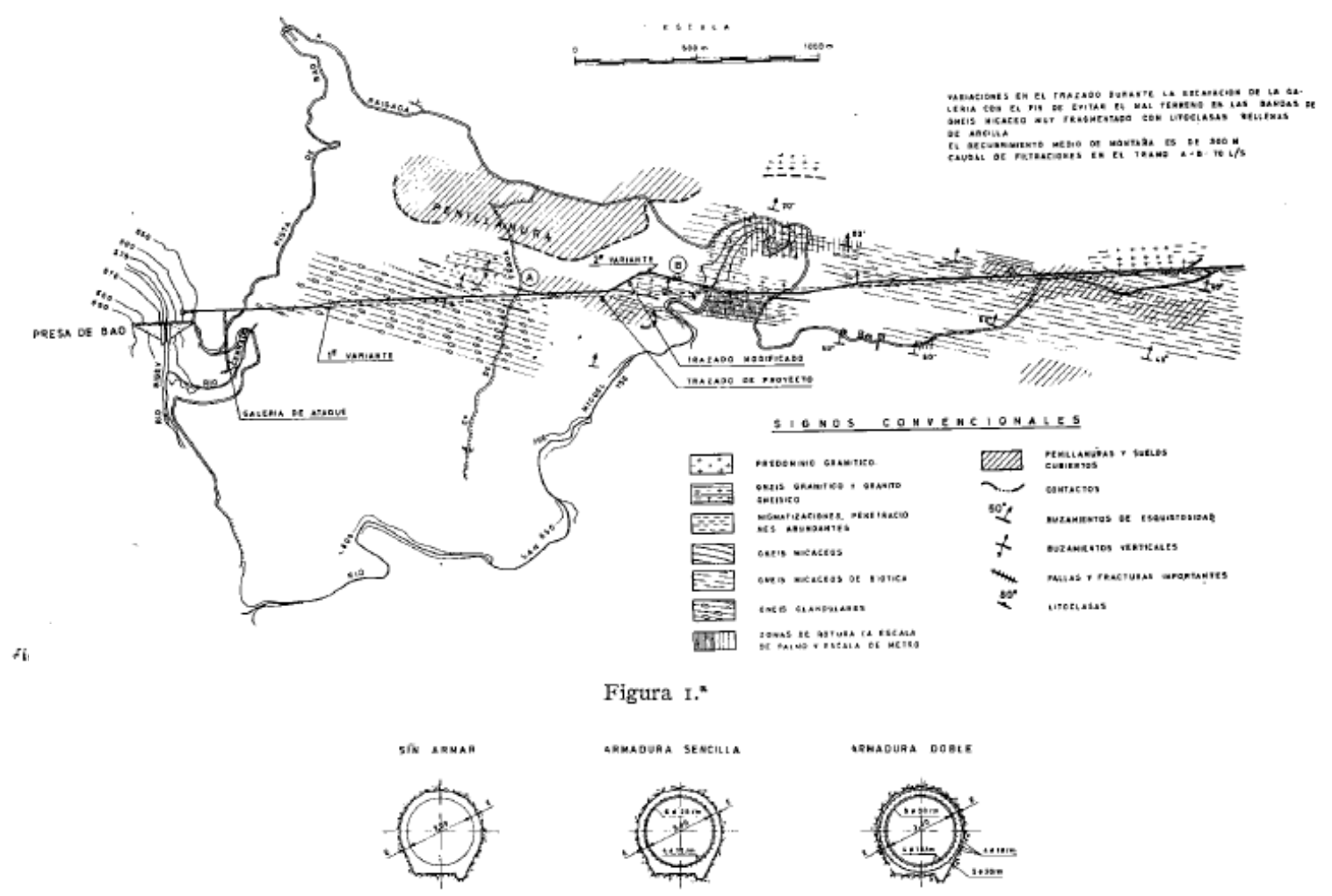
En cuanto a sección transversal de las galerías de presión, salvo en los casos de baja presión de servicio, la sección libre era circular, y en consecuencia, también era circular la sección teórica de la excavación. Esto, sin embargo, creaba serias dificultades de ejecución cuando se trataba de galerías de diámetro de excavación no superior a siete u ocho metros, debido a la fuerte curvatura de la solera.

La experiencia acumulada demostró que el mejor procedimiento para maniobrar las vagonetas en el frente de excavación era el empleo del cambio de vía "californiano". Este procedimiento exigía un ancho mínimo horizontal que oscilaba entre 2,30 y 2,80 metros, según fuera el tamaño de los vagones. Este ancho se conseguía mediante dos procedimientos, o elevando la rasante de la vía a suficiente altura, o bien adoptando una sección de excavación en herradura, con el suelo tangente a la circunferencia del perfil circular teórico de la excavación.

Además de la sección en herradura se estimaba indispensable la excavación de una cuneta más baja que la rasante de solera en aquellos tramos donde fuera presumible al existencia de filtraciones de cierta importancia (más de 25-50 l/s, según sea la pendiente de la galería).

En cuanto a la tecnología aplicada en la excavación de galerías, en España, la perforación de los barrenos en galería de presión y túneles sin carga, cualquiera que fuera el tamaño de la sección, se solía realizar utilizando martillos ligeros (alrededor de $22 \mathrm{~kg}$.), rápidos (3.000 golpes por minuto), con empujador sostenido a mano o bien utilizando gradas (ladders) tipo "Coromant", sobre plataformas de perforación en uno o varios pisos.

Por esos años, previos a los 70, no se habían utilizado apenas los "jumbos" con martillos pesados, en principio justificado por la heterogeneidad tan grande que tenía el subsuelo español.

Los esquemas de tiro utilizados eran los usuales en el resto del mundo, prefiriéndose el cuele de cuña cuando el ancho de la sección lo permitía, o bien el cuele paralelo con taladros sin cargar cuando se querían obtener longitudes de pega mayores o en galerías de sección reducida.

Los barrenos de corona solían cargarse con cargas espaciadas para obtener un mejor perfilado de la excavación.

Se empleaban detonadores eléctricos de microrretardo en los cueles, y de retardo de segundos en las coronas. Las voladuras se daban con explosores de 
generador o de condensadores, y en raras ocasiones, con la energía de la red eléctrica. El explosivo empleado era de fabricación nacional de buena calidad, la dinamita de elevado poder rompedor y de no tan buena la de bajo poder. En algunas obras, sin agua de filtraciones, en roca blanda se utilizó con éxito la sabulita.

Para el retacado de los barrenos, antes de los 70, empezaba a utilizarse a gran escala el taco de agua, consistente en una vaina de plástico de $30 \mathrm{~cm}$. de longitud que se llenaba de agua en el mismo frente de trabajo y que tenía la ventaja, sobre el taco clásico de arcilla o arena, que rebajaba sensiblemente la temperatura de explosión disminuyendo, además, la formación de polvo fino en la voladura. Permitía asimismo, introducir en el agua alguna sustancia oxidante que favoreciese la eliminación de los gases tóxicos, especialmente del dióxido de carbono.

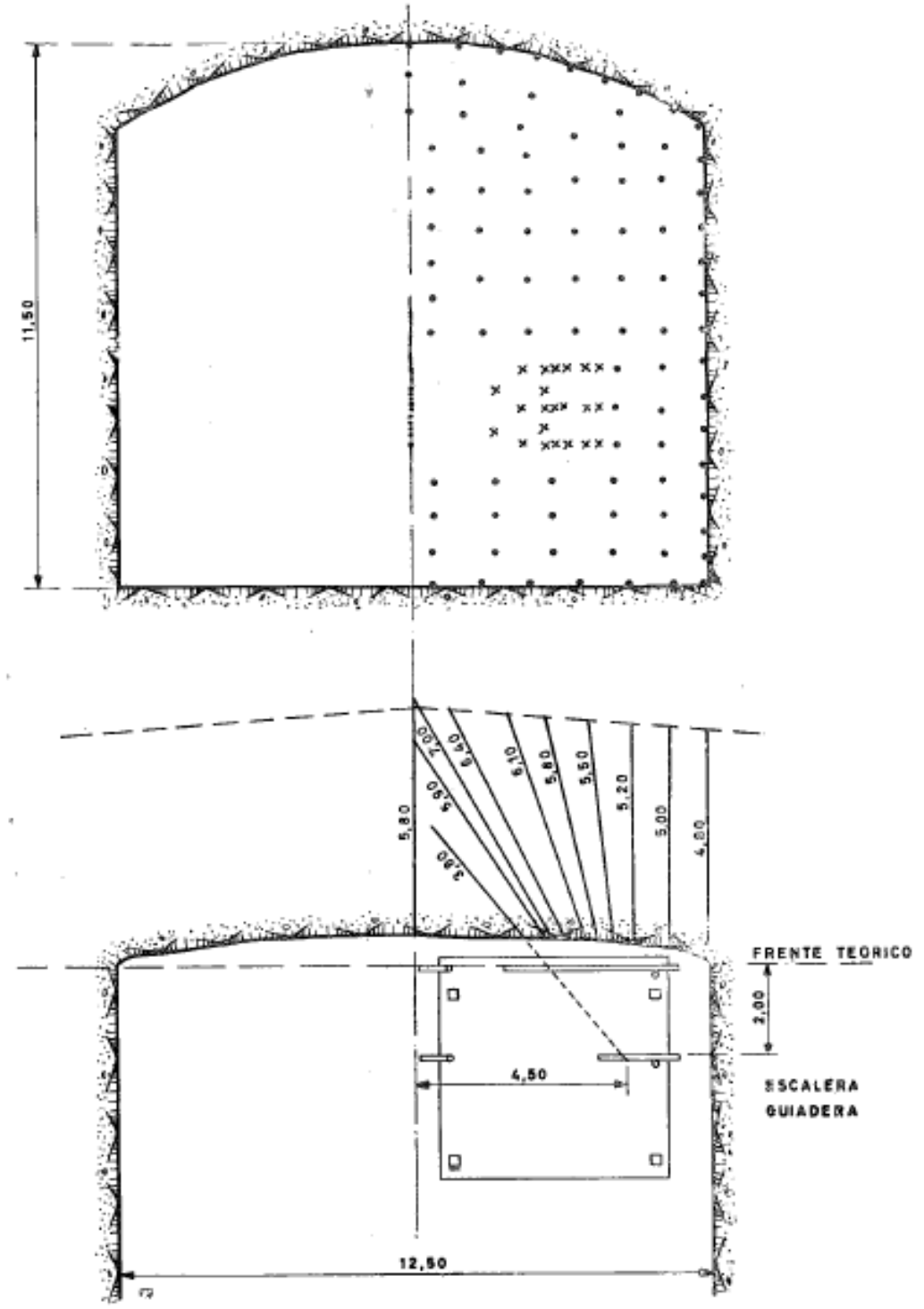

Sección transversal y esquema de barrenos de los canales de desagüe del Salto de Aldeadávila 
En cuanto a los medios de carga y transporte de escombros, el tipo de máquinas empleadas dependía de las dimensiones de la sección y de la forma de realizar el transporte, bien por medio de trenes de vagonetas o sobre vehículos neumáticos.

En galerías de presión de ancho no superior a 4 metros, se utilizaban habitualmente la vía de $60 \mathrm{~cm}$., palas cargadoras de aire comprimido y vagones de vaciado lateral de 2 a $3 \mathrm{~m} 3$ de capacidad, con locomotoras diesel y, en algunas obras, eléctricas de acumuladores.

En galerías y túneles sin presión, donde eran frecuentes anchos de sección superiores a 4 metros y longitudes no excesivas (menos de $3 \mathrm{Km}$.), se prefería el transporte con dumpers o camiones volquetes, y la carga con palas con cargadores frontales o de vuelco lateral. Cuando el ancho de la sección sobrepasaba los 7 u 8 metros, se prefería en roca, la excavadora de brazo corto.

En esos años, no estaba bien resuelto el transporte de escombros para secciones comprendidas entre 4 y 8 metros ya que las palas cargadoras antes citadas, que eran magníficas en cuanto a rendimiento, sin embargo, sufrían numerosas averías. $\mathrm{Y}$ las cargadoras sobre neumáticos $\mathrm{u}$ orugas de tipo frontal, extrapoladas del trabajo en tierras, tenían un escaso poder de arranque en escombro de roca dura.

En aquélla época era casi una regla general, que no existía en España un solo túnel o galería de cierta longitud, sin un 20 o 30\% de tramos en el que el terreno exigiera entibación.

En cuanto a los sostenimientos empleados, dependía de dos casos diferenciados:

- En terreno que permitía el avance a plena sección, pero que posteriormente, bien fuera por decompresión de la roca, o por meteorización o filtraciones de agua, daba lugar a desprendimientos. En este caso, el tipo de sostenimiento era:

o Colocación de pernos de anclaje de cuña de expansión, de tipo "perfo" o de varilla de acero con mortero previamente inyectado en el taladro.

o Colocación de pernos y malla metálica.

o Además de lo anterior, colocación de una capa de hormigón, o de mortero proyectado en toda la superficie.

o Entibación metálica con perfiles en $U$, unidos con grapas en secciones de galería no superior a $15 \mathrm{~m} 2$, y con perfiles laminados más resistentes en secciones mayores o de fuertes empujes del 
terreno. Con enfilaje metálico o de viguetas de hormigón y relleno contra la roca de viguetas de hormigón o piedra en seco. En galerías de presión no era admisible dejar madera embebida en el hormigón de revestimiento, y tampoco entre éste y la roca.

o La entibación anterior y revestimiento con hormigón proyectado.

o Revestimiento de hormigón, con preferencia fuera de la sección teórica de excavación, o bien con el revestimiento definitivo.

- En terreno que no permite el avance de la excavación ni entibación inmediata al frente por los continuos desprendimientos tras la voladura:

o Si la sección es grande (más de $15 \mathrm{~m} 2$ ) se pasaba a sección reducida, generalmente a media sección, con el fin de tener el techo más próximo y poder así colocar con mayor facilidad y menor riesgo el sostenimiento adecuado.

El paso de accidentes geológicos importantes del terreno, si eran conocidos de antemano, no suponían mayor contratiempo si estaban bien localizados, que la pérdida de tiempo en franquearlos.

En cambio, los derrumbamientos que se presentaban bruscamente en el mismo frente de avance de la excavación después de una voladura normal, eran los que producían verdaderas extorsiones en la marcha de la obra. Esas "chimeneas" podían ser de proporciones inusitadas, incluso superiores a 100 metros de altura, con constantes desprendimientos de piedras.

No existían conclusiones de tipo general sobre los procedimientos que se empleaban en España para resolver estos contratiempos, que en mayor o menor frecuencia, ocurrieron en todas las galerías de longitud de varios kilómetros.

Corrientemente, la primera "chimenea" era la difícil, ya que para las siguientes, el equipo de obra había adquirido ya cierta práctica no solo en resolverla sino también en pasarla. Un puntal de madera puesto a tiempo y la colocación inmediata de cerchas metálicas, o un simple tratamiento de hormigón proyectado de fraguado rápido, evitaban a menudo, chimeneas que podrían haber paralizado el avance durante varias semanas e incluso meses.

Por tanto, la evitación de formación de chimeneas dependía en gran parte de la pericia de los equipos de excavación, primero respecto del conocimiento (y reconocimiento) del terreno y en segundo lugar, en la rapidez en la aplicación de sostenimientos de emergencia, que luego fueran sustituidos por entibaciones definitivas. 
En terreno blando, entendiendo por tal el que se excava sin explosivos, no era frecuente que existieran galerías de presión, aunque sí existían túneles de canales o de poca carga en este tipo de terreno. En estos casos, el procedimiento utilizado en España fue, generalmente, el "sistema belga" (que fue aplicado por primera vez en el mundo en 1828), que consistía en la galería de avance en bóveda, con entibación de madera, ensanche de la sección con progresión de la entibación, hormigonado de la bóveda definitiva, destroza central si el terreno lo permitía, y en caso contrario, excavación de zanjas laterales y hormigonado de los hastiales por bataches para finalizar hormigonando la solera.

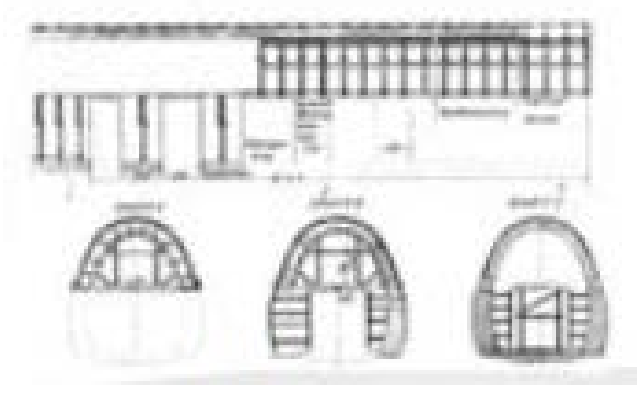

Respecto al revestimiento de las galerías, la construcción de una galería de presión no se podía planear correctamente sin tener en cuenta que la obra en su conjunto estaba formada por tres fases claramente diferenciadas:

- Excavación

- Hormigonado del revestimiento

- Inyecciones

Y cada una de ellas afectaba a la siguiente. Una excavación mal refinada daba lugar a sobreanchos excesivos que luego repercutían en la ejecución del revestimiento, no solo en el coste por metro lineal de galería, sino también en una menor velocidad de avance en el hormigonado, debido al mayor volumen de hormigón que era necesario colocar. Un deficiente cierre de clave en el hormigonado suponía grandes cantidades de cemento o mortero a inyectar posteriormente.

En cuanto al orden de ejecución, entre las fases de excavación y hormigonado del revestimiento, considerando el conjunto de la obra, existían las siguientes clásicas variantes en España:

- Las tres fases se realizaban con entera independencia en cada tramo entre ataques laterales de la galería.

- Excavación y hormigonado del revestimiento simultáneos, bien fuera por tramos cortos en trabajos intermitentes o bien, en el caso de que el 
ancho de la excavación lo permitiese, con los dos tajos de trabajo continuo.

- Excavación y hormigonado del revestimiento, excepto su solera, simultáneos. Posteriormente, el hormigonado de ésta una vez calado el tramo. Esta variante solo era admisible en galerías de presión no muy elevada.

Como norma general, se prefería la primera variante ya que el solape entre tajos en una galería, siempre producía interferencias entre ellos, originando finalmente mayor costo y un mayor plazo general de ejecución de la obra.

La menos aconsejable era, en principio, la segunda variante, debido a que los mismos equipos de personal tenían que realizar trabajos de tan distinta especialidad como eran la excavación subterránea y el hormigonado. Se llevaba a cabo este tipo de variante cuando eran de temer alteraciones del terreno por meteorización, decompresión de la roca, o por filtraciones de agua. Tenía además el inconveniente de que se producían escalones en el suelo delante de la zona revestida, en los que se acumulaba el agua.

La tercera variante era, sin embargo, frecuente en galerías sin presión o túneles de canales. Tenía la ventaja sobre la anterior de que no era preciso levantar la calzada de la solera para realizar la primera fase del revestimiento.

En cualquier caso, e incluso cuando se temía por meteorizaciones de la roca, se prefería aplicar la variante primera, aplicando una capa de gunita u hormigón proyectado, y si en alguna zona no era suficiente la entibación metálica, hormigonando anillos de refuerzo fuera de la sección teórica de la excavación.

Respecto a la limpieza y retirada del escombro y fango antes de colocar el hormigón del revestimiento, ésta era una de las operaciones más engorrosas de la ejecución de toda galería hidráulica. Muy a menudo esa operación de limpieza con chorro de agua y aire, limitaba la velocidad de avance del hormigonado. Por ello, se entendía que era conveniente la ejecución de una presolera de hormigón fuera de la sección media teórica, que por eliminar las desigualdades del terreno, facilitaba el movimiento de los equipos de maquinaria del hormigonado, y especialmente la limpieza inmediata y la colocación del hormigón de revestimiento.

Así se establecía una fase intermedia entre excavación y hormigonado, constituida por el trabajo simultáneo de refino del perfil, limpieza de escombro menudo y hormigonado de la presolera. 
Por otra parte, el hormigonado de las galerías se planteaba, generalmente, sobre la base de una instalación dosificadora en peso de áridos, agua y cemento en el exterior.

Los trenes de vagonetas, con las mezclas secas de cada amasada por separado, llegaban a las proximidades del frente de trabajo, donde sobre carretones estaba montado el equipo o tren de hormigonado constituido por una o dos hormigoneras que alimentaban un cañón o transportador neumático de hormigón. La tubería de 15 a $20 \mathrm{~cm}$. de diámetro, soportada sobre andamio móvil, terminaba en una lanza o tubo que se introducía entre el encofrado y la roca por la parte superior de la sección. Esta lanza podía tomar varias posiciones para verter el hormigón a ambos lados de la clave.

El hormigón transportable por medio de aire comprimido exigía una elevada dosificación de cemento (300 kg/m3 mínimo) y un alto porcentaje de arena fina. Sin embargo, en revestimientos de galerías largas, se penalizaba de alguna manera la calidad del hormigón en beneficio de la rapidez de ejecución.

Cuando se trataba de tramos de revestimiento con doble armadura se solía tener más posiciones de la tubería, en solera, y a media altura si la sección era de diámetro superior a tres metros. En revestimiento con simple armadura, se solía utilizar el mismo procedimiento que cuando se trataba de hormigón en masa.

En galerías de presión en que era preciso un hormigón de mejor calidad que el colocado con cañón, fuera porque la presión interior a que iba a ser sometida la galería la debía soportar en su mayor parte el revestimiento, o porque se tratara de conductos sometidos a fuerte presión, se empleaban bombas de hormigón que transportaban y colocaban el hormigón sin producir segregación y permitiendo un hormigón de menor relación agua/cemento.

En cuanto a los encofrados que se utilizaban, eran principalmente de dos tipos, el encofrado telescópico, casi siempre en galerías de diámetro no superior a 4 metros, y el encofrado de cerchas desmontables y tablas de aluminio o tableros de chapa de acero. La principal ventaja de éste último es que el hormigón puede vibrarse más fácilmente, puesto que el encofrado se iba cerrando a medida que subía el nivel del hormigón, pero tenía el inconveniente de requerir más mano de obra en su manejo.

La longitud de los anillos hormigonados sin junta vertical dependía del sistema de proceso de hormigonado que se empleara, hormigonado continuo o por anillos. 
El hormigonado continuo ya se había empleado en galerías españolas, por ejemplo en la galería de presión del salto de Bao-Bibey, de 4,80 metros de diámetro interior. Su única ventaja respecto al sistema clásico de hormigonado por anillos de 5 a 10 metros de longitud, residía en el mayor rendimiento que se conseguía.

Los inconvenientes de este procedimiento era la formación de las juntas de fraguado longitudinales que inevitablemente se producían cuando, por cualquier causa, se producía una paralización del hormigonado de duración suficiente para que quedara fraguada la capa superior antes de reanudarse el trabajo. Por ese motivo, no se aconsejaba ese método en los tramos de galería en mal terreno donde el revestimiento debía absorber toda o parte de la presión interior del agua. Tampoco era posible en los tramos de doble armadura.

El procedimiento aportaba grandes rendimientos y se debía emplear en tramos largos donde las condiciones de la roca lo permitían desde el punto de vista del proyecto, y en general, en los revestimientos de túneles o galerías sin carga.

Una vez desarrollados los aspectos fundamentales sobre las galerías de los aprovechamientos hidroeléctricos, se abordan a continuación los aspectos de interés relativos a los pozos verticales y sus procedimientos de ejecución antes de los años 70.

Los pozos verticales se clasificaban principalmente en dos grupos:

- Pozos como obra auxiliar de la ejecución de la obra definitiva del proyecto, para el establecimiento de frentes de trabajo en los casos en que no era económica la perforación de galerías de ataque auxiliares:

o Accesos de obra a centrales subterráneas

o Ataques intermedios en galerías o túneles de gran longitud

o Pozos para agotamiento de galerías inundadas

o Apertura de frentes de trabajo entre dos niveles de excavación subterránea

- Pozos como obra definitiva:

o Pozos de acceso a centrales subterráneas

o Pozos de salida de cables o barras en centrales subterráneas

o Pozos de toma de agua en obras hidráulicas hidroeléctricas

o Chimeneas de equilibrio

o Tuberías forzadas en pozo

Los sistemas de ejecución de los pozos variaban en función de la profundidad del pozo y la posibilidad o no de ataque ascendente. 
En los casos, muy frecuentes en centrales subterráneas, de tener acceso por ambos extremos del pozo, era frecuente el avance desde abajo hacia arriba en sección reducida o pozo piloto, para realizar después la destroza hasta completar la sección de la excavación en sentido descendente.

En la central de Aldeadávila, las chimeneas de equilibrio estaban formadas por 4 pozos de sección rectangular de $11 \mathrm{~m}$. x $14 \mathrm{~m}$., prolongado con dos semicírculos de 11 metros de diámetro. Fueron excavados en granito sano y compacto, perforando pozos de avance en sección reducida desde abajo hacia arriba y después la destroza en sentido inverso mediante wagon-drill, realizando previamente el precorte de la roca en el contorno de la sección.

En la central de Torrejón, en el río Tajo, los pozos para el agua de bombeo de 9 m. x 14 m., comunicados en su parte inferior con los tubos de aspiración de las turbinas, se excavaron en pizarras silúricas siguiendo el entonces moderno procedimiento de "cargas colgadas". En primer lugar se perforaron con wagondrill en toda su longitud (aprox. 18 metros) los taladros necesarios para la excavación en toda la sección del pozo piloto. Una vez hecha esa perforación, se dieron voladuras sucesivas de abajo a arriba en tramos de 2 metros de altura a base de cargas de dinamita sujetas a lo largo de una caña que quedaba colgada desde la superficie en el interior del taladro. El escombro de las voladuras sucesivas caía al tubo de aspiración, donde se acumuló todo el correspondiente al pozo piloto.

De esta forma, una vez realizada la perforación de los taladros verticales, en un solo día quedaba excavado totalmente y perfectamente perfilado el pozo piloto. La fase siguiente de excavación consistió en ensanchar la excavación de arriba a abajo, manteniendo como plataforma de trabajo los mismos escombros de las voladuras de ensanche del pozo piloto, cuyo nivel de escombros se regulaba sacando por el tubo de aspiración los escombros por medio de una pala cargadora. A medida que bajaba la excavación, se colocaban pernos de anclaje en las paredes del pozo definitivo.

En otros casos no hay alternativa y se veían obligados a excavar el pozo en sentido descendente. En España era usual utilizar este método para los pozos de cables o barras de las centrales hidroeléctricas, dejando hormigonado el revestimiento a medida que se profundizaba el pozo. Los motivos por los que se usaba podían ser múltiples, como por ejemplo no querer complicar la excavación del resto de la obra con un tajo más a través de los accesos en galerías, o ganar plazo de ejecución en el conjunto de la obra o facilitar la ventilación de la caverna de la central. 
Por este procedimiento se ejecutaron entre otros, los pozos de cables de las centrales siguientes:

\begin{tabular}{|c|c|c|c|c|}
\hline Central & Río & $\begin{array}{c}\text { Profundidad } \\
(\mathbf{m})\end{array}$ & $\begin{array}{c}\text { Diámetro ya } \\
\text { revestido (m) }\end{array}$ & Roca \\
\hline Aldeadávila & Duero & 317 & 5.00 & Granito compuesto \\
\hline San Agustín & Bibey & 227 & 4.80 & Gneis \\
\hline Puente Bibey & Bibey & 202 & 5.70 & $\begin{array}{c}\text { Gneis glanular y } \\
\text { micáceo }\end{array}$ \\
\hline
\end{tabular}

Por ejemplo, las fases de ejecución del último de estos pozos, fueron las siguientes:

- Perforación de barrenos con pegas de 3 metros con martillos pesados.

- Voladura con detonadores eléctricos de microrretardo y dinamita goma 2 especial B, antihumedad.

- Ventilación mediante tubería de 600 mm de diámetro y caudal de aire de $2 \mathrm{~m} 3 / \mathrm{s}$.

- Carga y extracción de escombros con pólipo accionado por aire comprimido y cubos de 1 a $2 \mathrm{~m} 3$ de capacidad, cabrestante y castillete de elevación de tipo minero.

- Hormigonado del revestimiento por tamos de unos 10 metros de altura, correspondientes al avance semanal desde el suelo de la excavación hasta el anillo del tramo anterior.

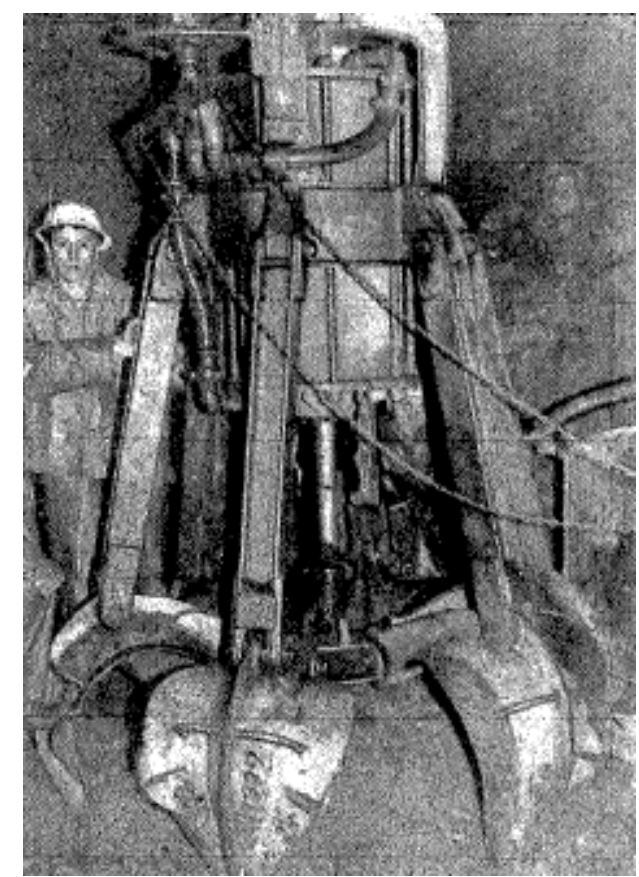

Pólipo neumático de carga de escombros 
Los rendimientos habituales que se obtenían eran los siguientes. En pozos de roca dura y diámetros libres de más de 3,50 metros, podía considerarse normal un avance medio mensual de 35-40 metros a pozo revestido. La mano de obra global era de 2 horas por metro cúbico de excavación sobre el perfil teórico y de 3,2 horas por metro cúbico de hormigón de revestimiento.

Las velocidades de avance anteriores se podían incrementar aumentando la potencia de las máquinas de carga y extracción o bien duplicando la extracción aunque esto supondría un mayor coste unitario.

A continuación se abordan los aspectos más relevantes relativos a la ejecución de tuberías forzadas en el ámbito de los aprovechamientos hidroeléctricos previos a los años 70.

Las tuberías forzadas, como obras de pendiente intermedia entre galerías y pozos, reunían las dificultades de ejecución de ambos tipos de obra subterránea, y se agravaba en ellos la peligrosidad del trabajo desde el punto de vista de la seguridad del personal, mayor conforme mayor longitud tenían los tajos a ejecutar sin ataques intermedios y cuanto mayor era la sección transversal, a parte de la calidad del terreno a efectos de sostenimiento. No se tenía la facilidad de extracción de escombros como en los pozos en los que el personal estaba protegido por plataformas con portones, siendo el único medio de extracción existente hasta esa época, la extracción ascendente mediante plano inclinado o el skip.

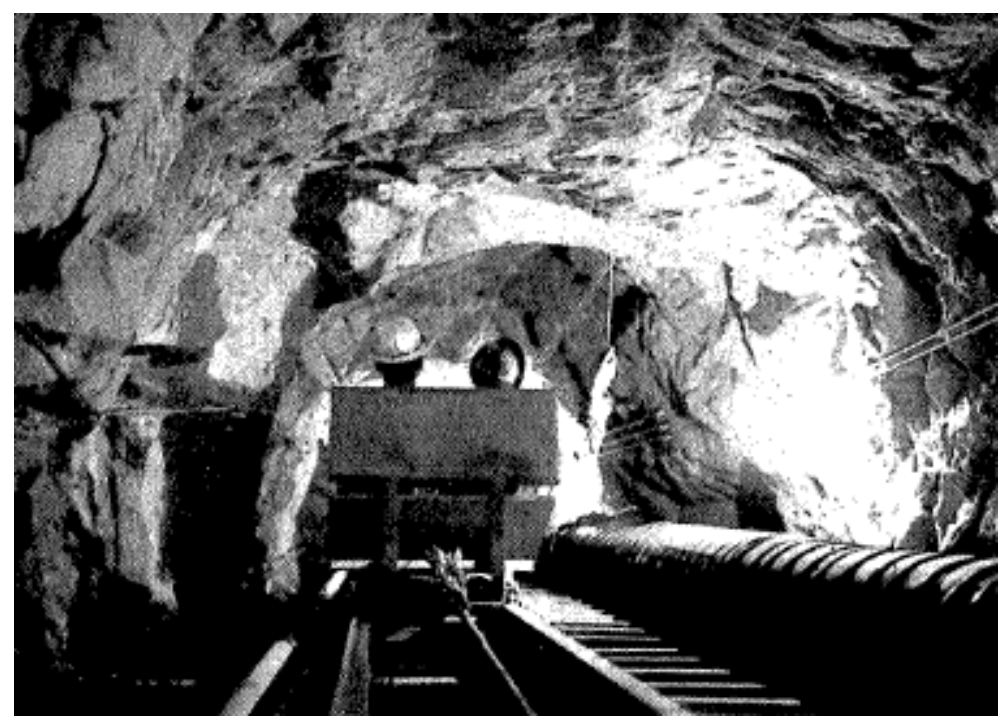

Skip para el acceso de personal y materiales

En las tuberías forzadas, el revestimiento estaba generalmente constituido por tubos, chapa de acero con o sin zunchado y nervios de rigidez, macizados al terreno mediante un hormigón de relleno entre la tubería metálica y la roca. 
Sólo en los saltos de poca altura o en condiciones excepcionales del macizo rocoso, el revestimiento era de hormigón armado.

Las tuberías forzadas verticales no eran habituales y se recurría a ellas o por aspectos relacionados con aspecto del terreno o en saltos de pequeña altura. Un ejemplo de tubería forzada vertical fue la del salto de Miranda, donde en principio se había proyectado una tubería inclinada que, después de conocido directamente el terreno en la excavación del túnel de acceso, fue sustituida por una vertical. Se trataba de cuarcitas en gran parte milonitizadas con capas de arenas silíceas con elevado contenido de agua. En este caso, la ejecución de una tubería forzada inclinada hubiera sido muy penosa. En cambio, el pozo para la tubería forzada vertical, fue excavado en sentido descendente y sostenido el terreno sin grandes dificultades.

En el caso de tuberías forzadas inclinadas, tenía mucha importancia la inclinación que en el proyecto se le daba. Era preferible que fuera la suficiente para asegurar que los escombros de la excavación cayeran por su propio peso, sin peligro de quedar parados en la solera de la galería. Para ello, la inclinación con la horizontal debía ser superior a 45ㅇ. Desde el punto de vista de la construcción, se consideraba que la pendiente más conveniente debía estar comprendida entre los 48 y $50^{\circ}$.

El procedimiento de ejecución más comúnmente empleado en España consistía en excavar primero una galería piloto de sección reducida, que se ensanchaba en una segunda fase de excavación, vertiendo los escombros por la galería piloto. En la base inferior de la galería piloto se recogían en una tolva de carga a los vehículos.

La excavación de la galería de carga solía realizarse en sentido ascendente, con el fin de evitar las operaciones de carga de escombros y también eludir el problema de los agotamientos, que frecuentemente eran necesarios en una excavación descendente.

Un buen ejemplo es la tubería forzada del Salto de Bao-Puente Bibey cuya inclinación fue de $50^{\circ}$ con la horizontal, con 370 metros de la longitud del tramo entre codos superior e inferior y 4,50 a 4,70 metros el diámetro de la excavación. Es un ejemplo adecuado ya que se realizó la galería piloto en ambos sentidos con el fin de ganar tiempo y también de reducir la longitud del tramo ascendente. Estaba previsto, no obstante, abandonar el avance descendente si hubieran aparecido manantiales cuyo caudal requiriese la instalación de bombas mayores que las neumáticas de tipo ordinario en los tajos de excavación. No aparecieron tales filtraciones con lo que se pudo calar la galería 
piloto avanzando 200 metros desde abajo y 135 metros desde arriba. El tramo inferior de la tubería, así como los ramales a turbinas y el distribuidor, fueron excavados independientemente del tramo principal, y extraídos los escombros desde el acceso a cimientos de la central.

La técnica utilizada en los avances de la galería piloto fue totalmente distinta entre uno y otro avance. En el descendente, atacado desde la cámara de válvulas de la cabeza de la tubería, el problema fundamental era la extracción del escombro. Sin embargo, en el avance ascendente, la principal dificultad consistía en el acceso al frente y el establecimiento de la plataforma de trabajo para la perforación después de cada voladura.

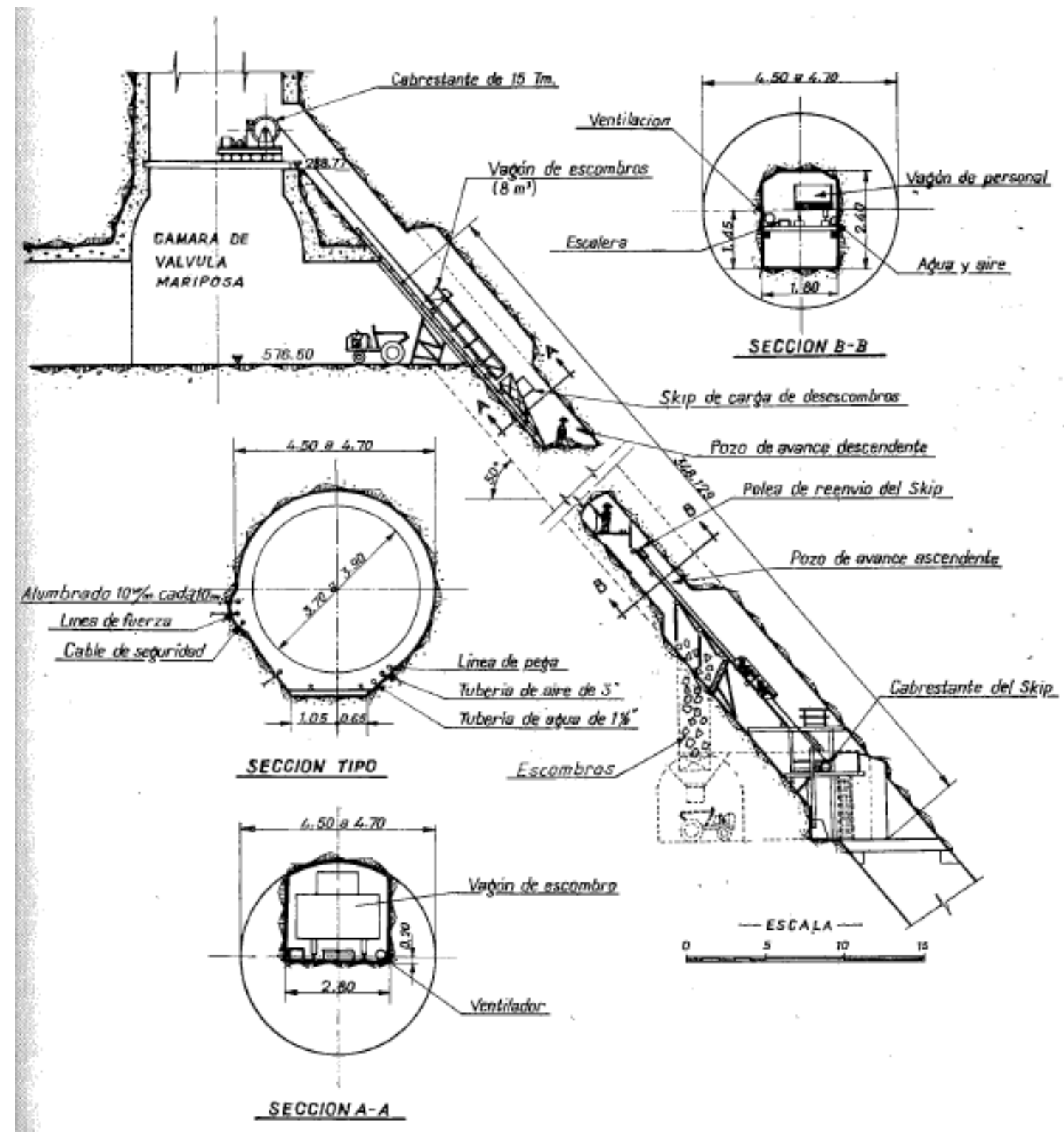


La excavación de ensanche a la sección definitiva se realizó de arriba abajo. Para el acceso del personal se construyó un carretón con frenos de seguridad, y para el trabajo de perforación en el frente, una plataforma móvil de planta poligonal, que cerraba el hueco de la excavación.

Los rendimientos obtenidos en los avances fueron los siguientes:

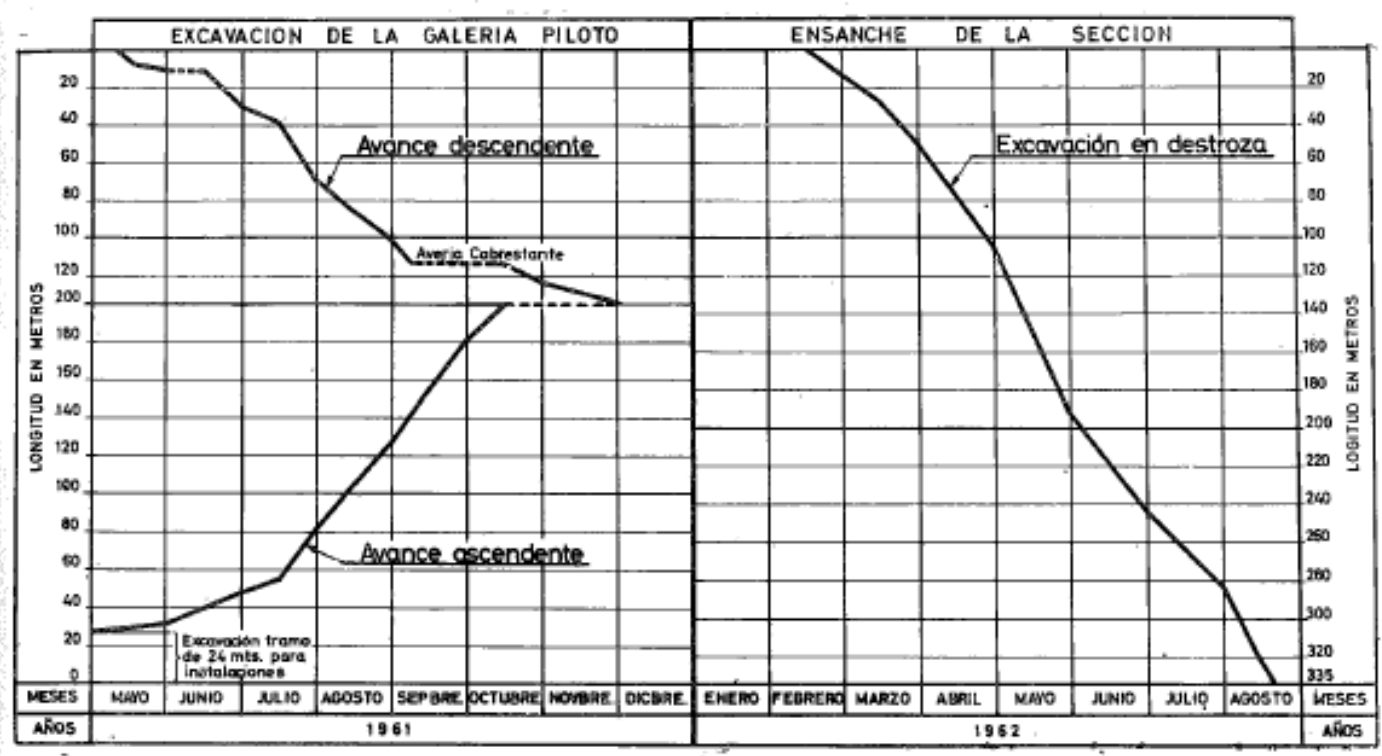

Respecto del revestimiento de las tuberías forzadas, que como se ha dicho con anterioridad, solía ser de chapa de acero y relleno de hormigón entre ésta y la roca, era frecuente en España que el hormigón de relleno fuera inyectado, generalmente, de tipo Prepakt.

Salvo en el Salto de Cornatel que se empleó mortero inyectado, se utilizó el procedimiento del párrafo anterior, por ejemplo, en los saltos de Tranco de Beas, San Esteban, Aldeadávila, San Agustín, Bao-Puente Bibey, etc.

Las fases de ejecución fueron en todos ellos similar describiéndose a continuación el del Salto de Bao- Puente Bibey. En este caso, los tubos de 6 metros de longitud y diámetro variable de 3,70 y 3,90 metros eran transportados desde el taller y acopiados en una explanada a la cota 626. Un pórtico-grúa de $25 \mathrm{Tm}$. los bajaba por un pozo de 40 metros de profundidad y 8 metros de diámetro hasta la cámara de la válvula mariposa del origen de la tubería en la que un carretón especial tomaba el tubo para transportarlo por el interior del pozo inclinado hasta su posición. La presentación del tubo al anterior ya montado y soldado se realizaba mediante los gatos que para este fin llevaba montados el carretón. Una vez presentado el tubo, se sujetaba por puntos de soldadura al anterior. 
En estos momentos se iniciaba la soldadura transversal y se retiraba el carretón de transporte de los tubos. Montados y soldados los tubos (tramo de 12 metros de tubería), se paralizaba la operación de soldadura y se daba comienzo a la colocación de la grava del hormigón Prepakt. La inyección del mortero se realizaba por tramo de cuatro a seis tubos en tajo independiente por debajo de la plataforma de soldadura.

Posteriormente y transcurridos por lo menos quince días de la inyección del mortero se procedía a la consolidación de la roca próxima a la tubería mediante taladros perforados través de los agujeros de la chapa, utilizados anteriormente en la inyección del mortero.

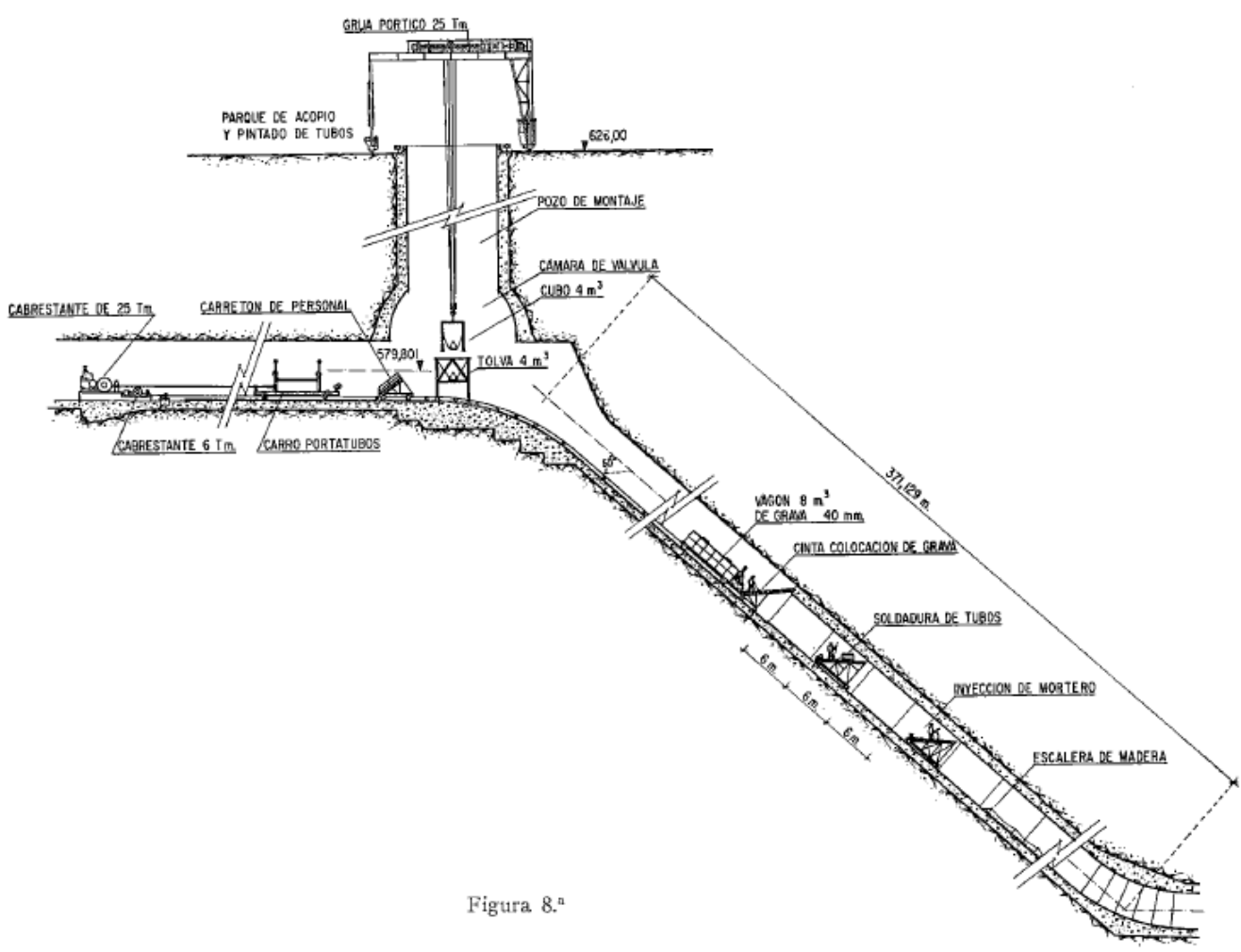

Con el fin de evitar el abollamiento de la chapa durante la inyección de consolidación de la roca que se realizó a presiones elevadas (de 10 a 30 $\mathrm{kg} / \mathrm{cm} 2$ ) y variables según la profundidad, se inyectó a través de obturadores que impedían el paso de la lechada de cemento entre la chapa y el hormigón de relleno.

Como operación final se soldaron tapones roscados en los taladros de inyección de la tubería y se repasó la pintura en la solera y en las juntas entre tubos. 
Dejando ya las tuberías forzadas, a continuación se describen los aspectos principales de las centrales subterráneas como obras complejas que son y ya lo eran, en España antes de los años 70.

En España, ya entonces se habían construido centrales subterráneas en toda clase de terrenos, pasando por toda la gama de macizos rocosos más o menos consistentes. Por ello, también las técnicas de construcción fueron muy diversas.

A continuación se detallan los procesos constructivos de cuatro de ellas, ejecutadas en terrenos muy diferentes por lo que se entiende que pueden aglutinar la mayor parte de la casuística que se dio en España previamente a los años 70. Éstas son las siguientes:

- Centrales subterráneas en buen terreno:

o En macizo rocoso compacto de roca granítico homogénea: Aldeadávila.

o En macizo gneísico con marcadas litoclasas, a veces rellenos de arcilla: Puente Bibey.

- Centrales subterráneas en mal terreno:

o En macizo rocoso triturado con alternancias en la roca siendo ésta dura y frágil: Miranda

o En macizo rocoso de escasa consistencia, aunque homogéneo, en roca blanda y meteorizable: Torrejón

En cuanto a la excavación de centrales en muy buen terreno, y tomando a la central de Aldeadávila como ejemplo de esta tipología, su ejecución aplicó las posibilidades modernas de la técnica en excavaciones subterráneas, tanto por su magnitud como por la calidad de la excavación y por los medios empleados en su ejecución. De hecho, en esa época se constituyó como el salto de mayor potencia de Europa (756.000 KVA).

Se emplearon martillos perforadores rápidos Atlas BBD 41 W., palas cargadoras Eimco 105, excavadoras Ruston Bucyrus de 1,5 m3 de capacidad, vehículos de transporte de escombros, perforadoras Wagon-drill, carretones andamios de peforación, voladuras eléctricas, etc. todo ello combinado con una moderna tecnología en los planes de los barrenos y replanteo preciso de éstos. Por todo ello se consideraba que las excavaciones del Salto de Aldeadávila habían sido una réplica de la técnica de excavación de las grandes centrales subterráneas suecas. 

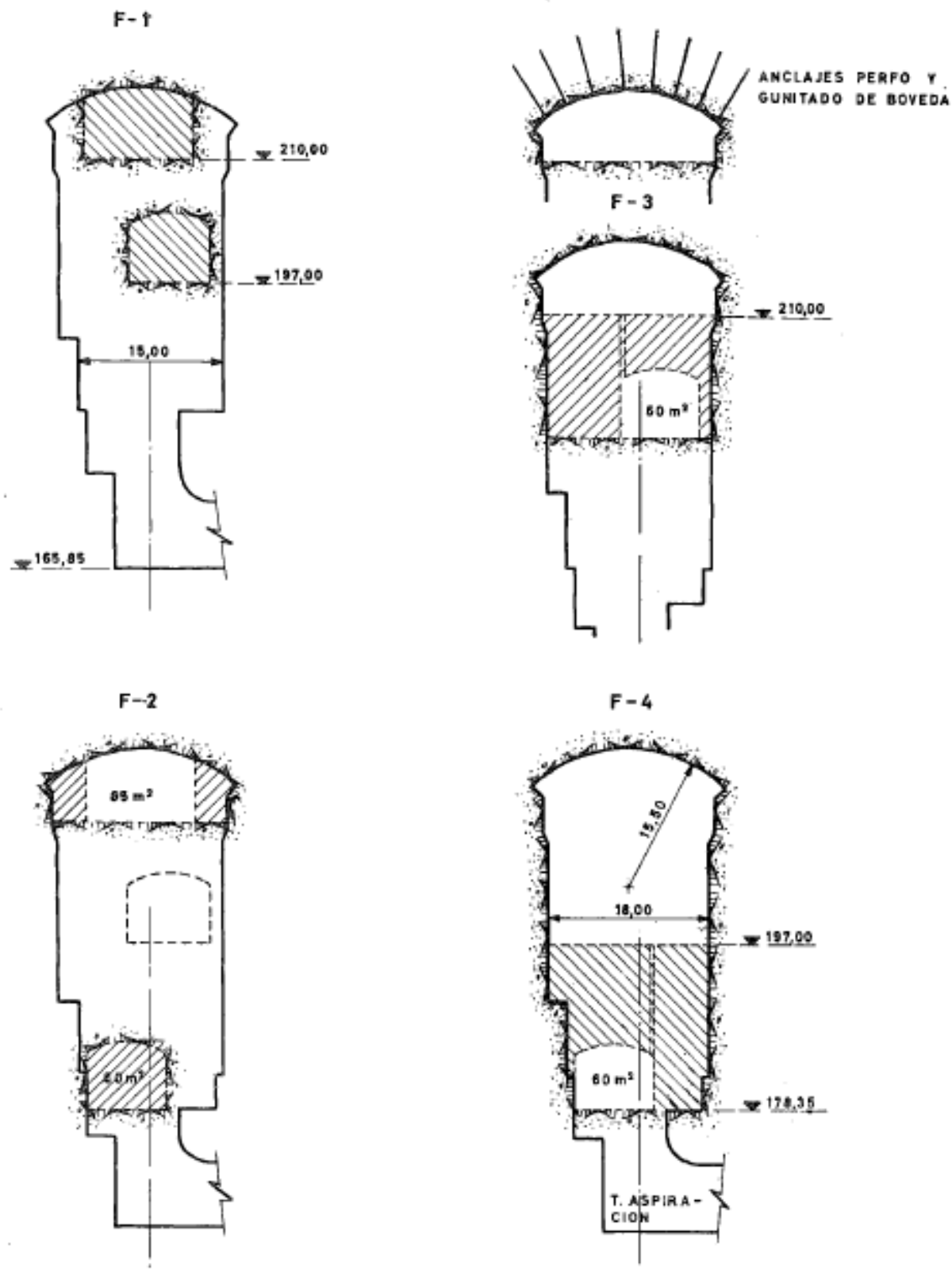

ROCA : GRANITO COMPACTO

Fue muy buena la calidad del recorte de las superficies excavadas, en las que quedaron marcadas las medias cañas de los barrenos una tras otra, sin producir agrietamiento de la roca que ha quedado in situ, así como la perfección de las formas geométricas de las secciones transversales. 


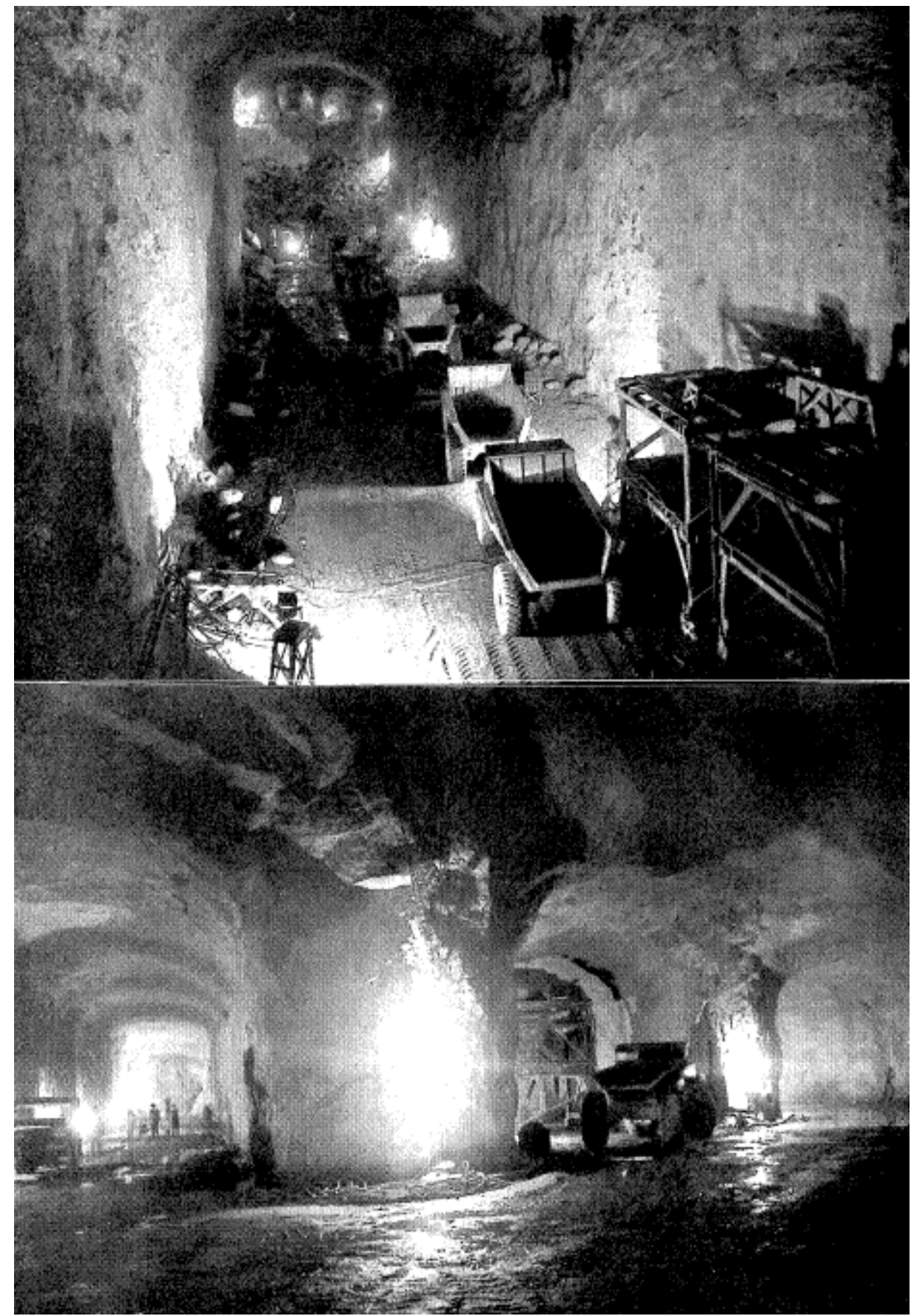

La caverna principal no requirió el abovedado con hormigón, sino que fue suficiente con una capa de gunita después de haber reforzado el techo con pernos de anclaje tipo perfo.

Como ejemplo de excavación de centrales en terreno bueno de tipo medio, se describen algunas consideraciones relativas a la construcción de la central de Puente Bibey. 
Las distintas fases de excavación de la nave principal fueron las siguientes:

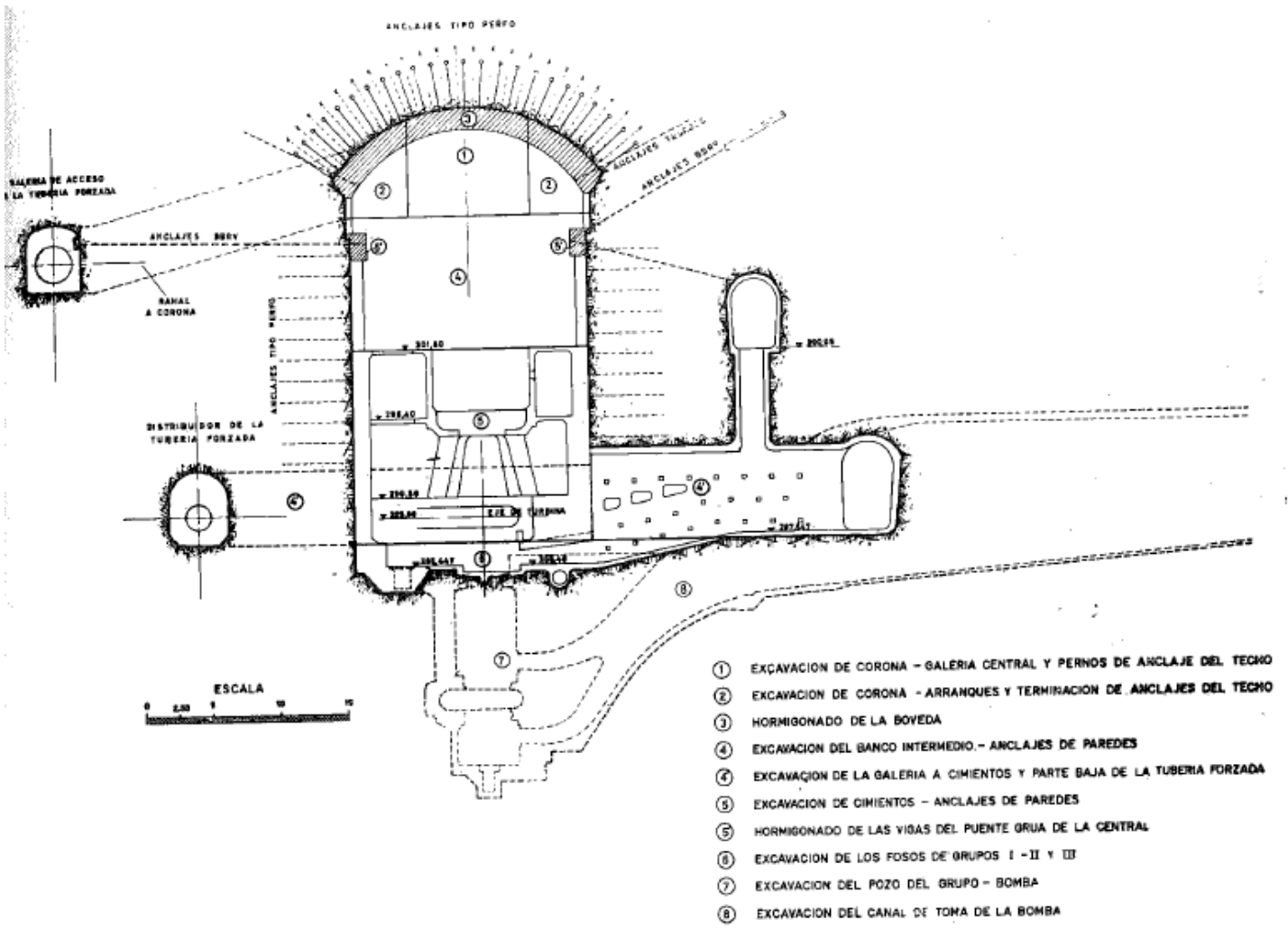

Se establecieron tres niveles de ataque de las excavaciones con acceso para camiones de $10 \mathrm{Tm}$ y palas cargadoras. Tanto las galerías de acceso interior como la iniciación de las distintas fases de la excavación interior fueron realizados con martillos Atlas BBD $41 \mathrm{~W}$ sobre andamios de perforación, trasladados con camiones volquete. La carga de escombros con dos palas Eimco 105 y el transporte de escombros con cinco dumper Muir Hill de 5,5 Tm., y cuatro camiones volquete de $10 \mathrm{Tm}$. En la excavación de la galería central se empleó una pala Nordest de $800 \mathrm{l}$. con brazo corto, y en los bancos de excavación intermedio y de cimientos se empleó, además una pala excavadora Menck de 1,5 m3. Las voladuras se realizaron con detonadores eléctricos y explosores de condensador.

Desde el principio de la excavación se prestó especial cuidado en evitar los desprendimientos de lajas o bancos de roca, para lo cual se realizaron numerosos anclajes de distintos tipos. En el techo de la bóveda se colocaron sistemáticamente anclajes tipo perfo de 4 a 6 metros de longitud. En las paredes de la caverna se colocaron anclajes de este mismo tipo, otros de mayor longitud, hasta 15 metros, tesados con gato hidráulico especial.

Además de los anclajes de sostenimientos necesarios, únicamente para la ejecución de la obra se habían realizado otros de proyecto. La bóveda de hormigón de la caverna se había anclado en sus arranques mediante pernos 
tesados con gato, de ocho metros de profundidad. Las vigas del puente grúa se comprimieron contra las paredes mediante anclajes de cables formados por hilos de alambres de acero tipo B.B.R.V. tesados a 80 Tm. cada uno.

También se emplearon anclajes tipo Barredo, de $40 \mathrm{Tm}$. por unidad para comprimir lateralmente los esbeltos macizos de roca que se quedaban entre los canales de descarga de las turbinas.

Se vigiló el comportamiento del macizo rocoso durante la excavación utilizando el aparato de auscultación de los ruidos internos del macizo denominado "microseism", así como la deformación de las paredes verticales de la caverna en tres secciones transversales mediante regletas graduadas, no apreciándose deformaciones superiores a dos milímetros.

Como ejemplo de excavación de centrales en mal terreno, de roca triturada, se describen detalles constructivos de la central de Miranda.

Su macizo rocoso está formado por bandas de cuarcitas muy fragmentadas, arenas silíceas y pizarras. El sistema de ejecución una vez excavado y revestido el túnel de acceso consistió en realizar una galería de clave de sección reducida en la bóveda a la que se llegó por medio de una galería en plano inclinado. Terminada la galería de clave se procedió al ensanche y hormigonado de la bóveda a medida que avanzaba la excavación.
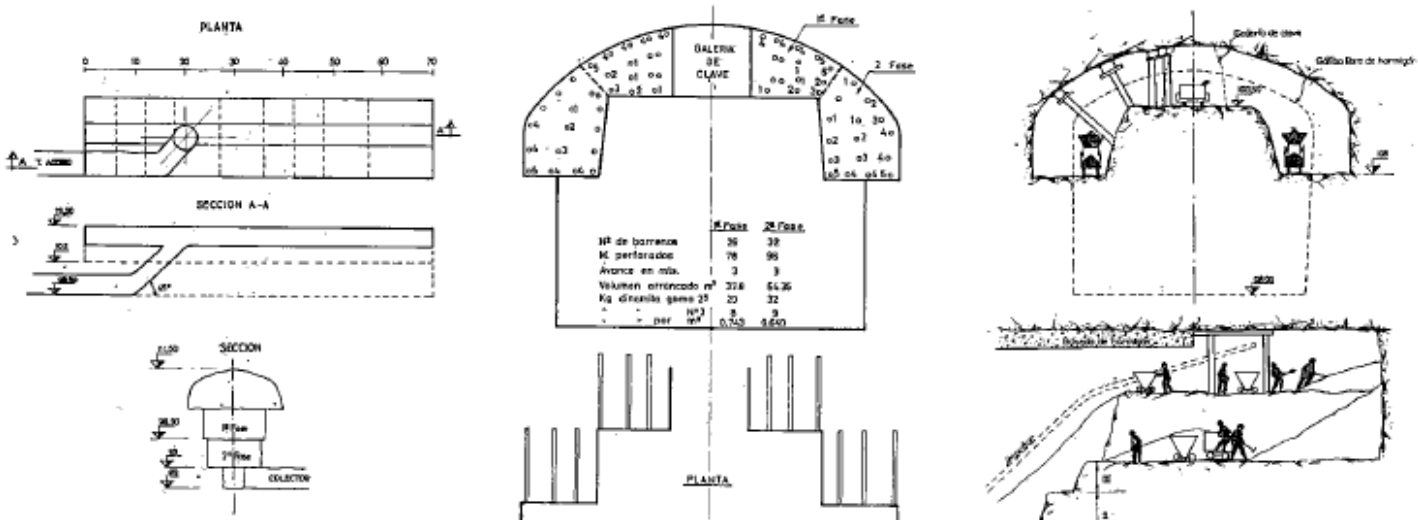

SALTO DE MIRANDA CENTRAL SUBTERRANEA

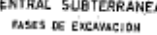
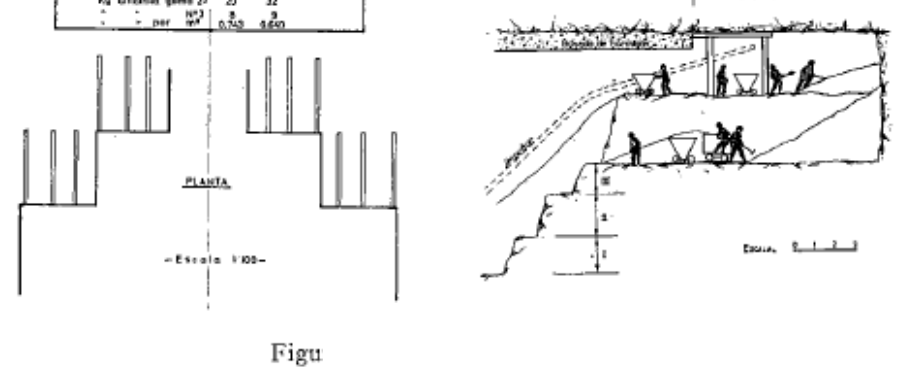

La obra requirió fuerte entibación de madera. La entibación de madera requería operarios especialidad de gran calidad como artesanos. 
Hormigonada la bóveda se excavó por bancos de 4 metros de altura hasta el fondo de la central, cuya parte más baja se extrajo por los canales de desagüe de las turbinas. El hormigonado de la central no presentó dificultades especiales.

Como ejemplo de excavación de centrales en roca blanda y esquistosa se van a describir detalles constructivos de la central del Salto de Torrejón que aprovecha las aguas de los ríos Tajo y Tiétar.

Fue en su día, un ejemplo en España de la entonces moderna técnica del precorte de la excavación en roca blanda.

La técnica del precorte just-spliting consistía en perforar taladros muy próximos y de cierto diámetro siguiendo el contorno del perfil de la excavación a más profundidad que la de avance de las pegas. Para el buen resultado del método era fundamental que los taladros fueran perfectamente paralelos, por lo que habían de realizarse con martillos o perforadoras guiadas. En Torrejón se realizaron con wagon-drill o con gradas tipo Coromat sujetas a los andamios de perforación.

Generalmente las longitudes de los taladros de precorte se habían limitado a 16 metros en los taladros verticales o casi verticales y a 10 metros en los horizontales.

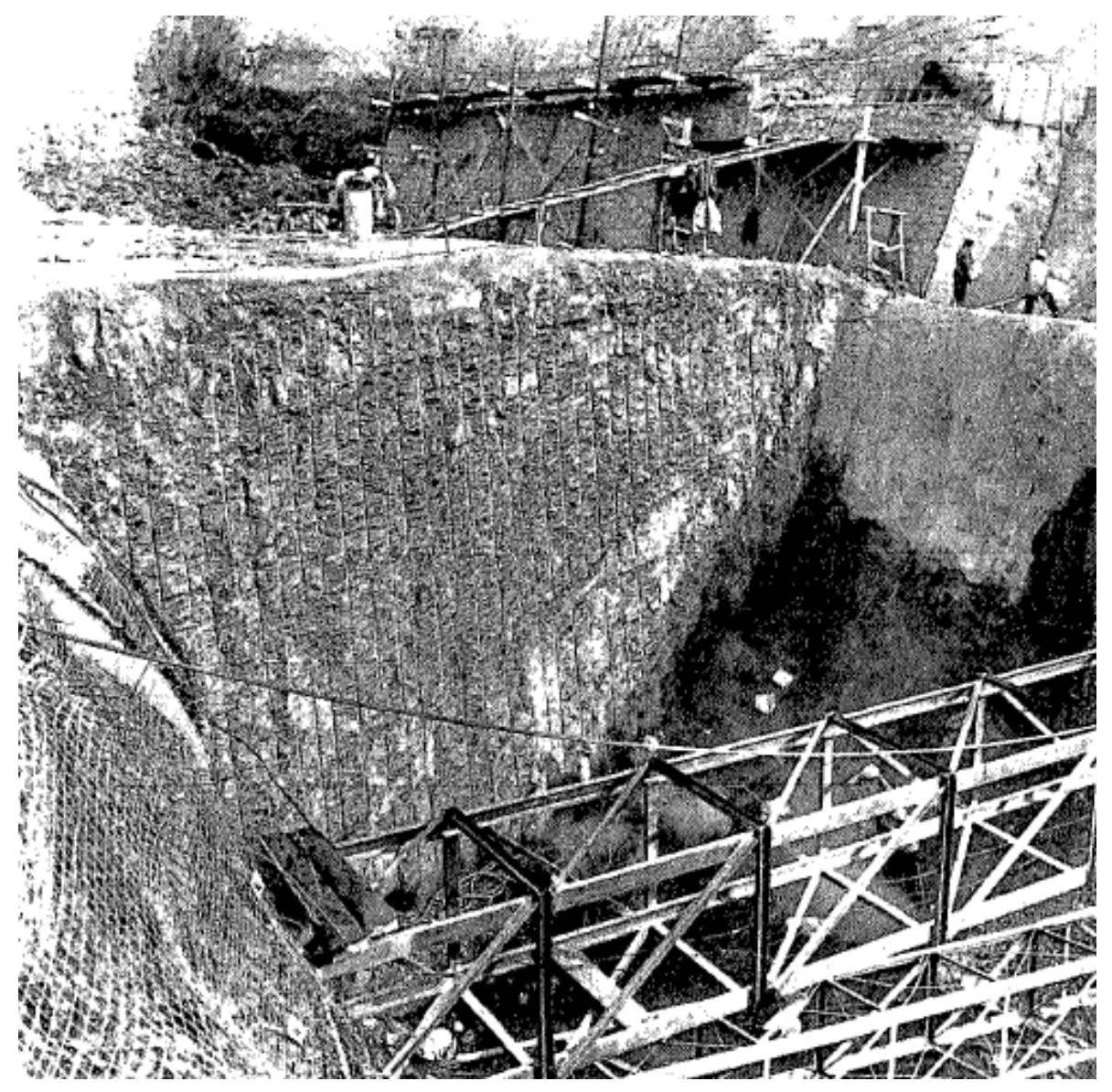


La distancia entre los taladros y la cantidad de explosivo variaba según la calidad de la roca, incluso en un mismo taladro, en función de la dureza de los estratos atravesados en la perforación de los taladros.

La disminución de la densidad de carga de explosivos se realizó colocando separadores de madera entre los cartuchos de dinamita.

Para conseguir que se mantuviera la superficie deseada de la excavación en las voladuras, tanto en su forma como en su posición, se realizó un prearmado. Con ello se consiguió reducir al mínimo los sobreanchos del hormigón definitivo y se evidenció como un buen método de sostenimiento del terreno cuando no existían empujes disimétricos de consideración.

El prearmado de Torrejón se realizó con barras de acero de 30 a $40 \mathrm{~cm}$. de diámetro colocadas en taladros de 57 a $64 \mathrm{~mm}$ de diámetro intercalados entre los taladros de precorte citados anteriormente. El extremo saliente de las barras se apoyó en una cercha metálica, realizándose las voladuras por tramos cortos hasta dejar unos dos metros de zona prearmada sin excavar.

Entonces se realizó el precorte y armado del tramo de los 8 a 10 metros siguientes, continuándose las pegas apoyando las barras de prearmado en cerchas metálicas o arcos de hormigón a medida que avanzaba la excavación.
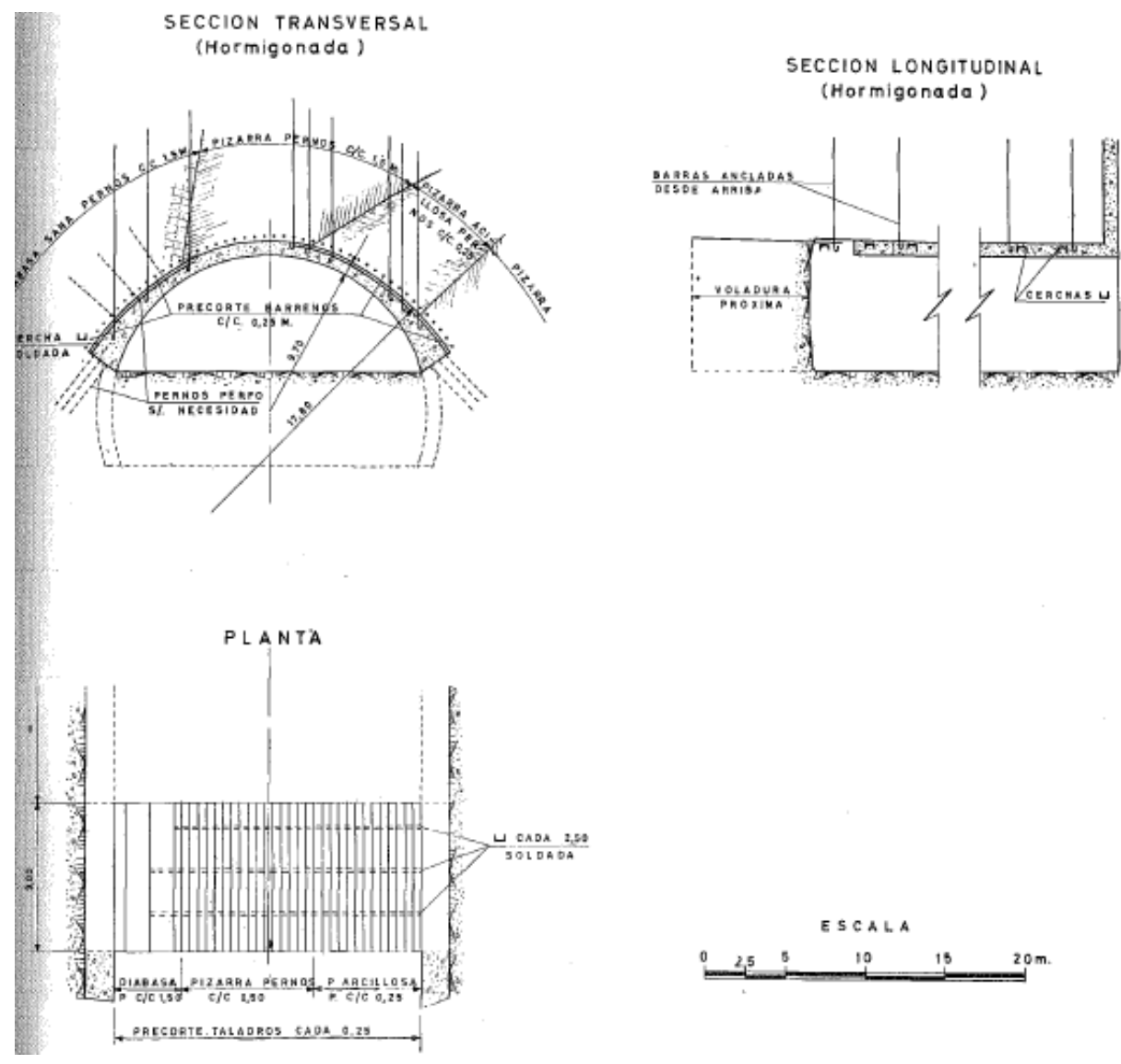
Mediante este método se realizó la excavación de la bóveda central de Torrejón en la que además se colocaron anclajes tipo perfo y una capa de gunita reforzada con barras transversales curvas soldadas a las longitudinales del prearmado. Posteriormente se hormigonó la bóveda definitiva antes de continuar la excavación de la nave principal.

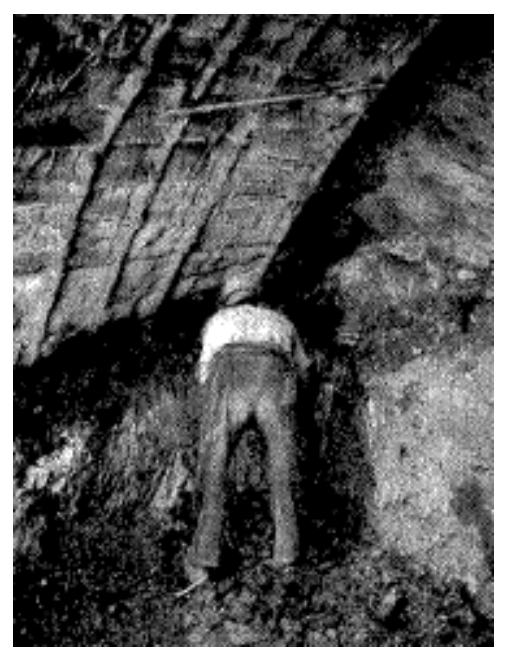

En los cortes verticales o próximos a la vertical, era más conveniente realizar el prearmado en un plano más profundo al paralelo a la superficie que ha de dejarse excavada, separada del orden de un metro. Además era aconsejable colocar anclajes inyectados con mortero o de tipo perfo normales a la superficie.
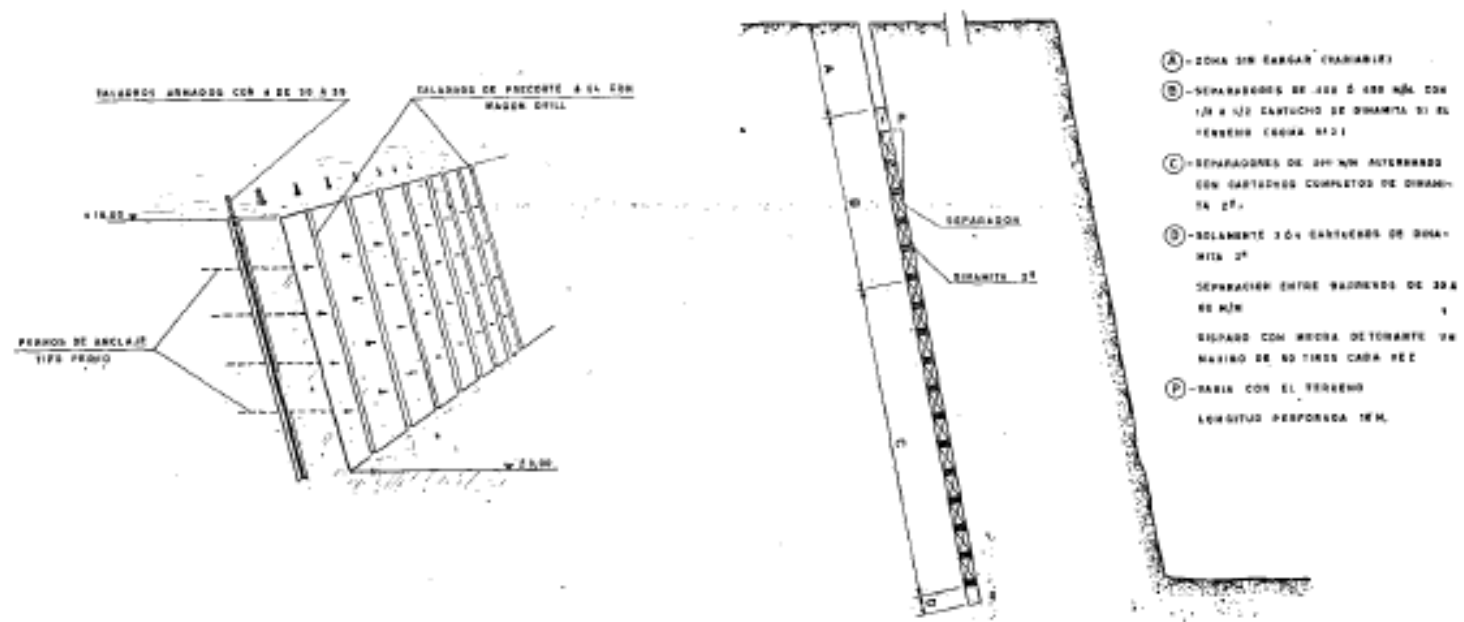

Para eliminar la posibilidad de meteorización se cubría además la superficie con una capa de gunita u hormigón proyectado que si era de algún espesor, producía a su vez un efecto bóveda nada despreciable. Con todo el proceso, los resultados eran la ejecución de grandes cavernas de roca blanda sin necesidad de entibaciones simultáneas al avance de la excavación. 
Abordando ya el hormigonado de las centrales subterráneas, en general, indicar que era corriente que los trabajos de hormigonado se solaparan en alguna de sus fases con las excavaciones, lo cual no dejaba de ser una dificultad debido a las interferencias que se producían en ambos tipos de tareas. Por ejemplo, las voladuras se tenían que interrumpir hasta el primer endurecimiento del hormigón, los encofrados se deterioraban con la proyección de piedras de las voladuras, etc.

Por ello, se intentaban evitar los solapes de ambos trabajos o por lo menos, reducirlo al mínimo.

Era casi regla general que el hormigonado de la bóveda del techo de la central se hormigonara al finalizar o simultáneamente con la excavación de la corona.

El resto de la central cuando la central se había excavado en terreno bueno, se podía iniciar una vez terminadas las excavaciones de la nave principal.

Los procedimientos utilizados en España en algunas centrales consistían en fabricar el hormigón en una instalación de hormigoneras situadas en el exterior, transportando el hormigón en mezcladores o agitadores sobre camión hasta el interior de la nave principal. La distribución o transporte a los tajos de esta nave se realizaba frecuentemente con bombas de hormigón.

\subsection{EVOLUCIÓN TECNOLÓGICA ESPAÑOLA A PARTIR DE LOS $\underline{\text { AÑOS } 70}$}

A partir de los años 70, en general en España, se siguen utilizando principalmente los métodos convencionales de Perforación y Voladura y se introduce el NATM (New Austrian Tunnelling Method) que más adelante se detalla. La maquinaria empleada ha sido máquinas de perforación, martillos de perforación con empotrador neumático, jumbos de 2 brazos, robojet de gunitado, manipulador telescópico, boomer, etc.

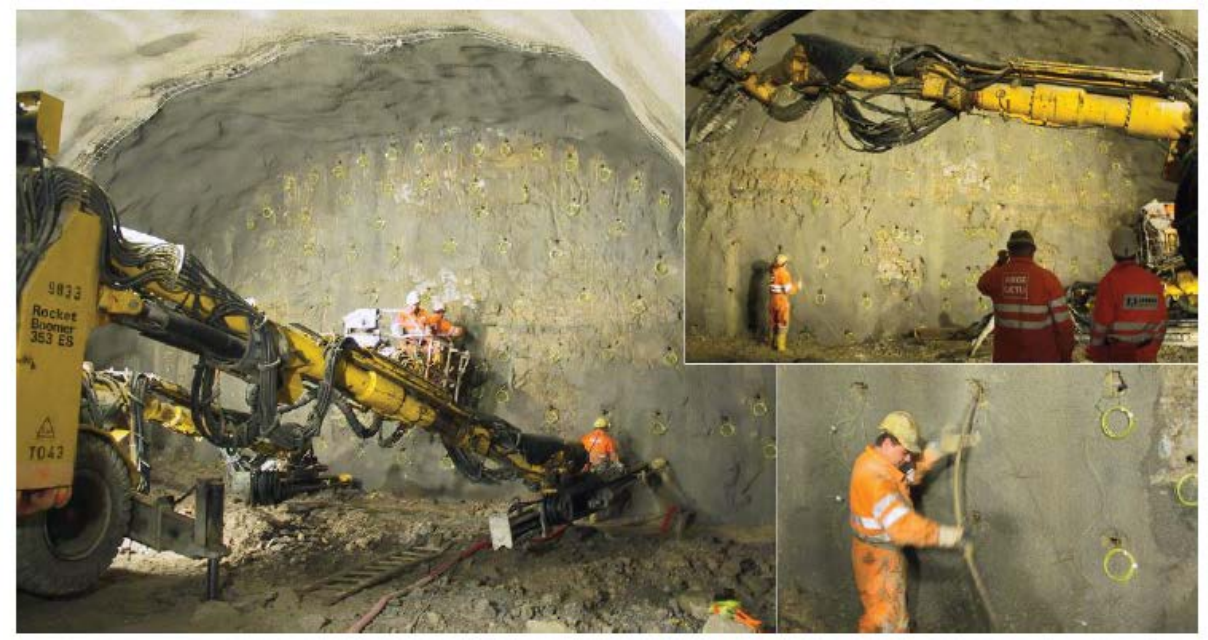


Por ejemplo, se han aplicado estos métodos convencionales de perforación en los saltos de Miranda, Jarés, Vallat, Sobradelo, Valdecañas, Aldeadávila, Ricobayo II, Millares II, Cortes-La Muela, La Muela II, Arnoya y Peneda, Arroibar, Anllo, Avia, San Esteban II, etc.

En algún caso, como es en Cortes-La Muela y en San Esteban II, se ha empleado también el Raise Borer.

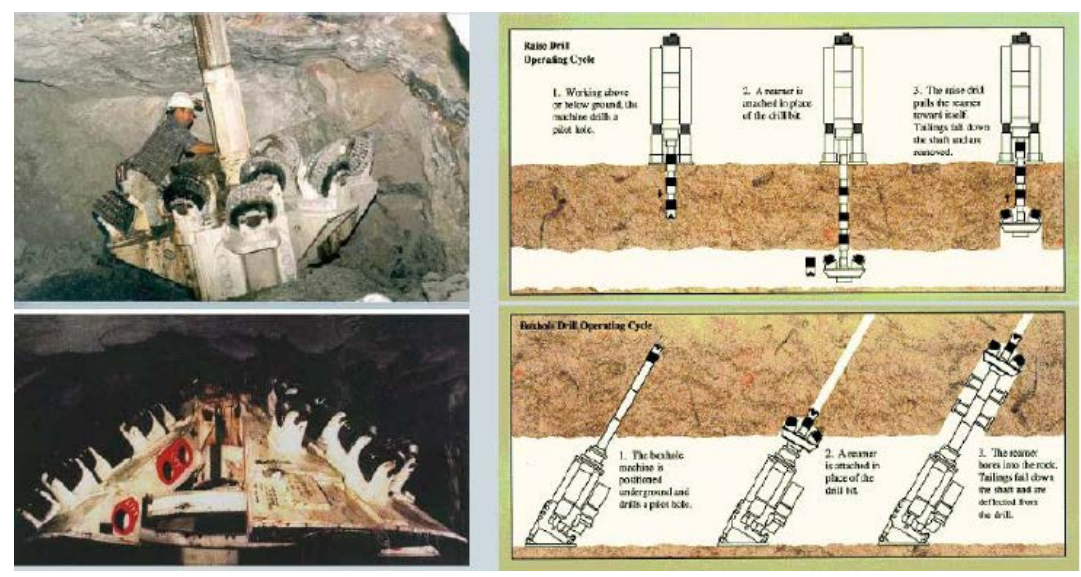

La construcción de grandes aprovechamientos hidroeléctricos con centrales subterráneas, ha sufrido durante bastante tiempo un parón en su desarrollo en España.

Desde la construcción en los años 80 del gran complejo de Cortes - La Muela, en el que se emplaza la central subterránea Cortes I, y en la segunda mitad de los años 90, la central subterránea de Millares II, ambas propiedad de Iberdrola, prácticamente no se ha desarrollado ningún nuevo proyecto hasta el siglo XXI en que se iniciaron los trabajos para la ampliación de la central de Cortes antes mencionada.

La construcción de San Esteban II, cuyas obras subterráneas empezaron en 2008 y acabaron en 2013, puede marcar, con aquélla, el comienzo de una nueva etapa para este tipo de actuaciones.

Se describen a continuación detalles interesantes de la construcción de la central de San Esteban II, como representación de los procedimientos constructivos utilizados en España en la actualidad para la ejecución de obras subterráneas en aprovechamientos hidroeléctricos.

La historia de la explotación hidroeléctrica de la cuenca del Sil comienza en 1.945. El 23 de septiembre de 1.956, se inauguró oficialmente el Salto de San Esteban. 
Entonces era la central hidroeléctrica más potente de Europa. La central es de tipo exterior con cuatro grupos y una potencia total instalada de 265,48 MW.

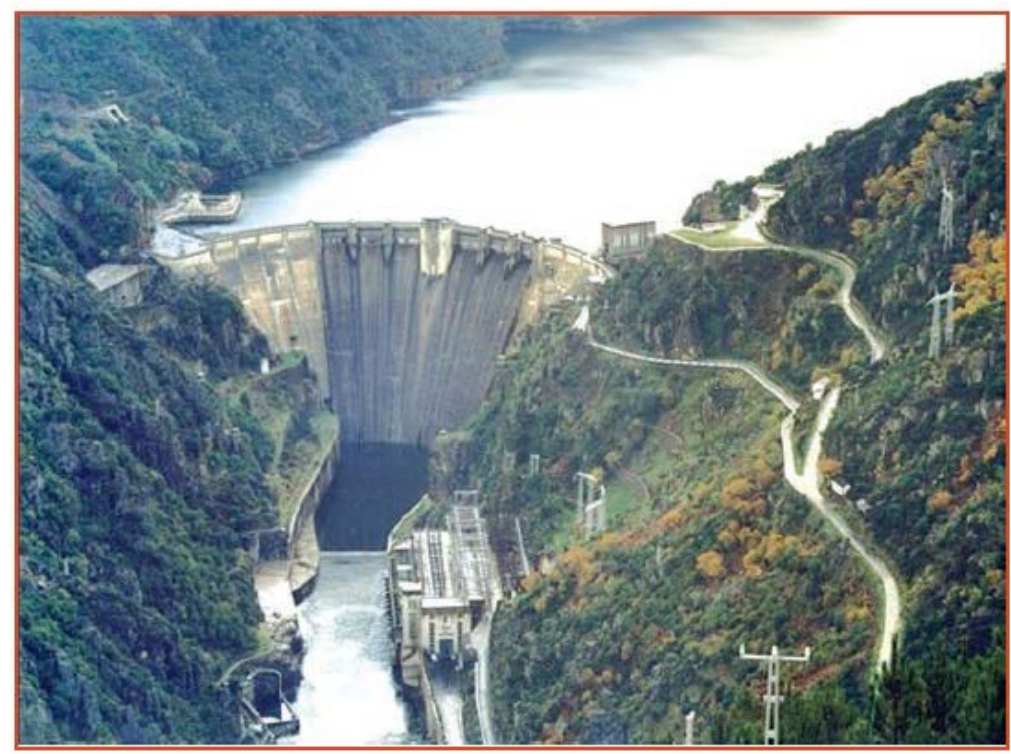

La central hidroeléctrica San Esteban, puesta en servicio a mediados de la década de los años 50 del siglo XX, es el penúltimo salto hidráulico del Sistema Sil explotado por Iberdrola Generación, S.A.U. antes de que este río desemboque en el Miño, a escasos $9 \mathrm{~km}$ de distancia. Consta de una central de cuatro grupos, instalada inmediatamente aguas abajo de la presa de San Esteban, por su margen izquierda.

La central hidroeléctrica San Esteban II que se describe a continuación, incrementa la potencia de este salto mediante la construcción de una nueva central subterránea, emplazada dentro del macizo rocoso que sustenta la margen izquierda de la presa.

El emplazamiento del salto se encuentra dentro de la denominada Zona de Galicia Tras-Os-Montes, área delimitada por el cabo Ortegal, Órdenes, Bragança y Morais, en el cuadrante noroccidental del Macizo Hespérico. Esta zona delimita al Este con la franja del Anticlinorio de Ollo de Sapo, y al Sur con la Zona Centro-Ibérica.

En cuanto a la calidad del macizo, las excavaciones llevadas a cabo en la construcción de la central de San Esteban II, se desarrollaban en dos litotipos bien diferenciados: granito de dos micas y diques de naturaleza diabásica.

En general, la calidad del macizo rocoso granítico presentaba fuertes variaciones; el índice RMR oscilaba entre los 40 y los 70 puntos, mientras que, el índice de calidad Q fluctuaba entre los 0,5 y 20 puntos. Los ensayos de 
compresión a resistencia de la roca matriz mostraban resultados variables: entre los 35 y $105 \mathrm{MPa}$.

Durante la construcción de la central de San Esteban se interceptaron cuatro (4) diques y un (1) filón de naturaleza diabásica. El RMR de los diques oscilaba entre los 30 y 45 puntos (calidad mala-regular) mientras que la $Q$ de Barton arrojaba valores comprendidos entre los 0,2 y 1,5 puntos (calidad muy malamala).

Atendiendo a estas clasificaciones geomecánicas, resultó necesaria la aplicación de tratamientos especiales en los tramos de galería y/o conducción excavados en este litotipo.

De acuerdo con los ensayos de compresión simple, realizados durante la campaña de investigación geotécnica de noviembre de 2007, la resistencia a compresión simple de la roca intacta, oscilaba entre los 5 y los $53 \mathrm{MPa}$.

Las filtraciones de agua inventariadas en el circuito subterráneo de San Esteban II, fueron escasas y muy sensibles a las precipitaciones. No obstante, el deshielo y las lluvias torrenciales acaecidas durante los meses de febrero y marzo de 2010, incrementaron el número y caudal de dichas surgencias.

En cuanto a las excavaciones para la construcción de la obra civil de la central, el procedimiento general de la construcción fue el siguiente. A continuación se representa el perfil del esquema general de la obra y una perspectiva tridimensional del conjunto subterráneo.

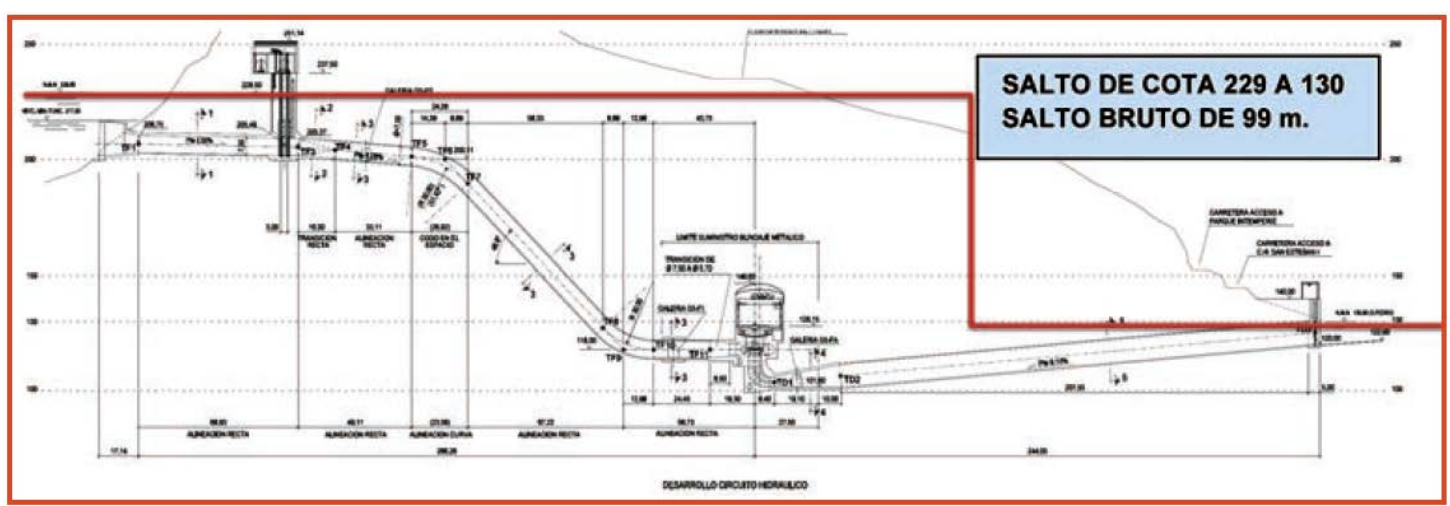




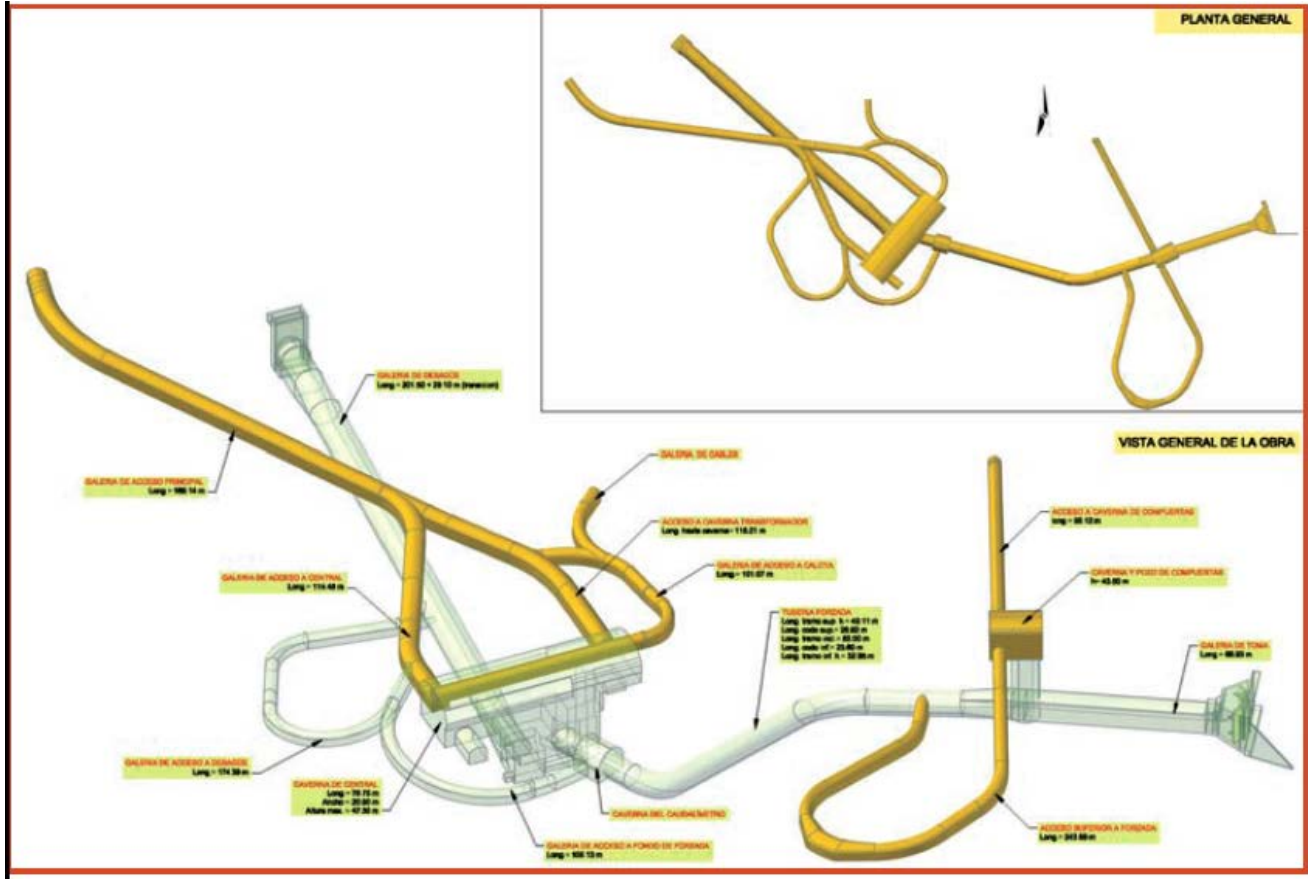

Las excavaciones se realizaron en terrenos constituidos por granitos con distintos grados de meteorización y fracturación. De forma general se empleó la técnica de perforación y voladura y utilizando diferentes tipos de sostenimientos: hormigón proyectado, bulones de varias longitudes y diámetros y, más ocasionalmente, cerchas metálicas.

El empleo de explosivos, por encontrarse próximo a una presa, una central hidroeléctrica y un parque exterior de transformación, exigió llevar un rígido control de las vibraciones producidas en las voladuras y acomodando los planes de tiro a las características de la roca, con el objeto de minimizar los efectos sobre las instalaciones existentes.

En cuanto a los accesos subterráneos, se resumen a continuación dichos accesos definiendo longitudes y secciones de los mismos.

\begin{tabular}{|c|c|c|c|}
\hline TRAMO & LONGITUD & DIMENSIONES & SECCION \\
\hline G-1 & $400 \mathrm{~m}$. & $6,70 \mathrm{~m} \times 6,7 \mathrm{~m}$. & $41 \mathrm{~m}^{2}$ \\
\hline G-2 & $95,12 \mathrm{~m}$. & $4,5 \mathrm{~m} \times 6,2 \mathrm{~m}$. & $28 \mathrm{~m}^{2}$ \\
\hline G-5 & $523,2 \mathrm{~m}$. & $4,5 \mathrm{~m} \times 5,5 \mathrm{~m}$. & $24,65 \mathrm{~m}^{2}$ \\
\hline
\end{tabular}

Para alguno de ellos, en concreto para el que constituye el acceso a la Caverna y Pozo de Compuertas, debido a su emplazamiento a media ladera y a la proximidad de instalaciones preexistentes, se tuvieron que diseñar con especial detalle protecciones específicas que evitaran las proyecciones en las primeras voladuras del emboquille. 

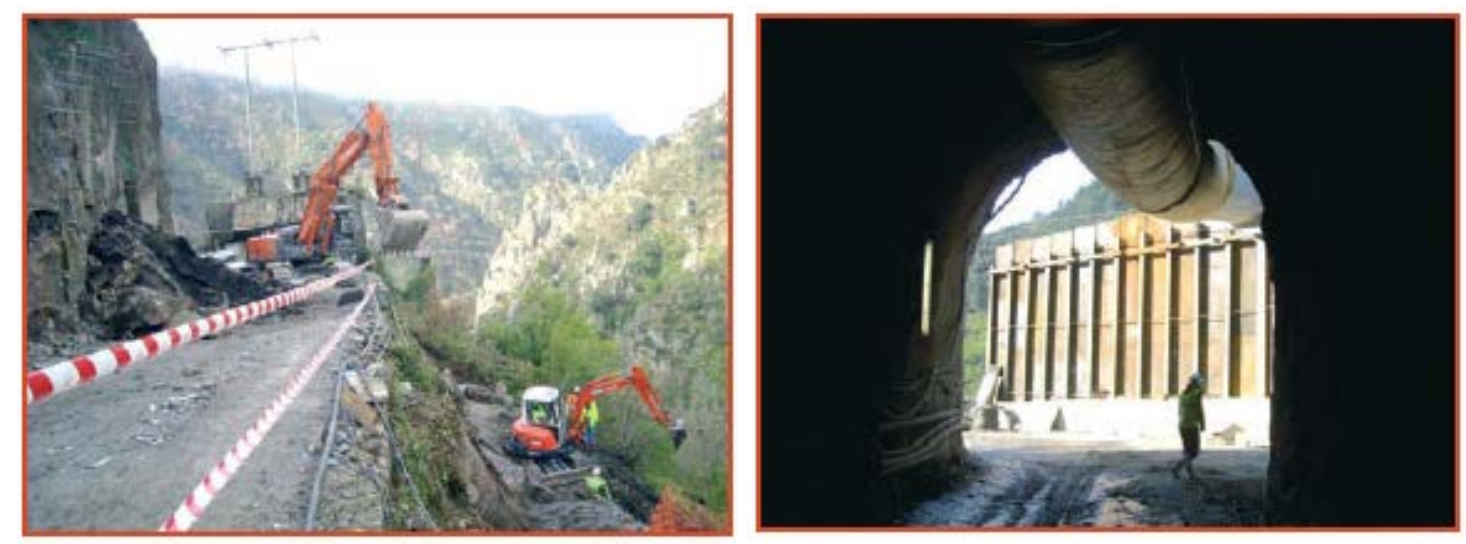

Respecto al circuito hidráulico, se muestra a continuación un perfil de dicho circuito.

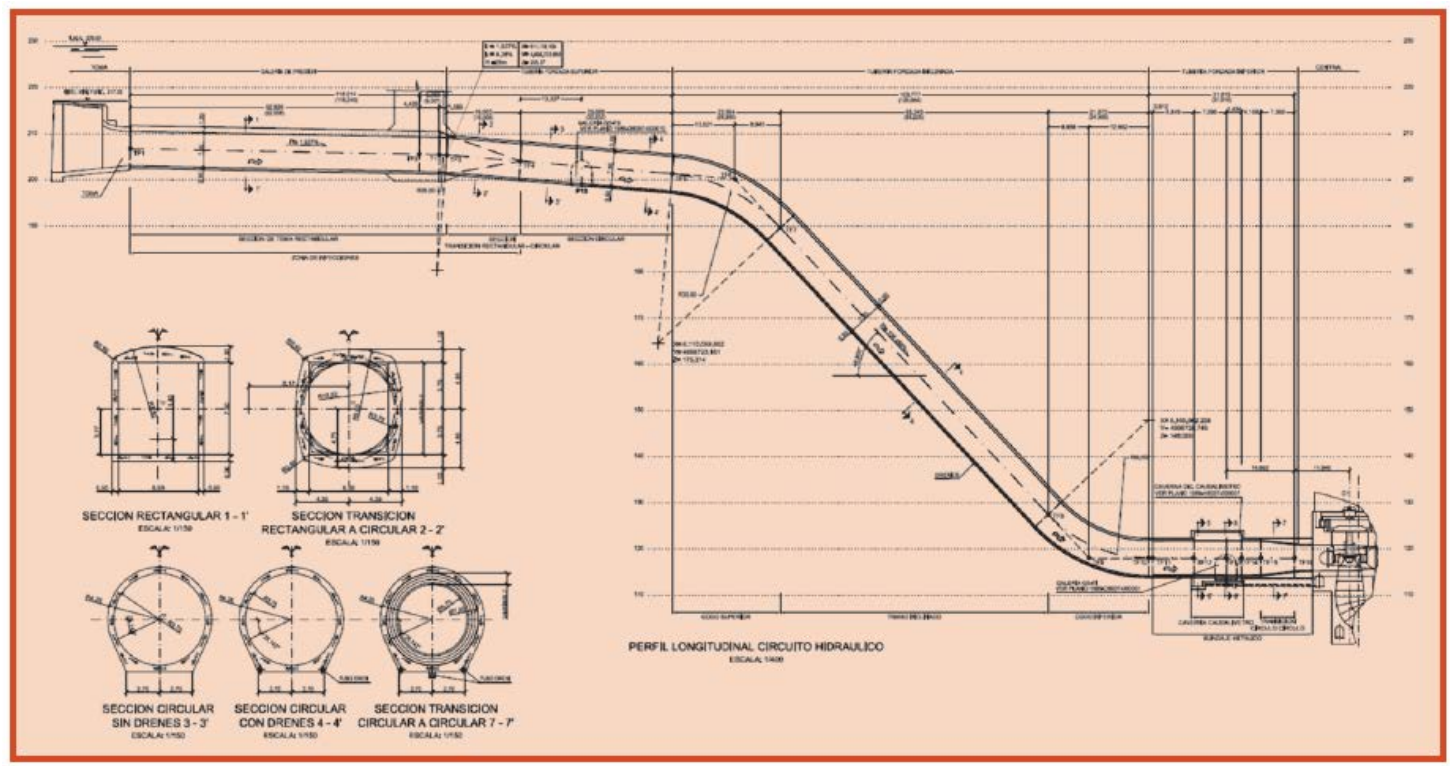

De aguas abajo a aguas arriba se compone de:

\section{Túnel de Desagüe}

Bajo el nombre de Desagüe se indica a la conducción existente entre la aspiración de la turbina y la restitución al río. En el sentido de avance del agua, está integrado por los siguientes elementos:

- Cono, codo de aspiración y transición de desagüe. Se inicia desde la salida de la turbina con una longitud total de $27,5 \mathrm{~m}$. La sección inicial a la salida de la turbina presenta una altura de 7,6 m, después de la transición, la sección finaliza con unas dimensiones de $9 \mathrm{~m}$ de ancho y una altura de $10 \mathrm{~m}$. 
- Conducción de desagüe. La conducción tiene una sección de 10,15 m. de diámetro, con una longitud de 219,55 m.

\section{$\bullet$}

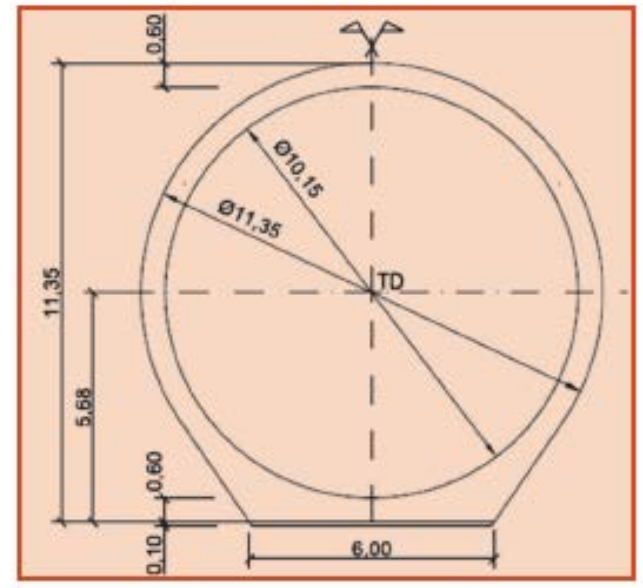

- Ataguía de desagüe. Entre la tubería y el canal de descarga se construye la ataguía de descarga en el exterior.

\section{Estructura de Ataguía, desembocadura y canal de restitución}

A partir de la estructura de ataguía se construyó la desembocadura y el canal de restitución, los cuales se ejecutaron con una longitud aproximada de $27 \mathrm{~m}$.

Al objeto de minimizar los efectos que tendría en la explotación de los embalses bajar el nivel del río para poder construir esta estructura, la excavación para su emplazamiento se ejecutó en pozo, construyéndose además una ataguía de protección de hormigón.

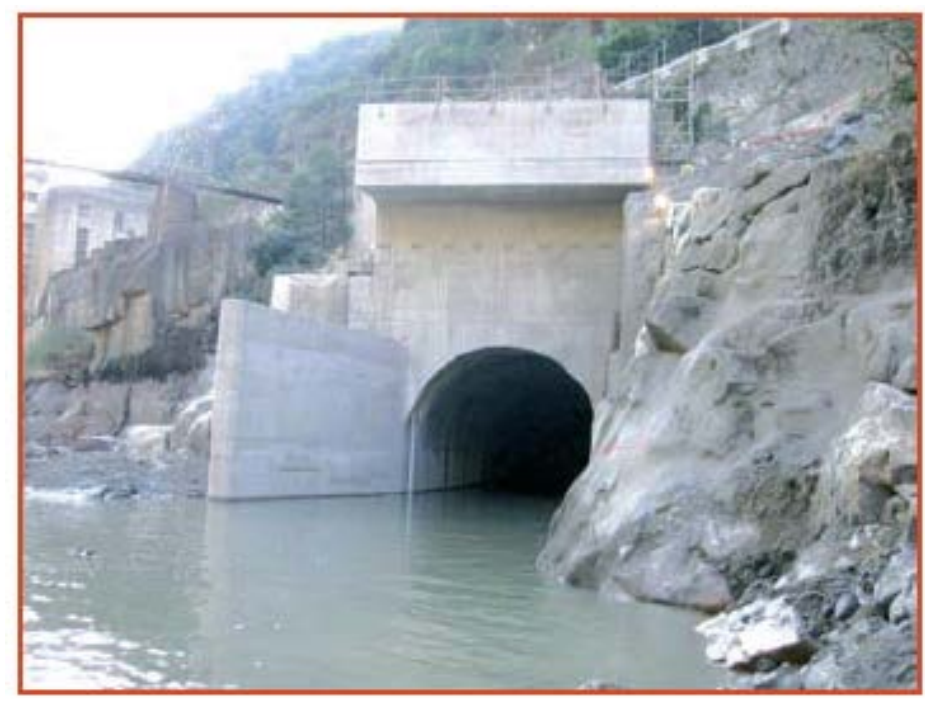




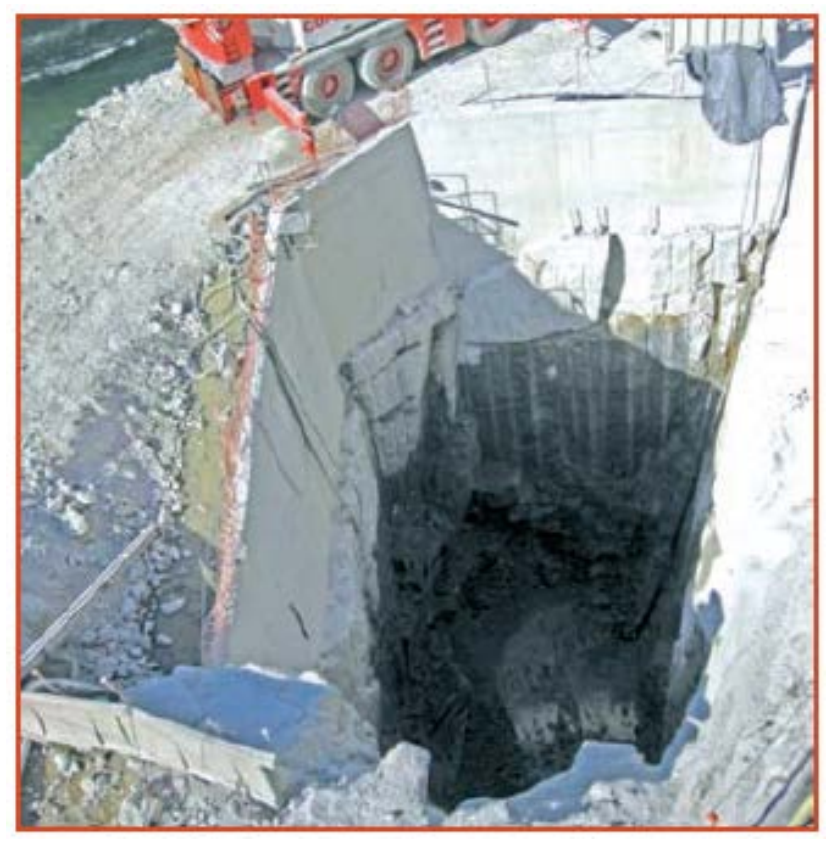

De esta forma, el período de cauce seco se redujo al mínimo imprescindible para construir la solera. El importante reto que suponía el cumplimiento de este hito se consiguió con éxito.

\section{Forzada}

Se denomina Tubería Forzada a toda la conducción entre el pozo de compuertas y la turbina, la cual se dividió en tres tramos:

- Tramo Sub-horizontal Superior. La tubería forzada sale del pozo de compuertas mediante una transición rectángulo-circulo, de diámetro interior 7,5 $\mathrm{m}$ y una longitud de $16,04 \mathrm{~m}$, a la que sigue un tramo de sección circular de 7,25\% de pendiente con una longitud de de 45,9 m y un codo en el espacio de $30 \mathrm{~m}$ de radio y $26,5 \mathrm{~m}$. de longitud.

- Tramo inclinado. La construcción del tramo de forzada que discurre en

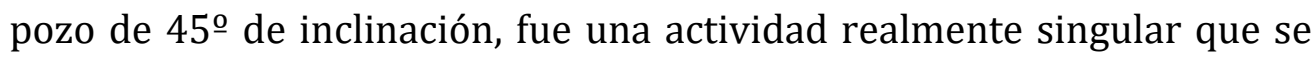
describe más adelante.

- Tramo horizontal inferior. A la tubería inclinada le sigue un codo recto de $30 \mathrm{~m}$ de radio y $23,5 \mathrm{~m}$ de longitud, posteriormente un tramo recto horizontal de 44,3 $\mathrm{m}$ de longitud de sección variable, inicialmente tiene 7,5 m de diámetro y finaliza con 5,8 m.

\section{Túnel de toma}

Esta conducción es de sección rectangular y une la obra de toma con el pozo de compuertas de la toma. 


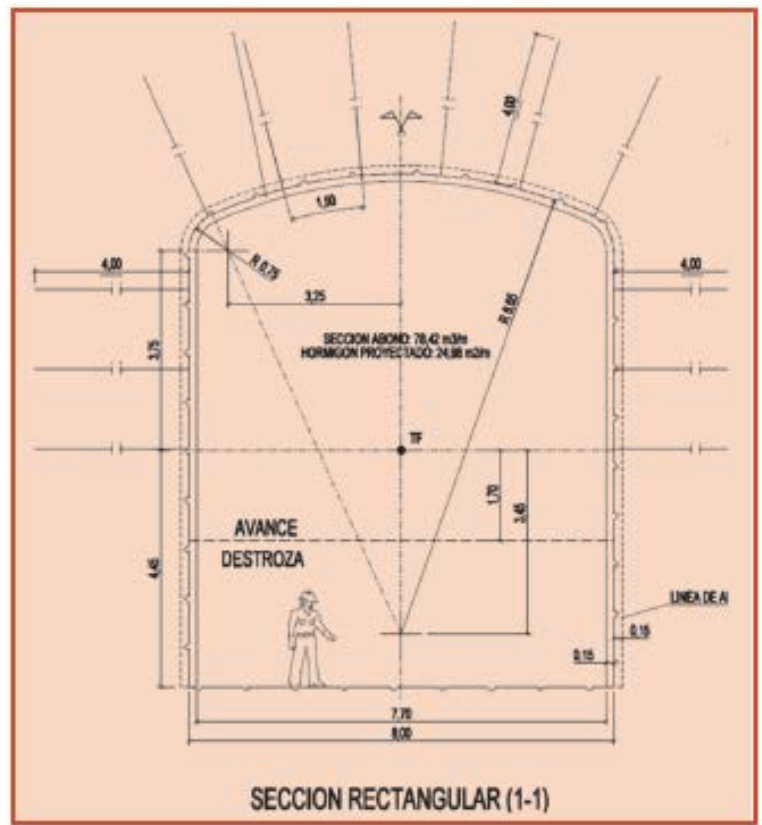

\section{Estructura de toma}

Se rediseñó su proceso constructivo para tratar de prefabricar el mayor número de elementos de la misma. Con esta solución, se reducía de forma significativa el tiempo previsto para su construcción y consecuentemente, una vez más, como en el caso de la Estructura de Desagüe, se afectaría lo mínimo posible la normal explotación de los embalses de San Esteban y San Pedro.

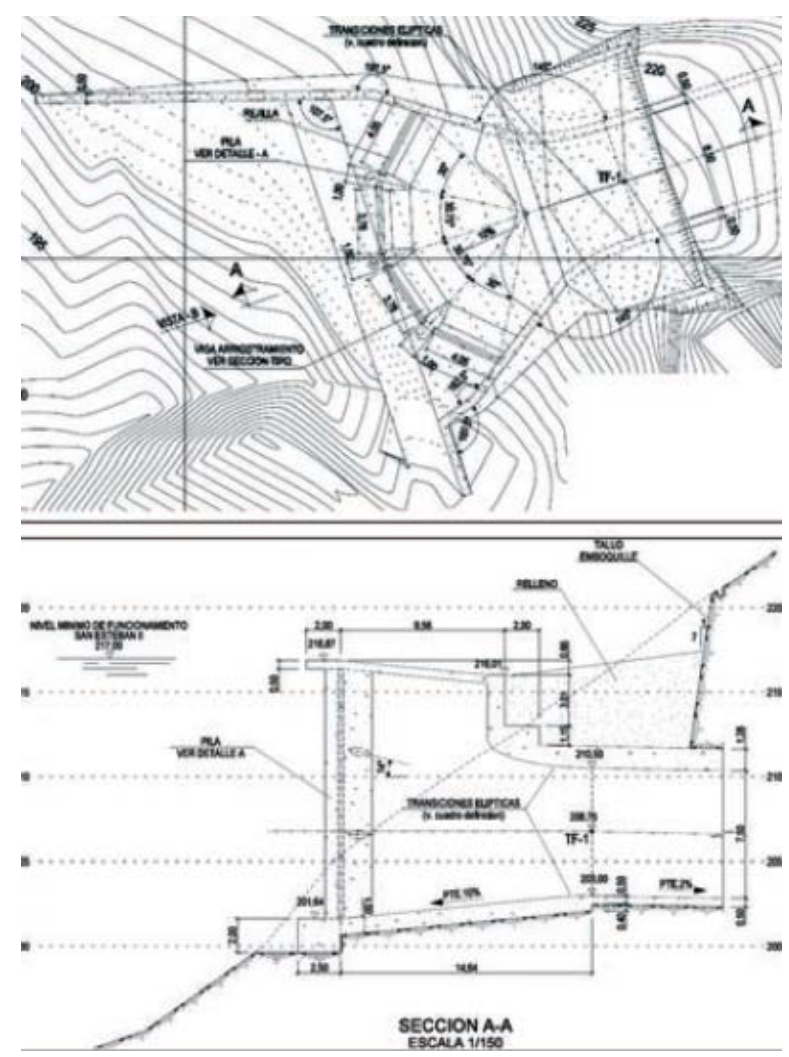




\section{Pozo inclinado de la Forzada}

En la Conducción Forzada existe un tramo inclinado 45으, cuya construcción merece ser calificada de singular, dada su gran dificultad y los medios específicos que fueron necesarios para su ejecución. La sección es circular con un diámetro de 8,50 m y su longitud es de 85 m aproximadamente.

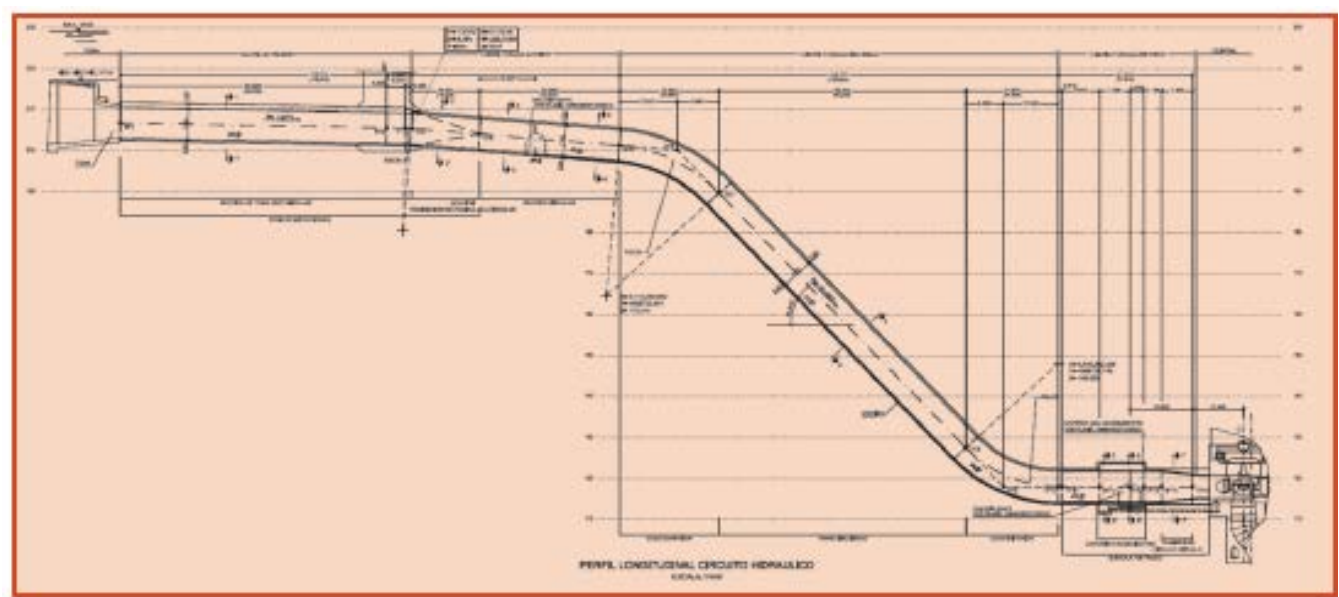

Para su construcción se ejecutó previamente un cuele escariando de abajo a arriba con la técnica de Raise-Boring, para posteriormente, y ya de arriba abajo, hacer la destroza por perforación y voladura.

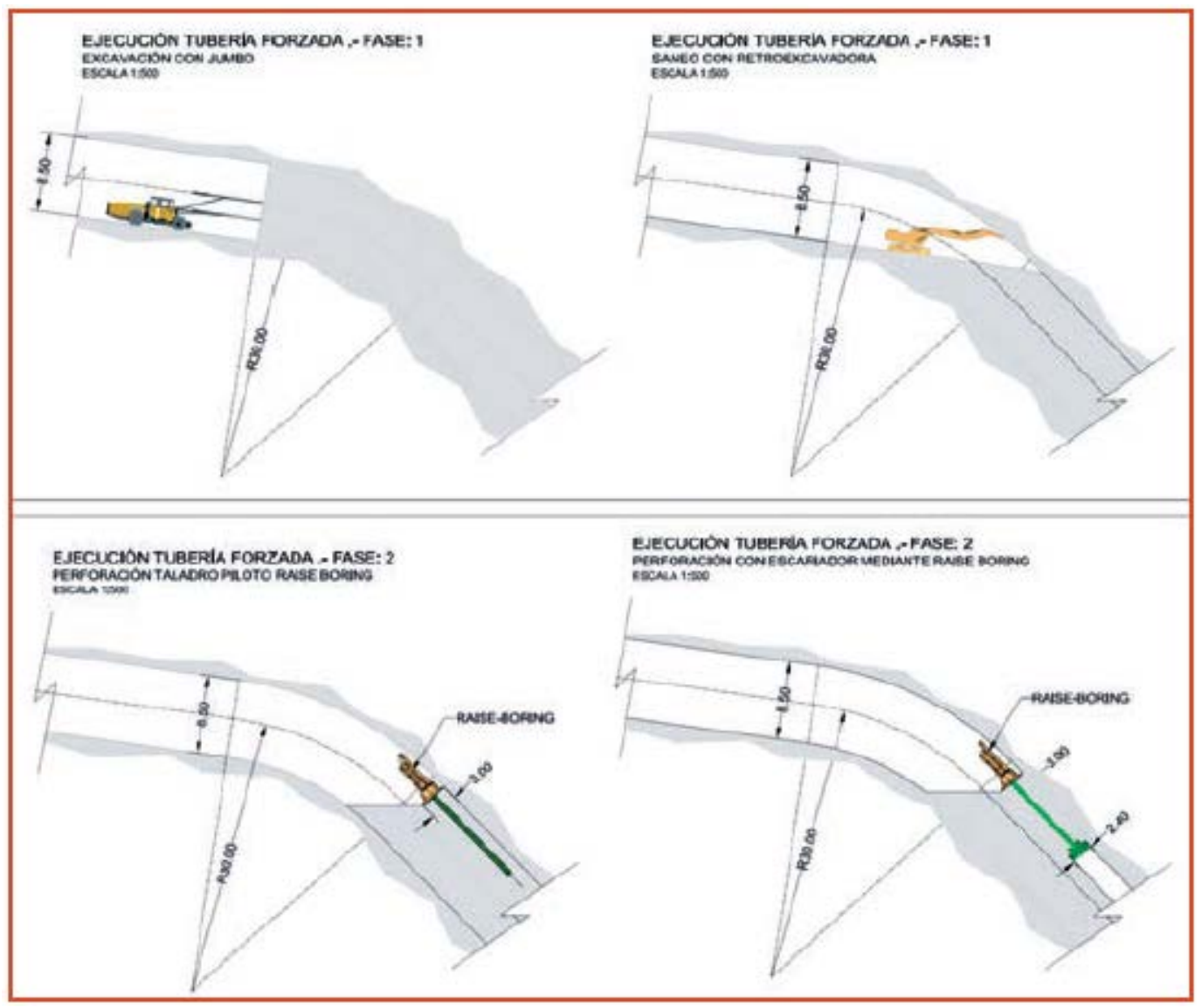




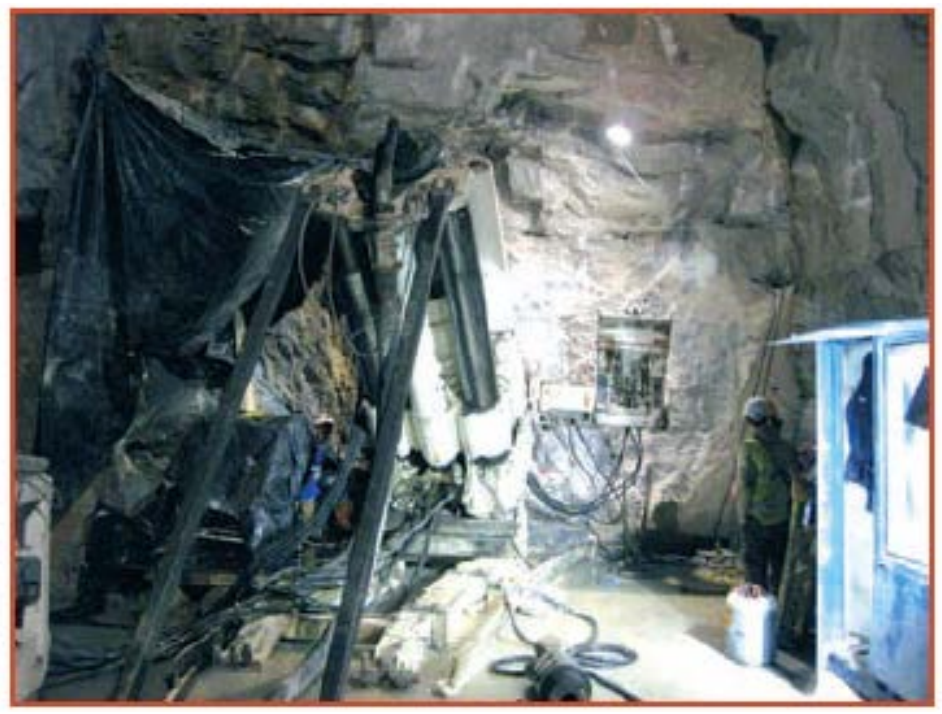

Fue necesario diseñar unas instalaciones complejas para descenso del personal y maquinaria en las máximas condiciones de seguridad.
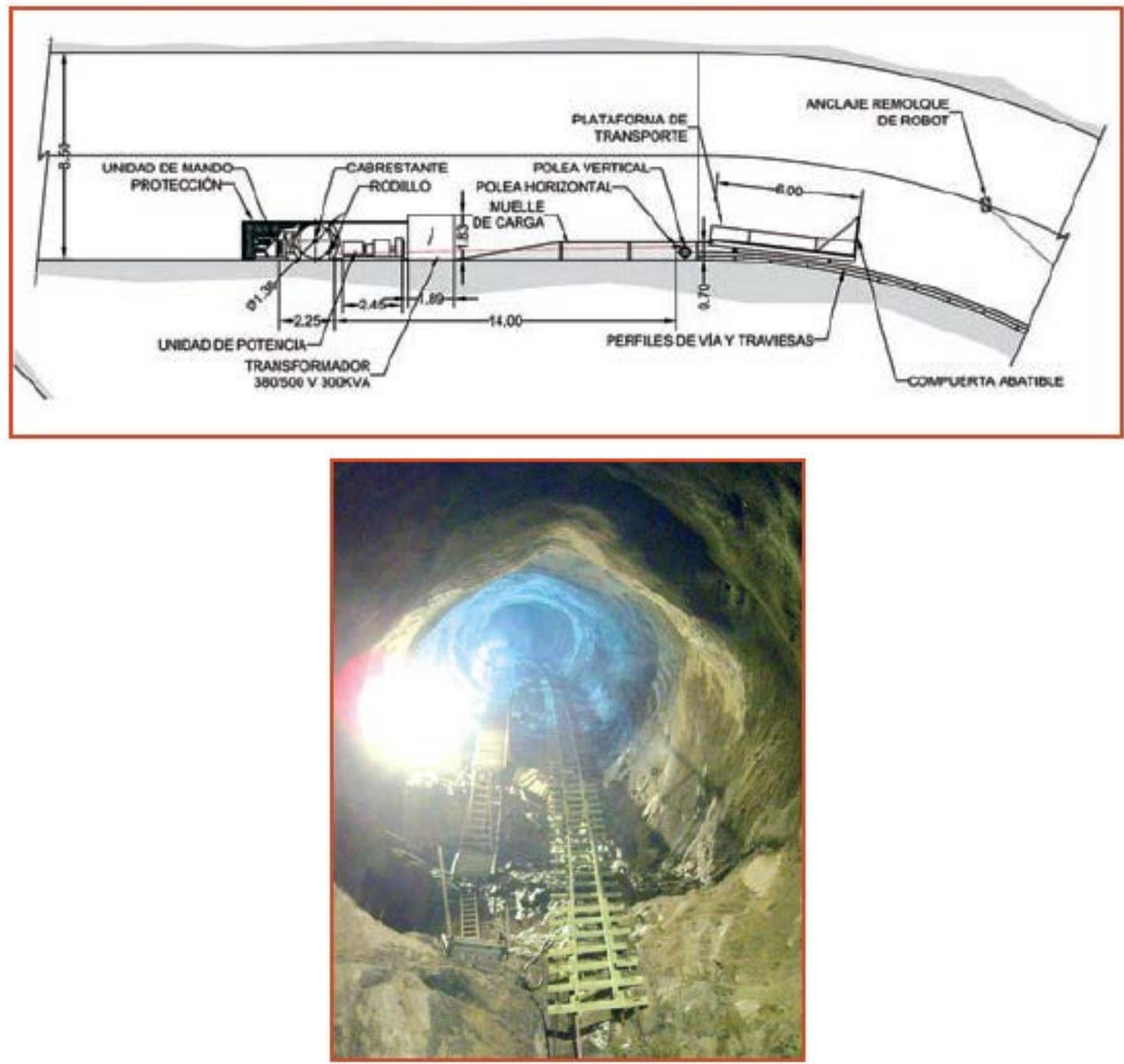
Los rendimientos alcanzados fueron:

- Ejecución del cuele con máquina para raise-boring: 5,5 m/día

- Destroza con explosivos: 1,5 m/día

\section{Caverna y pozo de compuertas}

La Caverna de Compuertas se sitúa en un ensanche excavado en la galería de acceso denominada $G-2$ a la cota 231 . Tiene unas dimensiones en planta de 12,80 m. x 14,90 m. y 13,50 m. de altura, con techo abovedado.

Desde ella se excavó un pozo de $32 \mathrm{~m}$. de altura y 10,80 m. de diámetro que fue el denominado Pozo de Compuertas, en el que, como su nombre indica, se colocan las compuertas de toma.

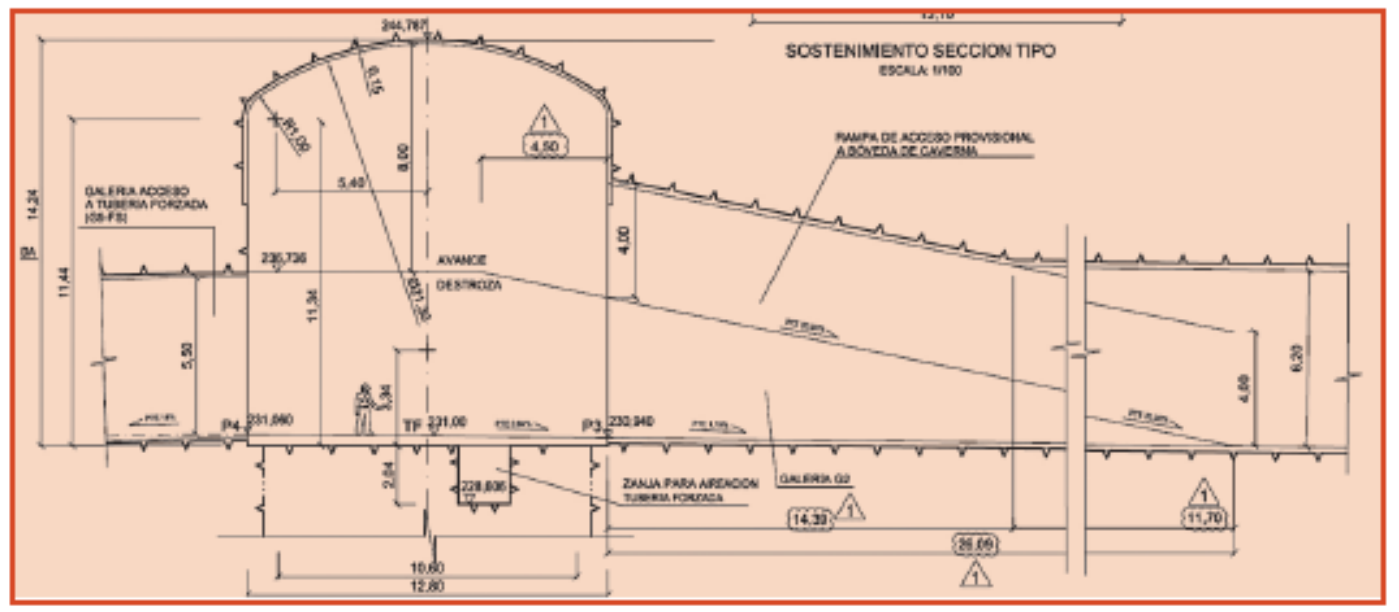

La excavación del Pozo se realizó ejecutando previamente un cuele de 2,40 m de diámetro mediante escariado con raiseborer, cuele que posteriormente fue ensanchado con explosivos a su diámetro final.
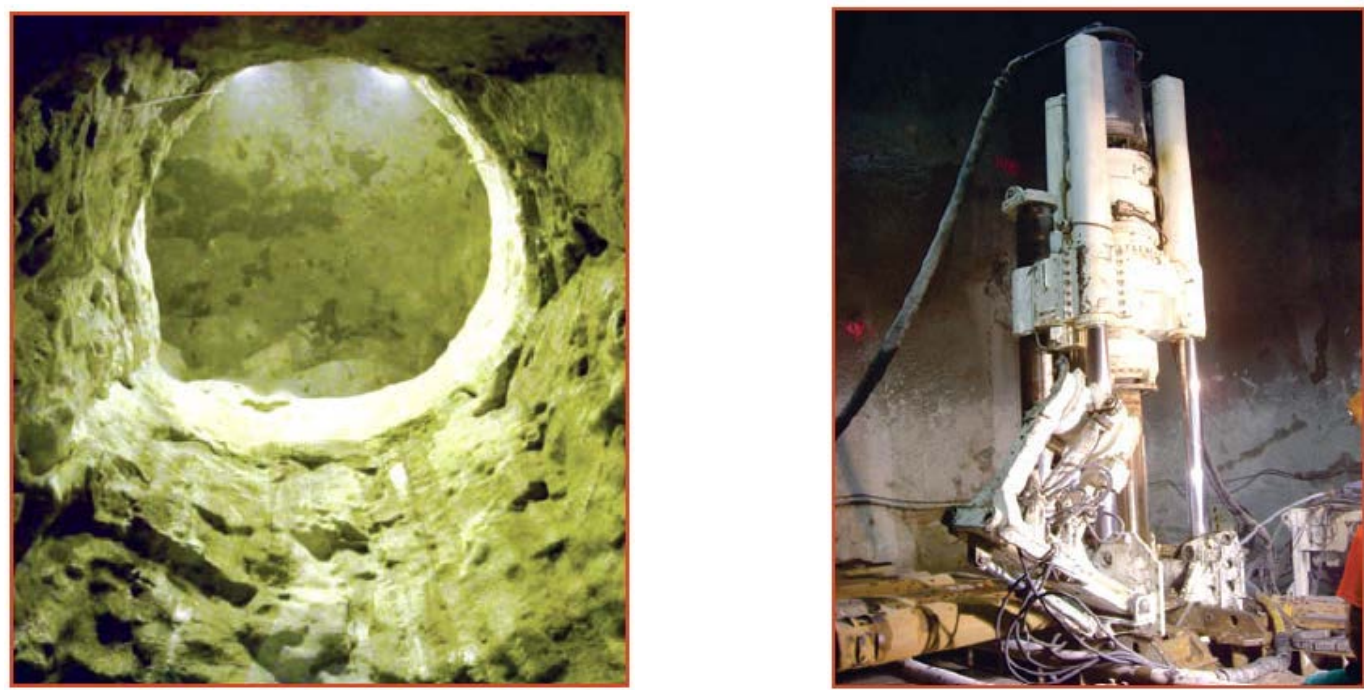


\section{Caverna de la central y del transformador}

La Caverna de la Central tiene unas dimensiones de 20,50 m x 58,25 m en planta, con la planta de la nave principal a la cota $133,15 \mathrm{msnm}$. La altura máxima de la excavación fue de 47,35 m., mientras que la altura final una vez construida la planta de alternadores fue de 18,35 m., siendo el acceso a la misma la galería denominada de Acceso Principal a la Central citado anteriormente.
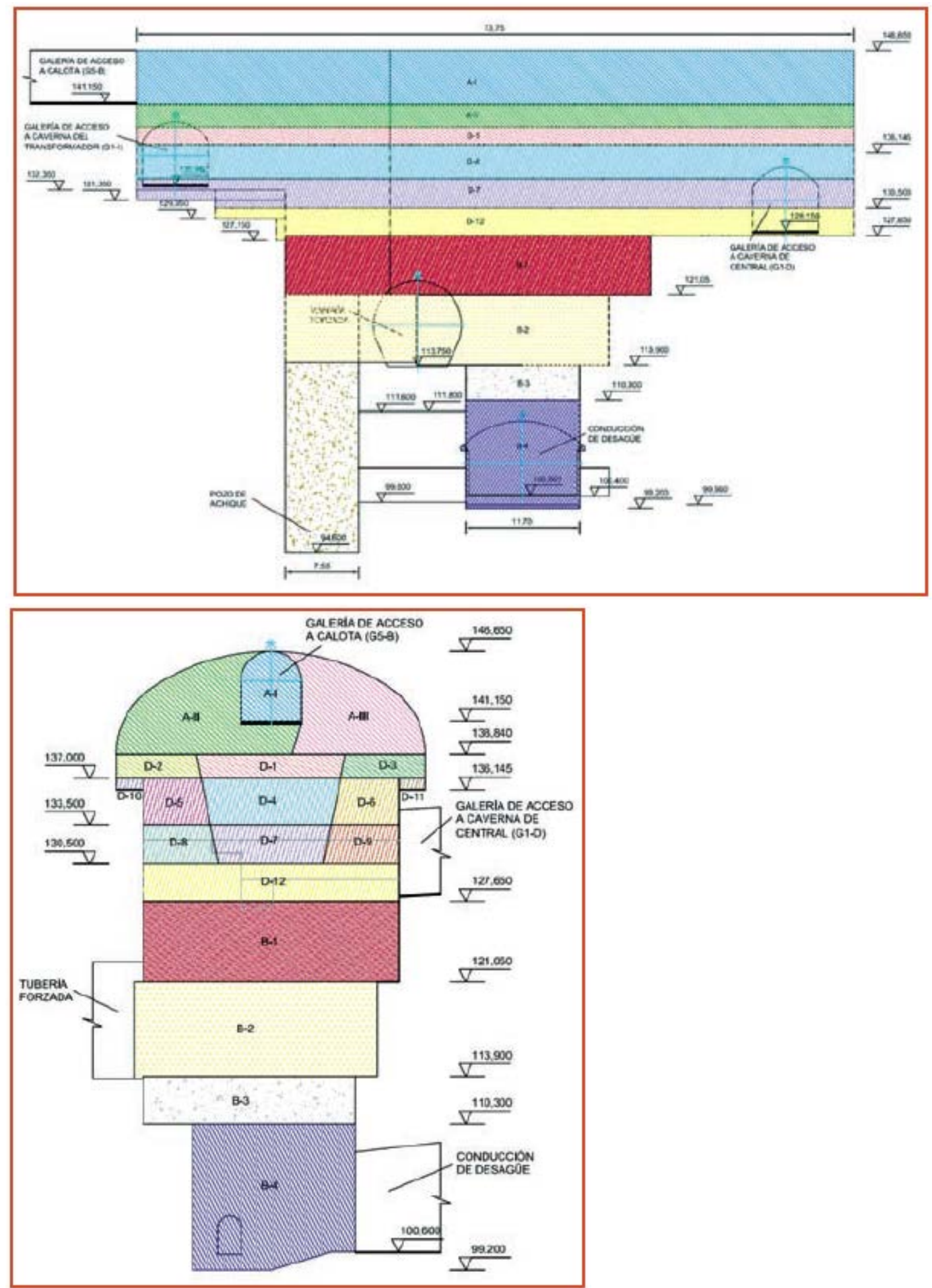
De forma general, el sostenimiento empleado consistió en la proyección de una capa de gunita de $15 \mathrm{~cm}$ de espesor y colocación de bulones de $32 \mathrm{~mm}$ de diámetro y $10 \mathrm{~m}$ de longitud en cuadrícula de $1 \mathrm{~m}$. x $1 \mathrm{~m}$. Como en otras centrales similares en macizos graníticos, no estuvo previsto revestir ni la bóveda ni los hastiales.

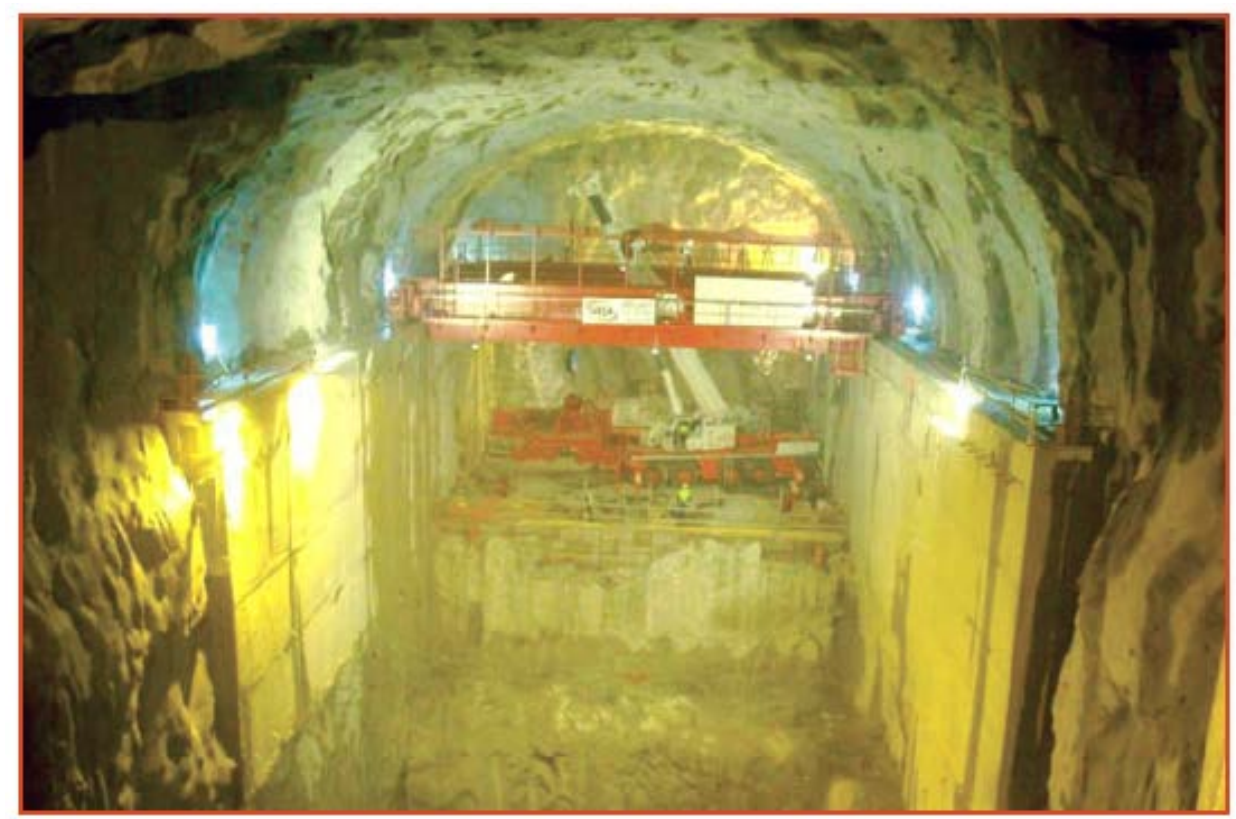

Merecen destacarse dos incidentes fundamentales surgidos durante la excavación. El primero se refiere a la aparición, durante la excavación de la bóveda, de un elemento anómalo dentro del cuerpo ígneo granítico, como fue un dique intrusivo de composición básica.

Este dique, similar a otros ya referenciados en el entorno, supone el relleno de una fisura de tipo distensivo, en una fase tardía y posterior al emplazamiento del plutón general. A efectos geomecánicos, las características principales del dique respondieron a un espesor aproximado de 3 a $4 \mathrm{~m}$., de tipo continuo (persistencia que excedió de las dimensiones de la caverna), relleno de diabasa de color gris en la zona central y verdoso en los contactos, de elevada resistencia pero intensa fracturación.

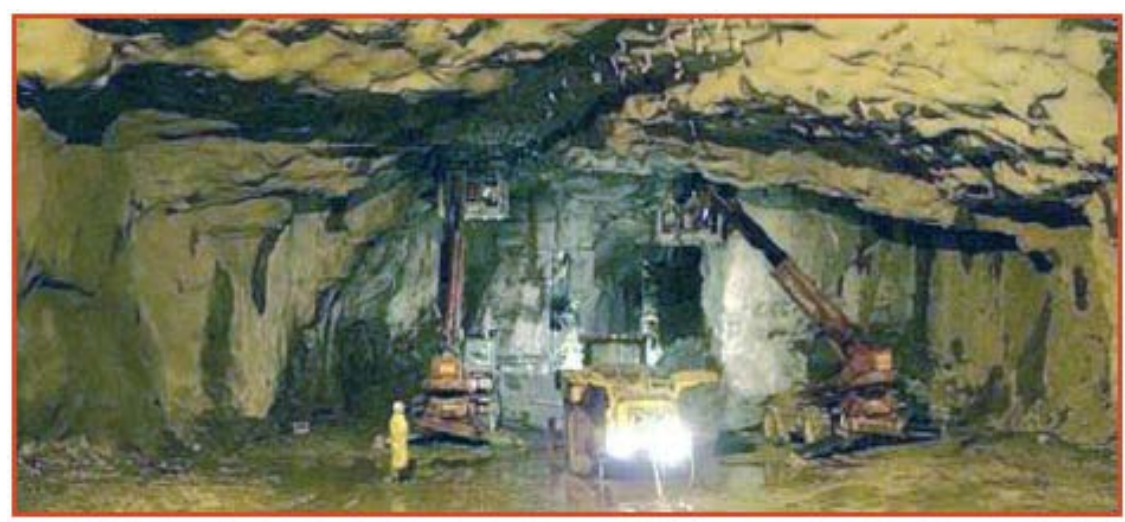


El sostenimiento en esa zona se reforzó saneando el dique hasta 1,00 m. de profundidad aproximada, colocando doble malla electrosoldada de acero de 150 x 150 x $12 \mathrm{~mm}$, entre capas de gunita proyectada (hasta alcanzar un espesor total de $90 \mathrm{~cm}$.) y cerrando la cuadrícula de bulonado hasta 0,5 m. x 0,5 m. aproximadamente (e inclinados hacia la roca encajante).

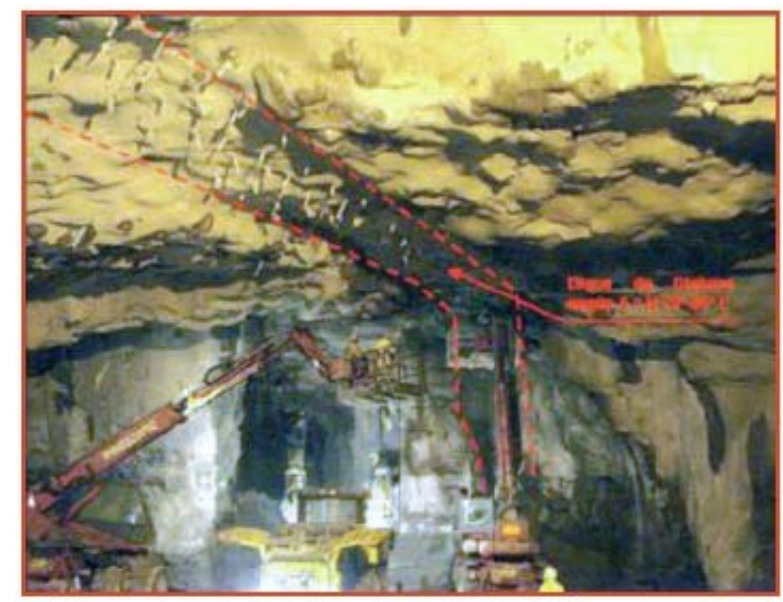

El segundo incidente fue la aparición, tanto en bóveda como en hastiales, de cuñas de terreno que se desprendían, fundamentalmente en la fase del obligado saneo, produciendo inevitables sobreexcavaciones que exigieron la reconstrucción a su geometría definitiva, con hormigón encofrado, de parte de los hastiales de la caverna, ya que en muchas zonas llegaba incluso a no haber apoyo para las vigas carril.

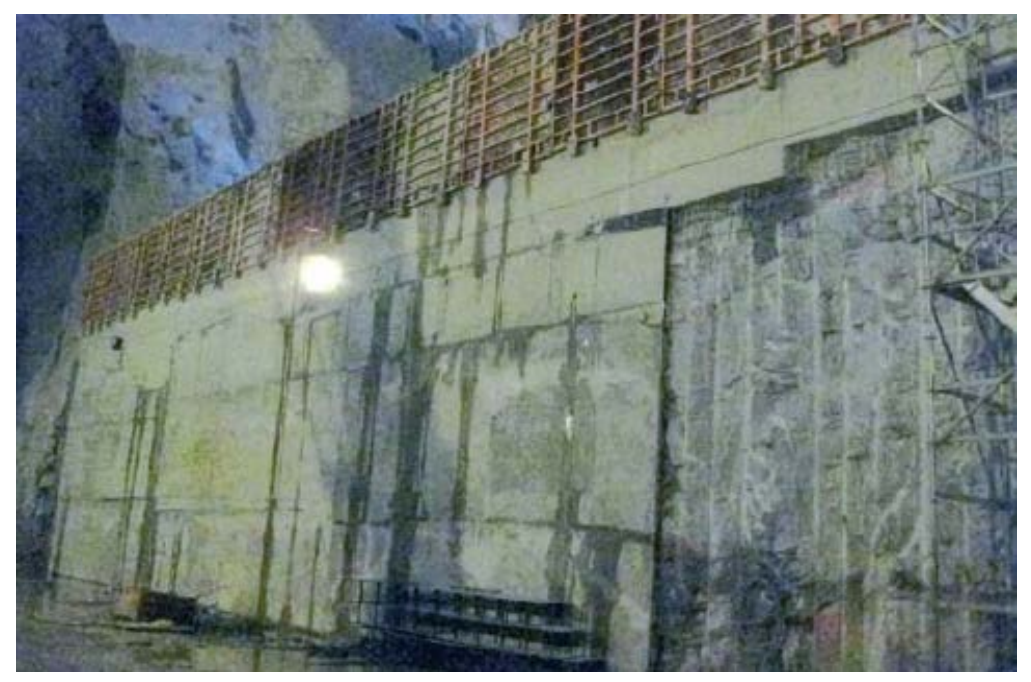

La Caverna del Transformador se diseñó prolongando, sin solución de continuidad, la bóveda de la Central. Es una caverna de 20,5 m x 16 m en planta y altura máxima $12,65 \mathrm{~m}$, con acceso rodado. 
En cuanto a las demoliciones es interesante mencionar que se demolieron todas las antiguas instalaciones que se utilizaron en la construcción del embalse de San Esteban por requerimiento municipal y como tal se atendió, a pesar de su indudable coste y de que, al menos algunas de ellas podrían haberse mantenido como recuerdo histórico de una obra tan importante.

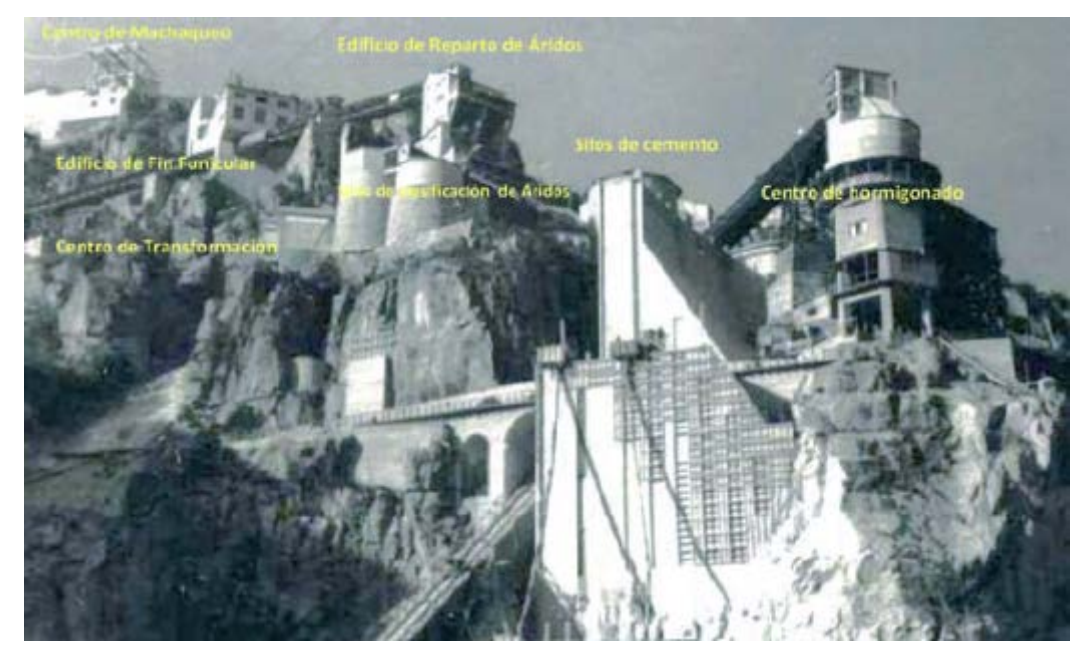

La industria de la construcción de obras subterráneas dispone hoy de un amplio abanico de metodologías constructivas, situación que permite abordar las diferentes condiciones de las obras en forma más eficiente, económica y segura que hace años. Actualmente se ha logrado un mayor grado de mecanización y automatización del proceso de construcción, además de identificar importantes innovaciones en los ámbitos de prospección, excavación, soporte, impermeabilización y extracción, asociados al proceso de construcción. Sin embargo, aún queda espacio para seguir avanzando.

Los métodos constructivos a aplicar en cada caso serán (influido especialmente por las características geológicas y geotécnicas del terreno a atravesar) de entre los existentes en la actualidad:

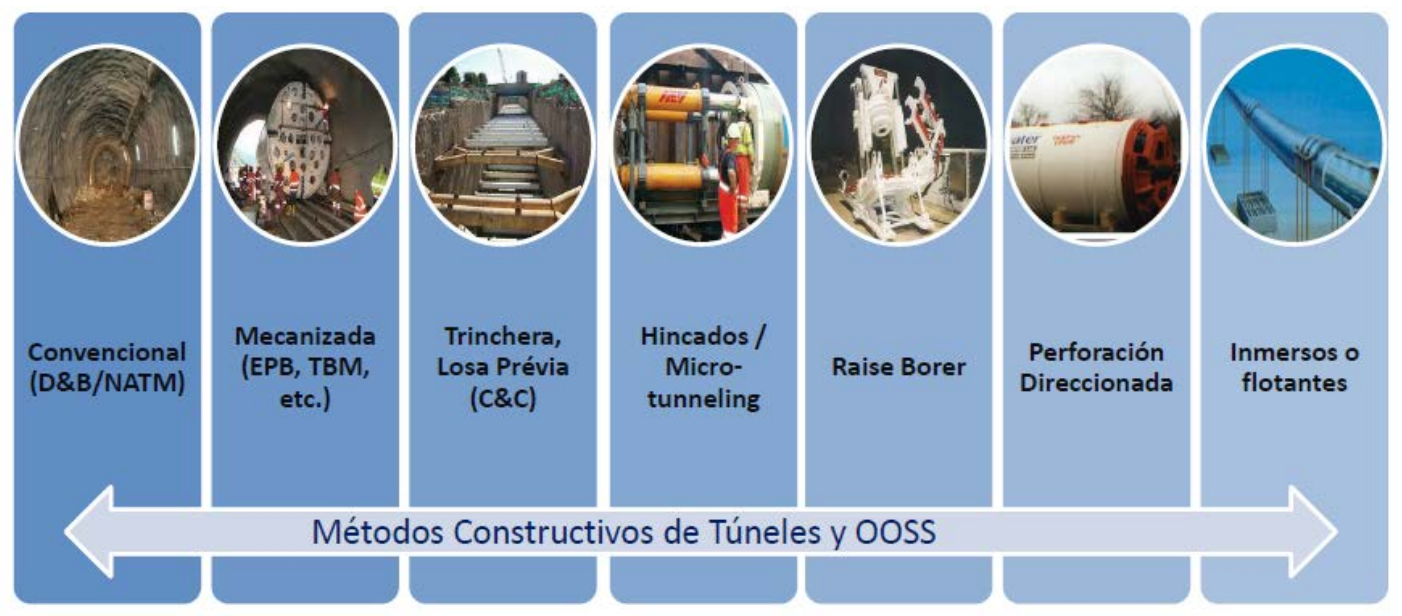


Aunque para el sector hidroeléctrico, los métodos más usuales pueden ser resumidos en términos del método convencional y del mecanizado, respectivamente.

Comparación entre ambos métodos:

\begin{tabular}{|c|c|c|c|c|}
\hline \multirow{2}{*}{\multicolumn{2}{|c|}{ Conditions }} & \multirow[b]{2}{*}{ Drilling and Blasting } & \multicolumn{2}{|c|}{ TBM } \\
\hline & & & For Hard Rock & For Soft Graind \\
\hline \multirow{3}{*}{$\begin{array}{l}\text { Tunnel } \\
\text { Features }\end{array}$} & tunnel length & $\begin{array}{l}\text { Equipment cost is relatiely low. } \\
\text { Excavation cost is not greatly } \\
\text { influenced by the tunnel length. }\end{array}$ & $\begin{array}{l}\text { The cost of tunnel boring machines is } \\
\text { generally high. It is suitable in longer } \\
\text { tunnel excavations. }\end{array}$ & $\begin{array}{l}\text { The cost of tunnel boring machines it } \\
\text { generally high. It is suitable in longet } \\
\text { tunnel excavations. }\end{array}$ \\
\hline & $\begin{array}{l}\text { shape of the cross } \\
\text { section }\end{array}$ & $\begin{array}{l}\text { Basically the shape of ecavation has } \\
\text { an arched shape at the cron. } \\
\text { The shape of the section can be } \\
\text { changed during the construction. }\end{array}$ & $\begin{array}{l}\text { Basically the shape of the excavation } \\
\text { is a circle. } \\
\text { After boring, other shapes are } \\
\text { possible using drilling and blasting as } \\
\text { the result of enlagement. }\end{array}$ & $\begin{array}{l}\text { Basically the shape of the Ecavation } \\
\text { is a circle. } \\
\text { Semicircle, multi-circle, val etc. are } \\
\text { also possible using special tunneling } \\
\text { machines for excavation. } \\
\end{array}$ \\
\hline & $\begin{array}{l}\text { size of the cross } \\
\text { section }\end{array}$ & $\begin{array}{l}\text { Generally it is possible up to } 150 \mathrm{~m} \\
\text { The largest record is bigger than } \\
200 \mathrm{~m}^{2} \text {. }\end{array}$ & $\begin{array}{l}\text { The laigest record is approximately } \\
12 \mathrm{~m} \text { for the maximum diameter of th } \\
\text { tunnel. }\end{array}$ & $\begin{array}{l}\text { The lagest record is approximatiy } \\
14 \mathrm{~m} \text { for the maximum diameter of th } \\
\text { tunnel. }\end{array}$ \\
\hline \multirow{4}{*}{$\begin{array}{l}\text { Geological } \\
\text { Conditions }\end{array}$} & hard rock & Suitable & $\begin{array}{l}\text { Suitable except for the extra-hard rock } \\
(s>200 \mathrm{MPa})\end{array}$ & Not applicable \\
\hline & semi-hard rock & Suitable & \begin{tabular}{l|l} 
Suitable & \\
\end{tabular} & Not applicable \\
\hline & $\begin{array}{l}\text { Weak layers such } \\
\text { as fractured zones } \\
\text { and aquifer zones }\end{array}$ & $\begin{array}{l}\text { Various countermeasures become } \\
\text { necessary }\end{array}$ & $\begin{array}{l}\text { It is not suitable in area where weak } \\
\text { ground or water inflw will be } \\
\text { frequently encountered. }\end{array}$ & $\begin{array}{l}\text { Applicable } \\
\text { See Table.2.2 }\end{array}$ \\
\hline & Soil & Not applicable & Not applicable & $\begin{array}{l}\text { Most suitable } \\
\text { See Table } 2.2 \\
\end{array}$ \\
\hline $\begin{array}{l}\text { Environmental } \\
\text { Conditions }\end{array}$ & $\begin{array}{l}\text { Noise and } \\
\text { Vibration }\end{array}$ & $\begin{array}{l}\text { Due to noise and vibration, it is not } \\
\text { suitable in the vicinity of houses and } \\
\text { important structures. } \\
\text { A supplementary method is necessary } \\
\text { to reduce the efects of noise and } \\
\text { vibration. }\end{array}$ & $\begin{array}{l}\text { Compared to the drilling and blasting } \\
\text { there is less efect of noise and } \\
\text { vibration to the houses and important } \\
\text { structures. }\end{array}$ & $\begin{array}{l}\text { There is less efect of noise and } \\
\text { vibration to the houses and important } \\
\text { structures than other rcavation } \\
\text { methods. }\end{array}$ \\
\hline
\end{tabular}

Otras conclusiones a las que se ha llegado tras la experiencia acumulada tanto en uno como en otro método, serían las siguientes:

1. Para túneles de gran longitud, conviene aplicar TBMs, respecto a la P\&V.

2. Para seleccionar una adecuada TBM intervienen muchos parámetros, siendo el principal el aspecto geológico.

3. La longitud mínima de túnel para aplicar una TBM sería $6500 \mathrm{~m}$, y para la P\&V con alta mecanización $2500 \mathrm{~m}$., en términos generales no exhaustivos.

4. La velocidad de excavación con TBM es 2 á 3 veces más rápido que con $\mathrm{P} \& \mathrm{~V}$, permitiendo recuperar la inversión en menor tiempo y con mayor rentabilidad de un proyecto tunelero.

5. El factor que más afecta la productividad de las TBMs descubiertas es el tipo de terreno.

6. En terrenos deleznables el mayor porcentaje del tiempo se emplea en sostenimiento.

7. La aplicación de minadores continuos ha aumentado vertiginosamente en sustitución de la P\&V. 
8. La TBM deja un contorno de excavación liso, no perturba a la roca remanente requiriendo menos elementos de sostenimiento $y$ revestimiento.

9. Su funcionamiento no produce emanación de gases ni polución.

10. El costo de excavación con TBM, sin considerar el sostenimiento, revestimiento, ventilación, etc., resulta superior a la de la P\&V. Sin embargo, para grandes longitudes esta diferencia es mínima o nula.

Dentro del sistema convencional hay algunas diferencias entre excavaciones en roca y en suelo. El primero, consiste en el uso de explosivos para desmontar la roca, con posterior instalación de soporte mediante shotcrete y pernos, con eventual instalación posterior de un revestimiento secundario o final.

El método en suelo, es el NATM (Nuevo Método Austriaco de Construcción de Túneles), corresponde a una excavación cíclica, mediante el uso de retroexcavadoras adaptadas e instalación contemporánea de un soporte de cáscara doble de shotcrete de carácter permanente. En algunos casos, también se ha aplicado el sistema de soporte mediante steel-liners inyectados, que reemplazan al shotcrete como elemento de soporte en túneles de pequeño diámetro.

Y por último, el sistema mecanizado consiste en la utilización de máquinas tuneladoras TBM. El desarrollo del sector hidroeléctrico fue primero pionero, y más tarde, gran usuario de los métodos mecanizados de ejecución de obra subterránea. Esta técnica permite perforar el túnel a frente completo, donde la máquina actúa como una broca de excavación continua del macizo, lo que es seguido de la instalación más automatizada de los elementos de soporte. Asimismo, también se puede mencionar el uso de raise-borers, que corresponde a otro tipo de excavación mecanizada para la realización de perforaciones verticales e inclinadas.

Los métodos de construcción tradicionales usados comúnmente durante el siglo $\mathrm{XX}$, derivaban básicamente de la experiencia en minería y mostraban que la masa de roca debía considerarse siempre en términos de una carga actuante sobre el revestimiento.

NATM, método de los años 60/70, puede ser definido como un método de producción de espacio subterráneo mediante el uso de todos los medios disponibles para desarrollar la máxima capacidad de auto-sostenimiento de la roca o suelo, para proveer estabilidad a la excavación subterránea. Fundamentalmente, pretende transformar el terreno que rodea el perfil del túnel, de una carga ejercida, a un miembro del sistema con capacidad de carga. 
Se basa en el principio de un diseño de dos cáscaras:

1. Revestimiento inicial:

- El control de la deformación del terreno es primordial:

- La deformación debería mantenerse al mínimo, de manera que los estados iniciales de estabilidad y resistencia a la compresión del terreno no se debiliten más de lo inevitable.

- La deformación es, más bien, necesaria; a tal extremo que la propia configuración del terreno actúa como un soporte general en forma de anillo.

- Se aplica un revestimiento delgado de hormigón para establecer un nuevo estado de equilibrio, que se reconoce al controlar el proceso de deformación.

2. Revestimiento interior (final):

- Sólo hasta que los movimientos quedan quietos, puede construirse el revestimiento interior. No será, dependiendo de las condiciones del terreno, absolutamente necesario en todos los casos.

- Deberá ser diseñado para permitir cambios en largo tiempo de los fenómenos de presión del terreno y el debilitamiento o falla total de la estructura de soporte general en forma de anillo.

Por ello, mientras que el método convencional antiguo tenía en cuenta un soporte rígido y puntual con encastillados de madera y ladrillos, el nuevo método utiliza hormigón proyectado, marcos metálicos, mallas y anclajes.

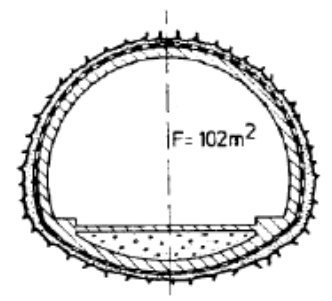

NATM

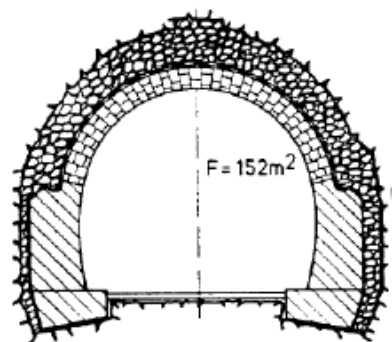

Antiguo ATM

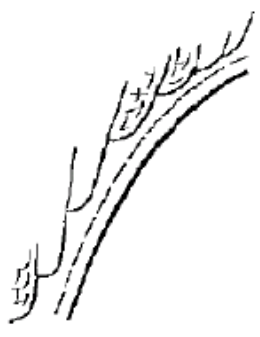

NATM

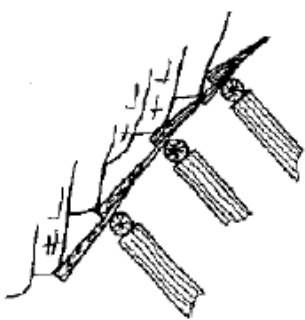

Antiguo ATM

La base del NATM es el aplicar un revestimiento semi-rígido, que actúa como una primera etapa de soporte, creando un nuevo estado de equilibrio, mayormente seguido por un revestimiento inicial que debería aceptar la deformación necesaria, pero previene los efectos del desarrollo de la carga del terreno. 
NATM es el método que cumple con un nuevo estado de equilibrio mediante el control de la liberación de presión.

En la actualidad, es destacable como aspectos técnicos, de los medios convencionales:

- Uso de equipos con sistema de control automático y computadorizado, jumbos de hasta 4-brazos.

- Uso de Road-header en suelos y rocas blandas.

- Equipos de extracción y transporte de última generación (ej. Pala Shaft, correas transportadores, camiones de bajo perfil).

- Diseño especifico de perforación y tronadura, monitoreo de vibraciones y control de daño. Uso de Emulsiones para tronadura.

- Instrumentación y Monitoreo.

- Uso de mano obra especializada y poli-funcional.

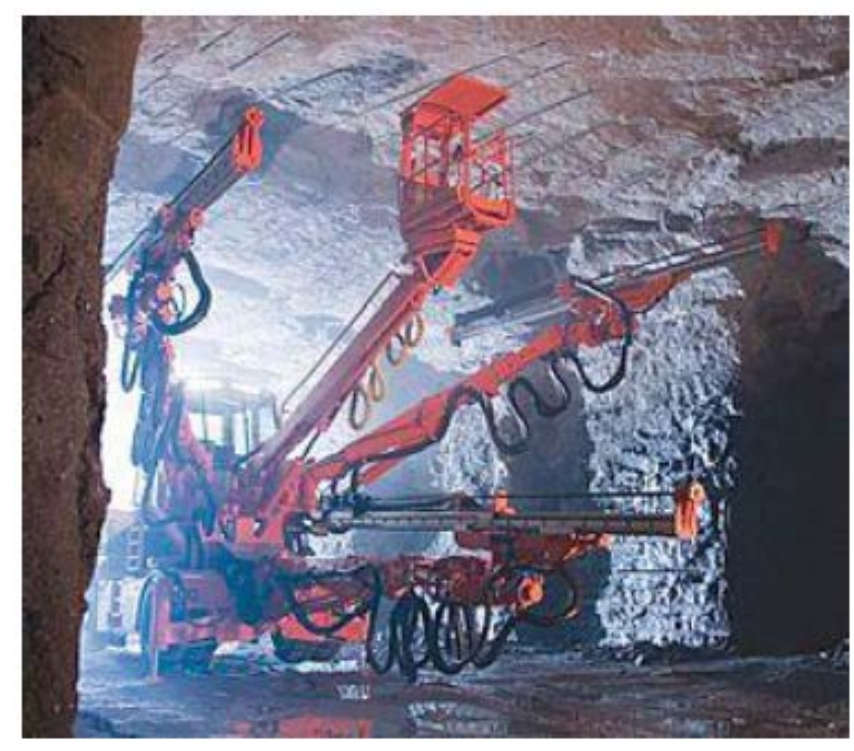

La reducción de los tiempos necesarios para la realización de cada actividad ha sido notable, resultado de la evolución tecnológica de la maquinaria y los mejores conocimientos relativos a ingeniería del terreno. Todo ello ha redundado en los rendimientos de perforación, aumentando desde los $5 \mathrm{~m} /$ hora de hace 100 años a los $450 \mathrm{~m} /$ hora actuales. 


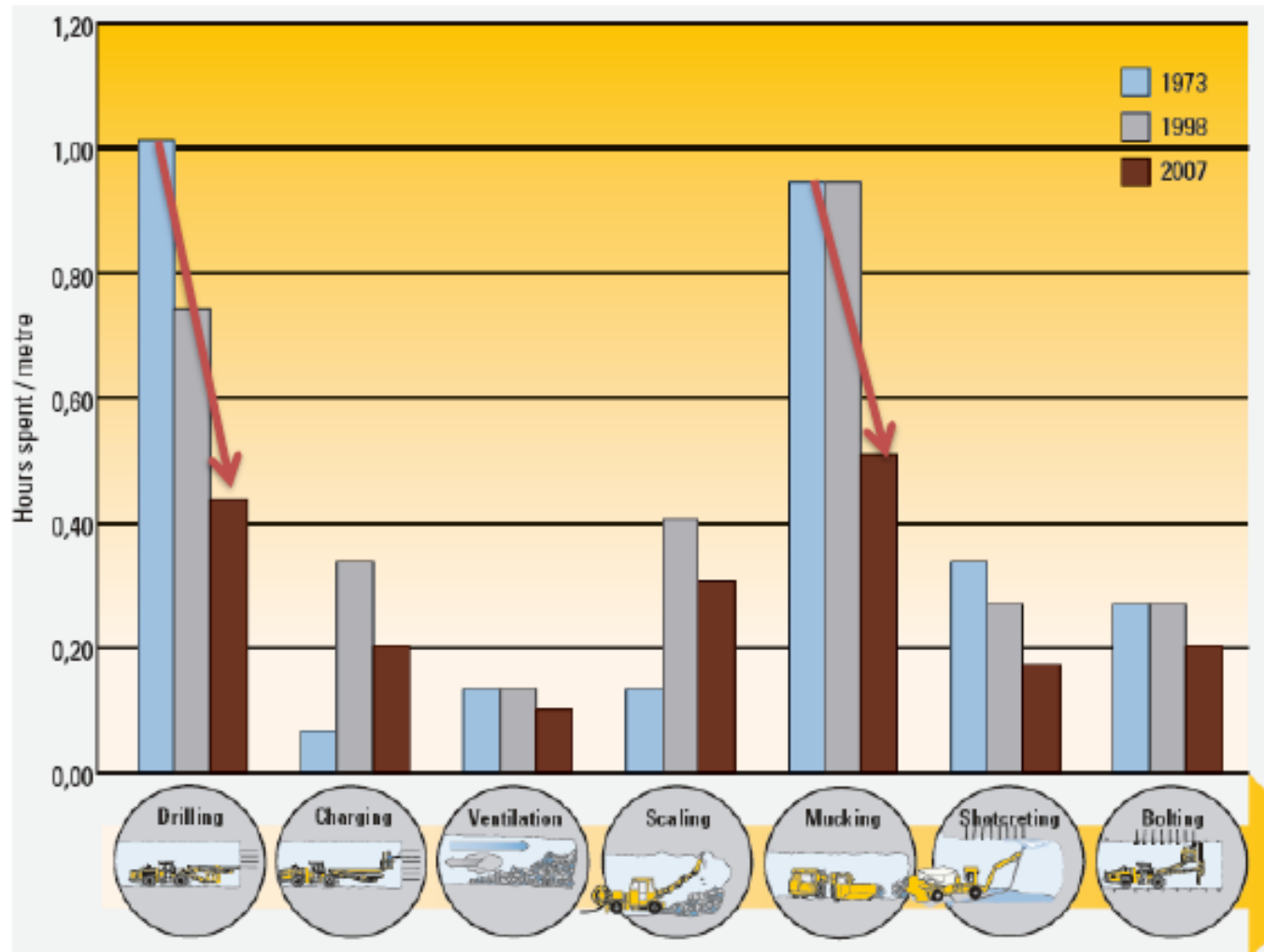

A nivel mundial, también se utilizan las tecnologías de perforación mecanizadas mediante TBM (Tunnel Boring Machine), máquina capaz de excavar a sección completa, a la vez que colabora en la colocación de un sostenimiento si éste es necesario, ya sea en forma provisional o definitiva, EPBM (Earth Pressure Balanced Machine), y SSM (Slurry Shield Machine).

- Hard Rock TBM: Es de las máquinas TBM para roca dura la más tradicional. Es la más rápida y efectiva para perforar túneles en formaciones de roca dura y sana.

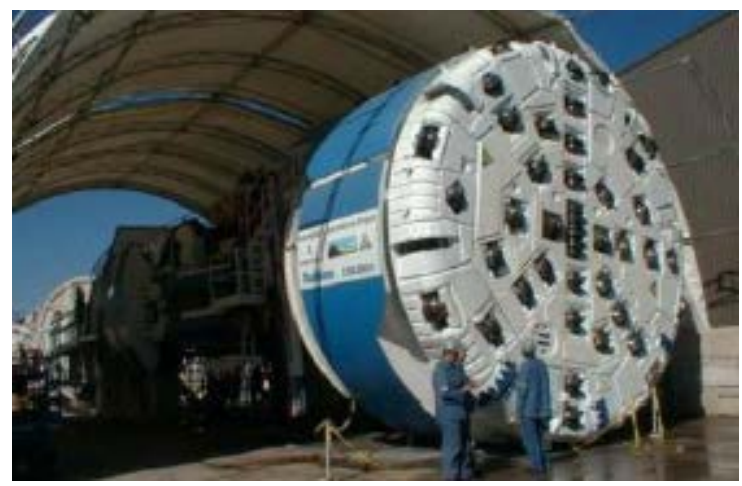

- Earth Pressure Balanced Machine (EPBM): Los productos acondicionadores del suelo son inyectados generalmente delante de la cabeza de corte y a menudo dentro del tornillo transportador. 


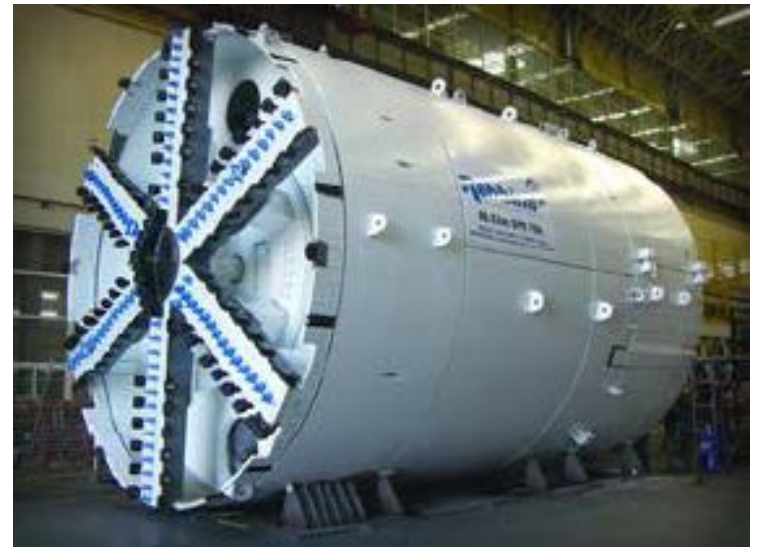

- Slurry Shield Machines (SSM): bombea agua o bentonita en el frente del túnel y en la cámara de excavación. La bentonita ayuda a mantener incluso una sobrepresión en el frente de la cabeza de corte de la TBM y también actúa con ayuda al transporte del suelo por bombeo.

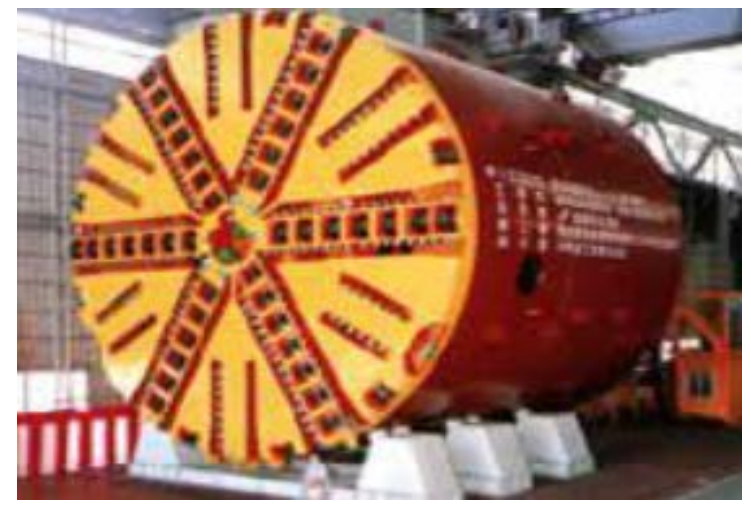

Como ejemplo, citar que ha sido utilizado en las centrales hidroeléctricas de Echaillon, La Coche, Belledonne, Bramefarine, Grand Maison - Eau Dolle, Brevon, Super Bissorte, Pouget, Grand Maison - Vaujany, Vieux Pré, Haut e Romanche Tunnel, Ferrières, Durolle, Mont Fermy, Takamaka, Oued Lakhdar, Cleuson Dixence, etc....con diámetros de perforación desde 3 metros hasta 8,10 metros, y longitudes desde 839 metros hasta 9.998 metros.

Actualmente, las características técnicas más destacables de la excavación mecanizada son las siguientes:

- Nueva generación de máquinas tuneleras.

- Mejores condiciones sanitarias y de seguridad para los trabajadores e industrialización del proceso de construcción

- Avances promedios $>10 \mathrm{~m} /$ día (hasta $500-700 \mathrm{~m} / \mathrm{mes}$ );

- Aplicable a un amplio espectro de condiciones de subsuelo (desde macizos con mucha competencia y alta cobertura, hasta suelos muy blandos con presencia de elevada presión hidrostática >10 bares); 
- Excavación en condiciones de subsuelo complejas y muy poco favorables en forma más económica y segura.

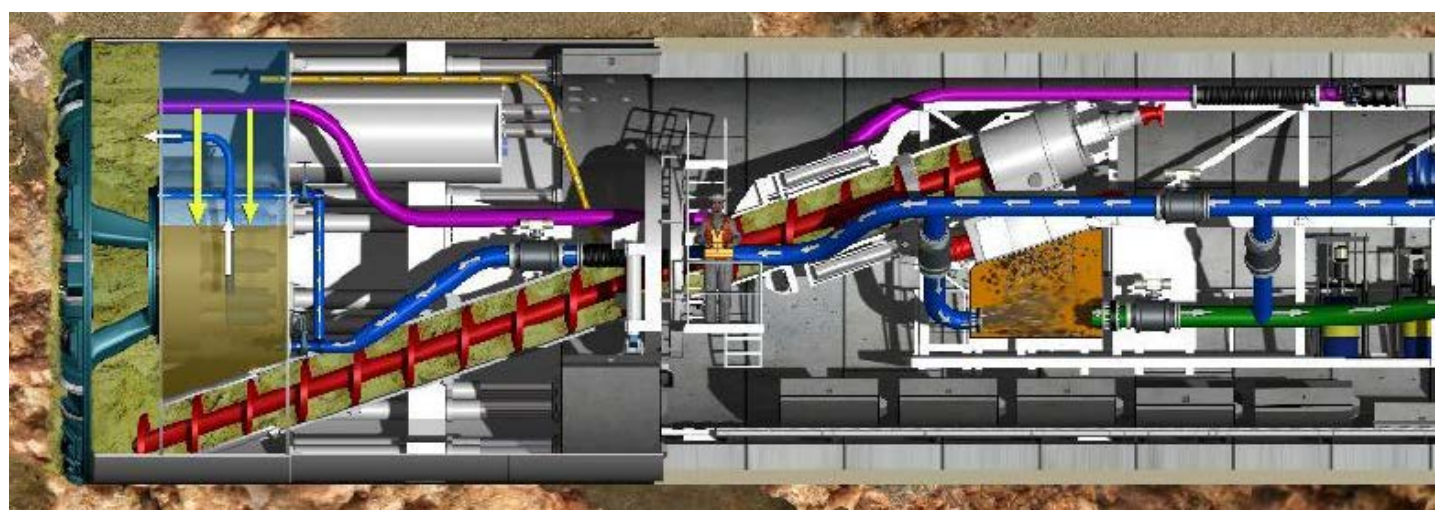

TBM de densidad variable

Las tecnologías constructivas de túneles más modernas, aplicados a las obras subterráneas asociadas a los aprovechamientos hidroeléctricos serían, en resumen, los siguientes:
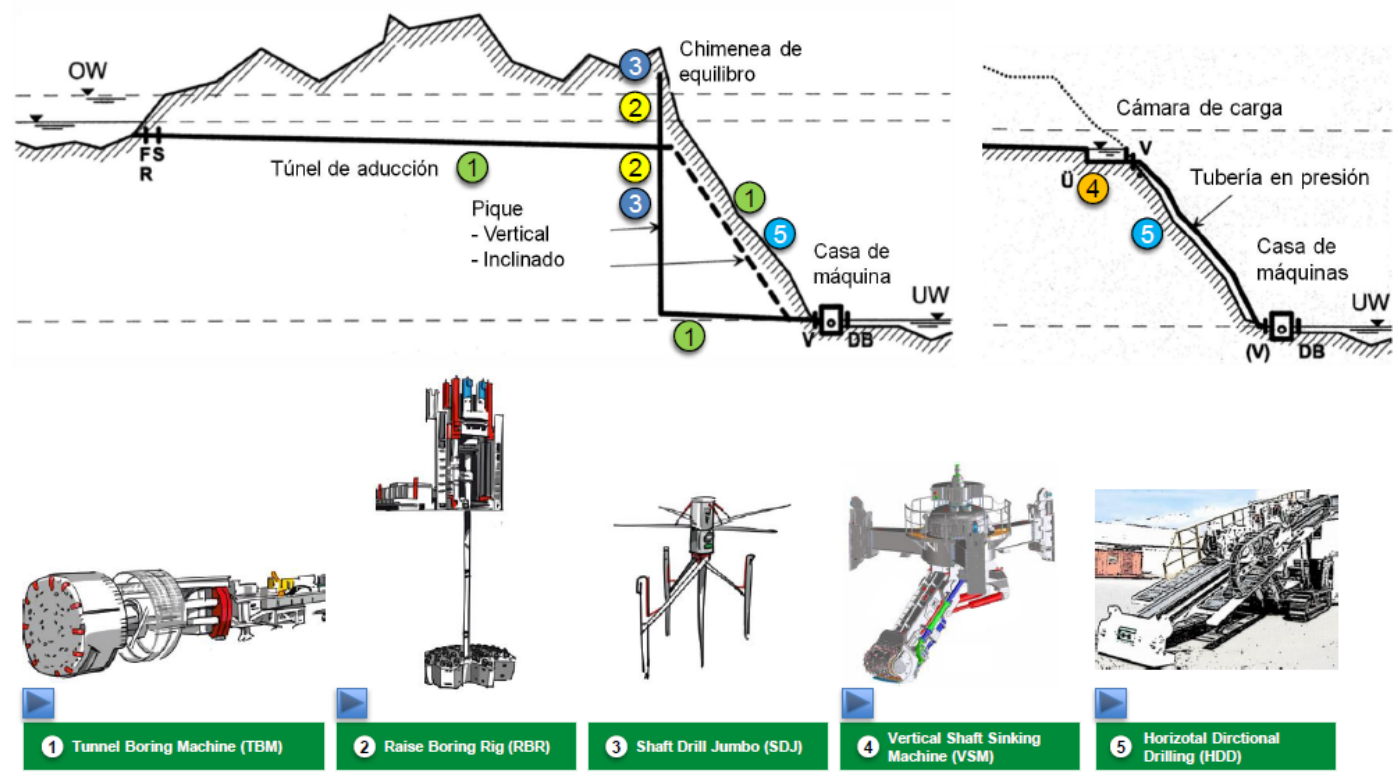

A continuación, se describen algunas de estas tecnologías que no se han abordado con anterioridad, detallándose más la correspondiente al Raise Boring, al ser una tecnología que se ha utilizado en España.

\section{RBR (Raise Boring Rig)}

Raise Boring es el sistema de ejecución mecanizada de pozos o chimeneas entre dos niveles. Los niveles pueden ser subterráneos o, el superior, estar en la superficie. 
Este método se desarrolló en los 50 en Estados Unidos. Consiste, básicamente, en la ejecución de un barreno piloto y luego ensanchar la perforación hacia arriba mediante una cabeza escariadora.

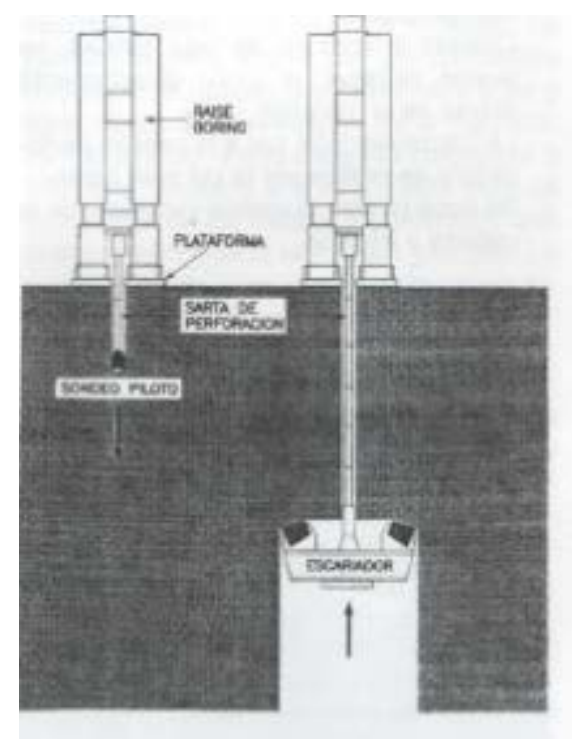

Desde entonces se ha innovado para encontrar nuevas aplicaciones en la perforación horizontal o con pequeño ángulo y en la vertical sin sondeo piloto.

Se han perforado con diámetros habituales entre 2 y $3 \mathrm{~m}$, a unas profundidades de 100 a 200 m, aunque se han llegado a 6 m de diámetro y más de 1.000 m de profundidad.

Este sistema tiene las siguientes ventajas e inconvenientes respecto a los métodos tradicionales:

Entre las ventajas de este sistema se encuentra:

- la alta seguridad y buenas condiciones de trabajo,

- la productividad más elevada que con explosivos,

- el sistema es de avance contínuo, con lo que se eliminan tiempos improductivos,

- el perfil liso de las paredes,

- la sobreexcavación inexistente

- la posibilidad de realizar excavaciones inclinadas.

En cuanto a los inconvenientes:

- la inversión elevada,

- el coste de excavación unitario elevado, 
- la poca flexibilidad en dimensiones y cambios de dirección,

- las dificultades en rocas en malas condiciones

- la necesidad de personal especializado.

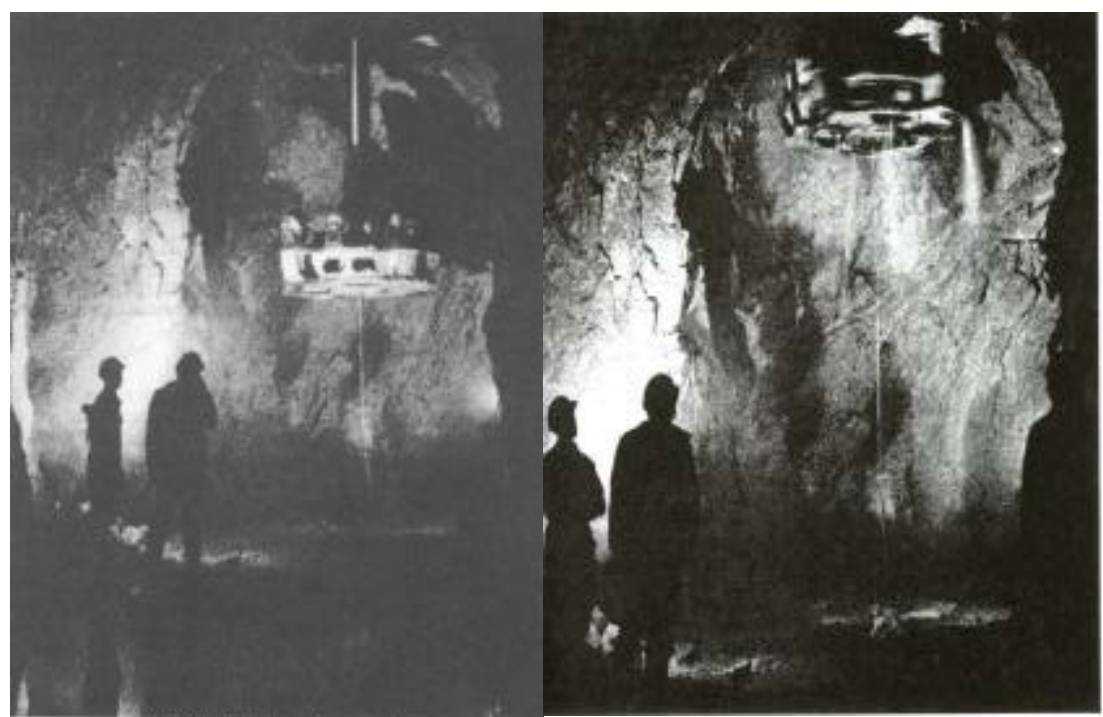

El principio de funcionamiento es el siguiente:

La roca se fractura por los mismos principios de la perforación rotativa. Los cortadores se hacen girar bajo un gran empuje contra la roca, rompiéndose ésta por la penetración del borde o de los botones de cada cortador. La velocidad de penetración está relacionada con la resistencia a compresión simple de la roca.

Si el empuje sobrepasa la resistencia a compresión de la roca, se producirán unas grietas debajo del cortador que se propagan hasta que la roca rompe. También es importante la separación entre los cortadores para que las grietas se unan y la roca se rompa en lajas. Para rocas blandas hay un menor número de cortadores y más espaciados que para rocas duras.

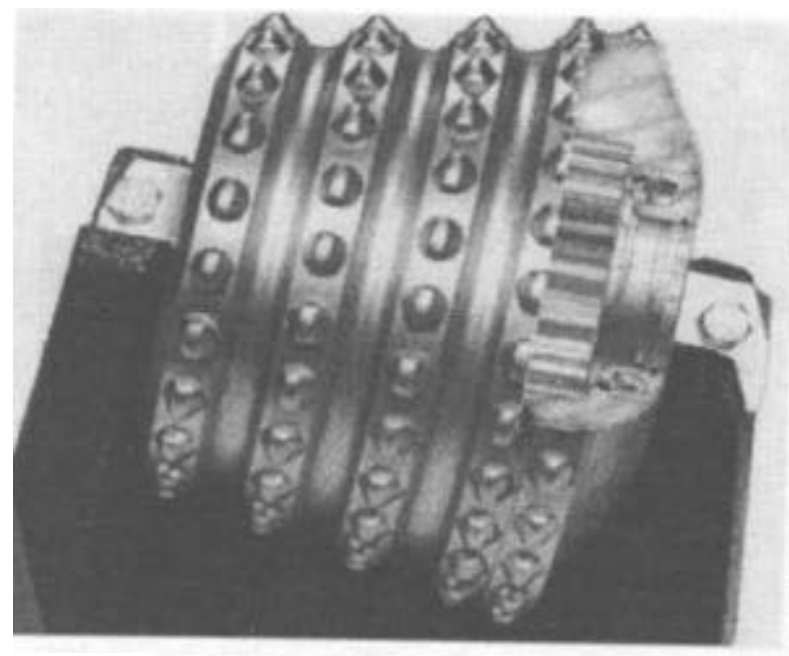

Cortador de botones de carburo de tungsteno 
Se realizará un sondeo o barreno piloto con un diámetro función del diámetro del varillaje y del de escariado.

Es muy importante que el taladro se desvíe lo menos posible (1\%). Entre los factores que influyen en la desviación están:

- Inclinación del taladro. A mayor inclinación, mayor desviación.

- Empuje aplicado. Un empuje excesivo favorece la desviación. Hay que tener en cuenta que a partir de cierta profundidad, el peso del varillaje puede superar el empuje necesario; así la máquina en lugar de empujar deberá compensar el exceso de peso.

- Buzamiento de la formación. El taladro tiende a avanzar paralelamente al plano de estratificación.

- Dureza. Tiende a desviarse a zonas más blandas.

- Diseño del varillaje. Barras de mayor diámetro mantienen mejor la dirección.
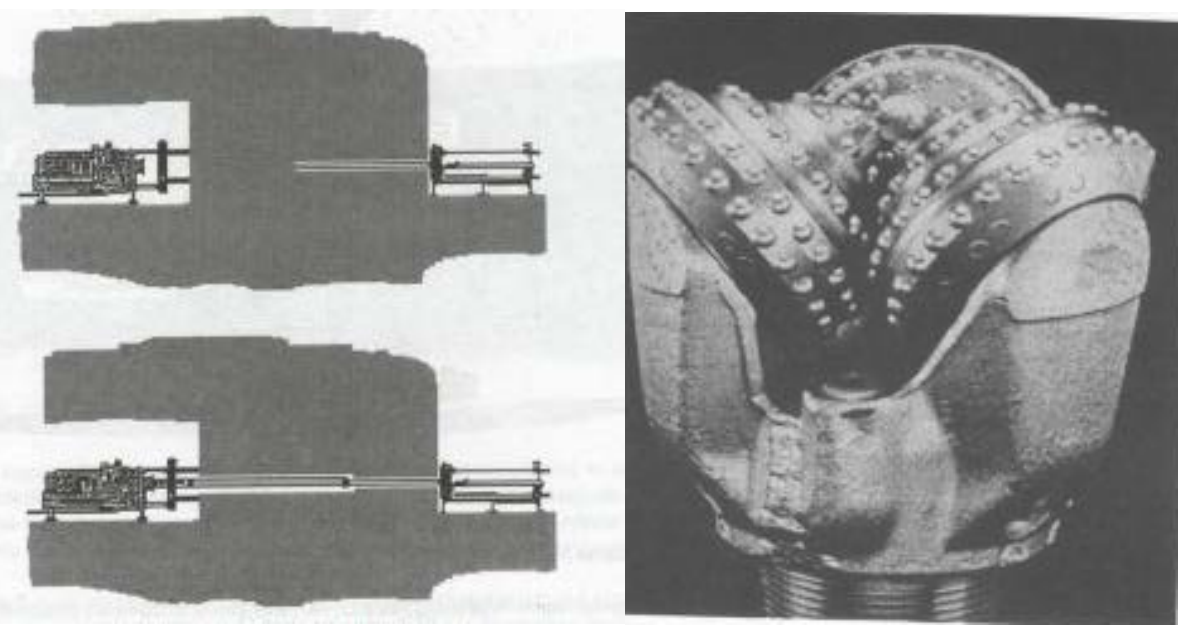

Respecto de la evacuación de los detritus, en el sistema tradicional, la fuerza de la gravedad ayuda a la evacuación de los detritus.

Sin embargo, cuando se excava hacia abajo o en perforación sub-horizontal la evacuación se realizará por inyección de fluido (aire o agua) directa o inversa.

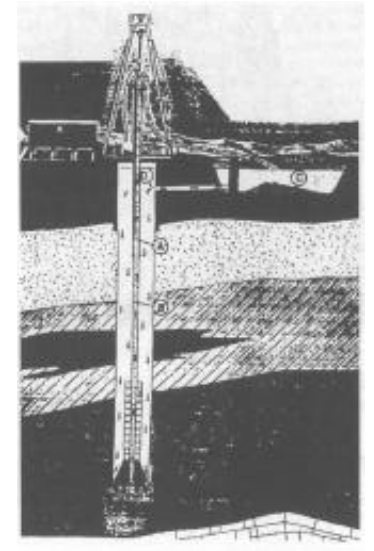


El sistema de agua es utilizado cuando se dispone de una buena cantidad de agua y el terreno no presenta mayores fracturas. El sistema de aire comprimido es utilizado cuando no se dispone de agua.

\section{Nuevas aplicaciones de la técnica raise-boring:}

- Sistema tradicional: Es un sistema seguro, eficiente y de bajo coste para realizar excavaciones en diferentes diámetros, longitudes y distintas formaciones geológicas.

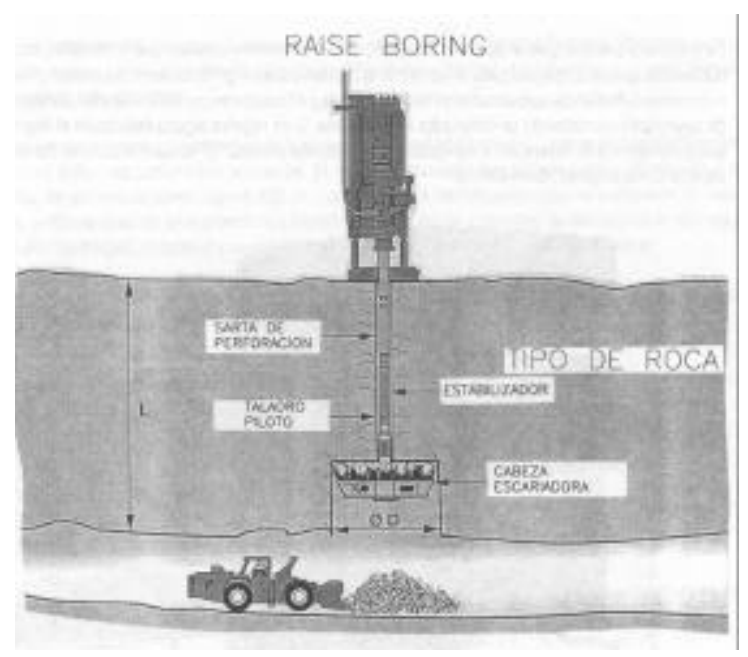

- Sistema horizontal: Nace como competencia a la perforación tradicional con voladura y a las TBM. Las claves de este sistema son un sondeo piloto certero (normalmente en dos etapas), una buena evacuación de los detritus y la estabilidad de la formación rocosa.

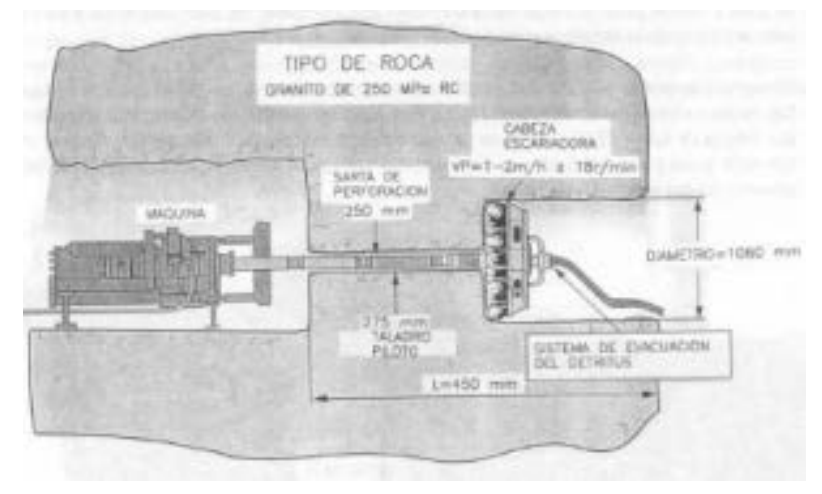

- Down Boring: Este método se ha desarrollado para perforar chimeneas entre los subniveles cuando no se puede utilizar el raise-boring tradicional. Primero se hace el sondeo piloto hasta llegar al subnivel correspondiente, se retira la sarta de perforación y se empuja la cabeza hacia abajo para escariar el sondeo. Los detritus caen por gravedad con la ayuda del flujo de agua. 


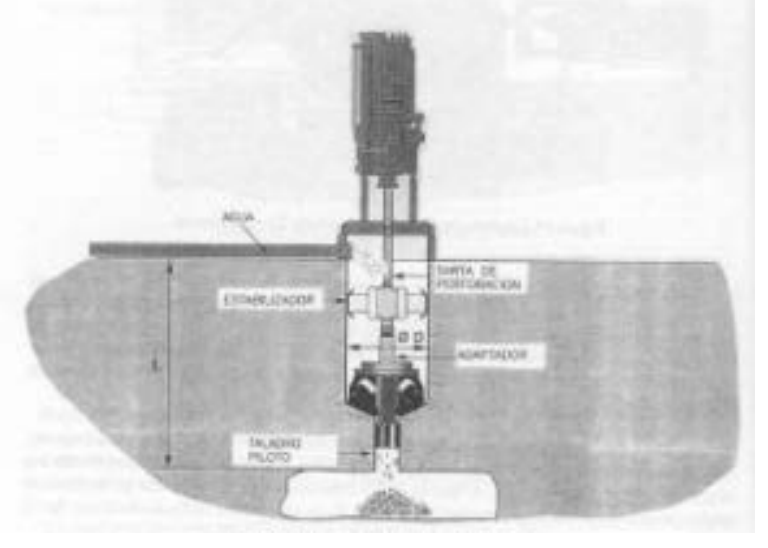

Este sistema se puede usar con evacuación inversa de detritus y sin sondeo piloto.

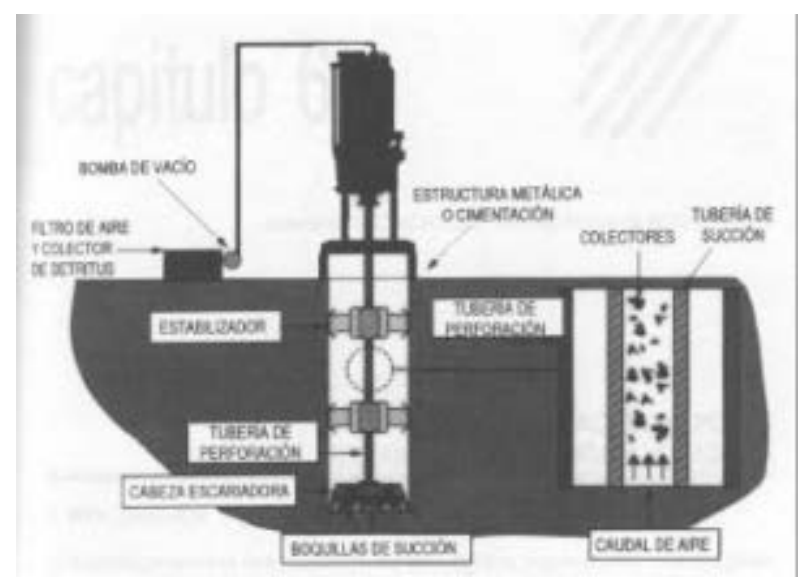

- Raise-boring ciego: Se usa para realizar chimeneas ciegas. La perforación se hace desde un nivel inferior, donde también está el control de la máquina. Esta es similar a una mini TBM, capaz de perforar verticalmente hasta con un ángulo de 30 grados. La máquina está expuesta a la caída de detritus por gravedad, de ahí que lleve unos pequeños transportadores para su evacuación. La dirección se controla por láser.

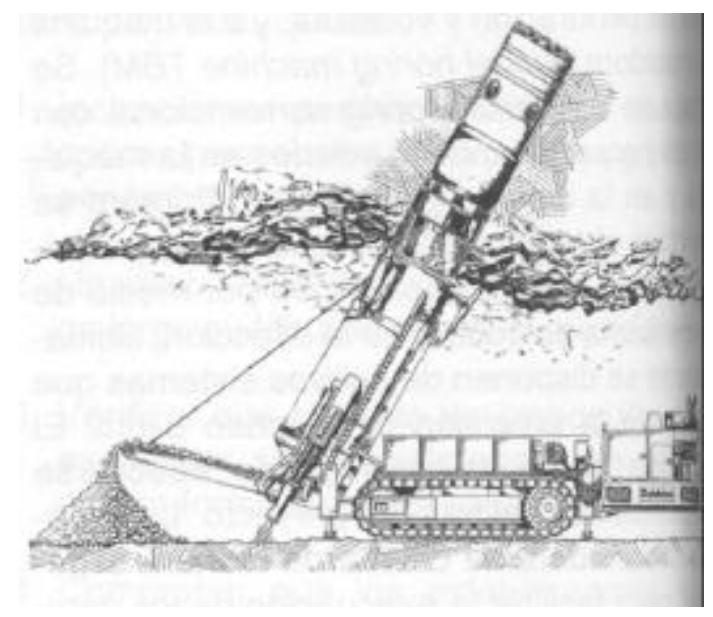




\section{SDJ (Shaft Drill Jumbo)}

El nuevo Jumbo de perforación de pozos o galerías verticales o con gran inclinación SDJ permite altas tasas de producción de perforación profunda llegando a diámetros donde otros métodos mecanizados no son adecuados.

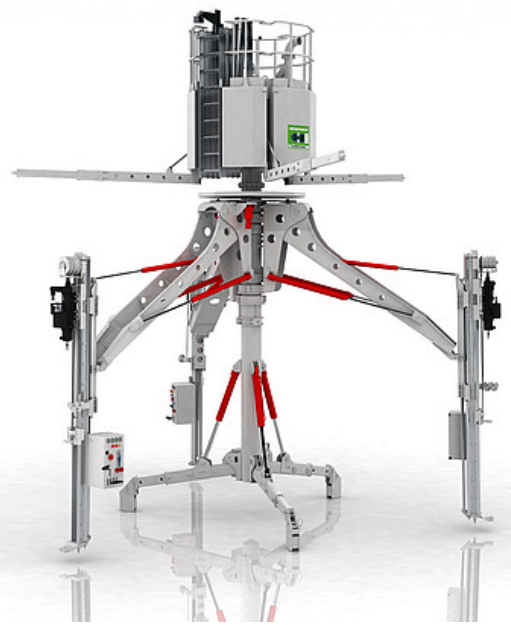

El principio de funcionamiento del Jumbo SDJ es el siguiente:

En un primer paso, el sistema se introduce en el centro del eje y se ajusta con sus estabilizadores hidráulicos a la pared del pozo.

Un trípode en la parte inferior y tres estabilizadores telescópicos en la parte superior proporciona al jumbo con soporte las operaciones de perforación, lo que le hace ser muy estable.

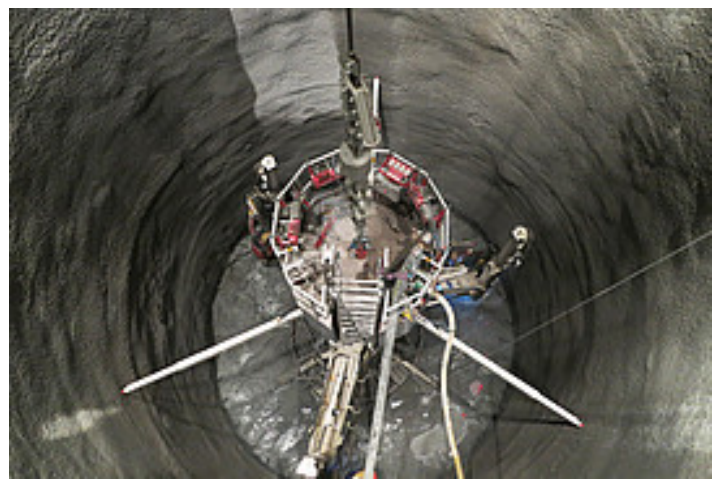

El ciclo de taladrado posterior se lleva a cabo de forma manual o de forma automática y con todos los brazos al mismo tiempo. El jumbo entra en acción realizando barrenos de perforación.

Después, el Jumbo se retrae y es levantado mediante un cabrestante para permitir la voladura, y posteriormente limpiar. Después de la voladura, una 
excavadora generalmente se lleva el material sobrante limpiando el orificio hasta el nivel más bajo.

Después de eso, el sostenimiento de la roca primaria mediante pernos de roca, hormigón proyectado o arcos de acero se lleva a cabo a partir de una plataforma de trabajo independiente. Al mismo tiempo, el SDJ ya está excavando el siguiente patrón de perforación. De este modo, 2-3 metros de pozo se pueden lograr por turno de trabajo, y el propio ciclo completo toma menos de 4 horas.

\section{VSM (Vertical Shaft Sinking Machine)}

Sirve para la excavación de todo tipo de pozos y consiste principalmente en una unidad de hundimiento y la unidad de excavación. Puede utilizarse en suelos estables e inestables. También funciona por debajo del nivel del agua, reduciendo los costos normalmente altos cuando se perfora en estas condiciones.
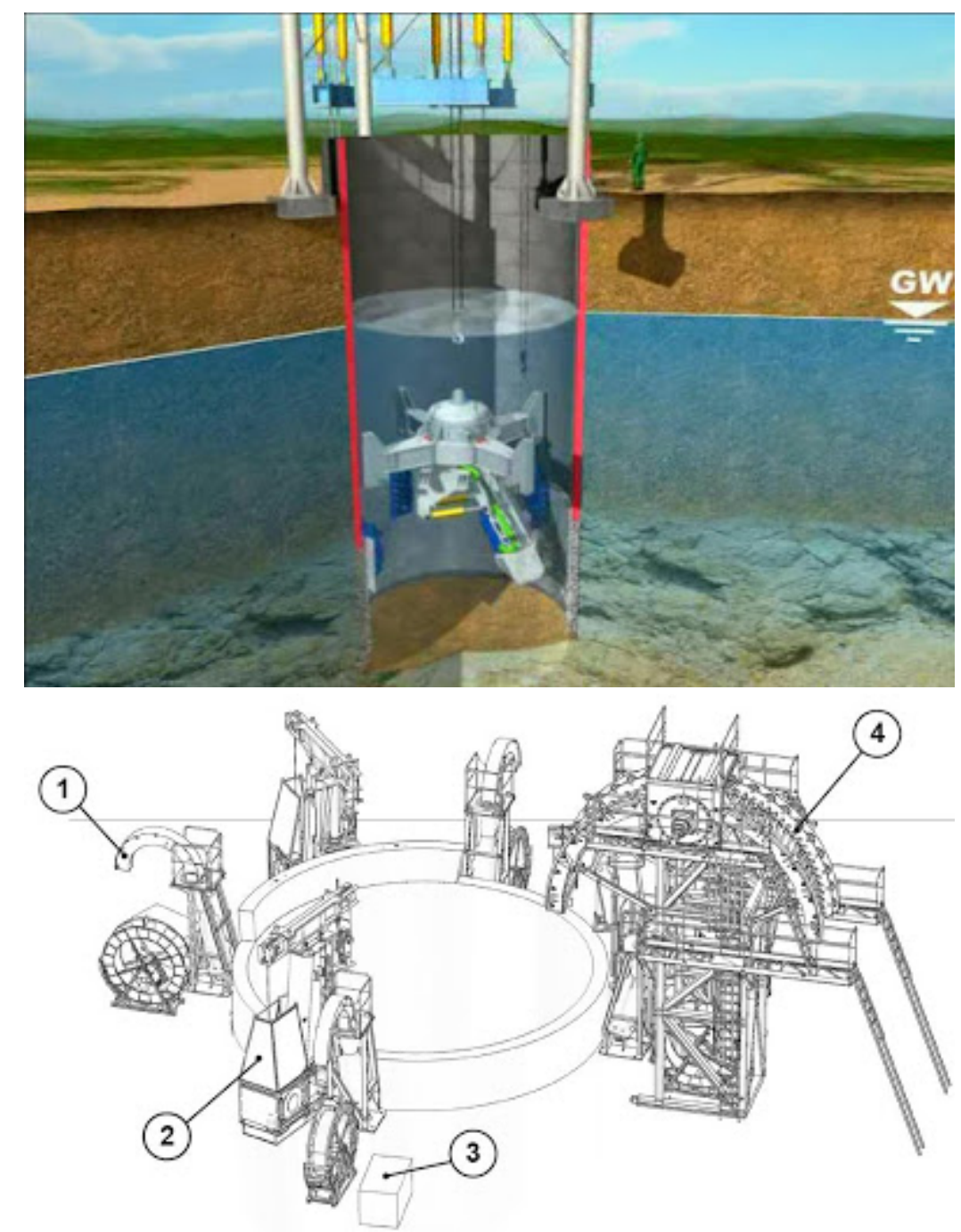
El proceso de corte funciona de manera similar a la de una máquina de excavación frontal parcial. El tambor rotatorio, el cual está equipado con herramientas de corte especiales se encuentra en el brazo telescópico y afloja la geología, haciendo movimientos de balanceo en la parte inferior del pozo.

El material excavado se elimina hidráulicamente a través de tuberías hasta la planta de separación en la superficie. Durante la operación, la máquina de perforación tiene cables de acero conectados a la unidad de hundimiento que se encuentra en la superficie. Esto significa que la máquina puede estar bajo vigilancia constante. Una variedad de diferentes opciones de revestimiento del pozo están disponibles, dependiendo de la geología.

Las unidades de control y el suministro se establecen en un nivel independiente y permanecen en la superficie. Así como el suministro de energía eléctrica e hidráulica. Esto significa que el operador de la máquina siempre es capaz de verificar los parámetros técnicos de la máquina mientras se está escavando y puede cambiarlos si es necesario para adaptar la máquina de perforación a las condiciones geológicas ambientales y realizar los ajustes óptimos de la máquina.

También existen en la actualidad una serie de soluciones complementarias que facilitan las labores de perforación como son:

- Prospección con Geofísica

- Paraguas de tubos de acero o de pernos

- Jet-grouting

- Inyecciones de consolidación - compensación

- Congelamiento del suelo

- Empleo de aire comprimido

Avances en el diseño de elementos de soporte y fortificación:

- Pernos de fibra, autoperforantes, expansibles, etc. (cemento, resina, etc.)

- Marcos metálicos de distintas secciones y diseños

- Hormigón (dovelas, colado y shotcrete) reforzado con fibras (acero, sintético, etc.)

- Shotcrete proyectado por vía húmeda (Aditivos) y de carácter permanente.

- Soporte con elementos de amortiguación para prevenir squeezing.

- Liners proyectables para soporte de roca. 
Avances en medidas de control del agua:

- Dispositivos para entrada controlada del agua.

- Lámina impermeable confinada entre sostenimiento provisional y revestimiento. definitivo "sándwich" (PVC, poliolefinas, geotextiles,etc.).

- Hormigones de carácter impermeable.

- Láminas proyectables.

Respecto a los avances antes indicados, merece la pena hacer un mayor hincapié en el revestimiento del túnel o galería, con una descripción de lo que supone el uso de fibras de refuerzo en la construcción subterránea, uso que se está haciendo extensivo y que está sujeto aún a mejoras continuas.

El papel de un revestimiento delgado de hormigón proyectado no es el de tratar de soportar las presiones originales del terreno sino que es el de estabilizar las deformaciones requeridas para movilizar la resistencia inherente del terreno.

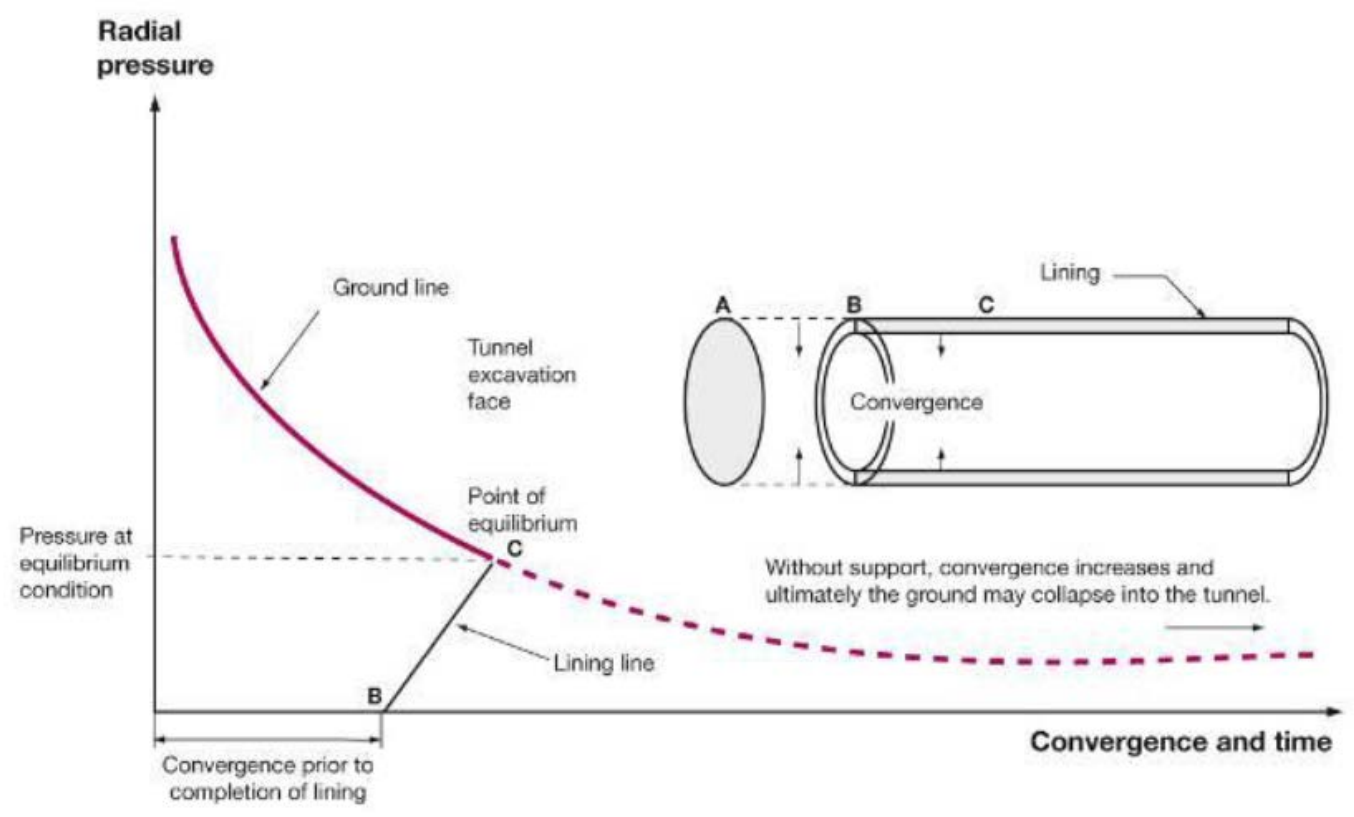

Los materiales con los que se refuerzan los hormigones para ofrecer mejores propiedades suelen ser fibras sintéticas y de acero, cuyas propiedades son las siguientes: 


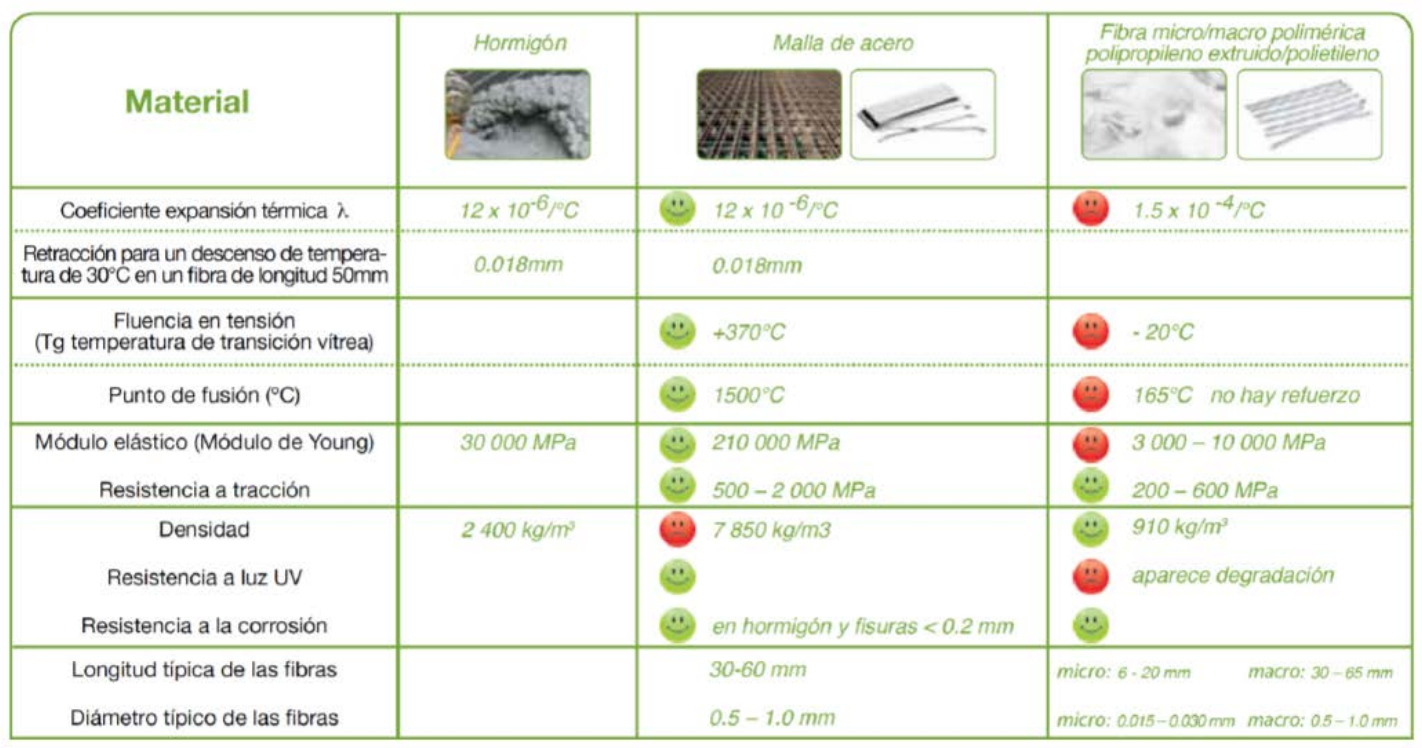

$$
\sigma=E \cdot \varepsilon
$$

\section{$E=$ Módulo de elasticidad}

$\varepsilon=$ deformación $\approx$ apertura de fisuras

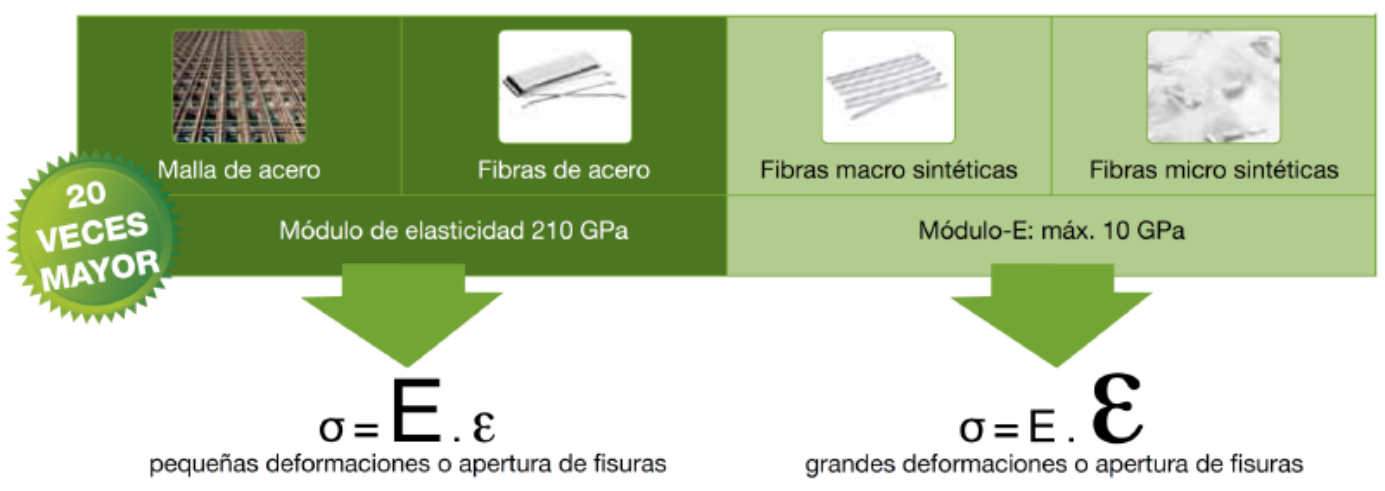

El hormigón proyectado reforzado con fibras de acero es una solución apropiada para estabilización de excavaciones, debe ser semi-rígido y su ductilidad no debe afectarse elevando la resistencia del hormigón, pues se rigidizaría el sistema.

Las fibras de acero suponen una mejora estructural para el hormigón. Después de la primera fisura del hormigón, las fibras de acero son activadas interceptando las fisuras y aportando una resistencia extra al material. Esta capacidad de deformación genera ductilidad (tenacidad). Es importante que el refuerzo con fibras controle las fisuras y que limite su abertura para permitir la redistribución de cargas. 


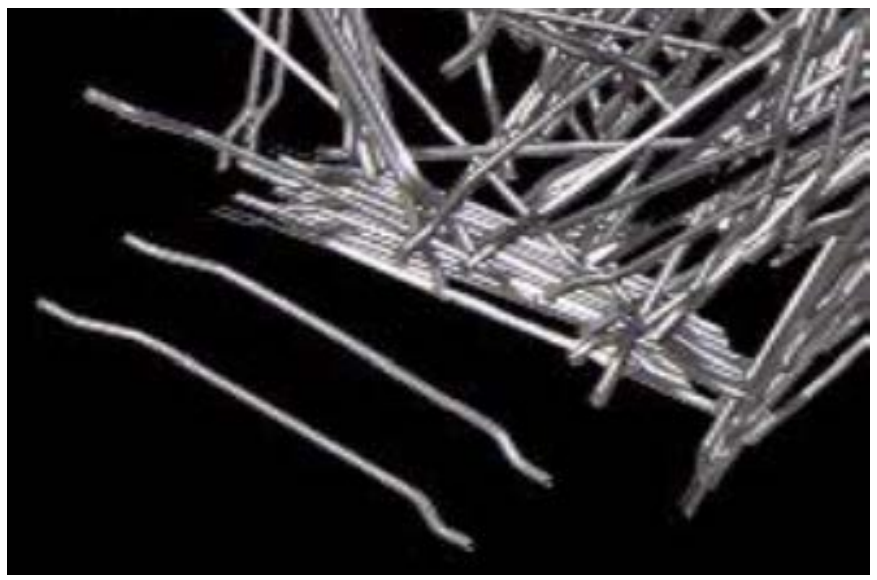

La adición de las cantidades apropiadas de fibras de acero incrementan sustancialmente las características del hormigón simple, pasando de su comportamiento inicial elástico-frágil a un elástico-plástico (dúctil), posibilitando algunas aplicaciones a nivel estructural. Todo ello da lugar a una elevada resistencia a las fisuraciones y mejor control de las mismas, y mayor durabilidad.

Las fibras microsintéticas, sin embargo, ofrecen una mejora material y ejercen de protección pasiva al fuego porque las fibras (de polipropileno) desaparecen generando canales en el hormigón cuando la temperatura alcanza $360{ }^{\circ} \mathrm{C}$. Las presiones internas generadas por el vapor serán aliviadas a través de esos microcanales reduciendo significativamente los posibles procesos de fractura (spalling).

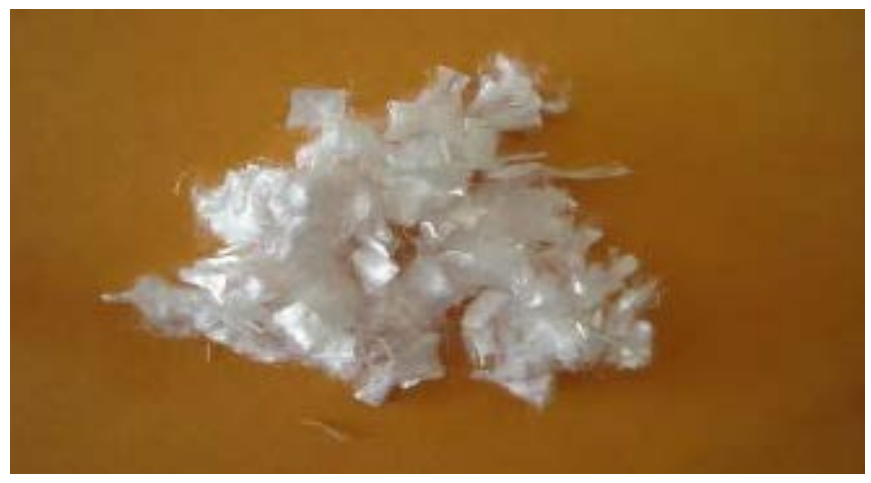

La comparación de características del hormigón convencional al reforzado con fibras, es la siguiente: 


\begin{tabular}{l|c} 
Resistencia a Compresión & No Cambia \\
\hline Resistencia de Primera Fisura & No Cambia \\
\hline Resistencia al Corte & \begin{tabular}{c} 
Incrementa \\
\hline Retacción Plástica en la Edad Temprana \\
Fisuración por los Efectos de Temperatura (fibras sinteticas)
\end{tabular} \\
\hline Corrosión & Reduce \\
\hline Durabilidad & Reduce \\
\hline Resistencia al Fuego (spallig) & \begin{tabular}{c} 
Incrementa \\
\hline Permeabilidad
\end{tabular} \\
\hline Resistencia al Abrasión & Leve Incremento (fibras de acero) \\
\hline Resistencia al Impacto & Incremento (fibras sinteticas) \\
\hline
\end{tabular}

En resumen, en la actualidad:

Las microfibras sintéticas además de dar lugar a un mejor control de las fisuraciones plásticas en las primeras edades del hormigón, son muy eficientes para proteger la estructura contra los problemas de incendio.

Las fibras de acero mejoran las principales propiedades del hormigón (flexión, cortante, fatiga y resistencia al impacto). Mejoran y controlan de forma muy significativa la fisuración del hormigón, incrementando consecuentemente su durabilidad.

Lo sistemas modernos de dosificación pueden ser instalados en la planta, logrando un control y dispersión de la fibra en la pieza de forma eficiente, homogénea y sin problemas.

Las fibras de acero pueden reemplazar el acero de refuerzo convencional, logrando un significante ahorro en el costo de los materiales y en los tiempos de producción.

Por todo ello, el empleo de hormigón reforzado con fibras está siendo utilizado cada vez más para obras subterráneas ya que se está mostrando como un material de construcción idóneo para los revestimientos de túneles, incrementando la durabilidad y productividad de la obra.

Otro aspecto a tener en cuenta en la realización de galerías o cavernas en los aprovechamientos hidroeléctricos y que supusieron una diferencia importante en cuanto al conocimiento en el comportamiento del terreno y de la ejecución de la obra en sí, fue la utilización de la auscultación. 
Su finalidad es la de controlar los movimientos de los túneles, galerías y cavernas así como el comportamiento de los terrenos anejos, presiones de agua, etc. durante las fases de construcción y poder asegurar su adecuación a las hipótesis y modelos de cálculo adoptados durante los trabajos de diseño.

Para cumplir tales objetivos se instalan los instrumentos y sistemas de auscultación, que en cada momento informan de las reacciones con que el terreno, los sostenimientos y los revestimientos, responden a las distintas operaciones que se lleven a cabo.

La comparación de los valores previstos en la fase de proyecto con los obtenidos en la auscultación permite calibrar el diseño o adoptar las medidas correctoras oportunas.

Los sistemas han de ser planeados con el mayor cuidado, y como condiciones esenciales, han de hacerse en íntima relación con las personas que lleven a cabo el proyecto, y ha de existir una organización que permita la interpretación clara y rápida, estableciendo una cadena de transmisión de las informaciones a los centros de decisión, con atribución clara de las responsabilidades de cada uno, de forma que no haya dudas ni dilaciones a la hora de tomar medidas correctoras.

Esencialmente en los túneles, galerías y cavernas se miden fuerzas y deformaciones. En ocasiones, durante las fases de ejecución más avanzadas de las obras se realizan también comprobaciones de resistencia, particularmente del terreno, ya que éste puede sufrir una descompresión, saturación u otros fenómenos que alteren sus condiciones.

Las medidas que se efectuarán normalmente en las obras subterráneas antes referidas son, fundamentalmente, en deformaciones y fuerzas y presiones.

Aun cuando en la fase de proyecto las fuerzas se hayan considerado de forma primordial, a la hora de efectuar el control con finalidades de seguridad, son las deformaciones las que deben medirse con mayor profusión y cuidado.

Se suele prever el control de corrimientos, convergencias y ovalizaciones mediante clavos para medida con cinta de convergencia.

Como la deformación se produce en todo el perímetro de la excavación, las medidas entre los puntos del perímetro del túnel dan desplazamientos relativos, por lo que hay que referir dichos desplazamientos a puntos fijos exteriores para convertirlos en deformaciones absolutas. 
En todas las secciones tipo se suelen medidas topográficas de precisión de asientos absolutos en la clave y solera del túnel, mediante nivelación de precisión. Normalmente se establece un programa de mediciones a realizar, adecuándolo al ritmo de construcción de la obra, empezando a tomar lecturas en aquellas unidades que estén terminadas y en las que se pueda iniciar la auscultación. A medida que se van acabando otras unidades nuevas, se van incorporando al control de auscultación, teniendo presente que dentro de la misma sección se controlarán lo más simultáneamente posible los diferentes equipos que la integren.

Las secciones con pernos de medida de convergencia se suelen instalar a distancias no superiores a $40 \mathrm{~m}$, o cuando se trate de zonas singulares. Cuando se coloquen clavos en la clave del túnel y en la solera de las secciones tipo instrumentadas, se tomarán las cotas absolutas de precisión con la frecuencia que se estime adecuada en cada caso.

Respecto a fuerzas y presiones, se distinguen entre presiones totales, radiales o tangenciales y entre tensiones internas, sobre los sostenimientos.

Se pueden disponer células de presión total, para medida y control de las presiones totales sobre el sostenimiento, y así conseguir un mejor conocimiento del comportamiento tensodeformacional de los terrenos en el entorno del túnel, para tener una mayor seguridad en los trabajos de excavación y revestimiento, para detectar las posibles tendencias de expansividad de determinados materiales y para la determinación más exacta de la presión sobre el revestimiento.

Es indudable que estas nuevas medidas proporcionarán un conocimiento mucho más completo del comportamiento del terreno ante la excavación.

También se pueden utilizar células de cuerda vibrante, cuya ventaja consiste en que han demostrado tener fiabilidad a largo plazo. Por otra parte, las células de cuerda vibrante son menos rígidas, midiendo deformaciones prácticamente nulas.

Por otra parte, la instalación en cada sección de extensómetros de cuerda vibrante permite el control y medida de las tensiones de trabajo en armaduras del revestimiento.

Toda la información que proporcione la auscultación junto con el registro geotécnico de las características del frente, terreno excavado, etc. durante la fase de excavación del túnel, y su representación en un perfil geotécnico 
longitudinal, ayudará sustancialmente en la ejecución de las complicadas obras subterráneas asociadas a los aprovechamientos hidroeléctricos.

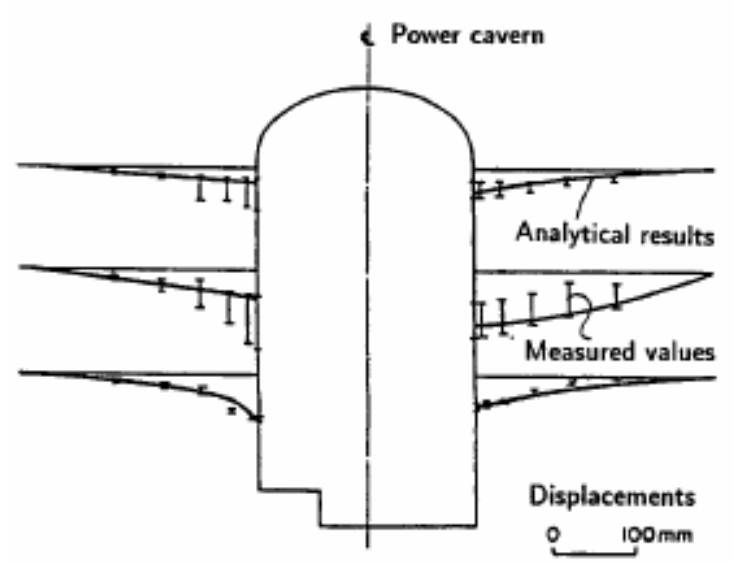

Comparación entre los desplazamientos calculados y medidos en seis extensómetros colocados en obra

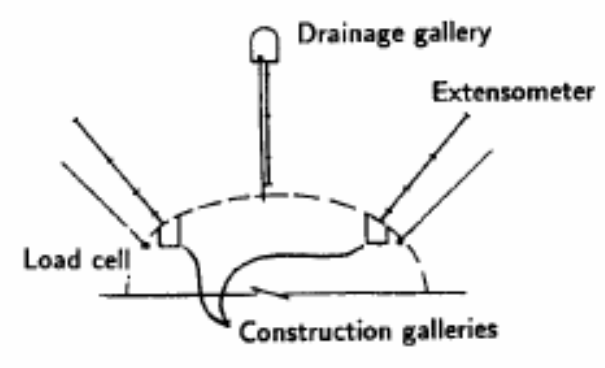

\subsection{TENDENCIAS FUTURAS}

Las perspectivas y desafíos globales para las galerías y obras subterráneas en general, asociadas a aprovechamientos hidroeléctricos son, en resumen, las siguientes (European Vision OOSS 2030):

- Equipos y sistemas de soporte inteligentes (auto-aprendizaje).

- Túneles de gran diámetro con costo-beneficio optimizado.

- Avances en tecnología de perforación en roca (sistemas laser).

- Completo conocimiento de las condiciones geotécnicas (terreno transparente).

- Máquinas TBM universales.

- Proyectos sin impacto ambiental.

- Costos de obras subterráneas similares a las de superficie.

- Operaciones de construcción remotas.

- Explosivos no contaminantes.

- Aumento importante de rendimientos de TBM.

- Equipos de seguridad de última generación (seguridad máxima). 
Ejemplos de proyectos y tecnología de mayor aplicación a futuro:
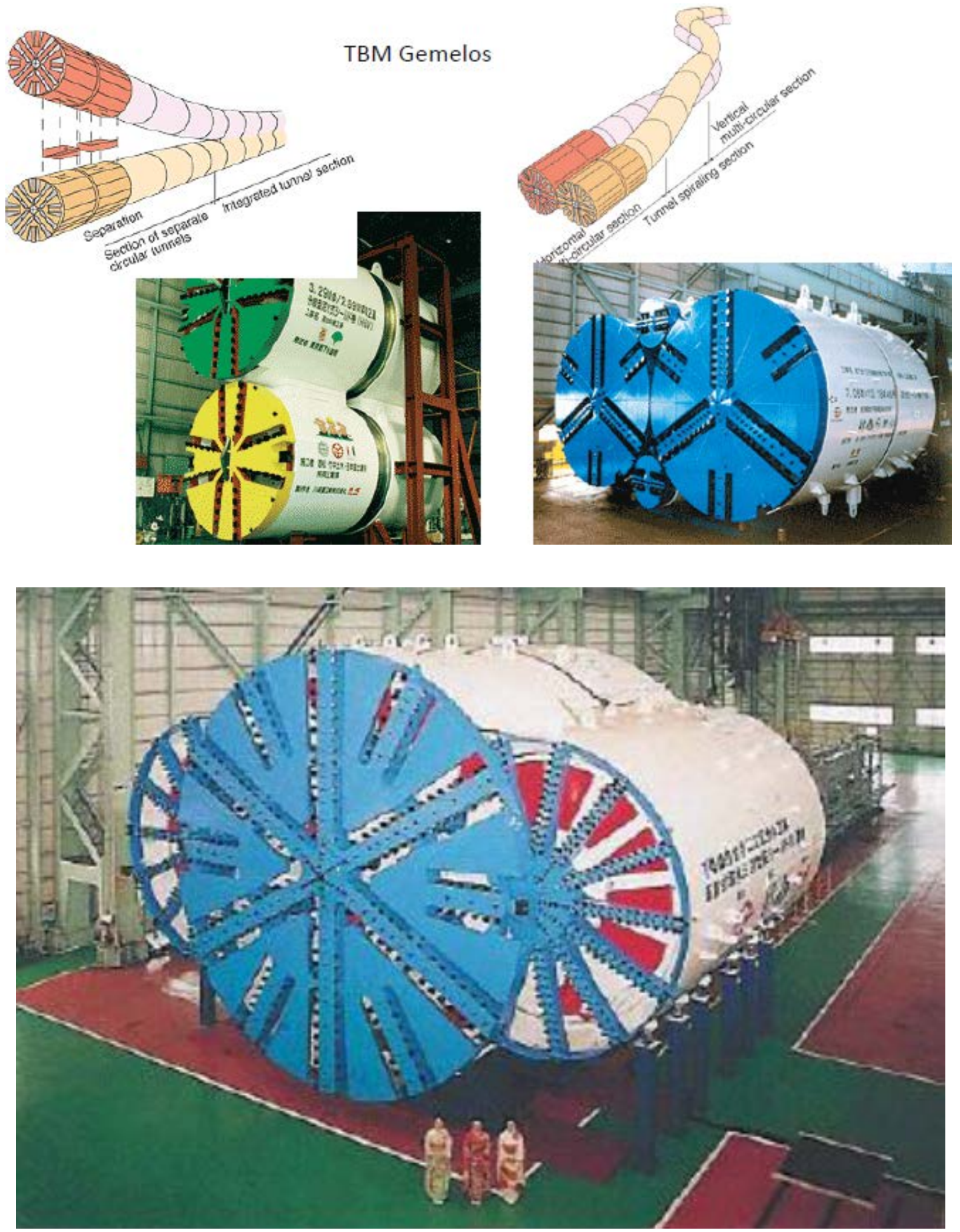

TBM TRIPLES 
Tecnologías innovadoras para aprovechamientos hidroeléctricos de pequeña escala:

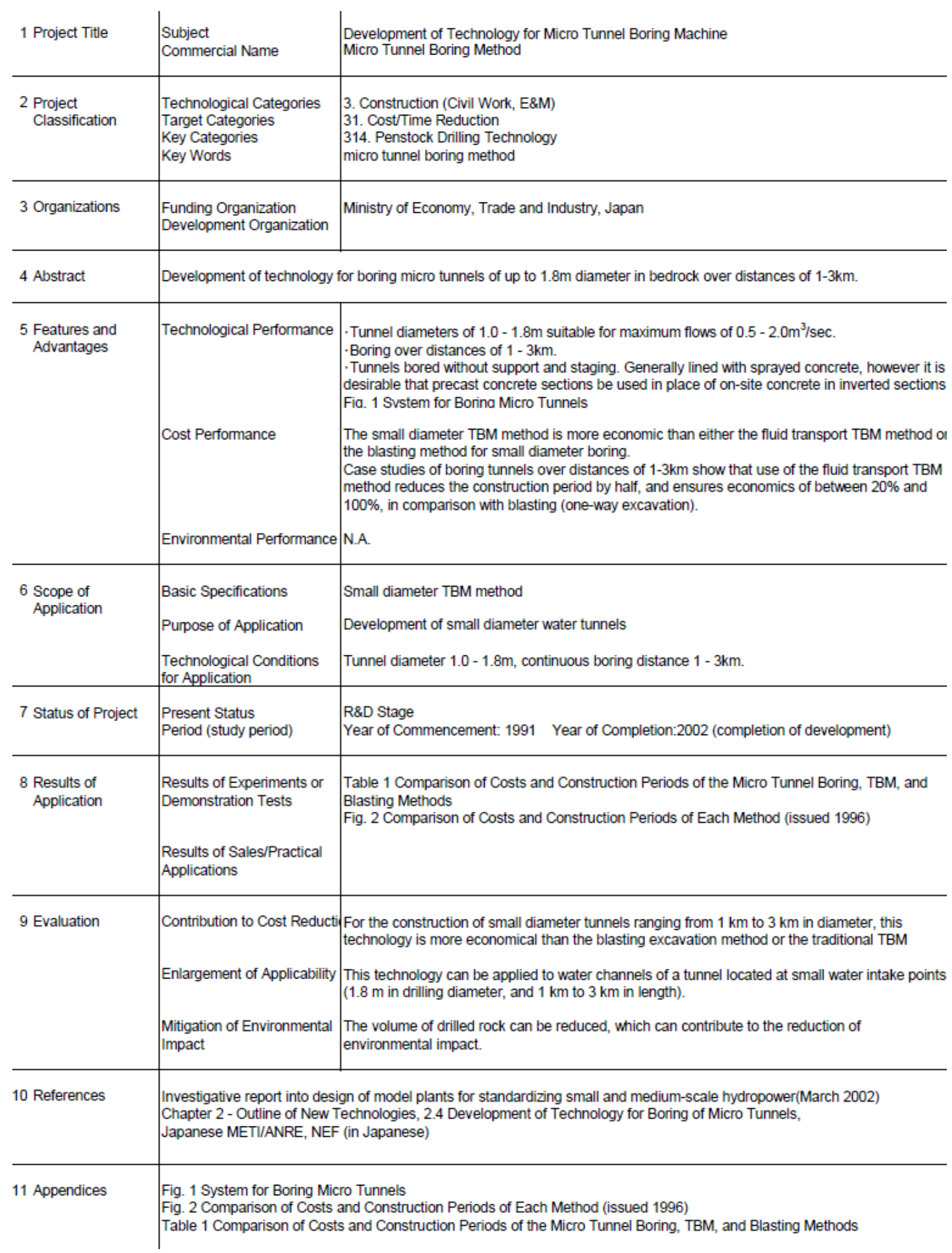




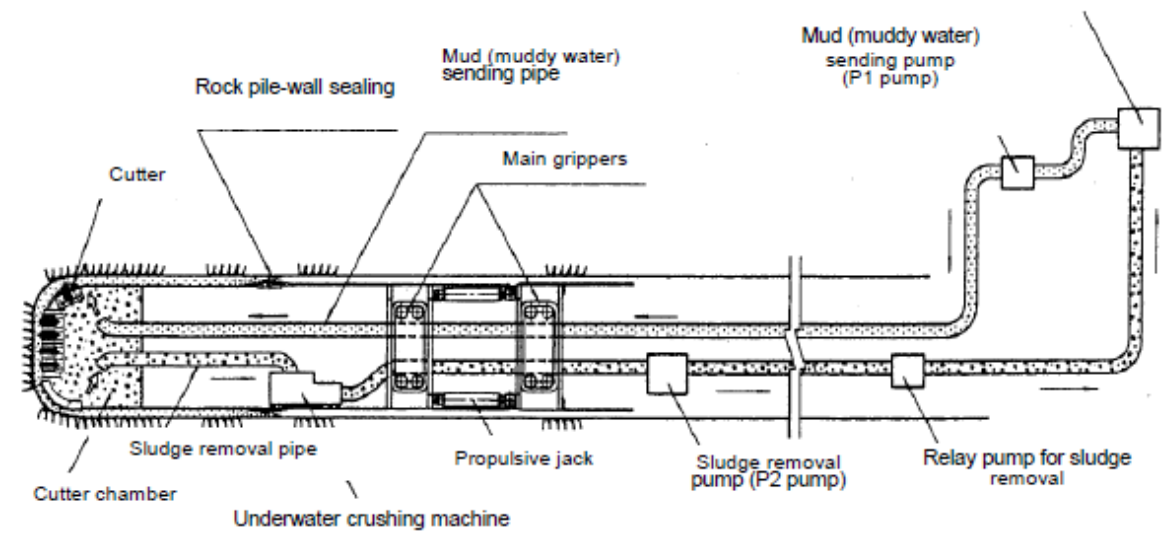

Fig. 1 Sytem for Boring Micro Tunnels

Table 1 Comparison of Costs and Construction Periods of the Micro Tunnel Boring, TBM, and Blasting

\begin{tabular}{|c|c|c|c|c|}
\hline Method & \multicolumn{2}{|c|}{ Boring distance (m) } & $\begin{array}{l}\text { Construction costs } \\
\text { (x 1,000 JPN Yen) }\end{array}$ & $\begin{array}{c}\text { Overall construction period } \\
\text { (months) }\end{array}$ \\
\hline \multirow{3}{*}{$\begin{array}{l}\text { Microtunnel boring method } \\
\text { (1.62m dia.) }\end{array}$} & & 1,160 & 556 & 9.5 \\
\hline & & 2,000 & 464 & 13.4 \\
\hline & & 3,070 & 425 & 18.5 \\
\hline \multirow{3}{*}{ TBM method ( $2.3 \mathrm{~m}$ dia.) } & & 1,160 & 609 & 9.2 \\
\hline & & 2,000 & 512 & 13.2 \\
\hline & & 3,070 & 470 & 18.5 \\
\hline \multirow{6}{*}{ Blasting method } & \multirow{2}{*}{1,160} & One-way excavation & 577 & 16.9 \\
\hline & & Two-way excavation & 697 & Average 9.1 \\
\hline & \multirow{2}{*}{2.000} & One-way excavation & 536 & 29 \\
\hline & & Two-y/ay excavation & 576 & Average 15.0 \\
\hline & \multirow{2}{*}{3,070} & One-way excavation & 501 & 42.7 \\
\hline & & \begin{tabular}{|l|} 
Two-way excavation \\
\end{tabular} & 522 & Average 21.2 \\
\hline
\end{tabular}

Table prepared 1996

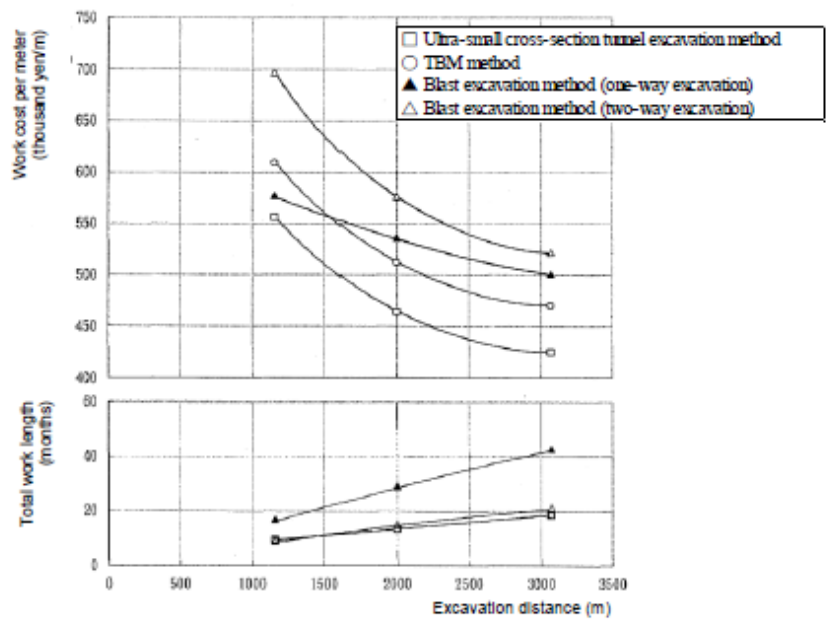

Fig. 2 Comparison of Costs and Construction Periods of Each Method (issued 1996) 



\section{Capítulo 6.}

\section{Evolución de los aprovechamientos hidroeléctricos}





\subsection{LOS INICIOS DE LA HIDROELECTRICIDAD. PERÍODO 1890- $\underline{1936}$}

Los inicios de la hidroelectricidad, enmarcados en una electrificación incipiente del país, comienzan a finales del S. XIX.

Hacia el año 1850 en Barcelona, Madrid u otras ciudades se instalaron pequeños alumbrados. El ritmo de adaptación de las innovaciones sí se va a ver continuado en el tiempo. Probablemente a ello contribuyeron dos hechos: el que el gas para alumbrado hubiese tenido una implantación en España mucho menor y más tardía que en otros países y el que la electricidad fuese empleada inicialmente como alumbrado, lo que facilitó una difusión de la tecnología antes de que esta forma de energía pudiera aplicarse al sector industrial.

Desde 1880 la prensa técnica española siguió con atención los avances en el terreno de la hidroelectricidad: las noticias sobre el éxito de aprovechamientos europeos en Saint Gallen, Viene y Bellagarde, y de la explotación en Estados Unidos de Niágara, que enviaba 100.000 caballos de potencia en corriente continua hasta Búfalo. No obstante, los proyectos que perseguían llevar electricidad a los núcleos urbanos españoles se consideraron inviables durante mucho tiempo.

El año de 1881, fecha de la constitución de la Sociedad Española de Electricidad, se ha mantenido como referente a la hora de señalar el inicio de la explotación industrial de la electricidad en España. Antes de ese momento fueron, no obstante, muchos y muy diversos los ensayos llevados a la práctica. Iluminaciones de espacios públicos, alumbrados de locales comerciales, de espectáculos, de domicilios particulares, incluso en muchas ocasiones el empleo de la electricidad estuvo vinculado a los más variopintos acontecimientos sociales que utilizaban esta nueva forma de energía para dar mayor realce a la celebración.

La electricidad va a ir consolidándose en España conforme al ritmo general de la evolución seguida en los países más avanzados del momento y aunque la dimensión e intensidad del fenómeno no pudo ser comparable con la de los grandes países, el recorrido cronológico fue similar e, incluso, en algunos momentos se estuvo a la vanguardia en lo que a la aplicación de la tecnología se refiere.

En fecha tan temprana como 1886, la Sociedad Electrodinámica Cousí, Mané y Compañía presentó un proyecto para la explotación de un salto en Chulilla a 56 
km de Valencia, pero sus propios promotores debieron concluir la inviabilidad del proyecto.

Al final del decenio, la situación estaba cambiando. En esta época se comenzó la electrificación de poblaciones próximas a los ríos. Aparte de la iluminación de Pamplona, se proyectaban otros alumbrados de origen hidráulico para Segovia, aprovechando las energías sobrantes de una fábrica de harinas; la de Calatayud; Guadalajara y, en 1890, se concedieron los primeros saltos importantes sobre el río Araya.

La distribución de energía en España estaba formada por una cantidad grande de pequeñas compañías que, aisladas unas de otras, funcionaban con criterios autóctonos, sin norma alguna en cuanto a la calidad del servicio.

Las compañías productoras nacen para abastecer a las grandes poblaciones, aprovechando la potencia hidráulica de los ríos más próximos o globalmente más interesantes. La construcción de estas instalaciones fue motivo de desarrollo para unas regiones que estaban hasta entonces, bastante deprimidas. Se crearon puestos de trabajos en esas zonas y se les dotaron de un mejor acceso que hasta entonces limitaba mucho su desarrollo.

A comienzos de siglo, existían en España unas 500 máquinas térmicas y unas 300 hidroeléctricas. Por ello, buena parte de la fase inicial del desarrollo eléctrico español estuvo ligado a la expansión de las instalaciones hidráulicas, ya que en 1901 representaban casi el 40\% de las centrales existentes.

El acceso y la tenencia de recursos hidráulicos en España se regían por la Ley de Aguas de 1879. Esta legislación de aguas marcadamente liberal contribuyó al éxito del aprovechamiento hidroeléctrico ya que apenas alteraba las condiciones de la explotación hidromecánica tradicional en que los saltos que se empleaban eran abundantes e indiferenciados y comprometían únicamente el uso de una parte del dominio público ocupando solo zonas colindantes.

Los usos eran no consuntivos y la explotación se llevaba a cabo en las cabeceras de los ríos o en sus remansos naturales mediante instalaciones de escasa magnitud. De este modo, este sistema concesional español allanó en sus primeras etapas el camino de la explotación eléctrica.

La Ley agilizó el acceso y proporcionó garantías de continuidad en la tenencia a los concesionarios, pero su escaso desarrollo reglamentario quebraría pronto la transparencia del procedimiento. En primer lugar, aun siendo obligatoria desde 1901 la inscripción de los aprovechamientos, muchos de los establecimientos tradicionales no la hicieron efectiva, entre otras causas, porque los organismos 
encargados se hallaban descentralizados y descoordinados entre sí. En segundo lugar, no se respetaban los plazos establecidos por la Ley y, aun sin comenzar las obras, no se perdían los derechos de aguas concedidos.

Se puede hablar de que esta etapa de origen y consolidación de la electricidad tiene tres periodos claramente diferenciados. El primero de ellos refleja la introducción de la nueva forma de energía y nos conduce hasta el año 1881; el segundo periodo estuvo caracterizado por la producción de origen térmico, con centrales de reducido tamaño y un mercado de distribución limitado por la propia capacidad de la tecnología disponible; y un último periodo, que se inicia con el siglo XX pero que se consolida en su segundo decenio, que tiene como especificidad el triunfo absoluto de la producción de origen hidráulico.

Desde 1905, se contó con la combinación de innovaciones que hicieron posible la transición hacia la hidroelectricidad en España. La experiencia en obra hidráulica, la disponibilidad de turbinas apropiadas y de los instrumentos de transformación y aislamiento de corrientes adecuados para la transmisión del fluido a larga distancia permitieron el transporte de electricidad desde distantes núcleos montañosos donde se ubicaban los saltos hidroeléctricos.

Pero era necesario disponer de un potencial hidráulico adecuado y realizar elevadas inversiones en obra civil de primer establecimiento, compra de maquinaria y tendido de líneas de centenares de kilómetros entre los puntos de producción y aquéllos de consumo. Aunque las ventajas en flexibilidad y organización que procuraba el motor eléctrico eran amplias, las manufacturas interesadas en transitar del vapor a la electricidad debían transformar sus equipos y adecuarlos a la nueva energía. Pero solo un distanciamiento relevante de los costes del vapor y de hidroelectricidad pudo provocar una transición del carbón al agua tan consistente como la que tuvo lugar en España entre 1905 y 1925.

Los costes de las compañías hidroeléctricas se mantuvieron relativamente constantes, una vez que se salvaron las dificultades del lanzamiento de las respectivas empresas. Este ahorro en los costes unitarios de la hidroelectricidad en España fue posible por la disponibilidad de un cúmulo de saltos técnicamente hábiles en territorio peninsular durante el primer decenio del siglo.

Si hasta 1900-1905 la clave del éxito de las compañías eléctricas residió en el acceso a la maquinaria y en crear un mercado apropiado para sus aplicaciones urbanas o intensivas, desde entonces, las empresas hidroeléctricas triunfaron cuando fueron capaces, primeramente, de atraer capital para comprar maquinaria y para adquirir concesiones, para luego, ser capaces de construir la 
obra civil necesaria y demostrar el aprendizaje electrotécnico adecuado para gestionar sistemas eléctricos.

En el cuadro adjunto se refleja con claridad una explotación muy desigual en cuanto al número de saltos y capacidad total por vertiente (según el recuento de 1909).

\begin{tabular}{|c|c|c|c|c|c|c|}
\hline CUENCA & $\begin{array}{l}\text { POTENCIA } \\
\text { INSTALADA } \\
\text { TOTAL EN KW }\end{array}$ & $\begin{array}{l}\text { PORCENTAJE } \\
\text { REGIONAL }\end{array}$ & $\begin{array}{l}\text { POTENCIA } \\
\text { MEDIA } \\
\text { EN KW }\end{array}$ & $\begin{array}{l}\text { ESTABLECI- } \\
\text { MIENTOS }\end{array}$ & $\begin{array}{l}\text { PROMEDIO } \\
\text { CAUDAL (Ns) }\end{array}$ & $\begin{array}{l}\text { PROMEDIO } \\
\text { ALTURA (m) }\end{array}$ \\
\hline Cantábrica & $12.033,36$ & 4,15 & 429,76 & 28 & $2.423,07$ & 19,06 \\
\hline Duero & $13.644,82$ & 4,71 & 505,36 & 27 & $3.017,19$ & 15,06 \\
\hline Ebro & $100.900,67$ & 34,80 & 410,17 & 246 & $2.325,47$ & 42,32 \\
\hline Guadalquivir & $21.895,12$ & 7,55 & 326,79 & 67 & $3.788,76$ & 29,44 \\
\hline Guadiana & $1.381,04$ & 0,48 & 230,17 & 6 & $4.051,67$ & 11,20 \\
\hline Júcar & $105.020,60$ & 36,22 & $12.810,70$ & 58 & $6.278,59$ & 14,49 \\
\hline Miño & $15.061,65$ & 5,19 & 602,47 & 25 & $2.071,60$ & 44,26 \\
\hline Pirineo Oriental & $3.328,80$ & 1,15 & 475,54 & 7 & $3.871,43$ & 83,76 \\
\hline Segura & $3.567,88$ & 1,23 & 222,99 & 16 & $4.426,88$ & 13,31 \\
\hline Sur España & $6.533,08$ & 2,25 & 816,63 & 8 & $1.187,50$ & 78,12 \\
\hline Tajo & $6.600,76$ & 2,28 & 206,27 & 32 & $7.847,56$ & 8,23 \\
\hline TOTAL & $289.967,78$ & 100,00 & 557,63 & 520 & $3.411,60$ & 32,74 \\
\hline
\end{tabular}

El aprovechamiento hidroeléctrico había ido trasladándose de las zonas tradicionales de explotación hidromecánica hacia las vertientes del Ebro y del Júcar. Esto es, hacia las zonas que servían al País Vasco y Cataluña de un lado; y Valencia y Madrid de otro. Sin embargo; excepción hecha del Júcar, donde se inauguró la primera gran central hidroeléctrica, la explotación hidráulica era a pequeña escala, con saltos que en promedio alcanzaban con dificultad los 500 kW de capacidad media, los cuales aprovechaban alturas considerables, pero disfrutando de concesiones de caudales medios (a menudo máximos) bastante limitadas. La eficiencia en el uso de los recursos era igualmente muy baja, si exceptuamos también el caso de Júcar.

Se percibe, pues, una explotación hidroeléctrica en la que aún predominaba el pequeño salto de uso estacional que explotaba las energías sobrantes de aprovechamientos tradicionales, aunque despuntaba lo que sería la explotación hidráulica a gran escala que emprenderían las grandes empresas eléctricas a partir de entonces.

Además, la estadística de obras públicas refleja que todavía en 1909 un 20\% de los saltos en explotación y registrados para su uso eléctrico lo era en algún tipo 
de aprovechamiento mixto. Este fue el mecanismo de difusión eléctrica en el medio rural.

Los usos mixtos consistían en la aplicación de dinamos a molinos hidromecánicos, que permitieron la conversión de su energía, y la de sus fábricas adyacentes, en eléctricas. Molinos harineros, aserraderos y manufacturas sobre todo textiles ubicadas en las cabeceras de los ríos conservaron una parte de su aprovechamiento hidromecánico, pero introdujeron algún convertidor eléctrico.

En línea con lo anterior, en muchos casos se transformaba una instalación hidromecánica, como eran las fábricas textiles, papeleras, harineras, etc. que funcionaban de forma directa o con un embarrado y correas, a una hidroeléctrica.

Las causas de su rápida difusión fueron la dificultad del acceso al carbón y el escaso coste de acondicionamiento de estos molinos. Su uso fabril era simplemente como fuerza motriz, sin contar aún con las ventajas del motor eléctrico. Además, estas fábricas extraían ventajas adicionales a sus reformas mediante la venta de la energía excedente para alumbrado en las horas nocturnas, durante las que no trabajaban.

Las regiones donde estos aprovechamientos proliferaron fueron el País Vasco y Aragón, aunque también en Cataluña la mitad de los saltos inscritos era de este tipo. De hecho, algunas de las compañías iniciadoras del desarrollo hidroeléctrico catalán eran en su mayoría empresas del textil ya acostumbradas a la movilidad a favor de precios de la energía más asequibles.

Al principio, los generadores eran de corriente continua, lo que limitaba enormemente el transporte de la electricidad debido a las elevadas pérdidas, lo que obligaba a que las industrias se situaran en los centros de consumo, junto a ríos y canales. Por la misma razón, únicamente se aprovechaban para generar electricidad los molinos hidráulicos cercanos a las ciudades.

Por ejemplo, en Cataluña esto pasaba en los ríos Ter, Llobregat y el Canal de Piñana en el Noguera Ribagorzana. Y en Castilla, esto ocurría en el Canal de Castilla, donde se juntaban el azúcar cubano que llegaba vía Santander y el Valle del Pas, con la harina de la Tierra de Campos y la energía hidráulica, dando lugar a la mayor concentración de fábricas de galletas del país.

Al disponer de cantidades relativamente importantes de electricidad, aparecieron nuevas aplicaciones industriales basadas en hornos eléctricos y la 
electroquímica, como el refino de grafito, electrólisis del aluminio, elaboración de carburos, etc. que empezaron a verse en los ríos. Ejemplos son las colonias de los ríos Ter y Llobregat, Monzón en el Cinca, Sabiñánigo y Triste en el Gállego, Sástago y Flix en el Ebro, etc.

La potencia instalada según el recuento del año 1910 era la siguiente:

\begin{tabular}{|c|c|c|c|c|c|c|c|c|c|}
\hline \multirow[b]{2}{*}{ REGIÓN } & \multirow[b]{2}{*}{$\begin{array}{l}\text { POTENCIA } \\
\text { TOTAL }\end{array}$} & \multicolumn{4}{|c|}{ HIDRO-ELÉCTRICA } & \multicolumn{4}{|c|}{ TERMO-ELÉCTRICA } \\
\hline & & POTENCIA & $\begin{array}{l}\text { ESTABLE- } \\
\text { CIMENTOS }\end{array}$ & $\begin{array}{l}\text { POTENCIA } \\
\text { MEDIA }\end{array}$ & $\begin{array}{l}\text { REGIONAL } \\
\text { TOTAL }\end{array}$ & POTENCIA & $\begin{array}{l}\text { ESTABLE- } \\
\text { CIMIENTOS }\end{array}$ & $\begin{array}{c}\text { POTENCIA } \\
\text { MEDIA }\end{array}$ & $\begin{array}{l}\text { REGIONAL } \\
\text { TOTAL }\end{array}$ \\
\hline Andalucia & $20.743,70$ & $10.670,35$ & 92 & 115,98 & 12,29 & $8.511,35$ & 118 & 72,13 & 15,83 \\
\hline Aragón & $5.296,07$ & $3.867,32$ & 80 & 48,34 & 4,45 & $1.069,75$ & 7 & 152,82 & 1,99 \\
\hline Astur-Sentander & $10.681,45$ & $7.794,80$ & 57 & 136,75 & 8,98 & $2.875,48$ & 54 & 53,25 & 5,35 \\
\hline Beleares & 739,00 & 100,00 & 2 & 50,00 & 0,12 & 620,40 & 10 & 62,04 & 1,15 \\
\hline Canaries & $1.042,00$ & 158,00 & 2 & 79,00 & 0,18 & 884,00 & 3 & 294,67 & 1,64 \\
\hline Castilla-Løón & $8.890,98$ & $6.563,77$ & 149 & 44,05 & 7,56 & $1.430,60$ & 38 & 37,65 & 2,66 \\
\hline Cataluña & $25.027,43$ & $11.882,32$ & 245 & 48,50 & 13,68 & $11.576,35$ & 26 & 445,24 & 21,52 \\
\hline Extremadura & $2.516,95$ & 693,95 & 10 & 69,40 & 0,80 & $1.026,00$ & 5 & 205,20 & 1,91 \\
\hline Gelicia & $15.706,04$ & $12.441,00$ & 36 & 345,58 & 14,33 & 158,40 & 28 & 5,66 & 0,29 \\
\hline La Manche & $10.591,85$ & $7.341,08$ & 66 & 111,23 & 8,45 & $2.726,27$ & 268 & 10,17 & 5,07 \\
\hline Madrid & $18.604,82$ & $2.808,00$ & 13 & 216,00 & 3,23 & $13.448,02$ & 34 & 395,53 & 25,00 \\
\hline Murcia & $4.184,00$ & 858,00 & 10 & 85,80 & 0,99 & $2.646,00$ & 5 & 529,20 & 4,92 \\
\hline País Veasco & $21.307,64$ & $15.858,38$ & 174 & 91,14 & 18,26 & $5.318,46$ & 40 & 132,96 & 9,89 \\
\hline Región Velenciena & $8.294,66$ & $5.806,75$ & 109 & 53,27 & 6,69 & $1.490,82$ & 36 & 41,41 & 2,77 \\
\hline TOTAL & $153.626,59$ & $86.843,72$ & 936 & 92,78 & $100, \infty$ & $53.781,90$ & 636 & 84,56 & 100,00 \\
\hline
\end{tabular}

Desde 1890, dos hallazgos transformaron el porvenir de la generación hidráulica y la transmisión eléctrica a larga distancia. De un lado, se efectuaron los primeros transportes con éxito de corriente alterna Lauffen-Frankfurt. Estos lograban unir mediante un tendido eléctrico en corriente alterna y sucesivas transformaciones de la tensión los centros de producción hidráulica a gran escala y los centros de consumo, disminuyendo notoriamente las pérdidas.

La utilización de la corriente alterna y la posibilidad del transporte de electricidad a larga distancia provocaron un cambio más que sustancial en la concepción y gestión hidroeléctrica de los aprovechamientos. En 1908 se creó la primera línea de alta tensión desde el Salto de El Corchado en Málaga a Sevilla. Este fue el punto de partida de la gran red nacional de transporte y distribución de energía eléctrica.

Entre 1907 y 1913, las principales ciudades españolas comenzaron a ser abastecidas por centrales hidroeléctricas con potencias instaladas en torno a los $5.000 \mathrm{~kW}$. Éstas enviaban la electricidad a las urbes desde sus localizaciones montañosas a través de largas líneas de transporte que salvaban varios centenares de kilómetros para que la oferta hidráulica y la demanda urbana se encontrasen. La corriente alterna y los sistemas universales de transformación 
de tensión facilitaron el abaratamiento del transporte a larga distancia de electricidad.

El segundo hallazgo fue la mejora de las turbinas Pelton y ya iniciado el siglo XX, también se recibieron las turbinas Francis. Las primeras permitían adaptarse con gran eficiencia a los saltos típicos de territorios que disponían de abundantes desniveles pero escasos caudales, y las segundas mejoraron el rendimiento de los saltos bajos y caudalosos.

Desde 1901 y hasta la inauguración de Millares y Saltos del Duero en el decenio de 1930, el modelo hegemónico constructivo consistió en un tipo de salto que aprovechaba localizaciones donde se explotaban alturas importantes mediante canales de derivación. Estas conducciones al aire o soterradas constituían en sí mismas obras de ingeniería del más alto nivel, que se complicaban con los depósitos naturales de agua, o pequeños embalses de acumulación. Incluso con caudales pequeños, las potencias logradas eran importantes debido a la aceleración que el agua alcanzaba en las casas de máquinas de las centrales, dotadas de turbinas de cámara cerrada preferentemente tipo Francis.

La mejora en las turbinas logró la explotación económica de aquellos saltos relativamente abundantes en territorio español: aprovechamientos en altura y de caudal escaso e irregular. Del lado de la demanda, la flexibilidad en la localización de la manufactura que proporcionó la electricidad se sumó a la difusión del motor eléctrico y de los nuevos sistemas de organización fabril más eficientes.

La maquinaria era suiza o alemana, con predominio de las casas Escher-Wyss y Voith, respectivamente, y, para evitar las habituales avenidas, los equipos hidráulicos se colocaban a menudo sobre eje vertical. La maquinaria eléctrica también tenía esa procedencia: Siemens y Brown-Bovery, antes, y luego también General Electric.

Estas circunstancias favorecieron la ampliación del mercado de las compañías, lo que también exigió reunir grandes capitales y crear nuevas empresas.

Así, al tiempo que tenía lugar un cambio de escala en la industria eléctrica, comenzó un proceso de concentración empresarial que terminó con la atomización y dispersión iniciales. La industria eléctrica podía obtener grandes economías al concentrarse, por su utilización intensiva de capital y equipos, sobre todo en la actividad de generación. 
En torno a 1913, las principales compañías hidráulicas, que facilitarían la nueva energía desde las distantes cordilleras, habían hecho ya su aparición. Además de la Gallega de Electricidad, constituida en 1900, el mercado de la ciudad de Zaragoza y los de las principales ciudades de la fachada norte de la península se encontraban abastecidos por centrales hidráulicas. Hidroeléctrica Ibérica (HI), que actuó desde 1901 como productor del mercado vasco, preferentemente guipuzcoano, puso en marcha tempranamente, y en su propio territorio, algunos saltos. En 1907 Hidroeléctrica Española (HE) inaugura, con la apertura de Molinar, la primera transmisión a gran distancia, desde Albacete a Madrid y Valencia. En 1912, Unión Eléctrica Madrileña (UEM) establece otro servicio de producción y distribución en Madrid, que, junto con $\mathrm{HE}$, constituirá el núcleo muy disputado en estos años de la producción con destino capitalino. Antes de la Gran Guerra también, las dos empresas que competirían por el mercado catalán, Riegos y Fuerzas del Ebro y Energía Eléctrica de Cataluña, comienzan la producción desde el occidente catalán, orientadas en este caso al aprovechamiento sistemático del Pirineo.

En la Cuenca del Júcar, Hidroeléctrica Española comienza la producción hidroeléctrica con el salto de El Molinar (Villa de Ves-Albacete). En 1913 inaugura su quinto grupo, con el que suma una potencia instalada de 100 millones de kWh. Dos hitos marcan esta central: es la más rentable de las que funcionan entonces en España y, por primera vez en el mundo, se consigue trasladar 16.000 caballos de vapor a una distancia de $240 \mathrm{~km}$, la existente entre la central y Madrid. En 1956 El Molinar deja de producir electricidad, coincidiendo con la inauguración de la central de Cofrentes. Concluida El Molinar se construye la central de Villora, sobre el Cabriel y el Guadazaón. Inaugurada en 1914, pronto se quedó pequeña para poder cumplir con la demanda en horas punta, por lo que en 1925 duplicó su potencia, dotándola de un grupo de 13,6 MW. Un año más tarde se inaugura la central de Batanejo como complementaria, con un grupo de $2 \mathrm{MW}$, y esta central culmina su capacidad con la incorporación en 1945 de un cuarto grupo de 14 MW. También en los años veinte del siglo pasado se inaugura la central de Cortes de Pallars, que suma $30 \mathrm{MW}$ tras la puesta en marcha de su segundo grupo en 1923. A finales de este periodo se inicia la construcción del salto de Millares, finalizado en 1933 con dos grupos de 20 MW cada uno, que se ampliarían a tres en 1935 y a cuatro en 1945; los $80 \mathrm{MW}$ generaban $400 \mathrm{GWh}$ anuales, lo que supone la mitad de la producción total de Hidroeléctrica Española en aquel periodo.

En vísperas de la I Guerra Mundial, España se encontraba aún lejos de alcanzar los logros en cuanto a disponibilidad eléctrica que se constataban en aquel entonces en otros países hidrodependientes. 
Según las estadísticas existentes, en 1913 la producción española por habitante era de $25 \mathrm{kWh}$, mientras que la de Francia era de $45 \mathrm{kWh}$, la de Italia de $63 \mathrm{kWh}$, la de Finlandia de $60 \mathrm{kWh}$, la de Suecia de $258 \mathrm{kWh}$, la de Suiza de $414 \mathrm{kWh}$ y la de Noruega de $900 \mathrm{kWh}$. La distancia que en torno a 1900 se apreciaba se había ensanchado en los primeros años del siglo XX. Y esto fue así pese a que, sin duda, la extensión de la electricidad para los usos urbanos había sido todo un éxito en España.

Las centrales se articulaban en sistemas de generación para el mejor aprovechamiento de altura y caudal y combinaban sucesivas centrales de derivación con otras a pie de presa. Ejemplos de estos aprovechamientos en escalera son, por ejemplo, los tempranos de Tremp o aquellos más sofisticados del alto Cinca de Hidroeléctrica Ibérica de 1915. Estas centrales se planificaban para caudales medios, que no solían superar los 9 meses de disponibilidad. De las centrales partían las redes de transmisión, y complejos sistemas de elevación y transformación de la potencia permitían su traslado hasta los centros de consumo con las menores pérdidas.

Hasta la I Guerra Mundial se habían empleado aquellos saltos de menor tamaño, tanto en términos de potencia como en sus correspondientes de altura y caudal. Todavía en 1917 se utilizaban primordialmente corrientes de uso estacional, fluyentes, en el interior peninsular, aunque comenzaran a aplicarse sistemas de derivación y almacenamiento de agua. La potencia media de las concesiones superaba ligeramente los $600 \mathrm{~kW}$ y se concentraba en el Ebro, con casi un 50\% del total concedido, pero con magnitudes importantes en Miño y Tajo.

Las inauguraciones se sucedían rápidamente durante los años del conflicto europeo. El propio 1918, la Cooperativa de Fluido Eléctrico, compañía que asimismo disputaba el mercado del Principado, comenzó también su producción en la misma cuenca del Ebro. Solo tras el final de la I Guerra Mundial, las empresas andaluzas emprendieron la producción hidráulica a gran escala, aunque ya contaban con importantes plantas termoeléctricas en la Andalucía occidental. Durante el decenio de 1920, la explotación de la cuenca del Júcar continuó por parte de HE, la del Pirineo leridano por parte de la Canadiense (Riegos y Fuerzas del Ebro), mientras que HI hubo de trasladar su principal centro productor a un punto lejano de su mercado vasco, al Cinca, en el Pirineo oscense.

Entre 1914 y 1935 se produce el despegue de la hidroelectricidad en el Valle del Ebro, y por consiguiente en España. Si en 1913 la potencia instalada en el valle suponía el 25\% del conjunto español, en vísperas de la Guerra Civil implicaba el 41\%. Desde el punto de vista espacial, este avance se debe esencialmente al 
aprovechamiento de los saltos del Pirineo oscense y leridano, por lo tanto de los ríos de las cuencas del Medio y Bajo Ebro.

Durante el primer tercio del siglo XX, en Aragón, el aprovechamiento de los recursos hidráulicos se vinculó sobre todo a aquellos caudales regulares que discurrían por pendientes pronunciadas. Las cabeceras de los afluentes pirenaicos del Ebro cumplen con estas características dado que, al tiempo que su alimentación nival les otorga una cierta regularidad de caudal, están asociados a fuertes pendientes orográficas. Es el caso de los tres grandes afluentes: Aragón, Gállego y Cinca-Esera. Asimismo, la importancia del caudal del Ebro a partir de la comarca del Bajo Aragón, a pesar de su escasa pendiente, le otorga un importante potencial hidroeléctrico. En 1907 las tres principales sociedades eléctricas locales zaragozanas se fusionan constituyendo la entidad Sociedades Eléctricas Reunidas, que junto con Teledinámica del Gállego dio lugar a la creación en 1911 de la nueva sociedad Eléctricas Reunidas de Zaragoza. Desde mediados de la década de 1910, grandes grupos vinculados a las zonas más desarrolladas del país y con mayor demanda eléctrica (inversiones de capital vasco, catalán y madrileño), aprovechando los progresivos avances de la tecnología del transporte de alta tensión, entran en el aprovechamiento eléctrico de los recursos hidráulicos existentes en Aragón. Esto posibilitó el desarrollo hidroeléctrico del Alto Aragón, consolidando a la provincia de Huesca, tras su vecina Lérida, en el orden productivo eléctrico español del periodo anterior a la Guerra Civil. Así, la producción hidroeléctrica aragonesa experimentó un crecimiento formidable durante las décadas de los años veinte y treinta, con un ritmo muy superior al global español. La casi totalidad de esta potencia instalada en Aragón, casi el 98\%, era de origen hidráulico y representaba en 1935 el 17,2\% del potencial hidráulico español.

La potencia y la producción eléctrica en España crecieron a un ritmo muy vigoroso. Entre 1913 y 1922 la potencia aumentaría a un ritmo anual acumulativo de casi un 15\%, y la producción alcanzó el 16,6\%.

La palanca de este rápido crecimiento del sector suministrador fue el aprovechamiento concienzudo del potencial hidroeléctrico español con predominio de los usos urbanos y manufactureros.

El reparto de la potencia entre las diferentes regiones españolas en 1920 mostraba una concentración territorial cada vez más acusada en las zonas productoras hidroeléctricas: Cataluña, País Vasco, Asturias-Santander, el País Valenciano y Aragón son, junto a la excepción madrileña, las únicas regiones que superan la media española de potencia eléctrica por $\mathrm{km} 2$. Estas regiones 
albergaban un potencial hidráulico que se hace más evidente a la vista de su reparto por habitantes.

\begin{tabular}{lcc} 
& & \\
\multicolumn{1}{c}{ REGIÓN } & KW $/ 1.000$ hab. & KW/ ${ }^{2}$ \\
\hline Andalucía & 6,80 & 0,32 \\
\hline Aragón & 50,09 & 1,06 \\
\hline Astur-Santander & 32,82 & 2,19 \\
\hline Baleares & 0,37 & 0,03 \\
\hline Canarias & 0,35 & 0,02 \\
\hline Castilla & 18,55 & 0,47 \\
\hline Cataluña & 80,55 & 5,86 \\
\hline Extremadura & 1,14 & 0,03 \\
\hline Galicia & 11,72 & 0,84 \\
\hline La Mancha & 40,71 & 0,87 \\
\hline Madrid & 12,54 & 1,66 \\
\hline Murcia & 5,64 & 0,32 \\
\hline País Vasco & 35,41 & 2,18 \\
\hline Valencia & 7,40 & 0,55 \\
\hline TOTAL & 23,99 & 1,01 \\
\hline & &
\end{tabular}

En 1920 las regiones más electrificadas eran las más industriosas: Cataluña, País Vasco y Asturias-Santander. La excepción es La Mancha, región de abastecimiento de la contigua Madrid, pues esta última apenas contaba con potencial hidráulico propio. Por tanto, en la localización de la potencia hidroeléctrica durante el período de entreguerras en España se conjugó una dotación de recursos hidráulicos adecuados con una cierta tradición manufacturera. 
GRUPOS GENERADORES MAYORES DE 5.000 KVA DE POTENCIA SEGÚN SU AÑo DE INSTALACIÓN

\begin{tabular}{|c|c|c|c|c|c|c|}
\hline CENTRAL & PAOMINCIA & CONPANIA & CLENCA & CORAIENTE & ANO & $\begin{array}{l}\text { POTENCIA } \\
\text { INSTRADA }\end{array}$ \\
\hline Carcarvila & Hunoca & ERE, & Ebra & Galogo & 1900 & 4.120 \\
\hline Marracos & Zaragaza & ERZ: & Ebro & Gialogo: & 1900 & 4.460 \\
\hline Lefourdn & Gublizoon & $\mathrm{H}^{2}$ & Eero & Lebartn & 1004 & 5,000 \\
\hline Ruortiolara & Alava & $\mathrm{H}$ & Ebro & Ebro & 1006 & 0000 \\
\hline Somindo & Ovesdo & H. DE CANTABACO & Norto & Vale & 1908 & 10.448 \\
\hline Undon & Sortandor & EI RCFA VESSCO & Norno & Undon & 1008 & 5.888 \\
\hline Molinar & Abacoth & HE & Juour & Juan & 1900 & 18.000 \\
\hline Bolargue & Gundalalara & Uem & Talo & Tajo & 1912 & 18960 \\
\hline Contral Da & Madrid & HE & Taio & Losopa & 1912 & 6.900 \\
\hline Ginclara & Sartandor & Plopolon Eaporiola & Norto & Gtrcana & 1913 & 5.376 \\
\hline Ruerto Araodn & Heesca & & Ebro & Eicoers & 1914 & 5.600 \\
\hline Capdola & Landa & E.E. CATALUNA & Ebro & Fumbell & 1914 & 26.400 \\
\hline Seroa & Lorda & AAFFE & Ebro & Soora & 1914 & 42.662 \\
\hline Nilora & Cuenca & HE & Jifear & Cabrial & 1914 & 12000 \\
\hline Marmota & Madrid & H. SANmLLANA & Tao & Monzanarea & 1914 & 5.204 \\
\hline La Molva & Ovindo & & Norto & Salonda & 1915 & 7854 \\
\hline Tremp & Lenda & RAFFE & Earo & Noosora Falareas & 1916 & 28000 \\
\hline Soira & Huecos & C. FUUDO ELECIRCO & Ebro & Eeora & $191 \mathrm{~B}$ & 7200 \\
\hline Soira & Huscos & c. FUUDO EIECIRCO & Etro & Eenra & 1918 & 7200 \\
\hline E Cortio & Logrono & & Etro & Ebro: & 1918 & 4.000 \\
\hline Solra & Hinoca & C. FUDDO FI ECIRCO & Ebro & Erena & 1918 & 7200 \\
\hline Cactib & Grannda & MENGEMCA & 8. do Enoafha & Gond & 1918 & 4.800 \\
\hline Lan Butroras & Maloga : & MANGEMCA & 8. da Eapakia & Gundiaro & 1918 & 7200 \\
\hline Anzariag & Huncos & EFE & Ebro & Galogo & 1919 & 4.400 \\
\hline Molnos & Linda & E.E. CATALUNA & Etro & Fiamiand & 1919 & 15.000 \\
\hline Carnerama & Lenda & RAFFE & Ebro & Noouern Palisneas & 1900 & 22.496 \\
\hline Pobla & Lenda & S. P. F MOTRICES & Emo & Fumbell & 1900 & 10000 \\
\hline Biocoas & Huesca & E. E. CATRUKA & Ebro & Galboo & 1901 & 8.400 \\
\hline CamarmaKa & Ovisdo & H. VESSO & Ebro & Carea & 1021 & 11200 \\
\hline Tonina & Sortander & H. VESSO & Norto & Totna & $108 t$ & 9.600 \\
\hline BCorno & Condoba & MANGEMOA & Guadaloidr & Guadilouvir & 1002 & 8.400 \\
\hline Contas do Palha: & Valencia & HE & Jufar & Juasr & 1002 & 150000 \\
\hline Latartunads Cinca & Hunaca & $\mathrm{H}$ & Ebro & Cinca & 1903 & 37.332 \\
\hline Pobla & Landa & S. P.FF MOIRICES & Etro & Flambel & 1003 & 6000 \\
\hline B Coatilo & Codrdoba & MaVGEMCA & Guadalaavir & Gonl & 1903 & 4.900 \\
\hline Corton do Fulas & Velonda & HE & Jucar & Juour & 1903 & 15000 \\
\hline Chono & Naloga & H. CAORRO & 8. Espana & Gusduhorca & 1023 & $7-160$ \\
\hline Aumadones & Murcia & & Socura & Sogura & 1003 & 8.400 \\
\hline Camarasa & Lenda & RAFFE & Etro & Noa Pallarona & 1005 & 11.248 \\
\hline Vialoa & Cuncal & Bectrica Cachla & Júar & Jivoar & 1905 & 10.400 \\
\hline Ruano & Huesca & E.LARAGONESAS & Elro & Coldanden & 1927 & 6.720 \\
\hline Cais & Sowals & SEMLLANADE & Gundalaiver & Cola & 1902 & 12200 \\
\hline Mibra & Cusenca & HE & Jucar: & Cabrial & 1927 & 13.600 \\
\hline Tambre & Conna & B. GNUECIADEE. & Mito & Tambre & 1207 & 10800 \\
\hline Central 2 & Zaragoza & B. M. ARAGCNESA & Ebro & BDro & 1000 & 16.488 \\
\hline Clodises & Lenda & S. P.FFMOTRCES & Ebro & Gorona & 1000 & 12.800 \\
\hline Ruorta Nuavo & Avla & SALTOS DEL AL REACHE & Tabo & Aborche & 1009 & 16.200 \\
\hline Barroan & Huecoso & $\mathrm{H}$ & Etro & Barroas: & 1980 & 7200 \\
\hline Undicoto & Huesca & $\mathrm{H}$ & Ebro & Undicos & 1900 & 7200 \\
\hline Camarma & Lenda & RARFE & Etro & Noowera Palarseas & 1980 & 11248 \\
\hline Sen Loronzo: & Lorda & RAFFE & Ebro & Seoro & 1000 & 8.000 \\
\hline E Encinarop & Jotn & MENGEMCA & Gundaloulver & Jandula & 1900 & 8.320 \\
\hline Ifndis & Jotn & MEVGEMCA & Gundalowivr & Jindisa & 1080 & 15.000 \\
\hline Torina & Bortandor & H. VESGO & Norso & Torina & 1900 & 5.600 \\
\hline E Burgulo & Avils & SALTOS DE ALBERCHE & Tabo & Aborche & 1900 & 30000 \\
\hline Gabet & Lendh & RAFFE & Etero & Cand Talarn & 1991 & 20000 \\
\hline SonAquath & Tenual & HE & Júcar & Miara & 1981 & 11.840 \\
\hline Cafhavero & Murcia & & Scoura & Sooura & 1981 & 4.800 \\
\hline Letortunsds Conqueta & Huesca & H & Ebro & Cinqueh & 1082 & 36.800 \\
\hline Alcold dol Plo & Somila & MEVGEMCA & Gundaloulvr & Gundalouir & 1932 & 6.080 \\
\hline velog & Granada & FF. MM. VAIFLECRIN & 5. do Eapahn & intoor & 1982 & 11.468 \\
\hline Milaros & Volencia & HE & Jucar & Juas & 1983 & 60000 \\
\hline Dokas & Ovido & & Norso & Novia & 1983 & 28.800 \\
\hline Eacoldes & Andorsa & & Ebro & Valma & 1904 & 13360 \\
\hline Eala & Zamora & SALTOS DEI DUERO & Duero & Fols & 1966 & 89.800 \\
\hline Terradns & Londa & & Ebro & Noouora Pallereas & 1905 & 27.360 \\
\hline $\mathrm{AlCOZ}$ & Navama & & Ebro & Solodo & 1906 & 6.800 \\
\hline
\end{tabular}

En torno a 1925, al fin, la producción hidroeléctrica se ubicaba preferentemente en la periferia española, pero en localizaciones novedosas respecto a las zonas de producción hidromecánica tradicional. Comenzaba además a apreciarse una 
notable desaceleración en la instalación de potencia hidroeléctrica, que contrastó con el crecimiento sostenido del consumo hasta la crisis del final del decenio.

Con todo, al lado de los importantes aprovechamientos hidráulicos que promovieron las grandes compañías hidráulicas, en 1925 pervivía en España un buen número de fábricas de electricidad de tamaño ínfimo.

Más de un 70\% del total de los centros productores distribuían directamente en baja tensión (menor de 250 V) y más de un 25\% tenía como utilización exclusiva el alumbrado.

Se diría que en algunas regiones, como las dos Castillas, Extremadura y Andalucía, los pequeños establecimientos desempeñaban aún en el decenio de 1920 un papel muy relevante en el abastecimiento de mercados extensos pero al margen de las grandes líneas, señalándose la prolongada pervivencia de centrales aisladas. Los llamados "sistemas periféricos" llevaron una vida floreciente hasta que, al agotar su capacidad productiva, dejaron de presentar batalla a las grandes compañías.

En 1925, más de un 50\% del consumo final de energía eléctrica se empleaba en utilizaciones industriales, incluidas aquellas intensivas. Las zonas de consumos globales más elevados corresponderían a áreas donde se ubicaba tradicionalmente esta industria e incluso los mayores consumos por habitante y año se localizaban asimismo en las zonas manufactureras (Cataluña, País Vasco y Cantabria) a las que se iban incorporando Aragón y Madrid, donde el despegue hidroeléctrico corrió, pues, parejo al de la electrificación industrial.

El parque hidroeléctrico español había crecido a buen ritmo hasta 1925, aunque el predominio de su empleo por la manufactura abocase a rendimientos irregulares del conjunto de la maquinaria eléctrica. No obstante, a partir de entonces su progresión se desaceleró. Una vez agotada la disponibilidad de saltos de tipo medio, las condiciones naturales de las ubicaciones aptas para la explotación hidráulica en la segunda mitad de 1920 precisaban la construcción de grandes presas que regularizasen por completo el caudal de los ríos. El previsible aumento de los costes de instalación no se ajustaba a un consumo que crecía a expensas de la iluminación y la manufactura.

Ante una situación semejante, durante el período de entreguerras la intervención pública salvó a los sistemas eléctricos francés e italiano de un previsible colapso. 
En Francia, las autoridades financiaron presas y contribuyeron al tendido de líneas de interconexión. En Italia, se auxilió a la construcción de los diques, constituyéndose en uno de los lemas básicos de su política económica. Y en ambos países se fomentaron los consumidores institucionales a fin de absorber los excedentes iniciales. Mientras, en España, la iniciativa pública apenas superó la fase especulativa y fueron las compañías privadas las que acometieron por sí mismas la construcción de los grandes aprovechamientos, de Millares o Saltos del Duero, y quienes establecieron una interconexión espontánea entre algunos mercados.

De todos modos, y respecto a la construcción de presas, en España, las compañías eléctricas se han venido considerando análogamente beneficiarias de ayudas extraordinarias para la construcción de presas en dos momentos bien distintos: de resultas de la Ley Gasset de 7 de julio de 1911 y por el otorgamiento de subvenciones directas a algunas empresas para la construcción de embalses durante la dictadura primorriverista.

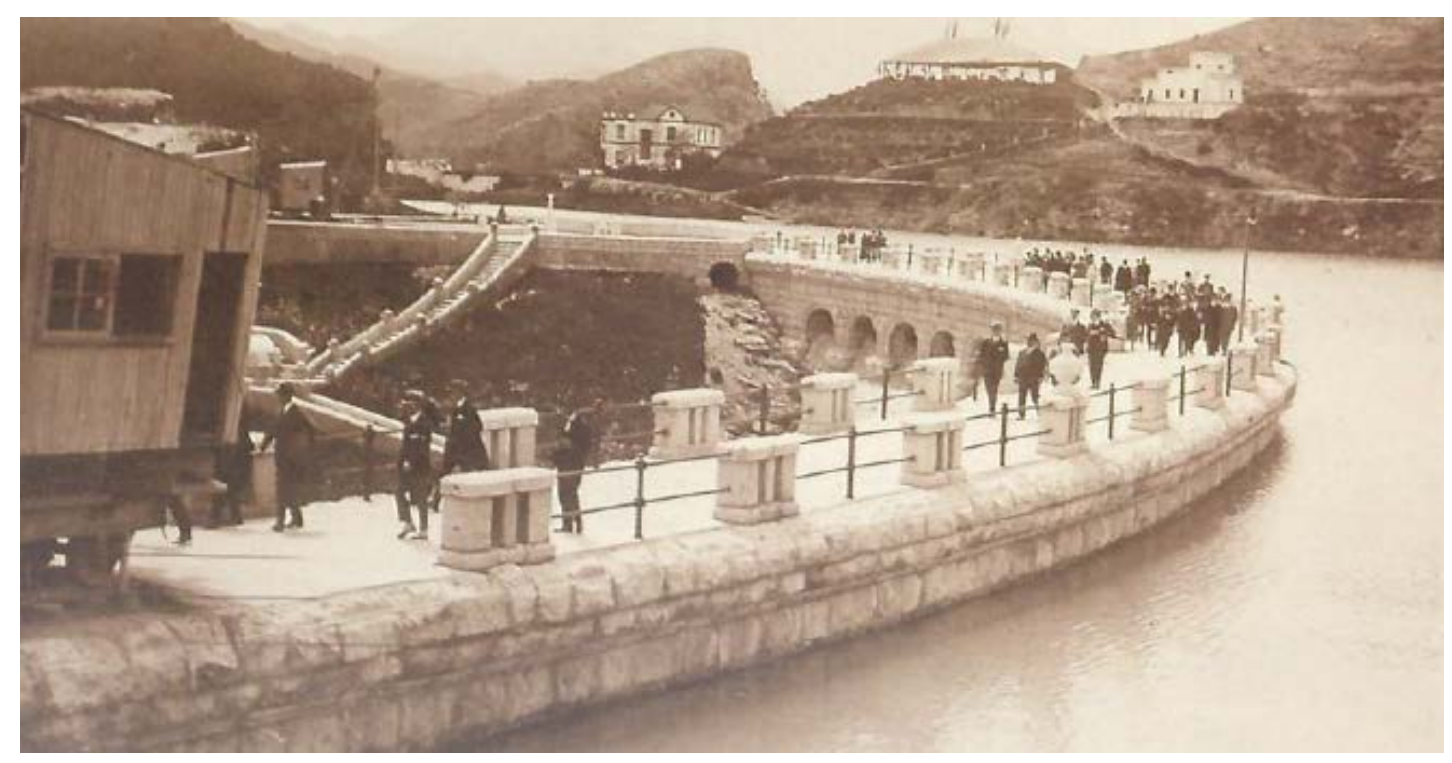

La Ley Gasset estableció subvenciones a la construcción de obras hidráulicas con destino a riegos, defensas y encauzamiento de las corrientes y estableció un procedimiento para su ejecución a cargo de los interesados con auxilio del Estado: recibir una subvención del 50\% del valor de la obra y un anticipo del $40 \%$. La literatura jurídica ha insistido en que sus grandes beneficiarios fueron los aprovechamientos hidroeléctricos, pero lo cierto es que el aireado caso de Hidroeléctrica del Chorro constituyó más bien la excepción a la regla.

Entre 1911 y 1926 las localizaciones más apropiadas para la obtención de energía eléctrica no coincidían en absoluto con las más aptas para el riego, que eran las que se primaban con subvenciones, de manera que hasta 1926 solo la 
mitad de los Hm3 embalsados en España lo fueron para uso eléctrico y mixto. Desde entonces se avanzó a gran ritmo, y en 1935 más de dos tercios de toda la capacidad de los embalses españoles incluían este uso. En 1925 los embalses admitían $985.38 \mathrm{Hm} 3$, de los cuales, con aprovechamiento eléctrico solo eran 504 Hm3. En 1935, de los 3.896 Hm3 de capacidad de los embalses españoles, $2.482 \mathrm{Hm} 3$ eran para empleo eléctrico o mixto.

Entre la Dictadura de Primo de Rivera (1923-1930) que asumió la política hidráulica entre sus prioridades, y los primeros Gobiernos de la II República, cambiaron las prioridades en la finalidad de la obra pública, pues los planes de construcción de infraestructuras para riegos continuaron a buen ritmo, desgajándose de su eventual empleo industrial. Ante la disyuntiva de priorizar infraestructuras hidráulicas para uso agrario o industrial, los Gobiernos republicanos se inclinaron por las primeras.

Con todo, los mercados eléctricos españoles seguían en 1925 sus primeros pasos hacia la constitución de mercados regionales integrados, pese a la ostensible conexión financiera de las grandes compañías, su estructura de holding. Frente a estos holdings establecidos, la iniciativa independiente de Saltos del Duero demostró con claridad que tanto la estructura productiva como el reparto de los mercados eléctricos estaban todavía abiertos en 1930 a nuevos actores.

En fin, los embalses que promovieron tanto la Ley de 1911 como las subvenciones del período de la Dictadura no alcanzaban en 1935 más de 70.000 kW de potencia instalada efectiva (menos de un $5 \%$ de la capacidad hidroeléctrica disponible).

Antes de 1926, las empresas estaban al acecho de saltos de gran potencial en la cabecera de los ríos. En la segunda mitad de los años veinte, las empresas eléctricas viraron su centro de atención hacia saltos con embalse regulador interanual. En los primeros treinta, los Gobiernos del bienio reformador recelaron de fórmulas de cooperación en que los intereses agrarios se subordinasen a los eléctricos.

Entre 1925 y 1935, las tasas de aumento del parque eléctrico español decrecieron pese a la incorporación a las redes de energía procedente de las mayores instalaciones hidráulicas y térmicas empleadas hasta entonces en España.

Aparte de la construcción de la primera gran central gallega en el Tambre, destacan la inauguración de los Saltos del Alberche en el centro peninsular, la 
culminación del sistema del Cinca-Lafortunada por Hidroeléctrica Ibérica, la continuación de la explotación del Segre y sus afluentes por Riegos y Fuerzas del Ebro, el comienzo de la explotación sistemática del Guadalquivir por parte de las empresas andaluzas $\mathrm{y}$, primordialmente, la puesta en marcha de los primeros equipos generadores de Millares en el Júcar para Hidroeléctrica Española y en el curso medio del Esla por parte de Saltos del Duero. Los equipos instalados en estas últimas centrales eran mayores que $50.000 \mathrm{~kW}$, y la obra civil permitía albergar otros equipos adicionales más adelante. Estas grandes centrales eran establecimientos dotados de embalse para almacenamiento de agua y para la regularización, por tanto, de los caudales que los abastecían.

Debido a la composición del potencial hidroeléctrico técnicamente explotable, el sistema hidroeléctrico español podía crecer solo en este modo. Así, en 1935, más de un $20 \%$ de la capacidad instalada en España lo era en centrales dotadas de presa con embalse regulador, y cuya potencia media era de $17.469 \mathrm{~kW}$, un porcentaje mayor que el italiano, donde las ayudas públicas contribuyeron largamente a su construcción.

Hasta 1935 los embalses para uso mixto tenían una capacidad eléctrica menor (un 20\%) que los exclusivamente eléctricos. Los embalses para riego se ubicaban en los cursos medios de las corrientes, donde se instalaba maquinaria eléctrica menos potente. Exigían obras caras: solo en obra civil el coste por $\mathrm{kW}$ instalado en los embalses de uso mixto era exactamente el doble que en las presas para uso eléctrico.

En consecuencia, la producción hidroeléctrica española se fue concentrando poco a poco en centrales de mayor tamaño. De establecimientos con una media menor que $60 \mathrm{~kW}$ instalados en 1901, se había pasado a superar los 2.500 en 1935. No obstante, solamente diez centrales superaban los $25.000 \mathrm{~kW}$.

En 1931, la explotación hidráulica había crecido en tamaño, respecto a un recuento similar de 1917, había abandonado la periferia peninsular para acercarse a su centro y sus características principales, altura y caudal, también habían aumentado.

Como apuntaba la orientación de las concesiones de 1917, el potencial técnicamente explotable de la periferia peninsular se constituía en aquel más aprovechado hasta 1930, pero esta tendencia se quebraría definitivamente con la puesta en marcha de Saltos del Duero, otorgando entonces un mayor peso a la meseta en la explotación hidráulica española. En 1918, el ingeniero José Orbegozo promueve la constitución de la Sociedad General de Transportes Eléctricos Saltos del Duero para explotar los recursos del Duero y sus afluentes, 
incluso de su tramo internacional. Resuelto, tras largas negociaciones, el litigio con Portugal a este respecto, se inició la construcción del vasto sistema, cuya obra máxima, de las terminadas antes de la Guerra Civil 1936-1939, fue la presa de Ricobayo, inaugurada en 1934. También eran muy importantes los aprovechamientos del Segre y del Noguera Pallaresa (Lérida) pertenecientes al grupo Barcelona Traction, y los del Cabriel (Cuenca) y Júcar (Valencia), propiedad de Hidroeléctrica Española.

EMBALSES CON PRESA MAYOR DE 15 M PARA UTILIZACIÓN HIDROELÉCTRICA Y MIXTA EN ESPAÑA EN USO ANTES DE 1936

\begin{tabular}{|c|c|c|c|c|c|c|c|c|c|c|}
\hline CUENCA & EMBALSE & COMPAN̂́A & AÑ̃o & $\begin{array}{l}\text { PRESA } \\
\text { (b) }\end{array}$ & MATERIALES & ALTURA & $\begin{array}{c}\text { CUBICANE } \\
\text { EN M }^{3}\end{array}$ & $\mathrm{HM}^{3}$ & KW 1935 & $\begin{array}{c}\text { CLASE } \\
\text { APROVECHA- } \\
\text { MIENTO (c) }\end{array}$ \\
\hline Tajo & Villar & Canal de Isabel II & 1882 & G & M & 48,90 & 49.000 & 24,0 & 6.240 & M \\
\hline Eoro & Capdella: Colomina & E. E. Cataluña & 1914 & G & HM & & 1.735 & 3,7 & 6.600 & $\mathrm{E}$ \\
\hline Ebro & Capdella: Cuvieso & E. E. Cataluña & 1914 & G & HM & & 8.540 & 3,7 & 6.600 & E \\
\hline Ebro & Capdella: Estangento & E. E. Cataluña & 1914 & $\mathrm{G}$ & HM & & 4.535 & 3,2 & 6.600 & E \\
\hline Ebro & Capdella: Salado & E. E. Cataluña & 1914 & $\mathrm{G}$ & $\mathrm{HM}$ & & 4.255 & 1,1 & 6.600 & E \\
\hline Ebro & Seros: Sela & RRFFE & 1915 & $T$ & $T$ & & 178.900 & 4,5 & 22.328 & E \\
\hline Ebro & Seros: Utxesa & RRFFE & 1915 & $T$ & $T$ & & 415.300 & 4,5 & 22.328 & E \\
\hline Ebro & Tremp & RRFFE & 1916 & $\mathrm{G}$ & $\mathrm{H}$ & 82.00 & 275.000 & 227,8 & 28.000 & M \\
\hline Tajo & Villora & H. E. & 1918 & G & $\mathrm{H}$ & & 2.440 & 0,1 & 24.400 & $E$ \\
\hline Tajo & Santillana & Santillana & 1920 & G & M & 28,00 & 91.504 & 45,6 & 9.000 & M \\
\hline Norte & Torina & Viesgo & 1921 & G & HM & & 48.000 & 12,6 & 15.200 & $E$ \\
\hline Tajo & Batanejo & H. E. & 1921 & G & $\mathrm{H}$ & & S.D. & 0,1 & 2.000 & $\mathrm{E}$ \\
\hline Eoro & Camarasa & RRFFE & 1922 & G & $\mathrm{H}$ & 92,00 & 218.000 & 163,4 & 44.992 & E \\
\hline Duero & Cervera & Estado & 1924 & G & HM & & 40.000 & 10,0 & 128 & M \\
\hline Guadalquivir & Gaitanejo & H. Chorro & 1927 & G & $\mathrm{HM}$ & & 2.000 & 4,0 & 2.400 & $\mathrm{E}$ \\
\hline Ebro & San Lorenzo & RRFFE & 1930 & M & $\mathrm{H}$ & & 36.000 & 9,5 & 8.000 & M \\
\hline Guadalquivir & Cala & Sevillana & 1931 & $\mathrm{G}$ & $\mathrm{H}$ & & 113.400 & 60,3 & 12.800 & $E$ \\
\hline Tajo & Burguillo & UEM y Estado & 1931 & G & $\mathrm{H}$ & 90,00 & 295.000 & 208,0 & 30.000 & M \\
\hline Duero & Agueda & Estado & 1931 & G & $\mathrm{HM}$ & 33,00 & 60.000 & 15,7 & 520 & M \\
\hline Guadalquivir & Jándula & Mengemor y Estado & 1932 & G & M & & 365.000 & 342,0 & 15.000 & M \\
\hline Guadalquivir & Encinarejo & Estado & 1932 & G & M & & 15.000 & 16,0 & 8.320 & E \\
\hline Ebro & Usoz & El Iratí & 1933 & G & $\mathrm{HM}$ & & 6.830 & 0,9 & 800 & E \\
\hline Norte & Doiras & Viesgo & 1934 & $\mathrm{G}$ & $\mathrm{H}$ & & 213.000 & 102,8 & 28.800 & $E$ \\
\hline Duero & Ricobayo & SD & 1934 & G & $\mathrm{H}$ & $92, \infty$ & 398.088 & $1.184,0$ & 59.200 & $E$ \\
\hline Ebro & Terradets & RRFFE & 1935 & G & $\mathrm{H}$ & & 25.000 & 33,2 & 27.360 & $\mathrm{E}$ \\
\hline Júcar & Millares & H. E. & 1935 & $\mathrm{G}$ & $\mathrm{H}$ & & 31.000 & 1,0 & 60.000 & E \\
\hline TOTAL & & & & & & & 2.897 .527 & 2.481 .7 & 454.216 & \\
\hline
\end{tabular}

a) Sevillana construyó en 1924 sobre el río Gaduares el embalse de Montejaque, que tuvo que abandonarse en fecha cercana a su construcción por problemas de filtración y llenado a causa de la permeabilidad de los terrenos calcáreos en que fue construido, así como por los fuertes estiajes de la corriente fluvial que lo alimentaba.

b) Las presas: Gravedad, Tierra y Mixta. Materiales: Hormigón, Tierra, Mampostería y técnica mixta (HM).

c) Clase aprovechamiento: Eléctrico y Mixto.

El mapa eléctrico que se dibujaba en 1935 en España era el de una industria cuya explotación había evolucionado caracterizada por tres rasgos principalmente. El primero consistía en el lento crecimiento del parque eléctrico en términos internacionales, fijándose este diferencial durante el primer decenio del siglo y acentuándose durante los primeros treinta. Como segundo 
rasgo destacaba un rendimiento de las instalaciones menos intenso que en otros países. Por último, llamaba la atención la estructura dual en la composición de los equipos, con pervivencia de tecnologías obsolescentes, al lado de un subsector hidroeléctrico que había avanzado a buen paso en el camino del uso de grandes unidades de generación y en el almacenamiento de agua mediante embalse. Esta dualidad en el terreno de la explotación tenía su correlato en un reparto territorial igualmente dicotómico, con zonas muy electrificadas y otras apenas transitadas por redes de ámbito local.

Este patrón de desarrollo sectorial se alejaba del común de otros países hidrodependientes.

Y la electrificación resultante era asimismo diferente: más lenta, a menor escala y escasamente intensiva. La evolución de la electrificación española se asemejaba a la trayectoria de los entornos térmicos: lugares en que la electricidad se adoptó inicialmente para iluminación y luego se impuso en el sector manufacturero al sustituir al vapor. En particular, la evolución de los precios energéticos fue la que primeramente orientó la extensión de la electricidad en el sector manufacturero.

\subsection{EL PERIODO DE LA AUTARQUÍA 1936-1960}

La situación anterior se vio bruscamente alterada por el estallido de la guerra civil.

Durante los tres años de la guerra no se acometieron nuevos proyectos y la producción disminuyó un 25 por ciento como promedio. Sin embargo, la incidencia del conflicto fue muy desigual según las zonas y épocas. El País Vasco tuvo problemas de suministro eléctrico desde el primer momento, al ser zona republicana y tener sus principales centrales y líneas de abastecimiento en territorio nacional.

En Cataluña, las dificultades se dejaron sentir en el último año de la guerra, cuando el Gobierno republicano perdió la región pirenaica que contaba con los mayores aprovechamientos hidroeléctricos.

Madrid y la zona de Levante pudieron mantener una situación casi normal hasta el final de la contienda, al estar bajo control republicano centrales productoras y puntos de consumo. 
En la zona nacional, predominantemente rural y con abundancia de recursos hidroeléctricos, no hubo más problemas que los propios de una situación y economía de guerra.

Al término del enfrentamiento armado, el suministro pudo normalizarse en relativo breve tiempo.

El desarrollo de la producción de energía hidroeléctrica en España en los años 1939-1955 fue muy considerable. La producción de energía eléctrica en España era de carácter eminentemente hidráulico, siendo sensiblemente la hidroeléctrica el 90\% de la total, proporción que se mantiene hasta el año 1944, desde el cual podría decirse que es aproximadamente el $75 \%$ de la total producida.

El carácter torrencial de los ríos españoles hacía precisa la construcción de embalses para su regulación, siendo la capacidad en octubre de 1956 de 12.779,6 Hm3.

La explotación integral de los recursos de las cuencas españolas es la que se llevó a cabo siguiendo un Plan General de Obras Hidráulicas, que mediante la colaboración del Estado y la economía privada, fue realizándose. En esos años, formando parte de la industrialización del país, se dio un importante impulso a las grandes obras hidráulicas, cuyo papel fue muy importante no solo como productoras y almacenadoras de energía eléctrica, sino también como fuente de riqueza al convertir los terrenos de secano en regadío.

La mayor parte de los grandes embalses reguladores de energía y almacenadores de agua para riego eran construidos por el estado, y una vez construidos, se concedían mediante concurso, en explotación, a las empresas privadas productoras de energía eléctrica, reservándose el Estado siempre el control de agua para riego.

En los primeros años del período 1939-1943 se empieza de nuevo a construir en España centrales, no obteniéndose nuevas potencias hasta 1943.

Los años inmediatos de postguerra, conocidos como los de sequía pertinaz, tuvieron en Andalucía un perfil aún más grave si cabe, que en el resto del territorio peninsular, debido a la penuria pluviométrica. En realidad fue una sequía particularmente severa y de amplia duración temporal que se inicia suavemente en 1941, se acentúa en 1942 y 1943, es especialmente grave en 1944 y 1945, se alcanza un cierto alivio hidráulico en 1946-1948 y, 
seguidamente (1949-1950), vuelve de nuevo a reproducirse una situación de lluvias escasas.

Entre 1941 y 1945 el incremento de la capacidad productiva es prácticamente nulo. Después, en pleno periodo de restricciones se reemprende el crecimiento, pero no es hasta 1952 cuando se hace intenso y regular.

A pesar de la influencia desfavorable de la segunda guerra mundial, que impidió la importación de turbinas y alternadores, así como de material auxiliar restante, se inauguraron en 1945 ampliaciones de centrales hidráulicas de relativa importancia. En años sucesivos se irán inaugurando centrales de nueva ejecución tan importantes como Viella, Flix, y se amplía el Salto del Esla con un cuarto grupo de 37.000 KVA en 1947.

En los años siguientes ya comienzan a inaugurarse centrales muy importantes como Villalcampo (R. Duero) de 96.000 KVA en 1949, Barasona (R. Ésera) de 28.000 KVA en 1949, y en general, la tendencia de aumento es muy grande, ya que si en 1950 la potencia instalada es 2.13 veces la de 1939, en 1955 llega a ser 3.75 veces mayor.

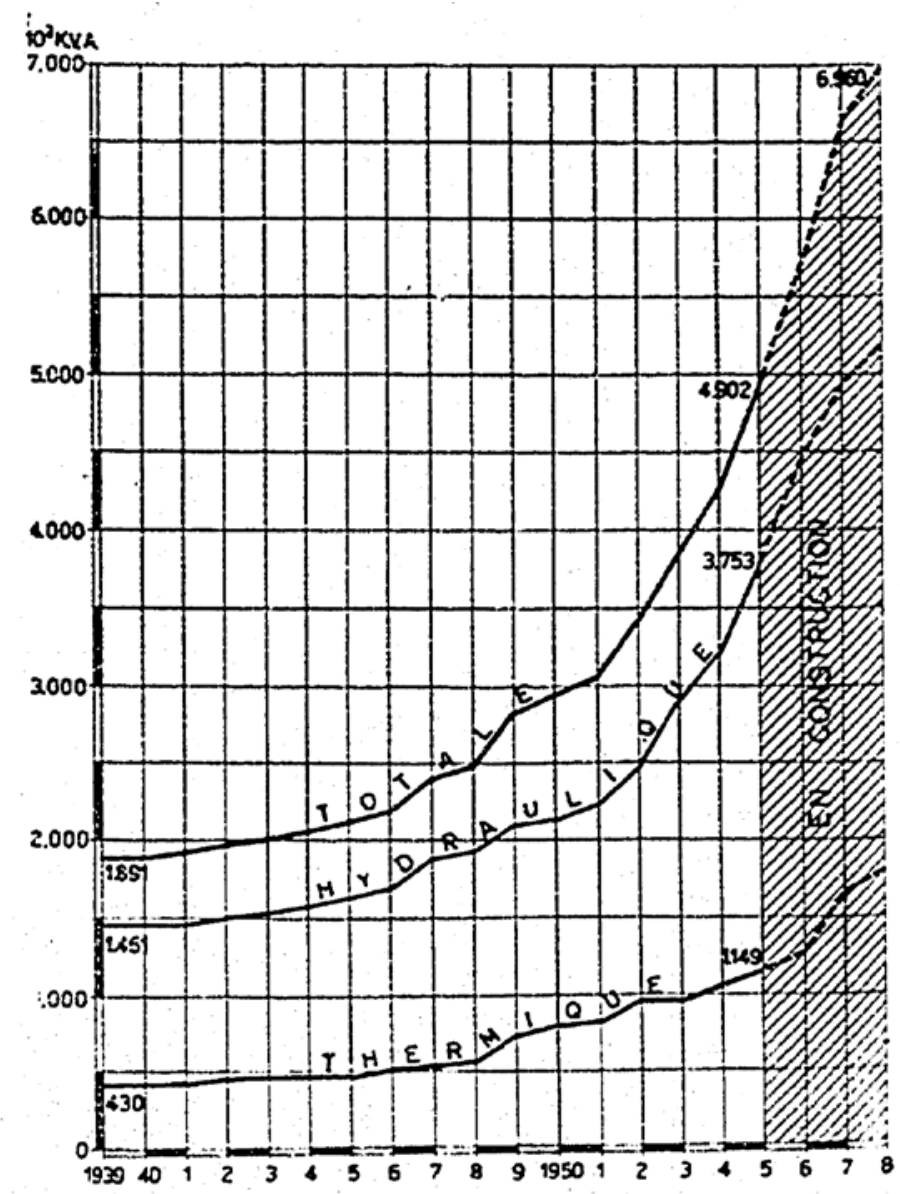


Hay que tener en cuenta también que en esos años, España sufría un aislamiento internacional que dificultaba de forma adicional el desarrollo hidroeléctrico mencionado. Por ello, el esfuerzo realizado por España, colaborando el Estado con las empresas privadas, fue notable, ya que durante el periodo 1939-1955, se instaló el 55.7\% de la potencia existente en España.

La energía producida seguía sensiblemente la instalación de potencias, pero mejorada por varias causas: por la interconexión de las centrales, la existencia de térmicas que permitían mejor utilización y explotación de las hidráulicas, y por el establecimiento de embalses reguladores que permitían un óptimo aprovechamiento del agua, en relación con la pluviometría y demás condiciones meteorológicas.

Las centrales hidroeléctricas más importantes inauguradas en este período fueron las siguientes:

\begin{tabular}{|c|c|c|c|c|}
\hline Central & Rio & Tipo de presa & Potencia & Ano de inauguraciòn \\
\hline 1. Villalcampo .... & Duero ... & Gravedad ............ & 96000 & 1949 \\
\hline 2. Coirentes ................................ & Júcar $\ldots \ldots \ldots \ldots \ldots \ldots \ldots$ & Ticrra ................ & 138000 & 1951 \\
\hline 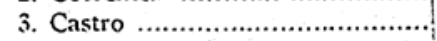 & 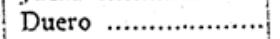 & Graveciad ............ & $\$ 4000$ & 1952 \\
\hline 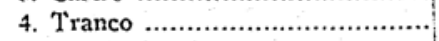 & Guadalquivir ........... & Arco sravedad ... & 49750 & 1953 \\
\hline 5. Los Peares ............................... & 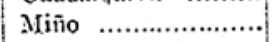 & Gravcdad ............ & 180000 & 1953 \\
\hline 6. Grandas de Salime ................... & Navia .................... & Gravedad ............ & 140002 & 1953 \\
\hline 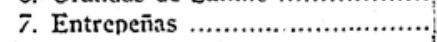 & 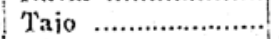 & Gravedad ............. & 35000 & 1954 \\
\hline 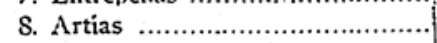 & 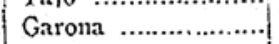 & Latros ................... & 72000 & 1955 \\
\hline 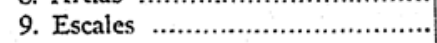 & N. Ribagorzana ....... & Gravedad ............... & $4 C 250$ & 1955 \\
\hline 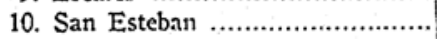 & 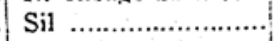 & Arco gravedad ... & 330000 & 1955 \\
\hline 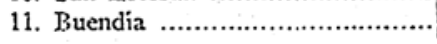 & Taio ....................... & Gravedad ............ & 57000 & 1955 \\
\hline
\end{tabular}

Tras la aprobación de las Tarifas Tope Unificadas (1951) se entró en la segunda etapa inversora de la industria eléctrica. Las construcciones alcanzaron su momento culminante en 1955-1957, en el caso de las grandes empresas. En la década de 1950 se añadieron 3.290 MW, en su mayoría de naturaleza hidráulica (67\%). En esta época empezaron a ganar protagonismo las centrales de más de 50 MW. Durante el segundo quinquenio de la citada década (1955-1960) se inauguran las centrales de San Esteban (266 MW), Saucelle (251 MW), Canelles (108 MW), Barazar (84 MW), Silvón (63 MW) y Bárcena (61 MW).

Es importante reseñar el impulso a la construcción de embalses reguladores que se dio en este período, amparado en el Plan General de Obras Hidráulicas, con el fin de mejorar las características torrenciales de los ríos españoles, asegurando el agua precisa para el regadío y situándose en aquellos cauces en que mayor producción de energía habría de producir la regulación de sus caudales.

Los principales embalses construidos en este período fueron los siguientes: 


\begin{tabular}{|c|c|c|c|c|c|}
\hline Embalse & Rio & Cue ne ล & $\begin{array}{l}\text { Capaciclad } \\
\text { en Hon.2 }\end{array}$ & $\begin{array}{l}\text { Potencia } \\
\text { instalada } \\
\text { KV }\end{array}$ & $\begin{array}{l}\text { Año de puesta } \\
\text { en servicio }\end{array}$ \\
\hline Chorro ........................... & Guatclalhores ................. & 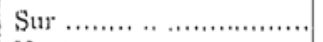 & S6 & 4180 & 1947 \\
\hline Las Conchas $. . . \ldots \ldots \ldots . . . . .$. & J fimia $\ldots \ldots, \ldots \ldots \ldots \ldots \ldots$ & Norte ......................... & 80 & 31000 & 1948 \\
\hline 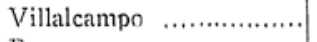 & 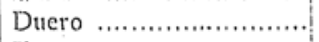 & Duero ...................... & 48 & 96000 & 1949 \\
\hline Barasona ..................... & Esera $\ldots . . . . . \ldots \ldots \ldots \ldots \ldots$ & 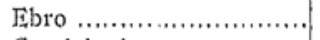 & 71 & 17500 & 1949 \\
\hline Pintado $\ldots \ldots \ldots, \ldots, \ldots, \ldots, \ldots$ & 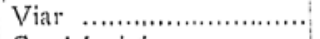 & Guadalquivir ,............... & 202 & 23500 & 1950 \\
\hline T'ranco ......................... & Gundalc|uivir ............... & Guaclalquivi; & 500 & 49750 & 1953 \\
\hline Cordobilla ..................... & Genil ............................. & Guarlalquivi; ................ & 34 & 15400 & 1953 \\
\hline 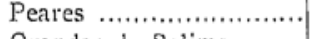 & Miño & Norte $\ldots \ldots \ldots \ldots \ldots \ldots \ldots \ldots$ & 170 & 180000 & 1953 \\
\hline Grandas de Salime ........ & Navia................... & 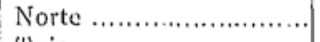 & 266 & 140000 & 1953 \\
\hline Entrepeñas $. . . \ldots \ldots \ldots \ldots \ldots . . . .$. & 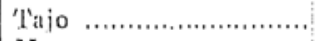 & 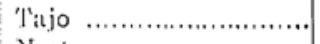 & 891 & 38000 & 19.54 \\
\hline Chandreja .................... & Naveat ,............................ & Norte ............................. & 61 & 4.500 & 1954 \\
\hline San Juan .................... & Alberche ... ................ & 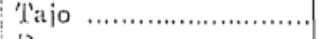 & 148 & 38000 & 1955 \\
\hline Barrios de Iuna ........... & 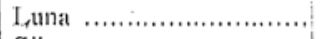 & 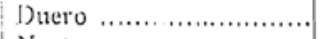 & 308 & 43500 & 195.5 \\
\hline San Esteban ................. & Sil $\ldots \ldots \ldots \ldots \ldots \ldots \ldots \ldots \ldots \ldots$ & Norte..$\ldots \ldots \ldots \ldots \ldots \ldots \ldots$ & 213 & 330000 & 1955 \\
\hline Escales $\quad \ldots \ldots \ldots \ldots \ldots \ldots \ldots$ & N. Ribagor\%ana ............. & Ebro $\ldots \ldots \ldots \ldots \ldots \ldots \ldots \ldots \ldots \ldots \ldots$ & 158 & 46250 & 1955 \\
\hline \multirow[t]{2}{*}{ Buendía ........................ } & \multirow{2}{*}{ Guadicla $, \ldots \ldots, \ldots, \ldots, \ldots, \ldots$} & \multirow{2}{*}{ 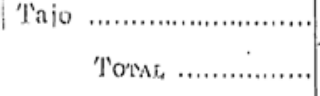 } & 1750 & 57000 & 1955 \\
\hline & & & 4986 & 1029580 & \\
\hline
\end{tabular}

La potencia hidroeléctrica instalada en estos saltos de pie de presa (823 MW), suponen el 45\% de la potencia total instalada en el periodo 1939-1955.

Los cortes por la escasez de la producción se inician en 1944, continúan con distinta intensidad hasta 1954, y se reproducen de forma muy débil en 1957. Por ejemplo en Cataluña acaban las restricciones eléctricas en 1958 con la entrada en servicio del salto de Puente de Montañana.

Una vez alcanzada la universalización del suministro se inició la lucha por la calidad del servicio. La red de transporte también se fue incrementando paulatinamente.

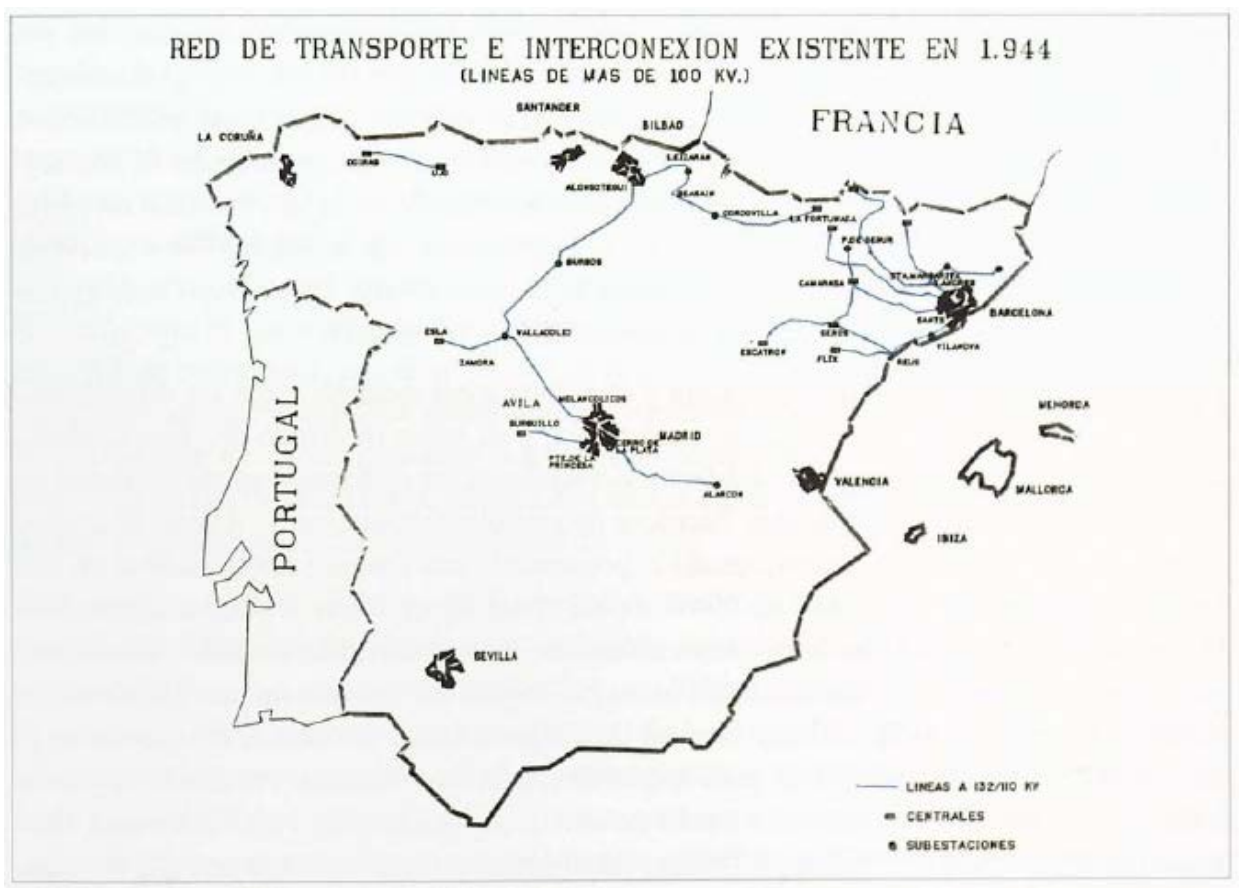




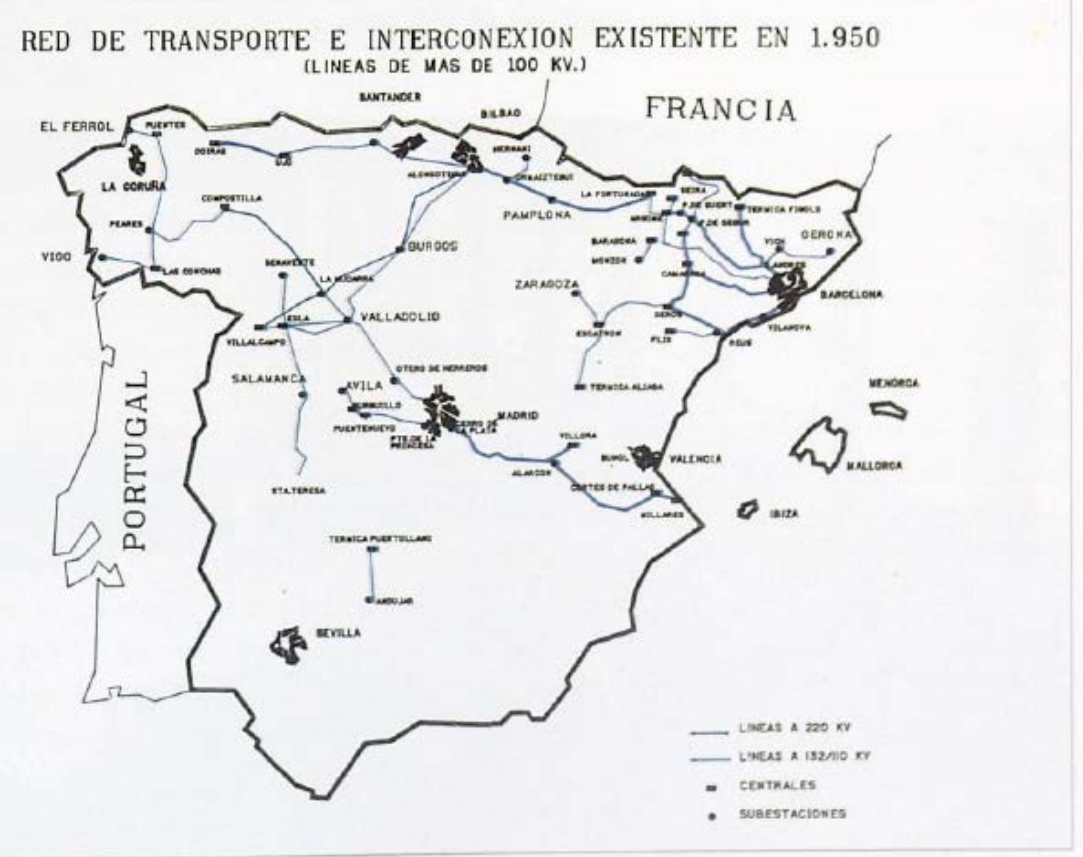

Aunque en los años 30 se estudió el primer gran aprovechamiento integral de un río español, el Duero, sin embargo, el primero en realizarse fue el del Noguera Ribagorzana, entre 1947 y 1962. Este río nace en el macizo de La Maladeta a la cota 2.470. Las aguas procedentes del mismo se derivan al lago Llauset a la cota 2.192. Desde esta cota, sus caudales no dejan de turbinarse a lo largo de sus $130 \mathrm{~km}$. de trazado hasta su confluencia con el río Segre en Corbins, alimentando 14 centrales, 1 de bombeo, 15 minicentrales, 3 hilaturas, 3 harineras y 1 papelera. Posteriormente, a través de canales, se utilizan sus aguas hasta la cota 73, cediendo sus aguas al rio Cinca en Fraga.

\subsection{LA HIDROELECTRICIDAD EN EL PERIODO 1960- ACTUALIDAD}

\subsubsection{LA ETAPA DE LOS PLANES DE ESTABILIZACIÓN Y DESARROLLO. 1960-1975}

Esta época puede considerarse como de electrificación madura y por tanto, se caracterizó por la búsqueda de la cantidad y de la calidad del suministro. Ya no bastaba con abastecer al mercado, sino que había que hacerlo con garantizando que las industrias dispusieran de una energía fiable y con unos mínimos de calidad establecidos en tensión y frecuencia estables.

Esto obligó a realizar un gran esfuerzo en cuanto a redes de transporte, para unir las distintas islas eléctricas que existían en el país, y en el incremento de la potencia instalada, especialmente de la hidráulica al principio del período, y de la térmica al final. 


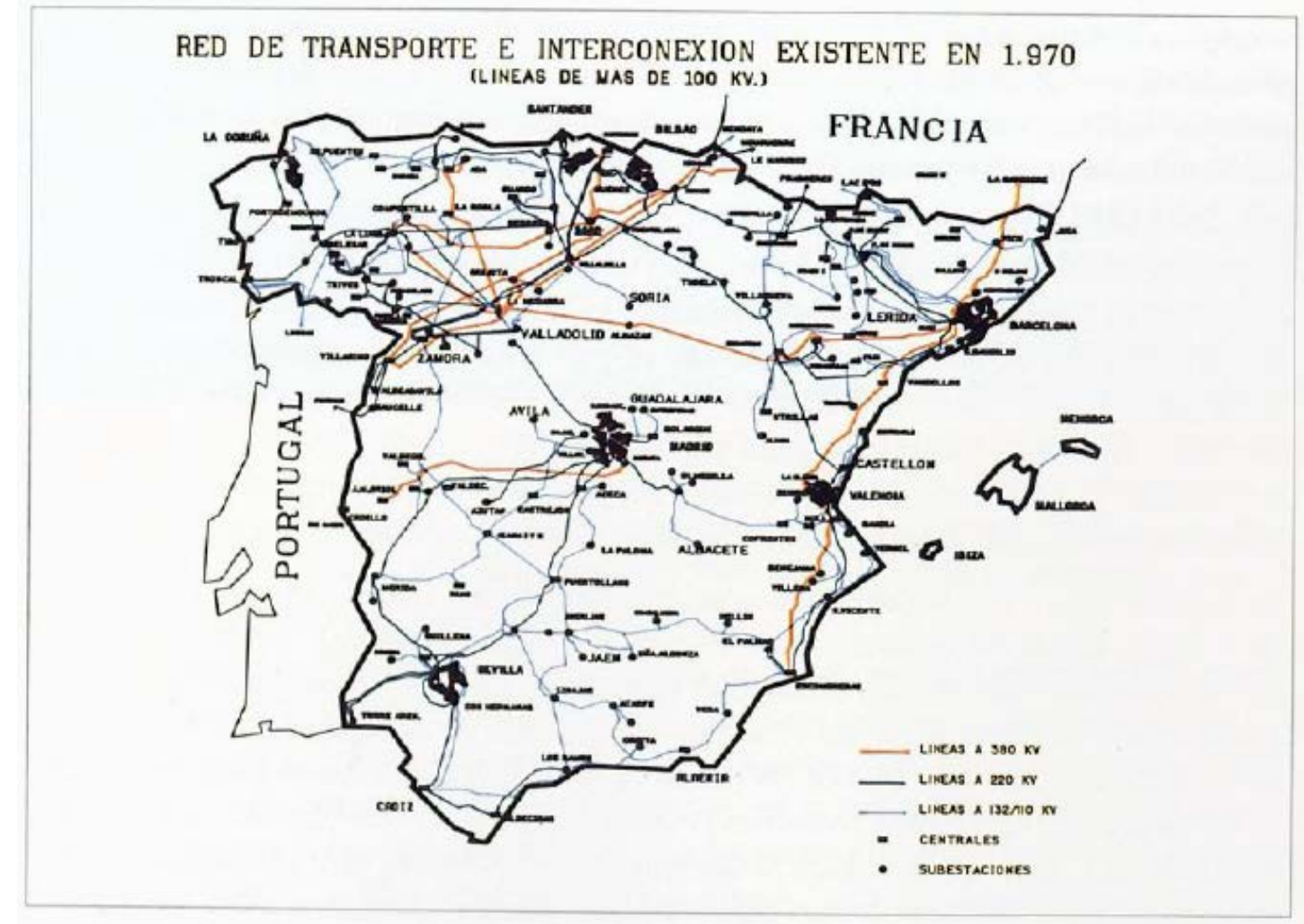

Entre 1960 y 1964 se instalan 2.584 MW en centrales hidroeléctricas. Durante estos cinco años se inauguran las centrales de Aldeadávila (810 MW), Mequinenza (324 MW), Puente Bibey (285MW), Belesar (225 MW), Valdecañas (225 MW) y Cornatel (122 MW). También son reseñables las nuevas aportaciones de las centrales con 55 MW de potencia: Eume, Sau y Puerto Peña; así como las de San Agustín y Miranda, de 65 MW cada una. Estas 11 centrales suponen el 88,5\% de la potencia hidroeléctrica instalada.

Durante el segundo lustro de la década de los sesenta la potencia instalada se incrementa en una cifra aproximada al quinquenio anterior: $2.312 \mathrm{MW}$. Mientras que en 1965 no se inaugura ninguna gran central, al año siguiente lo hacen las de Aguayo (339 MW), Las Ondinas (81 MW), Velle (80 MW) y Llavors (53MW). De 1967 son las de Ribarroja (263 MW), Torrejón (129 MW), Susqueda (86 MW), Portodemouros (76 MW) y las Arbón, La Barca Y SantiagoJares, con potencias comprendidas entre los 51 y 56 MW. Un año más tarde sólo se inaugura Iznajar (77 MW). En cambio, los dos años siguientes son un bienio de referencia en la historia hidroeléctrica de España. En 1969 se conectan a la red José María Oriol (934 MW), Castrelo (112 MW), Ip (84 MW), Eriste (80 MW), Mediano (66 MW) y Biescas 2 (62 MW); y en 1970 se inauguran AlmendraVillarino (810 MW), Azután (180 MW) y Frieira (130 MW).

En esta etapa se consuma el paso de la hulla blanca a la verde. La electricidad obtenida a partir de la regulación mediante embalses de cabecera ubicados en 
las grandes cordilleras montañosas, frecuentadas por las nieves, se completa con la conseguida en los cursos medios o valles de los grandes ríos españoles.

En el Valle del Ebro se incrementa la explotación de la hulla blanca oscense leridana por parte de un número reducido de compañías. Las inversiones de ENHER (241 MW), Productora de Fuerzas Motrices (154 MW), Cía de Fluido Eléctrico (69 MW), Energía e Industrias Aragonesas (85 MW) e Hidronitro (26 MW) explican casi dos tercios de la potencia creada antes de los años sesenta. En la década siguiente prácticamente se duplica la potencia instalada también bajo la actuación de varias empresas. Una vez más ENHER (735 MW), en este caso mediante el aprovechamiento de dos grandes embalses sobre el río Ebro (Mequinenza y Riba-Roja) y Fuerzas Eléctricas de Cataluña S.A. (FECSA) (341MW), a través de los últimos recursos en altura del Pirineo leridano, concentraron la mayor capacidad productiva. El resto de la potencia puesta en servicio se debe a las actuaciones de Energías de Aragón (178 MW) y ERZ (151 MW), también en Huesca, e Iberduero (131 MW) en el Alto Ebro.

El desarrollo hidroeléctrico en Aragón se produce especialmente durante el quinquenio 1951-1955 y en la década de 1960, y estuvo estrechamente vinculado a las obras hidráulicas del periodo. En esos años la potencia instalada hidroeléctrica aumentó a una tasa anual del 8,6\%, pero todavía algo inferior a la media española. Dos empresas protagonizaron este crecimiento: ENHER, que iniciaba su presencia en el Noguera Ribagorzana (Escales), y, en menor medida, Energía e Industria Aragonesas (EIASA) en el Alto Gállego. La etapa de mayor crecimiento se produjo durante la década de los sesenta, especialmente durante el primer quinquenio (la potencia instalada creció a una tasa anual del 15,9\%, muy superior a la media española, frente al 8,1\% del segundo quinquenio). La principal protagonista es ENHER y la importante central de Mequinenza destinada hacia la demanda catalana. En la segunda mitad de la década de los sesenta el protagonismo de ENHER es compatible con las nuevas centrales de EIASA, que pasó del Alto Gállego al aprovechamiento de saltos hidráulicos en el Ésera (Eriste), así como ERZ, que verificó en estos años un esfuerzo productivo en el Aragón, central de IP en Canfranc.

En Cataluña el segundo ciclo de expansión hidráulica despegó a comienzos de la década de los años cincuenta, y se extendió hasta 1970. Se diferencia del anterior en un aspecto importante: el protagonismo del capital público en las inversiones hidráulicas. Entre 1950 y 1960 se ponen en funcionamiento 23 nuevas centrales situadas, la mayor parte, en las cuencas altas de los ríos Noguera Pallaresa y Noguera Ribagorzana. El proceso de explotación está dirigido por ENHER, que construye, entre otras, las centrales de Senet (1951), Vilaller (1952), Escales (1953), El Pont de la Suert (1955) y Caldes de Boí 
(1958). Hidroeléctrica de Cataluña y Fuerzas Eléctricas de Cataluña (FECSA) también realizan obras, pero con una actividad más modesta: La Plana de Monrós (1940), Espot (1953), Esterri (1958), Unarre (1958). En los años sesenta, pese a que se habían agotado prácticamente las posibilidades de obtención de energía hidráulica, se ponen en funcionamiento dos centrales: Llavorsí-Cardós (1965) y Tavascan (1971).

Fue a partir de 1956, cuando la empresa Hidroeléctrica Española, una de las principales del sector y que atendía el abastecimiento de la zona centro-oriental, con Madrid y Valencia como principales mercados de consumo, consiguió la concesión para explotar los recursos hídricos del Tajo Inferior, esto es, el tramo que dicho río tiene desde poco antes de su entrada en la provincia de Cáceres. A partir de este momento inició la construcción de una serie de grandes saltos que culminarán con la construcción de la nuclear de Almaraz, con importante producción, y que colocará a Cáceres entre las primeras provincias españolas en el sector. La considerable potencia instalada en los saltos de la provincia confirma la existencia de unas condiciones favorables en la red fluvial cacereña, especialmente en el Tajo. Este río, poco después de entrar en la provincia, se encaja en el zócalo paleozoico y prácticamente continúa así hasta que abandona territorio español, incluso con mayor intensidad que al principio. En los $280 \mathrm{~km}$ de recorrido del Tajo por la provincia cacereña tiene un descenso de $302 \mathrm{~m}$., pendiente de cierta importancia. Además, los materiales por los que discurre el Tajo son en principio aptos para construir grandes presas y que los embalses resultantes no tengan grandes pérdidas por filtraciones y aterramientos. Es innegable que aquí es donde el Tajo y alguno de sus afluentes, como el Alagón, presentan las mejores condiciones para la producción eléctrica, pues a las características citadas se une el que aquí lleva más caudal, lo que explica la magnitud de los saltos y la elevada cuantía de la potencia instalada en ellos.

Entre los años cincuenta y setenta se instalaron 8.977 MW. Esto da idea del gran esfuerzo tecnológico e inversor. España, de hecho, pasó de ser un país que importaba ingeniería eléctrica a ser un país exportador, tanto de equipos como de ingeniería civil y electromecánica. En esta época estaba prácticamente garantizada la rentabilidad de cualquier salto hidroeléctrico.

En este período comenzó a desmontarse la autarquía y se inició el desarrollismo amparado en el plan de estabilización, planes de desarrollo, crecimiento del turismo, etc., por lo que la demanda de electricidad se incrementó espectacularmente.

Este crecimiento hizo que no fuera suficiente la energía hidroeléctrica y, en 1973, la producción térmica pasó a ser la principal. 
En conclusión los años sesenta muestran un perfil de ampliación de la capacidad de producción eléctrica con fluctuaciones muy pronunciadas. En el primer lustro el 78,8\% de la potencia de nueva creación (3.163 MW en total) fue hidráulica; mientras que en la segunda mitad de la década, 1965-1970, en cambio, se igualaron los megavatios térmicos e hidráulicos, que sumaron 7.122 MW en total, incluidos los 153 MW nucleares. Asistimos en los años finales de las Tarifas Tope Unificadas a una verdadera explosión de construcciones, de tal manera que la potencia instalada en 1970 aumentó en un 159\% respecto a 1959. Además, las centrales de gran tamaño reunieron la mayor parte de la nueva capacidad de producción. Nueve de un total de 49 centrales supusieron el $73,2 \%$ de la potencia total puesta en servicio en los sesenta: seis hidráulicas, con el 70,7\% del total de este tipo de generación, y tres térmicas, que supusieron el $80,9 \%$ de la potencia térmica.

En el año 1971 se inauguran las centrales de Tavascan (120 MW), en 1972 Albarellos (59 MW); el año 1973 supone un repunte en la potencia instalada con la puesta en funcionamiento del segundo grupo de Bolarque (208 MW) y de la central de Guillena (210 MW). De 1975 son las centrales de Conso (270 MW) y Contreras II (75 MW).

Otro aspecto a destacar en este periodo es la interconexión de las redes eléctricas de Francia y España, para el intercambio de electricidad entre los dos países y con el resto de la red europea.

\subsubsection{DE 1975-A LA ACTUALIDAD}

Entre 1976 y 1978 se da otro impulso fruto de la conexión a la red de las centrales de Cedillo (440 MW), Tajo de la Encantada (360 MW) y los segundos grupos de Villalcampo y Castro, cada uno con 110 MW.

Durante los años setenta y ochenta del siglo pasado se produce una ralentización en el proceso de crecimiento hidroeléctrico, debido a que estos recursos son cada vez menores, más costosos y más lentos en su primer establecimiento respecto a otras energías alternativas. Hay que señalar que el avance productivo de esta etapa se origina esencialmente por la utilización de las nuevas centrales de bombeo, mixto inicialmente y de bombeo puro desde mediados de la década de los ochenta. Ambas explican dos tercios del crecimiento de este periodo, el resto se debe a la puesta en funcionamiento de algunas centrales $\mathrm{y}$, en menor medida, a la rehabilitación de viejas y pequeñas instalaciones. 
En este período se confirma lo que empieza a vislumbrarse en el anterior, gran crecimiento de la térmica convencional, desarrollo de la térmica nuclear y dificultades crecientes para construir hidráulicas.

La gran masa de la producción eléctrica entendida como energía de base, la aportan las térmicas y las nucleares, que tienen un notable desarrollo, mientras que las hidráulicas tienen un ligero crecimiento debido principalmente a los saltos de bombeo como se ha indicado anteriormente, que son un complemento para el correcto funcionamiento de térmicas y nucleares.

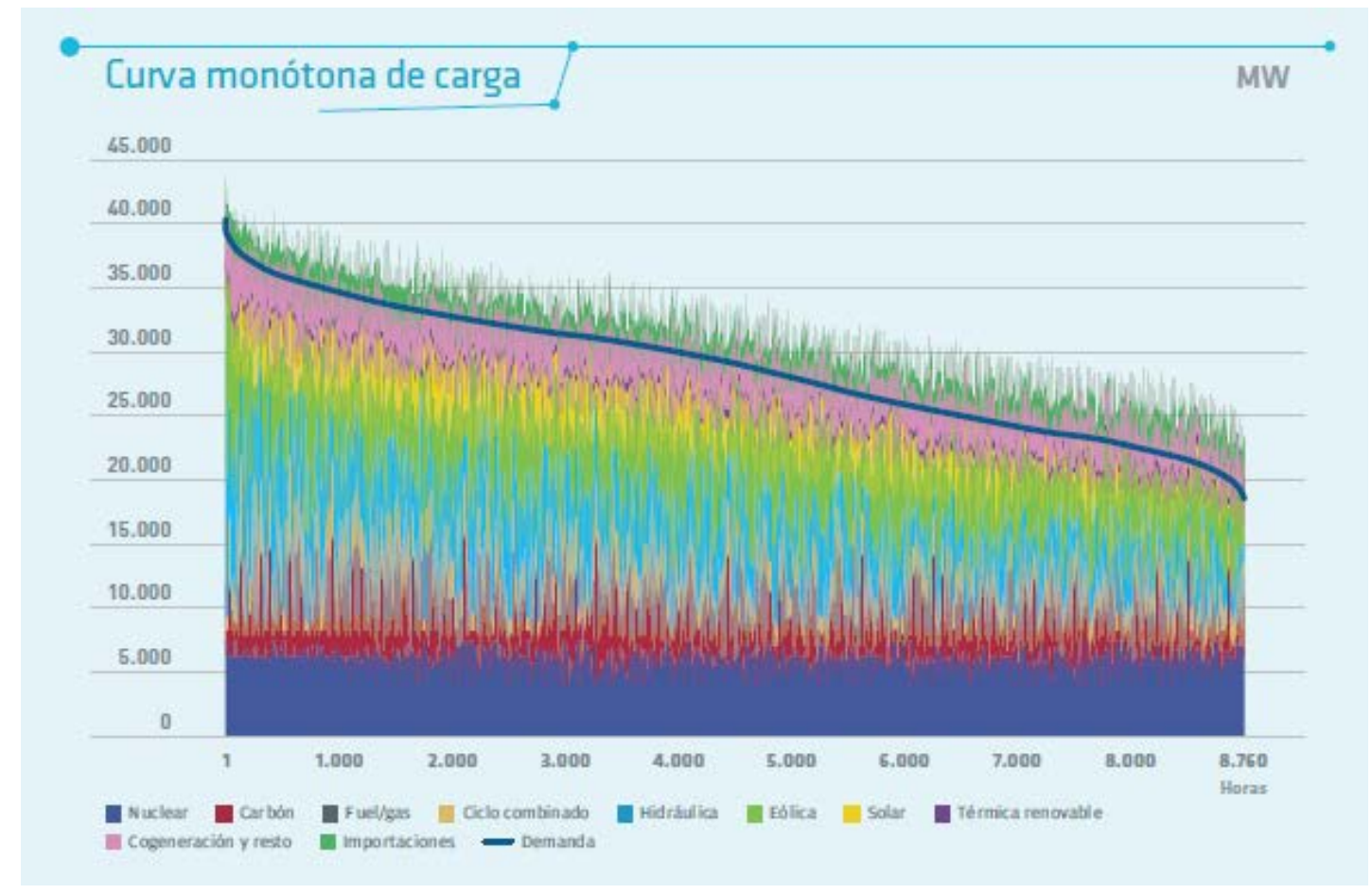

El último y gran momento de la gran industria hidroeléctrica española se vive durante el último lustro de la década de los ochenta, con las aportaciones de las centrales de bombeo: en 1985 Estany Gento-Sallente (451 MW), Moralets (221 MW); en 1986 el segundo grupo de Aldeadávila (421 MW); y entre 1988 y 1989 Cortes II (284 MW) y La Muela de Cortes (635 MW). El aprovechamiento hidráulico de Cortes-La Muela constituye el mayor sistema europeo de bombeo de agua, incluye el Salto de Cortes II y el Salto de Bombeo de la Muela. Éste último permite trasladar la energía producida durante la noche de forma continua por las centrales térmicas y nucleares a las horas de máxima demanda. Al mismo tiempo constituye una considerable reserva de energía, de disponibilidad inmediata y elevada potencia, para suplir cualquier desacoplamiento de un grupo térmico y estabilizar la red. Pieza clave de esta gigantesca estación de bombeo para acumular energía producida en horas valle es el embalse de 140 hectáreas de superficie y 23 hectómetros cúbicos de capacidad útil construido en la altiplanicie de la Muela de Cortes mediante 
excavación y empleo de los materiales extraídos en la construcción de un dique perimetral de escollera. La conexión de este embalse superior con la presa de Cortes, que actúa como depósito inferior de bombeo, se hace por una tubería forzada de acero, de $680 \mathrm{~m}$ de longitud y 4,8 $\mathrm{m}$ de diámetro. Una central subterránea de colosales proporciones alberga tres grupos reversibles turbinabomba con potencias de $630 \mathrm{MW}$ en turbinación y $540 \mathrm{MW}$ en bombeo, con capacidad global para impulsar 127,1 m3/s a $502 \mathrm{~m}$ de altura.

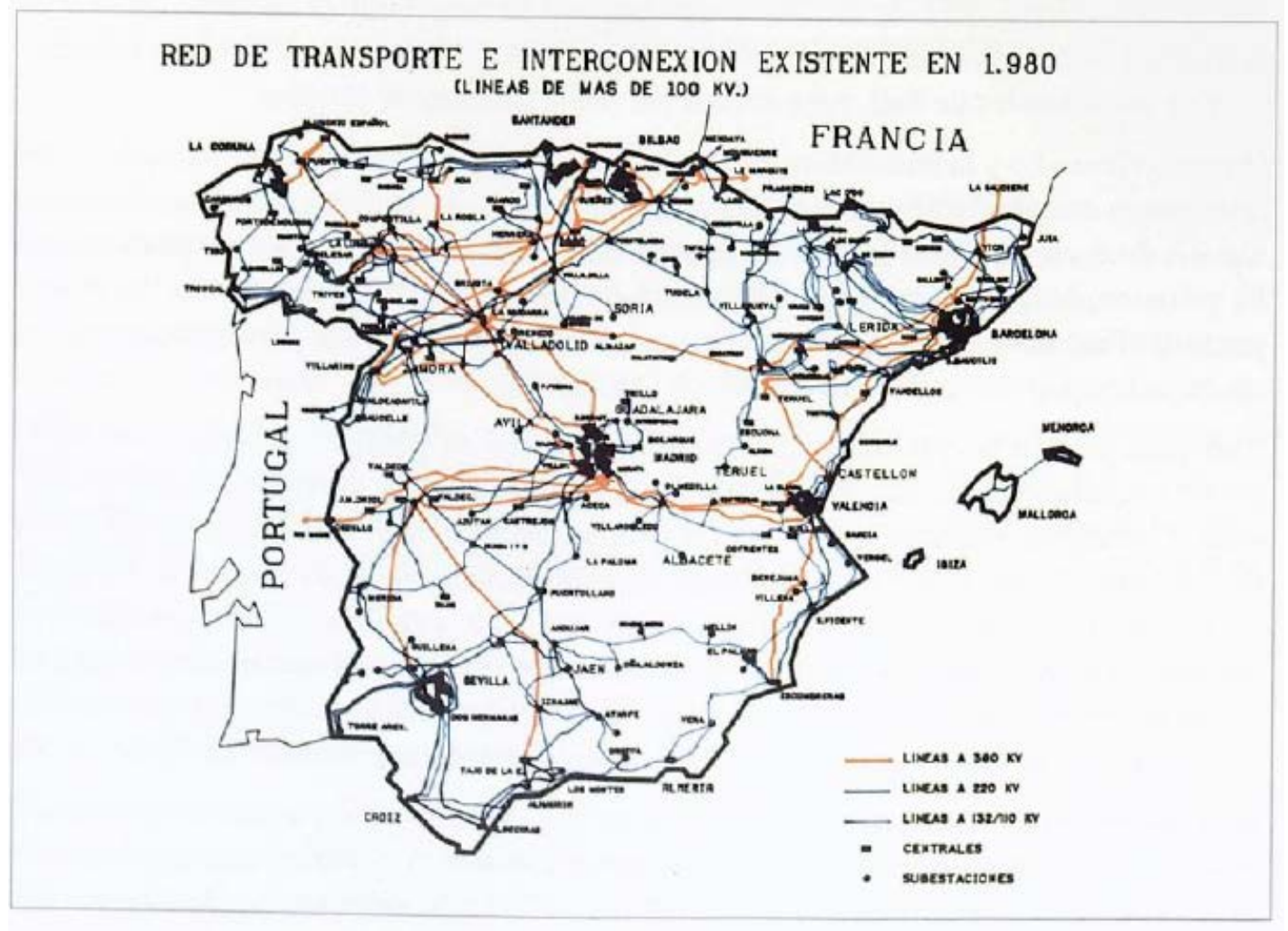

Aunque aparentemente la hidroelectricidad pierde importancia, sin embargo, se convierte en la energía que asegura calidad al sistema eléctrico. Esto es debido a que la energía hidroeléctrica se reserva para la regulación secundaria, terciaria (potencia disponible en 15 minutos) y potencia rodante (grupos hidráulicos trabajando a baja potencia, susceptible de incrementarla instantáneamente), las emergencias, así como para cubrir la demanda de las horas punta, y bombeo (almacenamiento de energía). 

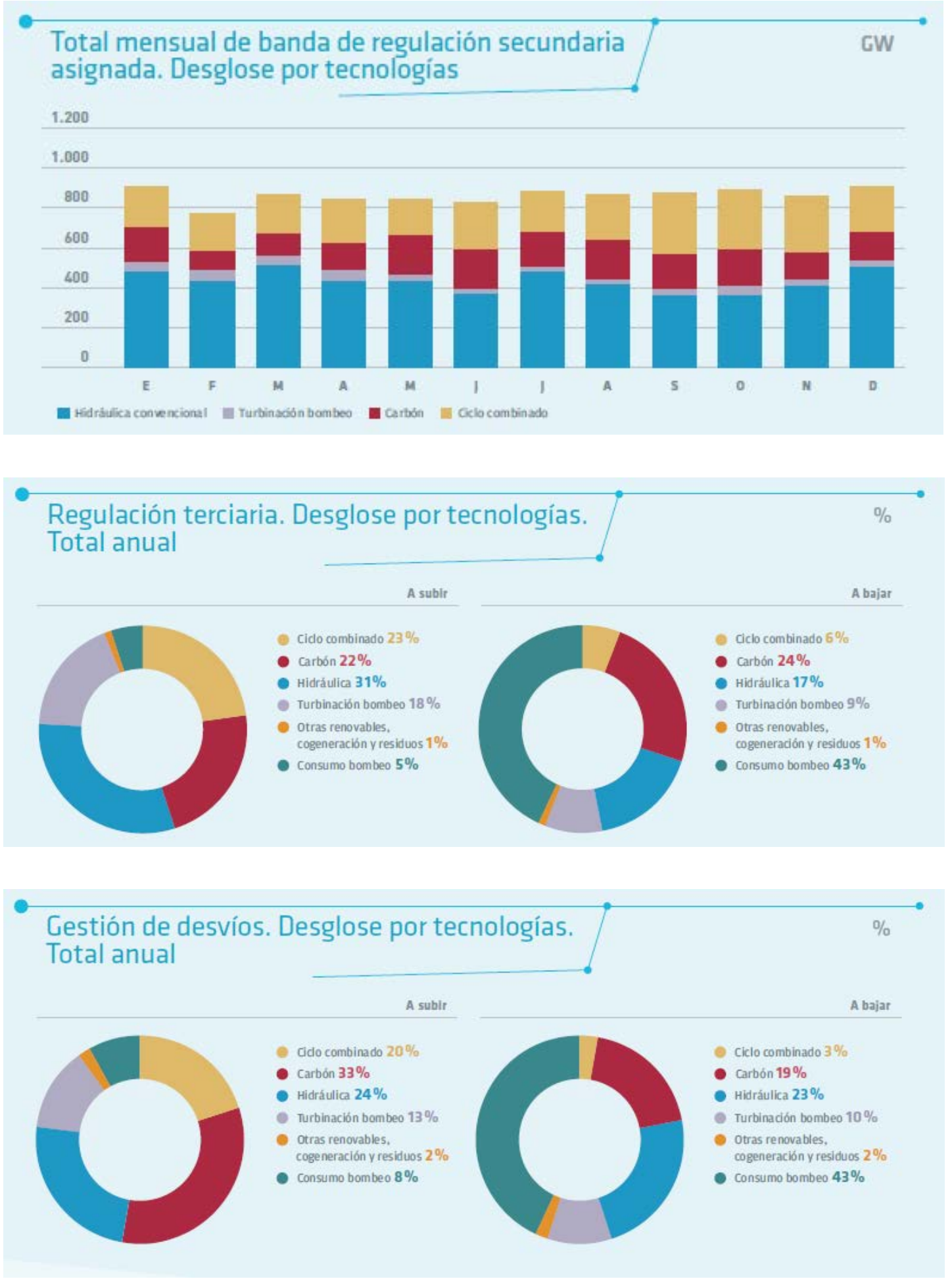

El Plan Energético Nacional de 1978 considera como objetivo primordial la utilización al máximo de la capacidad de producción hidroeléctrica del país, autóctona y renovable.

La Ley 82/1980 sobre Conservación de la Energía surge para hacer frente a la segunda crisis del petróleo. El desarrollo de dicha Ley da lugar al fomento de la autogeneración eléctrica, y establece como actividad que permite el 
otorgamiento de los beneficios previstos en la misma, la de construir, ampliar o adaptar para su utilización instalaciones de producción hidroeléctrica con una potencia de hasta $5 \mathrm{MW}$.

Con el Real Decreto 1217/1981 se instrumentan las medidas para fomentar la máxima capacidad de producción hidroeléctrica del país en el marco de las centrales a las que se refiere la Ley. Con esta disposición se incentiva la actividad mediante la concesión de créditos a la nueva inversión y el establecimiento de un precio de venta de la energía producida adecuado para activar la realización de las instalaciones.

El Plan Energético Nacional 1991-2000 establece un programa de incentivación a la cogeneración y de la producción de energías renovables. Dentro de este contexto, la Ley 40/1994 de Ordenación del Sector Eléctrico Nacional (LOSEN) consolida el concepto de régimen especial.

La Ley 24/1997 del Sector Eléctrico hace obligada la promulgación del R.D. 2818/1998, sobre el régimen especial de energía eléctrica, que comprende las instalaciones de energías renovables, residuos y cogeneración, en todos los casos para instalaciones de hasta $50 \mathrm{MW}$.

Como consecuencia de este marco legal y económico tan favorable, la potencia hidroeléctrica instalada en centrales hidroeléctricas de menos de $50 \mathrm{MW}$ se duplica en la década de los noventa y se triplica desde comienzos de esa década a la actualidad. 


\section{POTENCIA HIDRÁULICA INSTALADA EN RÉGIMEN ESPECIAL.1990-2008}

\begin{tabular}{|c|c|c|c|c|c|}
\hline Año & $\begin{array}{c}\text { Potencia } \\
\text { MW }\end{array}$ & $\begin{array}{c}\text { Incremento } \\
\text { anual MW }\end{array}$ & $\begin{array}{c}\text { Incremento } \\
\text { anual (\%) }\end{array}$ & $\begin{array}{c}\text { Potencia hidroeléctrica } \\
\text { total MW }\end{array}$ & $\begin{array}{c}\text { Potencia Régimen Especial } \\
\text { Potencia Total (\%) }\end{array}$ \\
\hline 1990 & 640 & & & 16.991 & 3,8 \\
\hline 1991 & 754 & 114 & 17,8 & 17.087 & 4,4 \\
\hline 1992 & 796 & 42 & 5,6 & 17.189 & 4,6 \\
\hline 1993 & 856 & 60 & 7,5 & 17.248 & 5,0 \\
\hline 1994 & 940 & 84 & 9,8 & 17.395 & 5,4 \\
\hline 1995 & 998 & 58 & 6,2 & 17.455 & 5,7 \\
\hline 1996 & 1.058 & 60 & 6,0 & 17.605 & 6,0 \\
\hline 1997 & 1.107 & 49 & 4,6 & 17.654 & 6,3 \\
\hline 1998 & 1.297 & 190 & 17,2 & 17.763 & 7,3 \\
\hline 1999 & 1.437 & 140 & 10,8 & 17.973 & 8,0 \\
\hline 2000 & 1.467 & 30 & 2,1 & 17.960 & 8,2 \\
\hline 2001 & 1.560 & 93 & 6,3 & 18.166 & 8,6 \\
\hline 2002 & 1.592 & 32 & 2,1 & 18.276 & 8,7 \\
\hline 2003 & 1.665 & 73 & 4,6 & 18.477 & 9,0 \\
\hline 2004 & 1.707 & 42 & 2,5 & 18.630 & 9,2 \\
\hline 2005 & 1.769 & 62 & 3,6 & 18.743 & 9,4 \\
\hline 2006 & 1.899 & 130 & 7,3 & 18.892 & 10,1 \\
\hline 2007 & 1.896 & -3 & $-0,2$ & 18.904 & 10,0 \\
\hline 2008 & 1.981 & 85 & 4,5 & 19.015 & 10,4 \\
\hline
\end{tabular}

\section{Cuadro 3: Mix de generación de energía eléctrica peninsular. 2000 vs 2013} (en GWh y \%) 22 .

\begin{tabular}{|c|c|c|c|c|}
\hline & \multicolumn{2}{|c|}{ Año 2000} & \multicolumn{2}{|c|}{ Año 2013} \\
\hline & GWh & $(\%)$ & GWh & $(\%)$ \\
\hline Hidráulica ${ }^{23}$ & 24.206 & 12,6 & 29.351 & 11,5 \\
\hline Nuclear & 59.808 & 31,1 & 54.198 & 21,2 \\
\hline Carbón & 71.793 & 37,4 & 37.384 & 14,6 \\
\hline Fuel & 9.599 & 5,0 & 0 & 0,0 \\
\hline Cido Combinado ${ }^{24}$ & 0 & 0,0 & 24.384 & 9,5 \\
\hline TOTAL RÉGIMEN ORDINARIO & 165.405 & 86,1 & 145.317 & 56,7 \\
\hline Hidráulica ${ }^{25}$ & 3.836 & 2,0 & 7.099 & 2,8 \\
\hline Eólica & 4.462 & 2,3 & 54.344 & 21,2 \\
\hline Solar Fotovoltaica & 23 & 0,01 & 7.918 & 3,1 \\
\hline Solar Térmica & 0 & 0,0 & 4.442 & 1,7 \\
\hline Térmica Renovable & 961 & 0,5 & 5.066 & 2,0 \\
\hline Térmica no Renovable & 17.358 & 9,0 & 32.037 & 12,5 \\
\hline TOTAL RÉGIMEN ESPECIAL & 26.641 & 13,9 & 110.905 & 43,3 \\
\hline TOTAL GENERACIÓN NETA & 192.046 & 100 & 256.222 & 100 \\
\hline
\end{tabular}

20 La Energia en España 2010 y Datos Estadisticos-Minetur

21 El carbón incluye los gases denivados del carbón

22 REE-Balance Eléctico Peninsular 2000 y 2013. En el momerto de pubficacón de este documento, se encontraban đ́sponbibles los datos provisionales para 2014, si bien por compa tbiildad con las datos de enengia primaria y final el ajadro no se ha actualicada. Los \% para cada una de las fuertes en 2014 sonc hidraúlica (12,7\%), nudear (22\%), carbón (16,5\%),

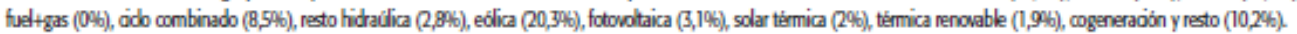

23 No induye la generación bombeo.

24 Induye funcionamiento en cido abierto.

25 Induye todas aquellas unidades menores de $50 \mathrm{MW}$ que no pertenecen a ninguna unidad de gestión hidráulica (UCH). 
La misión de las centrales de pequeña potencia consiste fundamentalmente en procurar ahorro en el consumo de los combustibles más caros. Se intenta construir e instalar pequeños grupos normalizados con inversiones económicas relativamente reducidas y con unos gastos de explotación (personal, mantenimiento y reparaciones) por kWh producido muy bajos en comparación con los saltos grandes.

Galicia y Navarra son dos de las regiones que más han incrementado su potencia en este tipo de centrales. En el caso de Galicia, a partir de 1980, coincidiendo con la entrada en vigor de la Ley sobre la Conservación de la Energía y otras iniciativas de la Xunta de Galicia, cobra interés la posibilidad de poner en servicio antiguos pequeños aprovechamientos hidroeléctricos que habían caído en desuso o en el olvido. Esta rehabilitación ofrece para Galicia un especial interés, puesto que con ello pudo tanto aumentar la producción global como diversificarla, atenuando así posibles crisis energéticas futuras. Pero, además, las minicentrales ofrecen la ventaja de estar adaptadas al rasgo principal de la población gallega, es decir, su extrema dispersión por el territorio y su ubicación mayoritaria en áreas rurales. El interés puesto por la Administración tanto central como autonómica, así como particulares y grandes empresas como Fenosa, se plasmó en la rehabilitación de algunas de esas pequeñas centrales. En 1992 funcionaban 75 de ellas a pleno rendimiento, tanto reacondicionadas como de nueva construcción. En Navarra también se ha incrementado la potencia hidroeléctrica en pequeñas centrales. En los años ochenta, el Gobierno de Navarra, junto a otras empresas, fundó Energía Hidroeléctrica de Navarra, con la intención de realizar un aprovechamiento racional y eficiente de las centrales que desde los años cincuenta se habían considerado marginales.

\begin{tabular}{|c|c|c|c|c|c|c|c|}
\hline \multicolumn{8}{|c|}{ Producción hidroeléctrica por cuencas } \\
\hline \multirow[b]{2}{*}{ Cuenca } & \multirow{2}{*}{$\begin{array}{l}\text { Potencia } \\
\text { MW }\end{array}$} & \multicolumn{3}{|c|}{ Producción (CWh) } & \multicolumn{3}{|c|}{ Producible (aWh } \\
\hline & & 2013 & 2014 & $\% 14 / 13$ & 2013 & 2014 & $\%: 14 / 13$ \\
\hline Norte & 4.879 & 11.669 & 11.766 & 0.8 & 11.298 & 10.922 & -3.3 \\
\hline Duero & 3.887 & 7.531 & 9.541 & 26.7 & 7.968 & 9.161 & 15,0 \\
\hline Tajo-Júcar-Segura & 4.349 & 5.034 & 5.563 & 10.5 & 4.280 & 4.362 & 1.9 \\
\hline Guadiana & 226 & 273 & 197 & $-28,0$ & 378 & 187 & $-50,5$ \\
\hline Guadalquivir-Sur & 1.025 & 1.224 & 945 & $-22,8$ & 889 & 553 & $-37,8$ \\
\hline Ebro-Pirineo & 3.425 & 8.239 & 7.847 & -4.8 & 7.818 & 7.223 & -7.6 \\
\hline Total & 17.791 & 33.970 & 35.860 & 5,6 & 32.631 & 32.408 & $-0,7$ \\
\hline
\end{tabular}




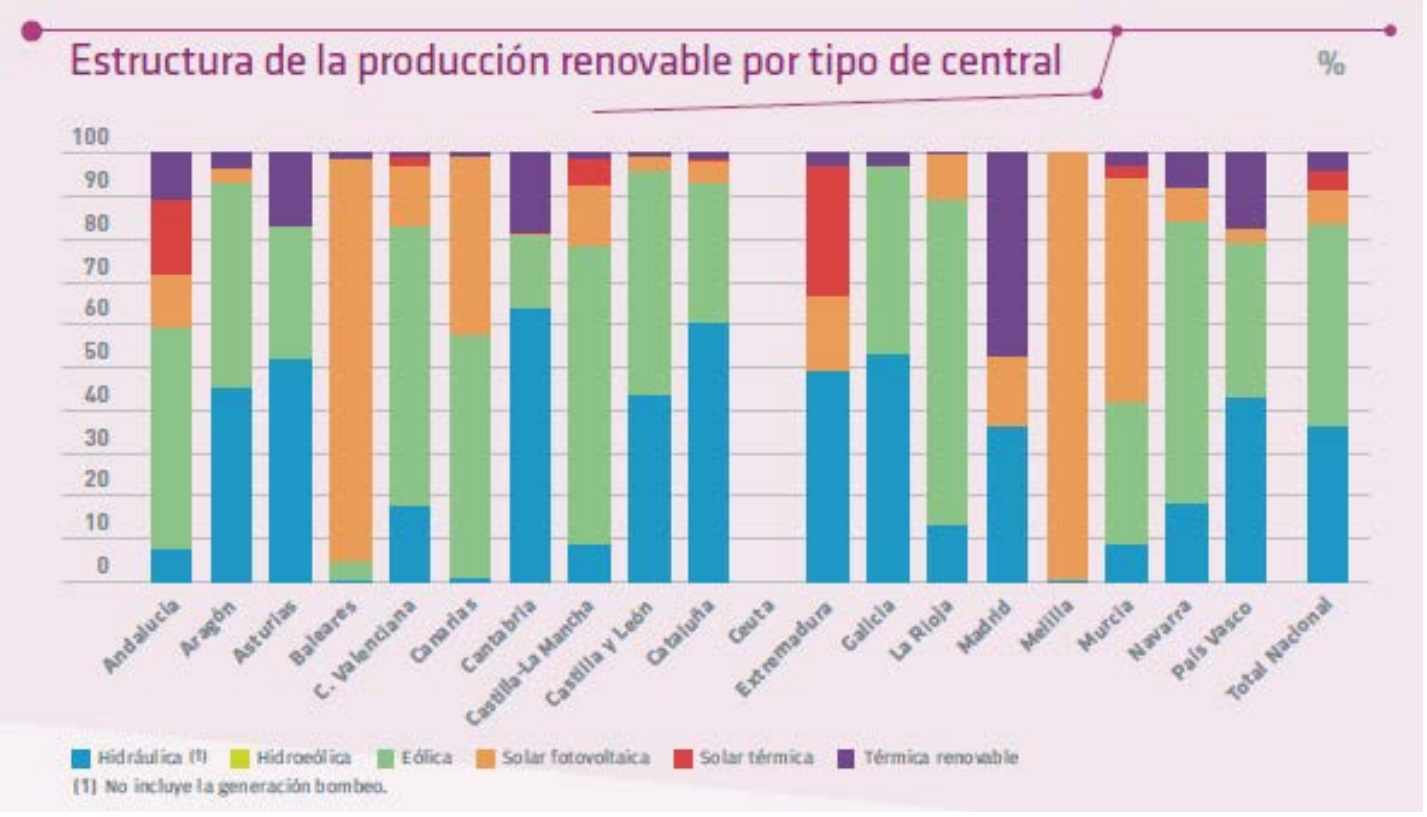

La participación de la energía hidráulica en el conjunto del sistema eléctrico español muestra desde hace años un patrón caracterizado por su relativo estancamiento en términos absolutos (curva cuasiplana de evolución de la potencia instalada) y una importancia relativa cuantitativamente decreciente en relación con otras fuentes de generación, en especial las denominadas renovables, RES o energías limpias (eólica, solar fotovoltaica y termosolar, concretamente). A finales del año 2014 la potencia de generación hidráulica en el sistema peninsular era de 19.891 MW (contando todos los tipos de instalaciones) lo cual representa aproximadamente el 19\% de la del sistema eléctrico (102.259 MW), mientras que ese mismo indicador en el año 1975 superaba el valor del $47 \%$. En las últimas cuatro décadas la hidroelectricidad ha experimentado una pérdida de importancia relativa de cerca de 30 puntos porcentuales en cuanto a presencia en el parque de generación. En lo que se refiere a la energía generada, que puede variar ampliamente de un año a otro debido a las diferencias de hidraulicidad, la evolución media comparativa ha sido bastante similar.

Las razones que explican el hecho anterior son múltiples y no se pueden simplificar en la argumentación del agotamiento del producible hidráulico aún por desarrollar en condiciones de rentabilidad. Es bien cierto que los aprovechamientos más ventajosos en la mayoría de las cuencas y sistemas hidráulicos ya se han incorporado al patrimonio hidroeléctrico. Sin embargo, el producible total que podría desarrollarse en condiciones de viabilidad en la Península se estima en torno a 70.000 GWh/año, del cual se encuentra actualmente en explotación una capacidad aproximada equivalente a 35.000 GWh/año. Por tanto existiría un remanente aún apreciable si de diesen las condiciones oportunas y el interés en desarrollarlo por parte de quienes tienen 
la capacidad legal, los medios y el modelo apropiado de negocio para ello. La decisión compete en gran medida a los agentes económicos o empresas que operan en el sector, dentro el marco legal que afecta a un tema dual como el anterior sujeto a la regulación ambiental y energética.

A partir de la Ley del Sector Eléctrico de 1997 la actividad de generación se encuentra liberalizada en España, en buena medida como consecuencia de las directrices de la política energética Europea. Ello significa que los agentes económicos adoptan las decisiones de inversión (o desinversión) que consideran adecuadas según su estrategia de negocio y objetivos. No obstante, la actividad de generación se encuentra regulada y sujeta a autorización administrativa y supervisión pública.

En lo que se refiere a su funcionamiento económico debe tenerse en cuenta que las empresas generadoras actúan en varios mercados organizados, tanto de energía como de servicios de ajuste, y también en otros contextos formalmente menos estructurados (contratos bilaterales). Su operación debe atenerse en todo momento a las consignas del operador técnico del sistema (REE).

En la actualidad, también los intercambios con Francia, Portugal y Marruecos son los siguientes:

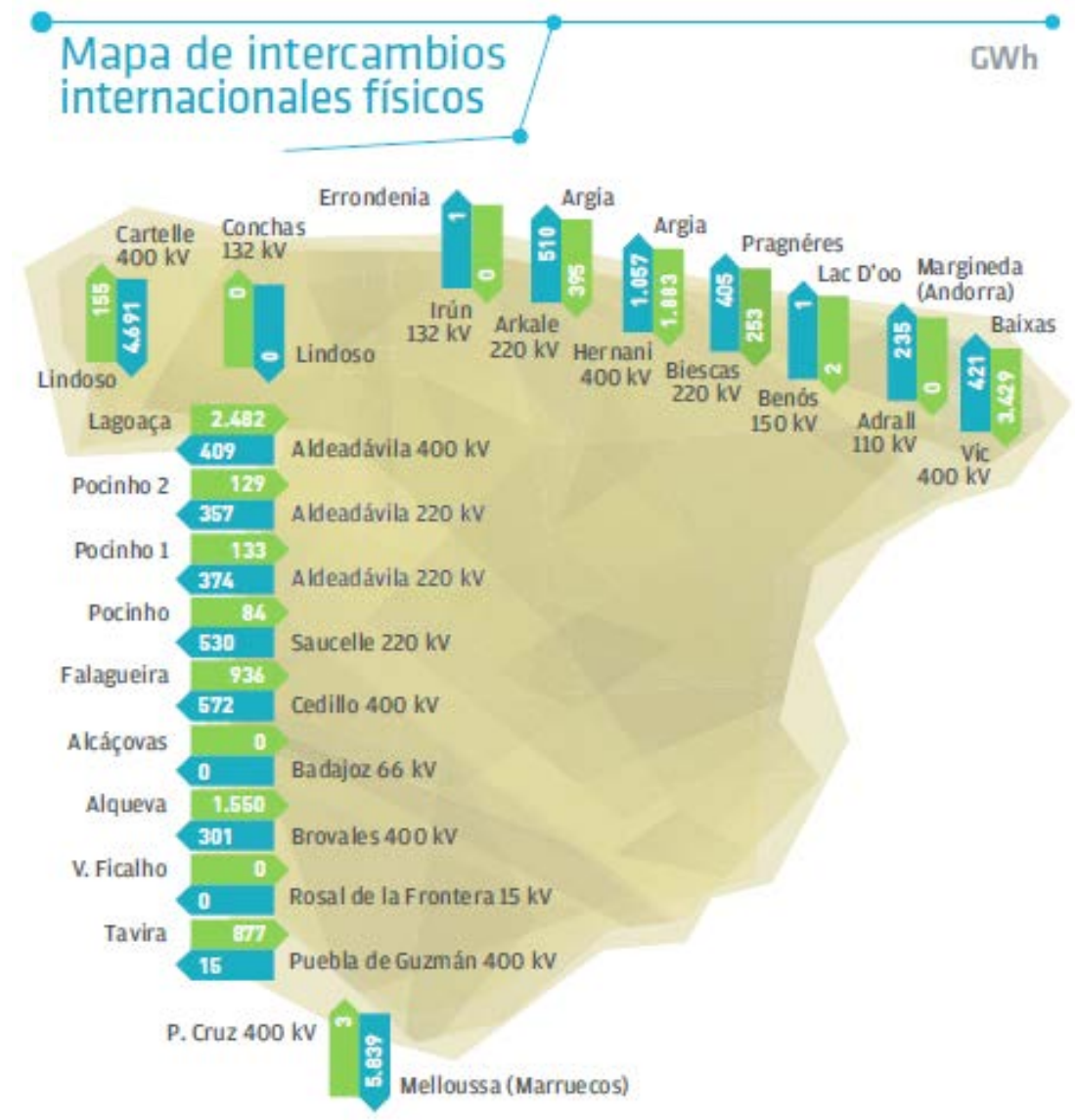




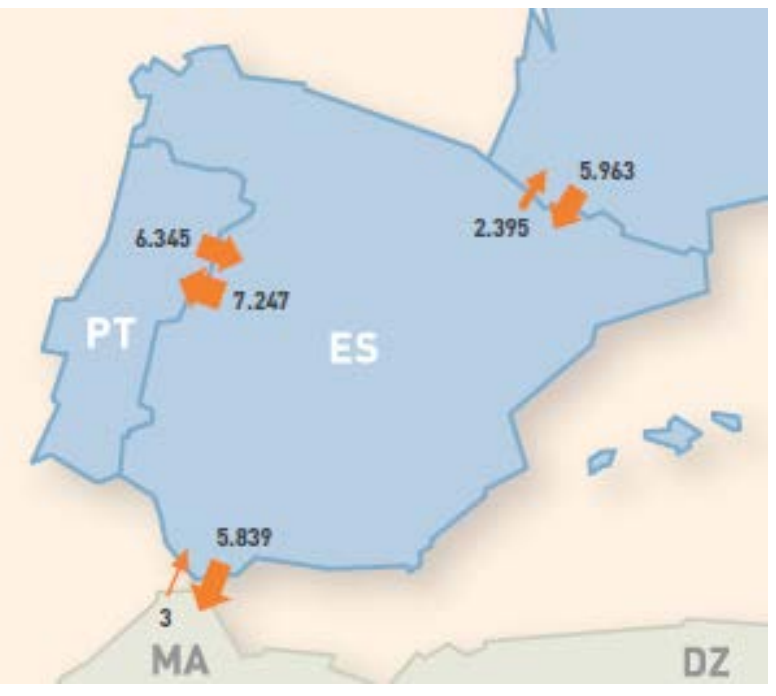

La situación en el presente de la actividad de generación y sus tendencias evolutivas pueden (y deben) por tanto contemplarse desde una doble perspectiva: la física (estructura y capacidad de la planta de generación y la correspondiente producción de energía) y la económica (funcionamiento de los mercados organizados y en su caso de las transacciones bilaterales). Algunos datos relativos a ambas facetas (sistema peninsular) servirán para aporta una visión rápida de la generación de electricidad.

\section{Variables físicas:}

\begin{tabular}{|l|r|r|c|}
\cline { 2 - 4 } \multicolumn{1}{c|}{} & \multicolumn{1}{c|}{ Año 2014 } & \multicolumn{1}{c|}{ Año 2004 } & $\begin{array}{c}\text { Variación } \\
2004-2014\end{array}$ \\
\hline Potencla total instalada & $102.259 \mathrm{MW}$ & $68.425 \mathrm{MW}$ & $+49 \%$ \\
\hline Potencia hidráulica & $19.891 \mathrm{MW}$ & $18.256 \mathrm{MW}$ & $+9 \%$ \\
\hline Potencia EOL+SFV+ST & $29.573 \mathrm{MW}$ & $8.926 \mathrm{MW}$ & $+231 \%$ \\
\hline Potencia CCGN & $25.353 \mathrm{MW}$ & $8.285 \mathrm{MW}$ & $+206 \%$ \\
\hline Generación neta total & $253.724 \mathrm{GWh}$ & $243.042 \mathrm{GWh}$ & $+4 \%$ \\
\hline Producción hidráullica & $42.738 \mathrm{GWh}$ & $34.321 \mathrm{GWh}$ & $+25 \%$ \\
\hline Prod. EOL+SFV+SF & $63.846 \mathrm{GWh}$ & $18.320 \mathrm{GWh}$ & $+249 \%$ \\
\hline Producción CCGN & $21.979 \mathrm{GWh}$ & $28.974 \mathrm{GWh}$ & $-24 \%$ \\
\hline
\end{tabular}

Datos correspondientes al sistema peninsular El año 2014 fue bueno desde el punto de vista hidráulico 


\section{Variables económicas:}

\begin{tabular}{|l|r|r|c|}
\cline { 2 - 4 } \multicolumn{1}{c|}{} & Año 2014 & Año 2004 & $\begin{array}{c}\text { Variación } \\
2004-2014\end{array}$ \\
\hline $\begin{array}{l}\text { Energía vendida en el } \\
\text { pool (mercado diario) }\end{array}$ & $173.901 \mathrm{GWh}$ & $198.057 \mathrm{GWh}$ & $-12,4 \%$ \\
\hline $\begin{array}{l}\text { Precio medio horario } \\
\text { ponderado en casación }\end{array}$ & 42 Euros/MWh & 27,9 Euros/MWh & $+50,5 \%$ \\
\hline $\begin{array}{l}\text { Spread máx. promedio } \\
\text { (mes de Junio) }\end{array}$ & 21,8 Euros/MWh & 18,5 Euros/MWh & $+17,8 \%$ \\
\hline $\begin{array}{l}\text { Hit ratio hidráulico } \\
\text { (horas p. marginal Junio) }\end{array}$ & $68,5 \%$ & $60,3 \%$ & $+13,6 \%$ \\
\hline
\end{tabular}

Datos correspondientes al mercado diario de energía

No incluyen los intradiarios, servicios de ajuste ni contratos bilaterales

Observaciones que pueden inferirse a partir de los datos anteriores (20042014):

- El crecimiento de la producción eléctrica durante los últimos 10 años ha sido muy bajo ( $+4 \%$ en total), consecuencia de una demanda interna prácticamente en recesión desde el año 2008. De hecho el valor de la demanda anual de energía eléctrica era en 2014 prácticamente análoga al del año 2005, lo cual denota un estancamiento atribuible a la crisis económica general, agudizado posiblemente por el incremento de precios del suministro. Conviene recordar que los precios de la energía a al consumidor final prácticamente se doblaron en la década 2003-2012.

- Sin embargo, el crecimiento de la capacidad instalada durante esos mismos años ha sido muy alto $(+49 \%,+34.000 \mathrm{MW})$, lo cual es representativo de una evolución anómala y muy desequilibrada del sector eléctrico.

- El hecho más relevante de la década 2004-2014 en términos de potencia y energía fue sin duda el crecimiento extraordinario de las CCGN (centrales de ciclo combinado) y de las RES (energía de fuentes renovables).

- Los activos de generación del tipo CCGN se encuentran actualmente muy infrautilizados. Este hecho es sin duda relevante dada la interdependencia de los sectores eléctrico y gasista (aproximadamente un $20 \%$ de la demanda actual de gas natural proviene de los CCGN, a la que habría que añadir la que corresponde a la cogeneración).

- Existe una amplia sobrecapacidad en el sistema. La punta de demanda instantánea en los últimos diez años alcanzó un valor máximo de 45.450 MWh (Diciembre, 2007), mientras que la capacidad instalada bruta es de 
2,25 veces ese valor. La potencia firme, sin embargo, es menor y su factor de cobertura de 1,60 (aun así, bastante elevado).

- El volumen de energía contratado en el pool se ha reducido (mercado diario) en un $12,4 \%$, lo cual apunta a una mayor participación de otras formas de suministro mayorista (contratos bilaterales).

- El precio medio de casación (marginal del mercado diario) ha aumentado significativamente en los últimos 10 años (+50,5\%).

- El hit ratio hidráulico entendido como el porcentaje del número de horas en las que la hidráulica convencional o las centrales reversibles marcan el precio de casación, se mantiene consistentemente en un valor muy alto (en el rango 60-70\%). Ello indica el valor que poseen este tipo de instalaciones para los generadores, que excede el de la propia producción hidroeléctrica.

- La utilización de la energía hidráulica en las puntas horarias permite por otra parte suponer que su retribución media en el mercado se sitúa en la banda alta de los precios horarios. Por esa razón, al hacer estimaciones sobre su valor económico, parece razonable tomar como referencia el promedio del precio de las seis horas más caras de cada día.

- Como muestra de lo anterior pueden aportarse los datos del último día del primer semestre (30 de Junio) de 2014. Mientras que la producción hidráulica proporcionaba una cobertura total del 6,9\% a la demanda diaria (45.980 vs. $665.570 \mathrm{MWh}$ ), en la franja de horas punta (9 a $14 \mathrm{~h}$ ) la cobertura hidráulica ascendió al 11,8\% (21.920 vs. 186.363 MWh). El precio medio horario del pool en las 6 horas punta fue un $30 \%$ superior al de las restantes horas del día (63,3 vs. 48,9 Euros/MWh). Estos datos ponen de relieve la capacidad de la hidráulica para elevarse económicamente en el mercado.

Y como característica de un sector maduro, la búsqueda continua de la mayor calidad del servicio, es una de sus premisas. Para ello, la red de transporte es fundamental: 

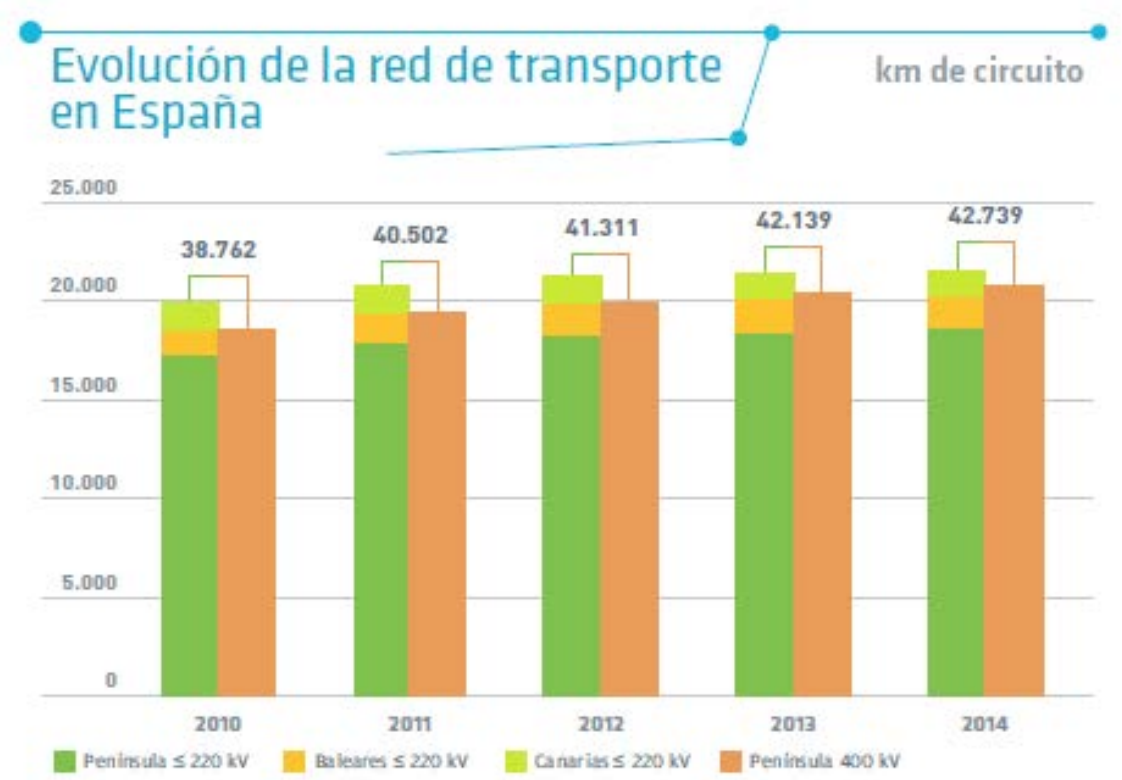

Los resultados de los indicadores de calidad de servicio del año 2014 muestran un ejercicio más el buen comportamiento de la red de transporte, evaluado en función de la disponibilidad de las instalaciones que la componen y de las interrupciones del suministro debidas a incidencias en dicha red.

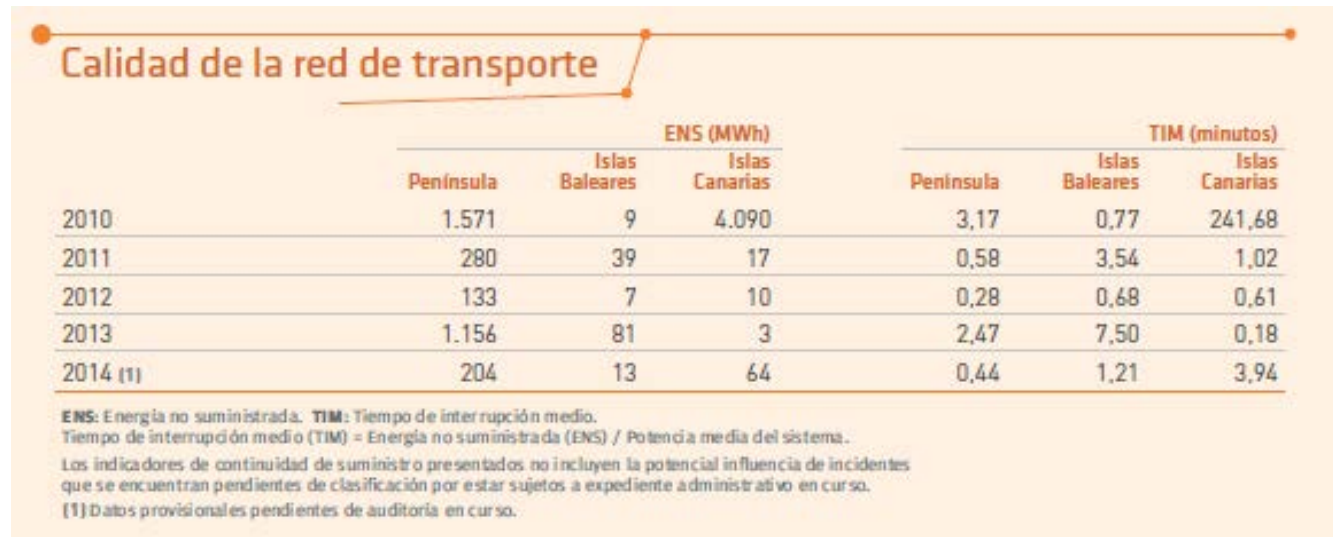

Los índices de disponibilidad de la red de transporte reflejan la disponibilidad media para el servicio de los elementos en cada sistema. En el año 2014, dicho índice ha sido para el sistema peninsular del 98,21\%, valor muy parecido a la disponibilidad de 2013 para el que se registró un 98,20 \%. 


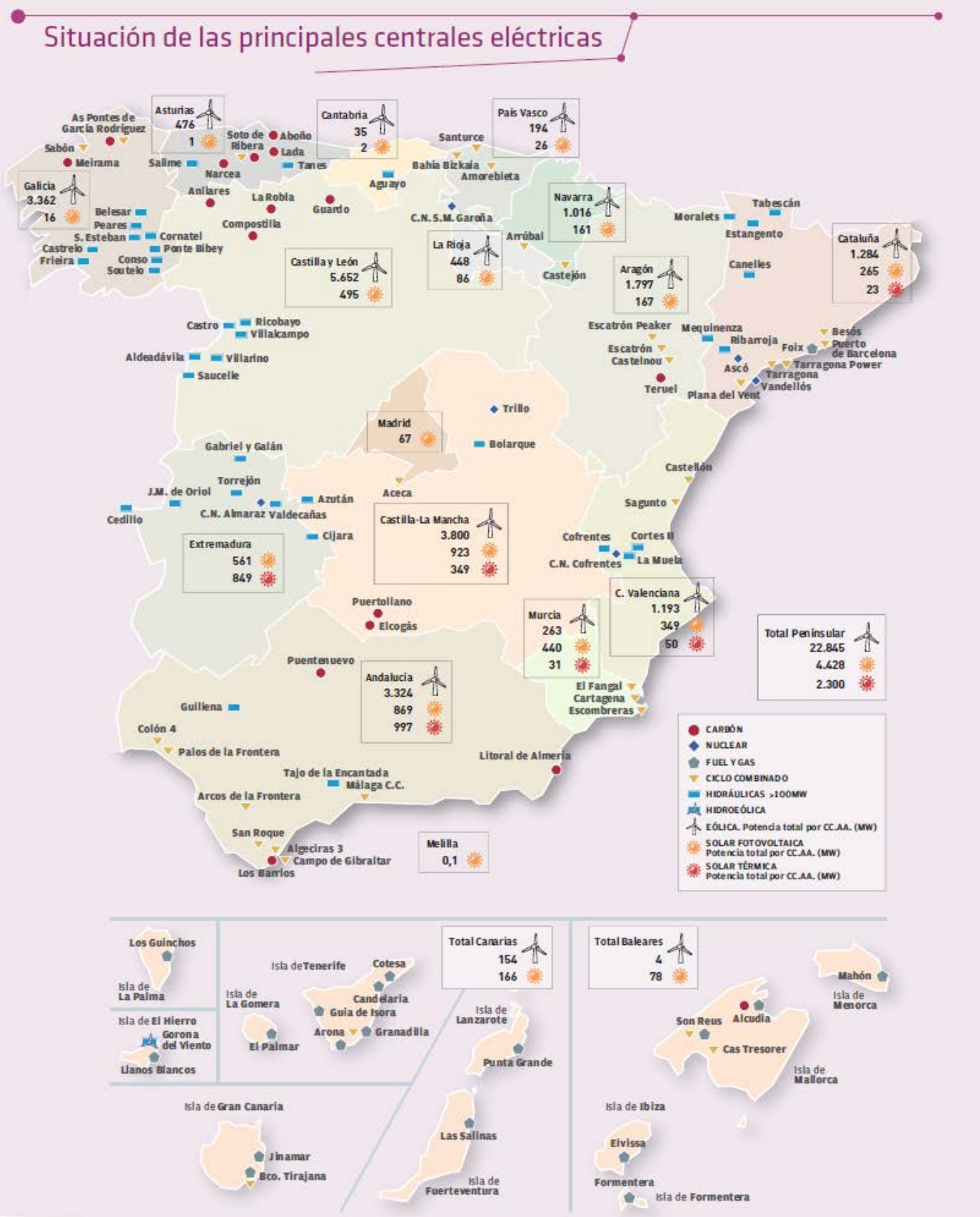




\begin{tabular}{|c|c|c|c|c|}
\hline \multicolumn{5}{|c|}{ Principales centrales hidroeléctricas en España } \\
\hline Hidroélectrica & $\begin{array}{c}\text { Potencia } \\
\text { (MW) }\end{array}$ & Río & $\begin{array}{c}\text { Cuenca } \\
\text { Hidrológica }\end{array}$ & Provincia \\
\hline Aldeadávila I y II & $1.243,4$ & Duero & Duero & Salamanca \\
\hline José Maria Oriol & 933,8 & Tajo & Tajo & Cáceres \\
\hline Cortes-La Muela & 914,8 & Júcar & Júcar & Valencia \\
\hline Villarino & 810,0 & Tormes & Duero & Salamanca \\
\hline Saucelle I y II & 520,0 & Duero & Duero & Salamanca \\
\hline Estany Gento-Sallente & 451,0 & Flemisell & Ebro & Lleida \\
\hline Cedillo & 473,0 & Tajo & Tajo & Cáceres \\
\hline Tajo de Encantada & 360,0 & Guadalhorce & Sur & Málaga \\
\hline Aguayo & 361,9 & Torina & Norte & Cantabria \\
\hline Mequinenza & 324,0 & Ebro & Ebro & Zaragoza \\
\hline Puente Bibey & 301,2 & Bibey & Norte & Ourense \\
\hline San Esteban & 265,5 & Sil & Norte & Ourense \\
\hline Ribarroja & 262,8 & Ebro & Ebro & Tarragona \\
\hline Conso & 270,2 & Camba & Norte & Orense \\
\hline Belesar & 258,0 & Miño & Norte & Lugo \\
\hline Valdecañas & 225,0 & Tajo & Tajo & Cáceres \\
\hline Moralets & 221,4 & N. Ribagorzana & Ebro & Huesca \\
\hline Guillena & 210,0 & Ribera de Huelva & Guadalquivir & Sevilla \\
\hline Bolarque I y II & 246,2 & Tajo & Tajo & Guadalajara \\
\hline Villalcampo I y || & 217,9 & Duero & Duero & Zamora \\
\hline Castro I y II & 194,4 & Duero & Duero & Zamora \\
\hline Azután & 180,0 & Tajo & Tajo & Toledo \\
\hline Los Peares & 167,7 & Мiño & Norte & Lugo \\
\hline Esla & 158,4 & Esla (Ricobayo) & Duero & Zamora \\
\hline Tanes & 125,5 & Nalon & Norte & Asturias \\
\hline Frieira & 144,6 & Міño & Norte & Ourense \\
\hline Torrejon & 130,6 & Tajo-Tietar & Tajo & Cáceres \\
\hline Salime & 150,2 & Navia & Norte & Asturias \\
\hline Cofrentes & 124,2 & Júcar & Júcar & Valencia \\
\hline Cornatel & 132,0 & Sil & Norte & Ourense \\
\hline Tabescán Superior & 120,4 & Lladorre-Tabescan & Ebro & Lleida \\
\hline Castrelo & 122,2 & Miño & Norte & Ourense \\
\hline Gabriel y Galán & 110,0 & Alagón & Tajo & Cáceres \\
\hline Canelles & 108,0 & N. Ribagorzana & Ebro & Lleida \\
\hline Cijara I y II & 102,1 & Guadiana & Guadiana & Badajoz \\
\hline
\end{tabular}




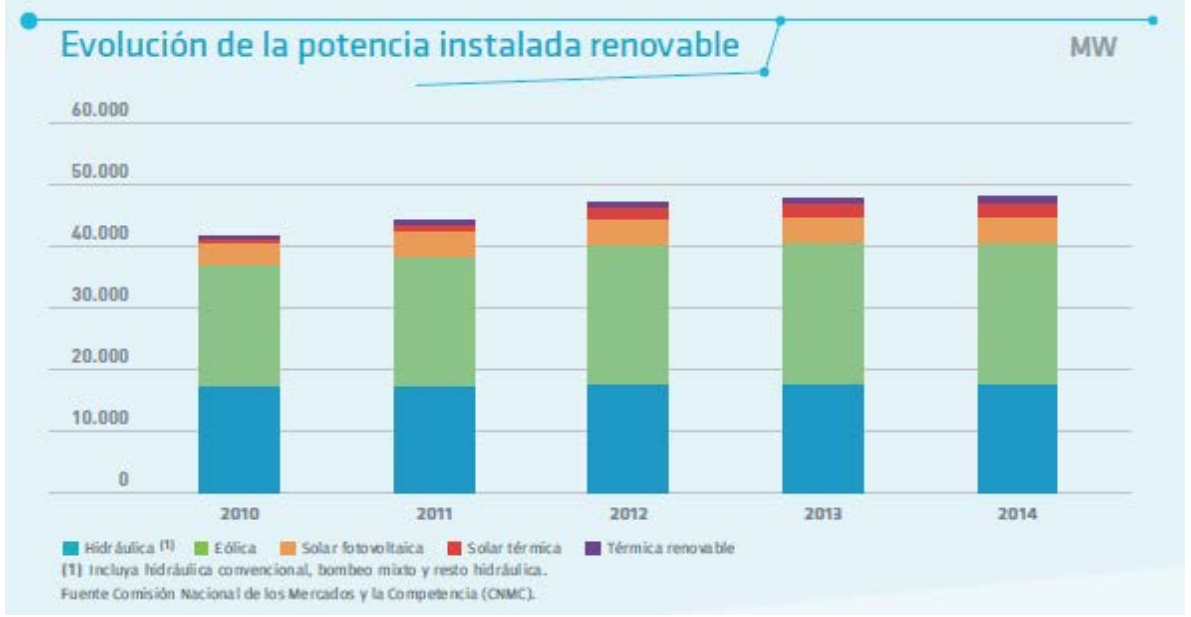

En el conjunto de los países de la Unión Europea la hidroelectricidad continúa ocupando la posición de cabeza entre las fuentes y tecnologías renovables. Su contribución a la producción eléctrica total está en tomo al 16\% en promedio y se considera que hasta la fecha se ha desarrollado únicamente un $45 \%$ de su potencial técnica, ambiental y económicamente viable. Sin embargo la madurez y otras circunstancias que afectan a esa forma de generación han ido desplazando en las últimas décadas el enfoque de autoridades, inversores y comunidad tecnológica hacia otros tipos de instalaciones de generación eléctrica. El interés hacia la hidroelectricidad se ha reavivado no obstante en los últimos años como consecuencia de la problemática de integración de fuentes irregulares (fundamentalmente la eólica y también la solar) dada su posible utilización como almacenamiento de energía a gran escala dentro del sistema eléctrico. La generación hidroeléctrica en Europa se sitúa actualmente en tomo a un valor de $340.000 \mathrm{GWh} / \mathrm{año}$, con un crecimiento promedio anual del $1 \%$. España ocupa actualmente el cuarto lugar en cuanto a potencia hidroeléctrica instalada tras Noruega, Francia e Italia, y el noveno en lo que se refiere a energía producida.

Las perspectivas de evolución de la generación hidráulica varían en función de cada país, dependiendo esencialmente del potencial por desarrollar. En la UE-28 se cuenta con un remanente de $380.000 \mathrm{GWh}$, que es una cifra muy considerable. La hidroelectricidad ha pasado de ser la fuente predominante en los años setenta a constituir una energía minoritaria pero se considera que es posiblemente la de mayor calidad del sistema eléctrico (eficiencia, flexibilidad, limpieza y bajo coste variable). A pesar de ello su participación relativa ha decaído en estas décadas en relación con la producción de los grupos térmicos (convencionales y nucleares) en la mayoría de países salvo Noruega, donde la hidráulica es la tecnología mayoritaria en potencia y producción (ese país no pertenece a la UE). Según Eurelectric, sus perspectivas de evolución a corto plazo (2020) pasarían por un aumento moderado de la potencia a instalar 
$(+7 \%)$ y algo menos de la mitad en cuanto a producción de energía (+3\%). En cualquier caso, se estima que en la mayoría de los países, salvo excepciones, se debe mantener la hidráulica como elemento de importancia central dentro de un mix de generación equilibrado y con la flexibilidad debida.

De hecho, las instalaciones hidroeléctricas desempeñan en buena medida un papel de columna vertebral de la planta de generación. El rango de participación de la hidráulica varía entre países del 15 al 25\% en potencia y es algo más bajo en energía producida (13\%-20\%), variable que depende de las particularidades de la hidrología y además varía de año en año. El país en este área de referencia en el cual se espera un mayor crecimiento hidroeléctrico en los próximos años es Turquía (tampoco pertenece de momento a la UE).

En la Unión Europea existe una visión compartida por la mayoría de los Estados miembro y agentes del sector sobre la importancia que posee la energía hidráulica como modalidad de almacenamiento de energía a gran escala, asociado a la gestión técnica y la operación del sistema eléctrico. Esta faceta, que se puede diferenciar de la simple producción de electricidad, constituye uno de los temas recurrentes en este campo a lo largo de estos últimos años.

Finalmente, no debe olvidarse que en el contexto Europeo actual, el agente empresarial más activo en el campo de la hidroelectricidad es una empresa de matriz española (IBERDROLA). A sus recientes actuaciones en las centrales de San Estevo (180 MW) y La Muela II (840 MW), situadas en España, hay que añadir los planes anunciados de ampliación de la central reversible de Cruachan (600 MW) en los Highlands - UK (Scottlsh Power) y el desarrollo adjudicado del aprovechamiento hidroeléctrico del Alto Támega (1.135 MW), en el norte de Portugal.

\begin{tabular}{|c|c|c|c|c|c|c|c|}
\hline \multicolumn{7}{|c|}{$\begin{array}{l}\text { Cobertura de la demanda de energía eléctrica de los países de la } \\
\text { Unión Europea miembros de Continental Europe (ENTSO-E) }\end{array}$} & \multirow{2}{*}{$\begin{array}{c}\text { TWh } \\
\text { Demanda }\end{array}$} \\
\hline & $\begin{array}{l}\text { Hidráulica } \\
\text { y otras }\end{array}$ & Nuclear & $\begin{array}{l}\text { Tèrmica } \\
\text { clásica }\end{array}$ & $\begin{array}{c}\text { Producción } \\
\text { total neta }\end{array}$ & $\begin{array}{l}\text { Consumos } \\
\text { en bombeo }\end{array}$ & $\begin{array}{r}\text { Saldo } \\
\text { intercambios }\end{array}$ & \\
\hline Alemania & 150,7 & 91,8 & 306,0 & 548,5 & 8,0 & $-35,7$ & 504,9 \\
\hline Austria & 46,0 & 0,0 & 19,5 & 65,5 & 5,5 & 9,3 & 69,3 \\
\hline Bélgica & 13,2 & 32,1 & 22,4 & 67,7 & 1,6 & 17,6 & 83,7 \\
\hline Bulgaria & 7,4 & 14,7 & 19,6 & 41,7 & 0,8 & $-9,6$ & 31,2 \\
\hline Croacia & 9,0 & 0,0 & 2,9 & 12,0 & 0,2 & 4,6 & 16,4 \\
\hline Eslovaquia & 6,2 & 14,5 & 4,7 & 25,4 & 0,3 & 1,1 & 26,1 \\
\hline Eslovenia & 6,8 & 6.1 & 3,4 & 16,3 & 0,4 & $-2,7$ & 13,2 \\
\hline España & 112,2 & 54,8 & 99,9 & 266,9 & 5,3 & $-3,4$ & 258,1 \\
\hline Francia & 97,9 & 415,9 & 27,4 & 541,2 & 7,9 & $-67,6$ & 465,7 \\
\hline Grecia & 11,6 & 0,0 & 29,1 & 40,8 & 0,2 & 8,6 & 49,3 \\
\hline Holanda & 11,7 & 4,1 & 80,4 & 96,2 & 0,0 & 14,7 & 110,9 \\
\hline Hungría & 2,6 & 14,6 & 8,9 & 26,1 & 0,0 & 11,5 & 37,6 \\
\hline Italia & 106,9 & 0,0 & 160,0 & 266,9 & 2,3 & 43,7 & 308,4 \\
\hline Luxemburgo & 1,4 & 0,0 & 1,5 & 2,8 & 1,5 & 4,9 & 6,3 \\
\hline Polonia & 17,0 & 0,0 & 128,6 & 145,6 & 0,8 & 2,2 & 146,9 \\
\hline Portugal & 31,2 & 0,0 & 17,7 & 49,0 & 1,1 & 0,9 & 48,8 \\
\hline República Checa & 9,8 & 28,6 & 41,7 & 80,0 & 1,4 & $-16,7$ & 62,0 \\
\hline Rumania & 26,9 & 10,7 & 23,0 & 60,7 & 0,3 & $-7,1$ & 53,3 \\
\hline
\end{tabular}


Puede considerarse, por tanto, como un aspecto fundamental a tener en cuenta en la actualidad, tal y como ya se ha apuntado con anterioridad, es la utilización de las centrales hidroeléctricas reversibles (CHR) de bombeo/turbinación para almacenamiento de energía a gran escala.

Es una tecnología totalmente madura tanto técnica como comercialmente, que se viene utilizando en España desde mediados del siglo pasado, dando lugar a la mayor base global instalada dentro de los sistemas de almacenamiento.

La energía hidráulica, a través de centrales en grandes embalses de regulación existentes y centrales de bombeo, será un pilar importante para posibilitar la gestión técnica del sistema en relación a la incorporación en la red de la energía renovable prevista en los objetivos del Plan de Energías Renovables (horizonte 2020).

Las interconexiones también son una pieza clave para facilitar la integración de la producción renovable no gestionable, evitando vertidos que se pueden producir cuando la capacidad de producción exceda la capacidad de integración. Por ello es fundamental el fomento del incremento de la capacidad comercial de intercambio entre España y Francia.

Actualmente es, sin duda, el más importante de los métodos de almacenamiento, ya que no solo es la más competitiva y madura de entre las tecnologías de almacenamiento potencialmente aptas para España, sino que constituye una solución idónea para compensar las variaciones a gran escala de la generación con fuentes renovables no gestionables, así como para el almacenamiento de los excedentes de estas. Se trata de una energía de gran calidad que contribuye a la seguridad y fiabilidad del sistema eléctrico, como energía regulada rápidamente disponible para el seguimiento de variaciones de la demanda y de la oferta, flexibilidad para control de frecuencia y tensión de la red, reposición del servicio, etc.

La función de las CHR dentro del sistema eléctrico ha ido evolucionando con el tiempo desde lo que fue inicialmente el fundamento económico de su existencia (arbitraje de precios valle-punta) hacia la aportación de estabilidad, flexibilidad y servicios de ajuste del sistema, cuya importancia ha ido creciendo con el tiempo debido a la penetración de fuentes intermitentes y estocásticas. Debe tenerse en cuenta no obstante que tanto la generación en puntas de demanda como la aportación de servicios técnicos de ajuste al sistema son funciones que hasta cierto punto pueden realizarse a través de centrales reversibles o bien mediante otras tecnologías de generación (hidráulicas convencionales reguladas o centrales CCGN). Un hecho importante a considerar es precisamente 
la dualidad funcional de las CHR, circunstancia que las puede situar en una posición variable entre las actividades de generación (en competencia) y las de operación del sistema (reguladas). Este hecho aumenta su interés pero las expone a conflictos regulatorios potenciales. El marco jurídico actual del sector eléctrico español, en armonía con la normativa de la Unión Europea, considera la explotación de las centrales reversibles (y en consecuencia del almacenamiento hidráulico conexo) como una actividad específicamente de generación que puede ofertar en competencia en dos mercados distintos: el mayorista de energía o pool (OMIE) y el de servicios de ajuste (REE). 



\section{Capítulo 7.}

\section{Evolución estética de los aprovechamientos hidroeléctricos}





\subsection{INTRODUCCIÓN Y ENFOQUE GENERAL}

Este capítulo aborda el aspecto estético de los aprovechamientos hidroeléctricos ya sea en cuanto a las presas, centrales, etc.

Estos aprovechamientos, como obras civiles e industriales que son, se han diseñado prioritariamente para cumplir con la funcionalidad que le es atribuida.

A pesar de ello y de forma particular, las centrales hidroeléctricas han constituido un escenario magistral de actuación en el ámbito arquitectónico. La presencia de la ingeniería a gran escala, la dotación de una alta capacidad financiera, así como la calidad y representatividad de sus edificios, han convertido un sector importante de estos conjuntos en bienes dotados de una destacada singularidad. En ellos, la presencia simultánea de la ingeniería y de la sensibilidad arquitectónica, responden al objeto de dotar al resultado final de la cualidad emblemática requerida, compatibilizando una gran calidad técnica y estética, atendiendo así mismo, a la resolución formal y paisajista de las obras.

En los aprovechamientos hidroeléctricos la arquitectura cuenta con unas posibilidades constructivas inéditas, de la mano de nuevos materiales y sus tecnologías respectivas, tales como el hierro fundido, el vidrio y el hormigón, explotados no sólo por sus capacidades estructurales, sino también por sus posibilidades plásticas, favoreciendo una nueva expresividad más atenta a la estructura y al volumen que a la composición y a la masa.

Los saltos de agua no se han de ver únicamente como valiosos activos de producción hidráulica. Las centrales y las presas que conforman muchos de esos aprovechamientos tienen un valor estético e incluso histórico que pueden llegar a considerarse ejemplos de land-art, confluyendo en ellos arte, técnica y naturaleza, a sabiendas que los aspectos estéticos son evaluados de manera subjetiva.

Las construcciones del agua están habitualmente poco expuestas a la visibilidad general pero poseen una enorme potencia expresiva. Por ejemplo, las presas son obras que se proyectan para cumplir unas determinadas funciones hidráulicas sin embargo pueden ser construcciones de gran belleza no solo en sí mismas sino por el paisaje que generan a través del espejo de agua de sus embalses asociados. Los materiales utilizados en su ejecución se toman generalmente del entorno en el que se ubican lo que, con el tiempo, les facilita una mayor integración con el medio. 
Por ejemplo, la presa de Susqueda, son ejemplo de cómo la técnica, en este caso la ingeniería hidráulica, añade encanto a un paisaje interesante con un diseño cuidadoso. En el caso concreto de Susqueda se aprecia un mimo en su diseño y construcción, hacia la obra y hacia el lugar, que se materializan en el cuidado perfil de la bóveda, en la originalidad de las torres de toma, en la curiosa cripta hipóstila alojada en el interior de la presa.
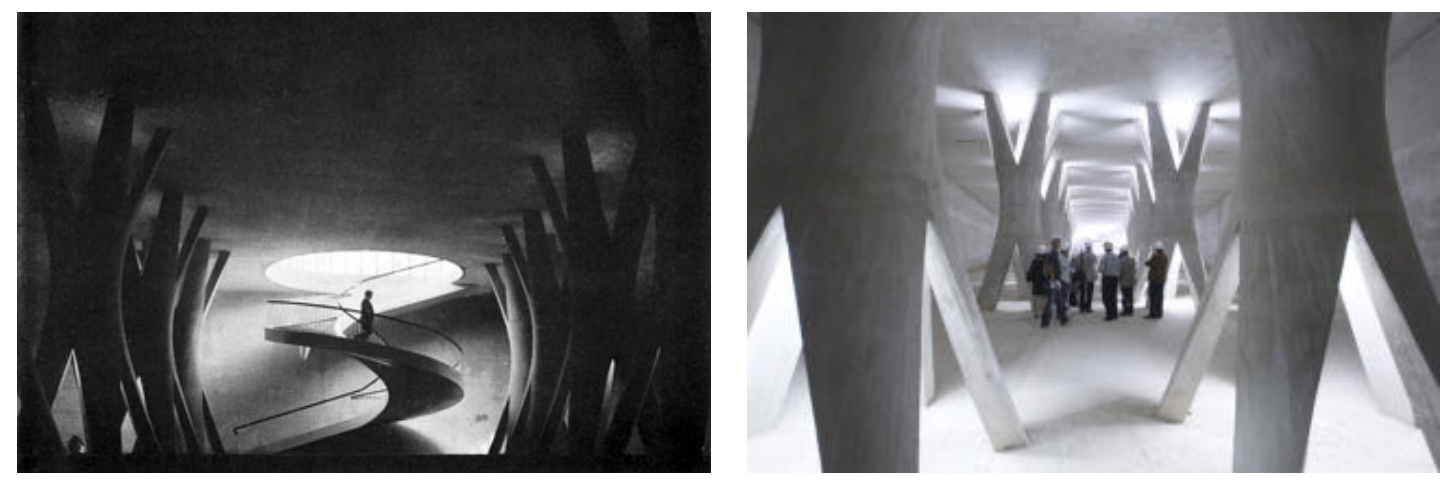

También los aliviaderos de las presas de Cervera-Ruesga, y el de Arquis, muestran un interés por integrarlos en el medio, a lo que ha ayudado el paso del tiempo.

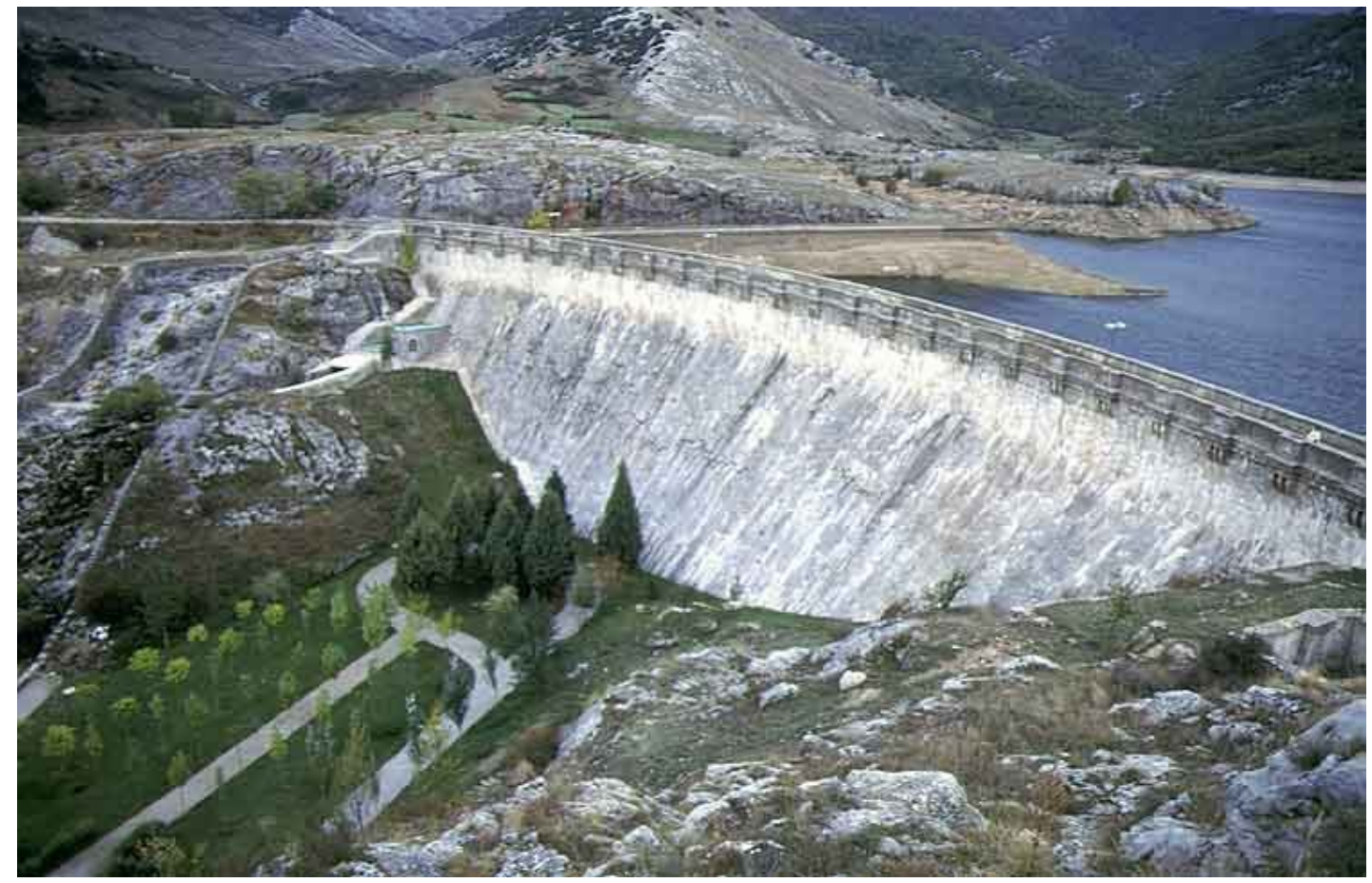

También un salto de agua puede ser una obra de arte o al menos, alojarla. Por ejemplo, el salto del Jándula es especialmente original por el alojo en su interior de la central eléctrica a modo de "barriga", diseñada por Casto Fernández-Shaw, otorgando al paramento de aguas abajo una marcada filiación expresionista. 

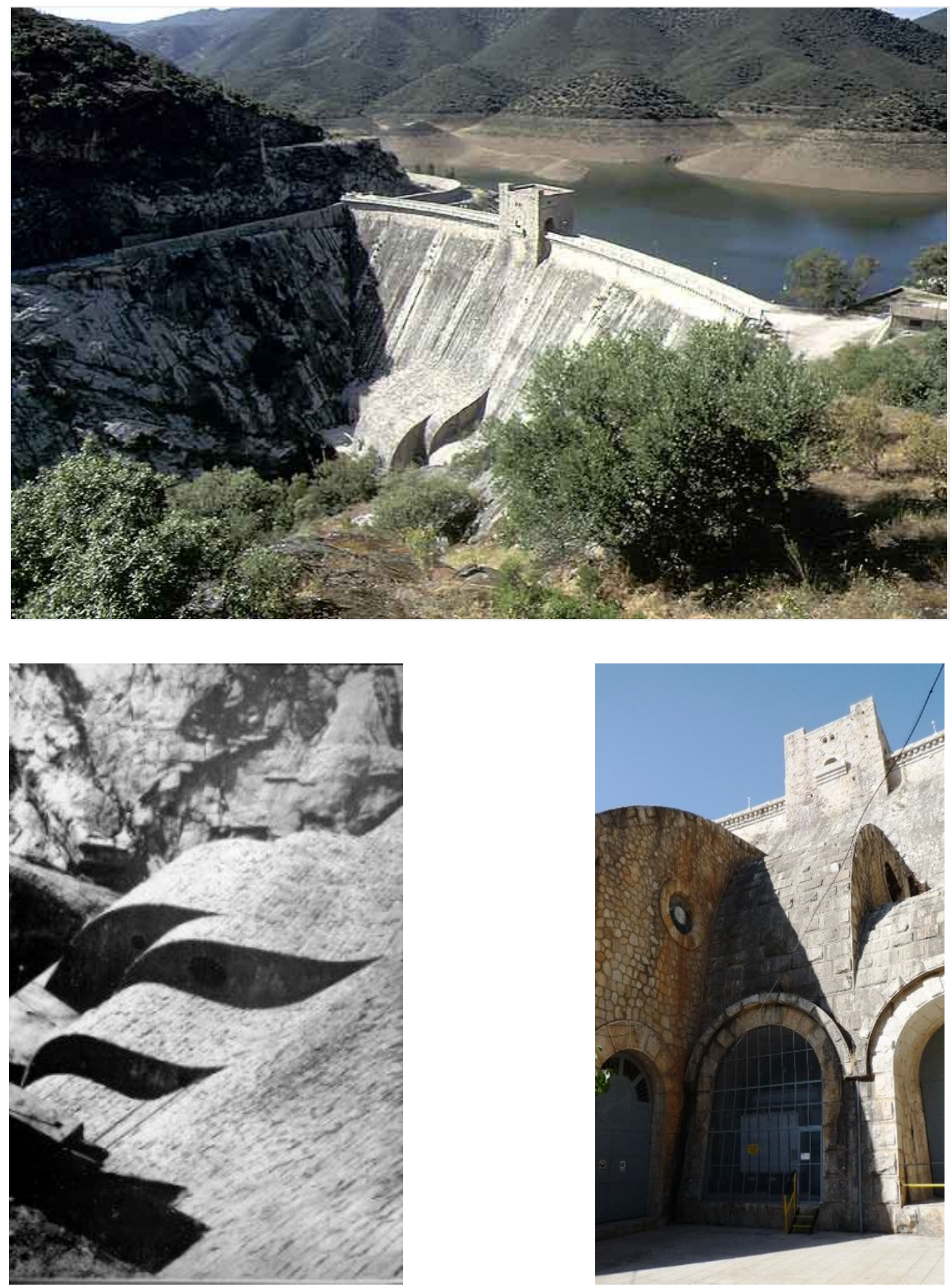

Otras intervenciones afortunadas, en este caso de Vaquero de Palacios, son la sala de turbinas del salto de Grandas de Salime, que completó artísticamente el interesante diseño hidráulico de esta obra sobre el Navia, y especialmente el edificio de maquinaria de la central de Proaza en el río Trubia, un de las mejores síntesis entre ingeniería hidráulica, arquitectura y artes plásticas de toda España. 
También merecen especial recuerdo las construcciones del agua de Juan José Elorza (ingeniero) e Ignacio Álvarez Castelao (arquitecto) en Arenas de Cabrales y Silvón, y sobre todo en el salto de Arbón.

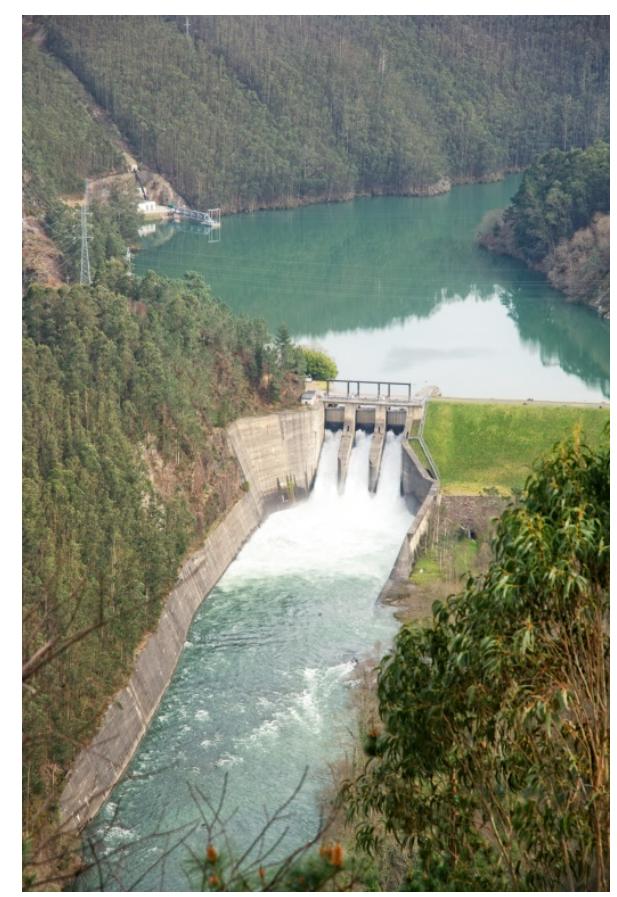

Salto de Arbón

La central del salto de Arenas de Cabrales, iniciado en el año 1952 y concluido en el 58, destaca por el respeto hacia el lugar de emplazamiento, disgregando sus funciones y con un tratamiento exquisito entre materiales y naturaleza. Consta únicamente de sala de máquinas con pórticos de hormigón, rematado con una viga superior a dos aguas. Solamente en los cerramientos entre estructuras se ha empleado el gres, en ocres rojizos, como revestimiento de las fábricas de ladrillo y, en otros casos, la piedra caliza, y en las puertas en "intemperie" se acentuaron notas de color.

El salto de Silvón (1959), situado en el río Navia, surge como resultado de recrecer la presa del Salto de Doiras. Se encuentra perfectamente integrada en el paisaje. La sala de máquinas está constituida por muros de carga, eliminando los consabidos pórticos, finalizando la cubierta en una estructura metálica muy simple con amplias vidrieras, consiguiendo una agradable iluminación interior. Los revestimientos exteriores se realizaron con gres de color "cuero", y en las puertas y tímpanos se dispuso una nota de color.

En ocasiones los escultores participan en este tipo de construcciones, como es el caso de Néstor Basterrechea y su intervención en la presa de Arriarán sobre el río Oria, aunque parezca a priori un poco pesada y algo desproporcionada. En 
cualquier caso, se cita a modo de ejemplo ya que, esta presa no tiene un fin relacionado con aprovechamiento energético alguno.
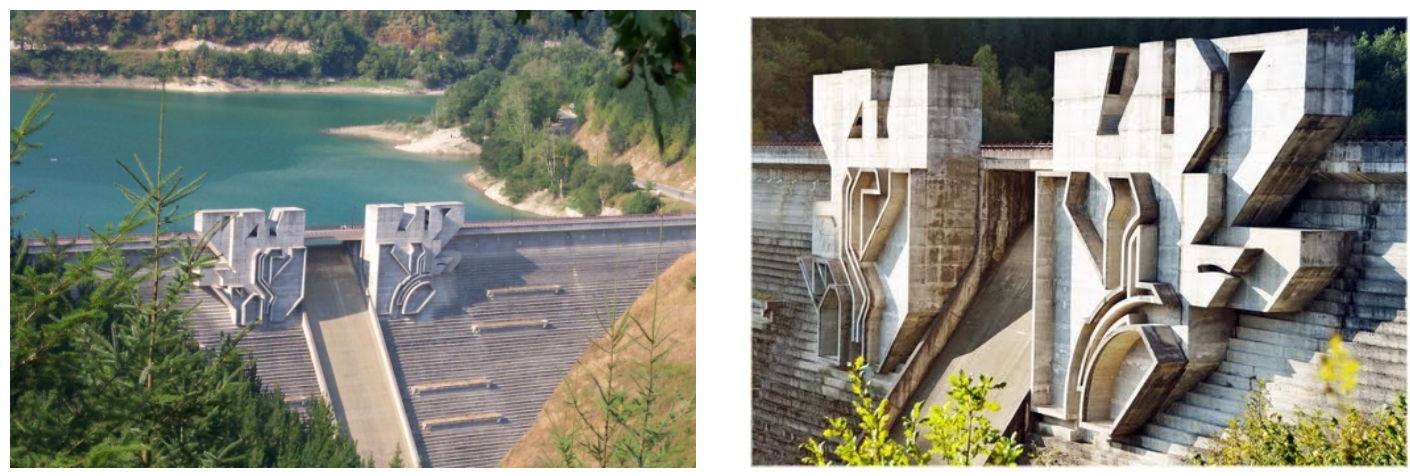

Los saltos de agua estaban presentes incluso de manera obsesiva en los dibujos industriales futuristas del arquitecto y urbanista Antonio Sant'Elia en los años 1913-14, influido tanto por sus estudios de la técnica hidráulica como por la estética de la Sezession vienesa de Otto Wagner y Emil Hoppe, y también por los proyectos industriales de Tony Garnier.
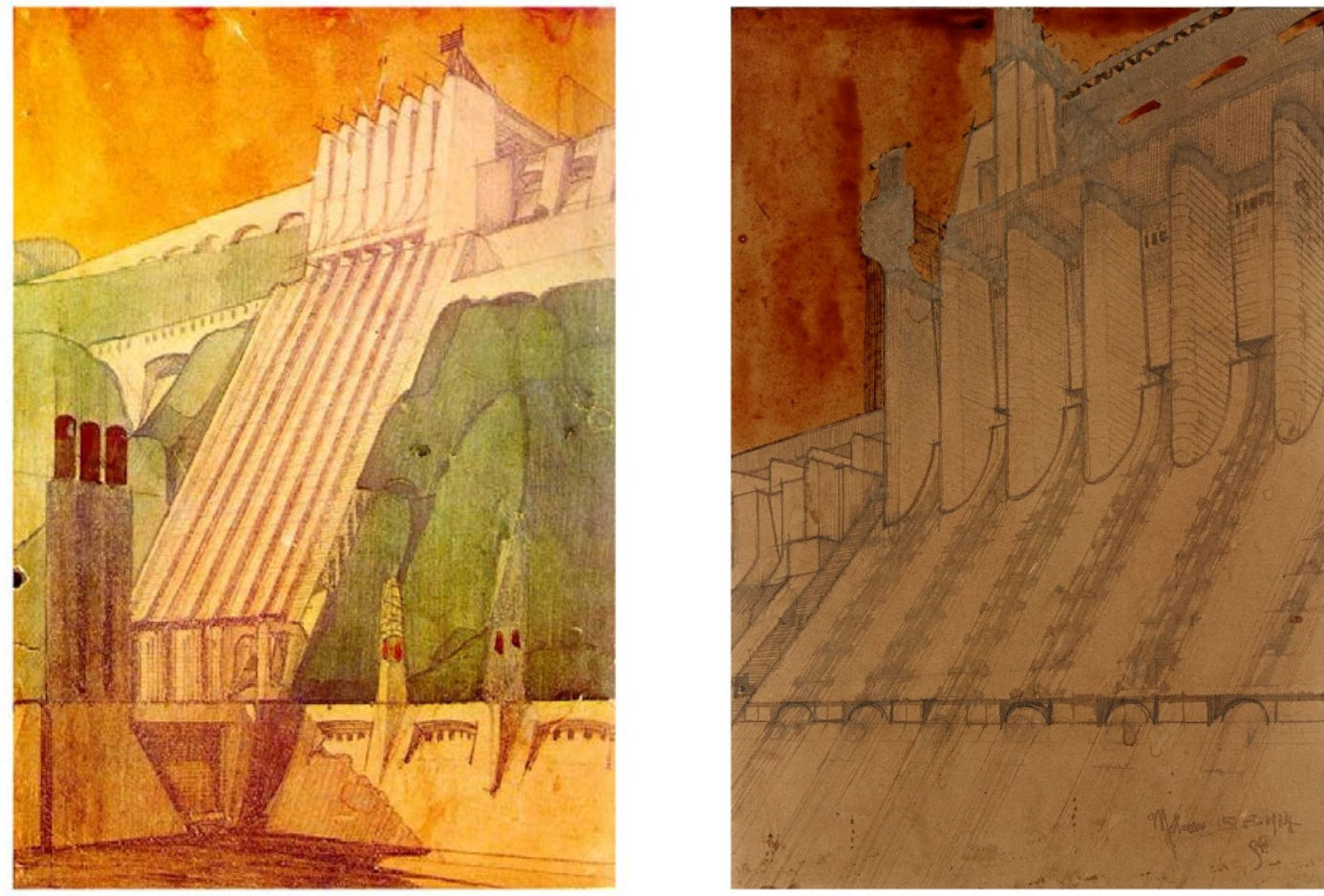

La unión entre agua y cultura es, por tanto, posible. Sirva como ejemplo el Turbine Hall de la Tate Modern en Londres y la escultura Marsyas, de Anish Kapoor, instalada en la citada galería (2002-2003), en que las formas fluidas de la energía recuperan sus espacios originales de la mano del arte contemporáneo. 


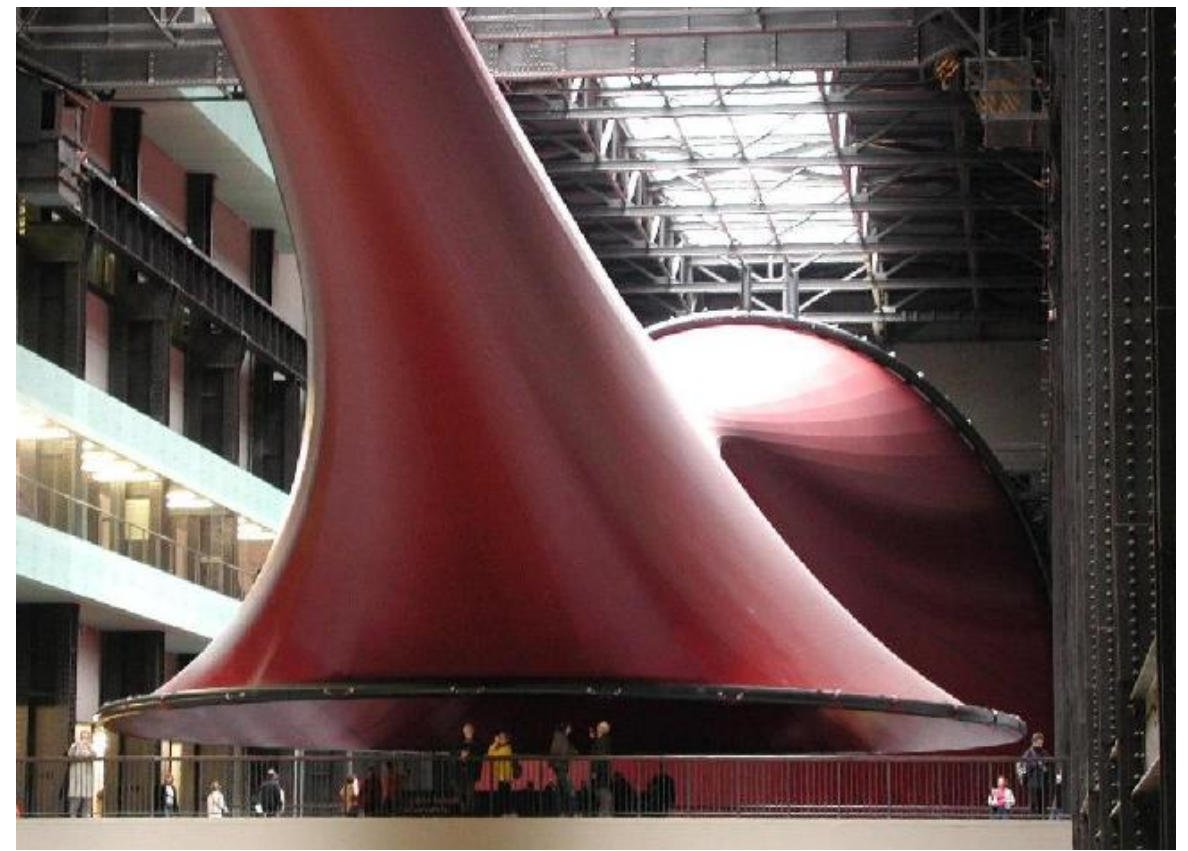

Es importante también para el aspecto estético, el interés creciente por la preservación del patrimonio histórico y la llamada arqueología industrial.

Desde la década de 1960 ha ido aumentando de forma espectacular el interés por la arqueología industrial, primero en Gran Bretaña y en Estados Unidos, y más tarde en otros países.

En España, aunque más tardíamente, el campo de la arqueología industrial se ha ido desarrollando también con gran fuerza, y han aparecido grupos de defensa del patrimonio histórico industrial en prácticamente todas las regiones.

Es mucho lo que se ha perdido, pero al mismo tiempo en toda España han surgido un gran interés por la conservación de este patrimonio. Ante todo, por la conservación del patrimonio histórico de las obras públicas.

A pesar de este ambiente que parece favorable, es también mucho lo que se continúa perdiendo, incluso en regiones en donde existe una amplia sensibilidad ante estos temas.

Naturalmente es grande también el interés por la conservación y estudio de los restos materiales de la actividad eléctrica, en los que se incluyen los aprovechamientos hidroeléctricos en su conjunto, a partir del conocimiento de sus principios técnicos y científicos y de su impacto en la vida económica y social. 
Muestra de todo lo anterior es la existencia del Comité Internacional para la conservación del Patrimonio Industrial (TICCIH) que fue creado en el año 1978 con motivo de la III Conferencia internacional sobre la Conservación de Monumentos Industriales que se celebró en Suecia.

El TICCIH está implantado en más de cuarenta países de los cinco continentes, en el que se incluye España, y tiene como objetivo promover la cooperación internacional en el campo de la preservación, conservación, localización, investigación, historia, documentación, la arqueología y revalorización del patrimonio industrial. También se propone desarrollar la educación en estas materias.

Los objetivos principales de esta institución en España son estimular el intercambio de información científica, técnica, práctica y organizativa entre investigadores, responsables de la conservación y restauración, educadores y enseñantes, empleados y obreros industriales y propietarios de empresas e Instituciones. También es otro de sus objetivos promover el Intercambio de ideas, concitando esfuerzos e intereses para apoyar y participar en reuniones internacionales sobre la materia del patrimonio industrial y la obra pública. Y en definitiva, preservar y defender el Patrimonio Industrial de España, definiendo y realizando posibles actividades en relación con el mismo, sensibilizando, valorizando y actuando en aquel que pueda considerarse en peligro de desaparición.

Esta institución seleccionó 100 elementos del patrimonio industrial en España enmarcados en sus correspondientes comunidades autónomas. De entre estos 100 elementos de especial relevancia patrimonial, existen tres centrales hidroeléctricas:

- Central hidroeléctrica El Run. Seira (Huesca)

- Central hidroeléctrica de Tambre. Noia (A Coruña)

- Salto y central hidroeléctrica de Grandas de Salime (Asturias)

A continuación se detallan algunos aprovechamientos de los ya citados en párrafos anteriores, además de otros, en los que se detecta una clara preocupación por lo estético, siempre atendiendo en primera instancia a lo funcional. El aspecto estético ha evolucionado a lo largo de los años y así se refleja en las distintas creaciones que se van a ir desgranando a continuación. 


\subsection{CENTRAL HIDROELÉCTRICA DE EL RUN O DE SEIRA (HUESCA)}

La vida en el Pirineo, a principios del siglo pasado, no era nada fácil. Al día a día austero y deprimido de muchas otras tierras, se le sumaban unas condiciones climáticas durísimas y un aislamiento si cabe más acusado. A menudo los hijos de las familias más humildes tenían que emigrar a trabajar, mayoritariamente, a las inmediaciones de Barcelona. En el valle del río Ésera, no obstante, el sentido del camino fue el inverso: una empresa de Barcelona llegó allí en 1912 con un gran proyecto que revolucionaría la comarca: la construcción de la central hidroeléctrica de Seira y de un pueblo ferviente de actividad en donde, años antes, todo languidecía.

Los empresarios e ingenieros de Catalana de Gas y Electricidad, la actual Gas Natural Fenosa, querían producir electricidad para la floreciente industria catalana.

La central hidroeléctrica de Seira no tenía presa. En Seira se construyó un nuevo pueblo para los trabajadores de la central, al igual que el resto de obras asociadas, como tuberías y carreteras para acceder a todas las instalaciones y conectarlas con el territorio. El nuevo pueblo de Seira, sobre una colina y con casitas unifamiliares, iglesia y escuela, se levantó en tiempo récord. En el nuevo poblado conocido como La Colonia, destacan equipamientos como la casa del jefe de ingenieros, la iglesia, la pensión o el salón social. Por lo tanto, el urbanismo también cambió, y junto a la aldea de estrechas calles y casas con tejados de lajas, se levantaron suntuosos chalets para los ingenieros, casitas para los especialistas y técnicos de mayor nivel y barracones para los trabajadores, todo ello con cierto aire centroeuropeo, quizá porque la ingeniería era suiza.

La concesión de las aguas del Ésera a Catalana de Gas y Electricidad, cambió en cuatro años la vida de sus habitantes, que de apenas conocer a los vecinos de los pueblos más próximos, convivieron con ingenieros y trabajadores que procedían de ciudades como Barcelona y París. De contar como mucho con una pequeña aguardentería, tuvieron al lado un café con escenario en el que los trabajadores mejor pagados dejaban fortunas en bebidas de las que hasta entonces ni habían oído hablar.

Los edificios de la central, con las turbinas y la maquinaria todavía en funcionamiento, son de una sobria arquitectura a caballo entre el modernismo y el novecentismo. 
No sólo en el Ésera, sino también en las cuencas de los ríos Cinca, Gállego y Aragón, otras empresas y gentes construyeron obras que querían ser hidráulicas y hoy, además, son paisaje.

Catalana de Gas y Electricidad inició en 1912 las obras de la central de Seira, en el río Ésera, para generar una potencia de 36,7 MW, que produciría $80 \mathrm{GWh} / a n ̃ o$ para suministro de Barcelona. La Central fue construida entre 1914 y 1918, convirtiéndose en la línea de alta tensión más larga y potente de Europa, en funcionamiento hasta 1987.

El aprovechamiento hidroeléctrico de Seira fue el primero construido en el Ésera. Utiliza únicamente aguas fluyentes, que desvía mediante el Azud de Villanova.

El azud, llamado de Villanova, es de mampostería, con vanos de compuertas y vanos de aliviadero de labio fijo.

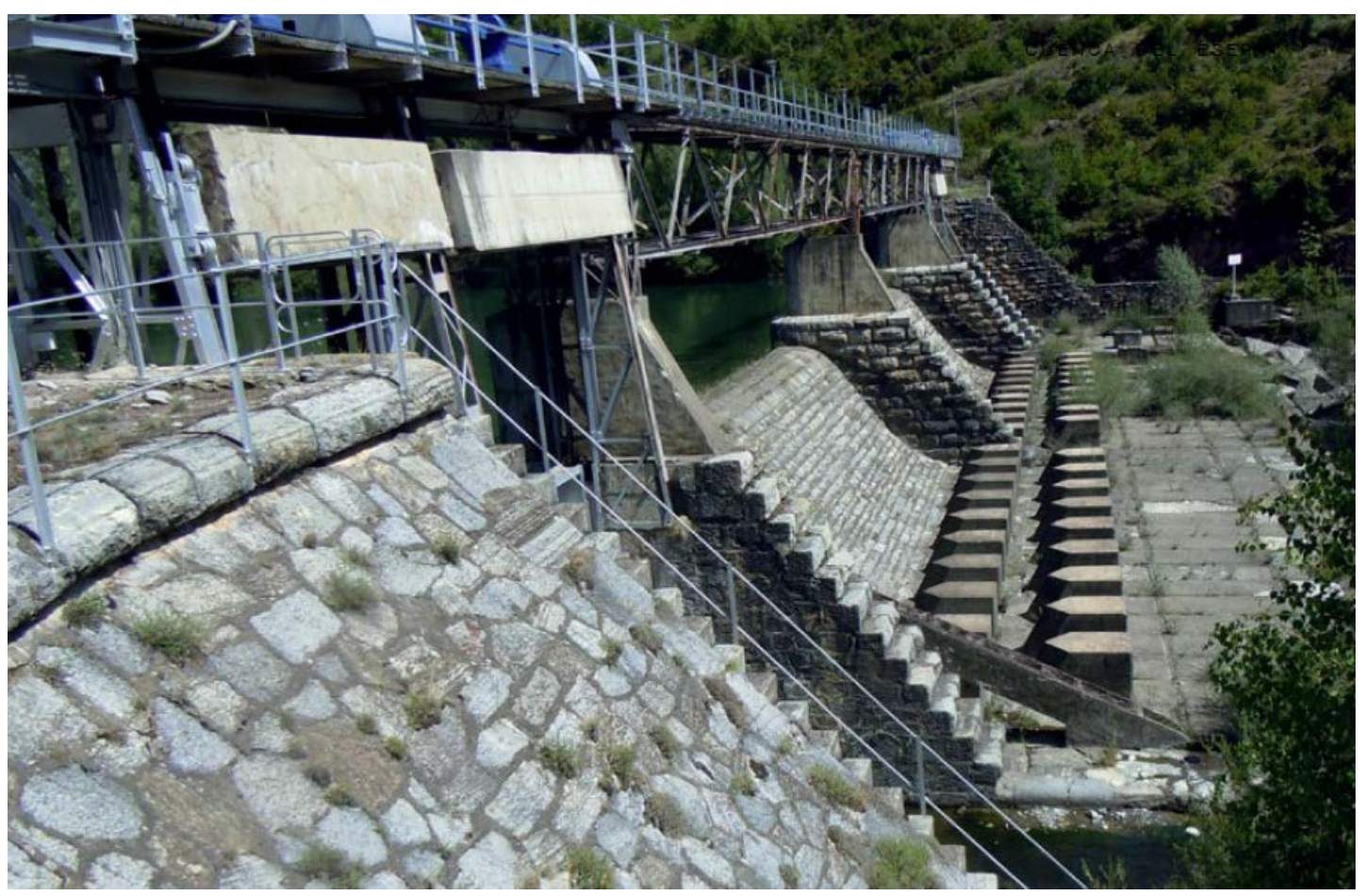

La cimentación se hizo con pozos indios (cajones de aire comprimido) hasta la roca. Es de destacar la calidad de los remates de piedra del azud, de la toma de las embocaduras de los túneles etc. Resulta llamativo su buen estado de conservación después de 100 años de funcionamiento.

Tiene una toma en la que se inicia la canalización, en lámina libre, hasta la cámara de carga de la central. La existencia de mano de obra abundante en el momento de la construcción dio lugar a que las rejas de la toma no tuvieran 
sistema automático de limpieza. Hoy día esta situación no es sostenible y se tiene previsto instalar, en todas las tomas, rejas de limpieza automática.

Es de destacar que cuenta, además de algunos de poca longitud, con un túnel de $8.771 \mathrm{~m}$ de longitud. En la memoria del proyecto justifican la opción del túnel "descartando la construcción de un canal a cielo abierto por la fuerte inclinación del terreno y la espesa capa de piedras sueltas". Hicieron un riguroso estudio del trazado eliminando algunos tramos "por lo deleznable del terreno."

Impresiona la construcción de un túnel de esa longitud hace 100 años y es obligado aludir a lo acertado de esta solución, ya que el túnel no ha dado nunca problemas. Es llamativa también la calidad de los inicios y terminaciones de los túneles.

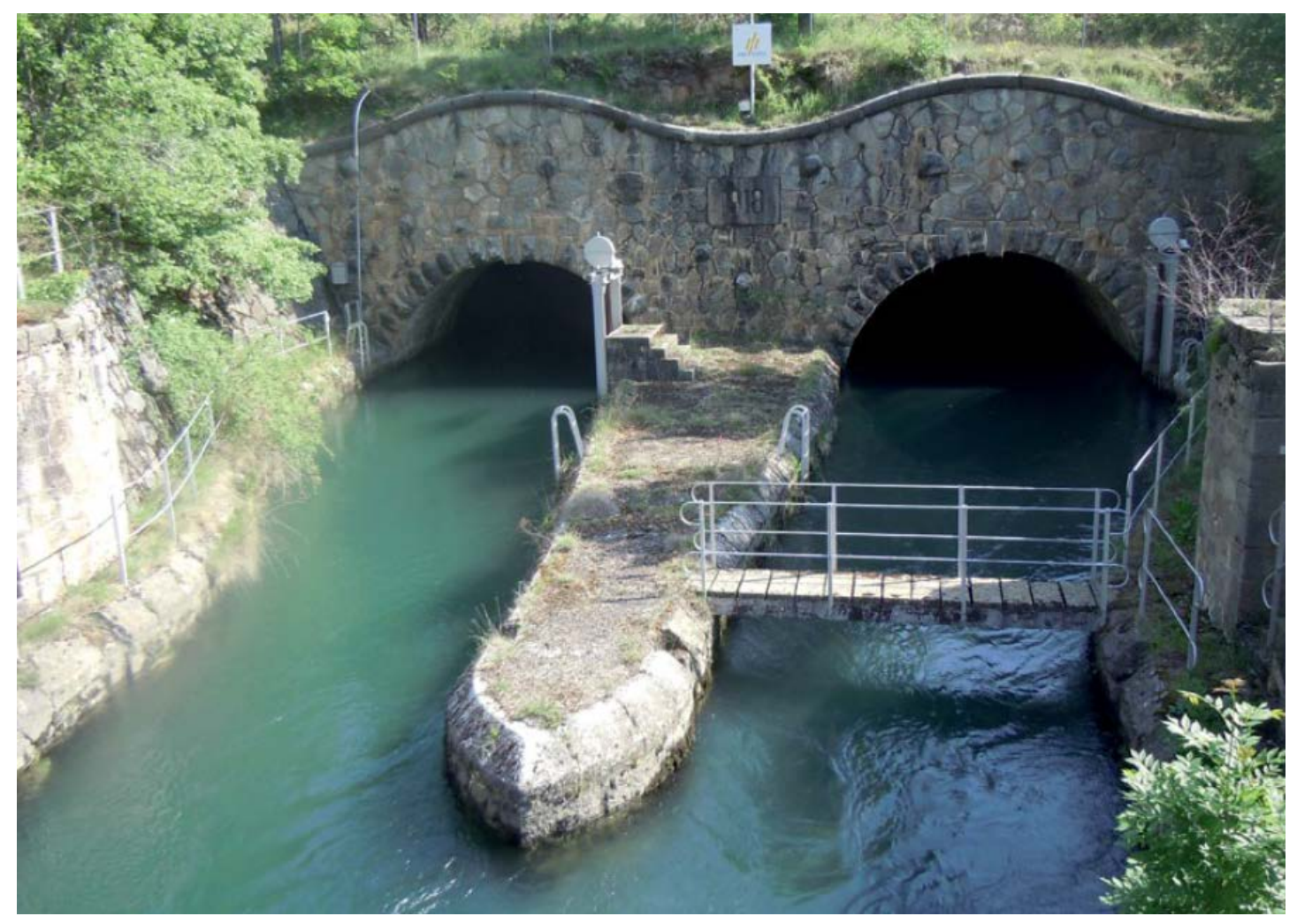

La central, además de ser la primera de las centrales del Ésera de gran potencia, es la más espectacular. El salto es de $144 \mathrm{~m}$ y consta de cuatro grupos Francis de eje horizontal con una potencia total de 36,7 MW. En las fotos siguientes puede verse el interior y el exterior. Se conservan todavía las tuberías de carga, que son de acero roblonado.

La central de Seira es coetánea de la estación de Canfranc y quizá sea el único edificio industrial aragonés que en su estilo pueda rivalizar con ella. 

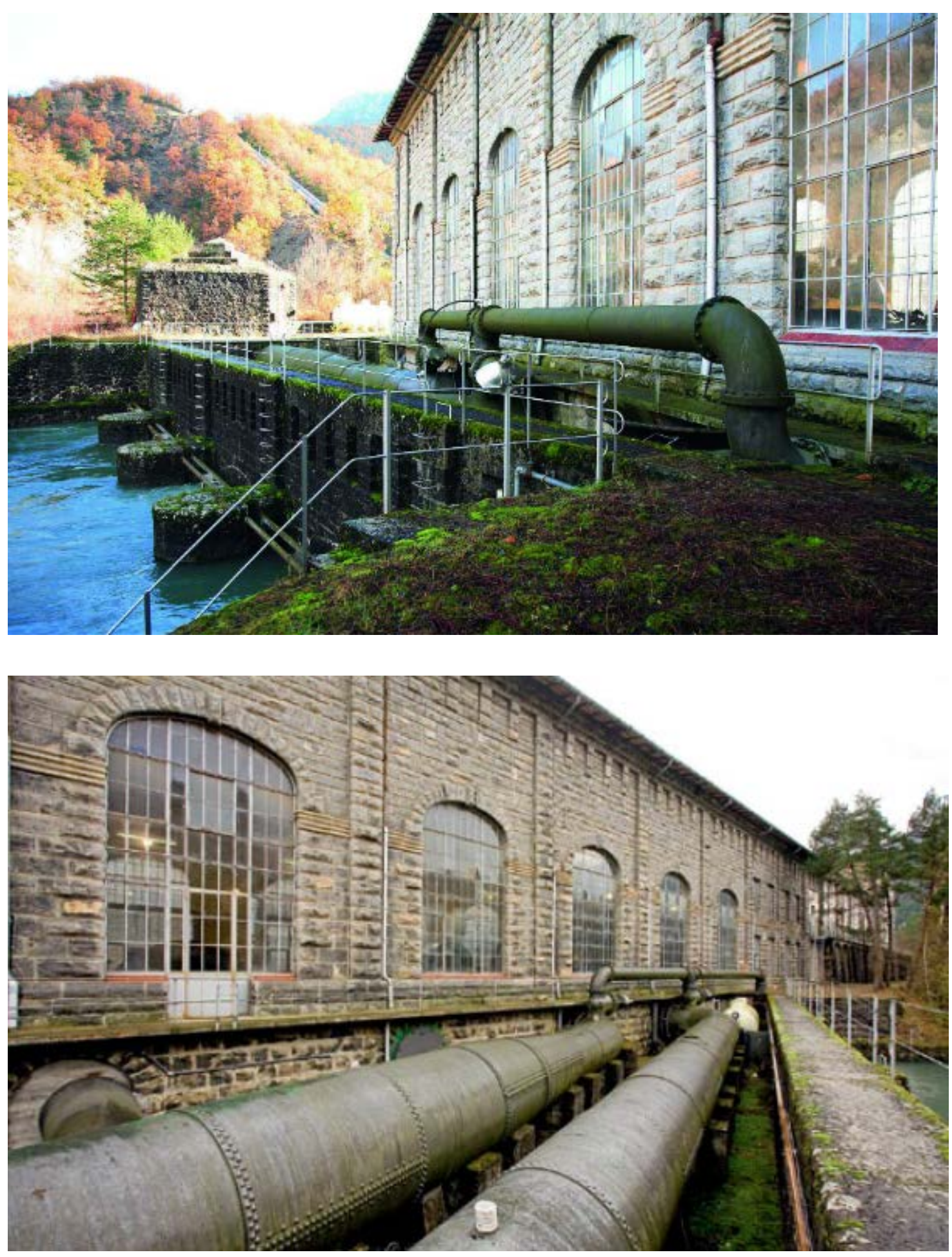

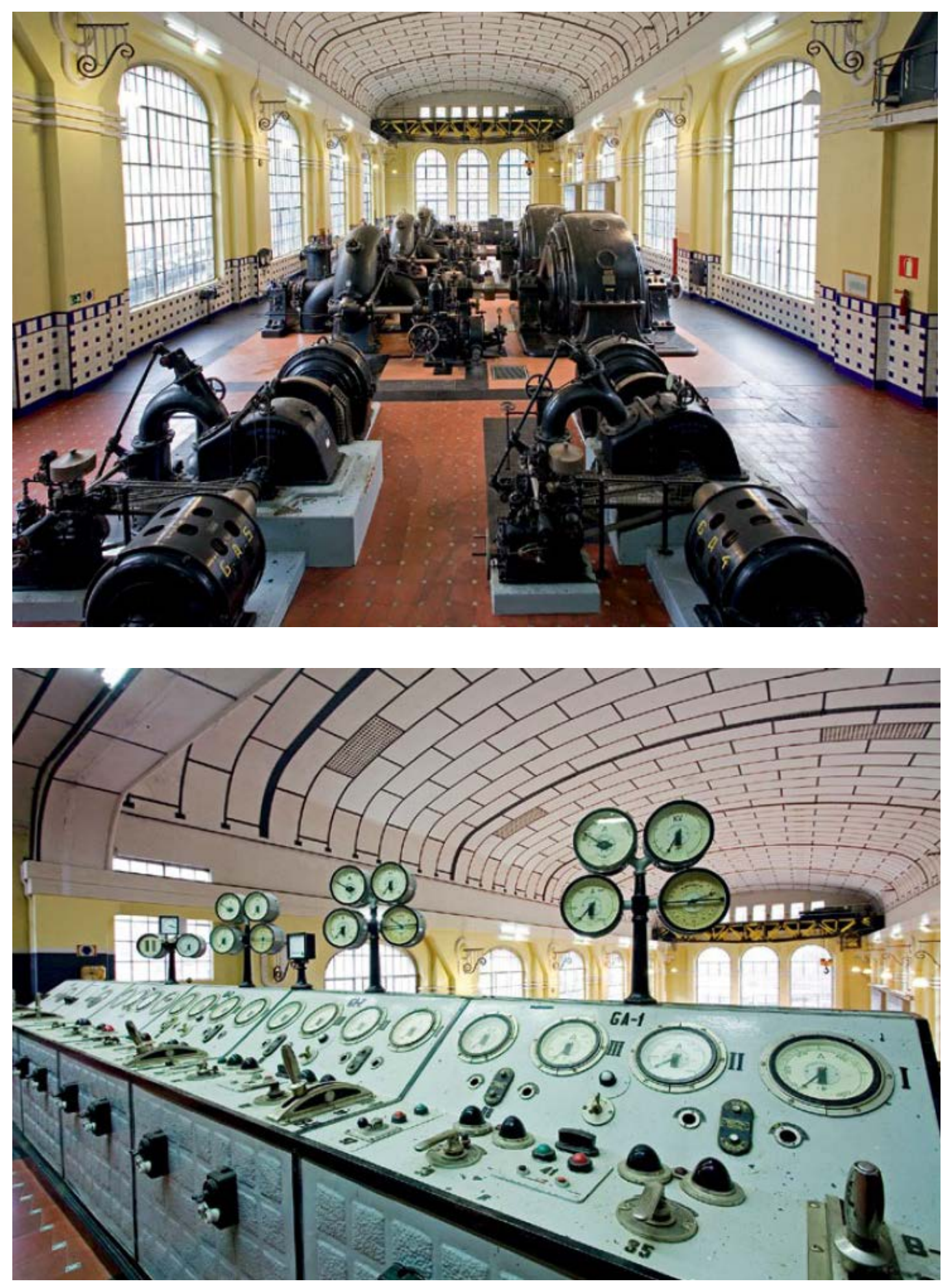

El edificio de la central es de planta rectangular, cubierto a dos aguas con teja. $\mathrm{Al}$ exterior los muros son de piedra abiertos mediante cinco vanos recercados de los que sobresale la clave. Entre ellos se disponen pilastras adosadas a modo de contrafuertes. Todo esto recuerda en gran medida a la arquitectura religiosa medieval. Al interior, el edificio sigue el modelo de fábrica en nave, con una decoración sencilla consistente en un zócalo de azulejos rodeando la sala y una 
triple moldura a la altura del segundo piso. La instalación se completa con otras dependencias como oficinas y talleres.

Puede verse el buen diseño, la calidad de la construcción, tanto interior como exterior, que ha permitido que se mantenga con sus condiciones iniciales, y la amplitud de los espacios, ya que el parque de transformadores estaba en el interior.

Actualmente el conjunto ha sido rehabilitado y junto con el Museo de la Electricidad de Seira, reúnen la historia de la construcción y desarrollo de la central y como ésta transformó tanto la región como a sus habitantes.

\subsection{CENTRAL HIDROELÉCTRICA DE TAMBRE. NOIA (A CORUÑA)}

En el año 1924 están en obras las instalaciones de la Central Eléctrica del Tambre en Noia proyectadas por el arquitecto Antonio Palacios Ramilo. Es un ejemplo destacado de la industria eléctrica en Galicia de finales del siglo XIX y principios del XX.

El caso de Antonio Palacios (1874-1945), es uno de los casos más interesantes de colaboración entre arquitectura e ingeniería. Relevante arquitecto de principios del S.XX, responsable de emblemáticos edificios de la capital (Círculo de Bellas Artes, Palacio de Correos...), realizó dos centrales hidroeléctricas, en Mengíbar (Jaén), y en Tambre (A Coruña).

La Central Hidroeléctrica de Mengíbar, está inscrita en el Patrimonio Inmueble de Andalucía. Es una central de agua fluyente, con presa por gravedad, que ocupa todo el margen del río Guadalquivir. Posee cuatro compuertas para controlar y aliviar el paso del agua. Está construida a base de muros de carga, con mampostería de piedra natural, llagueada y rejuntada mediante mortero de cemento. Los huecos forman un arco de medio punto con material de similar características. La cubierta se realizó a base de teja cerámica plana, montada sobre cercha metálica. Se encuentra en buen estado de conservación. Se construyó en 1918 y se utiliza actualmente para generar energía eléctrica e inyectarla a la red.

Respecto a la Central de Tambre, se detallan sus características a continuación.

Su estilo arquitectónico inicial se adhiere al Sezessionsstil vienés, citado en párrafos anteriores, y poco a poco evoluciona hacia un regionalismo arquitectónico, aunque sin abandonar raíces hispanas caracterizadas por los estilos plateresco y manuelino. 
Posee además fuertes influencias expresionistas. Preocupado siempre en sus obras por el tratamiento pétreo de sus fachadas, muestra ser desde los inicios un gran conocedor de la estereotomía en la piedra.

Palacios siempre estuvo ligado sentimentalmente a su patria, es por esta razón por la que intercala obras y diseños arquitectónicos en Galicia mientras trabaja en los proyectos madrileños.

Gran parte de su arquitectura regionalista se ve influenciada por la relación personal de Palacios con el grupo de pintores que intentaban definir una plástica peculiarmente gallega, como era José Seijo Rubio. Cabe destacar que él mismo poseía habilidades artísticas de pintura, desarrollando su afición frecuentemente.

El interés particular dentro del patrimonio arquitectónico gallego lo centra en el estudio de la arquitectura medieval gallega y concretamente en el denominado estilo románico de transición, así como en la arquitectura popular gallega.

Palacios imbuye a la Central de Tambre, un lenguaje historicista de base románica ahora aplicado a una edificación industrial que será reconocida por sus coetáneos como catedral industrial gallega. El lenguaje historicista se centra fundamentalmente en la fachada principal con una disposición que recuerda a las pequeñas ermitas rurales.

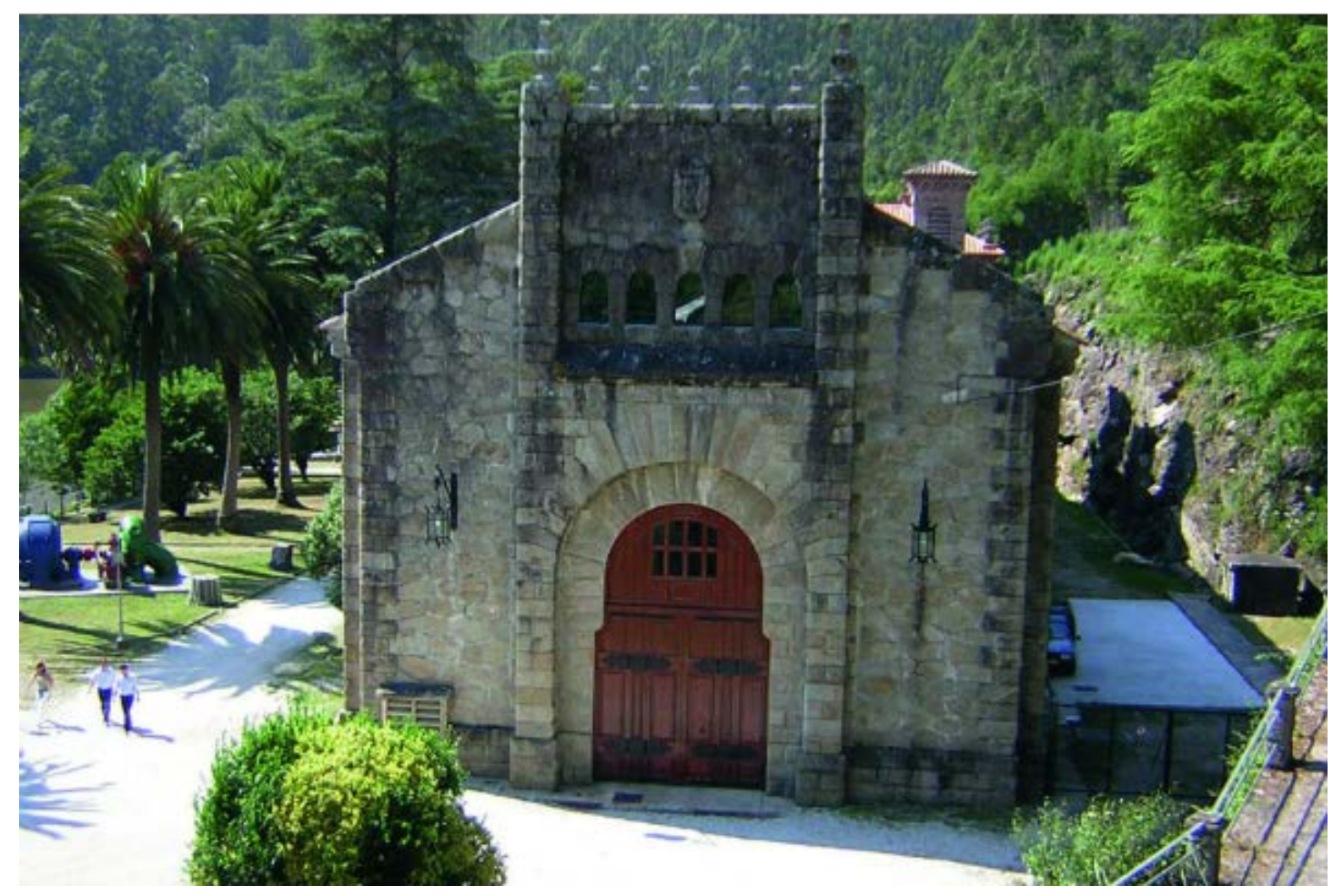


Presenta ya el rudo tratamiento de la piedra que se anunciaba en el proyecto de la Encarnación de Celanova. El anticipo de este tratamiento del granito está presente en el Hospital de Maudes de Madrid, proyecto ejecutado en aquellos años también fuera del ambiente cosmopolita del centro de la capital.
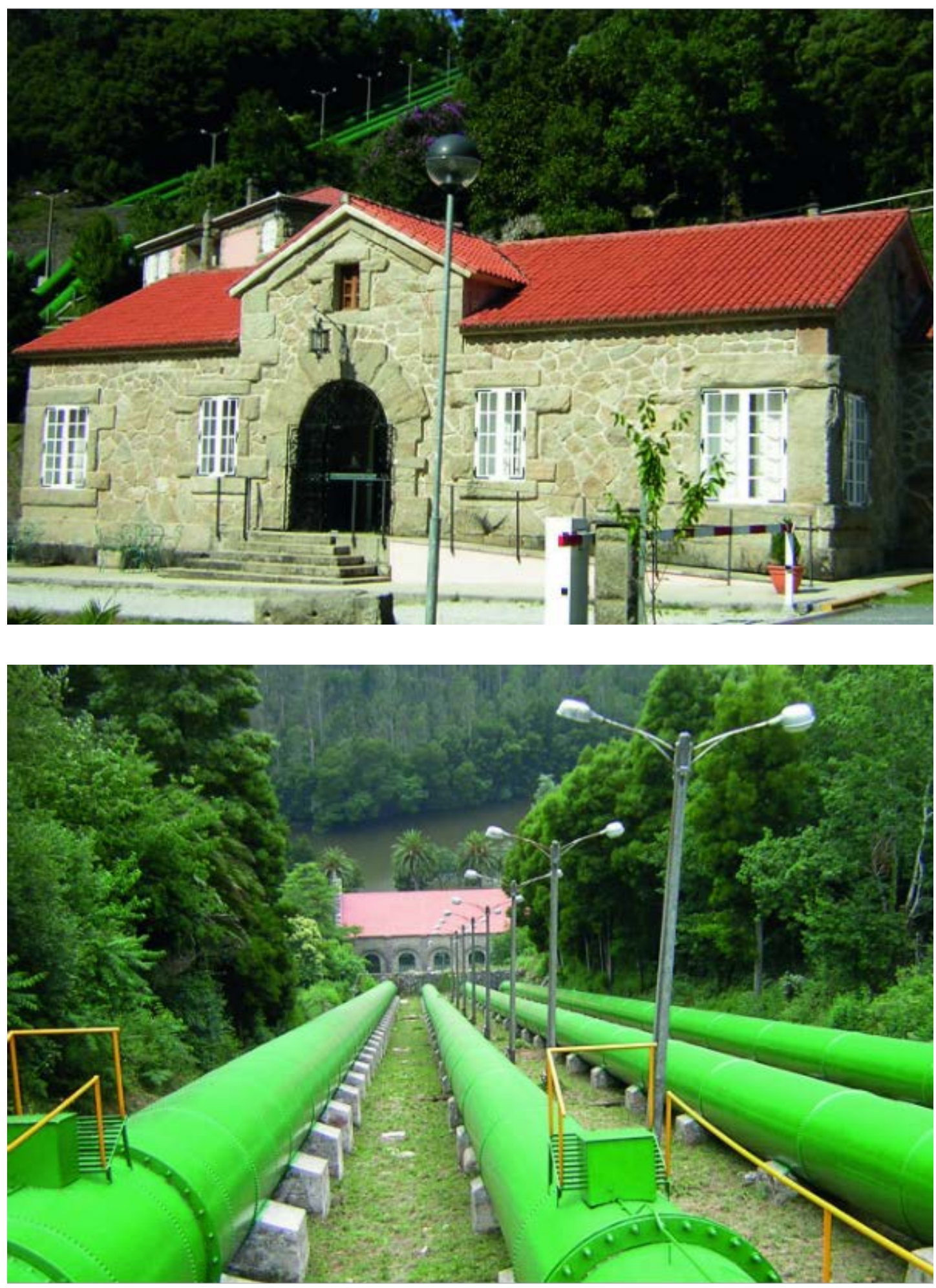


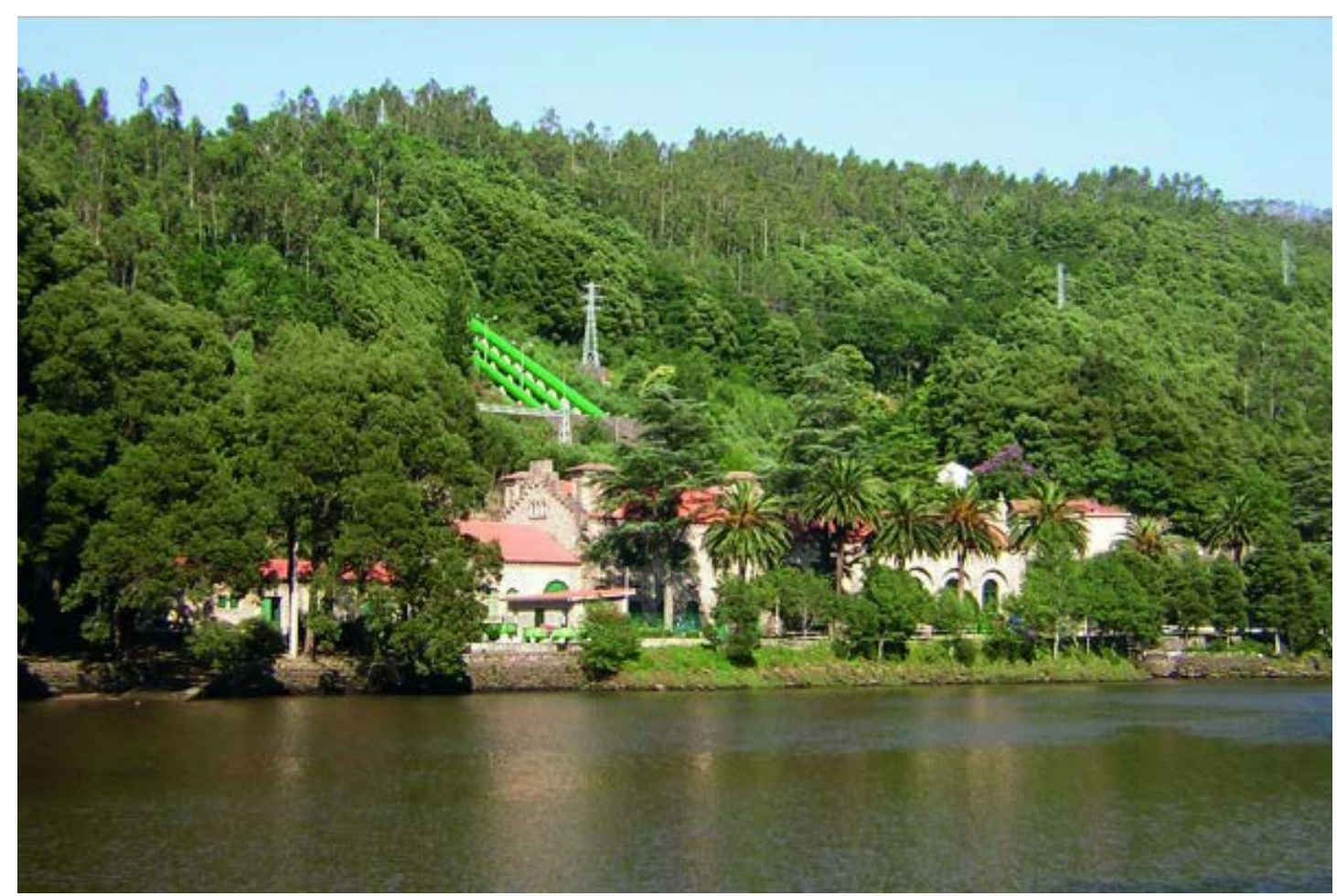

Otro aspecto que se puede considerar muy moderno en la obra de Palacios es la integración de sus propuestas en el entorno, como manifestaciones que transcienden la propia individualidad del arquitecto y pasan a ser creación de un ámbito determinado. Nunca se verán en Palacios construcciones fuera de lugar o incongruentes con el entorno.

Esta constancia del lugar es mucho más acusada en la importancia dada a la topografía y al paisaje en sus proyectos extraurbanos, en ámbitos rurales o naturales. El conjunto de edificaciones de la Central del Tambre surgen del entorno casi como cristalización pétrea del ambiente circundante, con sus construcciones complementarias y viviendas salpicadas entre el verdor del paisaje como motas rocosas o accidentes propiamente topográficos.

La Dirección Xeral de Turismo de la Xunta de Galicia, en colaboración con la compañía eléctrica Unión Fenosa y con el apoyo europeo del programa LIFE, ha desarrollado el proyecto Hotel de Naturaleza, Pesquería del Tambre , según el cual se ha puesto en valor turístico la zona que ocupa la central hidroeléctrica. El conjunto de casas dedicadas a los trabajadores de la central hidroeléctrica se ha rehabilitado para hotel (Hotel Pesquería del Tambre).

Se asienta sobre una antigua pesquería cisterciense que abastecía de pescado y mariscos a los frailes del monasterio de Toxosoutos en San Xusto a $5 \mathrm{Km}$. Este monasterio se fundó hacia 1132 bajo la regla de San Benito. 
El Rey Alfonso VII les concedió grandes favores y privilegios, llegando a ser a mediados del siglo XIII el monasterio con mayor poder económico de Galicia. En el año 1504 quedo anexionado a Sobrado dos Monxes, aceptando la reforma del Cister.

\subsection{SALTO Y CENTRAL HIDROELÉCTRICA DE GRANDAS DE SALIME (ASTURIAS)}

El Salto y la Central de Grandas de Salime constituyen uno de los mejores y más monumentales exponentes del patrimonio industrial del agua de Asturias.

Fueron realizados por iniciativa de las empresas Electra del Viesgo S.A. e Hidroeléctrica del Cantábrico S.A. Considerada una obra de absoluta prioridad nacional, se estimó en su momento indispensable en aras de mejorar, con su aportación, el suministro de energía a las zonas de Galicia, Asturias y Santander, sobre las que fundamentalmente se extendía el mercado propio de las dos empresas promotoras. La idea de construir una central comienza a gestarse en 1940 pero no fue hasta finales de la Segunda Guerra Mundial cuando empieza a tomar forma. En 1946 comienzan los trabajos preliminares, pero el grueso de la obra se realiza entre 1948 y 1953.

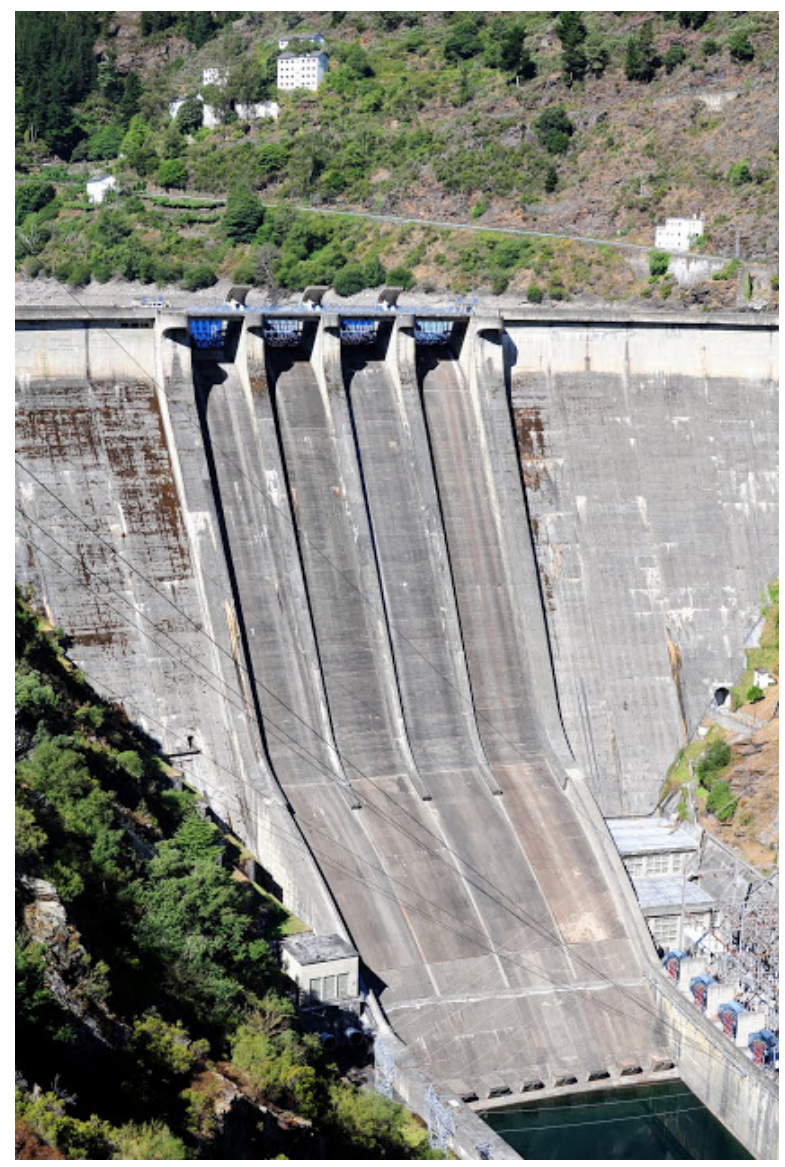




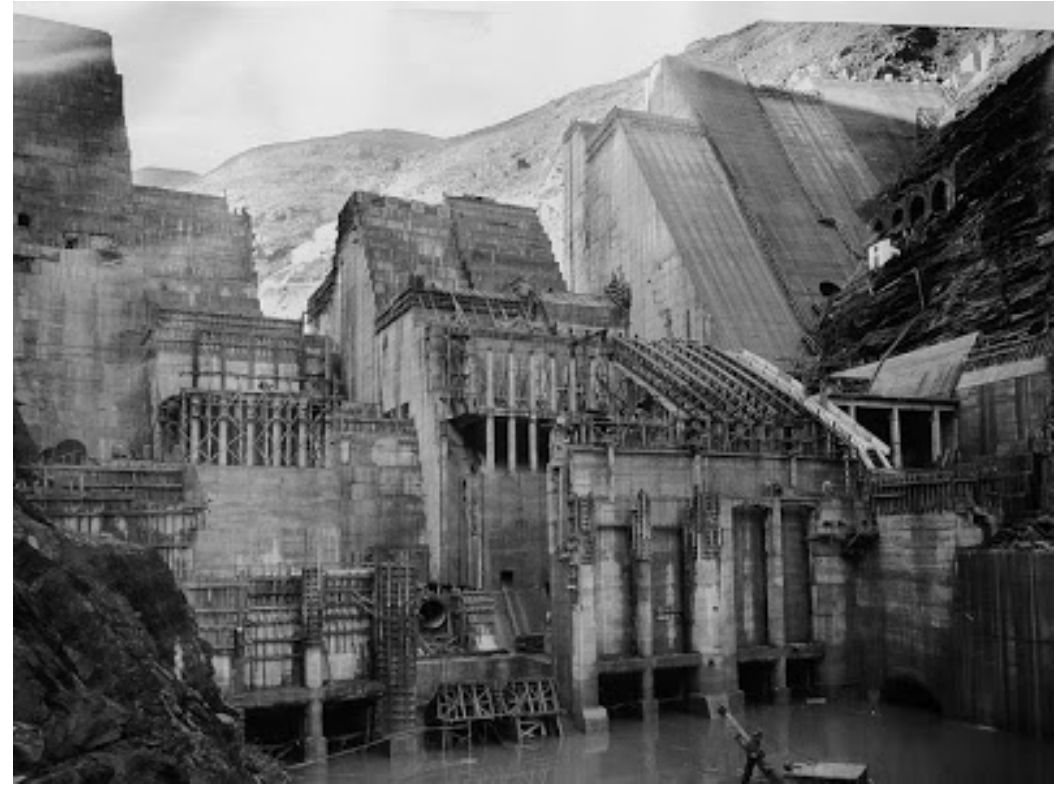

Fotografía del proceso de construcción de la presa de Salime

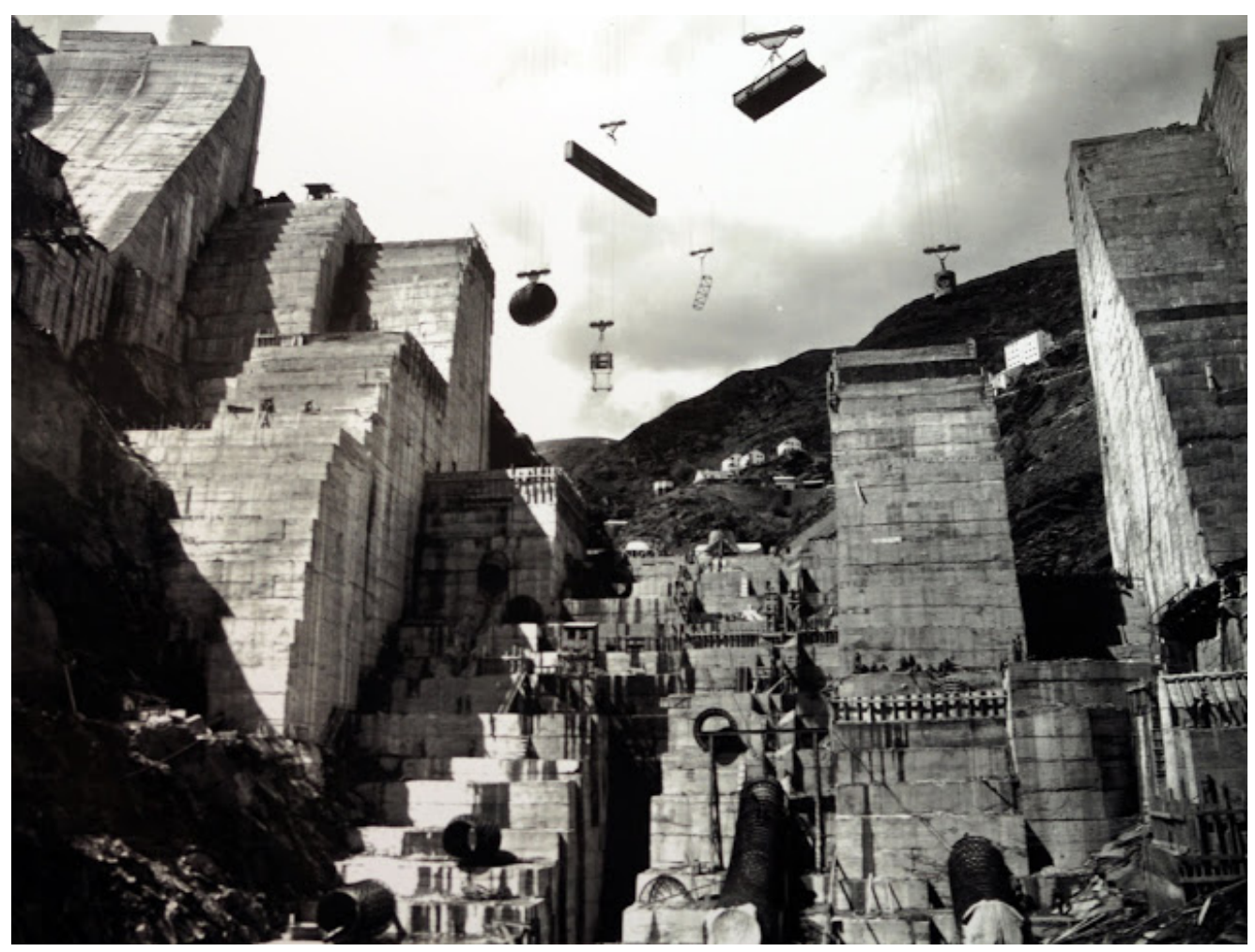

Fotografía del proceso de construcción de la presa de Salime 


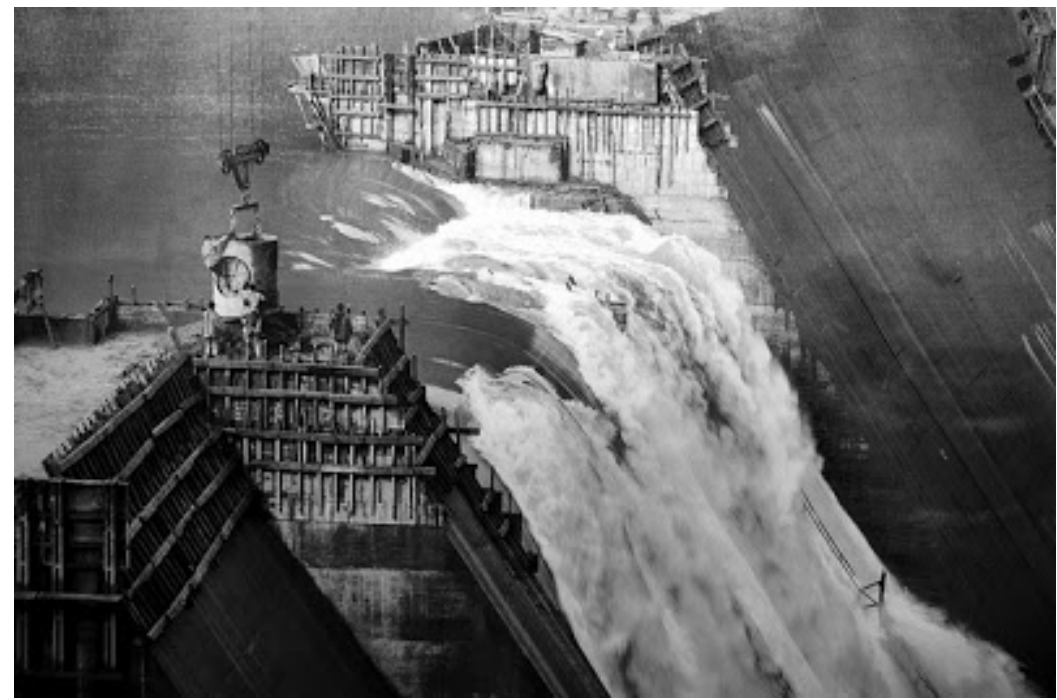

Fotografía del proceso de construcción de la presa de Salime
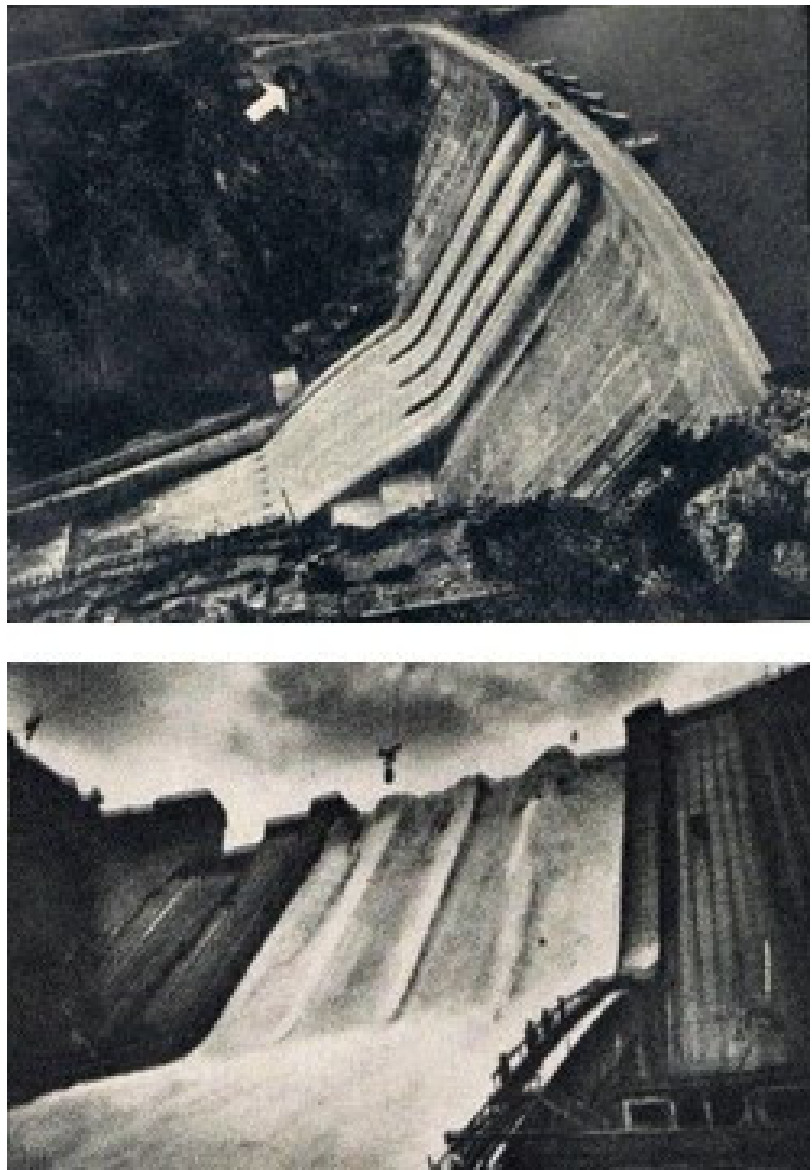

Fotografía de la presa de Salime en su inauguración

El equipo de ingenieros de Hidroeléctrica del Cantábrico es el encargado del diseño pero cuentan con la intervención arquitectónica, escultórica y pictórica de Joaquín Vaquero Palacios y su hijo, Vaquero Turcios.

De tal modo, ésta constituye la primera obra de la serie de centrales en las que los Vaquero intervendrán, más adelante, para Hidroeléctrica del Cantábrico. El 
polifacético artista ovetense Vaquero Palacios se incorpora a la obra cuando la construcción ya estaba avanzada para llevar a cabo un conjunto de intervenciones muy significativas, que abarcan los dominios de la arquitectura, la escultura, la pintura y el diseño de interiores, dando como resultado un testimonio muy notorio de una de las vocaciones más evidentes del artista: la de la integración o simbiosis de las artes y la de la aspiración a la obra de arte total. Su trabajo en la monumental obra de Salime responderá a una revalorización del orden industrial, pero también a una complacencia en las tecnologías de la industria. Una sabia combinación de lo estético y lo utilitario, así como una conjugación de los fines prácticos, económicos y armónicos, en aras de una revitalización del arte, la arquitectura y la ingeniería.

La intervención de Vaquero puede observarse en varios elementos del conjunto: en los miradores volcados sobre el aliviadero, en las dos terrazas proyectadas hacia el embalse y en los tres casetones que acogen las compuertas de entrada y salida del agua, muy prácticos y escultóricos, realizados en hormigón. También realiza la fachada principal por la que se accede a la central, donde coloca varios relieves de hormigón que forman un mural que representa los elementos naturales. El mirador de boca de ballena, que ofrece una visión del conjunto, es obra de su hijo Vaquero Turcios, una intervención que enlaza con la tradición expresionista alemana.

En el interior, concretamente en la sala de turbinas se disponen dos grandes murales que representan por un lado el proceso de construcción del salto y por otro la potencia eléctrica. Vaquero realiza también una sala conocida como "el refugio", con planta circular donde se busca el cobijo de los trabajadores del ambiente y los ruidos de la central. El chalet de dirección es también obra suya, muy enlazado con la arquitectura vernácula y actualmente utilizado para reuniones de los directivos.

La construcción del Salto y la Central Hidroeléctrica de Grandas de Salime trajo consigo, entre otros fenómenos, la proletarización de un gran número de campesinos de la zona, en particular, del Concejo de Grandas. Éstos fueron empleados como mano de obra no cualificada y barata, mientras se prolongó la construcción, y a ellos se unió personal cualificado procedente de diversas zonas del país. Para hacer frente al alojamiento de los asalariados se calcula que entre fijas e itinerantes habrían llegado a trabajar unas tres mil personas que venían acompañadas por sus familias y construyeron cuatro poblados: el poblado de Elitaña, el poblado del Campín, el de Vistalegre y el de La Paincega, actualmente abandonados casi en su totalidad. Se crearon también pabellones para hombres solteros. 


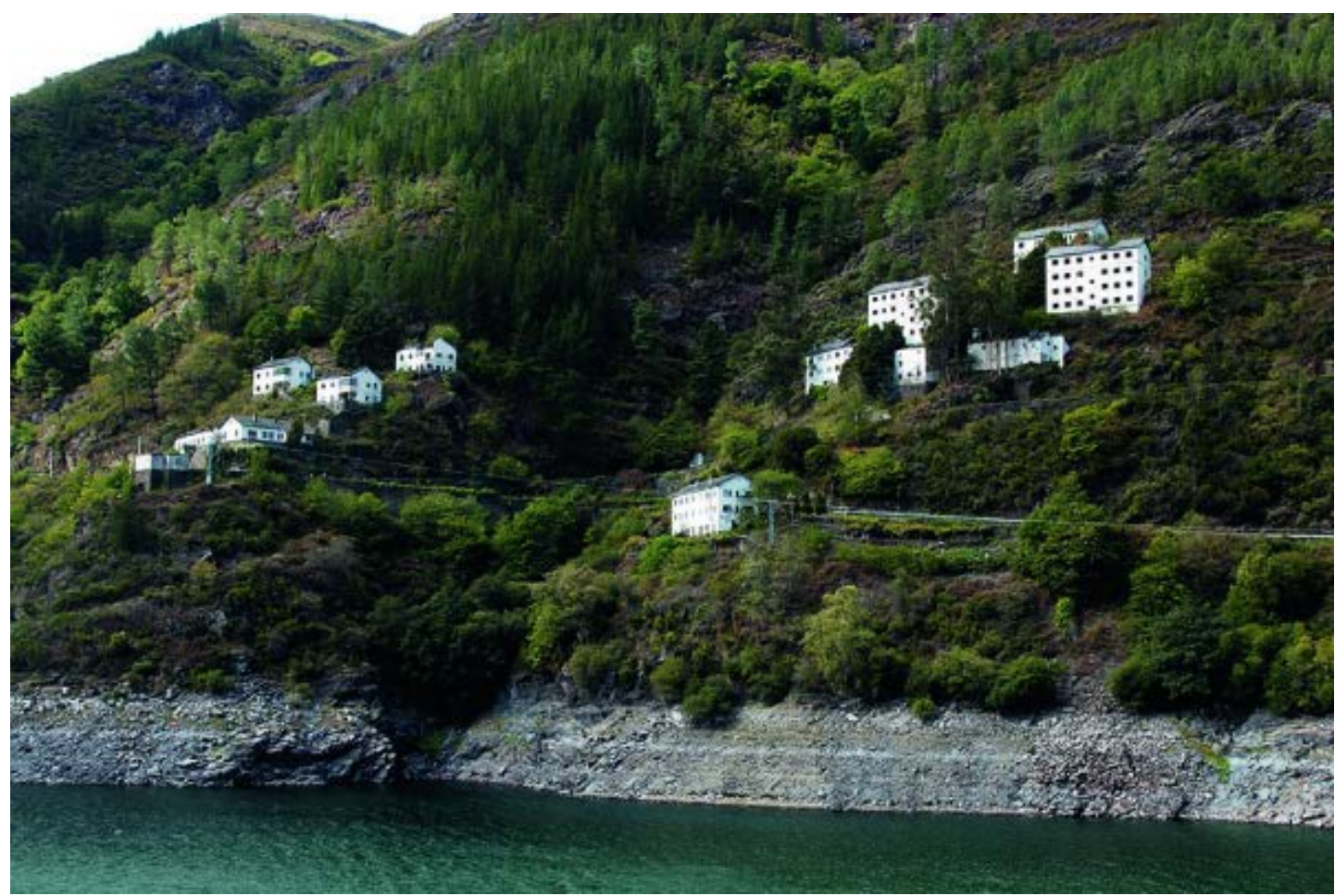

Revisten así mismo interés las obras de infraestructura que fueron llevadas a cabo con motivo de la construcción del Salto: planos inclinados, carreteras, túneles y, en particular, el teleférico trocable para transporte de materiales, con ocho estaciones, que culminaba en El Espín Coaña, en la margen izquierda de la ría del Navia, donde fue construido un muelle de descarga de los barcos, cuyas huellas pueden observarse en la actualidad.
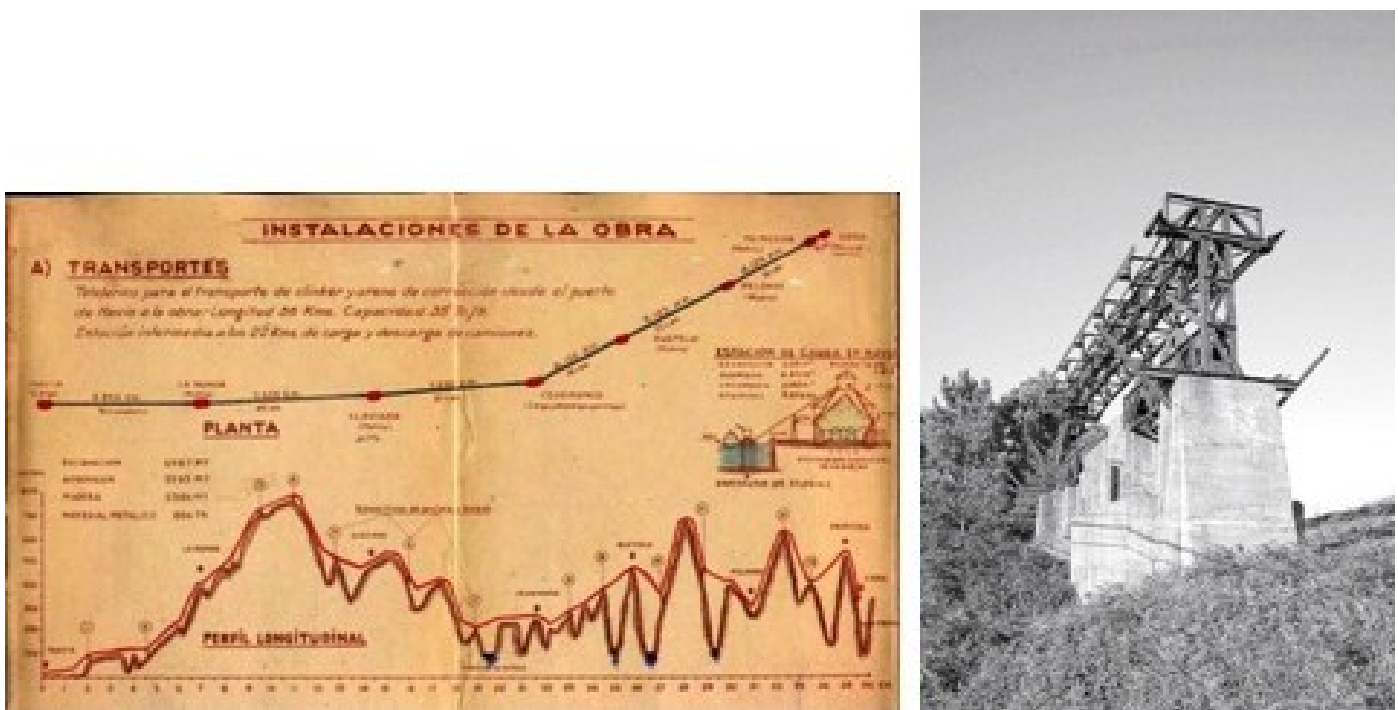

Trazado original del teleférico y foto actual del estado del mismo

Actualmente la central se encuentra en funcionamiento aunque se ofrecen visitas guiadas por las instalaciones. 
La labor de Vaquero Palacios merece de especial atención tanto por el conjunto de Grandas de Salime como por sus aportaciones en otras centrales hidroeléctricas.

Por ello, a continuación se detallan aspectos relevantes de su obra.

\subsection{LA OBRA DE JOAQUÍN VAQUERO PALACIOS (1900-1998)}

Las centrales hidroeléctricas han constituido un campo magistral de actuación en las vertientes arquitectónica, pictórica, escultórica y el diseño de interiores. El estilo de Vaquero Palacios responde a algunas de las premisas fundamentales planteadas desde el Movimiento Moderno. La presencia de la ingeniería a gran escala, la dotación de una alta capacidad financiera, así como la calidad y representatividad de sus edificios, dotan de una destacada singularidad a estos conjuntos.

La matriz mecanicista y, en un sentido amplio, el universo industrial han sido, en consecuencia, fuente de inspiración no sólo de las formas, sino también de los conceptos y principios sobre los que se asentó el Movimiento Moderno.

La arquitectura de la modernidad encontró en la industria más fácil acomodo, siendo asumida sin grandes contradicciones. Así, entre los diferentes programas a los que los arquitectos debieron responder, los espacios industriales constituyeron todo un campo abierto a la innovación y a la experimentación tanto en el plano de las técnicas, como en lo que respecta a las formas, la piel de los edificios, su relación con el componente estructural y la creación de nuevos elementos simbólicos.

El problema de la arquitectura y su relación con las artes plásticas, la pintura, la escultura y el diseño, planteado por algunos de los principales teóricos del Movimiento Moderno, heredado de las Arts and Crafts, el Art Nouveau, la Bauhaus o De Stijl, se concretó en buena parte de estos conjuntos en la búsqueda de una ansiada alianza de las artes bajo la protección de la arquitectura.

Destaca en este ámbito, la labor integradora emprendida por Joaquín Vaquero Palacios (Oviedo, 1900-Madrid, 1998) a partir de la Central de Grandas de Salime, contando con la colaboración de su hijo Joaquín Vaquero Turcios (Madrid, 1933-2010), en adelante ampliada a los aprovechamientos hidroeléctricos de Belmonte, Proaza y Tanes. 
La síntesis de las artes se ve favorecida en el caso de Vaquero Palacios por su compartida actividad arquitectónica, pictórica, escultórica y su preocupación por el diseño de interiores, aspirando con sus intervenciones a humanizar y dignificar los espacios, así como a dimensionar las posibilidades artísticas que brinda los aprovechamientos hidroeléctricos como soporte y espacio medioambiental.

Autor de vasto oficio, amplio registro e indiscutible competencia, Joaquín Vaquero Palacios entendió la arquitectura, la pintura y la escultura como parte integral de la amplia disciplina de la construcción. Formado en la Escuela de Arquitectura de Madrid (1921-1927), tuvo la oportunidad de conocer, a través de sus maestros -Teodoro de Anasagasti, Vicente Lampérez y Antonio Flórez, entre otros- la Arquitectura Moderna, dando además temprano inicio a su actividad de diseño de muebles y arquitectura de interior.

Su hijo, Joaquín Vaquero Turcios, heredando su visión multidisciplinar, dedicó una parte fundamental de su trayectoria, junto a su faceta arquitectónica, a la pintura y a la escultura.

La Central de Grandas de Salime, primer escenario de este tipo de intervenciones, constituye un testimonio notorio de una de las vocaciones más evidentes de Joaquín Vaquero Palacios, esto es, la integración o simbiosis de las artes, a partir de la fusión de arquitectura, pintura, escultura, diseño industrial y de mobiliario.

La Central es tratada por Vaquero como una unidad plástica total que abarca desde la construcción ingenieril, con su escala monumental y su estética sencilla y poderosa, incrustada en un espléndido paisaje, hasta la posibilidad de enriquecer el conjunto con la presencia de las artes plásticas y el diseño. Se logra así una armonía entre funcionalidad y un elemento de gran valor estético.

La construcción del conjunto puede inscribirse en los momentos iniciales de la llamada recuperación de la modernidad, en la arquitectura asturiana, entendida ésta, como una simplificación y liberación de las formas arquitectónicas, o como un medio de abordar con mayor economía y rapidez de ejecución las nuevas viviendas y los nuevos equipamientos propios de una sociedad de masas en proceso creciente de desarrollo que, todavía latente en los primeros años de la década de los cincuenta, se va a manifestar aceleradamente en la posterior década de la abundancia. Se trata de una recuperación verificada desde el concepto histórico de la arquitectura orgánica, enunciado y desarrollado desde inicios de los años cincuenta. En los aprovechamientos hidroeléctricos -en particular, en el caso concreto de los trabajos de Vaquero Palacios- se dio un singular punto de confluencia entre la industrialización y la arquitectura del 
Movimiento Moderno, que permitió hacer realidad el viejo ideal de la integración de las artes en la arquitectura de la modernidad.

El Salto de Grandas de Salime fue catalogado e incluido en el Registro de la Arquitectura Industrial de Asturias, adscrita al Movimiento Moderno y es uno de los elementos que han sido incluidos en el Plan Nacional de Patrimonio Industrial, entendido éste como el conjunto de elementos relacionados con la explotación industrial, generado por las actividades económicas de cada sociedad; este patrimonio responde a un determinado proceso de producción y a un sistema tecnológico concreto caracterizado por la mecanización dentro de un sistema socioeconómico concreto.
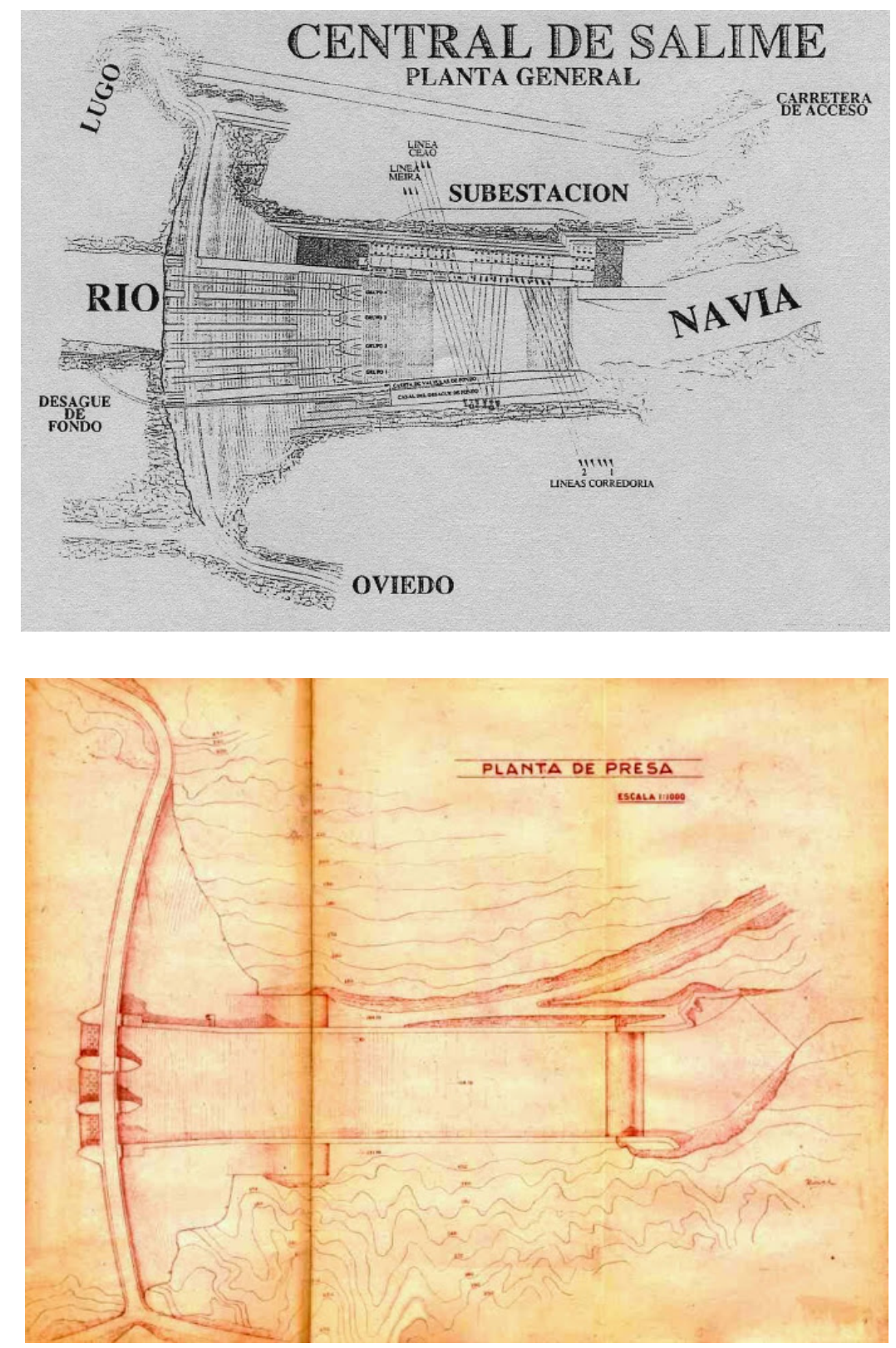

Planta del Proyecto Original 


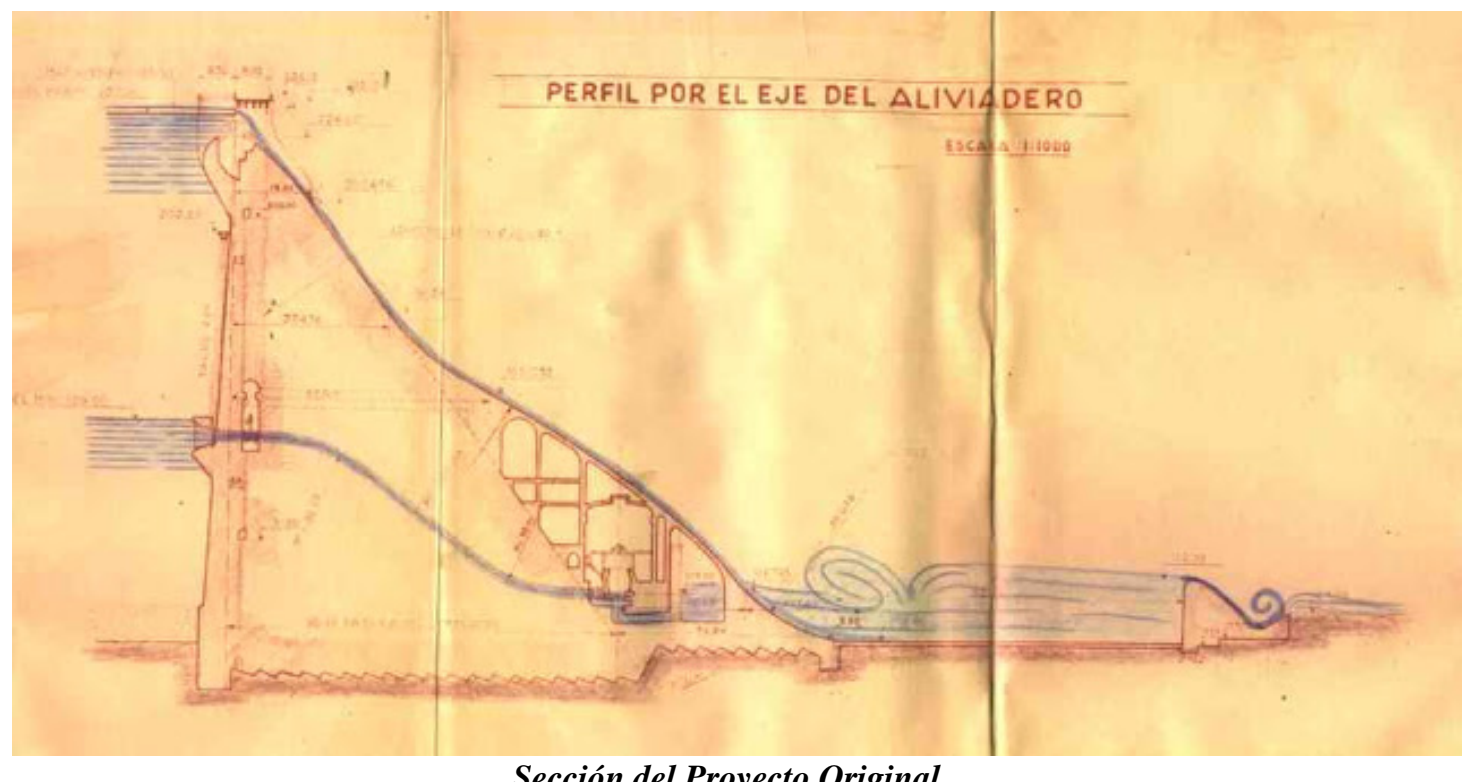

Sección del Proyecto Original

Con respecto a la intervención desarrollada por Joaquín Vaquero Palacios en la Central de Grandas de Salime, se desprende de la misma una sabia combinación de lo estético y lo utilitario, así como una conjugación de los fines prácticos, económicos y armónicos, en aras de una revitalización del arte, la arquitectura y la ingeniería.

Comenzando con su labor arquitectónica, uno de los principales problemas a los que Vaquero Palacios tuvo que enfrentarse fue el de la escala, esto es, la propia monumentalidad del elemento industrial sobre el que habría de actuar. En una primera fase, interviene en el tratamiento de la coronación del aliviadero, que sirve de paso a la carretera de Grandas de Salime a Oviedo. La cuidada intervención de Vaquero en esta zona enlaza con la tradición expresionista germánica, proporcionando una poderosa fuerza final a la monumentalidad de la presa. 

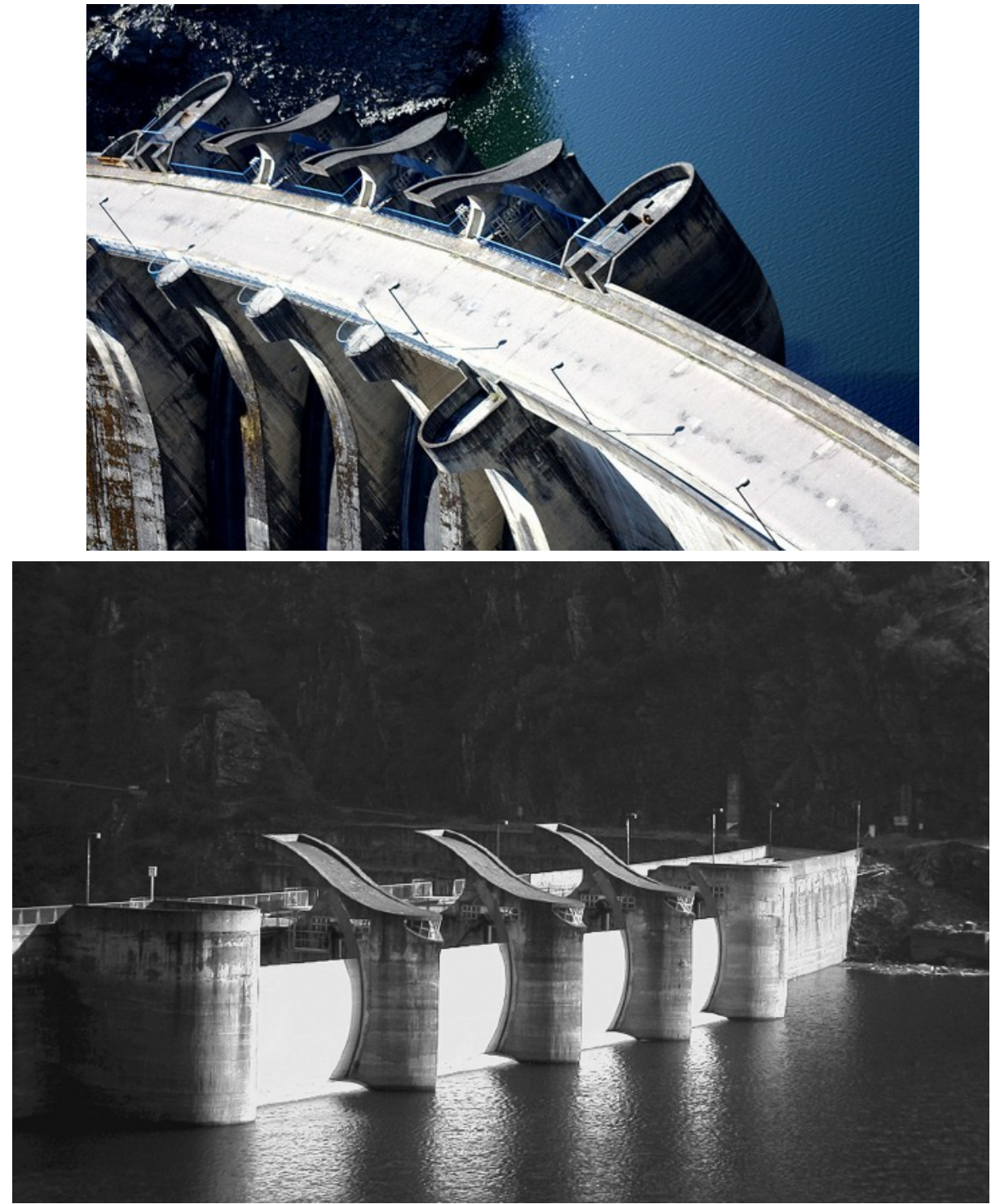

Aprovechando las posibilidades plásticas del hormigón armado, el artista utiliza los tajamares para conformar unos miradores. Se trata de cinco balcones de observación, erigidos sobre el aliviadero, que rematan de una manera rotunda y majestuosa la elevada pared de hormigón. A ellos se suman dos terrazas, proyectadas hacia el embalse, las cuales acogen las casetas que alojan la maquinaria de apertura y cierre de las compuertas. 

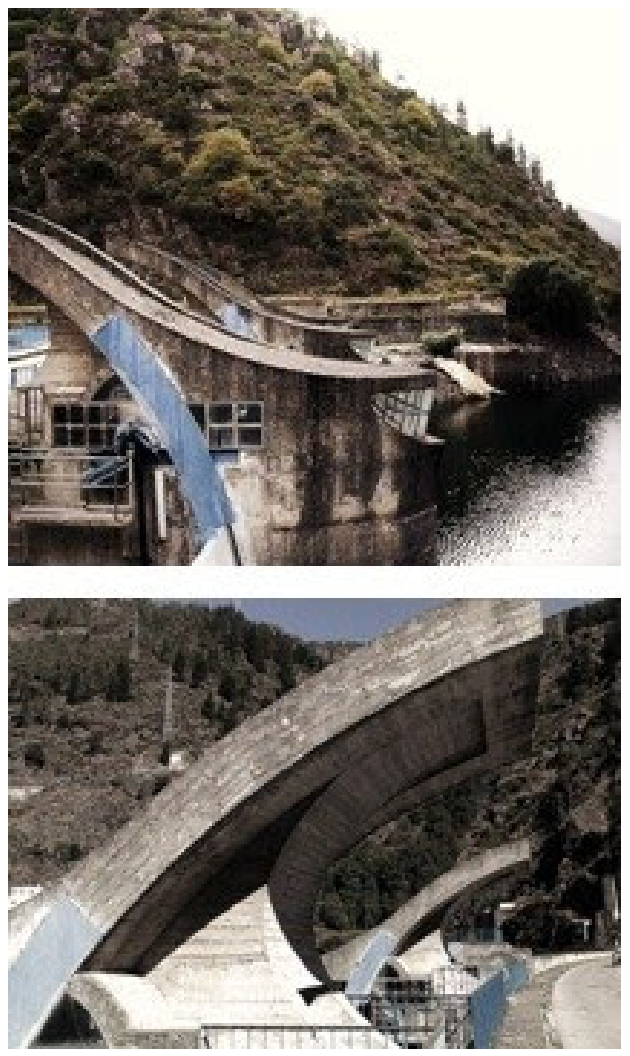

Miradores y espolones

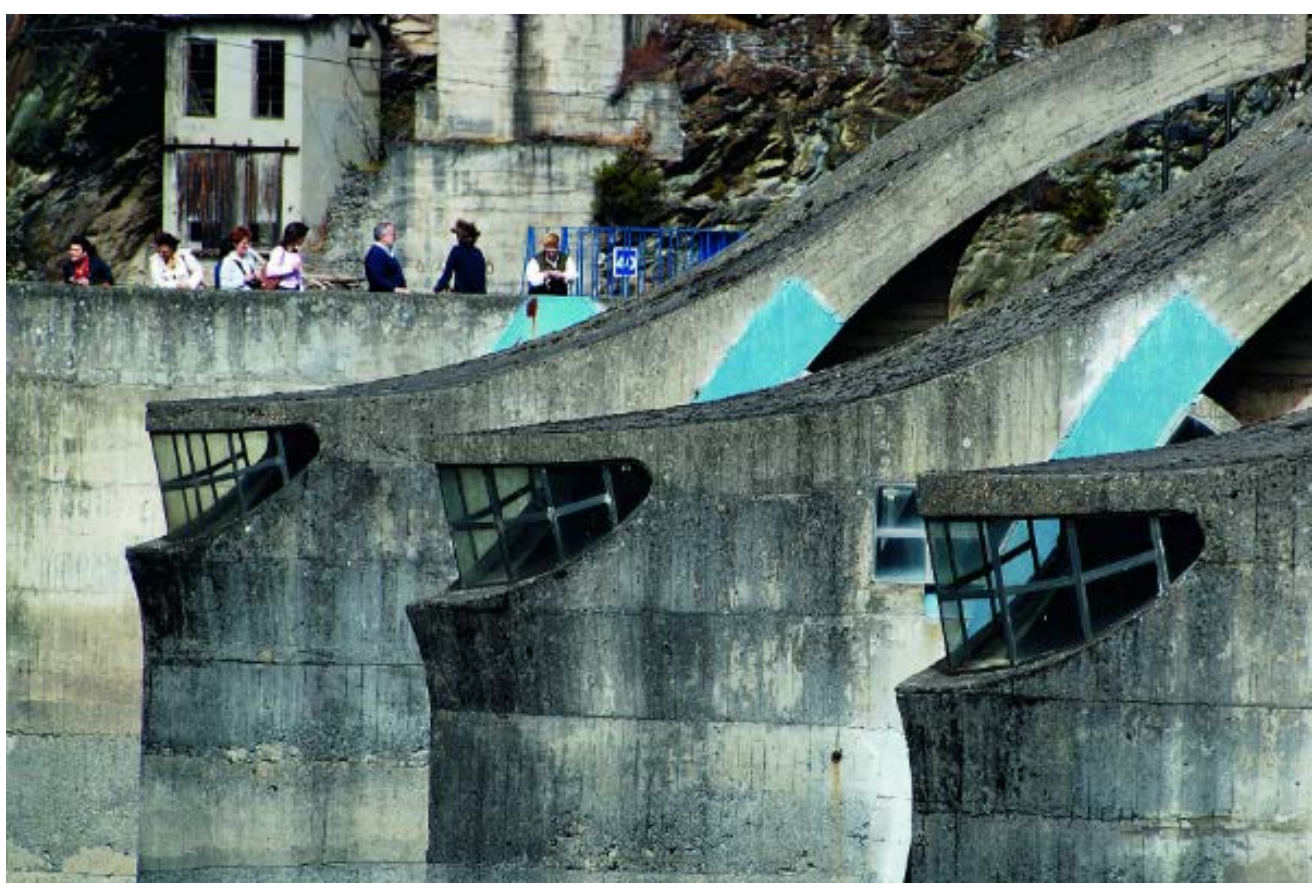




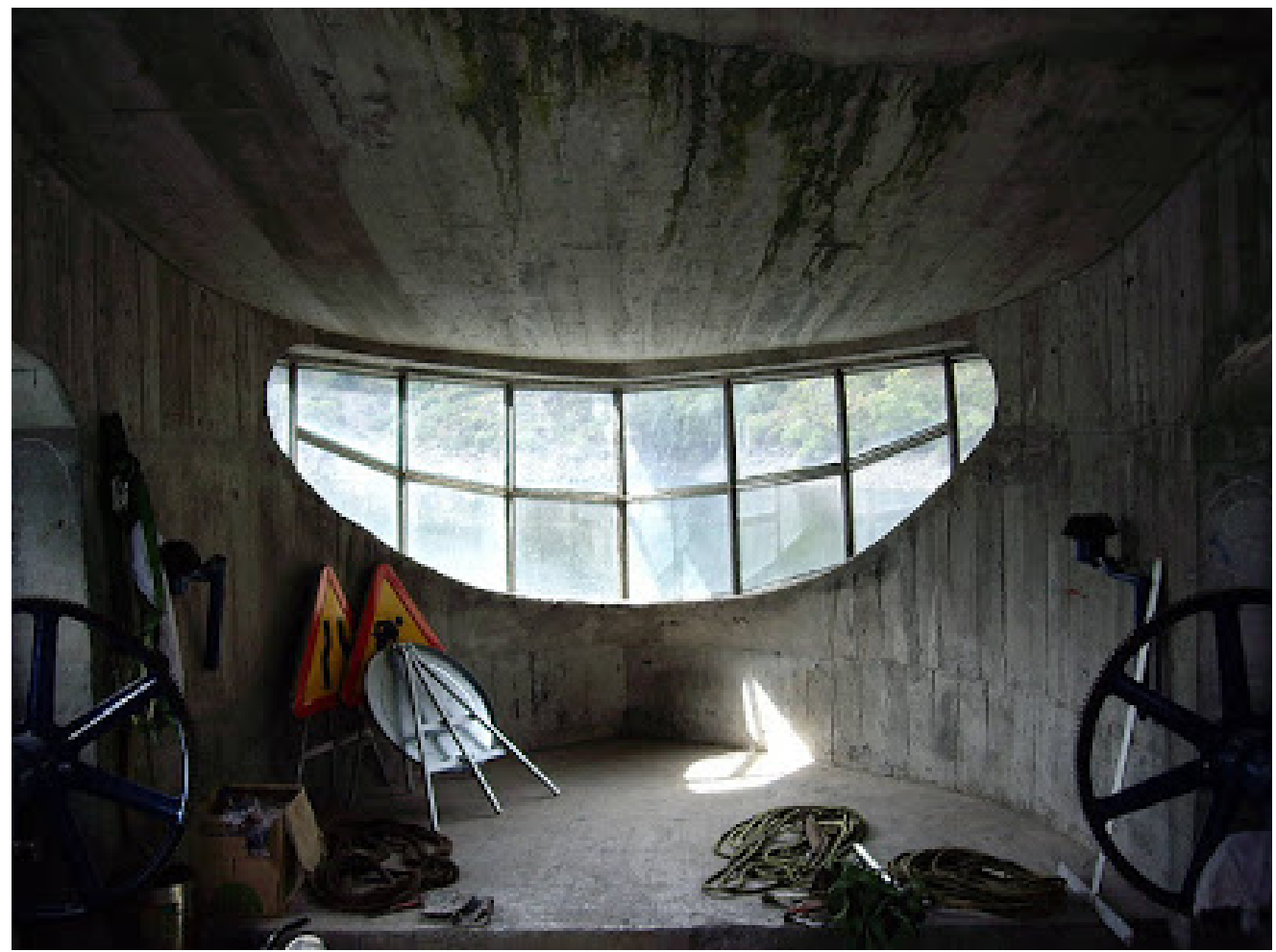

Interior de uno de los miradores

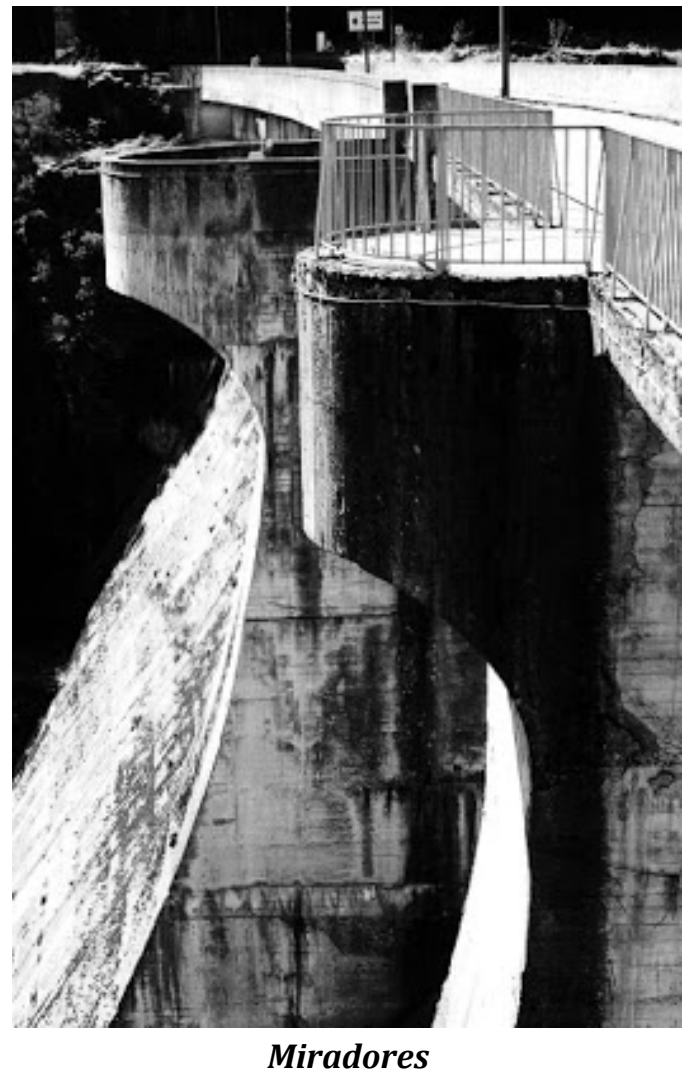

Conforman unos volúmenes escultóricos que se encuentran, de nuevo, en la línea de la arquitectura expresionista, poniéndose de manifiesto tanto en el movimiento generado como en la deformación expresiva de la materia. 
Originalmente, aunque finalmente no se llevaron a cabo, se había previsto la inclusión de dos grandes volúmenes escultóricos para rematar la coronación del Salto. Se trataba de dos representaciones

escultóricas alegóricas, de tamaño monumental, realizadas en hormigón, que estaban destinadas a

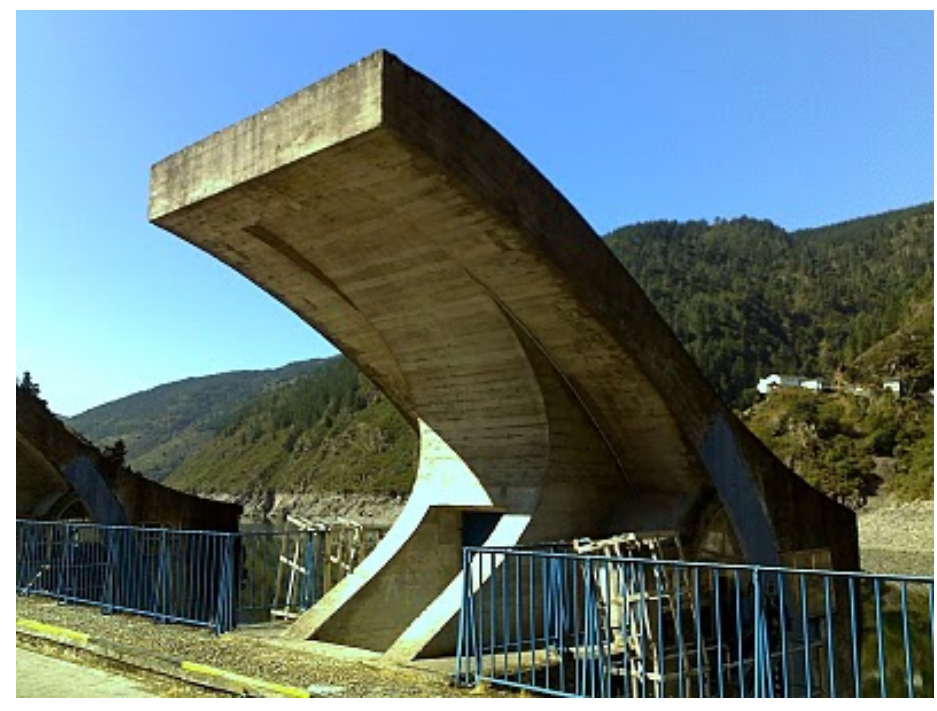
ser situadas en las dos plataformas laterales que avanzan sobre el aliviadero. Inicialmente, Vaquero había pensado en un símbolo de potencia, inclinándose por la figura de un centauro, híbrido entre la fortaleza del caballo y la inteligencia del hombre. Finalmente se decidió por dos ferres, aves de presa habituales en la zona, cuyos bocetos llevó a pequeñas maquetas y también a una mayor escala, a un décimo del que habría de ser su tamaño definitivo, que actualmente se conserva en el interior de la Central.

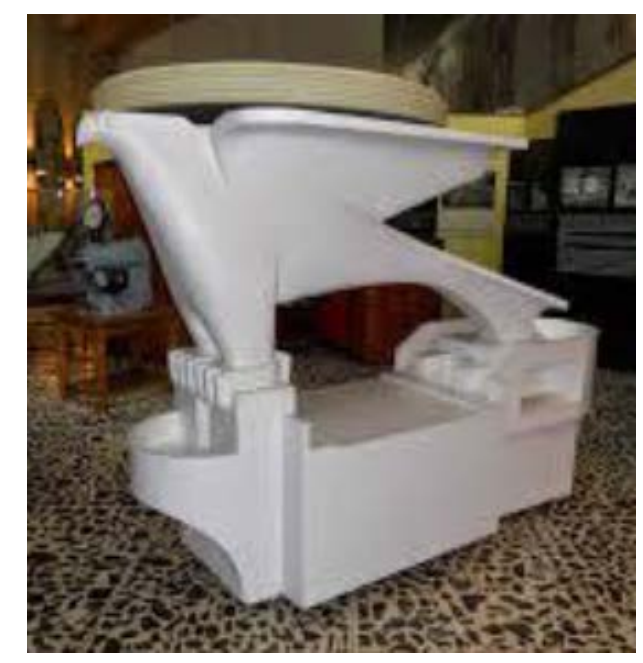

A los miradores que se elevan sobre el aliviadero debe añadirse el situado aguas abajo de la presa, en la margen derecha del río. Construido en el borde de la carretera, dominando la presa y el embalse, es un mirador colgante cuyo diseño se debe a Joaquín Vaquero Turcios.

Este mirador de boca de ballena, de porte escultórico, constituye un lugar de alcance visual privilegiado, en tanto que desde él puede contemplarse el conjunto de la obra en toda su magnitud. La obra incorporaba, originalmente, una ligera barandilla metálica que tuvo que ser sustituida por otra más pesada, 
que resta esbeltez al mirador. Un último mirador, actualmente no conservado, se emplazaba en las inmediaciones del acceso a la Central.
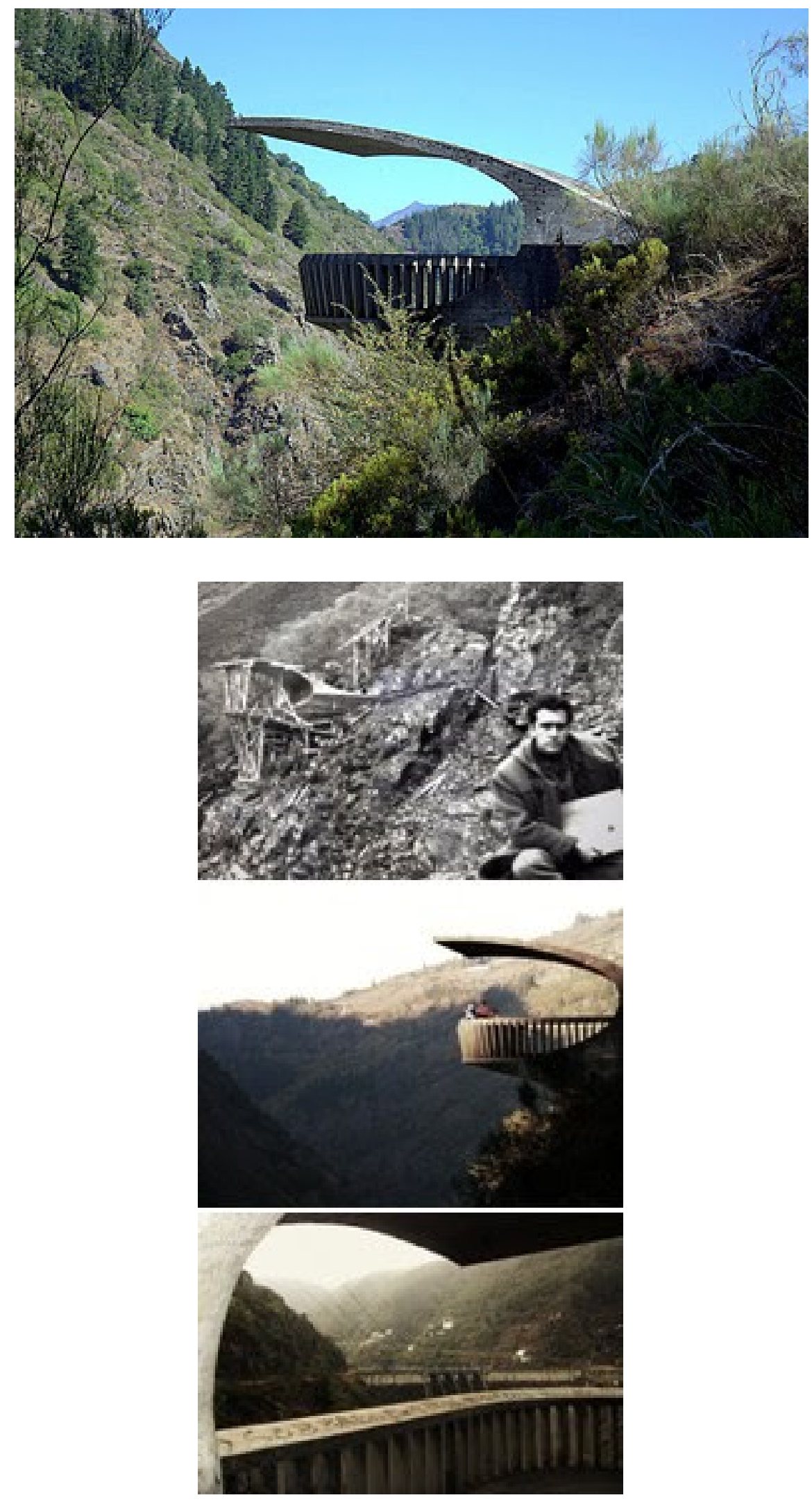

Joaquín Vaquero Turcios ante la "boca de ballena" 
De tal modo, en Salime, Vaquero Palacios responde con piezas de tamaño considerable a las dimensiones de la obra, moviéndose en el ámbito de la gran escala.

Por lo que concierne al trabajo escultórico, en la fachada del edificio que da acceso a la central y la subestación de intemperie, Vaquero Palacios, incorpora un conjunto de relieves. Se trata de una fachada prácticamente ciega, en la que se abre un único vano, de grandes dimensiones, por el que se practica el acceso a la Central a través de una galería. Dado que se trata de la única vía posible de acceso, el arquitecto decidió conferirle un carácter singular y otorgarle un atractivo visual.

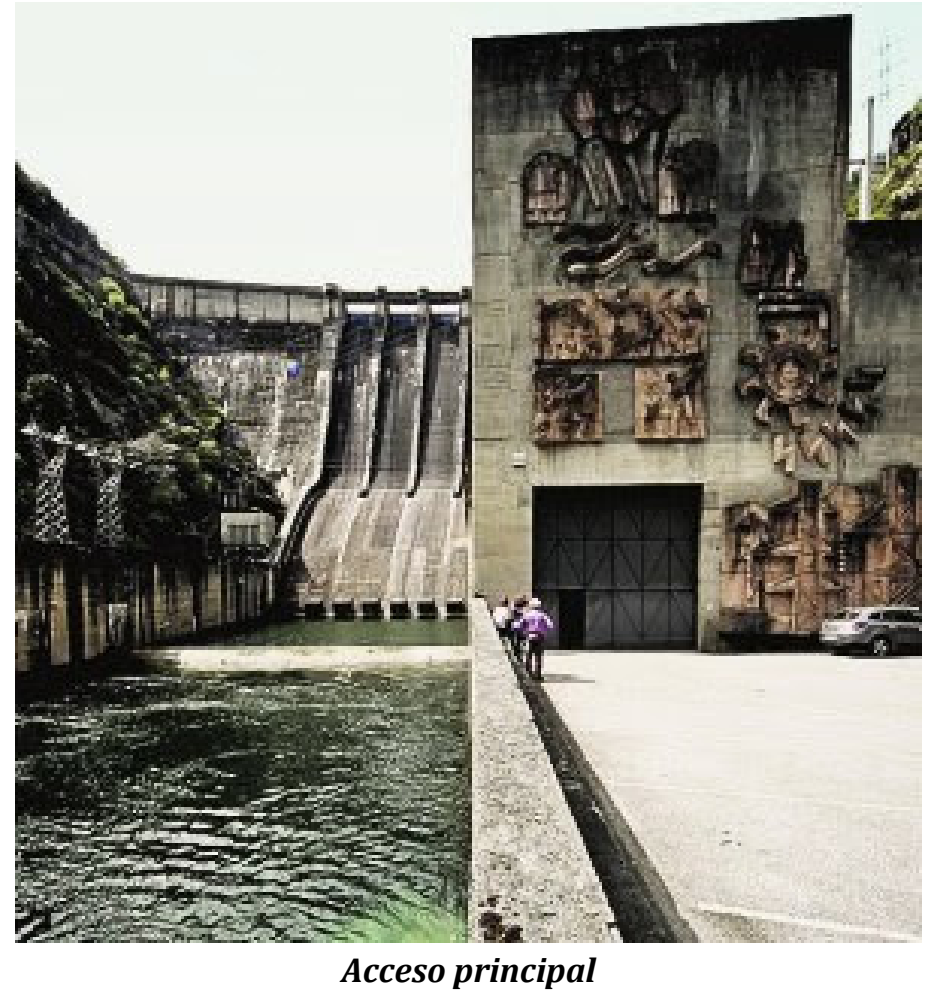

Proyectó así un conjunto escultórico que representa, de una manera esquemática, el proceso de producción de la energía eléctrica. Los relieves, que se encuentran empotrados en el muro, destacando cincuenta centímetros por término medio sobre el paramento, fueron realizados en hormigón, para cuya elaboración se empleó un árido menudo, de mármol rojo de Alicante. En lo que comporta a su instalación, fueron elevados y anclados en el muro y, una vez fijados, el propio artista procedió, con cincel y bujarda a concluir algunos detalles -como cabezas y manos-y dirigiendo la labor de algunos canteros que completaron el trabajo. 


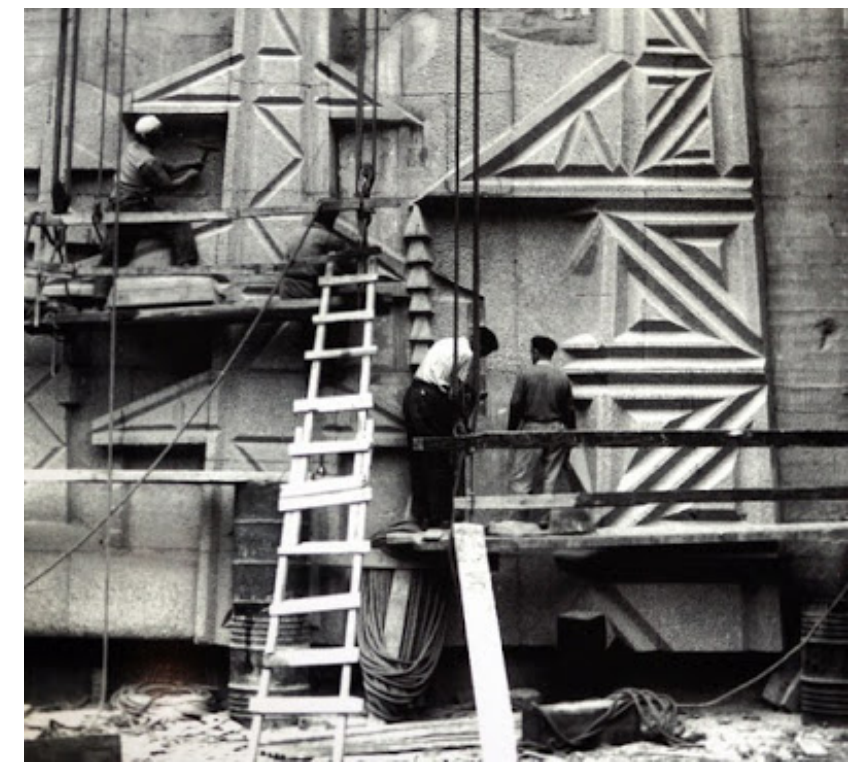

Trabajos en los frisos de hormigón de la entrada. 1954

Se recoge en estos relieves, cuyo color rojizo contrasta sutilmente con el gris del hormigón de la pared que queda como fondo, una esquemática reproducción del proceso de producción de energía en la Central. Ésta da comienzo con las nubes y la lluvia, las observaciones meteorológicas, la toma de

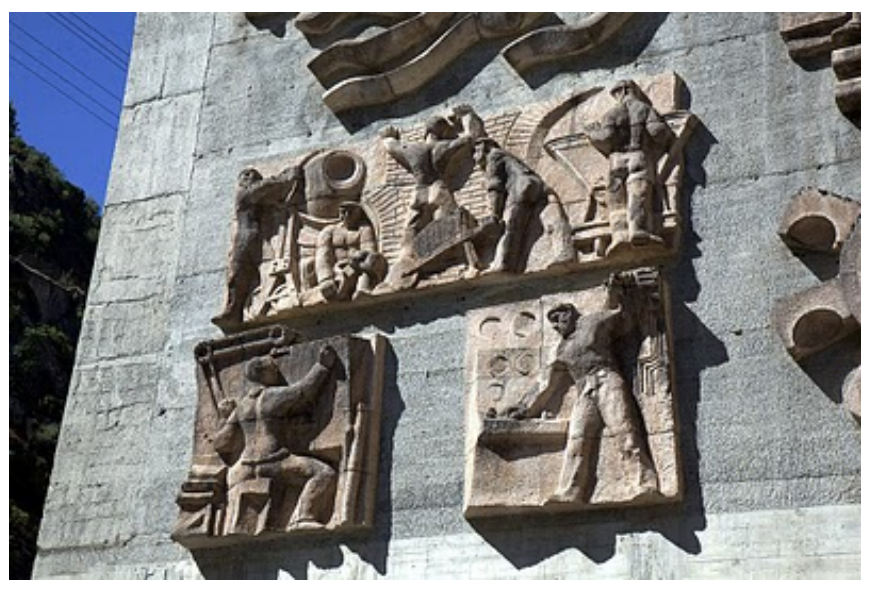
datos, las aguas en libertad, las embalsadas, las compuertas, la energía, las líneas de transporte, las obras... que conforman una serie de figuras y esquemas de elementos industriales cuya altura, aproximadamente, es de tres metros.

Otro elemento fundamental al que Vaquero se enfrenta es la decoración interior de la Central. Como acabados interiores, se dejan vistas las paredes de hormigón, combinadas con pequeñas zonas en estuco blanqueado y paramentos en mármol de la escalera, solados de hormigón en las plantas de instalaciones y mosaicos de piedra irregular en el cuadro de mandos. 


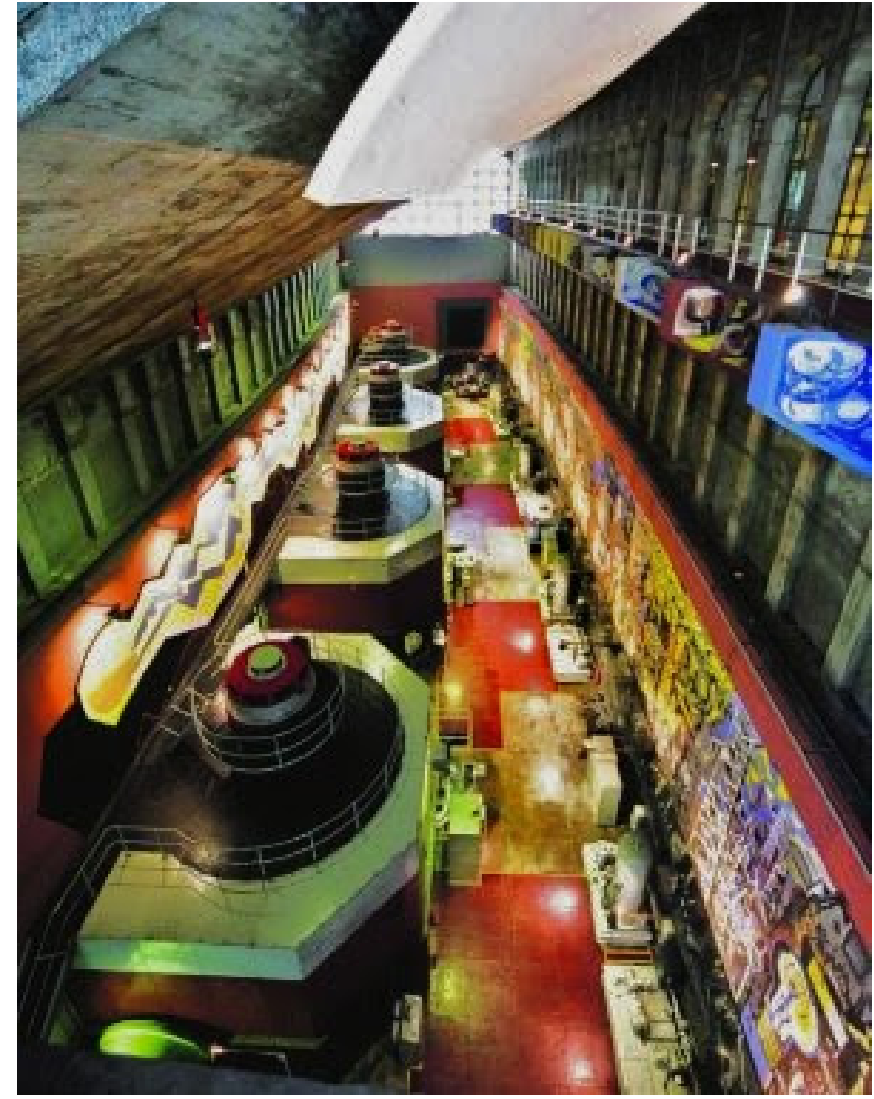

Sala de Turbinas

En la Central, junto con la Sala de Máquinas, que conforma el cuerpo principal, se sitúan la Sala o Cuadro de Mandos, oficinas y parte de los almacenes. La sala de turbinas constituye un cuerpo de sección transversal, en forma de trapecio, en el que se sitúa, aguas abajo, una fila de alternadores y, al lado opuesto, en cota superior, el Cuadro de Mandos, con un frente de balcón volado sobre grandes ménsulas de hormigón.

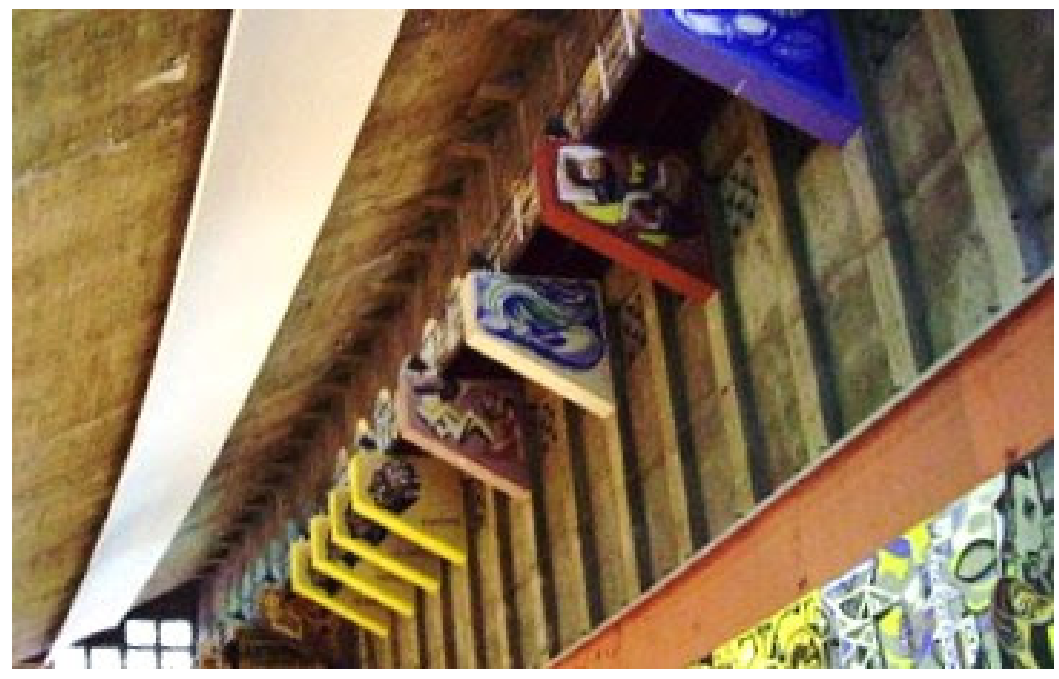

Cubierta y ménsulas de la sala de turbinas 


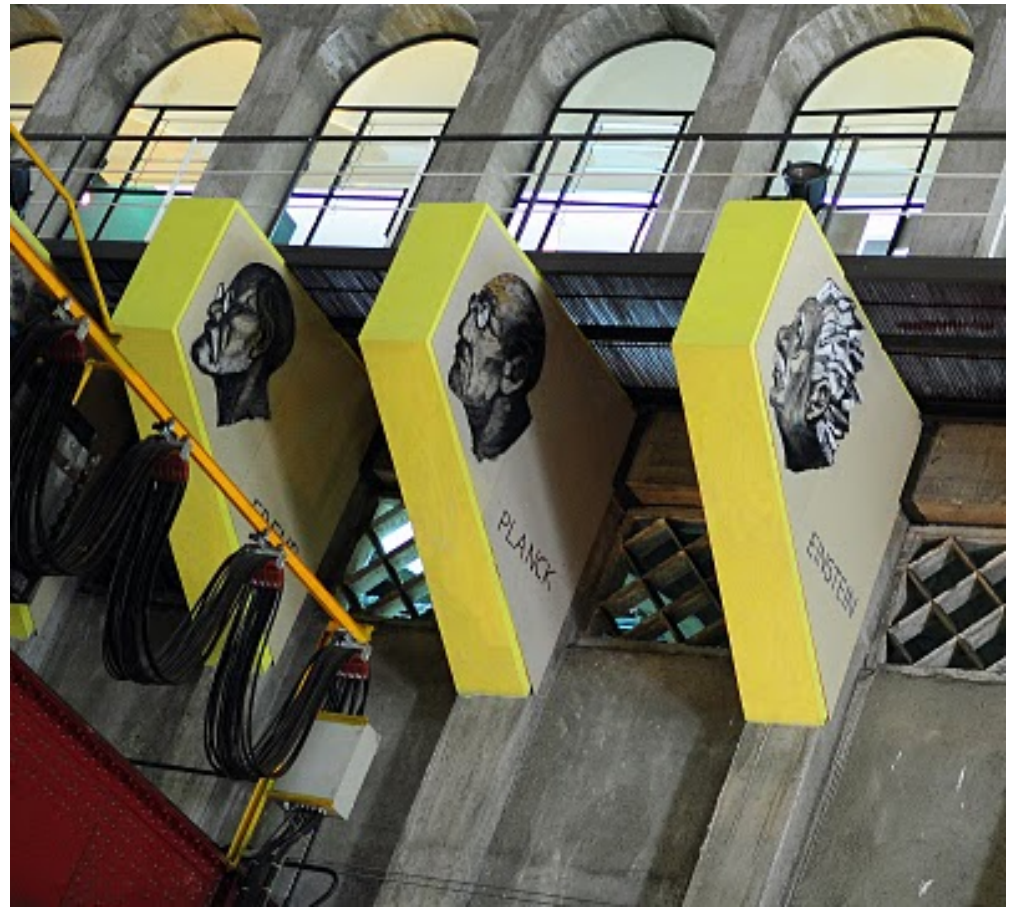

Sobre las ménsulas que sostienen el balcón de paso hacia el cuadro de mandos, también hay pinturas, cuatro de ellas realizadas en 2001 durante la reforma llevada a cabo por el propio artista. Entonces decidió eliminar los elementos relacionados con la producción energética, y pintar cuatro caras: las de Picasso, Planck, Freud y Einstein. No eran personajes que pudieran en pleno franquismo aparecer en escena y el artista los recuperó después con su rostro y algunos de sus pensamientos. Uno de ellos, el de Picasso, advierte: "La pintura no está hecha para decorar apartamentos".

Para este espacio fueron proyectadas dos pinturas murales, debidas al proyecto conjunto de Joaquín Vaquero Palacios y su hijo Joaquín Vaquero Turcios.

Junto a los dos murales ejecutados había sido previsto un tercero, que finalmente, por problemas de presupuesto, no llegó a realizarse. Se trataba de una espectacular chispa que debía reproducirse en la bóveda, dibujada con tubos de neón sobre fondo negro.

La chispa en la bóveda quedó como una banda cóncava de escayola, reflector de la luz lanzada desde la punta de las ménsulas por focos. En el muro aguas abajo, en la pared situada detrás de los alternadores, a poca distancia de las máquinas, se localiza la primera de estas pinturas murales. Se trata de una sencilla composición geométrica, de colores planos, que reproduce una forma ondulante y tensa la descarga eléctrica entre dos polos, situados éstos a los extremos de la sala. Acometida en el año 1955 por Vaquero Turcios, su longitud es de cincuenta y cinco metros. 
En la pared aguas arriba se ubicó un gran mural figurativo, que los Vaquero proyectaron entre el año 1953 e inicios de 1954 y que fue ejecutado por Vaquero Turcios. El proyecto fue elaborado en Roma, donde Vaquero Palacios alternaba sus obligaciones en la Academia Española de Bellas Artes con la pintura y el proyecto de Salime, mientras su hijo desarrollaba sus estudios en la Facultad de Arquitectura.

El diseño de la obra, de gran rotundidad, exigió la visión directa y el conocimiento por parte de los Vaquero del lugar y de la marcha de los trabajos de construcción del Salto, aspectos que se traducen firmemente en su composición.

El propio Vaquero Turcios lo relató del siguiente modo: «Llevaba aquí unas semanas viendo y viviendo la emocionantísima epopeya de la construcción de la presa; el espectáculo de la obra y el paisaje, los barrenos, las aguas, las rocas y, sobre todo, esos ejércitos de hombres que trabajaban en la obra, el poblado en el que vivían los trabajadores, los bueyes que arrastraban los castilletes, todo con medios primitivos. Era como la construcción de las pirámides, y me dije, tengo que contar eso. Y me puse a pintarlo».

Se trata de un monumental friso narrativo que exige una lectura continua, a fin de aprehender el sentido global de la obra y comprender la larga y laboriosa experiencia constructiva de la Central. De tal modo, son relatados en cadena, siguiendo un discurso cronológico, los diferentes momentos que implicó su ejecución, desde la génesis del proyecto hasta llegar a las aplicaciones de la electricidad producida por el Salto. Resulta oportuno señalar a este respecto la vinculación personal existente entre los Vaquero y la monumental empresa del Salto de Salime. No en vano, Narciso Hernández Vaquero, Presidente de la compañía Hidroeléctrica del Cantábrico-Saltos de Agua de Somiedo entre 1939 y 1958, fue padre y abuelo, respectivamente, de ambos artistas. Ayudante de Obras Públicas, Narciso H. Vaquero, había desempeñado una labor muy destacable en la idea fundacional del Salto.

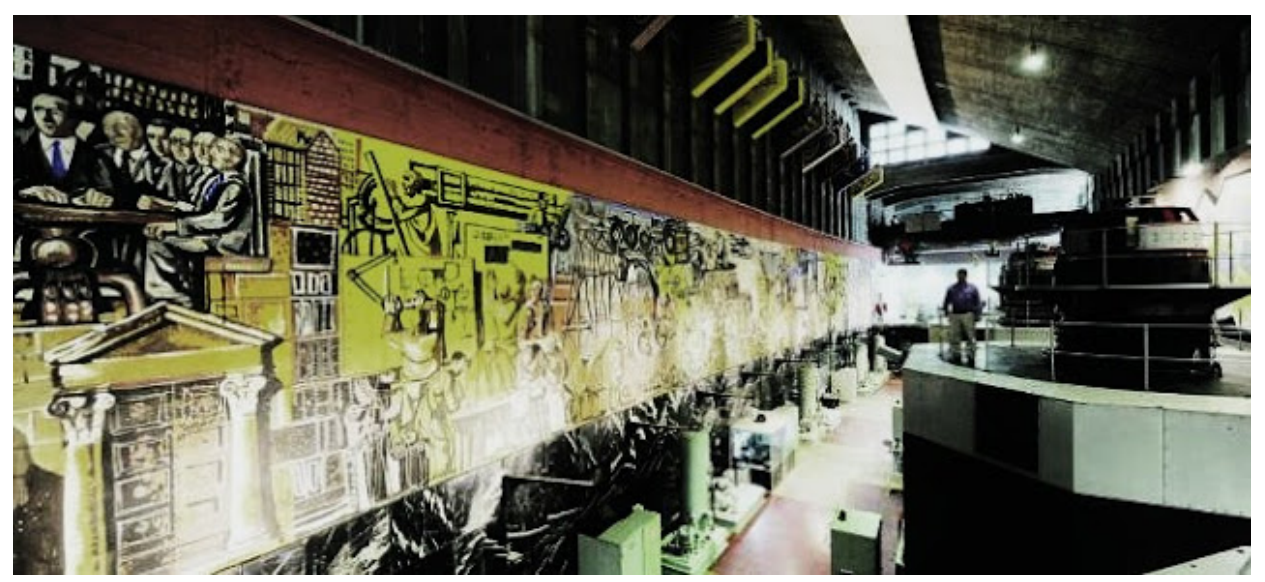

Interior de la sala de turbinas 

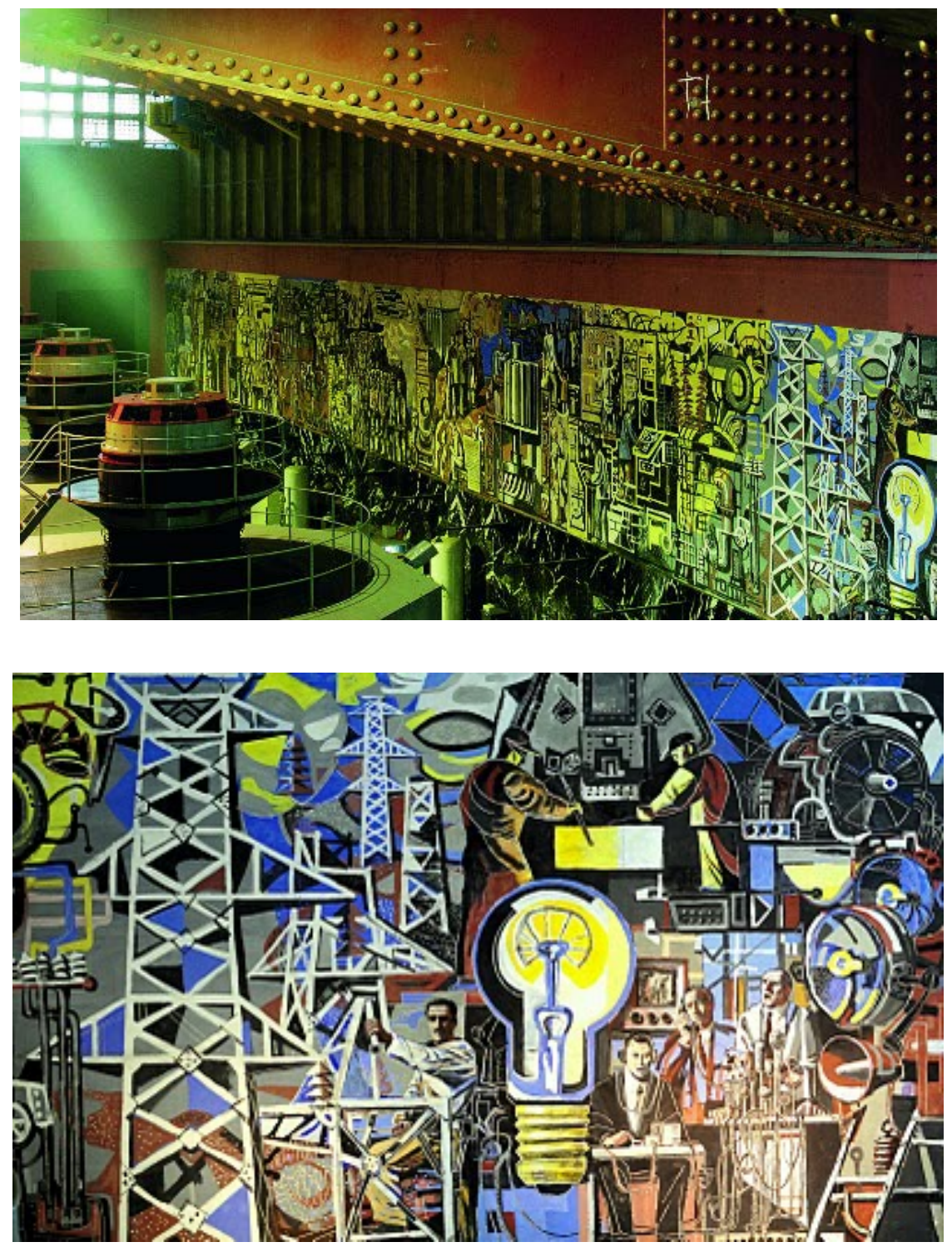

Detalle del mural de Vaquero Turcios

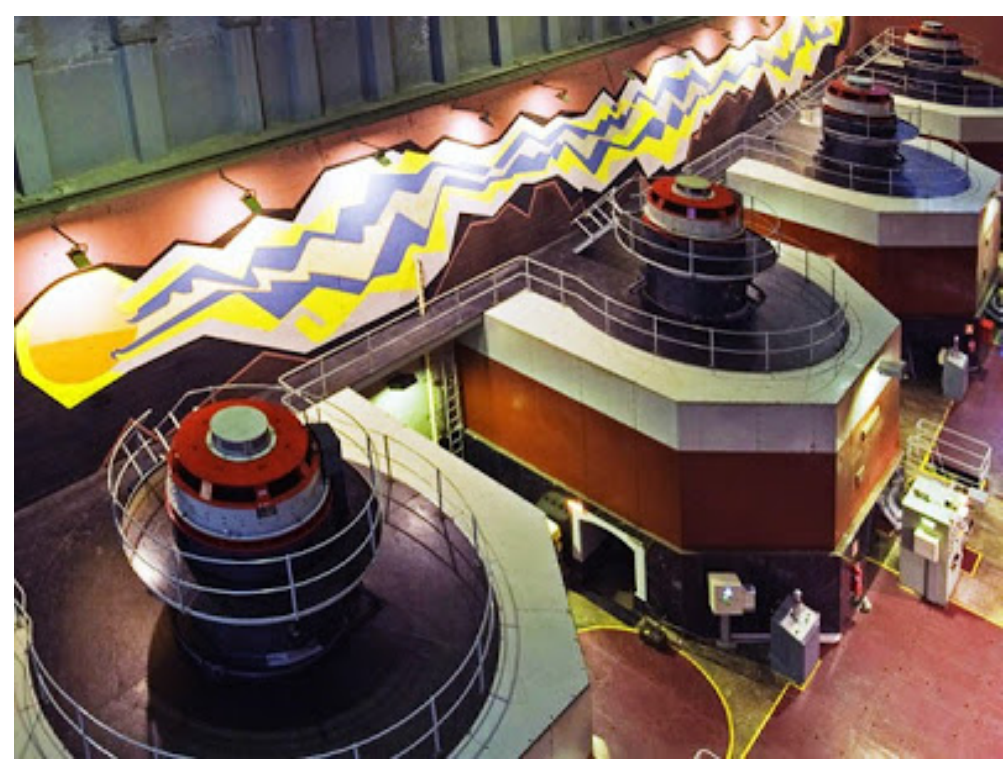

Mural "eléctrico" y turbinas 
Con relación a este friso monumental, la narración da comienzo con la invención del Salto, o lo que es lo mismo, la primera propuesta de ubicar en el entorno de Salime lo que habría de ser la futura presa. A continuación son representados los Consejeros, es decir, los miembros del Consejo de Administración de las dos empresas concesionarias, Hidroeléctrica del Cantábrico S.A. y Electra de Viesgo, S.A., discutiendo en torno a una mesa sobre la viabilidad del proyecto. Tras ellos, aparecen reproducidos los Ingenieros responsables de la elaboración de los distintos estudios técnicos para el diseño de la obra. Sigue, a continuación, el episodio que sintetiza los trabajos de construcción, donde aparece una concisa representación de las distintas fases de ejecución, arrancando de las tareas iniciales de apertura de caminos de acceso y levantamiento de edificios y alojamientos para albergar al contingente humano que se emplearía en la obra. Asimismo se alude a las distintas etapas del transporte de materiales, partiendo de la fuerza tractora de los animales de carga y camiones, hasta la construcción de un teleférico. Los Obreros son los grandes protagonistas del tramo central del mural. Aparecen representados portando sus instrumentos de trabajo, con la alusión a los poblados previstos para su alojamiento al fondo. Se incorpora en la parte superior de este tramo una escena de la Pietá, en la que una mujer apesadumbrada -madre o esposa- sostiene entre sus brazos al obrero muerto en accidente de trabajo. Sigue a esta escena la plasmación de los Directores de obra y de los Artistas. El padre, Joaquín Vaquero Palacios, es representado como escultor, mientras el hijo, Vaquero Turcios, mira hacia el espectador portando pinceles en su mano derecha. Más adelante, junto a la alusión al embalsamiento y el hundimiento de los pueblos, edificios y fincas preexistentes -incluyendo el éxodo de sus pobladores- son esquemáticamente reproducidos los más importantes elementos que integran el Salto, esto es: la presa, el aliviadero, la central, la subestación de intemperie, los grupos de turbina-alternador, los mandos y el transformador. La representación culmina con el encendido de una bombilla y, en consecuencia, con la producción final de la energía eléctrica, el calor, la fuerza, la luz y sus líneas de transporte. Por encima de este mural, en la parte superior también están decoradas las ménsulas, con motivos alegóricos, que sostienen el balcón de circulación de la planta del cuadro de mandos. La superficie total de las pinturas rebasa de este modo los mil metros cuadrados. Se trata de una obra rotunda, muy equilibrada desde el punto de vista expresivo y que podríamos entender como clasicista, en atención a la armónica integración que en ella se logra entre una representación realista y su valoración simbólica, aunque reinterpretada desde la modernidad. También en lo que comporta al tratamiento digno, severo, austero y solemne de las monumentales figuras, de porte épico, perfectamente adaptadas al escenario en las que se insertan. 
Pero además Vaquero Palacios extendió su actuación al diseño de interiores, comprendiendo detalles tales como los aparatos de iluminación, las escaleras, el pavimento y otros elementos del mobiliario, gracias a los cuales consiguió indudable una dignificación del espacio. Vaquero Palacios, obsesionado por la luz natural, no quería tirar de bombillas ni en una central eléctrica. Así que, en plenos cincuenta, ya se sirvió de paredes de pavés para iluminar el inmueble, que, sin embargo, también expone lámparas de diseño creadas por el arquitecto.

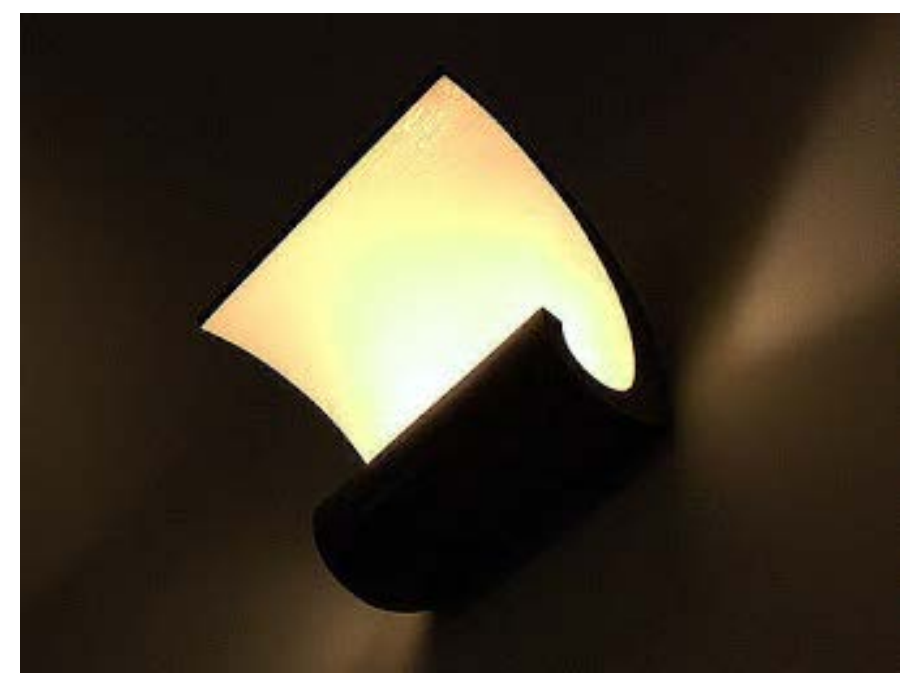

Diseño de una luminaria interior
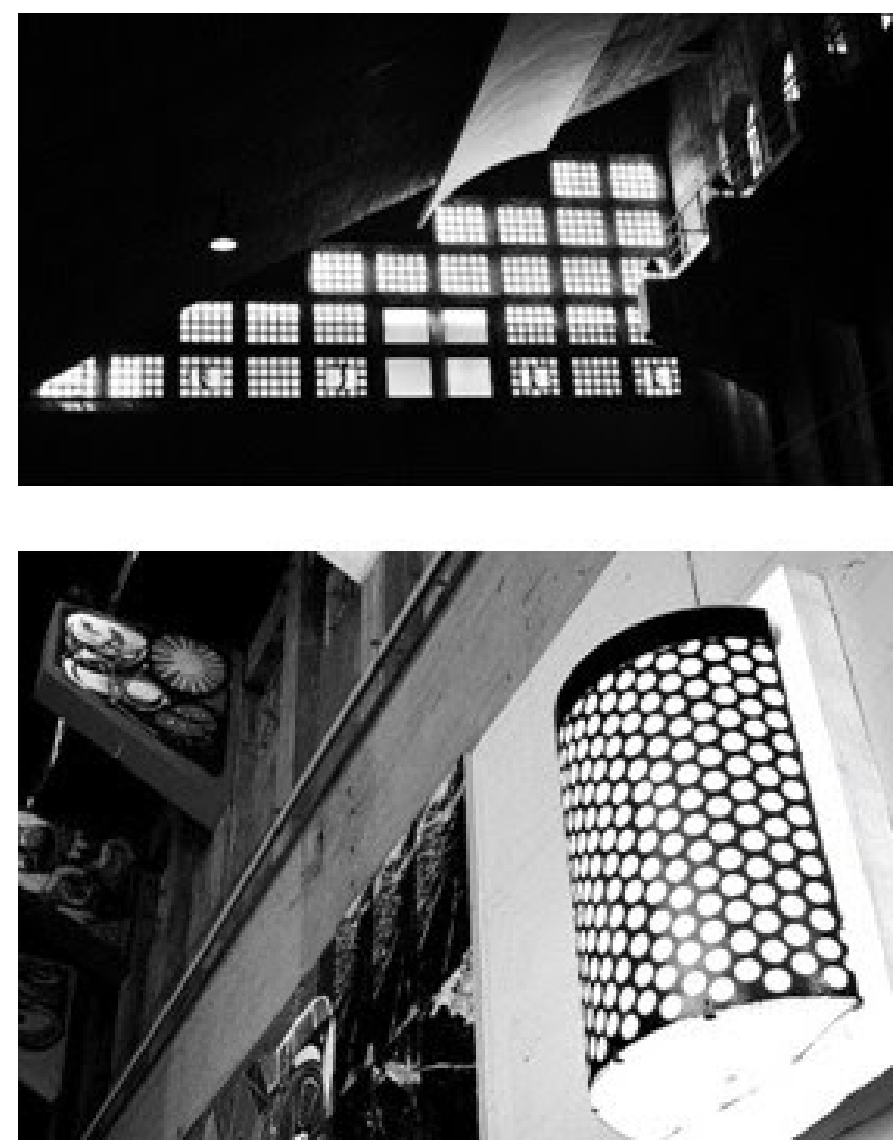

Lucernarios de la sala de turbinas y gran luminaria de recepción 
Así, el ingreso a la central se efectúa a nivel de planta baja, donde se emplaza el núcleo de comunicación, el acceso al cuadro de mandos, las salas de disyuntores y el resto de dependencias del personal. Para este espacio Vaquero Palacios diseña una escalera de hormigón con un ligero entramado metálico ondulante, que reaprovecha materiales sobrantes de instalaciones y maquinaria. Por ejemplo, los pasamanos están elaborados con el cobre que se emplea para las líneas de alta tensión. Se trata de una soberbia pieza, de gran potencial plástico, que enfatiza el movimiento ascensional.

En la planta del cuadro de mandos, con el objeto de disponer de un lugar tranquilo, Vaquero Palacios incluye un interesante espacio: el refugio. Se trata de una salita circular con tornavoz suspendido y confortables asientos, con la que el artista pretendió configurar un marco apacible en el que propiciar la conversación o el descanso de los técnicos, protegidos de la ruidosa agresividad de la planta. Acoge un mobiliario envolvente y se encuentra techada por un elemento suspendido circular de escayola. El sofá, de hecho, emula una turbina, pudiéndose distinguir el rodete, la distribución del grupo, el alternador y el rotor.

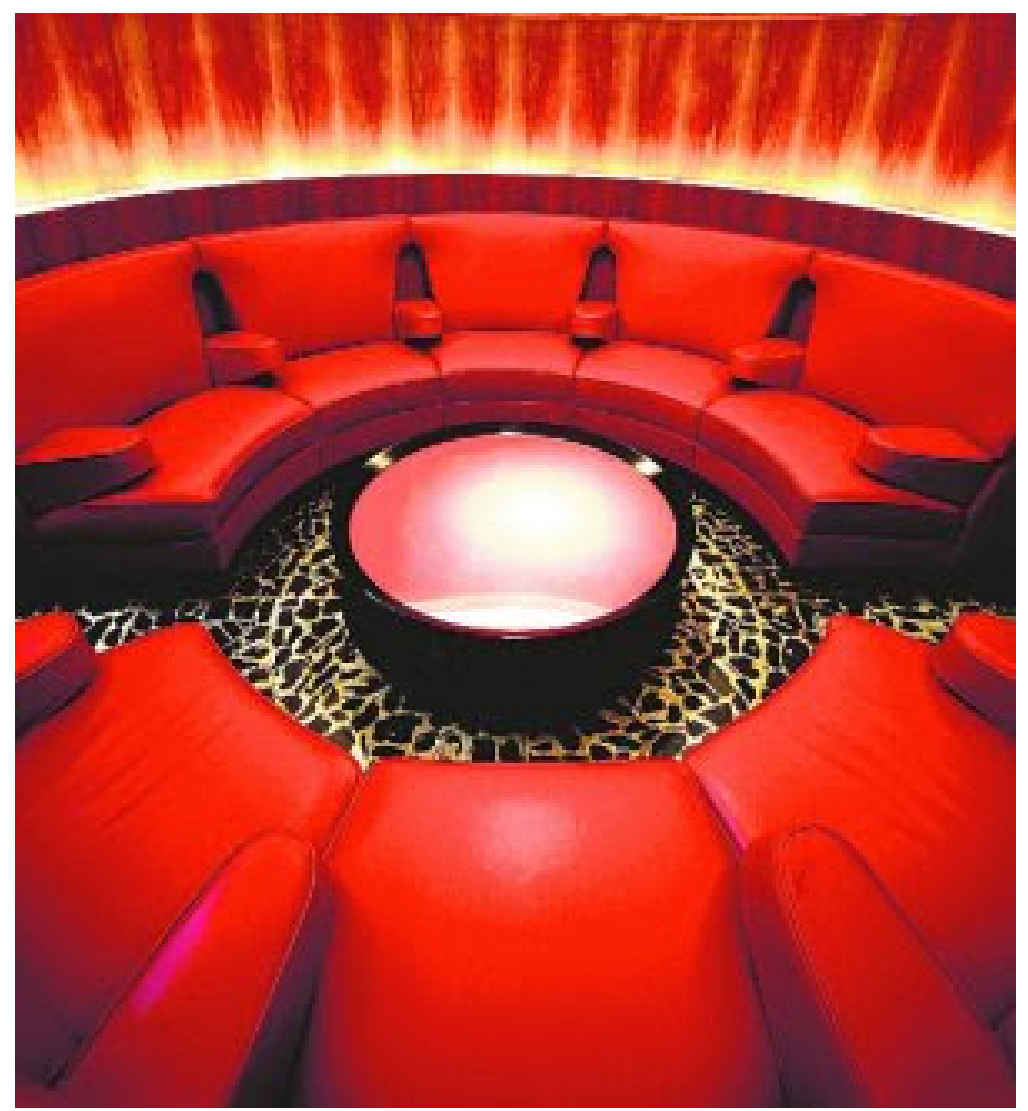

El sofá-turbina 


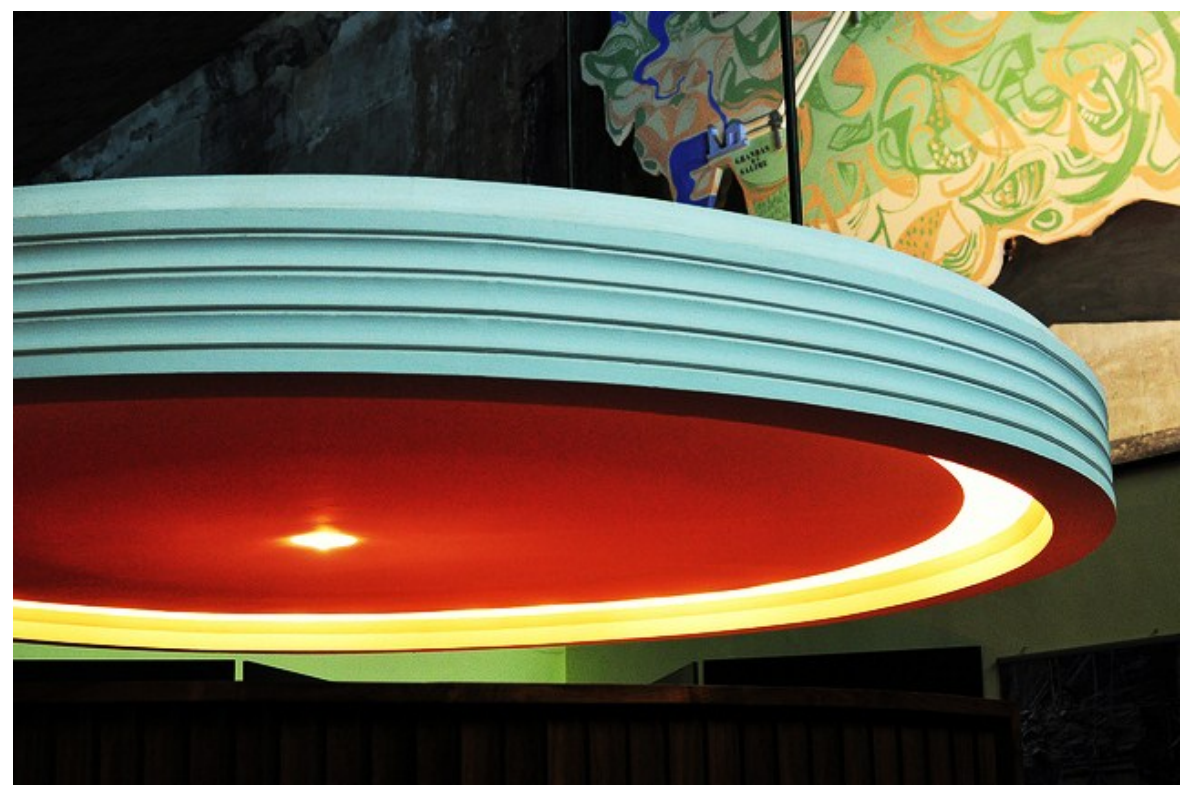

Gran luminaria sobre el sofá-turbina

A estos elementos hemos de unir dos representaciones pictóricas. Se trata de un pequeño mural que reproduce el perfil de la presa, así como una reproducción del mapa de Asturias que recoge la ubicación de las primeras centrales hidroeléctricas. El pavimento de toda esta planta, en respuesta al diseño de Vaquero Palacios, incorpora trocitos de pizarra sobre un lecho de cemento blanco.

A estas intervenciones se añaden, para finalizar, el proyecto ideado por Joaquín Vaquero Palacios para la construcción de un chalet-palacio destinado a residencia de la Dirección, ubicado en el núcleo de Grandas de Salime. Estaba previsto como alojamiento de ingenieros, otros técnicos y ocasionalmente directivos, respondiendo su diseño al espíritu y modo de construir de la zona. A fin de lograr una integración en el entorno rural y en la tradición constructiva local.

El arquitecto diseño un edificio a base de muros de carga, como sistema estructural, que utiliza los materiales vernáculos, esto es, mampostería de la zona y pizarra en la cubierta.

De tal modo, mientras que en la obra industrial de la Central utiliza lenguajes adscritos al Movimiento Moderno, en el caso de la vivienda, la solución responde a ideas más tradicionales, a las motivaciones originadas en lo autóctono.

Tras su intervención en la Central de Grandas de Salime, a partir de la década de los cincuenta y contando con la colaboración de su hijo Joaquín Vaquero Turcios, Vaquero Palacios inicia una serie de trabajos de integración para la empresa Hidroeléctrica del Cantábrico, que dan comienzo con la central 
hidroeléctrica de Miranda. Ubicada en el concejo de Belmonte, aprovechando las aguas del río Somiedo, sus obras constructivas se prolongaron entre 1956 y 1961/62. La labor que Vaquero emprende en este caso se concentra en la ordenación de los volúmenes exteriores, así como en el acondicionamiento del interior. Excavada en roca viva, la altura y capacidad de esta central subterránea permitieron que en su interior se alojase un edificio de siete pisos, de setenta metros de frente y doce metros de fondo. En el interior de la central, el artista consiguió, sirviéndose de una estudiada utilización de la luz artificial y del color, atenuar la sensación, de otro modo opresiva, de soterramiento, y dignificar el espacio de trabajo. Los paramentos quedan revestidos con una viva gama cromática, donde prevalecen los tonos cálidos, que se extiende a elementos como las barandillas, las canalizaciones y la maquinaria, combatiendo el aspecto frío y laberíntico de los subterráneos. Utiliza, además, otro ingenioso recurso, como es la situación de unas falsas ventanas iluminadas artificialmente. Los alternadores son pintados y revestidos para adquirir, finalmente, un aspecto escultórico.

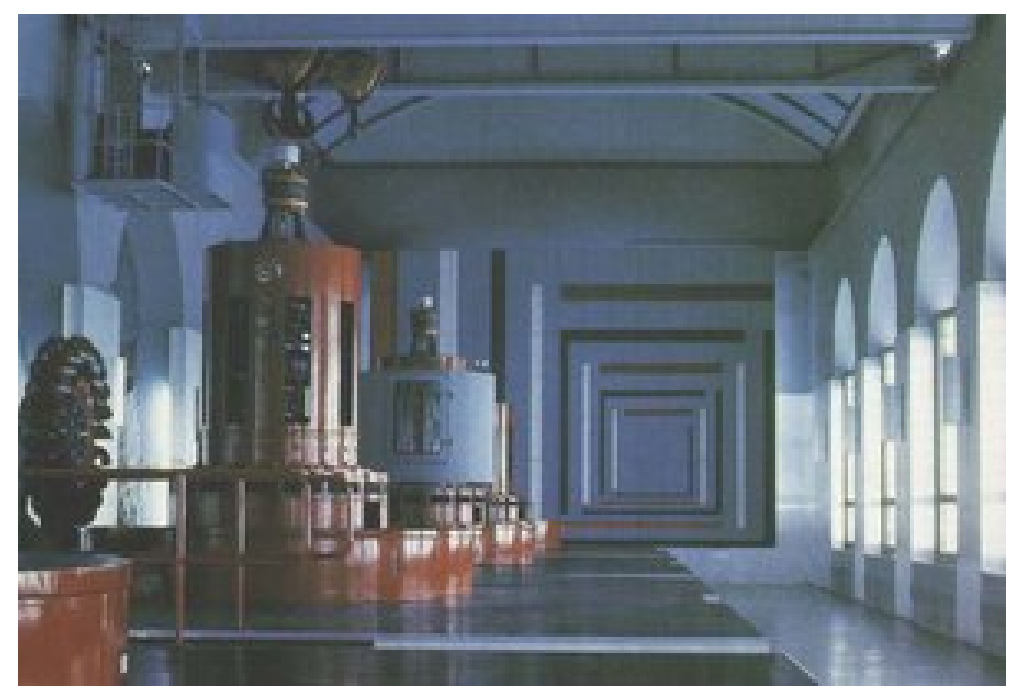

A esta labor en el interior, se añade la emprendida por Vaquero en el exterior, diseñando las chimeneas de ventilación, de trece metros de altura, que guardan el acceso al interior de las instalaciones y enfatizan la entrada del túnel. En sus frentes, fueron talladas dos gigantescas figuras en bajorrelieve, con cantos rodados coloreados. Representan a Prometeo y Atlas, imágenes alegóricas del calor y la luz, en el primer caso, y de la fuerza y el movimiento en el segundo; esto, es, cuatro de las aplicaciones fundamentales de la energía eléctrica. 


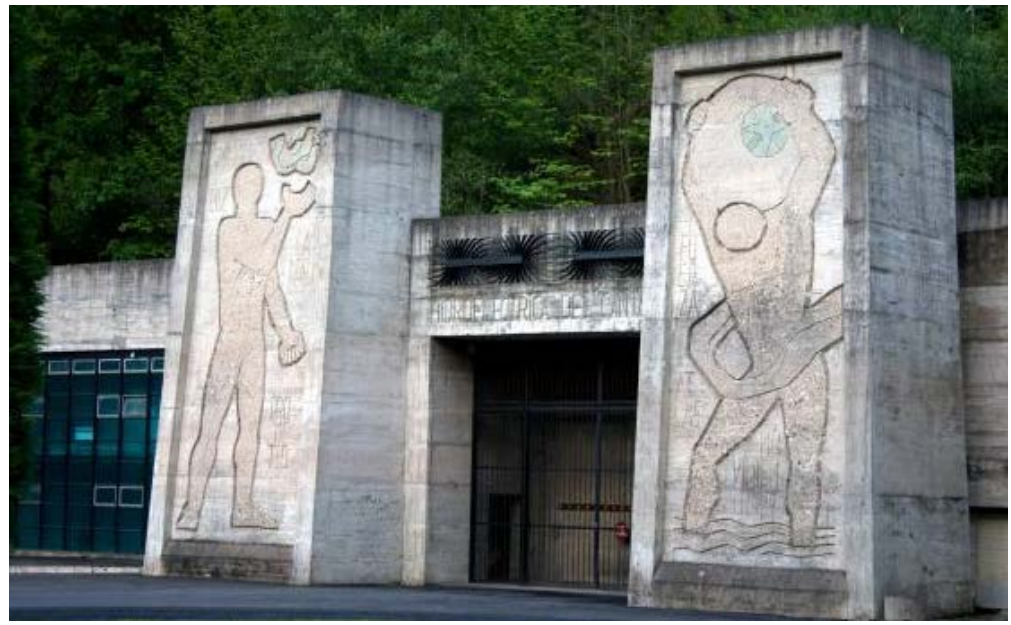

A modo de monumentales pilonos, proporcionan una singular solemnidad a la entrada a la central.

Más completa y compleja fue la actuación que Vaquero Palacios llevó a término para el Salto y la Central de Proaza (1964-1968), donde pudo actuar desde el arranque del proyecto.

Diseñó tanto el edificio de la central, como las pinturas murales del interior, los relieves escultóricos, las carcasas para los aparatos eléctricos, el mobiliario interior y las vidrieras. La estructura portante de hormigón armado queda revestida en su totalidad mediante piezas laminares prefabricadas in situ. En el interior de la sala de máquinas, dispuesta a doble altura, los alternadores se configuran como verdaderas esculturas. En el costado opuesto a los alternadores, se dispone una serie de seis pinturas murales que, esquemáticamente, reproducen elementos relacionados con la electricidad. Hay en esta central una escalera de caracol y una sala de líneas de salida que tiene también la firma de Vaquero Palacios.

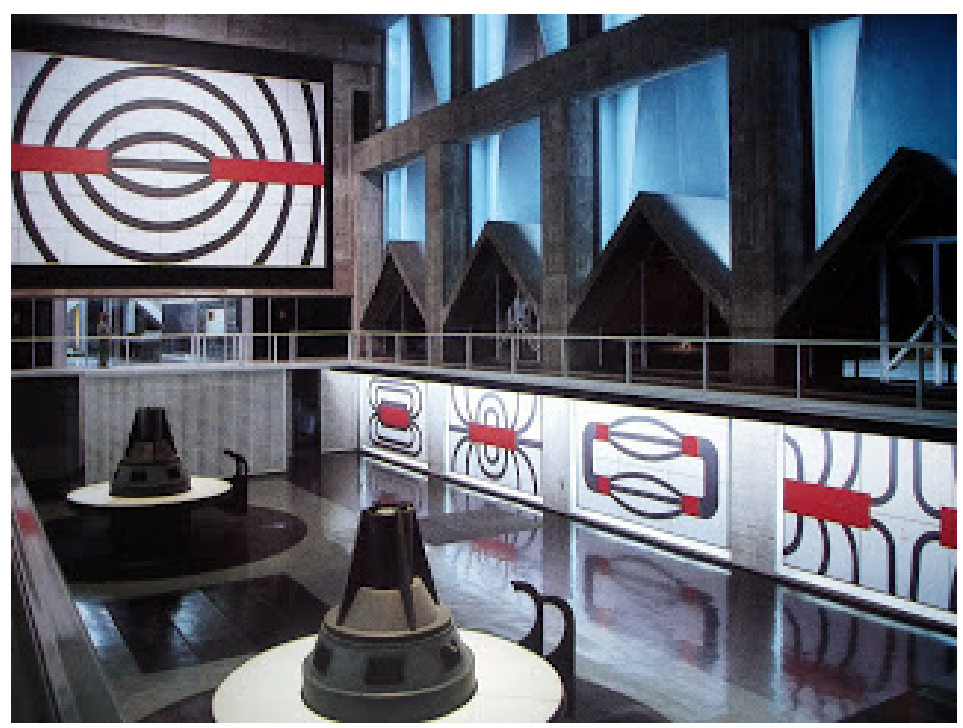


Junto a éstos, presidiendo la sala, se sitúa otro mural de amplias dimensiones que representa un campo magnético. Uno de sus aspectos más llamativos, en el exterior, es, sin dudas, el carácter que Vaquero imprimió a la fachada de la central. La solución de cerramiento adoptada, el tono brutalista de las aristadas facetas de hormigón, dispuestas en una superficie quebrada y desarrollable, con enfáticos juegos claroscuristas, genera una poderosa sensación de movimiento.

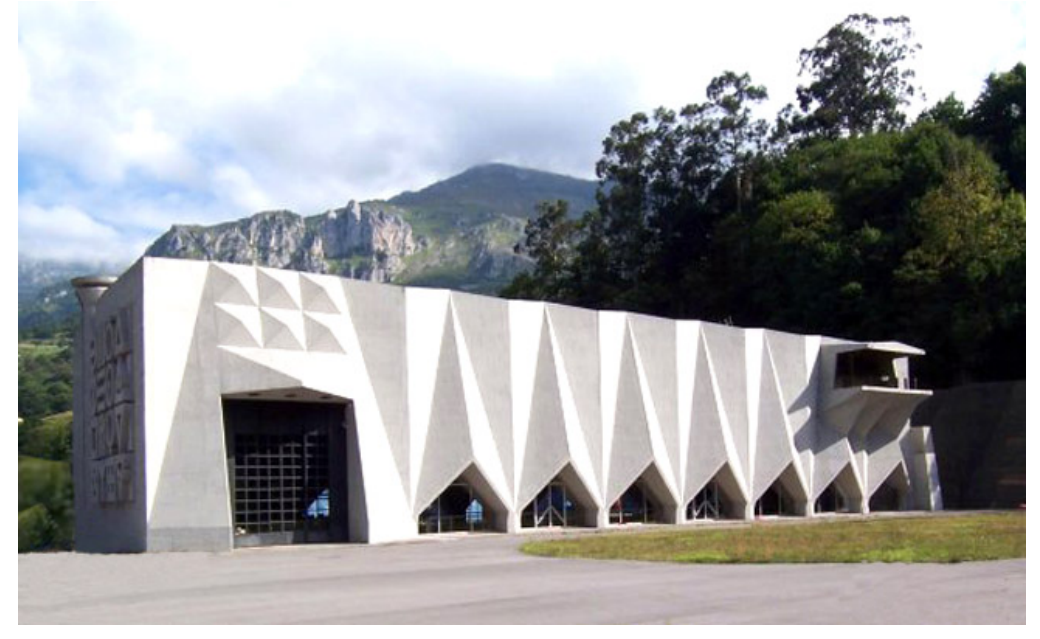

A modo de monumental carcasa de recio aspecto, la fachada así concebida, no sólo mimetiza las montañas del entorno -los pliegues de las calizas-, sino que también puede relacionarse con un sector muy significativo de la pintura paisajística de Vaquero, rotunda, densa y de duros trazos.

En uno de los muros testeros, se dispone un gran panel que recoge dieciséis bajorrelieves de hormigón, a través de los cuales se introducen esquemáticas representaciones diferentes signos de la antigüedad que hacen referencia a la relación entre el hombre y la naturaleza. Representan símbolos usados desde la

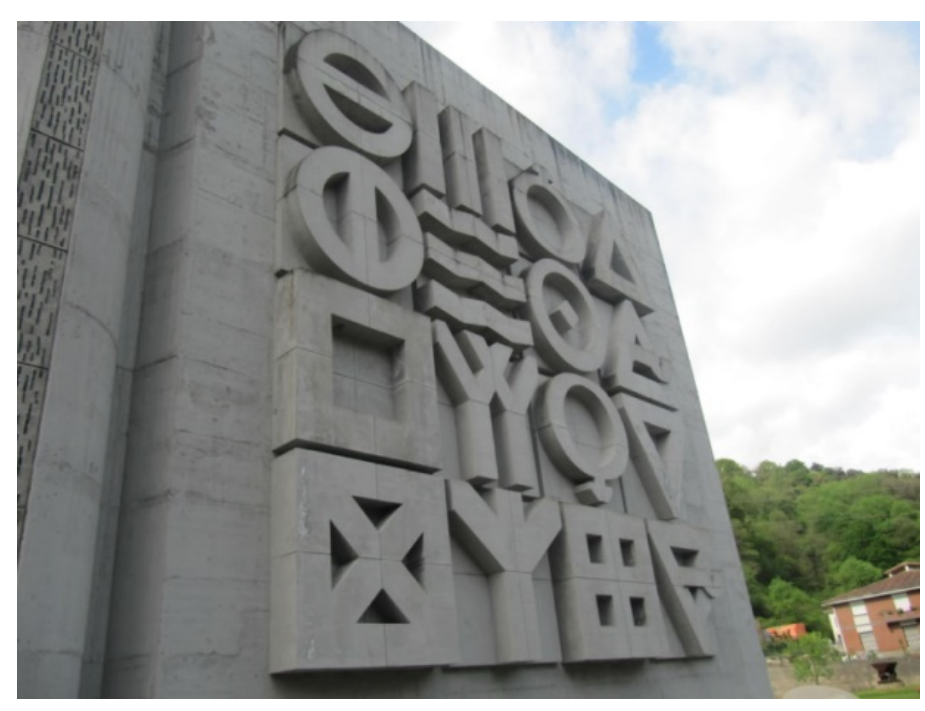
antigüedad en tallas, inscripciones y manuscritos. El agua, el hombre, la naturaleza, el intelecto, la paz, el alba, el sol, el ocaso, la noche, el fuego, el aire se exponen a la intemperie. 
Al igual que en otras de sus intervenciones, Vaquero reutiliza materiales empleados en la construcción, como restos de vías férreas y tubos, para la realización de relieves y esculturas. Con todo, la central de Proaza, es, en su conjunto, una verdadera obra de arte total.

Por otra parte, la intervención de Vaquero en la Central de bombeo de Tanes (1980), también subterránea como la de Proaza, se concentró en los paramentos interiores, coincidiendo con el afloramiento de la roca, en aras de conseguir una dignificación del espacio de trabajo. Los paneles rocosos fueron realzados por el artista revistiendo, con chapas de acero inoxidable, los pilares que soportan la carrera del puente grúa. La claustrofóbica sensación de estar bajo tierra es minimizada a través de la actuación que se lleva a cabo en la bóveda, reforzada con hormigón y sin nervaduras.

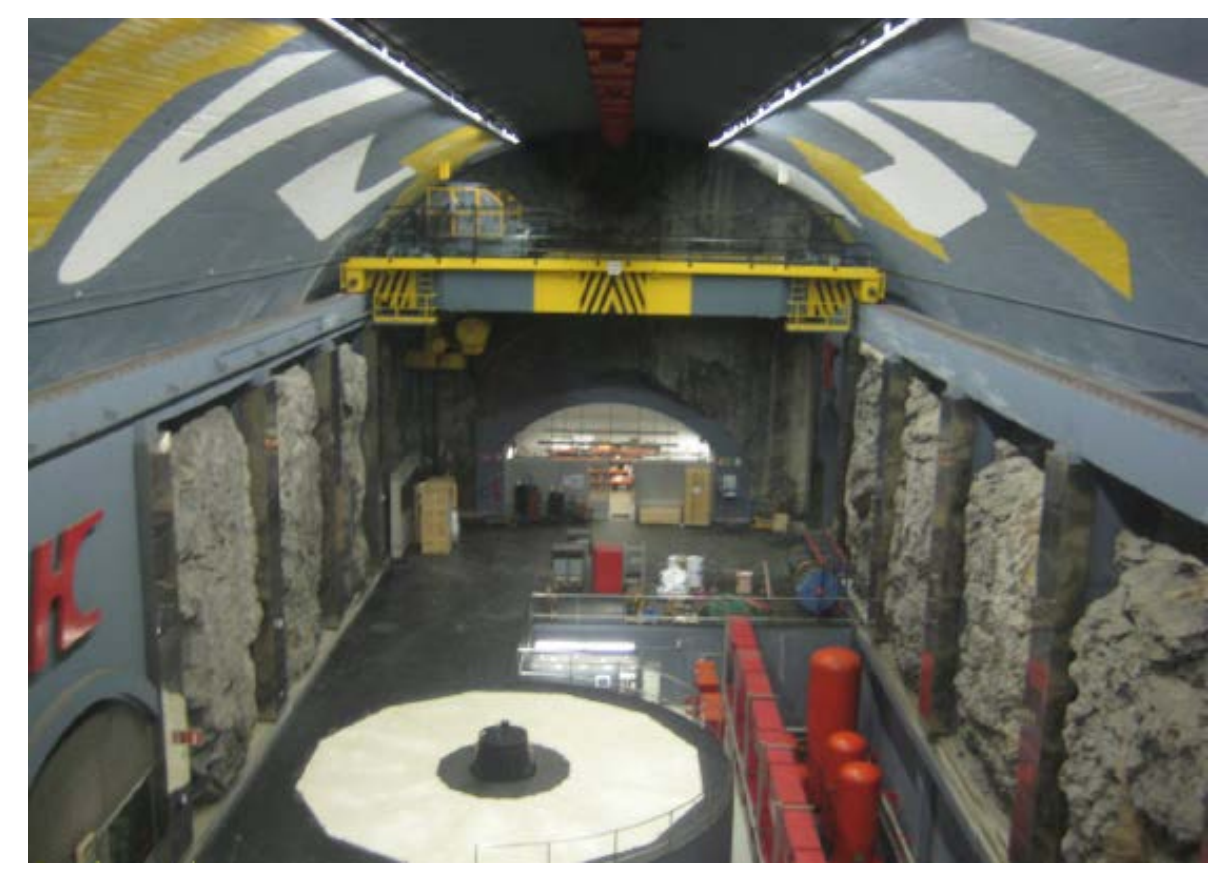

Sobre ella se incorporó una representación pictórica, a partir de formas abstractas que, sobre un fondo gris azulado, combina tonos amarillos y blancos. Las formas, que aparentan flotar en el vacío, a modo de geométricas nubes recortadas en el cielo, hacen que la central parezca estar situada en una inmensa claraboya. La iluminación de la sala se realizó por medio de una doble línea de tubos, dispuestos paralelos a su eje, manteniendo en oscuridad el tercio central.

\subsection{EMBALSE DE SANTILLANA}

Otro ejemplo de aprovechamiento en el que se tuvo especial cuidado con el aspecto estético, fue el Embalse de Santillana. 
Cuando el marqués decidió construirlo, puso un especial empeño para que la presa que iba a anegar el entorno del Castillo de Manzanares no desentonase con la fortaleza.

Con tal fin volvió a contratar al arquitecto Vicente Lampérez (1861-1923), quien propuso una recreación historicista, que no sólo recordase la arquitectura del castillo, sino que también le sirviese de antesala.

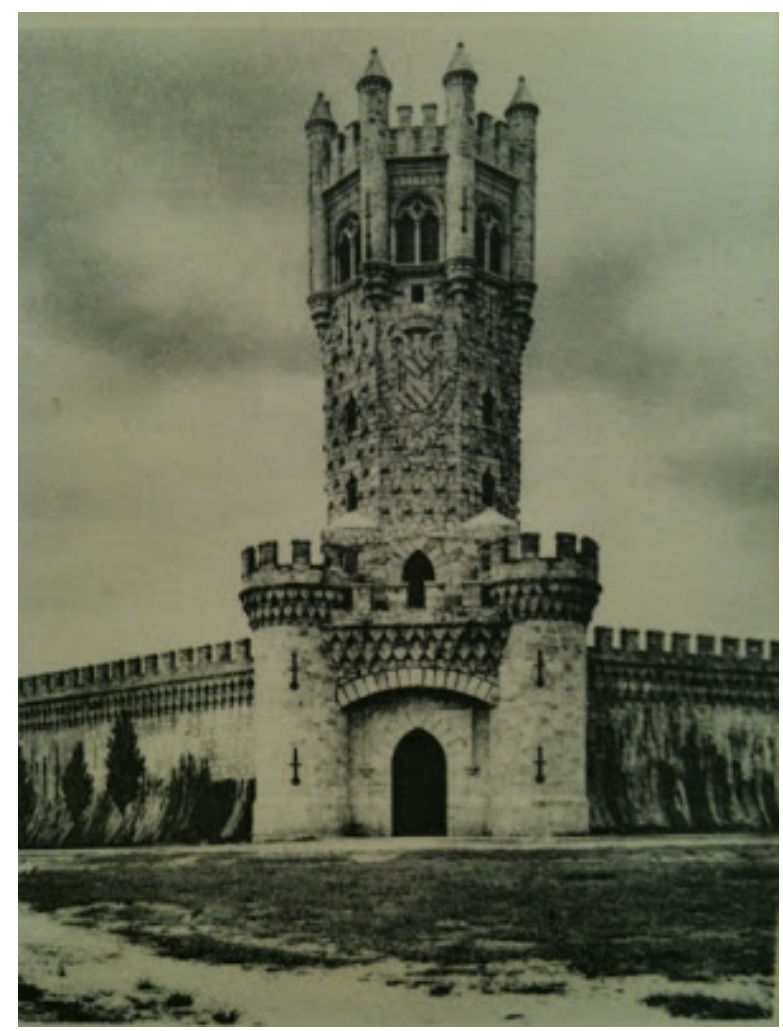

La presa se hizo en mampostería de granito. La forman dos arcos que cierran el valle el río y que alcanzan una altura máxima de 28 metros.

En el punto de confluencia de ambas secciones se eleva la torre de toma, que fue diseñada en estilo gótico isabelino, utilizando modelos de Juan Guas (14301496), el arquitecto que hizo las galerías exteriores del Castillo de Manzanares el Real y, entre otras obras, el Palacio del Infantado, de Guadalajara. 


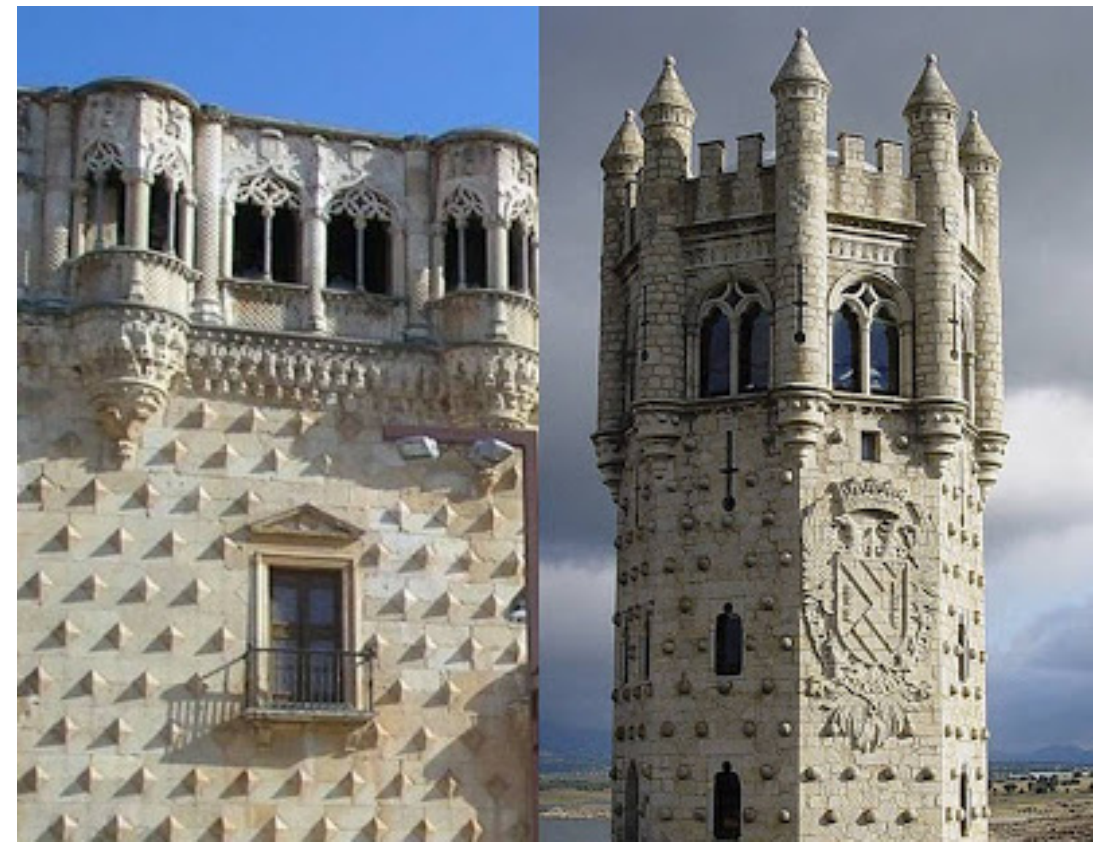

A la izquierda, Palacio del Infantado. A la derecha, la torre de la presa.

La torre de toma alcanza los 35 metros de alto y es de forma octogonal, la misma planta que tiene la torre del homenaje del Castillo de Manzanares.

Al igual que ésta, se encuentra decorada con bolas de piedra en todos sus lados y, en el principal, tiene labrado un grandioso escudo del Real de Manzanares, una de las posesiones históricas de los duques del Infantado.

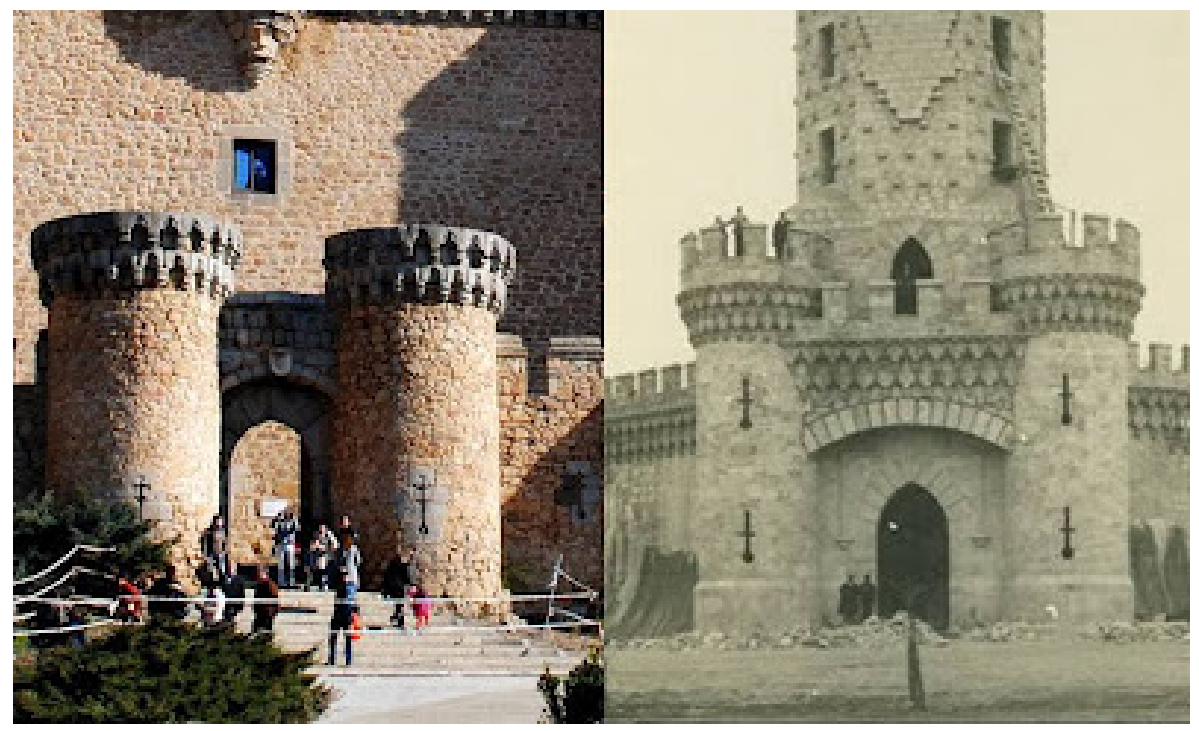

A la izquierda, el castillo. A la derecha, la presa.

En la base de la torre se extiende una especie de barbacana, hoy inundada, en la que se abre una puerta de ingreso, que emula a la portada principal del Castillo de Manzanares el Real. 
Con respecto al muro de la propia presa, éste se asemeja a una muralla, con sus almenas, matacanes y torres defensivas adosadas. Incluso hay una puerta de acceso, en la margen izquierda del embalse, que también sigue la línea de la existente en la fortaleza más famosa de la Comunidad de Madrid.

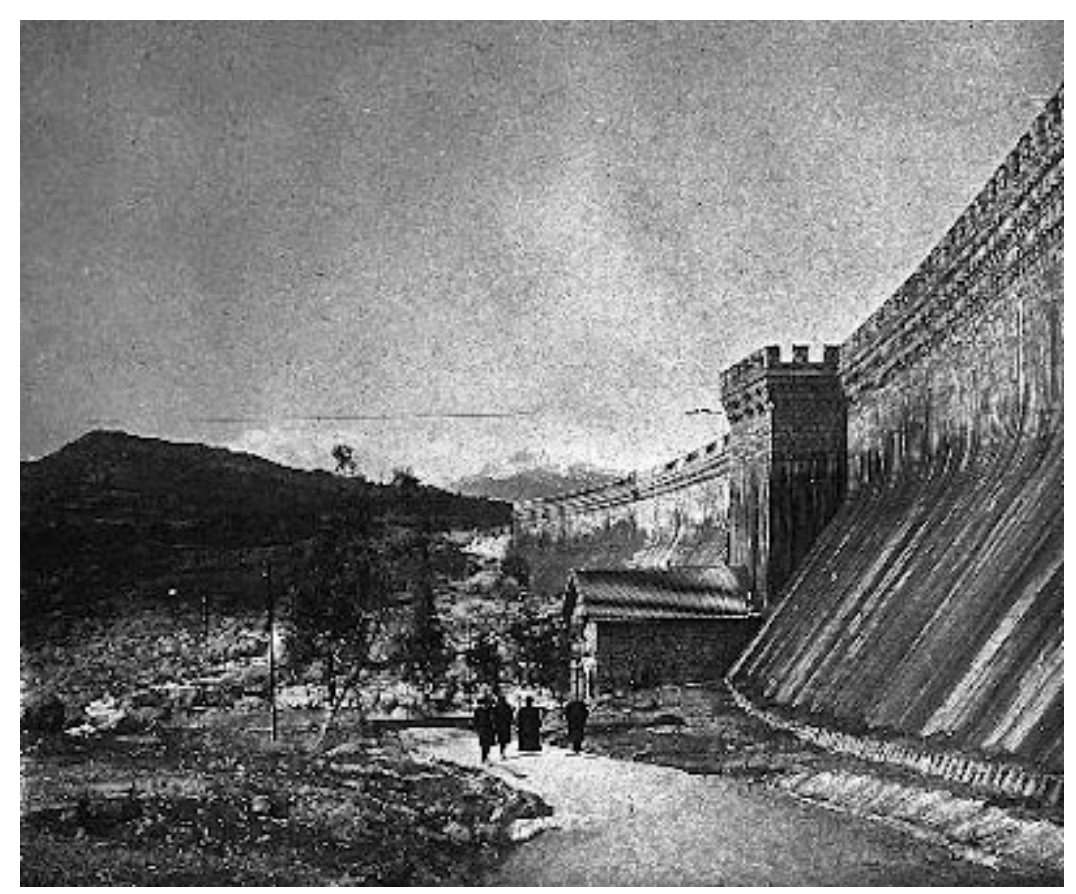

Archivo del Conde de Polentinos

La torre fue acondicionada como museo cuando, en 1971, se erigió la nueva presa, al tiempo que se habilitó una pasarela sobre las aguas para facilitar su visita. En la actualidad se encuentra cerrada y ni siquiera es posible acercarse a sus inmediaciones, salvo en contadas excepciones.

\subsection{CENTRAL HIDROELÉCTRICA DE KEMPTEN}

Como ejemplo de actuación reciente en el campo de las instalaciones hidroeléctricas desde el punto de vista estético, se detalla a continuación el caso de la central de Kempten en Alemania.

De sorprendente y bello diseño arquitectónico, ha sido realizado por la empresa Becker Architekten. La arquitectura siempre ha estado presente en los proyectos hidroeléctricos, especialmente a los largo del siglo pasado cuando se puso de manifiesto el fenómeno del "gigantismo" tanto en las obras hidráulicas y civiles, así como en los equipos de generación (turbinas y generadores), tal y como se ha descrito con anterioridad. 
En ese periodo, la arquitectura encontró su espacio de trabajo más al interior de la casa de máquinas; decorando con bellos murales o con refinados y costosos mármoles las plantas hidroeléctricas. Sin embargo, éste es el primer diseño en este estilo, sacando su impacto arquitectónico a los exteriores de forma tan llamativa y a nivel global. De hecho, ha sido galardonada con diferentes premios de arquitectura.

El arquitecto que la diseño se inspiró en las líneas de corriente, que corresponden a un enfoque teórico en la hidráulica o las que son observables en flujo laminar (régimen en el que nunca operan las hidroeléctricas ni los cursos naturales de agua) en los modelos a escala reducida.

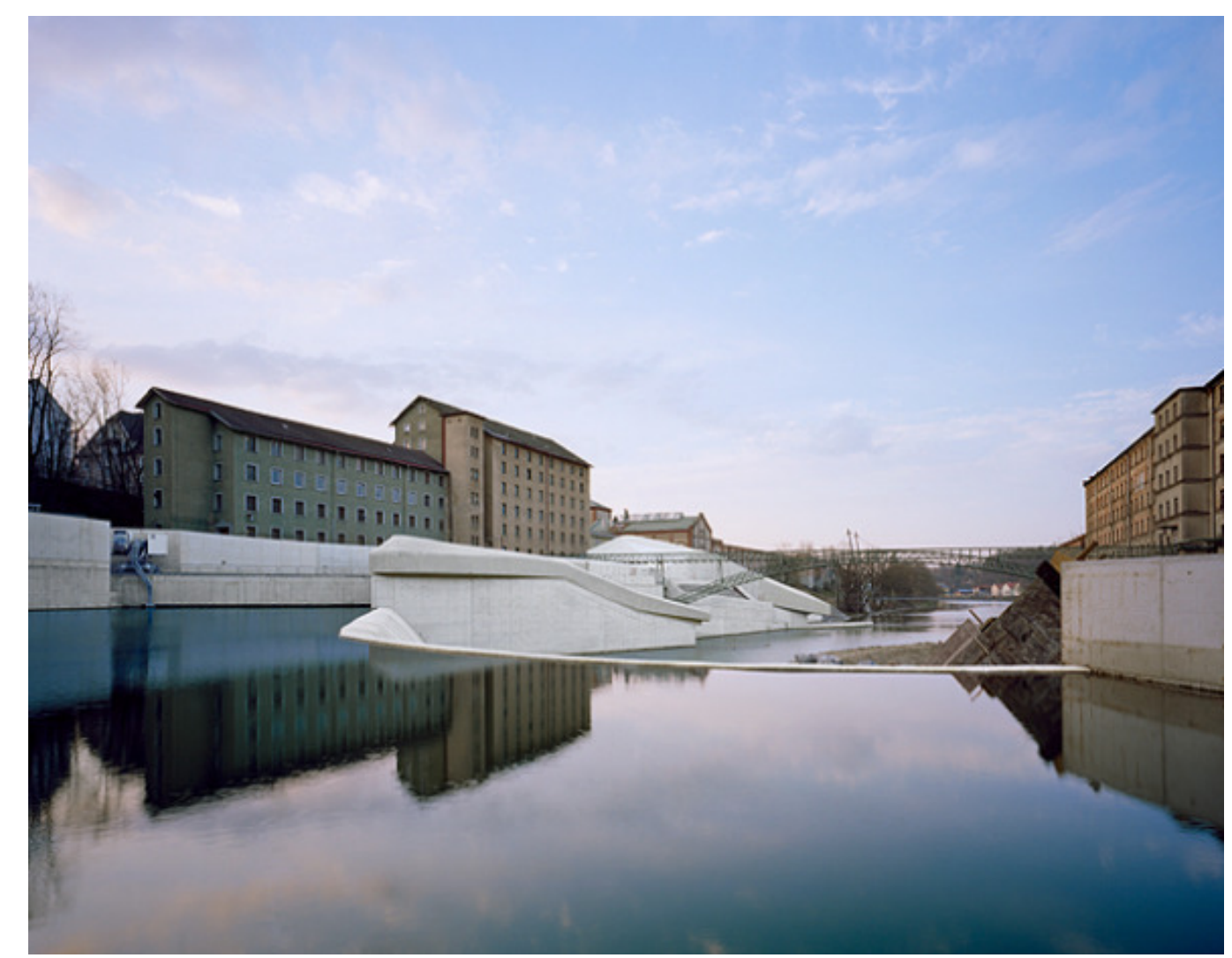

Se puede observar una buena integración entre el paisaje del río y los edificios históricos 


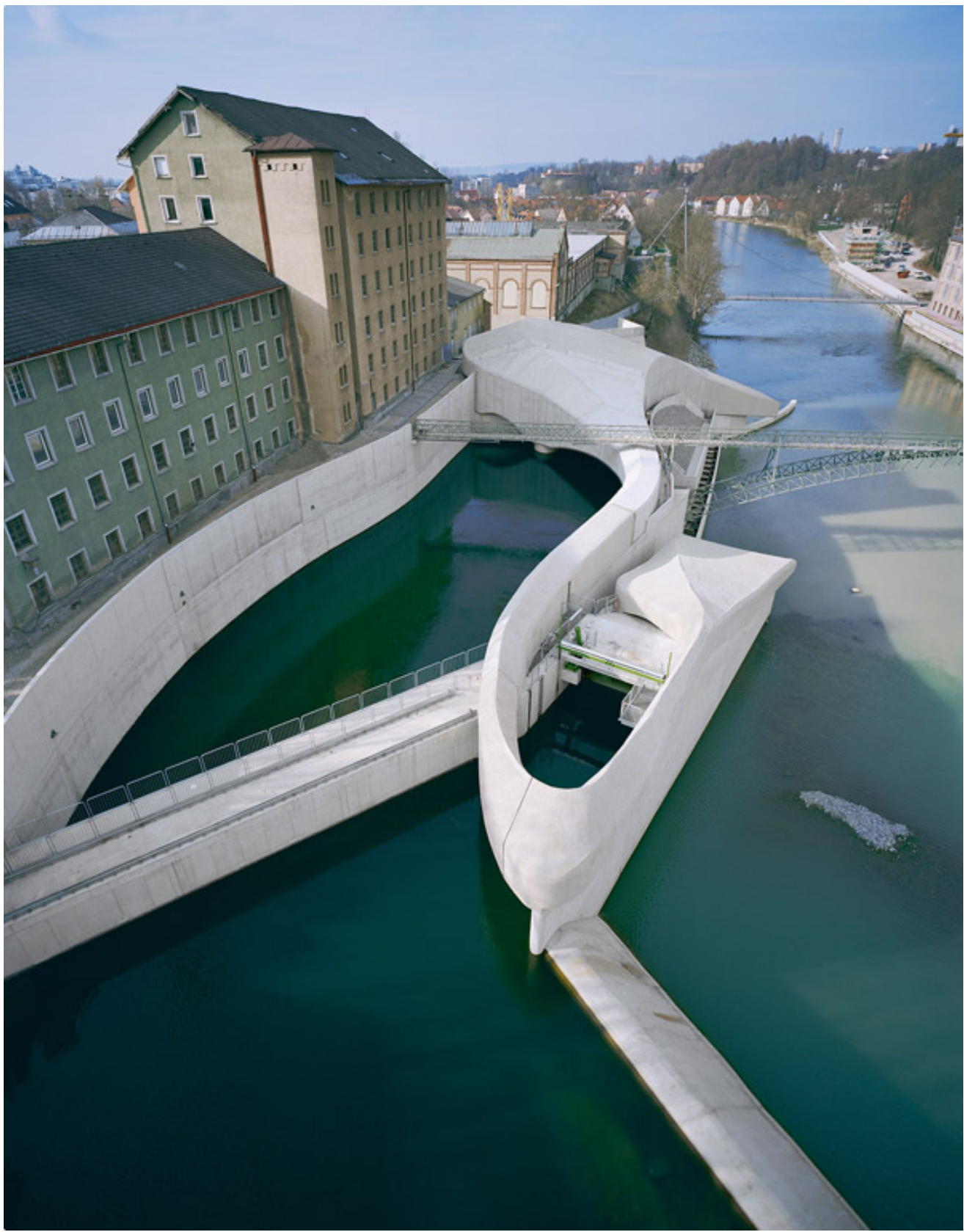

A diferencia de la mayoría de las centrales hidroeléctricas que tienen un diseño eminentemente funcional. Este nuevo aprovechamiento hidroeléctrico, es muy distinto a los que conocemos ya que se puso énfasis en lograr que fuera muy estético y moderno.

Entrando ya en la descripción de esta central hidroeléctrica, se encuentra en la margen izquierda del río Iller, (Alemania) es una nueva estación hidroeléctrica o que fue diseñada y construida para remplazar la antigua planta hidroeléctrica que operaba desde la década de los cincuenta. Hasta ahora este nuevo proyecto llega aproximadamente a 3000 hogares con 10,5 millones de kilovatios-hora de energía al año. Fue construida entre noviembre de 2007 y junio de 2010. 
Consultores especializados de ingeniería, trabajaron conjuntamente con el estudio de arquitectos para terminar la planificación del proyecto, hasta que el organismo autorizante aprobó el diseño final, que demandaba la adaptación de una manera sutil a una antigua estación hidroeléctrica que solo servía a una antigua ex hilandería que operaba en las márgenes del rio Iller.

El punto de partida de las consideraciones de diseño fue la representación simbólica de la dinámica del agua, que cambia de un estado de calma en la entrada de agua a la agitación y el cabeceo del agua cerca de las turbinas, antes de que posteriormente regrese a un estado de calma después de la generación de electricidad.

El objetivo de esta nueva planta hidroeléctrica es mejorar el paisaje fluvial a través de un diseño muy creativo además de producir energía hidroeléctrica.

La central hidroeléctrica tiene 150 metros de largo y fluye por el rio de forma muy agradable y compatible con el paisaje natural. Además posee un puente peatonal y para la circulación de bicicletas por sobre la central de energía.

Esta planta fue construida con diferentes materiales como hormigón, madera y acero, entre otros elementos de construcción, para poder darle forma a este novedoso diseño tanto por fuera como por dentro.

Este diseño no alteró en absoluto la operatividad o eficiencia en la producción de energía, sino que se adaptó mejor al medio urbano.

Esta central puede servir de ejemplo para poder tener plantas de energía que sean estéticas y no desentonen del resto de la ciudad. Cada vez es más importante, no sólo pensar en el servicio básico que deben dar, sino de que otra manera puede no solo integrase sino, incluso, colaborar en mejorar el paisaje.

A partir de unas vistas arquitectónicas, en planta y en corte, se puede observar en la casa de máquinas la disposición de dos turbinas tipo Kaplan.

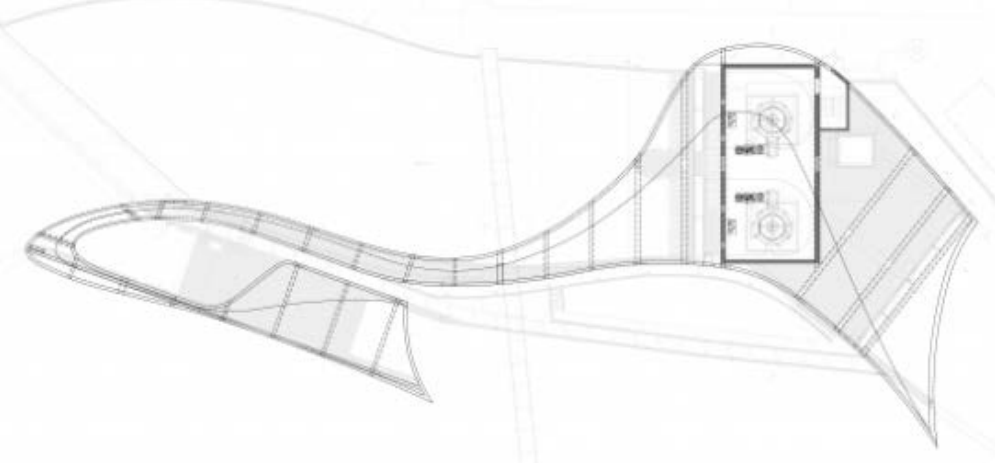

Planta hidroeléctrica Kempten - vista en planta 

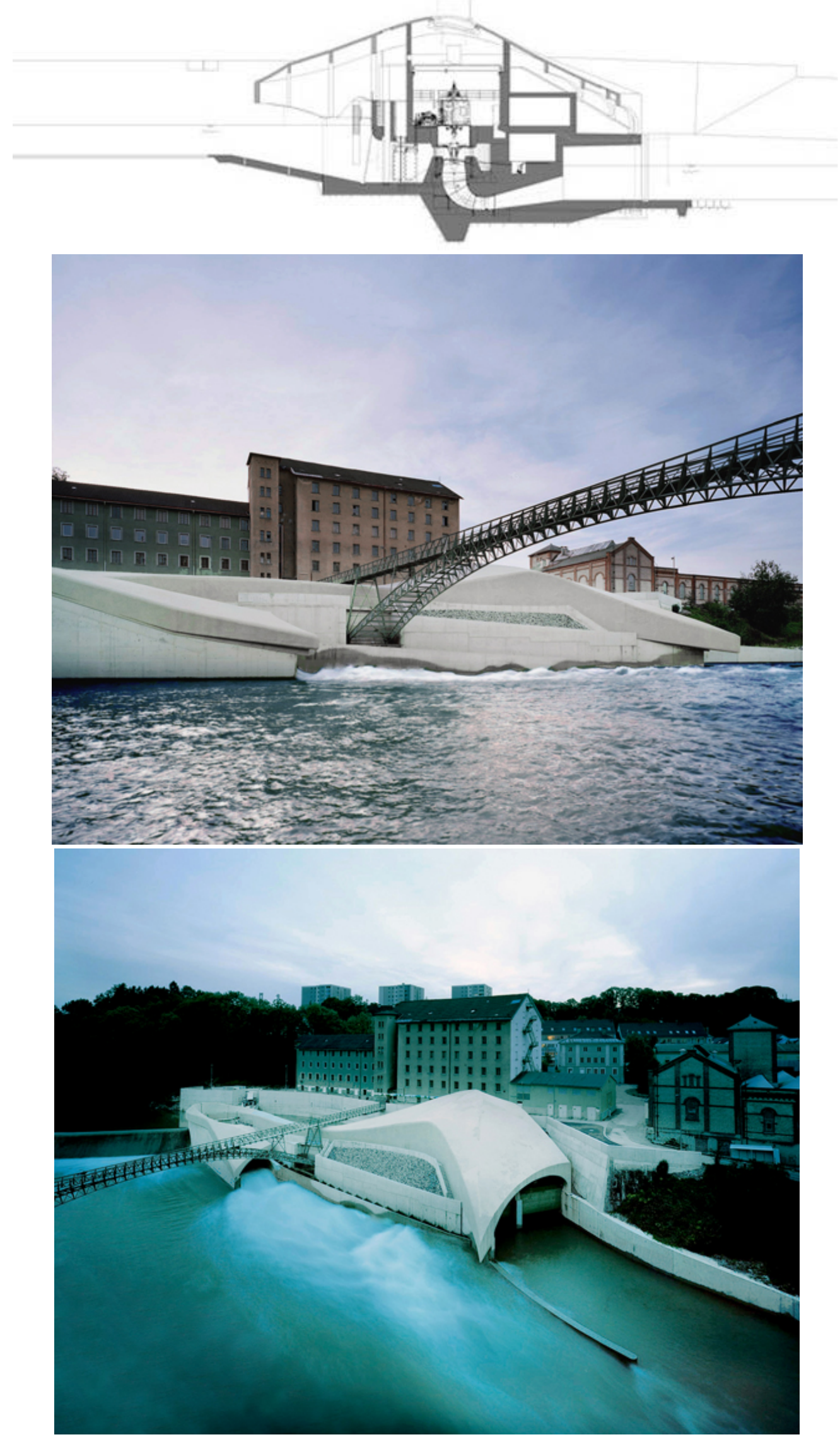

El diseño de la cubierta y la operación del canal lateral dramatizan el movimiento en la hidroeléctrica 


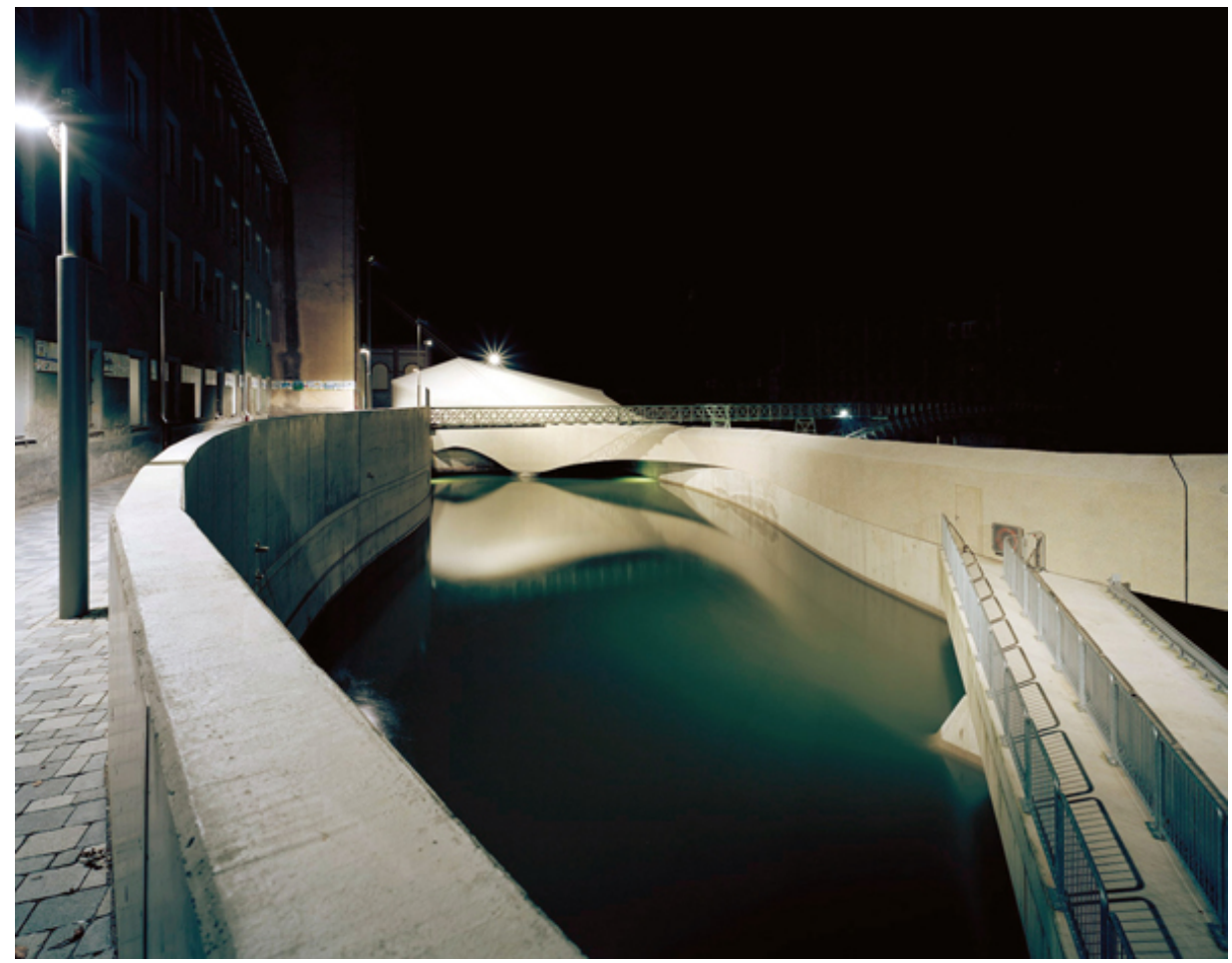

El punto de partida del diseño fue la representación del dinamismo del agua, que va cambiando del estado de calma de la entrada al remolino cercano a las turbinas, y vuelve a la calma tras la generación de electricidad. Otras inspiraciones incluyen las formaciones de roca a partir de la erosión del río. El objetivo fue conectar los límites de la máquina, incluidas turbinas, generadores y la presa de retención, con un envoltorio continuo que se sumerge bajo el acero, y salvar el puente para el cableado con el fin de evitar su total demolición.

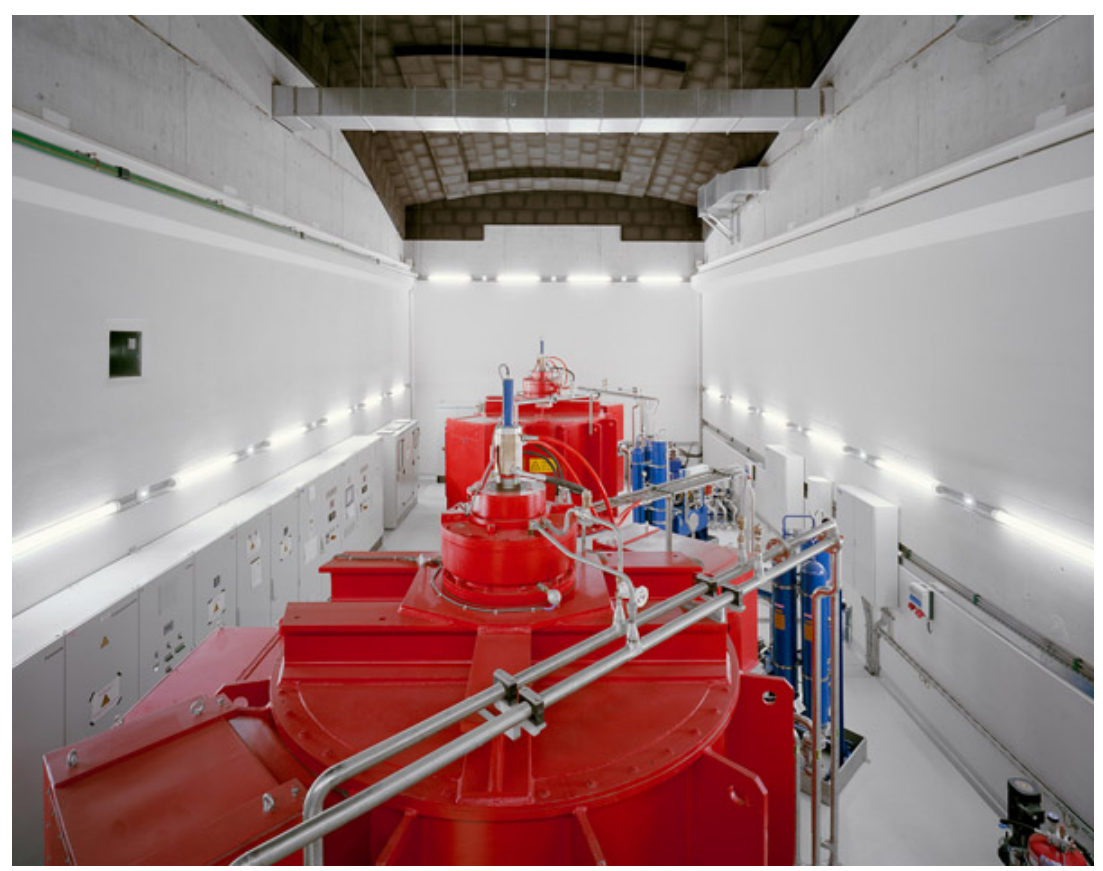


Las partes más técnicas están rodeadas de ese suave envoltorio, creando un espacio que se asemeja entre otras cosas a un canto rodado del río, una ola congelada, una ballena varada... y todo lo que cada observador imagine al ver el edificio.
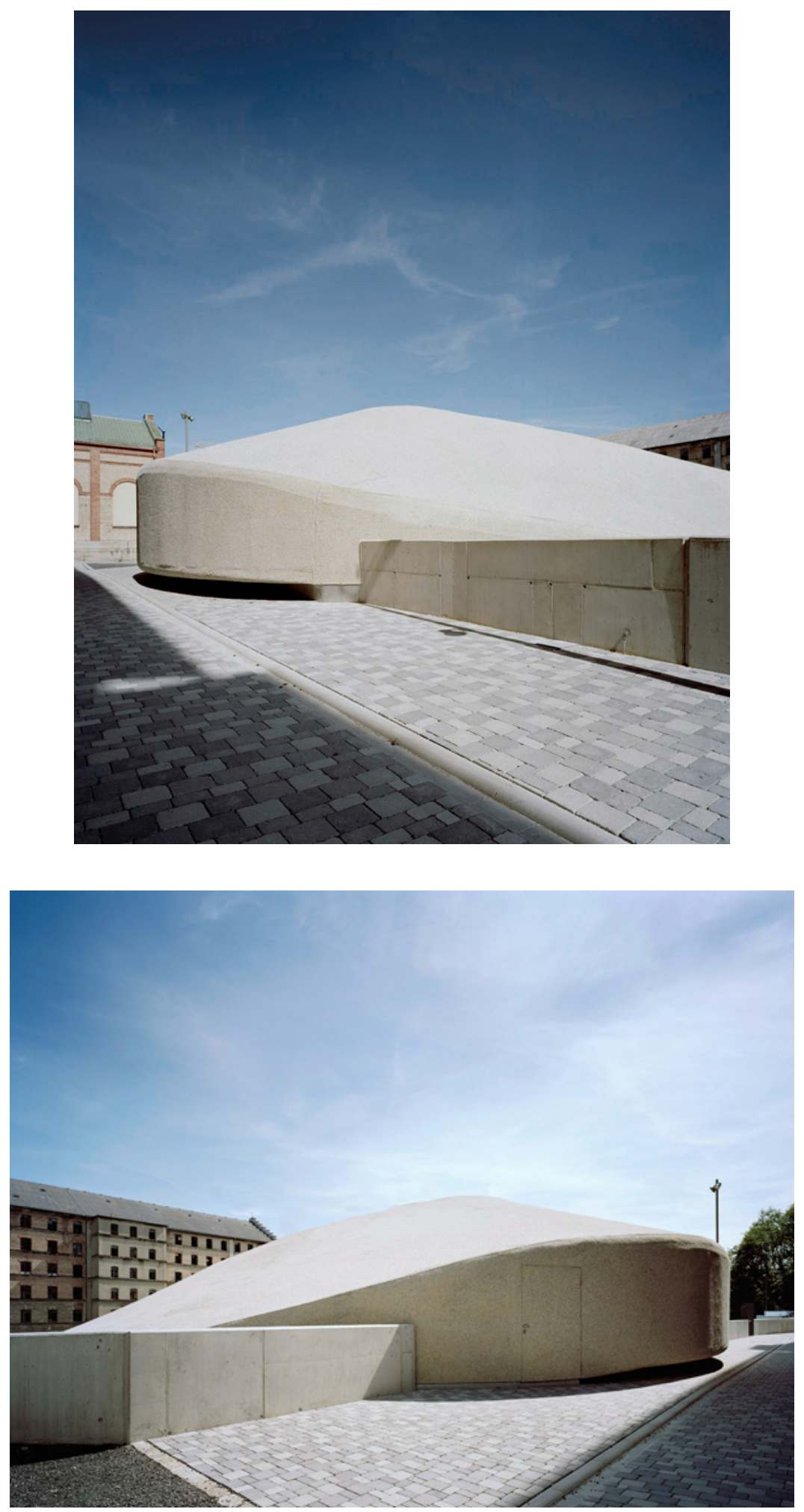


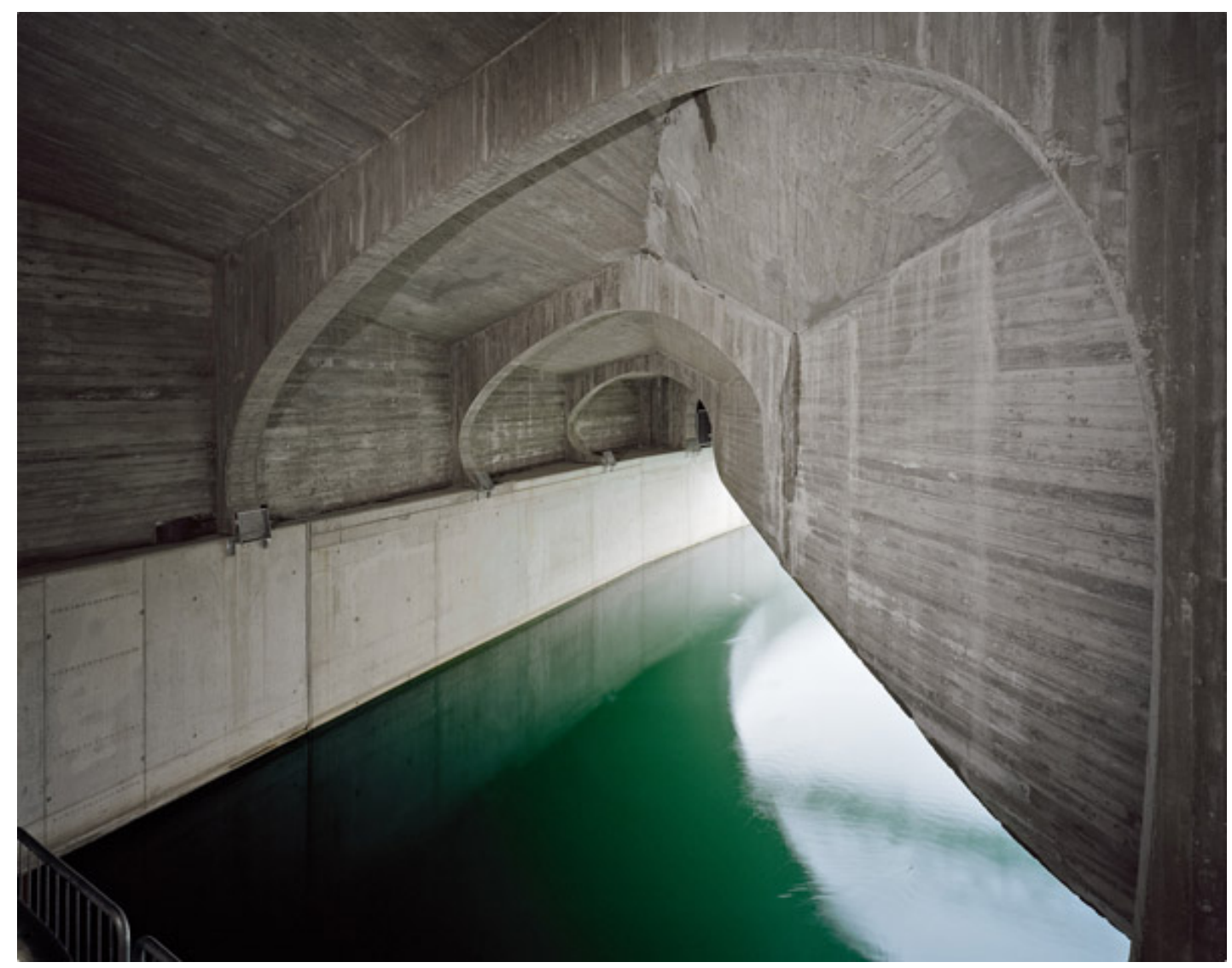

El envoltorio, reforzado de hormigón, se fija mediante cojinetes con un juego de $2 \mathrm{~cm}$ para compensar la deformación longitudinal. "Costillas" de dirección transversal estabilizan la construcción de forma parecida a las de un barco en construcción. La estructura en forma de esqueleto genera una secuencia fascinante de habitaciones interiores que varían de grandes cúpulas a espacios de dimensiones más íntimas. Todos los nodos, técnicamente esenciales, son reducidos lo máximo posible para obtener un aspecto más homogéneo. Se crean múltiples reflejos, y diferentes apariencias según los cambios de tiempo y de luz. 

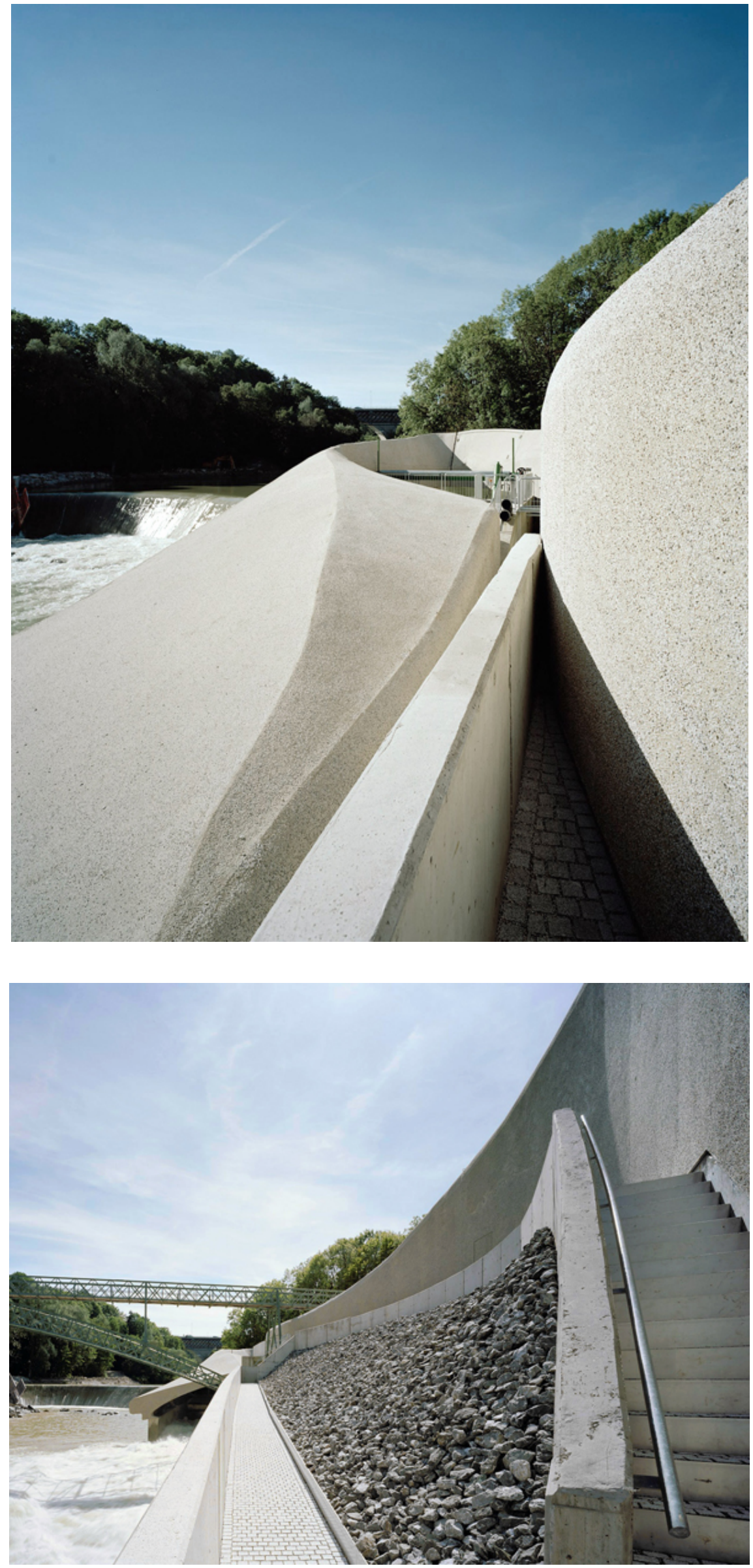


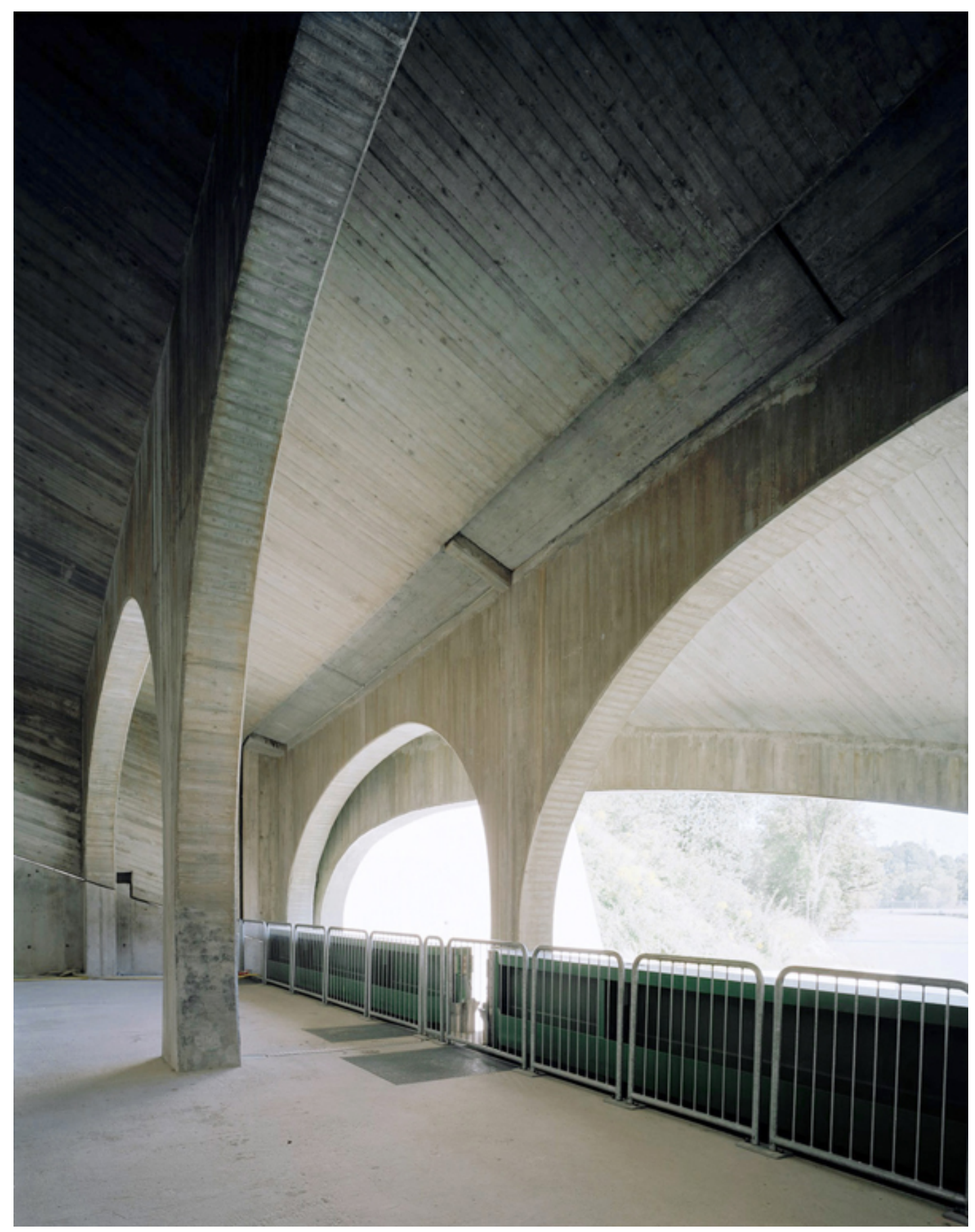




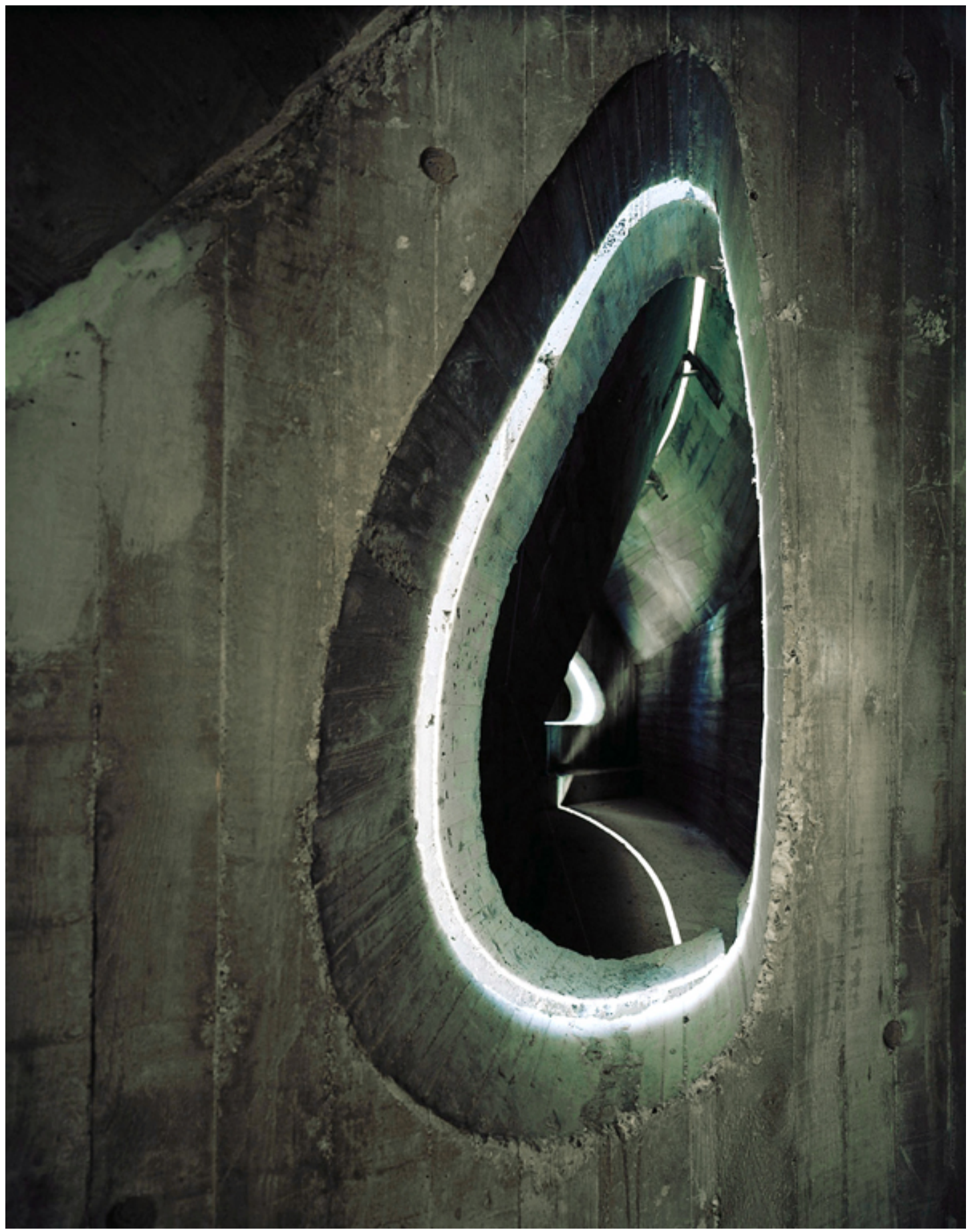

Durante la ejecución, los arquitectos consideraron temas ecológicos como la integración de una zona de pesca o medidas de prevención de ruidos. Existe también un camino para peatones y ciclistas que proporciona un gran impulso para la mayor integración de la ciudad con el río. 


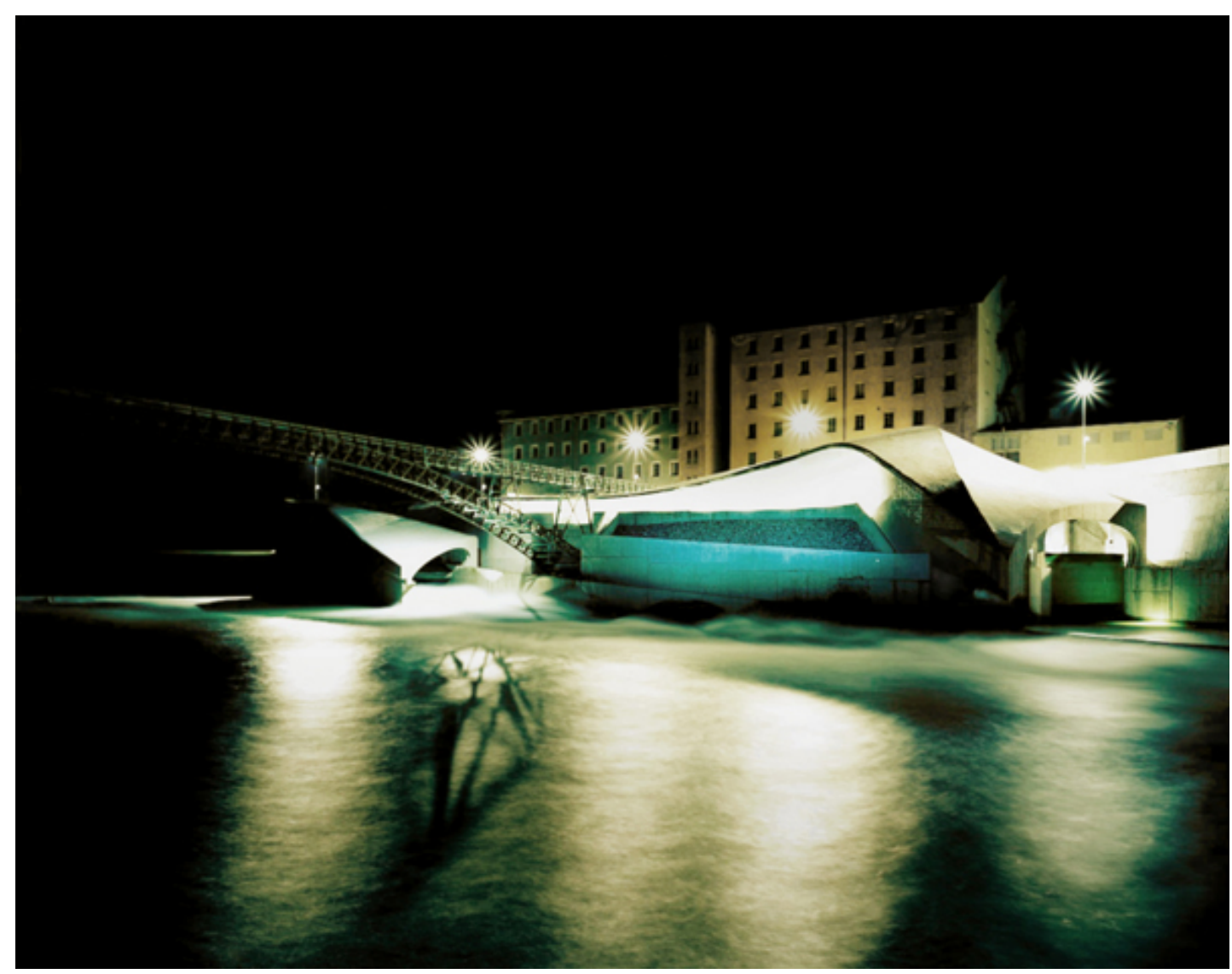

A pesar de sus grandes dimensiones, se encuentra muy diferenciado, su espacio, que por un lado asimila el entorno y en el otro lado es un edificio autosuficiente, que hará que esta zona olvidada del rio, ofrezca energía sin contaminación y que sea muy frecuentada por el público, convirtiéndose en una ruta continua para peatones y ciclistas a lo largo del cruce anterior ofreciendo un mayor impulso para la contribución adicional de la ciudad hacia el río. 


\section{Capítulo 8.}

\section{Tendencias a futuro}





\subsection{INTRODUCCIÓN Y ENFOQUE GENERAL}

La energía hidráulica es una energía altamente gestionable y es muy importante para la regulación del sistema eléctrico en España y para el casamiento de la oferta y la demanda.

De hecho, el $50 \%$ de la capacidad que participa en el mercado de banda de regulación secundaria en España es energía hidráulica. Este mercado de banda de regulación secundaria es clave para el funcionamiento del sistema eléctrico. Con el aumento progresivo de la generación eólica y solar en España, la energía hidráulica va a jugar un papel muy importante en garantizar la estabilidad del sistema de generación eléctrica.

Las posibilidades de evolución futura de la energía hidroeléctrica en España dependen esencialmente de una serie de factores que pueden considerarse determinantes.

Adicionalmente no deben perderse de vista otros factores secundarios, que con menor intensidad pueden influir en lo anterior.

En cualquier caso pueden considerarse dos tipos de factores:

1. Los factores que influyen en la evolución del equipo de generación del sistema eléctrico nacional, en su conjunto.

2. Factores que discriminan, positiva o negativamente, la generación hidráulica frente a otras tecnologías dentro del mix de generación.

Cualquier estimación que se efectúe en relación con estas cuestiones está condicionada por la incertidumbre en que se desarrollan los negocios energéticos. Por tanto las consideraciones sobre lo anterior deben entenderse en términos tendenciales y probabilísticos.

1. Factores generales

- La evolución de la demanda de electricidad

- La renovación del equipo de generación

2. Factores particulares (generación hidráulica)

- Las medidas de protección ambiental

- La pluralidad de usos del recurso hídrico (energético y ambientales)

- El funcionamiento de los mercados de energía (pool, bilaterales y servicios de ajuste)

- La evolución del sector gasista 
- La fiscalidad de la energía y otros aspectos regulatorios

- El nexo entre la hidráulica y la operación técnica del sistema

- El impacto del cambio climático sobre el recurso hídrico

- La conservación de la infraestructura hidráulica al servicio de la generación eléctrica

\section{Factores a tener en cuenta:}

\section{- La evolución de la demanda de electricidad}

Este factor depende a su vez de dos cuestiones principales, que son: la reactivación económica general del país y la posible penetración de la electricidad en sectores como el transporte y la climatización integral de edificios.

A mayor plazo (2030) las posibilidades de crecimiento se estiman en el 1.8\%. La planificación indicativa del MINETUR para el período 2010-2020 estimaba un crecimiento del consumo de electricidad a una tasa interanual media del 2,4\%, muy inconsistente con la realidad sobrevenida, al menos hasta la fecha.

Los datos de REE muestran que la demanda de distribución a finales de 2014 aún caía el 1,2\% en relación con la del año 2013, es decir nuestro país seguiría en ese sentido en recesión eléctrica.

En cuanto a los nuevos usos de la electricidad (vehículo eléctrico y climatización integral) las estimaciones son poco fiables en cuanto a su posible aportación a medio plazo.

\section{- La renovación del equipo de generación}

Esta es una cuestión importante que indudablemente afectará a la estructura del equipo de generación eléctrica en el plazo considerado (2030) por diversos motivos, principalmente los que se indican a continuación.

Las centrales térmicas de carbón que se hayan acogido al límite de 20.000 horas de funcionamiento (Directiva 2001/80/CE de Grandes Instalaciones de Combustión) deberían darse de baja antes de que finalice el año 2015.

Por otra parte las condiciones ambientalmente restrictivas de la Directiva 2010/75/UE de Emisiones Industriales pueden inducir a la baja de algún grupo adicional si las empresas propietarias no acometen las inversiones de acondicionamiento necesarias. 
Las autorizaciones de explotación del parque nuclear (40 años, salvo que se extiendan más allá de límite inicialmente establecido), caducarán entre el año 2021 (Almaraz) y el 2028 (Trillo).

Las propias centrales hidroeléctricas podrían también verse afectadas, en cierta medida, por la expiración del plazo concesional de algunas instalaciones de este tipo (65 años), su posible reversión o decomisión si fuera el caso.

Aparte de lo anterior hay que tener muy presente la situación anómala de las CCGN, con una capacidad instalada que supera los 25.000 MW y un factor de utilización realmente muy bajo (876 horas/año en 2014 sobre 6.000 inicialmente previstas). Estas instalaciones pueden verse afectadas por la regulación sobre hibernación y también por la de restricciones por garantía de suministro.

Todo lo anterior pone de manifiesto un panorama poco claro en cuanto a la evolución del parque español de generación eléctrica, más allá del año 2020. No debe olvidarse que desde la Ley del Sector Eléctrico de 1997, la generación es una actividad liberalizada y las decisiones de inversión competen plenamente a los agentes empresariales (no así las bajas de las instalaciones, que se encuentran reguladas).

\section{- Las medidas de protección ambiental}

Dos cuestiones tienen importancia en este sentido, el contenido de la propia regulación y el funcionamiento del mercado de emisiones.

El RD 815/2013 que aprueba el Reglamento de Emisiones Industriales establece, en conformidad con la normativa de la UE, las condiciones que aplican al equipo de generación y las fechas de entrada en vigor. Ello afecta a la generación térmica en ambos combustibles, carbón y gas natural, aunque en distinta medida. La generación térmica supone aproximadamente un 53\% de las emisiones de $\mathrm{CO} 2$ en España, mientras que la industria imputa el 36\% del total y el $11 \%$ restante corresponde a los denominados usos difusos.

Las tendencias a corto plazo apuntan al alza del precio de los derechos de emisión, aunque es difícil hacer predicciones más allá de unos meses vista. Un incremento sustancial del coste de las emisiones penalizaría la generación térmica en comparación con tecnologías limpias como la hidráulica y es por tanto un factor a tener en cuenta. 


\section{- La pluralidad de usos del recurso}

Como bien se sabe la hidroelectricidad no puede considerarse en general el fin exclusivo de la explotación de los aprovechamientos hidráulicos y debe compatibilizarse con otros usos concurrentes del recurso de acuerdo con un sistema de prioridades establecido legalmente. Aparte de ello, la propia operación de los embalses viene condicionada por las vicisitudes del régimen hidrológico, especialmente en episodios de avenidas y también lógicamente también durante los períodos de sequía. Todo ello supone que la hidroelectricidad está expuesta a ciertas restricciones que no sufren en igual medida otras tecnologías de generación.

La Administración hidráulica posee la capacidad legal para establecer limitaciones en caso necesario a la libertad del productor hidroeléctrico, de manera coordinada con el operador técnico del sistema eléctrico y las empresas de generación.

- El funcionamiento de los mercados de energía (pool, bilaterales y servicios de ajuste)

La generación hidráulica oferta su energía en el mercado diario en función de la modalidad de que se trate: centrales fluyentes como precio-aceptantes y las reguladas y reversibles como formadoras del precio marginal de casación. Estos dos últimos tipos ofertan energía de puntas, como es sabido, cuyo precio puede resultar significativamente más alto que el medio horario.

En cualquier caso, aparte de ingresos la generación hidráulica supone costes y ese aspecto es determinante desde el punto de vista de la propensión de las empresas hacia la inversión en este tipo de tecnología.

El coste anualizado de generación para plantas eléctricas varía entre 6-8 $€_{2010} / \mathrm{kWh}$ siendo muy similar para centrales de agua fluyente y centrales a pie de presa. 
La siguiente tabla muestra los costes de generación para diferentes tipos de plantas.

Coste de generación $\left(c \epsilon_{2010} / \mathbf{k W h}\right)$

\begin{tabular}{|l|l|l|}
\hline Potencia y antigüedad & Centrales de agua fluyente & Centrales pie de presa \\
\hline$<10 \mathrm{MW}$ (nueva) & $7-8$ & $7-8$ \\
\hline $25 \mathrm{MW}$ (nueva) & $6-7$ & $6-7$ \\
\hline$<10 \mathrm{MW}$ (rehabilitación) & $5,5-7,5$ & $5,5-7,5$ \\
\hline$<10 \mathrm{MW}$ (aprovechamiento de presa) & n.a & $5-7$ \\
\hline
\end{tabular}

El coste de inversión de una instalación de energía hidráulica de nueva construcción varía entre 1,3 y 1,6 M€ 2010/MW para una instalación de agua fluyente y entre 0,7 y 1,0 M€ ${ }_{2010} / \mathrm{MW}$ para una instalación de pie de presa. En España los costes actuales de inversiones se encuentran en la parte alta de este rango, tanto para instalaciones de agua fluyente como para instalaciones de pie de presa, ya que las instalaciones que se están poniendo en marcha en los últimos años se encuentran en el rango de 1-5 MW.

Los principales componentes del coste de la inversión son la obra civil, la turbina hidráulica y el generador.

\section{Distribución porcentual de la inversión en una central hidroeléctrica}

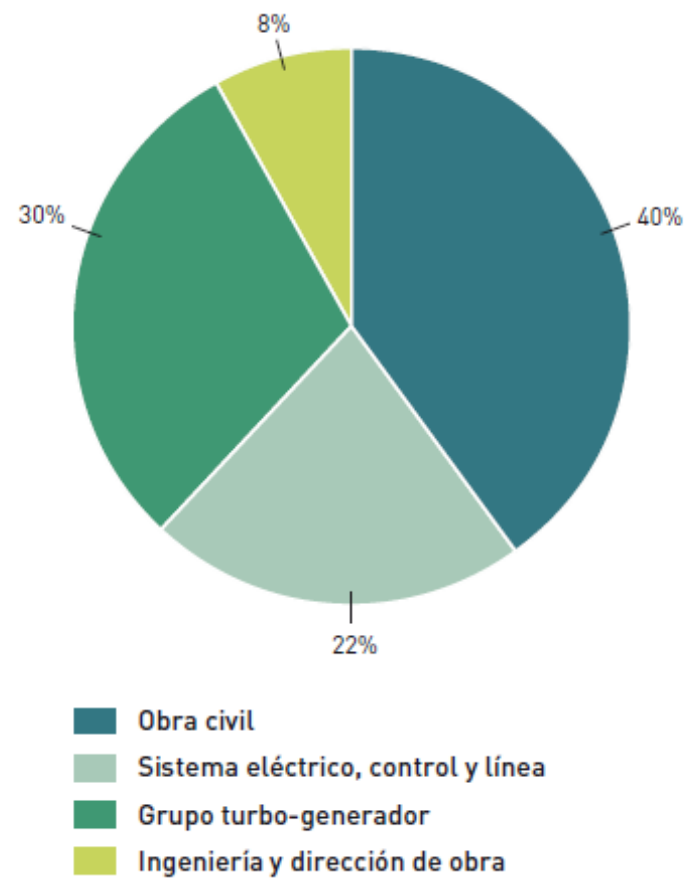



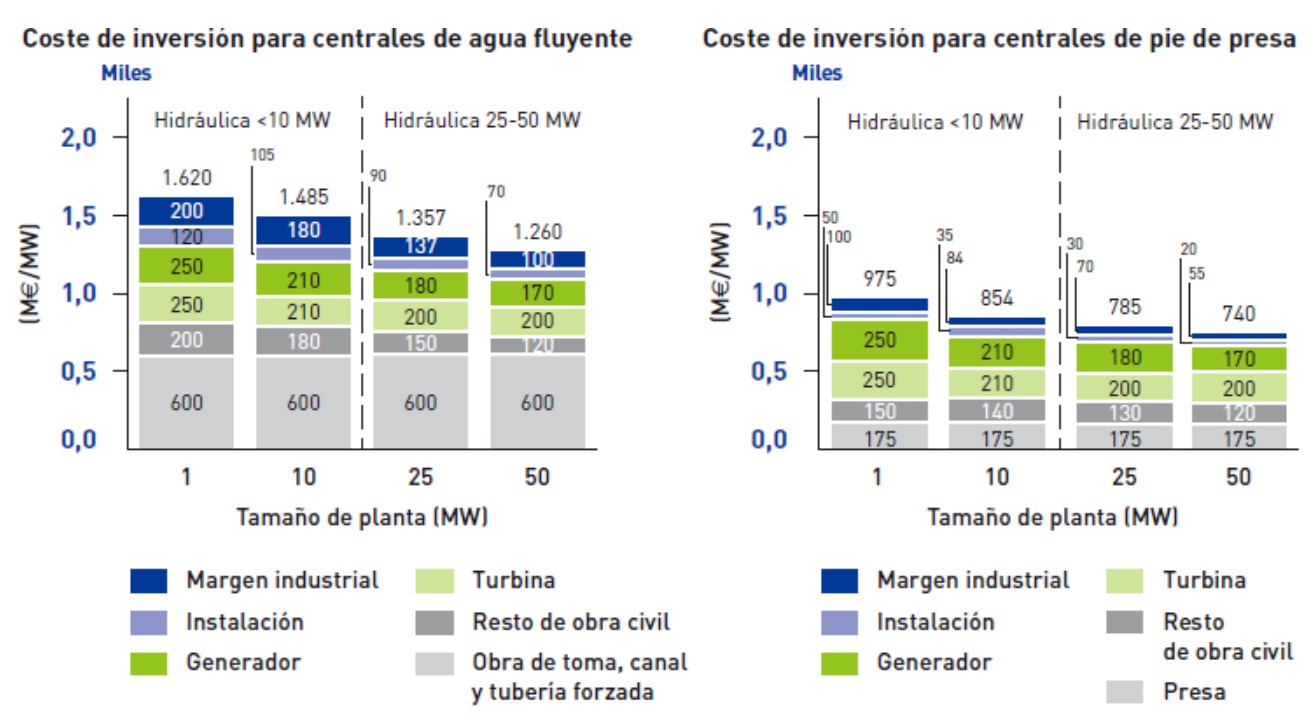

Nota: el margen industrial incluye el coste del proyecto (1,5\% del total de la inversión)

Para centrales de rehabilitación el coste de inversión es de 0,9-1,1 M€ $2010 / \mathrm{MW}$ para centrales de agua fluyente y de 0,6-0,9 M€ 2010/MW para centrales de pie de presa.

La inversión es inferior por el menor gasto en la obra civil que suele tener un coste un $75 \%$ inferior a la construcción de una nueva obra de toma, canal o tubería o de una presa.

El rango medio del coste de operación y mantenimiento es de 40-50 € 2010/Kw Los principales componentes del coste de operación y mantenimiento son el coste de la concesión, el mantenimiento, la operación y gestión de la planta y los seguros.

Debido a la madurez tecnológica, se espera una reducción muy limitada del coste de producción, de entre 1 y 7\% en el periodo 2010-2030.

\begin{tabular}{|c|c|c|c|}
\hline \multirow[b]{2}{*}{$\begin{array}{l}\text { Tipo de instalación } \\
\text { de nueva } \\
\text { construcción }\end{array}$} & \multicolumn{3}{|c|}{$\begin{array}{l}\text { Coste medio de la } \\
\text { producción }\left(c €_{2010} / \mathrm{kWh}\right)\end{array}$} \\
\hline & 2010 & 2020 & 2030 \\
\hline Agua fluyente & $\sim 7,5$ & $\sim 7,3$ & $\sim 7,1$ \\
\hline \multirow[t]{2}{*}{ Pie de presa } & $\sim 7,3$ & $\sim 7,2$ & $\sim 7,0$ \\
\hline & \multicolumn{3}{|c|}{$\begin{array}{l}\text { Coste medio de la } \\
\text { producción lc } €_{2010} / \mathbf{k W h}\end{array}$} \\
\hline $\begin{array}{l}\text { Tipo de instalación } \\
\text { de rehabilitación }\end{array}$ & 2010 & 2020 & 2030 \\
\hline Agua fluyente & $\sim 6,0$ & $\sim 5,5$ & $\sim 5,4$ \\
\hline Pie de presa & $\sim 6,9$ & $\sim 6,8$ & $\sim 6,6$ \\
\hline
\end{tabular}


Al tratarse de concesiones de uso privativo del dominio público hidráulico, las explotaciones tienen generalmente una vida útil a efectos económicos de 65 años, consistente con un período de amortización considerado en su día suficiente para amortizar la inversión en condiciones de rentabilidad económica. Su vida real en debidas condiciones de conservación puede ser sin embargo mucho más dilatada. Para el equipamiento electromecánico suele considerarse un plazo de amortización de 35 años.

Los costes de la generación hidráulica, al no estar sujetos a las habituales contingencias de variabilidad del precio de los combustibles fósiles son predecibles y en general estables, mientras que los ingresos dependen esencialmente de la meteorología. Esta circunstancia es relevante dada la irregularidad hidrológica de nuestro país. Así, la producción hidroeléctrica (todas las modalidades) en el año 2008 fue de 26.000 GWh mientras que en el 2010 superó los 45.000 GWh, es decir un 73\% superior, básicamente a igualdad de coste.

\section{Potencia total instalada en la UE a finales del 2008 en centrales menores de $10 \mathrm{MW}$}

\begin{tabular}{l|l|l} 
Pais & $\begin{array}{l}\text { Potencia } \\
\text { (MW) }\end{array}$ & $\begin{array}{l}\text { Producción } \\
\text { (GWh) }\end{array}$ \\
\hline Italia & 2.605 & 9.159 \\
\hline Francia & 2.049 & 6.924 \\
\hline España & 1.872 & 3.031 \\
\hline
\end{tabular}

\section{Potencia total instalada en la UE a finales del 2008 en centrales mayores} de $10 \mathrm{MW}$

\begin{tabular}{l|l|l} 
Pais & $\begin{array}{l}\text { Potencia } \\
\text { (MW) }\end{array}$ & $\begin{array}{l}\text { Producción } \\
\text { (GWh) }\end{array}$ \\
\hline Italia & 11.190 & 41.623 \\
\hline Francia & 18.823 & 64.239 \\
\hline España & 11.232 & 23.500 \\
\hline
\end{tabular}

En el año 2014 la producción hidroeléctrica en el sistema peninsular ascendió a $42.738 \mathrm{GWh}$. 


\section{Distribución de la potencia hidroeléctrica en España por tamaño de} centrales

\begin{tabular}{|l|l|l|l|l|}
\hline Tipo central & Potencia (MW) & \% Potencia & $\begin{array}{l}\text { Producción } \\
\text { (GWh) }\end{array}$ & \% Producción \\
\hline Menor de 1 MW (sin bombeo) & 242 & 1 & 802 & 2 \\
\hline Entre 1 y 10 MW (sin bombeo) & 1.680 & 9 & 5.432 & 13 \\
\hline Mayor de 10 MW (sin bombeo) & 11.304 & 61 & 35.981 & 85 \\
\hline Por bombeo & 5.347 & 29 & 3.106 & \\
\hline Total (sin bombeo) & $\mathbf{1 3 . 2 2 6}$ & $\mathbf{1 0 0}$ & $\mathbf{4 2 . 2 1 5}$ & $\mathbf{1 0 0}$ \\
\hline
\end{tabular}

\section{- La evolución del sector gasista}

La imbricación del sector gasista con el eléctrico proviene de la apuesta que las empresas de este último efectuaron en la última década del siglo pasado en centrales de ciclos combinados (CCGN), lo cual ha supuesto en los últimos quince años una dotación de capacidad superior a 25.000 MW y una inversión aproximada de 15.000 millones de Euros. La demanda prevista de gas para atender al funcionamiento de esas centrales, con un factor de carga que en su día se estimó en tomo a 6.000 horas/año (en 2014 el valor promedio sin embargo fue de unas 876 horas), junto con el resto de los usos del gas natural (industrial, comercial y doméstico) ha arrastrado una inversión significativa del sector gasista en infraestructura (gasoductos, plantas de regasificación y almacenamiento, esencialmente) que ahora se encuentra en parte infrautilizada.

Adicionalmente debe tenerse en cuenta la dependencia española del suministro exterior de ese tipo de combustible (aproximadamente el 99\%) y la elevada cuantía y rigidez de los contratos de aprovisionamiento (modalidad take or pay).

El sector gasista sufre actualmente en España una situación de contracción relativa de la demanda en parte por el estado económico general del país y además debido a la infrautilización sobrevenida de las centrales CCGN.

La evolución del sector gasista afectará a la estructura de generación eléctrica por dos razones de peso: la situación anómala del equipamiento CCGN, que sus propietarias intentarán volver a poner en valor en el mercado eléctrico de la mejor manera posible y la previsible mejora de las condiciones en la oferta de gas natural (cantidades y precios) como consecuencia de las explotaciones no convencionales. Es indudable que la situación de los CCGN y la evolución del gas 
influirán de manera notoria en la evolución en España del equipo de generación eléctrica durante los años próximos.

\section{- La fiscalidad y otros aspectos regulatorios}

En Diciembre del año 2012 se introdujeron en el régimen fiscal de la electricidad tres nuevos impuestos (uno de carácter directo y naturaleza real y otros dos especiales) más un canon por utilización de las aguas continentales para la producción de energía eléctrica (Ley 15/2012 de medidas fiscales para la sostenibilidad energética).

El impuesto sobre la producción eléctrica general tiene un tipo de gravamen del $7 \%$ y el canon hidroeléctrico es del $22 \%$ salvo en los casos de instalaciones de potencia $\leq 50 \mathrm{MW}$ y centrales reversibles, en las que la cuantía se reduce en un 90\% (tipo de gravamen 2,2\%). Lo anterior supone de facto establecer un coste del 'combustible agua' de casi el 30\% del valor de la producción, hecho que afecta extraordinariamente a la cuenta de resultados de los aprovechamientos hidroeléctricos. Por esa razón, el atractivo económico-financiero de la hidráulica para la inversión en nueva capacidad de generación se encuentra actualmente en entredicho.

\section{- El nexo entre la hidráulica y la operación técnica del sistema}

La problemática del almacenamiento de energía a gran escala, asociado a la gestión técnica y la operación del sistema eléctrico, aflora como uno de los temas visibles en el campo de la hidroelectricidad en estos últimos años.

\section{- El impacto del cambio climático sobre el recurso hídrico}

La posible alteración del ciclo hidrológico por razones derivadas del cambio climático y sus efectos sobre la generación de energía son dos cuestiones interesantes que se están empezando a estudiar con cierto detalle.

En su conjunto, la afección potencial del cambio climático, sea cual sea su magnitud, se extiende sobre un $70 \%$ de la potencia instalada en el equipo de generación, circunstancia que debería ser tenida en cuenta.

- El estado de conservación de la infraestructura hidráulica al servicio de la generación

La planta de generación hidroeléctrica se encuentra bien conservada en la parte del equipamiento electromecánico por razones de obvia diligencia de las compañías, pero la situación de la infraestructura u obra civil es más irregular. 
Es evidente que un posible deterioro de las características funcionales y/o resistentes de presas, conducciones y demás elementos de la obra civil puede significar a medio plazo un perjuicio no desdeñable a la aportación hidroeléctrica. La problemática sobre este particular es variada y en algunos de sus aspectos, nada trivial (p.e. problemas de expansividad de algunas presas).

\subsection{DESARROLLO A MEDIO PLAZO DE LA GENERACIÓN HIDRÁULICA EN ESPAÑA}

La decisión de invertir en generación hidroeléctrica por las vías del desarrollo de nuevos aprovechamientos o la mejora de los existentes se encuentra fuera de las obligaciones reguladas de los agentes y obedece exclusivamente a su interés y posibilidades, en función de la estrategia empresarial de cada compañía.

\section{Bombeos \\ Centrales de Bombeo puro \\ Centrales de Bombeo mixto}

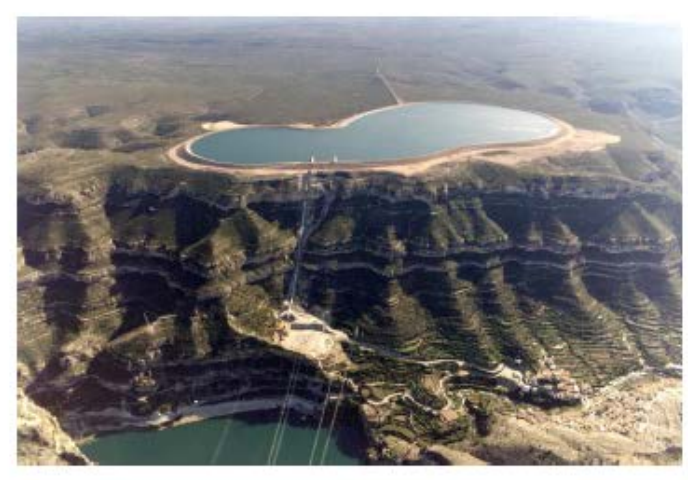

Central de bombeo de La Muela (Júcar)

\section{Embalses de regulación \\ Centrales de Turbinación pura \\ Centrales de Bombeo mixto}

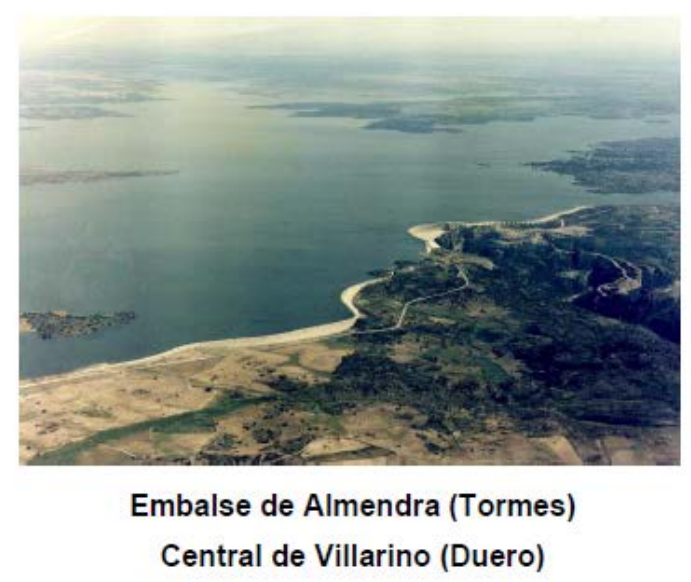

En ese sentido, las perspectivas de desarrollo de nuevas centrales hidroeléctricas o repotenciación de las existentes que puedan admitirlo, vendrán condicionadas en primer lugar por dos circunstancias: (1) la evolución de la demanda de electricidad y de la capacidad disponible en el sistema para atenderla, tomando como horizonte la fecha aquí prevista (año 2030); y (2) el mérito relativo de cualquier nuevo desarrollo hidroeléctrico en relación con otras tecnologías de generación que puedan considerarse competidoras para hacer frente a las nuevas necesidades de abastecimiento del sistema. 
Tabla 6. Estimación de la contribución total de cada tecnología renovable en España al cumplimiento de los objetivos vinculantes para 2020 en el sector eléctrico en 2005, 2010, 2015 y 2020

\begin{tabular}{|c|c|c|c|c|c|c|c|c|}
\hline \multirow{2}{*}{$\begin{array}{l}\text { Sector } \\
\text { eléctrico } \\
\text { [potencia y } \\
\text { generación] }\end{array}$} & \multicolumn{2}{|l|}{2005} & \multicolumn{2}{|l|}{2010} & \multicolumn{2}{|l|}{2015} & \multicolumn{2}{|l|}{2020} \\
\hline & $\begin{array}{l}\text { Potencia } \\
\text { (MW) }\end{array}$ & $\begin{array}{l}\text { Generac. } \\
\text { (GWh) }\end{array}$ & $\begin{array}{l}\text { Potencia } \\
\text { (MW) }\end{array}$ & $\begin{array}{l}\text { Generac. } \\
\text { [GWh] }\end{array}$ & $\begin{array}{l}\text { Potencia } \\
\text { (MW) }\end{array}$ & $\begin{array}{l}\text { Generac. } \\
\text { [GWh] }\end{array}$ & $\begin{array}{l}\text { Potencia } \\
\text { (MW) }\end{array}$ & $\begin{array}{l}\text { Generac. } \\
\text { [GWh] }\end{array}$ \\
\hline $\begin{array}{l}\text { Biomasa, } \\
\text { biogás y } \\
\text { residuos }\end{array}$ & 601 & 2.653 & 752 & 4.517 & 965 & 5.962 & 1.587 & 10.017 \\
\hline Eólica & 9.918 & 20.729 & 20.155 & 40.978 & 27.997 & 57.086 & 38.000 & 78.254 \\
\hline Geotérmica & 0 & 0 & 0 & 0 & 0 & 0 & 50 & 300 \\
\hline Hidroeléctrica & 18.377 & 34.802 & 18.687 & 34.617 & 20.049 & 36.732 & 22.362 & 39.593 \\
\hline $\begin{array}{l}\text { Energías del } \\
\text { mar }\end{array}$ & 0 & 0 & 0 & 0 & 0 & 0 & 100 & 220 \\
\hline $\begin{array}{l}\text { Solar } \\
\text { fotovoltaica }\end{array}$ & 60 & 41 & 4.021 & 6.417 & 5.918 & 9.872 & 8.367 & 14.316 \\
\hline $\begin{array}{l}\text { Solar } \\
\text { termoeléctrica }\end{array}$ & 0 & 0 & 632 & 1.144 & 3.048 & 7.913 & 5.079 & 15.353 \\
\hline Total & 28.956 & 58.225 & 44.247 & 87.673 & 57.977 & 117.565 & 75.545 & 158.053 \\
\hline
\end{tabular}

La preferencia de los inversores por la hidráulica en relación con otro tipo de instalaciones y tecnologías de generación (especialmente las que pueden considerarse equivalentes en términos de emisiones), tendrán en cuenta en términos comparativos los aspectos siguientes:

- Inversión, incluyendo el coste de capital

- Plazo de entrega y su predictibilidad (desde la decisión de invertir hasta la entrada en funcionamiento de la instalación)

- Costes de operación y mantenimiento

- Otros costes variables (combustible, derechos de emisión, etc.)

- Fiscalidad

En lo que se refiere a nuevas instalaciones, es decir desarrollos a iniciar ex-novo o proyectos greenfield, la generación hidroeléctrica no suele ser en general la más competitiva en relación con los dos primeros criterios de la lista, posiblemente los de mayor peso.

Incluso en aquellos casos en que pudiera serlo (comparativamente con la solar FV, por ejemplo) la abultada fiscalidad hidroeléctrica (canon de utilización, artículo 122 bis de la Ley de Aguas) hace que cualquier instalación de potencia > 50 MW sufra una penalización significativa en su rendimiento económico. 
Por tanto, teniendo en cuenta la situación actual regulatoria y de mercado, la probabilidad de que las empresas aborden desarrollos hidroeléctricos completamente nuevos parece baja a corto y medio plazo.

Los inconvenientes anteriores se atenúan sin embargo en el caso de las repotenciaciones, mejoras o transformaciones de aprovechamientos actualmente en uso que dispongan de tal posibilidad. En tales casos, los factores limitativos a la inversión en capacidad hidroeléctrica se moderan considerablemente (aproximadamente en un orden de magnitud) y ello, unido a los valores altamente positivos de este tipo de generación en otros aspectos, hace que la opción resulte potencialmente atractiva para los inversores, en general empresas que ya poseen activos de generación hidráulica. Las actuaciones emprendidas en España en los últimos años (CH de Belesar, San Estevo, La Muela II) y otras que están previstas en espera de aprobación, parecen corroborar la opinión anterior.

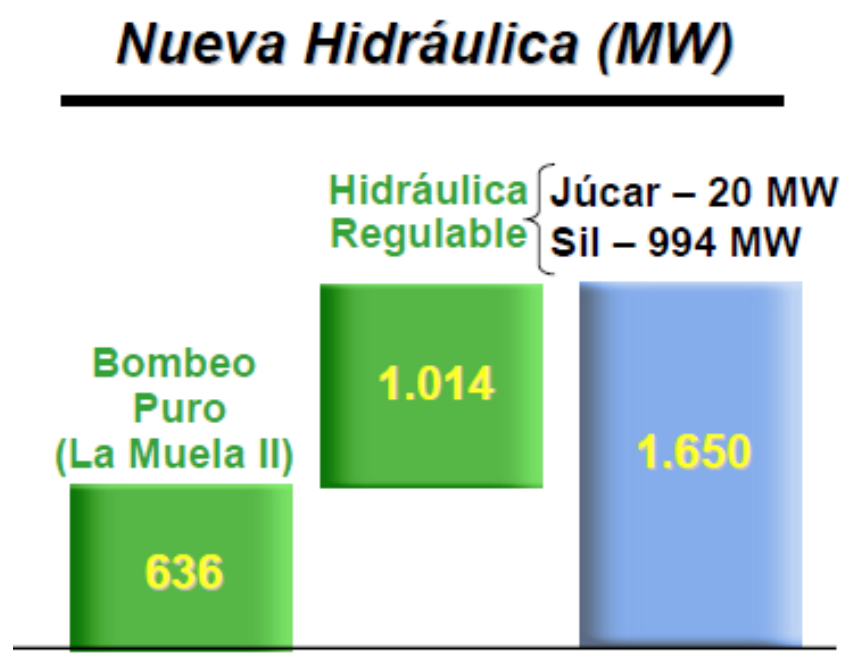

Mención aparte merece la hidráulica mediana $(\leq 50 \mathrm{MW})$ y la minihidráulica $(\leq$ $10 \mathrm{MW})$.

Exentas de tributar el canon de utilización (el 22\% de sus ingresos por venta de energía), poseen sin embargo la dificultad de encontrar nuevos emplazamientos rentables que puedan desarrollarse en un plazo aceptable.

La energía hidráulica tiene un potencial de aprovechamiento limitado. Se estima que existe un potencial adicional de otros $400 \mathrm{GW}$ de instalaciones de generación eléctrica con energía hidráulica, de los cuales 40 GW corresponden a instalaciones hidráulicas de menos de $10 \mathrm{MW}$. 
Potencial Hidroeléctrico español

\begin{tabular}{|l|c|}
\hline & GWh \\
\hline Potencial fluvial bruto & 150.000 \\
\hline Potencial técnicamente desarrollable & 70.000 \\
\hline Potencial desarrollado & 38.000 \\
\hline Máximo técnicamente desarrollable & $<20.000$ \\
\hline $\begin{array}{l}\text { Medioambientalmente aceptable } \\
\text { (sostenible) }\end{array}$ & 4.500 \\
\hline
\end{tabular}

Para el desarrollo de la tecnología hidráulica de pequeña potencia en España, tan necesaria para los mercados de regulación eléctrica, encontramos barreras de recurso hidráulico y barreras administrativas. Algunas de estas barreras son comunes con las de los aprovechamientos mayores, siendo sin embargo, otras de carácter particular para las centrales de menos de 10 MW. Éstas son:

\section{Barreras de recurso hidráulico}

- La falta de conocimiento en detalle del potencial de recurso hidráulico de pequeña potencia que dificulta o ralentiza la realización de proyectos.

- Aunque existe un conocimiento del recurso de energía hidráulica en España, sería conveniente desarrollar un conocimiento en detalle del recurso por emplazamientos.

En España existe un potencial adicional de 1 GW y $\sim 2,5$ TWh de energía hidráulica de menos de $10 \mathrm{MW}$.

El recurso está concentrado en la parte norte del país, principalmente en Galicia y Aragón. 


\section{Recurso aprovechable en minicentrales hidráulicas en España}

Zonas con recurso aprovechable Recurso en GWh

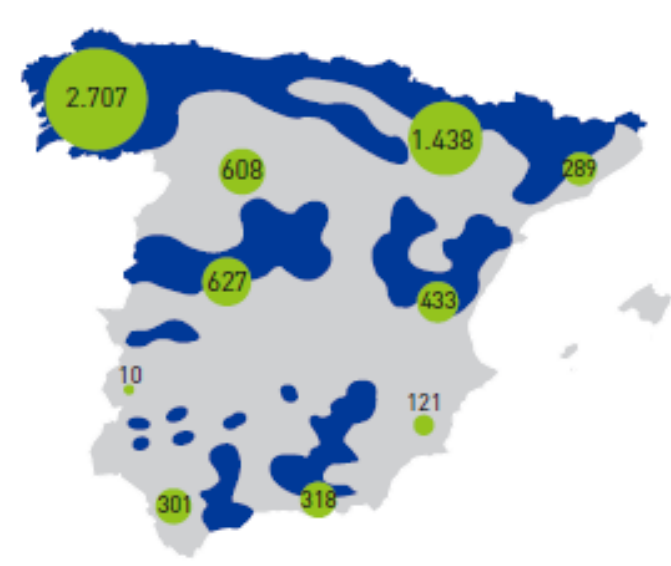

\section{Barreras administrativas}

- Dificultad a la hora de obtener los permisos para el uso del agua y dificultad en la obtención del permiso medioambiental para acometer las inversiones.

- Renovar el periodo de concesión de aguas en las instalaciones existentes. La no renovación de las concesiones puede derivar en el abandono y una inversión deficiente de las plantas existentes durante los últimos anos de explotación de las mismas.

\section{Barreras operativas}

- Existe una fuerte dependencia tecnológica del exterior sobre todo en la fabricación de turbinas y hay una falta de capacidad de "lobby" en la industria de la energía hidráulica en España. El sector tiene capacidades pero hay que ser capaz de desarrollar más mercado

\subsection{PERSPECTIVAS DE DESARROLLO DEL ALMACENAMIENTO HIDRÁULICO EN ESPAÑA A MEDIO Y LARGO PLAZO}

La energía hidráulica es una tecnología madura y no se esperan cambios tecnológicos a medio plazo. Sin embargo, el aumento de potencia de generación eólica y solar requiere aumentar la capacidad de almacenamiento energético en España para cubrir las horas de baja producción. En este sentido, la energía hidráulica de bombeo puede ser una solución que supla en parte la necesidad de almacenamiento energético bombeando con los excedentes de producción y turbinando en los momentos de pico de demanda eléctrica. 
La situación en España es suficientemente conocida: las CHR existentes son propiedad de las empresas eléctricas (generadoras) y atienden a las dos funciones que se han mencionado: arbitraje de precios valle/punta desplazando temporalmente la energía, y por otra parte, aportación de servicios de ajuste ofertando en función de la demanda del operador del sistema eléctrico.

Las perspectivas de desarrollo a medio plazo de este tipo de instalaciones dependerán esencialmente de la disposición de ejecución de los planes sobre nuevas centrales reversibles, o ampliación de las existentes, por parte de las empresas generadoras, en virtud de las autorizaciones y concesiones solicitadas o aprobadas hasta la fecha.

La capacidad hidráulica reversible instalada en España se sitúa actualmente en torno a 6.600 MW. Los incentivos al desarrollo de este tipo de centrales en el mercado dependerán esencialmente de la evolución del spread de precios entre punta y valle y de la evolución de la curva de demanda horaria, tanto en valores absolutos como especialmente en las puntas. El estancamiento de la demanda de estos últimos años, tanto en términos agregados como en los valores extremos, puede considerarse claramente que no favorece las perspectivas de inversión a corto plazo de las utilities en nueva capacidad. No obstante se sabe que las grandes empresas han estudiado aprovechamientos adicionales en España con una potencia adicional de aproximadamente 3.000 MW en centrales de este tipo, aunque aún no se han anunciado fechas concretas ni compromisos de inversión al respecto.

Otro factor adverso para el desarrollo de las CHR por la vía de las utilities es la existencia en España de un parque muy grande e infrautilizado de centrales de CCGN (aprox. 25.000 MW en el sistema peninsular) que poseen objetivos similares de mercado (puntas y servicios de ajuste).

Aun así, parece que la evolución del sistema eléctrico español a medio plazo y la variabilidad creciente de producción y consumo, unidos al desarrollo anunciado de la capacidad de interconexión internacional de la península Ibérica, justificarían un estudio en profundidad sobre la importante cuestión del almacenamiento hidráulico a gran escala.

Adicionalmente podría contemplarse la posibilidad de analizar en detalle una o varias cuencas hidrográficas como posibles reservas hidráulicas con funcionalidad multipropósito, atendiendo aparte de las necesidades de almacenamiento que pueda tener a medio plazo el sistema eléctrico, las demandas de abastecimiento y regadío en casos excepcionales del ciclo hidrológico (actuaciones de emergencia) que no son tan infrecuentes en España. 


\subsection{INNOVACIÓN $\quad \mathrm{Y}$ TENDENCIAS $\quad$ EN SISTEMAS HIDROELÉCTRICOS}

Como bien se sabe, la energía hidráulica constituye el primer ejemplo de producción de electricidad en sentido sistémico (generación unida con transporte y distribución) a escala industrial (MW), con orígenes que pueden situarse históricamente en la central Norteamericana de Niágara Falls (Tesla \& Westinghouse, 1895).

El considerable grado de madurez de esta forma de producción de energía, junto con su fiabilidad y la elevada eficiencia del equipamiento electromecánico que la caracterizan, son hechos que inducirían aparentemente a descartar a la hidroelectricidad como un ámbito actualmente atractivo para emprender actividades de innovación.

A pesar de lo anterior, una amplia mayoría de los agentes que participan del sector eléctrico, privados y públicos, reconocen la importancia singular que posee la hidroelectricidad para el sistema. También resulta perceptible su interés por el avance de las tecnologías asociadas a esta especialidad, en particular las que se refieren a generación, control y almacenamiento de energía. Es así, en primer lugar, porque la HE resulta aún crucial para el sistema eléctrico en lo que se refiere al seguimiento instantáneo de la curva de carga en puntas de demanda, y también desde el punto de vista del funcionamiento económico de los mercados, dado lo exiguo del coste marginal y el avanzado grado de amortización contable que en general caracteriza a sus activos de producción.

En ello residen las ventajas competitivas tradicionales de la hidroelectricidad sobre otras fuentes y tecnologías, que en parte se mantienen a pesar de las circunstancias cambiantes del sector eléctrico.

Pero además, y esto es importante, la energía hidráulica contribuye de manera muy destacada a aportar con un coste moderado la flexibilidad que necesita el sistema para funcionar en condiciones seguras y fiables en escenarios con elevada penetración de fuentes intermitentes y con variabilidad estocástica, como son la eólica y la solar.

Los cinco factores de avance o drivers de la innovación que se consideran más relevantes para esta tecnología son los siguientes: 
- Aportación de flexibilidad al sistema eléctrico

- Mejora de las características de las centrales HE actualmente en servicio, incluyendo su infraestructura

- Desarrollo de nuevas tecnologías para instalaciones de almacenamiento, centrales reversibles

- Centrales minihidráulicas gestionables

- Adecuación ambiental

Con la excepción de este último, todos los factores restantes inciden en la mejora de las características técnicas de las plantas hidroeléctricas en términos de capacidad física (generación y almacenamiento), eficiencia e inteligencia (automática y control), con el fin de adaptar sus tradicionales ventajas a los exigentes requisitos impuestos por las condiciones actuales de funcionamiento del sistema eléctrico.

Entre los incentivos actuales a la innovación en el ámbito de las tecnologías hidroeléctricas se señalan los tres siguientes:

- La ampliación del rango de operación eficiente de los equipos HE

- El avance en los sistemas de control y electrónica de potencia para facilitar la extensión de la velocidad variable a las operaciones de bombeo

- La atenuación del efecto ambiental de este tipo de instalaciones.

Aparte de las mejoras tecnológicas, la realización de las posibilidades de avance en el campo hidroeléctrico exige ciertas reformas en los mercados de electricidad y en el marco regulatorio del sector.

\section{Desarrollo tecnológico en equipos y sistemas $\mathrm{HE}$}

En relación con el desarrollo de la tecnología, materiales y procesos que corresponden a los equipos y sistemas hidroeléctricos, pueden apreciarse avances interesantes en las siguientes áreas:

- Nueva generación de turbinas y alternadores

- Electrónica de potencia y conversores

- Simulación a nivel sistémico

- Métodos y sistemas CAE de diseño

- Sensorización y procedimientos automatizados de supervisión y mantenimiento

- Aspectos ambientales y de conservación o mejora de la infraestructura 
A continuación se enuncian sucintamente algunos aspectos que, a la luz de las investigaciones y experiencias en curso, se estiman de interés en relación con cada uno de los puntos anteriores.

Los avances que se están produciendo en este campo involucran a distintas especialidades técnicas, especialmente en los ámbitos de la ingeniería mecánica, eléctrica de potencia, electrónica y automática, ingeniería civil y ambiental. En consecuencia se trata de frentes de avance que se caracterizan por un grado considerable de colaboración interdisciplinar.

\section{Turbinas y generadores}

Los avances tecnológicos en el equipamiento de una central hidroeléctrica, por tratarse de una tecnología madura y consolidada, van dirigidos a obtener la máxima eficiencia, mejora de rendimientos y reducción de costes, sin olvidar la protección medioambiental en cuanto a evitar cualquier tipo de fugas de aceite o grasas al medio acuático.

El objetivo global que se plantea actualmente la industria es la mejora de la eficiencia y la extensión del rango de operación de los equipos al deseable intervalo $0-100 \%$ de su potencia nominal, incluyendo frecuentes paradas y arranques, tanto en sistemas de velocidad variable como fija. En el caso de las turbo-bombas de las CHR, debe añadirse la posibilidad de trabajar con cambios igualmente frecuentes en el modo de operación del equipo y las adaptaciones necesarias para que la central pueda operar en régimen de cortocircuito hidráulico, usando para ello configuraciones ternarias.

En lo que se refiere a la adecuación y mejora del impacto ambiental de este tipo de instalaciones hay que mencionar que en los EEUU se han comprometido en las dos últimas décadas importantes inversiones en el diseño de turbinas fishfriendly, que reducen la mortalidad de los peces a su paso por el rodete, así como en el diseño las llamadas self-aerating turbinas, que aumentan la concentración de oxígeno disuelto en el caudal turbinado. Por otro lado, los principales fabricantes trabajan en el diseño de turbinas en que los sistemas de lubricación de los cojinetes utilizan agua o aceites biodegradables.

En general, sus nuevos desarrollos se basan en adaptar las mejoras de los grupos turbogeneradores de la gran hidráulica para los equipos mini hidráulicos. A continuación se listan algunas tendencias en la ejecución de proyectos de generación:

- Utilización de nuevos materiales, como polímeros reforzados de alta tecnología, en los cojinetes de turbinas: los cojinetes de bronce han sido 
la solución tradicional en las turbinas hidráulicas, pero requieren lubricación para vencer las fricciones de trabajo. Durante su funcionamiento, los lubricantes pueden pasar al agua, provocando graves daños en los ecosistemas fluviales. Las nuevas demandas medioambientales imponen que deban instalarse cojinetes sin engrases (auto lubricados), que no sean perjudiciales para la vida acuática. Asimismo, como material polímero, la elasticidad es significativa, no es tan rígido, y tiene un coeficiente de fricción dinámico muy bajo.

- Empleo de métodos numéricos de cálculo de flujo tridimensional, que permitirá la mejora del rendimiento de las turbinas.

- Nuevos tipos de álabes, para la mejora de eficiencias y poder aumentar el rango de operación.

- Refrigeración de generadores con agua e hidrógeno, para la mejora de la eficiencia.

- Frenado electromagnético, que elimina danos y recalentamientos al disminuir el tiempo de frenado, evitando costosas reparaciones e indisponibilidades.

- Rotores autoventilados, para reducir pérdidas por fricción, aumentan eficiencia, pero costos elevados.

- Generadores con bobinas de cable aislado, para la mejora de la eficiencia y reducción de costos.

- Equipos de control para monitoreos de eficiencia y cavitación, para la mejora del mantenimiento durante la operación.

Las tipologías Pelton y Francis tienen un grado de madurez tecnológico pleno, en cambio las tipologías de hélice (Kaplan o Semikaplan) aunque su madurez es alta, su evolución tecnológica pasa por poder aprovechar ubicaciones de muy bajo salto, por debajo de los 2,5-3 m, que hasta la fecha no se han desarrollado porque, aunque técnicamente realizables, los costes de inversión hacían inviable la instalación, ya que las turbinas convencionales necesitan una infraestructura enorme de obra civil aguas arriba y aguas abajo de la misma para minimizar las pérdidas de carga y las pérdidas de producción.

No obstante, en los últimos anos, se han desarrollado nuevas patentes de grupos turbogeneradores para centrales hidroeléctricas de muy bajo salto.

Estos nuevos diseños están basados en grupos compactos de simple regulación, totalmente sumergibles y de baja velocidad de paso, lo que hace que sus afecciones medioambientales sean mínimas y que requieran una infraestructura mínima en obra civil, lo que puede hacer viables económicamente el aprovechamiento energético de estos pequeños saltos. 
Asimismo, se están desarrollando micro turbinas hidráulicas con potencias inferiores a los $10 \mathrm{Kw}$, pensando en aprovechar la fuerza cinética de los ríos y generar electricidad en zonas aisladas. La turbina produce electricidad directamente en corriente alterna y no necesita caídas de aguas, infraestructuras adicionales ni elevados costes de mantenimiento, lo que las convierte en una óptima solución en sistemas aislados.

\section{Electrónica de potencia}

Las mejoras de eficiencia, rango de operación y respuesta dinámica de las centrales $\mathrm{HE}$ en su interacción con el sistema eléctrico apuntan a la generalización del uso de equipos conversores y switches de nueva generación. Para ello se trabaja activamente en el campo de la electrónica de potencia, alcanzando tensiones de $20 \mathrm{kV}$, así como en la reducción del tamaño y coste de este tipo de equipos, lo cual redunda en la mejora de su fiabilidad y rendimiento.

Un ejemplo de lo anterior es la central Grimsel II en Suiza, en la que se ha instalado el grupo hidráulico de mayor potencia hasta la fecha equipado con conversores de frecuencia para velocidad variable (4 máquinas síncronas de $100 \mathrm{MVA} \mathrm{c} / \mathrm{u})$.

\section{Simulación digital}

Las nuevas técnicas de simulación digital permiten la modelización y el análisis dinámico de las solicitaciones mecánicas sobre equipos y estructuras, así como el conocimiento de la distribución de las tensiones con un mayor grado de resolución dimensional y temporal. De esa manera se consigue mejorar la predicción de fallos y averías en las partes rotatorias y estáticas de la maquinaria, facilitando la comprensión y en su caso la mitigación de los fenómenos transitorios que involucran presiones o vibraciones y redundan en la inestabilidad o fallo de los equipos correspondientes. También poseen gran interés los avances técnicos en simulación de la respuesta dinámica (en términos eléctricos) de las centrales reversibles en su interacción con el sistema y la red de transporte.

\section{Sistemas avanzados de diseño (CAE)}

Los principales frentes de investigación y avance se refieren en este caso a los modelos computacionales de mecánica de fluidos, en particular en su aplicación al estudio y modelización informática de las interacciones agua-estructura en turbinas. Ello redunda en diseños no sólo más eficientes de este tipo de máquinas sino especialmente más robustos, por tanto más adecuados para soportar requisitos exigentes de rango y frecuencia de cambios en el modo de 
operación, aspectos a tener en cuenta singularmente en las centrales reversibles.

\section{Mantenimiento, supervisión y control}

El control en tiempo real de las variables físicas de operación de los distintos elementos (velocidades, presiones, temperaturas) y del estado físico de los componentes (alteración de su composición, corrosión y otros fenómenos de deterioro) constituye un campo interesante de aplicación de nuevas técnicas de monitorización y control. Todo ello supone una aportación creciente de tecnologías avanzadas de sensorización, comunicación, procesamiento y análisis de datos masivos en ambiente industrial.

\section{Mejora ambiental y de la infraestructura hidráulica}

En las obras civiles, su desarrollo tecnológico se basa en evitar en lo posible los daños medioambientales; en este sentido, la tendencia es el uso de nuevos materiales y sistemas de construcción y, sobre todo, el empleo de elementos prefabricados.

En lo que se refiere a la integración ambiental de las centrales HE, una de las líneas de investigación a tener en cuenta es la adecuación del equipo generador a que se ha hecho referencia anteriormente. Otros temas que son objeto de investigación son los denominados emplazamientos no convencionales, especialmente para los vasos superiores para uso de centrales reversibles, tales como minas abandonadas o pozos. Igualmente en cuanto a posibles emplazamientos de CHR en la costa, trabajando en combinación con parques eólicos offshore mediante bombeo y turbinación de agua salada.

Aparte de lo anterior deben mencionarse otras cuestiones relativas a la compatibilidad de la explotación hidroeléctrica con la piscifauna y los usos no energéticos del río, el aprovechamiento de los caudales ecológicos, la armonización paisajística de las centrales, el control de la sedimentación y muy especialmente la conservación de la obra civil que constituye en gran medida la infraestructura de soporte a las explotaciones HE. En relación con esto último hay que considerar varios temas de importancia relativos a la seguridad de las presas y su estado de funcionamiento hidráulico, el comportamiento reológico a largo plazo (especial atención al problema del concrete swelling) y la integridad estructural de todos los elementos a considerar. La complejidad y diversidad de actuaciones en relación con estos temas llevaría a redactar un informe específico sobre la problemática de cada uno de ellos, el estado de la técnica y las líneas de investigación activas en cada caso. 
En resumen:

El futuro de los aprovechamientos hidroeléctricos dependerá en gran medida de los siguientes aspectos:

\subsection{BARRERAS DE RECURSO HIDRÁULICO}

- La falta de conocimiento en detalle del potencial de recurso hidráulico por emplazamientos, dificulta o ralentiza la realización de proyectos.

Existen todavía muchos emplazamientos en infraestructuras existentes (por ejemplo, en el Convenio entre el MARM y el IDAE de diciembre de 2007 se identificaron 41 presas de titularidad estatal) o en zonas de mínima afección medioambiental, que pueden ser susceptibles de aprovechar hidroeléctricamente, de forma compatible con otros usos y desarrollables con criterios de sostenibilidad.

- Disminución de los recursos hídricos, por efecto del cambio climático, que afectara a la producción hidroeléctrica.

Esta futura disminución de las aportaciones hidrológicas afectara sobre todo a las centrales hidroeléctricas de tipo fluyente, que no tienen capacidad de regulación y se traducirá en una disminución en las horas equivalentes de funcionamiento.

\subsection{BARRERAS ADMINISTRATIVAS}

- Largas demoras para la obtención de las concesiones necesarias para el uso del agua, debido, entre otros motivos, a la dificultad para obtener la autorización medioambiental previa necesaria.

Para el otorgamiento de la concesión de aguas para uso hidroeléctrico es condición necesaria que el proyecto haya obtenido la Declaración de Impacto Ambiental favorable por parte del Organismo ambiental.

Fundamentalmente, dentro del proceso de tramitación concesional, largo y complicado, la mayor dificultad se encuentra en la obtención de la Declaración de Impacto Ambiental por parte del Organismo ambiental competente, ya que se vienen produciendo demoras de casi 2 años, lo que hace que el proceso global pueda llegar a durar hasta 10 años, desanimando a los inversores potenciales que preferirán otros proyectos más atractivos. 
También son comunes las dificultades en lograr conexiones a la red asequibles y no existen procedimientos rápidos para proyectos más pequeños.

- Oposición al otorgamiento de nuevas concesiones de agua de tipo fluyente por parte de determinados Organismos de Cuenca.

Actualmente, la interpretación de la Directiva Marco del Agua (DMA) está provocando sensibilidades en algún Organismo de Cuenca contrarias a la explotación de aprovechamientos hidroeléctricos existentes y al futuro desarrollo de los mismos.

El objetivo de esta Directiva es establecer un marco para la protección de las aguas continentales, costeras y subterráneas, que promueve un uso sostenible del agua, contribuye a paliar los efectos de inundaciones y sequias, mejora el medio acuático reduciendo vertidos y emisiones y previene todo deterioro adicional, mejorando el estado de los ecosistemas acuáticos y terrestres.

En este sentido, la implantación de la DMA puede impedir el desarrollo del potencial fluyente disponible en cauce de ríos y la eliminación de mini centrales en desuso.

Por otro lado, el establecimiento de los caudales de mantenimiento que se fijen en los instrumentos de planificación hidrológica puede afectar, en mayor o menor medida, a nuevos proyectos $y$ a centrales en funcionamiento si los valores fijados son muy altos.

- Dificultades para la renovación del período de concesión de aguas en las centrales hidroeléctricas existentes.

La no renovación de las concesiones puede derivar en abandono y subinversión de las plantas existentes durante los últimos anos de explotación de las mismas.

- Procedimiento de tramitación concesional complejo, incluso para proyectos pequeños.

- Dificultades para la obtención de las autorizaciones necesarias de los Organismos regionales y locales. 
- Dificultades en lograr conexiones a red asequibles.

Sus perspectivas futuras de desarrollo pasan por el cumplimiento de los criterios de sostenibilidad que demandan nuestros tiempos, es decir, los sectores implicados (agua y energía) deberán planificar, construir y gestionar teniendo en cuenta una mayor preocupación por los aspectos medioambientales, sociales y económicos.

Por ello, posiblemente los futuros desarrollos irán encaminados a la rehabilitación, modernización y/o ampliación de centrales hidroeléctricas existentes, mediante la renovación de instalaciones deterioradas, sustitución de antiguos equipos por nuevos de alta eficiencia, implantación de nuevos sistemas de automatización y tele gestión, conexión a la red eléctrica en el caso de centrales aisladas, etc., con el objetivo de mantener y/o aumentar la capacidad de producción de energía hidroeléctrica, de forma compatible con la preservación de los valores ambientales y acordes con la planificación hidrológica.

\subsection{ESCENARIOS DE DESARROLLO HIDROELÉCTRICO AL 2020}

\begin{tabular}{|c|c|c|}
\hline & Hipótesis & Actuaciones \\
\hline Escenario actual & $\begin{array}{l}\text { Sin mejorar el procedimiento de } \\
\text { tramitación concesional (sigue } \\
\text { vigente): plazo promedio de resolución } \\
\text { más de } 5 \text { años } \\
\text { Negativa al desarrollo del potencial } \\
\text { fluyente en cauce de ríos, por principio } \\
\text { de no deterioro de la Directiva Marco } \\
\text { de Aguas (DMA) } \\
\text { Eliminación de minicentrales en } \\
\text { desuso }\end{array}$ & $\begin{array}{l}\text { Ampliación de la capacidad de bombeo } \\
\text { de las centrales existentes (no nuevas) } \\
\text { por requerimientos del sistema } \\
\text { Desarrollo del potencial hidroeléctrico } \\
\text { "solo" en infraestructuras existentes } \\
\text { (CCHH pie de presa/canal de riegol y } \\
\text { repotenciación de centrales existentes }\end{array}$ \\
\hline Escenario óptimo & $\begin{array}{l}\text { Que exista nueva reglamentación } \\
\text { de procedimiento de tramitación } \\
\text { concesional, armonizado con la } \\
\text { regulación vigente en materia de } \\
\text { energías renovables } \\
\text { (Objetivo UE 20-20-20) } \\
\text { Establecimiento de "ventanilla única" } \\
\text { para las solicitudes, de forma que el } \\
\text { plazo de resolución máximo fuera de } \\
\text { un (1) año }\end{array}$ & $\begin{array}{l}\text { Máximo desarrollo centrales de } \\
\text { bombeo puro para permitir la mayor } \\
\text { penetración de la renovable no } \\
\text { gestionable (ampliaciones y nuevas) } \\
\text { Desarrollo del potencial hidroeléctrico } \\
\text { de tipo sostenible: infraestructuras } \\
\text { existentes del estado, turbinación } \\
\text { caudales ecológicos o ambientales, } \\
\text { rehabilitación de centrales } \\
\text { abandonadas y nuevas centrales } \\
\text { fluyentes de mínimas afecciones } \\
\text { medioambientales } \\
\text { Ampliación y repotenciación de } \\
\text { centrales existentes }\end{array}$ \\
\hline
\end{tabular}




\section{Conclusiones y líneas futuras de investigación}





\section{CONCLUSIONES}

Se resumen a continuación las conclusiones que se estiman más relevantes sobre los temas considerados. La argumentación detallada en que se basan puede encontrarse en los capítulos correspondientes de esta tesis.

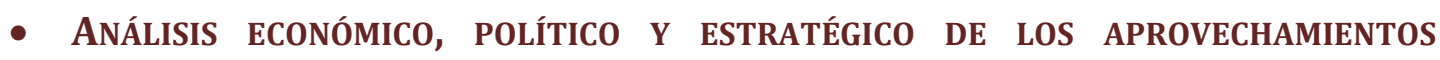
HIDROELÉCTRICOS A LO LARGO DE LA HISTORIA. EVOLUCIÓN DEL SECTOR.

Desde épocas tempranas el sector hidroeléctrico tuvo carácter oligopolístico.

El desarrollo de la industria eléctrica en España en las primeras décadas del siglo XX ha estado asociado con el primer gran empuje industrializador, simbiosis muchas veces instrumentada por el Estado.

Hasta la Guerra Civil, las empresas más importantes se repartían en dos grandes grupos, que controlaban en conjunto más del 50 por 100 de la potencia y de la producción: uno, el de la Barcelona Traction, que tenía prácticamente el monopolio del abastecimiento a Cataluña; otro, el de las empresas vinculadas al Banco de Vizcaya, que suministraba a Madrid y la zona de Levante, País Vasco y Andalucía.

La empresa Saltos del Duero, constituida en 1917, consiguió la concesión en 1926 de diversos aprovechamientos escalonados en el último tramo del río que suponía duplicar la producción nacional de electricidad de aquella época.

En cuanto al tendido de líneas, no existía una red general de interconexión entre las zonas, hasta que fue necesario dar salida a la energía generada por Saltos del Duero, que construyó en los años 30, varias líneas de $132 \mathrm{kV}$, principio de lo que llegará a ser, muchos años después, la red nacional.

En cuanto a tarifas, la declaración del suministro de electricidad como servicio público por un Real Decreto Ley de 1924, dio potestad a la Administración para exigir la obligatoriedad y regularidad de los suministros y fijar tarifas máximas "de aplicación".

El desarrollo de la industria y la creciente intervención administrativa en ella llevaron a las empresas a constituir en 1929 de la Asociación de Productores y Distribuidores de Electricidad.

En 1935, en vísperas de la guerra civil, la potencia instalada era de $1.480 \mathrm{MW}$ (el 75 por ciento de ellos en centrales hidroeléctricas, debido a la orografía 
española, y el 25 por ciento restante en centrales térmicas, necesarias para compensar la falta de generación hidroeléctrica por estiajes.). El consumo de electricidad por habitante era todavía muy inferior al de los países industrializados. Mientras que Cataluña y el País Vasco tenían consumos similares.

Analizando el período de postguerra hasta 1960 indicar que el sector eléctrico estuvo muy controlado por el Estado y congeló las tarifas a los niveles de 1936 hasta el año 1951. La reconstrucción se realizó lentamente sólo con medios nacionales.

Unos años de extrema sequía obligaron a implantar restricciones de suministro y generaron la creación de UNESA en 1944, firmada por las 17 empresas más importantes del sector cuya función coordinadora para hacer frente a la circunstancia de excepción que suponían las restricciones eléctricas fue encomendada por Orden Ministerial. Así, se evitó la nacionalización del sector a diferencia de otros países, como Gran Bretaña, Francia, Italia o Portugal.

La amenaza de las restricciones hizo nacer una nueva generación de sociedades eléctricas, debidas unas a decisiones gubernamentales (ENDESA Y ENHER) y las otras a la iniciativa privada. (FENOSA y Saltos del Sil). En 1944, la fusión de Hidroeléctrica Ibérica y de Saltos del Duero da lugar a la creación de Iberduero que pasó a ser la mayor compañía eléctrica española.

Se modernizó la gestión del sistema eléctrico y se actualizaron sus tarifas eléctricas. Se reguló el régimen de la Red General Peninsular obligando a las empresas integradas a efectuar los transportes e intercambios de energía acordados con otras empresas u ordenados por la Administración por razones de utilidad pública, así como a adquirir la energía disponible de reservas a favor del Estado o producida por centrales de empresas públicas o privadas. También estableció un sistema único de tarifas, las "tarifas tope unificadas".

En los años 50, la Compañía Sevillana de Electricidad absorbe a Mengemor en 1951, y March se adjudica en subasta los activos de la Barcelona Traction constituyendo con ellos la sociedad Fuerzas Eléctricas de Cataluña (FECSA).

En 1957 la potencia instalada era el 71\% hidráulica y el 29\% térmica.

Con todo, al término del período de la autarquía económica, el sector eléctrico había experimentado un gran crecimiento. Pese a las dificultades de la posguerra y a los problemas de abastecimiento en la época de las restricciones, 
el sector había tenido un desarrollo que le permitía continuar prestando un buen servicio al país, en momentos de despegue de la economía nacional.

En el período 1960-1975, el sector eléctrico vivió una de las mejores etapas de su historia. En los primeros años del periodo, el crecimiento del parque de generación español se debió principalmente a las instalaciones hidroeléctricas. Se construyeron grandes embalses y centrales muy notables de la ingeniería española pero no fue suficiente para cubrir la demanda por lo que se aumentó el parque termoeléctrico de carbón y fuel oil. Así, en el balance energético nacional, la producción termoeléctrica superó a la hidroeléctrica, convirtiéndose en la base del sistema eléctrico nacional.

Durante los años sesenta, se materializó en el Plan Energético Nacional 19721982.

Durante esta etapa, prosiguió también el proceso de concentración empresarial en el sector.

Se establecieron tarifas de estructura binómica.

Durante la primera crisis del petróleo, absorbió en gran parte el Estado en sus cuentas el incremento de coste de los productos petrolíferos. La Administración se limitó a promover la construcción de nuevas centrales hidroeléctricas y de carbón. En la segunda crisis del petróleo de 1979, el Gobierno acompaña a las medidas de fomento con el Plan Energético Nacional (PEN), paralizando las centrales de fuel.

El aumento anual de la demanda se redujo sensiblemente que trajo como consecuencia el deterioro de las cuentas de las empresas eléctricas y la bajada de sus cotizaciones en Bolsa. Cuando, además, el sector estaba inmerso en un ambicioso plan de crecimiento. La red de transporte también se había incrementado sustancialmente. Y ante el estancamiento de la demanda, era previsible una situación de sobre equipamiento.

En los años 1982-1986, Empresas y Estado acordaron el procedimiento de traspaso de la red al sector público, la revisión del Plan Energético Nacional de 1979 y la adopción de diversas medidas para el saneamiento económico del sector, entre ellas una política de tarifas suficiente.

Se creó una empresa mixta con mayoría de capital público, Red Eléctrica de España, que sería la propietaria de la red de alta tensión necesaria para optimizar la explotación unificada del sistema eléctrico. 
La generación de electricidad y su distribución en el mercado quedaban ahora separadas e independizadas funcionalmente en las empresas eléctricas.

Se llevó a cabo la reordenación del sector y su saneamiento económicofinanciero de manera acordada con Unesa. Parte esencial de este acuerdo fue un "intercambio de activos".

El Gobierno aplicó un nuevo régimen tarifario, el llamado Marco Legal Estable, que permitió a las empresas sanearse.

Durante el periodo del Marco Legal Estable, Iberduero e Hidroeléctrica Española, acordaron fusionarse y formaron Iberdrola, que representaba el 40 por ciento del sector eléctrico español. El grupo eléctrico público creció hasta hacerse con otro 40 por ciento del sector. El 20 por ciento restante se distribuiría entre Unión Fenosa (un 15 por ciento) e Hidroeléctrica del Cantábrico.

Entró en vigor en 1995 la Ley de Ordenación del Sistema Eléctrico Nacional (Losen), que dio solución al problema de la moratoria nuclear.

El período comprendido entre el año 1996 y la actualidad, se caracteriza por la liberalización del sector eléctrico. Se abría la puerta a la privatización de ENDESA, que previamente se hizo con el control de Fecsa y Sevillana.

Entró en vigor la Ley 54/1997 del Sector Eléctrico.

A partir de 1 de enero de 1998, comenzó a funcionar en España un mercado mayorista de producción de electricidad, gestionado por una entidad independiente, la Sociedad Operadora del Mercado.

Al entrar en vigor esta nueva regulación, las empresas eléctricas dejaron de percibir la retribución que les aseguraba el Marco Legal Estable. Para compensar los menores ingresos, la Ley del Sector Eléctrico les reconoció unos costes de transición a la competencia, los CTC, durante un plazo de diez años.

El sector eléctrico español se enfrentaba así, por primera vez en su historia, a la competencia. Las directivas europeas y la creciente globalización de los mercados han conducido a que esa competencia sea, no sólo entre empresas españolas, sino también con empresas extranjeras. En este escenario nuevo, los actuales actores del sector podrán moverse satisfactoriamente gracias a la concentración empresarial que en él se ha producido a lo largo de su historia. 
Ahora cada empresa habrá de establecer necesariamente sus propias políticas industriales y comerciales, que ya no podrán ser comunes a todo el sector.

\section{- EVOLUCIÓN DE LA INGENIERÍA DE TURBINAS Y TURBO-BOMBAS}

Para desarrollar las conclusiones sobre la evolución de los elementos mecánicos fundamentales en los aprovechamientos hidroeléctricos como son las turbinas hidráulicas, hay que remontarse a la rueda hidráulica y la evolución de la misma hasta las turbinas actuales.

En la Edad Antigua (desde 3.300 a.C hasta 476 d.C) se sitúan los comienzos de la rueda hidráulica hace 5.000 años en el pueblo sumerio que la utiliza para aprovechar la energía de los cauces disponiendo molinos.

Tanto griegos como romanos emplearon las ruedas hidráulicas, siendo anteriores las ruedas griegas inventadas por Filón De Bizancio en el S. III a.C, y eran ruedas horizontales de eje vertical llamadas norias o molino griego.

El molino romano se comenzó a construir en el S. I a.C, y fue porque les parecía que su antecesor griego ofrecía unos rendimientos bajos. Este molino de rueda vertical descrito por Vitruvio, tiene una rueda con eje horizontal que hace girar un tambor dentado, que se llamará más tarde "rodete". Sus dientes se entrelazan con los de otro tambor más grande cuyo eje vertical da lugar directamente al movimiento de rotación de las muelas.

Es reseñable el complejo industrial harinero de Barbegal del S. II o III, en el sur de Francia, formado por 16 molinos, del tipo conocido como aceña, pero con rueda vertical dotada de cangilones.

En provincias como Hispania y en Pompeya se utiliza un tipo especial de molino romano caracterizado porque las muelas estaban peraltadas en menor o mayor grado respectivamente.

Los tipos de alimentación de los molinos romanos son de alimentación inferior, alimentación por la espalda o a media altura, y alimentación superior.

Las dimensiones de los molinos romanos están comprendidas entre 1,5 y 3 metros de diámetro de rueda según el tipo, y ancho de 25 a $70 \mathrm{~cm}$. Las muelas son de un diámetro comprendido entre los 55 y $85 \mathrm{~cm}$.

La ubicación del molino romano es diversa pero gracias a la alimentación por acueducto, se podían separar de las riberas acercándose a los núcleos de consumo. 
El molino de rueda horizontal, precursor de las primeras turbinas, tenía el eje vertical haciendo girar la muela sin necesidad de tambores dentados. Este molino es más adecuado para caudales bajos, pero necesita una altura de caída bastante grande.

Son conocidos varios molinos de rueda horizontal construidos según distintos conceptos de alimentación, mediante pozos cilíndricos que dan lugar a un flujo en remolino dentro de los pozos, que hace rotar a la rueda horizontal que está en el fondo, necesitándose sólo un desnivel de 2 metros, o mediante alimentación por torre de caída de cuatro a diez metros, cuya parte baja hace que salga a presión hacia las palas de una rueda horizontal.

En China, el pilón hidráulico era de rueda vertical, utilizándose las ruedas horizontales con palas planas para mover los fuelles de las forjas para el desarrollo de la metalurgia china, de gran calidad, y para la molienda de cereales principalmente.

La importancia que tuvieron los molinos hidráulicos para las sociedades preindustriales fue primordial al tratarse de una herramienta fundamental para el cambio de una economía de subsistencia a una economía de mercado.

En la Edad Media (desde 476 d.C. hasta 1453 d.C.) la importancia de las ruedas hidráulicas era evidente ya que eran objeto de búsqueda de sabotaje en las guerras.

Molinos singulares de esta época fueron los molinos-barco, más baratos y prácticos, los molinos que se instalaron sobre pilotes en pleno cauce alejándose de la ribera para disponer de una corriente de mayor velocidad y los molinos de marea.

En el siglo VII, los molinos de agua son frecuentes en Irlanda y parecen expandirse a la Germania no romanizada en el siglo VIII. Sin embargo, en el interior de las antiguas fronteras del imperio, los acueductos no se mantienen y caen en la ruina, lo que provoca que las villas acerquen sus centros urbanos a la riberas de los ríos salvo en Roma.

Otra expansión particular de los molinos se ve acompañado en el S. VII del desarrollo de la regla benedictina que establecía que en cada monasterio se dispusiera de molino.

El molino hidráulico ganó terreno en toda Europa durante el siglo VIII hasta que llega su edad de oro que se desarrolla entre el S. XI-XIII. Es considerado uno de los mayores progresos técnicos de esa época al adaptarse a multitud de 
industrias, como por ejemplo, molinos harineros, en aserraderos, martillos y bombas, para accionar fuelles, para la batanadura de la lana, para exprimir la caña de azúcar, etc. utilizándose tanto en posición vertical como horizontal.

En la Península Ibérica preexiste la rueda horizontal de álabes planos, no apareciendo la aceña o molino de rueda vertical hasta el S. XI o XII en Castilla, y hasta después de la reconquista, en los S. XII y XIII entre el Duero y el Tajo.

Oriente presenta las mismas características.

Las evoluciones técnicas que se observan en la Edad Media son:.

- En el mundo árabe se encuentran ruedas horizontales en las que los álabes forman un ángulo con el eje de rotación y son curvos o en forma de cuchara.

- En el mundo chino, en el que el agua es abundante, la rueda horizontal de palas planas, paralelas al eje de rotación para ser la tipología dominante.

- En el mundo occidental, sin embargo, se observa una separación entre el norte y el sur. En el norte, los molinos hidráulicos son de rueda vertical.

A partir del S. XI, sobre todo en los monasterios de montaña, se ven molinos hidráulicos de cubo alimentados por arriba como era más habitual en la época romana. El "cubo" se aplicó a los molinos que utilizaban rueda hidráulica horizontal y un único eje para transmitir el movimiento a las muelas.

En el sur, los molinos hidráulicos eran principalmente de rueda horizontal.

Es característico en la Edad Media, el aprovechamiento progresivo de los cursos de agua más importantes gracias a la creación de presas con su embalse asociado para elevar el nivel de agua y así crear la altura de caída de agua necesaria para colocar los molinos.

Analizando la evolución de las turbinas desde el $\underline{\mathrm{S}}$ XVI en adelante, es interesante reseñar un bosquejo de una turbina de álabes helicoidales confinada en una cuba de piedra inventada en 1.565, que aparece en el libro de Besson, "Theatre des Instrumens mathematiques et mechaniques", y presentada como una nueva manera de hacer un molino de agua.

En 1607, Strada, describió en un libro las ruedas con cucharas similares a la posterior turbina Pelton. 
En esta época se da una importante concentración industrial en las riberas de los ríos importantes, como Bazacle en el Garona. Las ruedas horizontales de Bazacle son, de hecho, modelos de turbinas horizontales.

En el S. XVIII la construcción de grandes molinos en los ríos importantes se generaliza. Se describen en la enciclopedia de Diderot y D'Alembert..

Mención especial merece el complejo de los Molinos Nuevos de Murcia que es el más grande de Europa.

En 1750 Segner, diseña una rueda a reacción posiblemente inspirado por Bernouilli, y construyó la denominada rueda de Segner (1750), por ello es conocido como el padre de la turbina de agua.

A partir de cambios realizados sobre la rueda de Segner, se produce la evolución progresiva de la turbina salvo el caso de las turbinas de acción.

En 1954, Euler, propuso mejoras sobre la turbina Segner que afectaban a la fricción y a la reducción de peso, dándole una forma acampanada, que dio lugar a un nuevo concepto de turbina. La alimentación de la rueda en su parte superior por un distribuidor fijo.

Euler también mencionó que la presión siempre debe ser positiva, siendo la descripción temprana de la cavitación en turbomáquinas hidráulicas.

En 1824, Burdin diseña, por tanto, la primera turbina centrífuga con admisión de flujo a través de álabes inclinados.

En 1832, es Fourneyron consigue finalizar la turbina centrífuga mejorando principalmente las pérdidas en la misma respecto de la turbina de Burdin.

En 1840 se patenta la turbina Fontaine-Baron que regula el caudal de agua que atraviesa la turbina mediante pequeñas compuertas que permiten abrir $u$ obturar cada canal inter-álabes del distribuidor.

En 1841, se patenta la turbina Jonval. Es la primera turbina de reacción con tubo de aspiración.

En 1850, Koechlin realiza una turbina en que adjunta encima de la rueda con álabes un distribuidor fijo.

También en 1850, Thomson patenta la turbina tipo vortex.

En 1849, Francis pone a punto de la turbina de alimentación radial, con el flujo circulando desde el exterior hacia el interior. Es la famosa turbina Francis que se impondrá a partir de este momento como la más eficaz para los saltos de mediana altura con un caudal importante. 
A partir de los años 1886, se dotará a la turbina Francis de un tubo de alimentación en espiral que contribuirá a la orientación de la alimentación a la entada del distribuidor. Así la turbina Francis verá ampliarse su dominio de aplicación hacia grandes saltos con caudales importantes.

Las turbinas Francis son turbinas de reacción que se pueden clasificar en Francis lentas (de flujo radial) o Francis rápidas (de flujo diagonal). En las turbinas Francis lentas, el flujo a la entrada es prácticamente radial, con lo que se aprovecha al máximo la acción centrífuga, sin embargo, la descarga por el centro del rodete es complicada, por lo que el caudal se halla limitado. En las turbinas Francis rápidas, el flujo es diagonal, ya que el líquido penetra en el rodete con una cierta componente axial.

En 1912, Kaplan realiza una turbina con un rotor en forma de hélice con los álabes de ángulo variable para optimizar el rendimiento en función de la velocidad del agua.

La turbina Kaplan se considera mejor que la turbina Francis para alturas de salto bajas.

La evolución que se produjo hasta llegar a la turbina Kaplan es la siguiente:

- Se empezó a construir rodetes más rápidos del tipo Francis - $\mathrm{n}_{\mathrm{s}}=450$ rpm;

- Para estos rodetes hay un gran espacio entre el rodete y distribuidor, lo que permitía la obtención de mejores rendimientos debido la disminución de la fricción;

- Alrededor de 1912, Victor Kaplan construyó una turbina similar a del tipo Francis, en que el agua penetraba en dirección radial y después de dejar el distribuidor, circulaba sobre el rodete y caía completamente libre, alcanzando el mismo con dirección preponderantemente axial;

- Después, se siguió con una serie de perfeccionamientos hasta llegar a las formas actuales, tanto de los rodetes Hélices como de los rodetes Kaplan;

- Como primera etapa de perfeccionamiento, fue suprimida la corona exterior del rodete.

- Posteriormente, como resultado de varias experiencias, se observó que la curva de rendimiento en función de las diversas aperturas de los álabes del distribuidor se presentaba siempre muy aguda para el rodete con palas fijas. Es decir que la turbina solamente operaba con buenos rendimientos para determinadas posiciones de los álabes del 
distribuidor (aperturas correspondientes a los caudales próximos al caudal de diseño).

- Descubría que había una estrecha relación entre la posición de los álabes del rodete con la apertura del distribuidor y el rendimiento óptimo.

- Después de esto, empezó a construir turbinas dotada de un dispositivo de regulación que posibilitase las palas del rodete acompañar la variación de posición de los alabes del distribuidor, tomando siempre la correspondencia óptima entre $\beta 2$ (ángulo que define la posición de las palas del rodete) y $\alpha$ (ángulo que define la apertura de los alabes del distribuidor).

- De esta manera, las turbinas de esto tipo, con palas móviles, pasaron a ser llamadas de Turbinas Kaplan, en cuanto las de palas fijas recibieran la denominación de Turbinas Hélice.

- La curva de la turbina Kaplan es la envolvente de las curvas de rendimiento de diversas turbinas Hélice.

Las turbinas hélice y Kaplan también son de reacción, pero de tipo axial. Las turbinas Kaplan se emplean generalmente para caudales grandes y saltos pequeños. Gracias a los álabes móviles, las turbinas Kaplan mantienen rendimientos elevados, aún en los casos de grandes variaciones de salto y de caudal. Cuando por el contrario, se disponga de un caudal suficientemente constante, las turbinas hélice resultan más ventajosas, por lo que a coste se refiere.

La turbina Dériaz es una variante de la turbina Kaplan que consiste en disponer el eje de giro en los álabes del rodete inclinado respecto del eje de giro del rotor.

Esta turbina es la indicada para la explotación de los saltos de mediana y elevada altura, es decir de $20 \mathrm{~m}$ a $400 \mathrm{~m}$, y una potencia máxima de $300 \mathrm{MW}$ y tiene un buen rendimiento tanto funcionando como turbina o como bomba, lo que no sucede en el caso de las turbinas Francis.

La creciente demanda energética obligó a pensar en el posible aprovechamiento de saltos con pequeñas cargas y por ello fueron apareciendo las turbinas tubulares, Bulbo, de pozo, Harza-Straflo, S y Huguenin. La particularidad fundamental en todas ellas es que el eje se ha dispuesto en dirección horizontal o ligeramente inclinado.

En estos tipos desaparece la cámara espiral (caracol), practicándose la alimentación directamente desde el embalse. 
En cuanto a las turbinas de acción, hay que citar a la turbina Schwankrug como la primera, adecuada para saltos grandes con poco caudal.

En 1854, crea una variante de turbina, la de impulsión, que es de eje horizontal, en la que es posible controlar el flujo de agua enviado a las palas del rotor, regulando de esta manera la velocidad de rotación de la turbina.

En 1880, Pelton patenta una turbina (que sustituye a la Girard) que aplica el principio mediante el cual, si un jet de agua impacta en la arista en lugar de en el fondo de la cuchara, transmite al álabe una cantidad de movimiento mayor. Se adapta bien a caudales pequeños con grandes alturas de salto.

En 1919, y dentro de las turbinas de impulsión, se diseña la turbina Turgo para saltos de desnivel medio como una modificación sobre la Pelton.

En 1933 se patenta la turbina Crossflow. A diferencia de la mayoría de turbinas hidráulicas, que tienen un flujo axial o radial, en la turbina de flujo transversal el fluido atraviesa los álabes de forma diagonal. Así el agua pasa dos veces: del exterior al interior y del interior al exterior. Al pasar dos veces se obtiene una eficiencia elevada para flujos variables, además de limpiar el rotor de residuos. Es apta para bajas alturas pero elevados caudales.

Los grupos turbo-bomba se crearon para dotar a las centrales reversibles de equipamiento que permitiera tanto turbinar como bombear, por lo que deben disponer de bombas y turbinas por un lado y de motores y generadores, respectivamente, por otro.

Así se plantearon distintos esquemas evolucionando del "esquemas cuaternarios", al "esquema ternario" y finalizando en los "esquemas binarios" aprovechando que las bombas pueden funcionar razonablemente bien también como turbinas.

Estas centrales fueron teniendo cada vez saltos mayores, llegando casi a los 1.000 metros en la actualidad, por lo que a partir de los años 70 y sobre todo los 80 , se han generalizado las turbo-bombas multietapas, en los que la impulsión se realiza en tres etapas sucesivas.

La necesidad de flexibilidad de las centrales reversibles, ha obligado a que en los últimos diez-quince años se hayan ido desarrollando disposiciones nuevas y turbinas de velocidad variable que sean capaces de variar de forma casi inmediata su potencia.

Las soluciones y disposiciones que se están adoptando en los últimos años, desde el punto de vista de las turbinas, son las siguientes: 
- Disposición de sistemas ternarios.

- Utilización de turbinas de velocidad variable.

- Utilización de spleeters en las turbinas convencionales.

En cuanto a las tendencias actuales de equipamientos para pequeña hidroelectricidad, además y paralelas a los grandes desarrollos hidroeléctricos, se están desarrollando turbinas que se adapten al aprovechamiento de pequeños saltos sin presa, o incluso que se coloquen en el propio cauce. En este sentido, han aparecido en el mercado una serie de turbinas como la Gorlov, Darrieus, Tyson, Hydraulienne, Syphon, etc.

Respecto de las turbinas españolas cabe indicar que existieron fábricas de construcción puramente nacionales nacidas a finales del S. XIX o principios del $\mathrm{XX}$, que tuvieron su momento álgido para acabar cerrando su actividad sobre los años 70. Actualmente, las empresas principales fabricantes de turbinas son empresas extranjeras con fabricación en España.

Analizando las turbinas instaladas en centrales españolas, hay que indicar que en general, las turbinas españolas siguen el criterio de selección según los parámetros fundamentales de utilización de cada tipología en función de salto y caudal. Las turbinas Pelton se emplean para saltos elevados que tienen poco caudal. Las turbinas Francis son las más implantadas ya que se adaptan muy bien a casi todo tipo de saltos y caudales, siendo su rango de utilización por tanto, muy amplio. Y de hecho de todas las turbinas analizadas, la más utilizada es la Francis (61\%), seguida de la Kaplan (23.7\%) y de la Pelton (15.3\%).

\section{- EVOLUCIÓN DE LA TECNOLOGÍA ELÉCTRICA}

Desde el punto de vista de los equipamientos eléctricos y de sus tecnologías puede concluirse que:

En el campo de los alternadores y sistemas de excitación:

Se trata de tecnologías maduras, con alto grado de desarrollo en el que cabe esperar mejoras como consecuencia de avances lentos y continuados y no de grandes "descubrimientos".

En el caso de los alternadores la evolución ha ido en el sentido de potencias cada vez mayores, posibles fundamentalmente por el avance en el conocimiento y aplicación de los materiales aislantes. 
Esta evolución ha sido posible también gracias al uso de sistemas de refrigeración cada vez de mayor importancia.

La electrónica de potencia permitió el uso de sistemas de excitación estáticos, que simplificó en buena medida el diseño de los alternadores.

En los últimos años se está produciendo un cambio en el sentido de una mayor utilización de alternadores no convencionales, o mejor dicho no habituales en centrales hidroeléctricas. Estos alternadores no suponen una novedad en el campo eléctrico, pero sí su aplicación para conseguir grupos de velocidad variable, que les hace más flexibles y tener mayor operatividad, así como tener mayores rendimiento.

Es de esperar que en los próximos años este tipo de grupos se vaya generalizando, tanto en nuevos grupos o centrales, como en la mejora de los ya existentes.

En el campo del transporte de la energía:

El desarrollo de las líneas en corriente continua tendrá un fuerte desarrollo, fundamentalmente para largas distancias y para líneas submarinas.

La electrónica de potencia ha sido clave en el desarrollo de este tipo de transporte.

Este tipo de transporte de la energía permitirá mejorar las interconexiones entre países en general, lo que, al menos en teoría, debería contribuir a la seguridad de suministro y a la reducción de costes de la energía eléctrica.

En el caso de España está permitiendo y lo hará más en el futuro mejorar las interconexiones con los países vecinos.

En países en vías de desarrollo el transporte en corriente continua permitirá el desarrollo de aprovechamientos hidroeléctricos ubicados a grandes distancias de los centros de consumo.

Este hecho no es aplicable a España, en donde la energía hidroeléctrica parece haber tocado techo. 


\section{- EVOLUCIÓN DE LA INGENIERÍA DE LAS PRESAS HIDROELÉCTRICAS}

Las conclusiones principales obtenidas del estudio de la evolución tecnológica de las presas asociadas a aprovechamientos hidroeléctricos a lo largo de su historia, son las siguientes, siempre remontándonos a los precedentes de las centrales hidroeléctricas como fueron los molinos y aceñas, y posteriores presas de fuerza.

En la Edad Antigua, de los primeros años del S. I d.C., se tiene conocimiento de presas de origen romano, aunque incierto, cuyo uso era de Fuerza en Portugal, ésta es la presa arco (con dos contrafuertes) de Monte Novo, y las presas españolas de gravedad de Melque I, II, III, IV y V en Toledo cuyo uso era abastecimiento y fuerza, y la presa de gravedad zaragozana de San Marcos destinada a riego y fuerza.

En el período desarrollado de la Edad Media al S. XVIII, se caracteriza por la construcción de azudes para elevar el nivel de agua de los ríos creando la altura de salto necesaria de alimentación a molinos.

A partir de la Edad Media, son los ríos más importantes para los que progresivamente se planifica cada vez más su aprovechamiento. Como el río Guadalquivir en Córdoba en el que las instalaciones industriales se colocaban junto a presas de derivación. En el siglo IX, se construye en Córdoba un embalse sobre el río Guadalquivir que alimenta doce ruedas hidráulicas.

En el S. X, al sur de Persia construyen presas para molinos. Las presas de Amir y de Feizabad se equipan en el S.X. de 30 y 22 ruedas horizontales, respectivamente. La presa de Amir tenía una sección transversal, con el paramento de aguas arriba vertical y el de aguas abajo con un talud 1/1,4, siendo el ancho de la base algo superior al doble de la altura. Los materiales utilizados fueron sillería unida con mortero de cal.

Al principio del S. XII, presa de Bazacle junto con otras dos presas más pequeñas, permite alimentar más de 60 molinos-barco. La tipología de las presas era de pilotes de madera con piedras entre estos pilotes.

El río Eresma en Segovia, es otro ejemplo de la construcción de azudes o presas para obtener la energía que hacía mover las máquinas o ingenios. Son presas constituidas por un fuerte muro de sección rectangular de algo más de tres metros de grosor y, en la mayoría de los casos, formado por dos hojas exteriores de sillería o mampostería bien trabada con relleno de cal y canto. 
La forma en la coronación (chapadura) no está realizada por un plano horizontal, sino por dos planos inclinados. El faldón de aguas arriba es muy pequeño y el de aguas abajo mucho mayor. Esta forma hace que el agua, al coronar la presa, adquiera mayor velocidad y se aleje en su caída del muro de la presa para evitar el efecto de socavación.

Se podían construir con piedra, con madera y piedra e incluso sólo con madera. A partir del S. XV, se multiplican sobretodo en Suiza y en España las presas para molinos en los que los saltos son cada vez más grandes, de muchos metros hasta alcanzar más de la decena.

Las presas españolas son muy interesantes, en las que parece natural que se extrapole la antigua técnica de las presas romanas también para alimentar molinos.

La presa de Castellar, en el sur de España, con su altura de 19 metros se mantiene durante largo tiempo como record de la presa más alta. El molino se construye justo al pie de la presa, con 3 ruedas horizontales.

Es importante hacer una mención especial a las presas extremeñas. La "presa del estanque de Guadalupe", es precursora de una tipología autóctona de presas "albueras extremeñas". Se trata de presas de fábrica (básicamente mampostería), con sección transversal más o menos rectangular (como la mayoría de las presas "precientíficas", en la mayor parte de los casos con contrafuertes y molinos adosados aguas abajo.

La mayor de todas estas presas es la de Albuhera de Feria, una gran presa de 22 metros de altura, construida en 1747 para alimentar los molinos de la región.

Un poco más tarde, esta presa será equipada con una turbina para producir electricidad para dotar de ella a los pueblos de la región.

La entrada de agua al molino se hacía por un tubo embebido en el macizo de la presa que la atravesaba, hoy taponado.

Cabe hacer mención especial a Pedro Bernardo Villarreal de Bérriz por su importante aportación técnica al diseño y ejecución de presas en el S. XVIII, en el País Vasco y su influencia en el resto de España. Las innovadoras presas de arcos escarzanos y contrafuertes son su aportación más original a la ingeniería de su tiempo. Proporciona relaciones empíricas y criterios de diseño que permiten construir con seguridad este tipo de presas. 
Tampoco pierde de vista el régimen de los ríos de su territorio y por ello, a diferencia de otras presas anteriores de este tipo, se contempla el vertido frecuente de los excedentes de agua sobre la coronación sin que por ello se arruine la obra.

Aragón cuenta con un patrimonio hidráulico de presas y azudes antiguos numeroso. Incluso algunos, podrían haber sido de factura romana posteriormente rehabilitada. Cuentan con unas tipologías típicas para aquéllos que proporcionaban el agua para mover molinos que después se convertirían, muchos de ellos, en fábricas de luz. Estas tipologías eran azudes de piedra suelta y escollera, de selva o estacada, de madera y de cantería. Destaca el azud de Montearagón.

Del S.XIX a la actualidad se han producido cambios notables en la tecnología de presas, fundamentalmente favorecidos por las necesidades de producción de electricidad mediante el empleo de la energía hidráulica, y por lo tanto, presas más altas.

En 1826, Navier plantea la necesidad de considerar la distribución de tensiones en la estructura y los conceptos de módulo de elasticidad y coeficiente de seguridad. Una vez admitidos los principios de la mecánica racional, se comienzan a aplicar al diseño de presas.

En 1850, Sazilly defiende el perfil de igual resistencia, como resultado de imponer la condición de que la tensión en el paramento de aguas arriba, cuando el embalse está vacío, sea igual a la de aguas abajo, cuando el embalse está lleno, limitando, además, la tensión máxima admisible en la fábrica, para impedir la excesiva deformación y fisuración, así como, asegurando que no se produce el deslizamiento en cualquier plano horizontal del cuerpo de presa.

Sus teorías las pone en práctica Delocre en la construcción de la presa de Furens (1859 -1866) que se diseña con planta curva. Las modificaciones sucesivas de ese primer perfil darían lugar hacia el año 1900 a un tipo de presa de gravedad que fue conocida en el mundo entero bajo la denominación de presa francesa o perfil tipo Delocre, y que evolucionaría finalmente en 1923 en una presa de perfil triangular.

En España la primera presa que se proyecta teniendo en cuenta la Mecánica Racional, de 1882, es la presa de El Villar. 
Las propiedades resistentes de las bóvedas fueron pronto aplicadas al diseño y construcción de presas como en la presa de Zola, de 38 metros de altura y considerada la precursora de las presas arco modernas.

La sustitución de la mampostería por hormigón favorece en Estados Unidos la aplicación de esta técnica de presas bóveda.

Aparecen las presas de bóvedas múltiples que, en definitiva, son presas de contrafuertes con pantallas entre los mismos en forma de arco o bóveda.

Son presas de arcos múltiples la presa Daniel-Johnson, cerca de Quebec, Canadá y la presa de Dixence, que hizo necesario hacer contiguos a los contrafuertes en el paramento de aguas abajo para disminuir los efectos térmicos. Fue record mundial de altura de presa de contrafuertes hasta después de la Segunda Guerra Mundial, con sus 87 metros.

Rápidamente la construcción de presas se convierte en una técnica muy flexible por la multiplicación de formas gracias al empleo del hormigón armado. Las bóvedas múltiples y los contrafuertes aparecían como la solución que podía adaptarse a cualquier sitio en el que se quisiera implantar una presa.

Las presas de contrafuertes fueron perdiendo preponderancia debido, fundamentalmente, a razones económicas.

En cuanto a las presas arco, la presa de Sweetwater, en 1888, se convirtió en la más alta del mundo de este tipo con 30 metros y más de 100 de longitud en coronación. El perfil de la presa era bastante más robusto que el de la presa de Zola y según sus calculus, la resultante de las fuerzas externas quedaba dentro de la base.

La presa bóveda fue adoptada en Francia a partir de 1920 aproximadamente para los sistemas hidroeléctricos de montaña para abaratar costes frente a las presas de gravedad convencionales.

El número de países con suficiente conocimiento y maestría para construir una presa arco de características modernas a finales del siglo XIX y principios del XX era muy reducido.

La sofisticación de la construcción da lugar a lo largo de los años 50 al empleo de bóvedas delgadas permitiendo una economía de materiales sin sacrificar la seguridad, asegurando ésta por la forma rigurosamente calculada de la bóveda. 
En España, la evolución de las presas arco comprendía dos ámbitos simultáneos, el de las formas, y el de los métodos de cálculo.

En cuanto a las formas se habían dado dos criterios opuestos, el de las formas gruesas y el de las formas ligeras, que tendían ya a converger para dar lugar a tipos mixtos predominantes en los últimos años 30. El cambio de uso de material para este tipo de presas de mampostería a hormigón armado, favoreció la realización de estructuras más esbeltas.

Dados los problemas de cálculo que eran conscientes que tenían, se recurre al ensayo sobre modelo reducido.

Sin embargo, el progreso de la construcción en hormigón no hace abandonar totalmente la realización de presas de mampostería, ni ciertas técnicas tradicionales como las presas de materiales sueltos, derivadas de la técnica de construcción de diques marítimos y los diques de tierra.

Respecto a las presas de materiales sueltos, formadas principalmente por un núcleo central impermeable constituido por arcilla compactada introduciéndose en parte en la cimentación, se utilizan en sustitución de las presas de gravedad en el caso de largas cerradas o bajos saltos, cada vez que los imperativos económicos entran en juego.

La primera gran presa en tierras fue construida en Panamá en 1912. La técnica se fue perfeccionando en el curso de los años 30 para regularizar y explotar los grandes ríos.

En el año 1923 comenzó la construcción de la presa de Dix, concluyéndose en 1927, en Kentucky, presa de materiales sueltos con pantalla de hormigón. De 87 metros de altura, esta presa hidroeléctrica fue record de altura en presas de materiales sueltos en Estados Unidos antes de 1930.

En España, una de las mayores presas de materiales sueltos con núcleo de arcilla destinada a uso hidroeléctrico, es la de Portodemouros de 1967.

En general, las tipologías de las presas de materiales sueltos más habituales asociadas a aprovechamientos hidroeléctricos han sido heterogéneas, escolleras con núcleo impermeable y escolleras con pantalla de hormigón principalmente.

En España, la evolución de la tipología de presas en un siglo (1900-2000) ha sido la siguiente. Se observó un claro predominio de las presas de gravedad 
hasta la década de los años 70 porque eran las únicas que ofrecían garantías suficientes de estabilidad y de seguridad.

Las presas de materiales sueltos, no es hasta los años 70 cuando empiezan a adquirir mayor importancia. Debido a su menor coste, se produce un despegue en la construcción de este tipo de presa que, posiblemente, no se había producido con anterioridad por la falta de maquinaria que hiciese viable su construcción. Sin embargo y debido a los accidentes de los 80 , la tendencia que se venía dando se compensa, siendo al final del siglo XX el porcentaje de ambas tipologías, similar.

Las presas bóveda ocupan un lugar significativo a partir de la década de los 70, con porcentajes entre el 5-8\% aunque sí son una gran parte de las presas más importantes. Tardaron en aceptarse las presas arco debido principalmente a la dificultad de conocer el estado tensional, lo que provocaba incertidumbres inaceptables para muchos.

El buen comportamiento de presas arco como las de Amsteg, Spitallam, y Montejaque y Alloz en España, favorecieron ese cambio de mentalidad en la comunidad presística. Los ensayos en modelo reducido fueron un espaldarazo importante para la construcción de presas según esta tipología.

Las presas de contrafuertes constituyeron también alrededor de un 10\% de las presas construidas hasta la década de los 70. La escasez de materiales y una cierta experiencia en la realización de proyectos de este tipo a lo largo de décadas anteriores, dieron lugar a un principal apogeo de esta tipología de presas en los años 50. Sin embargo, a partir de los setenta no se construyeron más presas de esta tipología.

De las más de 250 presas hidroeléctricas analizadas, las presas de gravedad han sido las de tipología preponderante con diferencia. Hasta el año 1936, sólo hay 3 de materiales sueltos, 3 bóvedas, 2 móviles, siendo el resto de gravedad.

De los años 40 al 1975 es cuando aparecen las de tipología de contrafuertes, 7 en total, construidas en los años 50 principalmente, salvo dos de ellas que son del año 1969. En esta etapa de desarrollo intensivo de la hidroelectricidad, es cuando se detecta la mayor construcción de presas de materiales sueltos, concentradas en las décadas de los 60 y 70 . También es en esta etapa cuando se construyen, en mayor medida, presas bóveda.

Puede concluirse que las presas asociadas al sector hidroeléctrico, aunque su desarrollo tipológico es similar a las del resto de usos construidas en España, sí 
muestran un aspecto diferenciador, éste es, la apuesta más temprana por las presas bóveda, aunque en todas las décadas, el mayor desarrollo tipológico sea con diferencia la de gravedad, ya sea de planta recta o curva. Pero sin embargo sí hay coincidencia en que las presas de materiales sueltos analizadas se construyeron mayoritariamente en las décadas de los 60 y 70, y las presas de contrafuertes son todas ellas anteriores a los 70 .

Lo que es innegable es la importancia de las presas hidroeléctricas españolas, algunas de ellas, record en altura, o volumen de embalse según su tipología, que han colaborado indudablemente a enriquecer y engrandecer el conocimiento y desarrollo del diseño y construcción de presas en España.

\section{- EVOLUCIÓN DE LA INGENIERÍA DE TÚNELES Y OBRAS SUBTERRÁNEAS}

Las primeras actuaciones en túneles u obras subterráneas hidráulicas son las minas o galerías drenantes para alimentar a los precedentes de los aprovechamientos actuales, es decir, los molinos hidráulicos, cuyo origen se ubica en Persia en el siglo VII a. C. Cuentan en su trazado con pozos verticales, denominados pozos de aireación, registros, lumbreras o espejuelos, que la conectan con la superficie.

Las galerías drenantes aún existentes, algunas de ellas alimentan sistemas hidráulicos complejos, normalmente de gran longitud, en los que existen varios molinos.

Las técnicas básicas empleadas en la excavación de estas galerías son de carácter minero, y en general no experimentan cambios importantes en la época preindustrial, y es desde mediados del siglo XIX cuando se introducen los medios mecánicos y los explosivos.

Las técnicas y materiales empleados se han caracterizado por su continuidad a lo largo de los siglos, hasta la introducción del hormigón, el ladrillo y el hierro en época reciente, empleando para los refuerzos la piedra seca o la mampostería.

Los túneles en centrales hidroeléctricas y su evolución tecnológica, es la que se ha producido en la disciplina de ejecución de túneles de cualquier tipo, en general.

Las regiones con más desarrollo en la ejecución de hidrocavernas son África, Asia y Europa. En China, India y Japón se espera un crecimiento notable. 
La sección más utilizada a nivel mundial para la ejecución de cavernas es, con diferencia, la llamada "mushroom". Y para la ejecución de galerías, la circular o semicircular.

En España, túneles hidráulicos de referencia, son los túneles del Salto de Miranda en Asturias, y el Salto de Villarino en Salamanca.

En la actualidad, los aspectos técnicos generales destacables en las obras subterráneas son:

- Mayor investigación y comprensión del comportamiento del Terreno.

- Mejor conciencia sobre gestión de riesgo y evolución del monitoreo e instrumentación de obras.

- Modernas Tecnologías: construcción más eficiente, económica y segura.

- Mayor grado de mecanización y automatización del proceso de construcción.

- Innovaciones en los ámbitos de prospección, excavación, soporte, impermeabilización, extracción, entre otros.

- Negativo: Accidentes indeseables aún ocurren puntualmente.

El desarrollo tecnológico español antes de los años 70, hay que reseñar era una labor de artesanía hasta que se produjo la evolución y mejora de los procedimientos y medios auxiliares, así como la técnica en el uso de explosivos. Ello condujo también, a una reducción en los plazos de ejecución de este tipo de obras.

La ejecución de galerías de reconocimiento daba a conocer directamente la naturaleza de la roca. Los ensayos in situ que proporcionaba la entonces moderna mecánica de rocas, permitían además determinar, además de la deformabilidad de la roca, el estado tensional del macizo y sus características mecánicas. Los sondeos ofrecían la posibilidad de reconocer y situar geométricamente los accidentes geológicos, fallas, litoclasas importantes, etc. Todo ello en su conjunto, permitía definir la situación y orientación más conveniente para la caverna de la central.

La ejecución de galerías estaba condicionada a la correcta fijación del los ataques intermedios, tanto en número como en situación. El trazado en planta de la galería se solía acercar a los puntos de emboquille de las galerías de ataque lateral, para reducir la longitud de éstas. Antes de los años 70 era normal como criterio general, no pasar de $4 \mathrm{~km}$. de longitud en los tramos sin ataque intermedio. 
El perfil longitudinal de las galerías se excavaba en contrapendiente para evitar la acumulación de agua en el frente de trabajo. Era usual tener como criterio tener contrapendientes del orden del 2 al 4 por mil.

La sección transversal de las galerías de presión, era circular, y en consecuencia, también era circular la sección teórica de la excavación.

La tecnología aplicada en la excavación de galerías, la perforación de los barrenos en galería de presión y túneles sin carga, se solía realizar utilizando martillos rápidos. Por esos años previos a los 70, no se habían utilizado apenas los "jumbos" con martillos pesados.

Para el retacado de los barrenos empezaba a utilizarse a gran escala el taco de agua.

En cuanto a los medios de carga y transporte de escombros, se realizaba por medio de trenes de vagonetas o sobre vehículos neumáticos.

En aquélla época era casi una regla general, que no existía en España un solo túnel o galería de cierta longitud, sin un 20 o 30\% de tramos en el que el terreno exigiera entibación.

En cuanto a los sostenimientos empleados eran habituales los pernos de anclaje de cuña de expansión, pernos y malla metálica, colocación de una capa de hormigón, o de mortero proyectado en toda la superficie, entibación metálica con perfiles en $\mathrm{U}$, unidos con grapas, etc.

En terreno blando, que se excava sin explosivos, el procedimiento utilizado en España fue, generalmente, el "sistema belga".

Respecto al revestimiento de las galerías, la construcción de una galería de presión estaba formada por tres fases claramente diferenciadas: Excavación, hormigonado del revestimiento e inyecciones.

En principio, lo más aconsejable era que las tres fases se realizaran con entera independencia en cada tramo entre ataques laterales de la galería y si era necesario, aplicando una capa de gunita u hormigón proyectado.

Por otra parte, el hormigonado de las galerías se planteaba, generalmente, sobre la base de una instalación dosificadora en peso de áridos, agua y cemento en el exterior. La longitud de los anillos hormigonados sin junta vertical dependía del 
sistema de proceso de hormigonado que se empleara, hormigonado continuo o por anillos.

El hormigonado continuo ya se había empleado en galerías españolas y su única ventaja respecto al sistema clásico de hormigonado por anillos de 5 a 10 metros de longitud, residía en el mayor rendimiento que se conseguía.

Los inconvenientes de este procedimiento era la formación de las juntas de fraguado longitudinales.

En cuanto a los pozos verticales y sus procedimientos de ejecución antes de los años 70, los sistemas de ejecución de los mismos variaban en función de la profundidad del pozo y la posibilidad o no de ataque ascendente.

En los casos muy frecuentes en centrales subterráneas de tener acceso por ambos extremos del pozo, era frecuente el avance desde abajo hacia arriba en sección reducida o pozo piloto, para realizar después la destroza hasta completar la sección de la excavación en sentido descendente.

En otros casos no hay alternativa y se veían obligados a excavar el pozo en sentido descendente. En España era usual utilizar este método para los pozos de cables o barras de las centrales hidroeléctricas.

Los rendimientos habituales que se obtenían en pozos de roca dura y diámetros libres de más de 3,50 metros, podía considerarse normal un avance medio mensual de 35-40 metros a pozo revestido.

Respecto a la ejecución de tuberías forzadas en el ámbito de los aprovechamientos hidroeléctricos previos a los años 70, como obras de pendiente intermedia entre galerías y pozos, reunían las dificultades de ejecución de ambos tipos de obra subterránea, y se agravaba en ellos la peligrosidad del trabajo desde el punto de vista de la seguridad del personal, mayor conforme mayor longitud tenían los tajos a ejecutar sin ataques intermedios y cuanto mayor era la sección transversal.

Las tuberías forzadas verticales no eran habituales y se recurría a ellas o por aspectos relacionados con aspecto del terreno o en saltos de pequeña altura.

En el caso de tuberías forzadas inclinadas se consideraba que la pendiente más conveniente debía estar comprendida entre los 48 y $50^{\circ}$. 
El procedimiento de ejecución más comúnmente empleado en España consistía en excavar primero una galería piloto de sección reducida que se ensanchaba en una segunda fase de excavación, vertiendo los escombros por la galería piloto. En la base inferior de la galería piloto se recogían en una tolva de carga a los vehículos.

Respecto de las centrales subterráneas como obras complejas que son y ya lo eran, en España antes de los años 70, ya entonces se habían construido centrales subterráneas en toda clase de terrenos, pasando por toda la gama de macizos rocosos más o menos consistentes. Por ello las técnicas de construcción fueron muy diversas.

En cuanto a la excavación de centrales en muy buen terreno, y tomando a la central de Aldeadávila como ejemplo de esta tipología, su ejecución aplicó las posibilidades modernas de la técnica en excavaciones subterráneas, tanto por su magnitud como por la calidad de la excavación y por los medios empleados en su ejecución, como por ejemplo perforadoras wagon-drill, voladuras eléctricas, etc.

En la excavación de centrales en terreno bueno de tipo medio, se intentaba evitar los desprendimientos de lajas o bancos de roca, realizando numerosos anclajes de distintos tipos.

La excavación de centrales en mal terreno, se realizaba según un sistema de ejecución tal que, una vez excavado y revestido el túnel de acceso se realizaba una galería de clave de sección reducida en la bóveda. Terminada la galería de clave se procedía al ensanche y hormigonado de la bóveda a medida que avanzaba la excavación.

La excavación de centrales en roca blanda y esquistosa se hacía con la aplicación de la técnica del precorte just-spliting que consistía en perforar taladros muy próximos y de cierto diámetro siguiendo el contorno del perfil de la excavación a más profundidad que la de avance de las pegas. Para el buen resultado del método era fundamental que los taladros fueran perfectamente paralelos.

Abordando ya el hormigonado de las centrales subterráneas, era casi regla general que el hormigonado de la bóveda del techo de la central se hormigonara al finalizar o simultáneamente con la excavación de la corona.

Los procedimientos utilizados en algunas centrales consistían en fabricar el hormigón en una instalación de hormigoneras situadas en el exterior, transportando el hormigón en mezcladores o agitadores sobre camión hasta el 
interior de la nave principal. La distribución o transporte a los tajos de esta nave se realizaba frecuentemente con bombas de hormigón.

Respecto a la evolución tecnológica española sufrida a partir de los años 70, para el sector hidroeléctrico, los métodos más usuales de ejecución son los del método convencional y del mecanizado.

Dentro del sistema convencional hay algunas diferencias entre excavaciones en roca y en suelo. El primero, consiste en el uso de explosivos para desmontar la roca, con posterior instalación de soporte mediante shotcrete y pernos, con eventual instalación posterior de un revestimiento secundario o final.

El método en suelo, es el NATM (Nuevo Método Austriaco de Construcción de Túneles), corresponde a una excavación cíclica, mediante el uso de retroexcavadoras adaptadas e instalación contemporánea de un soporte de cáscara doble de shotcrete de carácter permanente. En algunos casos, también se ha aplicado el sistema de soporte mediante steel-liners inyectados, que reemplazan al shotcrete como elemento de soporte en túneles de pequeño diámetro.

Y por último, el sistema mecanizado consiste en la utilización de máquinas tuneladoras TBM. El desarrollo del sector hidroeléctrico fue primero pionero, y más tarde, gran usuario de los métodos mecanizados de ejecución de obra subterránea. Esta técnica permite perforar el túnel a frente completo, donde la máquina actúa como una broca de excavación continua del macizo, lo que es seguido de la instalación más automatizada de los elementos de soporte. Asimismo, también se puede mencionar el uso de raise-borers, que corresponde a otro tipo de excavación mecanizada para la realización de perforaciones verticales e inclinadas.

En la actualidad, es destacable como aspectos técnicos de los medios convencionales:

- Uso de equipos con sistema de control automático y computadorizado, jumbos de hasta 4-brazos.

- Uso de Road-header en suelos y rocas blandas.

- Equipos de extracción y transporte de última generación (ej. Pala Shaft, correas transportadores, camiones de bajo perfil).

- Diseño especifico de perforación y tronadura, monitoreo de vibraciones y control de daño. Uso de Emulsiones para tronadura.

- Instrumentación y Monitoreo.

- Uso de mano obra especializada y poli-funcional. 
A nivel mundial, también se utilizan las tecnologías de perforación mecanizadas mediante TBM (Tunnel Boring Machine), máquina capaz de excavar a sección completa, a la vez que colabora en la colocación de un sostenimiento si éste es necesario, ya sea en forma provisional o definitiva, EPBM (Earth Pressure Balanced Machine), y SSM (Slurry Shield Machine).

Las características técnicas más destacables de la excavación mecanizada son las siguientes:

- Nueva generación de máquinas tuneleras.

- Mejores condiciones sanitarias y de seguridad para los trabajadores e industrialización del proceso de construcción

- Avances promedios $>10 \mathrm{~m} /$ día (hasta $500-700 \mathrm{~m} / \mathrm{mes}$ );

- Aplicable a un amplio espectro de condiciones de subsuelo (desde macizos con mucha competencia y alta cobertura, hasta suelos muy blandos con presencia de elevada presión hidrostática >10 bares);

- Excavación en condiciones de subsuelo complejas y muy poco favorables en forma más económica y segura.

Otras tecnologías modernas serían el RBR (Raise Boring Rig) que es el sistema de ejecución mecanizada de pozos o chimeneas entre dos niveles. Los niveles pueden ser subterráneos o, el superior, estar en la superficie.

Respecto a los avances en el revestimiento es interesante resaltar el uso de fibras de refuerzo. Las microfibras sintéticas, además de dar lugar a un mejor control de las fisuraciones plásticas en las primeras edades del hormigón, son muy eficientes para proteger la estructura contra los problemas de incendio.

Las fibras de acero mejoran las principales propiedades del hormigón (flexión, cortante, fatiga y resistencia al impacto). Mejoran y controlan de forma muy significativa la fisuración del hormigón, incrementando consecuentemente su durabilidad.

Es importante resaltar la utilidad de la auscultación cuya finalidad es la de controlar los movimientos de los túneles, galerías y cavernas así como el comportamiento de los terrenos anejos, presiones de agua, etc. durante las fases de construcción y poder asegurar su adecuación a las hipótesis y modelos de cálculo adoptados durante los trabajos de diseño, pudiéndose adoptar medidas correctoras oportunas. 


\section{- EVOLUCIÓN DE LOS APROVECHAMIENTOS HIDROELÉCTRICOS}

Las conclusiones sobre la evolución que han sufrido los aprovechamientos hidroeléctricos a lo largo de su historia son las que se indican a continuación, atendiendo a los distintos escenarios temporales.

Respecto a los inicios de la hidroelectricidad y contemplando el período 18901936, se puede hablar de que esta etapa de origen y consolidación de la electricidad tiene tres periodos claramente diferenciados. El primero de ellos refleja la introducción de la nueva forma de energía y nos conduce hasta el año 1881; el segundo periodo estuvo caracterizado por la producción de origen térmico, con centrales de reducido tamaño y un mercado de distribución limitado por la propia capacidad de la tecnología disponible; y un último periodo, que se inicia con el siglo XX pero que se consolida en su segundo decenio, que tiene como especificidad el triunfo absoluto de la producción de origen hidráulico.

Buena parte de la fase inicial del desarrollo eléctrico español estuvo ligado a la expansión de las instalaciones hidráulicas, ya que en 1901 representaban casi el $40 \%$ de las centrales existentes.

Desde 1905 se contó con la combinación de innovaciones que hicieron posible la transición hacia la hidroelectricidad en España. La experiencia en obra hidráulica, la disponibilidad de turbinas apropiadas y de los instrumentos de transformación y aislamiento de corrientes adecuados para la transmisión del fluido a larga distancia permitieron el transporte de electricidad desde distantes núcleos montañosos donde se ubicaban los saltos hidroeléctricos.

Solo un distanciamiento relevante de los costes del vapor y de hidroelectricidad pudo provocar una transición del carbón al agua tan consistente como la que tuvo lugar en España entre 1905 y 1925.

Se percibe, pues, una explotación hidroeléctrica en la que aún predominaba el pequeño salto de uso estacional que explotaba las energías sobrantes de aprovechamientos tradicionales, aunque despuntaba lo que sería la explotación hidráulica a gran escala que emprenderían las grandes empresas eléctricas a partir de entonces.

En 1909 un 20\% de los saltos en explotación y registrados para su uso eléctrico lo era en algún tipo de aprovechamiento mixto. Este fue el mecanismo de difusión eléctrica en el medio rural. 
Los usos mixtos consistían en la aplicación de dinamos a molinos hidromecánicos, que permitieron la conversión de su energía, y la de sus fábricas adyacentes, en eléctricas. Molinos harineros, aserraderos y manufacturas sobre todo textiles ubicadas en las cabeceras de los ríos conservaron una parte de su aprovechamiento hidromecánico, pero introdujeron algún convertidor eléctrico.

Las causas de su rápida difusión fueron la dificultad del acceso al carbón y el escaso coste de acondicionamiento de estos molinos. Al principio los generadores eran de corriente continua, lo que limitaba enormemente el transporte de la electricidad debido a las elevadas pérdidas, lo que obligaba a que las industrias se situaran en los centros de consumo, junto a ríos y canales. Por la misma razón únicamente se aprovechaban para generar electricidad los molinos hidráulicos cercanos a las ciudades. La utilización de la corriente alterna y la posibilidad del transporte de electricidad a larga distancia provocaron un cambio más que sustancial en la concepción y gestión hidroeléctrica de los aprovechamientos. En 1908 se creó la primera línea de alta tensión desde el Salto de El Corchado en Málaga a Sevilla. Este fue el punto de partida de la gran red nacional de transporte y distribución de energía eléctrica.

El segundo hallazgo fue la mejora de las turbinas Pelton y ya iniciado el siglo XX, también se recibieron las turbinas Francis.

Desde 1901 y hasta la inauguración de Millares y Saltos del Duero en el decenio de 1930, el modelo hegemónico constructivo consistió en un tipo de salto que aprovechaba localizaciones donde se explotaban alturas importantes mediante canales de derivación. Estas conducciones al aire o soterradas constituían en sí mismas obras de ingeniería del más alto nivel, que se complicaban con los depósitos naturales de agua, o pequeños embalses de acumulación.

En 1907 Hidroeléctrica Española (HE) inaugura, con la apertura de Molinar, la primera transmisión a gran distancia, desde Albacete a Madrid y Valencia.

Hasta la I Guerra Mundial se habían empleado aquellos saltos de menor tamaño, tanto en términos de potencia como en sus correspondientes de altura y caudal. Todavía en 1917 se utilizaban primordialmente cursos de uso estacional, fluyentes, en el interior peninsular, aunque comenzaran a aplicarse sistemas de derivación y almacenamiento de agua.

Entre 1914 y 1935 se produce el despegue de la hidroelectricidad en el Valle del Ebro, y por consiguiente en España. Este avance se debe esencialmente al 
aprovechamiento de los saltos del Pirineo oscense y leridano, por lo tanto de los ríos de las cuencas del Medio y Bajo Ebro.

El parque hidroeléctrico español había crecido a buen ritmo hasta 1925, la palanca de este rápido crecimiento del sector suministrador fue el aprovechamiento concienzudo del potencial hidroeléctrico español con predominio de los usos urbanos y manufactureros, aunque el predominio de su empleo por la manufactura abocase a rendimientos irregulares del conjunto de la maquinaria eléctrica. No obstante, a partir de entonces su progresión se desaceleró. Una vez agotada la disponibilidad de saltos de tipo medio, las condiciones naturales de las ubicaciones aptas para la explotación hidráulica en la segunda mitad de 1920 precisaban la construcción de grandes presas que regularizasen por completo el caudal de los ríos. El previsible aumento de los costes de instalación no se ajustaba a un consumo que crecía a expensas de la iluminación y la manufactura.

Ante una situación semejante durante el período de entreguerras, la intervención pública salvó a los sistemas eléctricos francés e italiano de un previsible colapso. Mientras, en España, la iniciativa pública apenas superó la fase especulativa y fueron las compañías privadas las que acometieron por sí mismas la construcción de los grandes aprovechamientos, de Millares o Saltos del Duero, y quienes establecieron una interconexión espontánea entre algunos mercados.

En 1925 los embalses admitían 985.38 Hm3, de los cuales, con aprovechamiento eléctrico solo eran 504 Hm3. En 1935, de los 3.896 Hm3 de capacidad de los embalses españoles, $2.482 \mathrm{Hm} 3$ eran para empleo eléctrico o mixto.

Aparte de la construcción de la primera gran central gallega en el Tambre, destacan la inauguración de los Saltos del Alberche en el centro peninsular, la culminación del sistema del Cinca-Lafortunada, la continuación de la explotación del Segre, el comienzo de la explotación sistemática del Guadalquivir y, primordialmente, la puesta en marcha de los primeros equipos generadores de Millares en el Júcar y en el curso medio del Esla. Así en 1935, más de un 20\% de la capacidad instalada en España lo era en centrales dotadas de presa con embalse regulador.

Fueron importantes la presa de Ricobayo, inaugurada en 1934, los aprovechamientos del Segre y del Noguera Pallaresa (Lérida), y los del Cabriel (Cuenca) y Júcar (Valencia). 
Durante el período 1936-1960, al término del enfrentamiento armado, el suministro pudo normalizarse en relativo breve tiempo.

El desarrollo de la producción de energía hidroeléctrica en los años 1939-1955 fue muy considerable. La producción de energía eléctrica en España era de carácter eminentemente hidráulico, siendo sensiblemente la hidroeléctrica el $90 \%$ de la total, proporción que se mantiene hasta el año 1944, desde el cual podría decirse que es aproximadamente el $75 \%$ de la total producida.

En esos años, formando parte de la industrialización del país, se dio un importante impulso a las grandes obras hidráulicas, cuyo papel fue muy importante no solo como productoras y almacenadoras de energía eléctrica, sino también como fuente de riqueza al convertir los terrenos de secano en regadío.

A pesar de la influencia desfavorable de la segunda guerra mundial, que impidió la importación de turbinas y alternadores, así como de material auxiliar restante, se inauguraron en 1945 ampliaciones de centrales hidráulicas de relativa importancia. En años sucesivos se irán inaugurando centrales de nueva ejecución tan importantes como Viella, Flix, y se amplía el Salto del Esla.

En los años siguientes ya comienzan a inaugurarse centrales muy importantes como Villalcampo (R. Duero) en 1949, Barasona (R. Ésera) en 1949, y en general, la tendencia de aumento es muy grande.

La energía producida mejoraba por varias causas: por la interconexión de las centrales, la existencia de térmicas que permitían mejor utilización y explotación de las hidráulicas, y por el establecimiento de embalses reguladores que permitían un óptimo aprovechamiento del agua, en relación con la pluviometría y demás condiciones meteorológicas.

Tras la aprobación de las Tarifas Tope Unificadas (1951) se entró en la segunda etapa inversora de la industria eléctrica. Las construcciones alcanzaron su momento culminante en 1955-1957. Durante el segundo quinquenio de la citada década (1955-1960) se inauguran las centrales de San Esteban, Saucelle, Canelles, Barazar, Silvón y Bárcena. Se realiza el primer aprovechamiento integral, el del Noguera Ribagorzana entre 1947 y 1963.

Es importante reseñar el impulso a la construcción de embalses reguladores que se dio en este período, amparado en el Plan General de Obras Hidráulicas, con el fin de mejorar las características torrenciales de los ríos españoles, asegurando 
el agua precisa para el regadío y situándose en aquellos cauces en que mayor producción de energía habría de producir la regulación de sus caudales.

La época 1960-actualidad puede considerarse como de electrificación madura y por tanto, se caracterizó por la búsqueda de la cantidad y de la calidad del suministro. Ya no bastaba con abastecer al mercado, sino que había que hacerlo con garantizando que las industrias dispusieran de una energía fiable y con unos mínimos de calidad establecidos en tensión y frecuencia estables.

Esto obligó a realizar un gran esfuerzo en cuanto a redes de transporte, para unir las distintas islas eléctricas que existían en el país, y en el incremento de la potencia instalada, especialmente de la hidráulica al principio del período, y de la térmica al final.

Entre 1960 y 1964 se inauguran las centrales de Aldeadávila, Mequinenza, Puente Bibey, Belesar, Valdecañas, Cornatel, Eume, Sau y Puerto Peña; así como las de San Agustín y Miranda. Estas 11 centrales suponen el 88,5\% de la potencia hidroeléctrica instalada. Durante el segundo lustro de la década de los sesenta la potencia instalada se incrementa en una cifra aproximada al quinquenio anterior: 2.312 MW. Entre 1965 y 1970 se inaugura Aguayo, Las Ondinas, Velle, Llavors, Ribarroja, Torrejón, Susqueda, Portodemouros, Arbón, La Barca, Santiago-Jares, Iznajar, José María Oriol, Castrelo, Ip, Eriste, Mediano, Biescas 2, Almendra-Villarino, Azután y Frieira. Entre el año 1971 al 1975 se inauguran las centrales de Tavascán, Albarellos, segundo grupo de Bolarque, Guillena, Conso y Contreras II.

En este período comenzó a desmontarse la autarquía y se inició el desarrollismo amparado en el plan de estabilización, planes de desarrollo, crecimiento del turismo, etc., por lo que la demanda de electricidad se incrementó espectacularmente. Este crecimiento hizo que no fuera suficiente la energía hidroeléctrica y, en 1973, la producción térmica pasó a ser la principal.

Otro aspecto a destacar en este periodo es la interconexión de las redes eléctricas de Francia y España, para el intercambio de electricidad entre los dos países y con el resto de la red europea.

Desde 1975 a la actualidad, empieza ese periodo con la inauguración de las centrales de Cedillo, Tajo de la Encantada, y los segundos grupos de Villalcampo y Castro.

Durante los años setenta y ochenta del siglo pasado se produce una ralentización en el proceso de crecimiento hidroeléctrico, debido a que estos 
recursos son cada vez menores, más costosos y más lentos en su primer establecimiento respecto a otras energías alternativas. Hay que señalar que el avance productivo de esta etapa se origina esencialmente por la utilización de las nuevas centrales de bombeo, mixto inicialmente y de bombeo puro, desde mediados de la década de los ochenta. Ambas explican dos tercios del crecimiento de este periodo, el resto se debe a la puesta en funcionamiento de algunas centrales y, en menor medida, a la rehabilitación de viejas y pequeñas instalaciones.

En este período se confirma lo que empieza a vislumbrarse en el anterior, gran crecimiento de la térmica convencional, desarrollo de la térmica nuclear y dificultades crecientes para construir hidráulicas.

El último y gran momento de la gran industria hidroeléctrica española se vive durante el último lustro de la década de los ochenta, con las aportaciones de las centrales de bombeo: en 1985 Estany Gento-Sallente, Moralets, en 1986 el segundo grupo de Aldeadávila y entre 1988 y 1989 Cortes II y La Muela de Cortes. El aprovechamiento hidráulico de Cortes-La Muela constituye el mayor sistema europeo de bombeo de agua, incluye el Salto de Cortes II y el Salto de Bombeo de la Muela.

Aunque aparentemente la hidroelectricidad pierde importancia, sin embargo se convierte en la energía que asegura calidad al sistema eléctrico. Esto es debido a que la energía hidroeléctrica se reserva para la regulación secundaria, terciaria (potencia disponible en 15 minutos) y potencia rodante (grupos hidráulicos trabajando a baja potencia, susceptible de incrementarla instantáneamente), las emergencias, así como para cubrir la demanda de las horas punta, y bombeo (almacenamiento de energía).

También, el marco legal y económico, favorece la duplicación de la potencia hidroeléctrica instalada en minicentrales en la década de los noventa, triplicándose desde esa década hasta la actualidad.

La participación de la energía hidráulica en el conjunto del sistema eléctrico español muestra desde hace años un patrón caracterizado por su relativo estancamiento en términos absolutos (curva cuasiplana de evolución de la potencia instalada) y una importancia relativa cuantitativamente decreciente en relación con otras fuentes de generación, en especial las denominadas renovables, RES o energías limpias (eólica, solar fotovoltaica y termosolar, concretamente). A finales del año 2014 la potencia de generación hidráulica en el sistema peninsular era el $19 \%$ de la del sistema eléctrico, mientras que ese mismo indicador en el año 1975 superaba el valor del 47\%. 
Como característica de un sector maduro, la búsqueda continua de la mayor calidad del servicio es una de sus premisas, que se ve reflejado en los índices de disponibilidad de la red de transporte que son del 98.21\% en 2014.

En el conjunto de los países de la Unión Europea la hidroelectricidad continúa ocupando la posición de cabeza entre las fuentes y tecnologías renovables. Su contribución a la producción eléctrica total está en tomo al 16\% en promedio y se considera que hasta la fecha se ha desarrollado únicamente un $45 \%$ de su potencial técnica, ambiental y económicamente viable. Sin embargo la madurez y otras circunstancias que afectan a esa forma de generación han ido desplazando en las últimas décadas el enfoque de autoridades, inversores y comunidad tecnológica hacia otros tipos de instalaciones de generación eléctrica. El interés hacia la hidroelectricidad se ha reavivado no obstante en los últimos años como consecuencia de la problemática de integración de fuentes irregulares (fundamentalmente la eólica y también la solar) dada su posible utilización como almacenamiento de energía a gran escala dentro del sistema electric, utilizando la centrales reversibles de bombeo/turbinación.

En la Unión Europea existe una visión compartida por la mayoría de los Estados miembro y agentes del sector sobre la importancia que posee la energía hidráulica como modalidad de almacenamiento de energía a gran escala, asociado a la gestión técnica y la operación del sistema eléctrico. Esta faceta, que se puede diferenciar de la simple producción de electricidad, constituye uno de los temas recurrentes en este campo a lo largo de estos últimos años.

La energía hidráulica, a través de centrales en grandes embalses de regulación existentes y centrales de bombeo, será un pilar importante para posibilitar la gestión técnica del sistema en relación a la incorporación en la red de la energía renovable prevista en los objetivos del Plan de Energías Renovables (horizonte 2020).

Las interconexiones también son una pieza clave para facilitar la integración de la producción renovable no gestionable, evitando vertidos. Por ello es fundamental el fomento del incremento de la capacidad comercial de intercambio entre España y Francia.

\section{- EVOLUCIÓN ESTÉTICA DE LOS APROVECHAMIENTOS HIDROELÉCTRICOS}

A continuación se resumen los aspectos más relevantes respecto al aspecto estético de los aprovechamientos.

Estos aprovechamientos, como obras civiles e industriales que son, se han diseñado prioritariamente para cumplir con la funcionalidad que le es atribuida. 
A pesar de ello y de forma particular, las centrales hidroeléctricas han constituido en ocasiones un escenario magistral de actuación en el ámbito arquitectónico por su representatividad y su destacada singularidad, que las ha hecho atractivas a la participación conjunta de ingenieros y arquitectos.

Existe desde hace un tiempo una sensibilidad especial para la conservación del patrimonio industrial, siendo varios aprovechamientos hidroeléctricos seleccionados, tanto presas como centrales.

Los saltos de agua no se han de ver únicamente como valiosos activos de producción hidráulica. Las centrales y las presas que conforman muchos de esos aprovechamientos tienen un valor estético e incluso histórico.

En los aprovechamientos no se observa una evolución clara en materia estética conforme avanzan las épocas fundamentales de la hidroelectricidad. En general, sin embargo, parece haberse cuidado la integración en el entorno de centrales y presas, pero primando siempre su fin técnico para el que fueron diseñados y en algunos casos, sí se ha puesto especial empeño en que las construcciones fueran singulares desde el punto de vista estético.

En algunos casos se ha apostado por imprimir a las construcciones de un lenguaje historicista claro, como por ejemplo, la base románica que Palacios otorga a la Central de Tambre, o en la presa de Santillana en la que el arquitecto Vicente Lampérez diseña la torre de toma en estilo gótico isabelino y envuelve a todo el proyecto de un carácter de recreación historicista para que recuerde la arquitectura del castillo de Manzanares el Real, que se encuentra en el entorno, y le sirva de antesala.

En otros, las actuaciones se enmarcan en lo que se llamó Movimiento Moderno, como son las intervenciones de Joaquín Vaquero Palacios y su hijo Vaquero Turcios en varias centrales de Hidroeléctrica del Cantábrico en los ámbitos arquitectónico, escultórico, pictórico e incluso de diseño de mobiliario.

También son destacables las aportaciones de Casto Fernández-Shaw en la presa del Jándula en que incorpora la central dentro de la presa dando un aire expresionista al perfil de la presa, y las actuaciones de Juan José Elorza e Ignacio Álvarez Castelao (ingeniero y arquitecto respectivamente) en los saltos de Silvón y Arbón. Pero no son movimientos estéticos evolucionados de otros anteriores, sino que son actuaciones puntuales en los aprovechamientos citados. También es destacable la aportación que hace sobre el urbanismo la construcción de los aprovechamientos hidroeléctricos ya que, en la mayoría de los casos, al tratarse de ejecuciones de gran importancia, necesitan la ejecución 
de poblados en sus inmediaciones, que alberguen a sus trabajadores e incluso a sus familias, generándose verdaderos asentamientos poblacionales de cierta importancia cerca de las obras, y no siempre de carácter temporal, dotados de todos los servicios necesarios para atender las necesidades de sus habitantes.

Desde el punto de vista estético también es reseñable alguna central moderna que evidencia la importancia que este aspecto sigue teniendo sobre los actuales aprovechamientos. Muestra un cuidado exquisito en su diseño exterior, que lo integra en el río sobre el que se ubica de forma bella, inspirándose en las líneas de corriente.

\section{- TENDENCIAS A FUTURO}

Las conclusiones que se pueden extraer respecto de las tendencias que sufrirán los aprovechamientos hidroeléctricos en un medio o largo plazo se resumen a continuación.

La energía hidráulica es una energía altamente gestionable y es muy importante para la regulación del sistema eléctrico en España y para el casamiento de la oferta y la demanda.

Las posibilidades de evolución futura de la energía hidroeléctrica en España dependen esencialmente de una serie de factores que pueden considerarse determinantes. Éstos son:

Factores generales

- La evolución de la demanda de electricidad

- La renovación del equipo de generación

Factores particulares (generación hidráulica)

- Las medidas de protección ambiental

- La pluralidad de usos del recurso hídrico (energético y ambientales)

- El funcionamiento de los mercados de energía (pool, bilaterales y servicios de ajuste)

- La evolución del sector gasista

- La fiscalidad de la energía y otros aspectos regulatorios

- El nexo entre la hidráulica y la operación técnica del sistema

- El impacto del cambio climático sobre el recurso hídrico

- La conservación de la infraestructura hidráulica al servicio de la generación eléctrica 
El desarrollo a medio plazo depende de las decisiones empresariales que tome cada compañía en cada caso y de su estrategia empresarial, teniendo en cuenta que su preferencia en invertir en hidroelectricidad frente a otras opciones, dependerá de los siguientes aspectos:

- Inversión, incluyendo el coste de capital

- Plazo de entrega y su predictibilidad (desde la decisión de invertir hasta la entrada en funcionamiento de la instalación)

- Costes de operación y mantenimiento

- Otros costes variables (combustible, derechos de emisión, etc.)

- Fiscalidad

Se vislumbran como buenas oportunidades de desarrollo hidroeléctrico las repotenciaciones, mejoras o transformaciones de aprovechamientos actualmente en uso que dispongan de tal posibilidad.

Mención aparte merece la hidráulica mediana $(\leq 50 \mathrm{MW})$ y la minihidráulica $(\leq$ 10 MW). Para el desarrollo de la tecnología hidráulica de pequeña potencia en España, tan necesaria para los mercados de regulación eléctrica, encontramos barreras de recurso hidráulico y barreras administrativas aunque también operativas.

Por otro lado, respecto de las perspectivas del desarrollo del almacenamiento hidráulico en España a medio y largo plazo, se consolida la idea de que la energía hidráulica de bombeo puede ser una solución que supla en parte la necesidad de almacenamiento energético bombeando con los excedentes de producción y turbinando en los momentos de pico de demanda eléctrica.

Las perspectivas de desarrollo a medio plazo de este tipo de instalaciones dependerán esencialmente de la disposición de ejecución de los planes sobre nuevas centrales reversibles, o ampliación de las existentes, por parte de las empresas generadoras, en virtud de las autorizaciones y concesiones solicitadas o aprobadas hasta la fecha.

En cuanto a innovación y tendencias en sistemas hidroeléctricos, los factores de avance que se consideran más relevantes para esta tecnología y por donde tendrán que ir las líneas de investigación para que aporten valor a los aprovechamientos, son los siguientes:

- Aportación de flexibilidad al sistema eléctrico

- Mejora de las características de las centrales HE actualmente en servicio, incluyendo su infraestructura 
- Desarrollo de nuevas tecnologías para instalaciones de almacenamiento, centrales reversibles

- Centrales minihidráulicas gestionables

- Adecuación ambiental

Entre los incentivos actuales a la innovación en el ámbito de las tecnologías hidroeléctricas se señalan los tres siguientes:

- La ampliación del rango de operación eficiente de los equipos HE

- El avance en los sistemas de control y electrónica de potencia para facilitar la extensión de la velocidad variable a las operaciones de bombeo

- La atenuación del efecto ambiental de este tipo de instalaciones.

En relación con el desarrollo de la tecnología, materiales y procesos que corresponden a los equipos y sistemas hidroeléctricos, los avances que se contemplan interesantes ya hoy y a futuro, se dan en las siguientes áreas:

- Nueva generación de turbinas y alternadores

- Electrónica de potencia y conversores

- Simulación a nivel sistémico

- Métodos y sistemas CAE de diseño

- Sensorización y procedimientos automatizados de supervisión y mantenimiento

- Aspectos ambientales y de conservación o mejora de la infraestructura

Parece oportuno en este punto final de este apartado de la tesis, transcribir la primera de las conclusiones con las que finaliza el trabajo del grupo de expertos del Club Español de la Energía sobre la estrategia energética de España a medio y largo plazo:

"Es necesario y urgente proceder a una reflexión profunda e integral en materia energética, como se está haciendo en países relevantes de nuestro entorno (Alemania, Francia, Reino Unido y Estados Unidos), con vistas a establecer las bases claras, a largo plazo, expresadas en alternativas de política energética para España, en particular, sobre el mix futuro de tecnologías al que se aspira y el funcionamiento en régimen de mercado en competencia, de forma coherente también con las políticas y regulaciones europeas.

Todo ello, partiendo de la identificación de las claves de la situación actual y del análisis comparado de las orientaciones y medidas tomadas, o en curso, en 
algunos países significados de nuestro entorno y con la voluntad de llegar a un consenso entre autoridades, especialistas y agentes".

\section{LÍNEAS FUTURAS DE INVESTIGACIÓN}

El carácter globalizador de esta tesis favorece el que, a partir de ella, se puedan establecer distintas líneas de investigación futuras.

De hecho, cada uno de los capítulos principales en que se ha estructurado, desarrollados intensivamente, podrían ser una línea de investigación propiamente dicha.

Tras la investigación realizada de documentación existente relativa a los aprovechamientos hidroeléctricos también serían factibles como líneas futuras de investigación, el análisis y evolución de determinados sistemas de aprovechamientos de determinados ámbitos geográficos sobre los que no se ha hecho hasta la fecha mucho hincapié. Esas líneas futuras podrían plantearse con el mismo carácter totalizador de esta tesis, pero desarrolladas en un entorno territorial más reducido y concreto, investigándose así más detalladamente.

Dado que el ámbito de estudio de esta tesis son los aprovechamientos hidroeléctricos y su evolución desde sus inicios hasta la actualidad, y aunque también se incluye un capítulo de tendencias a futuro, de alguna manera sigue viva en el sentido de que líneas futuras de investigación pueden abordar esa temática acotando el ámbito temporal desde la actualidad a futuro, siendo este futuro más lejano que el que se aborda en esta tesis. De este modo, se podrían establecer metodologías de predicción de comportamiento del mercado eléctrico en el que se encuentra integrado el sector de los aprovechamientos hidroeléctricos, a partir de los datos de que se dispone en la actualidad, y de la evolución que ha sufrido el mismo desde sus orígenes hasta hoy en día. A partir de esa investigación se podrían proponer tipologías concretas de aprovechamientos que fueran rentables conforme a ese comportamiento previsto, integrando de este modo los aspectos técnico-tecnológicos y económicos.

También tras la realización de esta tesis, se vislumbra como un ámbito interesante de desarrollo de línea futura de trabajo, la investigación de la evolución de la hidráulica teórica y experimental asociada a los aprovechamientos hidroeléctricos. Esta tesis aborda estos aspectos en algún capítulo de forma somera y se considera interesante la realización futura de un trabajo de análisis más profundo sobre ello. 


\section{Bibliografía}





\section{BIBLIOGRAFÍA}

1. $\mathrm{ABC}$ (1956): El aumento de producción de energía eléctrica en España. Edición de la mañana del día viernes 28 de septiembre de 1956. Pág. 42.

2. ADEME (2011): Vers la centrale hydroélectrique du XXIème siècle.

3. ÁLVAREZ, M. I., ALCÁZAR, M. Y SOLER, J. (2012): La senda de los molinos. Patrimonio Industrial del río Eresma. Ayuntamiento de Segovia.

4. AnduagA, A. (2008): Biografía de Pedro Bernardo Villarreal de Bérriz. Enciclopedia Auñamendi.

5. ANES, G. Y FERNÁNDEZ, S. (2001): Endesa en su historia (1944-2000). Fundación Endesa.

6. ANTEQUERA, M., HERMOSILlA, J. E IRANZO, E. (2014): Las galerías drenantes en España: cuantificación y clasificación tipológica de los sistemas horizontales de captación de aguas subsuperficiales. Irrigation, Society, Landscape. Tribute to Thomas F. Glick, València, Universitat Politècnica de València, 2014.

7. ANTUÑA, M. (2011): Arte eléctrico. Periódico ABC.

8. ARANDA, F. (2015): Las presas en Extremadura, "algo de toda la vida". Web Agua Civilizada.

9. AVARIA, P. (2013): Desafíos para el sector. Desarrollo de la construcción subterránea. Revista Construcción Minera nº3.

10. BABENDERERDE, L. (2015): Estado del Arte en Excavación Mecanizada. Workshop Internacional: Excavación mecanizada de túneles.

11. BARCELÓ, M. (dir.) (1986): Les aigües cercades (Els qanat(s) de l'illa de Mallorca). Institut d'Estudis Baleàrics, Palma de Mallorca.

12. BARTOLOMÉ RODRIGUEZ, I. (2007): La industria eléctrica en España (1890-1936). Estudios de Historia Económica № 50.

13. BECERRIL, E. (1941): La evolución de las formas en las presas-bóvedas. Revista de Obras Públicas.

14. BESSON, D. (1602): Teatro de los instrumentos y figuras matemáticas y mecánicas. Impreso por Horacio Cardón. Facsímil.

15. BLÁZQUEZ, C. (1995): El agua y Aragón. Prensa Diaria Aragonesa, S.A. El Periódico de Aragón. Grupo Z. 
16. BLÁZQUEZ, C. Y PALlARUElO, S. (1999): Maestros Del agua. Tomo II. Colección Estudios y Monografías, 32. Diputación General de Aragón. Departamento de Educación y Cultura.

17. BREKKE H., (1996): The hydroelectricity in the World. Present and future. XVIII IAHR Symposium on Hydraulic Machinery and Cavitation. Ed. E. Cabrera, V. Espert y F. Martínez Volumen I. pp 3-16. Kluwer.

18. BUENO, F. (2004): Las presas españolas. Un importante patrimonio histórico y cultural.

19. BUENO, F. Y DIEZ-CASCÓN, J. (2001): Ingeniería de presas. Presas de fábrica. Servicio de Publicaciones de la Universidad de Cantabria.

20. BUENO, F. Y DIEZ-CASCÓN, J. (2002): Las presas de fábrica a lo largo del siglo $X X$.

21. BUENO, F. Y DÍEZ-CASCÓN, J. (2003): Las presas y embalses en España. Historia de una necesidad. I. Hasta 1900. Ministerio de Medio Ambiente.

22. BUENO, F., Y GIL, A. (2012): Evolution of hydropower in Spain. Elsevier pp. 309-341.

23. BUIL SANZ, J. M., (2000): Los aprovechamientos hidroeléctricos. Revista de Obras Públicas nํ52.

24. CAPEL, H. (1996): El turismo industrial y el patrimonio histórico de la electricidad. Actas I Jornadas sobre Catalogación del Patrimonio Histórico. Hacia una integración disciplinar, Sevilla, Instituto Andaluz del Patrimonio Histórico, pp. 170-195.

25. CARRIÓN. I.M. (2010): Una aproximación a la intensidad industrial vasca: la industria guipuzcoana en 1860. Investigaciones de Historia Económica.

26. CASANOVAS, T. (1990): Presas de Bizkaia. Diputación Foral de Bizkaia.

27. CAYÓN GARCÍA, F. (2001) : Electricidad e historia: la perspectiva de un siglo. Dossier.

28. CLUB ESPAÑOL DE LA ENERGÍA (2015): Estrategia energética española a medio y largo plazo: mix y mercados. Análisis comparado y propuestas. Biblioteca de la Energía.

29. COLLAZOS, J.A. (2012): Fibras de refuerzo para hormigón proyectado. Simposio de Túneles y Tecnologías de Hormigón Proyectado Antofagasta. 
30. COLMENAREJO, F. Y COLMENAREJO, P.L. (1991): Molinos y batanes de Colmenar Viejo. Ayuntamiento de Colmenar Viejo.

31. CÓRDOBA, R. (1999): Breve historia de las turbinas hidráulicas. Revista Desde la Ciencia.

32. CÓRDOBA, R. (2011): Los batanes hidráulicos de la cuenca del Guadalquivir a fines de la Edad Media. Explotación y equipamiento técnico. Pp. 593-622. Anuario de estudios medievales.

33. CROSS, S. (2007): El papel de la electricidad. Papeles de Cuadernos de Energía. Club Español de la Energía.

34. DAUMAS, M. (1996): Histoire générale des techniques. Presses Universitaires de France.

35. DAZA M, A.C. (2014): Evolución de la generación hidroeléctrica.

36. DELOITTE (2011): Impacto económico de las energías renovables en el sistema productivo español. Estudio técnico PER 2011-2020. IDAE.

37. DERRY, T. K: A short history of technology: from the earliest times to A.D. 1900.

38. DIDEROT Y D'ALAMBERT (1989): Encyclopedie. Reedicción de la editorial Hachette, Vol. I, pág. 37 y 39.

39. ENDESA (2009): Centrales hidráulicas en España. Dirección Corporativa de Comunicación de Endesa.

40. ESETENA, J. (2012): La antigua presa de Santillana. Web Pasión por Madrid.

41. ESPEJO MARÍN, C. Y GARCÍA MARÍN, R. (2010): Agua y energía: producción hidroeléctrica en España. Investigaciones Geográficas, no 51, pp. 107-129.

42. FIGUEROA, M. (2015): Tecnología con equipos de Raise Borer III. Escuela de Ingeniería de Minas - UNAS.

43. FRAILE, J. (1993): Introducción a las instalaciones eléctricas. Colegio de Ingenieros de Caminos, Canales y Puertos.

44. FRANCO, B. (2014): Tecnología de los revestimientos fibroreforzados para túneles excavados con TBM. Seminario «Soluciones y avances tecnológicos para proyectos de túneles». 
45. GALÁN. F. (2012): Centrales hidroeléctricas y presas del Alto Aragón. Fundación Esteyco.

46. GANCEDO, L. (2008): El agua, caudal de luz. Entrelineas.

47. GARCIA, J. (1964): La construcción de obras hidroeléctricas subterráneas en España. Revista de Obras Públicas.

48. GARCÍA-DIEGO, J.A. (1994): Presas antiguas de Extremadura. Fundación Juanelo Turriano.

49. GARRIDO MOYRON, J. (1957): Desarrollo hidroeléctrico español en la producción de energía desde 1939 a 1955 en relación con los recursos hidroeléctricos totales de España. Revista de Obras Públicas.

50. GAS NATURAL FENOSA (2014): Relación de activos y pasivos que se segregan de Gas Natural sdg, s.a. y se aportan a Gas Natural Fenosa generación s.l.

51. GIRALDO, E.M. (2011): TBM's como alternativa a la P\&V en la excavación de túneles.

52. GOBLOT, H. (1979): Les Qanats, une technique d'acquisition de l'eau. École des Hautes Études en Sciences Sociales, Ed Mouton, París.

53. GOMES, A. (2013): Pasado, Presente y Futuro de la Tunelería. Seminario "Desafíos en Túneles y Espacios Subterráneos".

54. GÓMEZ, J.Mํ. Y HERVÁS, R.Mํ. (2012): Patrimonio hidráulico y cultura del agua en el Mediterráneo. Fundación Séneca. Regional Campus of International Excellence «Campus Mare Nostrum». Agencia Española de Cooperación Internacional para el Desarrollo.

55. HAMMETT, R.D. AND HOEK, E. (1981): Design of large underground caverns for hydroelectric projects, with reference to structurally controlled failure mechanisms. ASCE.

56. HERMOSILlA, J. (dir.) (2006): Las galerías drenantes del Sureste de la Península Ibérica. Colección Gestión tradicional del agua, patrimonio cultural y sostenibilidad, №1. Ed. Ministerio de Medio Ambiente, Madrid, $226 \mathrm{pp}$.

57. HERMOSILLA, J. (dir.) (2008): Las galerías drenantes en España. Análisis y selección de qanat(s). Colección Gestión tradicional del agua, patrimonio 
cultural y sostenibilidad, №2. Ed. Ministerio de Medio Ambiente y Medio Rural y Marino, 269 pp.

58. HERMOSILLA, J. (dir.) (2012): Las galerías de agua en la cuenca hidrográfica del Júcar: un patrimonio hidráulico en el Mediterráneo español. Colección Patrimonio Hidráulico, №3, 229 pp. Ed. Confederación Hidrográfica del Júcar y Departament de Geografia, Universitat de Valencia.

59. HERMOSILLA, J. E IRANZO, E. (2005): Las galerías drenantes o foggaras de La Safor.

60. HOEK, E. (2006): Practical Rock Engineering.

61. HONICH, K. (2010): The world's underground hydro power plants in 2010. International water power \& dam construction. Year book 2010.

62. IBERDROLA (2006): Grandes Presas. Iberdrola.

63. IDAE (2011): Plan de Energías Renovables (2011-2020).

64. IEA (International Energy Agency), (2008): Energy Technologies Perspective, Scenarios \& Strategies to 2050. International Energy Agency, Paris, Francia.

65. IEA Implementing Agreement for Hydropower Technologies and Programmes. Annex-2: Small-Scale Hydropower; Subtask B2 "Innovative Technologies for Small-Scale Hydro". IEA Annex-2 STB2 Data Sheet about Innovative Technology ( 314-2 ).

66. INGENIERÍA EN LA RED. Blog de ingeniería civil y prontuario.

67. INTERNATIONAL HYDROPOWER ASSOCIATION (2000): Hydropower and the World's Energy Future.

68. ITA WG Mechanized Tunnelling (2000): Recommendations and Guidelines for Tunnel Boring Machines (TBMs).

69. ITA-AITES (2015): Centrales y túneles hidroeléctricos subterráneos.

70. IZAGA, J.M. (2011): El sendero del río Lea. Naturaleza e ingenios. Euskonews.

71. JUNTA DE ANDALUCIA: Molino Carbonell. Base de datos Patrimonio Inmueble de Andalucía. 
72. JUNTA DE ANDALUCIA: Salto del Jándula. Base de datos Patrimonio Inmueble de Andalucía.

73. LANZA, C. (2008): Hidrofolia: el sentimiento de alegría en la apreciación de las formas del agua. Revista Ingeniería y Territorio № 81.

74. LANZA, C. y otros (2015): El agua en la transición del modelo energético español: su valor y perspectivas.

75. LÁZARO, J. (1936): La presa de la Albuera de feria (Badajoz). Revista de Obras Públicas.

76. LEJEUNE, A. Y HUI, SL. (2012): Hydro Power: A Multi Benefit Solution for Renewable Energy. Pp. 25-27. Elsevier.

77. LOSTALÉ, E. (2012): La Central Hidroeléctrica subterránea San Esteban II. Revista IgP

78. MARCHER, T. Y SAURER, E. (2013): Design and verification challenges of hydropower plant caverns.

79. MARCOS, J.M. (2002): Historia y panorama actual del sistema eléctrico español. Monográfico Energía. Física y Sociedad.

80. MARISCAL DE GANTE, A. Y LASTRADA, J.E. (2008): Rehabilitación del desagüe de fondo y del primer tramo del río salado a la salida del contraembalse de la presa de Alloz. Comité Nacional Español de Grandes Presas.

81. MATAIX, C. (1974): Turbomáquinas Hidráulicas. Editorial ICAI.

82. MAYORAL, D. (1932): Estadística de las presas de gravedad de más de 35 m. de altura a 1 de julio de 1932. Ministerio de Obras Públicas. D.G.O.H.

83. MENDOZA, C. (1919): Proyecto de canalización y aprovechamiento de energía del rio Guadalquivir entre Córdova y Sevilla. Fundación Juanelo Turriano.

84. MENDOZA, C. (1926): Idea general del proyecto de canalización y fuerzas del Guadalquivir. Revista de Obras Públicas.

85. MINISTERIO DE AGRICULTURA, ALIMENTACIÓN Y MEDIO AMBIENTE: Inventario de presas y embalses.

86. MOLINA, J. (2013): Arquitecturas del agua: Las centrales hidroeléctricas de Antonio Palacios. Entre el clasicismo y la modernidad. 
87. MOLINA, M. (1983): La hidroelectricidad en España. Boletín de la Real Sociedad Geográfica, №. 119, pp. 115-140.

88. MUÑOZ, T. (2007): Las rutas del agua en Colmenar Viejo: Huellas de esfuerzos, medios y épocas. Los Canales de Isabel II y Santillana. Ayuntamiento de Colmenar Viejo.

89. NAVALÓN, B. (2006): La tecnología hidroeléctrica. IBERDROLA. IV Simposium sobre Sostenibilidad.

90. OSSA (2015): Dossier de obras.

91. OTAMENDI, M. (1902): La instalación eléctrica del Excelentísimo Sr. Marqués de Santillana. Madrid Científico. Revista de Ciencias, Ingeniería y Electricidad.

92. PIQUERO, A.: Central de Miranda.

93. PUJOL, T, MONTORO, L., VELAYOS, J., GONZÁLEZ, J.R. (2010): Evolución tecnológica en los molinos hidráulicos de rodete horizontal. XVIII Congreso Nacional de Ingeniería Mecánica. Asociación Española de Ingeniería Mecánica.

94. RAABE, J., (1987): Great names and the development of hydraulic machinery. Hydraulics and Hydraulic Research. An Historical Review. Balkema - IAHR.

95. RED ELÉCTRICA DE ESPAÑA (2014): El sistema eléctrico español.

96. REVISTA DE OBRAS PÚBLICAS (1914): La presa de cemento armado de Big Bear Valley (California, Estados Unidos). pp. 455-457.

97. RUIZ DE AZÚA, E. (1990): D. Pedro Bernardo Villarreal De Bérriz (1669 1740). Semblanza De Un Vasco Precursor. Fundación Juanelo Turriano. Editorial Castalia.

98. RUIZ, J. : Salto de Salime.

99. SÁENZ DE MIERA, G. (2011): Un análisis prospectivo de la electricidad en España. Papeles de Cuadernos de Energía. Club Español de la Energía.

100. SCHNITTER, N. (2000): Historia de las presas. Las pirámides útiles. CICCP.

101. SMITH, N. (1977): The origins of the water turbine and the inventions of its name. Reprinted from History of Technology.

102. SOTO, P.R. (2004): Construcción de túneles. Universidad Austral de Chile. 
103. THE BOSTON CONSULTING GROUP (BCG) (2011): Evolución tecnológica y prospectivas de costes de las energías renovables. Estudio técnico PER 2011-2020. IDAE.

104. TICCIH España: 100 elementos del patrimonio Industrial en España.

105. TIELVE, N. (2011): Arte, diseño y arquitectura industrial en la labor de Joaquín Vaquero Palacios (1900-1998). NORBA. Revista de Arte. pp. 111131.

106. TORTELLA, G. (2013): Energía y poder, pasado y presente. Periódico El País.

107. UNESA (2003): La electricidad en España. 313 preguntas y respuestas.

108. UNESA (2005): El sector eléctrico a través de UNESA (1944-2004).

109. UNESA (2008): Al corriente de la electricidad. 2a Edición.

110. VARIOS AUTORES (1984): Catálogo de noventa Presas y Azudes españoles anteriores a 1900. Comisión de Estudios Históricos de Obras Públicas y Urbanismo.

111. VARIOS AUTORES (2008): Las presas en España. CICCP/CNEGP.

112. VARLET, H. (1961): Amenagement utilisation et prix de revient: Des usines hydrauliques. Eyrolles.

113. VERNIER, J. (2013): Tecnologías Constructivas ¿Qué viene?. Seminario "Desafíos en Túneles y Espacios Subterráneos".

114. VILLA REAL DE BÉRRIZ, P.B. (1736): Máquinas hidráulicas de molinos y herrerías y govierno de los árboles y montes de Vizcaya.

115. VIOLLET, P-L. (2005): Histoire de l'énergie hydraulique: Moulins, pompes, roues et turbines de l'Antiquité au XXe siecle. Presses del ponts.

116. WILSON, P. (1974): Water turbines. A Science Museum Booklet.

117. WIRTH (2000). Tunnel Boring Machines. Erklenz, Germany. pp. 3-11.

118. WWW.CTES.CL

119. WWW.EDPENERGIA.ES

120. WWW.ENDESA.ES

121. WWW.EON.COM

122. WWW.FERROATLANTICA.ES

123. WWW.FLICKR.COM

124. WWW.GASNATURALFENOSA.ES 
125. WWW.GEOCONSULT.ES

126. WWW.HERRENKNECHT.COM

127. WWW.HIDROENERGIA.NET

128. WWW.IBERDROLA.ES

129. WWW.MIJAS.ES

130. WWW.MONTEXAQUEZ.ORG

131. WWW.PANADRILL.COM

132. WWW.PANORAMIO.COM

133. WWW.TICCIH.ORG

134. WWW.WIKIPEDIA.ORG

135. ZELlER, A.R. (2012): Diseño de turbinas hidráulicas. Seminario Internacional de Experiencias en construcción de proyectos hidroeléctricos. 